\title{
ELENA TADDEI
}

\section{Die Este und das Heilige}

Römische Reich im langen 16. Jahrhundert

KONTAKTE - KONFLIKTE - KULTURTRANSFER

\section{Confederati}

Svizzeri e alleati

voia

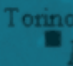

toms

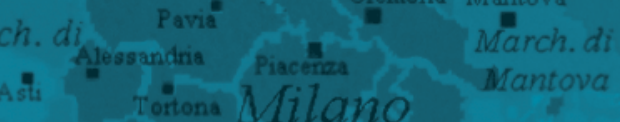
Tortona Milano.

Repubblica

童

di 
Publikation im Sinne der CC-Lizenz BY 4.0 
Publikation im Sinne der CC-Lizenz BY 4.0 
Elena Taddei

\section{Die Este und das Heilige Römische Reich im langen 16. Jahrhundert}

Kontakte - Konflikte - Kulturtransfer 
Der Wissenschaftsfonds.

\section{Veröffentlicht mit der Unterstützung des Austrian Science Fund (FWF): PUB 725-G}

Open Access: Wo nicht anders festgehalten, ist diese Publikation lizenziert unter der Creative-CommonsLizenz Namensnennung 4.0; siehe http://creativecommons.org/licenses/by/4.o/

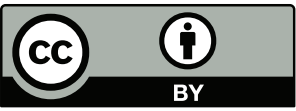

Die Publikation wurde einem anonymen, internationalen Peer-Review-Verfahren unterzogen

Bibliografische Information der Deutschen Nationalbibliothek:

Die Deutsche Nationalbibliothek verzeichnet diese Publikation in der Deutschen Nationalbibliografie; detaillierte bibliografische Daten sind im Internet über http://dnb.d-nb.de abrufbar.

Umschlagabbildungen:

Karte Italiens (Ausschnitt). Quelle: https://it.wikipedia.org/wiki/File:Grandi_Casate_Italiane_nel_I 499. png. Königs-/Kaiserfahne (die modernere Form mit dem doppelköpfigen nimbierten Adler). Quelle: https://de.wikipedia.org/wiki/Reichsbanner_des_Heiligen_R\%C $3 \%$ B6mischen_Reiches\#/media/Datei: Banner_of_the_Holy_Roman_Emperor_with_haloes_(I 400-I 806).svg; beide Zugriff: I 2.10 .2020

(C) 202 I by Böhlau Verlag GmbH \& Co. KG, Wien Köln Weimar

Zeltgasse I, A-ro8o Wien, www.boehlau-verlag.com

Korrektorat: Ulrike von Düring-Ulmenstein, Köln

Satz: Michael Rauscher, Wien

Einbandgestaltung: Michael Haderer, Wien

Druck und Bindung: Prime Rate, Budapest

Gedruckt auf chlor- und säurefreiem Papier

Printed in the EU

Vandenhoeck \& Ruprecht Verlage | www.vandenhoeck-ruprecht-verlage.com

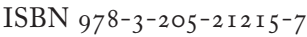




\section{Inhalt}

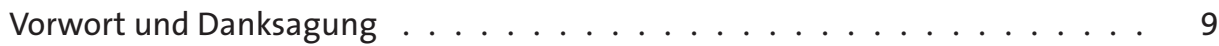

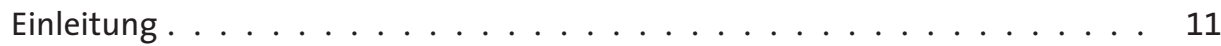

I. Forschungsfragen . . . . . . . . . . . . . . . . . 12

2. Forschungsstand . . . . . . . . . . . . . . . . 15

3. Theoretischer Ansatz und methodische Herangehensweise . . . . . . . 18

4. Aufbau der Arbeit und Quellen . . . . . . . . . . . . . . . . 21

1. VASAllität - PräZEDENZ - DeVolution

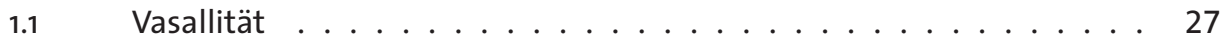

I.r.I Reichsitalien - Definition und Zusammensetzung . . . . . . . . . 27

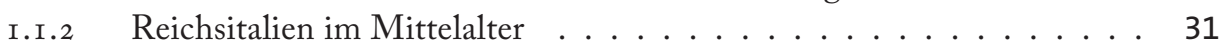

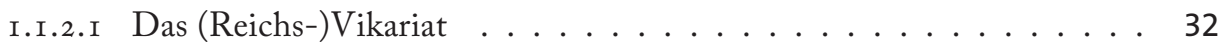

I.I.3 Reichsitalien am Übergang vom Spätmittelalter zur Frühen Neuzeit:

Die Hauptakteure . . . . . . . . . . . . . . . . . . . 43

I.r.4 Reichsitalien in der Neuzeit . . . . . . . . . . . . . 45

I.I.4.I Der Reichshofrat - eine wichtige Institution (auch) für Reichsitalien . 54

I.r.4.2 Subsidien aus Reichsitalien: Pflicht oder Druckmittel? . . . . . . . 57

I.I.5 Lehenswesen und Lehenssituation in Reichsitalien . . . . . . . . . . . . 59

I.I.5.I Entwicklungen im italienischen Lehenswesen . . . . . . . . . . . . 59

I.r.5.2 Lehensordnungen in (Reichs)Italien . . . . . . . . . . . . . 66

I.I.5.3 Die italienischen Reichslehen (feudi imperiali in Italia) in der

Kleinstaatsdebatte. . . . . . . . . . . . . . 72

I.r.6 Das Territorium der Esteherrschaft: Die Stati Estensi . . . . . . . . . . 78

r.r.6.r Ferrara......................... 78

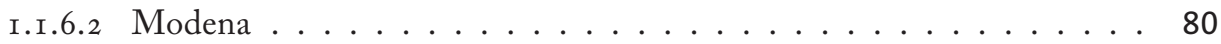

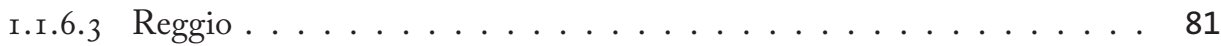

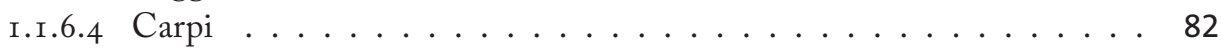

ı.r.6.5 Garfagnana . . . . . . . . . . . . . . . 84

I.r.7 Die estensischen Lehen . . . . . . . . . . . . . . . . . . 85

I.r.8 Die Este: Von Lehensnehmer zu Lehensgeber . . . . . . . . . . . . 95

I.r.9 Institutionen der estensischen Macht . . . . . . . . . . . . . . . 104

I.r.ı Die Lehenskrisen des r6. Jahrhunderts als Nagelprobe für das

Verhältnis zu Kaiser und Reich . . . . . . . . . . . . . . . . . 106

I.r.ıo. I Wie alles begann: "[...] Julio secondo ingordo e pronto« . . . . . . . . 108

I.ı.ı. 2 Erneut Vasallen - erneut treulos . . . . . . . . . . . . . . . . . 114 
$1.2 \quad$ Ein Präzedenzstreit als weitere Nagelprobe . . . . . . . . . . . . . . . 119

I.2.I Präzedenz als soziales Kapital - eine Definition . . . . . . . . . . . . . 119

I.2.2 Die Bedeutung von Rang und Ordnung im r6. Jahrhundert . . . . . . . 120

I.2.3 Der Präzedenzstreit zwischen Florenz und Ferrara . . . . . . . . . . . . . 124

r.2.4 Die Auswirkungen des Präzedenzstreites . . . . . . . . . . . . . . . . 143

I.2.5 Die Großherzogswürde der Medici und der verlorene Kampf um die Präzedenz . . . . . . . . . . . . . . . . . . 145

I.2.6 Der Thron von Polen - ein Königstitel als alternative Lösung des Präzedenzstreites . . . . . . . . . . . . . . . . . . 151

I.2.7 Weitere italienische Konflikte um Rang und Vorrang . . . . . . . . . 153

1.3 Die Nachfolgeregelung in den päpstlichen und kaiserlichen Lehen . . . . 157

I.3.I Die Belehnung der Seitenlinie mit den kaiserlichen Lehen und der Beginn einer neuen Beziehung zum Reich . . . . . . . . . . . . . . . 160

I.3.2 Die Devolution Ferraras: das Ende der Lehensbeziehung zum Papst . . 167

1.4 Zusammenfassung . . . . . . . . . . . . . . . . 184

\section{Kultureller Austausch und Transfer}

$2.1 \quad$ Der estensische Hof als Zentrum der Renaissancekultur . . . . . . . . 187

2.2 Die Heiratspolitik der Este als Grundlage der Netzwerkbildung ～. . . . . 198

2.2.I Das estensisch-habsburgische Heiratsprojekt: Alfonsos zweite Ehe mit Erzherzogin Barbara von Österreich . . . . . . . . . . . . . . . 201

2.2.2 Der Hofstaat der Erzherzogin Barbara, Herzogin von Ferrara . . . . . . 207

2.3 Aspekte von materiellem und geistigem Kulturaustausch zwischen Ferrara und dem Reich . . . . . . . . . . . . . . . . . . . . . 215

2.3.I Kulturaustausch und -transfer: Versuch einer Definition . . . . . . . . 215

2.3.2 Kulturaustausch mit Italien im Allgemeinen . . . . . . . . . . . . . . . 218

2.3.4 Musik als Import- und Exportgut in Ferrara . . . . . . . . . . . . . . 230

2.3.5 Bücher und Gelehrtenwissen in Bewegung . . . . . . . . . . . . . . 236

2.3.6 Produktionen der bildenden Künste für den kulturellen Austausch . . . 243

2.3.7 Netzwerke, Sammelwut, Kunst- und Wunderkammern als Motoren von Produktion und Austausch . . . . . . . . . . . . . . . . . 246

2.3 .8 Gabentausch und Geschenkpolitik . . . . . . . . . . . . . 253

2.3.9 Geschenktes und (An)Gefragtes: Der Austausch von Lebensmitteln, Tieren und Alltagsgegenständen . . . . . . . . . . . . . . . . . 255

2.4 Austausch von Personen - Austausch über Personen . . . . . . . . . . . . 264

$2.5 \quad$ Kulturaustausch durch Mobilität: Reisen und Besuche . . . . . . . . . . 269

2.6 Kulturaustausch und Heirat . . . . . . . . . . . . . . . . . . . 279

2.7 Die Universität als Ort des Kulturaustausches und Wissenstransfers . . . 290

2.8 Kulturaustausch im Rahmen des Gesandtschaftswesens . . . . . . . . . 297 
2.9 Exkurs: Kulturaustausch mit Frankreich . . . . . . . . . . . . . . . . 304

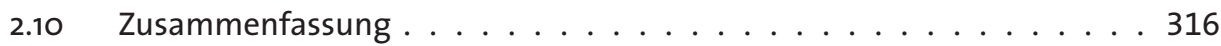

\section{KOMMUNIKATION UND WAHRNEHMUNG}

$3.1 \quad$ Fremd- und Eigenwahrnehmung allgemein . . . . . . . . . . . . . . 319

3.2 Italien und Reich: Gegenseitige Wahrnehmung . . . . . . . . . . . . . . . 324

3.3 Präsenz zeigen: Reisen und Besuche der Kaiser in Italien . . . . . . . . 330

3.4 Reisen, Besuche und Kontakte der Este . . . . . . . . . . . . . . . . . . . . . . . 333

3.5 Informieren - empfehlen - rechtfertigen . . . . . . . . . . 336

3.6 Gegenseitige Wahrnehmung in den Gesandtschaftsberichten und

Fürstenkorrespondenzen . . . . . . . . . . . . . . . . . 343

3.6. I Die Beziehungen zwischen den Este und Maximilian I. . . . . . . . . . 348

3.6.2 Die Beziehungen zwischen den Este und Karl V. . . . . . . . . . . . . . 363

3.6.3 Die Beziehungen zwischen den Este und Ferdinand I. . . . . . . . . . . 382

3.6.4 Die Beziehungen zwischen den Este und Maximilian II. . . . . . . . . . 385

3.6.5 Die Beziehungen zwischen den Este und Rudolf II. . . . . . . . . . . . 388

3.6.6 Die Este und der Reichstag . . . . . . . . . . . . . . . . . . . . 391

3.7 Die Beziehungen der Este zu anderen Mitgliedern des Reiches _. . . . . 403

3.7.I Die Beziehung zu den Habsburgern und ausgewählten katholischen

Reichsfürsten ... . . . . . . . . . . . . . 403

3.7.I.I Die Beziehungen der Este zu Erzherzog Ferdinand II. und zum

Innsbrucker Hof . . . . . . . . . . . . . . . . . . . 404

3.7.I.2 Die Beziehungen der Este zu Erzherzog Karl von Innerösterreich und zum Grazer Hof . . . . . . . . . . . . . . . . . . . . 413

3.7.I.3 Die Beziehungen der Este zu den Wittelsbachern . . . . . . . . . . 420

3.7.2 Die Beziehungen der Este zu den protestantischen Reichsfürsten . . . . 433

3.7.2. I Die Este und die Herzöge und Kurfürsten von Sachsen . . . . . . . . . 433

3.7.2.2 Die Beziehungen zwischen den Este und den Herzögen von

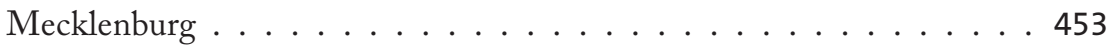

3.7.2.3 Die Beziehungen zwischen den Este und den Herzögen von

Braunschweig-Lüneburg . . . . . . . . . . . . . . . . . . . . . . . . . . . . . . . . . . . .

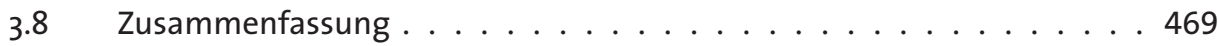

Schlussbetrachtung ......................... 471 


\section{ANHANG}

1. Die Dynastie der Este - biografischer Abriss . . . . . . . . . . . . . 485

I.I Der Beginn der Este-Herrschaft bis zur herzoglichen Erhebung . . . . 485

I.2 Die Herzöge von Ferrara, Modena und Reggio . . . . . . . . . . . . . . . . . . . . . 495

I.2.I Borso $($ reg. I450-I 47I) . . . . . . . . . . . . . 495

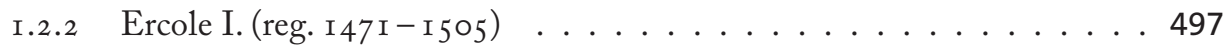

I.2.3 Alfonso I. (reg. I505-1534) . . . . . . . . . . . . . 500

I.2.4 Ercole II. (reg. I534-I559) . . . . . . . . . . . . . . . . 504

I.2.5 Alfonso II. (reg. I559-1597) . . . . . . . . . . . . . . 506

I.3 Der erste Herzog von Modena und Reggio - Cesare d'Este (reg. I $598-$ I628) . . . . . . . . . . . . . . . . . 507

2. Übersicht der estensischen Gesandten im Reich . . . . . . . . . . . . . 511

3. Bibliografie . . . . . . . . . . . . . . . . . . 512

3.I Archivquellen und Manuskripte . . . . . . . . . . . . . . . 512

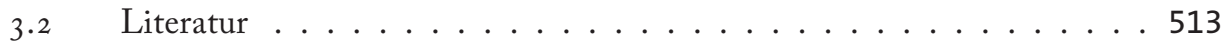

4. Register........................ 581 


\section{Vorwort und Danksagung}

Die vorliegende Arbeit ist eine gekürzte und stark überarbeitete Fassung der an der Leopold-Franzens-Universität Innsbruck im September 2016 eingereichten und im März 2017 angenommenen Habilitationsschrift mit dem Titel Die Este und das Heilige Römische Reich im langen I 6. Jahrbundert. Beziehungen - Kulturtransfer - Wabrnehmung.

Der oberitalienischen Dynastie der Este bin ich erstmals im Rahmen meiner Doktorarbeit über Renée de France, schlecht integrierte Ehefrau von Ercole II. d'Este, Sympathisantin des aufkommenden Calvinismus, Opfer eines Inquisitionsprozesses und Befürworterin einer toleranteren französischen Politik in der Zeit der Religionskriege, nähergekommen. Nach einem längeren Exkurs im Bereich der Medizin- und Psychiatriegeschichte des 19. Jahrhunderts hat mich mein Kollege Robert Rebitsch mit dem Hinweis, dass die Beziehungen der oberitalienischen Fürsten mit/zum Heiligen Römischen Reich noch spärlich beleuchtet seien, wieder zu den Herzögen von Ferrara, Modena und Reggio gebracht. Für diesen Impuls und die Mitgestaltung einer internationalen Tagung und eines Sammelbandes zum Thema »Reichsitalien« bin ich ihm sehr dankbar.

Im frühen Stadium der Arbeit, haben sich Prof. Dr. Harriet Rudolph, 20 I I- 20 I 2 Inhaberin der Professur für Geschichte der Neuzeit in Innsbruck, und Prof. Dr. Matthias Schnettger, Professor für Geschichte der Frühen Neuzeit am Historischen Seminar der Universität Mainz, viel Zeit genommen, um die Forschungsfragen und die Methodik mit mir zu diskutieren und zu reflektieren. Prof. Matthias Schnettger war auch einer der Begutachter der Habilitationsschrift, der sich eingehend mit der Arbeit auseinandergesetzt und wichtige Verbesserungsvorschläge gemacht hat. Für diese Hilfe, am Anfang und am Ende, danke ich sehr herzlich!

Auch die anderen Gutachter Prof. Dr. Alexander Koller, Prof. Dr. Heinz Noflatscher, Prof. assoc. Marco Bellabarba haben nicht nur »beurteilt«, sondern kritisch hinterfragt, Literaturhinweise gegeben und auf Ungereimtheiten aufmerksam gemacht, in einer akkuraten Weise, die unsere schnelllebige Arbeitswelt oft gar nicht mehr zulässt. Ich habe deren Vorschläge dankbar in die vorliegende überarbeitete Fassung übernommen.

Diese Arbeit basiert auf Quellenmaterial aus italienischen, österreichischen und deutschen Archiven, deren Leiter/innen und Mitarbeiter/innen durch große Bereitschaft, Interesse und das Teilen von Insiderwissen zur erfolgreichen Recherche beigetragen haben. Ohne Archive ist keine wissenschaftliche Forschung möglich; im Rahmen dieser Recherchearbeit ist mir einmal mehr bewusst geworden, wie wichtig der uneingeschränkte Zugang zu den Quellen und die fachliche Begleitung in den Archiven ist. Allen jenen, die meine zahlreichen (An)Fragen bestmöglich beantwortet haben und insbesondere den Archivar/inn/en des Archivio di Stato di Modena sei für ihre Hilfe aufrichtig gedankt. 
Große fachliche wie freundschaftliche Unterstützung habe ich am Institut für Geschichtswissenschaften und Europäische Ethnologie der Universität Innsbruck durch meine Kolleginnen und Kollegen erfahren. Ihnen allen und besonders meiner Mentorin, ao. Prof. Mag. Dr. Elisabeth Dietrich-Daum sei herzlich gedankt!

Meiner Familie und besonders meinen Eltern, die mir stets den Rücken frei gehalten haben für zahlreiche Archiv- und Tagungsreisen, kann ich nicht genug danken.

Das Habilitationsprojekt wurde von der Universität Innsbruck mit einer Nachwuchsförderung unterstützt. Die eingereichte Qualifikationsarbeit wurde $2017 \mathrm{mit}$ dem Preis der Landeshauptstadt Innsbruck ausgezeichnet. Das Kuratorium des Wissenschaftsfonds (FWF) hat im Mai 2020 den Antrag auf Förderung der Veröffentlichung bewilligt. Allen genannten Institutionen danke ich für die großzügige finanzielle Unterstützung.

Dieses über viele Jahre gewachsene Werk ist Sophia gewidmet als Dank für ihr großes Verständnis trotz ihres jungen Alters und für ihre ansteckende Begeisterungsfähigkeit für Geschichte(n) wegen ihres jungen Alters. Möge ihr beides erhalten bleiben!

Innsbruck, im Sommer 2020 


\section{Einleitung}

»[...] io né per l'imperatore

né per altri voglio porre a

rischio lo stato mio. ${ }^{1}$

$»[\ldots]$ quel nostro stato che riconosciamo

dal Sacro Imperio [...] essendo pur

noi antico feudatario di quello Imperio

et devotissimo servitore della Maestà Sua.«²

Weder für den Kaiser noch für andere wollte der Autor des ersten Zitates seinen Staat in Gefahr bringen. Im zweiten Zitat definierte der Sprecher seinen Staat als Teil des Reiches und sich selbst als treuen Vasall des Kaisers. Die beiden Aussagen an sich würden nicht Verwunderung hervorrufen, wenn sie nicht von ein und derselben Person und im Abstand von nur dreizehn Jahren stammen würden. Ercole II. d'Este, Spross einer italienischen Dynastie, deren Mitglieder sich seit dem I 3. Jahrhundert zuerst als Vikare, dann als Markgrafen und schließlich als Herzöge in der östlichen Po-Ebene etabliert hatten, war als Fürst über Ferrara, Modena und Reggio Vasall von Papst und Kaiser zugleich. Doch als principe eines territorialen Gebildes, das - wie viele andere im Laufe des I6. Jahrhunderts eine gewisse, wenn auch schwer definierbare Souveränität erreicht hatte, war er gleichzeitig auch Herr in seinem Staat. Dass man also von einem Lehensherrn (oder mehreren) abhängig und zugleich souverän sein konnte, ist nur ein Aspekt der verwobenen frühneuzeitlichen Realität.

Ein anderer bedeutender Aspekt der Lehensbeziehung zwischen dem Herzog von Ferrara Modena und Reggio und seinem kaiserlichen Lehensherrn war eine über die Jahrhunderte gewachsene, von einem reichen kulturellen Austausch geprägte klienteläre Beziehung. Die Este waren nicht nur Vasallen des Kaisers in Reichsitalien, vielmehr waren sie Teil eines europäischen Netzes, ${ }^{3}$ in dem das Reich nicht nur geo-

I »[...] weder für den Kaiser, noch für irgendeinen anderen will ich meinen Staat in Gefahr bringen«. In der Relazione des Gesandten Navagero von 546 zit. n. Gino Benzoni, »Ercole II d'Este«, in: Dizionario Biografico degli Italiani (DBI) 43, Roma I 993, http://www.treccani.it/enciclopedia/ercole-ii-deste_\%28Dizionario-Biografico \%29/, Zugriff: r 6.9.2020.

2 »[...] unser Staat, der zum Heiligen Römischen Reich gehört, [...] da wir von alters her Lehensnehmer des Reiches und untertänigster Diener Seiner Majestät sind.« Archivio di Stato di Modena (ASMo), Archivio Segreto Estense (ASE), Casa e Stato, Carteggio di ambasciatori, Germania, 3 I 2 I b. 20, Minute di dispacci per la Germania an Ippolito Turco, Januar I 559.

3 Mit Netz ist nach der Definition von Umberto Eco ein System gemeint, dessen Merkmal es ist, »daß jeder Punkt mit jedem anderen Punkt verbunden werden kann, und wo die Verbindungen noch nicht 
grafisch, sondern auch aufgrund seiner Bedeutung im Zentrum stand. Obwohl von Entscheidungsinstitutionen wie dem Reichstag ausgeschlossen, an der Peripherie des Reiches und ihrer militärischen und politischen Bedeutung nach eher im unteren Mittelfeld angesiedelt, waren die Este - wie andere (italienische) Fürstenfamilien an den sich ausfransenden Rändern ${ }^{4}$ des Heiligen Römischen Reiches - mit dessen Akteuren, so dem Kaiser selbst aber auch einzelnen Reichsfürsten, eng verbunden. Der Werdegang der Este-Familie war eng verwoben und verstrickt mit dem Schicksal anderer italienischer, französischer aber vor allem deutscher Fürsten und Dynastien, obwohl sie Fürsten über ein nur mittelgroßes heterogenes Lehensgebiet von geringerer politischer Relevanz als z.B. die Kurfürsten von Sachsen, die Herzöge von Bayern oder die Mitglieder der Casa de Austria waren. Als Vertreter und Verbreiter einer ressourcenreichen Hofkultur der italienischen Renaissance waren sie jenseits des Alpenhauptkammes nicht nur bekannt, sondern wurden bewundert und nachgeahmt. Diese Tatsache brachte sie gerade im I6. Jahrhundert von der geografischen und politischen Peripherie des Reiches ins Zentrum des kulturellen Interesses und der von Prestigedenken und Inszenierung geprägten Wahrnehmung.

Die vorliegende Arbeit will zeigen, welche Notwendigkeit für Fürsten am Rande des Reiches bestand, ein engmaschiges Netzwerk jenseits der Alpen zu etablieren und mit welchen kulturpolitischen Maßnahmen sie ins Reich hineinzuwachsen versuchten. Dabei sind die Este nur ein Beispiel unter vielen, denn dasselbe könnte man auch am Fall der Medici, Gonzaga, Sforza und von kleineren Fürstenfamilien aus Reichsitalien zeigen bzw. wurde dies zum Teil bereits gemacht. Die Este sind aber deswegen von besonderem Interesse, weil sie unter den Fürsten der größeren Territorien Reichsitaliens die einzigen mit einem substantiellen ${ }^{5}$ doppelten Lehenverhältnis waren, also gleichzeitig Vasallen des Papstes und des Kaisers mit zwei ähnlich großen, wenn auch in ihrer Charakteristik und Bedeutung sehr unterschiedlichen Lehensgebieten.

\section{Forschungsfragen}

Die vorliegende Arbeit basiert auf drei thematischen Schwerpunkten und wirft innerhalb dieser die folgenden ineinandergreifenden Forschungsfragen auf.

Zunächst wird der Frage nach der Bedeutung und Wahrnehmung ${ }^{6}$ Reichsitaliens im I 5. und I6. Jahrhundert nachgegangen. Davon ausgehend richtet sich das Augenmerk

entworfen sind, können sie trotzdem vorgestellt und entworfen werden.« Eco, Die Enzyklopädie als Labyrinth, Io5f.

4 Stollberg-Rilinger, Das Heilige Römische Reich, 20.

5 Zwar besaßen auch andere wie z.B. die Herzöge von Urbino als Vasallen des Papstes auch einige kleinräumige kaiserliche Lehensgebiete, doch kein anderes Fürstengeschlecht neben den Este war Vasall beider Lehensherren mit zwei fast gleich großen und bedeutenden Territorien.

6 Unter Wahrnehmung (Perzeption) ist der Prozess der Aufnahme von Informationen aus der Umwelt 
auf das estensische Doppellehen als politisch mäßig bedeutenden, auf dem Weg nach Rom situierten, kulturell bestimmenden und mit dem Reich eng verbundenen Teil der südlichen Reichsperipherie. ${ }^{7}$ Obwohl die Forschung dem Thema »Reichsitalien« in den vergangenen Jahrzehnten wieder größeres Interesse entgegengebracht hat, sind die Stati estensi - gerade hinsichtlich der neu bewerteten Bedeutung der feudi imperiali italiani - wenig berücksichtigt worden. Dies liegt zum Teil auch an ihrer Hybridität als heterogenes Gebilde mit einem doppelten Lehensverhältnis zu Kaiser und Papst.

Die Leitfragen zu diesem ersten Teil betreffen zunächst die Funktion, Bedeutung und den Wandel von Reichsitalien an der Wende vom Spätmittelalter zur Frühen Neuzeit. Mit Kaiser Karl V. erreichte die sogenannte Italienpolitik, d.h. das Interesse für Italien, die kaiserliche Präsenz und die Bedeutung italienischer Reichslehen ihren Höhepunkt. ${ }^{8}$ Was bedeutete dieses Vorrücken in das Zentrum des Interesses für die estensische Dynastie? Dieselbe hatte im I6. Jahrhundert mit drei großen Krisen zu kämpfen, die das Verhältnis zum Reich im weitesten Sinne, also nicht nur zum Kaiser, sondern auch zu den anderen Mitgliedern der habsburgischen Familie ${ }^{9}$ und schließlich zu verschiedenen Reichsfürsten, prägten. Diese Eskalationsmomente (Verlust der Lehen, Präzedenzstreit und Devolution) werden in diesem ersten Teil der Arbeit eingehend untersucht, da sie als Nagelprobe für die Beziehung der Este zu Kaiser und Reich im i6. Jahrhundert gewertet werden können.

Der zweite Themenbereich betrifft den reichen kulturellen Transfer und Austausch zwischen den Este und dem Reich und evoziert zwar eine Wechselwirkung, rückt die italienischen Fürsten jedoch eindeutig ins Zentrum, denn sie und die von ihren Höfen ausgehenden kulturellen Impulse wurden im I 5. und I6. Jahrhundert zum Ausgangspunkt vielfältiger Austauschprozesse. Es gilt zu zeigen, welche materiellen und immateriellen Aspekte des kulturellen Austausches von Ferrara ausgingen, und worin das Interesse deutscher Fürst/inn/en für die Este und ihren Hof lag. Auch muss geklärt werden, warum in dieser Analyse der Beziehungen der Este als kaiserliche Vasallen mit dem Reich nicht die Reichslehen Modena und Reggio, sondern fast ausschließlich der Hof des päpstlichen Lehens Ferrara als Zentrum der estensischen Macht und Kultur

mittels der menschlichen Sinne gemeint. Der Abgleich und die Verbindung einer Aufnahme mit den eigenen Bedeutungskategorien, Mustern und Erfahrungen führt zum Erkennen (Kognition). Durch das neue Menschen- und Weltbild der Renaissance und deren Unvereinbarkeit mit dem tradierten Wissen, aber auch durch die Entwicklung neuer Instrumente zur genauen Beobachtung, Messung und Klassifizierung wurde die Perzeption durch die Sinne von immer größerer Bedeutung. Vgl. zu Definition, Entwicklung und weiterführender Literatur den Artikel in der Enzyklopädie der Neuzeit von Wolfgang E.J. We ве R, »Wahrnehmung«, in: Friedrich Jäger, Enzyklopädie der Neuzeit I4, Sp. 536-542.

7 Vgl. Hans-Heinrich Nolte, »Peripherie«, in: Friedrich Jäger, Enzyklopädie der Neuzeit 9, Sp. 977-980.

8 Dazu siehe eingehender unten und vorerst allgemein nur Fantoni, Carlo V; Soly, Einleitung. Karl V., I I - 25 und zur Italienpolitik unter Gattinara: CzERnin, Gattinara, bes. I 76- I 78, 2 I $3 f$.

9 Familie wird hier, wie von Fouquet u.a. bereits definiert, als offene fürstliche Struktur bestehend aus komplexen, satellitenartigen Systemen verstanden. FouQUe T, Fürsten unter sich, I74. 
behandelt werden. Es wird in diesem Zusammenhang zu zeigen sein, dass die estensischen Fürsten im Reich allgemein und selbst vom Kaiser stets als Herzöge von Ferrara, also als päpstliche Lehensnehmer wahrgenommen wurden.

Im Rahmen des kulturellen Austausches spielten die Este nicht ausschließlich eine Aussender-, sondern auch eine Empfängerrolle, wodurch es gilt, die Transferprozesse in die umgekehrte Richtung ebenfalls auszuloten. Von besonderer Bedeutung ist hierfür die Rolle von Fremden ${ }^{10}$ am estensischen Hof, wobei nicht nur auf Besucher, Künstler und Gesandte einzugehen sein wird, sondern vor allem auf die fremden Fürstinnen, d.h. die aus anderen Kulturkreisen stammenden Bräute der Este-Fürsten.

Eng mit diesem Aspekt des kulturellen Austausches ist als dritter Schwerpunkt der Arbeit die gegenseitige Wahrnehmung und Bedeutung der so vehement verfolgten Netzwerkbildung ${ }^{11}$ verbunden. In diesem Teil sollen die Beziehungen der Este zu den Kaisern des r6. Jahrhunderts, zu verschiedenen Mitgliedern des Kaiserhauses und zu einzelnen Reichsfürsten beleuchtet werden. Grundlage und gleichzeitig Vorgabe für die Auswahl der Akteure/innen sind die im Staatsarchiv von Modena erhaltenen Korrespondenzen. Anhand dieser Briefwechsel und unter Heranziehung von Gesandtschaftsberichten soll versucht werden das Beziehungsnetz, in das die Este im I6. Jahrhundert verstrickt waren bzw. welches sie selbst mit aufgebaut hatten, darzustellen. Im Vordergrund steht dabei stets die Frage nach der Motivation dieser italienischen Fürsten internationale Beziehungen ${ }^{12}$ aufzubauen, regelmäßigen Austausch zu pflegen und eine diplomatische Vertretung bis in den Reichsnorden, so z.B. nach Mecklenburg,

ro Menschen gelten als Fremde, wo sie als »anders« wahrgenommen werden, wodurch Fremdheit immer relativ und meist ortsgebunden ist. Jemanden als »fremd « zu bezeichnen ist eine Form von Abgrenzung und dient der Identitätsbildung. Fremd ist, wer sich in Sprache, Glauben, Herkunft, Aussehen, Verhalten oder Kultur unterscheidet. Zu diesen möglicherweise objektiven Differenzen kommen zumeist imaginäre und vor allem tradierte Unterschiede, Stereotype vermischt mit Ängsten, Neugier, Ablehnung oder Bewunderung hinzu. Es gilt zu bedenken, dass der Grad der Fremdheit historisch wandelbar ist und dass es innerhalb der Gruppe von Fremden, wie in der vorliegenden Arbeit, auch sogenannte privilegierte Fremde wie ausländische Kaufleute, jüdische Ärzte, Diplomaten und angeheiratete Fürstinnen gab. Hering Torres/Max Sebastián, »Fremdheit«, in: Friedrich Jäger, Enzyklopädie der Neuzeit 3, Sp. I $226-$ I 229 .

I Sebastian Gießmann hat in seiner kulturhistorischen Dissertation den unterschiedlichen Grad der Dinglichkeit von Netzen und Netzwerken festgehalten: „Netze sind im Folgenden konkrete dingliche Artefakte, aber auch konnektive Strukturen, die in topologischen Diagrammen repräsentiert und codiert werden können. Sie sind vor allem im kartografischen Modus darstellbar. Netzwerke hingegen werden als wesentlich heterogene, interkonnektive und unscharfe Quasi-Objekte verstanden, die Menschen, Dinge, Zeichen, Institutionen und Räume integrieren.« (I 5) "Netzwerke benötigen eine materielle Grundlage, um operieren zu können« (i i g). Giessmann, Die Verbundenheit der Dinge. Zur Definition des Netzes und seinem Prinzip von »Knoten und Verbindung« für die Kontakte und Beziehungen dieser Untersuchung siehe Böнme, Einführung, I 8-24; BERG, »Netz/Vernetzung«.

I2 Vor allem Wolfgang Reinhard hat am Beispiel römischer Mikropolitik die verschiedenen Aspekte und die Intensität von Außen- und internationalen Beziehungen eines frühneuzeitlichen Hofes gezeigt und dadurch bewiesen, dass diese Außenverflechtung nicht erst mit der Entstehung des modernen Staates 
Sachsen und Braunschweig zu haben. Es wird zu eruieren sein, warum sie sich für diese weit entfernten Fürsten und Fürstinnen bzw. für deren Klienten engagierten, die sie oft ein Leben lang nicht zu Gesicht bekamen. Was verpflichtete sie zur Gewährung von Krediten, zur Entsendung von Briefen, Gesandten, Gaben oder zur Aufnahme von empfohlenen und weitervermittelten Personen? Dies führt zum Schluss zur Frage, wie die Este die verschiedenen Mitglieder des Reiches, allen voran den Kaiser, wahrnahmen und umgekehrt, wie sie selbst im Reich perzipiert wurden.

\section{Forschungsstand}

Wie bereits festgehalten, erfreut sich das Thema Reichsitalien seit einiger Zeit wieder größeren Interesses und hat in Teilbereichen bereits eine feingliedrige Untersuchungsebene erreicht.

Der erste, der sich eingehender mit Reichsitalien und seinen Strukturen und Ordnungen auseinandergesetzt hat, war Karl Otmar Freiherr von Aretin, der noch Ende der I990er Jahren monierte, dass dieser Teil des Heiligen Römischen Reiches weiter und genauer untersucht werden müsse. ${ }^{13}$ Dieser Aufforderung wurde aber nicht gleich nachgekommen. Zwar ist das Reich an sich, seine Institutionen, so der Reichstag, das Reichskammergericht oder der Reichshofrat in den Fokus des Interesses der deutschsprachigen Forschung der letzten Jahrzehnte gerückt, doch Reichsitalien wurde erst in einem zweiten Anlauf zum Untersuchungsthema.

Die österreichische Historiografie hat sich mit Italien vor allem hinsichtlich der erworbenen oder ererbten Gebiete auf der italienischen Halbinsel und vor allem mit den Entwicklungen ab dem I8. und 19. Jahrhundert befasst. ${ }^{14}$ Erst in den r 97oer Jahren wurde am Wiener Haus-, Hof- und Staatsarchiv mit der Aufarbeitung der Akten des Reichshofrates ${ }^{15}$ begonnen. Untersuchungen zu Investiturangelegenheiten,

einsetzte. Reinhard, Römische Mikropolitik. Einen ähnlichen Versuch hat am Beispiel der Eidgenossenschaft und der hier tätigen Gesandten Windler, Diplomatie als Erfahrung, gemacht.

I 3 Aretin, Das Alte Reich, hier besonders Band I: Föderalistische oder hierarchische Ordnung (I648I684), I I 2 ; Ders., Das Reich, hier besonders das Kap. Reichsitalien von Karl V. bis zum Ende des Alten Reiches. Die Lehensordnungen in Italien und ihre Auswirkungen auf die europäische Politik, 76- I63. Auch aufschlussreich die knappe Darstellung der Frage nach dem Wesen des Alten Reiches: Ders., The Old Reich. Eine frühe Arbeit Aretins ist ein gelungener Überblick über die politischen und kulturellen Entwicklungen in Italien von der Früh- bis zur Spätrenaissance: Ders., Die Geschichte der italienischen Renaissance; zum Hof von Ferrara besonders 57f, 90-93. Aus rechtsgeschichtlicher Sicht ist die Bedeutung des Reiches, des Reichsrechtes, des Reichstages etc. auch für Italien bereits in den I $970 e r$ Jahren von Emilio Bussi betont worden. Siehe: Bussi, Lo studio del Sacro Romano Impero.

I4 Benedikt, Kaiseradler über dem Apennin.

I 5 Vgl. zum Thema etwa Auer, Reichshofrat und Reichsitalien. Siehe auch die von FWF bzw. FWF und DFG geförderten Projekte zu den Appellationen und Suppliken an den Reichshofrat der Universitäten 
zu Kontributionen ${ }^{16}$ oder zu den kaiserlichen Kommissaren ${ }^{17}$ machten Reichsitalien zunächst von der lehensrechtlichen und -geschichtlichen Seite her für die Forschung interessant. $^{18}$

Die italienische Geschichtswissenschaft hat lange die Lehensbeziehungen zum Reich als Vorläufer einer die Schaffung des italienischen Einheitsstaates hinderlichen Fremdherrschaft rezipiert und sich daher erst spät für diese Forschungsdesiderata erwärmt, war sie anfangs noch ganz in derTradition der Habsburg feindlichen Geschichtsschreibung verhaftet. ${ }^{19}$ Erst Giovanni Tabaccos Untersuchung der Beziehungen zwischen Savoyen und dem Reich ${ }^{20}$ löste sich von dieser vor allem durch das Risorgimento geprägten Haltung und gab den Auftakt zu einer Reihe von Arbeiten, die sich auch auf regional- oder lokalhistorischer Ebene den Wechselbeziehungen, Verflechtungen und Wahrnehmungen widmen. Etliche Detailstudien und größere Zusammenhänge umspannende Monografien ${ }^{21}$ und vor allem Tagungsbände ${ }^{22}$ von deutsch- wie italienischsprachiger Seite versuchen seitdem das Bild Reichsitaliens, seine Entwicklung, Bedeutung und Wahrnehmung zu vervollständigen. Der Fokus liegt hierbei besonders auf dem Lehenswesen, der Reichsgerichtsbarkeit, ${ }^{23}$ den Agenden des Reichshofrates sowie auf dem Verschmelzen von Befehlsgewalt und Zuständigkeit innerhalb der feudi imperiali italiani. ${ }^{24}$ Neue Aufmerksamkeit haben von Seiten der spanischen Historiografie die Beziehungen italienischer Reichsvasallen zu Spanien und die Zeit des Spanischen Erbfolgekrieges erfahren. ${ }^{25}$

Wien und Graz: http://www.univie.ac.at/reichshofrat/index; http://www-gewi.uni-graz.at/suppliken/ de, Zugriff: 24.6.2020.

i6 Vgl. z.B. Nieder korn, Die europäischen Mächte; Schnettger, Subsidien und Kontributionen.

I7 Vgl. dazu Pflüger, Kommissare und Korrespondenzen.

I8 Rill, Reichsvikar; Ders., Die Garzweiler-Mission; Auer, Zur Rolle Italiens; Ders., Österreichische und europäische Politik. Zur Entwicklung des Lehensrechts in Italien siehe auch: STEIgER, Völkerrecht versus Lehnsrecht?

I9 Pugliese, Le prime strette dell'Austria in Italia, Milano 1932, in zweiter Auflage von I 935 unter dem Titel »I Sacro Romano Impero in Italia«. Pugliese findet für die Tatsache, dass sich die deutschsprachige Forschung viel mehr und intensiver mit den Beziehungen zwischen Reich und Italien auseinandergesetzt hat, eine plausible Erklärung: Während die Deutschen ein großes Interesse daran hatten, die fast vergessenen Rechte des Reiches in Italien immer wieder in Erinnerung zu rufen so wie die glorreichen Kämpfe und Eroberungen der Halbinsel, zogen es die Italiener vor, über die düstere Zeit der Fremdherrschaft den Mantel des Schweigens auszubreiten. Ebd., Vorwort, I.

20 Taвacco, Lo stato sabaudo.

2 I Beispielsweise: Bonora, Aspettando l'imperatore; Edelmayer, Maximilian II.; Schnettger, »Principe sovrano«.

22 Vgl. Cantù/Visceglia, L'Italia di Carlo V; Schnettger/Verga, L'Impero e l'Italia; Schnettger, Kaiserliches und päpstliches Lehnswesen; Cremonini/Musso, I feudi imperiali; Cremonini, Impero e feudi italiani; Bellabarba/Merlotti, Stato sabaudo.

23 Vgl. z.B. Schnettger, Die kaiserliche Gerichtsbarkeit, 607-625; Ders., Kooperation und Konflikt.

24 Vgl. z.B. Schnettger, Das Alte Reich.

25 Hier seien weiterführend nur genannt: Antonio Alvárez-Ossorio Alvariño (Hg.), Famiglie, nazioni 
Ebenfalls fundamental für die vorliegende Arbeit sind die mittlerweile zahlreichen Studien zum weitläufigen Thema des kulturellen Austausches und Transfers im I 5 . und I6. Jahrhundert, die Italien in den Vordergrund rücken. ${ }^{26}$ Hier konnte auf etliche Vorarbeiten zurückgegriffen werden, die die Dynastie der Este bereits punktuell berücksichtigt haben, wie z.B. die Arbeiten von Barbara Marx und Evelyn Korsch über die Verbindungen zwischen Dresden und Ferrara. ${ }^{27}$ Auch die Höfegeschichte, die Residenzforschung und die Dynastiegeschichte ${ }^{28}$ haben einen maßgeblichen Beitrag zum Thema des kulturellen Austausches mit einzelnen oberitalienischen Renaissancehöfen und zur Wahrnehmung der italienischen Renaissancekultur jenseits der Alpen geleistet. $^{29}$

Ein letzter wichtiger Aspekt, dem sich die Forschung der letzten Jahrzehnte wieder mehr und vor allem unter neuen Gesichtspunkten ${ }^{30}$ gewidmet hat, ist jener der diplomatischen Beziehungen zwischen dem Reich und Italien, die stark in den Bereich des Kulturellen hineinragen. In der neuen Diplomatieforschung wurde der Gesandte als Vertreter, Informant und gleichzeitig (Kultur)Vermittler mit großem Einfluss im Bereich der Eigen- und Fremdwahrnehmung neu entdeckt. Etliche Arbeiten haben bereits interessante Erkenntnisse zu den Handlungsspielräumen von fürstlichen Vertretern aber vor allem hinsichtlich ihrer Bedeutung bei der Tradierung von Stereotypen gebracht. ${ }^{31}$

Nach Aretins Pionierarbeiten hat Matthias Schnettger, der sich in zahlreichen richtungsweisenden Studien eingehend mit Reichsitalien und seinen Wechselbeziehungen zum Reich auseinandergesetzt hat, zusammen mit Marcello Verga eine erste maßgebliche Zusammenschau über diese italienischen Reichsgebiete und über die vielseitigen Aspekte ihrer Beziehungen zum Reich vorgelegt. ${ }^{32}$ In der Einführung des 2006 publizierten Tagungsbandes wurde aber erneut die Notwendigkeit betont, einen Überblick über die italienischen Reichslehen zu erarbeiten, über ihre Ausmaße und ihre Verteilung innerhalb der italienischen Territorien und über die in ihnen ausgeübte Souveränität und imperiale Rechtsgewalt (»di aprire un vero e proprio dossier collettivo sul Reichsitalien, sui feudi imperiali, sulla loro consistenza, sulla loro dislocazione

e Monarchia. Il sistema europeo durante la Guerra di Successione spagnola (= Cheiron 39-40), Roma 2004, I 59-22 I ; Martínez Millán, Carlos V; Rodríguez Salgado, Metamorfosi di un impero.

26 Hier seien nur die wichtigsten und richtungsgebenden Forschungen genannt wie: Middell/Middell, Forschungen zum Kulturtransfer; Paulmann, Kulturtransfer; Middell, Von der Wechselseitigkeit; Schmale, Einleitung; Fuchs/Trakulhum, Kulturtransfer in der Frühen Neuzeit.

$27 \mathrm{KoRsch}$, Ein »heimlicher Vorschlag«.

28 Spagnoletti, Matrimoni; Schnettger, Die Kaiserinnen.

29 Vgl. dazu Fregni, Archivi; Bellabarba/Nieder korn, Le corti come luogo di comunicazione. SignoRотто, Impero e Italia.

30 Bianchi, Al servizio del principe; Frigo, Politics and Diplomacy.

3 I Es seien nur genannt: Strohmeyer, Wahrnehmungen; Burschel, Das Eigene; Edelmayer, Habsburgische Gesandte.

32 Schnettger/Verga, L'Impero e l'Italia. 
nei territori degli stati italiani; sul significato reale dell'esercizio in questi feudi della sovranità e della giurisdizione imperiale $)^{33}$

Dieser Aufforderung wurde im September 2014 mit einer internationalen Tagung in Innsbruck nachgekommen, die von der Autorin zusammen mit Matthias Schnettger und Robert Rebitsch organisiert wurde. Deren Ergebnisse wurden in einem zweisprachigen Band der Reihe Innsbrucker Historische Studien unter dem Titel Reichsitalien in Mittelalter und Neuzeit/I feudi imperiali italiani tra Medioevo e Età moderna, veröffentlicht. Hier wurde versucht, sowohl aus der Sicht der deutschen wie der italienischen Reichsitalienforschung die 2006 genannten Forschungsdesiderata aufzugreifen und mit neuen epochenübergreifenden und retrospektiven Akzenten zu ergänzen. In der Einleitung zu diesem Tagungsband wurde allerdings darauf hingewiesen, ${ }^{34}$ dass eine Gesamtdarstellung des frühneuzeitlichen Reichsitaliens noch ausstehe. Dafür müssen, Steinchen um Steinchen, die einzelnen größeren wie kleineren Reichslehen in ihrem Werdegang und ihrer Verbindung zum Reich noch eingehender untersucht werden. Im genannten Band hat das estensische Fürstentum eine erste nähere Betrachtung durch die Autorin erfahren. So versteht sich die vorliegende Arbeit auch als Mosaikstein, welcher das Bild Reichsitaliens in der Frühen Neuzeit weiter vervollständigen soll.

\section{Theoretischer Ansatz und methodische Herangehensweise}

Die Arbeit ist - wie oben bereits erwähnt - in den Forschungen zu Reichsitalien eingebettet und will einen Beitrag zur Vervollständigung des Bildes der südlichen Reichsperipherie durch eine akteurszentrierte Untersuchung eines hier angesiedelten, nicht ausschließlich kaiserlichen Lehensfürstentums leisten. Die Stati estensi waren nämlich ein Konglomerat aus verschiedenen Gebieten, in denen die Dynastie der Este souverän agierte, während sie für Ferrara dem Papst und für Modena und Reggio dem Kaiser Vasallentreue und Lehenszins leisteten. Hauptaufgabe der Este-Fürsten des ausgehenden I 5 . und noch mehr des I6. Jahrhunderts, eingekeilt zwischen expandierenden italienischen und europäischen Mächten, war das »Obenbleiben« mithilfe eines durch Mäzenatentum wachsenden Renommees, gewinnbringender (Heirats-)Allianzen und eines früh etablierten diplomatischen Netzwerkes.

Hinsichtlich der Frage des kulturellen Austausches ${ }^{35}$ zwischen den Este und dem Reich und der gegenseitigen Wahrnehmung orientiert sich die Untersuchung methodisch an den Parametern der Neuen Kulturgeschichte/New Cultural History. ${ }^{36}$ Die Kul-

\footnotetext{
33 VERGA, L'Impero in Italia, I 5.

34 Taddei/Schnettger/Rebitsch, Reichsitalien.

35 Siehe besonders: Werner/Zimmermann, Vergleich, Transfer, Verflechtung; Werner/Zimmermann, Penser l'historie croisée; KaElble, Die interdisziplinären Debatten.

36 Daniel, Kompendium Kulturgeschichte, 2 rof. Für den Perspektivenwechsel in der Frühen Neuzeit
} 
turgeschichte hat ihre Wurzeln in der Schule der Annales, die sich von der Ereignisgeschichte weg- zu einer weitgefassten Sozial-, Wirtschafts- und Kulturgeschichte hinbewegte. Kennzeichen der Neuen Kulturgeschichte sind, wie Barbara Stollberg-Rilinger mit dem Begriff der Kulturgeschichte des Politischen ${ }^{37}$ definiert hat, die Verknüpfung von Makro- und Mikroperspektive, die enge Beziehung von Struktur, Praxis und Semantik, die Vernetzung von Methoden und Theorien auch aus anderen Disziplinen. ${ }^{38}$ Das Hauptaugenmerk liegt hierbei auf der Selbst- und Fremdwahrnehmung, auf Stereotypisierung und ihrem Ausdruck (linguistic turn ${ }^{39}$ ). Dabei hat die Darstellung des »Kleinen«, wie am Beispiel der Este zu zeigen sein wird, nicht Selbstzweck, sondern zeigt auf das »Große« hin. In diesem Sinne benutzt die Neue Kulturgeschichte weniger Strukturanalysen als »vielmehr >dichte Beschreibungen im Sinne Clifford Geertz', weil nur sie es vermöchten, jene Deutungs- und Sinnstiftungsweisen zu erhellen, die den Kern menschlicher Tätigkeit ausmachten. « ${ }^{40}$

Der Ansatz der Neuen Kulturgeschichte ist akteurszentriert, auf den Handelnden ausgerichtet und sieht Geschichte als »Ergebnis kultureller Praktiken von Individuen und Kollektiven «. ${ }^{41}$ Charakteristisch sind der Aspekt der Vernetzung, das Heranziehen von verschiedenen Quellentypen mit starkem "persönlichen« Bezug, so Korrespondenzen, Objektquellen im Rahmen des Gabentausches, Gesandtenberichte als Spielraum der Fremd- und Eigenwahrnehmung und der »erzählende Darstellungsmodus«. ${ }^{42}$ Typisch für die Neue Kulturgeschichte ist das »Interesse am Wechselseitigen, an der Rückkoppelung von Wahrnehmung und Verhalten sowie an der Konstituierung von Realität und damit verbunden von Macht durch Sprach- und Symbolhandlungen [... $\ll^{43}$ Ein Verdienst der Neuen Kulturgeschichte ist auch die Erkenntnis der Bedeutung von Symbolen, ${ }^{44}$ Zeremonien und Inszenierungen. ${ }^{45}$ Der Untersuchungsgegenstand »Kultur« wird »verstanden als Ensemble historisch wandelbarer Praktiken der Welt- bzw.

siehe Dülmen, Historische Kulturforschung; Landwehr/Stockhorst, Einführung; Landwehr, Kulturgeschichte; Reinalter, »Kulturgeschichte«.

37 Stollberg-Rilinger, Was heißt Kulturgeschichte, 2 I.

38 Landwehr/Stockhorst, Einführung, 87f, 97.

39 »Vereinfacht gesagt forderte der linguistic turn für die Geschichtswissenschaft eine Wendung von den historischen Fakten auf die Wahrnehmung und Deutung dieser Fakten. Jordan, Theorien, I 89. Durch diesen in den I 96oer Jahren in den Geistes- und Sozialwissenschaften eingeleiteten Paradigmenwechsel wurde die Sprache als einziges Medium des Erkennens, Kommunizierens und somit der Realitätskonstruktion in den Mittelpunkt gestellt. Durch Symbole, Zeichen und Wörter kann Sprache die Vorstellungen von Realität überhaupt erzeugen. Vgl. ENGEL, »Linguistic turn«.

40 Tschopp/Weber, Grundfragen, 73.

4 I Ebd.

42 Ebd., 74 .

43 Jordan, Theorien, 208.

44 Unter Symbol »ist ein sinnlich fassbares, materielles Etwas zu verstehen, das mit seinem Sinn bzw. mit seiner Bedeutung über sich selbst hinaus und auf ein Anderes verweist.« GRüN, »Symbol«, 774.

45 Tschopp/Weber, Grundfragen, 2 I. 
Wirklichkeitsdeutung, die nicht losgelöst von den institutionellen und strukturellen Determinanten rekonstruiert werden können, welche sie mit bedingen. Anders als die Alltagsgeschichte mit ihrer Präferenz für Angehörige sozialer Unterschichten nimmt die Kulturgeschichte auch die politischen, ökonomischen, religiösen und kulturellen Eliten in den Blick und gewährt beispielsweise wissenschaftsgeschichtlichen Fragestellungen breiteren Raum. ${ }^{46}$ In der vorliegenden Arbeit wird der Begriff »Kultur« vor allem im Sinne von Hofkultur verwendet, als Produkt einer bestimmten (höfischen) Elite, nämlich der regierenden estensischen Fürsten, ausgewählter Reichsfürsten und des Reichsoberhauptes inklusive deren Hof und familia. Was nicht berücksichtigt wurde bzw. nur gestreift werden konnte, ist die (ebenso interessante) Ebene der hoffernen Eliten, des Stadtpatriziats und der geistlichen Eliten. ${ }^{47}$

Ein weiteres Hauptanliegen der vorliegenden Studie ist die Darstellung und Sichtbarmachung von Netzwerkstrukturen im Sinne von Sebastian Gießmann, der festgehalten hat: "Erst durch den reflexiven Diskurs werden die Praktiken des Vernetzens zur Kulturtechnik der Netzwerke. ${ }^{48}$ Daher setzt Gießmann den Beginn von Netzwerken im heutigen Sinn erst mit dem I7. und I 8. Jahrhundert an, räumt aber »den mittelalterlichen und frühneuzeitlichen Vernetzungen eine formative Kraft zur - noch nicht als solcher reflexiv verstandenen - Netzwerkbildung « ein. ${ }^{49}$ Beim vorliegenden Untersuchungsgegenstand geht es nicht vorrangig um Verbindungen, die militärische oder politische Allianzbildungen widerspiegeln; vielmehr handelt es sich um Strategien des »Obenbleibens«, die auf einem Beziehungsgeflecht aus Freundschaften, Verwandtschaften und Klientelismus basieren, also im Sinne von Bourdieus ${ }^{50}$ mehrdi- $^{-}$ mensionalen Raum sozialer Beziehungen, vom sogenannten sozialen Feld ausgehen. ${ }^{51}$ In dieser Hinsicht folgt die Untersuchung den Ansätzen der Entangled History ${ }^{52}$, eine von Kreuzungsmomenten geprägten "gemeinsamen« oder "geteilten«, auf jeden Fall miteinander verstrickten Geschichte. (Soziale) Verflechtung ist hier im Sinne von Wolfgang Reinhard und des aus der Kulturanthropologie entlehnten Begriffs »net-

46 Ebd., 79 .

47 Am deutschen Beispiel hat Christian Hesse bereits gezeigt, dass Hof- und Verwaltungsämter nur in sehr beschränktem Maße den städtischen Eliten, also dem Patriziat zugänglich waren, was für italienische Verhältnisse auch angenommen werden kann. Vgl. Hesse, Städtisch-bürgerliche Eliten. Die »ruling class« am italienischen Fürstenhof besteht aus den dem Herrscher loyalen Adelshäusern und Einzelpersonen wie Fantoni betont hat: Fantoni, Corte e Stato.

48 Giessmann, Die Verbundenheit der Dinge, 9.

49 Ebd., 89.

50 Der Soziologieprofessor Pierre Bourdieu (1930-2002) hat in seiner soziologischen Milieuforschung der Kommunikation und den ritualisierenden Formen von Kapital, jenseits der marxistischen Deutung, eine neue und größere Bedeutung gegeben. Vgl. Denter, »Bourdieu, Pierre«.

5 I Bourdieu, Die feinen Unterschiede.

52 Hierfür siehe Conrad/Randeria, Einleitung. Zur Debatte über die unzureichenden Abgrenzungen siehe: Hartmut Kaelble, Die Debatte über Vergleich und Transfer und was jetzt?, in: H-Soz-Kult, 08.02.2005, http://www.hsozkult.de/article/id/artikel-574, Zugriff: 24.2.2020. 
work" gebraucht und meint verschiedentliche Interaktionen zwischen bestimmten Personen, wodurch bildlich ein laufend aufrechtzuerhaltendes Netz (Patron-Klient aber auch Klient-Klient) entsteht. ${ }^{53}$

Für den Versuch, am Beispiel der Este kulturelle Verstrickungen und Transfermöglichkeiten darzustellen, wurden auch Anregungen bei der von der Ethnologie und Soziologie angewendeten Netzwerkanalyse gefunden. Dieser Forschungsansatz ist bereits in den I95oer Jahren in der britischen und amerikanischen Sozial- und Kulturanthropologie als Ersatz oder Gegenbewegung zum Strukturfunktionalimus entstanden, mit dem Ziel soziale Beziehungen zu erfassen, Akteure selbst bei unterschiedlichen Beziehungsebenen und Inhalten in Beziehungsgeflechten sichtbar zu machen. ${ }^{54} \mathrm{Als}$ Netzwerk definiert Thomas Schweizer »eine Menge von Akteuren [...], die untereinander durch Beziehungen verbunden sind. $\aleph^{55}$ Diese meist computergestützte Methode erlaubt grafische Darstellungen von Netzwerken, wobei sie »Beziehungsbündelungen, Machtpotenziale, aber auch Abhängigkeiten und den unterschiedlichen Grad des Engagements in bestimmte soziale Beziehungen ${ }^{56}$ aufzuzeigen versucht. Die neue Netzwerkanalyse beschäftigt sich mit der Erfassung von komplexen Sozialstrukturen in jedem Gesellschaftstypus und mit Mikro-Makro-Verflechtungen. Zudem erlaubt sie eine Verbindung von Akteuren und Ereignissen herzustellen und die Intensität der einzelnen Beziehungen (strong/weak ties) zu unterscheiden. ${ }^{57}$ Obwohl es für die vorliegende Untersuchung nicht möglich war und nicht gewinnbringend schien, auf die computergestützte Methode der Netzwerkanalyse zurückzugreifen, hat die Untersuchung bezüglich der Fragestellung stark von den Ansätzen und Überlegungen dieser Herangehensweise profitiert.

\section{Aufbau der Arbeit und Quellen}

Die Arbeit soll am Beispiel der Herzöge von Ferrara, Modena und Reggio die Bedeutung Reichsitaliens für das Heilige Römische Reich im I6. Jahrhundert aufzeigen und darstellen, wie wechselvoll und intensiv die Beziehungen und Vernetzungen zwischen Zentrum/Zentren und Peripherie dieses räumlichen Konglomerats waren. Daher konzentriert sich die Untersuchung auf die Blütezeit der estensischen Herrschaft in den kaiserlichen und päpstlichen Lehen, die von zwei bemerkenswerten Zäsuren begrenzt ist. Am Anfang steht die Erhebung von Borso d'Este zum Herzog über die kaiserli-

53 Reinhard, Oligarchische Verflechtung, 48f; Fantoni, Corte e Stato, 456.

54 Dazu siehe Schweizer, Netzwerkanalyse, VIIf. und 5. Zur Methode der Netzwerkanalyse mit vielen

Beispielen: Jansen, Einführung; Schweizer, Muster sozialer Ordnung; Lang, Kulturelle Identität;

Mitchell, Social networks.

55 Schweizer, Netzwerkanalyse, I.

56 Ebd., 2.

57 Ebd., ıof, i5f. 
chen Lehen Modena und Reggio im Jahr I 452 (die päpstliche Erhebung folgte erst I47I); am Ende steht der Verlust Ferraras, des eigentlichen Macht- und Kulturzentrums der Este-Dynastie, durch den Heimfall des Lehens an den Kirchenstaat I $598 .{ }^{58}$

Die Untersuchung ist nicht nur auf die entwicklungs-, sondern auch auf die quellenreichste Zeit der Este-Herrschaft, von der Mitte des I 5. bis zum Ende des I6. Jahrhunderts fokussiert. Die befriedigende Quellenlage für diesen Zeitraum spiegelt sich auch in der starken Quellennähe der Studie wider.

Die Akteure sind auf der einen Seite die regierenden Fürsten aus der Dynastie der Este, von Borso d'Este, dem ersten Herzog von Ferrara, Modena und Reggio bis Alfonso II. d'Este, dem letzten männlichen Vertreter dieser Hauptlinie. Auf der anderen Seite finden sich die Kaiser derselben Zeit von Friedrich III. bzw. Maximilian I. bis Rudolf II., wobei bei Letzterem vor allem die Regierungszeit bis zur Wende von 16. zum I7. Jahrhundert von Interesse ist. Darüber hinaus sind die wichtigsten Protagonisten der Kreis der kaiserlichen familia (Kaiserinnen, Erzherzöge und Erzherzoginnen) und bedeutender, konfessionell gemischter Reichsfürsten, wie die Kurfürsten von Sachsen, die Herzöge von Bayern, von Mecklenburg und von Braunschweig-Lüneburg, die in diesem Zeitraum politisch und kulturell ebenso auf dem Höhepunkt ihrer Macht standen. Diese Auswahl ist aber nicht an der »Bedeutung « dieser Fürsten ausgerichtet, sondern von den Quellen vorgegeben. $\mathrm{Zu}$ diesen Mitgliedern des Reiches pflegten die Este eine mehr oder weniger ausgeprägte Korrespondenz, die im Staatsarchiv von Modena dokumentiert ist und ihre Pendants in den jeweiligen deutschen und österreichischen Staatsarchiven hat. Die Untersuchung ist somit vom estensischen Standpunkt ausgehend angelegt.

Neben den Korrespondenzen von Fürsten, Fürstinnen und auch nichtregierenden Mitgliedern der einzelnen Dynastien, die dann berücksichtigt wurden, wenn sie von Relevanz waren, sind die weiteren maßgeblichen Quellen die Gesandten- und zum Teil auch Nuntiaturberichte. Die Este hatten eine ständige diplomatische Präsenz im Reich, zumeist am Kaiserhof selbst. Die estensischen Gesandten des I6. Jahrhunderts mussten schwerwiegende Agenden wie die Präzedenzfrage, die Nachfolgeregelung, die Bewerbung um Titel und Königssitze durchfechten. Die tüchtigen Informanten und Repräsentanten des jeweiligen Herzogs von Ferrara, Modena und Reggio haben in ihren Briefen und in manchen ausführlichen relationi ein besonderes Bild von Kaiser und Reich gezeichnet, auf das hier besonders eingegangen werden soll.

Zuletzt seien noch einige Bemerkungen zur Orientierung angeführt. Für eine bessere Lesbarkeit und Strukturierung der Arbeit entlang der skizzierten drei Hauptthemen wurde auf einen biografischen Vorspann verzichtet. Stattdessen finden sich die Kurz-

58 Mit dem weiteren Werdegang Ferraras als von Legaten regierter Teil des Kirchenstaates und mit den Entwicklungen zur sogenannten decadenza hat sich Birgit Emich auf beeindruckende Weise auseinandergesetzt. Vgl. Емісн, Territoriale Integration. 
biografien der regierenden Este-Fürsten des Untersuchungszeitraumes eingebettet in einem Überblick zum Werdegang der Dynastie im Anhang. Hier sind auch die estensischen Gesandten im Reich aufgelistet. Um die Bibliografie zu diesen forschungsintensiven Themen übersichtlich zu halten, wurde nur die tatsächlich verwendete Literatur in der Bibliografie vollständig erfasst; Lexikoneinträge und die weiterführende Literatur sind vollständig aber ausschließlich in den Anmerkungen angeführt. Fremdsprachliche Begriffe sind kursiv gesetzt; ihre Groß- oder Kleinschreibung richtet sich nicht nach der deutschen Rechtschreibung, sondern danach, wie sie in der Originalsprache geschrieben bzw. verwendet wurden, so durchaus auch im Italienischen groß, wo allgemein die Kleinschreibung vorherrscht (z.B. als Titel Imperatore, Papa, Savi).

Die Sprachen der verwendeten Quellen sind vielfältig wie die Akteure, die sie produzierten: Lateinisch, Italienisch, Deutsch, Spanisch und Französisch. Die Zitate sind in der Originalsprache gehalten und von der Autorin gekennzeichnet übersetzt oder paraphrasiert worden. 
Publikation im Sinne der CC-Lizenz BY 4.0 
1. VASALLITÄT - PRÄZEDENZ - DEVOLUTION 
Publikation im Sinne der CC-Lizenz BY 4.0 


\subsection{Vasallität}

\subsubsection{Reichsitalien - Definition und Zusammensetzung}

Das Alte Reich, also das Heilige Römische Reich Deutscher Nation, umfasste in der Frühen Neuzeit weite Teile Europas und darunter seit dem Mittelalter auch Teile der italienischen Halbinsel, das sogenannte Reichsitalien. ${ }^{1}$ Darunter versteht man »die Reste des ursprünglich langobardischen regnum Italiae, das seit Otto I. im Io. Jahrhundert mit dem deutschen Königtum in Personalunion verbunden war und einen Teil des mittelalterlichen Heiligen Römischen Reichs bildete. « ${ }^{2}$ Mit oder ohne der Eisernen Krone der Langobarden und dem dazugehörenden Titel eines Königs von Italien beanspruchten die Kaiser der Neuzeit ihre bisweilen umstrittenen Lehens- und Reichsrechte über die sogenannten feudi imperiali italiani. Doch während das Alte Reich seit dem Ende des I 5. Jahrhunderts von Institutionen wie dem Reichstag, ${ }^{3}$ in dem Kaiser und Reichsstände ${ }^{4}$

I Dieses Kapitel über Reichsitalien dient der allgemeinen Einführung, Orientierung und dem Problemaufriss für die Einbettung italienischer Fürsten in den Reichslehnsverband. Es wurde daher bewusst auf eine ausufernde Angabe von weiterführender Literatur verzichtet. Der chronologisch ausgerichtete Abriss referenziert auf wenige, jedoch fundamentale Überblickswerke. Für die Entwicklung des Reiches vom Mittelalter bis in die Neuzeit ist besonders dienlich: Stollberg-Rilinger, Das Heilige Römische Reich; Herbers/Neuhaus, Das Heilige Römische Reich. Als Überblick über die historische Entwicklung der italienischen Halbinsel seit dem Mittelalter siehe: Haverkamp, Italien im hohen und späten Mittelalter; Seidlmayer, Geschichte Italiens; Pauler, Die deutschen Könige; Frenz, Italien im Mittelalter; Goez, Geschichte Italiens.

Als Einführung zu Reichsitalien siehe: Matthias Schnettger, »Reichsitalien«, in: Friedrich Jäger, Enzyklopädie der Neuzeit ro, Sp. 92 I-923; Baethaen, Das Reich und Italien; Edelmayer, Maximilian II.; Cavallera, Les fiefs impériaux; Cremonini, Impero e feudi; Schnettger/Verga, L'Impero e l'Italia; Cremonini/Musso, I feudi imperiali; Raviola, The Imperial System; Bellabarba/MerLOtTi, Stato sabaudo; Whaley, Germany and the Holy Roman Empire, in der deutschen Fassung: Das Heilige Römische Reich Deutscher Nation, zu Italien besonders 39-49, 99- ro7.

Als Primärliteratur immer noch gültig: Lünig, Codex Italiae Diplomaticus; Seidensticker, Beyträge zum Reichsstaatsrechte.

2 Schnettger, »Reichsitalien«, $92 \mathrm{I}$.

3 Mit dem Begriff Reichstag sind verschiedene Formen der Zusammenkunft der Großen des Reiches gemeint. Für die hier behandelte Zeit des I 5. und I6. Jahrhunderts sind damit die Versammlungen von Kaiser und Reichsständen gemeint, die seit I 495 diesen Namen tragen. Der Reichstag formierte sich ab I 470 und endgültig I 5 55. Peter Moraw, »Reichstag«, in: Lexikon des Mittelalters 7, München I 995 , Sp. $640-643$.

4 »Unter Reichsständen sind die in drei Kollegien (г. Kurfürsten, 2. geistliche, weltliche Fürsten, Prälaten, Grafen und Herren und schließlich 3. Städte) zusammengeschlossenen unmittelbaren Glieder des Reiches zu verstehen, die ihren Anspruch, das Reich gegenüber dem Herrscher zu repräsentieren, durchzusetzen vermochten und die daher berechtigt waren, auf Reichstagen ein Mitsprache- und Stimmrecht in 
zusammentrafen, dem Reichshof- ${ }^{5}$ und später Reichskammergericht ${ }^{6}$ für die Wahrung von Frieden und Recht, den Reichskreisen, ${ }^{7}$ in denen die Reichspolitik umgesetzt werden sollte, und dem Reichshofrat ${ }^{8}$ zusammengehalten war, wurden die zum Reich gehörenden italienischen Gebiete nur in bedingtem Maße von diesen Institutionen vertreten. ${ }^{9}$ Anders als die westliche Peripherie ${ }^{10}$ des Reiches, die in Kreise organisiert war (Burgundischer Reichskreis mit den habsburgischen Niederlanden und Franche-Comté) oder die östliche Peripherie mit Böhmen, dessen König im r6. Jahrhundert an der Kaiserwahl teilnahm, waren die italienischen Gebiete nur durch das Lehensrecht mit dem Reich verbunden. Anders verhielt es sich mit dem Herzogtum Savoyen, das zum Oberrheinischen Reichskreis und damit zum Heiligen Römischen Reich Deutscher Nation im eigentlichen Sinn zählte. Der Herzog besaß als einziger italienischer Fürst Sitz und Stimme im Reichstag; zudem hatten die Savoyer seit dem späten r6. Jahrhundert das Reichsvikariat in Italien inne. ${ }^{11}$ Auch wenn die anderen, aus der kommunalen Tradition entstandenen italienischen Territorien Ober- und Mittelitaliens, keine Stimme im Reichstag hatten und nicht

Form der ihnen jeweils zugestandenen Viril- oder Kuriatsstimmen auszuüben«. Ralf Miтsch, »Reichsstände«, in: Lexikon des Mittelalters 7, Sp. 639 f.

5 Das seit dem 9. Jahrhundert urkundlich nachweisbare Reichshofgericht bestand aus den am Hof anwesenden Adeligen als Urteiler und dem deutschen König oder seinem Vertreter. War es zunächst nur ein fallweise zusammentretendes Königsgericht, so wurde es ab I 235 ein ständiges Gericht unter dem Vorsitz eines hochadeligen Hofrichters. Friedrich Battenberg, "Reichshofgericht«, in Lexikon des Mittelalters 7, München 1995, Sp. 622 f.

6 Während das Reichshofgericht I45 I zum Ende kam, hatte sich seit I4I 5 unter Kaiser Karl IV. eine der Rechtsprechung gewidmete Institution das sogenannte »Kammergerich« (sic) entwickelt, wo der König auch eigene Ansprüche (Majestätsverbrechen) geltend machen konnte. I 47 I erhielt das Gericht durch Kurfürst Adolf von Mainz eine erste, später erweiterte Kammergerichtsordnung. Seit 1527 tagte das Gericht, das aus Juristen, Adeligen und einem Kanzleiverwalter bestand, in Speyer außerhalb des Kaiserhofes. Friedrich Battenberg, "Reichskammergericht«, in: Lexikon des Mittelalters 7, München I995, Sp. 626.

7 Mit diesen setzen sich die Tagungsbeiträge des Sammelbandes Wüst/MüLler, Reichskreise und Regionen auseinander. Hierbei konnte Matthias Schnettger zeigen, dass Reichskreise von italienischen Gesandten eher als geografische Einheiten denn als Reichsinstitutionen wahrgenommen wurden. Schnettger, Selektive Wahrnehmung.

8 Auf den Reichshofrat, einem Ratsgremium des Kaisers, das für Reichslehen, Gnadensachen und Rechtsangelegenheiten zuständig war und neben dem Reichskammergericht als zweites Höchstgericht des Reiches arbeitete, wird noch unten näher einzugehen sein. Hier vorerst nur: Eva Ortlieb, »Reichshofrat", in: Friedrich Jäger, Enzyklopädie der Neuzeit Io, Sp. 914-920.

9 Wendehorst/Westphal, Das Alte Reich, I.

Io Der Begriff Peripherie wird hier, wie allgemein in der Geschichtswissenschaft »zur Kennzeichnung der Verhältnisse von Regionen außerhalb des Zentrums benutzt« und soll im Fall des Heiligen Römischen Reiches bei der »Frage des Zusammenhalts auch als Verhältnis von Zentrum und Peripherie verstanden« werden, das durch bestimmte rechtliche Formen wie z.B. die Vasallität gestaltet ist. Hans-Heinrich Nolte, »Peripherie«, in: Friedrich Jäger, Enzyklopädie der Neuzeit 9, Sp. 977-980, hier 977.

I I Sehr übersichtlich ist die Struktur des Reiches und seiner Institutionen im Studienbuch von GotThARd, Das Alte Reich, 4-6, ${ }_{5}$ f dargestellt. Vgl. auch Zwierlein, Savoyen-Piemonts Verhältnis. 
Mitglieder des Reiches, sondern Vasallen waren, so galten Kaiser und Reich vor allem für die kleineren unter ihnen als bedeutende Schutzmacht gegen die Expansionsbestrebungen und Anspruchserhebungen der größeren Territorien bzw. des Papstes als des bedeutendsten Territorialfürsten auf der italienischen Halbinsel. ${ }^{12}$ Als Vasallen des Reiches mussten die italienischen Fürsten bei jedem Machtwechsel sowohl auf Reichsseite als auch in ihrer dynastischen Folge die Investitur mit dem Reichslehen erneuern. Zwar waren ihre Lehen de facto bereits seit dem Mittelalter erblich geworden, doch verlangte das Lehensrecht bei jedem Herrscherwechsel auf beiden Seiten die rituelle Erneuerung der Investitur und des Treueverhältnisses. Dieser Akt vollzog sich im I 5. und I6. Jahrhundert noch am ersten feierlichen Hoftag des neuen Königs/Kaisers in der aufwendigen Form eines Turniers. Diese öffentliche turnierähnliche Belehnungsform wurde im Laufe des I6. Jahrhunderts immer seltener, letztens wurde sie I 566 bei der Belehnung von Kurfürst August von Sachsen angewendet. Immer öfter fand die Belehnungszeremonie am Kaiserhof statt, vor allem nachdem der Kaiser höchst selten auf Reichstagen persönlich erschien. Ebenso selten nahmen die Zu-Belehnenden persönlich an ihrer Investitur teil, sondern ließen sich zunehmend vertreten. Der Akt spielte nun in der höfischen Öffentlichkeit und wurde immer mehr verschriftlicht. ${ }^{13}$

Ein für die vorliegende Untersuchung bedeutendes Recht des Kaisers im Rahmen des Lehenswesens war die Möglichkeit, ein Lehen beim Aussterben der Vasallenfamilie oder aufgrund von Felonie (Treuebruch) einzuziehen. Ebenso wichtig war die Möglichkeit des Kaisers aus Reichsitalien Kontributionen, z.B. zur Verteidigung des Glaubens bei Türkenkriegen und anderen Bedrohungen einzufordern - wenngleich diese unregelmäßig und zumeist in nicht vorhersehbarer Höhe dem Reichsoberhaupt zukamen. ${ }^{14}$ Eine weitere Einnahme des Kaisers waren die bei der Investitur eingehobenen Lehenstaxen. ${ }^{15}$ Der Kaiser war also für Reichsitalien oberster Lehensherr, Legitimationsinstanz z.B. bei Rangerhöhungen und höchster Richter. Seine wiederholte und langjährige Abwesenheit von Italien und seine eingeschränkten Mittel, Reichsansprüche geltend zu machen, standen seiner Macht in Italien im Weg. Dieses Machtvakuum wussten besonders die italienischen Fürsten der Frühen Neuzeit in ihrem Souveränitätsbestreben immer wieder auszunutzen. ${ }^{16}$

I 2 u einigen dieser päpstlichen Vorhaben siehe bei Strnad, Die Päpste, und Iserloh, Die Päpste.

I 3 Stollberg-Rilinger, Verfassungsakt oder Fest?, $97 \mathrm{f}$.

I 4 Wie Cornel Zwierlein letztens klargestellt hat, standen diese Geldleistungen der italienischen Vasallen »außerhalb des Matrikularsteuersystems [statt], da sie zum regnum Italiae und somit nur zum Lehensverband, nicht zur Korporation der Reichsstände gehörten«. Dazu und zum undurchsichtigen Fiskalsystem des Reiches: Zwierlein, Deutsche und italienische Staatsbeschreibungskunst, 594, Anm. 8.

I 5 Unter den sogenannten Laudemien sind im frühneuzeitlichen Heiligen Römischen Reich vor allem Zahlungen an den Lehensherrn bei der Neuvergabe von Lehen und bei Standeserhöhungen zu verstehen. Vgl. Dieter Hägermann, »Laudemium«, in: Lexikon des Mittelalters 5, Stuttgart 20 14, Sp. I 753.

i6 Schnettger, »Reichsitalien«, 92 I-923. Schnettger, Die Reichsgerichtsbarkeit; Bussi, Tradizione e innovazione; STORRs, Imperial Authority. 
$\mathrm{Zu}$ den italienischen Reichslehen (feudi imperiali italiani) gehörten sowohl große Territorialstaaten wie z.B. die Herzogtümer Modena und Reggio, welche das südwestliche Herrschaftsgebiet der Este darstellten, als auch kleinere und kleinste Lehen, einige davon innerhalb des Gebietes von Reichsvasallen. In den großen Territorialstaaten wie Mailand, Piemont, Mantua und eben Modena hatte der Kaiser allgemein nur einen eingeschränkten Handlungsspielraum, während er den kleineren Lehen, die von der neueren Geschichtsschreibung als das eigentliche Reichsitalien definiert wurden, vorrangig Schutzherr und Verteidiger vor den größeren Territorialstaaten und ihren Expansionsbestrebungen war. ${ }^{17}$

Doch bevor hier auf Reichsitalien in der Neuzeit allgemein und auf das kaiserliche Lehen der Este im Besonderen eingegangen wird, soll in groben Zügen die Entwicklung dieser Reichsgebiete auf der italienischen Halbinsel seit dem Mittelalter nachgezeichnet werden.

Auschlaggebendes Kriterium für die Zugehörigkeit zum Heiligen Römischen Reich Deutscher Nation war - wie bereits erwähnt - die Zugehörigkeit zu einem Reichskreis. Demzufolge gehörten in Italien ausschließlich das Herzogtum Savoyen als Teil des Oberrheinischen Kreises und das Fürstbistum Trient, das mit Brixen und der Grafschaft Görz mit Gradisca die welschen Konfinen des österreichischen Reichskreises bildete, dazu. Die restlichen italienischen Reichsgebiete bildeten das italienische oder lombardische Reich, also Reichsitalien (Italia imperiale). Es bestanden große und für die Entwicklung zum modernen Staat folgenreiche Unterschiede zwischen diesem und den Gebieten des deutschen Reiches. ${ }^{18}$

Beiden Bereichen gemein war, dass der Kaiser der oberste Lehensherr war, während die einzelnen Fürsten Territorialherren waren. Die kaiserlichen Reichslehen in Italien wurden in fünf Kategorien unterteilt: I3 lombardische Lehen, darunter Mailand, Mantua und die Herrschaftsgebiete der Gonzaga, ${ }^{19}$ I 9 ligurische Lehen mit den Besitzungen der Fürsten Doria, 2o Bologneser Lehen, darunter Modena und Spinola, zehn toskanische Lehen, darunter das Herzogtum Toskana und Soriano, I I tyrrhenische Lehen, darunter Massa und Malaspina. Darüber hinaus gab es auf der italienischen Halbinsel allodiale Reichsbesitzungen und reichsunmittelbare Gebiete. ${ }^{20}$

Anders als im Heiligen Römischen Reich Deutscher Nation, wo Kaiser und Reich, d.h. der Kaiser unter Mitwirkung der Reichsstände, herrschten, gab es in Italien bis auf Savoyen ${ }^{21}$ keine reichsunmittelbaren Fürsten, die Sitz und Stimme im Reichstag

I7 Schnettger, Feudi imperiali, in $7 \mathrm{f}$.

i 8 Brauneder, Impero e Stato, $62 f$.

I9 $\mathrm{Zu}$ dieser Dynastie und ihrem Werdegang siehe überblicksmäßig Reinhardt, »Gonzaga«.

$20 \mathrm{Vgl}$. Brauneder, Impero e Stato, ${ }_{3} \mathrm{f}$.

2I Nur der Herzog von Savoyen, seit I52I »Welscher Fürst« tituliert, und der Fürstbischof von Trient gehörten zu den Reichsständen, während die Grafschaft Görz am Reichstag vom Haus Österreich mitvertreten wurde. Vgl. Brauneder, Impero e Stato, $64 f$. 
hatten. Theoretisch bedeutete dies für den Kaiser, dass er in Italien mehr Handlungsspielraum besaß als im deutschen Reich, da einerseits die italienischen Fürsten nicht in Reichsständen geeint waren und somit wenig Einfluss hatten und andererseits die deutschen Reichsstände dem Kaiser in Italien freie Hand ließen. Die italienischen Reichsfürsten kamen - wenn überhaupt - als Bittsteller und nicht als entscheidungstragende Teilnehmer zum Reichstag.

Praktisch und tatsächlich aber waren die kaiserlichen Rechte in Italien stark eingeschränkt und vom Erfolg der Italienpolitik der einzelnen Könige und Kaiser sowie von ihrer Präsenz vor Ort abhängig. Wie erfolgreich die Kaiser seit dem Mittelalter in Italien waren, soll nun in der Folge aufgezeigt werden.

\subsubsection{Reichsitalien im Mittelalter}

Die italienische Halbinsel war seit dem Mittelalter von einer Dreiteilung geprägt: Der germanische Norden reichte bis zur Toskana, in der Mitte entwickelte sich der römische Teil zum Kirchenstaat, während der Süden zuerst unter byzantinischer und dann unter französischer und spanischer Herrschaft stand. ${ }^{22}$ Im nördlichen Teil Italiens, in den als Reichsitalien bezeichneten Resten des ursprünglich langobardischen Regnum Italiae $^{23}$, regierten also formal die deutschen Könige. Seit dem ro. Jahrhundert war dieses Gebiet mit dem deutschen Königtum in Personalunion verbunden und somit Teil des mittelalterlichen Heiligen Römischen Reiches. Der Begriff Regnum Italiae wurde nach 8I 7 mit Lothar I., der erstmals den Titel rex Italiae annahm, gebraucht, während seine Vorgänger wie Karl der Große noch den Titel rex Francorum et Langobardorum benutzt hatten.

Seit Karl dem Großen (seit 78 I König von Langobardien, 80o-8 I 4 Kaiser), ${ }^{24}$ also seit das einstige Langobardenreich dem fränkischen Reich und somit dem deutschen Imperium eingegliedert worden war, und bis in die späte Neuzeit blieb dieses Reichsitalien benannte Gebiet mit dem Reich jenseits der Alpen verbunden und wurde vor allem nach der Aufösung der staufischen Herrschaft von diesem verwaltet und beansprucht. ${ }^{25}$ Nicht nur, oder nicht so sehr, die Herrschaft Karls des Großen führte in Italien zu tiefgreifenden Veränderungen, sondern vor allem das europäische Phänomen der Feudalisierung. Diese profitierte in Italien von der vorherrschenden Grundherrschaft, der Großräumigkeit der Territorien und dem Versagen des byzantinischen Beamtentums, welches keine zentralisierte Verwaltung entwickeln konnte. Stattdessen

22 Frenz, Italien im Mittelalter, I5-I7.

23 Eckhard Müller-Mertens, »Regnum Italiae«, in: Lexikon des Mittelalters 7, Sp. 596-60r, hier 596 598; Gerhard Dilcher, »Reichsitalien« (Mittelalter), in: Handwörterbuch zur deutschen Rechtsgeschichte 4, Berlin I990, Sp. $642-648$.

24 Vgl. unter vielen Stefan Weinfurter, Karl der Große. Der heilige Barbar, München u.a. ${ }^{2} 2013$.

25 Seidlmayer, Geschichte Italiens, 66-68. 
waren die Befugnisse an den Grundbesitz gebunden und die Ämter wurden jenen übertragen, die dazu neigten, sie erblich an die Familie zu binden. Die Amtsträger, die den Herrscher in Angelegenheiten des bewaffneten Schutzes, der Verwaltung und der Rechtsprechung vor Ort vertraten, wurden Zwischenglieder zwischen König und Untertanen und für Letztere oft die einzigen Ansprechpartner und anerkannten Machtinhaber im Vergleich zum entfernten und von Italien meist abwesenden Herrscher. Statt eines weisungsgebundenen Beamtentums entwickelte sich also eine schwache, labile lehensrechtliche Verpflichtung zwischen dem König und von diesem anerkannten Grafen, die auch aus Verteidigungsgründen immer größere Gebiete zusammenfassten und unter ihren militärischen Schutz stellten. Diese Gebiete wurden zu Markgrafschaften, wie die Mark Friaul, die Mark Ancona, die Markgrafschaft Tuszien, Treviso, etc. Bereits unter Karl dem Großen und noch mehr unter seinen Nachfolgern verlor die königliche Macht in Reichsitalien durch die Vergabe von Privilegien und Regalien (Zölle, höhere Gerichtsbarkeit, Marktrechte) zugunsten der Lokalgewalten an Gewicht. ${ }^{26} \mathrm{Zu}$ den Begünstigten dieser Entwicklung gehörten auch kirchliche Organe, Bistümer und Klöster, die noch dazu eine Immunität gegenüber der weltlichen Machtausübung genossen. Die Macht des Königs war in Italien zudem durch die schon bestehenden und sich weiter entwickelnden Stadtkommunen geschwächt.

Mit Otto I. (ab 95 I König von Italien, 962-973 Kaiser) ${ }^{27}$ begann ein oft wiederkehrendes Schauspiel: Zunächst wurde der König in den Gebieten Reichsitaliens freudig empfangen und die Städte und Territorialherren unterwarfen sich ausdrucksstark der Reichsmacht; war das Reichsoberhaupt wieder weg, folgte ein Aufstand dem anderen, bis der amtierende Kaiser oder sein Nachfolger den nächsten Italienzug anberaumten. Dieser (Teufels-)Kreis sollte die Geschichte Reichsitaliens und des Reiches in den nächsten 300 Jahren prägen. Jeder König/Kaiser, der - mindestens einmal zur Krönung nach Italien kam, bemühte sich hier um die Festigung der kaiserlichen Macht. Aber in der überwiegenden Zeit, in der das Reichsoberhaupt nicht in Reichsitalien war, wurde das Land stellvertretend von vom ihm ernannten Reichsvikaren verwaltet. ${ }^{28}$

\subsubsection{Das (Reichs-)Vikariat}

Ein (Reichs-)Vikar war ein Substitut, ein Stellvertreter und Statthalter des Machthabers. Er regierte für diesen nach dessen Tod, bei Thronvakanz oder in dessen Abwesenheit. In der Peripherie des Reiches, in Reichsitalien oder Burgund, hingegen vertrat er das Reichsoberhaupt meist dauerhaft. Der Reichsvikar handelte anstatt des Königs und in seinem Namen, im Falle eines Interregnums im Namen des Reiches. Sein Amt war grundsätzlich widerrufbar, manche Bestallungen konnten aber auch erblich er-

26 Als ein Beispiel dafür siehe: Castagnetti, Dai da Ganaceto.

27 Vgl. Schneidmüller, Otto I.

28 Seidlmayer, Geschichte Italiens, 70-86. 
folgen. Sein Vikariatsbezirk und sein Kompetenzbereich konnten sehr groß sein und wurden von Fall zu Fall definiert. Städte- und Judensteuern oder Zolleinnahmen stellten zumeist Aufwandsentschädigungen für die Amtsführung dar. Besonders in Reichsitalien dienten Reichsvikarsbestallungen der Legitimierung von weltlichen und geistlichen lokalen Machthabern, während die kaiserlichen Entsender von Generalvikaren damit die Reichsrechte gewahrt haben wollten. ${ }^{29}$ Diese scheiterten jedoch in ihrem Vorhaben, die sich etablierenden Signorie zu verdrängen. So blieb als Alternative nur noch Letztere durch das Vikariat zu legitimieren und die einheimischen signori, ${ }^{30}$ in ihrer erstarkenden Stellung zu bestätigen. Von dieser Entwicklung sollte - wie noch zu zeigen sein wird - unter anderen auch die Familie der Este profitieren.

Es gab eigentlich zwei Formen von Vikariaten: Der seit Friedrich II. vom Reichsoberhaupt ernannte und über das Regiment der Kommunen eingesetzte Bevollmächtigte und der vom Volk bestimmte, der eigentlich - so Rill - »reichsrechtlich als Usurpator zu gelten hätte «. ${ }^{31}$ Es ist der zweite Typus, der sich in den italienischen Kommunen durchsetzte, jener, des gewählten signore, den das Reich dann "nur noch" legitimierte. Durch diese Legitimierung von einer oberen Instanz verstand sich der signore von den Verpflichtungen gegenüber der Kommune entbunden und in der Entfaltung seiner Alleinherrschaft bestätigt. Andererseits war die Bestätigung der königlichen Wahl des Vikars durch die Kommune wiederum ein Ausdruck ihrer Kompetenz, wenn nicht sogar ihrer letztinstanzlichen Befugnis. ${ }^{32}$

Im Spätmittelalter wandelte sich das Vikariat, verlor an Bedeutung und genauer Kompetenzdefinition und wurde zunehmend in Frage gestellt (auch weil es anders als das im Kirchenrecht genannte kirchliche Vikariat rechtlich nicht verankert war). ${ }^{33}$ Doch gerade diesem slangsamen Dahinsiechen verdankte dieses Amt sein Überleben bis in die Neuzeit und seinen Übergang in die Plenipotenz. ${ }^{34}$

Man kann also festhalten, dass das ständige Reichsvikariat die Etablierung von Fürstendynastien in Reichsitalien stark begünstigt hat. Unter Maximilian I. und Karl V. wurde dieses Amt zum Lehen, »als eine hohe, nicht näher definierte Würde «. ${ }^{35}$ Obwohl die Kaiser des I6. Jahrhunderts, allen voran Maximilian I. und Karl V., die Rechtsabhängigkeit der feudi imperiali italiani vom Reich zu betonen versuchten, ist

29 Eberhard Isenmann, »Reichsvikar«, in: Lexikon des Mittelalters 7, Sp. 647 f. Ausführlicher über diese und andere Stellvertreter Heскмann, Stellvertreter, besonders Kap. Das italische Reichsvikariat als Zankapfel zwischen Imperium und Sacerdotium I, 438-442.

30 Hier und in der Folge werden für diese lokalen italienischen Machtinhaber und ihr aus der kommunalen Tradition entwickeltes Machtzentrum die italienischen Begriffe signore und signoria, dt. Signorie verwendet. Am Ende dieser Entwicklung stand das erbliche Fürstentum, genannt principato.

3I RiLl, Reichsvikar, I8I.

32 Ebd.

33 Vgl. Heckmann, Stellvertreter, besonders zu den Este im Kap. Vikare der Päpste (I 3 I 4 - I365) I, 5 I 7 f.

34 RiLl, Reichsvikar, I 83 f. Zur Plenipotenz siehe unten.

35 Ebd., I87. 
nach Rill die Einsetzung der Markgrafen von Savoyen ${ }^{36}$ als ständige Reichsvikare in Italien I503 durch Maximilian I. nicht als Reformversuch der Reichsverwaltung zu werten, sondern vielmehr als Mittel zur Sicherung des aus Italien kommenden Geldflusses. ${ }^{37}$

Als spätmittelalterliche Vikare hatten auch die Este Machtbefugnisse, so z.B. die Kontrolle über Gerichtsverhandlungen, Urteile und Richter. Außerdem ermöglichten ihnen die kaiserliche und päpstliche Belehnung die Ausbildung von Organen zur Unterstützung und zum Ausbau der juridischen und allgemeinen potestas. Der erste Ausdruck ihrer juridischen Macht war der 1372 eingerichtete consilium domini marchionis, ein Expertenrat aus vom Markgrafen eingesetzten Vertretern, der sich ab dem I 5. Jahrhundert besonders um Vormundschaften, Witwen und Waisen sowie Arme kümmerte. Als frisch erhobener Herzog errichtete Borso nach dem Vorbild von Mailand und Mantua ein consilium iustitiae, das sich um Rechtsfälle und -zweifel, Gnadenbitten und alle Streitigkeiten kümmerte, in die ein estensischer Untertan verwickelt war. Es war der Ausdruck einer großen Macht, die dem Herzog nun durch kaiserliche Legitimation zustand, und die er auch ausübte. ${ }^{38}$ Ercole II. d'Este führte dann das Consiglio di Segnatura, ein politisch-juridisches Organ zur Entlastung des Consiglio di Grazia, das mit Gnadengesuchen überhäuft wurde, ein. ${ }^{39}$ Wie Gian Maria Varanini untersucht hat, bestand bei den oberitalienischen signori, und so auch bei den Este, seit der Mitte des I 4. Jahrhunderts die Praxis der an die Fürsten gerichteten Suppliken. ${ }^{40}$ Diese kamen von einzelnen Untertanen oder im estensischen Fall auch von Städten und Gemeinden vor allem nach der kritischen Zeit der Okkupation durch päpstliche bzw. kaiserliche Truppen (Reggio war I 5 I 2-I523, Modena von I5 IO- I 527 unter päpstlicher Herrschaft). Nachdem der status quo wiederhergestellt worden war und die Este sich mit dem Papst durch eine deutliche Erhöhung des Lehenszinses versöhnt hatten, gab es in Teilen des Fürstentums wie der Grafagnana noch Unruhen, begleitet

36 Zur Familie siehe Reinhardt, »Savoyen«.

37 Ebd., I73-r76. Die im Schmalkaldischen Bund vereinigten protestantischen Fürsten boten dem Dauphin, Henri (II.), I 546 das Reichsvikariat in Italien an, das zwar nicht Realität wurde, den Kaiser aber über die Gefahr dieses Verlustes nachdenken ließ. So ergab sich die Idee der Übertragung des italienischen Vikariats an Philipp II., der jedoch am Widerstand Ferdinands I., der darin die Auslieferung (Reichs)Italiens an Spanien sah, scheiterte. Ebd. I89- 192. Siehe auch Ficker, Forschungen zur Reichsund Rechtsgeschichte, besonders Kap. 30 und 3 I zu Vikariat.

38 So ist ikonografisch auch Borsos Darstellung als sitzender und Recht sprechender Fürst am Volto del Cavallo im Stadtzentrum vom Ferrara zu verstehen.

39 Mit der Umsiedlung nach Modena stießen sich die Statuten der Stadt mit den in Ferrara gängigen Vorgangsweisen und mussten angepasst werden, ein Prozess, der sich bis ins I8. Jahrhundert zog. Tavilla, La giustizia suprema, 905-9 I I. Vorreiter in dieser Verfeinerung der Kompetenzen einzelner Institutionen war die römische Kurie. Vgl. Nuвola, Die »via supplicationis«, 66.

40 Varanini verweist auf die entsprechenden Bestände im Staatsarchiv Modena, in denen diese Suppliken aufbewahrt werden. VARANINI, "An den prächtigen und mächtigen Herrn«, hier besonders das Kapitel zu den Visconti, Este, Gonzaga und da Carrara, I03- ro8. 
von Suppliken, in denen um die Tilgung der in der Krisenzeit angehäuften Schulden gebeten wurde. ${ }^{41} \mathrm{Da}$ aber die Ratsversammlungen von Modena und Reggio, also die kommunalen Eliten, neben dem Fürsten gleichzeitig auch Adressaten von Bittschriften und in einem gewissen Ausmaß Entscheidungsträger in manchen vorgetragenen Belangen blieben, konnte das Justizwesen lange nicht vereinheitlicht und zentralisiert werden und die Reichslehen behielten, anders als das päpstliche Ferrara, einen Sonderstatus innerhalb der stati estensi. ${ }^{42}$

Neben dem Amt des Reichsvikars gab es im mittelalterlichen Italien auch andere Stützen des Reiches: So lehnte sich die Herrschaft der Ottonen an die mit Grafschaftsrechten ausgestatteten Bischöfe, also an das ottonisch-salische Reichskirchensystem.

Obwohl auch Heinrich II. (seit 1004 König von Italien, IOI4- I024 Kaiser) ${ }^{43}$ den italienischen Episkopat in die Dienste des Reiches stellte, konnte er dennoch die kaiserliche Macht nicht dauerhaft konsolidieren, da die Bischöfe als Stellvertreter des Kaisers auch oder vor allem die Interessen ihrer Bistümer und des Oberhauptes der Kirche vertraten. ${ }^{44}$ Zudem waren viele in der Zwischenzeit beim Domkapitel und den Bürgern ihrer Stadt hoch verschuldet und mussten attraktive Liegenschaften und Rechte im Zuge der sogenannten dilapidatio, der Verschleuderung von Reichsrechten, verkaufen, um ihre Schulden zu tilgen. ${ }^{45}$ Dieses Phänomen stärkte in einem schleichenden Vorgang vor allem die Bürger der Städte, die dem Bischof nicht mehr ausschließlich beratend zur Seite standen, sondern mit ihm um die Macht in der erstarkenden Kommune wetteiferten. ${ }^{46}$

Die Nachfolgevakanz nach dem Tod von Heinrich II. I024 brachte die Einheit der Herrschaftsausübung wiederum in Gefahr, doch konnte sich König Konrad II. (Kaiser 1027-1039 $)^{47}$ auch in Italien behaupten und wurde 1026 in Mailand zum König von Italien und im Jahr darauf in Rom zum Kaiser gekrönt. Unter seiner Herrschaft zeichneten sich zwei Problemfelder in Italien ab: das Verhältnis zwischen niederen Lehensträgern und ihren weltlichen oder geistlichen Feudalherren und die erstarkende bürgerlich-städtische Bewegung. Zum ersten Problem kam hinzu, dass die von der Krone direkt Belehnten, meist deutscher oder fränkischer Herkunft, mittlerweile ihre Lehen erblich gemacht und sich in den königlichen Ämtern in Italien verselbstständigt hatten. Sie stellten die kriegerische Macht des Königs dar. Diesen gegenüber stand die von diesen abhängigen zahlreichen niederen Lehensnehmer aus dem heimischen und langobardischen Adel, deren Stellung auf dem nicht erblichen und daher stark um-

4I Turchi, Fürstliches Recht, 38 of.

42 Turchi, Fürstliches Recht, 409.

43 Vgl. Weinfurter, Heinrich II.

44 Goez, Geschichte Italiens, I I3.

45 Ebd., I 23. Seidlmayer, Geschichte Italiens, i I 8.

46 Goez, Geschichte Italiens, I 24.

47 Vgl. Wolfram, Konrad II. 
kämpften Grundbesitz basierte. ${ }^{48}$ Das zweite Problem waren die sich etablierenden Städte, in denen Handel- und Gewerbetreibende den Wunsch nach politischer Beteiligung äußerten. In den Städten gab es weniger rigide Standesgrenzen; die Bürger beteiligten sich an der Verwaltung und Regierung, die Lehensherren residierten nicht nur auf dem Land, sondern auch in den Städten. Hier spielten sich in den Jahrhunderten des Hoch- und Spätmittelalters heftige Kämpfe zwischen dem aufstrebenden Bürgertum und den in Stadt und Umland ansässigen Feudalherren unter Beteiligung von Episkopat, Papst und Kaiser ab. ${ }^{49}$

Als die Feindschaften der erstarkten ober- und mittelitalienischen Städte die Machtausübung des Kaisers in Reichsitalien erschwerten, suchte Konrad II. den Schulterschluss mit dem Adel, allen voran mit Markgraf Bonifaz von Canossa, wofür dieser die Markgrafenwürde der Toskana erhielt. Die Familie der Canossa ist nur ein Beispiel für die Machtsteigerung von Adelsfamilien aufgrund des Vakuums der kaiserlichen Herrschaft in Reichsitalien. ${ }^{50}$

Eine weitere Schwächung der kaiserlichen Macht in Oberitalien stellte auch die Reformbewegung der pataria dar, ${ }^{51}$ die neben einer Kirchenreform auch zum Kampf gegen den Adel und die bischöflichen Stadtherren aufrief. Von Mailand ausgehend breitete sich die pataria über ganz Oberitalien aus und bedrohte die Stützen des Kaisertums, den Adel und den Episkopat. Das Papsttum hingegen band sich durch den Kampf gegen diese religiöse Bewegung enger an die oberitalienischen Städte und legte so den Grundstein für spätere antikaiserliche Bündnisse. ${ }^{52}$

Neben solchen Konflikten waren das I I. und I 2. Jahrhundert von einem bemerkenswerten Aufschwung in der Landwirtschaft Oberitaliens und der Toskana durch die Bonifizierung von Ackerflächen, den Anbau von Oliven oder die Salzgewinnung aus Meerwasser in Ravenna, Comacchio und Ferrara charakterisiert. Diese vom Handel begünstigte wirtschaftliche Blüte ging mit der Entwicklung der norditalienischen Kommunen einher. ${ }^{53}$ Letztere erstarkten im letzten Viertel des I I. Jahrhunderts vor allem durch die Zurückdrängung zunächst der weltlichen Grafen durch die Bischöfe und daraufhin durch deren Zurückdrängung aus der Position von Stadtherren mit königlicher Gerichtsbarkeit (missi dominici) und Lehensherren in Stadt und Diözese durch die aufstrebenden Bürger. Die Stadtbewohner behielten zumeist ihre stadtherrlichen Rechte selbst. Der durch den wirtschaftlichen Aufschwung angezogene niedere Adel etablierte sich in den Städten und verschmolz mit dem Bürgertum zum Stadtpa-

\footnotetext{
48 Seidlmayer, Geschichte Italiens, 96f. Castagnetti, Introduzione, i 8f. Siehe dazu auch die Untersuchungen von Taвacco, Regni und Keller, Adelsherrschaft.

49 Seidlmayer, Geschichte Italiens, 98 - 100.

50 Goez, Geschichte Italiens, I I4- I 6 .

5 I Hagen Keller/Olaf Zumhagen, »Pataria«, in: Theologische Realenzyklopädie (TRE) 26, Berlin u.a. I $996,83-85$.

52 Seidlmayer, Geschichte Italiens, i io.

53 Goez, Geschichte Italiens, I 22.
} 
triziat. ${ }^{54}$ Außerdem schwächte der Investiturstreit die Bischöfe und ihre Position beim König merklich. ${ }^{55}$

In den Stadtkommunen hatten die hier und im Umland vielfach begüterten und über Herrschaftsrechte verfügenden Adeligen, die auch am Markt- und Handelsleben beteiligt sein konnten, führende Positionen inne. Vor allem wegen dieser besonderen sozialen Ausstattung der Städte waren der bischöflichen Stadtherrschaft in Reichsitalien erheblich engere Grenzen gesetzt als in Deutschland. Die oberitalienischen Städte agierten vereinzelt bereits seit dem ıo. Jahrhundert politisch und militärisch selbstständig und gingen dabei - zumeist im Verbund mit weiteren regionalen Kräftegruppierungen - ab der Wende zum i I. Jahrhundert gegen Nachbarstädte vor. Die aufstrebenden Kommunen hatten durch die Ansiedelung des Adels innerhalb der Stadtmauern an militärischer Stärke zugelegt. Auch ließen sie sich zur Vergrößerung ihres Einflusses gern von namhaften Adeligen nach außen hin vertreten. Dies hatte zur Folge, dass es zu teilweise heftigen und gewalttätigen Auseinandersetzungen zwischen den einzelnen mächtigen Adelsfamilien innerhalb der Stadt, zu Positionierungen bei Auseinandersetzungen mit anderen Städten oder mit Kaiser und Papst kam. ${ }^{56}$ Das Herrschaftsgebiet einer Kommune beschränkte sich nicht auf das Stadtgebiet, sondern bezog das zur Diözese gehörende Umland (contado von comitatus) mit ein und dehnte sich durch Unterwerfung kleinerer Nachbarstädte und Gemeinden zu mittelgroßen und großen Einheiten weiter aus. ${ }^{57}$ Indem sie jedoch die Konkurrenz zwischen den Städten ausnutzte, trug gerade die staufische Reichspolitik wesentlich dazu bei, dass sich keine größeren Machtblöcke durch einzelne Stadtkommunen bilden konnten. Die Machtausübung der Kommunen war und blieb im contado begrenzt und labil. ${ }^{58}$ Außerdem unterschied sich die Lebens- und Wirtschaftsweise der oberitalienischen Städte mit ihrem kontinuierlichen Bevölkerungszuwachs und einer wirtschaftlichen Blütezeit bis zum Ausbruch der Großen Pest zwischen dem I I. und dem I 4. Jahrhundert stark von den agrarisch-feudalen Strukturen auf dem Land. Neben den militärischen Motiven für die Unterwerfung des städtischen Umlandes gab es also auch ein rein praktisches, nämlich jenes der Versorgung mit landwirtschaftlichen Produkten für die immer bevölkerungsreicher werdenden Städte. ${ }^{59}$

54 Hagen Keller betont in diesem Zusammenhang: "Ein Adel als besondere soziale Gruppe war von Anfang an ein konstitutiver Teil der kommunalen Gemeinschaft; Adel und Volk bildeten zusammen eine Kommune«. Keller, Adel, 260.

55 Frenz, Italien im Mittelalter, $36 f$.

56 Goez, Geschichte Italiens, I $26 f$.

57 Frenz, Italien im Mittelalter, 40. Siehe auch: Chittolini, Cities.

58 Haver камp, Italien im hohen und späten Mittelalter, 603.

59 Pauler, Die deutschen Könige, 29f, 33, 36. Chittolini führt auch die häufigen Streitigkeiten zwischen den städtischen Großgrundbesitzern und den Bauern an, in denen der signore als Mediator und gegebenenfalls Verteidiger der Untertanen fungierte. Chit tolini, Feudalherren, 247. 
Die Kommunen, ausgestattet mit einem eigenen Verwaltungsapparat, mit frei gewählten Konsuln, mit einem erstarkenden Bürgertum, das den Feudaladel wieder aus der Stadt zu vertreiben versuchte, entstanden zunächst in der Lombardei und breiteten sich von hier aus. ${ }^{60}$ Die ersten Konsuln gab es in Pavia, Lucca und Pisa ro84, in Mailand 1097, in Como r109, in Piacenza I126, in Florenz erst I138. Sie regierten allerdings meist nur für kurze Zeit. Konsuln entstammten der aristokratischen Schicht oder waren königliche Amtsträger, Äbte oder Mitglieder des Domkapitels. ${ }^{61}$ In der östlichen und westlichen Ecke der Po-Ebene und hier vor allem in der Mark Verona und im Friaul war neben den aufstrebenden Städten der Feudalismus vorherrschend und verzahnte sich mit der neuen kommunalen Herrschaftsform. Die heranwachsenden Städte konkurrierten untereinander, versuchten sich gegenseitig oder zumindest die kleineren zu unterwerfen und riefen in diesen vehementen Nachbarschaftsstreitigkeiten nicht selten fremde Hilfe, d. h. den Kaiser oder den Papst, herbei, oder verbündeten sich gegen ihn, wenn ihre Erzfeinde sich auf die kaiserliche Seite stellten. So riefen z. B. Parma, Reggio und Modena Lothar III. zu Hilfe, als sich Mailand, Bologna, Verona und Cremona gegen den Kaiser verbündeten. ${ }^{62} \mathrm{Da}$ die italienischen Städte durchschnittlich reicher als die deutschen waren, ging mit dem Schutz dieser reichsitalienischen Gebiete auch immer ein finanzielles Interesse des Kaisers einher. ${ }^{63}$

Friedrich I. Barbarossa (Kaiser I I $52-$ I I 90) ${ }^{64}$ startete mit seinem Programm der renovatio imperii einen neuen Versuch der Stärkung der kaiserlichen Macht in Italien durch die Zurückdrängung dieser von den nord- und mittelitalienischen Städten ausgehenden Kräfte und des mit dem Papsttum verbundenen Normannenreichs im Süden. Gegen Friedrich Barbarossa schlossen sich I I67 die ostitalienischen Städte zum Veroneser Bund zusammen, der sich dann mit päpstlicher Unterstützung zum großen Lombardischen Städtebund erweiterte. Doch im Frieden von Konstanz I I 83 mussten die Städte, um ihre Selbstständigkeit anerkannt zu bekommen und ihre Regalien behalten zu dürfen, dem Kaiser den Treueeid schwören und sich so dem Reich zugehörig bekennen. Auch die frei gewählten Konsuln bedurften alle fünf Jahre einer neuen kaiserlichen Investitur. ${ }^{65}$

6o Selbst wenn diese kommunale Form in Norditalien die Herausbildung von anderen Rechtssubjekten, wie man sie im Reich findet, größtenteils verhinderte, kann man gerade an den genannten Gruppierungen (Patriziat, Burgherren, Landgemeinden, Adelsgeschlechter) eine vergleichbare Form von »Dialogpartnern« erkennen, die dem Fürsten Forderungen stellten, welche meistens nicht deckungsgleich mit jenen der Städte waren. Vgl. Gamberini, Das Herzogtum Mailand, 90.

6I Pauler, Die deutschen Könige, 25-27.

62 Seidlmayer, Geschichte Italiens, I I 9 - I 23.

63 Vgl. z.B. bei Deibel, Die finanzielle Bedeutung Reichsitalien.

64 Vgl. Ehlers, Friedrich I. Barbarossa.

65 Seidlmayer, Geschichte Italiens, I3 I - I35. Goez, Geschichte Italiens, I6r. 
Mit Heinrich VI. (Kaiser I I 91-1 I97) ${ }^{66}$ und besonders mit Friedrich II. (Kaiser I $220-$ I 250$)^{67}$ entfaltete sich der »christliche Cäsarismus«, das sacrum in der Titulatur des Heiligen Römischen Reichs und seines gottesnahen Herrschers, und entlud sich im Kampf gegen das Oberhaupt der christianitas. Gleichzeitig nahm unter Papst Innozenz III. der aus dem patrimonium Petri hervorgegangene Kirchenstaat mit ausschließlich päpstlicher Souveränität Gestalt an. Dieser neue Staat hatte nun festgelegte Grenzen und beinhaltete wichtige Gebiete wie die Romagna, die Mark Ancona und bedeutende Städte wie Ferrara, Bologna, Faenza und Urbino. ${ }^{68}$ Eine große Anzahl von Städten stellte sich auf die Seite des erstarkenden Papstes; der Kaiser fand nur wenige ihn unterstützende Kommunen. So entstand um I 2 I 5 aus dem Bedürfnis heraus, die Unabhängigkeit zu wahren, in den italienischen Städten die Parteiaufteilung in kaisertreue Ghibellinen und papsttreue Guelfen. Diese ab I 240 jeweils für die päpstlichen und kaiserlichen Anhänger nachgewiesenen Parteinamen waren allerdings oft nur ein Deckmantel für eigennützige, wandelbare Interessen und vielerorts eine bloße Etikettierung. Die Guelfen galten als Anhänger des Papstes, standen aber vor allem für eine kommunale Bewegung. Die Ghibellinen tendierten mehr zum Kaiser bzw. zur Adelsherrschaft. Tatsache war, dass diese Parteinahme Städte, Stadtregierungen und Familien entzweite und man schließlich den Ausweg allein in der Bestellung eines fremden und daher »neutralen « podestà (Stadtvogt) fand. Dies war eine standesgemäße und lukrative Aufgabe für den Adel, der in dieser zeitlich begrenzten Funktion in verschiedenen Städten Karriere und sich einen Namen machen konnte. Allerdings wurde die Arbeit des podestà immer mehr von den um die Macht in der Stadt kämpfenden Familien beeinflusst bzw. behindert, wie gerade das Beispiel von Ferrara zeigt.

Unter diesen leicht wandelbaren und teilweise chaotischen Zuständen entwickelten sich aus den Kommunen die signorie, an deren Spitze der signore stand, ein einheimischer oder auswärtiger Adelsmann bzw. eine durch ihre überragende wirtschaftliche Stellung übermächtige Familie oder auch ein vom Papst beauftragter Kardinal mit Sondervollmachten. ${ }^{69}$ Diese konnten sich in den verschiedenen Stadtgremien durch ein ständiges Podestat oder Volkskapitanat, durch manipulierte Wahlen, wie bei den Medici $^{70}$ in Florenz, durch militärische Stärke oder dadurch, dass ihre Partei in ei-

66 Vgl. EhLERs, Heinrich VI.

67 Eickels, Friedrich II.

68 Goez, Geschichte Italiens, r6gf. Seidlmayer, Geschichte Italiens, I 36- I 45. Der Anspruch der römischen Kirche auf jene Territorien, die den Kirchenstaat bildeten, basierte einerseits auf der Konstantinischen Schenkung und andererseits konkret auf dem Erbanspruch auf die Mathildischen Güter. Eine weitere Grundlage der kirchlichen Machtposition war der päpstliche Anspruch auf das Vikariat in Italien bei Thronvakanz, d.h. die Unterstützung und Vertretung der weltlichen Macht bei Ausfall oder Versagen. Pauler, Die deutschen Könige, I 2. Heckmann, Stellvertreter I , 438.

69 Frenz, Italien im Mittelalter, $4 \mathrm{I}$.

70 Für einen kurzen Überblick über den Werdegang dieser Familie siehe Pandimiglio, »Medici«. 
ner Stadt die Macht mit Gewalt an sich riss, durchsetzen. ${ }^{71}$ Hatte man beim podestà und capitano del popolo auf eine kurze oder auf jeden Fall begrenzte Amtszeit Wert gelegt, so ging man nun zu einem dauerhaften Regierungsauftrag zur Sicherung des inneren Friedens und zur Eindämmung der den wirtschaftlichen Aufschwung hemmenden Auseinandersetzungen zwischen Guelfen und Ghibellinen über. Auch diese längeren Beauftragungen waren anfangs noch zeitlich begrenzt; wenn sich aber ein signore bewährt hatte und wenn er drohte, die Führung von verfeindeten Nachbarstädten zu übernehmen, wurde die Befristung leicht hinfällig. Wichtige Maßnahmen des signore waren die Durchsetzung des Waffenverbots in den Städten, die Sicherung des Friedens und die Förderung der wirtschaftlichen Prosperität. Militärisch ließ er sich von kampferprobten Söldnertruppen unterstützen, deren Kommando er oft selbst übernahm. Der nächste angestrebte Schritt für einen signore war es, seine Regentschaft auch unter oder trotz Beibehaltung der Statuten, die er meist Schritt für Schritt zu seinen Gunsten veränderte, erblich zu machen. Besonders förderlich für diese Entwicklung zum principato, d.h. die erblich gewordene Herrschaft, war eine von außen kommende Legitimierung durch die Investitur mit einem Reichs- oder päpstlichen Vikariat und die Erhebung in den Fürstenstand. ${ }^{72}$

Beispielhaft war die Karriere von Castruccio Castracani, der als condottiere zum signore wurde. Weil er für Ludwig den Bayern (Kaiser 1328-1347) den Weg nach Rom freimachte, wurde er zum Reichsvikar der Toskana, zum Bannerträger des Heiligen Römischen Reiches und zum erblichen Herzog von Lucca erhoben. Dies war die erste Stadtherrschaft in Italien, die in ein Fürstentum umgewandelt wurde, »weshalb Castruccio Castracani den Prototyp aller Signoren darstellt. ${ }^{73}$

Einige dieser signori entwickelten sich zu regelrechten Tyrannen, deren Ruf ihnen vorauseilte, wie der berühmte Ezzelino da Romano, der I 232 mit Kaiser Friedrichs II. Unterstützung Verona, und in der Folge Vicenza, Padua und schließlich die ganze Mark Treviso unterwerfen konnte. Was Ezzelino nicht schaffte, nämlich eine Dynastie zu bilden, gelang hingegen Mastino Della Scala, der I 259 podestà von Verona wurde und nach seiner Ermordung I 277 die Macht seinem Bruder und dessen Söhnen weitergeben konnte. ${ }^{74}$ Der Della Scala ist auch ein gutes Beispiel dafür, wie die Kommunen und die sich etablierenden signori allfällige Machtzunahmen des einen oder anderen Prätendenten sofort einzubremsen versuchten. Mastino hatte nach und nach in Oberitalien eine Vormachtstellung eingenommen, indem er Verona, Padua, Vicenza, Treviso, Brescia, Feltre, Cività, Belluno, Parma, Modena und Lucca unterwarf. Als Ge-

7I Vgl. Frenz, Italien im Mittelalter, 4 If.

72 Vgl. Goez, Geschichte Italiens, I 92 - 194.

73 Goez, Geschichte Italiens, 197. Siehe auch Nadler, Ludwig der Bayer, $98 \mathrm{f}$ und zum Erhebungsdiplom für Castruccio Castracani, roof. Seine Erhebung ließ der condottiere auch gekonnt in Szene setzen: Als römischer Imperator gekleidet zog er auf einem Wagen stehend in Lucca ein. STrong, Feste der Renaissance, $8 \mathrm{I}$.

74 Vgl. Seidlmayer, Geschichte Italiens, I 78 - I 89. 
rüchte laut wurden, die behaupteten, er würde auch nach der Königskrone greifen, bildete sich gegen ihn eine große, fast alle lombardischen und toskanischen Machthaber bzw. Kommunen umfassende Liga mit Venedig und Florenz und auch den Este an deren Spitze. Doch obwohl Mastinos Herrschaft zerschlagen wurde, konnten ihn die untereinander zerstrittenen Verbündeten nicht völlig entmachten. ${ }^{75}$

Ein für Italien wichtiger Außenfaktor in diesem Kontext war der Beginn des Kampfes um die Vorherrschaft zwischen Frankreich und dem Reich seit der Mitte des I3. Jahrhunderts, an dem sich auch das Papsttum stark beteiligen sollte. Der Kirchenstaat machte in Verbindung mit Unteritalien fast zwei Drittel der Halbinsel aus, wodurch der Papst zum größten Territorialherrn Italiens wurde. Die Anjou, die vom Papst in Unteritalien eingesetzt worden waren, versuchten sich auch über den Rest Italiens auszubreiten, bis die französische Vormachtstellung I 282 auch im Süden durch den Volksaufstand der Sizilianischen Vesper ${ }^{76}$ aufgehalten wurde. Die Aufständischen in Sizilien holten mit König Peter III. von Aragón eine neue fremde Macht ins Land, die sich schließlich mit der aragonesischen Sekundogenitur auf der Insel festsetzte. So hatte das schwache Kaisertum in Reichsitalien ein Vakuum verursacht, das auch von Papsttum und Frankreich nicht gefüllt werden konnte. Zum Teil mithilfe der, zum Teil gegen die beiden Universalgewalten entwickelten sich also auf der italienischen Halbinsel einzelne Territorien und Herrschaftsbereiche zu Republiken und Fürstentümern (principati), also erblich gewordenen signorie unter Führung aufstrebender Dynastien. Diese beugten sich ihren Lehensherren, Kaiser und Papst, vor allem in Oberitalien nur dann, wenn es in ihrem Interesse lag. Die Kommunen und signorie hatten sich soweit souverän entwickelt, dass dem Kaiser nichts anderes übrigblieb, als sie und ihre Rechtshoheit anzuerkennen. Dennoch galt weiterhin - und zwar auch durch die Verbreitung des an den italienischen Rechtschulen gelehrten römischen Rechts - der Herrschaftsanspruch des Kaisers, dessen Gesetz über den Statuten und Erlässen der Kommunen und signori stand. Bei aller machtpolitischen Schwäche der kaiserlichen Gewalt in Italien blieben das Konzept, die Wahrnehmung und z.T. auch die Bedeutung des Kaisertums erhalten. Dafür sollten u.a. auch vom Kaiser immer wieder eingesetzte Reichsvikare sorgen. Der Reichsvikar, der rechtlich gesehen ein Amtsträger und kein Vasall war, hatte wie ein Reichslandvogt im deutschen Südwesten das Reichsgut zu schützen und Reichseinkünfte einzuziehen. Wo er - wie anfangs in Italien - landesfremd war und aus dem Kreis der deutschen oder burgundischen Vertrauten des Kaisers stammte, stieß er auf besonders großen Widerstand und konnte sein Amt nur selten zufriedenstellend ausüben.

75 Pauler, Die deutschen Könige, r69.

$76 \mathrm{Zu}$ diesem Aufstand gegen die französische Herrschaft in Sizilien I $282 \mathrm{vgl}$. Steven Runciman, Die sizilianische Vesper. Eine Geschichte der Mittelmeerwelt im Ausgang des I3. Jahrhunderts (englische Originalfassung 1958), München 1959. 
Seit dem Konstanzer Friedensvertrag, den Barbarossa i I 83 mit der lombardischen Liga geschlossen hatte, waren sowohl der Herrschaftsanspruch des Kaisers als auch der Anspruch der Städte auf Selbstverwaltung durch Statuten geregelt. Sowohl die Rechtsgewohnheiten (consuetudines) der Städte als auch die Verpflichtung zu Gehorsam und Treue waren dadurch beidseitig anerkannt worden. Allerdings durften die Statuten einer Stadt nicht der Reichs- und Kaisertreue widersprechen und wurden vom Kaiser mitunter in ihrer Freizügigkeit eingedämmt. ${ }^{77}$ Weit gingen diese Einschränkungen aber nicht, wenn König Rudolf (I 273- I 29I) I 282 den Bürgern von Siena und Florenz verbriefte, dass sie nicht zum Treueeid verpflichtet seien, ehe nicht der König selbst oder eine Truppe von mindestens 500 Deutschen in die Toskana kämen. So scheint die Anwesenheit des Herrschers rechtlich bindend gewesen zu sein, während sein Fernbleiben die Untertanen von Verpflichtungen dispensierte. Im Vergleich zu den ebenso königsfernen Gebieten Deutschlands kommt Pauler allerdings zu dem Schluss, dass es Unterschiede zu Reichsitalien gab: Obwohl die Kaiser öfter nach Italien als nach Norddeutschland kamen, zeichneten sich die deutschen Gebiete und Städte an der nördlichen Reichsperipherie durch eine größere Bindung an die kaiserliche Macht aus. ${ }^{78}$ Die größere italienische Unabhängigkeit von Kaiser und Reich hatte ihren Ursprung - wie gezeigt wurde - schon seit karolingischer Zeit in der vorherrschenden Unabhängigkeit des Adels und in der frühen, von der Königsferne begünstigten, autonomen Entwicklung der Städte Norditaliens.

Wollte man schließlich Bilanz ziehen und die Rolle und Bedeutung Italiens für das Reich bis zum Beginn des I 4. Jahrhundert definieren, so kann man mit Seidlmayer festhalten, dass Reichsitalien seit dem Mittelalter im Vergleich zu Deutschland »Nebenland « war, mit den Staufern aber, allen voran Friedrich I. Barbarossa und seinen sechs Italienzügen und I 4 Regierungsjahren in Italien, zeitweise zum Hauptland geworden war. ${ }^{79}$

Auf die Frage, wie die Italiener das Kaisertum in ihrer Heimat erfahren und empfunden haben mögen, gibt es mehrere widersprüchliche, quellenbelegte Antworten. Einerseits wurde der Kaiser als Friedensbringer und Ordnungsmacht besungen, andererseits diente er dazu, die zweite Macht in Italien, das Papsttum, zu bändigen; ${ }^{80}$ schließlich galt er bis in die Neuzeit als »ein[en] Schmarotzer, ein[en] bedürftige[r][n] Barbar[en], geprägt durch mangelnde Kultur und übermäßige Habgier. « ${ }^{81}$

Von kaiserlicher Seite war und blieb Italien in der Neuzeit mehr denn je begehrt. Nicht nur die kapitalstarken Städte reizten die Könige und Kaiser; spätestens seit Otto dem Großen und dem Kampf gegen die Sarazenen bzw. die Auseinandersetzungen

\footnotetext{
77 Vgl. Pauler, Die deutschen Könige, 2 I - 23.

78 Vgl. dazu Auge, Ein Integrationsmodell.

79 Vgl. Seidlmayer, Geschichte Italiens, $82-86$.

8o Seidlmayer, Geschichte Italiens, 87-89.

8I Pauler, Die deutschen Könige, 233.
} 
mit Byzanz war der Schwachpunkt der kaiserlichen Macht klar: Auf See war das Reich auf italienische Hilfe von Genua, Pisa oder Venedig angewiesen. ${ }^{82}$ Dies ließ das sogenannte Randgebiet des Reiches ${ }^{83}$ in seiner Bedeutung heranwachsen. Ebenso nahm die Bedeutung der familiären Beziehungen zu Reichsitalien für die Reichspolitik zu, wodurch vor allem im I6. Jahrhundert das Standbein im Süden immer wieder aufs Neue gefestigt wurde. ${ }^{84}$

\subsubsection{Reichsitalien am Übergang vom Spätmittelalter zur Frühen Neuzeit: Die Hauptakteure}

Im Gewirr und in der Unruhe der Machtentfaltung der italienischen Kommunen waren drei Städte im Laufe des Spätmittelalters durch den Erwerb der Herrschaft über Nachbarorte, allerdings mit unterschiedlichen inneren Macht- und Verfassungsstrukturen, zu überregionaler Bedeutung gelangt: Venedig, Mailand und Florenz. Venedig hatte als formaler Teil des byzantinischen Reiches, das mit den fränkischen und deutschen Königen und Kaisern nur ein vertragliches aber kein Lehensverhältnis besaß (Kaiserpakta) eine Sonderstellung inne. Hier standen die republikanische/oligarchische Herrschaftsstruktur, die wirtschaftliche Entwicklung durch den Seehandel und das Bemühen um eine Ausweitung auf der Terraferma gegen Ende des I 4. Jahrhunderts im Vordergrund. Mailand war Zentrum des Kampfes zwischen dem Papsttum und den Staufern gewesen, in dem sich mithilfe von König Heinrich VII., der Matteo Visconti zum Reichsvikar erhoben hatte, schließlich die Visconti ${ }^{85}$ durchsetzen konnten. Als kaiserlicher Stellvertreter regierte er über Mailand hinaus über ein weites Umland bestehend aus Pavia, Tortona, Alessandria, Vercelli, Bergamo, Como, Novara und Piacenza. I395 erhielt Gian Galeazzo Visconti von König Wenzel die erbliche Herzogswürde.

Neben der Herrschaft der Markgrafen von Toskana entwickelte sich in Florenz eine kommunale Selbstverwaltungsstruktur. Die Machtkämpfe zwischen Guelfen und Ghibellinen erweiterten sich um die Auseinandersetzung zwischen den Magnaten, den reichen Kaufleuten und Handwerkern und dem popolo, zu dem die niederen Handwerker und das übrige einfache Volk gehörten. Zu Beginn des I 5. Jahrhunderts spitzte sich die Auseinandersetzung zwischen den führenden Familien der Albizzi und den volksnahen Medici zu, die I 397 mit der Gründung der Medici-Bank ihren steilen

82 Vgl. Seidlmayer, Geschichte Italiens, 85-9i.

83 Vgl. Nolte, »Peripherie«. Zum Phänomen der Verschiebung von Peripherie zu Semiperipherie und Zentrum siehe unten im Abschnitt Kulturtransfer. Siehe auch die verschiedenen Ansätze des imperial turns im Sammelband Wendehorst, Die Anatomie frühneuzeitlicher Imperien.

84 Haver камp, Italien im hohen und späten Mittelalter, $55^{2}$.

85 Zur Familie siehe Schмidт, »Visconti«. 
Erfolgsanstieg begonnen hatten. Schließlich konnten sich die Medici nach anfänglichen Niederlagen durchsetzen und eine "Kryptosignorie « installieren. ${ }^{86}$

Nach den kostspieligen Italienzügen seiner Vorgänger, die mehr Geld verbrauchten als sie in Italien einnehmen konnten und das Ziel der Unterwerfung möglichst vieler Kommunen bezweckten, konnte Karl IV. (Kaiser I 355- I 378$)^{87}$ hingegen in Italien fast ohne Gewalt, oder mit Pauler gesprochen >ohne Schwertstreich ${ }^{88}$, das erreichen, was er sich zum Ziel gesetzt hatte. Er schaffte es, eine relativ überparteiliche Stellung einzunehmen, wodurch seine Herrschaft allgemein anerkannt wurde. Allerdings begnügte er sich damit nominell zu herrschen, ohne in die unmittelbaren Herrschaftsstrukturen in Stadt und Land einzugreifen. Ansonsten zeichnete sich die Herrschaft Karls IV. durch eine von der Diplomatie geprägte Friedenspolitik und einen für Italien neuen Regierungsstil aus: Auf beiden Romzügen führte er nur ein kleines Heer mit, begnügte sich mit der nominellen Anerkennung als Reichsoberhaupt, verzichtete zugunsten der ideellen Herrscherautorität (auctoritas) auf die reale Machtausübung bzw. Herrschergewalt (potestas) und überließ die Machtausübung und lokale Rechtspflege den Herrschenden vor Ort. ${ }^{89}$

Von dem I 400 abgesetzten König Wenzel (I376- r 400), dem Sohn von Karl IV., erkaufte sich der immer mächtiger werdende Gian Galeazzo Visconti I 395 den Herzogstitel und gab damit in Italien den Auftakt zum Wettlauf um kaiserliche und/ oder päpstliche Titel. I4I 6 folgte unter Kaiser Sigismund I4I 8 die Herzogswürde für die Savoyer. ${ }^{90}$ Neben den fünf Hauptmächten, dem Herzogtum Mailand, dem Herzogtum Savoyen mit der Markgrafschaft Montferrat, der Republik Venedig, der (noch) Republik Florenz, dem Königreich Neapel und dem Kirchenstaat, gab es im I 5. Jahrhundert weitere kleinere und kleinste unabhängige Territorien unterschiedlicher Staatsform wie Republiken $\left(\mathrm{Genua}^{91}\right.$, Siena ${ }^{92}$, Lucca ${ }^{93}$ ) und in der Folge neue

86 Vgl. Frenz, Italien im Mittelalter, Ior - Io7.

87 Vgl. Kintzinger, Karl IV.

88 Pauler, Die deutschen Könige, 228.

89 Ebd., 228. Etwas spöttischer beschreibt Mattingly Karls IV. »friedliche« Inanspruchnahme Italiens und der Kaiserkrone: »After the Emperor Charles IV's subsidized excursion to Rome to collect the imperial crown like a tourist's souvenir, [...]«. Mattingly, Renaissance diplomacy, 56.

90 Seidlmayer, Geschichte Italiens, 242.

9I Besonders die Republik Genua stand in einem engen, regelmäßig erneuerten Lehensverhältnis zum Reich. Sie besaß selbst einige Reichslehen und zahlte Kontributionen. Siehe: Schnettger, Feudi, privilegi, 28 of.

92 Diese an sich ghibellinische Stadt war von inneren Kämpfen und der ständigen Bedrohung durch Florenz stark in ihrer republikanischen Entwicklung gehemmt. Vgl. Mario Aschieri, Storia di Siena. Dalle origini ai giorni nostri, Pordenone 2013 .

93 Lucca war eine der ältesten Kommunen, die ihre »Freiheit« und Regierungsform bis I 799 behielt. 1369 unterstellte sie Kaiser Karl IV. unmittelbar dem Reich und seiner kaiserlichen Gerichtsbarkeit. Sie zählte trotz ihrer bescheidenen Größe zu den größeren italienischen Reichslehen, gehörte - obwohl sie nie regelrecht investiert wurde - zu den kaisertreuen und an Abgaben reichsten Lehen. Lucca blieb territorial 
Fürstentümer wie jenes der Gonzaga in Mantua (seit I 432 durch Kaiser Sigismund Markgrafen), der Este (seit I I 7 I Markgrafen, seit I 452 durch Friedrich III. Herzöge von Modena und Reggio und I47 I durch Papst Paul II. Herzöge von Ferrara) und dem seit I 399 bestehenden Fürstentum von Elba und Piombino; darüber hinaus gab es die selbstständigen Herren der Romagna und der Mark Ancona, die Malatesta ${ }^{94}$ in Rimini und die da Montefeltro in Urbino, die I474 vom Papst in den Herzogsstand erhoben wurden.

Als letztes Reichsoberhaupt des Spätmittelalters hatte sich Friedrich III. (Kaiser I 452- I 493) 95 $^{2}$ in seiner Italienpolitik hinter Papst Eugen IV. (I 43 I - I 447) gestellt und das Schisma beendet, doch außer einem Romzug zur Kaiserkrönung und auf dem Weg dahin die Erhebung der Este zu Herzögen von Modena und Reggio keinen Versuch zur Stärkung der Kaisergewalt auf der Halbinsel gestartet. ${ }^{96}$ Allerdings begann sich ein neues, bald unverzichtbares Medium der Herrschaftsausübung und politischen Kommunikation zwischen den italienischen Fürsten und Städten und dem Reichsoberhaupt zu etablieren: die Diplomatie, die gerade in Italien ihre Anfänge und ihre intensivste Ausprägung erfuhr und sehr früh in die Einrichtung von ständigen Gesandtschaften an fremden Höfen mündete. ${ }^{97}$

\subsubsection{Reichsitalien in der Neuzeit}

Während im Mittelalter die deutschen Reichsfürsten ${ }^{98}$ bestrebt gewesen waren, die Macht des Kaisers einzudämmen, hatte sich in Italien das stark verklärte, von Dichtern wie Dante und Petrarca vertretene Bild des Kaisers als Erlöser für die von Machtkämp-

unverändert, zielte nie auf Expansion ab und blieb dem Kaiser treu, da er als einziger die Unabhängigkeit der Stadt verteidigen konnte. Mit der Ausbreitung der spanischen Herrschaft auf der italienischen Halbinsel fuhr Lucca doppelgleisig und wandte sich in der Not sowohl an die österreichischen als auch an die spanischen Habsburger. Siehe Cresseri, La Repubblica; TAвассHi, Lucca.

94 Zur Familie vgl. DeAn, »Malatesta«.

95 Vgl. Heinig, Friedrich III.«

96 Vgl. Lнотsку, Kaiser Friedrich III. sowie Alfons Lнотsку, „Friedrich III.«, in: NDB, [Online-Version]: https://www.deutsche-biographie.de/pnd I 8535773. html\#ndbcontent, Zugriff: r 6.9.2020.

97 Vgl. Seidlmayer, Geschichte Italiens, 264, 284. Einen frühen Höhepunkt der diplomatischen Aktivitäten gab es am Konzil von Ferrara I 438/39, das zum Ziel hatte, die griechische und römische Kirche wieder zu vereinen. Auch wenn dieses Ziel nicht von Erfolg gekrönt war, so brachte die Initiative zur Ausbildung der diplomatischen Vertretung und zur Bereicherung des schon verbreiteten Humanismus durch griechische Gelehrte und Bücherschätze aus Byzanz. Vgl. auch das Kapitel »Diplomatie« in KoHLER, Expansion und Hegemonie, $3 \mathrm{I}-40$.

98 Reichsfürsten, principes regni, entstanden ohne bestimmte land- oder lehensrechtliche Kriterien im Zuge des »Konzentrationsprozeß[es], der aus den weit gestreuten Besitzungen des hohen Adels ansatzweise gebietsmäßig zusammengefaßte Herrschaften gestaltet[e]«, zunächst mit einem klaren Überhang an geistlichen Reichsfürsten gegenüber den weltlichen. Ernst ScHubERT, »Reichsfürsten«, in: Lexikon des Mittelalters 7, Sp. 6r 8. 
fen gebeutelte Halbinsel verstärkt. Als sich dann aber zeigte, dass das Reichsoberhaupt nicht als Schlichter und Rechtsprecher, sondern zur Festigung seiner Lehensherrschaft in das als erobertes Gebiet geltende Italien kam, änderte sich die Erwartungshaltung gegenüber dem Kaiser auch auf der Halbinsel abrupt. Das Bild des Reichsoberhauptes wurde ab dem Spätmittelalter ein widersprüchliches: Auf der einen Seite war er auch für die italienischen Gebiete oberster Herrscher, Lehensherr, Richter und Verteidiger des Glaubens gegen die Ungläubigen; auf der anderen Seite stellte er Ansprüche auf Gebiete der italienischen Halbinsel, die sich in der Zwischenzeit und in seiner Abwesenheit zu mächtigen kleinen und größeren Einheiten verselbstständigt hatten und oft nicht bereit waren, dem meistens weit entfernten Kaiser Abgaben zu entrichten. ${ }^{99}$

Dies führte zu großen Lücken im Rechtsverständnis, sodass am Übergang zur Frühen Neuzeit die eigentlichen Rechte des Kaisers in Italien vage und zum Teil vergessen wurden, es sei denn, das Reichsoberhaupt kam mit einem starken Heer, so wie es Maximilian I. versuchsweise und Karl V. mehrmals taten. ${ }^{100}$ Während seine Vorgänger vorrangig bzw. ausschließlich zur Krönung nach Italien gezogen waren und hier nur sporadisch versucht hatten, die Reichsrechte und Reichsmacht geltend zu machen, begann Maximilian I. eine aktive Italienpolitik, die darauf abzielte, die kaiserliche Macht hier zu behaupten und die Reichsrechte gegen die Ansprüche von mittlerweile etablierten Städten und Fürsten geltend zu machen. Problematisch war und blieb jedoch sein chronischer Geldmangel, der ihn im Reich zum Bittsteller des Reichstages und in Italien zu einem wenig ernst zu nehmenden Tributeintreiber machte, mit dem man aufgrund des Gelddruckes leicht über Belehnungen und Investituren verhandeln oder einflussreiche Verbindungen eingehen konnte. Ein erster Vorstoß kaiserlicher Macht in Italien kam von Maximilian I. im Rahmen seiner zweiten Heirat mit Bianca Maria Sforza, die ihm nicht nur eine substantielle Mitgift, sondern mit Mailand die »Pforte Italiens« einbrachte. Das Interesse des Königs an Reichsitalien allgemein und Mailand im speziellen kam auch Ludovico il Moro, dem Herrscher über Mailand, zugute, der durch den Versuch, Frankreich und das Reich gegeneinander auszuspielen, seine Herrschaft festigen wollte. Um den Franzosen den Eintritt nach Italien über dessen Herzstück Mailand zu verwehren, entschloss sich Maximilian im März I 495 auch zum Beitritt zur Heiligen Liga von Venedig zusammen mit Spanien, dem Papst und Mailand. Doch dieses Offensivbündnis blieb eher untätig und fadenscheinig. Noch dazu drängten die Kur- und Reichsfürsten dazu, sich aus Reichsitalien zurückzuziehen bzw. nur das Allernotwendigste für dieses Randgebiet des Reiches zu investieren, ${ }^{101}$ auch weil allfällige auswärtige Erfolge Maximilians eine Verschärfung der königlichen

\footnotetext{
99 Pugliese, Le prime strette, I I - i 7.

I oo Dazu siehe allgemein Karl Otmar von Aretin, »Reichsitalien« (Frühe Neuzeit), in: Handwörterbuch zur deutschen Rechtsgeschichte 4, Berlin I990, Sp. 648-65 I und die Beiträge in Schnettger, Imperium Romanum. Kohler, Das Reich. Immer noch brauchbar Pugliese, Le prime strette.

Io I Wiesflecker, Italien in der Kaiserpolitik Maximilian I., 272-275.
} 
Zentralgewalt im Inneren und eine Beschränkung der reichsfürstlichen Libertät ${ }^{102}$ befürchten ließen. Währenddessen wurde für das Reichsoberhaupt der Romzug als Lösung der Italienfrage immer dringlicher. Doch Venedig verweigerte ihm den bewaffneten Durchzug durch sein Gebiet. Mit der Liga von Cambrai I 508 schlossen sich Kaiser, Papst, Frankreich, Spanien und England gegen Venedig zusammen. Während der Papst hier vor allem die Erweiterung des Kirchenstaates in der Romagna vor Augen hatte, bedeutete für Maximilian das Bündnis die erneute Teilung Italiens. Erst als sich das Reichsoberhaupt I 5 I 2 von der Liga von Cambrai löste, gelang es mithilfe der Schweizer die Franzosen aus Mailand zu vertreiben, sodass die Lage für Maximilian I. in Reichsitalien wieder günstig aussah. ${ }^{103}$

Doch der Erfolg blieb aus und die Tragweite dieses Scheiterns hat Duchhardt folgendermaßen festgehalten : Der Versuch Maximilians I., die Lehenshoheit des Reiches über Reichsitalien zu reaktivieren, ist denn auch folgerichtig zum Scheitern gebracht worden; die europäische Staatenwelt war nicht mehr bereit, einen derart erheblichen Macht- und Prestigegewinn von Kaiser und Reich hinzunehmen. Der Anfall Mailands an Frankreich war somit, auch wenn damit das letzte Wort zu Reichsitalien noch längst nicht gesprochen war, symptomatisch dafür, daß für das Reich in territorieller Hinsicht allenfalls die Erhaltung des Status quo aktuell war; weder die herrschende Dynastie noch das Reich als solches waren in der Lage, den >Ausfransungsprozeß< der Reichsgrenzen und der Reichsrechte wieder rückgängig zu machen. « ${ }^{104}$

Diese Erhaltung des Status quo ging in der Folge mit einem langanhaltenden, für die norditalienischen Gebiete belastenden Wettkampf um die Vormachtstellung zwischen dem französischen König François I. (I 5 I 5- I 547) und dem König und dann Kaiser Karl V. (erwählter Kaiser seit I 520, Kaiser I 530-I556) einher. François I. konnte die Verluste seines Vorgängers Louis XII. durch den Sieg bei Marignano bei Mailand wieder wettmachen, I 5 I 5 die Sforza ${ }^{105}$ verbannen, Genua und Mailand zurückerobern und dem Papst Parma und Piacenza entreißen. Karl V., der eine mittelalterliche christlich-universale Herrschaftskonzeption vertrat, war nicht nur nicht bereit Reichsitalien seinem Gegner zu überlassen, sondern wollte es - auch auf Drängen seines Kanzlers Mercurino Arborio di Gattinara ${ }^{106}$ hin - zum Zentrum seiner Macht machen. Als

I02 Mit der ständischen oder reichsfürstlichen Libertät sind jene Grundgesetze des Reiches gemeint, wodurch dieses sich selbst regieren konnte, ohne einer Person oder einem Haus unterworfen zu sein. Mit dem Argument der Wahrung ständischer Freiheit versuchten die Reichsstände Alleinherrschaftsbestrebungen einzudämmen. Vgl. Georg Sснмірт »Freiheit«, in: Friedrich Jäger, Enzyklopädie der Neuzeit Online, 20I4, https://referenceworks.brillonline.com/entries/enzyklopaedie-der-neuzeit/ freiheit-COM_266320?s.num=o\&s.f.s2_parent=s.f.book.enzyklopaedie-der-neuzeit\&s.q=freiheit, Zugriff: 16.9 .2020$.

IO3 Wiesflecker, Italien in der Kaiserpolitik, 277-28I.

Iо4 Duchнardt, Deutsche Verfassungsgeschichte, 50.

I05 Zur Familie siehe IAnZiti, »Sforza«.

Io6 Dieser aus dem Piemont stammende hervorragende Diplomat, Berater Karls V. und Verfechter der 
erster Kaiser mit einem Herrschaftsvertrag (später Wahlkapitulationen) ${ }^{107}$ musste er seine Macht im Reich mit den Reichsständen teilen, während er in Reichsitalien bis auf Savoyen - mit keiner partizipativen Größe zu rechnen hatte. Der erwählte römische Kaiser und der französische König führten vier Kriege in Italien, mit dem Ziel, dieses Gebiet in ihren Machtbereich einzufügen, was aber erst ihren Nachfolgern gelingen sollte. Als Karl V. Mailand zurückforderte, verstrickte ihn der französische König in einem Mehrfrontenkrieg in Oberitalien, den Niederlanden und Navarra. Nach der Schlacht von Pavia I 525 jedoch, bei der François I. gefangen genommen wurde, musste der französische König im Frieden von Madrid I 526 zunächst auf die Ansprüche auf Mailand, Neapel, Flandern und Burgund verzichten. Gegen den Kaiser richtete sich jetzt allerdings Papst Clemens VII. (I 523 - I 534), der I 526 eine Heilige Liga von Cognac mit Frankreich, England, Venedig, Florenz und Mailand organisierte. Die kaiserlichen Truppen unter dem Konnetabel Charles de Bourbon und die deutschen Landsknechte unter Georg von Frundsberg rächten sich I 527 im Sacco di Roma am Papst, der - mit dem Leben davongekommen - im Vertrag von Barcelona I 29 Karl die Belehnung mit Neapel und die Kaiserkrönung versprach. Im Damenfrieden von Cambrai 1529 wurden die Bestimmungen des Friedens von Madrid mit Frankreich wiederholt, allerdings ohne Burgund, auf das Karl V. verzichtete. Aufgrund dieser Demonstration militärischer Stärke nahmen der Papst, Venedig und die Potentaten Italiens die kaiserliche Macht zunehmend ernst. Vor allem der Sieg des Kaisers über Frankreich in der Schlacht von Pavia sorgte für erste Verunsicherungen in Italien und für die Einsicht, dass man ab jetzt darauf bedacht sein musste, sich auf die Seite des Stärkeren zu stellen.

Den Willen seine Macht in Reichsitalien ausnutzen zu wollen, zeigte Karl V. auch durch den Einzug des kaiserlichen Lehens Mailand beim Aussterben der Sforza I 535, was Frankreich jedoch nicht daran hinderte, weiterhin Ansprüche zu stellen und das Herzogtum Savoyen als Revanche zu besetzen. In einem erneuten Krieg verbündete sich Frankreich mit den Türken und Karl benötigte Flottenhilfe aus Genua, um dieser Empörung hervorrufenden »unchristlichen« Koalition entgegenzutreten. Selbst nach dem vom Papst vermittelten Waffenstillstand von I 538 verblieb Savoyen bei Frankreich. Auch im vierten Krieg I 542 verbündete sich Frankreich mit den Türken. Doch im Frieden von Crépy I 544 musste der französische König erneut auf Mailand verzichten, das somit kaiserlich blieb, behielt aber Savoyen. I 556 dankte Karl V. ab, sein Sohn Philipp II. bekam als König von Spanien die italienischen Besitzungen, also Mailand, Neapel-Sizilien, Sardinien und den Stato dei Presidi, das I 557 aus dem Fürstentum Elba, dem Fürstentum Piombino und Teilen des sienesischen Territoriums entstanden

Idee der monarchia universalis starb in Innsbruck im Juni ${ }_{5} 50$ auf seiner Reise zum Augsburger Reichstag. Zu diesem siehe Headley, The Emperor and His Chancellor; Strnad/Rebitsch, Der Tod kam in Innsbruck.

Io7 Neunaus, Das frühneuzeitliche Heilige Römische Reich, 203. 
war. Der Frieden von Cateau-Cambrésis I 559 beendete zwar den Kampf um Italien, zeichnete aber gleichzeitig auch den Verlust der politischen Selbstständigkeit der einzelnen Territorien vor: Frankreich behielt nur Saluzzo, die Savoyer wurden wieder eingesetzt, die Farnese ${ }^{108}$ in ihrem eigens geschaffenen Fürstentum Parma-Piacenza von Philipp II. anerkannt. Damit begann eine relative konfliktarme Zeit unter dem strengen Regiment der spanischen Gouverneure und des obersten Rats für Italien. ${ }^{109}$

Anders als Karl V. war Kaiser Ferdinand I. in Reichsitalien eher geliebt als gefürchtet und tat sich schwer, hier Geldmittel für den Türkenkrieg einzuwerben. Während in der Regentschaft Maximilians I. und Karls V. die Gesandten der Republik Venedig noch vor der kaiserlichen Stärke warnten, belächelten sie nun die Geldknappheit des Reichsoberhauptes und seine schlecht ausgestatteten und unfähigen Söldner. ${ }^{110}$ Tatsächlich hatte seit der Übernahme der Kaiserwürde durch die österreichischen Habsburger das Reichsoberhaupt seine Territorialbasis in Italien weiter verloren. Zudem bedrohte die spanische Vorherrschaft ${ }^{111}$ die Reichsrechte in Italien und setzte der »Staaten->libertà der italienischen Renaissance ein Ende ${ }^{112}$ Ferdinand I. und Maximilian II. konnten zwar die kaiserliche Macht in Italien bewahren - u.a. indem ersterer Philipp II. das Reichsvikariat über Italien verweigerte,$-{ }^{113}$ doch der nachfolgende Rudolf II. verlor hier (und im Reich) zunehmend an Reputation und konnte dem spanischen Vordringen in den kleineren oberitalienischen Reichslehen kaum Einhalt gebieten. ${ }^{114}$

Für die zweite Hälfte des I6. Jahrhunderts hat bereits Salvatore Pugliese in seiner Habsburg-kritischen Studie ein wenig positives Bild der kaiserlichen Macht in Reichsitalien gezeichnet. Das Reich war in seiner Auffassung für die italienischen Vasallen ein »Wrack«, dem mehr aus Gewohnheit denn aus Überzeugung gehuldigt wurde. ${ }^{115}$

Io8 Vgl. zur Familie: VöLKel, »Farnese«.

ro9 Vgl. Seidlmayer, Geschichte Italiens, 30i-320. Wie Galasso und andere bereits festgehalten haben, waren die Kämpfe um und in Italien ausschlaggebend und richtungsweisend für das europäische Gleichgewicht. Das Engagement von Reich, Schweizer Eidgenossen und Spanien auf der italienischen Halbinsel diente weniger der territorialen Eroberung und Machterweiterung als vorrangig der Eindämmung der französischen Vorherrschaft. Galasso, Il quadro internazionale.

i io Pugliese, Le prime strette, 57. Siehe auch: Lutter, »An das Volk von Venedig«.

i i Igl. Dandelet/Marino, Spain in Italy; zu Mailand im Speziellen vgl. Álvarez-Ossorio AlvaRIÑo, The State of Milan and the Spanish Monarchy.

I 2 Schilling, Konfessionalisierung und Staatsinteressen, 243. Auch in diesem Überblickswerk finden die Este bzw. die kaiserlichen Lehen Modena und Reggio nur wenig Beachtung.

II3 $\mathrm{Zu}$ den Beziehungen zwischen Reich/Kaiser und Spanien siehe auch die Bände und Beiträge der Reihe Hispania-Austria, insbesondere: Edelmayer, Kaisertum und Casa de Austria. Zu den Gegensätzen zwischen Spaniern und Deutschen, zur Fremdheit der Kaiser (Karl V. und Ferdinand I.) hier und dort siehe: Kohler, Die spanisch-österreichische Begegnung.

I 4 Schnettger, Feudi imperiali, IzO.

I 5 "Per i principi e feudatari che ebbero signoria in Italia dopo la morte di Carlo $\mathrm{V}$ e sino al finire del secolo XVII, il Sacro Romano Impero non rappresentava altro che un rudere venerabile per l'antichità, ma omai [sic] destituito di potenza e di vitalità; al quale si prestava omaggio e reverenza più per consuetudine che per necessità; di cui si obbedivano gli ordini, se non arrecavano disturbo, o se erano 
Diesem Bild stehen aber berechtigte, von der neuesten Forschung hervorgebrachte Vorbehalte gegenüber. ${ }^{116}$ Vor allem gegen die Auffassung, dass die kaiserlicher Macht zwischen I 540 und I 648 nur wenig oder teilweise gar nicht in Reichsitalien präsent gewesen sei und diese krisenhafte Absenz die Ausbreitung der spanischen Macht überhaupt ermöglicht habe, wurde bereits mehrfach revidiert. ${ }^{117}$ Die italienischen Vasallen versuchten vielmehr das "Allianzsystem« Karls V. weiterzuführen, auf ihr Lehensverhältnis mit dem Reich zu pochen und damit einhergehend ihre Möglichkeiten, an der großen Politik teilzuhaben, auszuschöpfen, während sie gleichzeitig vor Ort ihre Autorität bewahrten. Während die Medici I 569 mit einer pompösen Erhebungsfeier in Rom ihren päpstlichen Großherzogstitel feierten, der ihre Unabhängigkeit vom Reich ausdrückte, versuchten andere, weniger unabhängige "potentadillos«, wie die Gonzaga und die Este, ihren Status dadurch zu verteidigen, dass sie weiterhin dem Reich die Treue hielten, um Verbindungen zum Kaiserhof bemüht waren und gleichzeitig durch ihre persönlichen Kontakte sich mit dem spanischen König und seinen Vertretern in Italien gut stellten. So spielte auch Spanien eine wichtige Rolle in den Beziehungen zwischen den italienischen Vasallen und dem Reich im I6. und I 7. Jahrhundert, aber nicht, wie bisher von der Geschichtsschreibung betont, als außenstehende Macht neben einem desinteressierten und schwachen Kaiser, sondern als Teil einer nicht immer durchschaubaren Spanien-Reich-Reichsitalien-Koalition. Die spanische Politik in der Regierungszeit von Philipp II. und Philipp III. fuhr gegenüber der kaiserlichen Politik von Ferdinand I., Maximilian II., Rudolf II. und Matthias meistens zweigleisig: Einerseits war Spanien bemüht, das Reich nicht offen zu kontrastieren und dessen Rechte vor allem in Italien nicht in Frage zu stellen; andererseits versuchte es die Allianzen und Beziehungen der italienischen Vasallen zum Reich zu untergraben und zu sprengen, um diese auf die eigene Seite zu bringen - nicht ohne die momentane Schwäche des Reiches auszunutzen. Die schlechten Beziehungen zwischen Philipp II. und seinem Onkel Ferdinand I., der tatsächlich eine eher schwache Italienpolitik verfolgen musste, ${ }^{118}$ und noch mehr mit dessen Nachfolgern Maximilian II. und Rudolf II., welche hingegen sehr offen die Reichsrechte in Italien betonten, sind bekannt und nicht zu unterschätzen. ${ }^{119}$ Cinzia Cremonini hat die Rolle Spaniens in Italien trotz der aggressiven Vorherrschaft weniger als "pars destruens«, wie es die bisherige Geschichtsschreibung getan hat, als vielmehr als »pars construens« definiert, das die Beziehungen

appoggiati dalla potenza di Spagna; altrimenti trascurati e disobbediti.« Pugliese, Le prime strette, 70.

I 6 Siehe dazu Verga, L'Impero in Italia, 20.

i 7 Rivero Rodríguez, Felipe II; Cremonini, Impero e feudi italiani, 44.

i 8 Siehe dazu Laubach, Ferdinand I., vor allem Kap. Italien, 65 I -66r.

i 9 Cremonini, Impero e feudi italiani, 46-49. Vor Cremonini hat bereits Franco Angiolini die Notwendigkeit einer eingehenderen Untersuchung der spanischen Herrschaft in Reichsitalien eingefordert. Vgl. Angiolini, Diplomazia e politica. 
zwischen Reich und italienischen Vasallen, in einer Zeit, wo ersteres in Italien sehr wohl immer noch präsent war (Lehnserneuerungen, Kommissare ${ }^{120}$ ) gefördert hat. ${ }^{121}$

Aber nicht nur von den Spaniern, sondern auch von den italienischen Fürsten, die sich mit ihnen arrangiert hatten, ging oft die Missachtung von kaiserlichen Anweisungen und Dekreten oder sogar eine unangemessene und unverschämte Behandlung kaiserlicher Vertreter aus. An der Wende vom i6. zum I7. Jahrhundert hielt Vincenzo I. Gonzaga entgegen den kaiserlichen Befehlen das Reichslehen Castelgoffredo besetzt, Carlo Emmanuele von Savoyen war nicht nur nicht bereit, Kontributionen für das Reich zu zahlen, sondern behandelte die Überbringer der kaiserlichen Aufforderungen besonders schlecht. ${ }^{122}$ Auch der kaiserliche Kommissar Bartolomeo Beccaria, der 1584 in Italien Kontributionen sammeln sollte, machte schlechte Erfahrungen. Zwar gab es auch erfolgreiche kaiserliche Emissäre wie Graf Antonio d'Arco, Graf Raimund von Thurn und Baron Hans von Kobenzl, die 1592 für den geplanten Türkenkrieg von der Republik Genua 25.000 scudi, vom Herzog von Ferrara und jenem von Mantua je 20.000 scudi und von Parma I 5.000 scudi zugesagt bekamen. ${ }^{123}$ Kontributionen und Subsidien kamen aber vor allem dann aus Italien, wenn es in einer Angelegenheit die Gunst des Kaisers zu gewinnen galt und wenn die kaiserliche Seite gerade die gewinnbringendere gegenüber der spanischen oder französischen zu sein schien. Dabei waren - wie Jan Niederkorn zu Recht betont hat - gerade Carlo Emmanuele von Savoyen und Alfonso II. d'Este berüchtigte Schaukelpolitiker dieser Zeit. Alfonso versuchte z.B. als Gegenleistung für seine Türkenhilfe von Kaiser Rudolf II. dessen diplomatische Intervention beim Papst für die Erhaltung Ferraras als estensisches Lehen zu erreichen. ${ }^{124}$ Investituren, die Verleihung des Großherzogstitels an die Medici, der Streit um die Präzedenz, der Wettlauf um Titel (Serenissimo, Illustrissimo) brachten dem Kaiser weitere dringend benötigte

I 20 Das Institut der Kommission unterschied sich in der Frühen Neuzeit vom »Amt « dahingehend, dass es ohne gesetzliche Grundlage, unmittelbar vom Souverän eingesetzt und in seinem außerordentlichen Charakter jederzeit widerrufbar war. Vgl. Rainer BABEL, »Kommission«, in: Friedrich Jäger, Enzyklopädie der Neuzeit Online, Brill Online, 20I6. https://referenceworks.brillonline.com/entries/ enzyklopaedie-der-neuzeit/kommission-COM_295 I08 ?s.num=o\&s.f.s2_parent=s.f.book.enzyklopae die-der-neuzeit\&s.q=kommission, Zugriff: r6.9.2020. Als Kommissare im Reich fungierten ab der Mitte des r6. Jahrhunderts Hofräte und Geheime Räte, Landvögte, Mitglieder der erbländischen Regierungen und auch des Hofstaates. Sie hatten ähnliche Funktionen wie die ständigen Gesandten an auswärtigen Höfen. Vgl. Pflüger, Kommissare, 82-92, 283.

I 2 I CRemonini, Impero e feudi italiani, 52, 6 I.

I 2 Wien, HHStA, Hofkammerarchiv HKA, Reichsakten, K. 6o, fol. 932, zit. n. Niederkorn, Reichsitalien und der Kaiserhof, 60.

I 3 Siehe die Relation des Grafen Raimund von Thurn über die Verhandlungen mit Ferrara, Mantua und Urbino v. 8.ro.I 592, Wien, HHStA, HKA, Reichsakten, K. 24b., fol. 6o9-6r 3. Alfonso II. soll zwar die Kontributionen zugesagt haben, ließ deren Höhe erst von Graf Luigi Montecuccoli in Prag übermitteln; siehe die Weisung des Herzogs an Montecuccoli vom 23.r 2.I 592 ASMo, ASE, Casa e Stato, Carteggio di Ambasciatori, Germania b.5o; Niederkorn, Reichsitalien und der Kaiserhof, 6r. Ders., Die europäischen Mächte, 386-397.

I 24 Niederkorn, Reichsitalien und der Kaiserhof, 62f. Dazu ausführlicher weiter unten. 
Geldmittel aus Reichsitalien ein. Für die Investitur der Seitenlinie der Este mit Modena und Reggio schlug Kaiser Rudolf II. 400.000 scudi für den Türkenkrieg heraus. ${ }^{125}$

Auf der Suche nach weiteren Finanzierungsmöglichkeiten schickte Kaiser Rudolf II. I603/4 zur Eruierung der Lehensverhältnisse den kaiserlichen Hofrat Paul Simon Garzweiler von Westerhofen, seit zehn Jahren Reichshofratsmitglied, nach Italien. Dies war zwar die berühmteste und von der Geschichtswissenschaft am häufigsten untersuchte Entsendung, aber nur eine von vielen Missionen, die das Ziel hatten, die Reichslehen in Italien zu erfassen, um sie besser zu Kontributionen verpflichten zu können. Es handelte sich nicht, wie von Aretin behauptet, um die Einführung der Plenipotenz, ${ }^{126}$ die - wie Cremonini richtiggestellt hat - erst in der zweiten Hälfte des I 7. Jahrhunderts und vermehrt ab den I69oer Jahren installiert wurde. ${ }^{127}$ War Garzweiler zu dem Schluss gekommen, dass es notwendig sei, die italienischen kaiserlichen Lehen und vor allem die Untertanen vor der spanischen Vorherrschaft zu schützen, auch weil kleinere Lehen von größeren unterdrückt wurden, so schwächte Rudolf II. die Position des Reiches in Italien selbst, indem er kaiserliche Lehen gerade hier an Spanien verkaufte wie z.B. I604 Roccoverano für 6.00o Gulden. Die Situation drängte zum Übergang zu einer Form ständiger kaiserlicher Präsenz in Reichsitalien, die aber erst später in der Plenipotenz Ausdruck fand. Garzweiler sprach von einer Kommission mit Vollmacht für die italienischen Angelegenheiten, was sich von der Plenipotenz des I 8. Jahrhunderts unterschied. ${ }^{128}$

Die Errichtung der Plenipotenz für Italien hat neben der Tätigkeit des Reichshofrats zu einer Wiederherstellung und Intensivierung der Beziehungen zwischen den italienischen Vasallen und dem Kaiser geführt. Der Reichshofrat war als oberstes Lehensgericht und oberstes Gericht ein weiteres Vermittlungsorgan in den Beziehungen zwischen den italienischen Lehen und dem Reich. Die Reichsplenipotentiarii waren meist italienische Adelige aus bedeutenden Häusern z.B. der Herzog von Massa oder die Gonzaga, Herzöge von Mantua und Montferrat. ${ }^{129}$

Auch das I7. Jahrhundert war - so Schnettger - mit Ausnahme des Mantuanischen Erbfolgekrieges (I628-I63I) von einem »rückläufigen kaiserlichen Einfluss[es] « ${ }^{130}$ geprägt. Ende des I 7. Jahrhunderts keimte der alte Kampf zwischen dem Reich und Frankreich wieder auf und betraf nicht mehr nur Mailand, sondern nun auch Mantua,

I 25 Niederkorn, Reichsitalien und der Kaiserhof $67 \mathrm{f}$.

I $26 \mathrm{Zu}$ dieser Form der kaiserlichen Vertretung in Reichsitalien siehe Aretin, Das Reich, 9I-Ior; Schnettger, Kooperation und Konflikt.

I 27 Cremonini, Impero e feudi italiani, $75 \mathrm{f}$.

I 28 Aretin, Die Lehensordnungen, 74f. (Berichte in: Plenipotenz für Italien I, Wien, HHSta, Abschlussbericht bei J.J. Moser im Anhang von Einleitung zu dem Reichshofratsprozess); Cremonini, La mediazione, 33 .

I 29 Siehe Cremonini, I feudi imperiali italiani; Weiterführend: Guido Del Pino, Un problema burocratico: La plenipotenza per i feudi imperiali in Italia e il suo archivio tra XVII e XVIII secolo, in: Rassegna degli Archivi di Stato 54 (I 994), 55 I - 583. Aretin, Die Lehensordnungen, 63 f.

I30 Schnettger, Feudi imperiali, I3O. 
das seit 1630 unter Herrschaft der französischen Nebenlinie des Hauses GonzagaNevers stand. Zur weiteren Wahrung der Reichsrechte wurde demzufolge ein commissarius plenipotentiarius eingesetzt, der neben den reichsitalienischen Angelegenheiten allgemein, also der Aufrechterhaltung der Verbindung zwischen dem Kaiser bzw. dem Reichsvizekanzleramt und dem Reichshofrat und den italienischen Vasallen (dem Großherzog von Toskana, den Herzögen von Savoyen, Modena, Parma und Piacenza, den Stadtrepubliken Genua, Lucca und San Remo und ca. 200 kleinen Vasallen, die lange nicht vollständig erfasst worden waren) vor allem mit der Betreuung des »Heimfalls« Mailands beauftragt wurde. Die Errichtung des Amtes eines plenipotentiarius und der Versuch ab r69o Kontributionen einzufordern zeigen - so Aretin - ein neues, gesteigertes Interesse an Reichsitalien. Erst als die spanische Vorherrschaft in Italien Ende des I7. Jahrhunderts an Kraft verlor und Kaiser Leopold I. und seine Nachfolger sich in Italien wieder stärker engagierten, wendete sich das Blatt. Selbst wenn die kaiserliche Italienpolitik weiterhin bescheiden blieb und die »feudi imperiali institutionell zu einem Anhängsel des österreichischen Besitzes in Italien wurden «, ${ }^{131}$ blieb Reichsitalien mit seinen Strukturen bis zum Frieden von Campo Formio I 797 erhalten.

Vom zurückgekehrten Herzogtum Mailand sollte dann im I8. Jahrhundert eine Intensivierung der Beziehungen des Kaisers zu Italien ausgehen. Diese vor allem von Joseph I. betriebene Italienpolitik sollte die Reichsrechte geltend machen und kaiserliche Lehen zurückfordern, z.B. dort, wo sich Fürsten wie die Gonzaga mit den Franzosen verbündet hatten. Die kleineren feudatari wurden wieder mehr an das Reich gebunden, was zu einer "Renaissance der Beziehungen zu Italien « ${ }^{132}$ führte. Die Intensivierung der Beziehungen zwischen Reich/Kaiser und feudi italiani zeichnete sich im I8. Jahrhundert durch eine regelmäßigere Eintreibung von Kontributionen, die Übernahme von Reichssymbolik, das regelmäßige Kirchengebet für den Kaiser aber auch durch die Errichtung einer kaiserlichen Salzversorgung für kleinere Lehen aus. Darüber hinaus wurden die Kaisersöhne gelehrt, dass der Kaiser gleichzeitig König von Italien war und sich in den Wahlkapitulationen verpflichten musste, die italienischen Reichslehen zu schützen, die Reichsrechte in Italien zu bewahren und jene, die in Vergessenheit geraten waren, wiederzubeleben. Außerdem wurde daran erinnert, dass die italienischen Reichsfürsten zu Kontributionszahlungen angehalten werden mussten und dass der Herzog von Savoyen das Amt des Reichsvikars in Italien, wie der Kurfürst von Köln jenes des Erzkanzlers für Italien innehatte. ${ }^{133}$

Kaiser und Reich bemühten sich also im ausgehenden 17 . und im I 8. Jahrhundert nachdem sie die reichsitalienischen Lehen vor der spanischen Übernahme verteidigt hatten - die eigenen Rechte und Möglichkeiten in Italien wieder auszuschöpfen. Dies taten sie auf rechtlicher Basis mithilfe von Institutionen wie dem Reichshofrat oder

I3 I Schnettger, Feudi imperiali, I3 I.

i32 Aretin, Der Heimfall, 87-89.

I33 Brauneder, Impero e Stato, 6r bezieht sich hier auf die Wablkapitulation des römischen Kaisers Franz des Zweiten vom Jahre I792, Greifswald I9I 2, Art. X, §6. 
der Plenipotenz, mithilfe von Historiografen wie Leibniz und Muratori ${ }^{134}$ und Juristen, die die rechtmäßigen, historisch gewachsenen Rechte von Kaiser und Reich in Italien bestätigen sollten, und schließlich auch mit militärischem Einsatz, so I 708 bei der Einnahme von Comacchio, das - wie die Este erfolglos ein Jahrhundert lang felsenfest behauptet hatten - ein Reichslehen war. Aber auch dynastische Verbindungen dienten dem Zweck der Festigung der Bindung der italienischen Vasallen an den Kaiser, vor allem dann, wenn sie zur Nachfolge des Kaiserhauses in den jeweiligen italienischen Reichslehen führten wie im Falle Modenas oder auch in der Toskana. Diese Mischung aus kaiserlichem Recht, Reichsinstitutionen und dynastischen Ansprüchen förderte in Italien die Entstehung des frühmodernen Staates. ${ }^{135}$

\subsubsection{Der Reichshofrat - eine wichtige Institution (auch) für Reichsitalien}

Der Reichshofrat (Consiglio imperiale aulico) ${ }^{136}$ war bis zum Ende des I6. Jahrhunderts der königliche/kaiserliche Hofrat und dann als Kaiserlicher Rat neben dem Kaiserlichen Kammergericht eines der höchsten Gerichte im frühneuzeitlichen Reich. ${ }^{137} \mathrm{Er}$ diente der Entlastung des Herrschers bei der Ausübung des Richteramtes. Der Name »Reichs«-Hofrat drückt die Zuständigkeit dieser Institution im und für das Reich außerhalb der Erblande und somit auch für Reichsitalien aus. Wenn auch seine gerichtliche Funktion Vorrang hatte, so diente er darüber hinaus der umfassenden Beratung des Herrschers in Regierungs- und Verwaltungsfragen mit politischem Akzent (Reichslehen, Gnadensachen). ${ }^{138}$

Leopold Auer, der sich intensiv mit dieser Institution auseinandergesetzt hat, definiert den Reichshofrat sehr treffend als die »institutionelle Klammer des Reiches «, ${ }^{139}$

I34 Zu beiden siehe unten.

I35 Brauneder, Impero e Stato, 69-7I.

I36 Dazu siehe vor allem Gschliesser, Der Reichshofrat. Peter Moraw »Reichshofrat«, in: Handwörterbuch zur deutschen Rechtsgeschichte 4, Berlin 1990, Sp. 630-638. Sellert, Der Reichshofrat. Ortlieb, Vom königlichen/kaiserlichen Hofrat. Zu den neueren und tiefgehenden Untersuchungen zum Reichshofrat und seinen Agenden in Italien gehören die Arbeiten von Leopold Auer. Hier vor allem Auer, Reichshofrat und Reichsitalien. Ders., The Role of the Imperial Aulic Council; Ders., Appellationen an den Reichshofrat.

I37 Über die erst im Zuge der Frühen Neuzeit sich entwickelnde Abgrenzung im Zuständigkeitsbereich dieser beiden Institutionen siehe weiterführend: Wolfgang Sellert, Über die Zuständigkeitsabgrenzung von Reichshofrat und Reichskammergericht, insbesondere in Strafsachen und Angelegenheiten der freiwilligen Gerichtsbarkeit (= Untersuchungen zur deutschen Staats- und Rechtsgeschichte NF 4), Aalen r 965. Darüber hinaus auch die Beiträge in dem Tagungsband von Ders. (Hg.), Reichshofrat und Reichskammergericht. Diestelkamp, Zur ausschließlichen Zuständigkeit.

I 38 Peter Moraw, "Reichshofrat«, in: Lexikon des Mittelalters 7, Sp. 623. Ortuieb, »Reichshofrat«, Sp. 9I 4-92O.

I39 Auer, Reichshofrat und Reichsitalien, 27. Fellner/Kretschmayr, Die österreichische Zentralverwaltung I, 23-33, I $43-$ I 53 . 
die aus dem Rat des Herrschers entstanden und als höchstgerichtliches Organ oft gegen die kaiserliche Politik gerichtet war, denn als unmittelbare Verbindung zwischen Untertanen und Reichsoberhaupt half der Reichshofrat bei der Durchsetzung von Rechten. In Reichsitalien, wo Reichstag und Reichskammergericht nicht die erste Vertretung darstellten, war er oft die einzige Anlaufstelle für Klagen. Dabei liegt der dokumentierte Schwerpunkt seiner Tätigkeit eindeutig im I 8. Jahrhundert. Aus dem I6. Jahrhundert hat Auer im Bestand Judicialia gerade einmal i 7 Appellationen aus Reichsitalien, konzentriert auf die Regierungszeit von Kaiser Rudolf II., ausmachen können. ${ }^{140}$ Eine der wichtigsten Aufgaben dieser Institution war die Kontrolle der Wahrung der Reichslehensordnung, das waren »die Aufrechterhaltung der kaiserlichen Lehensherrschaft, de[r] Schutz der Reichslehen, alle Agenden, die mit der Belehnung im Zusammenhang standen, Fragen der Erbfolge, der Verpfändung und Veräußerung sowie die Streitigkeiten, die sich daraus ergeben konnten. ${ }^{141}$ Bei den italienischen Reichslehen (wie Modena und Reggio) spielte der Reichshofrat eine wichtige Rolle bei der Erneuerung der Investitur. Die Vorgangsweise war immer dieselbe und wiederholte sich bei jedem Herrscherwechsel bzw. beim Antritt der Nachfolge im Reichslehen: Ein Reichshofagent brachte mit den notwendigen Dokumenten (Adelsnachweis, beglaubigte Kopie des letzten Lehensbriefes) die Erneuerung (Mutung) vor, nachdem der Reichshofrat die Richtigkeit überprüft hatte. Nach der Zahlung der Gebühren, der sogenannten Laudemien, die kein Fixum, sondern immer wieder neu verhandelbar waren, wurde der Lehensmann selbst oder sein Gesandter zum Eid vor dem Kaiser zugelassen; die kleinen Lehen (feuda minora) hingegen wurden vor dem Reichshofrat zugelassen. Ein Unterschied bestand auch zu den deutschen Vasallen, deren Vertreter von feuda minora beim Lehenseid nicht knien mussten, sondern stehen durften. Nach dem Eid wurde die Investitururkunde ausgestellt. Konfliktpotenzial gab es bei den verschiedenen Auffassungen der Belehnung und der räumlichen (oder zeitlichen) Dimension der Investitur und dementsprechend beim Inhalt des Lehensbriefes. ${ }^{142}$

Schließlich war der Reichshofrat als Gerichtshof Anlaufstelle für italienische Kläger und Beklagte, die z.B. gegen das Urteil eines italienischen Gerichtes appellierten. Problematisch war, dass der auf Vermittlung bedachte Reichshofrat die Verfahren in die Länge zog und die Exekution in den seltensten Fällen überwachen konnte. ${ }^{143}$ Die Funktionäre des Reichshofrates waren die entsendeten kaiserlichen Kommissare, später die plenipotentiarii, die somit das Verbindungsglied zwischen dem Kaiser, der Reichskammer und dem Reichshofrat auf der einen und den italienischen Untertanen auf der anderen Seite darstellten. ${ }^{144}$ Darüber hinaus gab es ab I765 in Pavia mit dem

\footnotetext{
I 40 Auer, Appellationen. Ehrenpreis, Kaiserliche Gerichtsbarkeit.

I4 I Auer, Reichshofrat und Reichsitalien, 29.

I42 Schnettger, Das Alte Reich, $367 f$. Ders., Impero romano, 56-62.

I43 Auer, Appellationen.

I44 Auer, Reichshofrat und Reichsitalien, 30-32. Schnettger, Feudi imperiali, I 29.
} 
Reichsvikar einen kaiserlichen Vertreter für die italienischen Reichslehnsnehmer vor Ort. Bis zum Beginn des I 7. Jahrhunderts war auch das Reichskammergericht für die von Italienern vorgebrachten Rechtsfälle zuständig. ${ }^{145}$

Die Dokumentation der Arbeit des Reichshofrates im Reich und in Reichsitalien ist im Archiv des Reichshofrates im Wiener Haus-, Hof und Staatsarchiv in den Beständen der Gerichtssachen (Judicialia ca. I 0.000 archivalische Einheiten) und jenen der Lehens- und Gnadensachen (Feudalia und Gratialia ca. I.ooo Einheiten) aufbewahrt. ${ }^{146}$ Wenn auch die Appellationen aus Reichsitalien im Vergleich zum übrigen Reich nicht so zahlreich, jedoch langwierig waren und die Urteile in ihrer Exekution problematisch blieben, so trug die Institution des Reichshofrates dennoch dazu bei, die Rolle des Kaisers als oberster Richter und Lehensherr in Reichsitalien zu betonen. Aufsehen erregte der langjährige Prozess Luccas ${ }^{147}$ gegen Modena zu Beginn des I7. Jahrhunderts, in dem die Republik, die Schwäche der Este nach dem Verlust Ferraras ausnutzend, Ansprüche auf das Grenzgebiet Garfagnana stellte. In diesem Streitfall vor dem Reichshofrat wurden von beiden Seiten neben dem Kaiser (zuerst Rudolf II. dann Matthias ${ }^{148}$ ) auch die Kaiserin, Anna, Tochter von Erzherzog Ferdinand II. und Anna Caterina Gonzaga sowie ihr Obersthofmeister Maximilian von Trauttmansdorff um Unterstützung angerufen. ${ }^{149}$ Zeitgleich lief am Reichshofrat eine Appellation der Fürstenfamilie Pio di Savoia gegen Modena ( I 60 I - I 609). ${ }^{150}$ Üblicherweise bediente sich der Reichshofrat der italienischen Gerichte und Vertreter vor Ort und bemühte sich um Ausgleich und einvernehmliche Lösungen. Auch der Herzog von Ferrara war in der zweiten Hälfte des r6. Jahrhunderts zeitweilig als kaiserlicher Kommissar in

I45 Brauneder, Impero e Stato, 67 f.

I46 Eva Ortlieb hat sich mit den Gnadensachen im Aufgabenbereich des Reichshofrates der ersten Hälfte des I6. Jahrhunderts auseinandergesetzt und festgehalten, dass es sich dabei um weit mehr als um Begnadigungen im Zuge von Vergehen bzw. Unrecht handelte. Im Bestand Gratialia wurden verschiedene Rechte beim Reichsoberhaupt beantragt, so auch Regalien und Reservatrechte, also die Erteilung von Privilegien oder von Geleitrecht, Standeserhöhungen, Legitimationen und Volljährigkeitserklärungen oder Bestätigung von Verträgen. Dazu kamen dann die verschiedenen Supplikationen um Gnade, Empfehlung, Schutz oder Zuwendungen. Ortwieb, Gnadensachen, I8o. Dazu siehe bereits: Auer, Das Archiv des Reichshofrats.

I47 Vgl. zu diesem Streitfall: Mancini, Storia di Lucca, 255-258; SAbbatini, La corte asburgica vista da Lucca, 27 I mit Anm. 48.

I48 Zu Kaiser Matthias (reg. I6r 2- I6 I 9) vgl.: Press, Matthias.

I49 So entsandte der Ältestenrat der Republik Lucca einen Gesandten, der dem Obersthofmeister die Auseinandersetzung mit dem Herzog von Modena erläuterte, die vor dem Reichshofrat vorzubringen war und diesen um Fürsprache bat. Wien, HHStA, AVA, FA Trauttmansdorff, Kart. I I 8 (I6r6- I620). Vgl. auch: TAddei, Anna von Tirol.

I 50 Auer, Appellationen, Anm. 39. Auers Untersuchung der Judicialia latina und die Stichproben in anderen Beständen (Protokolle, Feuda latina, Italien-Kleine Staaten) haben bis jetzt keine Appellation aus dem Herrschaftsbereich der Este im I6. Jahrhundert ergeben. Prof. Auer sei an dieser Stelle für die hilfreichen Hinweise herzlich gedankt. 
der Auseinandersetzung zwischen Savoyen und Alfonso del Carretto tätig. ${ }^{151}$ Zuletzt zeigte der bereits aufgearbeitete Fall des estensischen Agenten Giovan Battista $\mathrm{Mu}-$ neretti, dass und inwiefern der Reichshofrat noch im I8. Jahrhundert von reichsitalienischen Vasallen in Anspruch genommen wurde. ${ }^{152}$

\subsubsection{Subsidien aus Reichsitalien: Pflicht oder Druckmittel?}

Ein weiterer wichtiger Aspekt in den Beziehungen zwischen den italienischen Vasallen und dem Reich waren - wie bereits erwähnt - die Kontributionen, auf die hier noch kurz eingegangen werden soll, da sie auch für die Beziehungen der Este zu den Kaisern des i6. Jahrhunderts eine ausschlaggebende Rolle spielten.

Die vor allem für die Grenzverteidigung notwendigen Kontributionen in Millionenhöhe konnten nicht allein von Böhmen, Ungarn und den österreichischen Erbländern aufgebracht werden, ${ }^{153}$ sondern benötigten die Unterstützung des Reiches, der italienischen Lehen und Spaniens. Nach Peter Rauscher rechnete man in den letzten I 57 oer Jahren »mit jährlichen Zahlungen der niederösterreichischen und böhmischen Länder in Höhe von 600.000 Gulden, der innerösterreichischen von 400.000 und des Reichs in Höhe von 600.000 Gulden «. ${ }^{154}$ Winfried Schulze errechnete für den Zeitraum von I 556 bis I 607 Kontributionen für die Türkenkriege von Reich und Kreisen in der Höhe von 30,8 Millionen Gulden. ${ }^{155}$ Davon wurden nach Niederkorn 20 Millionen Gulden allein für den »Langen Türkenkrieg" von I 593 bis I 606 verbraucht. ${ }^{156}$ Ab der Mitte des I6. Jahrhunderts waren die Kontributionen in Form von Geld, die aus den Steuern der Untertanen kamen, die einzige durch die Reichsstände gewährte Unterstützung für die Türkenabwehr. Es gab keine Truppenhilfe aus den Reichskreisen mehr. Der jeweilige zu entrichtende Anteil der Reichsstände kam als Kopf- oder Vermögenssteuer, dem sogenannten Gemeinen Pfennig an die kaiserlichen Zahlämter und der Kaiser übernahm die Aufstellung und Besoldung der Truppen selbst, obwohl dies nicht immer im Sinne des Reichsoberhauptes war, wie die Forderung Rudolfs II. von I608 nach Bereitstellung von Streitkräften durch die einzelnen Reichsstände beweist. ${ }^{157}$

Auch Reichsitalien musste seinen Beitrag an der Türkenabwehr und an den allgemeinen Kontributionen leisten. ${ }^{158}$ Den »finanziellen Stellenwert Reichsitaliens im

I5 I Auer, Appellationen.

I 52 Bonacini, Giovan Battista Muneretti.

I53 Vgl. dazu die errechneten Kosten und Einnahmen für die Sicherung der Grenze bei Kenyeres, Die Kosten der Türkenabwehr.

I54 Rauscher, Nach den Türkenreichstagen, 434.

I55 Schulze, Reich und Türkengefahr, 360 , 369 .

I 56 Niederkorn, Die europäischen Mächte, 499.

I 57 Rauscher, Nach den Türkenreichstagen, 453-455. Als besonders ausführlicher Überblick: LanZINNER, Der Gemeine Pfennig.

I 58 Die erwartete Unterstützung aus Italien findet sich immer wieder in den Reichstagsakten, hier bei- 
Rahmen der Reichsgeschichte des I 7. und I 8. Jahrhunderts « hat Matthias Schnettger in drei Phasen eingeteilt: Ab der Mitte des I6. Jahrhunderts bis I69o bekam der Kaiser auf nachdrückliche Bitten von den reichsitalienischen Fürsten mehr oder weniger freiwillige finanzielle und militärische Unterstützung im Kampf gegen die sogenannten Ungläubigen an der Grenze zum Reich und die sogenannten Häretiker innerhalb der Reichsgrenzen. Dann folgte bis I733 eine Phase des erhöhten Drucks von Seiten der Kaiser, in der sie mit erstarktem Selbstbewusstsein und mithilfe von kaiserlichen Kommissaren Subsidien aus Italien einforderten (für den Spanischen Erbfolgekrieg sollen es I 7.728.00o Mailänder Lire gewesen sein ${ }^{159}$ ). In der dritten Phase bis zum Ende des I 8. Jahrhunderts war die Eintreibung von Kontributionen zumeist wenig erfolgreich. Von Interesse für unsere Überlegungen hier ist natürlich die erste Phase, die mit der Zäsur der Abdankung Karls V. und dem Verlust der kaiserlichen Vormachtstellung auf der italienischen Halbinsel beginnt. Trotz der Machteinbußen durch die Erbaufteilung und die Vormachtstellung Spaniens konnten die Kaiser bei jeder Türkengefahr Kontributionen von ihren italienischen Reichsvasallen erbitten und erhalten, wenn sie als oberste Lehensherren deren Forderungen weitestgehend entgegenkamen. ${ }^{160} \mathrm{Wie}$ Niederkorn für den "Langen Türkenkrieg" errechnet hat, kamen zwischen I 592 und I6 I6 knapp mehr als $450.000 \mathrm{fl}$ aus Italien. ${ }^{161}$ Im Gegenzug erhielt die spendable Republik Genua nach der Ausschüttung von 25.000 scudi den Titel Illustrissimo für ihren Dogen. Alfonso II. kostete die Nachfolge Cesares aus der estensischen Nebenlinie 400.000 scudi, die Rudolf ebenfalls für den Krieg benötigte. Eine weitere Möglichkeit an Beitragszahlungen zu kommen, waren, wie Schnettger auch am Beispiel Genuas zeigen konnte, die erhöhten Laudemien, die Taxen und Gebühren, die bei einer Neubelehnung anstanden. Die Superba ließ sich die Belehnungen mit der Markgrafschaft Sassello I6 I 2 I 60.000 Gulden und I 624 mit der Markgrafschaft Zuccarello 200.000 Gulden kosten. ${ }^{162}$

Die Kontributionen aus Italien und auch aus dem estensischen Fürstentum waren in der zweiten Hälfte des I6. Jahrhunderts also, wie Schnettger festgestellt hat, »keine quantité négligeable«; zwar war der Fluss dieser Gelder unregelmäßig und hart erkämpft, aber bei entsprechender Gegenleistung konnte er sogar aus den mittelgroßen und kleinen Reichslehen beachtlich sein. ${ }^{163}$ Zudem boten die italienischen Fürsten

spielhaft die Vorakten zum Reichstag zu Ausgburg 1566, wo es bezüglich der Bedrohung durch die Türken im Mittelmeerraum heißt: „Venedig könnte dagegen eine stattliche Hilfe leisten, ebenso Ferrara, Florenz, Mantua und andere italienische Ff.« Lanzinner/Heil, Deutsche Reichstagsakten, Reichsversammlungen I556-1662. Der Reichstag zu Augsburg 1566 I, 158.

I59 Pugliese, Le prime strette, 220.

i6o Schnettger, Subsidien und Kontributionen, 5466 .

i6 I Niederkorn, Die europäischen Mächte, 448.

I62 Schnettger, Subsidien und Kontributionen, 548, 553.

i63 Schnettger, Subsidien und Kontributionen, 57 r. Vgl. auch Niederkorn, Reichsitalien als Finanzquelle. 
neben Geldmitteln auch weiterhin Truppen und militärische Dienste an: I 566 folgte Alfonso II. d'Este dem Aufruf des Kaisers zur Verteidigung des Glaubens nicht mit Dukaten, sondern mit luxuriös ausgestatteten Streitkräften, die er selbst anzuführen verlangte. ${ }^{164}$ Noch in den I $590 e r$ Jahren bot er für die Nachfolge in den Reichslehen und im Papstlehen neben hohen Geldsummen auch an, ein Heer in den Türkenkrieg zu führen. Da die Türkenhilfe und die Kontributionen der italienischen Fürsten auch propagandistisch verwertet wurden, konnte Vocelka einigen Flugschriften entnehmen, dass der Herzog von Ferrara I 595 2.00o Fußsoldaten und 500 Berittene und somit mehr als der Herzog von Urbino mit 2.000 Fußsoldaten und 200 Berittenen und der Herzog von Mantua mit I.000 Fußsoldaten und 400 Berittenen für die Verteidigung der Reichsgrenzen bereitstelle. ${ }^{165}$ Auch daraus wird ersichtlich, dass aus Reichsitalien neben Geld weiterhin Truppen kamen.

Doch die Größe und Herrlichkeit der frühneuzeitlichen kaiserlichen Macht litt auch jenseits der Kriegszeiten unter einer chronischen Geldnot. ${ }^{166}$ Nicht nur in Italien, sondern auch im Reich waren viele reicher als der oberste Lehensherr, wie z.B. der Herzog von Sachsen, dessen Einkünfte in der Höhe von 660.000 Gulden um ein Vielfaches über jene des Kaisers lagen. Die finanzielle Notlage und die wiederholte Notwendigkeit, gegen Privilegienvergabe (z. B. Großherzogstitel für Florenz gegen roo.00o scudi) ${ }^{167}$ Geldmittel zu erstehen, Schulden zu machen ${ }^{168}$ und finanzielle Abhängigkeiten zu vertiefen, kratzten am Image der Kaiser der zweiten Hälfte des I6. Jahrhunderts.

\subsubsection{Lehenswesen und Lehenssituation in Reichsitalien}

\subsubsection{Entwicklungen im italienischen Lehenswesen}

Der Untersuchung der Este als Vasallen des Reiches (und des Heiligen Stuhls) soll ein Überblick über die kaiserlichen Lehen auf der italienischen Halbinsel, ihre Entstehung und Entwicklung bis zum Beginn des I 5. Jahrhunderts in groben Zügen vorangestellt werden.

i64 Pugliese, Le prime strette, $7 \mathrm{I}-75$.

I65 Fünfferley Warhafftige Newe Zeyttung, Die Erste auß Ungern ..., Prag I 595 (QV 257) zit. n. VoCELKA, Die politische Propaganda, 227, 252.

r66 Zum steigenden Finanzbedarf des kaiserlichen Hofes in der Mitte des r6. Jahrhunderts siehe: RAUSCHER, Die Finanzierung des Kaiserhofs.

i67 $\mathrm{Zu}$ den weiteren Geldleihen und Kontributionen der Medici siehe auch: Contini, Aspects of Medicean Diplomacy, 8of.

I68 Dazu vgl. die Aufstellung der Kreditgeber der Habsburger im I6. Jahrhundert bei: Winder, Die Kreditgeber. Hierbei fällt auf, dass vor allem bei deutschen und einigen italienischen Kaufleuten Kredite aufgenommen wurden. Ebenso verliehen die Erzherzöge Ferdinand II. und Karl II. Geld an den Kaiser, ebd., 457 f. 
Das Lehenswesen ist, nach der Definition von Karl-Heinz Spieß in seiner Einleitung zu dem 2013 von ihm herausgegebenen Tagungsband zum Lehenswesen im Reich und in Italien, »die Gesamtheit der rechtlichen Bestimmungen für das Verhältnis zwischen Lehnsherr und Vasall und deren Auswirkungen auf die staatlichen und gesellschaftlichen Strukturen «. ${ }^{169}$ Einige Beiträge des Tagungsbandes und die Einleitung von Spieß selbst setzen sich mit der I 994 erschienenen Untersuchung von Susan Reynolds mit dem Titel »Fiefs and vassals: the medieval evidence reinterpreted « ${ }^{170}$ auseinander, die damit eine vergleichende europäische Studie zu den Lehensverhältnissen in Frankreich, Italien, England und dem Reich vorgelegt hat. Für Reynolds spielte das I 2. Jahrhundert eine Schlüsselrolle bei der Entstehung des Lehenswesens, als nämlich akademisch geschulte Juristen Recht und Gewohnheit in der Landleihe vereinten. Das sich im I2. und I3. Jahrhundert konstituierende Lehensrecht entstand nämlich zum größten Teil aus mündlich gehaltenen Rechtsgewohnheiten und Rechtsurteilen. ${ }^{171}$

Die maßgebliche Rechtsquelle für das frühe Lehenswesen in Italien, mit der sich Reynolds und nach ihr besonders Gerhard Dilcher auseinandergesetzt haben, sind die Libri Feudorum, eine in der Lombardei im Zuge der Ausbildung des lombardischen Lehensrecht entstandene private Sammlung von Rechtstexten aus dem I 2. Jahrhundert aus der Feder von Obertus de Orto, die im darauffolgenden Jahrhundert zum Zwecke der Belehrung vor allem durch die Nähe zur Rechtschule von Pavia und dann von Bologna in die gelehrte Jurisprudenz Eingang fand. ${ }^{172}$ Diese Sammlung von spätmittelalterlichen Rechtstexten, von der es eine ältere (I I 50) und eine jüngere ( 1250 ) Fassung gibt, besteht aus Prozesssituationen, Fallbespielen, Urteilen und auch staufischen Kaisergesetzen, wie z.B. das Lehensgesetz von I037, das mit seinen Ausführungen zu den lehensrechtlichen Ständen und zum Erbrecht im Lehen die Libri Feudorum zu einer Grundlage des lombardischen Lehensrechts machte. Dass die Entstehungsgeschichte der Sammlung vom ersten Drittel des I I. Jahrhunderts bis in die Mitte des I3. Jahrhunderts datiert werden kann, bedeutet nicht, dass es in Oberitalien nicht schon vorher lehensrechtliche Beziehungen gab, die als Benefizialleihen oder Vasallität definiert werden können. Dilcher hat diese Textsammlung als ein aus

i69 Spiess, Einführung, io. Siehe auch Karl-Heinz Spiess, »Lehn(s)recht, Lehnswesen«, in: Handwörterbuch zur deutschen Rechtsgeschichte 2, Berlin 1978, Sp. I725-I74I. Einen früheren, mittlerweile aber überholten Überblick lieferte: Otto Brunner, Land und Herrschaft. Grundfragen der territorialen Verfassungsgeschichte Südostdeutschlands im Mittelalter (= Veröffentlichungen des Instituts für Geschichtsforschung und Archivwissenschaft in Wien I), Brünn/München/Wien ${ }^{3}$ I 943.

I70 Reynolds, Fiefs. Dass der Prozess der Neuinterpretierung und Revidierung von tradierten Vorstellungen über das Lehenswesen und seine Eigenschaften noch nicht abgeschlossen ist, beweisen die von Jürgen Dendorfer und Steffen Patzold seit 2013 koordinierten Tagungen und verschiedene DFGProjekte.

I7 I Spiess, Einführung, I3-I5.

I72 Dilcher, Das lombardische Lehnsrecht. 
kaiserlicher Gesetzgebung und der Rechtspraxis im Lehenswesen hervorgegangenes, praxisnahes, die Entwicklungen widerspiegelndes Rechtsbuch definiert. Wenn auch normativer Natur, ist es ein »Regelwerk zur Anleitung konkreter Konfliktentscheidungen in Lehenssachen «, ${ }^{173}$ das im Rahmen der sich ausbildenden Rechtswissenschaften um Definition und Begriffsschärfe bemüht war.

Sowohl Reynolds als auch Dilcher haben den von der älteren Literatur im Jahr 774 angesetzten Beginn eines rechtlich begründeten und klar abgegrenzten Lehenswesens daher eindeutig auf I037, dem Jahr der Konstitution von Konrad II. verlegt. ${ }^{174}$ Allerdings räumt Dilcher ein, dass es nichtsdestoweniger eine spezifische erste Phase des lombardischen Lehensrechts gegeben haben muss, »die sich noch weitgehend im Medium der Oralität, im Gefolge der Bildung der Lehenskurien und des ordo militum schon innerhalb des I I. Jahrhunderts vollzieht«. Das Regelwerk, das dabei entstand und sich fortwährend weiterentwickelte, floss schließlich in die Texte der Libri Feudorum ein. Diese schriftliche Ordnung des I 2. Jahrhunderts ist allerdings "noch keineswegs überwiegend rakademisch`, sondern auf der Grundlage von Rechtsgewohnheiten durch feudistische Rechtskundige geprägt [...].«175

Die Zeit an der Wende vom I I. zum i 2. Jahrhundert war somit von starken rechtlichen Umwandlungen, aber auch von regionalen und städtischen Unterschieden im Gewohnheitsrecht und daher von der Suche nach einer Ordnung geprägt. Das in den Lehenskurien einzelner oberitalienischer Städte (Cremona, Piacenza, Pisa, Lucca, Verona etc.) entstandene Gewohnheitsrecht ging auf die kaiserliche Konstitution Konrads II. von ro37 zurück. So fußte das lombardische Lehensrecht mit seiner eigenen Gerichtsform und einem eigenen Verfahren in Lehenssachen abseits der ordentlichen Gerichtsbarkeit dennoch auf der obersten gerichtlichen Instanz des Kaisers. Ausdruck fand das in der Treueformel für den Kaiser im Lehenseid der Libri Feudorum. ${ }^{176}$ Es handelt sich hier somit um einen Brückenschlag vom »lombardischen Partikularrecht zum europäischen ius commune«. ${ }^{177}$

Im Traktat wird, ausgehend von der aktiven Lehensfähigkeit (qui feudum dare possunt), also den geistlichen Großen, den Markgrafen und Grafen, die Hierarchie der Lehensberechtigten erläutert. Darunter sind »des Königs Valvassoren«, die Lehen an die kleinen Valvassoren valvassini oder minimi valvassores weitergeben können. Oberste Pflicht aller großen und kleinen Valvassoren, die als Stadtadel in der Führungsschicht der entstehenden Stadtkommune neben dem freien Bürgerstand zu finden sind, war

\footnotetext{
I73 Ebd., 49.

I74 Dilcher, Das lombardische Lehnsrecht, 77. Reynolds Thesen und die von ihr vertretene Umdatierung sind »mehr als eine Quisquilie: Sie zwingt dazu, die sozialen, wirtschaftlichen und politischen Auswirkungen des Lehnswesens neu zu diskutieren«, so Patzold, Das Lehnswesen, 270.

I75 Dilcher, Das lombardische Lehnsrecht, 78.

I76 Vgl. Dilcher, Das lombardische Lehnsrecht, 49-52.

I77 Ebd., 53 .
} 
der militärische Dienst für den König vor allem für den Romzug. ${ }^{178}$ Die von Friedrich Barbarossa nach dem Hoftag von Roncaglia in den Stadtkommunen eingesetzten Konsuln und podestà (Stadtvögte) ${ }^{179}$ hingegen gehörten nicht der Feudalverwaltung, sondern der städtischen Amtsverwaltung an, deren Amt von einem nicht vasallistischen Treueeid, einer fünfährigen Amtszeit und einer Einsetzung durch die Bischöfe, sofern sie Grafengewalt hatten, oder den Kaiser selbst charakterisiert war.

Zum Verlust des Lehens konnte es nach Obertus de Orto und den Libri Feudorum u.a. bei Verlassen des Herrn auf dem Schlachtfeld, einem fehdemäßigen Angriff auf den Herrn oder der Entfremdung des Lehens kommen. Überhaupt nicht investiert werden konnte, wer sich weigerte, den Treueeid zu schwören. Spätere Autoren haben dies erweitert: Nicht nur das Fernhalten von Bösem, sondern auch das Tun von Gutem konnte Bedingung der Investitur sein. Der Investierte musste seinem Herrn (und auch umgekehrt) mit Rat und Tat beistehen. Die Tatsache, dass dies in der Eidesformel ausgesprochen wurde, ist nach Dilcher der Beweis des »Niedergangs des Lehensrechts und der fehlenden Selbstverständlichkeit vasallistischer Treue «. ${ }^{180}$ Wenn also militärischer Königsdienst nobilitierte und feudalisierte, so konnte jemand demzufolge das Lehen verlieren, wenn er sich weigerte, diesen Dienst zu erbringen. Wie noch gezeigt werden wird, haben auch die Este in dieser Hinsicht keine vorbildliche Lehensbeziehung geführt. Gerade an ihrem Beispiel wird klar, wie sehr sich diese normativen Lehenspflichten in der Neuzeit aufgeweicht hatten und wie gering die Möglichkeiten des Kaisers waren, seine Vasallen zur Rechenschaft zu ziehen oder auf ihr mangelhaft loyales Verhalten Konsequenzen folgen zu lassen.

Insgesamt unterlag das Lehenswesen im Spätmittelalter und der Frühen Neuzeit einem Wandel, einer Aufweichung. So wurde die Frist für die Mutung (ein Jahr und ein Monat), die Erneuerung des Lehensverhältnisses nach dem Tod des Lehensnehmers oder -gebers, nicht immer genau eingehalten. Auch der militärische Dienst war nicht immer oder ausschließlich Inhalt des Lehensvertrages, der auch andere Dienste benennen konnte. Das Lehen trat immer mehr in den Besitzstand des Lehensnehmers, diente ihm als Existenzgrundlage, wurde weitervererbt und im Sinne der langobardischen Brüdergemeinschaft - so auch im Falle der Este des I 4. und I 5 . Jahrhunderts aufgeteilt oder als Afterlehen weitergegeben. Auch die Beistandspflicht beschränkte sich immer mehr auf den Fall, dass der Lehensherr angegriffen wurde; war er hingegen der Angreifer, konnte der Vasall gerade in der ausgeprägten Fähnchenpolitik der oberitalienischen Kommunen die Kriegsverpflichtung in Frage stellen (bellum iustum) ${ }^{181}$ und gegebenenfalls den Beistand verweigern. ${ }^{182}$ Nichtsdestotrotz blieb die Pflicht der

\footnotetext{
I78 Ebd., 54, 58.

I79 Nach dem Lateinischen potestas benannt, war es ein mit Amtsgewalt und Macht ausgestatteter, bestellter Gouverneur. Vgl. Ludwig, Untersuchungen über die frühesten »Podestaten«.

I80 Dilcher, Das lombardische Lehnsrecht, 65-69, Zitat 70.

i8 I Zu diesem Begriff und seinem Wandel siehe: Semmler, Bellum Iustum.

I82 Vgl. ebd., 7 I-74.
} 
Erneuerung des Lehens beim Tod des Lehensinhabers oder des Reichsoberhauptes in der Neuzeit weiterhin bestehen, so wie auch die dafür festgelegten, hohen - wenn auch oft verhandelbaren - Gebühren. ${ }^{183}$ Bei Thronlehen erfolgte die Wiederbelehnung in der Regel - mit Ausnahme von Feloniefällen - problemlos. ${ }^{184}$

$\mathrm{Zu}$ den mit dem Lehenswesen zusammenhängenden, im Mittelalter entstandenen und bis zur Neuzeit anhaltenden Problemen in Reichsitalien gehörte vor allem die ständige Absenz des Reichsoberhauptes von der italienischen Halbinsel mit der Folge einer sukzessiven »Inbesitznahme« von Gebieten durch eine Dynastie und ihre Etablierung über etliche Generationen, sodass es fast unmöglich wurde, sie davon wieder zu entheben. Außerdem vermischte und verwuchs sich das eigene, vererbbare Land (als Besitz) mit dem Lehen und mit dem Machtbereich, das man im Zuge eines Amtes oder beneficium von einem Feudalherrn erhalten hatte. ${ }^{185}$ Hinzu kam ab I Ioo, dass lokale Herrschaften ihre Jurisdiktionen bündelten und große Städte ihre Kontrolle auf das Umland auszudehnen begannen. Dies brachte den jeweiligen König, der zur Kaiserkrönung nach Rom zog, in die Position eines Verhandlers für die ihm eigentlich geschuldete Treue und Dienstbarkeit. ${ }^{186}$

Wenn es schwierig ist, das Lehenswesen im Allgemeinen zu definieren, so ist die systematische Darstellung des Lehenwesens in Italien noch komplizierter. Die Lehensbeziehungen »blieben lediglich eine von verschiedenen Möglichkeiten, soziale Relationen sowie geteilte Besitzrechte mehrerer Akteure miteinander zu koordinieren «, ${ }^{187}$ präzisiert Christoph Dartmann, der auch der Frage nachgegangen ist, warum feudovasallistische Bindungen überhaupt entstanden, wenn sie so unzuverlässig waren. Ein Grund lag sicher in der dringenden Notwendigkeit militärischen Beistandes. Vor allem Bischöfe benötigten militärischen Schutz, den sie sich durch die Vergabe von Kirchenbesitz oder kirchlichen Rechten als Lehen zu sichern versuchten. Mit dem Aufkommen der Stadtkommunen lag dann das Bestreben in der Sicherung des Umlandes. Ein weiterer Grund für das Aufkommen von Machteliten waren der Schutz vor den ständigen Feindschaften der benachbarten Kommunen und gerade im Apennin oder den Seealpen die Notwendigkeit schlecht greifbare und nach Unabhängigkeit strebende Lokalmächte unter Kontrolle zu halten. ${ }^{188}$ Oliver Auge hat diese Beweg-

I 83 Dazu siehe die Beispiele bei Schnettger, Rang, i 89f: Der König von Sardinien zahlte I 755 85.000 Gulden für seine Investiturerneuerung; unter Joseph II. konnten die Gebühren in Raten abbezahlt werden; die Republik Genua musste für die Erneuerung des Reichslehens Sassello erst nach I 50 Jahren und dann nur alle 50 Jahre entrichten.

I 84 Schnettger, Rang, i 88f; Zum Lehenswesen und Investiturprozedere siehe bereits Itter, De Feudis Imperii und Moser, Neues Teutsches Staats-Recht 9.

I 85 Reynolds, Fiefs, I9I.

I 86 ReYNolds, Fiefs, I92.

I 87 Dartmann, Lehnsbeziehungen, io6.

I 88 Ebd., i r6f, I 24. Für die estensische Herrschaft betraf dies vor allem die Grenzgebiete der Lunigiana und Garfagnana. Vgl. Chittolini, Feudalherren, 246. 
gründe für Oberitalien noch ausgeweitet und neben der militärischen auch die politische Funktion der Vasallität »als ein festerer Ordnungsrahmen«, als wirtschaftliche Ressource, als Möglichkeit an der Macht und der Entscheidungsfindung des Herrschers teilzunehmen und als Repräsentationsmittel betont. ${ }^{189}$

Wie unterschiedlich sich das Lehenswesen in Oberitalien entwickelte und welche Spuren von diesen disparaten Prozessen in der Neuzeit noch sichtbar waren, sollen nun einige wenige Beispiele zeigen.

Als erstes soll das Augenmerk auf die sogenannte Marca Veronese gelegt werden, die im weitesten Sinne das Interessensgebiet der Este miteinbezieht und von Andrea Castagnetti und Daniela Rando zum ersten Mal durch Einzeluntersuchungen in einer Gegenüberstellung mit der Lombardei beleuchtet wurde. ${ }^{190}$ Die Marca Veronese war um die Mitte des ro. Jahrhunderts von Otto I. erschaffen und 952 zuerst dem Herzogtum Bayern und 976 dem Herzogtum Kärnten angegliedert worden, obwohl sie weiterhin Teil des Regnum Italicum blieb. Um das Jahr rooo spricht man schon von Feudalisierung der Titel der Markgrafen und Grafen. Bedeutend war dabei Friedrichs I. Bestreben, die Lehenshierarchie zu intensivieren und die Ehrerbietung und den Treueeid hervorzuheben. Ebenfalls versuchte Friedrich I. die in der Zwischenzeit unter den zahlreichen Herren und Lehensnehmern verstreuten Regalien wieder unter seine Kontrolle zu bringen, indem er zur Auflage machte, dass diese nur im Zuge einer Investitur durch den Herrscher rechtmäßig innegehabt werden durften. Im somit stärker institutionalisierten Lehenswesen wurde auch das Verhältnis zwischen Herrn und Untertanen des Lehens reguliert. Rando spricht von einer »feudalizzazione della società rurale«, ein Feudalsystem der bäuerlichen/ländlichen Bevölkerungsschicht in der Marca Veronese im Unterschied zur Lombardei. ${ }^{191}$

Eine weitere Besonderheit neben der erstarkenden kommunalen Politik und dem Niedergang der Lehenskurien, also des mit lokalem Recht und niederer Gerichtsbarkeit ausgestatteten Bischofshofs/-sitzes (curiae vassallorum), scheint in der Marca Veronese das feudum sine fidelitate, das Lehen ohne Treueeid, also befreit von Verpflichtungen, gewesen zu sein, das vor allem dem Adel zur Anhäufung von Gütern und Grundbesitz zugutekam. Allerdings relativiert sich die Absenz von Treuebekundungen und Verpflichtungen insofern, als dass sie in der Belehnung enthalten waren bzw. vorausgesetzt wurden und deshalb nicht explizit genannt werden mussten. ${ }^{192}$

Aus der Marca Veronese entwickelten sich verschiedene Lehen, von denen einige, wie das Herzogtum Modena, bis in die Zeit der Schaffung des italienischen Nationalstaates Bestand hatten und ihre »Reichszugehörigkeit» stets betonten. Ähnlich offen

\footnotetext{
I 89 Auge, Ausbildung, 339f, 35 I.

I 90 Vgl. Rando, Vassalli. Zur Ausbildung und Entwicklung der Städte in diesem Gebiet siehe: Varanini, Lorganizzazione.

I 9 I RANDO, Vassalli, 282-287.

i 92 Vgl. Rando, Vassalli, 290-298. Siehe auch Reynolds, Fiefs, i 89.
} 
zeigte die Republik Lucca noch in der Neuzeit ihre vor allem auf kaiserliche Privilegien gegründete »Reichsanhänglichkeit«. Nicht nur bei Kaiserbesuchen präsentierte sich die Republik als freie Reichsstadt durch überdurchschnittliche Huldigung des Reichsoberhauptes, durch die ostentative Nutzung des Reichsadlers und konkret auch durch die Bitte um kaiserlichen Schutz, als die Auseinandersetzungen zwischen Reich und Frankreich sich wieder verstärkten. Ein ebenso starker Ausdruck von Reichszugehörigkeit waren die an den Kaiserhof zur Bestätigung der Privilegien entsandten Gesandtschaften und die mit den Laudemien verbundenen Geschenke. Mit der Bestätigung der Belehnung verstärkte sich der Status einer città imperiale. Obwohl Lucca vor allem aus wirtschaftlichen Gründen (Kaufleute aus Lucca hatten ihre größten Umschlagplätze in Lyon und Antwerpen) daran interessiert war, die Beziehungen zu Frankreich zu erhalten, blieb es über das gesamte i6. Jahrhundert und darüber hinaus immer wieder eine bestätigte Reichsstadt. ${ }^{193}$ Ein bedeutender Vertreter von Lucca, der Jurist und Gesandte Cesare de Nobili, der auch mit den Este korrespondierte, versuchte die Anziani vor allem nach dem Frieden von Crépy I 544 über die Notwendigkeit einer ständigen Vertretung beim Kaiser zu überzeugen. Dabei führte er das Beispiel des estensischen Herzogs an, der, obwohl er sowohl am französischen als auch am kaiserlichen Hof ständige Gesandte hielt, sich dennoch bemühte durch zusätzliche Botschafter den beiden Kontrahenten zum Frieden zu gratulieren. Diesem Beispiel sollte auch Lucca folgen: "Simili offitii non manco si appartiene a noi che ali altri, sì per l'universal benefitio che succede alla Christianità di questa santa pace, sì per il particulare interesse della città nostra et consservatione dello Stato et libertà di essa. « ${ }^{194}$ Aus der Notwendigkeit heraus, die Freiheit des Luccheser Handels zu erhalten, riet De Nobili seiner Stadt eine ähnlich offene prokaiserliche Haltung einzunehmen. ${ }^{195}$

Allerdings gab es in der Frühen Neuzeit auch italienische Lehen mit einer konfliktreichen Beziehung zu Kaiser und Reich, bei der das Lehensverhältnis immer wieder in Frage gestellt wurde. Es war dies der Fall der Republik Genua in der Frühen Neuzeit. Auch wenn es nicht zu einem Waffengang kam, spitzte sich die Auseinandersetzung im Laufe von drei Jahrhunderten immer wieder zu und drehte sich stets um den grundlegenden Dissens, ob und wenn ja inwieweit Genua ein Teil Reichsitaliens und deshalb reichsabhängig sei. Die Standpunkte auf den beiden Seiten waren klar: Die Kaiser des I6. und I7. Jahrhunderts nannten Genua »civitas et camera imperialis«, erneuerten regelmäßig ihre Privilegien und verstanden die Republik, die die Umschrift »Conradus Rex« auf ihren Münzen als Erinnerung an das I I 38 erlassene Münzprivileg

I93 Vgl. Mazzei, La Repubblica di Lucca, 299-30I.

I94 „Ähnliche Tätigkeiten stehen auch uns zu, sowohl wegen der allgemeinen Vorteile, die der gesamten Christenheit durch diesen hl. Frieden zuteil wird, als auch wegen des besonderen Vorteils unserer Stadt und die Erhaltung unseres Staates und dessen Freiheit«. ASMo, ASE, Casa e Stato, Carteggio di ambasciatori, agenti e corrispondenti all'estero, Lucca, b. unica; ASLucca, Anziani a tempo della libertà, Lettere originali, 453, 9 ottobre I 544, zitiert nach MAzzei, La Repubblica di Lucca, 302f.

I95 Mazzei, La Repubblica di Lucca, $305 \mathrm{f}$. 
trug, als Äquivalent einer deutschen Reichsstadt. Die mit den Privilegien anerkannte libertas verstand sich dabei auf kaiserlicher Seite als jene »Freiheit«, die auch die deutschen Reichsstädte genossen. Die Genueser hingegen verstanden darunter ein viel weiteres Feld: Kaiser und Reich waren nur rein formale Oberhoheiten, die sich nicht in die inneren Angelegenheiten der Republik einmischen und vor allem nicht ihre Gerichtsbarkeit über sie ausüben durften, was hingegen dem obersten Lehensherrn und Richter sehr wohl zustand. Zu einer endgültigen Klärung des Rechtsstatus der Republik im Reich kam es nicht. ${ }^{196}$ Die Situation blieb unklar: Genua bemühte sich im Laufe des I7. und I8. Jahrhunderts um eine Distanzierung vom Reich und vom habsburgischen und spanischen Haus. Um den Beweis ihrer Souveränität zu untermauern, versuchte sich die Superba einen Königstitel anzueignen und das Dogenamt aufzuwerten, der rangmäßig auf der Höhe eines italienischen Herzogs stand. Auf der anderen Seite fühlte sich die Republik weiterhin dem Reich verbunden, schickte Gratulationsgesandtschaften an jedem neuen Kaiser, ließ sich weiterhin ihre Reichslehen und Privilegien erneuern, zahlte ansehnliche Kontributionen für den Türkenkrieg. ${ }^{197}$ Die genuesische Forderung, auf den Namen »civitas et camera imperialis« verzichten zu dürfen, wurde allerdings vom Kaiserhof nicht akzeptiert, da eben diese Titulatur die Abhängigkeit vom Reich ausdrucksstark demonstrierte. ${ }^{198}$

\subsubsection{Lehensordnungen in (Reichs)Italien}

Der große Kenner der Entwicklung »Reichsitaliens«, Karl Otmar Freiherr von Aretin, ${ }^{199}$ beschreibt in mehreren Arbeiten vor dem Hintergrund des Kampfes um die Vorherrschaft auf der italienischen Halbinsel drei unterschiedliche, nebeneinander existierende Lehensordnungen im I6. und I7. Jahrhundert: Neben der kaiserlichen Lehensordnung, die fast alle nord- und mittelitalienischen Herzogtümer, Grafschaften und Städte betraf, und der päpstlichen für Neapel-Sizilien, den Kirchenstaat und einzelne kleinere Lehen in Nord- und Mittelitalien, band auch die spanische Ordnung reichstreue Vasallen an sich. Darüber hinaus gab es in Savoyen-Piemont und der Toskana auch regionale Lehen, die aus einem Gemisch aus kaiserlicher und päpstlicher Lehensordnung entstanden waren und von den regierenden Fürsten zu eigenen Gunsten abgewandelt wurden. ${ }^{200}$

i96 Vgl. Schnettger, Reichsstadt oder souveräne, 277-280.

I 97 Ebd., $282 \mathrm{f}$.

I98 Ebd., 286.

199 Aretin, Die Lehensordnungen, 53-84. Ders., Reichsitalien von Karl V. bis zum Ende des Alten Reiches, 76- I63, auch italienisch: Ders., Lordinamento feudale in Italia nel XVI e XVII secolo e le sue ripercussioni sulla politica europea, un contributo alla storia del tardo feudalismo in Europa, in: Annali dell'Istituto storico italo-germanico in Trento 4 (I980), 5 I -94. Ders. Das Alte Reich I648I $806{ }_{3}$ Bde./I Reg.bd., Stuttgart I $993-2000$.

200 Vgl. Aretin, Die Lehensordnungen, 53- 57. 
Die kaiserliche Lehensordnung, die ihren Anspruch vom Römischen Reich ableitete, umfasste in Italien ca. 250-300 Lehen im Besitz von 50-70 Familien; zu den größeren Lehen gehörten die Toskana, Mailand, Modena, Mantua, Massa, das Montferrat, Parma-Piacenza und die Städte Genua und Lucca. ${ }^{201}$ Zwar galt in Reichsitalien das Reichsrecht, doch hatte sich - anders als im Reich - nie eine Verfassung gebildet und ebenso wenig erlaubte man eine Vertretung der italienischen Reichsvasallen am Reichstag. ${ }^{202}$ Im I6. Jahrhundert gab es in Italien zudem 296 päpstliche Lehen innerund außerhalb des Kirchenstaates. Bedeutend für Entwicklungen in der päpstliche Lehensordnung des I6. und I 7. Jahrhunderts war die auf der Bulle Admonet nos ${ }^{203}$ von Papst Pius V., Antonio Michele Ghislieri (I 566- I 572), ${ }^{204}$ basierende Praxis, heimfallende Lehen nicht mehr weiterzuvergeben, sondern dem Kirchenstaat einzuverleiben. ${ }^{205}$

Karl V. verlieh - wie gesagt - der kaiserlichen Lehensordnung in Italien neue Konturen. Im Zuge der Kaiserkrönung gewährte er nämlich eine Reihe von Privilegien und Investituren in Reichsitalien, die bis I 806 erhalten blieben. Mit diesem Akt läutete er eine neue Zeit intensiver Beziehungen zwischen Reich und Reichsitalien ein. ${ }^{206}$ Unangezweifelt ist nach Cinzia Cremonini die Bedeutung, die ihm die Forschung mittlerweile in der sogenannten restauratio imperii zuschreibt. Diese Intensivierung der Lehensbeziehungen, die die Landkarte der italienischen Lehensordnung bis ins I 9. Jahrhundert prägten, diente auch der "Auffrischung « der mit der Investitur eingehergehenden Verbindlichkeiten: die verpflichtende Erneuerung bei jedem Amtsantritt, das Verbot der Veräußerung des Lehens ohne kaiserliche Genehmigung und die Möglichkeit der Rückholung des Lehens durch den Kaiser bei Aussterben der Dynastie oder Felonieverdacht. Die Befürwortung der Primogenitur und die Eindämmung

20 I Vgl. Aretin, Das Reich, Kap. »Die Lehensordnungen und ihre Organe«, 8 I - ror, hier 8rf.

202 Wie aktuell die Frage der Einbindung Reichsitaliens und der italienischen Fürsten im Reich noch im I 8. Jahrhundert war, belegt ein von Matthias Schnettger näher beleuchtetes Werk der Reichspublizistik von Friedrich Ludwig Edler von Berger mit dem Titel „Consultatio politica concernens quaestionem: utrum caesari et imperio Romano-teutonico, itemque Italiae ducibus ac principibus ipsis horum admissio as sessionem et suffragium in comitiis expediat«, in dem u.a. zur Diskussion gestellt wird, ob die Aufnahme der italienischen Vasallen in den Reichstag deren Treue zum Reich gestärkt hätte. Schnettger, Italienische Fürsten im deutschen Reichstag?.

203 Die Bulle ist in Bullarium Romanum Pontificum 4.2, Roma 1 745, 364-367.

204 Vgl. Simona FecI, »Pio V santo«, in: Enciclopedia dei Papi (2000), online verfügbar: http://www. treccani.it/enciclopedia/santo-pio-v_(Enciclopedia-dei-Papi)/, Zugriff: I6.9.2020.

205 Auflistung der päpstlichen Lehen in: Wien, HHStA, Lothringisches Hausarchiv, i 92. Aretin, Die Lehensordnungen, 6o. Zur Bulle und ihren Folgen vgl. unten. Zu den Reformen von Papst Pius V. siehe: PAstor, Geschichte der Päpste 8, Kap. 2.I. »Durchführung der Reformen der Kirche an Haupt und Gliedern, I00-105, 2.7. Gegen die Verschleuderung des Kirchengutes«, I66- I72. Der Heimfall betraf zunächst Ferrara $5_{5} 98$ und I63 r die Lehen der Montefeltro/Della Rovere in Urbino. Vgl. dazu: Becker, Dynastische Politik und Ders., Das Montefeltro.

206 Aretin, Die Lehensordnungen, 65. 
der Aufteilung des Lehens unter verschiedenen Familienmitgliedern waren weitere Maßnahmen, die die kaiserliche Lehensordnung im I6. Jahrhundert stärkten. Zwar wurde bislang zu wenig untersucht, welches Gewicht die Weigerung Karls V. hatte, auf den Vorschlag der deutschen Reichsstädte von I 548 einzugehen und die italienischen Vasallen zum Reichstag zuzulassen; zu behaupten, dieser Akt hätte die kaiserliche und auch die spanische Macht in Italien gemindert, wäre spekulativ. Sicher lässt sich hingegen die Bedeutung der (Neu)Belehnungen und besonders der Investiturserneuerungen unter Karl V., dem »Erschaffer des kaiserlichen Systems« ausmachen. Nach Cremonini wurde gerade damit das Verhältnis zwischen Karl V. und den italienischen Reichsvasallen positiver, interaktiv und verzahnt. Klarerweise zählte dabei auch die Tatsache, dass dies am Höhepunkt der kaiserlichen Macht und im Rahmen der Kaiserkrönung in Bologna geschah, aus der der Kaiser gestärkt für den Kampf gegen Frankreich, gegen die evangelischen Ständen und gegen die Türken ins Reich zurückkehrte. Wenn auch die prokaiserliche Partei unter den italienischen Dynastien nicht homogen war und sehr von verschiedenen Faktoren wie den persönlichen Karrieren bei Hof, Heiratsverbindungen und nationalen wie internationalen Verbindungen abhing, so hatten die in Italien erlebten Treuebekundungen und Unterstützungsangebote einen nicht zu unterschätzenden symbolischen, politischen Wert für den stark unter Druck stehenden Kaiser. ${ }^{207}$ Karl V., der bei und unmittelbar nach der Krönung in Italien von seinen Vasallen großen Zuspruch erhielt, erneuerte und verstärkte oft jahrhundertealte Allianzen mit dem Kaisertum und durch die Investituren ex novo - wie für Ferrante Gonzaga mit Guastalla und mit dem fürstlichen Titel über die Val di Taro ${ }^{208}$ für Agostino Landi schaffte er neue, enge persönliche und politische Beziehungen. ${ }^{209}$

Dass die Investituren nicht ausschließlich im Zuge der Krönung von I 530 erfolgten, beweist nach Cremonini, dass der Aufbauprozess des kaiserlichen Systems während der gesamten Regierungszeit Karls V. im Wandel blieb und mit der Devolution Mailands 535 sogar einen neuen Impuls erlebte. Man kann hier für die Zeit Karls V. weniger von einem kaiserlichen Kontrollsystem in Italien sprechen als vielmehr von ei-

207 Cremonini, Impero e feudi italiani, 3 I -36.

208 Dazu siehe die Untersuchung von Alexander Koller auf der Basis der Nuntiaturberichte aus Deutschland, in der nicht nur die jahrzehntelange Erzfeindschaft zwischen den Familien Landi und Farnese um das Lehen Borgo Val di Taro beschrieben wird, sondern auch zwischen Kirche und Reich, da beide das Lehen für sich beanspruchten. Koller zeigt die intensiven Verhandlungen zwischen dem Kaiser und den Nuntien am Kaiserhof bezüglich dieses Lehens, das eine gewisse strategische Bedeutung als Kreuzungspunkt wichtiger Verkehrsadern hatte. Agostino Landi wurde durch die Protektion Karls V. I 536 damit investiert, auch weil er den Kaiser ${ }_{5} 29$ in seinem Lehen empfangen hatte und zur Krönungsfeier nach Bologna begleitete. I 545 verlieh Papst Paul III. die Herzogtümer Parma und Piacenza an Pier Luigi Farnese und dieser besetzte auch Borgo Val di Taro. Koller konnte an diesem Beispiel aufzeigen, dass in den I $570 e r$ Jahren der Konflikt um Lehen zwischen Kaiser und Papst wieder verstärkt im Gange war. Dabei ging es nicht nur um die Zurückdrängung der kaiserlichen Macht in Italien, sondern auch um Nepotismus und Versorgung von Familienmitgliedern. KolLer, Reichsitalien. 
nem Allianzsystem, geprägt von lokalen teressen, persönlichen Ambitionen und einer Gleichgewichtspolitik. ${ }^{210}$ Viele Neubindungen kamen erst in späteren Zeitfenstern zustande: 535 erhielt Carlo Gonzaga das Lehen Bozzolo, Federico Gonzaga I 536 das Montferrat, Luciano und Ambrogio Spinola bekamen im gleichen Jahr Tortona, I 538 wurde Pier Luigi Farnese mit Novara belehnt. Eine weitere Welle von Belehnungen gab es I 547/8, im Zuge dessen die Markgrafschaft von Torriglia zur Familie Doria kam und Agostino Landi zum Fürst von Val di Taro erhoben wurde. I 548 wurde Serravalle zwischen den Familien Spinola und del Carretto als Lehen aufgeteilt. Der Kaiser verfolgte in diesen Investiturtranchen augenscheinlich die Stärkung des Herrschaftsraumes der Gonzaga und des ligurischen Raumes. ${ }^{211}$ Doch auch die Einschränkung der päpstliche Lehensmacht war ihm ein Ziel. So verfolgte das Reichsoberhaupt mit der Belehnung der stark nach Rom gerichteten Medici mit der Toskana deren engere Bindung an das Kaisertum. In diesem Fall hielt die Annäherung an Kaiser und Reich nicht lange an, denn Cosimo de'Medici versuchte - erfolgreich - durch seine Anlehnung an das Papsttum größere Unabhängigkeit zu gewinnen.

Die spanische Vorherrschaft in Oberitalien und die Teilung des kaiserlichen Herrschaftsraums geboten dieser erstarkten kaiserlichen Italienpolitik wieder Einhalt. Als Erbbegünstigter seines Vaters in Italien musste der zum König von Spanien avancierte Philipp II. dem Kaiser als Vasall für Mailand, Siena und Pavia den Treueeid schwören. Sowohl er als auch sein Nachfolger Philipp III. versuchten ihre Macht in Italien auszubauen und strebten das Amt des kaiserlichen Vikars an, das ihnen die Oberherrschaft über alle kaiserlichen Lehen in Italien gewährt hätte. ${ }^{212}$ Philipp II. von Spanien begründete seinen Wunsch, von seinem Onkel Ferdinand I. zum Vicario Imperial en Italia ernannt zu werden, mit dem Argument, dass der Kaiser im Reich und in Ungarn, also an der südöstlichen, von den Osmanen bedrohten Reichsgrenze, alle Hände voll zu tun hätte und nicht imstande sei, sich auch gegen die italienischen Fürsten durchzusetzen. Tatsächlich war dies eine zutreffende Einschätzung, ${ }^{213}$ denn erst mit dem Mantuanischen Erbfolgekrieg (I628- I63 I) konnte sich die kaiserliche Macht in Italien wieder über die spanische behaupten, italienische Adelige traten immer mehr in kaiserliche Dienste und es floss auch wieder Geld aus Italien in die Reichskasse. Die Zurückdrängung der Spanier und die Wiedergewinnung der Reichsrechte in Italien sollten wichtige Ziele der Reichspolitik des I 7. und I 8. Jahrhunderts werden. ${ }^{214}$

Gerade weil - wie Cremonini die Erkenntnisse von Aretin, Quazza, Pugliese und Spagnoletti durch die Mitberücksichtigung der spanischen Historiografie ergänzen und relativieren konnte - die kaiserliche und spanische Lehensordnung nicht neben-

\footnotetext{
2 io Cremonini, Impero e feudi italiani, $43 \mathrm{f}$.

2 I I Cremonini, I feudi imperiali, 48 - 5 O.

2 I 2 Aretin, Die Lehensordnungen, 69f. Zur Teilung allgemein siehe Kohler, Wege der Politik.

2 I 3 Instruktion für den Bischof von Avila vom 2I. Mai I 558 zit. n. Niederkorn, Reichsitalien und der Kaiserhof, 59.

2 I 4 Aretin, Die Lehensordnungen, 72-8I.
} 
einander bestanden, sondern ineinandergriffen, sich vermischten und oftmals ein gemeinsames Ziel verfolgten, hielten sie sich in Reichsitalien bis zum Ende des I 8. Jahrhunderts. Nicht zuletzt aufgrund der erneuten Intensivierung der kaiserlichen Italienpolitik im I7. und I8. Jahrhundert erlebte die Halbinsel anders als in Westeuropa sogar einen Refeudalisierungsprozess. ${ }^{215}$ Die spanischen Habsburger waren zudem als wichtigste Vasallen des Kaisers in Italien in der Zeit von I55 I bis I 700 zum Teil auch bedeutende Vermittler des Reiches und gegenüber dem Reich. Es ist Cremonini zuzustimmen, dass in der Komplexität der Beziehungen zwischen den deutschen und spanischen Habsburgern mit Reichsitalien viele Faktoren wie z.B. das Klientelsystem, die Wahl der Generalkommissare, die persönliche Komponente der Verschwägerungspolitik etc. berücksichtigt werden müssen. Spanien war bereits unter Karl V. eine bedeutende Rolle zugesprochen worden und die Belehnung mit Mailand, dem logistisch und strategisch wichtigsten Gebiet Norditaliens, gab dieser Vorstellung nur noch mehr Nachdruck. Die von der älteren italienischen Historiografie bemühte preponderanza die Übermacht Spaniens, wurde vor allem mit einer Obstruktions- und Machtpolitik, die unweigerlich zu Spannungen zwischen Wien/Prag und Madrid führte, gleichgesetzt. Auch wenn sich Spanien immer als Vasall des Reiches verstand, führte es tatsächlich eine - wie Cremonini es nennt - Politik der Dissimulation, bestehend aus Treuebekundungen und gleichzeitig Handlungen, die gegen das Reichsrecht in Italien gerichtet waren. Durch Einschüchterung kleiner Reichslehen, oder weil diese der Mailänder Kammer unterstanden, führte Spanien viele Vasallen des Reiches dazu, der spanischen Krone die Treue zu schwören, jedoch nicht als Akt gegen den Kaiser, sondern im Sinne eines habsburgischen Bündnissystems. Schließlich waren diese Fürsten und Lehensnehmer, wie die Gonzaga von Castiglione oder von Sabbioneta bereit, ihre Treue gegenüber dem Reich weiterhin zu bekunden, aber die spanischen Interessen - unter Berücksichtigung des eigenen Vorteils - ebenso zu wahren. ${ }^{216}$

Nach der Etablierung der Macht Spaniens in Italien/Reichsitalien entstand ein Kampf zwischen den vormaligen Anhängern des Kaisers vor Ort und den Verfechtern der neuen spanischen Vorherrschaft. Auf der einen Seite gab es die Fürsten der feudi maggiori, welche sich mit der kaiserlichen Macht arrangiert hatten und ihren erreichten Status nicht zugunsten der spanischen Vorherrschaft einbüßen wollten, wie Ferrante Gonzaga, seit 30 Jahren condottiere und kaiserlicher Höfling im diplomatischen Dienst. Auf der anderen Seite gab es die kleineren Lehensmänner, die sich sehr wohl mit beiden Herrschaften anfreunden konnten, und einen zweifachen Nutzen aus der

2 I 5 Chittolini, Feudalherren, 244-247.

2 i 6 Cremonini, Das Reichslehnswesen. Aretin, Die Lehensordnungen, 82-84. Solche hybriden Herrschaftszustände gab es auch im Machtbereich der Serenissima. Hier gab es - wie Lorenzo Comensoli Antonini am Beispiel der vom Kaiser vergebenen Pfalzgrafenwürde mit dazugehörendem Privileg, uneheliche Kinder legitimieren zu können, in Bergamo zeigen konnte - ähnliche Konstrukte, wo verschiedene Herrschaftsebenen ineinandergriffen bzw. nebeneinander bestanden, ohne sich deswegen gegenseitig auszuschließen. Vgl. Comensoli Antonini, Per uno studio dei titoli imperiali. 
Situation zu ziehen versuchten. Die meisten - von Cremonini so genannten - potentadillos gingen den mittleren Weg der Schaukelpolitik: Sie blieben dem Kaiser treu, doch stärkten sie die diplomatischen Kontakte zum spanischen König. Diese Linie verfolgten z.B. meisterhaft die Este und die Gonzaga, deren Bemühungen schließlich in Belehnungen und Bestätigungen ihrer Herrschaft mündeten.

Wenn das Reich seine Interessen und Rechte in Italien mit den Funktionen von "Vikariaten«, "Generalkommissaren" und "Plenipotenzen" zu wahren versuchte, so spiegelt diese Klimax nach Cremonini einen Wandel in den Beziehungen zwischen Reich und Italien, der nicht zuletzt durch Spanien verursacht und geprägt wurde. Der erste Ausdruck davon war das von Karl V. I 55 I an Gomez Suarez de Figueroa, kaiserlicher Gesandter in Genua, vergebene Vikariat über die italienischen Lehen. In seinen Arbeitsbereich fiel die Kontrolle der Investituren, die Wahrung der Reichsrechte und der Schutz der kaiserlichen Lehen und Belehnten. Der nächste bedeutende Schritt war dann das Vorhaben Karls V., Philipp von Spanien mit dem italienischen Vikariat zu beauftragen. Somit kam es - so Cremonini folgend - zur Mediatisierung der Reichsinteressen durch den König von Spanien als Oberaufseher der Reichsrechte in Italien, wenn auch nicht ständig namentlich als Vikar tituliert. Die Entsendung von kaiserlichen Kommissären nach Italien an der Wende vom I6. zum I7. Jahrhundert, oftmals unter den Italienern aus den spanischen Lehen auserkoren, bestand vorrangig in der Notwendigkeit der Eintreibung von dringend benötigten Kontributionen. Dessen ungeachtet bleibt die Tatsache, dass zwischen 1558 und I619, also in der Zeit der Regentschaften von Ferdinand I., Maximilian II., Rudolf II. und Matthias, das Reich in Italien wenig oder zu wenig stark präsent und aktiv gewesen ist. Doch es ist auch anzunehmen, so Cremonini, dass das Reich sich deshalb »nur« um Hilferufe kümmerte und wenig eigene Initiativen zur Stärkung der Lehensverhältnisse zeigte, weil es sich vor Ort durch die spanische Macht gut vertreten fühlte. Der Türkenkrieg I 596 - I 606 und damit die Notwendigkeit, an Kontributionen zu kommen, führten zur Entsendung von kaiserlichen Vertretern nach Italien, sogenannte Kommissäre, die - wie sich durch Garzweiler u.a. herausstellte - größerer Machtbefugnisse bedurften und eng mit Spanien zusammenarbeiten mussten. Diese "Zusammenarbeit« von Kaiser und Spanien in Italien schützte jedoch nicht vor Lehensstreitigkeiten und der Verletzung von Befugnissen wie im Falle von Finale. ${ }^{217}$ Auch der Westfälische Frieden sollte den Kaiser stark schwächen, wodurch das mitunter angespannte Verhältnis zwischen den zwei Habsburgerlinien historiografisch als präpotentes Verhalten Spaniens gedeutet wurde. Dabei versuchte das finanziell geplagte Spanien Grenzgebiete und ertragreiche Lehen einzuverleiben, die somit nicht nur dem Kaiser, sondern auch dem spanischen König die Treue schwören mussten. I683 kam es jedoch zur Wende: Nach dem Sieg über die Türken und unter Leopold I. erstarkte die kaiserliche Macht in Italien wieder und die spanische verlor an Gewicht. Der Kaiser ließ durch Generalkommissare wieder regel-

2 i 7 Dazu siehe Edelmayer, Maximilian II. 
mäßigere Kontributionen einziehen. Als r 706 Spanien das Herzogtum Mailand verlor, war die kaiserliche Macht auf der Halbinsel zweifellos wieder erstarkt. ${ }^{218}$

\subsubsection{Die italienischen Reichslehen (feudi imperiali in Italia) in der Kleinstaatsdebatte}

Aus dem von Cinzia Cremonini für ihre Untersuchungen herangezogenen Bestand Feudi imperiali im Staatsarchiv von Mailand wird ersichtlich, welche die sogenannten feudi maggiori in Reichsitalien waren: Mailand, Savoyen, Mantua, das spätere Großherzogtum Toskana, die Republik Genua und - wenn auch territorial kleiner - die Herzogtümer Modena, Parma und Piacenza, das Fürstentum Massa und Carrara, das Fürstentum Novellara und die Republik Lucca. Im I 7. Jahrhundert kam das Fürstentum Castiglione als Lehen der Gonzaga von Medole und Solferino hinzu. Zu den feudi minori hingegen zählten die kleineren Lehen in den Händen der Gonzaga, jene in den Langhe, im Monferrato und in der Lunigiana sowie die vereinzelten Rechtsbesitzungen in Umbrien und Toskana. Cremonini betont, dass der Unterschied zwischen feudo maggiore und feudo minore nicht ausschließlich in der territorialen Größe des Lehens lag - obwohl die größten und bevölkerungsreichsten selbstverständlich zu ersteren gehörten - sondern vielmehr in der politischen Rolle seiner Vasallen und in deren Beziehung zum Reich und zu den anderen Lehen. Es lässt sich nicht genau feststellen, ab wann und wie genau zwischen feudi maggiori und feudi minori unterschieden wurde; im Bestand Feudi imperiali werden sie später, in der Zeit der Plenipotenz, nach der Höhe der Kontributionen unterschieden. ${ }^{219}$

Der politischen Bedeutung der größeren Reichslehen zuträglich waren sicher die durch ihr Lehensverhältnis zum Kaiser gewonnenen internationalen Beziehungen, während für die kleineren und kleinsten Reichslehen ihre Zugehörigkeit zum Reich rechtliche und administrative sowie steuerliche Enklave-Stellung (extraterritorialità) und Schutz bedeutete. Dem Reich und dem Kaiser wiederum brachten die italienischen Reichslehen Parteibildung vor Ort, Kontributionen für die Kriegsführung und Unterstützung bei der Truppenunterbringung sowie Laudemien. ${ }^{20}$

Die fragwürdigen Kriterien zur Bestimmung "großer« und »kleiner« Lehen führt unweigerlich zur Debatte um den Souveränitäts- ${ }^{221}$ und Kleinstaatsbegriff, zwei für die italienischen Reichslehen bedeutende Aspekte.

2 i 8 Vgl. Aretin, Das Reich, Kap. „Der Konflikt zwischen den habsburgischen Linien«, Io6- 27.

2 I 9 Cremonini, I feudi imperiali italiani, 42f, 64. Siehe auch Schindling, Mindermächtige Territorien, $42 \mathrm{f}$.

220 Cremonini, Impero e feudi italiani, 66-68.

22 I Unter Souveränität (lat. summum imperium) ist am Übergang vom Spätmittelalter zur Frühen Neuzeit der Besitz und die Ausübung der höchsten Staatsgewalt durch eine Person (Fürst), Gruppe oder Volk gemeint, verbunden mit der Entstehung des modernen Staates die Unabhängigkeit desselben nach außen. Vgl. Diethelm KLippeL, »Souveränität«, in: Friedrich Jäger, Enzyklopädie der Neuzeit I 2, Stuttgart/Weimar 2010, Sp. 2 I 2-2 218, hier 2 I 2f. 
Wenn Souveränität erst mit dem Ende des Heiligen Römischen Reiches effektiv möglich wurde, so muss präzisiert werden, dass dieser Begriff in der Frühen Neuzeit noch schwammig und unklar war. Dies beweist nicht zuletzt die Tatsache, dass in Italien sowohl der Begriff superioritas territorialis (Landeshoheit) als auch alternativ der vor allem die Kleinstaaten charakterisierende Terminus media sovranitas (von der Investitur eingeschränkte Souveränität) benutzt wurde. Maßgebliche »messbare« Kennzeichen für die Einstufung in die Kategorie Kleinstaat waren Größe des Territoriums, Bevölkerungszahl und Ressourcen. ${ }^{22}$ Für die Größe hat Heinz Duchhardt auf der Basis der Quellen des Ancien Régime eine ungefähre "Schallgrenze« von I,2 Mio. Einwohnern eruiert, ${ }^{223}$ was bedeutet, »daß die überwiegende Mehrzahl der deutschen Reichsstände und italienischen Fürstentümer bzw. Republiken in die Kategorie Kleinstaat fiele. «224 Eine weitere Abstufung sind die Kleinst- und Mikrostaaten mit damit einhergehender, eingeschränkter Souveränität und begrenzten Ressourcen.

Klar ist, dass die meisten frühneuzeitlichen Kleinstaaten über eine eingeschränkte Souveränität verfügten, da sie entweder im Verband des Heiligen Römischen Reiches waren oder der päpstlichen, kaiserlichen oder eines anderen Monarchen Lehenshoheit unterstanden. Päpstliche Vasallen bezeugten ihre Unterordnung mit der Zahlung einer Abgabe an den Papst am Fest der Apostel Petrus und Paulus, wie dies die Dynastie der Este für das Lehen Ferrara tat. Reichsvasallen taten dies mit dem Treueeid und der Ausrichtung einer einmaligen Taxe bei der Investiturerneuerung. ${ }^{225}$ Die Lehensabhängigkeit verminderte zwar die Souveränität und konnte gefährlich sein (so bei Einzug/ Heimfall des Lehens), doch sie bot wichtigen Schutz. Einen bedeutenden Handlungsspielraum hatten die Vertreter von Kleinstaaten in der Repräsentation (Diplomatie), im Patronage- und Klientelwesen ${ }^{226}$ sowie im Zeremoniell ${ }^{227}$. Daraus erklären sich u.a. auch die zahlreichen Streitigkeiten um die Rangordnung und der Wettlauf um Titel im I6. und I7. Jahrhundert, welche die Kleinstaaten paradoxerweise in eine zum Teil noch größere Abhängigkeit versetzten. ${ }^{228}$ Eine weitere wichtige Ressource von Kleinstaaten lag in der Heiratspolitik, mitunter auch begünstigt von der finanziellen Stärke italienischer Ehefrauen und seit der Mitte des r6. Jahrhunderts vom Mangel an potenziellen katholischen Ehepartner/inne/n im Reich. ${ }^{229}$

222 Schnettger, Kleinstaaten, 609-6i i. Vgl. auch Bazzoli, Il piccolo Stato. Raviola, L'Europa dei piccoli stati, 68-7I.

223 Duchhardt, Kleinstaaten, 8of.

224 Schnettger, Im Schatten der Mediatisierung, 30.

225 Schnettger, Kleinstaaten, 6r $2 \mathrm{f}$.

226 Siehe Molhos Hinweis auf »the ubiquity of patronal-clientelar ties«. Molнo, Patronage, 242.

227 Schnettger, Kleinstaaten, 6r 4. Eмich, Frühneuzeitliche Staatsbildung, i95 und Diess., Zeremoniell, 92. Zum Staatsbildungsprozess selbst siehe auch die Beiträge im Sammelband Asch/Freist, Staatsbildung; auf Italien bezogen: Chittolini/Molho/Schiera, Origini dello Stato.

228 Schnettger, Kleinstaaten, 6i 7. Stollberg-Rilinger, Die Wissenschaft der feinen Unterschiede.

229 Schnettger, Kleinstaaten, 6r9, 636-639. 
Trotz der Abhängigkeit von einem Lehensherrn und dank alternativer Einflusssphären konnten deutsche Reichsstände ebenso wie Reichs- oder Papstvasallen in Italien demnach eine media sovranitas und gelegentlich das ius territoriale, die Landeshoheit ausüben; auch waren sie durchwegs nicht reformunfähig, wie Schnettger nachvollziehbar gezeigt hat. Diese »Souveränität« wurde den deutschen Reichsständen und den wichtigsten oberitalienischen Fürsten, wie dem Herzog von Modena, allgemein zweifellos zuerkannt. ${ }^{230}$

Die Bedeutung der Entwicklung des frühmodernen Staates, wie sie Wolfgang Reinhard (und Andere) nachgezeichnet hat, ${ }^{231}$ wurde im Zusammenhang mit der italienischen Lehenssituation auch von der italienischen Historiografie hervorgehoben. Hier hat vor allem Giorgio Chittolini bereits Ende der i 980er Jahre versucht den Begriff des Renaissancestaates ${ }^{232}$ (Stato del Rinascimento) zu revidieren, neu zu definieren und dadurch zu neuen Themenfeldern in der italienischen Forschung zu inspirieren. ${ }^{233}$ Gerade in unserem Untersuchungsraum, dem Gebiet der heutigen Region EmiliaRomagna, konnte sich im Unterschied zu Florenz, Mailand oder Venedig kein großer und starker Regionalstaat entwickeln. Stattdessen haben sich kleinere Einheiten bzw. relativ unabhängige Provinzen herauskristallisiert, die strategisch günstig lagen oder nur schwer zu kontrollieren waren. Hier konnten sich Lokalmächte (Gemeinden, einzelne Vasallen, bedeutende Familien aus Adel oder Patriziat) meist aus der spätmittelalterlichen Tradition heraus bis weit in die Neuzeit halten. Andere Teile dieses Gebietes entwickelten sich von der Kommune zum Fürstentum, wie die Stati estensi, oder das (spätere) Herzogtum der Gonzaga. Innerhalb dieser Herrschaftsgebiete wiederum banden sich Lokalmächte und Lehensnehmer an die Fürsten, wie diese an die Universalmächte (Papst und Kaiser) gebunden waren. Das ergab ein institutionelles Gewirr an Rechten, Ansprüchen und Abhängigkeiten. Aus dieser Situation heraus kann nach Chittolini nicht von einem Renaissancestaat gesprochen werden, wie es in seiner Einheitlichkeit und Souveränität die ältere Geschichtswissenschaft evoziert hat. Um dieses Gebilde erfassen und darstellen zu können, ist es hingegen notwendig, es in seinen verschiedenen Einheiten - das sind Fürstenhöfe, Eliten des Adels und des Patriziats - zu untersuchen. Dabei muss der Akzent der Untersuchung auf

230 Schnettger, Im Schatten der Mediatisierung, 28-35. Siehe auch: Verga, Gli antichi stati italiani sowie die Beiträge des Tagungsbandes: Barletta/Cardini/Galasso, Il piccolo stato; und darin besonders der Beitrag von Galasso, »Piccolo Stato«, I 27- I 47 (auch online verfügbar unter: http:// www.unirsm.sm/media/documenti/unirsm_9or.pdf, Zugriff: i I.6.2020). Vgl. auch Langewiesche, Kleinstaaten.

23 I Reinhard, Frühmoderner Staat; und ausführlicher: Ders., Geschichte der Staatsgewalt.

232 Vgl. Molno, Patronage, 236. Siehe auch die Beiträge im Sammelband: Gamberini/Lazzarini, The Italian Renaissance State.

233 Siehe dazu die oben zitierten und weiteren Arbeiten von Cremonini, Frigo, Musso, Spagnoletti, Schnettger, etc. 
die Charakteristika eines »Staates«, nämlich seine Außenbeziehungen (Diplomatie) ${ }^{234}$ und die verschiedenen Formen der Repräsentation sowie der Organisation von Macht und Souveränität, gesetzt werden; demnach stehen diese Aspekte ebenfalls im Vordergrund der vorliegenden Untersuchung. ${ }^{235}$

Beim Vergleich der Entwicklung deutscher und italienischer Fürstentümer hat Chittolini einen italienischen "Sonderweg « festgestellt. ${ }^{236} \mathrm{Zu}$ den bedeutendsten Unterschieden zählt er die Größe der als Stadt bezeichneten Siedlungen: Während im deutschen Raum I.000-2.000 Einwohner bereits eine Stadt bildeten, gab es in Italien und besonders in Oberitalien viel weniger Zentren, die als Städte bezeichnet wurden und zwar nur jene ab einer Größenordnung von 8.000- I 2.00o Einwohnern. Um die Mitte des I 5. Jahrhunderts zählten Pavia, Cremona und Piacenza, zu Beginn des I6. Jahrhunderts auch Ferrara mehr als 30.000 Einwohner, während Mailand und Venedig bereits bei 80.000 waren. Jene, die in Italien zwischen I.500 und 3.000 Einwohner zählten, wurden borghi, castelli oder terre genannt und sind zumeist im contado, d.h. im Umland der großen Städte zu finden. ${ }^{237}$ Im Unterschied zu den deutschen konnten die italienischen Fürsten zwar auf ein bestehendes und bewährtes Regierungsund Verwaltungssystem aus der kommunalen Ära zurückgreifen; allerdings erschwerte dieser vorhandene Apparat die Bildung von neuen Ämtern, die regional - also über die Stadt und den Fürstenhof hinaus - und im Sinne des Fürsten für Steuereintreibung, Justiz u.a. verantwortlich waren. Ebenso waren Stadtverfassungen, Statuten, Hierarchien und Kompetenzen nicht leicht zu umgehen bzw. außer Kraft zu setzen. Auch im Bereich der Steuerressourcen findet Chittolini große Unterschiede zwischen den Fürstentümern nördlich und südlich der Alpen, diesmal allerdings zum Vorteil der italienischen Fürsten, die mehr aus ihren Territorien ziehen konnten. Im Vergleich hatten die deutschen Fürstentümer bei gleicher Bevölkerungszahl weniger hohe Steuereinnahmen. ${ }^{238}$

Auf dem Phänomen der oberitalienischen »Kleinstaaterei« fußen auch die Überlegungen von Aldino Monti bezüglich der Entwicklung der Emilia, die sich nicht zu einem einheitlichen Territorialstaat etablieren konnte. Die Gründe dafür sieht Monti in

234 In diesem Zusammenhang siehe auch die von Hillard von Thiessen betonte Verflechtung von Staatsverdichtungsprozessen, Aufbau von Dauergesandtschaften und Ausbau der Kommunikationsnetze. Thiessen, Diplomatie, 479 .

235 Chittolinis Plädoyer für eine neue Sichtweise des »Renaissancestaates« ist auch in: Chittolini, Stati padani, 9- I r. Besonders in Bezug auf die »Krise« der Renaissance und den Prozess der »Refeudalisierung« siehe: Chittolini, Feudalherren, 243-259 und die zahlreichen Literaturhinweise hier.

236 Chittolini, Italienische und deutsche Fürstentümer, 63. Siehe zur italienischen Entwicklung die Beiträge in: Chittolini/Willoweit, Lorganizzazione del territorio.

237 Chittolini, Italienische und deutsche Fürstentümer, 64-66.

238 Chittolini, Italienische und deutsche Fürstentümer, 7 If, 76 . Hier sind auch im Einzelnen die Zahlen zu finden. Zum Wandel fürstlicher Einnahmen im Alten Reich siehe auch: Rösener, Die wirtschaftlichen Ressourcen. 
den zwei vorherrschenden unterschiedlichen Entwicklungssträngen: Im Westen und Osten der Emilia, also auch in den estensischen Gebieten, überwog eine institutionelle Entwicklung über einer geopolitischen, d.h. hier konnten sich zuerst die Kommunen und dann die Signorie (Gonzaga, Este) etablieren, deren Höfe schließlich den Mikrostaat ausmachten und prägten. Im Raum um Bologna hingegen konnte sich nur schwer eine institutionelle politische Herrschaft entwickeln; die Kommune bestand bis zur Mitte des I 5. Jahrhunderts, als die Bentivoglio ${ }^{239}$ - unter Berücksichtigung der vielzitierten libertà - die halbautonome Herrschaft derselben in eine signoria umwandelten. ${ }^{240}$ Fakt ist, dass diese unterschiedlichen Wege zu keinem regionalen Einheitsstaat/Territorialstaat führten.

Die in diesen oberitalienischen Kleinstaaten der Po-Ebene besonders ausschlaggebenden territorialen Ressourcen, wie z.B. das Wasser, dienten u.a. als Mittel der Legitimierung und Ausweitung von Macht. ${ }^{241}$ Dies betraf, wie noch zu zeigen sein wird, besonders die Este, die neben den zahlreichen Trockenlegungsmaßnahmen - von denen einige 20 Jahre lang dauerten - auch gegen die natürliche Versandung einzelner Arme des Po-Flusses und die damit einhergehende Veränderung des hydrografischen und landwirtschaftlichen Bildes des Gebietes und seiner Nutzbarkeit zu kämpfen hatten. Manche Gegenden, wo die Ernten aufgrund der Überschwemmungen vermehrt ausfielen, waren besonders dünn besiedelt, wie das Polesine di Rovigo (Polesine bezeichnet ein trockenes Stück Land zwischen zwei Flussarmen des Po). Verheerende Folgen hatten die Knappheit des landwirtschaftlichen Ertrages, Notauswanderung und die bis in die Stadt reichende Gesundheitsgefährdung durch die Malaria. Erst mit den von den Este vorangetriebenen großen Trockenlegungsmaßnahmen des r6. Jahrhunderts kam es zur Wiederbesiedlung dieser bevölkerungsarmen Gebiete. ${ }^{242}$

Das Herrschaftsgebiet der Este ist somit ein in vieler Hinsicht interessanter Untersuchungsraum Reichsitaliens, weshalb es verwundert, dass die Stati estensi-abgesehen von wenigen Detailuntersuchungen - bis vor Kurzem so geringe Berücksichtigung in diesem Zusammenhang gefunden haben. Die besser untersuchten Reichslehen befin-

239 Vgl. zu dieser Familie Pezzarossa, »Bentivoglio«.

240 Die Unterschiede in der Entwicklung zwischen Bologna und Ferrara, beide in den Kirchenstaat eingebundene Städte, hat Birgit Emich untersucht. Während Bologna bis auf das kurze Zwischenspiel der Bentivoglio, an eine republikanische Regierungsform festhielt und unter der päpstlichen Führung seine libertà als Kommune unterstrich, etablierte sich in Ferrara mit den Este eine jahrhundertelange Tradition fürstlich-dynastischer Herrschaft, die nach der Devolution getragen von einem starken Patronalsystem und Klientelismus in den Mythos der decadenza unter päpstlicher Führung mündete. Vg1. Емісн, Bologneser libertà, I I 8 - I 23.

24I Monti, La microfisica, 35 of. Zur Entwicklung der Wasserwege im estensischen Gebiet siehe die Beiträge im karten- und bilderreichen Band: (o.H.), Vie d'acqua. Giuseppe Coniglio erwähnt in der überarbeitungsbedürftigen, aber immer noch brauchbaren Arbeit über die Gonzaga-Dynastie einen Vertrag, den Alfonso II. d'Este mit Vincenzo Gonzaga bezüglich der Wasserregulierung in Ponte Molina bei Ostiglia I 594 geschlossen hatte. Coniglio, I Gonzaga, 359 .

242 Folin, Rinascimento estense, 77-79. 
den sich vorrangig entlang des Apenninenhauptkammes, von Ligurien bis zur Toskana verteilt, und einige auch im paduanischen Raum. Diese Lehen und die Vasallen, die sie innehatten, gründeten ihre Herrschaft zumeist auf ihre Reichsunmittelbarkeit und auf oft jahrhundertelange ununterbrochene Belehnungen durch den Kaiser; einige waren aber aufgrund von Teilungen oder Investituren von kleineren territorialen Einheiten gleichzeitig auch von umliegenden Staaten und potentati (als Beispiel seien nur die Reichslehen im Gebiet der Langhe zwischen Mailand, Genua und Montferrat genannt) und später auch teilweise von Spanien abhängig. Das Lehenswesen auf der italienischen Halbinsel war also nicht nur aufgrund des Nebeneinanderbestehens von Republiken und Signorien (die sogenannten antichi stati italiani ${ }^{243}$ ) vielfältig, sondern auch weil es darunter weitere Ebenen mit unterschiedlichen Abhängigkeitsverhältnissen gab. ${ }^{244}$ Diese Vasallen bemühten sich durch stetige Erneuerung ihrer (Lehns-) Beziehung mit dem Reich ihre Unabhängigkeit von und ihren Schutz vor den mächtigeren Nachbarstaaten zu sichern, scheuten sich allerdings nicht, auf vielfältige Weise mit anderen Lehensherren in Beziehung zu treten, so durch Heirat, Übernahme von Ämtern und Privilegien oder den Empfang von Pensionen für bestimmte Dienste. Die Lehenshierarchie verwickelte sich noch mehr durch die Tatsache, dass die Fürsten, mit denen sich die Reichsvasallen jener kleinen Reichslehen durch Lehensverhältnisse oder Verschwägerung (meist der Söhne und Töchter aus den Seitenlinien) verbanden, selbst wiederum Lehens- und Privilegiennehmer des Reiches oder des Papsttums waren und $a b$ der Mitte des r6. Jahrhunderts im einen oder anderen Fall auch von der spanischen Herrschaft abhängig waren. ${ }^{245}$ Diese verworrenen Realitäten auf der frühneuzeitlichen italienischen Halbinsel hat die Geschichtsschreibung lange unberücksichtigt gelassen. Wie Gianvittorio Signorotto und andere bereits eingefordert haben, müssen die einzelnen ineinander verwobenen Ebenen bis zur kleinsten Einheit untersucht werden. ${ }^{246}$

243 Vgl. unter vielen Greco/Rosa, Storia degli antichi stati italiani.

244 Cremonini/Musso, Introduzione, i i.

245 Cremonini/Musso, Introduzione, i2. Diese kleinen Lehen, die nach den Kriterien von Chabod (stehendes Heer, Diplomaten, Primogenitur und eigene Verwaltung) als kleine Staaten galten, von denen viele der Versorgung von Seiten- und Nebenlinien der großen italienischen Dynastien dienten, betrieben eine - trotz ihrer territorialen Beschränktheit - ansehnliche Heiratspolitik. So dienten sie der Verheiratung und dadurch Allianzbildung von unehelichen Söhnen und Töchtern der Este, Gonzaga, Cybo. Dadurch konnten sich nach Spagnoletti auch die kleinen Lehensnehmer gut im politisch-dynastischen System Italiens integrieren und eine wichtige Rolle als Pufferzonen zwischen den potentati spielen. Снавоd, Esiste uno Stato nel Rinascimento?, und Barotti, Esiste uno Stato del Rinascimento, 365 . Spagnoletti, Feudatari imperiali, 6o-64.

246 Signorotto, Impero e Italia, $52 \mathrm{f}$. 


\subsubsection{Das Territorium der Esteherrschaft: ${ }^{247}$ Die Stati Estensi}

\subsubsection{Ferrara}

Die Ursprünge Ferraras als Siedlung und Stadt gehen auf die Römerzeit zurück. Die erste Ansiedlung befand sich an der Abzweigung von zwei Armen des Flusses Po, Volano und Primaro, ein für den Verkehr zu Wasser und zu Land neuralgischer Punkt. ${ }^{248}$

Der Name Ferrara wird erstmals in Dokumenten des 8. Jahrhunderts beim Übergang von der langobardischen zur päpstlichen Herrschaft benutzt, als die Stadt zum Exarchat von Ravenna geschlagen wurde. Im päpstlichen Auftrag setzte der Erzbischof von Ravenna vor Ort Vikare ein, darunter die Markgrafen von Canossa, die 988 Ferrara als Lehen erhielten. Kurz darauf wurde Ferrara von Kaiser Heinrich III. dem Reich einverleibt und blieb ein Zankapfel zwischen Reich und Papsttum, während sich in der Stadt autonome Bestrebungen zur Schaffung einer Kommune breitmachten. Erst I I05 konnte sich die Stadt von der Vorherrschaft Ravennas lösen. Diese Autonomie ermöglichte eine wirtschaftliche Blüte, die jedoch mit den Interessen Venedigs konkurrierte, das seit jeher versuchte, dieses Handelszentrum unter die eigene Herrschaft zu bringen oder zumindest durch den Bau von Festungen seinen Warenverkehr zu kontrollieren. Die Bedrohung und Beeinträchtigung durch Venedig nahm im Spätmittelalter und in der Frühen Neuzeit kontinuierlich zu. ${ }^{249}$

Ferrara und sein Umland sind somit in einer geomorphologisch interessanten, aber in Mittelalter und Neuzeit von großer hydrografischer Instabilität charakterisierten Lage im Padanischen Delta entstanden: Die Bewegungen von Süden nach Norden des Hauptarmes des Po-Flusses, die Verschiebungen der Flussbette der Nebenarme, die Versumpfungen, das Vorrücken und der Rückzug des Meerwassers im Delta brachten Gefahren, Ernteausfälle, Erkrankungen und Abwanderung mit sich. Diese Naturgewalten hatte zu Beginn des I 2. Jahrhunderts den Entstehungsort der Stadt Ferrara und seine Verschiebung vorgegeben. Während die erste städtische Ansiedlung vor dem Jahr Ioo० am nördlichen Ufer des Po entstanden war, ein castrum zur Verteidigung gegen die byzantinischen Gebiete, führten um I I 22 Überschwemmungen und Überflutungen zur Verlagerung des Flusses und somit zur Versandung des bis dahin schiffbaren Wasserweges. ${ }^{250}$ So verschob sich das Zentrum des Handels vom Hafen in Richtung

247 Dazu siehe maßgeblich: Chiappini, Gli Estensi, 45-5 r. Tabacco/Merlo, Medioevo, insb. Kap. "Signorie« cittadine e chiusure oligarchiche nell'Italia dei comuni, 5 O2-5 I6. MARINI, Lo stato estense.

248 Zur Geschichte Ferraras siehe Manini Ferranti, Compendio della storia sacra e politica di Ferrara.

249 Vgl. dazu Rösch, Reichsitalien als Wirtschaftsraum.

250 Noch Ende des I6. Jahrhunderts wird der Gesandte Orazio Della Rena auf diese Schwachstelle hinweisen: „D'essi [fiumi] principale è il Po, il quale sebben con l'inondazioni sue fa soggetti quei popoli occupandoli gran tempo a far argini, e sponde, le quali ben spesso rompe con molto lor danno, et quantunque non di rado metta in necessità sino il Principe a farsi guardar con i suoi sudditi armati, acciocchè quei che son nell'altra spondo con ingano non trapassin l'argine oppostogli, e lo faccin sfogare nel Terren Ferrarese, come molte volte avviene; (Von der Flüssen ist der Po der Hauptfluss, der die Bevöl- 
Norden, wo mit dem Bau des Domes eine neue mittelalterliche Stadt entstand. ${ }^{251}$ Das darauffolgende Engagement von Herr und Untertanen galt nicht nur dem Schutz vor den alles zerstörenden Fluten, sondern auch dem Versuch durch Trockenlegung neues Ackerland zu gewinnen, um die im Laufe des I 5. Jahrhunderts durch den Bevölkerungszuwachs gestiegene Nachfrage nach Getreide zu decken. Gerade ab der Mitte dieses Jahrhunderts nahm der Kampf gegen das Wasser durch langjährige von den Machthabern geleitete und mitfinanzierte Trockenlegungsprojekte neue Ausmaße an. Dabei bekämpften die Este, die sich als Verteidiger des Fürstentums emporgehievt hatten, nicht nur aus herrschaftlichem Pflichtgefühl gegenüber den Untertanen die imminente Naturgefahr, sondern hatten als Großgrundbesitzer selbst am Schutz des bebauten Umlandes und an der Gewinnung von neuen landwirtschaftlichen Flächen Interesse. Das Fürstentum von Ferrara wurde somit im Laufe der Frühen Neuzeit zum Experimentierlabor bei der Weiterentwicklung von Techniken zur Eindämmung und Regulierung der Wasserwege, die gleichzeitig wichtige Handels- und Kommunikationswege waren. ${ }^{252}$ Obwohl die Este-Dynastie im Laufe der Jahrhunderte ihrer Herrschaft viele Mühen und Kosten in diese Regulierungsmaßnahmen steckte, konnte sie diesem Problem in ihrem heterogenen Fürstentum nicht allein Herr werden. Das Bergland (Apennin) des estensischen Fürstentums war stark abgegrenzt um nicht zu sagen abgesondert, hatte eine politisch-institutionelle Autonomie entwickelt, besaß im Unterschied zu anderen Teilen des Territoriums nur wenig natürliche Ressourcen und erfuhr deshalb nur mangelhafte Investitionen in Grund und Boden von Seiten der Städte. ${ }^{253}$ In den von Überschwemmungen heimgesuchten Gebieten hatten nicht nur die Este, sondern aufgrund der vorherrschenden Feudalstruktur - wie bereits gezeigt wurde - auch Vasallen des Reiches oder der Este selbst wie die Familien Pico, Pio, Gonzaga und Da Correggio das Sagen. Diese waren in ihren Mikrolehen von den Naturgewalten bedroht, hatten allerdings zumeist nicht genug Ressourcen, um große Regulierungsmaßnahmen einzuleiten und lavierten zwischen der Bedrohung durch unkontrollierte Gewässer und den wirtschaftlichen Vorteilen in der Fischerei und im Ackerbau (durch die Überflutung und Bewässerung der landwirtschaftlichen Güter).

kerung mit Überschwemmungen beschäftigt hält, welche viel Zeit darauf verwendet, Uferverbauungen zu errichten, die er oft mit großem Schaden zerstört; und nicht selten bringt er sogar den Fürsten in Bedrängnis, der mit seinen Soldaten den Fluss bewachen lässt, damit die Leute auf der anderen Flussseite nicht mit einer List den Fluss überqueren und ihn in das ferraresische Land fließen lassen, wie es oft passiert); Della Rena, Relazione, 24.

25 I 1577 soll die Stadt allein fast 42.000 Einwohner gehabt haben; noch einmal halb so viele lebten im Herzogtum Ferrara auf $3.470 \mathrm{~km}^{2}$ verteilt. Siehe: BецосH, Bevölkerungsgeschichte Italiens 2, ro8, I 20.

252 Donattini, Cultura geografica, 4I $\mathrm{I}$. Es wundert also nicht, dass die erste Schrift zur ferraresischen geografischen Kultur, die Chronica Parva des Notars Riccobaldo aus dem zweiten Jahrzehnt des 16. Jahrhunderts, sich eingehend mit den Charakteristiken und der Beschaffenheit des Territoriums und seiner Wasserwege auseinandersetzt.

253 Cazzola, Acque di frontiera, 69 und Ders., La politica del territorio, mit hydrografischen Karten. 
Es bedurfte somit einer ständigen »Diplomatie der Gewässer« zwischen den Fürsten und diesen halbautonomen Territorialeinheiten für die Errichtung und Erhaltung von Wasserwegen und Eindämmungsbauten. ${ }^{254} \mathrm{Um}$ die Mitte des I6. Jahrhunderts stieg durch die wachsende Lebensmittelnachfrage das Interesse an Trockenlegungsmaßnahmen zur Gewinnung größerer und besserer Ackerlandflächen weiter, das in ein regelrechtes Unternehmertum der sogenannten imprenditori della bonifica (Unternehmer der Trockenlegung) mündete. Herzogliche Verwalter, wie Pellegrino De Micheli im Dienst von Ferrante Gonzaga, planten nicht nur die notwendigen Trockenlegungsmaßnahmen, sondern konnten sie auch vorfinanzieren. Alle von den Maßnahmen betroffenen Besitzer mussten mit Geld oder Überlassung eines Teiles des bonifizierten Landes für die Investition aufkommen. Diese nun ertragreich gemachten Gebiete konnten gewinnbringend selbst bestellt oder weiterverkauft werden, sodass einige Personen im Umfeld des Hofes durch ein derartiges spekulatives Unternehmertum zu großem Wohlstand kamen. ${ }^{255}$

\subsubsection{Modena}

Die einst von den Römern unter dem Namen Mutina ${ }^{256}$ gegründete Stadt war zuerst ein florierendes Zentrum gewesen, um dann in der Völkerwanderungszeit zu verfallen. Im 9. Jahrhundert ließ Bischof Leodoino die Stadt befestigen und erhielt vom Kaiser weitgehende Befugnisse in der Gerichtsbarkeit. 96 I kam Modena zu den Canossa, in deren Hand die Stadt bis zum Aussterben der Dynastie I I 5 blieb. Wie in Reggio teilten sich auch hier Adelsfamilien aus dem Umfeld der Canossa mit dem Stadtpatriziat und der bischöflichen Klientel die einflussreichen Ämter und Funktionen. Vor allem die wenigen capitanei und bischöflichen Lehensnehmer aus den lokalen Adelsfamilien standen im Dunstkreis des Bischofs von Modena und konnten dementsprechend Einfluss ausüben. ${ }^{257}$ In der Zeit der Stadtkommune gab es zahlreiche Auseinandersetzungen mit den Nachbarstädten Reggio, Ferrara und Bologna. Unter anderem durch diese externen Bedrohungen, aber noch mehr durch die internen Auseinandersetzungen wurde die bischöfliche Macht langsam von der Stadtkommune aufgesogen, was eine freiere Entwicklung der inneren Verwaltung und der Körperschaften ermöglichte. Interne Machtkämpfe gab es unter den Familien Grasolfi und Aigoni, als sich die Stadt zuerst auf die kaiserliche Seite stellte, dann aber unter päpstliche Herrschaft kam, wie dies gleichzeitig auch in Bologna geschah. I 264 wurden die Ghibellinen vertrieben und es entstanden neue Kämpfe unter den rivalisierenden Guelfen-Familien, die Rangoni, Boschetti und Guidoni auf der einen und die Sassuolo, Savignano und Vignola

\footnotetext{
254 Cazzola, Acque di frontiera, i $70 f$.

255 Cazzola, Acque di frontiera, $178 f$.

256 Vgl. Spaggiari/Trenti, Lo Stato di Modena.

257 Bonacini, Capitanei.
} 
auf der anderen Seite. Als die Volksmacht in der Stadtkommune zu stark zu werden drohte, wandten sich die Adelsfamilien an die außenstehenden Este, die sich in Ferrara bereits bewährt hatten. I 288 wurde Obizzo d'Este mit der Führung der Stadt Modena beauftragt. Zwar gab es in der Herrschaft der Este in Modena einige Unterbrechungen, aber im Großen und Ganzen begann ihre Macht mit dem Bau des Castello für die Besatzung und endete erst mit der Schaffung des italienischen Einheitsstaates im I 9. Jahrhundert. I 452 wurde Modena mit Reggio zum Herzogtum erhoben und hatte, wenn auch nicht im gleichen Ausmaß wie Ferrara, wo der Hof meistens residierte, ein höfisches, künstlerisches und wissenschaftliches Leben. ${ }^{258}$ Nach der Devolution, dem Heimfall des päpstlichen Lehens Ferrara, wurde Modena zur neuen Residenzstadt der Este aufgewertet. Das Herzogtum war in sieben Verwaltungseinheiten eingeteilt: Modena, Reggio, Rubiera, Brescello, Sestola, Castelnuovo und Carpi. Diesen stand jeweils ein Statthalter vor. Es gab weiter eine Untereinteilung dieser Provinzen in castellanze, die von Kommissären verwaltet wurden. Es fehlte allerdings eine strenge Zentralgewalt, sodass die lokalen Adeligen und Grundbesitzer relativ freie Hand hatten. ${ }^{259}$

\subsubsection{Reggio}

Reggio war ein Gebiet, das lange seine Autonomie genossen hatte, weil aus den Reihen seiner Adelsfamilien keine lokale signoria entstanden war. Im breve capitaneorum von II69 schloss die Kommune eine erstmals urkundlich bestätigte Übereinkunft mit der gräflichen Herrschaft vor Ort. Neben der markgräflichen Macht der Canossa gab es seit dem ro. Jahrhundert eine starke kirchliche Präsenz, die sich in der Stadt Reggio und seinem Umland etablierte, während sich die Herrschaft der Canossa vor allem am Land festigte. Weder das Bistum noch die stetig wachsende Stadt konnten vor Unruhen bewahrt werden, vor allem nachdem sich in Zuge der mathildischen Erbstreitigkeiten die Kommune ausgebildet hatte, die sich zum Schutz ihrer Autonomie auf die Seite des Kaisers stellte. Obwohl etliche Notabeln von Reggio in Modena podestà (Landvögte) wurden und umgekehrt, blieben die Konflikte unter den Nachbarstädten bestehen. ${ }^{260}$ Am Ende akzeptierte Reggio - auch um die Ansprüche der Visconti, Herzöge von Mailand, zu vereiteln - eine den eigenen Verwaltungsstrukturen fremde Macht mit Sitz zuerst in Ferrara und dann in Modena. Dies führte unweigerlich zu Reibungen, da es auf der einen Seite die Este gab, die bestrebt waren aus ihren Teilgebieten einen zusammenhängenden Staat zu machen, indem sie die lokalen Machtstrukturen unterdrückten; auf der anderen Seite gab es die Kommunen und die Lehensnehmer, die sich für die Wahrung ihrer (meist kaiserlichen) Privilegien und Freiheiten einsetzten. Wie viele andere norditalienische Städte erlitt Reggio

\footnotetext{
258 Rimondi, Estensi, I 83 f.

259 Rimondi, Estensi, 204f.

260 Rinaldi, A Reggio.
} 
das Schicksal von einem kommunalen Mikrokosmos zu einem Teil einer signoria und schließlich eines erblichen Fürstentums zu werden, in dem es nur versuchen konnte, mit dem jeweiligen Regenten so viel wie möglich von der alten Selbstbestimmung auszuhandeln. ${ }^{261}$

Erstmals kamen die Este I 290 in Reggio an die Macht, wurden aber bereits I 306 wieder vertrieben. Nach dem Versuch der Usurpation durch den condottiere Ottobuono Terzi, übernahm I 409 schließlich Nicolò III. d'Este die Macht in Reggio mit einer seichten und wohlwollenden Politik. Auch wenn Reggio also eine Sonderbehandlung erfuhr, verlor die Stadt mit der Machtübernahme durch die Este ihre politische Bedeutung. Gewichtig waren in der Frühen Neuzeit nur mehr die Feierlichkeiten für die Erhebung zum Herzogtum 453 mit dem triumphalen Einzug von Borso d'Este. ${ }^{262}$

Für die Wirtschaft von Reggio kam ein wichtiger Impuls an der Wende vom I 5 . zum I6. Jahrhundert durch die neue Herzogin und »Unternehmerin ${ }^{263}$ Lucrezia Borgia, die hier die Kunst der Seidenherstellung einführte. Noch I 570 exportierte man diese Seide für einen Umsatz von 40.000 scudi ins Reich und nach Frankreich. Unter Ercole II. d'Este wurde in der Jahrhundertmitte das Stadtbild verändert; neue Befestigungsanlangen wurden errichtet und Trockenlegungsmaßnahmen eingeleitet.

Die Wahl Modenas als neue Hauptstadt der Este nach der Devolution, dem Heimfall Ferraras an den Kirchenstaat, wirkte sich nachteilig auf Reggio aus, dessen Wirtschaft und Bevölkerung zu schrumpfen begannen. Die geringe Unterstützung von Seiten der Este führte dazu, dass eine Volksvertretung gewählt wurde, die, wie in Zeiten der Kommune, die Präsenz des Fürsten ausschloss. Dies machte Reggio zu einem Anhängsel Modenas und für die Mitglieder der Este-Dynastie ausschließlich zu deren buen retiro. ${ }^{264}$

\subsubsection{Carpi}

Im Hochmittelalter war der Ort als Castrum Carpi ${ }^{265}$ bereits bekannt und unterstand zunächst der Markgrafschaft Tuszien und dann der Herrschaft der Stadt Modena. Seit

26I Badini, La città e il Ducato di Reggio, 5 I 3 .

262 Der aufwendige Einzug in Reggio sah unter anderem die Begrüßung durch eine Figur, die auf einer Wolke schwebend den Stadtheiligen San Prospero personifizierte und von Engeln der Gerechtigkeit auf einem von Einhörnern gezogenen Wagen begleitet wurde. Strong, Feste, 8I .

263 Zum Unternehmertum der zweiten Frau von Alfonso I. siehe: Ghirardo, Lucrezia Borgia.

264 Badini, La città e il Ducato di Reggio, 5 I 5 - 533.

265 Vgl. Z $\mathrm{ACCHÈ,} \mathrm{La} \mathrm{città} \mathrm{e} \mathrm{il} \mathrm{principato} \mathrm{di} \mathrm{Carpi.} \mathrm{Rimondi,} \mathrm{Estensi,} \mathrm{66.} \mathrm{Immer} \mathrm{noch} \mathrm{interessant:} \mathrm{Hans}$ Semper/F.O. Schulze/W. Barth, Carpi ein Fürstensitz der Renaissance, Dresden i882, in der italienischen Fassung: Carpi una sede principesca del Rinascimento hg. v. Luisa Giordano, Pisa I999. Giovanni Toccı, Piccole e grandi città negli stati italiani (secoli XV-XVII), in: Gian Carlo Garfagnini (Hg.), Giovanni Pico della Mirandola. Convegno internazionale di studi nel cinquecentesimo anniversario della morte (I494-1994) I, Firenze 1997, 53-94. 
I 336 herrschte die Familie der Pio $^{266}$ hier, die in Modena als Reichsvikare wirkten. Carpi war somit ein halbautonomes Fürstentum unter der Herrschaft der drei Brüder Galasso, Alberto und Giberto Pio und ihrer Kinder, auf die die Este aber großen Einfluss ausübten. Diese waren den Pio seit je her verhasst, sodass sie Borso d'Este durch eine Verschwörung zu entmachten versuchten.

Carpi blieb bis ${ }_{5} 25$ unter der Herrschaft der Familie Pio und wurde I 509 von Kaiser Maximilian I. zur Grafschaft erhoben. Dabei wurde Alberto III. Pio mit dem Lehen bedacht, nachdem er bereits I 490 mit der Herrschaft über das Gebiet von Carpi von Kaiser Friedrich III. I 490 investiert worden war, aber dann aufgrund von internen Machtkämpfen ins Exil gehen musste. Nach der Schlacht von Pavia I 525 hob Kaiser Karl V. die Investitur auf und überließ Carpi den Este, unter deren Herrschaft es bis I 796 blieb. Unter besagtem Alberto III. Pio erlebte Carpi seine kulturelle Hochblüte. Um seiner Herrschaft Stabilität zu verschaffen, bemühte er sich um eine Heiratsverbindung mit Margherita Gonzaga. Als der Brautvater die versprochene Heirat verzögerte, wandte sich der Graf an den Kaiser, der I 5 I6 seinen mantuanischen Vasallen - wenn auch schließlich erfolglos - zur Einhaltung des Versprechens aufforderte. Daraufhin heiratete Alberto III. Pio Cecilia Orsini und band sich so an Papst Leo X., der ihn mit Besitzungen um Modena und in der Romagna investierte. Alberto Pio ist ein leuchtendes Beispiel für einen mindermächtigen italienischen Fürsten in einem äußerst dichten Abhängigkeitsgeflecht, der gleichzeitig Herr und Höfling, condottiere und Diplomat, abhängig von seinen mächtigeren Nachbarn, wie den Este und Gonzaga, aber auch von Papst, Kaiser und Frankreich war. ${ }^{267}$ Wie in Mantua oder Ferrara versuchte auch diese mindermächtige Dynastie mit weit bescheideneren Mitteln ihre Festungen und Burgen als Ausdruck ihres fürstlichen Status zu herrschaftlichen palazzi umzugestalten. ${ }^{268}$

Das Lehen mit der Stadt Carpi, $20 \mathrm{~km}$ nördlich von Modena gelegen, wurde schließlich von Alfonso I. d'Este I 525 um roo.00o Dukaten vom Reich erworben. Die Belehnung durch Kaiser Karl V. erfolgte mit Diplom vom 8. April I 530 aus Mantua, nachdem die treuebrüchigen Pio aus ihrem Lehen vertrieben worden waren. Wie die anderen Teile des Fürstentums hatte Carpi Statuten, die sich über diesen Herrschaftswechsel hinausgehend hielten. Anders als die übrigen estensischen Gebiete besaß die Stadt - auch dank der Maßnahmen zur Bonifizierung des Bodens - eine besonders florierende und moderne Wirtschaft. Die gesteigerte landwirtschaftliche Produktion hier wurde vorrangig Mais angebaut - brachte vor allem den Este große Erträge, da sie den größten Teil des bonifizierten Landes als Allodialbesitz besaßen. In Carpi gab

266 Zur Familie der Pio di Carpi siehe: Pezzarossa, »Pio di Carpi«.

267 Fantoni, Un castello, 407-409.

268 Dies taten im ausgeprägten Maße auch die Gonzaga I 433 im Zuge der Vergabe des Markgrafentitels und 1530 des Herzogstitels für Mantua und die Este ${ }_{1452}$ bzw. I47 I bei der Erhebung Modenas und Reggios zuerst und Ferraras danach. Fantoni, Un castello, 4 I 9. 
es - auch aufgrund der geringeren Größe des Fürstentums - die niedrigste Armenrate der Stati estensi. Im Zuge der Devolution wurde auch Carpi als neuer Fürstensitz in Erwägung gezogen, wo es bereits eine standesgemäße Fürstenresidenz gab. Als jedoch Modena gewählt wurde, blieb es ein Zentrum des estensischen Statthalters und der Stadteliten, die sich in die Verwaltung und Stadtführung hineinreklamierten. Die Este selbst taten - im Vergleich zu Ferrara - nicht viel für Carpi, bis auf den Bau von Befestigungsanlagen und die Einführung von Mühlen unter Ercole II., der die Stadt im Gegenzug mit neuen Steuern belegte. Da es sonst keine baulichen Maßnahmen gab, blieb das Stadtbild bis in die späte Neuzeit unverändert, als es im I 9. Jahrhundert aufhörte eine eigene Provinz zu sein und Teil der Provinz Modena wurde.

\subsubsection{Garfagnana}

Als am i 8. Mai I452 Kaiser Friedrich III. den Markgrafen Borso d'Este zum Herzog von Modena und Reggio erhob, erkannte dieser formell die Autonomie der Provinz Garfagnana an, die - anders als die übrigen Provinzen im Umkreis - wie das Gebiet von Frignano politisch und administrativ von Modena unabhängig war. Die Provinz Garfagnana war im Laufe der vorangegangenen 20 Jahre aus dem Zusammenschluss von einzelnen Gemeinden und Vikariaten entstanden und bildete ein in sich geschlossenes Gebiet, das sich bis ins I9. Jahrhundert halten konnte. Dabei behielt es eine politisch-administrative gemischte Struktur bei: Einerseits unterlag die Provinz in Belangen des öffentlichen Lebens dem Generalkommissar oder herzoglichen Statthalter; andererseits konnte sie als übergeordnete Struktur lokalpolitische Beschlüsse erlassen und ihre Vertretung benennen. Dies bedeutete eine äußerst komplizierte Mischung aus kommunaler und »staatlicher« (im Sinne des Gesamtfürstentums) einander oft widersprechender Gesetzgebung.

Als die Este Ferrara verloren, blieb die Situation um die Garfagnana unverändert bis auf die Tatsache, dass die Republik Lucca den nun geschwächten Fürsten mehr denn je dieses Grenzgebiet streitig zu machen versuchte. Die Este kämpften verbissen um diese Provinz, deren Verlust gerade nach der Devolution eine (weitere) gravierende Autoritätsminderung gegenüber allen anderen Lehen gewesen wäre.

Auch die Beschaffenheit der Garfagnana unterschied sie vom restlichen estensischen Fürstentum: Die gebirgige Gegend hatte die Schaf- und Ziegenzucht bevorzugt, das Fehlen von Zufahrtswegen schottete das Gebiet vor allem im Winter stark ab und erschwerte die Kommunikation. Dies förderte bis weit in das I6. und I7. Jahrhundert hinein die Bildung von Anarchie und Banditenwesen, welche wiederum auch als Schutz gegen die vorpreschenden Lucchesen dienten. ${ }^{269}$

269 RAGGI, La Garfagnana. Vor allem Ercole II. sagte dem Banditentum den Kampf an und belastete aus diesem Grund die Gemeinden mit der Unterhaltung seiner Garnisonen. Turchi, Fürstliches Recht, 4 oIf. 


\subsubsection{Die estensischen Lehen}

Die Reichslehen des estensischen Fürstentums, die Herzogtümer Modena und Reggio mit den Gebieten der Garfagnana und des Frignano, mit Carpi (seit I 527 ) und Mirandola (seit I 7 I I) gehörten, wie auch das päpstliche Lehen Ferrara mit den dazugehörenden Gebieten der Romagna Estense und dem bedeutenden, von Kaiser und Papst gleichmäßig beanspruchten Comacchio, ähnlich dem Herzogtum Mailand oder dem Großherzogtum der Toskana zum besonderen Typus des bereits genannten stato regionale, einem Fürstentum mit einer Vielfalt von kommunalen und städtischen Ordnungssystemen ohne ständische Vertretung. ${ }^{270}$

Die mittelalterliche Kommunalstruktur überwindend war Ferrara eine der ersten Städte Norditaliens gewesen, die eine stabile signoria bildete, welche ab der zweiten Hälfte des I 3. Jahrhunderts sukzessive in ein erbliches, mehrteiliges Fürstentum (principato) überging, deren Hauptteile I 452 bzw. I47 I zu Herzogtümern erhoben wurden. Wie das savoyische Fürstentum, das Herzogtum Mailand oder die Republiken Genua und Venedig war das estensische Fürstentum eine »Landeshoheit«, also nicht ein vollständig autonomer Staat, sondern stand unter der maiestas/superioritas territorialis von Papst oder Kaiser - für das estensische Gebiet von beiden. Der einzige de iure und de facto souveräne Staat der italienischen Halbinsel war der Kirchenstaat. ${ }^{271}$

Sowohl in den estensischen Gebieten wie auch im Fürstentum Parma oder im Großherzogtum Toskana fehlte gänzlich eine einheitlich organisierte Vertretung der Stadt- und Landbevölkerung. Jede Stadt und jeder Ort hatten ihr kleines lokales Repräsentationsorgan, doch dieses integrierte sich nicht in eine regionale Vertretung, wie im deutschen Reich. Es handelt sich hier also um stati senza assemblee di stato o ceto, ${ }^{272}$ Territorien ohne Standesvertretung und Reichsstände. Die Macht lag konzentriert in den Hauptstädten, wobei es im estensischen Fürstentum klar erkennbare Unterschiede zwischen der stark zentralistisch ausgerichteten Hauptstadt des päpstlichen Lehens Ferrara und den dezentralisierten Hauptstädten der kaiserlichen Lehen Modena und Reggio gab.

Die Problematik der estensischen Gebiete lag eben im Plural dieses Begriffs: Ein Herzogtum, eine Hauptstadt/Residenz, zwei bzw. drei stark von ihrer kommunalen Vergangenheit und Entwicklung geprägte Städte, ein umkämpfter Zugang zum Meer, ein agrarisch geprägtes Umland und Hügelland, das eine weitgehend selbstständige Tradition aufwies, und schwer erreichbare Gebirgstäler, die sich der herrschaftlichen Kontrolle zu entziehen wussten. Das alles wurde von einer Dynastie beherrscht, die zwar sehr früh das Gebiet unter ihre Herrschaft bringen konnte, zur Ausübung der

\footnotetext{
270 Nach Santini definiert als "pluralità di ordinamenti comunali cittadini con i rispettivi contadi«. SANTINI, Lo Stato Estense, I I.

27 I Santini, Lo Stato Estense, i6.

272 »Territorien/Fürstentümer ohne Stände«. SAntini, Lo Stato Estense, I 2.
} 
Macht jedoch jeweils der päpstlichen und kaiserlichen Investitur bedurfte. Dem hier wenig ausgeprägten kommunalen Verwaltungswesen konnte der Fürst nach der Machtübernahme seinen eigenen Verwaltungs- und Gerichtsapparat (masserie, camerlengherie, Consiglio di segnatura, Consiglio di giustizia) gegenüberstellen und gewann als Schiedsrichter in den lokalen Konflikten immer mehr an Bedeutung. ${ }^{273}$

Die Entwicklung zur »Landeshoheit» der estensischen Gebiete erfolgte in wichtigen Meilensteinen seit dem I 2. Jahrhundert. In dem zum Kirchenstaat gehörenden Ferrara standen sich die guelfischen Este und die ghibellinischen Salinguerra im Kampf um die Vorherrschaft gegenüber. Wer auch immer die Oberhand gewinnen sollte, hätte das war der Kurie früh bewusstgeworden - in Ferrara eine stabile Signorie errichtet und die kommunale Wirklichkeit zurückgedrängt. Etwas später sollte im Kirchenstaat nach dem Vorbild Ferraras die Etablierung der Familie der da Polenta in Ravenna (ab I 275), der Ordelaffi in Forlì, ${ }^{274}$ der Malatesta in Rimini (I 280/I28 I), und der Montefeltro in Urbino folgen. ${ }^{275}$ Unter diesen innerhalb des Kirchenstaates entstandenen Signorien war jene der Este sicher die bedeutendste, nicht zuletzt auch aufgrund ihrer gleichzeitigen Herrschaft in einem kaiserlichen Lehen. Ihre Doppelstellung rührte von ihrer Herkunft her: Sie entsprangen der Verwaltung der tuszischen Markgrafschaft und der Herrschaft in Ligurien und etablierten sich sowohl in der Mark Verona als auch in den Euganeischen Bergen. Über Mantua und Verona kamen sie zu ihrem eigentlichen Machtzentrum Ferrara, welches aber nicht namensgebend war, da sie sich bereits nach ihrer $63 \mathrm{~km}$ von Ferrara entfernten Stammburg im Städtchen Este benannt hatten. Über das Amt des podestà setzten sie sich in Ferrara und kurz darauf mit Obizzo d'Este als dominus perpetuus auch in Modena und Reggio fest. Sie konnten sich gegen die rivalisierenden Salinguerra behaupten, erfuhren aber einen Rückschlag, als das Papsttum, sich auf die karolingischen Kaiserpacta und die Anerkennung durch Rudolf von Habsburg stützend, Ansprüche auf die Romagna erhob, da Azzo VIII. I 308 ohne Nachkommen starb. Zwar zerfiel vorläufig die Vorherrschaft der Este, doch die Wiederherstellung der estensischen Macht blieb nicht lange aus, da der Kirchenstaat als superioritas territorialis der Unruhen und Revolten sowie der Bedrohung durch Venedig nicht Herr werden konnte. ${ }^{276}$ Während die vertriebenen Este von der papsttreuen guelfischen Seite auf jene der Ghibellinen, allen voran der Della Scala ${ }^{277}$ von Verona, wechselten, wurde Robert von Neapel in Ferrara von der Kurie eingesetzt. Durch eine Revolte wurde die Herrschaft Roberts jedoch rasch beendet und die Este wurden I 3 I 7 wiedereingesetzt. Als König Johann von Böhmen nach Italien kam, schlossen sich ihm im Versuch sich von den machthungrigen Anführern, wie den Este, Della Scala und

273 Lazzarini, L'Italia degli Stati territoriali, I75.

$274 \mathrm{Zu}$ beiden Familien vgl. die Beiträge von Kunoff »Da Polenta« und »Ordelaffi«.

275 Seidlmayer, Geschichte Italiens, I 90-20I.

276 Goez, Geschichte Italiens, 200.

277 Vgl. Schwald, »Della Scala«. 
Visconti zu befreien, viele ghibellinische Städte darunter Modena und Reggio an. Diese Dynastien schlossen sich schließlich mit Robert von Neapel gegen den Böhmen zusammen und vertrieben ihn. Die Machthaber der Signorien waren somit wieder fest im Sattel und manche wie die Della Scala konnten ihre Macht sogar steigern. Mastino II. Della Scala gewann zu seinem Territorium Brescia, Parma, Modena, Reggio, Lucca und Massa hinzu. Die Notwendigkeit, den Della Scala in seinem Machtstreben Einhalt zu gebieten, führte zu einem Bündnis der Familien der Este, Gonzaga, Visconti und der Republiken von Florenz und Venedig gegen Mastino II. Als dieser erfolgreich besiegt werden konnte, versuchten sich die aufstrebenden Visconti seinen Besitz einzuverleiben. Ihre wachsende Macht und ihre gezielte Ausdehnungspolitik führten dazu, dass sich die da Carrara, Della Scala, Este, die Markgrafen von Montferrat und die Stadt Florenz mit dem Papst gegen sie verbündeten.

Den I 336 wieder nach Modena und I 409 nach Reggio zurückgekehrten Este gelang es in der Folge die Stadtregierungen zu stabilisierten. Gegen Bezahlung von Io.00o Florentiner Gulden konnten sie auch nach Ferrara (endgültig) zurückkehren. Rinaldo, Obizzo und Nicolò d'Este teilten sich die Herrschaft über die Stati estensi. ${ }^{278} \mathrm{Um}$ es also mit Jacob Burckhardt zu sagen: »Die Regierung der Este in Ferrara, Modena und Reggio hält zwischen Gewaltsamkeit und Popularität eine merkwürdige Mitte. ${ }^{279}$

Sowohl für ihre erste Etablierung in Ferrara und Modena/Reggio ab I 264 als auch für ihr gefestigtes Comeback im Laufe des I4. Jahrhunderts war die auf großen Besitzungen beruhende Wirtschaftskraft der Este ein ausschlaggebender Erfolgsfaktor. Die Familie gehörte zu den frühen Großgrundbesitzern, besaß darüber hinaus bedeutende Mühlen in der Region und trieb regen Handel, insbesondere mit Salz, Getreide und Fleisch. Die Este waren reiche Verpächter und Steuereinnehmer und somit immer mehr in das Wirtschaftssystem Ferraras und des Umlandes involviert. Sie kooperierten und interagierten mit den Zünften, den Juden, den kommunalen Institutionen der Finanz, Wirtschaft und Rechtsprechung, in denen sie ihre eigenen Vertrauten einnisteten, bevor sie selbst die Macht an sich zogen. Der Wunsch nach einer (weiter)blühenden Wirtschaft, die von den internen Machkämpfen beeinträchtigt worden war, und die schwache politische Vertretung der Zünfte in der Stadtkommune erleichterten schließlich die definitive Machtübernahme der Markgrafen in Ferrara. ${ }^{280}$ Die nächsten Schritte zur endgültigen Etablierung waren die kommunalen Freiheiten zu unterbinden, die reichsunmittelbaren Fürsten entweder einzubinden, indem man sie an den Hof brachte, oder jene, wie die Rangone, Sartori etc., die sich gegen die estensische Oberherrschaft wehrten, mit allen Mitteln zu bekämpfen. ${ }^{281}$ Der Höhepunkt der Festigung der estensischen Herrschaft war I 452 die Erhebung Borsos zum Herzog von Modena und Reggio

\footnotetext{
278 Seidlmayer, Geschichte Italiens, 2 19-227. Vgl. Auch Dean, Commune and Despot.

279 Burckhardt, Die Kultur, 45.

280 Vgl. Marini, Lo stato estense, I3-i6.

28 I MARini, Lo stato estense, 46.
} 
durch Kaiser Friedrich III. und I9 Jahre später zum Herzog von Ferrara durch Papst Paul II. Wie die Forschung bereits hinlänglich festgehalten hat, lag in der kaiserlichen Erhebung das Interesse von Friedrich III., in seiner Funktion als Herr von Tirol die venezianischen Expansionsvorhaben mithilfe eines treuen Vasallen zu unterbinden. ${ }^{282}$ Die Standeserhöhung war für die Dynastie der Este nicht nur persönlich unschätzbar wertvoll, sondern eine Eintrittskarte in die Welt der internationalen Elite, da nun Borso ein »locus honorabilis« in der italienischen Liga neben anderen Größen der Halbinsel reserviert wurde. Aber auch für die interne Etablierung war die Investitur von größtem Wert, denn der Este wurde nun formell und offiziell Herr über die bislang aufrührerischen Kleinadeligen von Modena und Reggio. Deshalb wundert es nicht, dass Borso gleich nach der Investitur eine Reihe von institutionellen Reformen einleitete wie die Schaffung eines Rechtsprechungsorgans (Consiglio di Giustizia), die Umsiedlung der Verwaltungsämter und Kanzlei in Hofnähe und die Bürokratisierung des Prozederes bei der Ernennung von Beamten. Ganz anders als oft angenommen, und wie die Este es selbst stets propagiert haben, schaffte es Borso nicht, eine gleichwertige Investitur für Ferrara vom Papst zu erhalten. I 47 I gewährte ihm Papst Paul II. nur nominell das Privileg sich Herzog nennen zu dürfen. Es war ausschließlich ein Ehrentitel und nicht übertragbar oder vererbbar. Erst I 50 I erhielt Ercole I. von Papst Alexander VI. Borgia die Herzogswürde für sich und seine Nachkommen im Gegenzug zur Verheiratung seines Sohnes Alfonso I. mit Lucrezia Borgia. Bezeichnenderweise war der in der Ernennungsbulle angeführte Grund für die Erhebung die von Ercole vorangetriebene Stadterweiterung und -verschönerung, die als Ausdruck der legitimen Ansprüche der Este auf die Stadt galten. Somit hatten die urbanistischen Projekte zur Steigerung des Herrscherprestiges einmal mehr Früchte getragen. ${ }^{283}$

Nachdem die Este bereits fest in ihrem Fürstentum verankert waren, versuchte Ercole II. I 534 in einem weiteren Schritt die Position der Dynastie unumstößlich zu machen: Als die Statuten von Ferrara neu aufgelegt und publiziert wurden, wollte er sie auf alle seine Gebiete angewendet haben, was z.B. in Reggio und anderen Teilen der Stati estensi auf offene Ablehnung stieß, da diese Städte und Orte nicht bereit waren, ihre eigenen Statuten aufzugeben. ${ }^{284}$

Vergleicht man die Genese der beiden Investituren und die Einsetzung der Este als Vikare $^{285}$ des Reiches und der Kirche, lassen sich - bis auf die knapp 20 Jahre früher

282 Ebd., I9.

$283 \mathrm{Vgl}$. M[arco] F[olin], Investitura imperiale di Borso d'Este a duca di Modena e Reggio/Bolla pontificia di investitura di Ercole I d'Este a duca di Ferrara, in: Bentini, Gli Este a Ferrara, 229 mit Darstellung der beiden Diplome. So ist Borso in Ferrara - heute noch am Volto del Cavallo - als sitzende und Recht sprechende Statue verewigt mit jenem baculum, dem Regierungs- und Richterstab »bachetta di iustitia e dela Segnoria di ferara in der Hand dargestellt, die ihm von Kaiser Friedrich III. I 452 in Rahmen der Investitur mit Modena und Reggio übergeben worden war. RIccI, Il libro, 243.

284 Marini, Lo stato estense, 62.

285 Vgl. RiLl, Reichsvikar, I73- I 98. 
erfolgte kaiserliche Erhebung zum Herzogtum auf der einen und die frühere Rückkehr der Este nach Ferrara nach der Krise am Anfang des r6. Jahrhunderts auf der anderen Seite - keine nennenswerten Unterschiede erkennen. Bis ins I6. Jahrhundert verliefen die kaiserlichen und päpstlichen Investituren mit allen Höhen und Tiefen relativ parallel, sodass hierin kein Grund für die Fokussierung der fürstlichen Macht auf Ferrara und die Überbetonung des päpstlichen Lehens innerhalb der Stati estensi zu erkennen ist. ${ }^{286}$ Die Pluralität und Heterogenität der estensischen Herrschaftsgebiete hingegen, scheint sehr wohl zu dieser Konzentration auf Ferrara beigetragen zu haben, wie in der Folge gezeigt wird.

Das kaiserliche Lehen der Este mit den Zentren Modena und Reggio bestand aus einer Reihe von Herrschaften mit mehr oder weniger Autonomie. Dieses Lehensgebiet war seit dem Spätmittelalter in acht Territorialeinheiten unterteilt: Das Herzogtum Modena und das Herzogtum Reggio unterstanden einem einzigen Herrn, nämlich dem estensischen Herzog. Die Fürstentümer von Novellara, Correggio, Guastalla, Rolo, Reggiolo, Carpi und Mirandola unterstanden als kaiserliche Lehen relativ autonomen, mindermächtigen Dynastien. Zwischen dem I6. und I 8. Jahrhundert wurden etliche dieser Fürstentümer von den Este übernommen, so Carpi im I6., Correggio $^{287}$ im I 7. und Mirandola und Novellara im I 8. Jahrhundert. Dabei wurden sie nicht den Herzogtümern von Modena und Reggio einverleibt, sondern gehörten ab der Zeit zum Konglomerat der »Stati appartenenti alla Casa d'Este«. Daraus ergab sich - bis zum Übergang in den italienischen Nationalstaat - ein Sammelsurium an unterschiedlichen Institutionen, Kompetenzen und Rechtssystemen. ${ }^{288}$

Die »estensischen Staaten « blieben somit de facto - wie Mozzarelli betont hat - zur Hälfte autonom gegenüber den von den Fürsten eingesetzten Institutionen; es waren somit »nur« die Person des Fürsten, sein Hof bzw. seine Höfe und seine Funktionäre vor Ort, die eine Klammer um dieses Konglomerat schließen konnten oder es zumindest versuchten. ${ }^{289}$

In den Stati estensi gab es außerhalb der Städte drei Arten von Lehen: Sogenannte feudi rustici ohne Gerichtsbarkeit, feudi rustici mit Gerichtsbarkeit und solche iure nobilis, die neben der Gerichtsbarkeit auch einen Adelstitel mit sich brachten. Die beiden Letzteren waren mittelbare Einheiten. Zum unmittelbaren Gebiet gehörten Städte, Gemeinden und Ortschaften, die direkt dem Herzog unterstanden und durch einen von diesem gewählten Statthalter und podestà regiert wurden. Diese Stellvertreter spra-

$286 \mathrm{Zu}$ dieser Problematik siehe bereits: TAddeI, Die Este, Herzöge von Ferrara.

287 Dieses kleine Herrschaftsgebiet wurde ${ } 452$ als kaiserliches Fürstentum anerkannt und fand zunächst unter den Sforza und dann unter den Habsburgern den notwendigen Schutz gegen die expandierenden Este und Gonzaga, um schließlich ein Vorposten der spanischen Macht in der Po-Ebene zu werden. Da hier die Macht auf alle Nachkommen aufgeteilt wurde, entstand eine weitverzweigte Mitregentschaft, die zu Streitigkeiten vor dem Reichshofrat führte. GARDI, Legati a Bologna, 333 .

288 Fregni, Premessa, i4.

289 Mozzarelli, Introduzione, 5 If. 
chen in Namen des Herzogs Recht und führten seine Anweisungen aus. In den mittelbaren Einheiten, also Städten, Gemeinden, Ortschaften, die der Herzog als Lehen vergeben hatte, besaß der Lehensnehmer die politische, wirtschaftliche und rechtliche Verantwortung. Im kaiserlichen Lehen der Este wurden I6 I 930 unmittelbare und 97 mittelbare Gerichte gezählt. ${ }^{290}$

Die einzelnen Este-Fürsten, vor allem Ercole II. und Alfonso II., waren bestrebt ihr Herrschaftsgebiet zu homogenisieren und eine einheitliche Rechtsordnung zu schaffen, indem sie - wie oben bereits gezeigt - die einzelnen Teile anhielten, die Statuten von Ferrara von I534 anzunehmen. Die Aufforderung wurde aber von den Städten Modena und Reggio - und diesem Beispiel folgend auch von den kleineren Territorialeinheiten - mit der Begründung, dass es sich hier um kaiserliche Lehen handelte, zurückgewiesen. ${ }^{291}$ So kann - Marco Folin folgend - auch für die estensischen Herrschaftsgebiete John Elliotts Modell der composite monarchies des fragmentierten Staates, der nicht durch die Verwaltungsinstanzen, sondern vielmehr durch die Mittel der Patronage des Fürsten zusammengehalten wird, angewandt werden. Es handelte sich auch hier um ein stark untergliedertes Gebiet mit divergierenden administrativen und juristischen Prägungen. Folin geht sogar einen Schritt weiter und sieht gerade in der Tatsache, dass es sich bei den Stati estensi um ein zusammengesetztes (um nicht zu sagen zusammengewürfeltes) politisches System handelte, die Voraussetzung und den Grund für die Etablierung ( $\mathrm{ab}$ I 264) und Festigung Familie d'Este im Laufe des I4. und I 5. Jahrhunderts. ${ }^{292}$ Den Este selbst und ihren Funktionären war die Heterogenität ihrer Herrschaftsgebiete durchaus bewusst, da in den Quellen nicht vom stato als Einheit bestehend aus verschiedenen Provinzen, sondern von stati und domini gesprochen wird, sozusagen um mit dem Plural des Begriffs die Unterschiede und Eigenständigkeit der einzelnen politischen Systeme abzubilden. Zu diesen stati, die auf ein Gebiet von $7.800 \mathrm{~km}^{2}$ verteilt waren, gehörten folgende im Laufe der Jahrhunderte hinzugekommene aber ihre administrative Selbstständigkeit zumeist bewahrenden Einheiten: Ferrara und sein contado, in der die Este I 264 als signori anerkannt worden waren und das I 47I zum Herzogtum erhoben wurde bis es r 598 an den Heiligen Stuhl zurückfiel; das Polesine di Rovigo seit dem I 3. Jahrhundert im Besitz der Este, I395 an Venedig abgetreten, I 438 zurückgeholt und I484 endgültig an Venedig verloren; die Städte Modena und Reggio und ihre contadi, I 336 bzw. I 409 von den Este als signori übernommen und ${ }^{4} 45_{2}$ zu Herzogtümern erhoben; das Gebiet Frignano, das zu Modena gehörte, doch I 494 zu einer eigenen Provinz erhoben wurde; die Ro-

\footnotetext{
290 Fregni, Assetti istituzionali, $59 f$.

29I Die Erhebung zum Herzogtum hatte I $45^{2}$ ganz dezidiert die terrae Imperii, nämlich Modena, Reggio mit Garfagnana und Frignano genannt. Das ius comunis eines Territorialstaates in Italien richtete sich nach dem in den Statuten der dominierenden Stadt verbrieften Recht zuzüglich einzelner Berichtigungen und Änderungen des Fürsten. SAntini, Giurisdizioni locali, 7 I.

292 Elliott, A Europe of composite monarchies, 8I.
} 
magna estense, ${ }^{293}$ zwischen I 408 und I 445 erworben und I 598 mit Ferrara verloren; das Gebiet Garfagnana estense zwischen I403 und I45 I erworben; das Fürstentum Carpi, ${ }^{294}$ dessen Herrschaft die Este von den Pio r 530 endgültig übernahmen; Cento und Pieve di Cento I 502 von Lucrezia Borgia als Mitgift in die Ehe mitgebracht. Das Fürstentum Correggio kam schließlich r635, das Herzogtum Mirandola I 7 I I sowie jenes von Massa I 74I hinzu. ${ }^{295}$

Diesen estensischen Staaten fehlte wie vielen anderen auf der italienischen Halbinsel trotz einiger Versuche zur Vereinheitlichung bis in der zweiten Hälfte des I 8. Jahrhunderts ein einheitliches Rechtssystem; in jeder territorialen Einheit galten die lokalen Statuten. Dies erschwerte nicht nur die Rechtsprechung und Verwaltung, sondern auch die Eintreibung von Steuern, die Verwaltung der Gewässer und der Allmenden. Die consuetudines loci der einzelnen Statuten waren nämlich nicht unerheblich. ${ }^{296}$ Vereinigend waren nur die vom Fürsten für alle Gebiete seines Fürstentums erlassenen Dekrete, von denen etliche so widersprüchlich waren, dass es nach Folin den Anschein hatte, als wollten die Este durch ihre Erlässe nicht die politischen Systeme vereinheitlichen - was ein unmögliches Unterfangen zu sein schien - sondern ausschließlich ihre Macht demonstrieren. ${ }^{297}$

So heterogen die kaiserlichen Lehen der Este untereinander waren, so sehr unterschieden sie sich von den päpstlichen Lehen. Während es in den contadi von Modena und Reggio sogar Ortschaften und Dörfer mit eigenen Statuten gab, gab es im ferraresischen Umland - bis auf die einzige Ausnahme Corbole - nur dort eine kommunale Gesetzgebung, wo vor oder von den Este eine Verwaltungsinstitution (podesteria) eingesetzt worden war. Wenn die Statuten im kaiserlichen Lehen Ausdruck von Autonomie waren, so stellten sie im päpstlichen Lehen eine enge Verbindung des Umlandes zur Stadt dar. Im ferraresischen Gebiet, wo die langobardische Besetzung ausgeblieben war, dominierte die Stadt über das Umland und es fehlte die Form und das Gewohnheitsrecht des dominatus loci, des mindermächtigen signore, der militärischen Schutz und Rechtsprechung gegen die Möglichkeit der Steuereintreibung garantierte. Die Este hatten sich hier eingebettet ohne diese Tradition zu verändern und die in

293 Lugo war der bedeutendste Ort der Romagna Estense. Frignano schlug den Vorschlag der Este, die Statuten von Ferrara zu übernehmen, nicht ab, da es sich davon die Abnabelung von Modena und die Verselbstständigung aus dem Einflussbereich dieser Stadt erhoffte; außerdem gab es auch keine wirtschaftlichen und sozialen historischen Gegebenheiten (Lehnsnehmer, Kommunen etc.), die sich diesem Prozess erfolgreich hätten entgegenstellen können. Vgl. Angiolini, Rettori, I 2 I - I 25.

294 Z ACCHÈ, La città e il principato di Carpi, 225f, 237. Siehe auch Bocchi, Il dominio estense. Die Este konnten sich hier nicht besonders verwurzeln und überließen die Führung des Lehens der Stadtregierung; sie setzten Gouverneure zur Einhaltung der Ordnung und zur regelmäßigen Berichterstattung ein.

295 Folin, Officiali e feudatari, 82.

296 Folin, Officiali e feudatari, 84.

297 Noch in der ersten Hälfte des i 9. Jahrhunderts litt die Verwaltung der Habsburg-Este am Fehlen allgemeiner Gesetze zur Regelung der Kompetenzen der Staatsämter. Folın, Officiali e feudatari, 87. 
diesem Gebiet von ihnen vergebenen Lehen trugen - bis auf einige wenige Ausnahmen - keine, auch nicht die niedrige Gerichtsbarkeit mit sich. Die Lehensempfänger waren hier fast ausschließlich Untertanen aus Ferrara und dem Umland und nur ganz vereinzelt aus Modena oder Reggio. Dies beweist auch die geringen Bemühungen der Este um soziale Integration innerhalb ihrer Staaten und Provinzen und die mangelhafte Nutzung eines Klientelsystems, d.h. ein System, in dem sich Einzelne freiwillig einem Patron unterstellen und dessen Macht in der Peripherie umsetzen, wofür sie im Gegenzug eigene Machtansprüche und Erwartungen aushandeln konnten. ${ }^{298}$ In Modena und Reggio hingegen hatte die langobardische Tradition des dominatus loci die Aufteilung des Umlandes und die schwache Herrschaft der Städte über den contado geprägt. Die Institutionen kommunaler Prägung blieben bestehen und die kleinen Herrschaften, z. B. die Cesi, Correggio, Manfredi, Montecuccoli, Pico, Pio wurden durch kaiserliche Belehnung bestätigt. Hier banden die Este den Adel nur im geringen Maß durch Belehnung an sich und wenn, dann investierten sie sie im Sinne der hiesigen Traditionen mit dem merum et mixtum imperium (Straf- und Zivilgerichtsbarkeit) und akzeptierten die Schaffung von juristischen Enklaven und von der Hauptstadt halbautonomen Einheiten. Erst als die heimischen Dynastien wie die Manfredi, Pico und Pio zu schwächeln begannen, gingen die Este dazu über, u.a. aus wirtschaftlichen Gründen, renditereiche Belehnungen iure feudi zu vergeben. Das päpstliche Lehen war also stark auf die Hauptstadt und seine Fürsten konzentriert und bestand im Umland aus großen Besitzungen der Este, die sie verpachteten oder auf denen sie ihre deli$z i e^{299}$ als Stützpunkte der Macht errichten ließen, während in den kaiserlichen Lehen zwischen Hauptstädten und Umland/Provinzen eine Abgrenzung und ein stark verzweigtes und komplexes System von lokalen Herrschaften bestand, das die Este nicht aufheben wollten oder konnten und deshalb in seinen Eigenheiten bestätigten. ${ }^{300}$

Im Zuge ihrer Etablierung als signori und dann principi mussten die Este mit zwei diametral unterschiedlichen, sich oft widersprechenden und den Traditionen bzw. dem Gewohnheitsrecht entsprungenen Realitäten umzugehen lernen. Wie andere italienische Fürsten versuchten sie sich anfangs das Wohlwollen der Kommunen und Untertanen zu garantieren, indem sie die vorherrschenden Statuten und Gewohnheitsrechte vollständig oder zumindest teilweise anerkannten. Sie pflegten die Wahrung der kommunalen Statuten auch in den Hauptstädten, führten Änderungen und Erweiterungen nur bedachtsam durch und wogen dadurch die Zustimmung zu ihrer Führung gegen eine einheitliche Verwaltung ab. ${ }^{301}$ Dies reichte allerdings à la longue nicht aus und die Este mussten dazu übergehen, die lokalen Mächtigen mit Regalien (Zölle, Steuern)

298 Asch/Емich/Engels, Einleitung, 8f.

$299 \mathrm{Zu}$ diesen und anderen Nebenresidenzen, Jagd- und Lustschlössern und wirtschaftlichen sowie militärischen Stützpunkten der estensischen Macht siehe: Ceccareldi/Folin, Delizie estensi; Taddei, Palazzo und Delizie; Ceccarelli, Palazzi.

300 Folin, Officiali e feudatari, 9I -93 .

30 I Folin, Officiali e feudatari, 95. 
und mit ihren Beziehungen zur römischen Kurie und den daraus resultierenden Möglichkeiten von kirchlichen Versorgungsposten an sich zu binden. Eine andere Möglichkeit der Anbindung war die Vergabe von Ämtern wie jenes des Podestà, Commissario oder Governatore ducale. Das Ämterwesen war die feingliedrige Klientelstruktur, ${ }^{302}$ in der sich die Eliten Güter, Gefälligkeiten und Informationen austauschten, um im Schatten des Fürsten ihr politisches und wirtschaftliches Gewicht auszubauen. Nichtsdestotrotz waren und blieben die Amtsinhaber von der Gunst des Herzogs abhängig, da sie nur von ihm ernannt und immer wieder bestätigt wurden. Deshalb nahmen sie aktiv an seinem Propagandaprogramm teil und leisteten somit einen Beitrag zur Imagebildung des Fürsten. ${ }^{303}$

Anders als die Inhaber von Hofämtern, die sich »nur« um die fürstliche Gunst kümmern mussten, ${ }^{304}$ hatten jene Funktionäre, die in die Provinzen des Fürstentums entsandt wurden, um allein oder zusammen mit einem Notar das ihnen zugesprochene Gebiet zu kontrollieren und verwalten, kein leichtes Leben. Auch sie scheiterten an der heterogenen Zusammensetzung der Stati estensi und an den geringen rechtlichen Mitteln, die ihnen zur Verfügung standen, um die lokalen Notabeln zur Mitarbeit zu bewegen/zwingen. Ihr Aktionsradius war durch die autonomen Herrschaftsformen so eingeschränkt, dass sich ihre regelmäßigen und zahlreichen Berichte an die herzogliche Kanzlei auf Informationen über das Wetter und die zu erwartende Ernte, auf Grenz- und andere nachbarschaftliche Streitigkeiten, auf Festlichkeiten, Prozessionen, Märkte und Jahrmärkte, auf den Machtmissbrauch von lokalen Lehensherren und Banditen und auf Truppenbewegungen in Grenzgebieten beschränkten. Rechtsprechungsakte dieser Gouverneure finden sich hingegen äußerst selten. Nichtsdestotrotz waren sie einflussreiche Vermittler zwischen Fürst und Bevölkerung und in den verschiedensten Belangen (Verwaltung, Finanzen, Wirtschaft, persönliche und familiäre Auseinandersetzungen) bedeutende Auskunftspersonen. Somit stellten sie einen bedeutenden Kommunikationskanal innerhalb dieses stark heterogenen Staatenverbandes und eine Verbindung zum Fürsten dar.

Ein anderes - vielleicht widersprüchlich anmutendes - »Bindemittel« für dieses facettenreiche Herrschaftsgebiet war nach Folin der in der höfischen Kultur weitverbreitete Topos der Untertanenliebe. Ausgehend von der Meinung, dass ein geliebter Fürst sich länger hielt als ein gefürchteter, hatten die Este es geschafft, dass es seit Borso keine nennenswerten Erhebungen gegen die Dynastie gegeben hatte und auch ihre unfreiwillige, fast zwanzigjährige Abwesenheit in Modena und Reggio zu Beginn des r6. Jahrhunderts tat ihrer Macht keinen Abbruch, obwohl oder vielleicht gerade

302 Chittolini, Feudalherren, $248 \mathrm{f}$.

303 Vgl. Folin, Rinascimento estense, 2 I 2- 2 I 9.

304 Diese »Günstlinge« konnten Einzelpersonen oder kleinere und sogar größere Gruppen am Hof sein, die »das Ohr des Fürsten« hatten. Vgl. Paravicini, Der Fall des Günstlings, i 7. 
weil ihre Verwaltung und ihr politisches System bis dahin keine Einheit geschaffen hatten. ${ }^{305}$

Ab dem r6. Jahrhundert kam dann auch das Lehenswesen als Mittel der Bindung an den Fürsten hinzu: Die Zahl von kleinen und kleinsten oft nur einige Dörfer oder einige Hundert Seelen zählende Lehen nahm exponentiell zu; man stand nicht mehr als kaiserlicher Lehensnehmer in Konkurrenz zum estensischen Herzog, sondern war stolz ein Lehensnehmer desselben zu sein und freute sich besonders auf den mit dem Lehen verbundenen Titel eines Grafen oder Markgrafen. Gleichzeitig bedeutete diese Belehnungsinflation für den Fürsten eine wichtige Einnahmequelle.

Eine weitere Änderung im Laufe der Frühen Neuzeit, die die estensischen Staaten enger an das Fürstenhaus binden sollte, war die Zusammensetzung der von den Este eingesetzten Funktionäre. War die Gruppe dieser Gouverneure bis in die erste Hälfte des i 6. Jahrhunderts sehr heterogen zusammengesetzt, einerseits aus dem Hofadel kommend, andererseits Fremde, die nur einige Jahre blieben und dann anderswo eingesetzt wurden, so änderte sich das im späten I6. und im I 7. Jahrhundert. Immer mehr aus der Gegend stammende Rechtsgelehrte mit einer Doktorwürde übernahmen auf längere Zeit, oft lebenslänglich, diese Ämter quasi als Beruf. Sie agierten allerdings zumeist wie rechtlich versierte Handlanger und weisungsgebundene Beamten des Fürsten. ${ }^{306}$

Doch obwohl die Este über ein - wie gezeigt wurde - in Verwaltung und Rechtsprechung stark heterogenes Gebilde herrschten, unterschied sich ihre politische Führung nicht von jener der Herrscher über eine einzige Stadt wie die Gonzaga, da Carrara ${ }^{307}$ oder Della Scala. Während sich Modena (20.00o Einwohner) und Reggio (I 2.000 Einwohner) im Laufe des r6. Jahrhunderts in ihrer Größe mäßig weiterentwickelten, blieb Ferrara mit seinen 40.00o Einwohnern die bevölkerungsreichste Stadt des Fürstentums und reihte sich - besonders nach der Erweiterung durch Ercole I. - unter den I 5 größten und daher bedeutendsten italienischen Städten ein. ${ }^{308}$ Dabei waren es vor

305 Vgl. Folin, Officiali e feudatari, 96 - Io6. Auch Dean, Ferrara and Mantua, I 24- I 26.

306 Vgl. Folin, Officiali e feudatari, I09- i 18.

307 Vgl. Girgensohn, »Da Carrara«.

308 »Ferrara ist die erste moderne Stadt Europas; hier zuerst entstanden auf den Wink der Fürsten so große, regelmäßig angelegte Quartiere; hier sammelten sich durch Konzentration der Beamtenschaft und künstlich herbeigezogene Industrie ein Residenzvolk; reiche Flüchtlinge aus ganz Italien, zumal Florentiner, wurden veranlaßt, sich hier anzusiedeln und Paläste zu bauen«, hielt Jacob Burckhart fest. Burckhart, Die Kultur der Renaissance, 46. Es gibt zwei Schätzungen für die Größe der Bevölkerung im I6. Jahrhundert in Italien, einmal von Beloch und einmal von C.M. Cipolla, wobei Cipolla für Norditalien eine viel kleinere Zahl (z.B. o,6 Mio. für Piemont) schätzt als Beloch (o,8 Mio.). Auf Cipolla maßgeblich stützt sich auch Alfani mit dem Fokus auf Norditalien. Alfani, Population. Nach Alfani muss das I6. Jahrhundert in seinen einzelnen Phasen und Norditalien in seinen Bestandteilen (Küste, Ebene, Gebirge) gesehen werden. Italien hatte im I6. Jahrhundert zwei große Krisenzeiten I 576-I577 und I591-1592 mit Missernten, Hungersnöten und Pestwellen zu überstehen. Für die Bevölkerungsentwicklung bedeutete dies eine demografische Stagnation bis I 560 ; I $560-$ I 589 kam es zu einer raschen demografischen Zunahme; I590-I593 folgte eine weitere Krise mit einem deutli- 
allem der Fürstenhof und die Nebenhöfe der Familienangehörigen, die sehr viele eine Anstellung Suchende und Wirtschaftstreibende anzogen und Ferrara zum wirtschaftlichen und politischen Zentrum der Stati estensi machten.

\subsubsection{Die Este: Von Lehensnehmer zu Lehensgeber}

Die Este, die sich als Inhaber verschiedener curtes und Teilnehmer am politischen Geschehen im südlichen Teil der Mark Verona ab den 7oer Jahren des I I. Jahrhunderts niedergelassen hatten, machten sich ab dem beginnenden I 2. Jahrhundert vermehrt als Lehensgeber ${ }^{309}$ und Verteidiger der Kirche einen Namen, vor allem durch ihre Bemühungen um das Kloster S. Maria di Vangadizza, das sie bald unter ihre Herrschaft bringen konnten.

Während sie sich im Umland etablierten, gab es in Ferrara zu Beginn des r 2. Jahrhunderts capitanei ${ }^{310}$ aus dem mathildischen Umfeld, die - wie z.B. Guglielmo di Marchesella oder die Familie Torelli - ihre Machtposition in der Stadt gegen die Expansionsbestrebungen der Este zu verteidigen versuchten. Als »Außenstehende« profitierten Letztere allerdings von der Tatsache, dass sich in Ferrara bisher keine Dynastie hatte entwickeln können, dass das Phänomen des »incastellamento ${ }^{311}$ fehlte und die Macht vorerst in der Hand der Kirche lag. Die capitanei Ferraras waren Einzelpersonen und konnten trotz ihrer edlen Herkunft aus bedeutenden Familien - anders als ihre Gleichgesinnten in der Lombardei - keine dynastische Kontinuität in ihrer politischen Funktion erreichen; darüber hinaus standen sie einer kommunalen Führung gegenüber, die sich außerstädtischen Einflusspersonen (u.a. den Este) anvertraute. ${ }^{312}$

In seiner Untersuchung der estensischen Herrschaft in Ferrara an der Wende vom Mittelalter zur Neuzeit hat Trevor Dean bereits auf die exzeptionelle Entwicklung Ferraras hingewiesen: ${ }^{313}$ Sie war die erste Stadt Mittel- und Norditaliens gewesen, in der

chen Geburtenrückgang; I 594- I6 I 9 gab es zunächst eine kleine Erholungsphase und erst Ende I6 10 war die Bevölkerung Norditaliens wieder auf dem Niveau von vor der Krise. Ebd., 566f., 583-586. Folin kommt in seiner Zählung der Angestellten in den verschiedenen von den Este direkt betriebenen Unternehmen (Manufakturen, Woll- und Seideproduktion, Landarbeiter, Salinen und Fischereirevieren von Comacchio etc.) in und außerhalb Ferraras auf ı 0.000 besoldete Personen. Folin, Officiali e feudatari, I I 8 .

309 So z.B. für die Familien da Lendinara oder da Monticello; mit einigen waren sie auch Heiratsverbindungen eingegangen. Siehe: Castagnetti, Da Verona a Ravenna, 378-382.

3 io Vgl. Castagnetti, Da Verona a Ravenna, 437-455.

3 I I Damit sind die zwischen dem Io. und dem I2. Jahrhundert im Territorium wahrnehmbaren Veränderungen durch neue Ansiedlungsformen (castra und befestigten Siedlungen) und eine zunehmende territoriale Verfestigung des Lehenswesens aufgrund der neuen Invasionswellen durch die Sarazenen und Normannen gemeint. Vgl. Toubert, Dalla terra ai castelli.

3 i 2 Vgl. Castagnetti, Da Verona a Ravenna, 45 I - 455 .

3 I 3 Vgl. Dean, Land and Power; Tristano, Vassals. 
sich eine stabile signoria installierte, in der aber feudale und lehensrechtliche Bindungen weiterhin bestanden und von Bedeutung waren. Zudem galt sie auch als Beispiel für eine städtische Wirtschaft, in der sich nicht ein für diese Größenordnung typischer sozialer und politischer Rahmen bildete. Beide Formen des Feudalismus, der politische und der wirtschaftliche/ökonomische Feudalismus, also feudalismo und feudalità, lagen an der Basis der signoria in Ferrara; beide Formen wurden von den Este nach I 240 verstärkt weitergeführt. ${ }^{314}$ Ferrara ist nach Dean aber auch wegen eines weiteren Paradoxons interessant: Obwohl sich hier keine merkantile Aristokratie entwickelte, waren die Zünfte dennoch nicht politisch aktiv und wenig vorherrschend. Außerdem gab es kein organisiertes popolo und somit keine antifeudale Volkslegislation. ${ }^{315}$

Ferrara war also untypisch, der Adel war städtisch geblieben und es entwickelten sich kaum ländliche Herrschaften mit ihren die Landschaft prägenden Burgen. Die Macht blieb in der Stadt konzentriert, vor allem am Hof und in den bedeutenden Kirchen und Klöstern. Es waren besonders die heimischen Adeligen und minderen Herrscher sowie die kirchliche Herrschaft Roms und Ravennas, die den Ausbau von ruralen Machtstrukturen verhinderten. Dies zeigt sich auch in der Landschaft: Das Fehlen von Burgen und Ansitzen auf dem Land, d.h. im ferraresischen contado war nicht nur auf die geomorphologischen Bedingungen des Territoriums mit weiten Ebenen und Sümpfen zurückzuführen, sondern auch auf die Abwesenheit von ruralen Herrschaften. ${ }^{316}$ Erst nach ihrer Etablierung begannen die Este mithilfe von Stützpunkten ihrer Macht, sogenannten delizie, Jagd- und Lustschlössern, Gutshöfen und Festungen, das Gebiet als ihres zu markieren. ${ }^{317}$

Der Grund warum Ferrara so rasch, also innerhalb von nur zwei Generationen, unter estensischer Herrschaft gekommen war, lag auch in der Tatsache, dass die Este stetig Land erwarben und dieses als Lehen weitergaben, sodass sie andere Adelige in einem Lehensverhältnis an sich banden. Darüber hinaus schafften sie zum Zweck der Festigung ihrer Herrschaft und ihrer territorialen Ambitionen sehr früh ein Netzwerk von Patronage, Allianzen und Freundschaften an ihrem Hof. Eine Reihe von Entwicklungen der zweiten Hälfte des I 4. Jahrhunderts deutete schließlich den Übergang von der signoria zum Fürstentum an. Erstes und bedeutendstes Zeichen war die Identifikation der Regierung mit der Person des Fürsten und seinen Beamten. I38 I wurden die gängigen Münzen ferrarini mit den marchesini ausgewechselt, die das Konterfei des Este-Fürsten trugen. Die Gründung der Universität r 39 I und andere Maßnahmen zur Steigerung des Wohlstandes der Bevölkerung von der Hand des Fürsten waren weitere Anzeichen. Parallel zur Etablierung der Este wuchsen die Institutionen der Macht

3 I4 Dean, Land and Power, Io.

3I5 Dean verwendet dafür den von Fasoli geprägten Begriff »legislazione antimagnatizia«. DeAn, Land and Power, 12 und Anm. 37.

3 I 6 DeAn, Land and Power, I 2 f.

3i7 Dazu siehe: Ceccarelli/Folin, Delizie estensi; Taddei, Palazzo und Delizie; Ceccarelli, Palazzi. 
wie die fürstliche Kammer und die Kanzlei, welche die zunehmende, nun in der Hand eines Einzelnen liegende Verwaltung bewältigen mussten. In den größeren Städten des estensischen Herrschaftsgebietes bestand die Stadtregierung aus einem podestà, einem Hauptmann für den militärischen Schutz und einem massaro für die Führung der Finanzen. Diese teilten sich die Macht mit der kommunalen Führung durch die Savi oder Anziani, an dessen Spitze der Giudice dei Savi stand. Doch mit dem Aufkommen und der Etablierung der Este-Herrschaft verkümmerten die kommunalen Machtführer zuerst zu Mitregenten und dann zu weisungsplichtigen Funktionären, deren Aufgaben und Kompetenzen sich auf den Erhalt von Straßen und Befestigungsanlagen, die Verteilung von Lebensmitteln und die Verwaltung von direkten Steuern beschränkten. In den kleineren Städten und im Umland verband der von den Este eingesetzte podestà - allerdings in nur sehr beschränktem Ausmaß - die militärische und juridische Macht in einer Person.

Für Dean bestand somit der Erfolg der Este, zuerst die signoria zu errichten und sie dann zu einem Fürstentum auszubauen, in der Anhäufung und Neuverteilung von Landbesitz und in der Beeinflussung der internen Machtstrukturen, die sie sukzessive unter ihre Kontrolle brachten. Nach der Etablierung ihrer Macht in Ferrara richteten die Este ihre Aufmerksamkeit auf die Nachbarstädte in der Emilia, Bologna, Modena und Reggio. In ersterer konnten sie sich nicht behaupten, doch in Modena und Reggio, wo keine einheimische Familie stark genug war, um selbst eine signoria zu installieren, wurde ihnen als Außenstehende die Macht angeboten. Vor allem hier verstanden es die Este die lokale Adelsschicht in die Führung des Landes einzubinden und durch feudale oder halbfeudale Strukturen an die neue Dynastie zu binden. Neben den Adeligen versuchten die Markgrafen bei ihrer Machtübernahme auch die lokale Kirche miteinzubeziehen. I 270 akzeptierte der Abt eines der größten Klöster des ferraresischen Raums (Badia) den militärischen Schutz von Obizzo II. d'Este für die Verteidigung der Grenzen und gegen rebellische Untertanen, die nicht den Pachtzins zahlen wollten; im Gegenzug versprach er, lediglich keine Landveräußerungen ohne Obizzos Einverständnis zu tätigen. I 286 wurde die Abtei in die päpstliche Investitur für Obizzo miteinbezogen. Die unmittelbar an den Landbesitz der Este angrenzende Abtei von Pomposa, konnte dem stetigen Druck durch die neue Dynastie zwar etwas länger, aber nicht dauerhaft standhalten. Dieser Prozess der langsamen Übernahme der kirchlichen Macht, Jurisdiktion und der Besitzungen vor Ort durch Einmischung bei der Wahl neuer Äbte und Positionierung von loyalen Personen an den Schaltstellen der kirchlichen Macht dauerte bis zum Ende des I 5. Jahrhunderts an. Verschiedene Klöster und Abteien gaben sogar freiwillig ihre Autonomie auf, um den Schutz der Este zu genießen. Als päpstliche Vikare hatten sie zwar sowieso die Pflicht diese zu beschützen, doch wie einnehmend und einengend dieser Schutz war, kann nur aus den Beschwerden mancher Klöster nach Rom gelesen werden. ${ }^{318}$

3 I Vgl. Dean, Land and Power, 2 I - 39. 
Der nächste Schritt zur Etablierung und Festigung der Macht war die Sicherung des neuerworbenen Landes durch regelmäßige Abgaben und die Einsetzung von Personen des inneren Hofkreises bzw. auch von Familienmitgliedern in Schlüsselpositionen der kirchlichen Hierarchie. Abteien wurden in commendae ${ }^{319}$ verwandelt, Landverschiebungen (Ankauf und Verkauf) der lokalen Kirche bedurften der Zustimmung der Este, die sich auch aller die Kirche betreffenden Rechtssachen annahmen. Weitere Landzugewinne kamen bei der Machtübernahme durch die Este von der Konfiszierung der Besitzungen ihrer vertriebenen oder verurteilten Feinde, allen voran der Familien Adelardi und Casotti, Torelli und Ramberti, von denen die meisten ins Exil geschickt wurden. Für Dean war die Übernahme des Landbesitzes der exilierten Familien eines der größten Trümpfe für die Etablierung der estensischen Macht. Das dazugewonnene Land wurde - weniger aus Großzügigkeit denn aus politischem Kalkül - weitergegeben. Die Este vergaben Lehen, ${ }^{320}$ Privilegien und Zuwendungen, Rechtsprechungsgewalt, Zölle und Steuern an ihre Beamte, Höflinge und sonstige Unterstützer und banden sie dadurch noch enger an sich. Kredite der Adeligen bei der Kammer wurden mit Steuereintreibungsprivilegien oder Landzuweisungen quittiert. Eine weitere gängige Form der Beschenkung und Auszeichnung war die Umwandlung von Lehen lokaler Adelsfamilien in Allodialbesitz. ${ }^{321}$

Bedeutend war im April I 394 die Verordnung, dass alle Vasallen der Este ihre Belehnungsurkunden zur Bestätigung oder Neubelehnung vorbringen mussten. Diese »Lehenszählung« ergab 37 I Lehen mit 700 Vasallen. Dieses Ungleichgewicht ergibt sich aus der Tatsache, dass ein Lehen oft von einem Dutzend Vasallen gehalten wurde, bzw. dass ganze Familien und Sippschaften als Lehensnehmer galten. Die belehnte Fläche entsprach nach Dean 5.000 ha in und um Ferrara und nochmals 500 ha in Polesine di Rovigo bei einem Lehensterritorium im I3. Jahrhundert von geschätzten I0.000 ha. Tatsache ist, dass es sich bei den Belehnungen oft um sehr kleine Landstriche handelte, eine Mühle, eine Festung, ein Brückenrecht oder ein einzelnes Haus. Erst im I4. Jahrhundert kamen einige wenige großflächige Lehen hinzu. ${ }^{322}$ Viele der Belehnten waren

3 9 Bei einer Kommende werden die Einnahmen aus dem Kirchen- oder Klostervermögen an Dritte übertragen.

320 Spaggiari, Gli archivi. Hier führt Spaggiari nicht nur die Archive der über roo Lehen in den estensischen Gebieten, sondern auch eine Liste aller Lehensnehmer an.

32 I Vgl. Dean, Land and Power, 46-6I, 74. Die Este hatten nach Dean schon vor der Etablierung der signoria I 264 Lehensmänner in Ferrara, doch die meisten, die sich bis weit in die Zeit ihrer Herrschaft halten sollten, stammten aus dem letzten Jahrzehnt des I3. Jahrhunderts, wie die Catastri delle Investiture zeigen. Zum vergleichbaren Phänomen der Hofbeamten als Kreditgeber im südböhmischen Raum siehe: HrdLIČKa, Kommunikation durch Geld.

322 Wie für andere Lehensgeber war es von größter Bedeutung, dass die Este von Anfang an über große Ackerlandflächen, Obsthaine, Wälder und Weiden verfügten. Riccardo Barotti hat für das Gebiet der Lunigiana eruiert, dass $70 \%$ der Einnahmen der Markgrafen aus der Landwirtschaft und nur $30 \%$ aus dem Lehenertrag, also den Privilegien über Mühlen, Schenken und Zolleinnahmen und jenen aus der Rechtsprechung kamen. So wie das Reich von seinen Lehensnehmern nicht das erhielt, was es sich 
fremde Adelige von außerhalb der Stadt, die nicht ständig in Ferrara residierten, aber mit den Este und ihrem Hof verbunden waren. Mit den Belehnungen wurden also nicht nur der heimische Adel, sondern auch Hofleute, im geringen Umfang Adelige aus den anderen Teilen des estensischen Fürstentums (Modena und Reggio) und für die Machterhaltung wichtige Persönlichkeiten wie z.B. condottieri an die Dynastie gebunden. Viele Lehen, die in der ersten Zeit der Machtübernahme an alteingesessene Familien vergeben worden waren, wurden durch Verarmung derselben oder Aussterben der Familie frei und konnten an neue, fremde, gerade etablierte und in der Gunst der Este aufgestiegene Familien oder Einzelpersonen, wie die aus Florenz geflohenen Strozzi, ${ }^{323}$ neu vergeben werden. Die Este bedachten in ihrem Feudalsystem aber nicht nur Adelige, sondern auch Beamte, Bürger, Ärzte, freie Bauern und Handwerker. Viele Lehen wurden gekauft und verkauft und so avancierten etliche Untertanen nicht direkt, sondern auf Umwegen zu Vasallen der Este. Einige Lehen wurden von Familienmitgliedern selbst gehalten, wie der illegitime Nicolò di Francesco, der sowohl im Gebiet von Padua als auch in dem von Ferrara Lehen besaß. Diese verschiedenen Formen, Größen und Zusammensetzungen von Lehen zeichnen das Feudalsystem der Este aus, mit dem sie Land und Leute an sich zu binden versuchten. ${ }^{324}$ Anders als Schenkungen oder Vererbungen brachten diese Lehen Einnahmen und Lehenstreue (Frondienste, Gefolgschaftsdienste) für die signori, da es sich um kein Besitztum im Sinne eines directum dominium, sondern um ein Nutzungsrecht (utile dominium) handelte und dementsprechend ein Jahreszins zu entrichten war. Auch wenn das Lehenswesen nichts Neues war, so war die estensische Interpretation davon und vor allem sein Einsatz zugunsten der Etablierung der signoria bemerkenswert. ${ }^{325}$

erhoffte bzw. benötigte, so erging es eine Stufe tiefer in der Lehenshierarchie auch den italienischen Fürsten, die somit auf ihren Eigenbesitz zurückgreifen mussten. Barotri, Esiste uno Stato, 377f.

323 Die ersten Strozzi kamen Ende des I4. Jahrhunderts nach Ferrara und strebten zumeist eine militärische Laufbahn an. Nanni di Carlo Strozzi war zuerst Soldat im Dienst von Nicolò III. d'Este, dann luogotenente generale dell'esercito estense. Aufgrund des dadurch erwachsenen hohen Ansehens und des Erwerbs von Grundbesitz wurden ihm ein Lehen und ein Titel durch die Este zuteil. Von da an hatten die Strozzi das Bürgerrecht und ein Haus in Ferrara und begannen sich unter der Schutzherrschaft des Fürsten mit den lokalen Eliten zu verbinden. Die Übernahme von Grundbesitz machte nicht nur die Familie reicher, sondern band sie in Treue an das Fürstenhaus. Der nächste Schritt war die Übernahme von bedeutenden öffentlichen Ämtern und Funktionen (Tito Vespasiano Strozzi wurde Giudice dei Savi), von wichtigen diplomatischen Angelegenheiten und die Verbindung mit den führenden Familien Ferraras und Modenas (Costabili, Rangoni) durch Heirat. Darüber hinaus gab es auch Heiratsverbindungen mit anderen italienischen Adelsfamilien (Gonzaga da Novellara, Cattanei di Mantova, Gambara di Brescia) mit Ausnahme von Florenz. Fabbri sieht darin den eisernen Willen bei aller Pflege der Blutsverwandtschaft die neu geschlagenen Wurzeln in Ferrara zu festigen und die florentinische Vergangenheit aufzugeben. Zur Familie siehe Pandimiglio, „Strozzi«. Fab в Ri, Da Firenze a Ferrara.

324 Vgl. bereits TAdDei, Die Este, Herzöge von Ferrara.

325 Vgl. Dean, Land and Power, 74- rog. 
Viele dieser kleinen Lehensnehmer versuchten mit ihrer Familie einen eigenen Staat im Staat zu schaffen und untermauerten ihre legitimen Ansprüche durch den Erwerb von Privilegien und Rechten von Kommunen, Klöstern, Bistümern oder von Papst und Kaiser selbst. Am begehrtesten war dabei eine kaiserliche Belehnung, wie sie verschiedene herrschaftliche Familien in den estensischen Territorien, z.B. die Pio, Pico und da Correggio hatte und die auch die Beziehung zu den estensischen Fürsten regelte. Während sich diese Vasallen zu Kriegsdienst, Gefolgschaft und Treuebekundung 326 verpflichteten, garantierten die Este eine geringe Einmischung in deren Lehen. Diese Vereinbarung schloss allerdings nicht unbedingt ein Nahverhältnis zum Fürsten aus. Chittolini, der diese Fürsten innerhalb eines Regionalstaates zu Recht "piccoli potentati, o aspiranti tali« kleine Machtinhaber oder Möchte-gern-Machtinhaber nennt, ${ }^{327}$ betont, dass »die Beziehung zwischen Herr und feudalem Untertan (wenn auch weniger stark als in den französischen oder deutschen Herrschaften) [konnte] dennoch sehr eng und von beachtlicher Beständigkeit sein [konnte], und das Leben der ländlichen Gemeinschaften [konnte] dadurch sowohl im positiven wie im negativen Sinn spürbar beeinflußt werden [konnte].« ${ }^{328}$

Einige Dynastien wie die Pico in Carpi oder die Pallavicini von Cortemaggiore fallen auch dadurch auf, dass sie regelrechte Miniatur-Renaissancehöfe erschufen. Wie ihre Vorbilder in Ferrara oder Mailand versuchten sie sich durch gewinnbringende Heiratspolitik mit den Seitenlinien bzw. illegitim Geborenen der großen Dynastien zu verbinden, durch condotte, militärische Aufträge, sich in die Dienste von Mächtigen zu stellen und durch geistliche Laufbahnen ihren Einfluss auch im kirchlichen Bereich geltend zu machen, wenn auch heruntergebrochen auf einem bescheideneren Niveau (Abteien, Bistümer). Dabei stellten diese mindermächtigen Herrscher die Überlegenheit der Fürsten von Ferrara oder von Mailand gar nicht in Frage, ebenso wenig wie ihre Verpflichtung zu Treue und Gehorsam; auch erwarteten sie nicht irgendeine Form der Bestätigung ihrer Macht, solange der Fürst diese unangetastet ließ, und ebenso pflegten sie ihre eigenen von den »Großen« separierten Beziehungen zum kaiserlichen Lehensherrn. ${ }^{329}$ Ab den I 53 oer Jahren begann aber der Einfluss der »kleinen Potentaten« diametral zur Konsolidierung der Este zu schrumpfen. Übrig blieben nur einige alteingesessene, vormals direkt vom Kaiser belehnte Familien, dann Lehensnehmer der Este, wie die Gonzaga da Novellara, Pico di Mirandola, da Correggio, oder die Pio di Sassuolo.

Beispielhaft einer durch Patronage und Klientelismus im Dunstkreis der Este einflussreich gewordenen Familie in Ferrara selbst ist jenes der Familie Romei. Als I 459

326 Dazu siehe als Vergleich die von Isabella Lazzarini untersuchten vor Federico Gonzaga abgelegten Treueeide: LAZZARInI, Il linguaggio del territorio.

327 Chittolini, Il particolarismo signorile, $37 \mathrm{f}$.

328 Chittolini, Feudalherren, 245.

329 Chittolini, Il particolarismo signorile, $42-44$. 
Papst Pius II. auf der Reise nach Mantua in Ferrara Halt machte, wurde er als Gast im Haus von Giovanni Romei untergebracht - ein Indiz für das bereits große Ansehen und den Einfluss dieser Familie innerhalb des Stadtadels. Diese wahrscheinlich aus Spanien stammende Familie war durch den Wollhandel reich geworden und hatte in der Folge Land und Rechte/Privilegien erworben. Durch Heiratsverbindungen mit Persönlichkeiten aus dem Dunstkreis des Hofes näherten sie sich langsam den sich mittlerweile etablierten Este. Dabei weitete sich ihre Handelstätigkeit auf Apotheken, die gerade in der Pestzeit große Erträge abwarfen, und ab der Mitte des I 5. Jahrhunderts auf das Bankgeschäft aus. Es folgten Aufträge und Ämter, so die Eintreibung des Zehenten für den Bischof von Ferrara. ${ }^{330} \mathrm{Ab}$ I 45 I war Giovanni Romei als Fattore generale einer der bedeutendsten Verwalter von Borso d'Este und wurde auch in den Consiglio dei Savi gewählt. Er stand somit an der Spitze der Einflusssphäre, was er für sich und seine Familie auch ausnutzte. Mittlerweile zum Hüter und Verwalter der ferraresischen Finanzen emporgestiegen, festigte er seine Bindung zum Fürstenhaus mit der Heirat mit Polissena, der Tochter von Meliaduse d'Este. Dadurch kam ihm die Ehre zuteil, die erstgeborene Tochter von Ercole I., Isabella, zum Taufbecken zu tragen. I 476 wurde er zum Consigliere segreto ducale ernannt und festigte dadurch den Ruf und Ruhm seiner Familie für lange Zeit in Ferrara. ${ }^{331}$

Neben der reichsrechtlichen Regulierung des Lehenssystems, das z.B. die Veräußerung der Lehen durch Vasallen verbot, gab es auch die regionale und städtische Gesetzgebung, also die von Stadt zu Stadt variierenden Statuten, sowie den ad personam erstellten Lehensvertrag zu berücksichtigen. Ab der Mitte des I3. Jahrhunderts wurden viele Lehensherren von ihren Vasallen unter Druck gesetzt, damit erstere ihnen größere Freiheiten z.B. in der Veräußerung und Vererbung von Lehen bzw. für deren Einsatz als Mitgift zugestanden. So legten die Statuten von Modena I 22 I fest, dass Lehen übertragen werden konnten. Darüber hinaus bestimmten die Statuten alle Stadtgebäude und das Umland im Umkreis von zehn Meilen als allodial und frei von jeglichen feudalen Bindungen. Ähnliche Bestimmungen gab es in Mantua und Verona betreffend die Übertragung und Veräußerung von Lehen gegen Kompensation des Lehensherrn. In Ferrara sollten die nach I 264 erlassenen Statuten nicht das Lehenssystem schwächen, sondern es zugunsten des signore kontrollieren. Durch das Verbot multipler Herrschaften sicherten sich die Este gegen die Abwerbung ihrer Vasallen ab. Anders als sie selbst durften ihre Untertanen - ohne ihre Zustimmung - nicht Vasallen zweier Herren werden.

330 TAgliati, Relazione, 62-64. Zur Familiengeschichte siehe auch Prandi, Il „Cortegiano«, besonders 9-22.

33 I Vgl. Tagliati, Relazione, 67-7r. Heute noch gehört Casa Romei zu den Sehenswürdigkeiten der Stadt. Einer seiner Nachfahren, Annibale Romei ( $523 / 30$ - I 590 ), wurde als Mitglied des Consiglio dei Savi, als Gesandter Alfonso II. in Rom I 580 und als Verfasser des Cortegiano Ferrarese berühmt. Vg1. PRANDI, Il »Cortegiano«, I $2-\mathrm{I} 6$. 
Wie Kaiser und Papst nutzten auch die Este die Belehnungszeremonien zum Ausdruck von Macht, zur Förderung von Bindung, Wohlwollen und Abhängigkeit. Als Beispiel führt Dean die Investitur von Cesare Montecuccoli in einer feierlichen Zeremonie in der Kathedrale I 453 mit Schwertübergabe und Treueeid an. Der Treueeid war durch die Handlegung, d.h. der Lehensnehmer legte seine Hand zwischen jenen seines Herrn, symbolisiert. In Ferrara war die Hommage an den Lehensherrn im I3. und frühen I 4. Jahrhundert noch nicht präsent und tauchte erst im Laufe des I 4. Jahrhunderts auf. Dabei veränderte sich der ursprünglich negativ konnotierte Charakter der Treuepflicht in ein positiveres Bild des Vasallen, der jederzeit seinem Fürsten zu Hilfe eilen durfte und, wenn nicht andere Dienste spezifiziert waren, »nur « die Pflicht hatte, die signoria bzw. das principato zu beschützen. ${ }^{332}$

Das Lehenswesen diente den Este also zur Etablierung und Demonstration von Macht, um territoriale Ambitionen zu erreichen und schließlich um die immer größere Anzahl von Hofleuten und Bediensteten an sich zu binden und zu versorgen. Die Beziehungen der Este zu den Adelsfamilien von Modena und Reggio waren oft getrübt und verkompliziert durch die Tatsache, dass diese zumeist im Besitz von kaiserlichen Lehen waren, also von Land, das sie direkt vom Kaiser erhalten hatten und sie von der Jurisdiktion der Kommune/Stadt und vom Machtbereich der Este ausnahm. Einige Familien wie die Montecuccoli oder Canossa hatten diese Lehen bereits im I 2. oder I3., andere erst im Laufe des I4. Jahrhunderts erhalten, als die Este bereits etabliert waren (Pio, Manfredi). Doch auch ein kaiserliches Lehen war nicht gefeit vor den Ansprüchen eines signore oder principe und als der Kaiser die Herzogtümer Modena und Reggio erschuf und Borso d'Este I $45_{2}$ damit belehnte, sicherte er den Este die Oberherrschaft über die kaiserlichen Lehen in diesen Gebieten zu. Aber schon vorher hatten die Este - als päpstliche Vikare in mehr oder weniger legaler Form - die direkte Kontrolle über Lehen übernommen, die von Klöstern und Abteien in diesem Gebiet stammten, mit dem Ziel, die eingesessenen Adeligen zu ihren Vasallen zu machen. Allerdings war die bevorzugte Vorgangsweise der Este nicht die Belehnung, sondern die accomandigia, ein loser, nicht-feudaler Vertrag, durch den die Adeligen Schutz und Privilegien und die Este militärische Unterstützung und eine bessere Kontrolle des Territoriums erhielten. Dieser Vertrag mit Ewigkeitscharakter wurde für jede Familie eigens verfasst und den Nachkommen weitergegeben, wodurch eine klienteläre Beziehung, eine besondere Bindung zwischen den Adelsfamilien und dem signore entstand. Die Verpflichtung zu militärischer Hilfe schloss auch mit ein, dass die raccomandati keine Verhandlungen oder Allianzen mit anderen bzw. mit den Gegnern des Herrn eingehen durften. Dean definiert die Annehmer von accomandigie daher eher als "clients« denn als Vasallen. ${ }^{333}$ Diese Form der Bindung eignete sich außerdem besonders $\mathrm{da}$, wo die Inhaber von kaiserlichen Lehen sich meist der Herrschaft des signore und

332 Vgl. Dean, Land and Power, i I $4-$ I 30.

333 Dean, Lords, vassals and clients, I rof. 
dem Treueeid mit der Begründung, dass sie als kaiserliche Vasallen nur dem Kaiser verpflichtet seien, entziehen wollten. ${ }^{334}$

Durch diese lose Form der Bindung konnten die Este nach und nach das Gebiet um die Städte unter ihre Kontrolle bringen und sogar die hier bestehenden kaiserlichen Lehensherrschaften umgehen. Viele Familien waren mit den Este verbunden und, wie die Roberti und Manfredi, sogar bereit, bzw. in der zweiten Hälfte des I 4. Jahrhunderts gezwungen, ihren Status als kaiserliche Vasallen aufzugeben und sich durch accomandigia den Este zu unterstellen. Selbst wenn es den Anschein erweckt, die accomandigia sei ein Vertrag von gleich zu gleich gewesen, so war sie de facto eine weitere Form der Unterwerfung und Abhängigkeit, mit der die souveräne Herrschaft der Este anerkannt und die eigentliche Herrschaft des Kaisers überlappt wurde. ${ }^{335}$ So anerkannten die oben genannten Montecuccoli die Este als ihre Herrscher über ein Land, das sie vorher vom Kaiser per Investitur erhalten hatten. Der Vertrag, der sie als Statthalter über das Gebiet von Frignano einsetzte, enthielt die Anerkennung der Souveränität und Gerichtsbarkeit der Este, die Festlegung einer zu entrichtenden Jahresrente und das Verbot der Veräußerung ihrer Ansitze. Im Gegenzug erhielten sie eine monatliche Rente und exzeptionell die Möglichkeit auch in andere Dienste treten zu können.

Mit dem Belehnungssystem und noch mehr mit der Form der accomandigia versuchten die Este schließlich auch der Probleme im Umland von Modena, Reggio und Ferrara Herr zu werden. Die Gebiete dieser Provinzen am südlicheren Rande des Fürstentums, teilweise in den Hügeln und Bergen des Apennins, waren besonders schwer zu kontrollieren; sie lagen in der Hand von Baronen, die sehr auf ihre Autonomie und Unabhängigkeit bedacht waren. Sie entzogen sich - nicht nur durch die geografische Lage geschützt - der Oberherrschaft, hielten unerlaubt Märkte, verhinderten den Warentransport, verweigerten die Zahlung von Steuern und erhoben selbst welche. Da sie eine Versorgungsgefahr für die Städte und eine Aufstandsgefahr für die Este bedeuteten, versuchten Letztere sie - mitunter auch durch Zugeständnisse - an sich zu binden. ${ }^{336}$ Die accomandigia wurde somit zur Kontrolle des Gebietes und des Staates benutzt. Hier folgten die Este den Gepflogenheiten der großen Monarchien. Dies paarte sich mit der Schaffung eines losen Klientelwesens, mit der Ansiedelung der Vertragsnehmer in der Stadt und in unmittelbarer Hofnähe, mit der Usurpation von kaiserlichen und päpstlichen Rechten, mit der Installierung von Protegés in der Peripherie und somit der Abhängigmachung von Gebieten, die nicht von Anfang an direkt unter der Herrschaft des signore standen. ${ }^{337}$

334 Vgl. Dean, Land and Power, I 33, I66- I75.

335 DeAn, Lords, vassals and clients, I I $2 \mathrm{f}$ : »[...] accomandigia was a de facto arrangement, overlapping and disregarding, if not replacing, the rights of the direct lord (whether abbot, bishop or emperor) of whom the client nominally held his land.« Ebd., I I 3 f.

336 Vgl. ebd., ro8-i I 4 .

337 Dean, Lords, vassals and clients, i i 9. Vgl. auch Molno, Patronage, $238 f$. 
Bezugnehmend auf diesen Machtbildungsprozess der Este-Dynastie hat Wolfgang Reinhard festgehalten: „Die Entwicklung zum Territorialstaat ist nicht zu verkennen. Machiavellis >Fürst‘ war eine Art nachträglich geschriebenes Lehrbuch für solche monarchische Parvenüs! ${ }^{338}$

\subsubsection{Institutionen der estensischen Macht}

Ihre Etablierung in Ferrara verdankten die Este maßgeblich ihrer nachdrücklichen persönlichen Präsenz bzw. später der Repräsentation durch Vertrauenspersonen, in den bedeutenden Institutionen der Stadt, also im Consiglio dei Savi, in der Stadtkanzlei und in anderen zuerst kommunalen (später markgräflichen) Ämtern und Funktionen. Anders war es hingegen in Modena und Reggio, wo den Este eine ähnliche Durchdringung und Einmischung in den Stadtämtern nicht gelang und sie deshalb auf die militärischen und gerichtlichen Ämter und Funktionen, z.B. des capitano oder podestà ausweichen mussten. Den anderen italienischen Signorien gemeinsam hatte Ferrara somit eine städtisch gewachsene Dynastie, die Verwaltung und Recht mit ihrer Präsenz und ihren Mitteln durchdrang und die Stadt gegenüber dem Umland emporhob. Dasselbe gelang den Este in Modena und Reggio, wo die Stadträte am kommunalen Stil festhielten, nicht im gleichen Ausmaß. Ungünstig war auch die Lage weit entfernt von dem sich etablierenden Machtzentrum Ferrara. ${ }^{339}$

Wenn hier im I 4. und teilweise I 5. Jahrhundert der Stadtrat der Savi noch wichtige Funktionen innehatte, Kontrollorgan für die jüdischen Geldverleiher oder die Wasserverbauungsarbeiten und die Getreideversorgung (annona) war, Steuern eintrieb, den Handel überwachte, Schulbildung und Gesundheitsmaßnahmen forcierte und auch für die Verteidigung zuständig war, weshalb die Este sich anfangs in seinen Reihen bewegten, so verlor er in der späteren Zeit immer mehr Befugnisse und Macht an den Fürsten und vor allem an den von diesen eingerichteten Hof- und Verwaltungsämtern. Zunächst übernahmen die Este immer mehr die Aufgabe der Landesverteidigung und daraufhin die Eintreibung der Zölle und der Mahlsteuer. Mit den zoer Jahren des I 5 . Jahrhunderts gab es unter Leonello d'Este auch institutionelle Änderungen, so z.B. die Tatsache, dass der Giudice dei Savi nicht mehr gewählt, sondern vom signore bestimmt wurde. Zudem begannen immer mehr Unterstützer der Este, darunter Bankiers, Kaufleute und Notare, eine steile Karriere als Ratsmitglieder und Hofbeamte, wobei sie zumeist die alteingesessenen Familien vertrieben bzw. den Mitgliedern der Zünfte den Weg zur Mitsprache verbauten. Nach und nach verschmolzen die Stadt- und die Hofverwaltung zu einer fürstlichen Verwaltung der einzelnen Territorien unter estensischer Herrschaft. Viele Stadtämter verloren ihre Kompetenzen an fürstliche Beamte und die Savi hatten im-

338 Reinhard, Geschichte der Staatsgewalt, 6I.

339 Turchi, Istituzioni cittadine, I3 I. 
mer mehr ausschließlich repräsentative Funktionen. Als diese Entwicklung beendet war, stand der Fürst als Garant für Sicherheit und Recht an der Spitze des Fürstentums und identifizierte sich nicht mehr mit der Stadt, die ihn einst gewählt hatte, sondern die Stadt identifizierte sich mit ihm, seiner Dynastie und vor allem seinem glanzvollen Hof. Dabei entstand ein Gefälle zwischen (Haupt)Stadt und Umland bzw. den ländlichen Gebieten des Fürstentums. Für die Este wie für die meisten anderen aufstrebenden Dynastien galt es, diese Stadt, die sie als Zentrum ihrer Macht auserkoren hatten, und den Fürstenhof auszubauen und zu verschönern. Dies drückte sich in den großen Stadterweiterungen und zahlreichen städtebaulichen Maßnahmen des Quattro- und Cinquecento aus. ${ }^{340}$

Betrachtet man den letzten Akt der Machtübernahme der Este, den Regierungsantritt von Alfonso II. beim Tod seines Vaters I 559, so wird klar - wie Folin festgehalten hat -, dass Ferrara nicht nur der Sitz des Fürstenhofes und die Hauptstadt des Fürstentums geworden war, sondern vor allem der ureigene Quell der estensischen Souveränität, die in der zweiten Hälfte des r6. Jahrhunderts zwar noch de iure aber nicht mehr de facto von Kaiser und Papst abhängig war. In einer ausgeklügelten und gut durchdachten Inszenierung baten die Vertreter der Stadt den aus Frankreich anlässlich des Todes seines Vaters zurückgekehrten Alfonso II., ihr Herr zu sein und über die Repubblica ferrarese herrschen zu wollen; ${ }^{341}$ quasi auf deren Wunsch übernahm dieser rechtmäßige Nachfolger seines Vaters diese Aufgabe, nachdem er die Insignien der Macht, Zepter und Schwert, aus den Händen der Ratsherren entgegengenommen hatte. So scheint es, dass Alfonso nicht aufgrund seiner legitimen Geburt und seines in den Lehensurkunden festgehaltenen Nachfolgerechtes oder durch die auf diesen Akt folgende Neubelehnungen durch Kaiser und Papst in der Herrschaft folgte, sondern auf Geheiß und Wahl eines Volkes mit seinen Vertretern, nämlich den - in ihren Befugnissen von seinen Vorgängern stark beschnittenen - Savi. Dies sollte wenigstens nach außen hin so dargestellt werden. Auch die Vertreter der Zünfte und die Ratsherren nahmen an den Zeremonien der Inthronisation des neuen Fürsten aktiv teil, obwohl die ersten seit Längerem aus dem politischen Leben und der Mitsprache verbannt worden waren und die zweiten vor allem Repräsentations- und Prestigeämter innehatten. Mit der Übergabe von Zepter und Schwert legten die Ferraresen die Herr-

340 Turchi, Istituzioni cittadine, I36- I52. Die berühmteste Erneuerungsmaßnahme ist sicherlich die Stadterweiterung unter Ercole I. zwischen $4_{42}$ und I 505, die sogenannte addizione erculea. Erst Ercole II. bemühte sich, die anderen Zentren seines Reiches (Modena, Reggio, Carpi, Brescello) zu befestigen und teilweise zu verschönern, wie es sein Vorfahre mit Ferrara bereits ausgiebig gemacht hatte. Dazu siehe TADDEI, »Optimo architecto«.

34I Folin hat bereits darauf hingewiesen, dass die Investitur mit der Herrschaft allein den beiden Lehensherren, Kaiser und Papst, oblag und der einzige Titel, den die Kommune vergeben konnte, jener des Herrn von Ferrara, ein antiker Titel war, der I 264 Obizzo d'Este verliehen worden war, aber mittlerweile jede Rechtsgültigkeit verloren hatte. Welchen geringen Wert de facto dieser Titel und die Inszenierung der Machtübergabe eigentlich hatten, beweisen, so Folin weiter, gerade die Bemühungen um eine Standeserhebung und neue Titel. Folin, Le cronache, 48 I. 
schaft über Ferrara und das Herzogtum in die Hände von Alfonso, wie sie nach seinem Tod 40 Jahre später und dem kurzen Intermezzo des vom Papst nicht anerkannten illegitimen Nachfolgers Don Cesare d'Este, die Schlüssel der Stadt dem päpstlichen Statthalter Kardinal Pietro Aldobrandini übergeben sollten.

In der Folge wurde die Zeremonie der translatio imperii und der Machtübergabe an Alfonso II. auch in den beiden anderen Städten des Stati estensi wiederholt. Dies verstärkte mitunter den Eindruck in der Bevölkerung, der neue Este-Fürst sei, wie seine Vorgänger, Herr über einzelne Fürstentümer, die schon vor seiner und seiner Vorfahren Ankunft kommunalpolitisch organisiert waren. ${ }^{342}$ Die Este, und vor allem Alfonso II., waren nicht erpicht darauf, diesen von der Realität nicht allzu weit entfernten Eindruck eines heterogenen Staates zu ändern; im Gegenteil sahen sie sich als Verteidiger und Garanten einer kommunalen Selbstbestimmung, die de facto nicht (mehr) existierte. Dabei nutzte es ihnen, im Rahmen ihres Klientelismus Einzelpersonen oder Familien zu privilegieren, die vorrangig aus Ferrara stammten. Gerade im I6. Jahrhundert kam das gesamte Kanzleipersonal und der Großteil des fürstlichen Gefolges ausschließlich aus Ferrara und auch unter den im Reich und im restlichen Europa eingesetzten Gesandten war nur einer von sechs nicht aus Ferrara. Zwischen I 450 und I 509 kamen auch zwei Drittel der Statthalter für Modena, Reggio, Garfagnana und Romagna aus Ferrara. ${ }^{343}$

Auf diese - wenn man so will - historisch gewachsene Überheblichkeit des päpstlichen Lehens Ferraras weist schließlich auch die Tradition der Stadtgeschichtsschreibung bzw. der frühneuzeitlichen Chroniken hin, die mit absolutem Desinteresse den Geschicken der übrigen estensischen Gebiete gegenüberstanden. Der Fürst selbst wurde in den Chroniken nicht als Herrscher über verschiedene Gebiete, sondern als Herr der Stadt Ferrara beschrieben. So wie Alfonso II. und seine Vorgänger in jeder Stadt separat »inthronisiert" wurden, so verlor man auch in den Chroniken der anderen Städte wie Modena und Reggio kein Wort über Ferrara. Nach Folin scheint es gerade, als hätten sich die Chronisten von Ferrara, Modena und Reggio als Vertreter und in erster Linie als Bewohner ihrer Städte und erst in zweiter Linie als Untertanen der Este gefühlt. ${ }^{344}$

\subsubsection{Die Lehenskrisen des 16. Jahrhunderts als Nagelprobe für das Verhältnis zu Kaiser und Reich}

Obwohl die Este - wie gezeigt wurde - auf verschiedene Weise dem päpstlichen Lehen Ferrara als Zentrum ihrer Macht den Vorrang in ihrer Herrschaft gaben, ${ }^{345}$ verabsäumten sie es nicht, ihre Treue, Loyalität und Zugehörigkeit zum Reich zu beto-

\footnotetext{
342 Folin, Gli Estensi, 26-30.

343 Ebd., 3 I -34 .

344 Folin, Le cronache, 48 I.

345 Vgl. bereits: TAdDEI, Die Este, Herzöge von Ferrara.
} 
nen. Über die Generationen pflegten sie ihre Beziehungen zum Kaiser und zu den deutschen (katholischen und protestantischen) Reichsfürsten und bemühten sich, den Kommunikationsfaden durch ständige Gesandtschaften, Korrespondenzen und Gabentausch nicht abreißen zu lassen. Die Kommunikationsstränge zwischen den Este und dem Reichsoberhaupt betrafen seit der Erhebung zum Herzogtum Mitte des I 5. Jahrhunderts und bis zu Devolution Ende des r6. Jahrhunderts im Wesentlichen drei Themen: Die Investitur bzw. Investiturserneuerungen bei jedem Machtwechsel (bzw. ihr befristeter Verlust unter Alfonso I.), die Frage der Rangordnung/Präzedenz vor allem gegenüber den Medici, und die Investitur der Seitenlinie der Este von Montecchio nach dem Tod des kinderlosen Alfonso II.

Der erstgenannte Interaktionspunkt der regulären Neubelehnungen nach Borsos Erhebung in den Herzogstand war nicht immer friktionsfrei und die damit einhergehenden Divergenzen betrafen zumeist die territoriale und rechtliche Ausdehnung der

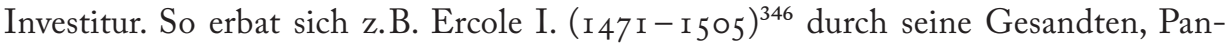
dolfo Collenuccio und Francesco Ariosti, ${ }^{347}$ von Kaiser Maximilian I. bei der Erneuerung der Investitur die Berücksichtigung auch jener Territorien, die die estensischen Fürsten I 484 verloren hatten (Polesine di Rovigo an Venedig, aber auch die Mark Treviso und das Gebiet um Padua); darüber hinaus erwartete Ercole eine günstigere Lehenstaxe, da er aus der Hauptlinie stammte, während sein Vorgänger Borso illegitimer Geburt gewesen war. Schließlich beantragte er - der letztgenannten Forderung widersprechend - die Belehnung für seine legitimen wie illegitimen Söhne. ${ }^{348} \mathrm{Ma}-$ ximilian I. stimmte aber der Erneuerung der Belehnung nur unter den gegebenen territorialen Ansprüchen und nur für die legitim Geborenen zu - sehr zum Ärger des estensischen Gesandten, der gegen diese »Standardbelehnung« mit dem Argument protestierte, dass sein Herr nicht irgendein einfacher Graf des Reiches sei, sondern ein Abkömmling eines der ältesten und renommiertesten italienischen Geschlechter, der sich mit der Investitur dem Reich und seinem Oberhaupt unterwarf. ${ }^{349}$

Dieses Problem des Investiturinhalts scheint nicht einmalig gewesen zu sein, da auch Ercole II. bei der Erneuerung anlässlich des Herrschaftsantritts von Kaiser Ferdinand I. in mehreren zum Teil chiffrierten Briefen den estensischen Gesandten im

346 Vgl. Dean, »Ercole I d'Este«; Rimondi, Estensi, 7 I - 78.

$347 \mathrm{Zu}$ dieser Gesandtschaft siehe bereits: TAddeI, Der Römische König Maximilian.

348 ASMo, ASE, Casa e Stato, Carteggio di Ambasciatori, Germania b I, Collenuccio an Ercole I., März I 494 .

$349 »[\ldots]$ che V. Signoria non era da esser trattato con bolle generale commo un simplice barone di Alemagna, ma che'l havesse respecto che V. Signoria era duca de Ferrara, e per vetustà e nobiltà de casa el primo Signor de Italia, e tra li principi imperiali d'Italia V. S. era el secundo, e per dignità e potentia è terzo principe con un bon stato oportuno, gagliardo e da valersene. [...] Considerato che V. Signoria de la condition predicta se viene ad inchinare a l'impero e desidera essere conosciuto per duca imperiale e sottomettersi a la protectione de Sua Maestà [...]«. Ebd., April I 494 . 
Reich, Graf Ippolito Turco, ${ }^{350}$ im November I 558 anhielt, zu überprüfen, ob die neue Belehnung wortgenau mit der alten sei. ${ }^{351}$

Sein Nachfolger, der I 560 neu investierte Alfonso II. bemerkte I 575 in einem Brief an seine Gesandten im Reich, Renato $\mathrm{Cato}^{352}$ und Paolo Carandini, dass die kaiserliche Investitur im Laufe der Zeit geschrumpft sei, sodass er nun in seinem Archiv nach Originaldokumenten suchen lasse, um eine Belehnung in der territorialen Ausdehnung zu Zeiten seiner Vorfahren zu beantragen. ${ }^{353}$ Hier war - neben einem gesunden Misstrauen in diesem ständigen Ausverhandlungsprozess der Lehenserneuerung - der Präzedenzstreit mit den Medici die Antriebsfeder für eine Vergrößerung des Lehens.

\subsubsection{Wie alles begann: "[...] Julio secondo ingordo e pronto«354}

Die oben beschriebenen Reibereien der Herzöge von Ferrara, Modena und Reggio im Zusammenhang mit der Investitur waren harmlos verglichen mit den Problemen, die Alfonso I. d'Este zu bewältigen hatte, als ihm zu Beginn des I6. Jahrhunderts Ferrara für einige Jahre und die kaiserlichen Lehen Modena und Reggio für fast 20 Jahre entzogen wurden.

Alfonso I. hatte I 508/9 an der Liga von Cambrai mit Frankreich und dem Papst gegen Venedig vor allem deshalb teilgenommen, weil er sich davon die Rückgabe des Gebietes von Polesine di Rovigo erhoffte, welches sein Vater bereits im Ansuchen um die Neubelehnung hinzugefügt hatte. ${ }^{355}$ Papst Julius II. ${ }^{356}$ wechselte aber vor der

350 Ippolito Turco/Turchi (? - I 57I), erster Graf von Crespino und Selva seit I 558 erster Graf von Aviano, Bürger von Ferrara, Mitglied des herzoglichen Geheimrates unter Alfonso II. und Gesandter im Reich sowie Statthalter von Modena. Vgl. Libro d'Oro della Nobiltà Mediterranea; online verfügbar: http:// www.genmarenostrum.com/pagine-lettere/letterat/Turchi.htm, Zugriff: i r.6.2020.

35 I ASMo, ASE, Casa e Stato, Carteggio di Ambasciatori, Germania b 20, Ercole II. an Ippolito Turco, November I 558. Auf der anderen Seite hatte sich auch Kaiser Ferdinand I. vorbehalten, erst in Augsburg und nachdem man über die Gebühren verhandelt und die alte Belehnungsurkunde eingesehen hatte, die neue Investitur/Mutung vollziehen zu wollen. Allerdings war dies dem venezianischen Gesandten nach das geringere Problem, hatte der ferraresische Gesandte aufgrund der schlechten Beziehungen zu Philipp II. Schwierigkeiten für die Gesamtbelehnung mit Modena, Reggio und Carpi erwartet. Turba, Venezianische Depeschen 3, Leonardo Mocenigo an den Dogen, [Wien], Oktober I 558 , Nr. 28,7 If, Anm. 3 .

352 Renato Cato (um I 5 I 9- I608), Doktor der beiden Rechte und Professor in Ferrara war ferraresischer Geheimsekretär, Sondergesandter in Rom I 560 und I 586, und I 570- I 575 Gesandter am Kaiserhof. Tiziano Ascari, »Cato, Renato«, in: DBI 22, Roma I979, online verfügbar: http://www.treccani.it/ enciclopedia/renato-cato_(Dizionario-Biografico)/, Zugriff: I6.9.2020.

353 ASMo, ASE, Casa e Stato, Carteggio di Ambasciatori, Germania b 31, Alfonso II. an Renato Cato/ Paolo Carandini, März I 575 .

354 El facto d'arme de Romagna: con la presa de Ravena, c. Ir, zit. n. Rospocher, Il papa guerriero, 226.

355 Vgl. Chiappini, Gli Estensi, 2 I $3-222$.

356 Giuliano della Rovere ( I $_{5} \mathrm{O}_{3}-\mathrm{I}_{5} \mathrm{I}_{3}$ ), genannt il terribile aufgrund seines jähzornigen Temperaments. Vgl. Alessandro PAstore, »Giulio II«, in: Enciclopedia dei Papi (2000), online verfügbar: http://www. 
Auseinandersetzung die Seiten und befahl seinem Lehensnehmer Alfonso I. den Krieg gegen Venedig und die Allianz mit den Franzosen zu beenden. Als sich dieser jedoch weigerte, folgten I 5 I o die Exkommunikation und die Belagerung Ferraras durch päpstliche Truppen, die dann bis I 5 I 2 auch Modena und Reggio einnahmen. ${ }^{357}$ Aufgrund des Ungehorsams des Este und gleichzeitig als Vorbedingung für ein kaiserlichpäpstliches Bündnis ${ }^{358}$ wurden ihm auch die beiden Reichslehen entzogen, die der Papst prompt seinem Herrschaftsgebiet einverleiben ließ. Mit dem Tod von Papst Julius II. ${ }^{359}$ I 5 I 3 kam zwar Ferrara wieder an die Este zurück, aber die Rückgabe Modenas und Reggios zog sich in die Länge, denn der nachfolgende Papst Leo X ${ }^{360}$ verfolgte die Idee eines neuen Fürstentums für seinen Neffen Giuliano de'Medici durch die Verbindung von Parma, Piacenza, Reggio, Modena und evtl. auch Ferrara. Dafür erwarb er Modena vom Kaiser für 40.000 Golddukaten. I 5 I 5 schlug er Alfonso I. d'Este vor, gegen die dem Kaiser bezahlten 40.000 zuzüglich weiterer I 4.000 Golddukaten Modena und Reggio zurückzukaufen; doch nachdem Alfonso, der aufgrund des Krieges und seiner Verbannung nur auf knappe Ressourcen zurückgreifen konnte, das Geld mühsam zusammengetragen hatte, zog der Papst das Angebot wieder zurück. ${ }^{361}$

treccani.it/enciclopedia/giulio-ii_(Enciclopedia-dei-Papi)/, Zugriff: I6.9.2020. In einer neueren Untersuchung, die sich vor allem der europaweiten, negativen wie auch positiven Wahrnehmung dieses Papstes widmet, definiert ihn Massimo Rospocher »cardinale-condottiero« (Kardinal-Condottiere), "politico consumato« (aufgeriebener Staatsmann), »uomo d'azione« (Tatenmensch), »impetuoso, collerico, dispotico e risoluto (ungestüm, cholerisch, despotisch und entschieden). Wenn auch andere Päpste vor und nach ihm ebenso eine gewaltreiche und militärisch geleitete Politik betrieben, so ist Julius II. sicher der Ausdruck des päpstlichen Kriegertums. Rospocher, Il papa guerriero, I 2, I 8.

357 Zuerst hatte die Exkommunikation den Allerchristlichsten König und dann seine Verbündeten und hier als ersten Alfonso I. erreicht, dem der Papst vorhielt, den väterlichen Ungehorsam gegenüber der apostolischen Autorität (Ercole I. gegen Papst Sixtus IV.) weiterzuführen. Rospocher, Il papa guerriero, I 37. Zum Krieg gegen Ferrara insgesamt und zu den in diesem Zusammenhang entstandenen satirischen, literarischen und bildlichen Werken, ebd. Kap. 7: Ferrara e il »mondan pastore«, 205-226.

358 Siehe das Schreiben von Matthäus Lang, Bischof von Gurk und Berater Maximilians I., an diesen aus Modena vom I3. Oktober I 5 I 2, HHStA Wien, Maximiliana-Akten, 28, fol.52, zit. n. Metzig, Kommunikation und Konfrontation, 206, Anm. 316.

359 Marin Sanudo kommentierte den Tod des Papstes ebenfalls mit Erleichterung für das von diesem gebeutelte Venedig: "Questo papa [...] è stà causa di la ruina d'Italia. [...] qual Dio volesse che fusse morto zà anni cinque, per ben de la cristianità e di questa repubblica e di la povera Italia [...]«(Dieser Papst [...] war die Ursache für den Ruin Italiens [...] hätte Gott doch gewollt, dass er schon fünf Jahre zuvor sterbe für das Wohl der Christenheit und dieser Republik und des armen Italiens). Stefani/ Berchet/Barozzi, I diarii di Marino Sanuto I5, i886, Nr. 314, 56 I.

360 Giovanni de'Medici (I5I3-I52I), zweiter Sohn von Lorenzo il Magnifico, ging als großer Mäzen und Kunstförderer, aber auch als jener Papst, der den Ablasshandel auf den Höhenpunkt brachte und Luther bannte, in die Geschichte ein. Vgl. Marco Pellegrini, "Leone X«, in: Enciclopedia dei Papi (200o), online verfügbar: http://www.treccani.it/enciclopedia/leone-x_(Enciclopedia-dei-Papi)/, Zugriff: 16.9.2020. Auch: PAstor, Geschichte der Päpste 4/I, Kap. ıо: „Leo X. im Bunde mit dem Kaiser Karl V. Niederlage der Franzosen und Vergrößerung des Kirchenstaates«, 303-340.

36r Vgl. Chiappini, Gli Estensi, 226-235; Milano, Casa d'Este, 65; Romolo Quazza, „Alfonso I«, in: 
In der Zwischenzeit versuchte der Este sein Lehensverhältnis zum Reich in die Waagschale zu werfen: Als die Venezianer seinen Transport von Holz und Stein über den Hafen von Magnavacca verhinderten, schrieb er im Juli I 5 I 8 an Kaiser Maximilian und bat ihn als seinen "vasallo«, der er eigentlich nicht mehr war, um Hilfe. ${ }^{362}$ Da keine Verbesserung der Situation in Sicht war, verbündete sich Alfonso mit Frankreich und befand sich bald in einer verschärften Zwicklage zwischen einer zu spärlichen französischen Hilfe und der Entscheidung des neuen Kaisers, Karls V., den Ambitionen des Papstes nachzugeben.

I 52 I nahmen die päpstlichen Truppen die Gebiete Garfagnana, Frignano, Modena, Cento, Pieve, Lugo und Bagnacavallo ein und der Herzog wurde von der Exkommunikation bzw. Ferrara vom Interdikt getroffen. Als Papst Leo X. am 2. Dezember I 52 I starb, ließ Alfonso aus Erleichterung und Freude darüber eine Münze prägen, die ein Lamm zeigte, das mithilfe eines Hirten »de manu leonis«, aus den Greifen eines Löwen befreit wurde, wie sich das gebeutelte Ferrara aus den Klauen der Kirche befreien konnte. ${ }^{363}$ Doch die Scharmützel zwischen den Este und dem Heiligen Stuhl gingen weiter: So beklagte und rechtfertigte sich Alfonso I. in einem Brief von I 52 I an Karl V., dass er sich deshalb immer mehr einer Frankreich unterstützenden Politik hingäbe, weil seine Person und sein Fürstentum ständig von den Päpsten bedroht wurden und zwar unter Einsatz von jenen Waffen, die die Kirche nicht gegen einen Christen, sondern nur gegen Ungläubige erheben sollte. ${ }^{364}$ In der Erwiderung aus Rom wurde betont, dass die Este sowohl die päpstlichen wie auch die kaiserlichen Lehen, also auch Modena und Reggio, unrechtmäßig und nur mit Gewalt eingenommen hätten. Außerdem hätte die Familie genug Unrechtmäßigkeiten angesammelt, um für alle Zeiten von der Macht enthoben zu werden wie z.B. die illegitime Nachfolge Nicolòs III., Leonellos und Borsos, die über Gebühr hohe Salzentnahme aus Comacchio, die tyrannische Herrschaft über das Volk. Das waren die Gründe, die Päpste wie Paul III. ${ }^{365}$ der Modena und Reggio an Parma und Piacenza als Pufferstaat angliedern

DBI 2 (I960) http://www.treccani.it/enciclopedia/alfonso-i-d-este-duca-di-ferrara_\%28DizionarioBiografico \% $29 /$, Zugriff: i6.9.2020.

362 ASMo, ASE, Casa e Stato, Carteggio di principi esteri, Germania, Minute di Lettere ducali a Principi e Signori fuori d'Italia b I63 I/r, Minute di lettere a Massimiliano I., Juli I 5 r 8.

363 Nach Quazza ließ Alfonso I. zum Todesfall eine weitere Münze prägen mit der Darstellung einer Magdalena und der Umschrift »Fides tua te salvam fecit« (Allein der Glaube rettete dich). Alfonso I. soll auch Tizian mit einem ähnlichen Bild beauftragt haben. Folin, Rinascimento estense, 336. Auch das Stundenbuch von Alfonso I. wurde von Matteo da Milano mit einer Darstellung des vor dem Tod fliehenden Papstes, der einen Geldsack greift, illuminiert. Rospocher, Il papa guerriero, 2 I $8 \mathrm{f}$ (mit Darstellung der Miniatur).

364 Dieses Rechtfertigungssschreiben ist ein dicker Faszikel in Carteggio di principi esteri, Germania, Minute di Lettere ducali a Principi e Signori fuori d'Italia, b I63 I/I, Alfonso I. an Karl V. ohne Datum.

365 Papst Paul III., (Alessandro Farnese, I 534-I 549). Vgl. Gino BenzonI, »Paolo III«, in: Enciclopedia dei Papi (2000), online verfügbar: http://www.treccani.it/enciclopedia/paolo-iii_(Enciclopedia-deiPapi)/, Zugriff: r6.9.2020. 
wollte, oder Gregor XIV., ${ }^{366}$ der eine eigene Kommission beauftragte, die Rechte des Heiligen Stuhls auf Ferrara zu überprüfen, zur Entmachtung der Este nutzten. ${ }^{367}$

In seiner aussichtlosen Lage versuchte Alfonso I. weniger mit militärischer Stärke als vielmehr mit diplomatischem Geschick seine Herrschaftsgebiete zurückzuholen. Er kam mit dem kaiserlichen Rat von Karl V., Girolamo Adorno, insgeheim überein, im Gegenzug zum freien Geleit der kaiserlichen Truppen durch das estensische Herzogtum und einer Verpflichtung, sich keiner anitkaiserlichen Liga anzuschließen, die Rückgabe der eingezogenen Gebiete einzuleiten, was unter dem neuen Medicipapst Clemens VII., ${ }^{368}$ der Modena und Reggio behalten wollte und dabei von Frankreich unterstützt wurde, nicht leicht zu bewerkstelligen schien. ${ }^{369}$

Inzwischen war der Kampf zwischen Karl V. und François I., König von Frankreich, um die Vorherrschaft in Italien erneut im Gange und das estensische Fürstentum hatte aufgrund seiner strategischen Lage eine große Bedeutung für beide Seiten, die beide Alfonso mit der Ehre des Oberbefehls für sich gewinnen wollten. Zusätzlich bot der Kaiser die Hand seiner Tochter Margarethe für den Nachfolger Ercole II. an, während Frankreich und seine Verbündeten mit Caterina de'Medici, Nichte von Papst Clemens VII. und Renée de Valois, Tochter des verstorbenen französischen Königs Louis XII., den Este auf ihre Seite lockten. Zunächst schlug sich Alfonso auf die Seite des Kaisers und bot Unterstützung und Verpflegung für die Truppen des Connetable de Bourbon und die Landsknechte von Georg von Frundsberg auf dem Weg nach Rom an; dafür sollte der Este mit Modena und Reggio wieder belehnt werden. Um Plünderungen zu verhindern, versorgte Alfonso die Soldaten mit Proviant und nahm Frundsberg, Opfer eines Schlaganfalles, sogar für längere Zeit im Palazzo ducale und dann im Palazzo Bentivoglio auf, wo Hof- und Leibärzte, wie Berengario da Carpi, ihn

366 Papst Gregor XIV. (Nicola Sfondrati, I590-I59I). Vgl. Agostino Borromeo, »Gregorio XIV«, in: Enciclopedia dei Papi (2000), online verfügbar: http://www.treccani.it/enciclopedia/gregorio-xiv_ (Enciclopedia-dei-Papi)/, Zugriff: 16.9.2020.

367 Folın, Gli Estensi, 4If. Noch I 530, während Karl V. darüber entscheiden musste, wer künftig über Modena und Reggio herrschen sollte, fand in Modena ein Gerichtsverfahren statt, das die Rechtmäßigkeit der Ansprüche Alfonso d'Estes auf der einen und des Papstes auf der anderen Seite prüfen sollte. In den betreffenden Archivunterlagen findet sich je eine Aufstellung der "Papeschi«, der Vertreter des Papstes, die Modena und Reggio als Teil der Emilia zum einstigen Exarchat und somit zum päpstlichen Territorium zählten; die »Ducheschi« als Vertreter des Este-Fürsten stellten dem die Aussage entgegen, dass die beiden Gebiete ursprünglich Teile der Lombardei und somit Reichsgebiete seien. ASMo, ASE, Casa e Stato, Controversie di Stato, Compromesso dinnanzi a Carlo V imperatore e lodo di quest'ultimo in merito alle controversie tra il Papa e il Duca di Ferrara per la restituzione di Modena e Reggio alla Casa d'Este, Processo compulsoriale davanti al Governatore Imperiale di Modena e al Podestà di Reggio I 530, b 500.

368 Giulio de'Medici, (I523-I 534), der große Widersacher von Kaiser Karl V. Vgl. Adriano Prosperi, „Clemente VII«, in: Enciclopedia dei Papi (2000), online verfügbar: http://www.treccani.it/enciclope $\mathrm{dia} /$ clemente-vii_(Enciclopedia-dei-Papi)/, Zugriff: r6.9.2020.

369 Frankreich rächte sich für die »Rückkehr« der Este in den Schoß des Heiligen Römischen Reiches, indem es den Papst stärker unterstützte. Chiappinı, Gli Estensi, 238f; QuAzZA, »Alfonso I«. 
behandelten. ${ }^{370}$ Von französischer Seite bedrängt, wechselte Alfonso aber schließlich wieder auf die Seite der Liga, wodurch er sich den Zorn des Kaisers zuzog. Seine neue Allianz mit Frankreich verstärkte er auch durch die Heiratsverbindung seines Sohnes Ercole mit der Königstochter Renée de France. ${ }^{371}$ Es war diese eine ebenso schlechte Entscheidung wie jene, während des Sacco di Roma I $527^{372}$ und der Bedrängnis des Papstes durch die Landsknechttruppen, Modena und Reggio zu besetzen. ${ }^{373}$ Der Kaiser ahndete seinen Verrat mit der Ankündigung im Friedensvertrag von Barcelona vom 29. Mai I 5 29, dass Modena und Reggio wieder unter päpstliche Herrschaft kommen sollten, da Alfonso durch seine Hinwendung zu Frankreich als treuebrüchig galt. ${ }^{374}$

Als nach dem Frieden von Cambrai im August I 529 François I. vorläufig auf den Kampf um Italien verzichtete, ließ er auch seine estensischen Verbündeten fallen. Dem Este blieb nichts Anderes übrig, als erneut eine Kehrtwende einzuleiten und sich dem Kaiser wieder unterwürfig zu zeigen. Als Karl V. I 530 zur Kaiserkrönung nach Italien kam, schickte Alfonso sogleich seine Gesandten, um ihm in Genua zu huldigen. Als das Reichsoberhaupt am 31. Oktober I 529 von Parma nach Reggio aufbrach, reiste ihm Alfonso I. entgegen. Er traf fünf Meilen vor der Stadt Reggio mit 600 Reitern auf den zu Krönenden, um ihm, im Schlamm kniend und mit dem Ausdruck höchster Demut, die Schlüssel von Modena und Reggio, den Hauptstädten der beiden, nicht mehr eindeutig estensischen kaiserlichen Lehen, darzubieten. In dieser Demutshaltung wandte er sich an das Reichoberhaupt mit folgenden Worten: Wenn der Kaiser behaupte, sein Vasall hätte Unrecht getan, so wolle sich dieser der kaiserlichen Gnade unterwerfen. Doch was die Auseinandersetzung mit dem Papst anbelangt, so bat der Herzog als untertänigster Diener den Kaiser, ihm Gerechtigkeit zuteilwerden zu lassen. ${ }^{375}$

Bei der vom Chronisten Luigi Gonzaga beschriebenen ersten Begegnung vor der Stadt Reggio, schien der Este allerdings keine schlechten Karten für eine Aussöhnung mit seinem Lehensherrn zu haben. Tatsächlich ließ der Kaiser ihn, der sich im Schlamm zu seinen Füßen geworfen hatte, erheben und umarmte ihn, während er ihm Hoffnung auf Gerechtigkeit im estensischen Kampf gegen den Papst gab und ihn dadurch ehrte, dass er ihn Vater nannte. ${ }^{376}$ Daraufhin soll - so der Chronist weiter -

370 Tatsächlich genas Frundsberg, blieb über ein Jahr als Gast in Ferrara bis er sich am I I. Mai I 528 auf dem Fluss Po einschiffte und die Heimreise nach Mindelheim antrat. Vgl. Rimond, Estensi, I I 2. Milano, Casa d'Este, 65-67.

37 I Dazu siehe unten.

372 Dazu siehe: Reinhardt, Blutiger Karneval.

373 Diesen Moment der Schwäche des Medici-Papstes nutzten auch Venedig und Florenz aus, erstere um Ravenna und Cervia zu besetzen, letztere um die Medici zu vertreiben. Vgl. Righi, Carlo V a Bologna, XV.

374 Rimondi, Estensi, Io3.

375 Entnommen und von der Autorin übersetzt aus der Chronik von Luigi Gonzaga bei: Romano, Cronaca del soggiorno.

376 Alfonso I. war I 476 geboren und fast doppelt so alt wie Karl. 
Alfonso erleichtert mit dem zu Krönenden über Verschiedenes geplaudert haben, bis sie Reggio erreichten, wo dem Kaiser ein prunkvoller Empfang bereitet wurde. Tags darauf begleitete der Este den Kaiser nach Modena, wo er ebenfalls feierlich empfangen wurde. Am 3. November geleitete ihn der Herzog schließlich noch bis zur Grenze seines Reichslehens auf dem Weg nach Bologna. Wieder kam es zum Austausch von Höflichkeiten und Zeichen der Unterwürfigkeit durch den Este und großzügiger Milde durch den Kaiser, der nicht zuließ, dass ihm sein Vasall die Hand küsste; stattdessen umarmte er ihn und bedankte sich für die ihm entgegengebrachte Ehre und die großzügige Gastfreundschaft. Und so kehrte Alfonso nach Ferrara zurück und wartete auf die vom Kaiser versprochene Mediation in den Differenzen zwischen ihm und dem Papst. Dieser, Clemens VII., für den Alfonso I. durch die Erlaubnis des Durchzugs der Landsknechte durch sein Gebiet am Sacco di Roma Mitschuld trug, zeigte sich zunächst unnachgiebig und verlangte die Räumung von Modena und Reggio und auch die Rückgabe des päpstlichen Lehens, da der Herzog durch sein Verhalten das Recht auf dieses verwirkt hätte. Der Papst ließ sich in keiner Weise umstimmen, den Herzog von Ferrara an den Krönungszeremonien teilnehmen zu lassen. Erst nach der Krönung erreichte der Kaiser das freie Geleit für Alfonso. Die Aussprache, die in Bologna nach der Krönung stattfand, brachte aber keine Früchte. Doch trotz der unbeugsamen Haltung des Papstes hatte der Autor der Chronik keine Zweifel, dass der Papst sich dem Kaiser beugen werde: «il Papa farà tutto quello vorrà l'Imperatore «. ${ }^{377}$

In dieser schwierigen Situation nahm sich der Kaiser der Sache als Schiedsrichter an und versprach, sie nach bestem Gewissen lösen zu wollen. Alfonso legte Modena und Reggio in die Hände des Kaisers, der innerhalb von sechs Monaten eine für alle annehmbare Entscheidung treffen sollte. Der Papst erinnerte das Reichsoberhaupt dabei an sein Versprechen im Rahmen des Friedens von Barcelona. So verblieben, reiste Kaiser Karl am 23. März von Bologna Richtung Mantua ab, wo es zu einer weiteren Begegnung mit Alfonso I. d'Este kam. Als nämlich der Hof des Gastgebers, Federico II. Gonzaga, zu einer Jagd aufbrechen wollte, trat Alfonso mit seinen Söhnen, Ercole und Ippolito, vor den Kaiser. Er hieß seine Sprösslinge die Hand des Reichsoberhauptes zu küssen und sprach: »Sacra M[aes]tà, sendo io servitore e fidelissimo di V.[ostra] M.][aestà] et havendomeli donato il con tutte le mie facultati, così anche acciò che non mi resti altro da donare, io dono a V.[ostra] M.][aestà] questi mei figlioli, quali voglio sempre siano fidelissimi schiavi et servitori di V.[ostra] M.[aes]tà.. «78 Der Kaiser - so der Chronist weiter - begegnete ihnen sehr wohlwollend und dankte dem Herzog für diesen Akt und Ausdruck der Treue.

377 Romano, Cronaca del soggiorno, 230.

378 "Als untertänigster Diener Eurer Majestät, der ich alles, was in meiner Macht war, bereits übergab, schenke ich Eurer Majestät als allerletztes diese meine Kinder, damit sie immer treueste Sklaven und Diener Ihrer Majestät blieben.« Romano, Cronaca del soggiorno, 256. 
Diese Bekundung von Frieden, Ergebenheit und Hommage in der Form des Kusses $^{379}$ und die zeremonielle Darbietung seiner eigenen Kinder brachten schließlich den erhofften Erfolg, denn in den in Köln am 2 r. Dezember I 530 veröffentlichten Bestimmungen teilte der Kaiser Modena und Reggio, entgegen den Versprechungen, die er dem Papst anfänglich gemacht hatte, als Reichslehen Alfonso zu, vorausgesetzt, dieser zahlte Ioo.00o Goldscudi an den Papst und erhöhte den Lehenszins von Ferrara auf 7.000 Dukaten. ${ }^{380}$

In der zitierten Chronik wie auch in anderen Quellen dieser Zeit, so z.B. in Gesandtenberichten, herrscht einhellige Meinung darüber, dass die Wiedereinsetzung der Este nie wirklich in Frage stand und die Verzögerung nur auf die Tatsache zurückzuführen war, dass der Papst vor allem hinsichtlich der langjährigen Auseinandersetzungen um Oberitalien nicht unnötig brüskiert werden durfte und vielleicht auch eine kleine Bestrafung für die mit Frankreich eingegangenen Bündnisse der Este war. Für die von vornherein geplante Wiedereinsetzung der kaiserlichen Vasallen - nicht zuletzt zur Eindämmung der päpstlichen Expansionslust - war aber dennoch eine aufwendige Farce, eine der Ehrerhaltung dienliche Inszenierung bestehend aus verschiedenen Aspekten symbolischer Kommunikation, aus Drohungen, Vermittlungen, Gesprächsangeboten, Bedenkzeiten und Hinhaltetaktiken notwendig. Auch die Darbietung der eigenen Söhne, der Stammhalter und designierten Nachfolger sollte ein Beweis der wiederhergestellten Treue und ein symbolisches Pfand für die Zukunft sein.

\subsubsection{Erneut Vasallen - erneut treulos}

Dank der Intervention von Kaiser Karl V. konnte der nachfolgende Ercole II. d'Este die Erneuerung der Belehnung für Ferrara durch Papst Paul III. ${ }^{381}$ erfolgreich abschließen. Dies war für die kommenden Jahrzehnte wohl der positivste Moment in der Beziehung zwischen dem Reichsoberhaupt und dem oberitalienischen Fürsten. Der Grund für die darauffolgende erneute Abkühlung der Beziehungen war vor allem die intensivere Hinwendung Ercoles II. nach Frankreich. Zwar stand der letztgeborene

379 Ма̨сZак, Ungleiche Freundschaft, 7 If.

380 Vgl. ausführlich die Dokumente im Bestand: ASMo, ASE, Casa e stato, Controversie di stato I.: Compromesso dinnanzi a Carlo V. imperatore e lodo di quest'ultimo in merito alle controversie tra il papa e il duca di Ferrara per la restituzione di Modena e Reggio alla Casa d'Este, buste 494-499.

38 I Papst Paul III. suchte in Ferrara für seinen zweiten Enkel Orazio Farnese eine Ehefrau und für sich Geldmittel. Eine Verbindung mit einer Este-Tochter wäre dem Papst mehr als willkommen gewesen, da das päpstliche Lehen Ferrara dadurch noch enger an den Heiligen Stuhl gebunden worden wäre. Sowohl die Anfrage um finanzielle Unterstützung als auch das Heiratsprojekt wurden von dem Este zwar in Aussicht gestellt, doch so lange hinausgezögert, bis der Tod des Papstes im Jahr I 549 den Herzog von Ferrara von seinen halben Versprechungen erlöste. Archivio Secreto Vaticano (ASV), Raccordi diversi della città di Ferrara, Cronaca Pio, Nr. I I4, I07. Vgl bereits: TAdDEI, Zwischen Katholizismus und Calvinismus, 238-240. Zu den Beziehungen des Papstes zum Kaiser und dem Tauziehen im Rahmen der Schaffung eines farnesischen Füstentums siehe: ToccI, Nel corridoio strategico-politico, 375-388. 
Sohn von Alfonso I. und Lucrezia Borgia, Francesco, ${ }^{382}$ im militärischen Dienst am Kaiserhof und gewann durch die Teilnahme an verschiedenen Feldzügen die Gunst des Kaisers, doch konnte er dadurch die ungleich stärkere estensische Präsenz am französischen Hof nicht wett machen. Ercole II. hatte nicht nur selbst eine französische Prinzessin, Renée de France (I 5 IO- I 575), ${ }^{383}$ Schwägerin des französischen Königs, geheiratet, er fädelte I 549 auch die Hochzeit seiner ältesten Tochter Anna d'Este mit dem Herzog von Guise, François de Lorraine, ein. Zudem stand auch sein frankophiler Bruder, Kardinal Ippolito d'Este, ${ }^{384}$ im Dienst des französischen Königs; schließlich - und das warf wohl auch in Ercoles Augen ein schlechtes Licht auf ihn als Vasall des Kaisers - floh sein ältester Sohn Alfonso (II.) nach Frankreich und trat in die Dienste des Erzfeindes des Kaisers ein. Demzufolge hatte der Este alle Hände voll zu tun, seine Reichstreue glaubhaft zu vermitteln. Er bemühte sich, dem Kaiser seine Empörung $^{385}$ über die Flucht seines Sohnes und seine Verzweiflung ob des Ungehorsams seiner Familienmitglieder mitzuteilen. ${ }^{386}$ Der Gang des ältesten Este-Sohnes nach Frankreich im Sommer I 552 wurde - mit der Bekräftigung der Ohnmacht des herzoglichen Vaters und von dessen Entsetzen darüber - als Jugendstreich abgetan. Dem Kaiser wurde brieflich das Bedauern ${ }^{387}$ über die »Flucht« mitgeteilt und der an-

382 Francesco d'Este, (1 5 I6- 1578) Bruder von Ercole II. stand seit ${ }_{5} 56$ im Dienst Kaiser Karls V. bis er sich I553, wie seine Verwandten, vom Kaiser entfernte und ab ${ }_{553}$ in die Dienste Frankreichs trat. Vgl. Luisa Bertoni, »Francesco d'Este«, in: DBI 43 (r 993), http://www.treccani.it/enciclopedia/ francesco-d-este_\%28Dizionario-Biografico \%29/, Zugriff : i 6.9.2020.

383 Vgl. TaddeI, Zwischen Katholizismus und Calvinismus.

384 Ippolito d'Este (I 509-I 572), Sohn von Alfonso I. und Lucrezia Borgia, verdankte dem französischen König François I. nicht nur etliche Pfründen in Frankreich, sondern auch die Unterstützung für das angestrebte Kardinalat. Vgl. Lucy Byatt, »Ippolito d'Este«, in: DBI 43, 367-374.

385 Siehe schon Frizzi, Memorie, 354f: "[...] Inoltre il giovane Alfonso vuole conoscere il mondo e se ne scappa con i suoi camerieri presso la corte di Francia dove viene ben accolto, decorato col Ordine di S. Michele, fatto Capitano di roo soldati con cospiqua pensione. Il Duca allora pien di rammarico non poté far altro che esporre alle finestre del Palazzo della Ragione la statua di Gio.[van] Tommaso Lavezzuolo appiccata per un piede, con cartello d'infamia, e prometter premio a chi vivo o morto glie lo consegnasse, per essere stato egl'il primo consigliatore di quella fuga. [...] Ció che nel Duca fe' maggiore il disgusto fu il timore che Carlo V. non giudicasse lui parziale del Re di Francia, delche anzi s'era sempre guardato di dar sospetto, che fosse de'suoi fratelli, della volontà de'quali non si credeva egli malevadore [...]«. Nach Alfonsos Flucht ließ Ercole in (gespielter) Erzürnung eine Statue von Alfonsos Freund und Begleiter, Kapitän Giovan Tommaso Lavezzolo, den er für den Initiator der Flucht hielt, in Auftrag geben und als Zeichen der Verurteilung kopfüber öffentlich anbringen. Andere Konsequenzen scheint der Zorn des estensischen Fürsten aber nicht gehabt zu haben, selbst als der junge Alfonso im militärischen Dienst für Frankreich und gegen den kaiserlichen Lehensherrn trat. Seine Mutter Renée de France drückte hingegen ihre Freude über die warmherzige Aufnahme Alfonsos am französischen Hof mit einer regelmäßigen finanziellen Unterstützung zur Bestreitung des kostspieligen Hoflebens aus ihren Privateinkünften aus. TAdDeI, Zwischen Katholizismus und Calvinismus, 266-270.

386 Druffel, Herzog Herkules, 330, 335.

387 Es ist der rhetorische Ausdruck von Emotionalität im Sinne eines performativen Schreibens, das - in diesem Fall - Mitleid und Verständnis evozieren soll. Vgl. FouQuet, Fürsten unter sich, I9I. 
gebliche Anstifter dieses Unternehmens, der Begleiter von Alfonso d'Este, in effigie gehängt. Clizia Magoni spricht zurecht von einer »commedia degli affetti«, von einer Inszenierung von französischer und ferraresischer Seite, von einer Farce, wenn man bedenkt, dass Alfonso schließlich zwei Jahre lang in Frankreich blieb, von Henri II. ${ }^{388}$ mit der Kollane des Ordens vom Heiligen Michael ausgezeichnet wurde und eine Truppe gegen Karl V. anführte. Ercole II. versuchte den möglicherweise Missgunst verursachenden Seitenwechsel seines Sohnes zu relativieren und instruierte seinen Gesandten Gregorio Rorario, die schlechte Meinung über Alfonso, dem nachgesagt wurde, dass er für die Nachfolge im estensischen Fürstentum ungeeignet sei, weil er im französischen Dienst stehe, zu widerlegen. ${ }^{389}$ Wie ernsthaft dieser "Jugendstreich « im Reich gewertet wurde, zeigt die Tatsache, dass sich Ferrante Gonzaga ( 507 - I 557), der nachgeborene Sohn von Francesco II. Gonzaga und Isabella d'Este, tatkräftiger Heeresanführer und Statthalter des Kaisers in Italien, ${ }^{390}$ ermächtigt fühlte, nach Alfonsos Weggang, einige nach Frankreich gerichtete Briefe des Herzog von Ferrara abzufangen und zu öffnen. Dies rief tiefe Empörung beim ferraresischen Gesandten hervor. Die venezianischen Diplomaten, stets über alles im Bilde, berichten über die Aufgebrachtheit des estensischen Vertreters: "L'ambassator del signor Duca di Ferara si ha doluto con questi signori ch'l signor Don Ferante habbia ritenuto un spazzo di lettere, che mandava al Re Christianissimo per causa della partita del principe, suo fiolo, et ha aperto le lettere, cosa che pare non si doveva far verso di un principe amico et confidente di Sua M[aes]tà Cesarea. « ${ }^{391}$

Es war aber schließlich nicht der angebliche Ungehorsam seines Sohnes, der den größten Riss im Beziehungsfaden zum Kaiser verursachte, sondern Ercoles Teilnahme an der Fürstenverschwörung ${ }^{392}$ gegen den Kaiser 1552 und sein Bündnis mit den aufständischen Fürsten und Henri II. von Frankreich. ${ }^{393}$ Auf Druck seines Schwiegersohns wurde der Herzog von Ferrara als Capitano generale del Papa und Luogotenente del re di Francia per la Lombardia an die Spitze der antikaiserlichen Liga gestellt, die er selbst mit 300.000 scudi unterstützte. ${ }^{394}$ Von einem Sieg der Liga erhoffte er sich die

388 Magoni, I gigli d'oro, 86-90.

389 ASMo, ASE, Casa e Stato, Carteggio di Ambasciatori, Germania b 1 8, Minute di dispacci per la Germania a Gregorio Rorario, ohne Datum, wahrscheinlich Frühjahr 1556.

390 Vgl. Giampiero Brunelli, »Gonzaga, Ferrante«, in: DBI 57, Roma 200 I, online-Version: http://www. treccani.it/enciclopedia/ferrante-gonzaga_(Dizionario-Biografico)/,Zugriff: I6.9.2020.

39I "Der Gesandte des Herzogs von Ferrara hat sich bei diesen Herren darüber beschwert, dass Don Ferrante einen Stapel Briefe abgefangen habe, die jener dem Rex Christianissimus bezüglich der Abreise seines Sohnes geschickt hatte und diese geöffnet habe, was man anscheinend gegenüber einem Fürsten, der dem Kaiser Freund und Vertrauter ist, nicht macht."Turba, Venezianische Depeschen 2, Marcantonio Damula und Domenico Moresini an den Dogen, Villach, Juli I 552, Nr. 2 I I, 527 f.

392 Vgl. dazu: Druffel, Herzog Herkules; Taddei, Moritz von Sachsen.

393 Henri II. von Frankreich (I 5 I 9 - I 55 9), zweiter Sohn von François I. und Claude, seit I 547 König von Frankreich, heiratete I 533 Caterina de'Medici. Vgl. BABEL, Heinrich II.

394 Vgl. Cittadella, Saggio di storia politica. 
in Aussicht gestellte Erweiterung seines Herzogtums sowie die mögliche »Befreiung« von seinem kaiserlichen Lehensverhältnis. ${ }^{395}$

Doch zu dieser "Befreiung" kam es nicht und als Widergutmachung für ihr treuloses Verhalten intensivierten die Este vor allem unter Alfonso II. ihre Beziehungen zum Reich. Die Treuebekundungen aus Ferrara häuften sich wieder und bekamen gerade unter Kaiser Maximilian II., zu dem ein inniges Freundschaftsverhältnis bestand, sogar einen Hauch von Aufrichtigkeit. Der "Zwischenfall« mit Frankreich und den verbündeten Reichsfürsten hatte also nicht sehr am Image des loyalen Reichsvasalls gekratzt, wenn Ercole II. I 559 kurz vor seinem Tod Kaiser Ferdinand I. mitteilte, dass er sich sehr wundere, dass Don Ferrante Gonzaga, mittlerweile Herr von Guastalla, in der Angelegenheit der Zolleinnahmen im Grenzgebiet des Fürstentums bei Brescello vom Kaiser so stark bevorzugt worden sei. ${ }^{396}$ Die kaiserlichen Bestimmungen seien sehr zu Ungunsten seines Staates, das Ercole vom Reich hatte ("quel nostro stato che riconosciamo dal Sacro Imperio«), und seiner Person ausgefallen. Dies enttäuschte ihn sehr, war er doch - wie er festhielt - von alters her ein Lehensmann des Reiches und untertänigster Diener seines Oberhauptes (»essendo pur noi antico feudatario di quello Imperio et devotissimo servitore della Maestà Sua«). ${ }^{397}$

Ercoles II. Nachfolger, Alfonso II. d'Este ${ }^{398}$ (reg. I 559- I 597), der bei seinem Herrschaftsantritt seinem Nachfolgerecht in den kaiserlichen und im päpstlichen Lehen die oben beschriebene inszenierte »Wahl« durch das Volk und eine »Beauftragung« durch den Stadtrat ${ }^{399}$ voranstellte, ${ }^{400}$ erbat trotz dieser Erweiterung des Zeremoniells dennoch im April I 56o durch seinen Gesandten am kaiserlichen Hof die Ausstellung der Investitur mit den üblichen Bekundungen von Treue und Lehenspflicht (»la solite e debita fedeltà«) und ließ mitteilen, in Treue und Ergebenheit keinem Vasall des

395 Siehe auch Lutz, Christianitas afflicta, 6of.

396 Die Verwunderung Ercoles II. ist unbegreiflich und eher rhetorisch zu verstehen, war doch der condottiere Ferrante Gonzaga einer der wichtigsten Handlanger der kaiserlichen Politik in Reichsitalien, selbst wenn es um die Eliminierung von Feinden des Kaisers ging. Siehe Bonora, Aspettando l'imperatore, $205 \mathrm{fzu}$ den »Expansionsplänen« des Gonzaga im Namen des Kaisers in Norditalien und 207-2 10 zur Ermordung bzw. Beteiligung am Mord von Lorenzino de’Medici, Pier Luigi Farnese, Giulio Cibo, Francesco Burlamacchi. Siehe auch: Podestà, Die Herzöge von Parma und Piacenza.

397 ASMo, ASE, Casa e Stato, Carteggio di Ambasciatori, Germania b 20, Minute di dispacci per la Germania an Ippolito Turco, Januar I 559 .

398 Romolo QuAzzA, »Alfonso II d’Este«, in: DBI 2, Roma 1960, http://www.treccani.it/enciclopedia/ alfonso-ii-d-este-duca-di-ferrara_\%28Dizionario-Biografico \%29/, Zugriff: I 6.9.2020.

399 Dass dieser seit der Übernahme der Herrschaft durch die Este praktisch inexsistent war, hat bereits Sitta gezeigt und Emich als Beleg für die Inszenierung der decadenza beim Übergang zur päpstlichen Herrschaft nach der Devolution, welche einen Stadtrat installierte, herangezogen. Vgl. SiтTA, Saggio sulle istituzioni und Емгсн, Bologneser libertà, г 23.

400 Diese Inszenierungen fanden zunächst in Ferrara unter Beteiligung der Gesandten Modenas und Reggios und daraufhin I 56r auch in Modena und Reggio mit ähnlichen Machtübergaberitualen statt. Vg1. BARBIERI, Entrata solenne, 328 
Reiches nachstehen zu wollen. ${ }^{401}$ Seine Beziehungen zu Kaiser und Reich intensivierten sich später durch seine Heiratsverbindung mit der habsburgischen Erzherzogin Barbara, von der er sich Unterstützung in der neu entfachten Causa der Präzedenz zwischen Ferrara und Florenz versprach. ${ }^{402}$ In diesem leidigen Streit um den Vorrang zwischen den Este und den Medici versuchte Alfonso II. vor allem mit dem Argument des guten Vasallen, als den er sich im Vergleich zu den schlechten Vasallen aus der Medici-Dynastie sah, zu punkten. Er entrüstete sich darüber, dass der Kaiser es zulasse, dass ihm seine Lehensmänner, gemeint waren die Medici, keinen Respekt entgegenbrächten und ihn nicht als Oberhaupt anerkennen würden: »[...] si ove la parte aversa fa tanta professione di non riconoscerla per soprana« [...] "per far che i vassalli suoi le portino la debita humiltà e riverenza«. ${ }^{403}$

Umgekehrt verwendete auch der Kaiser dieses Argument des guten Lehensmannes, wenn er sich im Mai I 575 beim Nuntius darüber beschwerte, dass einige Kardinäle die Herzöge von Mantua und von Ferrara mit Altezza und Serenissimo ansprechen würden, wozu kein Anlass bestünde, da diese Titel vom Kaiser nicht vergeben worden waren und noch dazu, weil der Herzog Alfonso mit Modena und Reggio eher ein Vasall des Reiches als des Papstes sei. ${ }^{404}$

40 I ASMo, ASE, Casa e Stato, Carteggio di Ambasciatori, Germania b 22, Minute di dispacci per la Germania an Fulvio Rangoni, April I 560. Am 22. Mai 1560 berichtete der venezianische Gesandte, dass Fulvio Rangoni für seinen Herrn belehnt worden war. Turba, Venezianische Depeschen 3, Giacomo Soranzo an den Dogen, [Wien], Mai I56o, mit Verweis auf die Depesche des 22. Mai, Nr. 68, I 47f, Anm. I.

402 Dazu siehe unten.

403 ASMo, ASE, Casa e Stato, Carteggio di Ambasciatori, Germania b 2 I, Dispacci ducali per Germania a Paolo Carandini, April I 575 .

404 Turba, Venezianische Depeschen 3, Vincenzo Tron an den Dogen, Wien, Mai I 575, Nr. 208, 552 - 554 , hier 554, Anm. I. 


\subsection{Ein Präzedenzstreit als weitere Nagelprobe}

Der Präzedenzstreit, der Kampf um den Vorrang an den europäischen Höfen, zwischen den Este und den Medici dauerte fast 50 Jahre lang und füllte Tausende von Korrespondenzseiten. Diese Auseinandersetzung war ein ständig vorgebrachtes Anliegen der Este und ein Gradmesser ihrer Beziehung zum Kaiser. Außerdem war sie Thema und Verhandlungspunkt in den Beziehungen zu den verschiedenen Reichsfürsten, die um Intervention zugunsten der Herzöge von Modena, Reggio und Ferrara beim Reichsoberhaupt und dem Reichstag als Entscheidungsorgane gebeten wurden. Mit dem Streit um den Vorrang hängen auch der Wettlauf um Titel und um den Thron von Polen sowie verschiedene Allianzbildungen zusammen. Aus diesen Gründen gilt der estensisch-mediceische Präzedenzstreit als eine Nagelprobe in der Beziehung zu Kaiser und Reich.

\subsubsection{Präzedenz als soziales Kapital - eine Definition}

Die Präzedenz, vom Lateinischen praecedere (= vorangehen und übertreffen), meinte in der Frühen Neuzeit vor dem Hintergrund der Vorstellung einer gottgewollten, hierarchisch gegliederten Gesellschaft, in der jedem ein fester Platz zukam, den Vorrang oder Vorzug einer Person oder Gruppe vor anderen und zwar besonders im Zusammenhang mit dem Zeremoniell, wo Symbole und Zeichen wie Kleidung und Sitzordnung eine bedeutende Rolle spielten. Doch da die ständische Gesellschaft wesentlich dynamischer als ihr Selbstbild war, konnte es trotz dieser unumstößlichen Ordnung leicht zu Auslegungsdifferenzen, zur Umkrempelung der Rangfolge und somit zu Präzedenzstreitigkeiten kommen. Reichs- und Fürstentage, der Hofalltag und die frühneuzeitliche Diplomatie boten dabei die meisten Angriffs- und Reibungsflächen. ${ }^{405}$

Der Rang und der Vorrang (Präzedenz) waren und sind zum Teil heute noch ein Ausdruck von Ehre, ${ }^{406}$ welche als ein »Grundwert $(\text { Paul Münch })^{407}$ und ein »Grundprinzip der ganzen Ständegesellschaft" (Richard van Dülmen) ${ }^{408}$ verstanden wird. Man unterscheidet zwischen innerer und äußerer Ehre. Sie unterliegt immer der Selbst- und Fremdwahrnehmung; sie ist ein soziales Regulativ, ein Kommunikations-

405 Thomas Weller, »Präzedenz«, in: Friedrich Jäger, Enzyklopädie der Neuzeit Io, Sp. 286f. Siehe auch: Levin, A New World Order. Stollberg-Rilinger, Die Wissenschaft der feinen Unterschiede. Weller, Theatrum Praecedentiae.

406 Dazu siehe: Spiess, Rangdenken. Schreiner/Schwerhoff, Verletzte Ehre. Burkhart, Eine Geschichte der Ehre. Bourdieu, Ehre.

407 Münch, Grundwerte, 7 If.

408 Dülmen, Der infame Mensch, ro8. 
mittel, ein »verhaltensleitender Code ${ }^{409}$ und sichert gesellschaftliche Wertschätzung und Positionierung sowie das richtige Verhalten im Umgang mit Anderen. Als Standesehre grenzt sie ihre Mitglieder von anderen gesellschaftlichen Gruppierungen ab. ${ }^{410}$ Besonders in Bezug auf die Adelsgesellschaft war Ehre nach Norbert Elias ${ }^{411}$ "existenzbegründend «, denn »er [der Einzelne, E.T.] gehört, unbeschadet seines Adelstitels, nur so lange faktisch zu der betreffenden sguten Gesellschaft‘, solange die anderen es meinen, nämlich ihn als zugehörig betrachten. « ${ }^{412}$ Ehre war und ist ein »symbolisches Kapital«, das auch knappe ökonomische Ressourcen wettmachen konnte. Allerdings wurde besonders in der frühneuzeitlichen Gesellschaft Ehre »auf dem >Markt nent getestet und ihr Wert neu bestimmt «. ${ }^{413}$

Wenn es also in der Folge »um die Stellung der beteiligten Personen auf dem >Achtungsmarkt « « ${ }^{414}$ einer Gesellschaft geht, so ist damit in unserem Zusammenhang zumeist der Hof des Kaisers, des Papstes, des französischen oder des spanischen Königs gemeint, dort wo sich »die Großen« bzw. ihre Vertreter trafen, wo es wichtig war, durch die - räumlich wahrnehmbare - Position die eigene Zugehörigkeit und Achtbarkeit immer wieder aufs Neue zur Schau zu stellen und zu bestätigen.

Nicht nur weltliche Fürsten mussten auf diesem »Achtungsmarkt « um ihre Position kämpfen: Auch Nuntien und Legaten waren verpflichtet und aufgefordert, auf eine angemessene Repräsentation, auf die Einhaltung des Zeremoniells und den Vorrang des Papstes zu achten. Es war also auch für die geistliche Universalmacht und gerade im Zuge der Glaubensspaltung »ein[] tägliche[r] symbolische[r] Machtkampf um die päpstlichen Ansprüche. «15

\subsubsection{Die Bedeutung von Rang und Ordnung im 16. Jahrhundert}

Die neuere und neueste Forschung hat sich bereits vielfach mit dem Thema der Rangordnung, ihrer strengen und komplizierten Reglementierung, ihrer Bedeutung und Symbolkraft für die mittelalterliche und neuzeitliche Gesellschaft auseinandergesetzt. ${ }^{416} \mathrm{Am}$

409 Schreiner/Schwerhoff, Verletzte Ehre, 9.

4io Schreiner/Schwerhoff, Verletzte Ehre, 3 -5.

4I I Der Soziologe und Kulturwissenschaftler Norbert Elias (I897-I990) entwickelte sein Zentraltheorem der "fortschreitenden Affektregulierung" als Grundlage des Zivilisationsprozesses. Vgl. Gruber, »Elias, Norbert«.

4I 2 Elias, Die höfische Gesellschaft, I45.

4I 3 Schreiner/Schwerhoff, Verletzte Ehre, it.

4 I4 Ebd., I3.

4I5 Reinhard, Historische Anthropologie, 62. Darüber hinaus betraf die Präzedenzfrage natürlich auch die geistlichen Fürstenhöfe. Als eines von vielen Beispielen sei hier nur Salzburg genannt: Ammerer, Präzedenz.

4I6 Bereits I 980 hielt Roosen fest: $[[\ldots]$ early modern diplomatic ceremonial is indeed worth taking seri- 
Beispiel der Stadt Leipzig konnte z.B. Thomas Weller eindrücklich aufzeigen, dass die sogenannte gesellschaftliche Ordnung in der Frühen Neuzeit nicht nur den Kaiserhof und die Fürstenhöfe betraf, sondern sich bis in die unteren Ränge der Gesellschaftshierarchie zog. Die Wahl von Leipzig ist nicht von ungefähr, arbeitete hier doch Anfang des I 8. Jahrhunderts jener Johann Christian Lünig als Stadtschreiber, der bis heute als einer der ersten Experten für Rang- und Zeremonialfragen gilt. Hier veröffentlichte er sein Werk Theatrum Ceremoniale historico-politicum oder historisch und politischer Schauplatz aller Ceremonien, Welche bey Päbst- und Kayser- und auch Königlichen Wablen [...] (Leipzig I 7 I9/20), eine zwei Bände und über 3.00o Seiten starke Sammlung von Zeremonialbeschreibungen und normativen Texten zur Festlegung von Rangordnungen bei verschiedenen Anlässen wie Krönungen, Fürstenhochzeiten, Begräbnissen und Einritten. Sein Material stammte einerseits aus seinem Rechtsstudium in Jena und Halle und andererseits aus seinen Erfahrungen im militärischen und adeligen Umfeld und spiegelt vorrangig das Zeremoniell der europäischen Fürstenhöfe und des Gesandtschaftswesens, auch wenn wie er es selbst erlebte - die Fragen nach Rang und Ordnung den Einzelnen auch außerhalb der Hofsphäre betreffen konnten. ${ }^{417}$ Im Ius Praecedentia wurde der Rang immer mehr zum Zeichen, zum Ausdruck einer Position, die nicht unbedingt den Tatsachen entsprechen musste. Es war diese »Differenz zwischen Sein und Schein«, der Versuch einer »symbolische[n] Inszenierung gesellschaftlicher Ordnung «, ${ }^{418}$ die zu den zahlreichen und endlosen Präzedenzstreitigkeiten führte. Weller beruft sich in seinen Thesen vorrangig auf die Theorien von Max Weber und Pierre Bourdieu, nach denen die Standesehre sich nicht nach objektiven Größen, sondern vielmehr nach Ausdrücken von Ehre und einer dementsprechenden Lebensführung, nach dem sogenannten symbolischen Kapital richtet. ${ }^{419}$ Denn die Position innerhalb einer sozialen Hierarchie konnte juristisch noch so gut fixiert sein, es galt sie durch ständige symbolische Inszenierung immer wieder zu bestätigen, zu bekräftigen und zu verteidigen, auch auf die Gefahr hin, durch die ostentative Demonstration von ökonomischem und sozialem Kapital, z.B. durch Kleider und den Wettlauf um Titel und Ämter, in den Ruin getrieben zu werden. ${ }^{420}$

Weller, der für die Untersuchung der Stadt Leipzig sein Augenmerk besonders auf die Kleiderverordnungen gelenkt hat, präzisiert, dass durch verschriftlichte Aufwands-, Luxus- oder Rangordnungen dem Einzelnen besonders bei symbolischen Handlungen, "genau die Menge an symbolischem Kapital zugemessen wurde, die ihm gleichsam `von Rechts wegen` zustand « und die er gegebenenfalls auch einklagen konnte. ${ }^{421}$

ously«; Roosen, Early Modern Diplomatic Ceremonial. Dazu siehe nur: Elıas, Die höfische Gesellschaft. Goetz, Der srechte Sitz.

4I7 Vgl. Weller, Theatrum Praecedentiae, 5-7.

4I 8 Ebd., 43.

4I 9 Vgl. Ebd., 43-47. Als Grundlage vgl. Weber, Wirtschaft und Gesellschaft, 534f. Bourdieu, Ökonomisches Kapital.

420 Weller, Theatrum Praecedentiae, 43 f.

42 I Weller, Theatrum Praecedentiae, 50. Nach Stollberg-Rilinger war die Praxis am Reichstag für das Ius 
Bevor in der Folge auf die Mittel eingegangen wird, mit denen die Este ihren Vorrang fast 50 Jahre lang einklagten, soll noch kurz ein Blick auf die Praxis gerichtet werden: Wie drückte sich der »Vorrang" tatsächlich aus?

In seiner Arbeit Der srechte Sitz fasst Goetz die Merkmale des Vorranges folgendermaßen zusammen: Sitzen war ein Privileg der Hoheit und stellte Macht dar, der Platz rechts neben oder gegenüber dem Ranghöchsten gebührte demjenigen, der in der gesellschaftlichen Ordnung Vorrang hatte. Die Streitfälle um den rechten Sitz waren spätestens seit dem Versuch, die Sitzordnung der Kurfürsten durch die Goldene Bulle I 356 zu regeln, ${ }^{422}$ zahlreich verbreitet. Dass Länder, Städte, Familien und Einzelpersonen keine Mühen und Kosten scheuten, Jahre bzw. Jahrzehnte lang Präzedenzkonflikte auszutragen, ergab sich aus Bedeutung des Vorrangs bzw. des rechten Sitzes: Ein nicht standesgemäßer Sitz drückte nämlich eine Herabwürdigung aus. ${ }^{423}$

Die Regelungen in der Goldenen Bulle (immerhin fast ein Drittel der 3 I Kapitel) weisen auf die erhebliche Notwendigkeit dieser ordnungsstiftenden Anweisungen hin, damit Kurfürsten und Fürsten auf Reichsversammlungen aller Art in keinen Präzedenzkonflikt gerieten. Dies erscheint umso bedeutender, als dass Matthias Schnettger den wiederholten Versuch der »Nivellierung der Unterschiede zwischen Kurfürsten und Reichsfürsten« aufgezeigt hat. Als nicht einmal mehr die Kurfürstenwürde für den Vorrang ausreichte, begann »der regelrechte >Run« auf die Königskrone«, der in Alfonsos II. d'Este Bewerbung um den polnischen Thron ein frühes Beispiel hatte. ${ }^{424}$

In der Goldenen Bulle sind zum Zwecke der Herstellung und Sicherung der kollektiven Handlungsfähigkeit - und nach Stollberg-Rilinger ${ }^{425}$ nicht »von den >eigentlichen verfassungsrechtlichen Formen zu trennen« - neben den Verfahren bei der Königswahl auch die zeremoniellen Vorgehensweisen bei allen anderen feierlichen Zusammenkünften von Kaiser und Kurfürsten festgelegt. Dazu gehört die Ordnung unter den Kurfürsten beim Sitzen, Gehen, in der Prozession und ihr Vorrang vor allen anderen Fürsten des Reiches bei der Wahl und der Krönung aber auch bei Gericht, Besprechungen, Belehnungen, an der Tafel etc. Die Öffentlichkeit der einzelnen Akte garantierte für ihre Verbindlichkeit, denn wer in der vorgegebenen Ordnung daran teilnahm, gab sein stillschweigendes Einverständnis mit dem Geschehen und den daraus resultierenden Folgen. Seine Missbilligung konnte man in ebenso ritueller Form durch demonstratives Fernbleiben oder durch Protest während des Aktes ausdrücken. ${ }^{426}$ Bei Streitigkeiten sollte der Herrscher oder der Vorsitzführende schlichten und einen Lösungsvorschlag

praecedentiae als reichspublizistische Spezialdisziplin seit dem I7. Jahrhundert der einzig handhabbare allgemein gültige Maßstab zur Festlegung der Ranghierarchie im Reich. Stollberg-Rilinger, Die Symbolik der Reichstage, 90.

422 Annas/Müller, Kaiser, I6.

423 Vgl. Goetz, Der >rechte< Sitz, 20-25, $32 \mathrm{f}$.

424 Schnettger, Rang, I 83.

425 Stollberg-Rilinger, Verfassungsakt oder Fest?, 97.

426 Stollberg-Rilinger, Verfassungsakt oder Fest?, 95 f. 
vorbringen, auf die Gefahr hin, den einen zu bevorzugen und den anderen zu brüskieren. So wundert es nicht, dass es oft zu Kompromissvorschlägen kam, die keine eindeutige Entscheidung zur Folge hatten, weil sie z.B. einen täglichen Wechsel des begehrten Sitzplatzes vorschlugen. Oft verzichtete man überhaupt auf den öffentlichen Auftritt, um Rangverletzungen zu vermeiden. Im Fall eines temporären Rangverzichts gab es das Non-Präjudiz-Mandat, womit klar festgelegt wurde, dass dieser Verzicht nur temporär war und keine dauerhaften Nachteile mit sich bringen würde. ${ }^{427}$

Neben der Thronbelehnung fiel dem Reichstag als förmlicher Akt eine besondere Bedeutung zu. Zwischen I 495 und 1653 fanden insgesamt 40 Tagungen statt, die meisten davon zwischen I 52 I und I 532 (zehn) sowie zwischen I 54 I und I 55 I (neun). Als Tagungsort dienten ab I 52 I die Reichsstädte Speyer, Worms, Nürnberg, Augsburg oder Regensburg, das schließlich auch den Immerwährenden Reichstag (von I663 bis I $80_{3}$ ) beherbergte. ${ }^{428}$ Die Hauptfunktion der Reichstage neben der Aufarbeitung von politischen Fragen war, »das >Reich` als handlungsfähiges politisches Ganzes« bestehend aus Kaiser und Ständen darzustellen und greifbar zu machen. Die dafür notwendigen eingesetzten symbolisch-zeremoniellen Mittel dienten dem politischen Handeln ebenso wie der Darstellung von Rang und Status, dem »Theatrum « und der Regulierung der Beziehungen zwischen den einzelnen Teilnehmern. ${ }^{429}$

Stollberg-Rilinger nennt den Reichstag zu Recht ein »theatrum praecedentiae«, das "zentrale[s] Forum symbolisch-zeremoniellen Handelns im Reich «. ${ }^{430}$ D.h. die einzelnen Handlungen in diesem Aktionsraum, nicht nur Schiedssprüche und Beschlüsse, sondern besonders der feierliche Einzug, die Eröffnungsmesse und das Festbankett waren formalisiert und normiert, nur durch Zeichen wahrnehmbar und spiegelten eine soziale Ordnung von größter Bedeutung. Die zeremonielle Ordnung und Rangordnung des Reichstages übertrug sich auch außerhalb dieses Ereignisses. Denn wer einmal am Reichstag oder an der päpstlichen Kurie nachweislich einen bevorzugten Platz eingenommen hatte, galt in Besitz desselben und verteidigte ihn vehement gegenüber anderen Anspruchhabenden. ${ }^{431}$

Die Kaiser, denen u.a. die Schlichtung der Streitigkeiten über den Vorrang oblag bzw. die deswegen angerufen wurden, gingen unterschiedlich vor: Karl V. und Fer-

427 Annas/Müller, Kaiser, Io6f.

428 Neben den Reichstagsakten selbst, gibt es auch eine weitere ausführliche schriftliche Quelle über den Reichstag, den »Traktat über den Reichstag«, der Ende der I $560 e r$ Jahre vom Mainzer Sekretär und interimistischen Kanzler Simon Bagen für den Mainzer Kanzler Christoph Faber verfasst und mehrfach kopiert wurde. Es ist eine genaue Beschreibung des Verfahrens und der einzelnen Abläufe, eine Art Instruktion oder Leitfaden für das Amt des Kanzlers. Aulinger, Die Reichstage, 3I 3-3I 7 .

429 Dabei handelt es sich bei diesen zeremoniellen Formen nicht um »bloßes Dekor der seigentlichen Politik«, sondern um Symbole und Rituale, die Teil der Politik und unabdingbar mit ihr verbunden waren. Stollberg-Rilinger, Zeremoniell, 83, 92. Diess, Die Symbolik der Reichstage, 77.

430 Ebd., 94 .

43 I Vgl. ebd., 96- Io6. 
dinand I. delegierten die Untersuchung von Präzedenzfällen meist an Kommissare, während Maximilian II. damit den Reichstag beauftragte. Das oberste Prinzip des Reichsoberhauptes, keine Partei zu verärgern, führte zumeist dazu, dass eine Entscheidung hinausgezögert oder gar nicht getroffen wurde. Auch den Reichshofrat als Schiedsrichter einzusetzen blieb meist erfolglos, ebenso konnte man nicht das Los entscheiden lassen. Und so ließ man die Parteien Beweise für ihren Vorrang vorbringen und dies allein zog den Streit in die Länge, wie der zwischen Aachen und Köln, der von der Mitte des I 5 . bis ins I 8. Jahrhundert reichte. Weder der Kaiser noch der Reichstag hatten genügend Autorität und Objektivität, um in Präzedenzstreitigkeiten zu entscheiden. Um den Vorrang vor einer anderen Partei zu erstreiten, wurden die verschiedensten und fantasievollsten Beweise angeführt: Das Alter des Fürsten, das Gewohnheitsrecht, die verwandtschaftliche Nähe zum Herrscherhaus, eine Kurwürde, das Alter des Fürstentums, die Dauer der Zugehörigkeit zum Fürstenrat, die machtpolitische Potenz des Territoriums, die Zugehörigkeit zu einem Erzbistum, eine Kardinalswürde, ja sogar das Engagement im Kampf gegen die sogenannten Ungläubigen. Ein weiteres Medium den Rang darzustellen und Distanzen und Unterschiede zu markieren, war die Sprache, so vor allem die genaue Anführung der Titel und die angemessene Anredeformen oder umgekehrt das Weglassen und damit Nicht-anerkennen-wollen von linguistischen Rangsymbolen. ${ }^{432}$

\subsubsection{Der Präzedenzstreit zwischen Florenz und Ferrara}

Der Präzedenzstreit, der das Leben und die Politik der Este und der Medici in der zweiten Hälfte des I6. Jahrhunderts bestimmte, der diplomatische Schwerstarbeit ${ }^{433}$ und zahlreiche politische Interventionen verlangte und so manches Scharmützel provozierte, begann in Lucca im September I 54 I, wohin sich Cosimo I. de'Medici ${ }^{434}$ und

432 Luttenberger, Pracht und Ehre, 293-299, 307f. Siehe auch: Aulinger, Das Bild des Reichstages.

433 Zum Präzedenzstreit mit den Medici gibt es im Staatsarchiv von Modena einen eigenen Bestand, in dem auch die im Zuge der Auseinandersetzung zum Beweis des Vorranges entstandenen Druckwerke, die Rechtsgutachten verschiedener Institutionen, kaiserliche Diplome und Privilegien etc. enthalten sind: ASMo, ASE, Casa e Stato, Controversie di Stato 2: Causa con Firenze per il diritto di precedenza, buste 500-508. Der Fall wurde bereits vielseitig, wenn nicht erschöpfend untersucht: CAPEI, Saggio di atti; Mondaini, La questione di precedenza. Ognibene, Le relazioni della Casa d'Este; Carteggio universale di Cosimo I dei medici Bd. I und II hg. v. A. Bellinazzi/C. Lamioni, Firenze 1982/1986, Bd. IV hg. v. V. Arrighi, Firenze 1990, Bd. V hg. v. C. Giamblanco/D. Toccafondi, Firenze I990. Bd. VIII und IX hg. v. M. Morviducci, Firenze 1990, I998; Del Piazzo, Il carteggio »MediciEste«.

434 Cosimo de'Medici war Sohn des condottiere Giovanni dalle Bande Nere und stammte somit aus der Seitenlinie der Medici-Familie. Mit der Heirat mit Eleonora von Toledo, Tochter des Vizekönigs von Neapel, und mit jener seines Sohnes Francesco mit Erzherzogin Johanna erreichte er die Anerkennung und Würde, die seine »Bankiersfamilie« noch benötigt hatte. Diese »Verbundenheit« mit dem Reich 
Ercole II. d'Este auf den Weg gemacht hatten, um Papst Paul III. und Kaiser Karl V. zu huldigen. Als Begleiter des Kaisers ritt Ercole zu dessen rechten und Cosimo zu dessen linken Seite. Beim anschließenden Bankett reichte der Este dem Kaiser die Serviette und wertete dies prompt als eindeutiges Zeichen für die Präzedenz seiner Person und seiner Familie vor dem Herzog von Florenz und dessen Vertreter für alle Anlässe und Zeremonien.

Bereits Paul Töbelmann hat in seinem Beitrag mit dem erheiternden und sehr plastischen Untertitel Wenn der Herzog dem Kaiser den Braten schneidet beispielreich gezeigt, wie schnell sich ein Recht bzw. ein Vorrang aus einer Einmaligkeit (Präzedenz im Sinne eines erstmaligen Ereignisses) ergeben konnte und wie umstritten der Anspruch auf einen Ehrdienst war. ${ }^{435}$ Das aus dem mittelalterlichen Zeremoniell herrührende Dienen der Kurfürsten und Fürsten, das unterwürfige Ritual des Bedienens bei Tisch, des Führens des kaiserlichen (ebenso des päpstlichen) Pferdes (Stratordienst) oder des Vorantragens der Insignien der Macht hatten die Funktion, die eigene Stellung in Bezug auf Kaiser und Reich zu demonstrieren. Der reklamierte Anspruch auf den einmal ausgeübten Dienst - verstanden als allgemein anerkannte Ehre und Partizipation an der Herrschaft - galt als Behauptung und Festigung dieser Stellung. ${ }^{436}$

Obwohl Adelige prinzipiell - mit Ausnahme der auszubildenden Edelknappen und der Hofdamen - keine dienenden Tätigkeiten im eigentlichen Sinn ausübten, findet man sie im Rahmen von Zeremoniell sehr wohl in ehrerbietenden Funktionen wieder, wie der die Serviette reichende Ercole II. d'Este beweist. Dabei handelte es sich nicht nur um Ehrerbietung im Zuge eines Lehensverhältnisses, sondern »um die Bestätigung seiner eigenen Rollenidentität und sozialen wie politischen Aktionssphäre « ${ }^{437}$

Diese Dienste wurden so verinnerlicht und zu einem Teil des Zeremoniells, dass ihre Verletzung zu Präzedenzfällen im doppelten Sinn wurde, also zu erstmalig auftretenden Auseinandersetzungen über das Vorrecht, die nach einer eindeutigen Lösung und Parteiergreifung von Seiten des Kaisers verlangten. Ein frühes Beispiel dafür ist jenes von Philipp von Schwaben, dem Herzog Bernhard von Sachsen I I99 das Schwert vorantrug. Um I 275 hatte sich die Verbindung von Schwertträgeramt mit dem Marschallamt so verfestigt, dass es zur Auseinandersetzung kam, als I 338 der Ritter von Kuck als Stellvertreter des Herzogs von Brabant am Hoftag von Koblenz das Schwert über Ludwig IV. hielt. Der Herzog von Sachsen legte zwar erst zwei Jahre später Einspruch ein, beharrte aber darauf, dass dieses Amt sein Recht sei. Der Kaiser wich einer Entscheidung gekonnt aus. Die Goldene Bulle schrieb das Amt des Schwertträgers dem Herzog von Sachsen als Reichserzmarschall zu. Dennoch kam es

zeigte er anlässlich der Vermählung von Francesco mit Johanna durch die Beauftragung einer Wandmalerei im Palazzo Vecchio mit Darstellungen österreichischer Städte. Schütz, Kunst und Mäzenatentum, $2 \mathrm{I}$.

435 Töвelmann, Dienst und Ehre.

436 Ebd., $562 \mathrm{f}$.

437 Ebd., $566 f$. 
am Hoftag zu Metz I356/7 erneut zu einer Auseinandersetzung zwischen Sachsen und Brabant. Auch Karl IV. fand keine eindeutige Lösung und ließ bei der Krönung seinen Sohn das Schwert tragen. Erst im I 5. Jahrhundert wurde die Auseinandersetzung eindeutig zugunsten des Sachsenherzogs geklärt.

Der I 54 I mit diesem Dienst an der kaiserlichen Tafel begonnene Präzedenzstreit zwischen den Este und den Medici wurde kurz darauf von Papst Paul III. verstärkt, als er bei den weihnachtlichen Gottesdiensten desselben Jahres in der päpstlichen Kapelle aufgrund seiner Divergenzen mit Cosimo dem estensischen Gesandten einen ehrwürdigeren Platz zuwies als dem Gesandten von Toskana, sodass dieser demonstrativ der Feier fern blieb. Die Proteste aus Florenz waren so vehement, dass der Papst schließlich beschloss, die alte Ordnung, die den Medici den Vorrang vor den Este gab, wiederherzustellen. Als Letztere dies nicht akzeptierten, wurden sie aufgefordert, Beweise für ihren Anspruch auf den Vorrang zu erbringen. Die Bevorzugung Cosimos hatte sicher auch mit der Zuwendung von I 50.000 Dukaten zu tun, die der Florentiner dem Papst hatte zukommen lassen. In einem venezianischen Gesandtenbericht vom April I 548 wird über den kaiserlichen Minister Granvelle der Kaiser bezüglich des Rangstreites wie folgt zitiert: "Was haben diese beiden Gesandten in der Kapelle zu thun, wo kaum Platz für alle Fürsten ist? Ich will nicht eines Tages mit diesen ihren Schwierigkeiten belästigt werden«, woraufhin, dem venezianischen Gesandten Mocenigo nach, ein Erscheinungsverbot für beide fürstlichen Vertreter ausgesprochen wurde. Daraufhin habe der Herzog von Ferrara mit dem Argument protestiert, dass sein Haus und Titel älter seien, worauf Granvelle erwidert hätte, dass Cosimo als Haupt der Republik über ein älteres politisches Gebilde aus Ämtern und Funktionen herrsche. ${ }^{438}$ Schließlich besaß Cosimo am Papsthof ${ }^{439}$ und am Kaiserhof seit dem Dekret vom 24. Dezember I 548, das Kaiser Ferdinand I. am 2 r.Oktober I 560 bestätigte, die Präzedenz. An allen anderen Höfen, die dem wachsenden Ansehen der Medici neidvoll gegenüberstanden, hatten die Este die Präzedenz, so auch am Hof des französischen Königs, mit dem die Este verschwägert waren und der die Spanien-treue Politik der Medici missbilligte.

Der Streit um den Vorrang kam vorerst zur Ruhe, als Cosimo in einer Auseinandersetzung der Este mit Philipp II. von Spanien, seinen territorialen Interessen folgend, als Vermittler zwischen den beiden Streitparteien fungierte. In den letzten

438 Turba, Venezianische Depeschen 2, Alvise Mocenigo und Lorenzo Contarini an den Dogen, Augsburg, April I548, Nr. I 70, 408-4I0, Anm. 2.

439 Die am Papsthof bereits Ende des 15. Jahrhunderts herausgebildete Rangordnung der Fürsten und ihrer Vertreter war zwar auch immer wieder Neuregelungen und Änderungen unterworfen, dennoch blieb das päpstliche Zeremoniell Richtschnur für alle anderen Höfe, sodass die Positionierung hier besonders wichtig war. Vgl. Visceglia, La città rituale. Schilling, Konfessionalisierung und Staatsinteresse, I60-I67. Am Florentiner Beispiel hat auch Christian Wieland, wenn auch für eine spätere Zeit, einleuchtend dargestellt, wie einerseits das Regelwerk des Zeremoniells das Verhältnis von Mitgliedern einer Gesellschaft zueinander und zum Papsthof ordnete und andererseits Papst und Kaiser dieses beugen und flexibel gestalten konnten. Wieland, Fürsten, 3 I 5 . 
Regierungsjahren Ercoles II. war es durch die sich auf der italienischen Halbinsel ausbreitende spanische Vorherrschaft I557 zu einer kriegerischen Auseinandersetzung gekommen. Das mit ihm verbündete Frankreich benötigte die Truppen im eigenen Land, der Papst versöhnte sich mit Philipp II. und Ercole musste den spanischen Groll über sich ergehen lassen. Auf Philipps Befehl sollte der Herzog von Parma, Ottavio Farnese, mit mediceischer Unterstützung in die estensischen Staaten einfallen. Allein die Knappheit der Truppen, die Spanien für Italien entbehren konnte, und Frankreichs erneuter Angriff, waren der Grund dafür, dass Ercoles Sohn Alfonso und sein Heer die besetzten Gebiete an der Grenze zu Mailand wieder befreien konnten. Den darauf folgenden Frieden von Pisa im März I 558 besiegelte das Heiratsversprechen zwischen Alfonso II. und Lucrezia, der Tochter von Cosimo de'Medici, das auch vorerst den Streit um den Vorrang beendete. ${ }^{440}$ Doch nach dem frühen Tod der MediciBraut im April I 562 stand keine verwandtschaftliche Bindung der Weiterführung der Auseinandersetzung um die Präzedenz im Weg. ${ }^{441}$

Bereits I56 I hatte Cosimo durch seinen Gesandten die Serenissima gebeten, den Medici den Vorrang vor den Este gewähren zu wollen. Doch die Republik befand mit Dekret vom 3. Juni I 56I, dass dem estensischen Gesandten die Präzedenz vor dem mediceischen zustand. Nach diesem Erfolg wandte sich Alfonso II. durch den Sondergesandten Girolamo Falletti ${ }^{442}$ an Kaiser Ferdinand I. mit der Bitte, auch am Kaiserhof die Präzedenz revidieren zu wollen. Zunächst schien Falletti erfolgreich gewesen zu sein, denn mithilfe der Gesandten von Polen, Sachsen und Bayern sowie der Erzherzöge Karl und Ferdinand und etlicher Minister und Hofleute, die dementsprechende Geschenke erhalten hatten, erließ der Kaiser am I 3. Februar I 562 ein Dekret, das alle vorangegangenen Bestimmungen zu Ungunsten der Este aufhob. Er bestimmte auch, dass die Causa des Vorrangs zwischen den Medici und den Este genau geprüft werde und bis zu einem eindeutigen Schiedsspruch durch den Reichstag die Kontrahenten und ihre Vertreter allen offiziellen Anlässen des Kaiserhofs fernbleiben sollten. ${ }^{443}$ In

440 LAzZARi, Le ultime tre duchesse, 29-3 I.

44 I Zu ihrer kurzen Präsenz in Ferrara siehe Ricci, Prigioniera dei simboli, 2 I 9.

442 Ge[i]rolamo Falletti (auch Hieronomus Faletti) (wahrscheinlich I 5 I 8 - I 564 ) entstammte einer Adelsfamilie aus dem Montferrat. Ab I 544 war er in Ferrara als Lehrer tätig; I 554 wurde er residierender Gesandter des Herzogs von Ferrara, der ihm die finanziellen Mittel bereitstellte, um den Doktorgrad in den Rechtswissenschaften zu erlangen. Bereits I 546 reiste er im Dienst von Francesco d'Este ins Reich und verfasste einen Bericht über die Ereignisse um den Krieg gegen die Schmalkaldener (»Prima parte della guerra di Alamagna«, Venezia I 552). Daraufhin war er Gesandter der Este in Rom, Venedig und im Reich. Sein Hauptwerk sollte eine unvollendet gebliebene Geschichte der estensischen Dynastie werden, die Alfonso ihm im Zuge der Präzedenzstreitigkeiten mit Florenz in Auftrag gab. Vgl. Franco Pignatti, »Falletti, Gerolamo«, in DBI 44 (i 994), online verfügbar unter: http://www. treccani.it/enciclopedia/gerolamo-falletti_(Dizionario-Biografico)/, Zugriff: I6.9.2020.

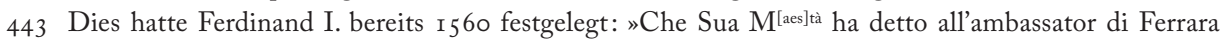
che non vadi ad accompagnarla, fino non habbia deciso la difficultà di precedentia del suo Duca con quello di Fiorenza/Und dass Seine Majestät dem Gesandten von Ferrara gesagt hat, er solle ihn nicht 
zwei Briefen von Ferdinand I. an Alfonso II. vom Januar und Oktober ${ }_{5} 62$ teilte der Kaiser mit, dass er durch die estensischen Schreiben und durch seinen Gesandten von der Kontroverse mit Florenz wegen der Präzedenz erfahren habe, es aber weder Akten noch Dokumente gäbe, die den Streit klären könnten. Außerdem sei es wichtig, in dieser Causa mit »prudentia« und »diligentia» vorzugehen. ${ }^{444}$ Ferdinand I. zog sich dann aus der Affäre, indem er die Causa 1561/2 vor den Reichstag brachte, was Alfonso II. stark befürwortete, weil er sich dadurch größere Erfolgschancen ausrechnete und wofür er dem Kaiser immer wieder über seine Gesandten danken ließ. ${ }^{445}$ Cosimo hingegen befürchtete einen negativen Ausgang, da Kaiser und Reich wegen seiner Besetzung von Pitigliano (in der Toskana, heute in der Provinz Grosseto) verärgert waren. Er wandte sich deshalb an Papst Pius IV. ${ }^{446}$ und stachelte diesen (nur) Namensvetter an, dem kaiserlichen Vorschlag entgegenzuwirken. Der Papst sollte als einziger Schiedsrichter fungieren; als solcher beauftragte er zehn Kardinäle mit der Prüfung der Präzedenzfrage ohne Anhörung des estensischen oder des kaiserlichen Vertreters. ${ }^{447}$

Währenddessen wurde der seit November I $55^{8}$ als estensischer Gesandter am Kaiserhof tätige Graf Ippolito Turco kontinuierlich, auch durch teilweise chiffrierte Schreiben von seinem Dienstherrn bezügliche der Präzedenzfrage instruiert. Ferdinand I. sollte vom Diplomaten an den durch das Zeremoniell in Lucca (das Reichen der Serviette) entstandenen Vorrang der Este und an Karls V. diesbezügliche Handhabung erinnert werden. ${ }^{448}$ Mit Jahresbeginn I 559 wurde Turco angeleitet den Kaiser immer wieder zu befragen, wie er den Präzedenzstreit zu lösen gedenke, ihn auch bei der Messe, bei Banketten und auf der Jagd zur Lösung der Präzedenzfrage zu drängen und ihn daran zu erinnern, dass - so die Gerüchte aus Venedig - die Medici eigentlich nie investiert worden wären, während die Este alteingesessene Vasallen des Reiches seien. Weiter sollte er Unterstützung bei den anderen Gesandten suchen und da der

begleiten bis er den Präzedenzstreit seines Herzog mit jenem von Florenz geklärt habe.« Turba, Venezianische Depeschen 3, Giacomo Soranzo an den Dogen, [Wien], Mai I 560, Nr. 65, I43-I45, hier 145 . Wiederholt wurde diese Vorgangsweise, allerdings mit dem Hinweis auf die Prüfung und Entscheidung durch den Reichstag im venezianischen Gesandtenbericht vom I6. Februar I 562. Ebd., Giovanni Micheli an den Dogen, [Prag], Februar I 562 , Nr. I00, 202f, hier 203.

444 ASMo, ASE, Casa e Stato, Carteggio di principi esteri, Germania b I575/I, Kaiser Ferdinand I. an Alfonso II., Januar und Oktober 1562.

445 ASMo, ASE, Casa e Stato, Minute di lettere ducali a Principi e Signori fuori d'Italia, Minute di lettere a Ferdinando I imperatore b I632/2, Dezember 156r und Minute di lettere all'imperatore Rodolfo II b I $635 / 5$, Juni 1584 .

446 Papst Pius IV. (Giovanni Angelo Medici 1559- I560) aus Mailand, nicht mit den Medici verwandt, aber dennoch eng mit ihnen verbunden. Vgl. Flavio Rurale, »Pio IV «, in: Enciclopedia dei Papi (2000), online verfügbar: http://www.treccani.it/enciclopedia/pio-iv_(Enciclopedia-dei-Papi)/, Zugriff: i6.9. 2020.

447 SAnti, La precedenza, $38-43$.

448 ASMo, ASE, Casa e Stato, Carteggio di Ambasciatori, Germania, Dispacci ducali/Minute di dispacci per la Germania an Ippolito Turco Cart. Rest., November 1558 und Januar 1559. 
Herzog von Savoyen I 559 wieder einmal nicht am Reichstag teilnehmen würde, sich an andere Fürsten halten. Dabei sollte er herausfinden, in wessen Gunst z.B. der Herzog von Mecklenburg stehe, und ob dieser eventuell als Fürsprecher der Este beim Kaiser in Frage käme. ${ }^{449}$ Die Vertreter der Este im Reich sollten also gezielt nach Unterstützern und Befürwortern suchen. Im November I 56 I erreichte August von Sachsen eine lange Abhandlung des ferraresischen Gesandten Girolamo Falletti über den Präzedenzstreit, ${ }^{450}$ ausgeschmückt mit vielen genealogischen und historischen Erklärungen und Vergleichen aus dem Reich, die den Vorrang der Este unterstrichen. Dabei spielte der Gesandte in seiner Bitte um Fürsprache beim Kaiser auf die Verbundenheit der Häuser Este und Sachsen an sowie auf die Erinnerung an die Beziehungen zu Kurfürst Moritz. Zu Beginn des darauffolgenden Jahres wandte sich Alfonso II. persönlich an August von Sachsen mit der Bitte um Unterstützung beim Kaiser. ${ }^{451}$

Im März I 562 erhielt Alfonso II. ein gedrucktes Büchlein ohne Erscheinungsort und ohne Angabe eines Autors mit dem Titel Ragioni di Precedenza, in dem dargelegt wurde, warum den Medici der Vorrang gebührte. Um diese als Verleumdungsschrift gegen das Haus Este gewertete Publikation zu entkräften, beauftragte Alfonso seinen Sekretär mit der Verfassung einer Gegenschrift, die eine Woche später ebenso anonym in Druck ging. Gleichzeitig wandte er sich mit einem Brief an den Kaiser und beschwerte sich über die Tatsache, dass die kaiserliche Bestimmung nicht befolgt worden sei. Grund für den erhöhten Handlungsbedarf sah der Herzog von Ferrara und Modena auch darin, dass sein neuer Gesandter am Kaiserhof, Sigismondo Descalzi, berichtete, dass bei den kaiserlichen Audienzen der Gesandte von Florenz immer zuerst zugelassen wurde; Alfonso II. übersandte ihm einen Brief für den Kaiser, in dem er in tiefster Ergebenheit und Treue mitteilte, dass er sich nicht mit Florenz streiten wolle, was aber unvermeidlich sein werde, wenn der Kaiser nicht endlich in der Causa tätig werde. ${ }^{452}$ Zur Bestätigung seiner Würde und in der Überzeugung, den Streit um den Vorrang mit der Hilfe von anderen Akteuren für sich entscheiden zu können, reiste Alfonso II. im April ${ }_{5} 62$ mit großem Pomp nach Venedig und wurde vom Dogen mit für einen italienischen Fürsten nie dagewesenen Ehren empfangen. ${ }^{453}$ Gleichzei-

449 Ebd., Januar bis Mai 1559.

450 Noch zwanzig Jahre später wurde Otto von Braunschweig-Lüneburg gebeten, die von Falletti zusammengestellte Genealogie der Häuser Sachsen, Braunschweig-Lüneburg und Este zu überprüfen, um die gemeinsame Abstammung richtig darstellen zu können. Herzog Otto ließ in seinem Schreiben Bezug nehmend auf Fallettis Arbeit Korrekturen in den Verwandtschaftsverhältnissen einiger Vorfahren anbringen und nach Ferrara schicken. Celle, HStAH Br. 7 I Nr. 62 I mit zwei Stammbäumen.

45 I Dresden, SächHSTA, Geheimer Rat (Geheimes Archiv) Loc 85 ro/3, Girolamo Falletti an August von Sachsen, ohne Datum, nach 156 r. In den $1560 e r$ Jahren intensivierten sich allgemein die Beziehungen zwischen Sachsen und Italien wieder. MAN F REDini, Identità storica, 236.

452 ASMo, ASE, Casa e Stato, Carteggio di Ambasciatori, Germania b 22, von Sigismondo Descalzi, Januar 1562 .

453 Lazzari, Le ultime tre duchesse, $88 \mathrm{f}$. 
tig bat er August von Sachsen erneut um sein patrocinium, um seine Unterstützung in der Präzedenzsache gegen Florenz beim Kaiser und eventuell auch beim König von Spanien. ${ }^{454}$

Im November I 563 erhielt der estensische Gesandte am Kaiserhof, Graf Ippolito Turco, die Instruktion, den Kaiser, dem er die Treue des estensischen Vasallen bekunden sollte, erneut aufzufordern, im Reichstag nach einer endgültigen Lösung zu suchen. ${ }^{455}$ Darüber hinaus sollte der Gesandte mitteilen, dass sich Alfonso über die angedachte Heiratsverbindung mit dem Kaiserhaus freue und er sich im Zuge dieser Verbindung mit einer Erzherzogin aus dem Hause Habsburg die Erhebung seiner Reichslehen zu einem Erzherzogtum erhoffe. Diesen Wunsch, der ihm einen eindeutigen Vorrang gebracht hätte, begründete er mit dem ehrwürdigen Alter seiner Dynastie und mit seiner territorialen Machtstellung: Er habe drei Herzogtümer in Italien (Ferrara, Modena und Reggio) und eines in Frankreich (die Erbschaft seiner Mutter Renée de France, die allerdings seiner Schwester Anna zufallen sollte). Allein damit wäre der Präzedenzstreit geklärt, wenn er nicht im Reichstag gelöst werden könne; seine Herzogtümer seien älter und edler als die anderer Fürsten des Reichs und Italiens. ${ }^{456}$ Außerdem wünschte er die Söhne des Kaisers, die nach Italien kommen wollten, zu empfangen, wie es sich für einen treuen Diener und Vasall gehöre; in diesem Zusammenhang wollte er die Präzedenzfrage auch mit ihnen erörtern und dadurch auch die kaiserliche familia in sein Befürwortungsnetzwerk einbinden. ${ }^{457}$

Im Dezember ${ }_{5} 6_{3}$ befahl Alfonso II. dem Gesandten Turco, die bis dahin ins Leere gelaufene Anfrage nach einer Erhebung zum Erzherzogtum weiter zu forcieren. Nachdem er vernommen hatte, dass ihm die ältere Kaisertochter Barbara und nicht die jüngere Johanna zugesprochen werden sollte, hielt er den Gesandten an, dennoch weiter für die Jüngere zu werben und nachdrücklich zu betonen, dass der Herzog von Ferrara bei der Wahl der Kaisertöchter als erster bedacht werden sollte und ihm eine zugeteilt werden müsse, die sicher Nachkommen hervorbringen könne. ${ }^{458}$

Zu Beginn des Jahres I 564 sollte Graf Ippolito Turco herausfinden, wie der Papst zur Präzedenzfrage stand und im Juni den Gerüchten über die Unpässlichkeit von Erzherzogin Barbara nachgehen. ${ }^{459}$ Auch wenn die Ältere zu heiraten nicht seinen

454 ASMo, ASE, Casa e Stato, Minute di lettere ducali a Principi e signori fuori d'Italia b I603/29, an August von Sachsen, Januar 1562. Zu den Beziehungen zwischen August von Sachsen und Philipp II. siehe Edelmayer, Söldner und Pensionäre, 21 5 - 224.

455 ASMo, ASE, Casa e Stato, Carteggio di Ambasciatori, Germania b 24, an Ippolito Turco, November I 563 .

456 Ebd. an Ippolito Turco, November 1563.

457 Allerdings sollte sein Gesundheitszustand es nicht erlauben, die Söhne des Kaisers in Mantua tatsächlich zu treffen und zu empfangen. Ebd.

458 Ebd., Dezember I 563.

459 Der Gesandte des Kontrahenten vermerkte, dass der Vertreter des Herzogs von Ferrara keine ernst gemeinten Verhandlungen um Barbara führe, entweder weil sie ihm zu hässlich erscheine oder weil er 
Vorstellungen entspreche, sollte der Gesandte dem Kaiser seinen Dank aussprechen, ungeachtet ob er Barbara oder Johanna zur Ehefrau erhalte, denn wichtig sei nur, dass sein Haus nicht aussterbe. ${ }^{460}$ Allerdings sollte Ippolito Turco den Kaiser erinnern, dass durch die Vergabe des Titels eines Erzherzogs infolge der Einheiratung in die habsburgische Dynastie das Problem der Präzedenzfrage geklärt werden würde. ${ }^{461}$ Im Juni desselben Jahres drückte er seinem Vertreter am Kaiserhof erneut seine Bedenken wegen Barbaras Indisposition und seine Befürchtungen über das Aussterben seiner Linie aus. ${ }^{462}$ Der Gesandte sollte unbedingt genügend Informationen über die Braut einholen und gegebenenfalls nochmals um Johanna werben; außerdem sollte er den Vorschlag eines estensischen Erzherzogtums weiter unterbreiten. ${ }^{463}$ Neben der Würde und Treue des angehenden Bräutigams sollte auch auf sein reiches Vermögen in Frankreich von über eineinhalb Millionen in Gold hingewiesen werden. ${ }^{464}$ Die Gesandtenkorrespondenz liest sich wie ein Dauerbeschuss des Kaisers mit Argumenten und Vorschlägen zur baldigen und eindeutigen Lösung des Präzedenzstreites.

Im Januar ${ }_{5} 6_{5}$ ließ Alfonso nach der Ratifizierung des Ehevertrages mit Erzherzogin Barbara über den Gesandten Sigismondo Morano dem Kaiser für dessen Heiratseinwilligung und der Kaiserin, sowie Kardinal Antoine Perrenot de Granvella, dem engsten Vertrauten des Kaisers, dem er häufig geschrieben hatte, und schließlich den Erzherzögen Ferdinand und Ernst für die Vermittlung und Unterstützung bei diesem Heiratsprojekt danken. Bezüglich der Präzedenzfrage sollte der Gesandte am Kaiserhof erwähnen, dass der Bischof von Ferrara, Rossetto, mittlerweile zum Kardinal erhoben worden war und auch diese Auszeichnung das Haus Este und das Herzogtum anderen voranstelle. ${ }^{465}$ Zur besseren Argumentation ließ er Morano eine Zusammenfassung des Präzedenzfalles schicken. ${ }^{466}$ Außerdem sollte dieser dem Kaiser die Meinung des französischen Königs, dass Ferrara Florenz vorangestellt werden sollte,

Widersprüchliches über ihre Gesundheit wisse oder weil er es übel nehme, dass der Fürst von Florenz die Jüngere und Schönere erhalte: »a pigliar la principessa Barbara, o perché li paia troppo brutta, o perché sia informato contra quello che vorebbe de la sua sanità, o perché troppo resti di mala voglia, vedendo che al S.[igno]r principe di Firenza habbia da tocchare la più giovane et la più bella«. STEINHERZ, Nuntiaturberichte II/4, Nr. 6, 22f, Delfino an Borromeo, Znaim, I 564 Februar 8.

460 Ebd., Nr. 38, I 54, Delfino an Borromeo, Wien, ${ }_{5} 64$ Juli I $3_{3}$ : "L'imbasciatore di Ferrara risoluto, che al duca suo sia per tochare la principessa Barbara insta per esser risoluto quanto al tempo, et allega chel suo principe non habbi anni per aspettare « (der Gesandte von Ferrara hat eingelenkt, dass seinem Herzog Barbara zugeteilt werde, aber er ist nicht einverstanden über die Zeit, die verstreicht und hält fest, dass sein Fürst nicht Jahre warten könne).

46r ASMo, ASE, Casa e Stato, Carteggio di Ambasciatori, Germania b 24, an Ippolito Turco, Juni I 564.

462 Dazu vgl. Antenhofer/Taddei, Fürstliche Körper.

463 Ebd., an Ippolito Turco, Juni 1564.

464 Ebd., Juli 1564.

465 ASMo, ASE, Casa e Stato, Carteggio di Ambasciatori, Germania b 25, Istruzione per Germania an Sigismondo Morano, Januar 1565 .

466 Ebd. 
mitteilen. Er sollte Maximilian II. bitten, endlich auch Position zu beziehen, zumal Florenz den Papst auf seine Seite ziehe. Sowohl er als auch der Herzog von Florenz hätten den Reichstag und viele Reichsfürsten in dieser Causa bereits bemüht. ${ }^{467} \mathrm{Im}$ Mai ${ }_{5} 65$ wurde der Gesandte Descalzi wieder an den Kaiserhof geschickt, um mit dem Kaiser den Präzedenzstreit mit Florenz zu erörtern und weitere Vorschläge zur Lösung desselben vorzulegen. ${ }^{468}$ Die Beharrlichkeit, mit der die Causa vorgetragen und besprochen wurde, nahm mit der Einheiratung der beiden Prätendenten in den habsburgischen Familienkörper noch weiter zu.

Als 566 Michele Ghisleri als Papst Pius V. ${ }^{469}$ auf dem Stuhl Petri kam, schien er sogleich den Este besonders gewogen zu sein. Besonders vielversprechend stellte sich die päpstliche Entscheidung dar, den Präzedenzstreit dem Kaiser nicht als Reichsoberhaupt, sondern als Schiedsrichter und gleichzeitig Schwager der beiden Kontrahenten zuzuspielen, damit dieser innerhalb eines Jahres eine Entscheidung herbeiführe. Bei Verstreichen der Frist wollte der Papst wieder die Entscheidungsfindung übernehmen. Der Kaiser nahm diese Aufgabe zwar an, zögerte aber den Beschluss trotz vehementen Einsatzes der estensischen Gesandten am Kaiserhof, Alessandro Fiaschi ${ }^{470}$ und Sigismondo Descalzi, ${ }^{471}$ aus taktischen Überlegungen immer wieder hinaus. So meinten die beiden Gesandten, dass die Entscheidungsfindung schließlich beim Geheimrat und Reichsvizekanzler Weber ${ }^{472}$ liegen würde und dieser wohl auf seine schöne Frau hören würde, sodass man ihr eine Aufmerksamkeit im Wert von roo scudi zukommen lassen sollte. Das Geschenk brachte jedoch keine Früchte. ${ }^{473}$ Behielt

467 Ebd.

468 ASMo, ASE, Casa e Stato, Minute di lettere ducali a Principi e signori fuori d'Italia, an Kaiser Maximilian II., Mai 1565 .

$469 \mathrm{Zu}$ diesem siehe auch: Schwaiger, Die Päpste, $82-88$.

470 Alessandro Fiaschi war Cavaliere, im Dienst dreier Este-Fürsten (Alfonso I., Ercole II. und Alfonso II.) am Hof von Ferrara und als Gesandter im Reich und in Venedig tätig. Unter Ercole II. war er Kämmerer und »commissario generale« in Reggio. Vgl. Maresti, Teatro genealogico, i68f.

47I Sigismondo Descalzi (auch Discalzi) von einer Adelsfamilie aus dem paduanischen Raum abstammend war ein Rechtsgelehrter und Professor in Ferrara. Auch stand er Alfonso II. als Diplomat am Kaiserhof zu Diensten. Vgl. UGHI, Dizionario storico, I 5 I.

472 Dr. Johann Baptist Weber war I 563 - I 570 Hofkanzler und zugleich Reichsvizekanzler sowie Mitglied des Geheimen Rates. Vgl. Fellner/Kretschmayr, Die österreichische Zentralverwaltung, Anhang: Verzeichnis der Inhaber der obersten Hofwürden und der Vorstände der Zentralbehörden I 526 - I 749 , 281, 283. Edel, Johann Baptist Weber (I $526-1584$ ).

473 Santi, La precedenza, 57-59. Wie üblich Zuwendungen und auch hohe Geldgeschenke für Räte und Sekretäre für die Weiterleitung von Informationen waren, hat Edelmayer für die kaiserlichen Gesandten in Spanien bereits dargestellt. I 572 erhielt auch der oben genannte Vizekanzler Dr. Weber 2.00o Escudos als Gratifikation; bereits ab I 566 erhielt er jährlich über den spanischen Botschafter am Kaiserhof eine Pension von 500 Talern für die Vertretung der Interessen Königs Philipp II. am Kaiserhof. Edelmayer, Habsburgische Gesandte, 65 f und Edelmayer, Söldner und Pensionäre, 7 I - 73. Schnettger hat bereits auf den Einfluss und den Handlungsspielraum von Kaiserinnen am Beispiel der beiden Eleonora Gonzaga als »Spitze des Eisbergs« aufgezeigt und auf die Forschungslücken bezüg- 
die kaiserliche Kanzlei unter Maximilian II. weiterhin ihren Ruf als schwerfälliges und entscheidungsschwaches Organ bei, so war dies tatsächlich auf den bereits unter Ferdinand I. tätigen Vizekanzler Johann Baptist Weber, ein Günstling am Kaiserhof, ${ }^{474}$ zurückzuführen, der vertrauliche Informationen und Absprachen nur mündlich führen wollte, was die Entscheidungsfindung natürlich stark verlangsamte. Darüber hinaus war Weber ein habgieriger Funktionär: Von Cosimos Zuwendung von 2.00o Dukaten für ihn und seine Familie animiert, unterstützte Weber schlussendlich die Anerkennung der päpstlichen Erhebung der Medici zu Großherzögen. Die kaiserliche Entscheidung wurde schließlich durch einen Kredit der Medici über 200.000 Dukaten für den Türkenkrieg zu ihren Gunsten gefällt. ${ }^{475}$

Zuvor aber, im Herbst I 567 , beauftrage der beharrliche Herzog von Ferrara, Modena und Reggio seine beiden Gesandten im Reich, Sigismondo Descalzi und Alessandro Fiaschi, die leidige Frage wieder aufzunehmen. Als treuer Vasall eines alten Hauses, das schon vielen Kaisern gedient hatte, bat Alfonso II. um ein Dekret zur endgültigen Fixierung des Vorrangs. ${ }^{476}$ Im September I 567 antwortete der Reichsvizekanzler, dass die estensischen Kredenzbriefe über den Fürstbischof Madruzzo und den Gesandten Descalzi eingelangt seien, doch die Präzedenz allein aufgrund dieser Schreiben nicht gewährt werden könne. ${ }^{477}$

Gegen Jahresende I567 bahnten sich die ersten Gerüchte über eine Standeserhebung der Medici durch den Papst an. Als Alfonso erfuhr, dass der Papst dem Kaiser ein Schreiben gesendet hatte, setzte er beide Gesandten darauf an, den Inhalt zu erkunden und instruierte sie gleichzeitig für eine Lösung der Präzedenzfrage zu seinen Gunsten auch auf die Hilfe von dem Kaiser nahestehenden Personen, besonders der Minister, zurückzugreifen. ${ }^{478}$ Im März I 568 nutzte der Este auch den Einfluss seiner Ehefrau und ließ Erzherzogin Barbara, nunmehr Herzogin von Ferrara, dem Kaiser bezüglich der Präzedenzcausa schreiben. Die Gesandten sollten indes das Reichsoberhaupt weiterhin an seine früheren Versprechungen erinnern. ${ }^{479}$ Bereits ${ }_{5} 65$ hatte der venezianische Gesandte Alvise Contarini bei seiner Rückkehr von den Hochzeitsfeierlichkeiten in Ferrara vor dem Senat über die Folgen der Heiratsverbindungen von

lich der hierarchisch niederen Akteurinnen am Hof hingewiesen. Die zitierte Bemerkung bezüglich der Ehefrau des Geheimrates Weber und ihren Einfluss beim Gatten weist genau auf diese einflussreichen Frauen außerhalb von Regierungsinstitutionen hin. Schnettger, Zwei Ehen und ihre Folgen. Siehe auch: Keller, Frauen - Hof - Diplomatie; ferner Nolde, Was ist Diplomatie.

474 Noflatscher, Regiment aus der Kammer?, 2 I $8 \mathrm{f}$.

475 Vgl. Sutter Fichtner, Emperor Maximilian II, 65, 88, i 26.

476 ASMo, ASE, Casa e Stato, Carteggio di Ambasciatori, Germania b 26, Dispacci ducali per la Germania an Sigismondo Descalzi und Alessandro Fiaschi, September 1567.

477 ASMo, ASE, Casa e Stato, Carteggio di principi esteri, Germania b I 576/2, der Vizekanzler des Reiches an Alfonso II., September 1567.

478 ASMo, ASE, Casa e Stato, Carteggio di Ambasciatori, Germania b 26, Dispacci ducali per la Germania an Sigismondo Descalzi und Alessandro Fiaschi, Dezember I 567 und März I 568.

479 Ebd., März I568. 
Alfonso II. d'Este und Francesco de Medici mit den beiden Erzherzoginnen gewarnt. Durch diese Verschwägerungen der beiden um die Präzedenz wetteifernden Fürsten würde deren Streit internationale Maße annehmen und nicht beigelegt, sondern nur intensiviert werden, womit der Gesandte Recht behalten sollte. ${ }^{480}$

Mitte des Jahres I 568 berichteten Descalzi und Fiaschi, der Kaiser sei weiterhin nicht zu einem eindeutigen Schritt zu bewegen und verstecke sich hinter Ausflüchten. Alfonso ließ ausrichten, dass der Vorwand Maximilians II. nicht gelten könne, dass sich Florenz an eine wie auch immer lautende Bestimmung gar nicht halten müsse, da es augenscheinlich von Rom abhängig sei. Der Kaiser solle das Versprechen eines Dekrets einlösen. ${ }^{481} \mathrm{Im}$ Oktober I 568 hatte er aber trotz der Überredungsbemühungen beider Parteien immer noch keine Entscheidung getroffen und antwortete den drängenden Gesandten, dass der Präzedenzstreit eine zu bedeutende Auseinandersetzung sei, als dass man leichtfertig darüber entscheiden könne. In der Zwischenzeit hatten sich die Beziehungen zwischen dem estensischen Hof und dem Heiligen Stuhl wegen des Streits um die Salinen von Comacchio deutlich verschlechtert. Außerdem warf Pius V. Alfonso II. d'Este vor, seiner Aufgabe als Fürst nicht nachzukommen und mit zu wenig Nachdruck die Juden ${ }^{482}$ und »Ketzer« aus seinem Herzogtum zu verfolgen und zu vertreiben. Darüber hinaus wurde dem Herzog von Ferrara vorgeworfen, mit dem protestantischen Herzog von Sachsen im Bündnis zu stehen. So kam es, dass sich der anfangs den Este wohlgesonnene Papst immer mehr auf die Seite der Medici schlug und für diese beim Kaiser Partei ergriff. Cosimo erleichterte ihm diese Fürsprache auch dadurch, dass er vehement den Kampf gegen die Gegner der Kirche, die Hugenotten in Frankreich und die Türken im Osten, propagierte und finanziell unterstützte. $\mathrm{Ob}$ das »Endprodukt « der Politik von Pius V., die Bulle de non alienandis von I 567, auch ein Hieb gegen die Este war - wie Santi behauptet - oder ganz allgemein der Rückführung von kirchlichen Lehen in den Kirchenstaat dienen sollte, sei dahingestellt.

Ab Januar I 569 versuchte Alfonso II. d'Este den Druck zu erhöhen und ließ seinen Gesandten Fiaschi berichten, was in Frankreich aufgrund der zögerlichen Vorgangsweise im Reich geschehen sei: Dort wo der französische König nicht interveniert habe, habe man - aus Angst die Rangordnung zu verletzten und aufgrund der Unentschlossenheit des Kaisers - weder den estensischen noch den florentinischen Gesandten vorgelassen. Der Gesandte sollte mit einer gesunden Portion Dramatik das Reichs-

\footnotetext{
480 Spagnoletti, Matrimoni, ioo.

48 I ASMo, ASE, Casa e Stato, Carteggio di Ambasciatori, Germania b 26, Dispacci ducali per la Germania an Sigismondo Descalzi und Alessandro Fiaschi, Juli I 568.

482 Tatsächlich ist die (teilweise forcierte) Einbindung der Juden in die estensische Wirtschaftspolitik belegbar. Von 1566 ist in der Sammlung Bartolomeo Gamba auch ein von Alfonso II. ausgestellter Passierschein für den aus Ferrara stammenden Juden Abram Catalano enthalten. Siehe das Autograf in der online gestellten Sammlung Emlo (Early Modern Letters online) der Universtät Oxford bezüglich der Bartolomeo Gamba collection unter: emlo.bodleian.ox.ac.uk/, Zugriff: 25.6.2020.
} 
oberhaupt überzeugen, dass der Herzog von Ferrara gezwungen sei, seinen residierenden Gesandten in Frankreich abzuziehen, was wiederum zu einer Verschlechterung der Verhältnisse mit dem rex christianissimus führen werde. Es sei nicht gerecht, dass er das Nachsehen habe, weil er sich in dieser Causa pflichtbewusst an das Reich gewandt hatte. ${ }^{483}$

I 569 nutzte schließlich auch der Papst die Unentschlossenheit des Kaisers und verlieh Cosimo de’Medici und seinen Erben am 24. August den Titel eines Großherzogs von Toskana. ${ }^{484}$ Alfonso II. fügte seinem obligaten Gratulationsschreiben an die Medici sogleich hinzu, dass er den neu verliehenen Titel nicht benutzen könne, solange nicht der Kaiser und der König von Spanien zur Erhebung Stellung genommen hätten. Gleichzeitig schickte er Camillo Gualengo ${ }^{485}$ zu Philipp II. und seinen Onkel Don Alfonso mit einer reichen Dokumentation zu Maximilian II., um gegen diese ungeheuerliche Anmaßung zu protestieren. ${ }^{486}$ Die Entsendung eines Blutsverwandten bezeugt die Dringlichkeit und die Verzweiflung, die nach dem Erhebungsakt durch den Papst entstanden waren. Zudem forcierte er die Drucklegung von Pignas erstem Band der Geschichte der Este, um auch damit den Kaiser zu bewegen, den Papst zur Rücknahme der Erhebung aufzufordern, bis der Reichstag, die in seinen Augen einzige kompetente Instanz, einen Beschluss bezüglich der Präzedenz gefasst hätte. Mit der Historiografie versuchte er zu beweisen, dass die Toskana kaiserliches Lehen sei und die Medici, die nicht den Kaiser, sondern den Papst um ihre Erhebung gebeten hatten, demnach Verräter waren. Brieflich und durch seine Gesandten versuchte er Cosimo und die Medici beim Kaiser, den Kurfürsten und den Reichsfürsten zu diskreditieren und diese in einem letzten Endspurt mit Geschenken und Zuwendungen noch für sich zu gewinnen. Der Kaiser nahm den Protest auf und leitete ihn durch Graf Prospero d'Arco, welcher eine die Reichsrechte verteidigende, aber nicht unbedingt die Este übermäßig unterstützende Haltung einnahm, an den Papst weiter. ${ }^{487}$ Vorerst forderte der Kaiser alle italienischen Fürsten auf, den missbräuchlich vergebenen Titel eines Großherzogs in der Kommunikation mit den Medici nicht zu benutzen. In der Präzedenzfrage sollten die beiden Kontrahenten innerhalb von drei Monaten persönlich

483 Ebd., Januar 1569 .

484 Vgl. zur Erhebung und zur Opposition des Kaisers Pastor, Geschichte der Päpste 8, 477-489.

485 Camillo Gualengo (auch Gualenghi) (um I 530- r6o2) Sohn des herzoglichen Seneschalls, trat zuerst in die Dienste des für die geistliche Laufbahn vorgesehenen Fürstensohnes Luigi d'Este und wurde dann vermehrt als Gesandter eingesetzt. Unter Alfonso II. war er vor allem in Spanien am Hof von Philipp II. für die Este tätig, aber vereinzelt auch im Reich und in Italien. Er wurde mit dem spanischen Orden des Heiligen Jakob ausgezeichnet. Mittlerweile zu einem bedeutenden Mitglied des estensischen Hofes avanciert, wurde er 1582 herzoglicher Rat. Laura Turchi, „Gualengo, Camillo«, in: DBI 6o, Roma 2003, online verfügbar: http://www.treccani.it/enciclopedia/camillo-gualengo_(Di zionario-Biografico)/, Zugriff: I6.9.2020.

486 ASMo, ASE, Casa e Stato, Carteggio di Ambasciatori, Germania b 27, Istruzione per la Germania an Don Alfonso d'Este, Januar 1570.

487 Vgl. Rill, Prosper Graf von Arco, 76 -80. 
oder mithilfe von Vertretern vor dem Reichsgerichtshof erscheinen und die eigenen Argumente vortragen. Dies schürte erneut die Hoffnung auf eine endgültige Lösung zu seinen Gunsten beim Herzog von Ferrara, der dieser Aufforderung sogleich nachkam, während Cosimo um mehr Zeit bat und die Dinge in die Länge zog. ${ }^{488}$

In der Zwischenzeit arbeitete die juristische und literarische Propagandamaschinerie der Este auf Hochtouren, um den Beweis des Vorrangs aufgrund des Alters und der Ehrwürdigkeit des Hauses d'Este zu erbringen. Bereits unter seinem Vater, Ercole II., hatte die Abfassung historisierender Abhandlungen zur Darstellung und Huldigung der Altehrwürdigkeit des Hauses Este ihren Anfang genommen. Gasparo Sardi hatte ein Werk über die Etablierung der Este in Ferrara verfasst und Giovan Battista Giraldi Cinzio hatte auf Basis der Notizen von Lelio Gregorio Giraldi das Werk De Ferrariae et atesinis Principibus Commentiolum hervorgebracht, mit dem Ziel zu beweisen, dass das Haus Este aufgrund seines Alters, seiner Tugend, seines Edelmutes und Glanzes über allen anderen Fürstenhäuser Italiens stehe. Unter Alfonso II. wurde Girolamo Falletti mit der Weiterführung und Intensivierung dieser dynastischen Huldigungsschriften beauftragt, wofür sich Alfonso II. mit einer Nobilitierung zum Grafen, einer Belehnung sowie der Steuereinnahmen von Massa Fiscaglia erkenntlich zeigte. Alfonso drängte Falletti zur Erarbeitung einer Dynastiegeschichte und eines Stammbaumes, woraus auf einem Blick ersichtlich werden sollte, wie alt und ehrwürdig die Este waren. Nach Fallettis Tod I 564 sollte Gian Battista Pigna, ${ }^{489}$ der mit der Archivrecherche beauftragte Sekretär, das Verherrlichungswerk für die Este weiterführen. Diese Darstellungen konnten auf eine bedeutende Vorarbeit zurückgreifen: Bereits in der zweiten Hälfte des I 5. Jahrhunderts war von anonymer Hand ein zweiteiliger Codex entstanden, der später die - nicht ursprüngliche - Titulierung $G e-$ nealogia dei Principi d'Este trug, wovon ein Teil in der Biblioteca Estense Universitaria di Modena und der andere in der Biblioteca Nazionale Centrale di Roma aufbewahrt ist. ${ }^{490}$ Zusammengelegt stellt der Codex eine Ahnengalerie der Este vom Stammvater Alberto Azzo II. bis zu Isabella d'Este-Gonzaga, Tochter von Ercole I. und zukünftige Markgräfin von Mantua, dar. Jede Seite hat Platz für neun Porträts in gleich vielen Medaillons (insgesamt I 67 Porträts), zu denen in Kurzform biografische, meist sachliche und nicht huldigende Anmerkungen angeführt sind. In dieser Genealogie werden alle Kinder, auch die illegitimen mit einem ${ }^{\mathrm{N}}$ « verzeichnet, angeführt. ${ }^{491}$

488 Vgl. Santi, La precedenza, 6o-66.

489 Giovan Battista Nicolucci (genannt il Pigna) (I 529-I575) war als Sekretär und Literat im Dienst Alfonso II. d'Este und stach durch seinen Kommentar zum Orlando Furioso des Ariosto sowie durch eigene literarische Werke, darunter Il Principe hervor. Siehe Salvatore Ritrovato, „Nicolucci, Giovan Battista«, in: DBI 78, Roma 2013, online verfügbar unter: http://www.treccani.it/enciclopedia/giovanbattista-nicolucci_\%28Dizionario_Biografico \%29/, Zugriff: I6.9.2020.

490 Vgl. Milano, Genealogia, 95. Corradini, Genealogia.

49I Interessant ist, dass Obizzo II. nicht das »N« der Illegitimen trägt, wahrscheinlich, weil sein Großvater Azzo VII. von Papst Innozenz IV. und vom Kaiser die Legitimation für ihn erhielt. Milano, Genealo- 
Wie gesagt, war das schlagende Argument der Herzöge von Ferrara und Modena das Alter ihrer Dynastie. In seiner 570 veröffentlichten Historia dei Principi di Este ließ Giovanni Battista Pigna das Geschlecht der Este auf Caius Atius zurückgehen, ein Mitglied der mit Augustus verwandten Sippe der Atia, von Vergil als Abkömmling der Trojaner Atys besungen, der sich im 5. Jahrhundert n. Chr. im Veneto, im Bereich von Ateste (dann sprachverzerrt Este) niedergelassen hatte. Von diesem Urvater, der seine Sippschaft vor den Westgoten verteidigte, konnte Pigna seine Auftraggeber, von denen einige Vorfahren den Vornamen Azzo trugen, bis in seine Zeit genealogisch verknüpfen. Das Auftragswerk hatte eine große Verbreitung und wurde ins Lateinische und Deutsche übersetzt. ${ }^{492}$

Das zweite schlagende Argument im Präzedenzstreit zwischen den Medici und den Este war die Verschiedenheit der historischen Vergangenheit, der Unterschied also zwischen einer republikanischen Stadt und einem von Fürsten - wenn auch im Rahmen eines Lehensverhältnisses - beherrschten Gebiet. Die mit der Argumentationsführung Beauftragten waren nicht nur bemüht, die eigenen Dienstherren hervorzuheben, sondern stets auch den Gegner zu verunglimpfen, wenn sie auf die wirtschaftlichen Tätigkeiten der Medici, auf ihre Herkunft als Bankiers und auf ihr Emporkommen aus einer Stadtoligarchie hinwiesen. Renato Cato und Alessandro Fiaschi führten dem Kaiser wiederholt vor Augen, wie schändlich und ungehorsam sich der Herzog von Florenz benommen hatte und wie unerfreulich der Papst vorgegangen sei. Alfonso ließ sogar durchscheinen, dass er bereit sei, den Kaiser in einem militärischen Vorgehen gegen Florenz zu unterstützen. ${ }^{493}$

Die Florentiner konterten auf diese Vorwürfe mit der Tatsache, dass sie seit I 532 als Fürsten anerkannt seien und mit ihren ebenso fantasievollen Abstammungsgeschichten von den Herren von Mugello, ${ }^{494}$ den Herzögen von Athen ${ }^{495}$ oder von den nach Italien gezogenen Gefährten von Karl dem Großen. Doch die Medici brachten

gia, r07. Bei Borso, wahrscheinlich dem Auftraggeber oder zumindest Adressaten der Schrift, machte der Autor eine Ausnahme und porträtierte ihn nicht nur im Tondo, sondern auch ganzfigurig im Profil mit dem Befehlsstab in der Hand. Auch die biografischen Angaben sind überdurchschnittlich lang und ausführlich. Angeführt wird seine Erhebung zum Herzog von Modena und Reggio und zum Grafen von Rovigo durch Kaiser Friedrich III., der auf dem Weg zur Kaiserkrönung in Rom war und jene für Ferrara I 47 I nach seiner Reise nach Rom durch Paul II. Ebd., I43.

492 Bizzocchi, Genealogie, I4, I97.

493 Ebd., Minute di dispacci per Germania an Renato Cato und Alessandro Fiaschi, Juli 1570.

494 Mugello ist ein Gebiet in der heutigen Provinz Florenz, aus der die Medici stammen. Die Villa di Cafaggiolo erinnert noch an ihre Präsenz. Vgl. Attilio MorI, »Mugello«, in: Enciclopedia italiana, online Version: http://www.treccani.it/enciclopedia/mugello_\%28 Enciclopedia-Italiana \%29/, Zugriff: I6.9.2020.

495 Das Herzogtum Athen war ein während des Vierten Kreuzzugs gegründeter Kreuzfahrerstaat in Griechenland, bestehend aus den heutigen Regionen Attika und Böotien. Die Herrschaft über das Herzogtum lag zuerst in burgundischer, französischer und dann aragonesischer Hand. Im ausgehenden I4. Jahrhundert besetzte der Florentiner Nerio I. Acciaiuoli mit einem Söldnerheer das Herzogtum 
auch weitere Argumentationspunkte neben ihrer angeblich ebenso antiken Abstammung vor: Sie versuchten auch mit ihrer patrizischen Vergangenheit und der aktiven Beteiligung an der Stadtregierung sowie ihrem Einfluss aufgrund ihrer Ämter und Funktionen zu punkten. Dabei beharrten sie auf die Tatsache, dass ihre Herrschaft und Macht nicht auf Heldenepen basierten wie jene ihrer Konkurrenten. Außerdem stellten sie die Bedeutung einer »Höflichkeit« wie das Reichen der Serviette, auf die sich die Este ja immer beriefen, als nichtige Handlung gegenüber ihren jahrzehntelangen Führungstätigkeiten dar. ${ }^{496}$

Von der ersten Auflage der Historia dei Principi di Este von Gian Battista Pigna wurden einige Exemplare in einer Prachtausgabe mit dem illuminierten Wappen im Frontispiz hergestellt, die dann an jene Fürsten, Prälaten, Gesandten und Literaten geschickt wurden, die in irgendeiner Weise im Präzedenzstreit für die Este Partei ergreifen konnten. Im Reich wurden Exemplare an den Kaiser, seine Minister, an die Kurfürsten und Reichsfürsten geschickt, damit diese die illustre Vergangenheit und die gemeinsame welfische Abstammung der Este mit den Sachsen, Wittelsbachern etc. nachvollziehen konnten. Das Werk verbreitete sich rasch. So gibt Santi an, dass im September I 570 die estensischen Gesandten Renato Cato und Alessandro Fiaschi berichten konnten, dass ein Edelmann des Herzogs von Mecklenburg mit dem Geheimrat des Kaisers, Weber, beim gemeinsamen Essen über das erhaltene Werk gesprochen hätten. Außerdem konnten sie berichten, dass die Herzöge von Sachsen und von Mecklenburg nach Erhalt der Schrift militärische Unterstützung in Form von Truppen gegen den Papst und den Herzog von Toskana in Aussicht gestellt hätten. Die notwendig rasche Verbreitung der Historia dei Principi d'Este im Reich wirkte sich allerdings auf die Qualität des Druckes aus: Einige Exemplare kamen unvollständig und daher fehlerhaft zu den Empfängern. Dieses genealogische Werk wurde von Triburtio Dreyfelder, der I 566 als Beichtvater der Erzherzogin Barbara von Wien nach Ferrara gekommen war, auch ins Deutsche übersetzt. I 570 wurde die deutsche Version den Gesandten Cato und Fiaschi ins Reich geschickt, damit sie kompetente Korrekturleser engagieren und sie schließlich in Mainz drucken lassen konnten. Ganze 80 Exemplare wurden dem estensischen Gesandten Gurone Bertani geschickt, auf dass er sie den Gesandten der verschiedenen Fürsten weiterreiche. ${ }^{497}$

Zur Weiterführung der Historia dei Principi d'Este empfahl der gesundheitlich angeschlagene Autor Pigna als seinen Nachfolger Alessandro Sardi. Dieser hatte bereits die Stammbäume der Fürsten und Monarchen von England, Spanien, Frankreich, Ungarn, Böhmen und Habsburg verfasst. Seit ${ }_{5} 563$ schrieb er an einem Werk Cagioni di Precedenza und sammelte Argumente für die Beweisführung, dass die Este aufgrund

Athen, bis es dann einige Jahre später unter venezianische und schließlich osmanische Herrschaft kam.

Vgl. Gregorovius, Geschichte der Stadt Athen.

496 Bizzocchi, Genealogie, 255-259.

497 Vgl. Santi, La precedenza, 70-74, 86. 
ihrer antiken Herkunft allen Fürsten Europas vorrangig wären. Das Werk blieb unvollendet und unveröffentlicht. ${ }^{498}$

Die literarischen Bemühungen blieben aber erfolglos. Im August I 570 schrieb Alfonso II. persönlich an Kaiser Maximilian II. und drückte sein Bedauern aus, dass trotz der neuen Bemühungen in der Beweisführung - in der Präzedenzfrage nichts weitergehe. Er betonte, dass, wenn nicht die Herzogin, die Schwester des Kaisers, krank wäre, er persönlich zu ihm kommen und seine Argumente vorbringen würde. ${ }^{499}$

Trotz des Versuchs der Este, die mediceische Dynastie mit ihrer altehrwürdigen Herkunft zu übertrumpfen, trotz der Versprechungen, Bestechungen und Drohungen ließ sich Papst Pius V. nicht dazu bringen, die dem Medici gemachten Konzessionen rückgängig zu machen. Im Gegenteil, da er befürchtete, dass der Kaiser den Este gegenüber wohlgesonnener sei als den Medici, verbot er Alfonso II. mit Dekret vom 9. April r 57 I als Herzog von Ferrara und als sein Vasall den Präzedenzstreit vor dem Reichstag weiterzuführen. Als Herzog von Modena und Lehensmann des Kaisers blieb es ihm unbenommen, damit fortzufahren. So schickte Alfonso II. im September I 572 seinem Gesandten im Reich, Ippolito Fontana, eine Abhandlung, die beweisen sollte, dass Karl V. die Republik Florenz gegründet und die Medici damit investiert hatte. Der Gesandte sollte dem Kaiser vor Augen führen, dass diese Tatsache durch die päpstliche Erhebung rechtlich missachtet worden war. Wie sollte man mit so einem Lehensmann umgehen, ließ Alfonso den Gesandten rhetorisch fragen ${ }^{500}$ Im Februar des darauffolgenden Jahres sollten seine Vertreter am Kaiserhof, Cato und Fiaschi, den Kaiser nicht nur an das Präzedenzproblem erinnern, sondern auch nebenbei erwähnen, dass man in den berühmten Waffenschmieden Ferraras für Frankreich einige Kanonen angefertigt habe. ${ }^{501}$ Doch auch der sanfte Druck einer erneuten Annäherung der Este an Frankreich gab nicht den Ausschlag. Der durch die Großherzogswürde zugunsten der Medici bestätigte Vorrang wurde immer wahrscheinlicher. In einer Instruktion von August I573 an Camillo Gualengo macht man sich in Ferrara bereits Gedanken über den zukünftigen Umgang mit Florenz, vor allem im Rahmen von offiziellen Anlässen wie der Einladung zur Hochzeit der Tochter des Herzogs von Kleve mit dem Markgrafen von Brandenburg in Königsberg am 23. August. ${ }^{502}$ Anscheinend kam es hier zu keinem Zwischenfall und der estensische Gesandte war entweder dem Floren-

498 Es gibt heute nur jeweils ein Exemplar in der Biblioteca Estense und in der Biblioteca Comunale. Wenn Pigna der Historiker des Präzedenzstreites war, so war Torquato Tasso der Poet dazu. In seiner „Gerusalemme Liberata« besang er die antike Herkunft und die hervorragenden Leistungen des Hauses Este. Vgl. SAnti, La precedenza, Io I- I07, i 6.

499 Wien, HHStA Serie Italien-Kleine Staaten Karton ro, Fasz. Ferrara I 528 - I 758.

500 ASMo, ASE, Casa e Stato, Carteggio di Ambasciatori, Germania b 28, Istruzione per Germania an Ippolito Fontana, September 1572.

50 I ASMo, ASE, Casa e Stato, Carteggio di Ambasciatori, Germania b 29, Minute di dispacci per Germania an Renato Cato und Alessandro Fiaschi, Februar 1573.

502 Ebd., Istruzione/Memoriale per Germania an Camillo Gualengo, August, I 573. 
tiner vorangestellt worden oder dieser war der Feier ferngeblieben (Quelle schlecht lesbar)..$^{503}$

Die Instruktionen des Jahres I 574 sind zumeist dem Thema des vakanten polnischen Throns und der Bewerbung des Estes (sowie des Kaisers) gewidmet. Mit einem Königstitel hätten die Este die Großherzöge der Toskana übertrumpft und die Präzedenz wieder umgekehrt. ${ }^{504}$ In diesem Jahr kam es auch zu einer persönlichen Begegnung zwischen Maximilian II. und Alfonso II. d'Este. Zunächst nahm der Herzog von Ferrara als Gast von Erzherzog Ferdinand II. an einer Jagdpartie in Innsbruck teil und zog dann weiter nach Wien, um sich dem Kaiser persönlich zu empfehlen und um die Erhebung zum Fürsten erster Klasse unter den Reichsfürsten zu bitten. Seinem Ansuchen verlieh er mit kostbaren Geschenken vor allem für die Minister des Kaisers Nachdruck. Tatsächlich stellte sich daraufhin ein erster Erfolg ein, denn im Dekret vom I 4. April I 574 hielt der Kaiser fest, dass der Herzog von Ferrara als ein Fürst des Reiches galt und dass es weder eine höhere noch bedeutendere Klasse als jene der Reichsfürsten gab, in der Alfonso II. war. Nicht zufrieden mit den damit einhergehenden Titeln von $E_{c-}$ cellenza und Illustrissimo, die auch Mantua und Savoyen führten, verlangte Alfonso im März I 575 die Titel Serenissimo und Altezza, mit denen sich alle Fürsten, auch der von Toskana fortan an ihn wenden sollten. So kam zu dem vor dem Reichstag immer noch offenen Streit um die Präzedenz auch noch jener über die Titulatur hinzu. Alfonso II. hielt seine beiden Gesandten im Reich an, beim Kaiser und seinen Ministern weiter auf die Lösung des Präzedenzstreites und die Vergabe der höheren Titel zu bestehen und vor allem gegen weitere Vertagungen zu protestieren. Doch der Kaiser zögerte weiterhin eine endgültige Entscheidung hinaus. Seit dem Tod seiner Schwester Barbara in Ferrara war seine Beziehung zu Alfonso II. zudem etwas abgekühlt. Als dann Henri III. von Valois 574 auf den polnischen Thron verzichtete und sich unter anderen Maximilian II. gegen Alfonso II. darum bewarb, verschlechterte sich die Beziehung erneut. Auch gefiel dem Kaiser die Anmaßung des estensischen Fürsten, sich selbst Titel zu geben, nicht. Deshalb wandte sich Maximilian am 25. Mai I 575 an den Papst mit der Bitte, die Titel weder für Mantua noch für Ferrara zu akzeptieren, da sie nicht rechtmäßig verliehen worden waren. Als sich herausstellte, dass die estensischen Gesandten in Polen das Haus Habsburg und speziell den Kaiser in ein schlechtes Licht rückten und ihn als Tyrannen verleumdeten, während Francesco de’Medici dem Kaiser ı oo.00o Dukaten lieh, war es nur noch eine Frage der Zeit, bis der Titel des Großherzogs von Toskana auch von kaiserlicher Seite (2. November I 575) anerkannt wurde. Der Herzog von Ferrara und Modena aber erhielt erst im Januar I 576 als kleine Entschädigung die kaiserliche Erlaubnis die beiden gewünschten Titel zu führen. ${ }^{505}$

503 Ebd., von Camillo Gualengo, Oktober 1573.

504 Siehe die fünf istruzioni per Germania an den Gesandten Carandini. ASMo, ASE, Casa e Stato, Carteggio di ambasciatori in Germania b 3 1 , Istruzioni per Germania an Paolo Carandini, November 1574.

505 Vgl. Santi, La precedenza, $76-84$. 
Noch im Februar 1575 hatte Alfonso mit einem persönlichen Brief auf den Kaiser Druck ausgeübt, eine endgültige Entscheidung in der Präzedenzcausa treffen zu wollen, jetzt wo der Herzog von Florenz nicht mehr lange zu leben habe, damit es nicht scheine, als ob alle anderen Gnade und Gefallen vom Kaiser bekämen und nur er nicht, der sich immer offen als Diener des Kaisers proklamiert habe. ${ }^{506}$ Gleichzeitig sollte auch der Gesandte Carandini das Reichsoberhaupt erneut daran erinnern, wie es dessen Vorgänger in der Causa der Präzedenz gehalten hatten. ${ }^{507} \mathrm{Da}$ vom Kaiserhof die Neuigkeit nach Ferrara gekommen war, dass sich nun auch der Herzog von Savoyen im Reichstag mit Serenissimo anreden ließ und es Florenz gleich nachmachen werde, ließ Alfonso den Kaiser im März desselben Jahres erneut bitten, die Causa der Präzedenz endgültig zu seinen Gunsten zu lösen. ${ }^{508}$ Im April sollten die beiden Gesandten Carandini und Cato den Kaiser darauf aufmerksam machen, dass er sich seitens seiner Lehensmänner (der Medici) keinen Respekt entgegenbringen ließe und sich nicht an die Bestimmungen seiner Vorfahren halte, wenn er Florenz einfach so gewähren ließe. Selbst der Papst könne sich nicht ungestraft über den Kaiser stellen und ein kaiserliches Lehen erheben. Dies sowie die Frage der Titelführung und der Präzedenz müssten zur Wiederherstellung der allgemeinen Ordnung geklärt werden. ${ }^{509}$

Selbst nach der kaiserlichen Bestätigung der Großherzogswürde wollte sich Alfonso nicht geschlagen geben und seinen Nachrang akzeptieren. Im Juli I 582 ließ Alfonso nachfragen, ob Ferrara in der allgemeinen Ordnung unmittelbar nach Savoyen gereiht sei, da offensichtlich jetzt Florenz vor Savoyen stehe. ${ }^{510}$ Im März I 583 hielt Alfonso II. seinen Gesandten im Reich, Minuccio Minucci ${ }^{511}$ an, bei den Teilnehmern des mittlerweile aufgelösten Reichstags von Augsburg (1582) um Fürsprache für ihn zu bitten, damit ihm die gleichen Titel und Privilegien wie den anderen Reichsfürsten anerkannt

506 Wien, HHStA Serie Italien-Kleine Staaten Karton ro Fasz. Ferrara I $528-1758$.

507 ASMo, ASE, Casa e Stato, Carteggio di Ambasciatori, Germania b 3I, Dispacci ducali per Germania an Paolo Carandini und Renato Cato, Februar 1575.

508 Ebd., März I 575 .

509 ASMo, ASE, Casa e Stato, Carteggio di Ambasciatori, Germania b 30/3 I, Dispacci ducali per Germania an Paolo Carandini und Renato Cato, April 1575.

5 ro ASMo, ASE, Casa e Stato, Carteggio di Ambasciatori, Germania b 36, Minute di dispaccio per Germania an Renato Cato, Juli 1582.

5 I I Minuccio Minucci (155 I-I604), Doktor utriusque iuris, war zunächst im Gefolge des Nuntius im Reich, Bartolomäus Portia. Nach dessen Tod 1578 trat er in die Dienste des Fürstbischofs von Trient, Kardinal Giovanni Ludovico di Madruzzo, den er 1582 zum Reichstag nach Augsburg begleitete. In diesen Jahren war er wie sein Bruder Andrea gleichzeitig als Gesandter des Herzogs von Ferrara tätig. ${ }_{1} 583$ beeinflusst er mitunter die Wahl von Ernst von Bayern zum Erzbischof von Köln, dem er im darauffolgenden Krieg um Köln beratend zur Seite stand, was ihm die Gunst des Hauses Wittelsbach sicherte. Als Protonotarius apostolicus verfasste er zahlreiche Abhandlungen über die konfessionelle Situation im Heiligen Römischen Reich. Vgl. Alexander Koller, »Minucci, Minuccio«, in: DBI 74 (2010), online-Version, http://www.treccani.it/enciclopedia/minuccio-minucci_(Dizionario-Biografico)/, Zugriff: I6.9.2020. 
würden. Daran erkennt man einmal mehr, dass der Reichstag auch von Nichtmitgliedern und Gesandten als Forum »am Rande« für Fürsprachen und Unterstützungsanfragen genutzt wurde. Außerdem fällt auf, wie sehr sich Alfonso bemühte, sich in diesem Rahmen eindeutig als Mitglied des Reiches darzustellen. ${ }^{512}$ Wenig ermutigend war allerdings die im Juni desselben Jahres zugesandte Kopie eines kaiserlichen Dekrets über die Gleichheit aller Fürsten. ${ }^{513}$ In weiteren Instruktionen des Jahres I 583 an Ascanio Geraldini ${ }^{514}$ wurde das schlechte Benehmen des florentinischen Gesandten angesprochen, das - so der Gesandte - nur beweise, dass Florenz allgemein ein unwürdiges Mitglied des Reiches sei. ${ }^{515}$

In einem Brief an Kaiser Rudolf II., der laut Gesandten sehr ungehalten wegen der ungebührlichen Titulierung war, bat Alfonso im Juni I 584 um die Anerkennung, dass er und sein altehrwürdiges Haus den anderen Reichsfürsten gleichgestellt sei, um sich von »Usurpatoren« abzuheben, womit einmal mehr - ohne dezidierte Nennung - die Medici gemeint waren. ${ }^{516}$ Noch im Mai 586 wurde der Gesandte Ascanio Geraldini instruiert, gegen die unfaire Erhebung von Florenz zu protestieren und um die Klärung der Präzedenz zu urgieren. ${ }^{517}$

Von 1588 sind mehrere Briefe und Instruktionen an den Gesandten im Reich, Ascanio Geraldini, erhalten, die u.a. vor dem Hintergrund eines neuen Ansuchens (einer neuen Nagelprobe), nämlich der Übergabe des Lehens an einen von Alfonso bestimmten Nachfolger aus einer Seitenlinie, darlegen, warum man bisher so wenig erfolgreich mit seinen Forderungen am Kaiserhof gewesen war. Der Gesandte informierte, dass es Sitte am kaiserlichen Hof sei, alle Ansuchen zuerst mit den Ministern zu bereden und diese mit Geschenken günstig zu stimmen, bevor man sie dem Kaiser vorbringen könne. Außerdem wies der Gesandte seinen Herrn darauf hin, dass man kaiserlichen Ministern eigenhändige Briefe oder zumindest ein paar Zeilen schreiben müsse, um sie für sich zu gewinnen. Weil das bisher aus Ferrara nicht oder nur unzureichend erfolgt sei, seien diese Mittelsmänner bisher wenig kooperativ gewesen. ${ }^{518}$ Möglicherweise lässt sich dieser Hinweis nicht nur als Rechtfertigung der erfolglosen Gesandtschaften lesen, sondern auch als Beweis, dass die Este in ihrem Beziehungs-

5 I 2 ASMo, ASE, Casa e Stato, Carteggio di Ambasciatori, Germania b 37, Minute di dispaccio per Germania an Minuccio Minucci, März 1583.

5 I3 Ebd., Juni 1583 .

5 I4 Ascanio Geraldini (Giraldini/o), Cavaliere, Gesandter des Herzogs von Ferrara in Mantua und zwischen I 580 und 1590 am Kaiserhof und im Reich, mehrmals zusammen mit Renato Cato.

5 5 Ebd., Mai 1583 .

5 I 6 ASMo, ASE, Casa e Stato, Minute di lettere ducali a Principi e signori fuori d'Italia, an Kaiser Rudolf II., Juni 1584 und Wien, HHStA Serie Italien-Kleine Staaten Karton io Fasz. Ferrara I 528 - I 758.

5 I7 ASMo, ASE, Casa e Stato, Carteggio di Ambasciatori, Germania b 38, Istruzione per Germania, an Ascanio Geraldini, Mai 1586.

5 I 8 Hierbei geht es um Minister Rumpf. ASMo, ASE, Casa e Stato, Carteggio di Ambasciatori, Germania b 39, Minute di dispacci per Germania an Ascanio Geraldini, ohne Datumsangabe aber 1588. 
netzwerk stark bzw. ausschließlich auf die Figur des Kaisers als Entscheidungsträger konzentriert geblieben sind und zu wenig die Entscheidungsprozesse in den darunterliegenden Akteurskreisen wahrgenommen haben.

Die Niederlage Alfonsos II. im Präzedenzstreit und der aufreibende Kampf um Titel und die »richtige« Anrede zogen weite Kreise. So konnte Lionardo Salviati I 576 sein Werk zur Poetik des Aristoteles, das er Alfonso II. gewidmet hatte, nicht drucken, da der Herzog von Ferrara sich weigerte, eine Widmung in einem Werk zu erhalten, in dem nicht die Titel Serenissimo und Altezza benutzt wurden und Salviati aber auch den Großherzog von Toskana, dessen Untertan und Vasall er war, nicht brüskieren wollte.

Auch Aldo Manuzio der Jüngere wollte mit seinem Werk Vita di Cosimo I de'Medici einerseits den Medici zu Diensten stehen, die ihm ein großes Honorar für sein Lebenswerk versprochen hatten, andererseits seine Gunst beim Herzog von Ferrara nicht einbüßen, sodass er versuchte, so wenig wie möglich auf den Präzedenzstreit einzugehen, bis er schließlich die Beendigung des Werkes auf entspanntere Zeiten verschob. ${ }^{519}$

Diese ruhigeren Zeiten brachen mit einer neuen Generation an, als die befreundeten Kardinäle Ferdinando de'Medici und Luigi d'Este die Streitigkeiten beendeten und ein Heiratsprojekt zwischen den beiden Häusern arrangierten. Der Sohn von Don Alfonso d'Este aus der Seitenlinie der Este von Montecchio, Cesare d'Este, heiratete I 583 Virginia, illegitime Tochter von Cosimo I. In diesem Zusammenhang tauschten sich die beiden ehemaligen Kontrahenten Alfonso II. und Francesco de'Medici über die jeweils beanstandeten Titel Serenissimo und Granduca aus. Diese Verbindung sollte nicht nur den Frieden zwischen den beiden Häusern herstellen, sondern nach Alfonsos Tod ohne männliche Nachkommen die neue Dynastie der Este, als Herzöge von Modena und Reggio, begründen. ${ }^{520}$

\subsubsection{Die Auswirkungen des Präzedenzstreites}

Der Präzedenzstreit hat in vielerlei Hinsicht die Historiografie ${ }^{521}$ um das Haus Este (so wie auf der anderen Seite natürlich auch jene der Medici) vorangetrieben und gefördert. Ohne diese Auseinandersetzung hätte es wahrscheinlich keine so akkurate Recherche in fürstlichen und in privaten Archiven, keine Analyse von heraldischen Symbolen, Stammbäumen, Genealogien, Investituren etc. zur verzweifelten (und zweifelhaften) Beweisführung der ehrwürdigeren, älteren Herkunft gegeben. ${ }^{522}$ Die viel-

5 I9 Vgl. Santi, La precedenza, 9i -95.

520 Bellinazzi/Martelli, Le relazioni, i i 84. Diese Verbindung wurde mit einer kostspieligen, aufwendigen und viel gerühmten Aufführung in Florenz gefeiert. Vgl. Strong, Feste, $226 f$.

52 I Siehe auch: Rubello, Scrittori.

522 Santi, La precedenza, i 20. Nicht nur den italienischen, sondern auch den deutschen Fürsten und unter diesen war es auch den habsburgischen Kaisern ein Bedürfnis, die eigene Herrschaft durch genealogische Geschichtsrekonstruktion zu legitimieren, wodurch es ebenfalls zu Formen von Kultur- 
leicht für heutige Verhältnisse lächerlich erscheinende Auseinandersetzung um den Vorrang animierte die beiden Familien - ohne Einzelfälle zu bleiben ${ }^{523}$ - ihre glorreiche Vergangenheit zur Bestätigung ihrer Erhabenheit zu rekonstruieren und auf verschiedenste Weise in Szene zu setzen. ${ }^{524}$

Neben den Hofhistorikern und -poeten wurden auch Juristen in diesen Prozess der Begründung des Vorranges eingebunden. Dabei ging es weniger um eine wahrheitsgetreue Bestätigung der Herkunft, ${ }^{525}$ als vielmehr um die Konsolidierung der illustren Herkunft im italienischen und europäischen Vergleich, wie die große Verbreitung der Genealogie des Pignas und ihre Übersetzung ins Lateinische, Deutsche, Spanische und Französische beweisen. ${ }^{526}$ Ebenso reich und kreativ war die Produktion auf der florentinischen Seite. In der Accademia Fiorentina stellten die Gelehrten Gelli, Bartoli, Giambullari der um einiges älteren und prestigeträchtigeren Dynastie der Este den von ihnen kreierten »herkuleische« Mythos von Cosimo I., des gerechten, gegen die Tyrannei kämpfenden Fürsten gegenüber. ${ }^{527}$ I 552 erschien in Venedig die Schrift Il ritratto del vero governo del principe dall'esempio vivo del gran Cosimo de'Medici von Lucio Paolo Rosello, demnach der Medicifürst neben dem Este, der einen altehrwürdigen, etablierten Staat besaß, aber noch vor den Savoyern, die noch keinen starken Staat besaßen, das einzig lebende Beispiel eines italienischen Fürsten war, der mit Besonnenheit und Weisheit in der Staatsführung der politischen Lage der Zeit Herr werden konnte. ${ }^{528}$

transfer kam. Dabei stellte sich im Zuge der frühneuzeitlichen Instrumentalisierung von Genealogien stets die Frage, wie weit in die Vergangenheit zurückgegangen bzw. recherchiert wurde, wie lückenlos die Abstammung rekonstruiert wurde/werden konnte und wie gut damit Kontinuität und Stabilität einer Dynastie nachgezeichnet werden konnte. Diese Genealogien und die Auseinandersetzung mit ihnen dienten aber nicht nur der Machtlegitimierung, sondern auch »der Strukturierung von Wissen«. Vgl. Bauer, Wurzel, Stamm, Krone; Kellner, Formen des Kulturtransfers. Zur »Affinität der genealogischen Methode zum adeligen Selbstverständnis« siehe auch CARL, Europäische Adelsgesellschaft, I 9 I-I 93. Außerdem eigneten sich Stammbäume besonders gut, um prestigeträchtige Heiratsverbindungen hervorzuheben. Vgl. dazu Turchi, Matrimoni, mit einigen Abbildungen zu den estensischen Stammbäumen im Anhang.

523 Vgl. dazu Nolte/Spiess/Werlich, Principes, 425-447 und letztens Heinemann, Das Herkommen des Hauses Sachsen.

524 Wie schon oben beispielhaft: SARdi, Libro delle Historie Ferraresi; Giraldi Cinzio, De Ferraria.

525 Dazu siehe Bizzocchi, Genealogie.

526 Chiappini, Gli Estensi, 8.

527 Rosa, La cultura politica, 78 .

528 Ebd. Medici und Este waren selbstverständlich nicht die Einzigen, die ihren Status durch historiografische und genealogische (Auftrags)Werke aufzupolieren versuchten. Hier sei nur als weiteres Beispiel Savoyen und die Dynastiegeschichte des Hofhistorikers und Rechtsgelehrten Filiberto Pingone genannt, der 158 I sein Inclytorum Saxoniae Sabaudiaeque principum arbor gentilitia veröffentlichte. Battista Guarini, der Autor des Pastor fido, war zwischen I 567 und I 588 im Dienst von Alfonso II. und wechselte dann zu Ferdinando de'Medici, dem er 1599 das Trattato della politica libertà widmete. Ebd., 8If. Vgl. auch MANFREDinI, Identità storica, 238. 
Es ist Santi zuzustimmen, dass der Präzedenzstreit aber nicht nur der Ansporn für eine reiche juristische, literarische und künstlerische Produktion war, sondern auch andere weitreichende Folgen hatte: Die Auseinandersetzung führte dazu, dass Maximilian II. und Alfonso II. nicht an der Liga von I 57 I im Kampf gegen die Osmanen teilnahmen; darüber hinaus kam es zu großen Verschuldungen aufgrund der Notwendigkeit, "zur Aufrechterhaltung der sozialen Struktur seines eigenen Hofes «, ${ }^{529}$ ostentativ Luxus und Glanz an den Höfen von Ferrara und Florenz zu zeigen. Auch beeinträchtigten die mit der Causa einhergehenden Verleumdungen die Errettung des päpstlichen Lehens Ferrara vor der Devolution. Gleichzeitig waren die Kompetenz und Befugnisse des Reichstages als rechtliche Entscheidungsinstanz stark in Frage gestellt worden. Schließlich hinderte die im gegenseitigen Unterbewusstsein immer noch präsente Auseinandersetzung noch lange nach ihrer formalen Beendigung in der ersten Hälfte des I7. Jahrhunderts die notwendige Zusammenarbeit zwischen den beiden Fürstenhäusern z.B. im Rahmen der Instandhaltung und Regulierung von Land- und Wasserstraßen im Grenzgebiet der beiden Fürstentümer. ${ }^{530}$ Aus diesen Gründen ist die Auseinandersetzung um den Vorrang in ihrer Bedeutung und Nachwirkung nicht zu unterschätzen. ${ }^{531}$

\subsubsection{Die Großherzogswürde der Medici und der verlorene Kampf um die Präzedenz}

Dieser rechtlich fragwürdige und die italienische wie europäische Politik aufwühlende Akt der Erhebung der Toskana zum Großherzogtum durch den Papst wurde bereits von Viktor Bibl ${ }^{532}$ in einer tiefgehenden quellenbasierten Arbeit untersucht, auf die auch die neuere Literatur aufbaut.

529 Zur Notwendigkeit der Sichtbarmachung von Prunk und Prestige siehe die Überlegungen bei: Ewert/Hirschiegel, Nur Verschwendung? Hier stellen die Autoren fest, dass prinzipiell die Wahl zwischen "prunken/parading « und »nicht prunken/not parading « bestand, letzteres sich allerdings nur ein sattelfester Erbmonarch einer der ältesten Königsdynastien leisten konnte. Halbsouveräne Fürsten wie die Este waren somit auf das »Prunken« angewiesen, wenn auch Karl-Heinz Spieß am Bespiel des deutschen Fürstenstands gezeigt hat, dass »materielle Defizite nicht den Verlust der Fürstenqualität verursachten«, sondern allenfalls »zu einer Verminderung an Qualität und Quantität« führten. Spiess, Fürstliche Höfe, 234. Zur Bedeutung des Fürstenhofes als Spielwiese des Luxus und demnach des Kapitalismus siehe bereits: Sombart, Liebe, 85- i I 7 .

$530 \mathrm{Zu}$ dieser Problematik siehe: Fumagalli, Duchi e granduchi.

53 I SAnti, La precedenza, I 2 If.

532 Die 162 Seiten starke Abhandlung baut auf die die Erhebung betreffenden Archivalien und Korrespondenzen und reicht von der ersten Idee über die tatsächliche Verleihung der Großherzogswürde durch den Papst bis zur schlussendlichen Anerkennung bzw. Verleihung durch den Kaiser am 26. Januar i 576. Bibl, Die Erhebung. Siehe auch Naffei, Dal titolo di Duca. De-Magistris, Lelevazione. 
Als Cosimo am r 3. Dezember r 569 in Rom die Bulle der Erhebung überreicht wurde, war an der Zeremonie auch der estensische Gesandte anwesend und kurz darauf erreichte ein Gratulationsschreiben von Alfonso II. den Medici, in welchem der Este Cosimo immer noch nur mit »Herzog « ansprach und sich versichern wollte, dass durch diesen Akt sein Haus den Medici nicht nachgereiht sei. Von Anfang an erklärte Cosimo, dass diese Erhebung vom Papst persönlich, spontan und ohne sein Zutun oder dahingehendes Ansuchen "passiert« sei. Das entsprach nicht ganz der Wahrheit, hatte er sich doch in den vorangegangenen zehn Jahren um diese Rangerhöhung bemüht, war aber sowohl auf päpstlicher wie auf kaiserlicher Seite auf Unwillen gestoßen. Die Verbindlichkeiten, in die sich Kaiser Ferdinand I. zuerst und Maximilian II. später mit den Medici verstrickten und die schlussendlich zur Akzeptanz der Erhebung führten, ergaben sich aus den zahlreichen Krediten und Geldanleihen, die Kaiser und Reich bei den Florentinern aufnahmen. Bereits im Zuge der Verheiratung der Erzherzogin Johanna mit Francesco de'Medici hatte sich der Kaiser ein Darlehen von 200.000 Dukaten erbeten. ${ }^{533}$

Die Medici versuchten ihr Glück bezüglich der Erhebung bei beiden Universalgewalten und hätten sie am liebsten aus den Händen des Kaisers empfangen. Da ihrem Wunsch nach einer Erhebung zum Königtum oder zumindest Erzherzogtum durch den Kaiser - wodurch sie die Vorrangstellung über alle italienischen Fürsten erreicht hätten - nicht entsprochen wurde, änderten sie ihre Argumentationstaktik und erklärten, dass Florenz - anders als Ferrara - frei sei und deshalb auch vom Papst erhoben werden könnte. ${ }^{534}$

Alfonso II., der sich seiner besseren Chancen am Kaiserhof bewusst war, versuchte die Entscheidungsfindung an den Kaiserhof zu ziehen, während Cosimo beim Papst erwirkte, den aufmüpfigen estensischen Lehensnehmer durch Sanktionsandrohung in die Schranken zu weisen, sodass dieser nicht als Herzog von Ferrara, sondern »nur» als Reichslehnsnehmer über die Herzogtümer Modena und Reggio diesen Rechtstreit ausfechten durfte. ${ }^{535}$ Bibl hat in seiner Untersuchung das Gewicht des Herzogs von

533 Vgl. BıвL, Die Erhebung, 7-I 2.

534 Diese Unterscheidung zwischen dem Este- und dem Medici-Fürst machte auch der parteiische Gesandte Orazio Della Rena bei seiner Beschreibung von Alfonso II. und der Auflistung von dessen vielen Titeln, von denen der eines freien und souveränen Fürsten aufgrund des doppleten Lehensverhältnisses - seiner Meinung nach - von den Rechtsgelehrten an den Haaren herbeigezogen war: „Con tutti questi suoi titoli, benchè alcuni Dottori si sieno sforzati, ch'egli è Principe libero, e di suprema potenza, poichè dà legge a suoi sudditi, fa la pace, e la guerra, provvede ne suoi paesi di tutti gli Officiali, et Magistrati, mette gravezze, e libera da esse ciunque li piace, fa gratia della vita a chi merita la morte, ha l'ultima cognizion delle Cause de'sudditi suoi che son tutte azioni da Principe libero, et di suprema potenza, non di meno, per le cose che si son dette nell'altra parte, apparisce non esser vero, poichè, come Duca di Modona, et di Reggio ne riconosce l'Imperio, benchè Giulio II pretendeva, che fu per feudi della Chiesa; come Duca di Ferrara ne riconosce il Papa, del quale è feudatario, e gli paga Censo annuale di 7.m fiorini d'oro [...]«. Della Rena, Relazione, 50.

535 Vgl. BıвL, Die Erhebung, I 4- I 8. Nicht einmal der persönliche Besuch Francescos de’Medici am Kai- 
Ferrara beim Kaiser auch deswegen höher eingeschätzt, weil die Este Gläubiger der französischen Krone und durch die mit den calvinistischen Lehren sympathisierende Mutter Alfonsos, Renée, konfessionell relativ frei waren, was - nach Bibl - der Gesinnung Maximilians II. entgegenkam. ${ }^{536}$ Dem kann - zum Teil - zugestimmt werden, obwohl diese Gründe nicht so ins Gewicht fallen dürften wie die Tatsache, dass durch die päpstliche Erhebung die kaiserlicher Autorität in Reichsitalien untergraben wurde. Die Argumentation Bibls, der Kaiser habe Florenz gegenüber verlauten lassen, dass er »auf Ferrara Rücksicht nehmen [müsse], weil durch dessen Hände die wichtigsten Staatsgeschäfte liefen «, ${ }^{537}$ mag eher den vielen vorangegangenen kaiserlichen Dissimulierungs- und Hinhaltetaktiken als der politischen Bedeutung der Este zuzuordnen sein. Bei aller Sympathie für die Este war es weder in Maximilians II. noch später in Rudolfs II. Interesse, eine "eindeutige « Entscheidung und somit eine klare Auseinandersetzung herbeizuführen. Schließlich brachte dem Kaiser die hinausgezögerte Entscheidung sowohl in der Präzedenz- als auch in der Erhebungsfrage große finanzielle Vorteile ${ }^{538}$ von beiden Prätendenten.

Die Beziehungen zwischen Florenz und dem Kaiser waren prinzipiell eher kühl, getrübt von den Reibereien zwischen den Medici und Spanien, der starken Anlehnung der Medici an Rom, der ständigen Behauptung der eigenen »Freiheit« und Unabhängigkeit vom Reich und schließlich auch wegen der schlechten Behandlung der angeheirateten Erzherzogin Johanna durch den Ehemann Francesco de’Medici. ${ }^{539}$

Die Beziehungen zwischen Alfonso II. d'Este und Kaiser Maximilian II. waren zwar besser, nach Bibl auch gefördert durch den persönlichen Kontakt im Feldlager ${ }^{540}$

serhof im Herbst ${ }_{5} 65$ weckte das Interesse des Kaisers. Zur Wiederaufnahme dieser Argumentation ebd., ro8f.

536 Bibl, Die Erhebung, i $25 \mathrm{f}$.

537 BıвL, Die Erhebung, 25. In einem weiteren Bericht des florentinischen Gesandten soll Maximilian II. behauptet haben, man müsse auf den Herzog von Ferrara Rücksicht nehmen, weil er - anders als Cosimo - mächtig und durch seine Verbindungen einflussreich sei. Ebd., 38.

538 Als Erzherzog Karl, Landesherr von Innerösterreich, I 569 von Spanien über Livorno und Florenz ins Reichs zurückkehrte, wurde er nicht nur von den Medici glanzvoll empfangen, sondern auch mit 50.000 scudi bedacht. Dieselbe herzliche Aufnahme fand der Erzherzog in Ferrara, was die Gerüchte über Alfonsos Vorhaben, einen Erzherzog als seinen Nachfolger zu adoptieren, zur Folge hatte. BiBL, Die Erhebung, 4If.

539 Ebd., 27f. Als Johanna I 578 starb, heiratete Francesco seine langjährige Mätresse Bianca Cappello und machte sie zur Großherzogin. Bis zur Geburt eines männlichen Thronfolgers war Johannas Dasein in Florenz von Demütigung und Zurückweisung geprägt, sodass sie mithilfe von Alfonso II. d'Este um die Erlaubnis, die Toskana verlassen zu dürfen, kämpfte. Aus Wien kamen jedoch wenig aufmunternde Ratschläge, sich ob der ehelichen Untreue des Gemahls nicht zu grämen und über diesen wenig bedeutenden Missstand hinwegzusehen. Schütz, Kunst und Mäzenatentum, 22 ; Rauch, Großherzogin Johanna, I 43. Zu ihrem kurzen aber dennoch politisch nicht unbedeutenden Leben in Florenz, wo sie u.a. veranlasste, dass von Boccaccios indizierten Decameron eine (zensierte) Fassung veröffentlicht wurde, siehe auch: Fubini Leuzzi, Un'Asburgo a Firenze.

540 Bibl mutmaßt, dass Alfonso in diesem Zusammenhang Maximilian den Vorschlag gemacht habe, bei 
als der Este mit seiner Armee - wenn auch nur kurz - in den Türkenkrieg eintrat; dennoch folgte der Kaiser beim Tod von Papst Pius IV. nicht der Bitte, Kardinal Ippolito II. d'Este bei der Papstwahl zu unterstützen, obwohl ihn der Kaiser beim darauffolgenden Konklave u.a. beim spanischen König wärmstens empfahl. ${ }^{541}$

Obwohl die Bulle der Verleihung der Großherzogswürde - von der lange keine Abschrift erhältlich war - einen Passus enthielt, der besagte, dass durch die Erhebung kein anderer italienischer Fürst von den Medici präjudiziert wurde und somit alles beim Alten blieb, schickte Alfonso II. sofort nach Kenntnisnahme seine Gesandten mit einem vehementen Protest nach Venedig, Savoyen, Frankreich und ins Reich. ${ }^{542}$ Der ebenfalls empörte Kaiser bestätigte zunächst dem aufgebrachten Herzog von Ferrara, dass seine Rechte durch die Erhebung in keiner Weise präjudiziert seien. Daraufhin wurden am Kaiserhof über mehrere Jahre Verhandlungen über die Reichszugehörigkeit der Toskana geführt und über die Befugnis des Papstes, eine solche Erhebung an einem Reichslehen vorzunehmen. Auf diesen Gegenwind hin, versprach der Papst in der Folgezeit wiederholt seinen Schritt rechtlich prüfen lassen zu wollen. ${ }^{53}$

In der Zwischenzeit ergriff man im Reich verschiedene Maßnahmen gegen diesen Akt. Es kam im März I 570 zu einer offiziellen Protestation gegen den päpstlichen »Despekt«, der Missachtung der kaiserlichen Autorität durch den Papst; gleichzeitig wurde die Unterstützung Spaniens angefordert, ${ }^{544}$ um den Medici Siena wieder zu entreißen. Auch dachte man daran, die Causa vor die Kur- und Reichsfürsten zu bringen, was den Papst insofern beunruhigte, als hier die Möglichkeit bestand, dass sich Maximilian II. mit den evangelischen Fürsten zu einem Zug gegen Rom einigte. Schließlich verbat man per kaiserliche Anordnung die Führung des neuen Titels.

Die Medici waren nun daran interessiert, von dieser Causa abzulenken und da half wie schon oft die Idee einer Fürstenliga gegen die osmanische Gefahr und deren finanzkräftige Unterstützung durch die neuen Großherzöge, um auch den Kaiser wieder freundlich zu stimmen. Nachdruck verlieh auch die Ankündigung, man erwarte die baldige Auszahlung der noch nicht eingeforderten Mitgift Johannas über ı 00.000 Gulden, um den zögernden Kaiser umzustimmen. ${ }^{545}$ Zudem wurden Vizekanzler Weber und andere Räte des Kaisers großzügig von Florenz bedacht, um die Weiterfüh-

Kinderlosigkeit einen Erzherzog für sein Fürstentum adoptieren zu wollen, was die kaiserliche Macht in Oberitalien gestärkt hätte. Dieser Vermutung Bibls kann man sich anschließen, wenn man bedenkt, dass das Gerücht über dieses Vorhaben noch lange in den Gesandtenberichten kursierte. BıвL, Die Erhebung, 23.

54 I Ebd., 22. Vgl. auch Pastor, Geschichte der Päpste 8, i 8f.

542 Da angenommen worden war, dass dieser Akt vor allem beim Kaiser auf Widerwillen stoßen würde, war er lang geheim gehalten worden. Vgl. Bıв L, Die Erhebung, 45-49.

543 Ebd., 52 f, 92.

544 Wobei hier wenig Einverständnis zwischen den beiden Habsburger Linien bestand, zumal Spanien kein Vorgehen gegen Papst und Kirche befürwortet hätte. Ebd., 88.

545 Ebd., 62f, 7 If. 
rung des Prozesses zu vereiteln. ${ }^{546}$ In den aus dem Reichstag von Speyer hervorgegangenen Gutachten der Kurfürsten wurde schließlich zwar die Bedeutung der Wahrung der Reichsrechte betont, doch es zeichnete sich bereits ab, dass wenig Aussicht auf die Rücknahme der Erhebung durch den Papst bestand. Dennoch war der Grundtenor eher jener der Kompromissfindung als des Affronts. Auch der Kaiser schlug einen versöhnlicheren Ton an und obwohl er darauf beharrte, dass Florenz Reichslehen und der Papst zur Erhebung nicht befugt gewesen sei, spielte er den Ball diesem zurück, mit der Bitte zu überlegen, wie das somit entstandene Präjudiz aus der Welt geschafft werden könnte.

Für den in diesem ausschlaggebenden Entscheidungsmoment mit den Folgen eines schweren Erdbebens beschäftigten Herzog von Ferrara, dem der Papst erneut die Beilegung des Streites befahl, entwickelte sich das Ganze zu einer aussichtslosen Causa. Dennoch führte er als Reichslehnsnehmer den Protest gegen die Präzedenz - wie oben gezeigt wurde - noch lange und beharrlich fort; und als der Papst diesen unterbinden wollte, griff Maximilian II. ein und ließ nicht zu, dass sich das geistliche Oberhaupt erneut in Reichsangelegenheiten mischte, da einem Mitglied des Reiches vom Papst nicht die Möglichkeit der Rechtshilfe genommen werden könne und in der Präzedenzsache der - wenn auch entscheidungsträge - Kaiser zuständig sei. ${ }^{547}$

I 57 I hatte der Papst eingewilligt, dass den Medici die Großherzogswürde oder eine höhere Würde gegen entsprechende finanzielle Zuwendung vom Kaiser verliehen werde. Antrieb dafür war natürlich die Notwendigkeit Maximilians, für Rudolfs Nachfolge und für die Thronwerbung in Polen Unterstützung der katholischen Fürsten und des Papstes zu bekommen. Da der Prozess ruhte und der Kaiser der Liga beitrat, die bei Lepanto einen großen Sieg davontrug, reiste Alfonso im gleichen Jahr erneut nach Wien, um seine Interessen weiter voranzutreiben. Es kam zu etlichen geheimen Besprechungen im Krankenzimmer Maximilians, wobei anzunehmen ist, dass es neben der Präzedenzfrage auch um die Nachfolgeregelung ging. Dabei muss Alfonso erfolgreich argumentiert haben, da der bis dahin ruhende Prozess gegen Cosimo wegen der unrechtmäßigen Erhebung wieder aufgenommen wurde. Dagegen ging Florenz mit einer altbewährten Argumentationstaktik vor, nämlich dass Modena und Reg-

546 Weber erhielt im Sommer I 5703.000 und kurz darauf nochmals 2.00o Dukaten, als man erfuhr, dass Alfonso nicht geneigt war, den rechtlichen Streit beizulegen und diesen vor dem Reichstag besprochen haben wollte, was in Speyer I570 auch geschah, wo die estensischen Gesandten Catound Fiascchi Klage gegen Cosimo einreichten. Um eine größtmögliche Unterstützung zu erhalten, wurden Weber im Oktober von den Medici erneut 10.000 scudi geschenkt und die Begleichung der Schulden seiner Verwandten versprochen. Nach dem für die Medici glimpflich verlaufenen Reichstag erhielt der Kanzler noch 2.000 scudi. Ebd., 80, 82, 89f, 94, 103. Zum Aspekt der (Bestechungs)Geschenke und Korruption von Funktionären siehe auch Koenigsberger, Patronage and Bribery, wo gezeigt wird, dass Geschenke und Zuwendungen für die Hofbeamten von Seiten der Adeligen als eine gerechtfertigte und weitverbreitete Praxis galten. 
gio eigentlich auch Kirchenbesitz seien, da der Papst diese einst von Maximilian I. um 40.000 Golddukaten abgekauft hatte. Diese Rechtsverdrehung, die die Wiederbelehnung durch Karl V. außer Acht ließ und die Este bedrohte, entflammte wieder den Zorn des Kaisers. Inzwischen kam 1572 mit Ugo Buoncompagni als Papst Gregor XIII. ${ }^{548}$ ein Anhänger der Medici an die Macht. ${ }^{549}$

Schlussendlich waren verschiedene Faktoren für das Einlenken und die Suche nach einem Kompromiss des vor sich hin schlummernden Prozesses ausschlaggebend, ${ }^{550}$ bei dem weder Papst noch Kaiser das Gesicht und Florenz die Großherzogswürde verlieren sollte. Spanien ließ sich nicht zu einer eindeutigen Positionierung gegen die Erhebung motivieren und der Herzog Alba erbat sich I 572 zudem von Florenz ein Darlehen von 200.000 scudi für die Niederschlagung des Aufstandes in den Niederlanden. Nun war die Auseinandersetzung an einem Wendepunkt angelangt und die finanziellen Möglichkeiten der Medici zerstreuten alle bisherigen kaiserlichen Bedenken gegen die Erhebung. Zurück blieb ein angespanntes Verhältnis der Este zum Kaiser, verstärkt durch weitere, kurz nach der Bestätigung der Großherzogwürde für die Medici folgende Krisenmomente wie die Konkurrenz bei der Werbung um den polnischen Thron und die oben genannte unrechtmäßige »Selbstverleihung« kaiserlicher Titel. ${ }^{51}$

Zwischen der päpstlichen Erhebung und der kaiserlichen Bestätigung der Großherzogswürde entstand ein Klima internationaler Anspannung. Nicht nur die Este, die nun dadurch endgültig ihrer Präzedenzmöglichkeiten beraubt worden waren, sondern auch die anderen italienischen Fürsten wollten diesen Akt nicht annehmen. Der Ausbruch einer militärischen Auseinandersetzung wäre nicht undenkbar gewesen, da mit der Erhebung das Gleichgewicht in und außerhalb Italiens erheblich gestört worden war. ${ }^{552}$

548 Papst Gregor XIII. ( I $_{572}$ - I 585 ). Vgl. Agostino Borromeo, „Gregorio XIII«, in: Enciclopedia dei Papi (200o), online verfügbar: http://www.treccani.it/enciclopedia/gregorio-xiii_(Enciclopedia-deiPapi)/, Zugriff: I6.9.2020.

549 Vgl. Bıвц, Die Erhebung, I r 4f, I 26- I32. Bibl behauptet hier (I 28f) Papst Julius II. hätte die beiden Reichslehen von Maximilian I. abgekauft, aber es war erst sein Nachfolger Leo X.

$55^{\circ}$ Grund dafür waren auch die meist absichtlich verursachten formalen Fehler oder die Haarspalterei, so als Florenz vorgab, verwirrt zu sein, da die Anklage zuerst vom Herzog von Ferrara und dann vom Herzog von Modena und Reggio gekommen war. Ebd., I $4 \mathrm{I}$.

55 I BibL, Die Erhebung, I36- I 54. Schlussendlich konnte der florentinische Gesandte Concino auch die ungünstigen Formulierungen aus der Erhebungsurkunde mithilfe von Weber und mit einigen $\mathrm{Zu}$ wendungen sowie mit der Auszahlung der mit ro.ooo scudi festgelegten Taxe beheben. Dabei ging es z.B. um Formulierungen wie Großherzog »in« Toskana statt »von« Toskana, um die Frage ob Siena inbegriffen sei, wie sehr durch die Verleihung die Vasallität Florenz ausgedrückt werde etc. Weber erhielt erneut 5.000 scudi, 3.000 waren für den Geheimen Rat Trautson und weitere Zuwendungen als Belohnung für das beteiligte Kanzleipersonal. Insgesamt muss Weber bis zu seinem Amtsaustritt im Dezember 1576 roo.000 Gulden durch Geschenke und Zuwendungen erhalten haben. Ebd., I 56 - i6 I und r6r Anm. 3 .

552 Contini, La concessione, $420 f$. 


\subsubsection{Der Thron von Polen - ein Königstitel als alternative Lösung des Präzedenzstreites}

Als Charles IX. von Frankreich I 574 plötzlich starb, tauschte sein Bruder Henri den polnischen Thron gegen den französischen und hinterließ in Polen eine Vakanz. Auf seiner Heimreise passierte er Ferrara, ${ }^{553}$ bevor er als Henri III. die Macht in Frankreich übernahm. Alfonso II. spielte daraufhin mit dem Gedanken, sich um den vakanten Thron zu bewerben und mit einem Schlag die Medici in der Präzedenzfrage zu überholen, ohne zu bedenken, dass seine Mitstreiter von ganz anderem Kaliber waren, nämlich der König von Schweden Johann III., der russische Zar Ivan IV., der Erzherzog von Österreich Ernst bzw. auch der Kaiser selbst und der Woiwode von Transsilvanien Stefan Báthory. Alfonsos Vertreter und Agent am polnischen Hof war Battista Guarini, ein talentierter Diplomat, der mit allen Mitteln den Vorteil seines Dienstherrn, nämlich die Sympathie der Polen für Italien und die Italiener, zu nutzen versuchte. ${ }^{554}$

Als am 7. November I 575 das Wahlparlament in Warschau zusammentraf, hatte Guarini Geld ${ }^{555}$ und kostbare Geschenke mit im Gepäck. Obwohl seine Reise katastrophal gewesen war und er in Hall in Tirol Halt machen musste, weil er an Fieber erkrankte, hatte er aufopfernd seine Mission fortgesetzt und zusammen mit dem estensischen Agent Ascanio Geraldini die Bewerbung seines Herrn in Polen vorgetragen. Doch wie voraussehbar war, ging die Krone schließlich an Báthory. ${ }^{556}$

Der Drang, selbst eine weit entlegene Königskrone anzustreben, war, wie Schnettger bereits am Beispiel Genuas belegt hat, mehr als nur ein Expansionswunsch, es war eine Notwendigkeit für eine »Vollmitgliedschaft` im Konzert der europäischen Mächte«

553 Seine Reise und der Aufenthalt in Ferrara sind bereits beschrieben worden von Nolhac/Solerti, Il viaggio in Italia. Dabei fält auf, wie der berechnende Alfonso II. dem Durchreisenden mit allen Ehren entgegenritt, ebd., 66-77, in Venedig auf ihn traf und ihn zu einem gemeinsamen geheimen Abendessen inklusive Unterhaltung durch die Gelosi einlud. Auch in Ferrara versuchte der Herzog nach einem triumphalen Einzug mit Unterhaltungen und Vergnügungen für den angehenden Herrscher Frankreichs alle anderen Gastgeber zu übertreffen. Als bei der Inszenierung einer Eroberung im Rahmen einer Aufführung Feuerkörper frühzeitig explodierten, wodurch Menschen ums Leben kamen, ließ man Henri in dem Glauben, dies sei mit Absicht geschehen. Dieser war vom Feuerwerk so begeistert, dass er die Ingenieure nach Frankreich in seine Dienste nehmen wollte. Ebd., I 7 I - I 79. Zu den Huldigungen des designierten, aber noch nicht gekrönten rex christianissimus siehe auch: Мıттт,

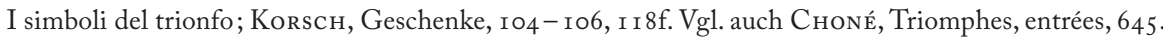

554 Rimondi, Estensi, i6r.

555 Angeblich lag das Angebot Alfonsos bei 2 Mio. Gulden. Daneben versuchte er auch mit seinen engen Beziehungen zu Frankreich und dem vom polnischen Thron abberufenen Henri zu punkten. Für die in Betracht gezogene Brautwerbung soll auch ein Porträt des Herzogs nach Polen geschickt worden sein. Vgl. Augustynowicz, Die Kandidaten, 2of, $39 \mathrm{f}$.

556 Dennoch wurden die Gesandten von ihrem Dienstherrn beschimpft und für unfähig erklärt. RImondI, Estensi, I62. 
gerade für die oberitalienischen Fürsten, die als »Reichsvasallen nach Reichsrecht den deutschen Reichsständen rangmäßig untergeordnet« waren und sich deshalb »um die Lösung aus der Oberhoheit von Kaiser und Reich« bemühten. ${ }^{557}$

Bei Alfonso II. spielte neben dem wichtigen Faktor seiner Position innerhalb der italienischen Staatenwelt auch die sich abzeichnende Nachfolgeproblematik eine bedeutende Rolle. Der erneut Verwitwete war auf der Suche nach einer (dritten) Braut, die ihm den ersehnten männlichen Nachfolger schenken und somit den Erhalt der Dynastie garantieren konnte. Nicht zuletzt dürfte der Ansporn zu großen Ehren bei Rang, Titeln und militärischen Aktionen auch seinem Charakter zuzuschreiben sein, wenn in Orazio Della Renas Beurteilung des Herzogs ein Fünkchen Wahrheit über dessen Eitelkeit und Darstellungsdrang enthalten ist:

È invidioso degli onori, e grandezze altrui, [...] et perchè è cupidissimo non men di fama, che di gloria, usa grand'arte, che i Signori gli vengano a Casa da diversi paesi, si partin soddisfatti, e quasi admirati della sua grandezza, et del suo Stato; [...] et si dee avvertire, che il Duca di Ferrara, se si misura dalla potenza, et dallo Stato suo, non è se non Principe mediocre, $[\ldots] .{ }^{558}$

Trotz der Niederlage bei der Königswahl dürften die Beziehungen zu Polen noch weiter bestanden haben, wenn - wie Lazzari aus der mantuanischen Korrespondenz der neuen Herzogin von Ferrara, Margherita, mit ihrem Bruder Vincenzo Gonzaga entnimmt zum Karneval I 580 der Gesandte des polnischen Königs und einige auffallend gekleidete Polen (»certi Polacchi vestiti alla più stravagante fogia «) anwesend waren. ${ }^{559}$

Als Stephan Báthory I 586 starb, dachte Alfonso erneut an eine Bewerbung für den polnischen Thron. Seine Kontrahenten waren diesmal Erzherzog Maximilian, Alessandro Farnese, Herzog von Parma und Sigismund Wasa von Schweden, der schließlich das Rennen machte. War unter den italienischen Prätendenten der Farnese zu arm für dieses kostspielige Bewerbungsunterfangen, so war Alfonso zu alt und schied deshalb bald aus dem Wettlauf um die Krone aus. ${ }^{560}$

Zusammenfassend kann festgehalten werden, dass es sich auch bei diesem Streben nach Rangerhöhung, wie Schnettger es bereits an anderen Beispielen dargelegt hat, nicht »um eine wirkliche Überordnung eines europäischen Potentaten über einen an-

557 Schnettger, Rang, 87 mit Verweis auf: Christian Schroter (Präs.)/Ludwig Konrad Dahn (Resp.), Dissertatio juridica de vasallo non statu Imperii. Von denen Reichs-Vasallen, welche nicht zugleich vor Reichsstände zu halten, Jena I704, I. Aufl. Wittenberg I 742.

$55^{8} »$ Er ist neidisch auf die Ehren und Reichtümer der Anderen, [...] er ist begierig sowohl Bekanntheit als auch Ruhm zu erreichen und er bemüht sich sehr, aufdass Fürsten aus fremden Ländern zu ihm kommen und zufrieden und voller Bewunderung seiner Größe und seines Staates wieder abreisen; [...] aber man muss festhalten, dass der Herzog von Ferrara bezüglich seiner Macht und seines Staates ein mittelmäßiger Fürst ist, [...]«. Della Rena, Relazione, $64 f$.

559 Lazzari, Le ultime tre duchesse, 267.

560 Eвd., 3 г 8. 
deren in dem Sinne, daß sie dem einen ein Mehr an Prärogativen oder womöglich gar Souveränitätsrechte gegenüber dem anderen eingeräumt hätte«, sondern um »die Ermittlung eines primus inter pares $«^{561}$ handelte.

\subsubsection{Weitere italienische Konflikte um Rang und Vorrang}

Die Auseinandersetzungen um einen höheren Rang oder um eine Krone konnten, wie oben gezeigt wurde, heftig, aufwendig und vor allem langwierig sein. Diese Konflikte waren in Italien, wo die Reichsvasallen den deutschen Reichsständen immer nachgereiht waren, besonders wichtig und ausgeprägt, weil durch Rang und Zeremoniell die Position im nationalen und internationalen System einigermaßen gehalten werden konnte, während andere Dynamiken diese gefährden konnten. Aus diesem Grund kann man mit Schnettger zu Recht von einer »Titelinflation« im I6. und I7. Jahrhundert sprechen und von großen Geldsummen, die für diese Machterhaltungsstrategien aufgewendet wurden. ${ }^{562}$

Tatsächlich waren auch der Präzedenzstreit zwischen den Este und den Medici und die Bewerbung um »Königstitel« nicht einzigartig. Neben dem Rangkonflikt mit den Este führten die Medici zeitgleich einen längeren und z.T. intensiveren Vorrangstreit mit den Savoyern, der Letztere den Herzögen von Ferrara und Modena näherbrachte. Voraussetzung für diese gegenseitige Unterstützung im Kampf um den Vorrang gegen den gemeinsamen Feind aus Florenz aber war eine innige Beziehung auf verschiedenen Ebenen zwischen den Reichsstandfürsten und den kaiserlichen Lehensnehmern aus Ferrara und Modena. Mit den Beziehungen zwischen den Dynastien der Este und der Savoyer im Zeitraum zwischen I $55^{\circ}$ und I650 hat sich letztens Pierpaolo Merlin auseinandergesetzt, der zu dem Schluss kommt, dass es zwischen den beiden Häusern verschiedene Beziehungsmomente gab, so z.B. auch finanzielle Unterstützung in Form von Krediten. Den Hinweis dafür liefert die I 556 an Emanuele Filiberto gerichtete Bitte von Ercole II., die Geldsummen rückerstatten zu wollen, die der Este dessen verstorbenen Vater geliehen hatte. Über diesen finanziellen Austausch hinaus gab es auch einen regen Personenaustausch: Antonio Maria di Savoia, Signore di Collegno war von I 545 und I 558 Berater und Gesandter der Este und maßgeblich an ihrer Wiederannäherung an das Reich beteiligt. Auch rekrutierte Emanuele Filiberto von Savoyen seine Oberbefehlshaber zumeist aus dem estensischen Herzogtum und selbst einer seiner engsten Berater, Filippo d'Este, gehörte der Seitenlinie der Este di San Martino an und heiratete Maria, die illegitime Tochter seines Dienstherrn. Zudem waren der französische Hof von Renée de France und allgemein die Beziehungen der Este zu Frankreich sowie zuletzt die Heiratsverbindungen von Anna d'Este nach Frankreich

56 I Schnettger, Rang, i 80.

562 Ebd., I80, I84, I87. 
und Savoyen ein Berührungspunkt mit diesem Haus. Sowohl Ercole II. wie auch sein Sohn Alfonso II. nutzten ihre Verbindung zum einflussreichen Emanuele Filiberto von Savoyen, um ihre Beziehungen zum Reich und zu Frankreich zu verbessern. ${ }^{563}$

Selbst nach dem Heimfall Ferraras blieben die Beziehungen zwischen den Herzögen von Modena und denen von Savoyen gut, bekräftigt auch I608 durch die Heiratsverbindung zwischen Alfonso III. d'Este und Isabella von Savoyen. Doch mit der zunehmenden Abwendung Savoyens von Spanien und die Auseinandersetzung um das Montferrat kühlte sich das freundschaftliche Verhältnis zwischen den beiden Häusern ab. Erst nach der Mitte des I7. Jahrhunderts, der Klärung einer Erbschaftssache und der beidseitigen Hinwendung zu Frankreich kam es wieder zu einer allmählichen Annäherung. ${ }^{564}$

Als Cosimo I. de’Medici Emanuele Filiberto von Savoyen im Dezember I 569 von seiner Erhebung zum Großherzog durch den Papst unterrichtete, erinnerte ihn dieser, dass sich dadurch nichts am Vorrang seines Hauses ändern werde. Doch um auf Nummer sicher zu gehen, ließ sich der Herzog von Savoyen seinen Vorrang nochmals von Papst Pius V. bestätigen. ${ }^{565}$

Als Maximilian II. I 575 dem Nachfolger in Florenz, Francesco I. de'Medici, den Großherzogstitel verlieh und damit einhergehend den Vorrang der Florentiner vor allen anderen Herzögen festlegte, ${ }^{566}$ kam zwar die 40 Jahre lange Auseinandersetzung mit den Este allmählich zum Erliegen, ${ }^{567}$ doch es entfachte sich ein neuer Streit mit Savoyen. Obwohl sich die beiden Kontrahenten gegenseitig versicherten, dass alles beim Alten bleiben würde, schlug der Savoyer zwei Wege ein, um seine Position zu wahren. Der eine führte ihn zum Kaiser, wo er als Reichsfürst Gehör zu finden erhoffte, sein Netzwerk aktivierte und vor allem die Unterstützung Brandenburgs und Sachsens suchte. Seine Argumente für die Beibehaltung des Vorrangs waren neben der altehrwürdigeren Herkunft und Genealogie der Savoyer finanzielle Unterstützungen für den Kaiser und seine Berater. ${ }^{568}$ Der andere Weg führte Emanuele Filiberto

${ }_{563}$ Merlin, Savoia ed Este, I $36 f$. Wobei nicht vergessen werden soll, dass die Ausrichtung der Este nach Frankreich schon vor Renée und ihrem französischen Hofstaat bestand.

564 Vgl. Merlin, Savoia ed Este, I 40- I 46.

565 Dazu siehe auch Gribaudi, Questioni di precedenza. Angrolini, Medici e Savoia, 435 f.

$566 \mathrm{Zu}$ diesem kam auch der von Rudolf II. I 576 festgelegte Vorrang der Medici in der kaiserlichen Kapelle, die somit gleich hinter Venedig standen. Angiolini, Medici e Savoia, 438.

567 Fast gleichzeitig wurden von kaiserlicher Seite die Gonzaga von Markgrafen zu Herzögen von Montferrat, Vespasiano Gonzaga zu Herzog von Sabbioneta und die Este zu Reichsfürsten erster Klasse erhoben, sodass alle die Titel Altezza und Serenissimo tragen durften, die eigentlich nur an die Großherzogswürde gebunden waren. Quazza, Preponderanza spagnuola, 352; Spagnoletti, Le dinastie, I 42 - i44. Angiolini, Medici e Savoya, 437, Anm. io.

568 Angiolini spricht von (Geld)Geschenken für den Kaiserhof im Wert von insgesamt I80.000 scudi; eine bemerkenswerte Summe für ein bescheidenes Fürstentum, die aber dennoch weit hinter den von den Medici für die Erhebung bereits ausgelegten 400.000 scudi standen, zu denen nochmals 424.000 scudi hinzukamen. Angiolini, Medici e Savoia, $438 \mathrm{f}$. 
zu Philipp II. von Spanien, der sich anfangs nicht mit Maximilians Entscheidung, den Medici die Großherzogswürde zu verleihen, einverstanden gezeigt hatte. Während Maximilian II. keine weiteren Maßnahmen ergriff, um seine Entscheidung zu rechtfertigen bzw. zu bekräftigen, bestimmte Rudolf II. I577 die väterlichen Bestimmungen in die Tat umzusetzen. Darüber hinaus verfügte er, dass die mediceischen Gesandten ihre Kopfbedeckung vor dem Kaiser nicht abnehmen mussten, was ebenso ein Zeichen von besonderer Ehre war. ${ }^{569}$ Allerdings konnte sich auch Philipp II. nicht überreden lassen, sich im Präzedenzkampf auf die Seite Turins zu schlagen, auch weil der spanische König - während er dem Savoyer sein Engagement beim Kaiser für die Causa versprach - gleichzeitig mit Francesco I. de'Medici verhandelte. Am Ende waren auch dem finanzschwachen Philipp II. 400.000 scudi aus Florenz für seine beachtlichen Kriegskosten eine Fürsprache für die Anerkennung der Großherzogswürde wert. Schließlich wandte sich Emanuele Filiberto als Reichsstandfürst in der Frage um die Rangordnung der italienischen Fürsten an den Reichstag, ${ }^{570}$ der 1582 in Augsburg u.a. auch mit einer Anfrage um Titelverbesserung einiger italienischer Fürsten ${ }^{571}$ befasst war. Obwohl der Reichstag dem Herzog von Savoyen Recht gab, vertagte Rudolf II. die Entscheidungsfindung, was einem Sieg für Florenz gleichkam. Dennoch blieben die Zusammenstöße zwischen den toskanischen und savoyischen Gesandten nicht aus. Außerdem hatten am französischen Hof sowohl die Savoyer als auch die Este weiterhin den Vorrang vor den Medici. So hielt der Präzedenzstreit zwischen Florenz und Turin weiterhin an und löste sich erst I7 I 3 im Zuge des Friedens von Utrecht mit der Erhebung von Vittorio Amedeo II. zum König von Sizilien als Belohnung für seinen Einsatz im Spanischen Erbfolgekrieg. ${ }^{572}$ Der Königstitel war - das hatten die Este bereits gewusst, die sich für die polnische Krone beworben hatten -

569 Angiolini, Medici e Savoia, 439 f. Siehe auch Roosen, Early Modern Diplomatic Ceremonial.

570 LeEв, Deutsche Reichstagsakten, Reichsversammlungen 1556-1662. Der Reichstag zu Augsburg I 582 , Zweiter Teilband, Supplikation Nr. 434, I383: Hg. Karl Emanuel von Savoyen Vorrang vor dem Großhg. von Toskana in der ksl. Kapelle.« Hier brachten Emanuel Philibert und Karl Emanuel von Savoyen die Klage vor, dass Florenz seit der Erhebung den Platz in der kaiserlichen Kapelle und auch allgemein hinter Venedig und somit vor Savoyen beanspruche und das, obwohl die Erhebungen (päpstliche wie kaiserliche) unter dem Vorbehalt der Nichtpräjudizierung der anderen Reichsstände erfolgt war und obwohl dem Herzog von Savoyen, als Vikar des Reiches, der erste Rang unter den italienischen Fürsten vorbehalten sei. Dieser bat den Kaiser um Intervention und um Entscheidung des Rangstreites gemäß seiner Zusage am Reichstag. Die Kurfürsten unterstützen diese Bitte.

57 I Ebd., Supplikation Nr. 396, I348: „Einige italienische FF. bitten um Verleihung des Titels >Serenissimuss. Ks. fordert dazu Gutachten der Kff. Beschluß des KR am 6.8.: Da nicht klar ist, welche Ff. im einzelnen um die Verbesserung des Titels bitten - Pfalz vermutet Florenz, Parma, Ferrara und Mantua -, soll zunächst in der ksl. Kanzlei nachgefragt werden. Eine weitere Beratung ist nicht protokolliert.«

572 Angiolini, Medici e Savoia, 442f. Hier wird präzisiert, dass beim Tod von Emanuele Filiberto 1580 der savoyische Gesandte am Kaiserhof instruiert wurde, die Causa der Präzedenz weiter zu betreiben und zwar nicht nur beim Kaiser selbst, sondern auch bei den Kurfürsten, den Reichsfürsten, den Erzherzögen und der Kaiserin. Es kann sich hier nur um die Kaiserinwitwe Maria von Spanien handeln, die 1582 noch in Wien weilte, aber im selben Jahr nach Spanien zurückkehrte. Zu ihr siehe zuletzt 
die letzte und einzige Möglichkeit den Vorrang ein für alle Mal zu fixieren. Auch die Medici bemühten sich seit den I $590 e r$ Jahren, den Titel »Könige von Toskana« vom Kaiser zu erhalten und hatten dafür fast 2 Mio. scudi investiert und eine angestrengte internationale Heiratspolitik betrieben. Die Savoyer hingegen, die sich nur innerhalb Italiens verheirateten, holten ihre antiken Rechte auf Zypern und demzufolge den Titel »Könige von Zypern« mit der gebührenden literarischen Unterlegung hervor. ${ }^{573}$ Der von Finanznöten geplagte Rudolf II. wäre sogar geneigt gewesen, Ferdinando I. de'Medici den Königstitel zu verleihen. Als sich aber Philipp III. dagegen stellte, war für den Medici das Risiko, Spanien zum Gegner zu haben, zu groß. ${ }^{574}$

Ein weiterer und gewaltvoller Präzedenzstreit, der die Este direkt betraf, war jener mit den Gonzaga im I 7. Jahrhundert, durch den sich die einst guten Beziehungen ab der zweiten Hälfte des I 6. Jahrhunderts stark verschlechterten. ${ }^{575}$ Ausgangpunkt war wie von Alessandro Bianchi übersichtlich rekonstruiert - die I 536 durch Kaiser Karl V. erfolgte Begünstigung der Gonzaga mit der Zuteilung des Montferrats gegen die erhobenen Ansprüche der Savoyer. Durch die Erhebung der Gonzaga zu »ersten Reichsfürsten«, durch Heiratsverbindungen zum Kaiserhaus und Ambitionen wie jenen von Guglielmo Gonzaga um den Titel Altezza serenissima, versuchten sie den anderen italienischen Fürsten, allen voran den Este, Konkurrenz zu machen. Der Wendepunkt kam mit der Devolution und dem Heimfall Ferraras, wodurch die Este von Modena aus unter großem Prestigeverlust ihre in- und ausländischen Beziehungen neu ordnen mussten. Ab jetzt verlangten die Gonzaga den Vorrang vor den degradierten Este und begannen eine erbitterte Feindschaft, die sich u.a. auch im Fehlen von Heiratsbeziehungen zwischen den beiden Familien und einer frostigen, knapp gehaltenen Korrespondenz ausdrückte. ${ }^{576}$ Unterstrichen wurde die Feindschaft zudem vom Streit um das Reichslehen Correggio, das schließlich nach Verhandlungen der Este mit Spanien und Frankreich r659 im Pyrenäenfrieden dem Herzog von Modena zugesprochen wurde. ${ }^{577}$ Allen französischen und kaiserlichen Interventionen zum Trotz blieben die Anfeindungen zwischen den Este und den Gonzaga ebenso wie wiederholte militärische Angriffe in den gegenseitigen Grenzgebieten und die Auseinandersetzungen um die Wasserversorgung am Fluss Po noch lange bestehen. ${ }^{578}$

Koller, Maria von Spanien. Wie die Este versuchten auch die Savoyer ihr Vorhaben bei mehreren Mitgliedern des Hofes (gleichzeitig) anzubringen und deren Hilfe zu erbitten.

573 Angiolini, Medici e Savoia, 446f. Siehe auch: Oresko, The House of Savoy.

574 Ebd., $452 \mathrm{f}$.

575 So nannte Carlo II. Gonzaga-Nevers den Herzog von Modena Francesco I. d'Este eine »hidra rinascente con moltiplicate teste/eine wachsende Hydra mit mehreren Köpfen«. Alessandro Luzio, L'Archivio Gonzaga di Mantova, La corrsipondenza familiare, amministrativa e diplomatica dei Gonzaga, Verona I 92 2, 201 , zit. n. BIANCHI, Una rivalità.

576 Bianchi, Una rivalità, 354-358. Vgl. zuletzt auch Schnettger, Zwei Ehen und ihre Folgen.

577 Dazu u.a. Cochrane/Villani/Cialdea, Gli Stati italiani.

578 BIANCHI, Una rivalità, $364-367$. 


\subsection{Die Nachfolgeregelung in den päpstlichen und kaiserlichen Lehen}

Auch in Reichsitalien legte das salische Gesetz fest, dass Lehen nicht an die weibliche oder illegitime Linie vererbt werden konnten. Doch zahlreiche Beispiele aus der südlichen Peripherie des Reiches zeigen, dass die Kaiser der Frühen Neuzeit aus staatspolitischen Überlegungen heraus bereit waren, das Gesetz zu beugen. So erreichte Vespasiano Gonzaga di Sabbioneta (I 53 I - I59I) von Kaiser Ferdinand I., dass sein einziges Kind, die Tochter Isabella, Ehefrau von Luigi Carafa, Fürst von Stigliano, ihm im Reichslehen folgen und somit ein anderes Haus hier die Herrschaft übernehmen durfte. Doch das beste Beispiel diesbezüglich ist die Übernahme des Reichslehens Mantua durch die Seitenlinie der Gonzaga-Nevers nach dem Ableben des kinderlosen Vincenzo II. I $627 .{ }^{579}$

Nicht anders hatten es die frühen Este-Fürsten mit kaiserlichem und päpstlichem Einverständnis gehandhabt. Für fast I 50 Jahre hielten illegitim geborene Mitglieder der estensischen Dynastie die Herrschaft in Ferrara und Modena-Reggio. Während die meisten der europäischen Monarchien seit der Mitte des I 5. Jahrhunderts die Nachfolge von Illegitimen ausgeschlossen hatten, blieb es in Italien länger üblich, noch den einen oder anderen »Bastard« unter den eigenen Herrschern zu dulden: so hatten die Malatesta aus Rimini fünf in ihren Reihen. Doch nach dem Tod von Borso I 47 I übernahm auch im Haus d'Este kein Illegitimer mehr die Herrschaft, was u.a. an den an die Herzogswürde geknüpften Investiturbedingungen von Papst und Kaiser lag. ${ }^{580}$

Die Wahl eines Nachfolgers entsprang nach Jane Fair Bestor bis zur Mitte des I 5. Jahrhunderts den Überlegungen nach der Eignung für das Amt, der Heiratspolitik und der von den Lehensherren ausgehenden Macht der Legitimierung. Das Fehlen eines legitimen Nachfolgers oder die gleichzeitige Existenz von legitimen und illegitimen bzw. legitimierten Söhnen war für eine Dynastie immer ein Risikofaktor, denn es rief die Debatte über brüderliche Gleichberechtigung und die Frage nach dem Vorrang der Legitimität vor dem Altersanspruch (Erst- bzw. Frühergeborenenanspruch) hervor. Die Gleichberechtigung von Brüdern und die gemeinsame Regentschaft von diesen war in Norditalien ein relativ weitverbreiteter Usus, auch wenn er nicht die Illegitimen miteinbezog, obwohl sie von gleichem Blut waren und von Natur aus "zum Haus« gehörten. Obwohl das Recht des Älteren Vorrang hatte, war es meist undenkbar, dass ein Illegitimer, weil älter, in der Nachfolge vorgezogen wurde, auch weil Papst und Kaiser die Macht hatten, diesen zu legitimieren. Im Mittelalter zogen es die Este wie auch andere italienische Fürsten vor, bei fehlenden männlichen Nachkommen eher ihre illegitimen Söhne zur Nachfolge zu bringen - gegebenenfalls durch Legitimie-

579 Spagnoletti, Le donne, 30.

580 Bestor, Bastardy, 549f, auch italienisch und mit anderen Beispielen: Gli illegittimi. 
rung - als ihre legitimen Töchter mit der Erbschaft der Macht zu betrauen. Dies ergab sich aus dem sozialen und kulturellen Verständnis von Nachfolge in ausschließlich agnatischer Linie. Schließlich floss in den Adern der »Bastarde« dasselbe Blut, sie gehörten zur Dynastie und trugen meist den gleichen Namen. Außerdem wurde die Wahl eines Illegitimen als Nachfolger mit der zwingenden Verpflichtung des Weiterbestehens der Herrschaft und somit des Friedens und Wohlergehens der Untertanen gerechtfertigt. Frauen hingegen waren und blieben Trophäen, eine hoch- oder höherrangige Braut zu erobern, galt als Auszeichnung und Möglichkeit, die eigene soziale Stellung zu verbessern. Die Este zeichneten sich in ihrer Staatsführungspraxis aber laut Bestor durch beide Faktoren aus: »bastardy and hypogamy «. ${ }^{581}$

Waren die »Überwinder« der mittelalterlichen Kommunen, die neu etablierten Herrscher auch im Rahmen der Wahl per Volksakklamation bemüht, ihre illegitimen Nachfolger auszuschließen, so nahmen die Este gerade am Anfang ihrer Etablierung diese Regelung wenig ernst. Der erste illegitime Este war Obizzo II., der I 264 noch minderjährig gewählt wurde. Er konnte auf dem schon etablierten Namen des Hauses Este aufbauen, das wiederum von den großen Besitzungen, vom Markgrafentitel und von einer Reihe von bedeutenden Heiratsallianzen sowie von der Vorherrschaft der Guelfenpartei in der Mark Treviso profitierte. Obizzo folgte dem Gewohnheits- und Feudalrecht und bestimmte in seinem Testament seine drei legitimierten Söhne Azzo, Aldobrandino und Francesco als gemeinsame Nachfolger und Erben. Doch der älteste Azzo monopolisierte die Macht und den Besitz. Er stillte seinen Durst nach internationalem Ruhm I 305 mit der Heirat mit einer Tochter von König Charles II. von Anjou. Diese Ehe war ausschlaggebend für eine Änderung der Nachfolgeregelung. Azzo führte die Primogenitur in seinem Fürstentum ein, an die er sich jedoch selbst nicht hielt, da er in seinem letzten Willen die Nachfolge Fresco, dem Sohn seines ältesten illegitimen Sohnes, übertrug und seinem Sohn ausdrücklich die Nachfolge verweigerte.

Auch Obizzo III. hatte keine legitimen, stattdessen I I illegitime Kinder, die er als Beweis dafür, dass er sie für die Nachfolge geeignet hielt - allesamt nach seinen Vorfahren benannte. Die ersten sieben waren während seiner rechtmäßigen, kinderlos gebliebenen Ehe geboren und daher als spurii vor einer rechtmäßigen Legitimierung durch Kaiser oder Papst nicht zur Nachfolge oder Erbschaft berechtigt. Die Kinder, die nach dem Tod seiner Frau aber noch vor seiner Heirat mit deren Mutter Lippa Ariosti $^{582}$ geboren worden waren, waren illegitim oder naturales, entsprungen einer Beziehung zwischen einem Mann und einer Frau, die frei von einer ehelichen Bindung

58 I Bestor, Bastardy, 556.

582 Die Konkubinen der Este kamen nicht oder nur sehr selten aus den großen Familien Ferraras, Modenas oder Reggios. Es waren vielmehr kleinadelige oder bürgerliche Töchter, für die die Ehre einer Liaison mit dem Fürsten die Schmach übertraf: Dazu gehörten Familien, die erst kürzlich nach Ferrara gekommen waren und sich etablieren wollten (Ariosti, Albaresani) oder in Armut gefallene ländliche Eliten (Roberti). Die vom Fürsten anerkannten Söhne und Töchter wurden ab einem Alter von sechs bis acht Jahren am Hof erzogen und ausgebildet. Bestor, Gli illegittimi, 83. 
waren. Diese natürlichen Kinder hatten begrenzte Erbrechte und wurden durch die auch nachträgliche - Heirat ihrer Eltern legitimiert. Doch in beiden Fällen war die Anerkennung durch den Vater und nicht der Grad der Illegitimität ausschlaggebend. Einige Jahre nach dem Tod seiner ersten Ehefrau beantragte Obizzo bei Papst Clemens VI. die Legitimierung seiner außerehelichen Kinder. Der Papst, der die estensische Unterstützung benötigte, stimmte der Legitimierung unter der Voraussetzung zu, dass Obizzo die Mutter der Kinder heirate. Dieser ging - aus Kalkül wie Bestor festhält - lange nicht auf diese Bedingung ein: Solange Kinder folgen konnten, war es besser, wenn alle illegitim blieben, als dass vorrangig die nach der Heirat Geborenen als legitim galten. Erst als der Este Lippa auf ihrem Sterbebett heiratete, konnte die päpstliche Anerkennung ihren Lauf nehmen. Juristisch gesehen konnte der Papst keine Legitimierung für die Titel und Lehen des Kaisers übernehmen. Doch Clemens VI. umging diese rechtlichen Vorgaben und legitimierte Obizzos Söhne auch für deren Nachfolge in den kaiserlichen Lehen mit der Begründung, dass der Papst in einer Zeit der kaiserlichen Vakanz diese Befugnisse besaß. ${ }^{583}$

Auch Alberto d'Este hatte nur einen illegitimen Sohn, Nicolò, den er legitimieren und namentlich in der Erneuerungsurkunde des kaiserlichen und päpstlichen Lehensverhältnisses anführen ließ. Wie sein Vater hatte Nicolò bis vor seiner dritten, späten Heirat nur illegitime Söhne. Daraus ergab sich ein Legitimations- und Erstgeborenenkonflikt. Das Ganze verschärfte sich mit seiner Entscheidung, Herrschaft und Besitz seinem ältesten, illegitimen Sohn zu übertragen. ${ }^{584}$

Tatsächlich baute Nicolò III. die Nachfolge seines natürlichen Sohnes Leonello auf die Allianz mit Gianfrancesco Gonzaga auf. Die Este waren dem Herrn von Mantua eine große Summe schuldig, der sie in die Mitgift seiner legitimen Tochter Margherita umwandelte, die Leonello heiraten sollte. Für diese vorteilhafte Eheschließung versprach Nicolò, die Legitimierung des unehelichen Sohnes beim Papst durchzubringen ebenso wie die Investitur mit Ferrara und mit den kaiserlichen Lehen. Er selbst schloss eine Heirat mit einer Tochter aus dem Haus Saluzzo und näherte sich so den mit diesen verwandten Häusern der Savoyer und Frankreichs. Aus dieser Ehe entstammten Ercole (* I43I) und Sigismondo (* I 433). Ab I 434 war Leonello bereits von seinem Vater mit großen Befugnissen ausgestattet worden und wirkte als Mitregent. Doch zum Universalerbe und Nachfolger ernannt wurde er erst auf dem Sterbebett seines Vaters I44I.

Anders als im vorangegangenen Jahrhundert waren die nicht regierenden Brüder nur Mitglieder des dynastischen Familienkörpers und nicht Anspruchsberechtigte auf die Mitregentschaft. ${ }^{55}$ Nichtsdestoweniger war es gerade die Einbindung der Brüder in die Herrschaft, die Leonello und Borso - trotz ihres Status' als Usurpatoren - an der Macht hielten. Erst mit Ercole (I.) begann die legitime Linie der Este die Herrschaft zu

583 Vgl. Bestor, Bastardy, 559-565.

584 Ebd., $568 f$.

585 Bestor, Gli illegittimi, 87 f. 
führen und die Primogenitur wurde unantastbares Gesetz. Ercole I. verfeinerte noch das Blut der Este mit der Heirat mit der legitimen Tochter von König Ferrante von Neapel, Eleonora von Aragón, sodass deren Nachkommen nun zu Kandidat/inn/en für Heiraten in königliche, kaiserliche und päpstliche Familien avancierten. Dieser neue erhöhte Status ergab sich nach Bestor nicht zuletzt durch den Übergang zur legitimen Linie und zum Ausschluss von Illegitimen/Legitimierten von der Nachfolge. Um ganz auf Nummer sicher zu gehen und diese Nachfolgelinie des Erstgeborenen zu wahren, verbot Ercole seinem jüngeren Sohn zu heiraten, bevor der Thronfolger Alfonso an die Macht gekommen war und selbst die Primogenitur garantieren konnte. Außerdem wies er den Jüngeren an, dem älteren Bruder und zukünftigen Herrscher in Gehorsam und Treue zu dienen und beendete somit eindeutig die einstige Tradition der Mitregentschaft. ${ }^{586} \mathrm{Ab}$ diesem Moment versuchte kein Bastard - wie vorher noch üblich - seine Nachfolgeansprüche zu erkämpfen, was mitunter auch am dynastischen Hierarchisierungsprozess innerhalb des Staatensystems gelegen haben könnte. Schließlich war ein Erfolgskonzept der dynastischen Herrschaft die Unterbindung von internen Machtkämpfen und die dadurch hervorgerufene Schwächung nach außen. Stabilität, Frieden und Konsolidierung von Wohlstand im Fürstentum verlangten Einigkeit und Zentralisierung der Macht im Herrscherhaus. Die Zunahme der Bedeutung von Ehre als persönliche und dynastische Eigenschaft ließ zudem illegitim Geborene in der Hierarchie des Hauses trotz ihrer Blutsbande und des Familiennamens nach unten steigen. Die Schwierigkeit für den kinderlosen Alfonso II. einen Sohn aus der illegitimen Linie der Este akzeptieren zu müssen, zeigt, wie sich die Auffassung im I6. Jahrhundert gegenüber den Gepflogenheiten des I 4. und z.T. I 5. Jahrhunderts geändert hatte. Verbindungen mit den wichtigsten Häusern Europas hatten zu einem hohen sozialen Status geführt, der nun durch Kinderlosigkeit gefährdet war. Es war also ein Wettkampf zwischen dem mittlerweile etablierten Nachfolgerecht und der Verpflichtung zur Reinheit der Blutlinie, deren Bedeutung im Präzedenzstreit mit den Medici wiederholt betont worden war, und der Notwendigkeit des Überlebens und der Weiterführung der Dynastie. ${ }^{587}$

\subsubsection{Die Belehnung der Seitenlinie mit den kaiserlichen Lehen und der Beginn einer neuen Beziehung zum Reich}

Die Verhandlungen mit dem Kaiser, die schlussendlich zur Entscheidung führten, Cesare d'Este aus der Seitenlinie der Markgrafen von Montecchio I 597 als Nachfolger des kinderlosen Alfonso II. mit Modena, Reggio und Carpi zu belehnen, begannen

586 Bestor, Bastardy, 575 f.

587 Der Makel der illegitimen Herrscher des I 5. Jahrhunderts war für die Hofchronisten eine große Herausforderung in der Rechtfertigung der »ungebrochenen« Ehre dieses Herrscherhauses gewesen. Vgl. die dahingehenden Bemühungen bei Bestor, Bastardy, 577-58r. 
bereits in den späten I 58 oer Jahren. Im Frühjahr I 587 ließ Alfonso II. seinen Gesandten Ascanio Geraldini dem Kaiser andeuten, dass der Papst Ansprüche auf die kaiserlichen Lehen Modena und Reggio stelle, die - dies sollte der Diplomat nebenbei erwähnen - im Jahr nicht mehr als 200 Dukaten an Rendite abwarfen. Außerdem fügte er den Instruktionen für den Gesandten eine Liste aller Gründe für die Weiterführung der Este-Herrschaft nach seinem Tod bei. Darunter waren Argumente zu finden wie die ständige Verteidigung der Reichsrechte durch die Familie d'Este gegen die Ansprüche der Kirche, und das - so Alfonso - obwohl die Este von der Kirche bessere Bedingungen als vom Kaiser hätte erhalten können (»che hanno intraprese guerre fin contra i Pontifici per difendere i diritti Imperiali anchorche havessero potuto haver partiti molto migliori da loro che dall'Imperatore«); weitere Gründe zugunsten seines Fürstengeschlechts waren die vorangetriebenen kostspieligen Verbesserungen und die territoriale Vergrößerung des Reichslehens (»che i miglioramenti sono stati fatti nel feudo, et sono debiti al Vassallo per giustizia, sono di tanta stima [...], che le spese sarebbero inestimabili«) und schließlich die Tatsache, dass die Este mit Reichsrechten und Einkünften ausgestattet, besser dem Kaiser dienen könnten. ${ }^{58}$ Tatsächlich hatten alle Estefürsten zur Vergrößerung, Festigung und Verschönerung ihres Fürstentums beigetragen, auch wenn sie sich dabei weniger der kaiserlichen Lehen als vielmehr des päpstlichen Lehens Ferrara angenommen hatten. Hier hatten sie die Pflasterung von Straßen, den Bau von delizie (Copparo und Montagnola), die Trockenlegung des Polesine sowie die Erweiterung der Verteidigungsanlage vorangetrieben.

Im November I 587 berichtete der Gesandte vom Kaiserhof von den Schwierigkeiten, Unterstützung für die Nachfolge Cesares zu finden. Er präzisierte, dass man sich einflussreichen Räten wie Vizekanzler Weber und Reichshofrat Harrach, ${ }^{589}$ die ja dem Kaiser die Causa vorbrachten, zumeist mit 25-30 Gulden für jeden erkenntlich zeigen musste. ${ }^{590}$ Prinzipiell sei der Kaiser nicht abgeneigt, die Investitur der Seitenlinie zu gewähren, wenn zwei Punkte geklärt seien: Der Kaiser ließ über den Gesandten fragen, wer dieser Don Cesare eigentlich sei, in welcher Beziehung er zu Alfonso II. stehe und wie er bzw. dessen Nachfolger das kaiserliche Lehen weiterzuführen gedenke. Zweitens - und das war wohl das eigentlich Wichtige - solle mitgeteilt werden, was Alfonso bereit sei für den Kaiser zu tun, um diese Investitur zu bekommen. ${ }^{591} \mathrm{Im}$

588 Alle Zitate: ASMo, ASE, Casa e Stato, Carteggio di Ambasciatori, Germania b 46, Istruzioni an Ascanio Geraldini, November 1587. Ähnliche Istruzioni mit denselben Gründen folgten im Februar und März i 588 .

589 Leonhard Freiherr von Harrach, Hofkanzler (I 5 I 4 - I 590 ), Reichshofrat, Obersthofmarschall, Oberstkämmerer, Obersthofmeister. Vgl. Fellner/Kretschmayr, Die österreichische Zentralverwaltung, Anhang: Verzeichnis der Inhaber der obersten Hofwürden und der Vorstände der Zentralbehörden I 526 - I 749, 275, 277, 278, 280.

590 Wie bescheiden dieses Bestechungsgeld war, zeigt der Vergleich mit den oben genannten Summen, die von den Medici für die kaiserliche Großherzogswürde an die Minister weitergereicht wurden.

59 I ASMo, ASE, Casa e Stato, Ambasciatori per la Germania b 46, Minute di dispacci per Germania an 
darauffolgenden Frühjahr erbat sich Alfonso vom Kaiser die Zusendung eines der italienischen und deutschen Sprache mächtigen Vertrauten, um die Causa der Investitur zu besprechen. Diesem Wunsch scheint der Kaiser entsprochen zu haben, wenn im Juli darauf hingewiesen wird, dass Rudolf II. »mit eigenen Augen sehen konnte«, wie gut es den Menschen unter der Herrschaft der Este ergehe. ${ }^{52}$

Die Verhandlungen zogen sich in die Länge und füllten die Gesandtenberichte und Instruktionen der folgenden zehn Jahre. Der jeweilige estensische Gesandte wurde genauestens instruiert, wie er das Investiturgeschäft dem Kaiser und den Ministern vorzubringen habe. Dabei sollte stets auf die Nachteile eingegangen werden, die dem Kaiser entstehen würden, falls er nicht Alfonsos Wille berücksichtigen sollte. In weiterer Folge wurde auch dadurch Druck ausgeübt, dass, wenn das Reichsoberhaupt sich weiter Zeit ließe, unweigerlich mit Rom verhandelt werden würde, auch weil man sich ja nicht sicher sein konnte, ob der Kaiser einschreiten würde, wenn der Papst Modena und Reggio bedrohen sollte. Provokant sollte auch vorgeschlagen werden, die Investitur mit den kaiserlichen Lehen dem Papst zu überlassen, der - so die gewagte und eher naive Annahme - sicher die Este einsetzen würde. Diese Argumentation kann rückblickend angesichts der päpstlichen Unbeweglichkeit bezüglich einer Weiterbelehnung mit Ferrara nur als eine der Unentschlossenheit des Kaisers geschuldete Verzweiflungstat verstanden werden, der Alfonso mit Erpressung - und nicht mit Naivität - Nachdruck verlieh. Im März I 590 sollte der Gesandte den Ministern »Curtz« und »Ronff « ${ }^{593}$ klar machen, wie aufreibend das Warten auf die Investiturzusage sei und dass sein Herr, wenn er nicht die kaiserliche Belehnung erhielte, wohl die päpstliche annehmen müsse. ${ }^{594} \mathrm{Im}$ darauffolgenden Monat hielt Alfonso den Gesandten Geraldini dazu an, den Kaiser in der Entscheidung der Investitur anzutreiben, aber mit

Ascanio Geraldini, November I 587 . Derselbe Gesandte klagte noch I 590 , dass der Kaiser Zeit verliere, während seine Minister viel anderes zu tun hätten und ihn deshalb abwimmeln würden, wenn er jeden Tag vorbeikäme und nachfrage. Ebd. B 49, Istruzione per la Germania an Ascanio Geraldini, Juli I 590.

592 ASMo, ASE, Casa e Stato, Ambasciatori per la Germania b 46, Istruzioni an Ascanio Geraldini, Mai/ Juli 1588 .

593 Damit sind in italianisierter Lautschrift Reichsvizekanzler Jakob Kurz von Senftenau (I 553/8 - I 594) und Wolf Sigmund Rumpf ( $5_{53} 6$ - r6o6) Oberhofkämmerer, Obersthofmeister und Geheimrat des Kaisers gemeint. Beide waren bereits unter Kaiser Maximilian II. tätig und gehörten zusammen mit den beiden Trautson zu den einflussreichsten Günstlingen am Kaiserhof. Rumpf war zusammen mit anderen kaiserlichen Räten wie Dietrichstein auch ein (gut bezahlter) Pensionär König Philipps II. und dementsprechend eine der bedeutendsten Figuren in der spanischen Gruppierung am Kaiserhof. Siehe Felix Stieve, Rumpf zum Wülroß, Wolfgang Sigmund, in: ADB 29, Leipzig r 889, 668 f. Weiterführend auch Friedrich Edelmayer, »Manus manum lavat«. Freiherr Wolf Rumpf zum Wielroß und Spanien, in: Erwein H. Eltz/Arno Strohmayer (Hgg.), Die Fürstenberger. 800 Jahre Herrschaft und Kultur in Mitteleuropa (= Katalog des Niederösterreichischen Landesmuseums N.F. 342), Wien i 993, 235-252; Edelmayer, Söldner und Pensionäre, 9i-94. Zu Jakob Kurz siehe Ehrenpreis, Kaiserliche Gerichtsbarkeit, 303 und Noflatscher, Regiment aus der Kammer?, 2 I 8 f.

594 ASMo, ASE, Casa e Stato, Ambasciatori per la Germania b 49, Minute di dispacci per la Germania an Ascanio Geraldini, März I 590 . 
dem Hinweis, dass nicht mehr Geld als vereinbart von ihm kommen werde, da er sich ja auch um die Nachfolge im päpstlichen Lehen Ferrara kümmern müsse; außerdem ließ er die unterschwellige Drohung einfließen, dass er andernfalls den Gesandten vom Kaiserhof abziehen müsse. ${ }^{595}$

Im Sommer r 59 I wurde dem Kaiser mitgeteilt, dass das Volk in den kaiserlichen Lehen die Este als ihre Fürsten gewählt hätte. Darauf ließ Rudolf II. über die Gesandten antworten, dass er den beiden Städten (Modena und Reggio) nicht das freie Wahlrecht zur Bestätigung der Este gegeben hätte. Die mittlerweile durchgeführte - eine kaiserliche Entscheidung präjudizierende - Wahl müsse somit für null und nichtig erklärt werden. Doch der Kaiser sei bereit, Alfonso diese rechtliche Dreistigkeit zu verzeihen. Der Este durfte - so der erste Ansatz - aufgrund seiner Treue und seiner guten Dienste einen Nachfolger aus der Seitenlinie vorschlagen. Im Gegenzug verlange der Kaiser 400.000 scudi d'oro, das Ende der Ansprüche auf die Mitgift der zweiten Gemahlin des Herzogs, Erzherzogin Barbara, und natürlich Treue und Gefolgschaft im Kampf gegen die Osmanen. ${ }^{596}$ Somit ist Jan Paul Niederkorn zuzustimmen, wenn er Alfonso II. d'Este unter jenen Potentaten zählte, »die mit dem Ausbruch des >Langen Türkenkrieges` die Gelegenheit zur Erfüllung eigener Wünsche gekommen sahen [...] «. ${ }^{597}$ Zum Jahresende I59I ließ Alfonso, dem die Verhandlungen zu langsam und die Bedingungen zu hoch waren, durch den Gesandten Marcantonio Ricci ${ }^{598}$ das Gerücht am Kaiserhof verbreiten, dass er nach Rom gehen wolle, um sich vom Papst auch die Belehnung der kaiserlichen Lehen für Cesare zusichern zu lassen. Dies war nicht nur unrechtmäßig und eine Beleidigung der Reichsautorität, sondern überspannte eindeutig den Bogen und führte zu einem Rückschlag in den Verhandlungen mit dem Kaiser. ${ }^{59}$ Nichtsdestotrotz oder gerade deswegen wurde die Drohung, sich an Rom wenden zu wollen, im April des darauffolgenden Jahres verstärkt und zusätzlich die Idee vorgebracht, Alfonso könnte jemanden unterbelehnen (subinfeudare). Der Gesandte Graf Calcagnini sollte nachfragen, ob es so etwas im Reich schon gebe. ${ }^{600}$

Im Oktober wurde der neue estensische Gesandte am Kaiserhof, Graf Luigi Montecuccoli, darüber instruiert, dass er - da der Kaiser immer noch über die Investitur nachdenke - das Angebot um 20.000 scudi erhöhen solle. Allerdings sollte der Gesandte anklingen lassen, dass, da Rudolf II. Alfonso augenscheinlich nicht gewogen sei,

595 Ebd., Mai I 590.

596 ASMo, ASE, Casa e Stato, Carteggio di Ambasciatori, Germania b 5 I, Minute di dispacci per la Germania an Marcantonio Ricci, Juli I 591.

597 Niederkorn, Die europäischen Mächte, 4 I I.

598 Graf Marcantonio Ricci war im diplomatischen Dienst der Este im Reich tätig und zudem Statthalter in der Gafagnana und herzoglicher Rat. Vgl. PACCHI, Ricerche istoriche, XC, CXXIV.

599 ASMo, ASE, Casa e Stato, Carteggio di Ambasciatori, Germania b 5 I, Istruzioni per Germania an Marcantonio Ricci, November I 59 I und Minute di dispacci per Germania an Marcantonio Ricci, Dezember I 59I.

600 Ebd., Istruzione per Germania an Guido Calcagnini, April I 592. 
das Reichsoberhaupt nach Meinung der italienischen Fürsten schuld sein werde, wenn es zu Skandalen und Unruhen in Italien kommen sollte. Außerdem versuchte Alfonso bei Rudolf II. mit dem Geschenk eines prächtigen Pferdes zu punkten. Die Strategien, den Kaiser für die Nachfolge eines Mitglieds der Seitenlinie zu gewinnen, waren also mannigfaltig und erfolgten zumeist zeitgleich: Bestechung, Drohungen, Treuebekundungen und Geschenkepolitik. ${ }^{601}$ Allerdings zeugen die knapp aufeinanderfolgenden weiteren Instruktionen für den Gesandten von einer verschärften Vorgangsweise und einem immer weniger geduldigen Ton. ${ }^{602}$

Im Frühjahr I 593 füllten ähnliche Argumente die Gesandtenkorrespondenzen von und zum Kaiserhof: Der - nicht rechtskräftige - „Volkswillen«, die Drohung auf das (angebliche) päpstliche Belehnungsangebot einzugehen und die Aussicht auf 200.000 scudibfür den Türkenkrieg, die Alfonso aber gern als Teilzahlung der Investiturgebühr angerechnet haben wollte. ${ }^{603} \mathrm{Im}$ Oktober desselben Jahres schrieb Alfonso dem Kaiser persönlich, dankte für die Neuigkeiten über den Türkenkrieg, ${ }^{604}$ sprach seine Hoffnung auf ein gutes Ende desselben aus und wiederholte seine Bereitschaft zur Kriegsteilnahme unter bestimmten, die Nachfolge betreffenden Bedingungen. ${ }^{605}$ Im Herbst I 594 teilte Kaiser Rudolf II. dem estensischen Herzog persönlich mit, dass er lieber Geld als bewaffnete Streitkräfte zur Unterstützung im Türkenkrieg hätte, womit sich Alfonso für die Zukunft seine Dankbarkeit sichern könne. ${ }^{606}$ Über Marcantonio Ricci ließ der Este daraufhin hartnäckig wiederholen, wie vorteilhaft seine Erfindungen und seine Waffen im Türkenkrieg wären und zeigte sein Entgegenkommen, indem er dem Kaiser vorweg die Pläne für eine bestimmte Armbrust schickte. ${ }^{607}$

Zu Beginn des Jahres I 595 ließ Alfonso, der den Kaiser im andauernden Türkenkrieg sofort unterstützen wollte, sobald die Investitursache endgültig geklärt sei, seinen Gesandten Ricci am Kaiserhof um Landschaftsbilder bitten, um vorab seine militärische Erfahrung in den Dienst des Kaisers zu stellen und um einschätzen zu können, wie die Türken vorrücken würden. Außerdem wollte er wissen, wie die kaiserlichen Truppen ihre Reiter ausrüsteten. Neben diesen recht unverbindlichen Interessensbe-

6or ASMo, ASE, Casa e Stato, Carteggio di Ambasciatori, Germania b 50, Istruzioni per Germania an Luigi Montecuccoli, Oktober 1592.

602 Darin teilte Alfonso mit, nicht mehr länger auf die kaiserliche Entscheidung warten und stattdessen die päpstliche Belehnung der kaiserlichen Lehen annehmen zu wollen. Allerdings instruierte er den Gesandten auch über das Angebot, das den Ministern zu unterbreiten sei. ASMo, ASE, Casa e Stato, Carteggio di Ambasciatori, Germania b 5o, Istruzioni per Germania an Luigi Montecuccoli, Oktober und Dezember 1592 .

603 Ebd., Februar und März I 593.

604 Allerdings erhielt er die meisten Nachrichten von seinen Gesandten und von Kaufleuten.

605 Wien, HHStA, Serie Italien-Kleine Staaten Karton io, Fasz. Ferrara I 528 - I 75 8, Alfonso II. an Kaiser Rudolf II., Oktober I 593.

606 Ebd., Rudolf II. an Alfonso II., September I 594.

607 ASMo, ASE, Casa e Stato, Carteggio di Ambasciatori, Germania b 5 I, Minute di dispacci per Germania an Marcantonio Ricci, November 1594. 
kundungen für das Kriegsgeschehen, sollte der Gesandte auch herausfinden, ob mittlerweile ein anderer Fürst dem Kaiser ein Angebot für das Lehen Modena und Reggio gemacht habe. Am wichtigsten jedoch sei, den Kaiser an die bereits bezahlten 200.000 scudi und die Reichsfürsten daran zu erinnern, dass Alfonso »abreisebereit« stehe und mit seinen militärischen Erfindungen zur Hilfe eilen werde, sobald eine Entscheidung in der Nachfolgeregelung gefallen sei. ${ }^{608}$ Im Juli desselben Jahres erhielt er endlich von Rudolf II. die Möglichkeit, seinen Nachfolger bestimmen zu dürfen und ernannte seinen Cousin Cesare d'Este. Allerdings blieben noch einzelne Belehnungsfeinheiten offen, so wie die Bitte um Unterstützung für Cesare Rom, um auch im päpstlichen Lehen nachfolgen zu können. ${ }^{609}$

Im Februar 1596 schrieb Alfonso dem Kaiser, dass er von seinem Gesandten Ricci erfahren habe, dass ihn dieser zum Heeresanführer (Luogotenente generale) gegen die Türken machen wolle und dass er den Gesandten in Ungarn beauftragt habe nach Rom zu reisen, ${ }^{610}$ um beim Papst die Investitur der kirchlichen Lehen für Cesare zu erwirken; dafür sei Alfonso ihm sehr dankbar und wolle Ricci, der am Kaiserhof gerade die »Wunderwaffen« seines Fürsten präsentierte, ${ }^{611}$ auch zur Unterstützung der »speditione« nachschicken. ${ }^{612}$ Tatsächlich bot ihm Rudolf II. in einem Schreiben im März I 596 diese militärische Funktion im Kampf gegen die Türken in Ungarn an und in einem zweiten Brief kurz darauf, mahnte er zu Geduld bezüglich der Investitur aus Rom, wo der kaiserliche Gesandte sicher alles Mögliche für den Erfolg machen würde. ${ }^{613} \mathrm{Da}$ aus Rom aber keine positiven Meldungen kamen, verschob sich Alfonsos angedachte Abreise mit 3.000 Männern unter der Führung von Ippolito Bentivoglio, auch weil immer noch einzelne Punkte der kaiserlichen Investitur offen waren und der Este festhielt, dass er ohne dahingehende Sicherheiten verständlicherweise nicht sein Herzogtum verlassen könne. ${ }^{614}$ In der Zwischenzeit sollte der estensische Gesandte dem kaiserlichen Sekretär eine Kollane im Wert von 300 scudi übergeben. ${ }^{615}$ Die Verzögerung der Abreise des Este-Fürsten nach Ungarn war nicht nur ein Druckmittel in der Causa der Investitur, sondern auch eine Hinhaltetaktik. Noch im Januar I597 ließ Alfonso

608 Ebd., Januar und Februar I 595. Zu den waffentechnischen Erfindungen, die mitunter auch als Druckmittel benutzt wurden siehe schon TADDEI, »Optimo architecto

609 ASMo, ASE, Casa e Stato, Minute di lettere ducali a Principi e signori fuori d'Italia, Alfonso II. an Kaiser Rudolf, Juli I 595 .

6ro In einem avviso des Nuntius Girolamo Portia aus Graz heißt es in ähnlicher Weise: »Il sig. duca di Ferrara è stato dechiarato generale in Ongheria da S. M. ${ }^{\text {tà }}$ et il sig. Ricci suo ambasciatore era partito di corte per quest'effetto.« Rainer, Grazer Nuntiatur II/4, Nr. 63, 67, Avvisi, Graz, I 596, Februar 5.

6i i Niederkorn, Die europäischen Mächte, 4I4.

6 2 Wien, HHStA, Serie Italien-Kleine Staaten Karton ro, Fasz. Ferrara I 528 - I 758, Alfonso II. an Kaiser Rudolf II., Februar I 596.

6r 3 Ebd., Rudolf II. an Alfonso II., beide März I 596.

6r 4 ASMo, ASE, Casa e Stato, Carteggio di Ambasciatori, Germania b 5 r, Minute di dispacci per Germania an Marcantonio Ricci, November und Dezember 1596.

6 I 5 Ebd., April I 596 . 
dem Kaiser seine Hilfe ausschließlich in Form von Empfehlungen zur Kriegsführung zukommen, ${ }^{616}$ während er gleichzeitig um die Beschleunigung des Investiturabschlusses bat, da das Gerücht kursiere, der Papst wolle die direkte Herrschaft über Modena und Reggio kaufen ${ }^{617}$ und bis dato ja nur eine Bestätigung von Rudolf II. über den Erhalt der 200.000 scudi und die Vereinbarung, dass die Zahlung der restlichen 200.000 noch folgen würde, ausgestellt worden waren. ${ }^{618} \mathrm{Im}$ Februar erhöhte Alfonso II. den Druck auf den Kaiser erneut und ließ mitteilen, dass der Papst bereits Truppen in der Romagna stationiert habe und nur auf Alfonsos Tod warten würden. ${ }^{619}$ Doch es scheint noch nicht allzu schlecht um ihn bestellt gewesen zu sein, wenn er einige Tage später den Gesandten neu verhandeln ließ: Er sei bereit, Kriegshilfe in Form von 300 Reitern zu schicken, wenn in der Investitur wenigstens das Lehen Ruolo noch aufgenommen werde und wolle dies als Zeichen kaiserlicher Wertschätzung verstehen. ${ }^{620}$ Doch die Entscheidung zögerte sich weiter hinaus und in den Gesandtenberichten und Instruktionen des Jahres 597 wiederholen sich die Drohung, sich an Rom wenden zu wollen, die Anspielungen über die angeblichen päpstlichen Ansprüche auf die kaiserlichen Lehen und die Gerüchte über den Verkauf von Modena und Reggio. ${ }^{621}$

Alfonso II. starb am 27. Oktober I 597 und sein designierter Nachfolger Don Cesare d'Este versuchte vergeblich, auch mit kaiserlicher und anderer Hilfe den Heimfall Ferraras zu verhindern. Wie sein Vorgänger ließ er sich die Macht von den Savi übergeben und feierte dasselbe Zeremoniell wie sein Vetter vor ihm, wenn auch in etwas beschleunigter Form. Auch hier sollte transportiert werden, dass die Herrschaft vom Volk kam. ${ }^{622}$

Drei Tage nach Alfonsos Tod teilte Cesare d'Este dem Kaiser Alfonsos testamentarische Verfügung mit, die ihn zu dessen Erben machte, und bat Rudolf II. über seinen Gesandten - denn er konnte sein vom Papst gefährdetes Fürstentum nicht verlassen - ihn als guten und getreuen Vasallen des Reiches und der Casa de Austria offiziell anzuerkennen, wie mit seinem Vorgänger mühsam und langwierig vereinbart. Der Gesandte brachte zur Bestätigung das Testament von Alfonso II. und jenen Brief mit, in dem Alfonso ihn ernannte und den der Kaiser eigenhändig unterschrieben hatte. In diesem ersten Schreiben gab Cesare an, immer noch auf eine Investitur von der Kirche zu hoffen und bat den Kaiser um entsprechende Unterstützung in Rom bei den Kardi-

6I6 Ebd., Mai und Juni 1596.

6r7 ASMo, ASE, Casa e Stato, Carteggio di Ambasciatori, Germania b 52, Minute di dispacci per Germania an Marcantonio Ricci, Januar 1597.

6i 8 ASMo, ASE, Casa e Stato, Carteggio di Ambasciatori, Germania b 5 I, Minute di dispacci per Germania an Marcantonio Ricci, Juni 596.

6r 9 ASMo, ASE, Casa e Stato, Carteggio di Ambasciatori, Germania b 52, Minute di dispacci per Germania an Marcantonio Ricci, Februar 1597.

620 Ebd., Februar 1597.

62 I Ebd., Mai-August 1597.

622 Vgl. Folin, Gli Estensi, 37-44. 
nälen und beim Papst. ${ }^{623}$ Als im Dezember ein päpstliches Heer Richtung Ferrara zog, um Cesare als nicht rechtmäßigen Nachfolger aus Ferrara zu vertreiben, ließ er seinen Gesandten, Giulio Thiene, Markgraf von Scandiano, um Hilfe bei der Verteidigung der kaiserlichen Lehen bitten. ${ }^{624}$

Noch im Dezember 597 musste Cesare kampflos aufgeben und die päpstliche Machtübernahme in Ferrara zulassen. ${ }^{625}$ Auch die kaiserliche Bestätigung der Investitur der estensischen Seitenlinie mit den Reichslehen Modena und Reggio hielt den Papst nicht davon ab, nach der Einverleibung Ferraras und des umstrittenen Comacchios, die Finger nach Modena und Reggio auszustrecken. Tatsächlich beauftragte Papst Clemens VIII. den Prager Nuntius Filippo Spinelli im März I6oo mit diesbezüglichen Geheimverhandlungen. Der Gesandte sollte Rudolf II. vorschlagen, dem Papst die beiden Reichslehen abzutreten, damit dieser eine neue Einnahmequelle hätte, um den Kaiser im Türkenkrieg substantiell zu unterstützen. Die Verhandlungen Spinellis blieben aber erfolglos und die Este weiterhin Vasallen des Reiches. ${ }^{626}$

Im Juli I603 schrieb Cesare d'Este, nun nur mehr (bestätigter) Herzog von Modena, Reggio und Capri, an Kaiser Rudolf II., dass er als treu ergebener Vasall und Diener (»com io sono fidelissimo Vasallo et servitore humilissimo della Maestà Vostra«) und trotz großer Schicksalsschläge, die ihn und seinen Staat, der auch gleichzeitig Teil des Heiligen Römischen Reiches sei (»che pur è membro del Sacro Imperio«), fast ruiniert hätten, dem Kaiser stets zu Diensten stehen werde. ${ }^{627}$ In Bezug auf den Langen Türkenkrieg blieb Cesares Unterstützung für den Kaiser allerdings bescheiden, wie die von Niederkorn eruierten Zahlen zeigen. ${ }^{628}$

\subsubsection{Die Devolution Ferraras: das Ende der Lehensbeziehung zum Papst}

Die Devolution, der Heimfall des estensischen Lehens Ferrara an den Heiligen Stuhl, ${ }^{629}$ betraf zwar schlussendlich nicht die Reichslehen Modena und Reggio, prägte

623 Wien, HHStA, Serie Italien-Kleine Staaten Karton Io, Fasz. Ferrara I $528-$ I 75 , Cesare d'Este an Rudolf II., November 1597.

624 ASMo, ASE, Casa e Stato, Carteggio di Ambasciatori, Germania b 66, Minute di dispacci per Germania an Giulio Thiene, Dezember 1597.

625 München, BayHStA, Fürstensachenoo59, Kasten Schwarz 7603, Ricardus Aranus an den Herzog (Maximilian ?) von Bayern, Dezember 1597.

626 Niederkorn, Die Geheimverhandlungen.

627 ASMo, ASE, Casa e Stato, Minute di lettere ducali a Principi e signori fuori d'Italia, an Kaiser Rudolf II., Juli I 603 .

628 Niederkorn, Die europäischen Mächte, $424 \mathrm{f}$.

629 Zum Heimfall Ferraras ist im Staatsarchiv von Modena ein eigener Bestand zu finden mit Kopien der päpstlichen Bullen und Investituren, kaiserlichen und anderen Dokumente zugunsten der Este, Berichte des ferraresischen Klerus' und Zeugnissen über die gestellten und belegten Ansprüche bis ins anfängliche I8. Jahrhundert. ASMo, ASE, Casa e Stato, Controversie di Stato 3: Devoluzione 
aber sehr wohl die Beziehungen des letzten Estefürsten aus der Hauptlinie, Alfonso II. und des ersten aus der Seitenlinie der Markgrafen von Montecchio, Don Cesare d'Este, zum Kaiser, zu den Reichsfürsten und auch zu anderen europäischen Mächten. Diese wurden nämlich alle von den Este aufgerufen, sich beim Papst und Kardinalskollegium für die Belehnung der Seitenlinie einzusetzen; in der kritischen Phase der Belagerungsgefahr durch päpstliche Truppen baten die Este Kaiser und Reich auch um militärische Unterstützung.

Bevor auf diese Krise der estensischen Herrschaft eingegangen wird, die - wie gesagt - das päpstliche Lehen Ferrara betraf, aber auch Auswirkungen auf das Lehensverhältnis zum Reich hatte, soll hier kurz auf die Beziehungen der Este zum Papsttum eingegangen werden.

Bereits Anfang des I 4. Jahrhunderts waren die Este von der Kirche als apostolische Vikare in Ferrara eingesetzt worden, hatten I 438 das ökumenische Konzil beherbergt und waren I 47I schließlich auch von päpstlicher Seite in den Genuss des herzoglichen Titels gekommen. Doch bereits Ende des I 5. Jahrhunderts verschlechterte sich die Beziehung zu den Päpsten unaufhaltsam. Ein erstes Indiz dafür findet Folin zu Recht in der Tatsache, dass unter den renommiertesten italienischen Fürstenhäusern die Este die letzten waren, die einen Familienkardinal stellen konnten. Ippolito d'Este erreichte den Kardinalshut erst I 493, viel später als Johann von Aragón, Amadeus von Savoyen, Ascanio Maria Sforza, Taddeo Paleologo, Francesco Gonzaga - die letzten beiden wurden vor den Este erhoben, obwohl sie in der Würde unter diesen lagen. Außerdem wurden im I 5. Jahrhundert neben Ippolito »nur« zwei Kardinäle aus dem estensischen Gebiet gekürt: Bartolomeo Roverella ( 146 г -76) und Giovan Battista Ferrari ( I $_{500}$ - I 502), die allerdings beide aus dem Umland stammten und nicht direkt mit dem Fürstenhaus verbunden waren.

Zwischen I 43 I und 4999 gab es insgesamt 25 Bischöfe aus den Stati estensi ( 2 davon aus Ferrara und drei von der Estefamilie) aber nur neun wurden eingeladen, auswärtige Diözesen zu leiten. Außerdem waren die wenigsten von ihnen Adelige. Ebenso wenige Ferraresen hatten im I 5 Jahrhundert wichtige Aufträge am römischen Hof. Auch die Bischöfe, die Ferrara vorstanden, waren meist Fremde und nur zwei von sieben kamen aus dem Fürstentum, während in Mantua der Bischofssitz ununterbrochen von Abkömmlingen des Fürstenhauses oder von Personen des engsten Hofkreises besetzt wurde. Neben den beiden einfluss- und erfolgreichen Ippolitos und Luigi d'Este sollte es außerdem in Rom nur noch einen Kardinal, Giulio Canani, aus diesem Herrschaftsgebiet geben. Ebenso wenige Kirchenmänner aus dem estensischen Fürstentum erreichten in Rom hohe Würden. Einige davon zeichneten sich sogar dadurch aus, dass sie in Opposition zur fürstlichen Macht der Este standen, wie Ercole

di Ferrara alla Santa Sede e questioni con questa collegate, buste 509-5 I9. Zur Aufarbeitung siehe: Callegari, La devoluzione. Prinzivalli, La devoluzione. Gasparini, Cesare d'Este. Rombaldi, Cesare d'Este. Ballarin, La devoluzione. Guerzoni, Le corti estensi. 
Rangoni oder Rodolfo Pio. Nach Folin scheint es, dass diese zu Kardinälen ernannt wurden, gerade weil sie Gegner der Este waren; wieder andere begannen ihre kirchliche Laufbahn in Rom in jungen Jahren und waren somit dem estensischen Hof nicht oder nur wenig verbunden wie Giacomo Sadoleto oder Tommaso della Badia. Daraus entnimmt man, dass die Bestellung von kirchlichen Würdenträgern nur minimal von den Herzögen mitbestimmt oder beeinflusst werden konnte. Dies sorgte nicht nur für Konflikte, sondern schmälerte den von der estensischen Herrscherfamilie dringend benötigten geistlichen Kommunikations- und Patronagekanal. Im I6. Jahrhundert verschlechterte sich die Situation zunehmend. Zu Beginn kam es - wie oben gezeigt zu kriegerischen Auseinandersetzungen zwischen den Päpsten und den Este, die ihre Spuren bis in die Mitte des I6. Jahrhunderts zogen.

Früher als am Kaiserhof entwickelte sich die Notwendigkeit eines residierenden Gesandten in Rom, ${ }^{630}$ dessen Aufgaben in loco die Pflege der Beziehungen zwischen dem Papst und den Este war; er musste die Bitten um Kirchenämter oder Dispensen und gegen Ende des Jahrhunderts die Bitten um Anerkennung der Seitenlinie als Nachfolger im päpstlichen Lehen vorbringen. Der stärkste Ausdruck dieses schwierigen Verhältnisses zwischen Ferrara und Rom ist die oben bereits zitierte Rechtfertigung Alfonsos I. vor Karl V. im Jahr I 52 I. Hier legitimierte er seine immer wieder beanstandete profranzösische Haltung mit der Aggressivität der päpstlichen Politik, gegen die er stets zu kämpfen hatte, um Ferrara vor der päpstlichen Gier zu retten. ${ }^{631}$ In dieser angespannten Beziehungslage zum Heiligen Stuhl, die im Laufe von drei Este-Generationen entstanden war, schienen die Chancen auf eine Umgehung des päpstlichen Verbotes der Investitur eines illegitimen Erbes von vornherein äußerst gering.

Bezugnehmend auf die Bulle von Pius V. von I 567 wurde dem illegitim geborenen Cesare, der nach Alfonsos Tod am 29. Oktober I 597 vom Consiglio dei Savi zum Herrn über Ferrara »ernannt« worden war, die päpstliche Investitur nicht erneuert. Im Gegenteil: Papst Clemens VIII. ${ }^{632}$ forderte die Rückgabe Ferraras und schien für die Umsetzung der Devolution bereits vortrefflich vorbereitet gewesen zu sein. ${ }^{633}$ Dem estensischen Gesandten in Rom, Girolamo Giglioli, den er nicht als Vertreter des »neuen« Herrschers von Ferrara anerkannte und ebenso wenig dessen Bitte um Investitur erhörte, teilte der Papst mit, dass wenn Cesare nicht sofort Ferrara räume, er Waffengewalt einsetzen würde. Dass dies keine leeren Drohungen waren, zeigt

$630 \mathrm{Zu}$ den frühen Gesandten gehörten der Bischof von Reggio Bonfrancesco Arlotti (I472-I49I), der Bischof von Modena Giovanni Andrea Boccaccio (I49I-I495), der Bischof von Adria Beltrando Costabili, (I 50I - I 509). Folin, Rinascimento estense, 29 I.

63 I Folin, Rinascimento estense, 287-304, 337 mit Verweis auf Gattoni, L'antagonsimo, 639.

632 Papst Clemens VIII. (Ippolito Aldobrandini I 592 - I605). Vgl. Agostino Bor romeo, „Clemente VIII«, in: Enciclopedia dei Papi (2000), online verfügbar: http://www.treccani.it/enciclopedia/clemente-viii_ (Enciclopedia-dei-Papi)/, Zugriff: r6.9.2020.

633 Vgl. auch Pastor, Geschichte der Päpste i I, Kap. 9.2.: "Erwerbung von Ferrara«, 587-605. 
die Tatsache, dass eine Kardinalkongregation mit der Finanzierung des Krieges um Ferrara beauftragt wurde (Monte della recuperatione di Ferrara) und unter dem Oberkommando des Papstneffen, Kardinal Pietro Aldobrandini, und dessen Schwagers, Giovanni Francesco Aldobrandini, Truppen aus dem Kirchenstaat und von außerhalb angeworben wurden. Mit diesen Papstnepoten hatte Clemens VIII. treue und zuverlässige Funktionäre, die sich bewähren wollten, um selbst belehnt zu werden. ${ }^{634}$ Außerdem kam indirekt auch Hilfe aus dem Reich, wie Johann Rainer bereits festgehalten hat. Der Papst ließ durch den päpstlichen Nuntius in Graz, Girolamo Portia, zunächst aus der Steiermark und Kärnten und dann auch aus Wien, Nürnberg und Augsburg Waffen und Schießpulver für die päpstlichen Truppen im Wert von 34.000 Gulden zur Rückeroberung Ferraras erstehen. ${ }^{635}$

Auf diese Bedrohung hin wandte sich Cesare an verschiedene europäische Mächte und bat um Unterstützung. ${ }^{636}$ Die meisten übten sich in Zurückhaltung. Zwar versprachen einzelne italienische Mächte, allen voran Venedig, Hilfe in Form von Fürsprache durch ihre Gesandten beim Papst, blieben ansonsten aber neutral. Der venezianische Gesandte Giovanni Dolfin war sehr bemüht, den Papst vor einem für den Kirchenstaat katastrophalen Krieg zu warnen, wollte aber im Endeffekt nur keine neuen (päpstlichen) Grenznachbarn für Venedig, die der Lagunenstadt das zuletzt eingenommene Rovigo streitig machen konnten. Nicht einmal das Angebot der Herrschaft über Comacchio und seine Täler konnte die Signoria zur konkreten Hilfeleistung überreden. ${ }^{637}$ Der spanische König, von jeher kein Freund der Este, hätte sich nicht offiziell gegen den Papst gestellt, selbst wenn die Ausbreitung der päpstlichen Territorialmacht in Italien auch für ihn nicht erstrebenswert war. Inoffiziell wurde die kirchliche Expansion nur durch den Gouverneur von Mailand, der Cesare militärische Hilfe anbieten sollte, gebremst. ${ }^{638}$ Auch der Kaiser, der vom Kirchenoberhaupt

634 Емiсн, Territoriale Integration, $85-88$ und zuvor schon CALLEGari, La devoluzione und MasetTi ZanNini, La capitale perduta.

635 Nachdem es nicht zum militärischen Konflikt kam, reiste im April I 598 Erzherzog Ferdinand von Innerösterreich inkognito nach Ferrara, wo er herzlich vom Papst und seinen Nepoten empfangen wurde, mit denen er die Vergabe von Kirchenämtern an seine Vertrauten (so z.B. das Bistum Adria für den genannten Nuntius Portia) sowie die Heirat seiner Schwester Margarethe mit Philipp III. von Spanien verhandelte. Der Erzherzog reiste nach Loreto und Rom weiter, um vier Monate später in einem beeindruckenden Brautzug von 650 Menschen wieder nach Ferrara zu ziehen, wo Margarethe vom Papst mit dem König von Spanien verheiratet wurde. Vgl. Rainer, Österreich und Ferrara. Zu den Waffenlieferungen aus Augsburg siehe z.B. den Brief von Pietro Aldobrandini an Portia vom I I. Dezember I 597 in: Rainer, Grazer Nuntiatur II/4, 40 If.

636 Nicht nur seine Hilferufe, sondern auch die Bannbulle wurde europaweit verbreitet. Ein gedrucktes Exemplar der Exkommunikationsbulle von Papst Clemens VIII. für Cesare d'Este befindet sich auch in Hannover, HStA Cal. Br. 2 I Nr. 7.

637 Folin, Gli Estensi, 53.

638 Емісн, Territoriale Integration, 90-93. Zu Venedigs Haltung aus Contarinis Istorie Veneziane siehe: Salmons, An unpublished Account. 
dringend militärische Hilfe im Türkenkrieg benötigte, war nicht gewillt, dessen Pläne zu durchkreuzen. Enttäuschend für Cesare war die Haltung von Henri IV. von Frankreich, der entgegen der alten Freundschaft und Verbindung mit den Este, dem Papst sein Heer gegen Ferrara anbot und dadurch auch Mailand und Venedig von ihren (schwachen) Unterstützungsangeboten abbrachte. Auch von Mantua kam keine Hilfe, im Gegenteil: Vincenzo erbat die sofortige Auszahlung der Mitgift seiner Schwester, die Witwe Margherita Gonzaga-d'Este und auch Anna d'Este, Alfonsos II. Schwester, verlangte aus Frankreich, dass der französische Familienbesitz ihr und nicht Cesare überschrieben wurde.

Im Dezember I597 erreichte Cesare schließlich der Kirchenbann, weshalb nun auch Teile der seit der Regentschaft Alfonsos II. von Steuern und Not geplagten Bevölkerung sich gegen den Prätendenten wandten. Die Untertanen von Comacchio z.B. widersetzten sich der herzoglichen Macht und plünderten die Delizia delle Casette, während sich Vertreter des Adels von Ferrara bereits mit dem neuen päpstlichen Herrscher gut zu stellen bemühten. Mittlerweile hatte Clemens VIII. die Bannbulle gegen Cesare auch Frankreich, dem Kaiser und allen christlichen Fürsten zukommen lassen mit der Drohung, dass jeder Herr wie Untertan gebannt würde, der Cesare Hilfe zukommen ließe. ${ }^{639}$

Dieser war somit auf sich selbst gestellt. Doch auch seine von der Historiografie stark kritisierte bigotte Haltung stand ihm im Weg, denn er brachte es nicht über sich, dem Papst als Gegner zu begegnen. So schickte er Lucrezia d'Este, die einzige Este, die noch in guten Beziehungen zu Rom stand, zu Verhandlungen. Ihre Ressentiments gegenüber Cesare, dessen Vater Don Alfonso maßgeblich an der Aufdeckung ihrer Liaison mit Ercole [Ercolino] Contrari und wahrscheinlich an dessen Ermordung beteiligt gewesen war, beeinflussten den für die Seitenlinie der Este negativen Ausgang der Verhandlungen maßgeblich. Im daraus entstandenen Traktat, die sogenannte Convenzione faentina vom I2. Januar I 598 wurde Cesares Exkommunikation unter der Bedingung seines Verzichts auf Ferrara zurückgenommen; er musste das Herz der

639 Siehe den Eintrag in den Fuggerzeitungen bezüglich des »Bannfluches gegen Cesare von Este« aus Rom vom 27. Dezember r 597: "In dem am vorigen Montag im Beisein des Papstes abgehaltenem Consistorium wurde vor dem ganzen heiligen Collegium vom Cardinal Peretti als Diaconus mit heller Stimme das Urteil des Bannes gegen den Don Cesare d'Este und seine Beistände verlesen. Nachher ist der Papst in die Knie gefallen, hat die in seinen Händen gehaltene Kerze geküßt und darauf alsbald den Don Cesare und seinen Anhang verflucht. Dann ist er wieder auf seinen gewöhnlichen Platz gegangen. In diese Excommunication will Ihre Heiligkeit auch alle diejenigen, welche die Verkündung des Bannes verhindern und Proviant des päpstlichen Kriegsvolks nicht passieren lassen wollten, einschließen. Es ergeht auch hiermit an die kaiserliche und königliche Majestät und alle christlichen Fürsten der Befehl, dem Don Cesare und seinen Lehensleuten nicht die geringste Hilfe zu leisten. Wer diesem Befehl zuwiderhandelt, verfällt ebenfalls dem Bann. Die Prediger ermahnen auch das Volk, sich vor dieser Excommunication zu hüten. Dem Don Cesare ist aber ein zwölftägiger Termin gewährt worden.« KLARWill, Fugger-Zeitungen, Nr. I 86, $205 \mathrm{f}$. 
Este-Herrschaft verlassen, durfte aber die Bibliothek, die Kunstsammlung ${ }^{640}$ und das Archiv sowie die Hälfte seiner Artillerie mitnehmen. Er behielt mit seinen Mitziehenden die Allodial- und Kreditansprüche in Ferrara, musste aber die Stadt Ferrara mit Cento, Pieve und Comacchio und die estensischen Gebiete in der Romagna dem Papst übergeben. Nach Unterzeichnung des Traktates wurde der Kirchenbann aufgehoben, und Cesare zog am 28. Januar 1598 nach Modena. ${ }^{641}$

Alfonsos und Cesares Bemühungen, Rom von der Durchführung der Devolution Ferraras abzubringen, waren somit gescheitert. ${ }^{642}$ Der Versuch, den Heimfall abzuwenden, hatte Alfonso II. sein letztes Lebensjahrzehnt beschäftigt: Um den Papst und die Kardinäle wohlwollend zu stimmen, hatte er sich I 59 I bereit erklärt, das Gebiet der Romagna von Banditen ${ }^{643}$ und Gesetzlosen zu befreien und hatte dafür den condottiere Enea Montecuccoli mit Truppen dahin entsandt. Im Juli desselben Jahres war Alfonso II. sogar persönlich nach Rom gereist, um dem neuen Papst Gregor XIV., Sfondrati, zu huldigen und ihn um die Möglichkeit, seinen Nachfolger zu bestimmen, zu bitten. ${ }^{644}$ Dabei dachte Alfonso - als es klar wurde, dass er seinen Bruder Luigi

640 Wenigstens Teile der Sammlungen gingen mit nach Modena. Von dem, was nicht sofort mitgenommen werden konnte, bedienten sich der Papst, sein Nepot und verschiedene Kardinäle wie Scipione Borghese und bereicherten mit diesem Kunstraub ihre Sammlungen. Der Kardinalnepot Pietro Aldobrandini bemächtigte sich z.B. der berühmten Kunstwerke Festino degli Dei von Giovanni Bellini Offerta a Venere von Tizian und Baccanale von Dosso Dossi. Emiliani, Il ritorno delle Muse, I 5 .

64 I Vgl. Rimondi, Estensi, i 8 if. Marini, Lo stato estense, 65-67. Емich, Territoriale Integration, 99 f. Frizzi, Storia di Ferrara 4, I3-I6.

642 Schnettger hat bereits darauf hingewiesen, dass nicht allein das Fehlen von männlichen Nachfolgern, sondern vielmehr die "strukturellen Veränderungen des europäischen Staatensystems« vor allem den italienischen Fürsten, wie den Este hier als frühes Beispiel, zum Verhängnis wurden. Schnettger, Geschichte als Dekadenz?, 73 .

643 Wie virulent das Banditenproblem vor allem an der Grenze zum Kirchenstaat war, beweist ein Eintrag in den Fuggerzeitungen von I4. März I 592: „[...] Die Banditen haben dem neuen Nuntius für Neapel, Monsignor Aldobrandini, unterwegs dermaßen stark nachgesetzt, daß er sich mit großer Gefahr salvieren mußte. Sie haben auch vor wenigen Tagen ein Schloß und einen Markt, eine Tagesreise von hier, geplündert und über sechzigtausend Kronen an Wert geraubt. Viele Manns- und Weibspersonen haben sie weggeführt und den Markt in Brand gesteckt. Sie sollen dreitausend Mann stark sein. Der Papst hat befohlen, viertausend Soldaten anzuwerben und sechzigtausend Kronen dazu verordnet.» Klarwill, Fugger-Zeitungen, Nr. I40, I64. Dieselben Probleme gab es aber auch im Reich: Der Kaiserhof-Nuntius Carafa bedurfte r62 I auf seiner Reise von Mähren nach Wien aufgrund der Gefahr durch umherziehende Ungarn einer größeren Eskorte. BraUn, Imagines imperii, 445.

644 Um das Verhältnis zu Rom zu verbessern, wandten sich die Este auch an die päpstlichen Legaten in Bologna. Zwischen I 565 und I 59 I hat Gardi an die 60 estensischen Gesandtschaften dahin gezählt. Es handelte sich dabei zumeist um Höflichkeitsbesuche durch Hofadelige oder um Audienzen von Rechtsgelehrten, die über die Ausfuhr von Getreide, über Grenz- und Gewässerstreitigkeiten, Gerichtsfälle und das Bandenproblem diskutieren sollten. Dort wo die Beziehungen mit dem amtierenden Legaten gut waren, häuften sich die Korrespondenzen, Instruktionen und Gesandtschaften, so z.B. mit den Gouverneuren Melchiorri, Peretti und Sfondrati, die Alfonso II. minutiös über alle Neuigkeiten aus Rom informiert hielten und ihm Hoffnungen auf die Neubelehnung Cesares machten. Mit den 
nicht von den Weihen lösen lassen konnte - zunächst an Filippo d'Este Markgraf von San Martino in Rio ${ }^{645}$ als Nachfolger, der mit den Sfondrati verwandt war und vom Papst stark befürwortet wurde. Diese Seitenlinie der Este-Dynastie herrschte zwischen I 5 Or und I 752 über ein Gebiet im Raum von Modena und Reggio, das die Kommune San Martino in Rio, Campogalliano, Castellarano und Roteglia umfasste. ${ }^{646}$ Der sigismundeische Zweig der Este hatte mit der Investitur Ercoles I. für seinen Bruder Sigismondo mit den genannten Lehen als Dank für dessen treue Dienste begonnen. Die Nachfolger, Ercole und Sigismondo II., lehnten sich weniger an die estensische Hauptlinie als vielmehr an Mailand an, wo sie das Bürgerrecht besaßen und gewinnbringende Heiratsverbindungen und Investituren fanden. Eine Tochter dieser Seitenlinie, Sigismonda, heiratete Paolo Sfondrati, Bruder des Bischofs von Cremona und zukünftiger Papst Gregor XIV., der deshalb einer Belehnung der Seitenlinie der San Martino nicht abgeneigt gewesen wäre. Die männlichen Sprösslinge aber richteten sich zunehmend nach Spanien und Savoyen aus, in deren Dienste sie eintraten, was sich u.a. in der Namensgebung der Nachfahren (Filippo, Carlo Filiberto, Carlo Emmanuele) zeigt. ${ }^{647}$

Auch mit finanziellen Anreizen hatte Alfonso versucht, den Papst für sein Anliegen zu gewinnen: Er bot diesem Türkenhilfe mit 6.00o Mann, ${ }^{648}$ die Erhöhung des Lehenszinses auf 20.000 scudi und eine einmalige Zahlung von I.000.000 scudi an die päpstliche Kammer sowie die Bereitstellung einer nicht näher definierten »Wunderwaffe ${ }^{649}$ bei Bestätigung des von ihm ausgewählten Nachfolgers an. Der wohlgesonnene Papst traf im Konsistorium aber auf Gegenwind vor allem bei den toskanischen Gruppierungen und wurde an die Einhaltung der Bulle von Pius V. gemahnt. ${ }^{650}$

weniger Wohlgesinnten wurden die Kontakte hingegen minimal gehalten oder sogar unterbrochen. Vgl. Gardi, Legati a Bologna, 325, 332 .

$645 \mathrm{Zu}$ diesem Sohn von Sigismondo, Erbe von Nicolò III., geboren I 537, für Alfonso II. in diplomatischer Mission tätig, siehe: Luisa Bertonı, »Filippo d'Este«, in: DBI 43, Roma I993, 339-342.

646 Donati, Una famiglia lombarda, 435.

647 Ebd., $438-442$.

648 Nach Herzog Wilhelm von Bayern gehörte Alfonso II. trotz seines Alters zusammen mit dem Herzog von Lothringen oder jenem von Urbino 1595 zu den potenziell geeigneten Oberbefehlshabern des kaiserlichen Heeres gegen die Türken. Stieve, Die Politik Baierns, 25 I, Anm. I.

649 Wie Niederkorn gezeigt hat, war der Kaiser viel mehr daran interessiert als der Papst. Nieder korn, Die europäischen Mächte, $422 f$.

650 Mit dieser hatte Pius V. sich und seinen Nachfolgern verboten, neue Lehen aus dem Kirchenstaat zu vergeben. Außerdem sollten die Lehen nur von legitimen Erben weitergeführt und heimgefallene nicht mehr neu vergeben werden. Diese Praxis sollte zum Ende des mehrere Jahrhunderte alten Nepotismus führen. Tatsächlich aber wurde diese alte "feudale« Form des Nepotismus durch eine andere ersetzt. Емісн, Territoriale Integration, 68-72. Vgl. dazu auch Fatтori, Clemente VIII, 97- I07. Bezüglich dieses »Gegenwindes« im Kardinalskollegium hat Maria Teresa Fattori bereits gezeigt, dass mit der Devolution Ferraras die prinzipielle Frage der Beteiligung des Kardinalskollegiums an den päpstlichen Entscheidungen einherging. Während der Papst auf seine Machtvollkommenheit und absolute Entscheidungsgewalt verwies, beharrte der Großteil der Purpurträger auf die genaue Auslegung der Bulle 
Bevor er eine eigene Investiturinitiative ergreifen konnte, verstarb er. Sein Nachfolger, Clemens VIII. aus der ursprünglich florentinischen Familie der Aldobrandini, hatte sich bereits als Kardinal gegen die Befürwortung der Este ausgesprochen und behielt diesen Kurs auch als Papst bei, ohne sich von Kaiser Rudolf II. umstimmen zu lassen. Die Rückführung kirchlicher Lehen sollte ihm nämlich zu Ehre gereichen. ${ }^{651}$ Alfonso II. hatte alle Hoffnungen in den Wunsch des Papstes, die Christenheit vor der osmanischen Gefahr zu befreien, gesetzt und seine Gesandten in Rom dementsprechend instruiert. Er wollte sich als Heeresanführer der italienischen/päpstlichen Truppen im Kampf gegen die Türken anbieten, doch schließlich sollte diese Aufgabe und Ehre dem Papstneffen, Gian (Giovanni) Francesco Aldobrandini, zuteilwerden. Somit hatte Alfonso die Möglichkeit verpasst, sich die Dankbarkeit des Papstes in Form der Investitur seines außerwählten Nachfolgers zu sichern. ${ }^{652}$ Auch die weiteren dahingehenden Bemühungen des Herzogs von Ferrara blieben erfolglos; obwohl ihm eine aktive Rolle im Türkenkrieg zugestanden wurde, gelang es ihm und seinen Gesandten nicht, diese Verpflichtung an die Nachfolgeregelung zugunsten der Este-Dynastie zu binden. ${ }^{653}$

Nachdem er im Juli I 594 vom Kaiser die Erlaubnis erhalten hatte, für Modena und Reggio seinen Nachfolger zu bestimmen, verfasste Alfonso II. sein Testament und bestimmte trotz einiger Widrigkeiten innerhalb seines Hofstaates nicht mehr Sigismondo, sondern Cesare zum Nachfolger. Dieser war der Sohn von Don Alfonso, der wiederum aus der Verbindung von Herzog Alfonso I. d'Este und seiner langjährigen Geliebten Laura Boccacci, Tochter eines Hutmachers, die aber unter dem Namen Laura Eustochia Dianti den Lebenswandel einer Adeligen führte, entsprungen war. Don Alfonso (* ${ }^{*}$ 27) hatte, wie sein früh verstorbener Bruder Alfonsino (* ${ }^{*}$ 530), vom herzoglichen Vater Lehen in Montecchio und Castelnuovo bei Reggio erhalten. Vergeblich wurde bei und nach der Devolution nach einer Heiratsurkunde gesucht, die die Legitimität der Verbindung seiner Eltern bestätigen konnte. Als Laura Dianti I 573 starb und mit großen Ehren begraben wurde, erbte der älteste und mittlerweile einzige Sohn ihre gesamten Güter und wurde - auch durch jene, die er selbst vom Vater erhalten hatte - zu einem sehr reichen Mann. I 549 gelang ihm mit der Verbindung mit Giulia della Rovere, Tochter des Herzogs von Urbino, die Einheiratung in die obere dynastische Ebene. Doch die große politische Karriere blieb aus, da die Stiefbrüder seine Einflussnahme befürchteten. Erst unter Alfonso II. bekam Don Alfonso, dessen Stiefonkel er war, wichtige Aufträge und eine Rolle als Berater. I 562 erhob der Kaiser Montecchio zur Markgrafschaft und belehnte Don Alfonso damit. ${ }^{654}{ }_{5} 67$ ging die-

Admonet nos, auch um einen möglichen territorialen Verlust zu vermeiden. Vgl. FATtori, Lehnsrecht, besonders Absätze I - 7.

65 I Quazza, "Alfonso II«. Lazzari, Le ultime tre duchesse, 32 of.

652 Nieder korn, Die europäischen Mächte, 4 I $6 f$.

$653 \mathrm{Zu}$ den weiteren Versuchen siehe ebd., 418-425.

654 Vgl. Frank, Standeserhebungen, 285: Don Alfonso d'Este, Erhebung des Schlosses und Gebietes 
ser mit dem savoyischen Heer nach Frankreich und unterstützte Charles IX. gegen die Hugenotten. Hier zeichnete er sich aus, wurde in den sonst für Fremde selten zugänglichen Geheimen Rat aufgenommen und mit dem Orden vom Heiligen Michael geadelt. Don Alfonso hielt in Ferrara einen prestigeträchtigen Hof, an dem er u.a. Ferdinand von Bayern und Erzherzog Karl von Österreich empfing. I 570 trug er maßgeblich zum Erfolg des Heiratsprojekts zwischen Lucrezia d'Este und dem Erben von Urbino, Francesco Maria della Rovere, bei. Für diese unglückliche und ungewollte Verbindung sollte sich Lucrezia an Don Alfonso und seinen Verwandten am Ende der Este-Herrschaft rächen. ${ }^{655}$

Als sich abzeichnete, dass die angedachte Nachfolgeregelung im päpstlichen Lehen nicht reibungslos über die Bühne gehen würde, versuchte der waffenversierte Alfonso II. mit seinen Ingenieuren und Waffenschmieden in den letzten Jahren seiner Herrschaft die bereits legendäre Uneinnehmbarkeit Ferraras zu verstärken. ${ }^{656}$ Kurz vor seinem Tod, als die Unbewegbarkeit des Aldobrandini-Papstes auch die letzte Hoffnung auf eine Neubelehnung Cesares verblasen hatte, bat Alfonso als "Notlösung" zumindest um eine Verlängerung der Investitur. Doch Papst Clemens VIII. zeigte mit Unterstützung des Kollegiums die größte Entschlossenheit bei der Rückholung des Lehens und seiner Einbindung in den Kirchenstaat. ${ }^{657}$

Trotz der genannten Bemühungen um eine Kontinuität der Herrschaft in Ferrara und in den Reichslehen, wurde der letzte Este-Fürst der Hauptlinie bei seinem Ableben äußerst schändlich behandelt, wenn man den von Biondi zusammengetragenen Berichten $^{658}$ glauben darf. Als Alfonso II. Anfang Oktober I 597 zu kränkeln begann und das Bett nicht mehr verlassen konnte, soll Cesare in sein Gemach gekommen sein und alles Kostbare daraus entnommen haben. Nachdem der Tod am 27. Oktober

Montecchio zu einem Marchesat und Grafschaft, mit dem Recht Münzen zu schlagen, Verleihung des Marchese- und Grafenstandes für ihn und seine sämtliche männliche Deszendenz und für ihn ad personam: Palatinat, Reichsakt gegeben zu Frankfurt 25.IO.I562. Alfonso d'Este, Marchese und Graf von Montecchio, Bestätigung des ihm von Kaiser Ferdinand I. verliehenen Marchese- und Grafenstandes und Erhebung des Schlosses und Gebietes von Montecchio zu einem Marchesate und Grafschaft, Palatinat und dessen Ausdehnung und Vermehrung für seine sämtliche männliche Deszendenz, Reichsakt gegeben zu Prag, 5.2.1570.

655 Don Alfonso ( $1527-1587$ ) hatte auch eine Tochter, Eleonora, die den neapolitanischen Fürsten von Venosa und berühmten Musiker, Carlo Gesualdo, heiratete. Als seine erste Ehefrau starb, heiratete A1fonso von Montecchio Violante Signa, die ihm Ippolita und Alessandro schenkte, der später Kardinal wurde. Rimondi, Estensi, ro5 - I08. Siehe auch neuerdings die unveröffentlichte aber online zugängliche Dissertation MARchesI, L'«illustrissimo bastardo«.

656 Biondi, Ferrara, 494-498.

657 Fattori, Lehnsrecht, Absatz i 8-22.

658 Darunter Annali di Ferrara [...] per Filippo Rodi Dottor di Leggi, e Cittadino della medesima Patria [...] tomo IV, I99v-204r aufbewahrt in Biblioteca Estense di Modena, alpha, H. 3.7- Io und Marco Antonio Guarini, Compendio historico dell'origine, accrescimento e prerogative delle chiese, e luoghi pii della Città e Diocesi di Ferrara, e delle memorie di que' personaggi che in esse sono sepeliti [...] Ferrara, Baldini I62 I, Libro IV, 286. 
eingetreten war, wurde der Leichnam geöffnet aber nur mit Stroh ausgestopft und dann zwei Tage ohne Bewachung zur Schau gestellt, sodass er geschändet werden konnte. Dann wurde er in einen zu kleinen Sarg gelegt, sodass die Beine gebrochen werden mussten, damit er Platz fand. Schließlich wurde er ohne Feierlichkeiten und ohne Kreuz ins Kloster Corpus Domini gebracht, wo er bis Ende Januar I 598 unbestattet blieb. Eine offizielle Trauerfeier erfolgte erst am I2. Januar I599, I 5 Monate nach seinem Tod, im Dom von Modena. Offiziell aufgrund der Schwierigkeiten in der Regelung der Rangordnung beim Trauerzug, aber eigentlich wegen der Ressentiments gegenüber der Este-Familie, blieben einige Adelige wie die (von der Nachfolge schließlich ausgeschlossenen) Este von San Martino, die Rangoni und Marco Pio di Savoia, Herr von Sassuolo, den Trauerfeierlichkeiten fern. ${ }^{659}$

Selbst wenn das Bild überzogen erscheint, stellt sich die Frage, warum Cesare in Ferrara so wenig Unterstützung und Anerkennung fand und warum demzufolge die Devolution so einfach und gewaltfrei über die Bühne gehen konnte. Dieser Frage ist Folin in seinem Beitrag im vierten Band der Storia di Ferrara nachgegangen.

Wie sein Vorgänger ließ sich auch der illegitime und deshalb von Rom nicht zur Nachfolge anerkannte Cesare d'Este die Macht von den Savi übergeben und drückte mit demselben Zeremoniell aus, dass die Herrschaft vom Volk ausging. Er vollzog in aller Eile seine Inthronisierung, ließ die Stadttore schließen, um die Übergabe des erwarteten - Bannedikts zu verhindern und vergaß dabei, den Leichnam seines Erbonkels beerdigen zu lassen, der fast drei Monate über der Erde blieb. ${ }^{660}$ Doch für eine auch nur minimale Chance gegen die päpstlichen Waffen (Kirchenbann und Truppen) zu bestehen, hätte Cesare die Treue der Ferrareser benötigt, die ihm aber von Anfang an versagt blieb. Diese war - nach Folin - nicht plötzlich nach drei Jahrhunderten Este-Herrschaft gekündigt worden, sondern hatte bereits seit Langem im Laufe des r6. Jahrhunderts zu bröckeln begonnen. Den Anfang machte die Niederlage im Krieg von Ferrara $\mathrm{I}_{482}-84$ und der demütigende Friede von Bagnolo, bei dem das Polesine di Rovigo verloren ging. Es handelte sich dabei nach Folin nicht nur um einen Gebiets-, sondern vor allem um einen militärischen und diplomatischen Imageverlust. Diesem musste das mittelgroße Fürstentum durch Anlehnung an internationale Schutzmächte im Zuge einer außeritalienischen Heiratspolitik und durch ein forciertes prestigesteigerndes Mäzenatentum entgegenwirken. Sowohl die Heirat zwischen Ercole II. und Renée de Valois als auch jene von Alfonso II. mit Erzherzogin Barbara von Österreich waren kostspielig und wenig gewinnbringend gewesen, vergleicht man z.B. die Mitgift dieser »fremden « Fürstinnen ${ }^{661}$ mit jener der in Italien nicht mehr ganz fremden Lucrezia Borgia, als sie Alfonso I. zur Frau gegeben wurde. Für die Hand der französischen Prinzessin Renée waren dem französischen König noch dazu etliche Hundert-

659 Biondi, Ferrara, 498-500. Ricci, Vacanze di potere.

660 Folin, Gli Estensi, 44-46.

66r Dazu siehe unten. 
tausende Dukaten "geliehen« worden, die nie zurückgegeben wurden. Auch über das Heiratsprojekt mit der Kaisertochter Barbara, von dem sich Alfonso II. zwar Prestige und die Klärung des Präzedenzstreites mit den Medici zu seinen Gunsten erhoffte, erwartete sich der Herzog von Ferrara keinen finanziellen Zugewinn. Im Gegenteil soll er der Meinung gewesen sein, dass »le nozze colle figliuole dell'imperatore valevano poco e costavano molto ${ }^{662}$

Hinzu kamen I 539 weitere hohe Ausgaben: So I 30.000 Dukaten für die päpstliche Investitur, die Kosten für die I 566 dem Kaiser versprochene Türkenhilfe ${ }^{663}$ mit 4.000 üppig ausgestattete Schützen, ${ }^{664}$ mit denen Alfonso II. nach Wien zog, um bald darauf einsatzlos wieder zurückzukehren und schließlich 400.000 scudi für die kaiserliche Investitur für Cesare. Doch auch die der Imagesteigerung gezollte Stadterweiterung unter Ercole I., die Repräsentations- und Befestigungsbauten, die Auftragswerke und das Hofleben verschlangen enorme Summen.

Darüber hinaus waren die Este - wie unten noch gezeigt werden wird - gerade innerhalb ihres dichten Verwandtschafts- und Freundschaftsnetzwerkes eine gefragte Anlaufstelle für Geldleihen. Beim Besuch von Papst Paul III. I 543 organisierten die Este nicht nur pompöse Feierlichkeiten zu seinen Ehren, sondern liehen dem Papst auch 50.000 Golddukaten. Auch für die Erhebung von Luigi d'Este zum Kardinal I 56 I scheute man keine Kosten. Wenn man bedenkt, dass zum Ende des Jahrhunderts die Einnahmen des Fürstentums ungefähr 400.000 Dukaten jährlich ausmachten, ${ }^{665}$ dann wundert es nicht, dass - aufgrund der gesteigerten Kosten für die Errettung der Investituren am Ende des I6. Jahrhunderts - der zwischen I 590 und I 597 herrschenden Hungersnot im Fürstentum kaum Abhilfe geschaffen werden konnte. ${ }^{666}$

Die größte Finanzlast trug die Stadt Ferrara selbst, da Modena und die anderen Städte sich relativ gut gegen die Geldforderungen des Fürsten zu wehren wussten. Folin hat errechnet, dass Ende des r 6. Jahrhunderts zwei Drittel der Steuereinnahmen der Este aus dem östlichen Bereich des Fürstentums, also aus dem päpstlichen Lehen Ferrara kamen. Die letzten Jahre der Herrschaft Alfonsos II. waren hier von großen und wiederholten Steuererhöhungen geprägt. Auch die kostspielige Unterstützung des Kaisers im Türkenkrieg I 566 stieß im Fürstentum auf laute Kritik, weil sie ebenfalls

662 Zit. n. Lazzari, Le ultime tre duchesse, 93 (Brief vom 26.I0.1563). »die Hochzeiten mit den Töchtern des Kaisers waren wenig wert jedoch kostspielig«. Tatsächlich entsprach die Mitgift von roo.ooo Rheingulden eher einer Bürgerstochter als einer Kaisertochter. Siehe auch TADDEI, Barbara von Österreich-d'Este.

663 Laut Reichstagsakten nahm der Pfennigmeister am 3I.I0.I 566 auch ein Darlehen über 50.000 Kronen vom Herzog von Ferrara entgegen. Lanzinner/Heil, Deutsche Reichstagsakten, Der Reichstag zu Augsburg 1566 I, 797, Anm.I 4.

664 Vgl. Ricci, Cavalleria.

665 Folin, Gli Estensi, 47 f.

666 Емгсн, Territoriale Integration, го9. Dazu als Vergleich mit anderen Fürsten wie jenen von Parma und Mantua: Romani, La carestia. 
während einer Hungersnot geleistet wurde. Zudem förderten Maßnahmen wie das Verbot, Holz aus dem Jagdrevier des Herzogs zu schlagen, um das Wild nicht zu vertreiben, nicht gerade die Sympathie für den Herrscher. ${ }^{667}$

Rom hatte schon länger den steigenden Missmut der Ferraresen beobachtet und bereits vor der Devolution versucht, einflussreiche Familien auf die eigene Seite zu bringen. Dies erreichte der Heilige Stuhl vor allem durch die Erhebung zu von Sprösslingen aus den führenden Familien Giraldi, Rangoni, Tassoni etc. zu Bischöfen. Als die Exkommunikationsbulle in Ferrara eintraf und sich das päpstliche Heer in Richtung der Stadt bewegte, ließen die meisten ferraresischen Adeligen und Hofleute (große Namen wie Cesare Trotti, Onofrio Bevilacqua, Guido Calcagnini, Tommaso Sacrati, Scipione Giglioli, Antonio Montecatini) Cesare im Stich und garantierten sich die Gunst der neuen Herren durch die Weitergabe von Informationen und durch die Möglichkeit der Stationierung der päpstlichen Truppen auf ihren Gütern vor der Stadt. Der Papst, dem bewusst war, dass eine militärische Aktion zur Rückgewinnung Ferraras riskant und kostspielig war, arbeitete daher am Zerfall von Innen. ${ }^{668}$ Es waren aber nicht nur die Steuerlast der Bevölkerung und die Versprechungen für die ferraresischen Eliten, die dem Papst als neuem Herrscher zum Vorteil gereichten. Cesare fehlte ein standing in Ferrara und am Hof. Er war recht spät und dazu als zweite Wahl nach Sigismondo zu Alfonsos Erbe ernannt worden; es war ihm in der knappen Zeit und aufgrund seiner Herkunft nicht möglich gewesen, ein Netzwerk am Hof aufzubauen. Dass er in Ferrara (noch) nicht Fuß gefasst hatte, beweist nach Folin auch die Tatsache, dass Cesare in der heiklen Phase vor der Devolution Männer wie Luigi Montecuccoli, Gherardo Rangoni und Claudio Rangoni, Bischof von Reggio, sowie Giulio Thiene, Markgraf von Scandiano, drei Modenesen und einen kürzlich nach Ferrara Gezogenen als Gesandte an die europäischen Höfe schickte. Dass er diesen »Stadtfremden« die Rettung der Stadt vor der Machtübernahme Roms anvertraute, war ein strategischer Fehler. Kein Wunder also, dass die Ferraresen Cesare keine Träne nachweinten, als dieser mit wenigen Vertrauensmännern die Stadt verließ. ${ }^{669}$

Selbstverständlich bedeuteten der Weggang des Hofes und der Verlust des Status einer Residenzstadt den Beginn des Niedergangs. Schließlich führte die Einverleibung in den Kirchenstaat zur Deklassierung Ferraras von der Hauptstadt zu einer Provinzstadt. Mit der »Plünderung« durch die päpstlichen Statthalter wurde das einstige Renaissancezentrum nicht nur vieler Kunstobjekte beraubt, sondern verlor das Flair

667 Rimondi, Estensi, I 58.

668 "Wer in Ferrara etwas erreichen wollte, brauchte gute Beziehungen zur Papstfamilie und ihren Brokern«, hat Emich treffend festgehalten. Емісн, Bologneser, libertà, I 28. Folın, Gli Estensi, 49-5 I. $\mathrm{Zu}$ Recht hat Emich von einer regelrechten Krise der höfischen Gesellschaft im ausgehenden I6. Jahrhundert und von der »Suche des Ferrareser Adels nach einer neuen Identität« gesprochen. Емісн, Territoriale Integration, I Io.

669 Ebd., 56-58. Ausführlicher bei Barbiche, La politique de Clément VIII. 
und das Image eines Kulturzentrums. ${ }^{670}$ Zwar blieben die Eliten in Ferrara, da nur wenige mit Cesare nach Modena zogen, und sie profitierten zunächst von den päpstlichen Zuwendungen, doch war ihre Integration in den Kirchenstaat alles andere als einfach, wie Birgit Emich in ihrer Untersuchung des Prozesses territorialer Integration von Regionen gezeigt hat. ${ }^{671}$ Es darf indessen nicht vergessen werden - so Emich folgerichtig -, dass, auch wenn das Schicksal Alfonso keinen legitimen Erben beschert hatte, die Devolution Ferraras eindeutig ein Tribut an die frühneuzeitliche Entwicklung des Kirchenstaates war: Um den ständigen Finanzbedarf zu decken, förderten die Päpste in der zweiten Hälfte des r6. Jahrhunderts den Ausbau und die Stärkung der Zentralgewalt, wodurch mehr Geld nach Rom fließen sollte, bei gleichzeitiger Eindämmung der kommunalen und feudalen Kräfte. ${ }^{672}$

Ferrara gehörte in der "Rückholungspolitik« des I 6. Jahrhunderts zu den terrae mediate subiectae, also zu den von Stadtherren oder Familien des Feudaladels gehaltenen Gebieten, in denen diese autonom und uneingeschränkt herrschten. Für die Stärkung der Zentralgewalt im Kirchenstaat war es jedoch notwendig, diese feudalen Mächte aufzulösen, wofür die Bulle Admonet nos die Weichen gestellt hatte. ${ }^{673}$ Einerseits hielten sich die päpstlichen Nachfolger gewissenhaft an die Bestimmungen der Bulle, wie Gregor XIII., der I 578 die Rechtmäßigkeit der Lehen überprüfen ließ und etliche einzog. Außerdem wurde die Bulle dahingehend streng ausgelegt, dass ein Lehen auch dann eingezogen wurde, wenn man mit dem Lehenszins in Verzug war. Andererseits aber führt Emich verschiedene Beispiele an, die diese antifeudale Politik Roms Lügen strafen. ${ }^{674}$ Die Päpste versorgten also weiterhin ihre Nepoten, doch sie hielten sich auch an die Bulle und ihre Bestimmungen: Die Nepoten verlangte es vor allem nach Titulatur, die sie in die hohen Adelsränge eintreten ließ, und so wurden sie mit sehr kleinen und stark in ihren Feudalrechten beschnittenen oder sogar außerhalb des Kirchenstaates gelegenen Lehen im Sinne eines Kleinnepotismus bedacht. ${ }^{675}$ Zur Stilllegung des "großen Nepotismus« wurde hingegen an der Devolution Ferraras trotz der verlockenden Angebote der Este (estensisch-aldobrandinische Doppelhochzeit, Verdoppelung des Lehenszins und Einmalzahlung von 500.000 scudi, Abtretung eines Teiles der estensischen Besitzes an den Papstneffen Giovanni Francesco Aldobrandini)

$670 \mathrm{Zu}$ diesem Zerfallsprozess siehe De Benedictis, Il Seicento, 48I.

67 г Емісн, Territoriale Integration, 8f; PArdi, Sulle cause della devoluzione. Vgl. zur Ausweitung der päpstlichen Macht auch den Aufsatz von Delumeau, Les progrès de la centralisation.

672 Емісн, Territoriale Integration, 57. Dazu auch: Prodi, La sovranità temporale.

673 Емісн, Territoriale Integration, 68-72. Vgl. dazu auch Fatтori, Clemente VIII, 97- ro7.

674 Pius V.erließ den Carafa die Strafe und den Orsini di Steuern; Gregor XIII. kaufte das neapolitanische Herzogtum Sora für seinen Sohn, Gregor XIV. versah einen Nepoten mit Monte Marciano. Емісн, Territoriale Integration, 73. Weiter auch: Prodi, Lo sviluppo.

675 Ebd., 77 . 
im Sinne eines gewachsenen Bewusstseins für die Interessen des Kirchenstaates festgehalten. ${ }^{676}$

Unisono vertritt die Historiografie die Meinung, dass Cesares Scheitern die Folge seiner Fehler gewesen sei: die schlecht instruierten Gesandten, die finanzielle Not, die schlechte militärische Vorbereitung und die unglückliche Wahl seiner Vertreterin bei den Verhandlungen mit dem Papst. Aber vor allem verlor er die päpstlichen Lehen aufgrund der Entschlossenheit des Papstes das Lehen heimzuführen. Cesare hatte die falsche strategie angewendet, indem er auf den schwächelnden spanischen König und nicht auf das nach den Bürgerkriegen langsam wieder aufstrebende Frankreich gesetzt hatte. Der Papst hingegen nahm die Hilfe des "Ketzers«, Henri IV., an und sah aus Dankbarkeit über das Edikt von Nantes vom April I 598 hinweg, das den Hugenotten Kultausübung einräumte. ${ }^{677}$

Als am 29. Januar I 598 Kardinal Pietro Aldobrandini Ferrara für den Apostolischen Stuhl in Besitz nahm, wandelte er als erstes das Herzogtum in eine Legation mit dem Namen Città e Ducato di Ferrara um, dessen erster Legat er wurde. Vor Ort regierte sein Vizelegat, Kardinal Francesco Biandrata de'Conti di S. Giorgio. Am 8. Mai I 598 kam Papst Clemens VIII. persönlich in einer langen, seine territoriale und geistliche Macht inszenierenden »Prozession « durch den Kirchenstaat ${ }^{678}$ nach Ferrara, um sechs Monate lang hier zu residieren und die Organisation des neuen Gebietes in Gang zu setzen. Diese wollte gut durchdacht sein, denn das neu und unblutig gewonnene Gebiet ließ sich nicht mit Waffengewalt halten und sollte ein Bollwerk gegen das verfeindete Venedig sein. Es war wichtig, Ober- und Unterschicht des einstigen Herzogtums für Rom zu gewinnen. Dies geschah mit verschiedenen strategischen Maßnahmen: sofortige Erhöhung des Brotgewichtes, Genehmigung der Karnevalsfeiern, ständige Präsenz von Tausenden Soldaten, Reform des Justizwesens (Costituzione Aldobrandina), Halbierung bzw. gänzliche Abschaffung sämtlicher Steuern auf lebenswichtige Güter, persönlicher Besuch des Papstes, Beibehaltung der Privilegien. Die Universität wurde finanziell unterstützt und mit Privilegien bedacht; Ferrara bekam einen Berufungsgerichtshof, die Rota, und das Privileg eigene Münzen prägen zu dürfen. Emich hat diese Art der Politik treffend »Stabilität durch Loyalität« genannt. ${ }^{679}$

Der Großteil des Adels und des Bürgertums war nicht Cesare nach Modena gefolgt, sondern in Ferrara verblieben und hoffte nun auf neue Privilegien unter dem römischen Herrscher. Vor allem erwarteten die ferraresischen Eliten bessere Aufstiegschancen im Militär, in der Verwaltung und in der Kirchenhierarchie. Sie wurden nicht enttäuscht. Zunächst bestätigte der Papst mit Breve vom 24. Oktober I 598 sämtliche Privilegien, die die Ferrareser schon unter den Este erhalten hatten, und gewann damit

676 Ebd., 95, Anm. I I 8.

677 Емісн, Territoriale Integration, IоO- IO2.

678 Fattori, Lehnsrecht, Absatz $28 f$.

679 Емісн, Territoriale Integration, I I3 - I35, bes. I 24. 
die Gunst des Adels. Er erneuerte auch die Konzessionen auf Mühlen, Marktständen und Gastwirtschaften. Er bestätigte die Oberschicht in ihren Landbesitzungen, die die größte Einnahmequelle blieben. Er gab Ferrara mit dem I 5. Juli 1598 eine Verfassung (Bolla Cenumvirale), die jedoch keine Mitsprache in der erhofften Art und Weise brachte, sondern einen Rat mit roo Mitgliedern, zu dem auch Vertreter der Zünfte gehörten. Jene, die an Cesare und den Este Verrat begangen hatten, durften sich über stattliche Belohnungen freuen: Privilegien wie Exportlizenzen, Abgabenermäßigungen und -befreiungen und vor allem Aufstiegschancen in der römischen Hierarchie. Jene, die zunächst den Este die Treue gehalten hatten und dann doch die Seite wechselten, hatten nichts zu befürchten. Emich hat an verschiedenen Beispielen diese päpstliche Werbung um die ferraresische Oberschicht und die neuen Chancen gezeigt, die sich durch den Heimfall Ferraras eröffneten. So waren waus Höflingen der Este [waren] Klienten der Aldobrandini geworden. $\varkappa^{680}$

Sowohl in der zeitgenössischen Empfindung als auch in der Historiografie wurde mit der Vertreibung der Este aus Ferrara der Beginn des Niedergangs dieses einstigen Herzstücks der Dynastie definiert. Es ist Emich zuzustimmen, dass die decadenza, die I 598 mit dem Auszug Cesares und dem Verlust der Stellung Ferraras als Hauptstadt eingeläutet wurde, nicht ausschließlich ein durch die päpstliche Herrschaft verursachter Verfall war; vielmehr war dieser »Niedergang« inszeniert und hausgemacht. Mit dem Mythos der decadenza versuchte die zurückgebliebene Oberschicht ihre klientelären Bindungen, in die sie verflochten waren seit Rom in Ferrara herrschte, zu rechtfertigen. Die schließlich nicht gelungene Integration der Provinz in den Kirchenstaat lag nicht in der Verwahrlosung nach dem Abgang der Este-Dynastie, ebenso wenig wie in einer steuerlichen Ausbeutung durch den Papst. Die Ursachen lagen vielmehr in der Tatenlosigkeit der auf ihre persönlichen Privilegien fixierten Oberschicht und ihrer "schmarotzenden « Gewinnbeteiligung an der Papstherrschaft. ${ }^{61}$

Diese Argumente finden sich bereits in einer zeitgenössischen Aufarbeitung des ferraresischen Heimfalls aus der Feder eines Venezianers. Nicolò Contarini war nicht nur Doge von Venedig, sondern auch Geschichtsschreiber, I620 sogar offizieller Historiograf der Republik. Seine Istorie Veneziane, die im weitesten Sinn eine Geschichte der Serenissima von 1597 bis I 605 sind, blieben zwar unvollendet und unpubliziert, erfreuten sich aber - bis heute - großer Beliebtheit, trotz - oder gerade wegen - der darin enthaltenen gegen den Papst und gegen Spanien gerichteten offenen Kritik.

In seiner Abhandlung widmet Contarini der Devolution Ferraras viel Raum und misst ihr auch für das Schicksal Venedigs eine große Bedeutung zu, da das estensische Herzogtum an die Gebiete der Terraferma grenzte, da die beiden Herrschaftsgebilde in wirtschaftlichen Beziehungen zueinanderstanden und weil der Verlust Ferraras für die

680 Ebd., I4 I - r6o, Zitat r6o.

68 г Eмiсн, Territoriale Integration, ro84- ro96 und besonders im Vergleich zu Bologna Dies., Bologneser libertà, I $29 f$. 
Este die Ausdehnung der päpstlichen Macht in Norditalien bedeutete. Ohne ein Hehl aus seiner antipäpstlichen und antispanischen Haltung zu machen, stellt der Autor die Ursachen und Folgen des Heimfalls dar. Dabei führt er zwei Erklärungsmodelle an: Die päpstliche Gier und die estensische Schwäche. Er rollt die Geschichte der Beziehungen zwischen den Päpsten und der Este-Familie vom Mittelalter her auf und sieht die Gründe für die päpstlichen Ansprüche auf Ferrara im Jahr I 328 begründet, als sich Rinaldo d'Este - Versöhnung mit der Kirche suchend - als päpstlicher Vikar und Ferrara als päpstliches Vikariat in die Abhängigkeit des Heiligen Stuhls begab. De facto waren nach Contarini die Este in Ferrara souveräne Herrscher, wie auch ihr kriegerisches Vorgehen gegen den Papst beweist. Ein weiteres Merkmal dieser estensischen Souveränität war die Möglichkeit der Bestimmung des Nachfolgers. Dass die Este legitime wie illegitime Nachfolger bestimmen konnten, zeigt ihre von den Päpsten sogar verbriefte Macht. ${ }^{682}$ Nach dem Tod von Papst Alexander VI. war aber diese Souveränität der Este immer wieder in Frage gestellt worden. Gleichzeitig steuerte die Dynastie - nach Contarini - selbst ihrem Untergang entgegen, als sie freiwillig die Investitur durch Papst Paul III. annahm und als Alfonso II. in Rom um die Möglichkeit seinen Nachfolger ernennen zu dürfen bat, was einer - schließlich erfolglosen - Unterwerfung unter die päpstliche Herrschaft gleichkam.

Auch an der Wahl des Kandidaten aus der estensischen Seitenlinie hat Contarini einiges auszusetzen: Cesare hatte - und dies war vorrangig Alfonsos Schuld - keine Unterstützer und Freunde am Hof, kam unvorbereitet an die Macht und galt von vornherein als schwach und ungeeignet. So war es für den Papst ein Leichtes, die Bestechlichkeit des ferraresischen Adels und Cesares Schwäche und Dummheit - also sein Zögern militärische Hilfe von protestantischer Seite anzunehmen - auszunutzen. Contarini beanstandet auch die Gleichgewichtspolitik Venedigs, an das sich sowohl der Papst als auch Cesare mit der Bitte um Unterstützung gewandt hatten. Er kritisiert die Vorgangsweise von Giovanni Dolfin, den venezianischen Gesandten in Rom, der zunächst auf die Neutralität Venedigs beharrte, dann aber propäpstliche Tendenzen erkennen ließ, auch wenn er weiterhin bekräftigte, dass die Serenissima für niemanden Partei ergreifen könne. In der Zwischenzeit hatte der Senat Cesare Hilfe angeboten und animierte den Este, diplomatisch und militärisch beherzter vorzugehen, doch dieser zögerte. Contarini hätte sich hier von Cesare, aber vor allem von Venedig mehr Tatkraft gewünscht, da durch den neu geschaffenen Herrschaftsbereich das Papsttum einen weiteren, nördlich gelegenen Zugang zur Adria erhalten hatte und den ohnehin durch den Atlantikhandel geschwächten venezianischen Handlungsspielraum einschränken würde. Außerdem prophezeite Contarini unter päpstlicher Führung den Untergang der einst glanzvollen Stadt, wozu es in der Tat kommen sollte. ${ }^{63}$

682 Vgl. Salmons, An Unpublished Account, I 23- r 29.

683 Vgl. Salmons, An Unpublished Account, I30- i 40. 
Die mit dem Abzug von Cesare d'Este eingeleitete Devolution des ferraresischen Lehens an den Kirchenstaat war nicht die einzige und letzte der Frühen Neuzeit. Ein ähnliches Schicksal ereilte die Montefeltro ${ }^{684}$ als Herzöge von Urbino, die ebenso im Mannesstamm ausstarben und deshalb ihr Herrschaftsgebiet I63 I an den Kirchenstaat verloren. Da im anheimfallenden Fürstentum auch kleinere Reichslehen inbegriffen waren, führte dieser Heimfall zu einer vergleichbaren, allerdings für die Lehensnehmer problematischeren Krise mit dem Kaisertum. Sebastian Becker, der den Heimfall der Grafschaft Montefeltro untersucht hat, kommt zu dem Schluss, dass die Umstände um r63I eine kaiserliche Intervention in Italien zur Geltungsmachung reichsrechtlicher Ansprüche unmöglich machten. Zudem lag das kaiserliche Interesse für eine Einmischung weniger am Lehen selbst, als vielmehr an der Möglichkeit, die Medici wieder enger an das Reich zu binden. ${ }^{685}$

684 Zur Familie siehe Clough, "Montefeltro«.

685 Vgl. Becker, Dynastische Politik. 


\subsection{Zusammenfassung}

Dieser erste Abschnitt hat die Einbindung der Stati estensi als Teil Reichsitaliens im Reichslehnsverband gezeigt. Dabei wurde versucht, die Entwicklung und Bedeutung dieses Teiles der südlichen Reichsperipherie seit dem Mittelalter und am Übergang zur Neuzeit nachzuzeichnen. Die italienischen Kleinstaaten Oberitaliens unterstanden der päpstlichen, kaiserlichen oder der Lehenshoheit eines anderen Monarchen und waren somit Vasallen, besaßen aber gleichzeitig eine historisch gewachsene, wenn auch eingeschränkte Souveränität, genannt sovranità media, die sie gerade am Übergang vom Spätmittelalter zur Frühen Neuzeit zu bedeutenden oder zumindest ernst zu nehmenden, wenn auch - bis auf Savoyen - nicht entscheidungsbefugten Mitgliedern des Reiches machte.

Die frühneuzeitlichen Reichslehen auf der italienischen Halbinsel waren sehr unterschiedlich in Größe und Herrschaftsform: Republiken wie Genua, Lucca oder wenigstens theoretisch - Venedig gehörten ebenso dazu wie aus mittelalterlichen Kommunen hervorgegangene signorie. Anders als die benachbarten Gonzaga, deren kompaktes Fürstentum auf die Stadt Mantua und deren Umland konzentriert war, herrschten die estensischen Herzöge über ein heterogenes Gebiet, dessen Vielfalt und Verschiedenheit im Plural des Begriffs Stati estensi Ausdruck fand. Die Macht der Este lag in den Hauptstädten konzentriert, wobei es deutliche Unterschiede gab zwischen der zentralistisch ausgerichteten Hauptstadt des päpstlichen Lehens Ferrara, Sitz des Hofes und der Universität, und den dezentralisierten Hauptstädten der kaiserlichen Lehen, Modena und Reggio.

Obwohl die Este in ihren beiden Lehen spätestens seit dem I4. Jahrhundert etabliert waren, kam es zu Beginn des r6. Jahrhunderts zu einer Lehenskrise, durch die sie die Herrschaft im päpstlichen wie auch in den kaiserlichen Lehen für mehrere Jahre verloren. Um die Mitte des I6. Jahrhunderts begann dann ein über 40 Jahre lang anhaltender und die Beziehungen zum Reich kompromittierender Kampf um den Vorrang gegenüber den Medici. Schließlich musste die Dynastie im letzten Jahrzehnt des I6. Jahrhunderts alle Reserven und das im Reich aufgebaute Netzwerk mobilisieren, um zu einer Regelung der Nachfolge in den Reichslehen aufgrund des Aussterbens der Hauptlinie im Mannesstamm zu gelangen, während das päpstliche Lehen Ferrara trotz aller Bemühungen - dem Kirchenstaat anheimfiel. ${ }^{686}$

686 Richard M. Tristano hat den Kampf um die identitätsstiftende Präzedenz und den Heimfall päpstlicher Lehen als Zeichen eines schleichenden Niedergangs in der Bedeutung kleiner Staaten auf der italienischen Halbinsel gedeutet. Tristano, The Precedence Controversy, 68 I. 
2. KULTURELLER AUSTAUSCH UND TRANSFER 
Publikation im Sinne der CC-Lizenz BY 4.0 


\subsection{Der estensische Hof als Zentrum der Renaissancekultur}

Die Forschung zu Hof und Hofkultur im Alten Reich und in Frankreich/Burgund hat vor allem durch den Wolfenbütteler Arbeitskreis ${ }^{1}$ und in den letzten Jahrzehnten durch die Arbeit der Kommission zur Residenzforschung der Akademie der Wissenschaften in Göttingen einen enormen Impuls erhalten. ${ }^{2}$ Von dieser Institution kommt durch Werner Paravicini, ein ausgewiesener Experte dieser Thematik, die Definition von »Hof« als »herrenmäßige[r] Haushalt, der eine organisierte Ausweitung um öffentliche Regierungs- und Verwaltungsfunktionen erhalten hat, wobei man verschiedene quantitative und qualitative Grenzen setzen kann, z.B. die fürstliche Standesqualität, die ihrerseits verschieden definiert werden kann. Der Hof hat im Haushalt einen festen Kern, um den sich bei gewissen Gelegenheiten weitere Ringe lagern: interne Herrschaftsträger, Verwandte und auswärtige Besucher, Unterhaltungspersonal, Kaufleute, Spezialisten jeder Art. ॥ $^{3}$

Im Alten Reich der Frühen Neuzeit zählte man neben dem Kaiserhof 300-350 deutsche Höfe, unterteilt nach geografischen und konfessionellen Aspekten in »norddeutsch" und "süddeutsch", in »katholisch«, "protestantisch", "geistlich" und »weltlich«. Sie waren untereinander meist durch verwandtschaftliche Beziehungen verbunden, unterschieden sich aber durch eine hierarchische Ordnung. ${ }^{4}$

Im norditalienischen Raum gehörten die Höfe von Mailand, Mantua, Ferrara und Urbino zu den bedeutendsten weltlichen Höfen und waren (außer Ferrara und Urbino) reichsitalienische Lehensgebiete. Auch die Höfe der Seerepubliken Venedig (wenigstens theoretisch bis Anfang des 16. Jahrhunderts) und Genua sowie der Republik Lucca waren wie vereinzelte kleinere Höfe in der Po-Ebene Vasallen des Kaisers. Schließlich gehörte auch Florenz, als der ab der Mitte des r6. Jahrhunderts bedeutendste italienische Fürstenhof neben dem Papsthof, zum Heiligen Römischen Reich. ${ }^{5}$

Der Hof galt diesseits und jenseits der Alpen als »Produktionsstätte« von Kultur im weitesten Sinn. Dabei spielten die kulturellen Ereignisse (Einzug, Turnier, Hoch-

I Siehe hier nur die drei Bände zur Hofkultur des Wolfenbütteler Arbeitskreises: Buck/Kauffmann/ Spahr/Wiedemann, Europäische Hofkultur.

2 Allen voran sei hier die wichtige zweibändige dynastisch-topografische Erfassung und der Überblick über weltliche und geistliche Reichsfürstentümer und Residenzen genannt: Paravicini, Höfe und Residenzen.

3 Paravicini, Von materieller Attraktion, 272.

4 Vgl. das als Nachschlagewerk konzipierte und sehr nützliche Werk von MüLler, Der Fürstenhof, mit einem Abschnitt über die italienischen Renaissancehöfe, I 2 - I 5 .

5 Vgl. Bertelli/Cardini/Zorzi Gambero, Le corti italiane. 
zeit) und die dafür eingesetzten Künste nicht die wichtigste Rolle; ausschlaggebend war ihre Wahrnehmung, Verbreitung und Symbolhaftigkeit für die Teilnehmer und Anwesenden. ${ }^{6} \mathrm{Zu}$ dem zu Recht als "glänzend« bezeichneten Fürstenhof der Este in Ferrara ist die Forschungsliteratur ${ }^{7}$ reich und erschöpfend, sodass hier nur in Hinblick auf die Thematik des kulturellen Austausches und der Wahrnehmung im Reich einige besondere Aspekte hervorgehoben werden. Wie bereits gezeigt wurde, lag das Zentrum der estensischen Macht und der Hofkultur in Ferrara. Mit dieser bevölkerungsreicheren (fast 42.000 Einwohner I 577), ${ }^{8}$ mit mehreren fürstlichen Residenzen und einer gut besuchten Universität (Studio di Ferrara) ausgestatteten Stadt konnten Modena und Reggio bis zum Ende des I6. Jahrhunderts nicht mithalten. Modena zählte I 58 I I 8.000, Reggio I 2.500 Einwohner ; ${ }^{9}$ seit der Etablierung der Universität in Ferrara gab es - bis nach der Devolution - keine zweite Universität in den Stati estensi und auch die Residenzen in den Reichslehen waren eines Statthalters aber nicht eines Herzogs würdig.

Dass die Entwicklung Ferraras seit dem Mittelalter eng mit den Markgrafen und späteren Herzögen d'Este verbunden war, zeigt unter anderem auch das Stadtbild bzw. die Konzentration von Residenz, politischem, religiösem und wirtschaftlichem Zentrum an einem Ort, wo hingegen in Mantua, Bologna, Vicenza, Verona, Padua und Mailand die Fürsten darauf bedacht waren, ihr Herrschaftszentrum an einem anderen, von den schon bestehenden Machtzentren der Kommune und der Kirche distinguierten Ort entstehen zu lassen. In Ferrara hingegen befinden sich der Dom, das Handelszentrum mit den wichtigsten Geschäften, der Palazzo della Ragione aus der kommunalen Vergangenheit und das estensische Machtzentrum, der Castello Estense, auf einem Platz, deshalb Piazza maggiore, Piazza del comen, Piazza del duomo, Piazza del mercato oder nur Piazza genannt, womit das Bild eines einheitlichen Zentrums evoziert wird. ${ }^{10}$ Hier wurde 1393 die Statue des Markgrafen Alberto d'Este als Pilger gekleidet an der Fassade des Domes angebracht, um die fürstliche Schirmherrschaft über die Kirche in diesem Gebiet auszudrücken. Mit Borso d'Este entstanden neben dem zentralen Sitz des Hofes nach und nach periphere Residenzen, sogenannte delizie, mit Gärten und Jagd- bzw. Fischereirevieren ausgestattete Nebenresidenzen, die vorrangig der Erholung und Unterhaltung dienten, doch gleichzeitig auch Stützpunkte der Macht im Territorium und Zeichen der fürstlichen Präsenz waren. ${ }^{11} \mathrm{Be}-$ sonders die illegitime Herrscherlinie der Este mit Nicolò, Leonello und Borso hat diese architektonische Mittel der Inszenierung und Legitimierung der Macht neben

\footnotetext{
6 Grubb, Corte e cronache.

7 Gundersheimer, Ferrara; Bertozzi, Alla corte degli Estensi. Venturi, Cultura e società; Natale, Les artes à Ferrare.

8 BeLoch, Bevölkerungsgeschichte, I I 2 .

9 Ebd. $260-273$.

io Vgl. Folin, Il Castello.

i I Vgl. Folin, Rinascimento estense, 248-25 I. Siehe auch: CAzzola, Lorto di Belfiore.
} 
den literarischen und künstlerischen in und außerhalb Ferraras exzessiv genutzt. ${ }^{12}$ Dass dies von Erfolg gekrönt war, beweisen nicht zuletzt die beiden Erhebungen in den Herzogsstand unter Borso, der bereits durch den von ihm beauftragten Freskenzyklus in der Delizia Schifanoia ${ }^{13}$ und durch seine berühmte illuminierte Bibel ${ }^{14}$ Bekanntheit erlangt hatte.

Auch die Hofdichtung des Quattro- und Cinquecento ${ }^{15}$ und das Theater ${ }^{16}$ stan- $^{-}$ den im Dienst der Herrscherfamilie wenn sie - zusammen mit der oben genannten Genealogie - die altehrwürdigen Ursprünge der Este rekonstruieren und besingen sollten. Die Dichtung sowie die Musik und die Malerei dienten als politisches Medium: Künstler, Musiker und Literaten am Hof von Ferrara machten die Este - oft mit neuen Kunstgattungen - über die Grenzen ihres Herzogtums hinaus berühmt. Außerdem standen die künstlerischen wie literarischen Produktionen in enger Verbin-

I 2 Vgl. Fantoni, Corte e Stato, 466.

I 3 Die estensische Dynastie hatte auch außerhalb der Stadt und des zentralen Castello Stützpunkte der Macht und des Prestiges. Ein ausgeklügeltes System von über das gesamte estensische Territorium verbreiteten delizie sollten allen Untertanen und Fremden die Inbesitznahme, die Macht und Zugehörigkeit des Landes zur Familie d'Este vor Augen halten. Die delizie waren nicht einfache Behausungen, sondern mit Gärten und Jagdrevieren sowie vielen Kunstgegenständen und Ausschmückungen kostbar gestaltete Residenzen. Paradebeispiel ist die von Alberto d'Este erbaute und von Borso erweiterte und verschönerte Delizia Schifanoia. Glanzstück der delizia ist der Festsaal Salone dei Mesi mit den berühmten dreigeteilten insgesamt $525 \mathrm{~m}^{2}$ großen Fresken, die das buon governo, die gute Staatsführung Borsos darstellen. Mittlerweile hat die Forschung festgestellt, dass mindestens fünf Künstlerwerkstätten (botteghe) an der Umsetzung der Fresken beteiligt waren. Dies setzte voraus, dass es einen von Humanisten (wie Ludovico Casella, Teofilo Calcagnini, Lorenzo Strozzi) vordefinierten Plan gab, der die Freskenflächen unter den Werkstätten aufteilte und die Änderungswünsche des Fürsten berücksichtigte. So weiß man, dass der Maler Francesco del Cossa für die Realisierung der Darstellungen zu den Monaten März, April und Mai zuständig war. Die Magie des Raumes ist nicht nur auf die Darstellungen des Lebens und Wesens eines glanzvollen Renaissancehofes zurückzuführen, sondern auch auf die Tatsache, dass es kein natürliches Licht und nur eine Tür gibt, durch die der Herrscher kam. Die Antike ist durch die Darstellung von Grazien, Parzen, Musen und weiteren Inhalten aus den Heldensagen allseits präsent. Die Tierkreiszeichen stehen nicht nur für das große Interesse der Zeit und der Fürsten für diese Wissenschaft, sondern stellen auch die Verbindung zwischen den Göttern des oberen Abschnittes und den Menschen am Hof im unteren Teil her. Vgl. VArese, Gli affreschi.

I 4 Dieses Kunstwerk der Buchproduktion war zwischen I 455 und I46I unter der Führung von Taddeo Crivelli und Franco dei Russi von einer Gruppe von Illuminatoren erschaffen worden. Neben Themen des Alten und Neuen Testamentes wurde der Mäzen Borso immer wieder dargestellt. Weitere Kunstwerke dieses Kalibers waren das Breviario di Ercole I (Modena, Biblioteca Estense Universitaria, ms. V. G. I I = Lat. 424) das Messale von Kardinal Ippolito d'Este (Innsbruck, Universitätsbibliothek, cod. $\mathrm{N}^{\circ}{ }_{43}$ ) und das Stundenbuch Libro d'ore di Alfonso I (Museu Calouste Gulbenkian Lissabon Inv. L.A. I 49). Vgl. Toniolo, Fantasia e intellettualismo.

I 5 Hier seien nur die zwei bekanntesten Auftragswerke Matteo Maria Boiardos Orlando Innamorato oder Ludovico Ariostos Orlando Furioso genannt. Vgl. überblicksmäßig den Beitrag von Venturi, »Magnificentia«, mit dem Frontispiz von Giovan Battista Pignas Historia de Principi di Este.

I6 Vgl. allgemein Cairns, Comédie. 
dung mit den politischen Ereignissen und Schwerpunktbildungen der ersten Hälfte des I6. Jahrhunderts, wie Linda Carroll aufgezeigt hat. ${ }^{17}$

Seit dem frühen I 5. Jahrhundert holten die Este-Fürsten und -Fürstinnen Künstler an den Hof - ganz ihrer humanistischen Bildung und u.a. Machiavellis Forderung, die Künste zu einem Werkzeug der Politik zu machen ${ }^{18}$ folgend. Doch nicht nur von auswärts kamen berühmte Musiker, Maler, Architekten etc. an den estensischen Hof; im ferraresischen Raum blühte auch die einheimische Kunst bzw. Klein- und Handwerkskunst auf, deren Artefakte mit dem Namen »ferraresische Schule« bekannt wurden. Dass das estensische Gebiet und insbesondere Ferrara reich an Kunstbegabten und Kunsttreibenden war, hat Peter Burke festgehalten. In seiner Untersuchung der wie er sie nennt - »kreativen Elite« der italienischen Renaissance kommt er zu dem Schluss, dass im Veneto, das sich größtenteils mit dem estensischen Fürstentum deckt, $20 \%$ der Bevölkerung Italiens lebte und davon 23 \% zur kreativen Elite (davon mehr als die Hälfte bildende Künstler) gehörten. Diese Relation ist nach Burkes Berechnung die zweitgrößte und wird nur von der Toskana übertroffen. Die kreative Elite war verständlicherweise in der Stadt konzentriert und vor allem vom Hof abhängig. Die Niederlande und besonders Norditalien waren am frühesten und am stärksten urbanisiert und brachten somit die größte Anzahl von Künstlern und Handwerkern auf. Burke errechnete für das 44.00o Einwohner starke Ferrara in der ersten Hälfte des I6. Jahrhunderts I 5 Angehörige der kreativen Elite, die hier geboren worden waren. ${ }^{19}$

Neben der Förderung der Künste, der Literatur und Musik am Hof waren auch die Universität und das wissenschaftliche Umfeld (accademie) ein Markenzeichen Ferraras. ${ }^{20}$ Dazu gehörten im weitesten Sinn auch die Zentren der Buchproduktion und -miniatur. Vor allem unter Leonello, Borso und Ercole I. bekam die estensische Miniatur landesweit Bekanntheit für ihre Exklusivität und die Fantasie der Ornamente. Es bildete sich in Ferrara eine regelrechte Schule, aus der Künstler wie Marco dell”Avogaro, Giorgio d'Alemagna oder Guglielmo Giraldi hervorgingen.

Einen weiteren hohen und nachahmungswürdigen Maßstab setzten die Este bei den cavallerie, jenen Festveranstaltungen, bei denen sich themenbezogene Turniere

I7 An verschiedenen Beispielen konnte Carroll den Wechsel der Allianzen in den am ferraresischen Hof entstandenen Werken nachzeichnen. Da die Habsburger und besonders Karl V. den Mythos von Troja und Äneas für sich beanspruchten, übernahmen die Künstler und Dichter der Este und vor allem der kaisertreuen Gonzaga ebenso diese Themen z. B. durch die Werke von Dosso, wenn es ihnen politische Vorteile brachte. Wo sich hingegen nach dem Frieden von Cambrai die Beziehungen zwischen den Este und Frankreich verstärkten, wurde mit Dossos Melissa und Ariostos Orlando Furioso dieser Verbindung gehuldigt. CARroll, »Fools of the Dukes of Ferrara«, 68.

I 8 "Debbe ancora uno principe monstrarsi amatore delle virtù, et onorare li eccellenti in una arte / Ein Fürst muss die Künste lieben und jene ehren, die in einer Kunst hervorragen.« Niccolò di Bernardo dei Machiavelli, Il Principe, hg. v. Sálvio M. Soares, MetaLibri, 2005, http://metalibri.wikidot.com/ title:il-principe, Kap. XXI, 3 I 8.

I9 Ebd., 42f. Vgl. auch Meijer, Ferrara e il Nord.

20 Venturi, Cultura e società. 
mit Aufführungen und Festlichkeiten zu verschiedenen Anlässen wie Karneval, Fürstenbesuche oder Hochzeiten vermischten. Dabei brillierte man mit Theateraufführungen, Gesang, szenischen Spezialeffekten, Theaterarchitektur, Feuerwerk und Choreografie, Letztere unter besonderer Beteiligung von Alfonso II. d'Este, der sich auch damit auf eine Stufe mit den Fürsten der großen europäischen Höfe stellte. Eigene, meist in Versform gehaltene libretti begleiteten - manchmal auch in andere Sprachen übersetzt - die Aufführung und garantierten die Vermittlung der moralischen Inhalte der Allegorie. ${ }^{21}$

Wenn unter den Este-Fürsten der Renaissance vorrangig Ercole I. mit seiner europaweiten Liebe und Pflege der Musik bekannt wurde, so darf nicht vergessen werden, dass schon unter Nicolò III. und Leonello d'Este diese Kunst ein konsolidierter Bestandteil des Hoflebens war, wenn auch zunächst vor allem im liturgischen Bereich. Von den ersten intensiven Beziehungen zum burgundischen und französischen Hof inspiriert, hatte Leonello als erster seinen Hof mit einer eigenen ständigen Kapelle für liturgische Musik ausgestattet. Ab den ersten Jahrzehnten des I 5. Jahrhunderts gab es am estensischen Hof auch eine profane Musikkapelle, für die Philipp von Burgund Nicolò einige Instrumente geschickt hatte. In dem von Borso geförderten Kloster San Cristoforo alla Certosa wurden des Weiteren Choräle mit aufwendigen Miniaturen geschmückt. Aber erst unter Ercole I. erreichte die Hofkapelle ihren Höhepunkt mit bedeutenden ultramontanen Komponisten und Kapellmeistern, deren Hofmusik mit eigenen Kompositionen jedes höfische Ereignis sowie den fürstlichen Alltag begleitete. Schließlich wurde die größtenteils aus fremden Musikern bestehende estensische Hofkapelle so berühmt, dass einzelne Musiker und Sänger von anderen Höfen und Fürsten angefragt oder sogar abgeworben wurden. Erst unter Alfonso II. wuchs die Zahl der italienischen Sänger und Musiker und bald war mit Francesco della Viola auch der Kapellmeister kein Ultramontane mehr. ${ }^{22}$

Neben den literarischen Künsten und der Musik stand auch die Architektur im Dienst der Este und ihres Geltungsdrangs. Der am aragonesischen Hof von Alfonso V. aufgewachsene und viel gereiste Ercole I. sah die höchste Aufgabe des Fürsten darin, das Erscheinungsbild seiner Stadt zu prägen und zu verbessern, da sie ja dem Prestige und der Ehre seines Geschlechts dienen sollte. Die Bautätigkeiten sollte also den Ruhm der Fürstenfamilie steigern und wurden gezielt zur Förderung des Mythos des fürstlichen Bauherrn (»principe architecto«) eingesetzt. Die Bautätigkeit lag den Este fast schon im Blut, denn seit sie einst die byzantinische Siedlung am Ufer des Flusses Po übernommen hatten, mussten sie sich mit den unzähmbaren Gewässern vor

2 I CAvicchi, Le Cavallerie estensi. Zu diesen in der englischsprachigen Forschungsliteratur »tournaments« genannten Vergnügungen siehe: Watanabe-O'Kelly, Tournaments in Europe, 6 I $_{5}$. Berühmt und für nachahmungswürdig befunden wurde das Turnier Il Tempio d'Amore im Rahmen der Hochzeitsfeier von Alfonso II. und Barbara von Österreich. STrong, Feste, 98.

22 Vgl. Faвв Ri, Gli Este e la musica. 
Ort auseinandersetzen. Die Bändigung des Wassers förderte somit die Bautätigkeit der Este. Doch mit der addizione erculea, der Erweiterung der Stadt zwischen 1492 und I 505, übertraf Ercole I. die Bemühungen seiner Vorgänger und die Pläne seiner Nachkommen bei Weitem, indem er die Ausdehnung Ferraras verdoppelte und das Stadtbild komplett erneuerte. ${ }^{23}$

Die oben genannten Aspekte prägen allesamt das Bild des Hofes als »Behälter«, wie Trevor Dean ihn definiert hat, ${ }^{24}$ also als Ort von Inklusion und Exklusion, bestehend aus einem festen Kern und gleichzeitig einer »fluktuierenden Menschengruppe« von Künstlern, Bauleuten, Schauspielern, Turnier- und Theatertechnikern, die sich zeitoder auftragsweise in der Nähe des Fürsten aufhielten und für ihn und seine Familie arbeiteten, im Zuge des Patronagesystems ${ }^{25}$ der Zeit rekrutiert wurden, sich integrierten oder durch fürstliche Vermittlung neue Anstellungen fanden. Hier soll aber kurz auch ein Blick auf den estensischen Renaissancehof als Raum, also auf den mehr oder weniger fixen Bestand dienstbarer Geister verschiedener Gesellschaftsschichten um den Machthaber und seine familia, geworfen werden.

Im Sinne der jüngeren Neuzeitforschung werden Hof und Staat als komplementär zueinander und nicht als getrennte Realitäten gesehen. Dabei gilt der Hof als Spielraum für adeligen Einfluss und als Integrationsort für territoriale und fremde Eliten, eine Definition, durch die Ronald Asch Norbert Elias' Sicht vom Hof als Werkzeug zur Domestizierung des Adels etwas abgeschwächt hat ${ }^{26}$ und die Trevor Dean auf die italienischen Fürstenhöfe, die er Hochburgen (roccaforte) des adeligen Einflusses definiert, übertragen hat. $^{27}$

23 Folin, L'architettura.

24 Personen, Dinge und Interessen waren - nach Dean - zeitbedingt am Hof anzutreffe und tätig, wodurch der Hof den Aspekt eines offenen Raumes mit viel Fluktuation bekommt und weniger den einer geschlossenen Realität. Allein das Kommen und Gehen von Gesandten, Künstlern, Kaufleuten, Kirchenmänner, Gästen und anderen Fürsten brachten neue Weltanschauungen und Erfahrungen mit und beeinflussten unweigerlich das Hofleben. Dean, The Courts, I43f.

25 Dean beruft sich auf Kettering, Patrons, wenn er behauptet, dass patron-client-Beziehungen charakteristisch für einen nicht komplett zentralisierten Staat mit einer schwachen Regierung zwischen Zentrum und Peripherie sind. Ein wichtiger Schritt in Richtung moderner Staat war getan, wenn Patronage sich am Hof zentralisierte und lokale und regionale Klientelnetzwerke der Patronage des Fürsten unterstellt waren. Dean, The Courts, r 5o. Zu Patronage und Klientelismus allgemein ist die Literatur umfassend. Hier sei nur auf einige wenige Werke und die weiterführenden Hinweise darin verwiesen: Mа̨сzак, Klientelsysteme; Asch/Birke, Princes; Droste, Patronage. Eine gute Darstellung eines - späteren Hofes bietet die Homepage des Forschungsprojektes Patronage- und Klientelsysteme am Wiener Hof: http://www.univie.ac.at/Geschichte/wienerhof/, Zugriff: I 4.06.2020.

$26 \mathrm{Asch}$, Hof, I22f. Siehe auch Elias' Theorien ebenso relativierend die Vergleichsstudie von Duindam, Vienna and Versailles, und Ders. The Keen Observer.

27 Dean, Le corti, 426f. Einen lebhaften Einblick in das Leben einer Dynastie von Höflingen, die sich durch eine gewinnbringende Heiratspolitik mit Abkömmlingen verschiedener Hofeliten über Jahrhunderte im Dienst der Este halten und Rang und Titel erreichen konnten, bietet die Autobiografie von 
Der estensische Hof der Frühen Neuzeit wurde von Guido Guerzoni in einer prosopografischen Studie über die Mitglieder der Höfe von Ercole I., Alfonso I., Ercole II., Alfonso II., Cesare und Francesco I. sowie jene der Nebenhöfe von Eleonora von Aragón, Lucrezia Borgia, Laura Eustochia Dianti, Renée de France, Lucrezia de’Medici, Barbara von Österreich, Margherita Gonzaga und Virginia de'Medici untersucht. ${ }^{28}$ Mithilfe einer computergestützten Datenbank hat der Autor auch die Bediensteten der Höfe der vier estensischen Kardinäle (Ippolito I., Ippolito II., Luigi und Alessandro d'Este) sowie der nicht regierenden Fürstenkinder erfasst und somit eine Grundlage für die italienische Hof- und Patronageforschung geschaffen. ${ }^{29}$

Wichtige Erkenntnisse hat Guerzonis Arbeit vor allem zur Größe des estensischen Hofes gebracht. Dieser zählte Mitte des I6. Jahrhunderts 500-550 Einzelpersonen, während die Nebenhöfe nochmals I.000-I.200 Personen umfassten, sodass sich für die Eliten des Herzogtums verschiedenste Machtpositionen im fürstlichen Dienst boten. Hoch war auch die Zahl der »übernommenen« Bediensteten bei der Aufösung eines Hofstaates im Zuge des Ablebens des Dienstgebers/der Dienstgeberin, oder wenn es für die Dienste einer Person in der ursprünglichen Entourage keine Verwendung mehr gab. In der Regel übernahm der Nachfolger einen mehr oder weniger großen Kreis von Bediensteten von seinem Vorgänger/Vater, außer im Fall einer politischen Zäsur wie bei der Übernahme der Macht durch den illegitimen Cesare: Hier folgten nur 38 der 376 Bediensteten von Alfonso II. Cesare nach Modena. ${ }^{30}$

Giovanni Galliani (I635-I7I I), Rechtsgelehrter, Sekretär von drei Este-Fürsten und I698 zum Markgraf von Montebaranzone erhoben. Siehe die Erkenntnisse über die Fürsten, denen Galliani diente, und über den schwierigen, von Intrigen und Neid vergifteten Hofdienst in der Edition seiner Lebensbeschreibung: Montanari, Vita del segretario Giovanni Galliani.

28 Guerzoni, Le corti estensi.

29 Über die Hofbediensteten hinaus hat sich Guerzoni mit den Beamten, Ratgebern und Hoflieferanten sowie mit den Abgängern der Universität von Ferrara auseinandergesetzt. Mit dem prosopografischen Ansatz konnte er nicht nur Unmengen von Daten, vorrangig Personendaten, aus den Archivquellen verarbeiten, sondern vor allem Netzwerke, Sippschaften, Beziehungen und Verstrickungen der Hofgesellschaft sichtbar machen, die historische Elitenforschung bereichern und die Makro- und Mikrogeschichte miteinander verbinden. Guerzoni, Le corti estensi, I5 - I 7, 24.

30 $\mathrm{Zu}$ den loyalen Anhängern Cesares aus den höheren Gesellschaftskreisen gehörten der locotenente Ippolito Bentivoglio, Cesares alter ego in den ersten turbulenten Jahren in Modena, dessen Bruder Enzo, der Hauptmann der Kavallerie, Galeazzo Tassoni Estense, der Hauptmann der herzoglichen Garde und seit 1599 Statthalter von Carpi, Enea Montecuccoli, der Hauptmann der Lanzen von Lugo, Ernesto Bevilaqua, die Obersten Roberto Obizzi, Camillo Martinengo und Paolo Brusantini, der Statthalter von Modena, Ferrante Tassoni Estense, und sein Sohn Ercole, der Statthalter von Reggio, Graf Ercole Rondinelli, und der Statthalter von Garfagnana, Orazio Sacrati, die Markgräfin Tassoni, die Grafen Guidobaldo Rovella, Tiberio Ricci, Ugo Rangoni, Giovanni Molza, die Edelmänner Carlo Forni und Geminiano Roncà und der Oberst Molla. Die übrigen waren niedere Bedienstete, Diener, Stallburschen, Buchhalter, Falkner, Wäscherinnen, Pagen und einige Hausbedienstete. Guerzoni, Le corti estensi, $36-38$, I9I-I 94 . 
Der frühneuzeitliche estensische Hof war ähnlich strukturiert wie andere italienische und europäische Höfe und bestand aus dem engsten Kreis um den Fürsten, zu dem Familienmitglieder, Verwandte, Verschwägerte oder durch ein klienteläres Abhängigkeitsverhältnis an den Fürsten Gebundene gehörten, und deshalb familia genannt wurde. Zum Hof gehörten auch die Hofbediensteten (cortigiani), also nur jene, die über einen längeren Zeitraum angestellt waren und einem Mitglied der Fürstenfamilie dienten. Ein cortigiano war in unmittelbarer Nähe, wenn nicht sogar direkt bei Hof wohnhaft. Die heute noch den betreffenden Archivbeständen namensgebende Casa beinhaltete den Hof und die familia, so war die Casa d'Este die Summe der verschiedenen familiae und Höfe bzw. Nebenhöfe. ${ }^{31}$ Der estensische Hof in toto also als Summe aller Einzelhöfe bestand aus der Casa, der Cancelleria (Kanzlei), den Consigli (Ratsgremien) und der Camera Ducale (Hofkammer). In den Untergruppen der Casa kümmerte sich die Camera um die Person des Fürsten, die Gesundheit der Hofleute, die Guardaroba um die Kleidung und die Ausstattung der Räume, die Uffici di bocca um die Lebensmittelversorgung, die Ställe und die Mobilität, die Musicha um die Unterhaltung, Bildung und das Seelenheil und die Castellania um die Sicherheit und Verteidigung. ${ }^{32}$ Es gab am Hof cortigiani immediate salariati (salariati di bolletta), also solche, die in einer Besoldungsliste aufgeführt wurden und ein festgesetztes Gehalt in Geld, ein höher angelegtes in natura erhielten und sonst auch anderweitige Privilegien genossen; die zweite Gruppe bestand aus jenen, die in einem Abhängigkeitsverhältnis zum Hof standen und nur in natura bezahlt wurden (bocche). Guerzoni hat sich in seiner Studie auf Erstere beschränkt, die schließlich die Gesamtheit der cortigiani ausmachten. Diese entstammten adeligen Familien oder sogar den Este gleichrangigen fürstlichen Nachbarn und Verwandten, die oft bereits als junge Pagen in den Fürstendienst traten. Am Hof von Ferrara lernten sie das höfische Benehmen, genossen meist noch eine Ausbildung und dienten auch als Austausch und Beweis für gute freundschaftliche Beziehungen, als Garanten für die Einhaltung von politischen und diplomatischen Abmachungen (vor allem dort, wo sie als Geiseln gehalten wurden), verstärkten die Lehensbeziehungen des estensischen Adels und Patriziats mit den Este und waren nicht selten »Spielfiguren « des höfischen Heiratsmarktes. ${ }^{33}$

$\mathrm{Zu}$ den Hofbediensteten und Besoldeten gehörten auch die residierenden Gesandten (oratori, comissari). In der Regel waren es vier bis fünf Männer aus dem estensischen Hochadel oder aus den Reihen der Giudici del Consiglio di Giustizia oder aus den Spitzenpositionen der Kanzlei. Bis I 5 ro waren nur einige italienische Höfe mit dauerhaft residierenden Gesandten versehen, so Venedig, Mailand, Florenz, Neapel

3i Guerzoni, Le corti estensi, 47-5o. Vgl. auch die allgemeinen Überlegungen bei MączaK, Il principe.

32 Guerzoni, Le corti estensi, 75-78. Die Struktur des Fürstenhofes unter Alfonso II. war auch Vorlage für die Idealvorstellung des perfekten Hofstaates, dem ein perfekter Fürst vorstand im Il Principe von Giambattista Pigna. Vgl. Larivaille, Familiari.

33 Guerzoni, Le corti estensi, 54-56, i 27 . Viele Patron-Klient-Beziehungen begannen in dieser Ausbildungszeit am Fürstenhof, also in der unmittelbaren Nähe zum Fürsten. Droste, Patronage, 583 f. 
sowie der Papsthof. Ab I 5 I I hatten die Este einen Gesandten beim »christianissimo re di franza« (der erste war Aldrovandino Turchi mit einem Gehalt von 700 Dukaten jährlich) nach I 525 einen am Kaiserhof, nach I 528 einen am englischen Hof und ab I $55^{8}$ am Hof von Philipp II. von Spanien (diese allerdings nicht durchgehend). Neben den Gesandten gab es zahlreiche Sondergesandte, Agenten und negociatori, die für ganz bestimmte diplomatische Aufträge herangezogen wurden, von denen einige hauptberuflich Musiker, Kaufleute, Kirchenmänner, Bankleute und dementsprechend nicht angestellt waren, sondern nur für den Zeitraum ihrer Dienste, oft nur einmalig, besoldet wurden. ${ }^{34}$

Der am besten untersuchte und für die vorliegende Arbeit relevanteste Hof ist jener von Alfonso II., auf den hier - den Ergebnissen von Guerzoni folgend - ausführlicher eingegangen werden soll. Der Hof von Alfonso II. konstituierte sich I 554/5, als der 2 I-Jährige von seinem Vater mit einem repräsentativen Gefolge ausgestattet wurde. Anders als sein für die geistliche Laufbahn bestimmte Bruder Luigi, der Alfonso I 558 nach Frankreich folgte und hier sogleich zahlreiche Franzosen in seine Dienste nahm, umgab sich der junge Alfonso II. in Frankreich, wohin er aus der väterlichen Obhut entflohen war, zu $90 \%$ mit Italienern vor allem aus Ferrara. Als er dann I 560 die Herrschaft in den Stati estensi übernahm, zählte sein Hofstaat bereits 398 Besoldete, die 1567 mit der Zusammenführung des Hofstaates seiner zweiten Gemahlin, Barbara von Österreich, auf $48 \mathrm{I}$ anstiegen. Hierzu kamen noch die Bediensteten der Hofställe ( IоO- I 20), die Schweizer und Deutschen Landsknechte (je 50), die Hofgarde ( IO- I 5), die Pagen (20-25), die Laufburschen der Kanzlei und der Kammer (30-40) und eine große Anzahl an weiteren bocche, da auf fast jeden Bediensteten I- 2 Diener kamen, die nicht für ein Gehalt, sondern nur für Kost und Logis arbeiteten. So gehörten am Ende der I $560 e r$ Jahre mehr als 900 Personen zu Alfonsos und Barbaras Hofstaat, eine Zahl, die durchaus den Gegebenheiten an anderen Höfen Italiens (Gonzaga, Medici, Savoyen) und Europas entsprach. Nur der Papst und der Kaiserhof überschritten diese Zahlen bei Weitem. ${ }^{35}$

Die Größe des estensischen Hofes und seine stetige Erweiterung in der Frühen Neuzeit spiegelten durchaus den Versuch wider, die bedeutenden europäischen Höfe, allen voran den französischen, nachzuahmen; ein Trend, der auch bei den deutschen Fürsten- und Kurfürstenhöfen erkennbar ist. ${ }^{36}$ Hatte Kaiser Friedrich III. am Ende des I 5. Jahrhunderts 600 Bedienstete gehabt, ${ }^{37}$ so zählte der Hof des Herzogs von Burgund 1474 bereits I030. ${ }^{38}$ Auch die maison du roi steigerte sich von 540 (I 523 ) auf

\footnotetext{
34 Guerzoni, Le corti estensi, 92.

35 Guerzoni, Le corti estensi, I 57- i6o.

36 Müller, Hofstaat, $46 f$.

37 Heinig, How large was the Court of Emperor Frederick III?.

38 Paravicini, The Court of the Dukes of Burgundy.
} 
892 Bedienstete bis $1557,{ }^{39}$ während der glänzende Hof von Philipp II. von Spanien in den I $560 e r$ Jahren I $200-$ I 500 Angestellte hatte. ${ }^{40}$

Wie sein Schwager Vincenzo Gonzaga und andere italienische Fürsten versuchte vor allem Alfonso II. - den finanziellen Ruin in Kauf nehmend - mit den enormen Hofentouragen europäischer Fürstenhäuser mitzuhalten. ${ }^{41}$ So hielt auch der florentinische Gesandte Orazio della Rena fest, dass Alfonso II. an sich nur ein mittelmäßiger Fürst sei, aber sich große Mühe gebe, dass sein Hof besonders groß und reich an cortigiani erscheine, indem er viele aufnehme, die ihm nicht dienen müssten (»procura che la Corte all'apparir sia piena di Cortiggiani, et di gentiluomini, facendo invitar ancor quelli, che non hanno obbligo di servire $)^{42}$

Alfonso II. hatte nach seiner Etablierung als Herzog im Vergleich zu seinen beiden Vorgängern nicht nur den größten, sondern auch den »buntesten« Hofstaat bestehend aus Personen aus dem Reich (I6), aus Frankreich (3 I) und einzelnen Bediensteten aus Flandern, der Schweiz, Österreich, Bayern und dem unter osmanischer Herrschaft stehenden Griechenland. Diese Offenherzigkeit gegenüber Ausländern, die bei Alfonso besonders von seinen Aufenthalten in und engen Beziehungen zu Frankreich sowie dem Reich rührten, zeigte er nicht gegenüber den Eliten der übrigen estensischen Gebiete. Von den einheimischen Hofleuten kamen die meisten aus dem ferraresischen Stadtadel und Patriziat und nur wenige aus Modena, Reggio oder anderen Teilen des estensischen Fürstentums. ${ }^{43}$

Alfonso II. vererbte dem von ihm designierten Nachfolger Cesare d'Este aus der Linie der Markgrafen von Montecchio nicht nur die kaiserlichen Lehen und wenige Getreue, die dem Herzog von Modena und Reggio folgten, sondern auch einen durch die teure Hofhaltung verursachten Schuldenberg, zu dem Kredite von Cesares Vater (200.000 Lire marchesane) kamen und jene seines Vetters, Kardinal Luigi, der in Ferrara bei den bedeutenden estensischen Adelsfamilien (Bevilacqua, Pio, Obizzi, Tassoni, Ariosti, Cybo Malaspina) 450.00o Lire und in Rom nochmals I 85.000 Lire Schulden hinterlassen hatte. Allein aufgrund dieser »Erbschaft« konnte sich Cesare selbst keinen pompösen Hofstaat leisten, sondern musste sogar beim Großherzog von Toskana um Geld bitten, um die laufenden Kosten zu decken. ${ }^{44}$ Diesem klagte Cesare I 603 seine (Geld)Not aufgrund der geerbten Schulden, seiner kinderreichen Familie, der

39 KNecht, La corte di Francia, 229.

40 Alvar Ezquerra, Felipe II, i5 - i 8. Zum Vergleich: Einer Beschreibung des Hofstaates von Erzherzog Ernst von ${ }_{5} 53$ in den Fuggerzeitungen zufolge bestand dieser aus 480 Personen. Klarwill, FuggerZeitungen, Nr. I48, I $72 \mathrm{f}$.

4I Guerzoni, Le corti estensi, i6r.

42 Della Rena, Relazione, 65.

43 Guerzoni, Le corti estensi, i6gf.

44 Guerzoni, Le corti estensi, i 85. In Cesares Hofstaat gab es aber immerhin noch neun Deutsche gegenüber vier Franzosen und zwei Flamen, was bei einer Größe von 969 Personen immerhin noch die größte »ausländische« Fraktion darstellte. Ebd., 209. 
dürftigen Einkünfte aus seinem Rest-Fürstentum und der Tradition seiner Vorgänger, die Untertanen nicht zu sehr mit Steuern zu belasten: »[...] ch'io mi trovo sette figlioli quattro maschi, et tre femine, et la moglie giovine, che figlia quasi ogn'anno [...] che non cavo di questi stati, benchè assai grandi, et numerosi di popolo, molta rendita. Havendo costumato i miei predecessori, i quali havevano entrate grosse in Ferrara, di non gravare questi sudditi ${ }^{45}$

Doch vor diesem »bitteren« Ende galt der Hof von Ferrara im Untersuchungszeitraum als personenreiche familia des Fürsten, Ort der Kunstförderung und des Mäzenatentums, zentraler Verwaltungsort eines sehr heterogenen Fürstentums und glänzender Mittelpunkt der estensischen Dynastie, deren Mitglieder am italienischen und europäischen (katholischen) Heiratsmarkt in Erwägung gezogen wurden.

45 Archivio di Stato di Firenze, Archivio Mediceo del Principato, nr. 2915, Modena, Lettere di duchi e di principi estensi, I597-I609, lettera di Cesare al Granduca del I4 marzo I603, zit. n. Guerzoni, Le corti estensi, 4 of. Hier sei auf die Ironie des Schicksals hingewiesen: Alfonso II. war es mit verschiedenen Strategien in der zweiten Hälfte des I6. Jahrhunderts gelungen, sein Fürstentum zu stärken und international bekannt zu machen, doch konnte er es keinem legitimen Erben vermachen. Cesare erbte schließlich ein reduziertes, verschuldetes Fürstentum, dessen Zentrum in Modena erst auf- bzw. ausgebaut werden musste. Er hatte im Gegenzug zahlreiche Kinder, eine überaus fruchtbare Frau und Schwierigkeiten diese Nachkommen ihrem Stand entsprechend zu versorgen bzw. zu verheiraten. 


\subsection{Die Heiratspolitik der Este als Grundlage der Netzwerkbildung}

Katrin Keller hat in ihren Untersuchungen der Korrespondenznetzwerke frühneuzeitlicher Fürstinnen zu Recht festgehalten, dass das Alte Reich nicht nur lehensrechtlich als Personenverband galt, sondern auch aufgrund der vielfältigen, wechselseitigen dynastischen Verflechtungen die Züge eines Familienverbandes hatte. ${ }^{46}$ Wie (überlebens-)wichtig Netzwerkbildung auch für die Este, Herrscher über ein mittelgroßes, dem Papst und dem Kaiser lehensrechtlich verpflichtetes Fürstentum war, soll in der Folge verdeutlicht werden.

Eine der Grundlagen für die Netzwerkbildung, für eine erfolgreiche Einbettung und Verflechtung im nationalen und internationalen Rahmen, ${ }^{47}$ war neben einer kontinuierlichen Präsenz durch Gesandtschaften eine weitsichtige Heiratspolitik, wie bereits andere Untersuchungen klar gezeigt haben. ${ }^{48}$ Insofern dient dieses Kapitel zur estensischen Heiratspolitik als Grundlage für das bessere Verständnis des kulturellen Austausches und des internationalen Beziehungsgeflechtes zwischen den Este und dem Reich.

Sowohl auf der Seite des Reiches, und hierbei besonders der Habsburger, als auch auf jener der italienischen Fürsten, und hier wiederum vor allem der Este, dienten Söhne und Töchter als »Humanressourcen der Familie«, ${ }^{49}$ d.h. der Allianzbildung, Friedensherstellung oder -wahrung, dem territorialen Zugewinn, der Annäherung und der Intensivierung bestehender Beziehungen. Diese Ziele dynastischer Verbindungen galten sowohl für realisierte Heiraten als auch für angedachte, denn, wie Jan Paul Niederkorn und vor ihm Hermann Weber ${ }^{50}$ festgehalten haben, es reichten die Absicht und der - jederzeit auflösbare - Vertrag, um die politischen Hintergründe einer Verbindung zu konkretisieren. ${ }^{51}$

Die frühen Heiratsprojekte des i4. und anfänglichen I 5. Jahrhunderts der EsteDynastie zielten auf territoriale oder militärische Vorteile und große Mitgiften ab. Einige der Bräute wie Jacoma und Lippa hatten einfache, aber reiche Vorfahren, andere wie Tadea oder Verde, Costanza oder Parisina kamen aus den einflussreichen Familien

46 Keller, Kommunikationsraum, 2 ro.

47 Vgl. auch den Abschnitt über Italien in Kohler, Expansion und Hegemonie, ro9- I 25.

48 Iotti, La politica dell'Amore. Spagnoletti, Le dinastie. Parallel zu Mantua siehe: Schnettgeer, Zwei Ehen und ihre Folgen.

49 Niederkorn, Die dynastische Politik, 3r. Überblicksmäßig, aber ohne Anmerkungsapparat auch: WEIss, »Habsburgs verkaufte Töchter« und WALsH, Verkaufte Töchter.

50 Weber, Die Bedeutung der Dynastien, gf. Für einen bis in die späte Neuzeit reichenden Überblick über die Heiratspolitik der italienischen Fürsten siehe: Schnettger, Geschichte als Dekadenz?

5 I Nieder korn, Die dynastische Politik, 3 I. 
der Umgebung, also der Della Scala und der Malatesta. Noch andere wie Stella dei Tolomei dann umbenannt in dell'Assassino waren vor allem schön und wurden als langjährige Geliebte geheiratet und deren Kinder oft legitimiert; sie selbst wurden allerdings nicht zu Fürstinnen gemacht.

Den sich in der Po-Ebene etablierenden Este war seit jeher die Verbindung mit den Mantuanern wichtig. ${ }^{52}$ Die Heiratsprojekte mit den Nachbarn begannen bereits im frühen I 4. Jahrhundert - als noch die Corradi Herren über die Stadt waren - mit der Eheschließung von Nicolò, Sohn von Aldobrandino II. d'Este, mit Beatrice. ${ }_{3} 56$ heiratete Alda d'Este, Tochter von Obizzo III., Ludovico I. Gonzaga. Weiter ging es mit Leonello und Margherita Gonzaga I 435. Hier lag der Vorteil der Este in der Verschwägerung mit einem kaiserlichen Lehensmann, der noch dazu kurz darauf vom Kaiser zum Markgrafen erhoben wurde. Die Gunst des Kaisers, so hoffte man, würde sich auch auf die verwandten Este ausdehnen. Erst in seiner zweiten Ehe weitete Leonello den estensischen Heiratshorizont und holte mit Bianca Maria von Aragón eine Braut aus dem entfernten Neapel und von königlichem Geblüt nach Ferrara. Für seine Kinder suchte er die Verbindung zum aufstrebenden Stern Francesco Sforza und wollte seinen Sohn Nicolò mit einer Tochter des condottiere verheiraten, aber das Heiratsprojekt verlief im Sand, wenn auch ohne die guten Beziehungen zwischen den Este und den Sforza zu beeinträchtigen. ${ }^{53}$

Wenn man die Heiratsverbindungen der Este seit ihrer Erhebung in den Herzogstand betrachtet, so erkennt man einerseits den weitergeführten Trend der Bildung von Allianzen mit anderen italienischen Fürstenhäusern wie den Aragonesen von Neapel (Eleonora), den Sforza (Beatrice d'Este-Sforza und Anna Sforza), den Gonzaga (Isabella d'Este-Gonzaga, Margherita Gonzaga-d'Este), den Medici (Lucrezia de'Medici-d'Este) und den Fürsten von Urbino (Lucrezia d'Este-della Rovere); andererseits sieht man auch deutlich den Versuch der Festigung und Intensivierung der Beziehungen zu Frankreich (Renée de France-d'Este, Anna d'Este-de Lorraine/de Savoie). ${ }^{54}$ Zwei Verbindungen, jeweils am Anfang und am Ende des r6. Jahrhunderts dienten der Annäherung der Herzöge von Ferrara und Modena an den päpstlichen

52 Diese bestanden das gesamte 16 . Jahrhundert hindurch und dienten auch der gegenseitigen Stärkung und Unterstützung wie Bonora am Beispiel der Beziehung und Korrespondenz zwischen Kardinal Ercole Gonzaga und Herzog Ercole II. d'Este gezeigt hat. Bonora, Aspettando l'imperatore, I6 I, I 70.

53 Іотті, La politica, I54- I59.

54 Wie Schnettger bereits festgehalten hat, gab es mehr französische Fürstinnen, die mit italienischen Fürsten verheiratet wurden als italienische, die in Frankreich in bedeutende Häuser Einzug fanden. Dies beweist nach Schnettger die geringere Attraktivität einer italienischen Verbindung für den König von Frankreich und eine Zumutung für eine königliche Braut einen »Herzog« zu ehelichen, während eine solche hypogame Verbindung für die italienischen Fürsten erstrebenswert war. Schnettger, Geschichte als Dekadenz?, $57 \mathrm{f}$. 
und kaiserlichen Lehensherrn, nämlich die mit Lucrezia Borgia-d'Este) und jene mit Barbara von Österreich-d'Este). ${ }^{55}$

Die Heirat von Alfonso I. mit Lucrezia Borgia brachte den Este nicht nur Schutz vor den Eroberungszügen der Borgia-Familie, sondern auch eine überaus großzügige Mitgift: Die Braut brachte 200.000 Golddukaten und dazu Juwelen, Kleider und Bücher, von denen viele auf Spanisch waren, ${ }^{56}$ nach Ferrara. Zudem wurde der Lehenszins an den Papst deutlich vermindert und das Herzogtum Ferrara um Cento und Pieve erweitert. ${ }^{57}$ Wenn Vocelka die durchschnittliche Summe der Brautaussteuer der Habsburgerinnen (bestehend aus Bargeld und/oder als Naturalaussteuer aus Kleidern, Schmuck und Erträgen) auf ı oo.0oo Golddukaten ansetzt ${ }^{58}$, dann übertraf die Mitgift Lucrezias alle Erwartungen. Allerdings rührte die Großzügigkeit der Borgiafamilie auch von den Schwierigkeiten, die Tochter des Papstes aufgrund der zahlreichen Gerüchte über sie und ihre Familie vorteilhaft zu verheiraten.

Bei den beiden anderen frühneuzeitlichen Bräuten der Este, Renée de France und Barbara von Österreich, wog hingegen der mit diesen ranghöheren Verbindungen einhergehende Prestigezuwachs mehr als die tatsächliche Mitgift. Im Fall der Heirat mit Renée de France erbat sich der französische König und Schwager der Braut, François I., noch vor der Hochzeit eine Geldanleihe ${ }^{59}$ von Ercole (II.), der in der Befürchtung, Renée doch nicht zu bekommen, seine Wertsachen in Frankreich verkaufte, um zu Geld zu kommen. ${ }^{60}$ Theoretisch wäre Renées Mitgift ${ }^{61}$ einer Königstochter wohl würdig und die ihrer Schwiegermutter aus dem Haus Borgia ähnlich gewesen (»200.000 ducati d'oro del sole«) hätte es nicht eine von François I. dem Heiratsvertrag hinzugefügte Klausel gegeben, die festlegte, dass nur 50.00o Golddukaten am Tag der Hochzeit ausgezahlt werden sollten; der Rest sollte in Form einer Rente von Io.০oo Golddukaten aus den Einnahmen eines Herzogtums kommen. ${ }^{62}$ Und so bekam Ercole anstelle von Bargeld den Titel eines Herzogs von Chartres, Graf von Gisors und

55 Ein Überblick über diese Heiratsverbindungen der Este findet sich auch bei Prosperi, Histoire, $34 \mathrm{f}$.

56 Ghirardo, Lucrezia Borgia, I3 1 .

57 Accorsi, Le donne estensi, 97.

58 Vom Bräutigam kam eine meist gleich hohe Summe als Widerlag, Morgengabe und Witwenunterhalt. Vocelka, Habsburgische Hochzeiten, 3 of.

$59 »[\ldots]$ un prestito di cinquantamila ducati d'oro del sole/ein Darlehen über 50.000 Golddukaten«, FonTANa, Renata di Francia, I, 36.

60 Dem Vater klagte er dieses Leid und bat ihn um finanzielle Unterstützung: "Io procurerò de cavare quel chio potrò, del resto donnerò quel che non potrò vendere; $[\ldots]$ et essendo quasi come finiti quelli chio portai meco, prego la Vostra Signoria che me ne voglia far provisione [...]/Ich werde versuchen, rauszuholen was ich kann, was ich nicht verkaufen kann, werde ich wohl verschenken; [...] und da das Geld, das ich mit mir trug, schon aufgebraucht ist, bitte ich E.D. mir welches zukommen zu lassen«, ASMo, ASE, Casa e Stato, Carteggio tra principi, Ercole an Alfonso I, Mai 1528.

6r ASMo, Archivio privato Fiaschi, b 42, fasc. II., I 527 : Dote di Madama Renea con rinunzie di diritti sui beni paterni.

62 Vgl. Fontana, Renata di Francia i, 39 f. Rodocanachi, Une protectrice, $38 \mathrm{f}$. 
Herrn von Montargis, Herrschaftsgebiete, die der König jederzeit mit der Zahlung von 250.000 Goldgulden wieder an sich ziehen konnte. Der Bräutigam musste sich in der Folge mit den - wie sich herausstellen sollte - dürftigen und unpünktlichen Einkünften aus diesen französischen Besitzungen zufriedengeben. ${ }^{63}$

Auch die Verbindung mit dem Hause Habsburg war eher prestigeträchtig als finanzstark. ${ }^{64}$ Es waren vor allem zwei Gründe, die Alfonso II. zur Werbung um das elfte Kind von Kaiser Ferdinand I. und Anna von Ungarn antrieben: Einerseits die Aussicht auf einen männlichen Nachfolger, der das Herzogtum Ferrara vor dem Rückfall an den Kirchenstaat retten, oder im schlimmsten Fall für die nötige kaiserliche Unterstützung dagegen sorgen konnte. Andererseits erwartete sich Alfonso durch die engere Verbindung mit dem Kaiserhaus im schon heftig wütenden Präzedenzstreit mit der Familie der Medici einen Schritt voranzukommen. ${ }^{65}$ Die Tatsache, dass sein Kontrahent, Francesco de'Medici, ebenfalls und gleichzeitig um eine Kaisertochter warb, verschärfte allerdings die Auseinandersetzung zwischen den beiden italienischen Fürsten. ${ }^{66}$

\subsubsection{Das estensisch-habsburgische Heiratsprojekt: Alfonsos zweite Ehe mit Erzherzogin Barbara von Österreich}

Die Heiratspolitik der Habsburger verfolgte, wie jene der anderen großen und kleinen europäischen Dynastien, das Ziel Bündnisse zu schließen, Beziehungen zu knüpfen oder zu bekräftigen und nach Möglichkeit die eigenen Chancen auf die Erbschaft eines Landes zu vergrößern. ${ }^{67}$ Viele Ehen der Habsburger wurden mit den benachbarten Wittelsbachern sowie mit der Tiroler und der innerösterreichischen Linie der Casa de Austria geschlossen. Grund dafür waren die räumliche und sprachliche Nähe, die eine unkomplizierte Abwicklung versprach, die besseren Möglichkeiten der Bekanntschaft durch häufige gegenseitige Besuche und somit ein größerer "gefühlsmäßige(r)« Faktor und ab dem I6. Jahrhundert die Konfession als ein bedeutendes Ausschlusskriterium. ${ }^{68}$ Die Ausrichtung nach Süden hingegen war mit Maximilians I. zweiter Ehe mit Bianca Maria Sforza eingeläutet worden und spitzte sich mit der Heiratspolitik Ferdinands I.

63 Vgl. Benzoni, »Ercole II«, ro9.

64 Immerhin wurden roo.000 Rheingulden in zwei Auszahlungen festgelegt. Siehe den ratifizierten Heiratsvertrag in Innsbruck, TLA, Ferdinandea, Kart. 3 I, Pos. 28, Oktober 1564.

65 Spagnoletti, Intrecci matrimoniali, igf, 28.

66 Dazu siehe: Grons, Die Hochzeiten. Eine gekürzte, aber nicht maßgeblich überarbeitete Fassung wurde in den Mitteilungen des Instituts für Österreichische Geschichtsforschung (MIÖG) 96/3-4 (I 988), 33 I-38 I veröffentlich. Siehe auch ScherL, Die Brautreise.

67 Vocelka, Habsburgische Hochzeiten, ir.Weiter siehe: Kohler, "Tu felix Austria nube ...«. DuchHARDT, Die dynastische Heirat.

68 Vocelka, Habsburgische Hochzeiten, I7. 
zu: Von seinen zehn Töchtern, die das heiratsfähige Alter erreichten, ehelichten zwei deutsche Reichsfürsten (Anna Herzog Albrecht von Bayern und Maria Herzog Wilhelm von Jülich-Kleve), zwei (Elisabeth und Katharina in zweiter Ehe) den polnischen König, drei durften ein geistliches Leben wählen (Magdalena, Margarethe, Helena) und vier heirateten italienische Fürsten (Katharina, Eleonore, Barbara, Johanna) ${ }^{69}$

Fürstinnen aus dem Reich oder aus Frankreich, die einen italienischen Herzog oder Großherzog heirateten, stiegen zumeist rangmäßig ab und hielten nicht selten dem Ehemann und seinem Hof ihre ranghöhere Herkunft vor Augen, ${ }^{70}$ so z.B. durch einen großen, fremden Hofstaat, durch die Einführung von Hofzeremoniell, Traditionen und Riten aus ihrer Heimat und durch die Intensivierung ihrer Beziehungen zum Vater oder den Brüdern an ihrem Heimathof, für die sie Informantinnen, Beraterinnen oder Bittstellerinnen waren. ${ }^{71} \mathrm{Zudem}$ brachten diese Gattinnen ob der Auszeichnung ihres hohen Rangs oft nur bescheidene oder symbolische Mitgiften mit, wenn sie auch potenzielle Inhaberinnen von Rechten und Privilegien sein konnten. So brachte Barbara von Österreich eine Mitgift in Juwelen und Aussteuer statt in Geld mit; gleichzeitig verlieh Alfonso II. im Rahmen der Heiratsverhandlungen 60.00o Dukaten an den Kaiser. ${ }^{72}$

Mit dieser Verbindung zwischen Alfonso II. und Barbara von Österreich und den anderen Heiratsprojekten mit italienischen Fürstensöhnen bewiesen Kaiser Ferdinand I. und Maximilian II. nach ihm, dass die dynastischen Verbindungen nach Italien in der zweiten Hälfte des I6. Jahrhunderts immer noch politisch interessant und finanziell verlockend, weil "günstig", waren. ${ }^{73}$ Außerdem bestand mit diesen Netzwerken die Möglichkeit der Sicherung der kaiserlichen Macht in Reichsitalien.

Bevor es allerdings für Alfonso II. zu einer Heiratsverbindung mit dem Kaiserhaus kam, war aus der Friedensvermittlung Cosimos de'Medici zwischen Ercole II. d'Este und Philipp II. von Spanien die erste Eheschließung mit Lucrezia de'Medici ( 545 - I56I) hervorgegangen. Lucrezia war anderthalb Jahre als per procurationem verheiratete Frau an ihrem Heimathof geblieben, bevor sie im Februar 1560 in Ferrara einziehen konnte. Ihr kurzes Leben hier kann nicht als glücklich bezeichnet werden, da sie sich - unbedarft und nicht übermäßig gebildet - in Ferrara nicht integrieren

69 Laubach, Ferdinand I., 704-709; Sutter Fichtner, Ferdinand I., 22 I; Weiss, Zur Herrschaft geboren, Kap.: "Kinder als politisches Kapital. Die Töchter Kaiser Ferdinands I.«, I 7 1 - 192.

70 Demnach soll Alfonso II. Barbara bei seinem Besuch in Innsbruck 1565 mit einer Krone vorgefunden haben, denn schließlich waren sie und ihre Schwestern Töchter eines Kaisers. Frizzi, Memorie, 389. Johanna von Portugal, Schwester von Philipp II. und Witwe, war von Ercole II. für seinen Sohn als Frau angefragt worden, doch diese weigerte sich, einen rangniederen Herzog zu heiraten. Spagnoletti, Le dinastie, I67, Anm. 43.

7i Spagnoletti, Le dinastie, i6if.

72 Spagnoletti, Le dinastie, i63, Anm. 25. Dem florentinischen Gesandte Delfino nach mussten sowohl sein Herr als auch der Herzog von Ferrara den Kaiser in der Türkenabwehr unterstützen, wenn sie beide Schwager des Reichsoberhauptes werden wollten. Steinherz, Nuntiaturberichte II/4, Nr. IO2, 385 .

73 Spagnoletti, Le dinastie, i68-i 72, igof. 
konnte, lastete ja schließlich der alles bestimmende Präzedenzstreit auf dieser Verbindung. ${ }^{74}$

Nachdem diese erste kinderlose Ehe mit dem Tod von Lucrezia de'Medici im April I 56 I zu Ende gegangen war, machte sich der Herzog auf die Suche nach einer neuen profitablen Heiratsallianz. Seine Annäherung an Savoyen und durch ihn an den König von Spanien ließ den Este-Fürsten auf die Hand einer Schwester Philipps II. hoffen. ${ }^{75}$ Auf der anderen Seite der Casa de Austria schlugen die kaiserlichen Vertreter vor, eine der Töchter Kaiser Ferdinands I. zu ehelichen. ${ }^{76}$ Diese Verbindung mit dem Kaiserhaus sollte der Bekräftigung der über 300-jährigen Lehensbeziehungen zwischen den Este und dem Reich dienen und Alfonso II. eine vorrangige Stellung unter den italienischen Fürsten verschaffen. Unverheiratet, und deshalb in Frage kommend, waren Magdalena, die elf Jahre lang mit Emanuel Philibert von Savoyen verlobt war, Margarethe, Helena, Barbara und Johanna; doch zur Auswahl standen de facto nur die letzten beiden, da der Kaiser dem Wunsch nach einem geistlich votierten Leben der ersten drei entsprechen wollte.

Erzherzogin Barbara ${ }^{77}$ war als elftes Kind von Ferdinand I. und Anna von Ungarn am 30. April 1539 in Wien geboren worden. Als ihre Mutter beim Tod ihrer Schwester Johanna I 547 starb, zogen alle fünf Erzherzoginnen nach Innsbruck, wo sie - abgesehen von ihrer durch das Vordringen des Kurfürsten Moritz von Sachsen notwendigen Evakuierung $155^{2}$ - bis zur Verheiratung bzw. zum Eintritt in das von Magdalena unter jesuitischer Aufsicht geführte Haller Damenstift ${ }_{5} 67$ blieben. $^{78}$

Die Verhandlungen des Herzogs von Ferrara um die Heirat mit einer der habsburgischen Erzherzoginnen dauerten mehr als drei Jahre; schlussendlich sollte es Barbara sein, die nach Ferrara verheiratet wurde. Grund für die Verzögerung waren sowohl das Ableben von Kaiser Ferdinand I. mitten in den Verhandlungen ${ }^{79}$ als auch die späte Wiederaufnahme derselben durch den Nachfolger Kaiser Maximilian II. bzw. die

74 Ricci, Prigioniera dei simboli, 219-225.

75 Lazzari, Le ultime tre duchesse, 86.

76 Nach den venezianischen Gesandten Moresini und Badoer stand eine solche Verbindung mit einer Erzherzogin bereits 1550 im Raum. Vgl. Turba, Venezianische Depeschen 2, Domenico Moresini und Federigo Badoer an den Dogen, Augsburg, September I 550, Nr. 186, 455-457, Anm. 2.

77 Zu ihrer Biografie siehe: LAZZARI, Le ultime tre duchesse, 85-204; Gerhard RiLl, Barbara d'Asburgo«, in: DBI 6, Roma I964, 4of; TAddeI, Barbara von Österreich-d'Este; SeidL, Herzogin Barbara.

78 Erzherzogin Magdalena von Österreich (I532- I 590), Gründerin des königlichen Damenstiftes in Hall. Zu ihrer Biografie vgl. Robert Rевітsсн, »Magdalena, Erzherzogin«, in: Biographisch-Bibliographisches Kirchenlexikon 2I (Ergänzungen 8), Herzberg 2003, 876-88г. Zur Kindheit und Jugend der Erzherzoginnen siehe WeIss, Zur Herrschaft geboren, I 77- 192.

79 Obwohl der venezianische Gesandte am r. März 1563 dieses Heiratsprojekt mit den Worten »esser come concluso il parentado del Duca di Ferrara « für abgeschlossen erklärte. Turba, Venezianische Depeschen 3, Giovanni Micheli an den Dogen, [Innsbruck], März I 563 , Nr. I I 3, 222 f. Am 8. Dezember I 563 sprach derselbe Gesandte von »ultima conclusione del matrimonio«, ebd., Nr. I 23, 247-249, hier 249. Im Februar 1564 hingegen hieß es im venezianischen Bericht »non si intendea però alcuno con- 
Komplikationen durch das gleichzeitig geführte Heiratsprojekt mit den Medici und den damit einhergehenden Präzedenzfragen.

Dass Ferdinand I. in seiner Heiratspolitik eine Ausrichtung nach Süden und Verbindungen zu italienischen Fürsten wünschte, wurde bereits oben gesagt. Der Wunsch, sich mit den Este zu verschwägern, war auch an das Ziel gekoppelt, diese Familie von ihren weit zurückliegenden, engen Beziehungen zu Frankreich zu lösen. Dies zeigt u.a. auch die Tatsache, dass bereits wenige Tage nach dem Tod von Alfonsos II. erster Gemahlin Lucrezia de'Medici-d'Este der kaiserliche Gesandte im Zuge der Verheiratung von Erzherzogin Eleonora mit Guglielmo Gonzaga in Mantua im April 1 56 ${ }^{80} \mathrm{dem}$ estensischen Gesandten gegenüber eine mögliche Verbindung auch zur Este-Dynastie andeutete. Im Herbst I 56 I sollte der estensische Gesandte am Kaiserhof, Girolamo Falletti, nicht nur bezüglich der neu angefachten Präzedenzfrage, sondern auch wegen einer möglichen Heiratsverbindung vorsprechen. Gleichzeitig versuchte auch Cosimo de'Medici über die Vermittlung von König Philipp II. um eine kaiserliche Braut für seinen Sohn zu werben. Das führte zu den ersten Unstimmigkeiten bezüglich der Frage, welche der Erzherzoginnen jeweils an Alfonso d'Este und Francesco de Medici verheiratet werden sollte. Als sich abzeichnete, dass Kaiser Ferdinand gewillt war, dem geistlichen Leben von Magdalena, Margarethe (verstarb bereits I 566) und Helena zuzustimmen und nur noch die ältere Barbara und die jüngste Tochter Johanna übrig blieben, kam es zu einer weiteren Unterbrechung als Johann Sigismund Zapolya, der Fürst von Siebenbürgen, ältere Rechte auf Johanna anmeldete, die ihm tatsächlich im Zuge von Friedensverhandlungen versprochen worden war. ${ }^{81}$ Doch obwohl Zapolya auch nach mehrfachen Aufforderungen nicht gewillt war, nach Wien zu kommen, um den Frieden mit dem Kaiser und das Heiratsprojekt zu verhandeln, wurden die Verhandlungen mit den Italienern von Herbst ${ }_{5} 6_{3}$ bis Sommer I 564 stillgelegt und die drängenden italienischen Gesandten immer wieder vertröstet. Auch wartete man auf die Zustimmung Philipps II., ${ }^{82}$ denn schließlich mussten Heiratsprojekte von den Oberhäuptern beider habsburgischen Linien bewilligt werden. Erst der offenkundige Friedensbruch des siebenbürgischen Fürsten und sein Desinteresse über die angedachte Verbindung brachten Florenz und Ferrara mit spanischem Einverständnis wieder ins Spiel. ${ }^{83}$

Doch nun standen der Weiterführung der Verhandlungen die türkische Bedrohung und der Tod des Kaisers im Juli I 564 im Weg. Darüber hinaus war das Kaiserhaus

clusione del matrimonio«, da Florenz und Ferrara für dieselbe Erzherzogin warben. Ebd., Leonardo Contarini an den Dogen, [Prag], Februar I 564, Nr. I 27, 2586 .

80 Vgl. Sandbichler, Eleonore. Niederkorn, Die dynastische Politik, 45.

8i Steinherz, Nuntiaturberichte II/4, Nr. 6, 23, Delfino an Borromeo, Znaim, ${ }_{5} 64$ Februar 8 und Nr. 28, I 29, diess., Wien, 1564 Mai 17 .

82 Ebd., Nr. I 8, 91, Delfino an Borromeo, Wien, I 564 April I 2/ I3 : "Questo figlio di Barlamont chiamato Mons. di Hiersè qui con commissione del re Cath.co, per ultimare il parentado di Ferrara con la principessa Barbara, et poi quello di Fiorenza con la Giovanna.« Auch ebd., Nr. 28, I 30.

83 Vgl. Grohs, Die Hochzeiten, 23-39. Siehe auch Rauch, Verkaufte Bräute? 32. 
verschuldet und es zeichnete sich ab, dass die Zusammendstellung der Mitgift der beiden Erzherzoginnen eine große Herausforderung darstellen würde. Schließlich konnte man sich bis zum Herbst ${ }_{5} 64$ auf eine Mitgift von I00.000 Rheingulden einigen und am r6. Oktober den Vertrag mit dem Este unterzeichnen. ${ }^{84}$ Für Johanna wurde im Vertrag vom 4. Januar I 565 die gleiche Summe festgelegt, doch keiner der beiden Herzöge erhielt diese, wie auch verschiedene Aufforderungen zur Auszahlung (vor allem im Zuge der Titelfrage in Florenz) zeigen. ${ }^{85}$

Im Juni ${ }_{5} 65$ reiste Alfonso II. mit prächtigem Hofstaat und kostbaren Geschenken über Innsbruck, wo er seiner Verlobten seine Aufwartung machen und sich ihrer Gesundheit und Anmut versichern konnte, nach Wien, um auf Einladung Maximilians an den Exequien für den verstorbenen Kaiser teilzunehmen ${ }^{86}$ und persönlich über die Heimführung seiner Braut zu diskutieren. ${ }^{87}$ In Wien hatte Alfonso zusammen mit den edelsten Männer seines Herzogtums seinen ersten Auftritt unter den Reichsfürsten. ${ }^{88}$ Dabei wurde er von Kaiser Maximilian II. besonders herzlich empfangen. Dieser war ihm unter dem Vorwand der Jagd weit vor die Stadt hinaus entgegengeritten, hatte ihn mit Zuneigung begrüßt und auf die Jagdpartie eingeladen. Der venezianische Gesandte Leonardo Contarini hat diese besondere Ehrbekundung wie folgt festgehalten: »Hoggi è giunto qui il signor Duca di Ferrara et l'Imperatore con li seren ${ }^{\mathrm{mi}}$ Arciduchi sotto nome di andare à caccia è uscito due leghe fuori della città ad incontrare Sua Eccellentia, che veniva per barca, ricevendola in un bregantino, dove si trovava la $\mathrm{M}^{\text {tà }}$ Sua con loro Altezze [...].«" Alfonso wurde in der Hofburg eine besondere Unterkunft zugeteilt und bei den Begräbnisfeierlichkeiten ein Ehrenplatz hinter den Habsburgern und vor Bayern zugewiesen, wie Contarini weiter berichtet: "Alloggia nelle medesime stantie dove stava l'Imperatore et è servito da quei medesimi gentilhomeni et con l'istesso piato chè solito esser fatto à Sua $M^{\text {tà }}$, dalla quale li è usata ogni demostratione di amore et di honore $[\ldots] \ll .{ }^{90} \mathrm{Als}$ der zweite Bräutigam, Francesco de’Medici im Oktober desselben

84 Sobald der estensische Gesandte den Heiratsvertrag unterzeichnet hatte, soll dem florentinischen Gesandten nach eine Kopie sogleich an den französischen König geschickt worden sein. Steinherz, Nuntiaturberichte II/4, Nr. 46, I87, Delfino an Borromeo, Wien, ${ }_{5} 64$ August 24.

85 Vgl. Grohs, Die Hochzeiten, 40-45. Weder die Mitgift noch die Legate aus Barbaras Testament wurden von Maximilian II. bzw. Rudolf II. ausbezahlt. Lazzari, Le ultime tre duchesse, 202.

$86 \mathrm{Zu}$ den Exequien ein Jahr nach dem Ableben Kaiser Ferdinands I. siehe bei KoHLER, Ferdinand I., Kap. "Exequien und Aufteilung der väterlichen Schulden«.

87 Grohs, Die Hochzeiten, 56f. Lazzari, Le ultime tre duchesse, 96.

88 Spöttisch bemerkte der florentinische Gesandte in einem Brief an seinem Fürsten, dass die große Anzahl der Begleitpersonen unüberlegt war und fast Übelkeit verursache: »il venire del S.r duca di Ferrara con tante genti ha qui fatto mezza nausea, e certo a tuttol palazzo è parso cosa mal pensata." STeinherz, Nuntiaturberichte II/4, Nr. I I 3, 426, Anm. 6, Delfino an Francesco de'Medici, Wien 1564 Juli 28.

89 »Heute ist der Herzog von Ferrara hier mit dem Boot angelangt, und mit dem Vorwand auf die Jagd zu gehen, sind ihm der Kaiser und die Durchlauchten Erzherzöge bis zwei Meilen vor die Stadt in einem Boot entgegengefahren«.

90 »Er ist in den Räumen neben dem Kaiser untergebracht und ist von den gleichen Edelmännern bedient 
Jahres mit ebenso großem Pomp und noch reicheren Geschenken ${ }^{91}$ den Kaiser besuchte, wurde er von diesem nicht sofort, sondern zunächst nur von Erzherzog Karl empfangen. ${ }^{92}$ Die bevorzugte Behandlung des Este in diesem Zusammenhang lässt auf eine intensivere persönliche Beziehung zwischen Maximilian II. und Alfonso II. schließen, die sich auch durch andere Hinweise in der Korrespondenz bestätigen lässt. ${ }^{93}$

Als Gastgeschenk, aber vor allem als Beweis seiner Würde, eine Kaisertochter heiraten zu können, hatte Alfonso II. eine von Girolamo Falletti erstellte prächtige Genealogie des Hauses d'Este, in der die germanische Abstammung der Dynastie hervorgehoben wurde, nach Wien gebracht. Darüber hinaus hatte der Este in Ferrara hergestellte Arzneimittel im Gepäck, die an die Mitglieder der Kaiserfamilie verteilt wurden. ${ }^{94}$

Obwohl Maximilian II. nicht auf die genaue Einhaltung des Trauerjahres für den verstorbenen Vater bestand, konnten Alfonso und Francesco ihre Bräute nicht sogleich heimführen. Zudem hatte Francesco vor, von Wien nach Prag zu reisen und bat den Kaiser die Abreise der Erzherzoginnen weiter zu verzögern, sodass nun eine Trauung für Mitte November 1565 angedacht wurde. Da man voraussah, dass die beiden Kontrahenten auch diesen Anlass zu Auseinandersetzungen bezüglich der Präzedenz nutzen würden, bestand man - auch aus Kostengründen - auf einer gemeinsamen Heimführung der beiden Bräute und eine gemeinsame Trauung in Trient. ${ }^{95}$

Die Kosten und das Zusammentragen der Aussteuer waren, wie gesagt, ein großes Problem, zumal der Türkenkrieg wieder ausgebrochen war. Der Kaiser musste deswegen bei seinen »neuen« italienischen Verwandten alsbald um Geldleihen anfragen. ${ }^{96}$

und mit den gleichen Speisen, die für den Kaiser gemacht werden, von dem er alle Zeichen von Liebe und Ehre erfährt. Er hat etwas weniger als 200 Personen mitgeführt, die alle von Seiner Majestät bezahlt werden [...].« Turba, Venezianische Depeschen 3, Leonardo Contarini an den Dogen, Wien, August I 565 , Nr. I 49, $298-300$, hier 300. Vgl. auch Lazzari, Le ultime tre duchesse, 98 f. Alfonso sollte allerdings erst Ende August abreisen.

9I Darunter Statuen (einen Apollo, Sokrates, Christus und Merkur von Giambologna), Pferde, Geschmeide und etliche Zuwendungen für Minister und Räte. Groнs, Die Hochzeiten, 66. War der Austausch von Geschenken vor dem Abschluss eines Heiratsprojektes und im Zuge von Besuchen durchaus gängig, so sieht es Marx als einen besonderen Brauch der Medici, ihre Heiratsverhandlungen mit kostbaren Kunstgegenständen zu begleiten, um ihre Großzügigkeit, ihren Reichtum und die exquisite Produktion der Florentiner Kunstwerkstätten zu bewerben. Dies alles sollte über die bescheidene Herkunft der Dynastie hinwegtäuschen und deren kulturelle und künstlerische Überlegenheit zum Ausdruck bringen. MARX, Politica culturale al femminile, I 49 f.

92 Bei Grohs werden verschiedene Quellen angeführt, denen zufolge der Kaiser bei Tisch bzw. bei der Jagd war, weshalb der persönliche Empfang des Medici-Fürsten am Donauufer ausblieb. Groнs, Die Hochzeiten, $58 \mathrm{f}, 64$.

93 Dazu siehe im Kapitel »Beziehungen und Wahrnehmung« mehr.

94 Spagnoletti, Le dinastie, 324; Grohs, Die Hochzeiten, 59 f. Solerti, Ferrara, XXVIII-XXX.

95 Grohs, Die Hochzeiten, 48, Anm. 3.

96 Groнs, Die Hochzeiten, 52f, Anm. 4: Er bekam immerhin 200.000 scudi von Florenz und I 20.000 scudi von Ferrara. Florenz versuchte dieses finanzielle Entgegenkommen sogleich mit der Großherzogswürde zu verrechnen, was Maximilian II. (zunächst) abschlug. 
Eigentlich sollten alle drei erzherzoglichen Brüder für die im Testament von Kaiser Ferdinand I. festgesetzte Aussteuer im Wert von 20.000 Gulden für jede Schwester aufkommen, doch die Mittel flossen auch aus Innsbruck und Graz nur spärlich und die beauftragten Handwerker weigerten sich, ohne Vorauszahlung und auf bloße Zahlungsversprechen hin $\mathrm{zu}$ arbeiten. ${ }^{97}$ Beide Erzherzoginnen erhielten ein in Wien von mehreren Handwerkern hergestelltes vergoldetes spanisches Bett, ein I6-teiliges Service mit dem habsburgischen Wappen und weiteres Tafelgeschirr sowie sakrale Gegenstände.

Als der doppelte Brautzug aus Wien bzw. Innsbruck endlich aufbrach, war es bereits Mitte November; am 2o. November erreichte er Trient, wo die Kardinäle Cristoforo und Giovanni Ludovico di Madruzzo die Anweisung hatten, ${ }^{98}$ die Schwestern am selben Tag zu verheiraten, um Präzedenzstreitigkeiten zu umgehen. Als aber unerwarteterweise der Bruder des Herzogs von Ferrara, Kardinal Luigi d'Este, zur Begrüßung der Braut nach Trient kam und Francesco de’Medici auf der Rückreise aus Prag/Wien auch noch eintraf, wenn er auch nicht zur Hochzeit blieb, brachen trotzdem Rangstreitigkeiten aus. So reisten die beiden Erzherzoginnen getrennt weiter und Barbara hielt am 2. Dezember ihren feierlichen Einzug in Ferrara. ${ }^{99}$

\subsubsection{Der Hofstaat der Erzherzogin Barbara, Herzogin von Ferrara}

Nicht nur die Mitgift und die Aussteuer, sondern auch die standesgemäße Zusammensetzung des Hofstaates der beiden Erzherzoginnen für die Heimführungsreise stellte sich als große Herausforderung heraus. Viele Posten blieben bis zuletzt unbesetzt und man wartete auf passende Amtsinhaber aus Tirol oder Böhmen. ${ }^{100}$ Erzherzog Ferdinand II. wurde gebeten, den Kammerpräsidenten der oberösterreichischen Regierung, Blasius Khuen, ${ }^{101}$ als Barbaras Oberstkämmerer für die Wochen der Heimführung anzufragen, da sich dieser bereits als Dolmetscher für den Herzog von Ferrara bewährt hatte und der Erzherzogin vertraut sei. Aus dem Tiroler Adel, der wenig erpicht auf die kostenintensive Ehrenaufgabe war, gab es bereits etliche Absagen und auch Erzherzog Ferdinand befürchtete, dass die Regierungsgeschäfte durch die Teilnahme am Brautzug liegen bleiben würden. Doch schließlich erweichte der persönliche Brief Barbaras Fer-

97 Grohs, Die Hochzeiten, $72 f$.

98 Steinherz, Nuntiaturberichte II/4, Nr. I23, I 460, Delfino an Altemps, Wien, ${ }_{5} 65$ September 14.

99 Ebd., $82-87$.

Io० Im Hofstaatsverzeichnis von ${ }_{5} 65$ finden sich bei einigen Posten, wie dem »Camerdiener«, Küchenmeister oder der »Obriste Camererin« Anmerkungen wie »wird hinnach darin gesetzt«, »soll noch einer verordnet werden« oder »ain Mundzkoch wirdn von Kay. Mt. Hierher verordnet werden«. Innsbruck, TLA, Ferd, Cart. 3I, pos. 27: Copey Der Durchlauchtigsten Fürstin Frauen Barbara Erzherzogin zu Österreich etc. Unserer gnedigsten Frauen, Fürstlich[e] Haimbführung und beglaittung gehen Ferrar Hofstatt (1565).

Iо I $\mathrm{Zu}$ diesem Tiroler Adelsgeschlecht siehe Franz von Krones »Khuen« in: ADB I5 (I882), $708 \mathrm{f}$. 
dinand, der Khuen für die Brautreise freistellte. ${ }^{102} 74$ Personen mit 290 Pferden begleiteten Erzherzogin Barbara nach Ferrara; davon blieben 32 bei der neuen Herzogin, von diesen waren wiederum ${ }_{5} 5$ eindeutig deutschsprachiger, zumeist Tiroler Herkunft. ${ }^{103}$ Im Testament der bereits sieben Jahre später verstorbenen Herzogin von Ferrara wird ihr Hofstaat in »dame todesche« und »dame italiane« unterteilt, was ebenfalls auf das Weiterbestehen eines »in sich geschlossenen « deutschen Hofstaates hinweist. ${ }^{104}$ Beide zusammen ergaben zuzüglich der vom Herzog gestellten bzw. mitbeanspruchten Ärzte, Sekretäre und Edelknaben eine Entourage von 82 Personen. ${ }^{105}$

Der Bräutigam und sein Hof bemühten sich, mit einem prunkvollen Einzug die neue Herzogin und die mitgereisten deutschen Hofleute, die dem Kaiser berichten sollten, zu beeindrucken und vor allem den Medici-Hof zu übertrumpfen. Doch das Wetter, die Verzögerungen, der frühe Einbruch der Dunkelheit, die man durch ungenügende Fackeln nicht wettmachen konnte, und eine eingebrochene Saaldecke machten den Einzug der Erzherzogin am 2. Dezember I 565 tatsächlich - wenn auch im negativen Sinn - erinnerungswürdig.

Zur Eheschließung am 5. Dezember I 565 hatte Alfonso II. im Festsaal des Palazzo Ducale Porträts seiner estensischen Vorfahren als tapfere Kriegshelden und jene der Kaiser des Reiches anbringen lassen, die dem Hause d'Este besonders verbunden gewesen waren (Otto I., Rudolf I., Friedrich III.). ${ }^{106}$ Bei den zahlreichen Festlichkeiten und Vergnügungen, die der plötzliche Tod von Papst Pius IV. unterbrach, wurde auch ein Theaterstück aufgeführt mit dem Titel »Tempio d'Amore«, in dem Barbara als Inspiration der Tugendhaftigkeit (auch auf Deutsch) besungen wurde. Während die im Stück namentlich genannten habsburgischen Kaiser (Rudolf von Habsburg, Ferdinand I. und Karl V.) wohlwollend auf Alfonso blicken sollten, wurden die vorangegangenen EsteFürstinnen, Mathilde von Canossa, Eleonora von Aragón und Renée de France angerufen, die neue Herzogin von Ferrara gütig aufzunehmen. ${ }^{107}$ Für die allegorischen und an die antike Mythologie angelehnten Inszenierungen ${ }^{108}$ im Rahmen der Hochzeitsfei-

Iо2 Grohs, Die Hochzeiten, 78f; ASMo, ASE, Casa e Stato, Carteggio di principi esteri, Germania b I $583 / 9$, Erzherzog Ferdinand II. an Barbara, Oktober I 565 Antwortschreiben auf ihre Bitte hin, er möge Khuen mitreisen lassen.

I03 Die Auflistung der Namen bei: TAdDEı, Barbara von Österreich-d'Este, 640.

I04 ASMo, ASE, Casa e stato 358, Testamentum Serenissime Barbarae de Austria, fol. Ir- I 8r (I 572 ).

I05 TAdDEI, Barbara von Österreich-d'Este, 634.

Io6 Vgl. LAzzari, Le ultime tre duchesse, ro4-i io.

I07 Ebd., I 29.

Io8 So inszenierte Rossetti bei dem von Don Alfonso zu Ehren des Brautpaares gegebenen Festessen im Palazzo Bevilacqua mit eigens aus Genua importierten Früchten und Blumen einen sommerlichen Garten im Inneren des Festsaals, im Sinne eines hortus conclusus. Di Pascale, Banchetti Estensi, I If. Ein zweites von Kardinal Luigi d'Este beauftragtes und von dessen Mundschenk Giacomo Grana inszeniertes Festbankett verwandelte hingegen den Saal in eine Unterwasserwelt mit Fischen, Meeresmonstern und einem Neptun, mit dem Alfonso gleichgesetzt wurde. Vgl. ebd., I 5 - I 7. 
erlichkeiten, und darüber hinaus, waren eigene, humanistisch ausgebildete Truchsesse/ Seneschalle wie Cristoforo di Messisbugo ${ }^{109}$ und Giovan Battista Rossetti ${ }^{110}$ am Werk.

Anders als ihre Schwiegermutter, Renée de France, die in Ferrara nie heimisch geworden und I 560 nach dem Tod ihres Ehemannes nach Frankreich zurückgekehrt war, versuchte sich die Kaisertochter der neuen Umgebung und den Landessitten anzupassen. Doch auch wenn sie bald die italienische Mode und Usancen übernahm - so empfing sie ihren Neffen Herzog Ferdinand von Bayern I 566 in italienischer Tracht mit eine Kopfbedeckung "alla italiana ${ }^{111}$ - erlernte sie nur schwer und bruchstückhaft die italienische Sprache und musste sich eines Dolmetschers und beider Sprachen mächtigen Sekretärs bedienen. Im Unterschied zu ihren älteren Schwestern und den Brüdern, die neben Deutsch und Latein auch Italienisch erlernt hatten, ${ }^{112}$ war die sprachliche Ausbildung der jüngeren Kaiserkinder - vielleicht aufgrund des frühen Ablebens der Mutter - weniger sorgfältig gewesen. So kam Barbara mit fast keinen Italienischkenntnissen nach Ferrara. Ihrem in der Ferne weilenden Ehemann schrieb sie auf Deutsch, während dieser sich bemühte, wohl eher um dem Kaiser zu gefallen, einige unbeholfene Zeilen auf Deutsch zu verfassen. ${ }^{113} \mathrm{Zu}$ diesem Mangel an sprachlichen Vorkenntnissen kam hinzu, dass sie sich in ihrer neuen Heimat mit einem ansehnlichen deutschen Hofstaat ${ }^{114}$ umgeben durfte, der ihr in der Abwesenheit ihres Gatten,

Io9 Dieser hatte ab I 5 I 5 diplomatische Missionen für die Este-Fürsten übernommen und begleitete Alfonso I. bei seiner Unterredung mit Karl V. I532/33. Dabei erhielt er vom Kaiser I 533 die Pfalzgrafenwürde mit der Möglichkeit illegitime Kinder zu legitimieren, ein Privileg, von dem er als Hofmundschenk auch Gebrauch machte. I 549 veröffentlichte er bei den Ferrareser Verlegern De Buglhat und Hucher einen Kardinal Ippolito d'Este gewidmeten Traktat Banchetti, composizioni di vivande e apparecchio generale (eine moderne Ausgabe ist hg. von Fernando Bandini, Vicenza ${ }^{2}$ I992), in dem er seine Erfahrungen bei der Erstellung von zahlreichen Banketten zwischen I 524 und I 548, seinem Todesjahr, niedergeschrieben hatte. Di Pascale, Banchetti Estensi, 42f, 6 I .

I Io Auch der unter Alfonso II. und dann unter dessen Schwester Lucrezia d'Este tätige Mundschenk Rossetti verfasste 1584 einen Traktat mit dem Titel Dello scalco (Neuauflage, Bologna I 99i). Hier vergleicht er u.a. die italienische Essenszubereitung mit anderen und seit der Ankunft Erzherzogin Barbaras besonders mit der deutschen Esskultur.

I I Wie auch ihre Schwester Eleonora Gonzaga hatte sie sogleich die Tracht ihrer neuen Heimat angenommen. LAzzari, Le ultime tre duchesse, I 43. Lazzari mutmaßt, dass sich Ferdinand von Bayern aufgrund eines angedachten Heiratsprojekts zwischen ihm und Alfonsos Schwester Lucrezia, der zukünftigen Herzogin von Urbino, in Ferrara aufhielt. Ebd., I 86.

I 2 Rauch, Verkaufte Bräute?, 30.

I 3 So schrieb er auf der Rückreise vom Kaiser: "Ich bin Gott sei lob woh[1] auff und ganzlich au[s] fieber, und ich hoff, das ich wirdt morgen im erchtag zu Ferrar[a] sin und E. L. sehen und umbgreiffen, wie ich bege[h]r«. ASMo, ASE, Casa e Stato, Carteggio fra principi, ramo ducale, b 7o, Alfonso II. an Luigi d'Este im Anhang an Barbara d'Este, März I 570 . Auch bei Lazzari, Le ultime tre duchesse, I 58.

I 4 Zum Vergleich siehe die bei Katrin Keller angeführte Größe von Hofstaaten deutscher Fürstinnen des I 7. und I 8. Jahrhunderts, die im herzoglichen Bereich ähnlich groß waren. Kelle R, Das Frauenzimmer. 
der dem Kaiser im Türkenkrieg zu Hilfe eilte, zwar ein Trost war, aber gleichzeitig das Erlernen der Landessprache verhinderte. Ihre Gefühle der Einsamkeit und Verlassenheit drückte sie auch in ihren Briefen an den entfernten Gatten aus mit den Worten: »allein dass mit die waill gar lang ist nach E. L. und nach mein herz liebsten herrn und preudter, ich hab auch ain herzlich verlangen zu wissen, wie es E. L. an ienen haus get $[\ldots] \ll{ }^{115}$ Wenn sich Barbara in Ferrara nur langsam und schwer integrierte, so war sie dennoch ein bedeutendes Bindeglied in dem über die Alpen reichenden Familiennetzwerk, wie auch ihre erhaltene Korrespondenz zeigt. Sie nutzte ihre neue Position als Fürstin, um Kaufleuten, Hofdamen, Gesandten und Edelmännern zu helfen oder sie weiterzuempfehlen. ${ }^{116}$ Mit diesem Heiratsprojekt kamen nämlich nicht nur Gegenstände ${ }^{117}$ aus dem Kulturraum nördlich des Alpenhauptkamms nach Ferrara, sondern auch Personen. Wie bereits erwähnt, durfte Barbara einen deutschen Hofstaat behalten. Kaiser Maximilian II., hatte zunächst - eingedenk der schlechten Erfahrungen seiner Schwester Eleonore am mantuanischen Hof, die keine Personen ihrer Wahl bzw. aus ihrer Heimat beschäftigen durfte - in Barbaras und Johannas Eheverträge einen Passus aufnehmen wollen, der ihnen die Freiheit zur Auswahl der eigenen Dienerschaft garantieren sollte. Auf Anraten des estensischen Unterhändlers Turchi hatte er diese Klausel, die den souveränen Ehegatten wenig willkommen gewesen wäre, jedoch wieder gestrichen. ${ }^{118}$ Nichtsdestotrotz scheint Alfonso - die negativen Erfahrungen seines Vaters mit der großen französischen Entourage seiner Mutter nicht berücksichtigend - gegen diesen fremden Hofstaat im eigenen Haus nichts einzuwenden gehabt $\mathrm{zu}$ haben. Es ist aber auch wahrscheinlich, dass er - eingedenk des höheren Ranges seiner Ehefrau - die durch die Heirat intensivierte Beziehung zum Reichsoberhaupt nicht wieder einbüßen wollte und dem stillen Wunsch nach einem eigenen Hofstaat für die Erzherzogin nachkam.

Von den Personen, die mit Barbara nach Italien gekommen waren, verließen einige nach ihrem Ableben Ferrara, wie die Empfehlungsschreiben Alfonsos an Erzherzog Ferdinand II. für den Mundschenk Wolf Steger, den Türdiener Antonio Cavedali und den Diener Nicolo Filippach zeigen. ${ }^{119}$ Dass sich Barbara und ihr Hofstaat in der

I 5 ASMo, ASE, Casa e Stato, Carteggio fra principi, ramo ducale, b I67, Barbara d'Este an Alfonso II, April 1566.

II 6 Siehe einige Quellenbeispiele bei TADDEI, Barbara von Österreich-d'Este, 638.

I 7 Siehe im Anhang A an ihrem Testament das "Verzaichnis des silber geschyrrs so Ir. Fst. Drl. mit herein aus dem Deutschlandt pracht und gefiert hatt wie volgt ...«, ASMo, ASE, Casa e stato 358, Testamentum Serenissime Barbarae de Austria, I990, all. A. Unter den notwendigen Aussteuerdingen fehlte auch hier nicht die silberne "pättpfanne« (Bettpfanne). Ebd., fol. 2. Lazzari erwähnt als besonderes, aus Wien mitgeführtes Stück eine Schmuckschatulle aus Bernstein in der Form eines Tempels mit drei Medaillons mit dem Konterfei der Kaiser Karl V., Ferdinand I. und Maximilian II. Lazzari, Le ultime tre duchesse, i Io.

i 8 Steinherz, Nuntiaturberichte aus Deutschland I 560-I 572 nebst ergänzenden Aktenstücken II, Abteilung 4,267 .

I 9 Innsbruck, TLA Ferdinandea, Kart. 3 I Pos. 26 Ferrara, Alfonso II. an Erzherzog Ferdinand, Dezember I $57_{2}$, März und Mai 1573 . 
Kürze der Zeit dennoch besser in Ferrara integriert hatten als Renée de France und ihre für die damaligen Verhältnisse enorme Entourage, beweist nicht zuletzt die Tatsache, dass einige der deutschen Hofdamen an italienische Höflinge verheiratet wurden, wie Sabina Wazler[ine], die den Grafen und Obersthofmeister Federico Mirogli heiratete, so wie eine gewisse Lena, die Scipione Bonlei ehelichte. Heftig von den italienischen Edelmännern umworben und herrlich von Torquato Tasso besungen waren in diesem Zusammenhang die Gräfin Beatrice von Lodron und die Adelige Elena Botzlein. ${ }^{120}$

I 568 reiste Barbara mit Alfonso per Schiff 2 I Tage lang durch die Stati estensi, kam nach Modena, Reggio, Carpi und Sassuolo, wo sie den Untertanen als neue Herzogin vorgestellt und von diesen herzlich empfangen wurde. In Sassuolo übernahm sie die Patenschaft für Marco, den Letztgeborenen der Familie Pio. ${ }^{121}$

Anders als ihre Schwiegermutter war die Habsburgerin eine strenge Verteidigerin des Katholizismus und eine Förderin der katholischen Reform. Aus diesem Grund unterstützte sie den Jesuitenorden, der in Ferrara durch sie leichter Fuß fassen konnte. ${ }^{122}$ Nach dem verheerenden und langanhaltenden Erdbeben von I 570 kaufte sie einige Häuser in der Via Giovecca und gründete hier ein Waisenhaus für Mädchen (Conservatorio delle Orfane di Santa Barbara). ${ }^{123}$

Bereits im Winter I 57 I hatte Barbara an Fieber, Husten und Katarrh gelitten, wovon sie sich aber im Frühjahr erholte. Am i 9. September I 572 erlag sie jedoch am den vermutlich mit Tuberkulose einhergehenden Symptomen und starb in Anwesenheit ihrer Schwester Eleonora Gonzaga. Sie wurde in der von ihr mitgestifteten Jesuitenkirche in Ferrara beigesetzt. Trotz ihrer sprachlichen und kulturellen Isoliertheit war sie eine »Landesfürstin« mit internationalen Kontakten und aufgrund ihrer karitativen Fürsorge in Ferrara sehr beliebt geworden. ${ }^{124}$

I 20 LAZZARI, Le ultime tre duchesse, I 72 .

I 2 E Ebd., I 75 f.

I 2 Dasselbe taten Johanna in Florenz und Eleonore in Mantua; damit vertraten sie, die von jesuitischen Beichtvätern nach Italien begleitet worden waren, auch die Interessen ihrer angestammten Familie. Rauch, Großherzogin Johanna, I43. Lazzari, Le ultime tre duchesse, 227. Fubini Leuzzi, Un'Asburgo a Firenze, 252.

i23 Lazzari, Le ultime tre duchesse, i88-i93. Zum "Conservatorio« siehe: Calore, Ferrara delle Donne, I35f. Dies war die zweite Armeninstitution neben dem von Ercole II. I 544 errichteten Orfanotrofio di S. Maria della Rosa, zu dem I 594 das von Alfonsos II. dritter Frau Margherita mit dem Namen S. Margherita hinzukam. Peverada, Istituzioni ecclesiastiche, 330.

I 24 Vgl. Lazzari, Le ultime tre duchesse, r39f, r 97f. Keller hat am Beispiel der Kurfürstin Anna von Sachsengezeigt, dass die einer Fürstin zugeschriebene Rolle als Fürbitterin zwar allgemein gegeben war, doch das "Ausmaß, in dem diese Funktion wahrgenommen wurde, differierte. "Ausschlaggebend waren das Klientelverhältnis, also das Verhältnis zu dem/der Bittsteller/in und andererseits die eigene Beziehung zum Ehegatten und Machtinhaber. Nur in einer funktionierenden Ehe konnte die Fürstin Fürsprache halten und erhalten. So wundert es nicht, dass Renée de France oder Barbara von Österreich als Vermittlerinnen zwischen dem Fürsten und seinen Untertanen oder anderen Fürsten nicht zuletzt aufgrund ihres Sprachhandicaps weniger erfolgreich waren und seltener angerufen wurden. Vgl. Keller, Kommunikationsraum, 2 ro. 
Mit Eleonora, Johanna und Barbara endete zwar die verwandtschaftliche Bindung der Habsburger zu den Este, doch noch lange nicht zu den anderen italienischen Fürsten der Frühen Neuzeit: Maria Magdalena, Tochter von Erzherzog Karl II. von Innerösterreich und Maria von Bayern heiratete r6o8 Cosimo II. de'Medici; 1626 ehelichte Claudia de’Medici Erzherzog Leopold V.; deren Sohn Ferdinand Karl heiratete r646 Anna de'Medici; Kaiser Ferdinand II. erneuerte die bereits intensiven Beziehungen zum Haus Gonzaga und heiratete I622 Eleonora Gonzaga d.Ä. und sein Sohn Ferdinand III. Eleonora Gonzaga-Nevers d.J. Schließlich ist auch die I649 geschlossene Ehe zwischen Isabella Clara von Tirol und dem Herzog von Mantua Carlo II. Gonzaga-Nevers zu erwähnen. ${ }^{125}$ Auch wenn Margot Rauch in ihrem Beitrag über die habsburgischen Erzherzoginnen prinzipiell zuzustimmen ist, dass »die zahlreichen Kriege des I5. bis I 8. Jahrhunderts belegen [jedoch], wie wenig nachhaltig dynastische Eheverbindungen in politischer Hinsicht wirkten ${ }^{126}{ }^{16}$ zeigt doch gerade das Beispiel des estensisch-habsburgischen Heiratsprojekts, wieviel politisches Potenzial in diesen Verbindungen steckte. Aus der Korrespondenz der Este mit dem Kaiser und den anverwandten Reichsfürsten wird nämlich ersichtlich, dass dieses durch Heirat gesponnene Netzwerk sehr wohl nachhaltig war und über den Tod der Braut anhaltend neue Verbindungen fördern konnte; die erhoffte Lösung der Präzedenzfrage brachte die verwandtschaftliche Bindung an das Kaiserhaus hingegen nicht. Alfonso II. wurde aber zu einem »Reichsfürsten erster Klasse» und konnte zuletzt den sich selbst angeeigneten Titel Altezza Serenissima behalten. Auch die Nachfolgeregelung fiel schlussendlich für die Reichslehen nach seinem Wunsch aus, wofür neben den finanziellen Zuwendungen und der unaufhaltsamen »Bearbeitung" des Kaisers mittels persönlicher Korrespondenz und ständiger diplomatischer Vertretung sicher auch die einstige "Anverwandtschaft« eine Rolle gespielt haben dürfte.

Nach kurzer Witwerschaft dachte der fast 40-jährige Alfonso an eine dritte Vermählung und zog eine Intensivierung der Beziehungen zu den Wittelsbachern durch die Heirat mit einer Tochter von Albrecht V. und der Schwester von Barbara, Erzherzogin Anna, in Erwägung. Diese Möglichkeit sondierte er auf seiner Reise ins Reich, als er I 574 nach Innsbruck und Wien kam. Andere angedachte Heiratsprojekte waren jenes mit der Tochter des - verstorbenen - polnischen Königs im Zuge seiner Kandidatur für den polnischen Thron, eine weitere mit Erzherzogin Elisabeth, der Witwe von Karl IX. von Frankreich, und schließlich auch mit der reichen Marfisa d'Este aus der Seitenlinie seines Hauses. ${ }^{127}$

Als aber I 576 die Erhebung der Medici zu Großherzögen auch von kaiserlicher Seite erfolgte, schien es von Vorteil, sich mit den anderen benachteiligten italienischen Fürsten zu verbünden. So entstanden aus dieser Notwendigkeit ${ }^{128}$ heraus die Heirats-

I25 Vgl. unlängst Schnettger, Zwei Ehen und ihre Folgen. Einen Überblick über fremde Ehefrauen der Habsburger bietet: Weiss, Die Österreicherin, Kap. »Die Ehefrau aus der Fremde«, I 39-2oo.

I26 RaUCH, Verkaufte Bräute?, 32.

I27 Lazzari, Le ultime tre duchesse, 209, 2 I $6 f$.

I 28 Doch die (Heirats-)Beziehungen zwischen den Gonzaga und den Este hatten bisher keiner besonderen Begründung bedurft und waren auf beiden Seiten stets in Erwägung gezogen worden. Wenn man 
verbindung zwischen Alfonso II. und Margherita (1564-1618); auch die Gonzaga hielten sich bei der Brautwahl für Vincenzo an die Erbtochter der Farnese, Margherita, und schlugen ein mediceisches Angebot zunächst aus. Für das estensische Heiratsprojekt wurde Don Alfonso d'Este, Markgraf von Montecchio, 1578 in geheimer Mission zu Verhandlungen und im Jahr darauf erneut, um die Gonzaga-Braut per procuram zu ehelichen, nach Mantua geschickt. ${ }^{129}$ Wie im Fall der späteren Heiratsverbindung zwischen Erzherzog Ferdinand II. und Anna Caterina Gonzaga war der Bräutigam 30 Jahre älter (beim Habsburger waren es sogar 37 Jahre) und mit der Braut eng verwandt (Onkel und Nichte). Durch ihre habsburgische Mutter Eleonore von Österreich, war Margherita wiederum mit dem Kaiserhaus verwandt und gab der Verbindung Alfonsos ins Reich eine gewisse Kontinuität. Diese neue Heirat beflügelte den Este, der für die junge Braut ein großartiges Hochzeitsfest planen ließ und den Bau eines viel bewunderten, 300 Personen fassenden vergoldeten Schiffes (Bucintoro) für ihren würdevollen Einzug in Ferrara in Auftrag gab. ${ }^{130}$

Bevor Alfonso II. am 27. Oktober I 597 starb, fügte er seinem Testament ein Kodizill an, nach dem Margherita die doppelte Mitgift (insg. 200.000 scudi) und ein Witwendeputat von 4.000 scudi jährlich ausbezahlt werden sollten. Darüber hinaus sollte sie die Delizia Diamantina und allen Schmuck behalten dürfen. ${ }^{131}$ Wie Renée de France zuvor blieb sie - wenn auch aus anderen Gründen als ihre Schwiegermutter - nicht als Witwe in Ferrara, wo sie seit jeher ihre Position gegen die aus Urbino geflüchtete Schwägerin, Lucrezia d'Este, verteidigen musste. Sie gründete 1603 in Mantua ein Ursulinenkloster, das nach den Vorbildern jenseits der Alpen standesgemäße Ausbildungsstätte für junge Gonzaga-Frauen und Rückzugsort für Witwen war. Hier führte sie ein zurückgezogenes Leben, nachdem sie eine kurze staatspolitisch tragende Rolle

der Einschätzung des venezianischen Gesandten Glauben schenken kann, dann hätte auch Gugliemo Gonzaga, falls sich keine Erzherzogin zur Ehe mit ihm bereit erklärt hätte, eine Schwester Alfonsos II. d'Este geheiratet. Turba, Venezianische Depeschen 3, Giacomo Soranzo an den Dogen, [Wien], Dezember I 560 , Nr. 8I, I $72-$ I 75 , hier I 73 .

I29 Lazzari, Le ultime tre duchesse, $223 \mathrm{f}, 232$.

I30 Lazzari, Le ultime tre duchesse, 228f. Dieses Schiff und die junge Ehefrau sollten die Bewunderung Montaignes auf sich ziehen: „Wir sahen ferner den Bucentaurus, den der Herzog für seine letzte Gemahlin - sie ist schön und zu jung für ihn - mit dem Staat Venedig wetteifernd hatte verfertigen lassen: er hatte sie auf dem Po nach Hause gebracht.« Montaigne, Tagebuch einer Reise, ro5. Über das (zu) zarte Alter der letzten Herzogin von Ferrara tauschten sich auch Erzherzog Ferdinand II. und der estensische Gesandte Renato Cato bei dessen Durchreise auf dem Weg nach Prag im Januar 1579 aus. Der Erzherzog erkundigte sich nach dem Alter Margheritas und als der Gesandte erwiderte, dass sie zwischen I 4 und I 5 Jahre alt sein müsste, äußerte Ferdinand, der selbst seine I6-jährige Nichte heiraten sollte, Bedenken über die zu erwartende Fruchtbarkeit einer so jung verheirateten Frau. Vgl. die Auszüge des Gesandtenbriefes an den Bräutigam, Alfonso II. d'Este, bei: Koller, Nuntiaturberichte aus Deutschland III/ro, 88f, Anm. 5 .

I3 I Lazzari, Le ultime tre duchesse, 337. 
in der Statthalterschaft des Monferrato gespielt hatte. ${ }^{132}$ Diese Tatsache zeigt einmal mehr den größeren politischen Handlungsspielraum von Witwen. ${ }^{133}$

Sowohl Eleonora von Aragón, Ehefrau von Ercole I., als auch Lucrezia Borgia (zweite) Ehefrau von Alfonso I., wie Renée de France, Gattin von Ercole II., haben die einer Fürstin auferlegten Pflicht einer reichen oder zumindest ausreichenden Nachkommenschaft erfüllt. Allein die drei Ehen Alfonsos II. konnten diese Stabilisierungspolitik der vorangegangenen drei Generationen nicht weiterführen.

Die angeheiraten Este-Fürstinnen versuchten - unter verschiedenen Voraussetzungen - in den frühneuzeitlichen Fürstinnen zugedachten Wirkungsbereichen tätig zu werden. Die Aufgabe der Haushaltsführung und der Versorgung des »erweiterten Hofstaates « ${ }^{134}$ sind in den Nachlässen von Lucrezia Borgia und Barbara von Österreich und die darin festgelegte Versorgung von (auch italienischen) Hofdamen und anderem weiblichen Personal, bzw. die Fürsorge für Frauen unterer Gesellschaftsschichten wie Witwen und Waisenmädchen nachweisbar. Das Engagement für das Gemeinwohl hat Renée de France, wenn auch nicht ausschließlich, doch vorrangig auf ihre nach Italien gekommenen Landesleute und Glaubenssympatisant/inn/en beschränkt. Die Statthalterschaft, die Führung der Regierungsgeschäfte in Abwesenheit des Fürsten bzw. während der Thronvakanz, hat Eleonora von Aragón in der Krisenzeit mit (in den Quellen belegter) besonderer Bravour gemeistert. Renée gelang es, das Fürstentums bis zur Ankunft des Nachfolgers aus Frankreich zu schützen und sicher zu übergeben, ebenso wie Barbara, die ihren Gatten während seiner Reisen ins Reich vertrat. An alle diese Fürstinnen wandten sich Familienangehörige, nahe oder entfernte Verwandte aus dem Reich und darüber hinaus so wie Untertanen mit Fürbitten, Gnadengesuchen und Empfehlungsansuchen. Wenn Katrin Keller festgehalten und an mehreren Beispielen gezeigt hat, dass ein gutes Verhältnis zwischen den Eheleuten »stets Voraussetzung für die Realisierung politischer Spielräume einer Fürstin « ${ }^{135}$ war, so trifft das auf die meisten Este-Frauen zu. Allerdings zeigen aber gerade die Beispiele von Renée de France und Erzherzogin Barbara, dass auch der höhere Rang der Braut und eine große Hausmacht im Rücken Möglichkeiten boten, die ein eher schlechtes Eheverhältnis und eine misslungene Integration der fremden Braut anderenorts gemindert hätten.

I32 Lazzari, Le ultime tre duchesse, 360-368. Spagnoletti, Le donne, 25.

I33 Einige bemerkenswerte Untersuchungen zu den allgemeinen und politischen Handlungsmöglichkeiten von Frauen, darunter auch Adelsfrauen und Fürstinnen, sind: Wunder, Herrschaft und öffentliches Handeln, besonders zu den Adelsfrauen, 45-50; Dies., Die Fürstin bei Hofe. Siehe auch die Beiträge im Sammelband Hirschbiegel/Paravicini, Das Frauenzimmer, und hier besonders KelLer, Kurfürstin Anna von Sachsen, 263-285. Dies., Mit den Mitteln einer Frau. Zum Handlungsspielraum von Witwen siehe z.B. die Beiträge im Sammelband von Sснатткошsку, Witwenschaft in der Frühen Neuzeit. Schnettger, Zwei Ehen und ihre Folgen.

I34 Keller, Mit den Mitteln einer Frau, 228.

I35 Ebd., 230. 


\subsection{Aspekte von materiellem und geistigem Kulturaustausch zwischen Ferrara und dem Reich}

\subsubsection{Kulturaustausch und -transfer: Versuch einer Definition}

Seitdem das Thema des »kulturellen Austausches« wissenschaftlich untersucht wird, gibt es Diskussionen darüber, ob »Austausch«, »Transfer« oder eher das englische »exchange« der geeignetere Begriff für dieses Phänomen sei. ${ }^{136}$ In dem von Michael North 2009 herausgegebenen Band »Kultureller Austausch« wurde mit Nachdruck auf die bereits von Peter Burke monierte Bevorzugung des Begriffs »Austausch" vor »Transfer« aufmerksam gemacht und präzisiert, dass, Ideen, Praktiken und Objekte nicht einfach nur übernommen werden, sondern in ihrer neuen Umwelt dekontextualisiert und rekontextualisiert, ja sogar »domestiziert « werden. ${ }^{137}$ Allerdings hat Stefan Brakensiek im gleichen Band zurecht darauf verwiesen, dass im Fall von »asymmetrische[n] Machtverhältnisse[n] « der Begriff Transfer im Sinne der Übertragung von oben nach unten, z.B. von einem Fürstenhof auf lokale Eliten sehr wohl treffend sei. Hierbei handelt es sich nämlich nicht um Austausch, sondern um Vermittlung bzw. Nachahmung mit dem Zweck des sozialen Aufstiegs und der »kulturelle[n] Zugehörigkeit «. ${ }^{138}$ Selbst der Begriff »exchange« hat nach Burke seine Grenzen in der Darstellung der Verpflanzung von rezipierten ${ }^{139}$ Ideen, Techniken und Moden. Besser eignen würde sich der Begriff »translated «, wenn ein Kulturgut angeeignet und verpflanzt wird. ${ }^{140}$

Die sicher weitreichendste Definition von »Kulturtransfer», noch vor dieser Begrifflichkeitsdebatte, hat Michael Werner gegeben, der sich bereits früh mit dem Kulturtransfer-Diskurs ${ }^{141}$ auseinandergesetzt hat. Er meint:

Kulturtransfer findet in menschlichen Gesellschaften nahezu überall und zu jeder Zeit statt. [...] Jede Fertigkeit, jedes Wissen, aber auch jede Obsession oder Neurose kann übertragen,

I 36 Als Einführung und Überblick besonders hilfreich sind: Middeld/MiddelL, Forschungen zum Kulturtransfer; Paulmann, Kulturtransfer; Middell, Von der Wechselseitigkeit; Schmale, Einleitung; Fuchs/Trakulhum, Kulturtransfer; Schmidt, Kultureller Austausch; Mitterbauer, Kulturtransfer.

I37 North, Kultureller Austausch, 2.

i38 Brakensiek, Herrschaftsvermittlung, I63.

I39 Vom Lateinischen »recipere« sind damit unterschiedliche Formen des Transfers, der Vermittlung und Aneignung, des Aufnehmens und In-Gebrauch-Nehmens besonders im Rahmen von interkulturellen Begegnungen gemeint. Vgl. ArEND, »Rezeption/Rezeptionsforschung«.

I4O BUR Ke, Translating Knowledge, 70.

I4I Tatsache ist, dass Kulturtransfer sowohl Gegenstand der Forschung als auch ein theoretischer Ansatz ist. Nolde/Opitz-Belakhal, Kulturtransfer über Familienbeziehungen, I. 
also Gegenstand eines zwischenmenschlichen Austauschs werden. Es lohnt sich, über die genuine Uferlosigkeit des Kulturtransferbegriffs nachzudenken, der mit der Allgemeinheit unseres Kulturbegriffs zusammenhängt, der jede Art menschlicher Tätigkeit umfasst. Transfer ist ein Grundbaustein kultureller Entwicklung. ${ }^{42}$

In seinem Abriss über die Entwicklung des Kulturtransfer-Konzepts und -begriffs hat Matthias Middell, ebenfalls ein Experte dieses Themas, "Transfer « als »Bewegung von Menschen, materiellen Gegenständen, Konzepten und kulturellen Zeichensystemen im Raum und dabei vorzugsweise zwischen verschiedenen, relativ klar identifizierbaren und gegeneinander abgrenzbaren Kulturen mit der Konsequenz ihrer Durchmischung und Interaktion ${ }^{143}$ definiert.

Der kulturelle Austausch bzw. Transfer ist nach Friedrich Jäger neben der Kommunikation ein wesentlicher Aspekt der neuzeitlichen Kulturgeschichte. Beide, Kommunikation und Kulturtransfer, haben sich ab der Frühen Neuzeit tiefgreifend verändert: Einerseits hat die Entwicklung von neuen Medien zur Herausbildung neuer Formen von Öffentlichkeit und politischer Kommunikation geführt; andererseits kam es in Folge der frühneuzeitlichen Entdeckungsreisen zu neuen Formen von Kulturkontakten und von kultureller Fremdwahrnehmung. Die Aspekte des Kulturkontaktes und -austausches waren dabei sowohl dinglicher wie theoretischer Natur (Institutionen, Sprache, Glaubenslehren, Bildung, politische Ordnungen etc.). ${ }^{144}$ Auch Arno Strohmeyer ${ }^{145}$ hat Kulturtransfer »als sinterkulturelle[n] Kommunikationsprozess finiert, dessen Kern die Übertragung materieller wie ideeller Kulturgüter aus einem spezifischen System gesellschaftlicher Verhaltens- und Deutungsmuster in ein anderes bildet. ${ }^{146}$ Strohmeyer analysiert dabei vor allem den Export von Gütern aus einer und den Import derselben in eine andere Wirklichkeit unter besonderer Berücksichtigung ihrer dabei entstehenden Neuinterpretation und Umfunktionierung. Doch handelt es sich hierbei nicht um eine unveränderte Aufnahme bzw. Übernahme von Werten und Gütern, denn schon der heute als »Architekturtheoretiker« bekannte Hans Vredeman de Vries (1527-1609) sah die Notwendigkeit, das Kulturgut dem Geschmack und den Bedürfnissen der Zielkultur anzupassen und nicht sklavisch den Urzustand aus der Ausgangskultur beizubehalten.

\footnotetext{
I42 Werner, Zum theoretischen Rahmen, I 5. Dabei weist Werner erneut auf die Idee der Verflechtung, des Re-Transfers oder Rück-Transfers hin, ebd. r9.

I43 Middell, Von der Wechselseitigkeit, I7.

I44 Friedrich JäGER, »Kultur«, in: Friedrich Jäger, Enzyklopädie der Neuzeit Online, http://referenceworks.brillonline.com/entries/enzyklopaedie-der-neuzeit/kultur, abgerufen am I 3.6.20.

i45 Strohmeyer, Kulturtransfer durch Diplomatie. Siehe auch die Beispiele in Zwierlein, Komparative Kommunikationsgeschichte.

I46 Ebd., 206.
} 
Prinzipiell gab/gibt es nach Peter Burke drei mögliche Reaktionen auf einen kulturellen Import (oder kulturelle Invasion): Akzeptanz, Abwehr oder Segregation. ${ }^{147}$ Für unser Thema des kulturellen Austausches gilt natürlich die Reaktion der Akzeptanz, oder wie Burke es formuliert, der »sogar freundliche[r] Empfang. Als Extremfall lässt sich die Begeisterung für alles Ausländische nennen: etwa die Italophilie in der Renaissance, das Zeitalter des italianisierten Engländers oder Deutschen (des tedesco italianato wie er damals zuweilen genannt wurde). ${ }^{148}$ Bezüglich des Ergebnisses des kulturellen Austausches gibt es nach Burke zwei Formen: die Mischung oder bricolage und die »Kristallisation«, wenn in diesem Vermischungsprozess »das Flüssige sich verfestigt, gerinnt, zur Routine und dem Wandel gegenüber unangreifbar wird «. ${ }^{149}$

Den Begriff der »Verflüssigung « bezogen auf verschiedene Bereiche des menschlichen Daseins, als Erklärungsmodell für die Aufweichung von sozialen Kategorien und den schnellen Wechsel von Loyalitäten haben auch Zygmunt Baumann und Wolfgang Schmale ${ }^{150}$ benutzt. Vor allem Letzterer hat aufgezeigt, wie kulturelle Transferprozesse durch »Vernetzung, Mobilität, Kommunikation, Neugier, Ehrgeiz, Modernisierungsdruck, Anpassung, soziale[r] ökonomische[r] und andere[r] Verflechtung« entstehen und in welchem Ausmaß die Renaissance einen über die Grenzen Italiens reichenden, europaweiten Schub kulturellen Austausches geleistet hat. ${ }^{151}$ Dabei ist nicht der von der Ausgangskultur hervorgehende Export ausschlaggebend, sondern der - wie auch immer gestaltete, abgewandelte, weiterentwickelte - Import in der Rezeptionskultur. Im Zentrum stehen die Transformationen, die "produktive Umdeutung «. ${ }^{152}$ Auch wenn der einhelligen Meinung der bisherigen Forschungen zuzustimmen ist, dass »nicht jede Form kulturellen Austausches - etwa der Erwerb von Kulturgütern, wie Gemälde oder Druckwerke - [...] bereits mit Kulturtransfer gleichzusetzen [ist] «, ${ }^{153}$ so muss dennoch bedacht werden, dass es ohne diesen Erwerb, ohne das Kennenlernen des »Anderen«, ohne die Mobilität von Menschen, Dingen und Ideen gar nicht zum Austausch und Transfer kommen kann. Somit sind das Sehen und Kennenlernen in erster Instanz und die Suche nach bzw. der Erwerb von einem Gemälde oder Buch sehr wohl ausschlaggebend für die Beeinflussung des Geschmacks, für das Interesse und die Nachahmungswürdigkeit, für das Habenwollen und In-einen-neuen-Rahmen-stellen und somit ein Filter bzw. eine notwendige Vorarbeit für jeden kulturellen Austausch

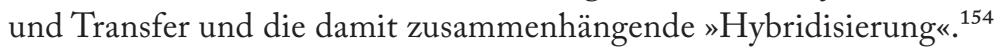

I 47 Burke, Kultureller Austausch, 20-28.

I 48 Ebd., 28.

I49 Burke, Kultureller Austausch, 35, 38 .

I50 Schmale, Kulturaustausch. Baumann, Liquid Modernity.

I 5 I Schmale, Kulturaustausch, I3.

I 52 Nolde/Opitz-Belakhal, Kulturtransfer über Familienbeziehungen, 3.

I53 Ebd.

I54 Beim Phänomen der Rezeption der Renaissance außerhalb Italiens ist nach Burke »das hydrauli- 
Es geht also beim Kulturtransfer um mehr als um den bloßen Vergleich ${ }^{155}$ von Kulturen: Es geht um die Untersuchung der »sozialen Träger des Kulturimports« - Menschen wie Dinge (Bücher, Bibliotheken) - und um die Fragen der »Übersetzungsprozesse von identitätsstiftenden Formen sowie »nach dem Abbau der Kulturdistanz zwischen diesen importierten Gütern oder den angereisten Fremden und dem Aufnahmekontext «. ${ }^{156}$

Das »kulturelle Exportland« des I 5 . und I 6. Jahrhunderts par excellance war Italien, auf das nun in der Folge ein großflächiger Blick geworfen wird, bevor dann in einem zweiten Schritt der Fokus auf das estensische Fürstentum und seine Austauschmomente mit dem Reich gelegt wird.

\subsubsection{Kulturaustausch mit Italien im Allgemeinen}

$\mathrm{Zu}$ den glorreichen Momenten in der Geschichte Italiens zählte der Historiker der zweiten Generation der Annales-Schule, Fernand Braudel, neben der Zeit des römischen Reiches und der ersten oder frühen Renaissance vor allem die zweite und eigentliche Renaissance seit der Mitte des I 5. bis zur Mitte des I 7. Jahrhunderts. ${ }^{157}$ In diesem Zeitraum der Verästelung der Macht und der Inbesitznahme des Mittelmeerraums durch Schifffahrt, Handel, Frühkapitalismus und Kolonialismus gewann die italienische Halbinsel einen eindeutigen - und in manchen Bereichen uneinholbaren - Vorsprung gegenüber dem restlichen Europa. ${ }^{158}$ Von den Städten Italiens gingen Ingenieure, Handwerker, ${ }^{159}$ Fachleute, Künstler, Händler, Kaufleute und Geistliche über die Alpen und brachten italienisches Kulturgut in seinen verschiedenen Facetten (Kunst, Wissen, Arbeitstechniken, Sprache, Waren) vorrangig nach Frankreich und ins Reich. ${ }^{160}$

Die italienische Sprache war - neben dem Latein - für Handeltreibende, Gesandte, aber auch für Fürsten eine lingua franca, eine »internationale« Sprache und ihre Beherrschung gleichzeitig Merkmal humanistischer Bildung. ${ }^{161}$ Die Verbreitung des Ita-

sche Modell, demzufolge die Bewegung nach dem Muster von >Ausbreitung`, Einfluß, Kanälen und Absorption gesehen wird « maßgeblich. Burke, Die europäische Renaissance, I 9, 23.

I 5 Dazu siehe: Espagne, Kulturtransfer; Ders., Jenseits der Komparatistik; Werner/Zimmermann, De la comparaison.

I 6 Espagne, Der theoretische Stand, 64f.

I 57 Braudel, L'Italia fuori d'Italia, 2092.

I 8 Vgl. Friedell, Kulturgeschichte der Neuzeit I, 4. Kapitel: »La Rinascita«, I73-230, besonders I75I 82 .

I59 $\mathrm{Zu}$ deren Wanderung im Sinne der Ausbildung und (Arbeits-)Migration siehe ganz allgemein: Bräuer, Probleme der Migration.

I6o Braudel, L'Italia fuori d'Italia, 2093 f.

I6 I Zur Wertschätzung der Konversation nach dem Vorbild des Cortegiano und zur Vormachtstellung der italienischen Sprache siehe: KRUse, Sprachlich-literarische Aspekte. 
lienischen zeigt sich in der Zahl der Übersetzer und in der Tatsache, dass sich mancher Fürst mit den zahlreichen, ins »Ausland« berufenen Architekten, Künstlern und Literaten aus Italien verständigen konnte. Braudel spricht zu Recht von einem "großen Italien « außerhalb der italienischen Halbinsel. ${ }^{162}$

Während die italienische Architektur, obgleich nationalisiert, also mit einheimischen Besonderheiten vermischt, in Frankreich früh Fuß fasste, griff sie in den Städten und Territorien des Reiches zunächst wenig, mit Ausnahme der Fürstenhöfe, die die italienische Renaissance in all ihren Facetten rezipieren und nachahmen wollten. Es waren also die Fürsten und ihre Höfe, die Italien ins Ausland brachten. Auffallend war dies in Böhmen, wo in Prag und Pilsen ganze Kolonien italienischer Handwerker ansässig wurden. ${ }^{163}$ Besonders am Beispiel der Architektur lässt sich nach Stefan Paulus zeigen, wie spät, aber vor allem wie vereinzelt nur der italienische Renaissancebaustil jenseits der Alpen rezipiert wurde und wie sehr er dann in hybriden Bauformen ("Zwitterarchitektur «) und in den Traktaten verarbeitet wurde. ${ }^{164}$ Die italienische Architekturtheorie kam vor allem durch Albrecht Dürer, der im Zuge seiner Italienreise u.a. auch Ferrara und Mantua besuchte, ins Reich. Ab den I 53 oer Jahren flossen immer mehr italienische Stilformen in die Baukunst jenseits der Alpen ein. ${ }^{165} \mathrm{Wie} \mathrm{Pau}-$ lus am »Spätzünder« Architektur zeigen konnte, zeigt sich der kulturelle Austausch nicht nur auf konkrete und materialistische Art, sondern auch durch die Übernahme von Methoden, Stilen und Denkweisen. "Allerdings lässt erst diese Integrationsleistung den Austausch von Kulturgütern oder Denkmodellen zu einem erfolgreichen Kulturtransfer avancieren. « ${ }^{166}$

Als Beispiel eines Kulturtransfers im Architekturbereich führt Stephan Hoppe den Residenzbau des Wittelsbacher Herzogs Ludwig X. in Landshut an. Ab I 536 ließ dieser in der Stadt eine unbefestigte Anlage errichten. Kurz nach Baubeginn reiste der Herzog nach Mantua und besuchte dort den eben fertig gestellten Palazzo Tè. Daraufhin wurden die Baupläne für die Landshuter Residenz geändert und hinter dem Deutschen Bau entstand ein dem besuchten Vorbild ähnlicher, von einem mantuanischen Baumeister entworfener Welscher Bau. ${ }^{167}$

I62 BRAUDEL, L'Italia fuori d'Italia, 2098f, 2 I 5 3. "La grandezza italiana è stata una dimensione del mondo« (2099). Das Italienische war eine für die Reichsgeschäfte wichtige Sprache, die laut Goldener Bulle von den Kurfürsten und ihren Nachfolgern erlernt werden sollte. Zu dieser »Ausbildungsvorschrift« und dazu weiterführender Literatur siehe BrAUn, Imagines imperii, I $92 \mathrm{f}$ und vorher WAGNER, Princeps litteratus aut illitteratus?, I 53.

I63 Braudel, L'Italia fuori d'Italia, 2 I $54 \mathrm{f}$.

I64 So z.B. die Fuggerkapelle St. Anna in Augsburg mit Charakteristika aus der italienischen Renaissance ebenso wie aus der Spätgotik. PAulus, Zwischen Kontinuität und Wandel, 237f, 240.

I65 Ebd., 244-247.

I66 Ebd., 247.

I67 Dieser Baumeister könnte nach dem Autor auch Zeichnungen und Entwürfe von Giulio Romano im Gepäck gehabt haben. Hoppe, Die Wittelsbacher Residenzen, I4I, I44. Nach Elisabeth Scheicher kann der Ausbau des Ambraser Innenhofs auch auf Vorbilder Mantegnas bzw. der Villa Pescheria 
Doch der Austausch im Bereich der Architektur beschränkte sich nicht auf die Nord-Süd-Achse. Für die Frühe Neuzeit konnte Marina Dmitrieva-Einhorn Aspekte von Kulturtransfer auch zwischen Italien und dem Osten des Reiches aufzeigen. Auch hier fungierten »die Metropolen [Krakau, Prag, Wien, E.T.] [fungierten] als Kommunikationszentren und Drehscheiben für neue Erfahrungen und Praktiken, zu denen nicht zuletzt die italienischen Bräuche und Formen als Zeichen der Modernität, als 'fashion` gehörten. « ${ }^{168}$ Als klaren Beleg dafür führt Dmitrieva-Einhorn die Sigismundkapelle in Krakau an, die Grablege für die Königsfamilie, die als Perle der italienischen Renaissance gefeiert, vom italienischen Architekten Bartolomeo Berrecci realisiert wurde. ${ }^{169}$ Neben diesem polnischen Beispiel gibt es den ersten Renaissancebau in Böhmen, nämlich das Lusthaus von König Ferdinands Gemahlin Anna unter der Regie von Paolo della Stella errichtet. Ebenso bedeutend für die Umsetzung italienischer Vorbilder war Erzherzog Ferdinand II. als Statthalter Böhmens. Unter ihm befestigten und erneuerten zahlreiche Italiener in den I 53 oer Jahren die Prager Burg. ${ }^{170}$ In Ungarn wurde die Renaissance durch Matthias Corvinus besonders dank seiner Kontakte zu verschiedenen italienischen Höfen früh rezipiert. ${ }^{171}$ Italienische Künstler, Architekten, Bildhauer und Handwerker, die von den jeweiligen Herrschern engagiert wurden und ihre heimischen Stiltraditionen wie die Fassadendekorationen in sgraffito ${ }^{172}$ mitbrachten, ließen sich in den osteuropäischen Zentren nieder, erhielten Aufträge auch vom einheimischen Adel, heirateten hier und wurden in eigenen Gemeinden, den sogenannten italienischen Kolonien, sesshaft. Dabei vermischten sich, im Sinne eines erfolgreichen Kulturtransfers, die eingeführten architektonischen Formen mit den bestehenden und die mitgebrachten Spezifika, passten sich den Bedürfnissen der Auftragsgeber, ihrem Geschmack oder aber auch den Besonderheiten von Klima und Umwelt an. ${ }^{173}$

Dass neben Polen und Ungarn auch Sachsen eine zentrale Rolle für den innereuropäischen Kulturtransfer gespielt hat, konnte Katrin Keller bereits an verschiedenen Beispielen, allen voran an den verschiedenen Gruppen von Reisenden wie dem Adel, den Glaubensflüchtlingen, den Kaufleuten und den Diplomaten eindrücklich zeigen.

Vecchia in Verona zurückgeführt werden. Scheicher, Ein »böhmisches« Schloss. Siehe auch die Vergleiche zwischen dem Landshuter Bau und Palazzo Te bei Endemann, Die Fassaden des Italienischen Baus. Zur Beeinflussung durch Reisen siehe auch: Tönnesmann, Reisen und Bauen.

i68 Dmitrieva-Einhorn, Case molto simile all'italiane, 232.

I69 Ebd., 234.

I70 Bis zur Mitte der 1550er Jahre waren italienische Steinmetze und Maurer in Prag auf Anordnung Ferdinands tätig. Vgl. BŮžEK, Ferdinand von Tirol, i r $8 f$.

i7 i Dmitrieva-Einhorn, Case molto simile all'italiane, 235 f.

I72 Es handelt sich hierbei um Kratzputz, d.h. um in noch feuchtem Putz eingekratzte Muster. Um die Mitte des I6. Jahrhunderts wurde die aus Oberitalien stammende Sgraffittomalerei als Fassadendekor auch nördlich der Alpen angewandt. Vgl. Weninger, Zur Sgraffitomalerei in Österreich.

Dmitrieva-Einhorn, Case molto simile allitaliane, $237-242$. 
Eine besonders engagierte Betreiberin kulturellen Austausches war die sächsische Kurfürstin Anna (I 532- I 585) aus Dänemark, die für die beliebte dänische Weißstickerei Näherinnen aus Dänemark und für ihren berühmten Garten französische und niederländische Gärtner kommen ließ. Aus Italien importierte sie Samen und Pflanzen von Kirschen, Quitten und Hyazinthen, die sie in ihrer neuen Heimat akkulturierte. ${ }^{174}$

Ebenso bedeutend und stark vertreten ist die Gruppe der sogenannten Transporteure, also Künstler, Musiker, Gelehrte und Schriftsteller, die Kulturgüter mit sich trugen. Dazu kann Antonio Scandello (I5I7- I580) aus Bergamo gezählt werden, der als Zinkenist und Posaunist zuerst bei Kardinal Cristoforo di Madruzzo in Trient und dann ab I 547 in der Kapelle von Moritz von Sachsen, I 568 sogar als Kapellmeister der sächsischen Hofkapelle tätig war. Als Liedkomponist verschmolz er deutsche evangelische, niederländische und italienische Musikstile. Er wurde in Dresden sesshaft, benannte seinen Sohn nach Kurfürst August und konvertierte zum Luthertum; seine Integration ermöglichte ihm den Kauf eines Hauses in Dresden. ${ }^{175}$

Enge Beziehungen gab es zwischen Sachsen und Florenz, wie Barbara Marx an der Migration von Künstlern nachgezeichnet hat. ${ }^{176}$ Nach der oben genannten italienischhabsburgischen Doppelhochzeit, bei der eine Tochter Kaiser Ferdinands I. Francesco de'Medici geheiratet hatte, wusste die florentinische Dynastie diese Heiratsallianz besonders für ihre Imagepflege im Reich zu nutzen. Die bereits bestehenden Beziehungen über die Alpen wurden durch die neue Verbindung intensiviert, wie man u.a. an der Tatsache erkennt, dass unter den Festgästen der Sohn von Herzog Albrecht von Bayern, Ferdinand, anwesend war, den Marx auch aufgrund seines deutschen Berichts über den Hochzeitseinzug unter den »Multiplikatoren des Ereignisses « nennt. ${ }^{177}$ Erst die neuere Forschung hat die Bedeutung der Achse Florenz-Dresden jenseits der »konfessionelle[n] oder reichsorientierte[n] gemeinsame[n] Interessen ${ }^{178}$ u.a. im Zuge der Untersuchung der florentinischen Geschenke in den Dresdener Kunstsammlungen ${ }^{179}$ unterstrichen. Der seit I 549 zum Kurfürsten avancierte Moritz von Sachsen hatte seine internationale Politik auf Italien gelenkt und sich zunächst an Frankreich nahen Fürsten, wie die Este, angelehnt. Während seiner vierwöchigen Oberitalienreise

I74 Keller, Zwischen Wissenschaft und Kommerz, 275 f. Im Gegenzug zu I 27 Obstbäumen, die Erzherzog Ferdinand II. I 575 nach Dresden schickte, erhielt er elf friesländische Kühe für die Zucht. Kuster, »Eur Lieb gannz williger Brueder«, $47 \mathrm{f}$.

I75 Ebd., 280-282. Insgesamt kamen sechs Musiker von Trient nach Dresden in die Dienste von Kurfürst Moritz, darunter auch der Instrumentalist und Chronist Cerbonio Besozzi, von dem das Eingangszitat dieses Kapitels stammt. Vgl. auch Korsch, Ein »heimlicher Vorschlag«, 39.

I76 Marx, Künstlermigration.

I77 Ebd., 2 I 5. Marx hat auch auf die bedeutende Rolle der Medici-Frauen im image building Prozess der Medici vor allem im Ausland und besonders jenseits der Alpen hingewiesen. Marx, Politica culturale al femminile, i $48 f$.

I78 MARx, Künstlermigration, 224.

I79 Zu den ältesten Kunstkammern gehört die I560 von Ernst August gegründete kurfürstliche Kunstkammer in Dresden. Vgl. Schlosser, Die Kunst- und Wunderkammern, I 35. 
nahm er viele Impulse für das Dresdner Schloss und die von Cristoforo di Madruzzo empfohlenen Baumeisterbrüder Gabriele und Benedetto Tola aus Brescia mit. Erst seine Nachfolger, August I., weitete diese italienischen Kontakte bis zur Toskana aus; Cosimo I. de'Medici suchte geeignete Facharbeiter für den Erz- und Metallabbau, sodass es zu einem ersten Austausch von Bergbauexperten mit Sachsen kam. ${ }^{180} \mathrm{Da}-$ raufhin intensivierte sich der kulturelle Austausch durch Migration von Architekten und Künstlern, die u.a. aus Florenz nach Dresden berufen bzw. empfohlen wurden, ohne dass sich aber eine kontinuierliche Beschäftigung italienischer Künstler hier ergab. Marx spricht von einer eher »turnusmäßigen Beschäftigung italienischer Künstler oder der Entsendung sächsischer Künstler nach Italien «. ${ }^{181}$ Dies entsprach zumeist dem Trend der Zeit: In ähnlicher Weise verlieh Francesco de'Medici I 576 seinen Baumeister Simone Genga an Erzherzog Karl von Österreich, I 578 seinen Architekten und Festungsbauer Antonio Lupicini ${ }^{182}$ an Kaiser Maximilian II. und Erzherzog Ferdinand in Innsbruck. ${ }^{183}$ I 572 war das Hauptziel der Gesandtschaft des Baumeisters Rocco di Linar, ${ }^{184}$ den August von Sachsen nach Florenz, Mantua und Ferrara schickte, um dort die Terracotta- und Bronzeherstellungstechniken zu erlernen. Umgekehrt kamen auch Meister und Auszubildende nach Florenz, um den stile fiorentino kennenzulernen und in die Arbeiten in ihrer Heimat zu übertragen.

Den Grund für die Intensivierung der Achse Dresden-Florenz sieht Marx in dem Bestreben der Medici im Reich auch unter den protestantischen Fürsten Unterstützung für die Anerkennung der Großherzogswürde durch den Kaiser zu suchen und sich in die »alten« italienischen Beziehungen Sachsens mit den Este und den Savoyern hinein zu reklamieren. Für Sachsen bedeuteten diese mehrfachen Verbindungen nach Italien einen stetigen und vielseitigen kulturellen Austausch in Form von Waffentechniken, Mess- und Präzisionsgeräten, Künstlern ${ }^{185}$ und Kunstwerken, Architekturformen, Geschenken ${ }^{186}$ und nicht zuletzt kulinarischen Spezialitäten. ${ }^{187}$

I 549 war Kurfürst Moritz von Sachsen nach Oberitalien gereist und hatte von hier nicht nur Kulturgüter und Inspirationen mitgenommen, sondern auch die persönliche

I 80 MARx, Künstlermigration, 225-228.

I 8 I Ebd., 230.

I $82 \mathrm{Zu}$ Antonio Lupicini (I 530- I607), Architekt und Ingenieur im Dienst der Medici und anderer Fürsten siehe Gerardo Dotı, »Lupicini, Antonio«, in: DBI 66, 2006, online verfügbar: http://www.trec cani.it/enciclopedia/antonio-lupicini_(Dizionario-Biografico)/, Zugriff: I6.9.2020.

I 83 Marx nennt noch weitere Beispiele für diese menschlichen »Leihgaben«, die allerdings nicht in alle "Betriebsgeheimnisse«, so bestimmte Techniken, Herstellungsverfahren und sogenanntes technologisches Arkanwissen eingeweiht wurden. MARx, Künstlermigration, 234-237.

I 84 Vgl. dazu auch CAstor, Rocco di Linar.

I 85 So schreibt Marx dem I 575 nach Dresden gezogenen Bildhauer Giovanni Maria Nosseni die "Italianisierung « Dresdens zu. MARx, Künstlermigration, 242.

I 86 MARX, Künstlermigration; siehe das florentinische Geschenkinventar im Anhang ebd., 286-290.

I 87 Dazu gehörten Parmesankäse, Ö1, Fisch, Schinken, Oliven und Kapern, Wurst und eingesalzenes Fleisch sowie verschiedene Weine. Siehe im Anhang ebd., 2966. 
Bekanntschaft mit Ercole II. intensiviert und wahrscheinlich war hier die Idee geboren, den Herzog von Ferrara als Mittelsmann für eine Verbindung mit Frankreich zur Unterstützung der konfessionspolitischen Sache einzusetzten. ${ }^{188}$ In Ferrara wurde der Sachse auch zum Ausbau seiner neuen kurfürstlichen Residenz inspiriert ${ }^{189}$ und nahm neben italienischen Musikern für seine I 548 gegründete Hofkantorei auch Baumeister, Handwerker und Maler für den Umbau des Dresdner Schlosses (I 547-I 552) mit, dessen Fassade er mit der italienischen Sgraffitotechnik dekorieren ließ. Das Stadtbild Dresdens, das hier entstand und von den nachfolgenden Wettinern geprägt wurde, war von diesem Kulturtransfer mit Italien bestimmt und vereinte italienische Techniken und Stilelemente mit einheimischen »sächsischen « Themen. Dies alles verlieh der Stadt den Beinamen »Elbflorenz«. ${ }^{190}$ Die Inhalte waren jedoch protestantischer und nicht - wie in Italien zumeist - katholischer/gegenreformatorischer Natur, wobei es vorrangig die Fürstenhöfe von Wien, Prag und München waren, die »den Grad und die Ausprägung der Italianisierung « ${ }^{191}$ vorgaben, wie Barbara Marx präzisiert hat. Dies weist erneut auf die Bedeutung des Beziehungsgeflechts der europäischen Dynastien des I6. Jahrhunderts hin. Bedeutend und mit den (späteren) Este, den Herzögen von Modena, verflochten ist auch die Entwicklung der berühmten Dresdner Kunstkammer. Bereits Moritz ließ naturalia, curiosa und Werke der bildenden Künste ins »hintere Gewölbe« zu einer Sammlung zusammentragen. Doch erst August I. beschäftigte einen eigenen Kurator für seine ausgedehnte Sammeltätigkeit und für den Ausbau eines studiolo nach italienischem Vorbild aus seinem umgestalteten Reißgemach. Mithilfe des Künstlers Gabriel Kaltemarckt, der die Umgestaltung der Uffizien miterlebt hatte, wurde aus der stark auf Werkzeug und Instrumente ausgerichteten Sammlung seines Vaters unter Christian I. eine auf Gemälde und Skulpturen sowie naturalia konzentrierte und institutionalisierte Zusammenschau im »Grunnen Gewelb«. Nach Kaltemarckt hatte der sächsische Kurfürst gerade aufgrund seiner italienischen Verbindungen die besten Voraussetzungen für die Schaffung einer hervorragenden Kunstkammer: »Es ist offenbar, Das E. Churf. G. mit den Fürstlichen Heusern Österreich und Beyern [...] gleichergestalt mit dem Grohsherzögen Zu Florencz, und andern Italianischen Fürsten Sophoy, Ferara, Mantua, Parma. Urbin etc. in solcher Freundt- und Kundtschafft stehen [... «. ${ }^{192}$ Tatsächlich fanden hier Giambolognas Bronzeskulpturen als Geschenk von Francesco de'Medici und Filarets Statue des

I 88 Winter, Kurfürst Moritz, 53.

I89 Dazu siehe Rudolph, Stadtliche gemeinde, besonders den Überblick über die Bauprojekte 267.

I90 Korsch, Ein »heimlicher Vorschlag«, 40; MARX, Italianità, I I. Ein besonders prägendes Beispiel dieser Vermischung von Eigentradition, Protestantismus und italianità ist nach Marx im Grabmalprojekt des Kurfürsten Moritz im Dom von Freiberg zu finden. Ebd., I 2. Siehe auch: Magirius, Das Moritzmonument.

I9I MARx, Italianità, 8.

192 Dresden, SächHStA, Loc. 9835, bl. 42r, zit. n. Doмв rowski, Dresden-Prag, 66. 
Marc Aurel von Guglielmo Gonzaga übersandt ${ }^{193}$ sowie die von Kaiser Maximilian II. an August geschenkten Vier Jahreszeiten von Arcimboldo einen ehrenvollen Platz. ${ }^{194}$ Nach Dombrowski war besonders die Achse Prag-Dresden durch eine hohe Mobilität von Künstlern und eine rege Vermittlungsarbeit fruchtbar für den italienischen Kulturtransfer, wie nur zwei von mehreren Beispielen zeigen sollen: Der neapolitanische Architekt und Festungsbauer Carlo Theti war in Italien in Ferrara, Florenz und Venedig und im Reich in München, Wien, Prag und Dresden tätig, so wie der oben genannte Architekt und Ingenieur Rocco/Rochus di Linar von Ferrara über Frankreich, die Pfalz und Brandenburg an den Kaiserhof kam. Prag hatte mit König Ferdinand bereits einen "Italienisierungsschub« erlebt, sodass Moritz nicht nur in Oberitalien, sondern im Juni 549 auch in Prag italienisches Kulturgut bewundern konnte, ebenso wie sein Bruder August, der ein Jahr lang zwischen Wien und Prag verbrachte und mit den Erzherzögen Ferdinand II. und Maximilian (II.) befreundet war, wodurch eine »kulturelle Durchlässigkeit« zwischen dem Kaiserhof und dem sächsichen Hof gefördert wurde. Letzterer kam selbst vor und nach seiner Kaiserkrönung einmal nach Dresden. ${ }^{195}$

Kunst und Künstler, Handwerker, italienischer Baustil, Musiker, Festungsanlagen nach oberitalienischem Vorbild und Sprache waren nach Dombrowski »das Resultat eines bewußt betriebenen Kulturtransfers « in Sachsen. ${ }^{196}$ Dieser kulturelle Austausch und Transfer zeigt sich auch an einer weiteren Besonderheit, die die sächsischen Kurfürsten, die Este und die Kaiserfamilie verband: die Instrumentalisierung des antiken Herkulesmythos für die Herrschaftsrepräsentation, wie schon Harriet Rudolph in ihrer Untersuchung zum Mythos des Hercules saxonicus gezeigt hat. ${ }^{197}$ Die mythologische Figur des Herkules war sowohl für die Herzöge von Ferrara und Modena als auch für die Kaiser des I6. Jahrhunderts und insbesondere für Karl V. von großer Bedeutung in den Repräsentationspraktiken. Auch für die Wettiner begann nach Rudolph mit Moritz und mit der moralisch wie rechtlich fragwürdigen Übernahme der Kurwürde $^{198}$ das - später von August dem Starken zum Höhepunkt geführte - Bedürfnis

I93 Weiterführend zum Kulturtransfer zwischen den Gonzaga und dem Reich: Elena Venturini, Le collezioni Gonzaga. Il carteggio tra la corte cesarea e Mantova (I559- I636), Milano/Mantova 2002.

i94 Syndram, Über den Ursprung. Vgl. auch: Syndram/Kappel/Weinhold, Das Historische Grüne Gewölbe.

I95 Dombrowski, Dresden-Prag, 66, 69. August kam I 566 nach München und konnte das bereits weit gediehene Kunstkammergebäude des bayerischen Herzogs Albrechts V. bewundern, mit dem er ebenso - obwohl dieser ein energischer Verfechter der katholischen Reform war - eine freundschaftliche Beziehung pflegte. Vgl. Syndram, »Diese dinge sind warlich wohl wirdig«, 20.

i96 Dombrowsкi, Dresden-Prag, 65.

i97 Rudolph, Hercules saxonicus. Siehe auch Dombrowski, Dresden-Prag, 7 of.

I98 Zu Recht weist Rudolph darauf hin, dass die Johann Friedrich aufgrund seines Verbrechens gegen das Reich aberkannte Kurwürde auf seinen Nachfolger aus der ernestinischen Linie hätte übergeben werden müssen. Außerdem war es moralisch auch nicht vereinbar, dass sich Moritz gegen die eigene Familie gerichtet hatte. Rudolph, Hercules saxonicus, 73. 
der Identifizierung mit den Tugenden und Stärken des zeitgenössischen Herkulesbildes. ${ }^{199}$ Ebenso lässt sich für Ottheinrich von der Pfalz zeitgleich eine Auseinandersetzung mit dem Herkulesmythos und seine plastische Verarbeitung nachweisen. ${ }^{200}$ Die Ersten, die die herkulischen Tugenden für die fürstlichen Inszenierungsprogramme einsetzten und sich als Herrscher mit dieser antiken Figur gleichsetzten, waren die frühneuzeitlichen Herrscher aus den Dynastien der Este, Gonzaga und Medici. Bei den Este findet sich dieser Bezug bereits in der Namensgebung der Stammhalter (Ercole I., Ercole II.) und in der Herkulesthematik im Palazzo Paradiso, die Moritz I 547 auf seiner Reise durchaus wahrgenommen haben könnte. Nicht nur in den darstellenden Künsten, sondern auch in der Hofliteratur und -poetik setzte Pellegrino Prisciani die Stadterweiterung Ferraras durch Ercoles I., die berühmte addizione erculea, und die Trockenlegungsmaßnahmen im Fürstentum mit einer der schwierigsten Aufgaben des Herkules, der Tötung der Hydra, gleich. ${ }^{201}$

In weiterer Folge ließ sich der Herzog von Florenz, Cosimo de'Medici, als Herkules porträtieren, während im mantuanischen Palazzo Te Federico Gonzaga ebenfalls Darstellungen von Szenen aus den Herkulessagen in Auftrag gab. Sowohl Kaiser Maximilian I. als auch Karl V. sowie die französischen Könige beanspruchten den Herkulesmythos für sich, sodass Rudolph zu Recht von einer herrschaftlichen Instrumentalisierung und Inanspruchnahme dieser mythologischen Figur sprechen kann. Außerhalb dieser Herrscherliga scheint die Identifizierung und Inszenierung mit Herkules immer dann notwendig gewesen zu sein, wenn die Legitimität der Herrschaft in Frage gestellt wurde, wie bei Philipp dem Guten und Karl dem Kühnen von Burgund, den Medici, den Este oder eben dem neuen Kurfürsten von Sachsen aus der albertinischen Linie. ${ }^{202}$ Bei Moritz drückte sich diese an die Figur des Herkules angelehnte Art der Herrschaftsrepräsentation nach der Übernahme der Kurwürde in gesteigertem Ausmaß auch in den Kunst- und Bauwerken und in der Förderung von Musik, Kunst und Wissenschaft als Kultivierer des Landes aus. ${ }^{203}$ In dem I 547 geschaffenen Kurschwert findet sich der Herkulesmythos ebenso verarbeitet, wie in dem von Lucas Cranach d.J. gemalten Tafelgemälde ${ }^{204}$ und bei den Innenhofsgraffiti der Außenfassade des umgebauten Dresdner Schlosses. ${ }^{205}$ Hinzu kamen die Taten

I99 Ebd., 6o.

200 Vgl. Нuвасн, Kurfürst Ottheinrich.

20 I $\mathrm{Zu}$ diesen und weiteren Parallelen mit dem Herkulesmythos innerhalb der estensischen Panegyrik siehe: Ferrari, La corte degli dei, 696-699.

202 Rudolph, Hercules saxonicus, $69 \mathrm{f}$.

203 Ebd., 62.

204 Zwei Tafeln haben den schlafenden bzw. erwachenden Herkules bei den Pygmäen zum Thema, das der Haupthofmaler Dosso Dossi für Ercole II. gemalt hatte. Ebd., 83. Nachdem er Dossis Interpretation gesehen hatte, beauftragte Moritz Lucas Cranach d.J. mit diesem Bildthema. In beiden Interpretationen lassen sich jeweils die Züge der beiden Fürsten erkennen. Vgl. WEB ER, LA collezione, $37 f$.

205 Rudolph, Hercules saxonicus, 75, 80. 
des Herkules als Wandteppichmotiv, ${ }^{206}$ so wie im Vorzimmer zu Ercoles I. d'Este Privaträumen ein Stoffvorhang die Mühen des antiken Helden zeigte. ${ }^{207}$ Auch im I 553 geschaffenen Moritzmonument sieht Rudolph einen versteckten Hinweis durch die zwei Säulen - die Säulen des Herkules -, die Moritz und August im Akt der Übergabe des Kurschwerts (eigentlich ein Privileg des Kaisers) »umrahmen «. ${ }^{208}$

Wie die verschiedenen Beispiele gezeigt haben, war das Kennenlernen und der Austausch von neuen, fremdartigen materiellen Gütern, die in den Besitz der Fürsten (und Fürstinnen) kamen, von besonderer Bedeutung für den Kulturtransfer. Gegenstände kamen durch Heirat, Reisen oder Kriegsbeute ${ }^{209}$ in die Fürstenschätze. ${ }^{210}$ Dabei handelte es sich vor allem um Objekte wie Tafelgeschirr oder Schmuck, die in der Fremde gesehen, kennengelernt und dann im eigenen Kulturraum nachgeahmt, d.h. von eigenen Künstlern und Handwerkern nach eigenen Beschreibungen und Vorgaben, aber oft in Material und Aussehen den eigenen Ansprüchen angepasst, reproduziert wurden. ${ }^{211}$ Als besonders wichtige Vermittlerinnen in diesen Kulturtransferprozessen gelten natürlich die in die Fremde verheirateten Bräute, die neben einer aus zahlreichen Gegenständen zusammengesetzten Mitgift auch Traditionen, Bräuche, Moden und (Glaubens-)Auffassungen mitbrachten. ${ }^{212}$ Ute Kümmel führt als markantes Beispiel die 1474 mit Eberhardt im Bart von Württemberg verheiratete Barbara Gonzaga ${ }^{213}$ an, die in ihrer Ausstattung Krausen als Trinkgefäße mitführte, die erst ab dem Zeitpunkt ihrer Hochzeit in diesem Gebiet zur Verwendung kamen. ${ }^{214}$

Nicht nur die singuläre »Verpflanzung" einer Braut und ihrer Objekte von einem Kulturraum in einen anderen, sondern die fürstliche Mobilität im Allgemeinen, bestehend aus Kriegszügen, Pilgerreisen, Familienbesuchen, Teilnahme an Reichs- und

206 Das Herkulesmotiv war bereits früher bei ferraresischen Wandteppichen verarbeitet worden. Vgl. Forti Grazzini, Leonello d'Este.

207 FABER, Ercole II d'Este, 28.

208 Rudolph, Hercules saxonicus, 88.

209 Als Beispiel für Schätze aus Kriegsbeute, die dem Ausdruck der eigenen Macht und Stärke dienen sollten, führt Kümmel den Raum in der Bibliothek Margaretes von Österreich in Mecheln an, in dem u.a. aztekische Trophäen ausgestellt waren und mit »einheimischem «Zubehör wie einem blauen Damastvorhang für die Goldschmiedearbeiten, in Szene gesetzt wurden, Kümmel, Heirat, I 5 .

2 Io Vgl. allgemein zum Reisephänomen in der Renaissance: Ertzdorff/Neukirch, Reisen und Reiseliteratur.

2 I I Kümmel, Heirat, I 5 f. Bereits Peter Burke hat dieses Phänomen gekonnt auf die Spitze getrieben mit der Behauptung, dass »französische Steinmetze[n] in Linlithgow Palace italianisierende Motive in die schottische Architektur einführten«. Burke, Die europäische Renaissance, I 8.

2 I 2 Kümmel, Heirat, ro6.

2 I 3 Dies war nicht die erste Verbindung des Hauses Württemberg nach Reichsitalien. Eberhard der Milde hatte I 386 Antonia Visconti, die Tochter des Herzogs von Mailand, Bernabò Visconti, geheiratet. I 453 folgte die Ehe von Ulrich dem Vielgeliebten von Württemberg mit Margarethe von Savoyen. Vgl. Wunder, Kleine Geschichte des Herzogtums Württemberg, I 9.

2 I 4 Kümmel, Heirat, ro8. 
Fürstentagen, boten Anlass zum kulturellen Austausch. Reisende Fürsten/innen kauften für sich und die Familie »Reiseandenken «, ${ }^{215}$ brachten dem Gastgeber Geschenke mit und erhielten ebensolche oder wurden eingeladen, dessen Schätze und Sammlungen zu bewundern. Hier lernte man Neues kennen und transportierte es gedanklich, schriftlich oder gegenständlich - oft nach eigenem Geschmack adaptiert - nach Hause. ${ }^{216}$

Viele Impulse kamen aus Venedig, dem Tor nach Osten und dem Beginn jeder Pilgerreise ins Heilige Land, wo man sich das oft monatelange Warten auf das Ablegen des Schiffes mit dem Besuch der Stadt und ihrer Schätze verkürzte. ${ }^{217}$ Als sich Herzog Bogislaw von Pommern auf der Rückreise aus dem Heiligen Land 4497 in Venedig aufhielt, sah er in der Kirche San Marco in Venedig zwei Einhörner über dem Hauptaltar hängen und erfuhr, welche Verehrung diesen Stücken aus dem Kirchenschatz zuteilwurde. Daraufhin forderte er noch aus der Lagunenstadt seine Hofräte brieflich auf, das Einhorn, das in der Kapelle von Rügenwald verwahrt wurde, sicherzustellen. ${ }^{218}$ $\mathrm{Zu}$ diesen Fürsten an der nördlichen Peripherie des Reiches gab es - wie Oliver Auge festgestellt hat - gerade dank seiner Mobilität noch weitere Kontaktmomente mit dem Süden, die zu einem kulturellen Austausch führten. ${ }^{219}$ Den ersten Anlass bot der Aufruf Maximilians I. an alle Reichsfürsten zur Teilnahme am Italienzug, dem der Herzog von Pommern, Bogislaw X., mit 300 Berittenen Folge leistete und dafür im April I 497 in Innsbruck eintraf. Als sich der Romzug nicht (mehr) abzeichnete, wandelte Bogislaw seinen Feldzug in die oben genannte Pilgerreise ins Heilige Land um. Auf seiner Rückreise erhielt der Herzog von Pommern, der sich im März I498 wieder in Innsbruck aufhielt, seine Privilegien und Besitzungen bestätigt und das Münzprägerecht obendrein. In Tirol nahm er an Turnieren teil und wurde reich beschenkt, nachdem er selbst dem kranken Maximilian Wein, Hafer ${ }^{220}$ und einen Ochsen zur Genesung hatte überbringen lassen. Diese Art des Kontakts und der Beziehung waren nach Auge, neben der Bereitschaft, das politische Vorhaben des Königs zu unterstützen, ausschlaggebend für das Ziel der direkten Belehnung durch das Reichsoberhaupt. Wie die Fürsten von Pommern, so versuchten auch jene von Mecklenburg durch die Nähe und den steten Kontakt zu Maximilian und seinen Nachfolgern politische Ziele zu

2 I 5 Auch von Pilgerreisen kamen "Mitbringsel« an den Heimathof und beeinflussten nicht selten die Handwerkskunst daselbst. Vgl. die Beispiele bei Tripps, Pilgerfahrten.

2 I 6 Kümmel, Heirat, I Io- I 3 .

2 I 7 Schudt, Italienreisen, 40. Auch der oben genannte Eberhardt im Bart wagte sich über die Alpen und das Mittelmeer und erhielt seinen Beinamen durch den Pilgerbart, den er zusammen mit dem Symbol der Palme und der Devise Attempto (ich wage es) aus seiner Fahrt ins Heilige Land mitbrachte. WunDER, Kleine Geschichte des Herzogtums Württemberg, $29 f$.

2 I 8 Frey, Fürstliche Kultinnovationen, I $22 \mathrm{f}$.

2 I 9 Vgl. Auge, Reichsverdichtung.

$220 \mathrm{Zu}$ diesen noch in der Neuzeit verbreiteten, aus der spätmittelalterlichen Tradition und altem Schenkritual kommenden Präsenten Wein und Hafer siehe Groebener, Gefährliche Geschenke, 6r. 
erreichen. Vor allem die Anwesenheit an den Reichstagen, so z. B. in Worms I495, bot ihnen die Möglichkeit, um Belehnungen zu bitten und Privilegien zu erhalten, die »für den weiteren Ausbau ihrer Landesherrschaft wichtig waren«. Wenn auch den Fürsten des Reichsnordens ihre Anwesenheit bei Hof, ihre Dienste und die Bereitschaft zum Romzug kein Gewinn, sondern eher ein Verlustgeschäft waren, so saßen sie durch ihre Mobilität an der Quelle der Macht, und ihre Heimathöfe im weiten Norden waren dadurch stets aus erster Hand mit Informationen und Neuigkeiten versorgt. Demzufolge kam es durch diese Kontaktmomente und die Pflege von Beziehungen auch zu Aspekten des Kulturtransfers. ${ }^{221}$ Der nächste Schritt zur Intensivierung der Beziehungen war nämlich durch persönliche Kontakte, Gesandtschaften, Besuche und dem Gabentausch geprägt. So kam Bogislaw X. auf seiner genannten Reise und am Innsbrucker Hof, an dem Bianca Maria Sforza residierte, mit der italienischen Kultur in Kontakt. Der Fürst aus dem Norden nahm aber nicht nur Schätze, Stoffe und Modetrends mit, sondern auch Menschen, wie die Rechtsgelehrten Petrus von Ravenna und Vincentius aus Padua, Vater und Sohn, die in Pommern Römisches Recht lehren sollten. ${ }^{22}$

Bei den verschiedenen Momenten des kulturellen Austauschs zeigt sich immer wieder die Bedeutung des sozialen Netzwerks und der Kommunikationswege von Mitgliedern der Fürstenhöfe, Gesandten und Kaufleuten für die Ausforschung, Erwerbung und Übersendung von Kulturgütern, vor allem jenen aus fremden Ländern. Gerade die weitreichenden Kontakte der Fugger ermöglichten den sammelwütigen Fürsten des i6. Jahrhunderts, Artefakten, Kostümen, Waffen etc. aus den neuen und fremdartigen Gegenden durch direkten Handel habhaft zu werden. ${ }^{223}$ Dabei treten zwei weitere für den Kulturtransfer wichtige Aspekte auf: Einerseits der Informationsstand über Produktion und Verfügbarkeit von Werken und Künstlern in der Fremde und andererseits die Werteinschätzung fremder wie eigener materieller Kulturgüter, nach dem Motto: Wo konnte man eine Rarität erwerben und wie wertvoll war sie, damit man im Gegenzug mit eigenen Produktionen handeln konnte? In diesem Sinn begehrte Kurfürst Friedrich III. von Sachsen ( 1463 - I 525 ) I 507 in einem Brief an Francesco II. Gonzaga eine »schilderey«, ${ }^{224}$ also eine Malerei des großen Andrea Mantegna, wofür er als Ge-

22 I Auge, Reichsverdichtung, I93-I97.

222 Auge, Reichsverdichtung, 204.

223 Paradebeispiele waren die Wittelsbacher und die Habsburger, allen voran Erzherzog Ferdinand II. Die herzogliche Kunstkammer in München erlebte eine erste Hochblüte unter Albrecht V. und Wilhelm V. in der zweiten Hälfte des I6. Jahrhunderts, die beide begeisterte Sammler und Mäzene waren. Der Leibarzt Albrechts V., Samuel Quiccheberg, versuchte dem Sammelsurium an Kuriositäten und Kunstwerken eine methodische Ordnung zu geben. Vgl. Schlosser, Die Kunst- und Wunderkammern, I42-I 50. Über die Fugger erhielt Erzherzog Ferdinand II. auch die vom spanischen König gewährte Pension von 6.00o Talern. Edelmayer, Söldner und Pensionäre, I68. Zu bemerken ist ferner, dass die Fugger und andere in Übersee tätige Handelsfamilien nicht nur Kaufleute, sondern auch selbst Sammler und Auftraggeber von Kunst waren, wie z.B. die Darstellungen in Christoph Weiditzs Trachtenbuch, in dem Hernando Cortés und seine mitgeführten indigenen Amerikaner festgehalten wurden.

224 Hansmann, »Schilderey«, 27 If. 
genleistung ein anderes Kunstwerk nach Mantua schicken wollte. ${ }^{225}$ Der Kurfürst war ein großer Mäzen und Förderer der Hofkunst sowie Auftraggeber zahlreicher Kunstwerke und ließ seine Agenten sowohl im Reich als auch in Italien regelmäßig nach Meisterwerken suchen und diese ankaufen. ${ }^{226}$ Beim Konstanzer Reichstag 1507 hatte er über einen Diener des Markgrafen von Mantua von der herausragenden künstlerischen Leistung Mantegnas erfahren, von dem er sich nun ein Werk erbat. Hier zeigt sich nicht nur die Funktion von Gesandten, Agenten, Sekretären etc. als Vermittler und Informanten im Kulturtransferprozess, sondern auch die kulturelle Bedeutung von politisch motivierten Zusammenkünften wie dem Reich- oder Kreistag. ${ }^{227}$ Hier kam es nämlich nicht nur zum (Informations-)Austausch unter den Fürsten bzw. ihren Vertretern, sondern es kamen auch zahlreiche Künstler, Handwerker und Kaufleute zum Austragungsort dieser Reichszusammenkunft, die hier mit großen Verdienstmöglichkeiten rechneten. In diesem Sinn hat Leeb den Reichstag als einen »Ort der interkulturellen Begegnung und Wechselbeziehung im Sinne des Kulturtransfers, als Institution der Kulturvermittlung ${ }^{228}$ definiert. Hansmann hat am oben genannten Beispiel des sächsischen Kurfürsten auch die »persönliche Note« des eigenhändigen Schreibens im Rahmen des Austauschprozesses betont, das der Anfrage Bedeutung und Nachdruck verleihen sollte. Dieses Beispiel des Erwerbs von italienischen Werken von Seiten des wettinischen Fürstenhauses belegt den bestehenden Kontakt und die kulturellen und z.T. auch persönlichen Beziehungen zu Italien und zu den oberitalienischen Fürstenhäusern. Die Rezeption der italienischen Vorbilder und ihre »Verarbeitung « in der eigenen Kunstpatronage ${ }^{229}$ sind auch am Beispiel der Entwicklung und Veränderung des »Konzept[s] eines ästhetischen Profils nach italienischem Vorbild« bei den wettinischen Fürstenporträts erkennbar; demnach wird klar, warum Friedrich der Weise selbstbewusst den Mantuaner Fürsten ein »entsprechendes«, also ebenso wertvolles Gegenstück aus seinem Land anbieten konnte. ${ }^{230}$

225 Mantegna kam 4459 von Padua nach Mantua, arbeitete u.a. an der Camera degli Sposi im Palazzo Ducale und blieb bis zu seinem Tod 1506 im Dienst der Gonzaga. Zu seinen in Mantua geschaffenen Werken siehe überblicksmäßig: Lucco, Mantegna a Mantova. Nach Marx kam er auch nach Ferrara, Bologna, Piemont. Barbara MARX, Italianità, I 2.

226 Hansmann, "Schilderey«, 272.

227 Bedeutend ist der Aufenthalt Tizians in Augsburg während der Reichstage von I 548 und I 550/I, an denen der Kaiser persönlich teilnahm und sich mit dem Künstler traf. Hier entstand eine freundschaftliche Beziehung, die sich auch in einer Pension für den Künstler ausdrückte, obwohl er nicht umgestimmt werden konnte, am Kaiserhof zu dienen. Roeck, Kulturtransfer zwischen Bayern und Italien, 32. Ausführlicher zu den in Augsburg entstandenen Werken: Schweiknart, Tizian in Augsburg. Zu den besonderen vom Kaiser verliehenen Ehren Tizians siehe auch bei Kohler, Karl V., Kap. »Karl V. und die Künstler«, I I I - I r6.

228 LeEb, Stereotype, I 77.

229 Zahlreiche frühe Beispiele zur Rezeption der italienischen Renaissance - in ihren verschiedenen Facetten - in den österreichischen Erbländern sind in: STRNAD, Die Rezeption der italienischen Renaissance.

230 Hansmann, »Schilderey«, 297. 


\subsubsection{Musik als Import- und Exportgut in Ferrara}

Der Beginn eines konsistenten musikalischen (Kultur)Transfers zwischen dem Norden und dem Süden Europas ist nach Martin Staehlin ziemlich genau mit I 400 festzumachen, als der Lütticher Komponist Johannes Ciconia zum zweiten Mal nach Italien reiste und den Auftakt für eine bemerkenswerte und stetige Migration von Musikern aus dem heutigen Nordfrankreich, Belgien und Holland an die Hof- und Kirchenkapellen Italiens und darunter auch Ferraras gab. Diese Komponisten und Musiker für weltliche wie geistliche Musik, zu denen unter den Bedeutendsten Gilles Binchois, Jacob Obrecht, Josquin des Prez/Prés, Adrian Willaert, Ciprian[o] de Rore etc. gehörten, füllten das Vakuum komponierender Italiener bis zum Beginn des I6. Jahrhunderts und prägten den Geschmack der Hofmusik, die sich immer mehr $\mathrm{zu}$ volkssprachlichen weltlichen Liedern wie der Frottola ${ }^{231}$ oder dem Madrigale ${ }^{232}$ bekannte. Bis auf die Ausnahme des tirolischen Grenzgebietes blieb das Reich von diesen Musikentwicklungen in der frühen Phase unberührt. Erst Kaiser Maximilian I. holte mit Heinrich Isaac (auch Isaak) ${ }^{233}$ einen Niederländer von europäischem Rang in seine Hofkapelle. ${ }^{234}$ Während es in Italien dank dieses regen Austausches eine reiche Produktion gab, spricht Staehelin von »eine[r] gewisse[n] Rückständigkeit und Armut Deutschlands in der Hervorbringung eigener mehrstimmiger Musik«. Dies sei auch der Grund, warum das Reich dementsprechend begeistert auf die musikalische Produktion aus Italien zurückgriff und sich von dieser inspirieren ließ. Staehelin hält fest, dass es sich hierbei - trotz einer mäßigen deutschen Eigenproduktion - um eine »kulturelle Einbahn« handelte, denn deutsche Kompositionen strahlten kaum auf Italien aus. ${ }^{235}$

War Ferrara vor dem Beginn des I 5. Jahrhunderts, anders als Verona, Padua oder Florenz, kein Zentrum der Musik gewesen, so änderte sich das spätestens mit Nicolò III. und der Ankunft des Humanisten Guarino da Verona, der den Fürstensohn Leonello unterrichten sollte. Dank seiner humanistischen Erziehung sollte Letzterer als neuer Fürst eine eigene Hofkappelle haben, die er mit Musikbüchern, Instrumen-

23 I Vgl. Meine, Die Frottola.

232 Das Madrigal war ursprünglich eine Gedichtform, die vertont wurde und sich zur Gattung der in erster Linie italienischen und zumeist weltlichen Vokalmusik entwickelte. Vgl. Markus Grass L, »Madrigal«, in: Oesterreichisches Musiklexikon online, http://www.musiklexikon.ac.at/ml/musik_M/Madrigal. xml, Zugriff: $3 \cdot 7 \cdot 2020$.

233 Heinrich Isaac (um I 450- I 5 I 7) war ein franko-flämischer Komponist und Sänger. Dazu siehe: Martin Just, »Isaac, Heinrich«, in: NDB ı。, Berlin I974, I 84.

234 Vgl. auch Krones, Die Geschichte der Wiener Hofmusikkapelle.

235 Staehelin, Musikgeschichtliche Beziehungen, i78-i8 I und i 87. So war im i6. Jahrhundert auch S. Maria dell'Anima als eine der bedeutendsten Nationalkirchen Roms bestrebt, den anderen Kirchen in nichts nachzustehen und eine eigene Musikkapelle einzurichten. Vgl. auch Heyınk, Fest und Musik, 286. 
ten und vor allem Musikern aus Frankreich und den Niederlanden ausstatten ließ. Mit Leonello verdichteten sich das Bedürfnis und die politische Notwendigkeit, das kulturelle Prestige Ferraras und des Fürsten durch die Qualität des Musiklebens zu steigern. Parallel zu der im liturgischen Bereich angewandten Musik entwickelten sich auch die profane und vor allem die instrumentale Tanz- und Unterhaltungsmusik am Hof. ${ }^{236}$ Mit Borso wandelte sich der Geschmack weiter von der polyphonen zur Instrumentalmusik und vor allem zum musikalisch begleiteten Gesang. I456 waren vierzehn Musiker in Borsos Diensten, darunter ein einziger Sänger mit Namen Nicolò Tedesco. Der Este war nicht bereit, die von ihm angestellten Musiker zu verleihen, auch wenn sich diese Praxis als politisches Mittel schon bald verfestigen sollte. Als ihn Galeazzo Maria Sforza ${ }_{4} 65$ um seine Pifferi (Pfeifer) bat, schlug er dessen Bitte mit der Begründung ab, dass er sie nicht entbehren könne, ohne dass seine Ehre und die seines Landes darunter litten. ${ }^{237}$

Der nachfolgende Ercole I. war allgemein ein hervorragender Mäzen und ein übermäßiger Musikliebhaber und -förderer. Für ihn eignete sich diese Kunstform vor allen für religiöse Zwecke und für die Glorifizierung von Fürst und Fürstentum. Stets darauf bedacht, die Position Ferraras im italienischen und europäischen Mächtegleichgewicht zu stärken, näherte er sich zunehmend Frankreich. Seine Verbindungen zum französischen Hof intensivierte er durch Gesandtschaften, aber auch durch kulturellen und insbesondere musikalischen Austausch. Er gründete eine neue Hofkappelle, stattete diese mit eigens in Auftrag gegebenen Manuskripten aus und suchte außerhalb seines Fürstentums nach Musikern und Sängern. Mit der ersten Anwerbung schnappte er seinem Rivalen, Galeazzo Maria Sforza, selbst auch auf der Suche nach Virtuosen für die eigene Hofkappelle, den Komponisten Johannes Martini vor der Nase weg. I 472 zählten I 5 Musiker aus den maßgeblichen Rekrutierungsgebieten Frankreich, Niederlande und Italien zu Ercoles Hofkappelle. ${ }^{238}$ Andere Virtuosen, wie Guillaume Dufay, Johannes Ockeghem und Josquin des Prés standen dem Fürsten aus der Ferne zu Diensten und schrieben Musik für ihn, die sie nach Ferrara schickten. ${ }^{239}$

Ercole I. ließ immer wieder seine Agenten und Gesandten jenseits der Alpen nach guten Sängern und Musikern suchen und Musikstücke kopieren. Es war wichtig, vor allem die musikalischen Errungenschaften der anderen Höfe im Auge zu behalten und notfalls Musiker abzuwerben. Für ein so kleines Fürstentum wie Ferrara war es lebensnotwendig, sich im kulturellen Bereich auf einem hohen Niveau zu positionieren und international wahrgenommen zu werden. Nachdem sich der estensische Hof unter Ercole I. einen Namen gemacht hatte, war es nicht mehr schwierig, Musiker nach Ferrara zu holen. Sie für längere Zeit dort zu behalten, war jedoch ein heraus-

236 Lоcкwood, Musica a corte, 314-316.

237 Burke, Die Renaissance in Italien, I 26.

238 Dazu siehe auch: Fiala, Les musiciens italiens.

239 Lookwood, Musica a corte, 3 I 9 f. Siehe auch: Sefan Kunze, Höfische Musik, 72 - 74. 
forderndes Unterfangen, wie das Beispiel von Jacob Obrecht zeigt, den Ercole I 487 an seinem Hof einlud, ohne ihn aber zum längeren Bleiben überreden zu können. Wo Sänger und Musiker nicht auf Dauer verpflichtet werden konnten, wurden sie unter Fürsten zumindest »ausgeliehen « oder gegen andere ausgetauscht. Diese Usance blieb das gesamte r6. Jahrhundert bestehen, wie das Beispiel des ebenso musikbegeisterten Ercole II. zeigt, der sich durch seinen Gesandten, Gregorio Rorario, zwei Kantoren vom Herzog von Savoyen borgen ließ. ${ }^{240}$

Natürlich spielte auch die Finanzkapazität eines Fürsten eine große Rolle bei der Anwerbung von berühmten Musikern. Deshalb bat Ercole I. den Papst um das Privileg, selbst kirchliche Pfründen vergeben zu können, um so einen finanziellen Anreiz für die Musiker am Hof (die Hälfte davon immer noch Franzosen) zu haben; doch die päpstliche Bürokratie ermöglichte diese zusätzliche Finanzquelle nur widerwillig und eingeschränkt. ${ }^{241}$

Nicht nur die erwartete Besoldung eines Künstlers oder Musikers war ausschlaggebend für seine Anwerbung, sondern auch seine Dienstbarkeit und seine "Arbeitsmoral«. Der von Maximilian I. engagierte Heinrich Isaac wurde um I 500 auch von Ercole I. angeworben, nachdem sein Agent die Vorzüge desselben gegen den berühmteren Josquin des Prés abgewogen hatte. Wenn des Prés auch der bessere und berühmtere Komponist zu sein schien, so sei nach Meinung des herzoglichen Beauftragten, Isaac fleißiger und verlässlicher, während der Andere nur arbeite, wenn ihm danach zumute sei. Diese - größtenteils auf Gerüchten basierende - Einschätzung gab schließlich den Ausschlag für Isaacs Anstellung. ${ }^{242}$

Musik wurde auch von Fürsten und Fürstinnen persönlich zur Erbauung und Erholung von der Regierungsarbeit gepflegt. Alle sechs Kinder Ercoles I. d'Este, allen voran die berühmte Isabella d'Este ${ }^{243}$, wurden musikalisch ausgebildet und förderten dann selbst diese Kunst, so auch der jüngere Sohn Sigismondo, der aufgrund einer venerischen Krankheit im Palazzo Schifanoia eingeschlossen war und sich ausschließlich der Musik widmen konnte. Dabei pflegten Ercoles Kinder zunehmend neue Musikgenres, wie die italienische Frottola, und vermehrten weiterhin die Familiensammlung an In-

240 ASMo, ASE, Casa e Stato, Carteggio di Ambasciatori, Germania b I7, Minute di dispacci per la Germania an Gregorio Rorario, Dezember 1555 .

24I Lookwood, Musica a corte, 32 If.

242 Burke, Die Renaissance in Italien, 82 $\mathrm{f}$ und 107. Verzögerungen in der Abgabe von Auftragswerken waren ein leidiges Thema bei den Fürsten und nicht anders bei den Este. Als Tizian für Alfonso I. d'Este ein Auftragswerk nicht rechtzeitig fertigstellte, drohte der Fürst mit seinem Zorn, den sich der Künstler zuziehen würde, wenn das Werk nicht schnellstens fertiggestellt werden würde. Dazu siehe Cavalcaselle/Crowe, Tizian, I43-I55. Viele Werke Isaacs wie auch Ockeghems und anderer in Italien bekannter Musiker und Komponisten finden sich in den Chanson-Büchern Margaretes von Österreich, der Tochter Kaiser Maximilians I. Koldau, Familiennetzwerke, 6r.

243 Bevor Isabella d'Este nach Mantua kam, gab es am Gonzaga-Hof ein eher bescheidenes Musikleben, was sich nach I 490 besonders durch diese neue Fürstin, ihre Liebe zur Musik aber auch ihre Geltungssucht eindeutig änderte. Fenlon, Gender and Generation, 2 I 6. 
strumenten und Partituren. ${ }^{244}$ Die eingeheirateten Fürstinnen Lucrezia Borgia und Isabella d'Este waren jeweils in Ferrara und Mantua die wichtigsten Fördererinnen dieser Renaissancemusik, die sie nicht nur genossen, sondern auch mitzugestalten versuchten. Bartolomeo Tromboncino, der zuerst im Dienst von Isabella stand und dann an den Hof von Lucrezia kam, galt als eine der Hauptfiguren unter den Hofmusikern. Er war der einzige Frottolist außerhalb Roms und Neapels, der für Lucrezia Werke mit spanischen Texten verfasste. Auch in der Musik wie bei Kleidung, Bücherbesitz, Hofpersonal und im Alltag brachte Lucrezia Borgia spanische Kultureinflüsse nach Ferrara. Aus Rom kamen auch spanische Hofnarren ${ }^{245}$ in ihrer Entourage nach Ferrara mit. Für Weihnachten I 506 ließ sie dem spanischen Sänger Sanazar Spagnolo 25 lire für seine musikalische Darbietung auszahlen. ${ }^{246}$

Nicht nur die herrschenden Fürsten selbst, sondern auch deren Geschwister und Ehefrauen engagierten eigene Musiker, kauften Instrumente und Musiktexte und erhöhten so das musikalische Prestige des estensischen Hofes. ${ }^{247}$ Selbst die geistlich votierten Zweitgeborenen der Este, die Kardinäle Ippolito I., Ippolito II. und Luigi d'Este pflegten in ihren Residenzen die Musik außerordentlich. ${ }^{248}$ Kardinal Ippolito I. holte z.B. Pierre Regnac, genannt Sandrin, aus der königlichen Kapelle in Frankreich als Hofkapellmeister an seinen Hof. ${ }^{249}$ Lewis Lockwood hat anhand der Rechnungsbücher des Geistlichen feststellen können, dass dieser den Flamen Adrian Willaert als Musiker bereits im Juli I 5 I 5 in seine Dienste nahm. Der Virtuose reiste mit dem Este nach Ungarn, dann wieder zurück nach Ferrara und trat nach dem Tod seines Dienstgebers in die Hofkappelle Alfonsos I. d'Este ein, obgleich dieser aus finanziellen Gründen die Zahl der Musiker reduzieren musste. ${ }^{250}$

Am Anfang des r6. Jahrhunderts intensivierte sich der bereits vorhandene ultramontane Einfluss nicht nur durch den weiteren Austausch und die Anstellung von französischen und flämischen Musikern und Komponisten, sondern auch durch die Verbreitung der Chansons in Ferrara. Die Tatsache, dass Ferrara unter der französischen Königstocher Renée de France ein Zufluchtsort für religiöse Flüchtlinge wurde, darunter auch viele Künstler, verstärkte diesen kulturellen Austausch nur noch mehr. ${ }^{251}$

244 Lookwood, Musica a corte, $326-328$.

245 Über die Funktion von spanischen Hofnarren als Agenten in Italien siehe Kubersky-Piredda/ Salort Pons, Ein Hofnarr als Agent.

246 Prizer, Isabella d'Este, 2 2f; Meine, Hofmusik als Herrschaftsraum.

247 FabBri, Una capitale in musica, 340. Ders., Les Este et la musique.

248 Vgl. zu Ippolito II: Cogotti/Fiore, Ippolito II d'Este.

249 FAвв в , Una capitale in musica, 356f. Zu diesen Musikmäzenen und dem Austausch von Musikern mit dem Fürstbischof von Trient bzw. seiner Vermittlung von Virtuosen nach Dresden an den Hof von Moritz von Sachsen siehe auch: Lunelli, Contributi trentini.

250 Wie Ippolito d'Este zu Willaert gekommen war, kann Lockwood nur mutmaßen. Wahrscheinlich wurde ihm dieser im Zuge seiner engen Beziehungen zu Frankreich von Musikern aus der königlichen Hofkappelle, allen voran Jean Mouton, empfohlen. Lockwood, Adrian Willaert, $87 f$.

25 I Vgl. auch die Überlegungen dazu bei Asche, Glaubensflüchtlinge und Kulturtransfer. Ferrara war 
Der berühmt-berüchtigte Clément Marot war nicht nur Sekretär der Herzogin von Ferrara, sondern auch Verfasser und Vertreiber von französischen Musiktexten. Auch der folgenträchtige Karfreitagsskandal von I 536 war am ferraresischen Hof von einem französischen Kantor, Jehannet de Bouchefort, verursacht worden, der sich öffentlich weigerte, das Kreuz anzubeten. Selbst durch die Musik fand die sogenannte Rechtsgläubigkeit ihren öffentlichen Ausdruck. Maistre Jhan (= Jean de Maistre) schrieb eine antiprotestantische polyphone Komposition (Te Lutherum damnanus) und Jacquet de Mantua 555 die Missa la fede unque debba esser corrotta. Mit der Niederlassung der Jesuiten in Ferrara I 55 I erhielt die fürstliche Musikkapelle eine weitere Verstärkung. I 549 waren am Hof 16 Kantoren, von denen die meisten von jenseits der Alpen kamen, ein Organist (Jaches Brumel) und elf Instrumentenspieler. Die Leitung der Kapelle hatte Cipriano de Rore (I 5 I6- I565) inne, der sich seit I545 in Ferrara aufhielt und die Madrigalkunst verfeinerte. Dieser komponierte u.a. die Missa Vivat felix Hercules secundus, dux Ferrariae quartus, vivit et vivit, auch unter dem Namen Missa Praeter rerum seriem bekannt, ${ }^{252}$ die als Geschenk an den Herzog Albrecht V. von Bayern geschickt wurde, nachdem dieser I 557 eindringlich von Ercole II. d'Este »schöne Melodien des Kapellmeisters Cyprianus für die Messe« erbeten hatte. ${ }^{253}$

Ercoles II. französische Ehefrau, Renée de France, hatte u.a. für den Musikunterricht der Fürstenkinder bald nach ihrer Ankunft am estensischen Hof den Instrumentalisten Jean Milleville aus Frankreich geholt, der mit seinem neun Jahre alten Sohn Alessandro anreiste, welcher später auch als Instrumentalist unter ihrem Sohn Alfonso II. bis zu seinem Tod I 589 tätig war. Man kann in diesem Fall sicher von einem generationsübergreifenden Kulturaustausch sprechen. ${ }^{254}$

Die Hofkapelle Alfonsos II., von welcher sogar der kritische florentinische Gesandte Orazio della Rena beeindruckt war, ${ }^{255}$ bestand trotz der Affinität dieses Fürs-

schon immer ein Anziehungsort für die flämische Kunst und Kultur gewesen. Dies drückte sich in den Beziehungen zum burgundischen Hof, in der Nachahmung der Ritterromane, in denen die Este die Ursprünge ihres Geschlechtes suchten, in der Sammlung von französischen Manuskripten und Drucken und im Austausch von Künstlern wie Rogier van der Weyden aus. Limentani Virdis, La corte estense. Von Rogier van der Weyden ist auch das Porträt eines Mannes am burgundischen Hof mit einem Spielhammer in der Hand als Zeichen seiner Schiedsrichtertätigkeit beim Turnier, das mit ziemlicher Sicherheit Francesco d'Este, den illegitimen Sohn von Leonello, der sich von I444 bis i 475 am burgundischen Hof aufhielt, darstellt. Vgl. Armstrong, Das goldene Zeitalter, $72-74$ mit Abbildung des Porträts.

252 FAB BRI, Una capitale in musica, 345 f.

253 ASMo, ASE, Casa e Stato, Carteggio di principi esteri, Germania b I 593/r 9, Albrecht von Bayern an Ercole II., April I 557 .

254 Jensen, Music at Ferrara, 33 I.

255 »di musica e dell'armonia di musicali strumenti grandemente vi consuma gran parte di tempo, e se ben non ne fa professione oltre all'essere intelligentissimo ha nella sue Corte fra diversi professori di questa virtù fin a quattro, o cinque Dame, che cantano benissimo, et suonano alcuni varj instrumenti eccellentissimamente.« Della Rena, Relazione, 79. 
ten zum französischen Hof mehrheitlich aus Italienern, Spaniern und Flamen. Auch der erste Organist, Jaches Brumel, wurde vom Italiener Luzzasco Luzzaschi abgelöst. Ebenso ging der Titel des Hofkapellmeisters zum ersten Mal nicht an einen Ultramontanen, sondern an Francesco della Viola. Hier lässt sich für die zweite Hälfte des r6. Jahrhunderts eine eindeutige Kehrtwendung zu heimischen Künstlern im Musikbereich erkennen. ${ }^{256}$

Ein weiterer neuer Trend an den Fürstenhöfen war die sogenannte Kammermusik, Unterhaltungsmusik für den Fürsten, seine Familie und wenige Auserlesene meist als Begleitung während der Mahlzeiten oder Abendveranstaltungen im engen Kreis. Hierbei handelte es sich vor allem um weiblichen Gesang, der von einem oder mehreren Instrumenten begleitet wurde. Beim Karneval I 583 durften einige florentinische Adelige an einem solchen Privatkonzert teilnehmen mit dem - von Erfolg gekrönten - Hintergedanken Alfonsos, dass sie in höchsten Tönen von der hervorragenden Kunst und dem erlesenen Geschmack des Fürsten nach Hause berichteten. Auch als im Sommer I 57 I die Erzherzöge von Österreich, Ernst und Rudolf auf der Rückreise aus Spanien waren, wurden sie von Alfonso II. sowohl zu einem imposanten Konzert mit sechzig Stimmen und Instrumenten als auch zu einem privaten Konzert mit zwei Sängerinnen eingeladen. ${ }^{257}$

Musikalisch geprägt waren auch die Beziehungen zu Bayern: Herzog Albrecht V. von Bayern schickte I 570 Alfonso II. eine Empfehlung für den Musikus Johannes Baptista Pinelli. ${ }^{258}$ Der am bayerischen Hof tätige Orlando di Lasso, ${ }^{259}$ der ${ }_{5} 85$ mit seinem Musikkollegen Josephus Ascanius auf dem Weg nach Loreto in Ferrara Halt machte und Briefe Herzogs Wilhelm V. von Bayern mitbrachte, ${ }^{260}$ berichtete seinem Herrn von den musikalischen Wunderwerken am estensischen Hof. Doch die Bewunderung oder zumindest die Höflichkeit war gegenseitig, denn Wilhelm von Bayern bedankte sich ${ }_{5} 85$ bei Alfonso, dass er seinen Musiker Orlando di Lasso so gelobt habe und empfahl ihm im Jahr darauf - so als wolle er einem möglichen Abwerben vorgreifen - Antonius Murarius und I 59 I Johannes Fridunaldus, ${ }^{261}$ nachdem

256 FABBRI, Una capitale in musica, 350.

257 Fавв Ri, Una capitale in musica, 353 f. Diese Sängerinnen hatte auch Orlando di Lasso während seines Aufenthalts in Ferrara bewundert. LAzzari, Le ultime tre duchesse, 276. Ebenso begeistert schien I 58 I Dr. Andreas Paul, sächsischer Gesandter, der sie am estensischen Hof singen gehört hatte. Dennoch dauerte es fast Ioo Jahre, bis am wettinischen Hof eine Sängerin engagiert wurde. MARX, Italianità, 22.

258 ASMo, ASE, Casa e Stato, Carteggio di principi esteri, Germania b I593/r 9, Albert von Bayern an Alfonso II., Juni I 570 .

259 Dazu unten mehr sowie Hesl, Orlando di Lasso; siehe auch in der Auflistung der Widmungsempfänger die Nennung von Alfonso II. für das Werk Libro quarto de magrigali a 5 voci 1567 mit Widmung vom 3 I. Mai I 567 , ebd. I 8 I.

260 München, BayHStA, Kurbayern_Äusseres_Archivo ı6, Alfonso II. an Herzog von Bayern, Oktober I 585 .

26 I ASMo, ASE, Casa e Stato, Carteggio di principi esteri, Germania b I 593/r 9, Wilhelm V. von Bayern an Alfonso II., Dezember I 585 , August I 586 und Mai I 59 I. 
er selbst Dutzende italienische Sänger, Instrumentalisten und Schauspieler engagiert hatte. ${ }^{262}$

Nicht nur in der Musik, sondern auch im Tanz waren die italienischen Fürstenhöfe "Vorbild[er] in [...] Langzeitperspektive «; ${ }^{263}$ der Austausch mit dem Reich war durch Musiker und Tanzmeister, die sich in Italien zur "Ausbildung" aufhielten, wie ein gewisser Pfeifer Marco, der I 490 nach Ferrara zu Michele Tedesco geschickt wurde, um bei diesem Unterricht zu nehmen, bemerkenswert. ${ }^{264}$

Bezüglich ihrer Liebe zur Musik waren der letzte Herzog von Ferrara, Alfonso II., und Kaiser Maximilian II. in einem besonderen Maß seelenverwandt. Anders als sein Vater und Vorgänger pflegte und liebte Kaiser Maximilian II. die Musik und setzte sie gezielt zur politischen Repräsentation ein. Seine Hofkapelle gehörte zu den größten Europas; er ließ vor allem in Italien nach Virtuosen suchen und auch Musikerinnen anheuern. ${ }^{265}$ Viele Briefe, z.B. von und an Stefano Rossetto, ein in mediceischen Diensten stehender Musiker und Komponist, der für Maximilian als Agent in Italien tätig war, handeln von Anstellungsmöglichkeiten und der Weitergabe von Musikern, so z.B. bezüglich des Trompeters Luigi Zanobbio, der sich in den I 58 oer Jahren auch in Ferrara aufhielt. ${ }^{266}$ I 568 empfahl Maximilian II. Alfonso II. den Trompeter Giovanni Francesco Rizzo, der dem Erzherzog und nun Kaiser fast 20 Jahre lang zufriedenstellend gedient hatte. ${ }^{267}$

Unter Kaiser Rudolf II. wurde die Hofkapelle noch weiter »italienisiert « und mit Werken und Virtuosen aus Italien bereichert. ${ }^{268}$ So wie die Musik und die beeindruckende Kunstkammer den Kaiser der Jahrhundertwende unvergessen machten, verdankten die Este ihren ungebrochenen Ruf als große Mäzene auch im neuen, bescheideneren Machtzentrum Modena, ihrer Leidenschaft für Kunst und Musik. ${ }^{269}$

\subsubsection{Bücher und Gelehrtenwissen in Bewegung}

Durch die Weiterentwicklung der Drucktechnik mit beweglichen Lettern und die Etablierung von Verlagszentren wurde das Buch eines der bedeutendsten Medien des Wissens- und Kulturtransfers der Frühen Neuzeit. Im Vergleich zu den großen

262 Rоеск, Kulturtransfer zwischen Bayern und Italien, 36. Nach Messmer wurde di Lasso in Ferrara eher kühl aufgenommen und Alfonso II. zeigte sich auch nicht sonderlich begeistert von dem ihm gewidmeten Werk. Messmer, Orlando di Lasso, i 23.

263 Paravicini, Von materieller Attraktion, 28I.

264 Salem, »Alla tedesca«, $209 f$.

265 Vgl. Einstein, Italienische Musik, $3-8$.

266 Lindell, New Findings on Music, 238.

267 Ebd., 24I, Brief 2 I

268 Einstein, Italienische Musik, 5.

269 Zur Musik am Hof von Modena siehe: Chiarelli, Fonti e vita. 
Druckerzentren Venedig, Mailand, Bologna und Florenz konnte Ferrara im ausgehenden I 5. und im I6. Jahrhundert zwar nur eine bescheidenere Produktion vorweisen, stach aber durch die Herstellung von besonderen Werken wie jener von Grafiken dennoch hervor. Es war ein Franzose, Andrea Belforte oder Beaufort, der zu Ercoles I. Herrschaftsantritt I 47 I die Druckkunst nach Ferrara brachte und mit ihr weitere Handwerkskünste wie die Papierproduktion und das Verlagswesen. Eine brauchbare Liste von Bibliotheksbesitzern des I 5. Jahrhunderts zeigt, dass auch in Ferrara - wie nicht anders zu erwarten - Kleriker, Juristen, Mediziner und der Fürstenhof die besten Kunden der Buchhändler waren. ${ }^{270}$

Im zweiten Jahrzehnt des i6. Jahrhunderts war ein bedeutender humanistischer Drucker, Giovanni Mazzocchi da Bondeno, in Ferrara tätig, der die Erfolgschancen des Ritterromans richtig einschätzte und einige davon gewinnbringend druckte, u.a. I 5 I6 auch Ludovico Ariostos L'Orlando furioso. Darüber hinaus machte Mazzocchi dem berühmten Verleger Aldo Manuzio in Venedig Konkurrenz, indem er die von Guarino Veronese kommentierte griechische Grammatik und eine Neuausgabe der Proverbiorum Chiliades von Erasmus von Rotterdam druckte. ${ }^{271}$

An der I39I von Alberto d'Este gegründeten Universität von Ferrara kamen in Zuge der peregrinatio academica viele Studenten aus dem deutschsprachigen Raum, den Niederlanden, Portugal, Spanien, Ungarn, England, Polen ${ }^{272}$ und Frankreich, um hier die Sprache zu erlernen, aber vor allem für das Studium des Lateinischen und - seit Guarino Veronese - des Griechischen; darunter befanden sich nicht nur potenzielle Buchkäufer, sondern auch der spätere flämische Drucker, Humanist und frühe Herausgeber von Werken des Erasmus von Rotterdam, Josse Bade (Jodocus Badius I462-I535). Bereits Mitte des I5. Jahrhunderts war Ferrara - auch aufgrund der hier Lehrenden - zu einem von zahlreichen Studierenden von jenseits der Alpen besuchten und renommierten Studienzentrum ${ }^{273}$ geworden. Dieser Trend förderte neben der fürstlichen Nachfrage maßgeblich die Produktion von und den Handel mit Büchern.

270 Zum Vergleich: Im I6. Jahrhundert gab es in Venedig 9I, in Padua 40, in Ferrara 38, in Mailand I 2 I, in Bologna 77 und in Florenz 88 Drucker. Perini, La stampa a Ferrara, 370-373 und Anm. 5. Der Hof scheint bis I $_{5} 62$, als der Mantuaner Valente Panizza das Privileg, als Hofdrucker tätig zu sein, erwirkte, nicht sonderlich an dieser Kunst interessiert gewesen zu sein. Grund war, wie auch anderswo, dass die Adeligen und Wohlhabenden sich eher an kostbaren Manuskripten und illuminierten Werken erfreuten als an günstigeren Drucken. Hof und Fürstenfamilie waren vor allem Abnehmer von teureren Drucken, Liedtexten und Musiknoten. Dazu siehe: Nuovo, Il commercio librario.

27I Perini, La stampa a Ferrara, 374-377.

272 Vgl. die einzelnen Beiträge im Tagungsband Babel/Paravicini, Grand Tour und besonders zu Polen Bömelburg, Adelige Mobilität.

273 Es gehörte aber sicher auch zur kulturellen Überheblichkeit, wenn venezianische Gesandte die Qualität der jüngeren deutschen Universitäten im Vergleich mit Bologna, Padua, Ferrara, Pisa, Siena etc. despektierlich abwerteten. Vgl. bei Zucchi, Deutschland und die Deutschen, 4 Iof. 
Der Austausch von Wissen und Werken bestand nicht nur mit dem Reich, ${ }^{274}$ sondern auch mit Frankreich, besonders gefördert von den Heiratsverbindungen der Este. ${ }^{275}$ Mit Renée de France, Ehefrau von Ercole II. kam auch der französische Drucker Jean Buglhat an den ferraresischen Hof, der als erster Musikbücher druckte. I 549 veröffentlichte er eine Sammlung von Zeremonialen für die höfischen Feste, darunter die Beschreibung des triumphalen Einzugs der Brautleute Ercole und Renée/Renata in Ferrara. Als François I., König von Frankreich, I 547 starb, ließ Bartolomeo Ricci beim Drucker Francesco Rossi in Ferrara die In Francisci Regis Galliae funere Oratio, in der die Taten und das Mäzenatentum des Königs besungen wurden, drucken und nach Frankreich schicken. Mit den Franzosen in der Entourage der neuen Herzogin von Ferrara waren auch viele verbotene, weil sogenannte häretische Bücher mitgereist. Auch wenn solche in Ferrara selbst anscheinend nicht gedruckt wurden, gab es durch den Austausch mit Frankeich genug Material, um den Inquisitor von Bologna zu beauftragen, Ferrara diesbezüglich besonders streng zu überwachen. Renée de France selbst hat wahrscheinlich viele verbotene Bücher besessen, doch ihre Bibliothek wurde im Zuge des Inquisitionsverfahrens gegen sie beschlagnahmt und I6oo verbrannt. Scheint der Herzog von Ferrara einerseits auf politischem - vor allem päpstlichem Druck hin gegen die Anhänger heterodoxer Lehren in seinem Fürstentum und deren Besitz verbotener Bücher vorgegangen zu sein, war er andererseits den wirtschaftlich erfolgreichen Juden gegenüber, auch was die Drucklegung von jüdischen Werken anbelangte, äußerst entgegenkommend und tolerant. ${ }^{276}$

Einen Eindruck über das mögliche Ausmaß des Wissenstransfers von außerhalb Italiens gibt die von Luca D'Ascia untersuchte reichhaltige Bibliothek des ferraresischen Humanisten, Gelehrten und Universitätsdozenten Celio Calcagnini, eine der repräsentativsten Persönlichkeiten der ferraresischen Kultur der ersten Hälfte des I6. Jahrhunderts. D'Ascia hat die Bestände der I.249 Werke umfassenden Bibliothek katalogisiert und einige Erkenntnisse über die Interessen, den Wissensstand und die Bildungsvorstellungen der Zeit gewonnen. Großes Gewicht scheint die Germania docta, die Produktion deutscher Druckerhäuser gehabt zu haben, die mit Einzelwerken wie dem De inventione dialectica ( 5 29) von Rudolf Agricola oder Margarita poetica von Albrecht von Eyb von I472, in der Bibliothek vertreten sind. Anders schaut es mit späteren Werken des I6. Jahrhunderts aus: Hier reicht die Palette von Ziegler bis Camerarius, von Zasius bis zu den Astronomen Stöffler, Ringelberg und Regiomontanus, von Agrippa bis Reuchlin; die Werke deutscher Gelehrter sind unter den letzten Ankäufen Calcagninis stark vertreten, was bemerkenswert ist, da nach Luthers

274 Dazu siehe, wenn auch vorrangig auf das I7. Jahrhundert konzentriert die Beiträge der Sektion 3. Saperi. Praktiken der Wissensproduktion und Räume der Wissenszirkulation zwischen Italien und dem Deutschen Reich im i7. Jahrhundert, in: Brendecke, Praktiken der Frühen Neuzeit; hier vor allem BECKER, Wissenstransfer durch Spionage.

275 Vgl. allgemein Bepler, Women's Books.

276 Perini, La stampa a Ferrara, $380-382$. 
Bruch mit der Römischen Katholischen Kirche alles, was aus dem Reich kam oder deutschsprachig war, oft a priori verboten und konfisziert wurde. Calcagnini hatte zu Beginn mit den Ideen Luthers sympathisiert, um sich bald darauf, von den gewalttätigen Entwicklungen dieser Glaubensrichtung enttäuscht, wieder davon zu distanzieren. Trotzdem hörte er nicht auf, sogenannte häretische Werke zu sammeln. Gut vertreten in seiner Büchersammlung ist Melanchthon mit verschiedenen humanistischen, philosophischen und theologischen Werken; auch besaß er eines der bedeutendsten Werke Zwinglis, De vera et falsa religione, und das Pro christiana religione adversus Lutheranos von Augustinus Steuchus. Doch der am meisten vertretene Ultramontane ist mit 20 Werken Erasmus von Rotterdam, mit dem Calcagnini auch eine rege Korrespondenz pflegte. Auch fehlen die italienischen und spanischen Erasmianer nicht: Jacopo Sadoleto, Gasparo Contarini, Niccolò Leonico Tomeo, Andrea Alciati, Marino Becichemo, Aonio Paleario, Girolamo Savonarola und Juan Luis Vives. ${ }^{277}$

Neben dieser beachtenswerten Anzahl von Schriften deutscher - auch reformierter - Autoren, sammelte Calcagnini auch antike und neuere Literatur über Aberglauben (Sallust, Livius, Plutarch, aber auch Pomponazzi) und über Astronomie. Von Machiavelli besaß er die Discorsi und die Istorie fiorentine. Allgemein zeugt seine Bibliothek von einer großen Offenheit und den - zwar nicht uneingeschränkten - aber breiten Möglichkeiten des Austausches des Ferraresen mit den großen ultramontanen Verlags- und Druckerzentren Lyon und Basel. ${ }^{278}$

Mit dem oben genannten bayerischen Gelehrten Jakob Ziegler ${ }^{279}$ und Calcagnini hatte auch Giovanni Manardo, der Leibarzt von Alfonso I. d'Este und Universitätsprofessor in Ferrara, einen lebhaften Gelehrtenaustausch. Manardo schrieb sein berühmtestes Werk, die Epistolae medicinales, in Buda, wo er als Leibarzt von König Wladislaw von Ungarn tätig war und wo er Ziegler kennengelernt hatte. In Ungarn lernte Ziegler auch Celio Calcagnini kennen, der I 5 I 7 dort im Gefolge des Kardinals Ippolito d'Este auf dem Weg zu dessen Diözese, Eger, war. Calcagnini führte den Bayern in den Kreis um den Kardinal ein, der ihn wiederum Papst Leo X. empfahl. So kam Ziegler nach Rom, wo er Zugang zu wichtigen geografischen Werken hatte. Auch wenn er gegen Ende seines Lebens mit den reformierten Ideen sympathisierte und im Verdacht der Heterodoxie stand, blieb er mit den Ferraresen in Kontakt und besuchte I 525 und I53 I Ferrara. Sein Kommentar zum zweiten Buch des Plinius ist mit einem Vorwort von Calcagnini versehen und ist Alfonso Trotti, dem Finanzverwalter von Alfonso I. d'Este gewidmet, der den Druck finanziert hatte, während seine I 532 veröffentlichte Beschreibung von Palästina an Herzogin Renée de France gerichtet ist. ${ }^{280}$

\footnotetext{
277 D'Ascia, La biblioteca, 398f.

278 Ebd., 40I-403.

279 Vgl. Walther Kılly, »Ziegler, Jakob«, in: Deutsche Biographische Enzyklopädie ıo, München I 999, 654 .

280 Donattini, Cultura geografica, 420 .
} 
Wie nicht zuletzt Calcagninis Bücherbesitz beweist, gab es in Ferrara eine besondere Aufmerksamkeit für Ptolomäus und andere mathematisch-astronomische Werke, von denen viele aus dem deutschsprachigen Raum kamen. Der in Florenz sesshafte Benediktinermönch Nicolò Germanus (oder Tedesco oder Donis) war einer der fleißigsten Verfasser und Kopierer von ptolemäischen Schriften und einer der bekanntesten Kartografen der zweiten Hälfte des I 5. Jahrhunderts. Er widmete die Cosmografia de Ptolomeo I 466 Borso d'Este und erhielt dafür eine reiche Belohnung. War die Hoffnung auf eine angemessene Entschädigung sicher ausschlaggebend für seine Arbeit gewesen, so führte er in der Widmung auch an, dass er hoffte, Borso würde - im Sinne eines Wissenstransfers - sein Werk am Hof zeigen und es verbessern lassen, was auch tatsächlich durch die Hofgelehrten Bianchini und Avogaro geschah. ${ }^{281}$

Die Este drückten ihren Wissens- und Prestigedurst durch ein ausgeprägtes Interesse für die Transkribierung von Ptolemäischen Karten, des Mappamondo Catalano und der Carta del Catino aus, eine der ersten, zehn Jahre nach der Entdeckung durch Kolumbus angefertigten Darstellungen des amerikanischen Kontinents. Es war vor allem Ercole I. d'Este, der ein großes Interesse an der Neuen Welt hatte. Obwohl die italienischen Staaten zu klein und unbedeutend waren, um mit den großen Seenationen neue Welten zu entdecken, wollten die Este stets über die Entdeckungen und ihre wirtschaftlichen Vorteile anhand geschriebener und kartografischer Berichte, wie jene von Alberto $\mathrm{Ca}[\mathrm{n}]$ tino an den Herzog von Ferrara, informiert sein. ${ }^{282}$ Doch die kartografischen Fertigkeiten hatten auch einen hauseigenen Nutzen: Das kartografische Interesse und Können kam besonders der Darstellung der heterogenen Stati estensi und den Trockenlegungsmaßnahmen bzw. den Maßnahmen zur Regulierung der Wasserwege zugute. ${ }^{283}$

Wie andere Fürsten auch sammelten die humanistisch gebildeten Este-Fürsten und -Fürstinnen Karten, Manuskripte und Drucke meist in kostbaren Fassungen und Illustrationen, um die estensische Bibliothek zu bereichern, die der Romanist Giulio Bertoni auf der Basis von Bücherinventaren untersucht hat. Auch wenn es schon zu Beginn der Regentschaft der Este vereinzelten Bücherbesitz gab, so begann die dezidierte Sammlung und Erstellung einer privaten Bibliothek im Castello erst im I 5 . Jahrhundert unter dem Einfluss des Humanismus. Den Beginn machte Nicolò III. d'Este, der nicht nur

28 I Ebd., 432-435.

282 So war eine der ersten Meldungen über das Eintreffen der spanischen Schiffe mit Edelmetallen aus der Neuen Welt in einer handschriftlichen Neuen Zeitung am 23. Juni I 496 von Mailand Richtung Ferrara losgeschickt worden, wo sie am 2. August eintraf. Unter den von Renate Pieper anhand dieser Nachricht untersuchten Informationszentren ist Ferrara als Empfänger verzeichnet. I 50 I reiste $\mathrm{Ca}[\mathrm{n}]$ tino selbst nach Oran in Nordafrika, von wo aus er den Herzog von Ferrara über die Edelmetallschöpfung aus den Antillen berichtete. Pie PER, Informationszentren, $55 \mathrm{f}$.

283 Dazu siehe Federzoni, Gli Stati di Casa d'Este, 45 If. Zu den Gründen für die kartografische Darstellung des Fürstentums, darunter die hydrografische Erfassung des Gebietes siehe auch kurz: Gaмві, Stato degli studi. 
Dichter an seinen Hof rief, sondern auch gezielt nach edel verzierten Manuskripten und Codizes suchen ließ. Er ließ auch ein erstes Inventar seines Bücherbesitzes anlegen. ${ }^{284}$ Trotz der Vorliebe der Este für mit reichen Miniaturen versehene Handschriften bereicherten ab den ersten Regierungsjahren Ercoles I. auch Druckwerke die estensische Bibliothek. Noch mehr Engagement zeigte diesbezüglich der letzte Herzog von Ferrara, Alfonso II., der mithilfe seines Bibliothekars und Archivars, Pellegrino Prisciani, versuchte, die Bibliothek mit allen bis dato hervorgebrachten Druckwerken $\mathrm{zu}$ vervollständigen. ${ }^{285}$ Alfonso II. muss von den Büchersammlungen von Henri II. von Frankreich, die er während seines Aufenthalts kennenlernte, beeindruckt gewesen sein, sodass er bald nach Herrschaftsantritt die eigene Hofbibliothek ${ }^{286}$ in Ferrara vervollständigen ließ. Er beauftragte Girolamo Falletti vor allem am venezianischen Markt kostbare griechische und lateinische Codizes, u.a. auch aus der aufgelassenen und verstreuten Bibliothek von Matthias Corvinus, zu erwerben. I 57 I - 72 veranlasste Alfonso II. den Kauf der berühmten Kunst-, Bücher- und archäologischen Sammlungen von Alberto und Rodolfo Pio aus Carpi, die das Interesse von Gelehrten aus ganz Europa weckte. ${ }^{287}$ Aus der stets wachsenden estensischen Bibliothek wurden Manuskripte, Codices und Drucke an die Höflinge, an Gelehrte und innerhalb der Familie an die Fürstenkinder zu Studienzwecken verliehen. Über die Leihe wurde zwar genau Buch geführt, doch verhinderte dies nicht den Verlust von einzelnen Werken. So ließ Borso I 467 "seinen Plinius« am Hof suchen. ${ }^{288}$

Bereits ab dem I 4. Jahrhundert waren französische Werke aus der Gattung der Heldenepen nach Ferrara gekommen. Mit Eleonora von Aragón und später mit Lucrezia Borgia erhöhte sich - wie Inventare zeigen ${ }^{289}$ - der Anteil von ausländischen, in diesem Fall spanischen Handschriften und Drucken. ${ }^{290}$ Beide Este-Fürstinnen gelten im Bereich der Buchkunst, wie auch in anderen Bereichen, als Kulturvermittlerinnen: Eleonora wuchs in einem kosmopolitischen und mehrsprachigen Kulturkreis mit Vorrang für Katalanisch und Kastilisch auf. Die aragonesische Buchtradition war von Luxusausgaben, edlen Buchbindungen und vor allem von liturgischen Texten geprägt. ${ }^{291}$ Mit Eleonora von Aragón begann eine von Lucrezia Borgia weitergeführte kulturelle Verbindung der ferraresischen und neapolitanischen/spanischen Kultur, die sich auch

284 Bertoni, La biblioteca estense, 2, 6f.

285 Ebd., 3 I.

$286 \mathrm{Zu}$ den bedeutendsten in Ferrara aufbewahrten Miniaturen gehört das Missale von Ippolito d'Este so wie jenes von Anna Sforza, der ersten Ehefrau von Alfonso I. Bertoni, La biblioteca estense, 46.

287 Ricci, Il libro e il monumento, 265.

288 Bertoni, La biblioteca estense, 57.

289 Das Inventar der Bücher von Eleonora führte I 493 insg. 74 Bücher an, jenes von Ercole I. von I 495 insg. 5 I 2. Siehe Bertoni, La biblioteca estense, Anhang und ASMo, ASE, Casa e Stato, Inventario del I 493, c I34.

290 Bertoni, La biblioteca estense, 77f, $9 \mathrm{If}$,

29I BonazzA, »Frammenti«, $29 f$. 
in der Kochkunst und der dazugehörenden Traktatliteratur niederschlug. Eleonora brachte aus Neapel eigenes Küchenpersonal und einen Küchenmeister namens Giovan Francesco Colle mit, Autor des ersten italienischen Werkes über die in Neapel besonders gepflegte Tranchierkunst. ${ }^{292}$ Aber erst mit der zweisprachig (italienisch/spanisch) aufgewachsenen Lucrezia Borgia wurde die spanische Literatur in Ferrara in die Lokaltradition aufgenommen, wie die zahlreichen sakralen und profanen Werke in ihrem Inventar zeigen. Ist Lucrezias Bibliothek vielseitiger in Sprachen und Themen, so sind die Bücher von Eleonora in ihrer Machart wertvoller. ${ }^{293}$

Handschriften und Druckwerke wurden aber nicht nur gesammelt oder in Auftrag gegeben, sondern waren unter Fürsten/Fürstinnen beliebte und kostbare Austauschgeschenke und wurden manchmal als Abschrift auch direkt angefragt. Im April I 583 dankte Otto von Braunschweig-Lüneburg Alfonso II. d'Este für seine Briefe und schickte ihm ein Exemplar einer sächsischen Chronik in deutscher Sprache aus dem Jahr I 402. ${ }^{294} \mathrm{Im}$ Jahr darauf schickte Johann Friedrich von Braunschweig-Lüneburg ein nicht näher definiertes deutsches Büchlein über die Kölnische Causa nach Ferrara. ${ }^{295}$ Auch zwischen Kurfürst Moritz von Sachsen und Ercole II. d'Este wurde selbst während kriegsbedingter Krisenzeiten - der Austausch von Kulturgütern, und mitunter Büchern, gepflegt: Der sächsische Rat Christoph von Carlowitz ${ }^{296}$ wurde mehrmals an sein Versprechen erinnert, ein Buch nach Ferrara schicken zu wollen, das die Verwandtschaft zwischen den Este und den Sachsen darstellte. ${ }^{297}$

Vielleicht ist es diesem Besitz von deutschsprachiger Literatur zuzuschreiben, dass der florentinische Gesandte Orazio Della Rena die gewagte Behauptung aufstellte, dass Alfonso II. nicht nur Französisch, Latein und so viel Spanisch spreche, dass er die Gesandten verstehe, sondern »legge molto spesso libri in lingua Todesca« (er liest sehr oft deutschsprachige Bücher). ${ }^{298}$ Die herzoglichen Deutschversuche in den Briefen an seine zweite Ehefrau Barbara blieben sprachlich allerdings im Anfangsstadium stecken, wie oben bereits gezeigt wurde.

292 Di Pascale, Banchetti Estensi, 37 f.

293 Sie brachte u.a. auch einen Kodex mit spanischen Liedern nach Ferrara. Vgl. Bonazza, »Frammenti«, 30-33. Siehe auch Nalini Montanari, I luoghi della devozione.

294 ASMo, ASE, Casa e Stato, Carteggio di principi esteri, Germania b I 599/25, Otto von BraunschweigLüneburg an Alfonso II., April I 583 .

295 Ebd., Johann Friedrich Herzog von Braunschweig-Lüneburg an Alfonso II., Januar I 584 .

296 Christoph von Carlowitz (I507-1578) stammte aus einem alten sächsischen Adelsgeschlecht, studierte in Leipzig, Basel und Frankreich, war zunächst Rat von Herzog Georg, bevor er von Moritz von Sachsen übernommen wurde. Sein Aufgabenbereich war die auswärtige Politik, bei der er eine den Habsburgern nahe Position einnahm, die er auch als Rat von August I. beibehielt. Vgl. Winter, Kurfürst Moritz, 205.

297 Dresden, SächHStA, Loc. 8499/r, bl. 79 je eine italienische und deutsche Abschrift, zit. auch in Korsch, Ein »heimlicher Vorschlag«, 43.

298 Della Rena, Relazione, 66, 78. 


\subsubsection{Produktionen der bildenden Künste für den kulturellen Austausch}

Von den bildenden Künsten als dem gewichtigsten Bereich des fürstlichen Mäzenatentums im I 5. und I6. Jahrhundert hat Peter Burke im Sinne eines regelrechten »Marktes« gesprochen. ${ }^{299}$ Neben den dem Geschmack und dem Kunstsinn von Fürst und Fürstin entsprechenden Auftragswerken gab es auch »Fertigprodukte«, Darstellungen von vielgefragten Themen, sozusagen »Klassiker» (Maria Muttergottes, Kreuzigung, Johannes der Täufer etc.), die vor allem durch Mittelsmänner und Kunstagenten, von denen unten noch ausführlicher die Rede sein wird, vertrieben wurden. ${ }^{300}$

Dass die bildenden Künste am ferraresischen Hof im wahrsten Sinne des Wortes Schule machten, ist hinlänglich bekannt. Große Namen wie Pisanello, Bellini, Mantegna, Rogier van der Weyden, Piero della Francesca, die Gebrüder Dossi, um nur die frühesten zu nennen, wurden von den Este-Fürsten nach Ferrara geholt, gaben der ferraresischen Schule ${ }^{301}$ den Namen und machten sie zu Vorbild. So hat z.B. der Aufenthalt Dürers in Ferrara 506 nachweislich seine Malerei beeinflusst. ${ }^{302}$ Doch hier soll und kann nicht die künstlerische also inhaltliche Beeinflussung behandelt werden, sondern es geht um den Austausch von Objekten wie Werken der bildenden Künste, als Ausdruck des Beziehungsgeflecht zwischen den Este und dem Reich.

Neben den »klassischen« bildenden Künsten wie Malerei, Wandmalerei und Skulptur waren in Ferrara die bereits genannte Buchmalerei und die Herstellung von Wandteppichen (arazzi, Gobelins) sowie von Gegenständen in Majolika ${ }^{303}$ besonders beliebt und gefragt. Zwei heute im Louvre aufbewahrte Wandteppiche mit Szenen aus Ovids Metamorphosen gehören zu einer fünfteiligen Reihe, die in der Werkstatt der Gebrüder Johannes/Hans und Nicola Karcher Mitte des I6. Jahrhunderts in Ferrara entstanden ist. Sie widerspiegelt in ihrer naturnahen Darstellung die Vorliebe der ita-

299 Burke, Die Renaissance in Italien, I I I.

300 Ebd.

30I Dazu siehe allgemein: CAmpori, Gli artisti italiani; Franceschini, Artisti a Ferrara. Es handelt sich hierbei um eine nützliche Quellenedition von in Ferrara tätigen Handwerkern und Künstlern aus den Quellen des Archivio Storico di Ferrara, Archivio Notarile und ASMo.

302 Dazu und zu den weiteren bedeutenden Künstlern in Ferrara siehe: Bentini, La pittura nel Cinquecento.

303 Darunter versteht man zweifach gebrannte Tongegenstände von einer weißen Zinnbleiglasur überzogen und mit feuerfesten Farben aufwendig dekoriert. Der Name stammt aus den frühen Zentren dieser Steingutproduktion auf Mallorca und Malaga. Weitere Produktionszentren der Renaissance waren in Ferrara, Florenz, Faenza, Venedig und Urbino. Die Kunstwerke aus Faenza wurden nördlich der Alpen "Fayence« genannt und waren sehr begehrt. Auch die Este förderten die Keramikproduktion in ihrem Fürstentum. Für sein Hochzeitsbankett anlässlich seiner Verheiratung mit Erzherzogin Barbara gab Alfonso II. ein 24-teiliges Tafelservice aus Majolika in Auftrag. Dass dieses Kulturgut oft nach Norden verschickt und verschenkt wurde, beweisen nicht zuletzt die brieflichen "Bestellungen« und die verschiedenen fürstlichen und kaiserlichen Inventare. RAUch, Großherzogin Johanna, Katalogteil, I 84; Visser Travagli, L'art de la céramique. 
lienischen Renaissancegesellschaft für Gärten und verbindet sie mit Motiven aus der Antike und der Mythologie. Außerdem sind im Hintergrund Ferrara und verschiedene delizie sowie das Wappen der Este zu erkennen. Die Herstellung von Wandteppichen erreichte unter Herzog Ercole II. d'Este ihren Höhepunkt. Zuerst waren französische und flämische Weber zur Reparatur dieser bevorzugten Innenraumdekorationen nach Italien gekommen. Dann hatten sich mit den Gebrüdern Karcher zwei flämische Webkünstler auf Veranlassung des Herzogs in Ferrara niedergelassen, die in ihren Werkstätten eine reiche Produktion begannen und weitere Weber wie Jean Roost, Gerard Slot und zahlreiche Hilfskräfte aus ihrer Heimat holten. Mit dem Tod Ercoles II. verlagerte sich diese mittlerweile hochqualifizierte Produktion nach Florenz, wo sie unter den Medici noch lange gefördert wurde. Die von Ercole II. engagierten flämischen Weber zeichneten sich durch ein großes, in ihrer Heimat erlerntes technisches Können aus, aber auch durch ihr Gespür für die Verarbeitung von Motiven der italienischen Renaissance nach Vorlagen großer Künstler wie Dosso Dossi, Mantegna oder Giulio Romano. ${ }^{304}$ Auch der anfangs noch wenig bekannte Giuseppe Arcimboldo hat an Entwürfen für Fenster- und Wandteppiche gearbeitet, so einer Darstellung des Marientods, die die Gebrüder Karcher ${ }_{5} 62$ in Ferrara in ein arazzo webten. Als er dann durch Maximilian (II.) an den Kaiserhof kam, hatte er zunächst vor allem die Aufgabe, Porträts zu kopieren und zeichnete sich hierbei besonders durch seinen italienischen Stil aus. ${ }^{305}$

Der reichste und regelmäßigste Austausch von Kunstwerken bestand aufgrund der räumlichen und verwandtschaftlichen Nähe und aufgrund ähnlicher »Inszenierungsbedürfnisse« zwischen Ferrara und dem Innsbrucker Hof und besonders zwischen Alfonso II. d'Este und Erzherzog Ferdinand II. Bereits wenige Monate nachdem Erzherzogin Barbara, Ferdinands Schwester, Herzogin von Ferrara geworden war, erbat sie sich sein Konterfei, ${ }^{306}$ welches der Landesfürst von Tirol daraufhin bei einem Ma-

$304 \mathrm{Zu}$ den vor allem in Flandern hergestellten und von den Este in Auftrag gegebenen und angekauften arazzi gehörten Wandteppiche, Bettüberwürfe, heraldische Teppiche wie Pferdedecken und religiöse Gewänder (Kaseln etc.). Die darin verarbeiteten Motive waren zunächst höfisch-ritterlicher Natur ( $a$ la francese) und dann immer mehr im Sinne des Humanismus antikisierend. Auch die arazzi dienten den Este als visuelles Mittel der Herrschaftsinszenierung, um sich in den Reigen der ultramontanen großen Höfe einzugliedern.Vgl. Forti Grazzini, Gli arazzi. Siehe die Beschreibung der Wandteppiche auf der Website des Museums des Louvres; http://www.louvre.fr/en/oeuvre-notices/tapestrydepicting-scenes-ovid-s-metamorphoses,abgerufen: 22.6.2020.

305 Siehe auch Liana De Girolami Cheney, Arcimboldo (Google eBook), Parkstone International, 05.7.2013, abgerufen am 22.6.20. Siehe siehe: DaCosta Kaufmann, Giuseppe Arcimboldo.

306 Diese Bitte stellt - wie Barbara Marx bereits an den Medici-Frauen festgestellt hat - einen wichtigen Aspekt der weiblichen Sammeltätigkeit dar. Vor allem in der Fremde verheirateten Fürstinnen war es ein Anliegen, ihre Verwandten und Familienangehörigen in effigie bei sich zu haben, eine Familienmemoria zu pflegen, um vor allem den Nachkommen ihre Familienherkunft plastisch vor Augen führen zu können. MArx, Politica culturale al femminile, i $56 f$. 
ler in Innsbruck in Auftrag gab. ${ }^{307}$ Auch nach Barbaras frühem Tod ${ }_{572}$ brach der Kontakt mit Ferrara nicht ab, sondern intensivierte sich parallel zu den Bestrebungen Ferdinands, seine Ambraser Sammlung zu vervollständigen. In drei deutschen Briefen im ersten Halbjahr I $5_{3}$ bedankte er sich für das erhaltene Verzeichnis der kriegerischen Expeditionen und Taten von Alfonso II. d'Este zur historischen Erfassung. ${ }^{308}$ Wie er in einem Brief an einen Minister des Herzogs von Ferrara bereits zwei Jahre zuvor angekündigt hatte, benötigte er Bildnisse von großen Kriegsherren in Rüstung, also auch von Alfonso II. und von dessen Vorgängern. ${ }^{309}$ Seit I 576 sammelte und beauftragte Erzherzog Ferdinand II. nämlich Bildnisse berühmter Feldherren »von unseren hochlöblichen Haus Österreich und desselben nahen verwandten und befreundeten personen «. ${ }^{310}$

Der Austausch von Bildern und Porträts an den Renaissancehöfen diesseits und jenseits der Alpen hatte eine bedeutende politische Funktion, war eine gängige Praxis des Schenkens, der Gunstbekundung, des Kennenlernens für potenzielle Heiratspartner ${ }^{311}$ und frönte der allgemein verbreiteten Sammelleidenschaft der Fürsten und Fürstinnen und ihrem Interesse für ihre Zeitgenossen sowie deren Ahnen (mit denen man meistens aufgrund von Heiratsallianzen irgendwie immer, wenn auch manchmal weitläufig verwandt war). Auch der Kurfürst von Sachsen ließ über seinen Berater Andreas Paul[li] Alfonso II. um je zwei Kopien eines Porträts von Ercole I., Alfonso I. und von ihm selbst bitten. ${ }^{312}$

Neben dem Spezifikum des Porträts wurden ganz allgemein auch Kunstwerke zu einem bestimmten Thema oder von einem bestimmten Künstler, den man an einem Hof angestellt wusste, erbeten bzw. verschenkt. Im Dezember I 582 bedankte sich Al-

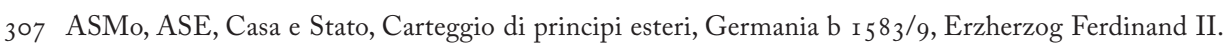
an Barbara v. Österreich, Februar 1566.

308 Ebd., Erz. Ferdinand II. an Alfonso II., Januar, März und Juli I 583.

309 Ebd., Erz. Ferdinand II. an einen Berater des Herzogs von Ferrara (wörtl. »a un ministro del duca di Ferrara«), Januar 158r. Auf Schloss Ambras sind in der Kunst- und Wunderkammer die kleinformatigen Porträts aus dieser besonderen Sammlung berühmter Krieger ausgestellt, darunter jenes von Philipp dem Großmütigen, Francesco Maria della Rovere, Markgraf Albrecht von Brandenburg, Francesco und Ferdinando Gonzaga, Kurfürst Johann Friedrich von Sachsen, Johann Casimir Pfalzgraf bei Rhein etc. Von Alfonso II. ist nur das großformatige Porträt in Rüstung erhalten. Aus der Reihe der Feldherrendarstellungen sind nur die Porträts von Erzherzog Ferdinand II., von Alfonso II. d'Este und von Alessandro Farnese erhalten. Rauch, Gesammelte Wunder, I 7 .

3 Iо Zit. n. Seide, Herzogin Barbara, i 18.

3 I I Für die Heiratsverhandlungen der Este-Töchter hatte Cosmé Tura Lucrezia, Isabella und Beatrice d'Este für ihre potenziellen Ehemänner, Annibale Bentivoglio, Francesco Gonzaga und Ludovico Sforza, porträtiert. Burke, Die Renaissance in Italien, I 20. Porträts hatten nicht nur Erinnerungsund Memoriawert für die eigenen Angehörigen, sondern waren vor allem diplomatische Gaben und Austauschobjekte zur Besiegelung oder Anbahnung einer Allianz. Cheles, Il ritratto di corte, i 8.

3I 2 ASMo, ASE, Casa e Stato, Carteggio di principi esteri, Germania b I603/29, Andrea Pauli Rat des Kurfürsten von Sachsen an Alfonso II., September 1582 und daraufhin Dankesschreiben (Januar I 583 ) desselben für die Benachrichtigung, dass die Porträts in Auftrag gegeben wurden. 
fonso II. bei Otto Heinrich, Herzog von Braunschweig-Lüneburg, für die Zusendung eines - nicht näher beschriebenen - antiken Gemäldes. ${ }^{313}$

Die Zusendung von Kunstwerken über die Alpen verlief - jenseits des stilistischen Vorsprungs und des tonangebenden Geschmacks der italienischen Renaissance - in beiden Richtungen. Sie diente nicht nur der Befriedigung von Anfragen nach Werken eines berühmten Künstlers oder der Gunstbekundung, sondern auch als Gegenleistung. I 559 wurde dem Herzog von Savoyen vom ferraresischen Hof aus ein Gemälde übersandt und man erbat sich dafür im Gegenzug sechs englische Hunde. ${ }^{314}$ Der Akt des Schenkens war, wie Harriet Rudolph bereits festgehalten hat, entweder eine Pflicht (so z.B. bei Besuchen) und Erwartungshaltung, oder mit bestimmten politischen Interessen verbunden, deren Erfüllung der Geber erwartete und der Empfänger durch das Geschenk zu leisten verpflichtet wurde. ${ }^{315}$

Neben dem Gabentausch gab es natürlich auch den regulären Erwerb von Kunstgegenständen. Der bayerische Hof scheint besonders an der oben genannten Kleinkunst Ferraras interessiert gewesen zu sein, nämlich der Herstellung von Vasen, Tellern und anderen Objekten aus Majolika. Der Herzog von Bayern hatte durch den estensischen Gesandten Ascanio Geraldini Vasen aus Majolika erhalten und bat um weitere. ${ }^{316} \mathrm{Al}-$ lerdings verzögerte sich die Produktion und Alfonso musste den Herzog von Bayern vertrösten. Schließlich informierte er ihn, dass er drei scudi für die Majolika ausgelegt hatte, ${ }^{317}$ was darauf hinweist, dass der Austausch von Kunst- und Kulturgütern nicht immer unentgeltlich oder auf einen Tausch hin, sondern auch als Erwerb erfolgte.

\subsubsection{Netzwerke, Sammelwut, Kunst- und Wunderkammern als Motoren von Produktion und Austausch}

Die Bedeutung von Sammlungen aller Art (Gemälde-, Münzen-, Medaillen-, Naturaliensammlungen), die zumeist - manchmal bereits nach bestimmten Kriterien geordnet - in sogenannten Kunst- und Wunderkammern aufbewahrt wurden, ist für den Kulturtransfer in dieser Zeit unumstritten. ${ }^{318}$ Ausschlaggebend für die »Befüllung»

3 I 3 ASMo, ASE, Casa e Stato, Minute di lettere ducali a Principi e signori fuori d'Italia b I634/4 an Otto Heinrich von Braunschweig und Lüneburg, Dezember 1582.

3 I 4 ASMo, ASE, Casa e Stato, Carteggio di Ambasciatori, Germania b 2 I, Dispacci ducali an Girolamo Montecuccoli und Camillo Gualegno, Februar I 559.

3 I 5 Rudolph, Fürstliche Gaben?, 8of.

3 r6 München, BayHStA, Fürstensachenooo7 und ooro, Kasten Schwarz 7603, Lettere del Sig. Duca di Ferrara e del Conte Montecuccoli al Ser.mo Duca di Baviera, August I 583 (?).

3 7 München, BayHStA, Fürstensachenoo3o, Kasten Schwarz 7603, Lettere del Sig. Duca di Ferrara e del Conte Montecuccoli al Ser.mo Duca di Baviera, Mai I 590.

3 I 8 Siehe: Distelberger, "Quanta rariora tanta meliora«; Minges, Das Sammlungswesen; Olmi, L'inventario del mondo; Pieper, Papageien. 
dieser eigens geschaffenen Kunsträume waren die persönlichen Kontakte, das Netzwerk, wodurch der Sammler/die Sammlerin zunächst einmal zu Know-how und Informationen über vorhandene und erwerbbare Kostbarkeiten $\mathrm{kam}^{319}$ und dann Freundschafts- und Verwandtschaftsbeziehungen spielen lassen konnte, um in den Besitz der begehrten Objekte zu kommen. Dabei wurde auch nicht vor unredlichen Mitteln Halt gemacht, um der Sammelleidenschaft (oftmals auch Sammelwut) zu frönen: Isabella d'Este-Gonzaga, Schwester von Alfonso I., die wegen ihres Mäzenatentums und ihrer Kunstsammlung vom Dichter Nicolò da Correggio auch "prima donna del mondo« tituliert wurde, scheute nicht davor zurück, den von kriegerischen Ereignissen bedrohten italienischen Fürsten in der Not ihre Kostbarkeiten abzuwerben oder abzuringen. Als die Herzöge von Urbino von Cesare Borgia bedroht wurden und ihr Fürstentum verlassen mussten, nahm sie die Verwandten aus Urbino zwar in Mantua auf, erbat sich aber von Cesare einen Venustorso und einen schlafenden Amor aus dem eroberten Urbino. Als die Montefeltro wieder in ihr Fürstentum zurückkehrten, war von der Rückgabe der Kunstwerke keine Rede. Auch als ihr Schwager, Ludovico il Moro, in Mailand gestürzt wurde, war sie vorrangig an der Beschaffung eines dort aufbewahrten Klavichords von Lorenzo da Pavia bemüht. ${ }^{320}$

Doch nicht immer wurden Verwandte hinters Licht geführt oder arg bedrängt, um Kunstobjekte zu erhalten. ${ }^{321}$ Meistens kam es dank des bestehenden und gepflegten Beziehungsnetzwerks zur Bereicherung der eigenen Sammlung durch Anfragen, Tausch, Handel und Ankauf von Kulturgütern, von denen man selbst durch persönliche Besuche oder durch Vermittlung von Agenten Kenntnis hatte. Wenn der Erwerb trotz aller Bemühungen durch Verwandte und Bekannte nicht glückte, blieb nur noch das Kopieren und Nachahmen, wie es bei Majolika-Arbeiten von Faenza häufig der Fall war. ${ }^{322}$

Kunstkammern dienten der Machtdarstellung des Fürsten bzw. seines Hauses und ahmten als Mikrokosmos den Makrokosmos seiner Herrschaft nach. Hier fanden seit

3 I 9 Reinhard Jakob hat hierbei von »Information als Ware " gesprochen und an Beispielen die Entwicklung von Informationen über Waren in den Briefen Nürnberger Handelstätiger zu Informationen als gehandelte Ware aufgezeigt. ЈАков, Zucker, $78 \mathrm{f}$.

320 Weitere Beispiele von Isabellas Sammelgier sind in Bongiovanni, Isabella d'Este, I 38 - I 40 und im Ausstellungskatalog Ferino-Pagden/Seipel, Isabella d'Este, 7of.

32 I Allerdings hat auch Ferdinand von Tirol Glasbläser aus Murano, denen verboten war, ihre Kunst »auswärts« auszuüben oder weiterzugeben, mit viel Geld bestochen, damit sie in der Innsbrucker Hofglashütte für ihn tätig sein konnten. HAAg, Fürstlich Tafeln, 62. Siehe auch: Schlosser, Die Kunst- und Wunderkammern, 47. Dabei verlangte der Erzherzog von den namentlich bekannten Glasmeistern weniger ausgefallene Kunstwerke als vielmehr die Sorge um die Materialbeschaffung und die technische Verarbeitung. Vgl. z.B. Vasenpokal mit eiförmigem Einsatz bei Sandbichler, Kunstkammerschätze, Katalogteil, I 43

322 RAffler, Von "studiolo«, 3 I 8f. Nach Schlosser gab es in der Ambraser Sammlung Erzherzog Ferdinands II. Tiroler Majolika, aber es fehlten solche aus Italien. Schlosser, Die Kunst- und Wunderkammern, Ioo. 
dem Beginn der Entdeckungsreisen vor allem Naturalien als begehrte Kostbarkeiten neben den Kunstwerken ihren Platz. Umschlagplatz für beides, sowohl für Exotika als auch für europäische Kunstwerke, war Venedig und ab der Mitte des i6. Jahrhunderts Spanien. Für die Sammlungen von Herzog Albrecht V. von Bayern und der Familie Fugger wurden Südfrüchte, Parfüms, Glas und Antiquitäten über Agenten und Verwandten aus Italien und aus dem Ausland vorrangig über Venedig bezogen. ${ }^{323}$ Bernd Roeck hat betont, dass gerade durch die ultramontanen Handelsaktivitäten der Familie Fugger oder der Augsburger Firma Ott »am Rialto [dürfte] im r6. Jahrhundert der wichtigste Kunstmarkt Europas bestanden haben [dürfte]. ${ }^{324}$ Diese auch als Kunsthändler in Venedig tätigen deutschen Kaufleute machten - ihr Netzwerk im Fondaco dei Tedeschi nutzend - selbst berühmten Kunstagenten wie Jacopo Strada aus Mantua, ${ }^{325}$ Antiquar für den Kaiser und die Herzöge von Bayern, in der Beschaffung und Versendung von begehrten Gütern Konkurrenz. Doch anders als Strada verfügten sie über wenig »höfisches« Hintergrundwissen, wenn sie nicht direkt um ihre Dienste, also um die Beschaffung von bestimmten Sammelstücken gebeten wurden. Strada hingegen wusste nach Maximilians II. und Rudolfs II. Besuch in Dresden I 575, dass es um die sächsische Kunstkammer ${ }^{326}$ schlecht bestellt war und bot August I. die Vermittlung von zum Kauf stehenden Sammlungen an. ${ }^{327}$ Der Erfolg der Kaufmannsfamilie Ott hingegen lag in ihrer Zulassung zum Fondaco dei Tedeschi ${ }^{328}$ und in der Tatsache, dass sie dadurch »- im Gegensatz zu den italienischen Kaufagenten - direkt Zugang zur gesamten Infrastruktur, die für die Abwicklung des Kunsthandels zwi-

323 Raffler, Von »studiolo«, 323-326. Zu den Erwerbungen für Herzog Wilhelm V. in Italien siehe: BAADER, Der bayerische Renaissancehof, 350-355.

324 Roеск, Kulturtransfer zwischen Bayern und Italien, 30. Siehe auch: Backmann, Kunstagenten.

$325 \mathrm{Zu}$ diesem und seinem Verhältnis zu Kaiser Maximilian II. siehe: Jansen, The Instruments of Patronage. Seine Enkelin Anna Maria war die Langzeitgeliebte von Rudolf II. mit der der Kaiser vier Kinder hatte. Press, Rudolf II., Ioo.

326 Dazu siehe die »Anleitung« von Gabriel Kaltemarckt für eine Kunstkammer, die der Repräsentation des sächsischen Fürsten gerecht werden sollte, bei: Gutfleisch/Menzhausen, "How a Kunskammer should be formed«. Vgl. auch den Ausstellungskatalog Staatliche Kunstsammlungen Dresden/ Kunsthistorisches Museum Wien, Kaiser Rudolf II.

327 MARx, Italianità, I 4. Generell nutzte Strada den Einfluss seines kaiserlichen Dienstgebers, um mittels Empfehlungsschreiben neue Kunden anzuwerben. So wandte er sich mit einem lateinischen Schreiben vom 30. September 573 an die Herzöge von Ferrara, Florenz, Mantua, Parma, Savoyen, Urbino und an einzelne italienische Stadtrepubliken. Vgl. Lietzmann, Der kaiserliche Antiquar, 384, mit den Schreiben an Kurfürst August im Anhang. Strada erbaute ${ }_{5} 64$ in Wien ein bewunderswertes Haus "alla italiana", von dem selbst Alfonso II. bei seinem Besuch am Kaiserhof ${ }_{5} 66$ beeindruckt war. Jansen, Gli strumenti del mecenatismo, 729 f. Siehe auch das Kapitel »Jacopo Strada and the transformation of the imperial court« bei Louthan, The quest for compromise, $24-48$.

328 Hier hielten sich auch Reisende auf dem Weg ins Heilige Land auf. Es war nach Matschinegg ein "Zentrum für die Deutschsprachigen« und gleichzeitig Kontrollinstanz der Fremden in der Lagunenstadt. Matschinegg, Ausländer in Italien, 75 . 
schen Oberdeutschland und Venedig nötig war« besaßen. ${ }^{329}$ Die Ott nutzten ihre Zusammenarbeit mit den Fuggern, ihre vielseitigen Aktivitäten in der Hochfinanz sowie ihre Kenntnisse und Netzwerke auch für den Bereich des Kunsthandels und standen dabei u.a. auch Erzherzog Ferdinand II. von Österreich zu Diensten. ${ }^{330}$ Wie Mark Häberlein untersucht hat, waren diese (einfluss)reichen Kaufleute nicht nur in der Beschaffung und Vertreibung von Kunstobjekten oder Exotika tätig und als Menschen mit großer Mobilität sowie vielseitigen Kontakten durch den Besuch von Messen, Märkten und Kontoren im kulturellen Austausch direkt involviert, sondern frönten diesem auch durch eigene Kunst- und Büchersammlungen. Letztere hatten zumeist einen ganz praktischen Entstehungshintergrund und rührten aus der Ausbildungszeit in der Fremde her, dem Erlernen der wichtigsten Handelssprachen dortselbst und der Nachfrage nach »Spezialliteratur«, nach Wörterbüchern, Lexika und kaufmännischen Hilfsmitteln wie Rechen- und Buchführungsbüchern. ${ }^{331}$

Doch Kaufleute waren nicht nur handelstüchtig, sondern - wenn sie als Kunstagenten tätig waren - zugleich kunstsinnige Vermittler und oft selbst Sammler, wodurch sie auch als »Hoffremde« für die Erfüllung der Sammelwünsche von Fürsten und Fürstinnen in Frage kamen. ${ }^{332}$

Auch wenn sich alle Este-Herzöge bemühten, ihr Prestige, ihre edle Herkunft und ihren Reichtum durch Kunstpatronage zur Schau zu stellen, konnten sie bezüglich der Sammlung und Beauftragung von Kunstwerken das Engagement und die Erfolge des letzten Herzogs von Ferrara nicht übertreffen. Durch die Gelehrten Enea Vico und Pirro Ligorio wurden Alfonso II. d'Estes Sammlungen von Medaillen, Münzen, Edelsteinen und Antiquitäten sowie die estensische Bibliothek in großem Maß bereichert. ${ }^{333}$ Die Gesandten und Agenten in Venedig oder Rom, wie Alessandro Grandi, wurden stets angehalten, nach weiteren Kostbarkeiten Ausschau zu halten. Nur ein Teil dieser reichen Sammlung kam I 598 im Zuge der Devolution nach Modena. Die Inventare zeigen deutlich - dem Trend der Wunderkammern Europas folgend - eine Konzentration von naturalia (Schwämme, Muscheln, Tierskeletten, Korallen ${ }^{334}$ ) neben

329 Backmann, Kunstagenten, I 82.

330 Ebd., I 84 .

33 I Vgl. Häвerlein, Aneignung.

332 So konnte der niederländische Kaufmann Daniel Nijs für König Charles I. von England den Ankauf eines großen Teils der Sammlung der Gonzaga arrangieren. Keblusek spricht hier zu Recht von »cultural agents«. Vgl. Keвluseк, Commerce, 299.

333 Auch die estensische Sammlung unterschied sich wie die meisten italienischen von jenen jenseits der Alpen durch die saubere Trennung von Naturalienkabinetten und Kunstwerken. Allerdings waren die Kuriosa oder Besonderheiten wie Elfenbeinarbeiten in Italien weniger gefragt als im Reich. SchlosSER, Die Kunst- und Wunderkammern, 20I-204, 225. Ebenso wertvoll mit besonderem Bezug zur Wunderkammer von Schloss Ambras ist Seipel, Die Entdeckung der Natur.

334 Die Korallensammlung Erzherzog Ferdinands II. auf Schloss Ambras enthält nicht nur die meisten Korallen, sondern vor allem etliche in natura nicht mehr existente aus dem Mittelmeerraum und den 
Bildern, Statuen und Büchern. ${ }^{335}$ Diese Sammlungen, die für die Este Statussymbole waren, wandelten sich im Laufe der Frühen Neuzeit bezüglich ihrer Zusammensetzung und ihrer inhaltlichen Schwerpunkte und passten sich dem Zeitgeist und dem sich weiterentwickelnden Begriff des »Kuriosen« an. ${ }^{336}$ Im Laufe des I 7. Jahrhunderts entwickelte sich auch am Hof von Modena die in der Renaissance typische Wunderkammer immer mehr zu einer Kunstkammer, nach den durch Darstellungen und Beschreibungen bekannt gemachten Vorbildern der Sammlungen der Herzöge von Württemberg ${ }^{337}$ in Stuttgart oder des Kurfürsten von Sachsen in Dresden. Mit der Ordnung und Ausstellung der Kostbarkeiten wurde Ludovico Antonio Muratori beauftragt, der in der herzoglichen Bibliothek die Kataloge der Sammlungen jenseits der Alpen aufbewahrte und auch diesbezüglich mit Gottfried Wilhelm Leibniz in Kontakt stand. Dennoch hatte die estensische Kunstkammer wenig von der asketischen Aufbereitung ihrer reichsfürstlichen Pendants. Die estensische ähnelte auch noch im I7. und I 8. Jahrhundert mehr einem überfüllten Sammellager.

Noch im I8. Jahrhundert dienten Francesco III. d'Este (reg. I737- I780) seine Sammlungen als politisches und diplomatisches Mittel. Zwischen I 743 und I 746 verkaufte er roo Gemälde an August III., Kurfürst von Sachsen und König von Polen, um die prekäre finanzielle Lage seines Fürstentums zu verbessern. Trotz dieses Aderlasses wurde seine durch Mundpropaganda berühmte Galleria immer noch Ziel der Italienbesucher. Viele Edelsteine und Gesteinsproben der estensischen Sammlung stammten von Domenico Paggiari, Conte di Serrazzone, aus Reggio, aber wohnhaft in Mannheim, der zwischen I 759 und I796 eine wichtige Rolle in der Beziehung und im Austausch der Este mit den Kurfürsten von der Pfalz spielte. Dies beweist, dass die kulturellen, auf den Austausch von Kostbarkeiten fußenden Beziehungen der Este zu einzelnen Reichsfürsten auch weit über das I6. Jahrhundert hinaus reichten. ${ }^{338}$

Die Herzöge von Modena versuchten die reiche Kunstsammlung, die sie aus Ferrara hatten mitnehmen bzw. vor dem päpstlichen Zugriff hatten retten können, in einem neuen Glanz erstrahlen zu lassen und nach Möglichkeit zu erweitern. Über die Inhalte

italienischen Küsten, wodruch sie auch zoologisch besonders interessant sind. Vgl. RAUCH, Kunstkammerschätze, Katalogteil, I 59 .

335 Corradini/Cavani, »La preziosa Galleria«, 4I3-4I 5 .

336 Ebd., 4 I 7 .

$337 \mathrm{Zu}$ dieser auf dem Reichstag zu Worms I495 in den Herzogsstand erhobenen Fürstenfamilie siehe: Wunder, Kleine Geschichte des Herzogtums Württemberg, 32-49. Zur Sammlung siehe: Landesmuseum Württemberg (Hg.), Die Kunstkammer der Herzöge von Württemberg. Bestand, Geschichte, Kontext, Ostfildern 2017.

338 Mit Ercole III. d'Este (reg. 1780- I 796, I 803) neigte sich die Glanzzeit der Galleria dem Ende zu. Er selbst hatte diese ausgebeutet, um Geschenke zu machen und seine Unterkünfte außerhalb Modenas zu verschönern. Außerdem sendete er 1796 zahlreiche Kostbarkeiten nach Venedig, als er vor Napoleon flüchten musste. Die Franzosen entnahmen weitere Bestandteile der Galleria, die nach Frankreich kamen und von denen nur wenige nach dem Sieg über Napoleon den Weg zurückfanden. Vg1. Cor RADINI/CAVANI, "La preziosa Galleria«, 42 I -425 . 
der Sammlung scheinen Auswärtige, so z.B. der Kaiser mehr Kenntnis gehabt zu haben, als manch anderer am Hof von Modena. Mit dem Reichsoberhaupt bestand gleich nach dem Heimfall Ferraras trotz Rudolfs ${ }^{339}$ Zusage immer noch ein angespanntes Verhältnis wegen der noch zu bestätigenden Investitur Cesares mit den kaiserlichen Lehen. Der nach Prag entsandte Markgraf Giulio Thiene stellte schnell fest, dass, »la strada sola dei denari è quella che ci può dare qualche cosa di buono" (Geld sei der einzige Weg/ das einzige Mittel, um etwas Gutes zu erreichen). ${ }^{340}$ Doch Cesare bzw. sein Vorgänger Alfonso hatten sich die Belehnung bereits 400.000 scudi kosten lassen und der designierte Herzog von Modena hatte mit dem reduzierten Herzogtum auch etliche Schuldenberge geerbt. Da der Belehnungsakt ausblieb, schlug auch der residierende Gesandte Marcantonio Ricci vor, Rudolf II. einige Pferde, Statuen und vor allem qualitätsvolle Bilder von Renaissancemeister, ${ }^{341}$ die der Kaiser mit Freuden sammelte, ${ }^{342}$ zukommen zu lassen, um den Belehnungsprozess zu beschleunigen. Der Kaiser hatte die Gewohnheit, die italienischen Gesandten nach dem Aufbewahrungsort von bekannten Stücken fragen zu lassen. Dadurch wusste er, was er sich als "Geschenk« erbitten konnte, so wie jene Kunstwerke der Este, die zwischen I 598 und I604 in die sogenannte rudolfinische Sammlung ${ }^{343}$ aufgenommen wurden. Auch als der estensische Gesandte Ricci mit den Ministern Wolfgang Siegmund Rumpf und Paul Sixt Trautson über die Vergabe des Titels Illustrissimo an den illegitim geborenen Cesare verhandelte, stellte er fest, dass das Angebot, mit Geld und Truppen den Türkenkrieg des Kaisers zu unterstützen, geringen Reiz hatte. Mehr Erfolg versprach sich der Vertreter hingegen durch die Zusendung weiterer Kunstwerke, die sich aber zu seinem Bedauern verzögerte. ${ }^{344}$

Bereits im August I 598 war Zdeněk Vojtěch Popel von Lobkowitz, späterer Großkanzler von Böhmen und Vertrauter von Kaiser Rudolf II., nach Modena gekommen und reich beschenkt nach Prag zurückgekehrt. Der zeitgenössische Chronist

339 Rudolf II. soll unter erblicher Schizophrenie gelitten haben. Schuld an den degenerativen physischen und psychischen Leiden der Habsburger waren nicht zuletzt die engen, oft inzestuösen Heiratsverbindungen innerhalb der drei habsburgischen Linien. Vgl. Vocelka/Heller, Die private Welt, I I 5 . Weniger gut belegt, aber angenehm zu lesen: Gertrude von Schwarzenfeld, Rudolf II. Der saturnische Kaiser, München r 96 r.

340 ASMo, ASE, Casa e Stato, Carteggio di Ambasciatori, Germania b 66, von Giulio Thiene, Januar I 598.

34I Ghelfi, „Le pitture«. Dazu auch: Venturi, Zur Geschichte der Kunstsammlungen; Trevor-Roper, Princes and artists. Zu dieser Sammlung des Kaisers, die bunt gemischt, wenig methodisch angelegt war und u.a. auch aus Kopien bestand, soll Kardinal Ippolito d'Este, der sie I604 besichtigte, zweideutig gesagt haben, dass »der Schatz [sei] seines Besitzers würdig [sei]«. Siehe Schlosser, Die Kunstund Wunderkammern, I 2 I ohne Angabe der Quelle.

342 Dazu siehe auch das Kapitel »Die Kunstsammlung als Mittel der srepraesentatio maiestatis« in VoCELKA, Die politische Propaganda, I97-202.

343 Diese wurde dann durch den Ankauf der Ambraser Sammlung I 605 für I 70.000 Gulden, die der Erbe Erzherzog Ferdinands II., Markgraf Karl von Burgau erhielt, bereichert. Schlosser, Die Kunst- und Wunderkammern, 54 f.

344 Ghelfi, »Le pitture«, 94-97. 
Giovan Battista Spaccini hielt dies in seinen Aufzeichnungen folgendermaßen fest: "L'imbasciatore imperiale s'è partito di costì con bellissimi presenti, che vi ha fatto il signor duca di valore di sei mila scuti $[\ldots]$ «. ${ }^{345}$

I60 I teilte der Minister Karl von Liechtenstein dem estensischen Gesandten, der mittlerweile auch die Causa um die Belehnung mit Sassuolo verhandelte, mit, dass der Kaiser gerne Werke von Raffael oder Michelangelo hätte. Sowohl Liechtenstein als auch Rudolfs Geliebte Maria Manriquez de Lara von Pernštein boten Cesare ihre Intervention beim Kaiser gegen verschiedene Gaben wie Lebensmittel (Salami, Trüffel), Goldschmiede- und Keramikarbeiten, Pferde und vor allem Bilder an. ${ }^{346}$

Ende des r 9. Jahrhunderts ist Adolfo Venturi in den Archiven von Modena, Turin und Venedig den Hinweisen zum Transfer von Kunstgegenständen aus Italien nach Prag in die Residenz von Kaiser Rudolf II. nachgegangen und hat versucht die damit einhergehenden Gunstbeweise des Kaisers, der bekanntlich dazu neigte »seine Gnade denjenigen zu schenken, die seine Kunstkammer bereicherten, so dass die Fürsten gar kein besseres Mittel finden konnten, seine Gunst zu erkaufen, als durch Geschenke kostbarer Kunstgegenstände ${ }^{347}$ zu rekonstruieren. ${ }^{348}$ Dies wissend versuchte auch Cesare d'Este, die kaiserliche Unterstützung mit Pferde- und Kunstgeschenken zu gewinnen. Doch damit war die Gier des Kaisers nach Kostbarkeiten nicht gestillt. Das Reichsoberhaupt ließ sogar dem estensischen Gesandten Ricci ein Verzeichnis über verschiedene Statuen aushändigen und trug ihm auf, diese für ihn ausfindig zu machen. Der gut informierte Kaiser wusste besser als die Este - oder meinte es zumindest -, welche Kunstwerke sie besaßen, während die Herzöge selbst seit dem eiligen Umzug aus Ferrara anscheinend noch nicht über die mitgenommenen und zurückgelassenen Schätze im Bilde waren oder dies nur vorgaben. Cesare war aber zunächst nicht bereit, sich an dieser Suche nach Kunstwerken für den Kaiser zu engagieren, solange nicht sichtbare Zeichen der Anerkennung und der Unterstützung aus Prag kamen. Der estensische Gesandte musste ihn

345 "Der kaiserliche Gesandte ist mit außerordentlich schönen Geschenken des Herzogs im Wert von 6.0oo scudi von hier abgereist [...]«. Giovan Battista Spaccini, Cronaca di Modena. Anni I 588 - I602, hg. v. Albano Biondi/R. Bussi/C. Giovannini, transkribiert von C. Giovannini/Franco Cosimo Paniani, Modena I993, I46, zit. n. Ghelfi, »Le pitture«, 99, Anm. I 8.

346 Tatsächlich kam jeweils im Januar I 599 und I 602 eine »Lieferung« von Bildern von Modena nach Prag ohne Nennung der Anzahl oder der Autorenschaft der Werke. Ein wichtiger Mittelsmann in diesem Zusammenhang war auch der Künstler Hans von Aachen, der in Tirol Erzherzogin Anna, Tochter von Erzherzog Ferdinand II., und in Mantua MargheritaGonzaga malte. Bei seinem Aufenthalt in Modena wurde er am Hof aufgenommen und konnte dort Marmorwerke bewundern, die daraufhin auch den Weg nach Prag fanden, nachdem der Künstler sich beim Kaiser für Cesare d'Este eingesetzt hatte. Ghelfi, »Le pitture«, IO3, I I 8-I27.

347 Venturi, Zur Geschichte der Kunstsammlungen, r. Zur rudolfinischen Sammlung und zur Kunst am Hof siehe den reichen Ausstellungskatalog: Fučírové, Rudolf II and Prague.

348 Kunstgegenstände waren besonders geeignete diplomatische Geschenke, weil sie ihrem Inhalt nach symbol- und bedeutungsbehaftet sowie auch auf einen Anlass bezogen sein konnten. Vgl. KubERSKYPiredda/Salort Pons, Ein Hofnarr als Agent, hier i 24. 
schließlich darauf aufmerksam machen, dass bei den Deutschen zuerst die Geschenke kamen und dann erst die Belohnung, als Begleichung einer Schuldigkeit. ${ }^{349}$ So kam der Herzog schlussendlich dem Wunsch der oben genannten Maria von Pernštein entgegen und ließ u.a. Porträts seiner Familienmitglieder, allen voran der schönen Giulia d'Este, einer potenziellen Heiratskandidatin für Rudolf II., anfertigen. Da diese Werke aber dem Geschmack des Kaisers nicht entsprachen, kam I603 der kaiserliche Hofmaler Hans von Aachen mit dem zweifachen Auftrag nach Italien, neue Porträts anzufertigen und an den oberitalienischen Höfen nach Kunstwerken zu suchen. In Modena wurde der Maler nicht nur mit höchsten Ehren aufgenommen, sondern er durfte aus der Medaillen-, Statuen- und Gemäldesammlung etwas nach dem Geschmack des Kaisers aussuchen, was - allerdings mit Verzögerung - schließlich nach Prag geschickt wurde. Die Freude Rudolfs darüber und die positive Fürsprache von Hans von Aachen mündeten schließlich in der Belehnung mit Sassuolo für die Este. ${ }^{350}$

\subsubsection{Gabentausch und Geschenkpolitik}

Geschenk und Gegengeschenk hatten in der Frühen Neuzeit eine beachtliche sozio-politische Bedeutung. Sie dienten der Anbahnung, Pflege und Aufrechterhaltung von Beziehungen und förderten den "Zusammenhalt[s] innerhalb einer Dynastie bzw. zwischen Herrscherhäusern und Regierungen«, so Mark Häberlein und Christof Jeggle in ihrer Einführung zum maßgebenden Sammelband Materielle Grundlagen der Diplomatie. ${ }^{351}$ Damit eine Gabe diese Aufgaben auch erfüllen konnte, musste der Akt des Schenkens öffentlich gemacht werden, z.B. im Rahmen einer möglichst gut besuchten Audienz. ${ }^{352}$ Für Stollberg-Rilinger gehört die Gabe wie die Opferhandlung zu den menschlichen Ritualen; ${ }^{353}$ Valetin Groebener definiert sie als Kommunikationsmedium. ${ }^{354}$ In ihrer Definition der Gabe und Gegengabe folgen diese Wissenschaftler/innen dem französischen Soziologen Marcel Mauss, der festgehalten hat, dass ein Geschenk materiell oder immateriell (Heiratspartner, Empfehlung, Ehrung, Dienstleistung, Patronage) zwar freiwillig erfolge, jedoch erwartet werde, (dankbar) angenommen und erwidert werden müsse und dadurch doch einem gewissen Zwang ${ }^{355}$ unterliege. Der Austausch von Geschenken und

349 Ebd., 2f, 9.

350 Venturi, Zur Geschichte der Kunstsammlungen, Io-I3.

35 I Häberlein/Jeggle, Einleitung, I 3 .

352 Fantoni, Feticci di prestigio, i42, i 5o. Vgl. auch Maria Visceglia/Brice, Cérémonial; Roosen, Early Modern Diplomatic Ceremonial. Siehe auch die Beiträge im Sammelband: Algazi/GroebeNER/Jussen, Negotiating the Gift.

353 Stollberg-Rilinger, Rituale, $78 \mathrm{f}$.

354 Groebener, Gefährliche Geschenke, 230.

355 Natalie Zemon Davis spricht von einer »verdichteten Kultur der Verpflichtung«. ZEmon Davis, Die schenkende Gesellschaft, Ioo. 
Gegengeschenken sei demnach unaufhörlich. ${ }^{356}$ Gerade diese Intensität des bilateralen Gabentauschs aber drücke - so auch Fantoni - die Qualität und Intensität der frühneuzeitlichen diplomatischen und persönlichen Beziehungen aus. ${ }^{357}$

Die Gabenkultur gehört als Form sozialer Beziehungen zur sozialen Institution der Patronage, vor allem da der unterschiedliche Zugang zu Ressourcen ${ }^{358}$ - und seien dies nun Titel oder Rassepferde - die Patron-Klient-Beziehung prägte. Die durch das Patronageverhältnis aufgebaute vertrauensvolle Beziehung war vom gegenseitigen Austausch von Gaben und einer die emotionale Bindung aufrechterhaltenden Korrespondenz begleitet. ${ }^{359}$ Durch Besuche, Gegenbesuche, Briefe, Gesandtschaften und Geschenke zeigten die Beteiligten Bereitschaft zum Kontakt und zur Kommunikation, während das Ausbleiben dieser Verhaltensnormen Beziehungsprobleme oder Konflikte signalisierte. ${ }^{360}$ Besonders nach dem Erstbesuch galt es, regelmäßig und kontinuierlich Kontakt zu halten bzw. eine reibungslose Übergabe von einem Diplomaten zum nächsten zu garantieren. Dazu diente mitunter die regelmäßige Überbringung von Grüßen, Höflichkeitsadressen, Glückwünschen und Gaben, die eine Nahbeziehung des Schenkenden und des Beschenkten für alle sichtbar machte und eine Festigung und Aufrechterhaltung des Kontaktes nicht nur mit dem Fürsten, sondern auch mit seinen Verwandten und anderen einflussreichen Persönlichkeiten des Hofes wie Minister, Sekretäre und Hofleute ermöglichte. Dabei entsprachen Art, Menge und Wert der Gabe der Rangordnung des Empfängers. Wieland hat dies anhand der Anzahl der vom toskanischen Gesandten nach Rom mitgeführten Austern und deren Verteilung - von 2.00o für Kardinal Borghese bis roo für andere Mitglieder der Kurie und des Papsthofes - aufgezeigt. ${ }^{361}$

Je höher der Schenkende und der Beschenkte in der hierarchischen Gesellschaft standen, desto wertvoller, ausgefallener und schwer erhältlich musste das Geschenk sein. Neben dem Eingehen auf Wünsche, Vorlieben, Leidenschaften musste das Präsent vor allem dem Rang aller am Gabentausch Beteiligten entsprechen. So war es ein Freundschaftsbeweis, wenn Kurfürst August von Sachsen Erzherzog Ferdinand II. auf dessen Bitte hin, aber nur unter dem Vorbehalt der Verschwiegenheit, sein persönliches Geheimrezept für die Herstellung eines vielseitig einsetzbaren Gegengifts übersandte. ${ }^{362}$

Geschenke erhielten nicht nur die Freundschaft, sondern versetzten den Gebenden in die Gunst des Empfängers. Gaben, die Entscheidungsfindungen erleichtern sollten,

356 Vgl. besonders Mauss, Die Gabe, insb. Einführung, I 5 - 26.

357 Fantoni, Feticci di prestigio, I 52.

358 Vgl. die Überlegungen bei MączaK, Ungleiche Freundschaft, 4If.

359 Droste, Patronage, 574 f.

360 Wieland, Fürsten, 3 I 7 .

36I Ebd., 3 I 8, 32 I, 334-346. Vgl. auch die Untersuchung von Ewert und Hirschbiegel zum Austausch von Neujahrsgeschenken zwischen Frankreich und Burgund: Ewert/Hirschiegel, Gabe und Gegengabe.

362 Minning/Kuster, Schenken \& Sammeln, I94f. 
gab es allerdings nicht nur für den Kaiser oder für potenzielle Fürsprecher im Reich, sondern auch für Minister, deren Einfluss kaum überschätzt werden kann. I59 I, in der heiklen Phase der Nachfolgeregelung, ließ Alfonso seinen Gesandten am Kaiserhof in Prag, Marcantonio Ricci, Paul Trautson 500 scudi bringen, damit diesem ein goldener Pokal $^{363}$ zum Geschenk gemacht werde, doch dieser bevorzugte das Geld, um eine Kette zu kaufen, wie der Gesandte berichtete. ${ }^{364}$

Wendet man sich in diesem Zusammenhang dem Beziehungsgeflecht zwischen den Este und den Fürsten jenseits des Alpenhauptkammes zu, dann wird nicht nur am letztgenannten Beispiel ersichtlich, dass das Heilige Römische Reich und Reichsitalien als Teil davon, wie Rudolph treffend formuliert hat, nicht nur ein »lehnsrechtliche[r] Herrschaftsverband «, sondern auch ein »Schenkraum» waren. ${ }^{365}$

\subsubsection{Geschenktes und (An)Gefragtes: Der Austausch von Lebensmitteln, Tieren und Alltagsgegenständen}

Neben Kunstwerken, Büchern und Kuriositäten wanderten auch Dinge ${ }^{366}$ des täglichen Gebrauchs, Nahrungs- und Genussmittel und vor allem Tiere ${ }^{367}$ (sowohl zum Verzehr als auch für Zucht, Ansiedlung und zur Gesellschaft) über die Alpen von

363 Groebener hat die Bedeutung der »flüssigen« Geschenke, so des Weines und der mit Münzen gefüllten Trinkgefäße hervorgehoben. Auch der Pokal gehört zu den flüssigen Geschenken aufgrund seines »leicht liquidierbaren Metallwert[es]«. Groebener, Gefährliche Geschenke, 64, 230.

364 ASMo, ASE, Casa e Stato, Carteggio di Ambasciatori, Germania b 48, von Marcantonio Ricci, Mai r 59 r. Zum Vergleich sei hier aus Rudolph, Fürstliche Gaben?, 97, Anm. 68 das Beispiel von August von Sachsen angeführt, der mit einer goldenen Kette den böhmischen Kanzler von Pernštein für sein Anliegen bezüglich des Vogtlandes für sich gewinnen wollte. Für das I7. und I 8. Jahrhundert hat Stollberg-Rilinger einen moralischen turn des Schenkens festgestellt. Hierbei rutschte der Akt des Schenkens immer mehr ins Private, einerseits weil es nicht möglich war, eine Leistung, die einem Geschenk voranging oder folgte, zu berechnen und andererseits, weil die Kritik immer lauter wurde, dass durch die Annahme eines Geschenks die Interessen des Einzelnen dem Gemeinwohl vorangestellt würden. Mit Geld hingegen konnte die Leistung leichter bemessen werden. Vgl. Stollberg-Rilinger, Zur moralischen Ökonomie, 202.

365 Rudolph, Fürstliche Gaben?, ro2.

366 Hier kann nicht weiter auf das derzeit große Forschungsinteresse für die materielle Kultur eingegangen werden. Es sei deshalb nur auf die Notwendigkeit hingewiesen, Objekten - nicht nur im Rahmen des hier beschriebenen Kulturtransfers, sondern auch allgemein - eine größere Bedeutung und Aufmerksamkeit zukommen zu lassen. So hat Kim Siebenhüner unlängst pointiert die Forderung formuliert, »die materielle Welt in das Verständnis des Sozialen und Kulturellen einzubeziehen. Wenn die Dinge Teil der menschlichen Umwelt und des alltäglichen Handelns sind, steht nicht nur die Soziologie, sondern auch die Geschichtswissenschaft vor der Aufgabe, diese Dinge in ihren Betrachtungshorizont (wieder) einzuschließen und zu fragen, in welcher Weise sie historische Gesellschaften, ihre Politik, Ökonomie und Kultur beeinflußten und mitbestimmten.« Kim SiebenhüNer, Things that matter, 384. Im letzten Teil dieses Beitrages geht Siebenhüner auf die bisherige Forschingslandschaft zum Thema ein.

367 Siehe auch: Weber, Lebende Geschenke; Taddei, Animals as Agents. 
Süden nach Norden und umgekehrt. Selbstverständlich war dieser Gaben- und Kulturgüteraustausch wie zahlreiche Quellen aus Mantua, Mailand oder Florenz belegen, nicht eine ausschließlich ferraresische Angelegenheit. So dankte - um nur ein Beispiel unter vielen zu nennen - der Berater des Kurfürsten von Sachsen im Namen seines Dienstherrn dem Herzog von Mantua für die Pferde und die Kristallvasen, die alle heil angekommen waren. ${ }^{368}$ Allerdings waren die Este mit ihrer europaweit bekannten Pferdezucht ${ }^{369}$ und ihrem musikalischen und künstlerischen Mäzenatentum bei vielen Anfragen nach bestimmten Gütern sehr wohl der erste Ansprechpartner.

Falken, Hunde und Pferde gehörten zu den beliebtesten lebenden Geschenken unter Fürsten und Fürstinnen. Vor allem Erzherzog Ferdinand II. hatte als Prager Statthalter einen solchen Bedarf an Raubvögeln und Hunden, dass er sich nach Bůžek dafür "ein Netzwerk von Zulieferern ${ }^{370}$ aufbaute, unter denen auch die Este zu finden sind. Auch Herzog Ulrich von Württemberg erhielt I 539 Falken aus Ferrara. ${ }^{371}$ Sowohl der estensische als auch der mantuanische Hof stachen unter den übrigen vor allem durch ihre mit Leidenschaft gepflegte Pferdezucht hervor, um die sie in Italien und im Reich beneidet wurden. ${ }^{372}$ Vor allem Alfonso II. hatte einen bemerkenswerten Reitstall, von

368 Dresden, SächHStA, Geheimer Rat (Geheimes Archiv) Loc. 8233/7 7-35-36, Andreas Pauli, Gesandter des Kurfürsten von Sachsen an den Herzog von Mantua, Juni 5 58 I.

369 Darin waren sie den Fürsten von Mantua fast ebenbürtig. Vgl. Bayreuther, Pferde und Fürsten, $44 f$. In Anm. 24 (I 55 ) verweist Bayreuther darauf, dass der Verfasser eines Lehrbuchs über die Reitkunst (Trattato dell'imbrigliare, ateggiare E ferrare cavalli, Bologna 1556), Graf Cesare Fiaschi, aus Ferrara und somit »einem der besten Pferdezuchtgebiete Italiens" stammte. Für das ausgehende r6. und beginnende I7. Jahrhundert spricht Bayreuther von einem "gut funktionierende[n] hippoliogische[n] Neztwerk [...], das vor allem die direkt Beteiligten, also (Ober)Stallmeister, Bereiter, Reitmeister uind Pferdehändler, umfasste." Bayreuther, Pferde in der Diplomatie, 230. Zum Einsatz von Pferden als diplomatisches Mittel zur Förderung der mantuanischen Beziehungen zu England siehe Tonnı, Allevamento; Ders., The Renaissance Studs of the Gonzagas.

370 BŮžEK, Ferdinand von Tirol, 236.

37 I ASMo, ASE, Casa e Stato, Minute di lettere ducali a Principi e signori fuori d'Italia, an Herzog Ulrich von Württemberg, Oktober I 539. Zu diesem I 498 - I 5 I 9 und I 534- I 55 O Herzog von Württemberg und ersten protestantischen Fürsten hier siehe Hermann Eнmer, Ulrich, Herzog von Württemberg, in: Biographisch-Bibliographisches Kirchenlexikon (BBKL) I 2, Herzberg I 997, Sp. 900-902.

372 Lazzari spricht von fast 400 Pferden der erlesensten Rassen in den estensischen Ställen. Lazzari, Le ultime tre duchesse, I4r. Nach den erhaltenen Pferdelisten im Bestand »Stalla« des Staatsarchivs in Modena belief sich der Tierbestand auf 200-300. So gab es im estensischen Gestüt z. B. I 5262 I I Pferde, Maultiere und anderes Packtier, im Jahr I56I 305, im Jahr I 563 3 1 8, im Jahr I 688 nur mehr 235. ASMo, ASE, Camera Ducale, Amministrazione della Casa, Stalla, Carteggio b. I, fasc. I : Ruoli e note dei cavalli. Besonders Kardinal Ippolito d'Este war ein Pferdenarr und Sammler von verschiedenen edlen Pferderassen, die er in zahlreichen Ställen der Stadt züchtete. Siehe Farinelli Toselli, Il Palazzo, 54f. Zum Vergleich: Für den fränkischen Raum hat Bayreuther einige Größenordnungen der Marställe eruieren können: So besaß Georg der Fromme, Markgraf von Ansbach, in den I 53 oer Jahren 70 Pferde bei einem Hofstaat von I 50 Personen und später I 36 Pferde bei ${ }_{2} 63$ Personen. Bayreuh ${ }^{-}$ TER, Pferde und Fürsten, Iogf. Im I 7. Jahrhundert besaß ein minderjähriger Erbprinz im Fürstentum Brandenburg-Bayreuth I3 Pferde (ohne Hofreitpferde), als regierender Landesherr ca. 65. Ebd. I 7 . 
dem man bis in den Norden des Reiches durch Mundpropaganda wusste. Die Herzöge von Bayern erhielten von den Este-Fürsten immer wieder so beeindruckende Pferde, dass sie wiederholt um weitere baten. ${ }^{373}$ Im Februar I 549 bedankte sich Herzog Moritz von Sachsen nicht nur für die Gastfreundschaft, die ihm in Ferrara durch Ercole II. zuteil geworden war, sondern auch für das Gastgeschenk ${ }^{374}$ eines überaus beeindruckenden Pferdes, ${ }^{375}$ mit dem er in die Schlacht von Sievershausen zog. ${ }^{376}$ Ebenso erbat und erhielt I57 I Johann Albert Herzog von Mecklenburg von Alfonso II. ein Pferd zum Geschenk. ${ }^{377}$ Während Ercole II. vor allem Hunde nach Brandenburg schickte, ${ }^{378}$ suchte Alfonso II. für Markgraf Joachim Friedrich von Brandenburg unter allen Pferden ein schönes braunes Exemplar mit weißer Stirn aus; das im Brief betonte persönliche Zutun bei der Auswahl steigerte den Wert des Geschenks. ${ }^{379}$

In Italien gezüchtete und dressierte Pferde, meist spanischer oder türkischer (also exotischer) Abstammung, galten im ausgehenden I 5. und im I6. Jahrhundert als ein Kunstwerk, ein außerordentliches, dem hohen Rang des Schenkenden und des Beschenkten entsprechendes Ehrengeschenk und waren ein heißbegehrtes Gut. ${ }^{380}$ Vor allem die nordischen Fürsten bemängelten die Tiere ihrer Gegenden und erbaten sich von den italienischen Verwandten und Freunden die Zusendung von Prachtexemplaren und laufend die Neubestückung ihrer Ställe. Herzog Georg II. von Brieg und Wohlau (I 523-I 586) vom Liegnitzer Zweig der Schlesischen Piasten, Verweser des Herzogtums Liegnitz, wandte sich mehrmals an Alfonso II. mit der Bitte um Pferde. Im März I 577 informierte er den Este über die Lage im Königreich Polen und fügte den Neuigkeiten sogleich hinzu, dass er dringend Pferde italienischer/neapolitanischer Rasse brauche, da es in seinem Land keine für einen Fürsten geeignete Tiere zu kaufen

373 ASMo, ASE, Casa e Stato, Carteggio di principi esteri, Germania b I593/r 9, Ludwig von Bayern an Alfonso I. und Ercole II., Juni und November I 536, Otto Heinrich von Bayern an Ercole II., Juli I 533, September I 536 und April und November I 540, Albert von Bayern an Ercole II., Juli I 559, Wilhelm von Bayern an Alfonso II., Juli und Oktober I 577, Oktober 1578.

374 Unter Gastgeschenk versteht man sowohl das Geschenk, mit dem sich der Besuchende beim Gastgeber für die Gastfreundschaft bedankt, als auch jenes, das der Gast als Dank für die Ehre seines Besuches erhält. Vgl. z.B. Rudolph, Fürstliche Gaben?, 95f, die den Besuch des Kaisers bei Reichsfürsten und in Reichsstädten untersucht.

375 ASMo, ASE, Casa e Stato, Carteggio di principi esteri, Germania b r6o3/29, Moritz von Sachsen an Ercole II., Februar I 549 .

$376 \mathrm{Konsch}$, Ein »heimlicher Vorschlag«, 40.

377 ASMo, ASE, Casa e Stato, Carteggio di principi esteri, Germania b I603/29, Johann Albert von Mecklenburg an Ercole II., Juni I 554 und an Alfonso II., April I 57 I.

378 ASMo, ASE, Casa e Stato, Carteggio di principi esteri, Germania b I599/25, Albert von Preußen an Ercole II., November 1556 .

379 ASMo, ASE, Casa e Stato, Minute di lettere ducali a Principi e signori fuori d'Italia, an Joachim Friedrich von Brandenburg, Mai 1577 .

380 Für manche Pferde wurde im r6. Jahrhundert auch I.00o bzw. I.500 Dukaten bezahlt. Bayreuther, Pferde in der Diplomatie, 234, 250. 
gäbe (»non abbiamo niente tra i cavalli nostri che sia molto a proposito o buono per la persona nostra, ne manco sappiamo ove haverne per denari «. ${ }^{381}$

Ebenso wichtig wie die Schönheit und Gesundheit der Tiere war ihre Ausbildung, die meist durch italienische Reitmeister (magister equorum) ${ }^{382}$ bzw. später durch einheimische, aber in Italien ausgebildete Fachkräfte erfolgte. ${ }^{383}$ So erbat sich z. B. Herzog Ludwig von Württemberg I580 von Alfonso II. die Ausbildung seines Pferdemeisters. Dieser sollte in Ferrara die Pferdedressur erlernen und dann in die Heimat zurückkommen. ${ }^{384}$ Die Geschenkpolitik ging somit mit einem fachspezifischen Wissenstransfer einher.

Der Austausch von lebenden Tieren war für die Este vor allem mit dem - verhältnismäßig - nahen Innsbrucker Hof sehr rege. I 575 bedankte sich Erzherzog Ferdinand II. bei Alfonso II. für die Zusendung von gewissen Medaillen, aber besonders für die mitgeschickte Hündin ${ }^{385}$ und revanchierte sich mit anderen im estensischen Fürstentum benötigten Tieren wie Vögel und Ziegen aus der eigenen Haltung, aber auch Hunden, die der Erzherzog aus England bezog. Am meisten vernarrt in Hunde war die dritte Ehefrau von Alfonso II., Margherita Gonzaga, die ihre sechs eigenen in Gedichten verewigte und für die sie aus Mantua Kleider besorgte, damit sie im Winter nicht froren. ${ }^{386}$ Weitere Hunde vom Innsbrucker Hof kamen als Gegengeschenk für die zwei Ochsen, ${ }^{387}$ die Alfonso II. Erzherzog Ferdinand II. neben einigen

38 r ASMo, ASE, Casa e Stato, Carteggio di principi esteri, Germania b I626/32, Georg von Schlesien und Lignitz an Alfonso II., März r 577 (mit der italienischen Übersetzung des estensischen Sekretärs anbei).

382 Mit diesen kamen auch Reitzubehör, Lehrbücher und schließlich italienische Fachausdrücke in den deutschen Sprachraum (z.B. Capriole = Bocksprung, vom Italienischen »capra»). Auch bei der Namensgebung der Pferde kam die Inspiration oft aus Italien. Bayreuther, Pferde und Fürsten, IOI-IO3.

383 Vgl. MARx, Italianità, I6- I g. Marx führt in ihrem Beitrag etliche interessante Beispiele namentlich bekannter Rittmeister an, die in Sachsen tätig wurden.

384 ASMo, ASE, Casa e Stato, Carteggio di principi esteri, Germania b I604/30, Ludwig von Württemberg an Alfonso II., September 1580 .

385 Innsbruck, TLA, Kart. 20I Pos. I 82 Welsche Schreiben, Erzherzog Ferdinand an Alfonso II., Oktober I575. Medaillen erfreuten sich im Renaissancehumanismus großer Beliebtheit: Sie waren klein und handlich, günstig und leicht herzustellen, gut zu verbreiten und von den Darstellungen der antiken Kaiser inspiriert. Man konnte das eigene Konterfei in der Manier der römischen Herrscher oder als Porträt bzw. Reiterstandbild darstellen und sich auf der Rückseite mit dem eigenen humanistisch inspirierten Emblem oder Motto verewigen. Vgl. Trenti Antonelli, Il ruolo della medaglia, 25.

386 Lazzari, Le ultime tre duchesse, 273.

387 Diese beiden Tiere gehörten zu den wenigen Besonderheiten, die Michel de Montaigne im Zuge seiner Badereise auf Schloss Ambras zu Gesicht bekam und in seinem Tagebuch erwähnte, da ihn weder der Erzherzog - aufgrund der Feindschaft der Habsburger mit Frankreich - empfing, noch eine Besichtigung des Schlosses ermöglicht wurde. »Auf den Feldern seines Schlosses sahen wir zwei Ochsen von ungewöhnlicher Größe, ganz grau mit weißem Kopf, ein Geschenk des Herzogs von Ferrara, der eine seiner Schwestern geheiratet hatte [...].« Montaigne, Tagebuch einer Reise, 76. Ochsen 
Fasanen hatte zukommen lassen. ${ }^{388}$ Die Ochsen hatte Ferdinand zusammen mit vier Stieren wiederholt über seine Schwester Barbara, mittlerweile Herzogin von Ferrara und Alfonsos Ehefrau, anfragen lassen, was wieder einmal die Bedeutung der Fürsprache durch - in diesem Fall verwandte - Fürstinnen beweist. ${ }^{389}$

Die verschiedenen Gaben, aber vor allem das Verschenken von Tieren scheint generationsübergreifend fortgeführt worden zu sein. I 559 dankte Kaiser Ferdinand I. dem Herzogssohn Alfonso für die Zusendung von Falken aus Ferrara. ${ }^{390}$ Als Römischer König hatte er bereits von dessen Großvater, Alfonso I. Tiere zum Geschenk bekommen, von denen er berichtete, dass die gut, gesund und vor allem lebend angekommen waren. ${ }^{391}$ Die Gesundheit und Unversehrtheit der wertvollen Tiere war - trotz der schwierigen Transportmöglichkeiten ${ }^{392}$ - ein wichtiges Kriterium und eine Ehrensache. I 564, kurz nach dem Tod Kaiser Ferdinands I., beauftragt Alfonso II. seinen Gesandten am Kaiserhof die bösen Gerüchte über die angebliche Krankheit seiner Pferde, die er dem Kaiser zum Geschenk gemacht hatte, vehement zu dementieren. ${ }^{393}$ I 569 bot Alfonso dem neuen Kaiser die Zusendung eines besonderen Pferdes ("parda [...] d'assai buona vita «) an, das er ausfindig gemacht hatte und mit dem er hoffte, Maximilian II. eine besondere Freude zu machen. ${ }^{394}$ Auch das Geschenk an Kaiser Rudolf II. ${ }^{395}$ I 586 war gelungen, wenn auch wenig überraschend, nachdem dem estensischen Gesandten die kaiserlichen Wünsche nach vier Rassestuten und einem Hengst genau mitgeteilt worden waren. ${ }^{396}$

waren als Zug- und Pflugtiere in Norditalien stark verbreitet, während man im deutschen Raum kaum auf sie zurückgriff und stattdessen mit Pferden arbeitete. So meinte auch der venezianische Gesandte Federico Badoer I 557: "In loco de bovi quasi p[er] tutto vien la terra arata da Cavalli«. Archivio di Stato di Venezia (ASVe), Collezione (Col.) V. Relazioni di Ambasciatori (Rel. Amb.) I 2 (6), rb, zit. n. Zucchi, Deutschland und die Deutschen, 4r6, Anm. I 508.

388 ASMo, ASE, Casa e Stato, Carteggio di principi esteri, Germania b I $583 / 9$, Erzherzog Ferdinand II. an Alfonso II., August und Oktober I 567 , Dezember 1585 .

389 Ebd., Erzherzog Ferdinand II. an Barbara von Österreich, August I 567.

390 ASMo, ASE, Casa e Stato, Carteggio di principi esteri, Germania b I 575/I, Kaiser Ferdinand I. an Alfonso II., Januar I 559 .

39I Wien, HHStA, Serie Italien-Kleine Staaten Karton ıo, Fasz. Ferrara I 528 - I758, Ferdinand, Röm. König, an Alfonso I., Juni I 535 .

392 Siehe die Schwierigkeiten der kaiserlichen Gesandten, in Spanien lebende Tiere nach Prag/Wien überführen zu lassen bei Strohmeyer, Kulturtransfer durch Diplomatie.

393 ASMo, ASE, Casa e Stato, Carteggio di Ambasciatori, Germania b 24, Minute di dispaccio per Germania an Ippolito Turco, August ${ }_{5} 64$.

394 Wien, HHStA, Serie Italien-Kleine Staaten Karton Io, Fasz. Ferrara I 528 - I 75 8, Alfonso II. an Kaiser Maximilian II., September I 569.

395 Über Rudolfs Geschenkepolitik siehe das Kapitel »Geschenke als Mittel der Repräsentation« bei VoCELKa, Die politische Propaganda, I66-i 73 .

396 ASMo, ASE, Casa e Stato, Carteggio di principi esteri, Germania b I 576/2, Kaiser Rudolf II. an Alfonso II., April r 586. ASMo, ASE, Casa e Stato, Carteggio di Ambasciatori, Germania b 38, minute di dispacci per Germania an Valentino Florio, Juli I 585 . 
Neben diesen Nutz- und Gesellschafts- bzw. Zuchttieren kamen zumeist über den Verkehrs- und Netzwerk-Knotenpunkt des Innsbrucker Hofs viele verschiedene Lebensmittel aus Ferrara ins Reich und umgekehrt. So überbrachte der Gesandte und Sekretär von Anna Caterina Gonzaga, der zweiten Gemahlin von Erzherzog Ferdinand II., Dario Castelletti da Nomi, Alfonsos Geschenke bestehend aus Obst, Wein, Salami, Süßigkeiten (Panpepati), Feigen, Käse, Mortadella, Cervelat und Spatzen. ${ }^{397}$ Doch auch Obstbäume (Pfirsich-, Marillen-, und Apfelbäume) und junge Pflanzen kamen aus dem milden Süden nach Tirol, wofür sich der Erzherzog mit Worten, aber auch mit Gegengeschenken bedankte: Da er wusste, dass Alfonso II. im Sommer gern Leder trug, schickte er ihm Gams- und Hundefelle zur Probe. ${ }^{398}$ Dazu kamen verschiedene Weine, Rhein- und Neckarwein, ${ }^{399}$ Stockfische, Hirschfett und Hirschhörner nach Ferrara. ${ }^{400}$

Oft wurden Geschenke und Delikatessen wie Mandeln, Granatäpfel, Zitrusfrüchte und Weine, die an den Innsbrucker Hof geschickt worden waren, weitergeleitet, weil sie für den Kaiser, für Minister oder andere Verwandte, so am bayerischen oder kursächsischen Hof gedacht waren. ${ }^{401}$ Über Innsbruck kamen auch die meisten Pflanzen für den Kaiserhof, wie die r 554 vom estensischen Gesandten Antonio Maria Col-

397 ASMo, ASE, Casa e Stato, Carteggio di principi esteri, Germania b $5_{5}$ 83/9, Erzherzog Ferdinand II. an Alfonso II., März und April I 59 o, Mai 1572.

398 Ebd., Erzherzog Ferdinand II. an Alfonso II., März I 574 und April I 576.

399 Dem Urteil von Orazio Della Rena nach hatten italienische Weine noch nicht das spätere Renommee. Über jene in Ferrara üblichen Sorten meinte der Gesandte, dass sie nicht besonders edel und dass viele französischer Herkunft seien. Della Rena, Relazione, zof. Montaigne befürchtete in Ferrara vom Wein, der gleich trüb, wie das Flusswasser war, sogar einen erneuten Kolikanfall zu bekommen. MonTAIgne, Tagebuch einer Reise, I05. Ähnlich urteilte der venezianische Gesandte Alvise Mocenigo, der von den deutschen Weinen lobend behauptete: »[...] sono eßi vini cosi buoni, che $\mathrm{p}[\mathrm{er}]$ giuditio mio sono migliori aßai di questi d'Italia«. ASVe., Col.. V, Rel. Amb. I I (I 5 ) 5 Ib, zit. n. Zucchi, Deutschland und die Deutschen, 4I7, Anm. I 52 I. Auch der Begleiter des Kaiserhof-Nuntius Commendone, Ruggieri, lobte in seinem Reisebericht die Qualität des Rheinweins. Braun, Imagines imperii, $596 \mathrm{f}$. Nach Frizzi hatte Alfonso II. aus Burgund Rebstöcke importieren lassen, die es zu seiner Zeit, also Anfang des I9. Jahrhunderts in Ferrara noch gab und Wein aus "goldenen Trauben« produzierten. Frizzi, Memorie, 449 .

400 ASMo, ASE, Casa e Stato, Carteggio di principi esteri, Germania b I 583/9, Erzherzog Ferdinand II. an Alfonso II., Mai I 588. Zum Vergleich sei hier auf die »Belieferung« des Prager Hofs als weiterer Knotenpunkt mit ähnlichen Lebensmitteln verwiesen: Hausenblasová, Prag, I9-2 I.

40I So kamen Geschenke aus Ferrara auch für die Minister und Berater Ferdinands und für seinen Sohn Kardinal Andreas von Österreich, der auch Wein und Obstbäume erhielt. ASMo, ASE, Casa e Stato, Carteggio di principi esteri, Germania b I583/9, Erzherzog Ferdinand II. an Alfonso II., April I 594. Pier Andrea Mattioli (I 500-I577), Arzt von Erzherzog Ferdinand II., machte sich als Botaniker auf Schloss Ambras einen Namen. Er war beim Anlegen der Pflanzenkulturen in Ruhelust und Ambras und für die Sendung von Samen nach Wien und Prag verantwortlich. Raffler, Von »studiolo«, 322. $\mathrm{Zu}$ den weitergeleiteten Lebensmitteln siehe auch die Hinweise in den Innsbrucker Quellen: Innsbruck, TLA, Raitbücher; HaAG, Fürstlich Tafeln, Katalog, 32. Vgl. auch dieselbe Praxis am Hof in Prag, Hausenblasová, Prag, 2 I. 
legno di Savoia mitgeführten Pfirsichbäume. ${ }^{402}$ Die Frischware traf allerdings nicht immer den Empfänger vor Ort: Vergebene Mühe war die Entsendung von Obst ${ }^{403}$ nach Wien für den Kaiser I 575, wenn dieser gerade nicht am Kaiserhof war. ${ }^{404}$ Im gleichen Jahr bedankte sich Erzherzog Karl bei Alfonso II. im Namen des Kaisers für die Zusendung der von ihm nach Prag weitergeleiteten Samen und Bäume. ${ }^{405} \mathrm{Im}$ Gabenaustausch fehlten auch Arznei- und Wundermittel, ärztliche Ratschläge und Behandlungsmethoden sowie Selbstgemachtes nicht: Der von Krankheit geplagte Erzherzog Ferdinand II. bestellte aus Ferrara Heilwasser der Aquariobäder für seine Gesundheit und erbat sich auch die Dienste des berühmten estensischen Hof- und Leibarztes Brasavola. ${ }^{406}$ I 553 bedankte sich Kaiser Karl V. mit einem spanischen Schreiben bei Ercole II. für die Zusendung einer »triaca«, eines Gegengifts, das sehr gut gewirkt haben soll. ${ }^{407}$ Auch die Zusendung von selbst Gekochtem, Gebackenem oder Gebranntem war eine besondere Aufmerksamkeit, schenkte der/die Gebende schließlich seine/ihre fürstlichen Fachkenntnisse und seinen/ihren Zeitaufwand dazu, was den Wert des Endproduktes steigerte. ${ }^{408}$

Nicht nur Lebensmittel und Speisen bzw. Rezepte wanderten von einem Hof und Kulturkreis zum anderen, sondern auch Besonderheiten bei der Tischgestaltung und dem Esszeremoniell. So kamen aus den oberitalienischen Höfen von Ferrara und Mantua bestimmte Formen von Tischdekorationen, darunter sehr aufwendige Serviettenfalttechniken, wie auch das mittlerweile zur Kunst avancierte Zerlegen von Fleisch und Fisch, die sogenannte Tranchierkunst am Tisch, an die Fürstenhöfe des Heiligen Römischen Reiches. ${ }^{409}$

402 ASMo, ASE, Casa e Stato, Carteggio di Ambasciatori, Germania b I5, Minute ducali an Antonio Maria Collegno di Savoia, Oktober 1554.

403 Am ferraresischen Obst lässt Orazio Della Rena ebenso kein gutes Haar, wenn er behauptet, dass es Wein im Überfluss, aber von schlechter Qualität gäbe, den die Ferrareser besonders liebten, wenn er etwas Schimmel angesetzt hätte. Es gäbe darüber hinaus wenig und schlechtes Obst, das nach Gewicht verkauft würde und geschmacklich nicht mit jenem der Hügellandschaft vergleichbar wäre. DeLla Rena, Relazione, 32-34.

404 ASMo, ASE, Casa e Stato, Carteggio di Ambasciatori, Germania b 3 I, Dispacci ducali per Germania an Paolo Carandini und Renato Cato, März 1575.

405 ASMo, ASE, Casa e Stato, Carteggio di principi esteri, Germania b I 585/r I, Erzherzog Karl an Alfonso II., April I 575 .

406 ASMo, ASE, Casa e Stato, Carteggio di principi esteri, Germania b I $583 / 9$, Erzherzog Ferdinand II. an Alfonso II., April 1576 und Juni 1584.

407 ASMo, ASE, Casa e Stato, Carteggio di principi esteri, Germania b I575/r, Kaiser Karl V. an Ercole II., Juni I 553. Um die Mitte des I6. Jahrhunderts war das Studieren von Giften und Gegengiften und das Experimentieren damit besonders an den Fürstenhöfen von Ferrara, Mantua und Modena stark vertreten. Bonora, Aspettando l'imperatore, 55.

408 Vgl. Hirschilegel/Ewert, Mehr als nur der schöne Schein, 45.

409 Die Tranchierkunst war zu einem regelrechten Unterhaltungsmoment der fürstlichen Tafel avanciert und verlangte eine dementsprechende Ausbildung, die sich auch in dazugehöriger Traktatliteratur und in Nachschlagewerken niederschlug. HAAG, Fürstlich Tafeln, 50, 76. 
Die gegenseitige Gunstbekundung und das verwandtschaftliche wie freundschaftliche Bindungsgeflecht drückte sich nicht ausschließlich im Austausch materieller Gaben aus, sondern auch in der Vermittlung und Einholung von Informationen, die zum Teil sogar wertvoller waren als Kulturgüter. So bat Erzherzog Ferdinand Alfonso II. um Auskunft, wo man Hunde bretonischer Rasse beiderlei Geschlechts erhalten könne und um die Vermittlung von Züchtern. ${ }^{410}$ I 576 entsandte der Erzherzog im Gegenzug einen Tiroler Experten in der fachgerechten Hirschhaltung an den estensischen Hof, der sein Wissen hier weitergeben sollte. ${ }^{411}$ Alfonso II. bedankte sich in seinem Brief an den Erzherzog und erläuterte, dass der geschickte Jäger ihnen gezeigt habe, wie die Umgebung (Gehege?) für die Hirsche gestaltet sein sollte; die Erfolge [dieses Wissenstransfers, E.T.] werde man nun abwarten müssen. ${ }^{412}$

Bereits 1533 hatte König Ferdinand I. über seinen königlichen Rat Hans Ungnad Freiherr von Sonneck, bei Alfonso I. anfragen lassen, ob dieser ihm seinen Gärtner, den aus Klagenfurt stammenden Hans Wolgemuet, der in den Ruf stand, ein Fachmann im Aufziehen und Pflegen von Kräutern und Bäumen auch exotischer Art zu sein, leihen könnte. Ferdinand wünschte sich nämlich die Wiederherstellung der verwahrlosten Burggärten in Wien. Der Gärtner kam über Innsbruck mit Gehilfen, "Pelzern«, Stecklingen und Setzlingen nach Wien und blieb mehr als einen Monat am Kaiserhof. Seinem Wunsch und dem des Königs, im Herbst mit weiteren Samen, Pflanzen und seiner Familie nach Wien zu kommen und zu bleiben, wollte Alfonso aber nicht stattgeben. ${ }^{413}$

Die Este hatten nicht nur eine berühmte und hervorragende Pferdezucht, sie waren auch wegen ihrer Waffen- und Reitkunst über ihr Fürstentum hinaus bekannt. Deshalb empfahl Herzog Albert von Preußen den Kriegsmann Bartholomeus Hengestium, damit er nach Ferrara kommen könne, um hier die Feuerwaffenkunst (bombantam) zu vertiefen. ${ }^{414}$ Herzog Ferdinand von Bayern hingegen bat I 577 um die Zusendung von Reitmeistern, die seinen Jungen in der Reitkunst unterreichten könnten. ${ }^{415}$

4IO Innsbruck, TLA, Kanzlei Erzherzog Ferdinand II. Ein-/Auslauf, Kart. Io, Erzherzog Ferdinand II. an Alfonso II., März I 564 .

4I I ASMo, ASE, Casa e Stato, Minute di lettere ducali a Principi e signori fuori d'Italia b I632/2, Alfonso II. an Erzherzog Ferdinand II., März I 576.

4I 2 Innsbruck, TLA, Kart. 3 I Pos. 26 Ferrara, Alfonso II. d'Este an Erzherzog Ferdinand II., April I 576.

4I3 Lietzmann, Irdische Paradiese, 46-48 und die hier angegebenen Archivquellen. Auch für den königlichen Lustgarten in Prag ließ König Ferdinand zahlreiche Früchte und Bäume, oder wenn diese den Transport nicht überstehen konnten, deren Samen und Kerne, wie jene der Mandeln und Pfirsiche, ankaufen. Auch hier war Innsbruck ein wichtiger Dreh- und Angelpunkt in der Vermittlung und in der Zustellung. Vgl. ebd., 74f. Vgl. auch Hausen blasová, Prag, 2 r.

4I4 ASMo, ASE, Casa e Stato, Carteggio di principi esteri, Germania b I599/25, Albert von Preußen an Alfonso II., April 1550.

4I 5 ASMo, ASE, Casa e Stato, Carteggio di principi esteri, Germania b I 593/ I 9, Ferdinand von Bayern an Alfonso II., März I 577 . 
Schließlich wirkten Geschenke auch in der Familienmemoria nach. Als Kurfürst August von Sachsen 1586 starb, wollte sein Sohn Christian I. mit einem italienisch inspirierten Repräsentativbau, genannt Neuer Stall, seine memoria ehren und schickte Gesandtschaften an die einzelnen italienischen Fürsten mit der Bitte um freundschaftlichen Verkauf von edlen Pferden. Alfonso II. beteiligte sich mit zwei braunen Hengsten, einer Fuchsstute und einer schwarzen Stute und Francesco de'Medici und Vincenzo Gonzaga standen ihm in der Auswahl ihrer Tiere in nichts nach. Dazu schenkten die Herzöge von Florenz, Mantua, Ferrara und Turin Prunkwaffen und Harnische, darunter auch einige orientalischer Herkunft. ${ }^{416}$ Die geschenkten Prunkrösser waren aber nicht der einzige Ausdruck dieses Austausches. Für das fürstliche Andenken wurden die Tiere in Dresden "porträtiert«. Deren Konterfeis wurden dann im Langen Gang, in der hofseitigen offenen Bogenhalle, zusammen mit der Ahnengalerie des sächsischen Herrschers angebracht und stellten eine Beteiligung der befreundeten italienischen Fürsten an der Fürstenmemoria dar. ${ }^{417}$

4I6 MArx, Künstlermigration, 26r-263 und Dies., Italianità, I7-20. Dazu siehe auch die Quellen in Dresden, SächHStA, Loc. 85 I7/5, 257r-v, Kurfürst Christian I. von Sachsen an die Herzöge von Savoyen, Mantua, Florenz, Ferrara und Urbino, 9. Oktober 1586.

4I7 Vgl. Bäumel, »so vil Dings zu sehen«, 40. 


\subsection{Austausch von Personen - Austausch über Personen}

Personen waren - wie schon an einzelnen oben genannten Beispielen sichtbar wurde innerhalb des kulturellen Austausches nicht nur als Vermittler tätig, sondern aufgrund ihrer Fertigkeiten und Talente oft als »Austauschgegenstand « selbst Bestandteil des Transferprozesses. Diese Personen unterschiedlichen Ranges wurden unter Fürsten und Fürstinnen, oft über ihren Kopf hinweg und auch gegen ihren Willen, weitergereicht, aufgenommen und wieder entlassen. Dies betraf Künstler und Handwerker, Schreiber, Sekretäre oder Gelehrte, Beichtväter und Ordensleute und im ferraresischen Fall auch Offiziere. ${ }^{418}$ Durch den Aufenthalt dieser »Fachleute« in einem fremden Land bzw. an einem kulturell anderen Fürstenhof, brachten sie, ebenso wie fremde Fürstinnen im Rahmen von Heiratsbeziehungen, eigene, materielle wie geistige Kulturgüter in ihr neues bzw. temporäres Zuhause und bei ihrer Rückkehr neue Impulse in ihre alte Heimat. Dieser Personenaustausch geschah manchmal auf Empfehlung, manchmal auf dezidierte Nachfrage. So wünschte sich Erzherzogin Barbara den Hofmeister Blasius Khuen in Ferrara und bat ihren Bruder eindringlich, er solle diesem erlauben, in ihre Dienste zu treten, was Erzherzog Ferdinand aber nur für die Dauer des Brautzuges und der Hochzeitsfeierlichkeiten erlaubte. ${ }^{419}$ Erzherzog Karl bedankte sich 1570 bei Alfonso II. dafür, dass er ihm für die Verhandlungen mit Venedig über Friaul ${ }^{420}$ seinen Hofanwalt Fontana und den Rechtsgelehrten Doktor Roncagalli geliehen hatte. ${ }^{421} \mathrm{Da}$ der Erzherzog mit den Diensten der ferraresischen Juristen zufrieden war, bat er I 5 Jahre später wieder um jemanden aus der juridischen Fakultät in Ferrara, um einen Streit über die freie Durchfahrt in der Adria von Venedig nach Malta zu verhandeln. ${ }^{422}$

Doch Fürsten und Fürstinnen schoben nicht nur Personen von ihrem Hof zu einem anderen, sondern sie waren auch erste Ansprechpartner/innen und Fürsprecher/ innen für die Mobilität und Karrierechancen von Dienstnehmer/innen. Wohlwollende

4I 8 Die zahlreichen Empfehlungen für eine Möglichkeit der Ausbildung bzw. Anstellung in Ferrara rührten nicht zuletzt vom Renommee der herzoglichen Garde: Alfonso umgab sich mit roo Hellebardieren, 50 Schweizern und 50 Deutschen Landsknechten, roo Leichtbewaffneten und noch etlichen Dutzend Reitern. Auf seinen Spaziergängen war er stets von zwei hünenhaften deutschen Gardisten begleitet. LAzzari, Le ultime tre duchesse, I 40, 3 I 9. Im Castello Estense gab es eigene Dienstzimmer für diese Garde, die Tedeschi genannt wurde. Borella, Il Palazzo di Corte, 24.

4I9 ASMo, ASE, Casa e Stato, Carteggio di principi esteri, Germania b I 576/2, Erzherzogin Barbara an Erzherzog Ferdinand II., Oktober ${ }_{5} 65$.

420 Hier ging es um den venezianisch-habsburgischen Grenzstreit, den Achim Landwehr in seiner Studie zu Venedig als Beispiel für das damals vorherrschende "partiell durchlässige[s] « Raumverständnis näher beleuchtet hat. LANDweHr, Die Erschaffung Venedigs, 88.

42 I ASMo, ASE, Casa e Stato, Carteggio di principi esteri, Germania b I 585 / I , Erzherzog Karl an Alfonso II., Januar und August I 570.

422 Ebd., Erzherzog Karl an Alfonso II., Februar I 585 . 
Fürsten und Fürstinnen trugen an sie gerichtete Interzessionen, d.h. Bitten um Empfehlung, Anstellung oder Aufnahme bzw. Rückkehr an einem bestimmten Hof ihrem fürstlichen Pendant weiter und bedankten sich bzw. revanchierten sich gegebenenfalls für die erfolgreiche Vermittlung. Meistens wussten die Bittsteller, an wen sie sich in welcher Angelegenheit besser wenden sollten und wer ihnen mehr Gehör zu geben versprach. Für eine Fürsprache am Kaiserhof eignete sich in ihrer, wenn auch kurzen Anwesenheit in Ferrara Erzherzogin Barbara, an die sich z.B. Girolamo Tonca, Doktor der Rechte, mit der Bitte um eine Empfehlung wandte, da er gern im Dienst des Kaisers tätig sein wollte. ${ }^{423}$

Vor allem beim Ableben einer in der Fremde verheirateten Fürstin galt es, die oft mitgereisten Hofdamen und Hofbediensteten wieder zurück an ihren Heimathof oder einen anderen Hof zu vermitteln. ${ }^{424}$ Das tat auch Alfonso II., der Erzherzog Ferdinand in Innsbruck einige Hofbedienstete ${ }^{425}$ und dem Kaiser die Gräfin Beatrice, Nichte des Grafen Gasparo di Lodrone, Hofdame der Herzogin Barbara, empfahl. ${ }^{426}$

Doch auch der Kaiser selbst empfahl seinem estensischen Vasallen Söhne und Töchter seiner Vertrauten und Hofmänner. So legte z.B. Rudolf II. Alfonso II. die Kinder seines consiliarius, Seyfried Preyner, ans Herz, damit sie in Ferrara gut aufgehoben seien. ${ }^{427}$

Der glückliche Austausch und die erfolgreiche Vermittlung von Personen waren natürlich auch von den allgemein bekannten oder durch Diplomaten verbreiteten Interessen, Vorlieben und dem aktuellen Bedarf eines Fürsten oder einer Fürstin abhängig. Ein Beispiel - für viele - aus den estensischen Quellen zeigt dies: Dorothea von Lothringen, Herzogin von Braunschweig, hatte in Perugia ein Mädchen zu sich genommen, das hervorragend singen konnte. Dieses hatte sich in ihren Sekretär verliebt; weil die Herzogin aber Italien wieder verlassen musste, empfahl sie die beiden Alfonso II. d'Este, in der Hoffnung, dass er - u.a. als bekannter Förderer der Musik und Liebhaber des weiblichen Gesangs - Verwendung für die Beiden hätte. ${ }^{428}$ Dieselbe Dorothea von Braunschweig bat I 596 wiederum um Lizenz (d.h. um Dienstentlassung) für einen Pagen aus dem Hause Vergi, den Alfonso bei ihrem Aufenthalt in Ferrara auf der Rückreise von der Hochzeit des Großherzogs von Toskana über-

423 Ebd., Erzherzogin Barbara an Kaiser Maximilian II., April I 570.

424 Vgl. diese vom Tod einer Fürstin bedingte Fluktuation im I7. Jahrhundert bei: Keller, Hofdamen, $66-72$.

425 ASMo, ASE, Casa e Stato, Minute di lettere ducali a Principi e signori fuori d'Italia b I632/2, Alfonso II. an Erzherzog Ferdinand II., Dezember I 572, März, Mai I 573.

426 ASMo, ASE, Casa e Stato, Minute di lettere ducali a Principi e signori fuori d'Italia b I63 I/I, Alfonso II. an Kaiser Maximilian II., Februar I 576.

427 Wien, HHStA, Serie Italien-Kleine Staaten Karton Io, Fasz. Ferrara I 528 - I 75 8, Kaiser Rudolf II. an Alfonso II., November 1585 .

428 ASMo, ASE, Casa e Stato, Carteggio di principi esteri, Germania b I 599/25, Dorothea von Braunschweig an Alfonso II., September I 590. 
nommen hatte. Da dieser nun fast erwachsen sei und wie alle Adeligen zu Hause in der Kriegskunst fertig ausgebildet werden sollte, bat sie darum, ihn zurückkehren zu lassen. ${ }^{429}$ Es verwundert, dass die Herzogin von Braunschweig besagtem Pagen nicht in Ferrara auch den letzten Schliff in der Kriegskunst geben ließ, war der Hof der Este auch dafür berühmt. Kurfürst August I. von Sachsen empfahl Alfonso II. nämlich u.a. den Sohn von Petrus Loys de Donden, der in der Kriegs- und Reitkunst in Ferrara ausgebildet werden wollte. ${ }^{430}$

Künstler, Fachleute und fähige Handwerker gingen also nicht nur ins Reich, ${ }^{431}$ sondern sie kamen auch nach Ferrara, um ihre Fertigkeiten zu beweisen und neue zu erlernen. So schickte ${ }_{55} 6$ Herzog Johann Albrecht von Mecklenburg seinen Architekten, Francisco Vuarano, zu Ercole II. nach Ferrara, um sich von der dortigen Bauweise, vor allem im Festungsbau, belehren und inspirieren zu lassen. ${ }^{432}$ Manchmal waren die Beweggründe für die Migration an einem anderen Hof nicht nur die Anfrage eines Fürsten/einer Fürstin oder der eigene Wunsch, sich in einer Fertigkeit, wie der Sprache oder den Waffenkünsten zu verbessern, sondern die Religion/Konfession. Erzherzog Ferdinand II. empfahl I 587 Alfonso II. einen gewissen Sigismund von Tettelbach, der am Hof von Johann Friedrich Markgraf von Brandenburg tätig war, aber aufgrund der dortigen Konfessionsverhältnisse nicht mehr bleiben konnte. Da er in Padua studiert hatte und in der Musik und den Waffenkünsten geübt war, bat er nach Ferrara kommen zu dürfen, wo er hoffte, seine Fertigkeiten und seinen Glauben ausüben zu dürfen. ${ }^{43}$

Eine häufige an den ferraresischen Hof gerichtete Empfehlung betraf ein Universitätsstudium und/oder einen Sprachaufenthalt. ${ }^{434}$ Die Universitätszentren der PoEbene wie Bologna, Padua, Ferrara und Pavia waren besonders im I 5. und I6. Jahrhundert beliebte Ziele der peregrinatio erudita. I 537 bat Herzog Otto Heinrich von Bayern Ercole II. einen gewissen Rudpertus und seine Familienangehörigen aufnehmen zu wollen, die in Ferrara Italienisch lernen wollten. ${ }^{435}$ Manchmal war der (Sprach-)Aufenthalt Bestandteil der Kavalierstour, aber manchmal diente er auch der sprachlichen Vorbereitung für das Studium an einer italienischen Universität und - nicht selten der Ausbildung für den Hofdienst. ${ }^{436}$ So empfahl Erzherzog Ferdinand II. Gabriel

429 Ebd., Dorothea von Braunschweig an Alfonso II., August 1596.

430 ASMo, ASE, Casa e Stato, Carteggio di principi esteri, Germania b r603/29, August I. von Sachsen an Alfonso II., März I 574 .

43 I Vgl. - wenn auch vermehrt mit Beispielen aus dem I7. Jahrhundert - Schinding, Bei Hofe.

432 ASMo, ASE, Casa e Stato, Carteggio di principi esteri, Germania b I603/29, Johann Albert von Mecklenburg an Ercole II., November 1556.

433 ASMo, ASE, Casa e Stato, Carteggio di principi esteri, Germania b I $583 / 9$, Erzherzog Ferdinand II. an Alfonso II., September 1587.

434 Vgl. dazu auch TADdeI, »Nach Italien nit allein zur Erlehrnung der Sprache«.

435 ASMo, ASE, Casa e Stato, Carteggio di principi esteri, Germania b I 593/r 9, Otto Heinrich von Bayern an Ercole II., August I 537.

$436 \mathrm{Zu}$ den Aufstiegschancen im habsburgischen Hofdienst siehe u.a.: Noflatscher, Funktionseliten. 
Strein Freiherr in Schwarzenau, Rat am kaiserlichen Hof, der seinen Sohn Gianni Gothardo Strein (in der bereits italienisierten Form seines Namens) nach Ferrara schicken wollte, um neben anderen »Adelsfähigkeiten« die Sprache zu erlernen. ${ }^{437}$ Auch der kaiserliche Rat, Graf Joachim Kollowrat bedankte sich I 583 bei Alfonso II. d'Este für die Aufnahme in Ferrara von seinen Sohn, bereits Page am Kaiserhof, der bei ihm sowohl die Sprachkenntnisse als auch seine Persönlichkeit verbessern sollte: »acchiochè cercase del mondo e imparase virtute et gregie. ${ }^{438}$ Ebenso verwendete sich Erzherzog Ferdinands zweite Gemahlin, Anna Caterina Gonzaga, für Höflinge, die das Italienische erlernen wollten und verwies sie, interessanterweise nicht nach Mantua an ihren Heimathof, sondern nach Ferrara, wo ihre Schwester Margherita Alfonsos II. dritte Ehefrau geworden war. Sie empfahl ihrem Schwager den Sekretär und Doktor Henrics Starck aus Innsbruck, der die italienische Sprache erlernen und in Ferrara dienen wollte. ${ }^{439}$

Nicht nur der Landesfürst von Tirol, sondern auch die Herzöge von Bayern und jene von Mecklenburg betätigten sich als Vermittler von Sprachaufenthalten; im Falle des von Albrecht von Bayern an Ercole II. empfohlenen jungen Sebastianus Zenger appellierte ersterer mit der Angabe an die Interessen des Este, dass der Junge militärisch versiert und aus gutem Hause sei. ${ }^{440}$ Wilhelm von Bayern sprach sich für den jungen Johannes Mattheus Soner aus, der am estensischen Hof die italienische Sprache

437 ASMo, ASE, Casa e Stato, Carteggio di principi esteri, Germania b I 583/9, Erzherzog Ferdinand II. an Alfonso II., März I 588.

438 ASMo, ASE, Casa e Stato, Carteggio di principi esteri, Germania b I 577/3, Joachim von Kollowrat an Alfonso II., Mai I 583 . Allerdings bat er den Este auch um Hilfe in einer peinlichen Notlage: Er hatte seinen Sohn einem gewissen Scipione Piramo anvertraut und diesem viel Geld für die sorgene Aufsicht gegeben. Der Italiener hatte jedoch keine Rechenschaft über die Ausgaben ablegen können. Der Vater bat daraufhin den Herzog von Ferrara besagten Piramo zur Rechenlegung zwingen zu wollen.

439 ASMo, ASE, Casa e Stato, Carteggio di principi esteri, Germania b I 586/ I 2, Erzherzogin Anna Caterina Gonzaga an Alfonso II., März I 585 . Für die zweiten Hälfte des I6. Jahrhunderts hat Savio am Beispiel von kaiserlichen Vasallen in dem von der Serenissima beherrschten Veneto, wie der Familie der Valmarana, gezeigt, dass die »Auswanderung« von jungen Adeligen, die in den Hofdienst traten und eine Fremdsprache erlernen wollten, auch in die entgegengesetzte Richtung verlief: Die Söhne und eine Tochter von Leonardo Valmarana wurden an die habsburgischen Höfe von Innsbruck, Graz und Wien zur höfischen und sprachlichen Ausbildung geschickt und blieben hier als Befehlshaber bzw. Hofdamen in habsburgischen Diensten. SAvio, Nobili vicentini. Zu den Italienern im militärischen Bereich siehe Rевітsсн, Italienische Militärs. Diese adelige »Karrieremigration« aus Italien an den Kaiserhof intensivierte sich im darauffolgenden Jahrhundert weiter. Aus der Analyse von Testamenten vom Habsburgerhof zwischen 1638 und 1663 hat Alessandra Dattero 323 Italiener/innen gezählt, von denen 30 \% Musiker, 23 \% Kleriker, 6 \% Bedienstete, 5 \% Ärzte, 4 \% Sänger, 4 \% Boten und die restlichen Mathematiker, Physiker, Sekretäre, Hofdamen und -männer, Pagen oder andere Amtsanwärter waren. Im Zuge des Dreißigjährigen Krieges waren vor allem italienische Offiziere im kaiserlichen Heer gefragt. Dattero, Corte, $344 f$.

440 ASMo, ASE, Casa e Stato, Carteggio di principi esteri, Germania b I593/r 9, Albert von Bayern an Ercole II., Februar I 555 . 
erlernen wollte. ${ }^{441}$ I 555 schickte der Herzog von Mecklenburg Johann Albert Daniel a Lahden und Baltazar Klinten nach Italien, um Sprache und Land kennenzulernen. ${ }^{442}$

Die Sprachbarrieren zwischen den europäischen Fürstenhöfen zwangen auch zum Austausch von fähigen Übersetzern. Alfonso II. bat den erzherzoglichen Gesandten Dario Castelletti da Nomi, im Dienst von Ferdinandvon Tirol und seiner zweiten Gemahlin Anna Caterina Gonzaga tätig, ihm einen fähigen Übersetzer, der des Deutschen und Italienischen mächtig sei, zu empfehlen, damit der Erzherzog in Zukunft auch Deutsch schreiben könne. ${ }^{443}$

Entweder beherrschte man die Sprache verwandter und befreundeter Fürsten außerhalb Italiens, oder man behalf sich mit geeignetem »Personal«, was wiederum auch eine Form des kulturellen Austauschs durch Personen bedeutete: Herzog Julius von Braunschweig-Lüneburg rühmte sich Alfonso II. gegenüber, genug fähiges Übersetzungspersonal an seinem Hof zu haben, sodass er seine Briefe auf Deutsch aufsetzen (lassen) konnte, welche dann übersetzt würden. Der Este könne somit getrost Italienisch, Französisch oder Latein schreiben, wie er gerade möchte. ${ }^{444}$

44I Ebd., Herzog Wilhelm von Bayern an Alfonso II., Februar I 569 .

442 ASMo, ASE, Casa e Stato, Carteggio di principi esteri, Germania b 1603/29, Johann Albert von Mecklenburg an Ercole II., Juni r 555.

443 ASMo, ASE, Casa e Stato, Carteggio di Ambasciatori, Germania b 47, Minute di dispacci per Germania an Dario Castelletti, Juni und Oktober I 59r.

444 ASMo, ASE, Casa e Stato, Carteggio di principi esteri, Germania b I5 99/25, Julius von BraunschweigLüneburg an Alfonso II., Juli I 588 . 


\subsection{Kulturaustausch durch Mobilität: Reisen und Besuche}

In der Frühen Neuzeit gab es neben der »berufsbedingten« Mobilität von Kaufleuten, Gesandten oder Soldaten, auch anders motivierte, nach außen hin "freiwillige«, aber zumeist politisch konnotierte Ortswechsel. Fürsten und Fürstinnen reisten zu Krönungen, Reichstagen oder anderen politischen Zusammenkünften mit einem hohen Präsenzzwang und Öffentlichkeitscharakter, aber auch zu Familienbesuchen, besonders anlässlich von Feierlichkeiten (Hochzeit, Taufe) oder Vergnügungen (Karneval, Kunstkäufe), aus beruflicher, gesundheitlicher oder spiritueller Notwendigkeit (Ausbildung, Kur, Wallfahrt) oder im Zuge der Brautwerbung, -abholung bzw. Brautreise. ${ }^{445}$

Das Reisen war - unabhängig vom Mobilitätsgrund - ohne Zweifel ein wichtiger Impuls zum Kulturaustausch zwischen Germanità und Romanità. Im Zuge der peregrinatio academica kamen Studierende an die dem estensischen Fürstenhof nahen Universitäten von Padua, ${ }^{446}$ Bologna oder Ferrara zum Zwecke der Erlangung einer Doktorwürde und aufgrund der Nachfrage nach juristisch geschulten Verwaltungsfunktionären im Reich. ${ }^{447}$ Bei der peregrinatio erudita, der Bildungsreise, kamen Gelehrte nach Italien, um sich z.B. im Griechischstudium zu perfektionieren und oft gleichzeitig, dem Ruf eines Fürsten folgend, eine Zeit lang an seinem Hof tätig zu sein und an »seiner« Universität zu lehren.

Zur adeligen Mobilität der Renaissance gehörten auch die seit dem Mittelalter üblichen Pilger- und Wallfahrten und die frühe Form der Kavaliersreisen (Grand Tour) nach Frankreich und Italien, die »als adlige >Initiationsform prägtes Reisekonzept eingebunden wurden ${ }^{4}{ }^{48}$ In all diesen Bewegungen war Italien nicht das einzige, aber aufgrund der Anziehungskraft der Renaissancekultur sicher das am häufigsten angestrebte Ziel. ${ }^{449}$ Auch wenn die ritterlich-höfisch geprägte Lebensweise und der Bildungskanon junger Adeliger an der Wende vom I 5. zum I6. Jahrhundert noch keinen Universitätsbesuch mit akademischem Abschluss vor-

445 Ganz allgemein zur Reise und Reisekultur in der Frühen Neuzeit siehe: Bausinger, Reisekultur; Gräf/Pröve, Wege ins Ungewisse; Maurer, Neue Impulse; Mączak, Viaggi; Schlesinger, Reisen; Stauber, Bayern und Italien, hier bes. das Kapitel: „Unterwegs über die Alpen«, 38. Interessante Aspekte der frühneuzeitlichen Mobilität sind auch im Bd. 28 der Innsbrucker Historischen Studien aufgearbeitet worden: Taddei/Müller/Rebitsch, Migration und Reisen. Zur Brautreise siehe: Spiess, Unterwegs zu einem fremden Ehemann.

446 Zur Bedeutung der natio germanica in dieser Universitätsstadt siehe: Galtarossa, Padova città imperiale.

447 Vg1. die zahlreichen Angaben von Ferrara als Studien- oder temporärer Aufenthaltsort im Rahmen der peregrinatio academica in der prosopografischen Studie über die Universitätseliten von Rostock, Greifswald, Trier und Mainz. Irrgang, Peregrinatio academica, I I 5, I 24, I 29 und passim.

448 Bender/Herzog/Niehaus, Die Kavalierstour, 57 I.

449 Matschinegg, Ausländer in Italien, $73 \mathrm{f}$. 
sahen, entwickelte sich in der ersten Hälfte des r6. Jahrhunderts eine neue Form der humanistisch geprägten Erziehung junger Adelssöhne (weniger der Adelstöchter), die zur Ausbildung am Heimathof auch die Erfahrungen fern von zu Hause durch eine ausgedehnte Bildungsreise, später Kavalierstour genannt, und/oder den Aufenthalt an einem anderen Fürstenhof vorsah.

Bei den aufstrebenden, nicht aus dem Adel kommenden Bürgerssöhnen oft angesteuerte Reiseziele waren die renommierten Juristenhochschulen in Frankreich und Italien, wo - gerade in Bologna - die deutsche Nation (natio germanica) unter den Studierenden am stärksten vertreten war. Italien war aber besonders wegen des an den hofnahen Universitäten und accademie gelebten Renaissancehumanismus und für das Erlernen der italienischen Sprache als eine lingua franca interessant. ${ }^{450}$ Die hier studierenden und residierenden Deutschen waren oft Anlaufstelle für Reisende im Rahmen der Kavalierstour, die sich auch für eine Zeit lang immatrikulierten (Ehrenimmatrikulationen) und das Studentenleben mit all seinen Privilegien und der größtmöglichen Sicherheit für Reichsuntertanen im Ausland genossen. ${ }^{451}$

Vor allem für Katholiken war Italien ein beliebter Aufenthalts- und Studienort, da sich die Frage der Konfession nicht stellte. Doch das Renommee Paduas als Medizin- oder Bolognas und in zweiter Linie auch Ferraras als Rechtsuniversität zogen auch viele Protestanten nach Italien, wofür eigene Maßnahmen hinsichtlich der öffentlichen Ruhe, der Gottesdienste, theologischer Diskussionen und Fastenregelungen erlassen werden mussten. Diese »konfessionelle Flexibilität«, gepaart mit dem Ruf der italienischen Hochschulen und mit den Anforderungen des humanistischen Bildungsideals (Griechischkenntnisse), steigerte die Frequenz von Studierenden aus dem Reich an den italienischen Universitäten. ${ }^{452}$ Neben den Fürstensöhnen, die sich im Zuge der Kavalierstour in den italienischen Städten und an den dortigen Höfen aufhielten, zogen vor allem die Sprösslinge von Hof- und Stadteliten zum Studium nach Italien,

450 Matschinegg, Das Studium in Italien, I6 If. Siehe auch Dies., Österreicher als Universitätsbesucher. Wenn eine Schätzung für den Zeitraum von ${ }_{5} 50$ bis I630 von ca. 8.000 deutschen Studierenden in Padua spricht, dann kann davon ausgegangen werden, dass darunter viele inskribierte Durchreisende auf Kavalierstour so wie jene, die nur den rechtlichen Schutz der Universität genießen wollten, waren. Matschinegg, Ausländer in Italien, 74.

45 I Matschinegg, Das Studium in Italien, I66. Auch in den von Stefan Ehrenpreis untersuchten Biografien der Reichshofräte finden sich Studienaufenthalte und -abschlüsse in Italien und darunter vor allem in Bologna, Padua und auch in Ferrara. Seyfried Freiherr von Breuner studierte in Wien und Padua Rechte und kam in diplomatischer Mission nach Ferrara, bevor er 1568 in den Reichhofrat berufen wurde; Dr. Timotheus Jung studierte die Rechte in Tübingen, Bologna und Ferrara und wurde hier promoviert. Ehrenpreis, Kaiserliche Gerichtsbarkeit, 292, 302. Zur Arbeit und Tätigkeit der Reichshofratsagenten siehe auch Ders., Navigatoren des Imperiums.

452 Vgl. auch die Untersuchung des Universitätsbesuchs von Studenten aus Innerösterreich: MatschiNEGG, Zum Universitätsbesuch. Hierbei waren die Hochschulen von Padua, Siena und Bologna am meisten besucht; Ferrara steht zusammen mit Perugia, Pisa und Pavia hinter diesen. Vgl. ebd., 5 I 6. 
um - wie Häberlein es ausdrückt - neben Sprachkenntnissen »Weltläufigkeit« und »kulturellen Geschmack« als »Status- und Distinktionsmerkmal« zu erwerben. ${ }^{453}$

Verständlicherweise führte auch diese Form von Kontakt mit Fremden zu Aspekten kulturellen Austausches. Ingrid Matschinegg hat aufgezeigt, wie sehr sich im Zuge des studentischen Italienaufenthalts und Zusammenlebens von Katholiken und Protestanten hier die Alltagsgewohnheiten und insbesondere das Essverhalten aufweichen konnten. ${ }^{454}$

Eine Kavalierstour dauerte durchschnittlich ein bis drei Jahre und hatte Italien als alleiniges oder zumindest als Hauptziel; man reiste in Gruppen mit genügend »Personal«, darunter ein Präzeptor oder Hauslehrer, oft auch ältere Brüder und andere Verwandte; man war in den größeren Städten wie Venedig, Padua, Florenz, Rom oder Neapel stationiert und unternahm von dort aus Ausflüge und Kurzreisen zu »Sehenswürdigkeiten«, wie nach Loreto, zu den Heilbädern von Abano oder den Höfen der verschwägerten oder befreundeten Fürsten von Mantua, Ferrara, Urbino und Mailand. Die urbs aeterna und die Papstaudienz waren dabei selbst für Andersgläubige eine fast zwingende Etappe.

Was von diesen frühneuzeitlichen Reisen ganz allgemein mitgenommen wurde, waren Anstrengungen und manche Leiden, aber vor allem Erfahrungen, Reiseberichte, architektonische, künstlerische und modische Elemente, die zu Hause verarbeitet wurden, Bücher-, Kunst- und Geschenkeeinkäufe und die Festigung oder Auffrischung von Beziehungen zu den besuchten Personen. ${ }^{455}$

Wie die Gabe trugen auch Besuche zum Phänomen der immerwährenden Verpflichtung bei. Die Gastfreundschaft gehört zu den menschlichen Verhaltensnormen. Sie zu verweigern galt - zum Teil bis heute - als Affront, als offensichtliches Zeichen von Feindschaft. Jeder, der sich in einem herrschaftlichen Gebiet befand, hatte das Recht auf mehr oder minder ausgeprägte Gastfreundschaft - abhängig von seinen Beziehungen oder denen seiner Familie zum Gastgeber und auch von der Tatsache, ob der Gast offiziell oder inkognito reiste. Dieselbe Gastfreundschaft durfte der Gastgeber als Reisender dann auch im Gegenzug erwarten. ${ }^{456}$

Eine bedeutende Quelle für die Frage der Gastfreundschaft am estensischen Hof stellt das Libro dei Forestieri, das Verzeichnis aller Besuche aus der Regentschaft von Alfonso II., dar. Neben vielen Gästen von den benachbarten oder verschwägerten italienischen Fürstenhöfen Mantua, Urbino, Mirandola, Modena, Bologna kamen immer wieder Gesandtschaften aus Frankreich, Spanien und dem Reich, welche anscheinend besonders fürstlich bedient wurden, da sie als teuerste Posten bei der Verpflegung auf-

453 Häberlein, Die oberitalienischen und die oberdeutschen Städte, 2 I 5 .

454 Matschinegg, Ausländer in Italien, 76f. Diess. Studium und Alltag.

455 Matschinegg, Das Studium in Italien, i68f.

456 Fantoni, Feticci di prestigio, I 53. 
scheinen. ${ }^{457}$ Doch nicht nur Gesandtschaften von Reichsfürsten und Kaiser kamen in die Este-Stadt, sondern auch manche Fürsten und Fürstensöhne selbst reisten über die Alpen nach Italien und besuchten gezielt oder im Zuge ihrer Durchreise auf dem Weg nach Loreto, Rom oder Neapel die Herzöge von Ferrara und Modena. Im Spätherbst I 58 I kündigte Erzherzog Maximilian, der spätere Deutschmeister, einen Besuch in Ferrara an, da er auf der Durchreise nach Florenz war. ${ }^{458}$ Auch der älteste Sohn von Herzog Wilhelm von Bayern, Maximilian, sollte auf seiner Romreise I 593 in Ferrara Halt machen und herzlich empfangen werden. ${ }^{459}$

Besonders interessant sind die Reise und der Aufenthalt eines protestantischen Fürstensohns in Ferrara, der deutliche Spuren in den estensischen Archivquellen hinterlassen hat. Im August I 580 bereitete der bereits in Venedig weilende Erbprinz von Braunschweig-Lüneburg, Otto Heinrich, die geplante Reise seines Bruders, Johann Friedrich, nach Italien mit Aufenthalt in Ferrara vor und schickte einen Gesandten, Nicolas Rasch, zu Vorgesprächen an den estensischen Hof. ${ }^{460} \mathrm{Im}$ September sollte Rasch erneut eruieren, wie die Glaubenssituation in Ferrara sei und ob die Messe verpflichtend besucht werden müsse, da, wie Otto Heinrich in seinem Begleitbrief erklärte, sein Vater sehr religiös sei und von den Antworten auf diese Fragen die Reiseerlaubnis für seinen Bruder abhängen würde. ${ }^{461}$ Noch zu Beginn des neuen Jahres äußerte der Fürstensohn große Bedenken an der geplanten Reise seines Bruders, da der Vater diesen aus Glaubensgründen nicht gern an andere (katholische) Höfe schicke. ${ }^{462}$

Bezüglich der Bedenken eines Vaters und evangelischen Fürsten, seinen Sohn an den katholischen Hof eines päpstlichen Lehensnehmers zu entsenden, hat auch Barbara Marx ähnliche Befürchtungen des Kurfürsten August aufgezeigt, der seinen in der italienischen Sprache ${ }^{463}$ und nach italienischem Kunstgeschmack ausgebildeten

457 Cazzola, Economia, 237. Siehe die im Anhang angeführten Besuche mit Kosten ( $1562-$ I 566 ), wie z.B. »ambasciatore del re dei Romani Io.I 2.1 5622 giorni, 6 bocche, 2 piatti, 7 scudi di spesa«, 238.

458 ASMo, ASE, Casa e Stato, Carteggio di principi esteri, Germania b I585/r I, Erzherzog Maximilian III. an Alfonso II., November und Dezember 158r. Bei dieser Reise zog er weiter nach Genua I 579 war er mit Erzherzog Ferdinand II. nach Ferrara und Mantua gereist, als dieser bereits - obwohl noch nicht verwitwet - auf der Suche nach einer neuen - diesmal standesgemäßen - Ehefrau war, die er schließlich in seiner Nichte, Anna Caterina Gonzaga, fand. Vgl. Nof latscher, Glaube, 49.

459 München, BayHStA, Fürstensachenoo42, Kasten Schwarz 7603, Herzog Wilhelm von Bayern an Alfonso II., März und April I 593 .

460 ASMo, ASE, Casa e Stato, Carteggio di principi esteri, Germania b I599/25, Otto Heinrich von Braunschweig-Lüneburg an Alfonso II., August 1580.

46r Ebd., September I 580.

462 Ebd., Herzog Otto Heinrich von Braunschweig-Lüneburg an Alfonso II., Januar I58r. Diese Befürchtung der religiösen Beeinflussung oder sogar des Abfalls vom eigenen Glauben bestand - nicht ganz unbegründet, wie Irene Fosi gezeigt hat - noch im I7. und I8. Jahrhundert und reihte sich in die allgemeinen Gefährdungen für einen Thronnachfolger auf Reisen ein. Vgl. Fosı, Conversions de voyageurs bzw. Diess., Convertire lo straniero und Keller, Die italienische Reise, 607.

463 Die Sachsenfürsten pflegten seit dem I6. Jahrhundert die italienische Sprache und ließen ihre Kinder 
Sohn Christian nicht nach Italien reisen lassen wollte. Er schrieb am I 8 . Mai I 580 an Alfonso II., dass die Gerüchte, über eine geplante Reise seines Sohnes nach Italien unwahr seien. ${ }^{464}$ Nach Marx besagten die Gerüchte, dass der Sohn eine nicht protestantische italienische Braut suche bzw. besuche. Um diese Gerüchte zu zerstreuen, die seiner konfessionell-politischen Allianzausrichtung nach Norden (Christian sollte Sophie von Brandenburg ehelichen) widersprachen, ließ er den Sohn die Reise nicht antreten. ${ }^{465}$

Nicht nur religionspolitisch anders ausgerichtete Fürsten aus dem hohen Norden des Reiches machten Italien und Ferrara zu ihrem Reiseziel, sondern auch die räumlich und konfessionell »näheren« Habsburger; allen voran besuchte der ab I 565 verschwägerte Erzherzog Ferdinand II., Landesfürst von Tirol, mehrmalig den Hof der Este. Besonders interessant und in Bezug auf den Kulturaustausch zwischen dem Tiroler und dem estensischen bzw. mantuanischen Fürstenhof informativ ist die von Peter Diemer untersuchte, etwas eigenartige »Inkognito«-Reise ${ }^{466}$ von Erzherzog Ferdinand II. nach Oberitalien zu Beginn des Jahres I 579, die auch Ferrara zum Etappenziel hatte. Sie fand in Begleitung des oben genannten Herzogssohns Otto Heinrich von Braunschweig-Lüneburg statt, der - wie gesagt - die Italienreise (und den FerraraAufenthalt) seines Bruders in die Wege leiten sollte und lange Zeit Gast am Innsbrucker Hof war. ${ }^{467}$ Erzherzog Ferdinand II. reiste in dessen Begleitung und zusammen mit Erzherzog Maximilian (späterer Hochmeister des Deutschen Ordens), mit seinem Sohn, Markgraf Karl von Burgau, und mit Herzog Ferdinand von Bayern, der schon als Vertreter seines Vaters, Herzog Albrecht von Bayern, I 565/66 nach Florenz zur Hochzeit von Erzherzogin Johanna mit Francesco de'Medici gereist war ${ }^{468}$ und des Italienischen mächtig war. Der bayerische Fürstensohn verfasste einen offiziösen Reisebericht (Diurnale), ${ }^{469}$ der zusammen mit seinen Briefen an den Vater Einblick in diese nicht ganz konventionelle Italienreise gewährt. Erstes Ziel der Reise war, wie allgemein üblich, Venedig, wo die Reisegesellschaft Kunst ankaufen und den Karneval genießen wollte; dann ging es weiter zu Freundschaftsbesuchen nach Ferrara und Mantua. Die

darin unterrichten. Keller, Die italienische Reise, 6r 2. Siehe auch Ebert-Schifferer, Scambio culturale.

464 ASMo, ASE, Casa e Stato, Carteggio di principi esteri, Germania b I603/29, August I. von Sachsen an Alfonso II., Mai I 580 .

465 Marx, Künstlermigration, $253 \mathrm{f}$.

$466 \mathrm{Zu}$ dieser nicht selten vorkommenden Art des Reisens siehe: Conrads, Das Inkognito.

467 Diemer, Vergnügungsfahrt.

468 Hier war schon aus der Feder seines Sekretärs Johann Jakob Fugger ein Diarium entstanden, das den Einzug Johannas in Florenz beschreibt. Vgl. KAт riтz Ky, The Florentine Entrata, mit der Transkribierung der Einzugsbeschreibung im Anhang.

469 Diese »Schreibübung des Reiseberichts« gehörte zu den mit der Kavalierstour verbundenen "AußerHaus-Aufgabe«. Bender/Herzog/Niehaus, Kavalierstour, 57 I. Siehe auch die Abschnitte zur Neuzeit bei Brenner, Der Reisebericht. 
benutzten Transportmittel waren Schlitten, Pferde, Wagen und Schiffe. ${ }^{470}$ Das Vorhaben, unerkannt zu reisen und sich in den oberitalienischen Städten ohne Zeremoniell bewegen zu können, glückte nicht zur Gänze und aus staatspolitischen Überlegungen sah sich z.B. die Serenissima, trotz des Wunsches nach Geheimhaltung, genötigt, den Reisenden das obligate Staatgastprogramm zu bieten, wenn auch in etwas gelockerter Form: Mittagessen mit Musik der Markuskapelle, Bootsfahrt auf dem Canal Grande, Besichtigung des Arsenals und des Domschatzes, Besuch beim Dogen, Theateraufführungen, Regatta und Messe in San Marco. ${ }^{471}$ Mit Don Alfonso d'Este, Markgraf von Montecchio, fuhr die Reisegesellschaft per Schiff nach Ferrara, wo am I 7. Januar I 579 Kardinal Andreas von Österreich zur Reisegesellschaft stieß. In der estensischen Hauptstadt war man eifrig mit der Vorbereitung der dritten Hochzeit von Alfonso II. d'Este mit Margherita Gonzaga ${ }^{472}$ beschäftigt. Dennoch gab es Karnevalstreiben, Jagden und als Überraschung die Bewirtung in einer "uf theutsch new gemacht ${ }^{473}$ getäfelten Stube in einer estensischen Residenz (wahrscheinlich die bevorzugte Delizia Montagna di San Giorgio), ${ }^{474}$ wo sich die Gäste nach dem Trinkgelage (»ainer gutten mas«) in der Täfelung mit ihren Initialen verewigten. ${ }^{475}$ Diese ultramontanen kulturellen Formen, die deutsche Einrichtung und die Trinkgewohnheiten, hatte Alfonso am Innsbrucker Hof I 565 bzw. I 57 I und in München I $566^{476}$ selbst kennengelernt. Durch die Bedienung von »heimelig machenden« Stereotypen wollte er seine Gäste ehren, aber sicher auch beeindrucken, wie man am Eintrag erkennen kann. Die Essund Trinkgewohnheiten der Deutschen waren den Italienern bekannt, vor allem durch die von Gesandten tradierten, mit Stereotypen angereicherten Beschreibungen. Auch der englische Gesandte am Augsburger Reichstag von I 582, William Ashby, benutzte die Wendung des Trinkens alla tudesca. ${ }^{47}$ Dass in diesem Stereotyp auch ein Fünkchen Wahrheit steckt, beweisen die berühmten Ambraser Trinkbücher von Erzherzog Ferdinand II. Hier wurden Besucher des Fürsten, Männer wie Frauen, nach Bestehen der Initiation - dem Austrinken eines festgelegten Maßes an Wein in einem Zug, also ohne Absetzen des Glases - in der Bruderschaft aufgenommen und durften sich

470 Diemer, Vergnügungsfahrt, $249-253$.

47 I Ebd., $256 f$.

472 Nicht wie Diemer fälschlich angibt Eleonora Gonzaga. Ebd., 259.

473 Diurnale, fol. 22,22v zit. n. ebd., 299.

474 Lazzari, Le ultime tre duchesse, i66. Diese war ein viel bewunderter Festungsbau aber auch die von Weinbergen umgebene fürstliche Residenz für den 1574 zur Krönung zum König von Frankreich reisenden Henri III. Siehe auch Ceccarelli, Principi, i $36 f$.

475 Diurnale, fol. 22v zit. n. Diemer, Vergnügungsfahrt, 300.

476 Alfonso II. und der junge Henri de Guise folgten nach ihrer wenig glorreichen Teilnahme am Türkenkrieg I 566 im November, nachdem sie den Kaiser nach Wien begleitet hatten, der Einladung des Herzogs von Bayern. Turba, Venezianische Depeschen 3, Geronimo Albini an Leonardo Contarini aus dem Lager bei Raab, September I 566, Nr. r6o, 35 2-357, hier 357, Anm. I.

477 Mehr zu diesen Stereotypen bei Lees, Stereotype, I80 und in vielen anderen Beiträgen desselben Sammelbandes. 
mit Name und Leitspruch im Trinkbuch verewigen. ${ }^{478}$ Im Jahr I 57 I haben sich auch Alfonso II. d'Este und seine Mitreisenden ${ }^{479}$ im Ambraser Trinkbuch eingetragen. ${ }^{480}$

Nicht nur das Trinkritual und die Tradition, sich zu verewigen, sondern auch die Übertragung von Wohnkultur in ein anderes Land, damit sich Reisende oder Besucher in einem Stück Heimat in der Fremde wohl fühlten, war nicht ungewöhnlich. Für deutsche Reisende, vor allem jene, die auf die Überfahrt ins Heilige Land warteten, gab es in Venedig ein eigenes Gasthaus »Sanctus Geosius« auf Deutsch »Zu den Fleuten «, in dem von der Einrichtung bis zum Essen alles Deutsch war und auch kein Wort Italienisch gesprochen wurde. ${ }^{481}$

Zeichen des Kulturtransfers sieht man nicht nur in der Berichterstattung des Bayernherzogs an sich, sondern auch darin, dass dieser für seinen Vater Albrecht V. eine Fischbestellung in Venedig aufgab, Neuigkeiten zur Hofmusik mitteilte, die den Vater und dessen Hofmusiker Orlando di Lasso sehr interessierten, und - aufgrund der knappen ihm zur Verfügung stehenden Mittel - einige wenige Kunstwerke erwarb. ${ }^{482}$ $\mathrm{Zu}$ den Folgen und Erfolgen dieser besonderen Reise zählt Diemer zu Recht die Heiratsanbahnung zwischen Anna Caterina Gonzaga und Erzherzog Ferdinand, die Idee einer - schlussendlich nicht realisierten - Verbindung zwischen den Gonzaga und Herzog Ferdinand von Bayern, die nicht quantifizierbare Anschaffung von Antiquitäten und Kunstwerken und die Karnevalsvergnügungen mitsamt den Freundesbesuchen. ${ }^{483}$

Erzherzog Ferdinand II. reiste nicht nur, sondern war auch ein bemerkenswerter Gastgeber, wie die oben genannten Ambraser Trinkbücher mit ihren ca. 900 Eintragungen von Gästen aus Böhmen ${ }^{484}$, Polen, Italien, Spanien und anderen Durchreisenden, darunter auch Protestanten, bezeugen. ${ }^{485}$ Selbstverständlich ist die hohe Anzahl

478 Dazu siehe Igálffy von Igály, Die Ambraser Trinkbücher, vor allem den einleitenden Beitrag über die Quelle und den Trinkritus von Igálffy von Igály/Zeleny, Die Trinkbücher, i - I9. Zeleny, Der Ambraser Trinkritus.

479 Darunter Giovanni Battista Pigna, der Sekretär von Alfonso II., Giulio Estense Tassoni, Paolo Carandino, Camillo Gualegno, Scipione Giglioli, Ercole Contrari, Ercole Giglioli, alle als Gesandte am Kaiserhof und Berater im Dienst Alfonsos tätig. Alle auf folio I6 v links oben, Igálffy, Die Ambraser Trinkbücher, 85 .

480 Alfonso machte sich mit dem Spruch »memor esto« (sei eingedenk) unvergessen. IGÁLfFy, Die Ambraser Trinkbücher, I6 $\mathrm{r}$ rechts, 82. Das Namensregister der Trinkbücher führt außer einem Orazio Gonzaga aus der Linie Castiglione und einem Hieronymus Visconti keine weiteren namhaften italienischen Fürsten an.

48 I Schudt, Italienreisen, 4I.

482 Diemer, Vergnügungsfahrt, $262 \mathrm{f}$.

483 Ebd., 27 of.

484 Dazu siehe BŮžEK, Ferdinand von Tirol, 272 f, Anm. 828.

485 Neben diesem Renaissance-Trend des Trinkritus hatte Erzherzog Ferdinand auch Literatur zum Wein, seinem Anbau und den Folgen des übermäßigen Genusses in seiner Bibliothek. Im Inventar sind das Opusculum de vite vinifera von Jakob Horst, dem Leibarzt der Herzöge von Braunschweig, und die His- 
von Besuchen auf die zentrale Lage der erzherzoglichen Residenz an der Hauptverkehrsroute über die Alpen zurückzuführen. Der Aufenthalt in Innsbruck war eine willkommene und erfreuliche Reisepause auf dem Weg nach Italien oder ins Reich vor/ nach der Überquerung des Brennerpasses. I 574 hielt sich Erzherzog Ferdinands II. Neffe, Herzog Karl Friedrich von Jülich-Kleve-Berg (I 555-I 575), Sohn von Herzog Wilhelm von Jülich-Kleve-Berg und Erzherzogin Maria von Österreich, Tochter von Kaiser Ferdinand I., im Zuge seiner Italienreise in Schloss Ambras auf. ${ }^{486}$ Von seinem Sekretär und Erzieher Steven Winand Pigge (Stephanus Winandus Pighius) ist die herzogliche Reise und die Aufnahme in die Ambraser Trinkbruderschaft (erst im zweiten Versuch) in seinem I 587 erschienenen Reisebericht mit dem Titel Hercules Prodicius beschrieben. Der Wunsch nach einer Italienreise und die Bewunderung des Erbprinzen für die italienische Renaissance gehen auf zahlreiche Kontakte und Einflüsse der Herzöge von Jülich-Kleve-Berg mit Italien und mitunter auch den Este zurück. Schon Johann I. Herzog von Kleve, Graf von Mark (I4I9- I48I) hatte sich an den (noch) Markgrafen Borso d'Este mit der Bitte gewandt, seinem famulus einige neapolitanische Pferde mitgeben zu wollen. ${ }^{487}$ Karl Friedrich fühlte sich aufgrund des Nahverhältnisses seines Vaters zu den oberitalienischen Fürsten I 572 , vor den Hochzeiten seiner beiden Schwestern, zu denen Alfonso II. d'Este eingeladen wurde, verpflichtet, dem Herzog von Ferrara zu berichten, dass er sich bei den Waffenübungen, die eine italienische Spezialität seien, so verletzt habe, dass er längere Zeit nicht schreiben konnte. ${ }^{488}$ Zwischen Kleve und Ferrara entwickelte sich im Laufe des 16. Jahrhunderts eine von Briefen, Geschenken, Anfragen und Empfehlungen geprägte Beziehung. Im Mai I 585 empfahl z.B. Herzog Wilhelm V. von Jülich-KleveBerg seinen Untertan, Joannes Breger, einen Absolventen der Kölner Universität, der hier die italienische Sprache nur rudimentär erlernen konnte und deshalb nach Italien gehen wollte und die Unterstützung des Herzogs von Ferrara benötige. ${ }^{489}$

Wilhelm V. von Jülich-Kleve-Berg war, auch in den Augen seiner Zeitgenossen, Italien gegenüber sehr aufgeschlossen. Der Reisebegleiter des Nuntius Commendone, Fulvio Ruggieri aus Bologna, zeichnete in seinem Reisebericht denselben Herzog als untypischen Deutschen, da er selten trinke und den Alkoholkonsum an seinem Hof sehr einschränke. Der Berichterstatter führte dies nicht auf eine Charaktereigenschaft

toria vitis vinique von Rembert Dodoens, dem kaiserlichen Leibarzt, sowie ein Buch über Weinsorten des sizilianischen Arztes Jacopo Perfetti verzeichnet. Vgl. Zeleny, Der Ambraser Trinkritus, i6, i 8.

486 Diedenhofen, Die Italienreise.

487 ASMo, ASE, Casa e Stato, Carteggio di principi esteri, Germania b I626/32, Johann von Kleve an Borso d'Este, Januar I4? (der Brief ist teilweise zerstört, das Jahr nicht mehr lesbar, muss aber vor der Herzogserhebung I 452 verfasst worden sein, da Borso als Markgraf angesprochen wurde).

488 ASMo, ASE, Casa e Stato, Carteggio di principi esteri, Germania b I626/32, Karl Friedrich von Kleve an Alfonso II., August I 572.

489 ASMo, ASE, Casa e Stato, Carteggio di principi esteri, Germania b r626/32, Wilhelm V. von Kleve an Alfonso II., Mai I 585 . 
Wilhelms von Kleve zurück, sondern auf dessen italienisch geprägte Lebensweise. ${ }^{490}$ Diese drückte sich auch in dem durch italienische Baumeister und Architekten, wie Alessandro Pasqualini aus Bologna, geprägten Wohnstil in den kleveschen Residenzen und in den nach italienischem Vorbild gestalteten Gärten aus. ${ }^{491}$ Der oben genannte Sohn Wilhelms V., Karl Friedrich, hatte in seiner Ausbildungszeit neben Latein und Französisch auch Italienisch und Spanisch gelernt. Darüber hinaus hatte sein Erzieher und Reisbegleiter, Pigge, einschlägige Italienerfahrungen, da er Sekretär des Kardinals und Papstes Marcello Cervini (Marcellus II.) und mit diesem in der Bibliothek und Kunstsammlung des Vatikanpalastes tätig gewesen war. ${ }^{492}$ Die von Pigge geplante Reise führte den Herzogssohn und die aus jungen heimischen Adeligen bestehende Reisegesellschaft über Wien nach Venedig, über Mantua nach Mailand, über Ferrara nach Rimini, weiter nach Rom, Neapel und zurück nach Rom, wo der Prinz an Pocken starb und in S. Maria dell'Anima begraben wurde. Allein in Wien hielt sich die Reisegesellschaft am Hof Kaiser Maximilians II. zwei Jahre lang auf und nahm I 572 an der Krönung von Erzherzog Rudolf zum König von Ungarn teil. Außerdem nutzte man die Gelegenheit zu einem Ausflug an die ungarische Militärgrenze. ${ }^{493} \mathrm{Im}$ selben Jahr reiste Alfonso II. d'Este nach Graz und Wien. Eine Begegnung mit dem Herzogssohn ist nicht auszuschließen und sogar sehr wahrscheinlich, da der Este daraufhin eine Einladung zur Hochzeit der Tochter Herzogs Wilhelm V. von Jülich-Kleve-Berg, Maria Eleonore, ${ }^{494}$ mit Albrecht Friedrich Herzog in Preußen (I553-16r8) nach Königsberg für den 23. August I 573 erhielt, zu der er seinen Gesandten schickte, Camillo Gualengo, der auf dem Weg dorthin berichtete, er müsse Hausrat und Betten kaufen, da er in Gegenden kommen werde, wo er annahm, dass es keine Unterkunft gäbe. Der estensische Gesandte wurde gebeten, der Braut in Königsberg Geleit zu geben und berichtete im Sinne der immer noch virulenten Präzedenzfrage, welchen Platz er dadurch in der Rangordnung eingenommen hatte: vor dem Gesandten von Mantua und vor Florenz, aber nach Erzherzog Ferdinand, dem Pfalzgrafen, Sachsen, Brandenburg und Bayern. ${ }^{495} \mathrm{Im}$ Jahr darauf verkündete Wilhelm von Kleve die Verlobung seiner zweitältesten Tochter Anna (I 552- I632), ${ }^{496}$ mit Philipp Ludwig Pfalzgraf bei

490 Vgl. Braun, Imagines imperii, 448f. Der Reisebericht (Viaggio d'Alemagna fatto dal Illustrissimo Signore Cardinale Commendone l'anno MDLX et descritto dal signore Fulvio Ruggieri suo gentil'buomo) ist in den Nuntiaturberichten aus Deutschland II/2 im Anhang, 57- I70 ediert.

49 I Vgl. Diedenhofen, Die Italienreise, Einleitung, 6. Zu diesem Ausbau, der neben einem palazzo in fortezza möglicherweise dem Vorbild der addizione erculea folgend eine Stadtbefestigung und eine innerstädtische Neuplanung vorsah, siehe: Büren, Der Ausbau Jülichs, 25 o.

492 Diedenhofen, Die Italienreise, Einleitung, $9 \mathrm{f}$.

493 Ebd., I5-I 9.

494 Vgl. Rita Scheller, »Maria Eleonore von Jülich-Kleve-Berg« in: NDB i6 ( I 990), r 95 f.

495 ASMo, ASE, Casa e Stato, Carteggio di Ambasciatori, Germania b 3 I, an Camillo Gualengo, AugustOktober 1573 .

496 Vgl. zu dieser und ihrer Konfessionsproblematik WestphaL, Konversion und Bekenntnis. 
Rhein, Herzog von Bayern, Graf von Valdentz und Spanheim und sprach Alfonso II. wegen ihrer jahrelangen Freundschaft eine weitere Einladung aus. Wieder ließ sich der Este durch seinen Gesandten Gualengo vertreten, da er die weite Reise nicht auf sich nehmen konnte. Die Braut und ihr Vater hatten Verständnis dafür, bedankten sich nach der Hochzeit brieflich bei Alfonso II. für den kostbaren goldenen Ring, den der Herzog von Ferrara über seinen Gesandten Anna hatte zukommen lassen. ${ }^{497}$

Aufgrund dieser Beziehungen zum Herzog von Jülich-Kleve-Berg verwundert es nicht, dass Karl Friedrich auf seiner Italienreise bereits in Venedig eine Gesandtschaft des Herzogs von Ferrara empfing, den er allerdings erst auf der Rückreise aus Mailand über Mantua, Parma und Bologna besuchte. Am I6. November I 574 wurde er festlich in Reggio und Modena und schließlich in Ferrara empfangen, wo zwei Jahre zuvor seine Tante Barbara, die Schwester seiner Mutter, verstorben war. In den hier verbrachten drei Tagen wurden ihm Bibliotheken und Sammlungen gezeigt und er besuchte die Kartause S. Cristoforo. Der Sekretär Pigge traf in Ferrara den Architekten und Baumeister der Villa d'Este in Tivoli, Pirro Ligorio, ${ }^{498}$ den er bereits in Rom kennengelernt hatte, wieder. Nach Festen und Banketten reiste der klevesche Herzogssohn mit dem vergoldeten Bucintoro von Alfonso d'Este auf dem Po-Fluss über Argenta nach Ravenna weiter. ${ }^{49}$

497 ASMo, ASE, Casa e Stato, Carteggio di principi esteri, Germania b 1626/32, Wilhelm V., Anna an Alfonso II., August und Oktober 1574.

498 Ligorios Pläne für die Villa d'Este hatten Vorbildcharakter und wurden u.a. von Kaiser Maximilian II. für das Wiener Neugebäude angefragt. Vgl. Hajós, Renaissancegärten, I 84- 86 mit weiterführender Literatur.

499 Diedenhofen, Die Italienreise, 37-39. 


\subsection{Kulturaustausch und Heirat}

Einen wichtigen Beitrag zum Kulturaustausch und -transfer in der Frühen Neuzeit leisteten zweifellos die durch Heirat entstandenen und gefestigten Familienverbände.$^{500} \mathrm{Kam}$ es bereits im Zuge von Reisen, diplomatischen Missionen, Kriegsdienst oder einem anders begründeten befristeten Aufenthalt in einem fremden Kulturraum $\mathrm{zu}$ einem Kulturkontakt, einer Beeinflussung und einem Transfer von Ideen oder materiellen Gütern, so eröffnete der (meist permanente) Umzug einer Braut an einem fremden Hof besonders viele Möglichkeiten des Austausches. Oft heiratete die Fürstentochter in eine Familie ein, dessen Sprache sie (noch) nicht verstand, dessen Sitten und Gebräuche, Mode und Esskultur sie nicht oder nur unzureichend kannte. Dies und die Tatsache, dass oft wenige Landesleute der Braut am neuen Hof geduldet wurden, hatte zur Folge, dass Letztere sich vermehrt mit kulturellen Merkmalen und Objekten ihrer Heimat umgab, zumeist auch, um den Heimweh zu lindern. Doch der materielle Kulturaustausch ist nur ein Aspekt von interkulturellen Heiraten. Dorothea Nolde und Claudia Opitz haben zu Recht bei ins Ausland Verheirateten von »regelrechten Vorposten des Kulturtransfers « ${ }^{501}$ gesprochen. Durch die Vermählung von fremden Fürsten und Fürstinnen entstanden nämlich grenzüberschreitende Familiennetzwerke, die sich oft durch weitere Heiratsprojekte, aber vor allem durch das Protegieren von Familienmitgliedern aus der Heimat weiterentwickelten. Frauen kamen hierbei gleiche, wenn nicht in manchen Fällen sogar größere Einflussmöglichkeiten zu als Männern. Dabei war der Ausbau eines weitreichenden sozialen Netzwerkes innerhalb eines Patronagesystems $s^{502}$ oder Freundes- und Verwandtenkreises ${ }^{503}$ nicht nur für den Gunstempfänger von Bedeutung, sondern diente ebenso der Stärkung der sozialen Identität des Patrons/der Patronin und seiner/ihrer Familie. ${ }^{504}$

500 Dazu siehe die einzelnen Beiträge in Nolde/Opitz-Belakhal, Kulturtransfer über Familienbeziehungen und letztens auch Palos/Sánchez, Early Modern Dynastic Marriages.

50I Ebd., 7 f.

502 Wie Heiko Droste pägnant definiert hat, war »Patronage [...] Kulturform wie soziale Institution $[. .$.$] .$ Droste, Patronage, 557.

503 Droste u.a. haben bereits auf die Schwierigkeit der Trennung bzw. Unterscheidung von Nepotismus und Patronage und auf die Überschneidungsmomente hingewiesen. Ebd., 567-569. Siehe auch: JANCKE, Patronage: „Für die Frühe Neuzeit lässt sich jedenfalls auch über die Gelehrtenkultur hinaus generell sagen, dass diese Beziehungen wie Patronage, Verwandtschaft, Freundschaft, Gastfreundschaft, Nachbarschaft, Feindschaft, Patenschaft u.a. sich vielfach miteinander kombinieren ließen und dass daher mit mannigfachen Überschneidungen zu rechnen ist.« Ebd., I95.

504 »Klientel und Patronagebeziehungen sind jedenfalls nicht zu trennen vom self fashioning der Beteiligten; ebenso wie Freundschaftsbeziehungen konstituieren sie soziale Identitäten, die weder Patrone noch Klienten nach Belieben wieder ablegen können«. Asch, Freundschaft, 276. 
$\mathrm{Zu}$ diesem besonders ergiebigen Bereich des kulturellen Austauschs im Rahmen von interkulturellen Heiraten hat vor allem Karl-Heinz Spieß als Vorreiter und vielseitig ausgewiesener Kenner dieser Materie für das Spätmittelalter - aber gleich geltend auch für die Frühe Neuzeit - die bedeutendsten Aspekte der »Verheiratung in die Fremde» dargelegt. ${ }^{505}$ Für unseren Untersuchungszeitraum können die von Spieß erarbeiteten drei Phasen, die zu einer interkulturellen Heirat führten, ebenso gelten: Die Anbahnung durch diskretes Anfragen direkt oder durch Dritte am besten natürlich über Verwandte, wo bereits ein Familiennetzwerk bestand; die Verhandlungen durch Gesandte bezüglich der Mitgift und Widerlage meist in unterschiedlichen Landeswährungen bei gleichzeitiger Berichterstattung über Aussehen und Charakter der Braut und ab dem Ende des I 4. Jahrhunderts vermehrt durch Übersendung von Brautbildern. Schließlich blieb nur noch die Konkretisierung des Rechtsgeschäfts durch die Zelebrierung der Hochzeit per procuram in der Heimat der Braut und bei ihrer Ankunft am neuen Hof.

Nicht die Höhe der angemessenen, manchmal eine Rangungleichheit austarierende Mitgift, sondern auch die unterschiedliche Rechtslage in den einzelnen Ländern bot Anlass zu ausgedehnten diplomatischen Verhandlungen: Im Reich gehörte die Brautausstattung nicht zur Mitgift und wurde dementsprechend auch nicht in ihrem Wert quantifiziert, während dies in Italien sehr wohl der Fall war. Dies bedeutete, dass der italienischen Braut mehr zu ihrer Verfügung blieb, da die Aussteuer zu ihrem persönlichen Besitz gehörte. ${ }^{506}$ So kamen in den in Italien üblichen, kunstvoll angefertigten Brauttruhen genau aufgelistete Kulturgüter (Kleider, Schmuck, Bücher, ${ }^{507}$ neben praktischen Ausstattungsgegenständen wie Tisch- und Bettwäsche, Betten, Bettflaschen etc.). Diese hatten nicht nur einen materiellen, sondern - wie Spieß darauf hingewiesen hat - einen emotionalen Wert, eine Erinnerungsfunktion an die Heimat für die in die Fremde verheirateten Frau. ${ }^{508}$ Diese einem »fremden « Kulturraum entstammenden Gegenstände konnten zusammen mit Essgewohnheiten, Modetrends und Bräuchen Eingang am neuen Hof und Nachahmung bzw. Adaptierung im neuen Kulturraum finden. Wie Duchhardt festgehalten hat, konnte »aus dynastischen Eheschließungen [...] ein bemerkenswerter Kulturtransfer erwachsen, der die Braut auf ihrem Weg von ihrem Stammland in ihre neue Heimat begleitete. ${ }^{509}$ Dieser mit einer Heirat in die Fremde einhergehende Gütertransfer entspricht dem anthropologischen Ansatz von Claude Lévi-Strauss, indem die Ehe als »Tauschgeschäft « definiert wird. ${ }^{510}$

505 Siehe die vielfältigen Arbeiten von Spieß zu diesem Thema, darunter vor allem SpIEss, Internationale Heiraten; Ders., Europa heiratet; Ders., Fremdheit.

506 Vgl. Spiess, Internationale Heiraten, i I 6- I I 9.

507 Siehe beispielhaft: Unterkircher, Bücher.

508 Berühmt wurde die von Mantegna für die nach Görz verheiratete Markgräfin Paola Gonzaga gefertigte Truhe. Spiess, Internationale Heiraten, I 2 of.

509 Duchhardt, Die dynastische Heirat.

5 Io Lévi-Strauss, Die elementaren Strukturen, vor allem Kap. 29. "Die Prinzipien der Verwandtschaft«, $639-663$. 
Doch der mit einer Heiratsverbindung einhergehende kulturelle Austausch war eigentlich nur eine unbeabsichtigte Nebenwirkung. Vorrangig verfolgte die Heiratspolitik $^{511}$ der großen europäischen Dynastien wie jene der kleineren italienischen Fürsten, das Ziel, Frieden zu schließen, Bündnisse zu festigen, Garantien auszutauschen und nach Möglichkeit die Chancen einer Dynastie auf die Erbschaft eines Landes oder im Wettlauf um Titel und Vorrang zu erhöhen. ${ }^{512}$

Mit Maximilians I. zweiter Ehe mit Bianca Maria Sforza verstärkte sich die (Heirats-)Ausrichtung des Habsburgerreiches nach Süden, Richtung Italien, ${ }^{513}$ die mit Ferdinands I. Heiratspolitik ihren Höhepunkt fand. ${ }^{514}$ Für den Kaiser bedeuteten die Heiratsprojekte mit den italienischen Fürsten, die aufgrund des Rangunterschiedes keine übermäßig hohe Mitgift erwarteten, eine Möglichkeit, auf der italienischen Halbinsel wieder verstärkt kaiserliche Präsenz zu zeigen und durch die gleichzeitige Verheiratung mehrerer Töchter unter den italienischen Prätendenten ein Machtgleichgewicht zu halten. Die Este-Fürsten waren wie die Gonzaga gute Heiratspartien hinsichtlich ihres Renommees, Prestiges, ihrer Katholizität, die Medici - die als »Krämerfamilie« beschimpft wurden - punkteten hingegen mit ihren finanziellen und militärischen Möglichkeiten.

Hochzeiten - besonders jene mit einer Kaisers- oder Königstochter - boten Anlass zu überaus pompösen Feierlichkeiten und zum Zusammenkommen vieler Fürsten, Fürstinnen und Gesandten. Vocelka nennt diese Zusammenkünfte zu Recht "politische Tagungen«, boten sie doch die Möglichkeit, allen Anwesenden Prestige, Reichtum und Macht vorzuführen und gleichzeitig Kontakte zu knüpfen. Außerdem entstanden anlässlich von Hochzeiten viele künstlerische und literarische Werke und Gegenstände verschiedener Art (Schmuck, Waffen, Rüstungen, Kleider, Kleinodien, Bilder), die als Hochzeitsgeschenke ihren Weg in einem anderen Kulturraum fanden. Zu den Hochzeitfeierlichkeiten kamen besonders in den grenznahen Fürstenhöfen in Innsbruck oder München wandernde italienische Schauspielgruppen, Vertreter der italienischen Stegreifkomödie, die mitunter das Ereignis auf italienische Art prägten. ${ }^{515}$

Die Feste am Hof - sowohl die Hochzeitsfeierlichkeiten, wie auch die anderen wiederkehrenden Festereignisse und vor allem der Karneval - waren mehr als ein bloßes Zusammentreffen oder den Alltag unterbrechende, vergnügliche Ereignisse. ${ }^{516}$ Hier

5 I I Vgl. dazu als Überblick: Lebe, Ein Königreich als Mitgift. Weiterführend auch Trevor DeAn/Kate Lowe (Hgg.), Marriage in Italy, I 300- I600, Cambridge I 998.

5 I 2 Vocelka, Habsburgische Hochzeiten, i I.

5 I 3 Besonders hatten sich die Visconti im I 4. und an der Wende zum I 5 . Jahrhundert mit einigen Heiratsprojekten nach Norden, also mit dem Haus Habsburg, Württemberg, Bayern-Landshut oder der Kurpfalz hervorgetan. Zu diesen und den damit verbundenen Formen des fürstlichen kulturellen Transfers siehe die Beiträge im Tagungsband Rückert/Lorenz, Die Visconti.

5 I 4 Vgl. Vocelka, Habsburgische Hochzeiten, I 2.

5 I 5 EвD., I 8, $27 \mathrm{f}$.

5 I 6 Brandstätter, Aspekte der Festkultur, I 59. 
passierte - wenn auch manchmal nur schwer nachweisbar - Kulturtransfer, wo Anregungen und Einflüsse von mehreren Höfen und Ländern aufeinandertrafen. Durch Reisende, Gesandte und Besucher wurden Besonderheiten, Stilelemente, Moden, die im Rahmen von Feierlichkeiten besonders zur Schau gestellt wurden, weitererzählt und vermittelt. So fanden auch am Hof von Maximilian I. mit den zweiten Hochzeitsfeierlichkeiten »italienische Anregungen« im Bereich der Musik, der Mode und des Tanzes ihren Weg ins Reich, wenn auch der italienischen Herzogin prinzipiell - im Vergleich zu Maximilians erster Gemahlin, Maria von Burgund ${ }^{517}$ - keine so bedeutende politische Rolle eingeräumt werden kann. ${ }^{518}$ Bei der Untersuchung der Modetrends am Innsbrucker Hof nach der Ankunft Bianca Maria Sforzas, konnte Sailer eine »Übersetzung von Kulturelementen im Rahmen des kulturellen Transfers« erkennen. ${ }^{519}$ Als ein Beispiel dafür kann die italienische Haar- oder Goldhaube genannt werden, die durch Bianca Maria Sforza in die deutsche Mode Eingang fand. Die Garderobe der italienischen Braut Maximilians brachte nicht nur italienische, sondern auch spanische, niederländische und sogar osmanische Stilelemente mit ins Reich. ${ }^{520}$ Maßgeblich war dabei die reiche Mitgift der Mailänderin, die nicht nur aus Bargeld, sondern - wie die ausgewerteten Inventarlisten zeigen - im großzügigen Ausmaß aus Kleidung, Schmuck und Alltagsgegenständen bestand. Ein Beleg für die Festsetzung von Modeelementen kann das Wandbild auf Schloss Tratzberg in Tirol sein, das Bianca Maria mit den »italienischen Hemdärmeln« (an Schultern und Ellbogen offen) und einer Goldhaube (scuffia) dargestellt zeigt.

So maßgeblich die italienische Mode aber auch war, so sehr hat sich Bianca Maria auch à la tedesca gekleidet, was ein verständliches politisches Zeichen der Integration einer in die Fremde verheirateten Fürstin war. Durch das Wechseln des Gewandes, z.B. bei ihrer Hochzeitsfeier, wurden der Übergang und die Aufnahme in die neue Dynastie ausgedrückt (rite de passage). Gerade dadurch kam es zur Vermischung von Stilelementen. Stoffe und Kleider wurden weiterhin in Italien angekauft oder in Auftrag

5 I7 Diese hatte aus Burgund die höfische Maskerade mitgebracht, die in die Festkultur des Königs-/Kaiserhofes unter dem Begriff Mummereien Eingang fand und an deren Entwürfen und Ausführungen Maximilian selbst beteiligt war. Mit Anregungen auch aus dem Süden bereichert, wurden einzelne Festelemente verändert und weiterentwickelt und an andere Höfe weitergegeben. BRAnDSTÄTtER, Aspekte der Festkultur, I6I - i63.

5 I 8 Ebd., I 59 f. Zu Bianca Maria Sforzas eingeschränktem Handlungsspielraum aufgrund verschiedener Faktoren wie ihrer Kinderlosigkeit, der zunehmenden Kritik an der »Unordnung« ihres wenig integrierten Hofstaates und der hohen Ausgaben siehe: Lutter, Geschlecht; Diess./Unterholzner, Fürstin ohne Ort.

5 I 9 Sailer, Kleidung I $7 \mathrm{I}$.

520 Letztens haben Häberlein und Jeggle in ihrem Einführungsbeitrag betont, dass interkulturelle Beziehungen auch mit Fürsten und Reichen divergierender politischer und ideologischer Mentalitäten nicht abrissen, sondern sich vor allem aufgrund des gegenseitigen fürstlichen Interesses für exotische und kulturell fremde Güter sogar intensivierten. HäbERLEIN/JeGgLE, Einleitung, I 4. 
gegeben und mit der »deutschen « Mode kombiniert. ${ }^{521}$ In einem Porträt von Bernhard Strigel trägt Bianca Maria die »italienischen Hemdärmeln« aber »zusammen mit Barett und Netzhaube, als typisches Kennzeichen der deutschen Renaissancemode « ${ }^{522}$

Am Beispiel der jungen Mailänderin konnte Sailer auch aufzeigen, wie wichtig Kulturgüter aus der Heimat für in die Fremde Verheiratete waren. So kann »das teilweise Festhalten an alten Kleidungsgewohnheiten - noch ihr Leichnam zierte ein Gürtel nach ‘welscher Art $-[\ldots]$ als Bewältigungsstrategie ihrer ansonsten unglücklichen Lebenssituation gedeutet werden. ${ }^{523}$

Nicht nur in ihrer Kleidung, Sprache und in der Festkultur (Tänze), sondern auch in der Esskultur brachte die Mailänderin italienische Einflüsse an den Innsbrucker Hof und von hier ins Reich. Anhand der Tafelordnung und anderer Inventare hat Unterholzner festgestellt, »dass Bianca Maria vor allem bis I 500 einen lombardisch-italienischen Mikrokosmos um sich versammelte«. Diese kulturellen Differenzen waren z.B. im »befremdliche[n] Essverhalten der `welschen Jungfrauen« sichtbar. In den Berichten verschiedener Gesandten kamen viele (Auto)Stereotypen zum Ausdruck, so die Naschhaftigkeit der Italienerin(nen) ${ }^{524}$ sowie die allgemeine Verschwendungssucht der Lombarden. Dies unterstreicht die Tatsache, dass Bianca Maria einen welschen Koch hatte, der Speisen aus ihrer Heimat zubereitete und dass sie von ihrem Onkel Ludovico il Moro regelmäßig Delikatessen aus der Lombardei, wie Käse uvm. erhielt.

Pompöse Hochzeitsfeierlichkeiten waren also ein wichtiger Moment zum Kennenlernen, Nachahmen und Übertragen von materiellen wie immateriellen Kulturformen. Dieser Ausnahmezustand bot Möglichkeiten der Rezeption von Kunst, Unterhaltung und Vergnügungen. Allerdings wurde auch hier selektiv vorgegangen. Nicht alles, was an einem fremden Hof gesehen wurde, fand Anklang und Nachahmung. So fanden z.B. die in Italien weit verbreiteten Pantomimen und Akrobaten am Hof Maximilians I. keinen Eingang. ${ }^{525}$ Erst später, unter Erzherzog Ferdinand II. wurden sie bedeutende Festelemente. Beim Transfer von kulturellen Elementen muss also neben dem subjektiven Geschmack auch eine gewisse Zeitverzögerung bei der Aufnahme berücksichtigt werden.

Wie schon oben erwähnt, heirateten einige Mitglieder der Este-Dynastie in der zweiten Hälfte des I 5. und im I 6. Jahrhundert »fremde« Fürstinnen, d.h. Frauen aus einem anderen Sprach- und Kulturkreis. Dies führte verständlicherweise zu einer kulturellen Beeinflussung und zur Übertragung von materiellen und ideellen Kulturgütern, war es

\footnotetext{
52 I Ebd., I73-I75.

522 Ebd., I 82.

523 SaIler, Kleidung, I75; I494 zog sie italienisch gekleidet mit Hofdamen aus Mailand und Italien in Mecheln ein und erregte dadurch viel Aufsehen. Sie wurde als fremd rezipiert, was zwar politisch kontraproduktiv, aber eine wichtige Voraussetzung für den Kulturtransfer war. Ebd., I 85 .

524 Vgl. Unterholzner, Essensalltag, $296 f$.

525 Brandstätter, Aspekte der Festkultur, r64.
} 
doch der Braut und ihrem Gefolge ein Bedürfnis, ein Stück Heimat mitzunehmen und sich in der Fremde - trotz aller Anpassungsbestrebungen - mit Dingen und Merkmalen aus dem eigenen Kulturraum und mit Personen gleicher Muttersprache zu umgeben.

Die »fremden« Fürstinnen der Este waren im vorliegenden Untersuchungszeitraum Eleonora von Aragón und Lucrezia Borgia aus dem spanischen/süditalienischen Raum, Renée de Valois aus Frankreich und Barbara von Österreich. Auch die estensischen Fürstinnen, d.h. Schwestern und Töchter der regierenden Herzöge, waren begehrte Ehefrauen, kamen aber - bis auf Anna d'Este, die nach Frankreich verheiratet wurde vor allem für »inländische« Heiratsverbindungen in Frage. ${ }^{526}$

Vor dem Hintergrund eines von den großen Mächten Kaiser, Papst, Frankreich und Spanien bedrängten Italiens nutzten die Este als Fürsten eines mittelgroßen, zentral gelegenen Herrschaftsgebiets vor allem Heiratsverbindungen für die Wiederherstellung, Festigung und Wahrung der "guten« Beziehungen zu ihren beiden Lehensherren und zu Frankreich. So diente die Ehe von Ercole I. mit Eleonora von Aragón (I 450- I 493 $)^{527}$ der (Wieder)Annäherung an die aragonesische Herrschaft zu Ungunsten Frankreichs und Venedigs. Mit der Heirat von Alfonso I. mit der Papsttochter Lucrezia Borgia (1480-I5I9) 528 schützten sich die Este vor der von Cesare Borgia, dem Sohn von Papst Alexander VI., ${ }^{529}$ vorangetriebenen päpstlichen Expansion in Mittel- und Norditalien. Die Heirat zwischen Ercole II. und Renée de France diente der (Wieder)Annäherung an Frankreich und der Suche nach einem neuen Verbündeten gegen Papst und Kaiser. Als Gemahlinnen des letzten Este-Herzogs in Ferrara, Alfonso II., erneuerten und verstärkten hingegen Erzherzogin Barbara von Österreich und indirekt auch Margherita Gonzaga, Tochter von Leonore von Österreich, die Beziehungen zum Kaiserhaus.

Doch jenseits der Rolle, die fremde Bräute im politischen Schachspiel hatten oder haben konnten, brachten diese Heiratsverbindungen über die Landes- und Kultur-

526 Hier seien nur einige prominente Beispiele genannt: Isabella d'Este wird mit Markgraf Francesco Gonzaga nach Mantua, Beatrice d'Este mit Ludovico (il Moro) Sforza nach Mailand, Lucrezia d'Este mit Francesco Maria II. della Rovere nach Urbino verheiratet.

527 Eleonora von Aragón, Tochter von Ferdinand I. von Aragón, König von Neapel, I472 mit Ercole I. d'Este verheiratet. Pietro Messina : „Eleonora d'Aragona, duchessa di Ferrara«, in DBI 42, Roma 1993, online verfügbar unter: http://www.treccani.it/enciclopedia/eleonora-d-aragona-duchessa-di-ferrara \%28Dizionario-Biografico\%29/, Zugriff: r6.9.2020. Immer noch nützlich: ChiAppinı, Eleonora d'Aragona.

528 Jenseits der allseits bekannten biografischen Werke von Ferdinand Gregorovius und Maria Bellonci sind folgende neuere Detailuntersuchungen zur Person Lucrezia Borgias interessant: VANcini, Lucrezia Borgia; Feci, Signore di curia; Ghirardo, Lucrezia Borgia; Accorsi, Le donne estensi, 9 I - IO4.

529 Alexander VI., mit bürgerlichem Namen Rodrigo Borgia (I492-I503), seit 1492 Papst. Vgl. Giovanni Battista Picotti, Matteo Sanfilippo, »Alessandro VI«, in: Enciclopedia dei Papi (2000), online verfügbar: http://www.treccani.it/enciclopedia/alessandro-vi_(Enciclopedia-dei-Papi)/, Zugriff: I6.9.2020. Siehe auch: Susanne Schüller-PIroli, Borgia. Die Zerstörung einer Legende. Die Geschichte einer Dynastie, Olten/Freiburg i.Br. I 963. 
grenzen die Migration von mehreren Personen eines Kultur- und Sprachraums mit sich. Aufgrund ihrer »Fremdheit « und ihres meist hohen Standes bzw. Bildungsgrades waren die Bräute zusammen mit ihren Begleiter/inne/n Vermittlerinnen eines oft regen materiellen und geistigen, kulturellen Austausches. Ausländische Bräute wie Eleonora von Aragón, Lucrezia Borgia, Renée de France und Barbara von Österreich haben nachweislich eine Bereicherung und eine Beeinflussung von Sprache, Mode, Glaubensfragen, Kunst, Esskultur und nicht zuletzt in der politischen Führung ihres neuen Fürstentums mit sich gebracht. Trotz der - nicht immer gegebenen - Integrationsund Anpassungsbestrebungen behielten die fremden Fürstinnen ihre sprachliche und kulturelle Identität ${ }^{530}$ nicht zuletzt zur Ausübung jener machtpolitischen Funktionen und Erwartungen, die von ihrem Heimathof in sie gesetzt wurden. Von einer in die Fremde verheirateten Fürstentochter wurde somit einerseits Integration und Anpassungsfähigkeit erwartet und andererseits, dass sie ihrer Herkunftsfamilie treu blieb und deren Interessen in der Fremde vertrat.

So vorteilhaft eine rasche »Sesshaft-Werdung«, Akklimatisierung, Integration und Akzeptanz der fremden Fürstin und ihrer Begleiter/innen für alle - gerade in Hinblick auf die Sicherung der Nachfolge - war, so reich war der Kulturaustausch gerade aufgrund der Betonung des "Fremd-Seins» und "Fremd-Bleibens", also durch die Beibehaltung der eigenen kulturellen Identität und die Betonung der eigenen »Fremdheit «. ${ }^{531}$ Eine besondere Förderung dieser »Fremdheit« ergab sich, wenn die Braut einen großen Hofstaat aus ihrer Heimat am neuen Hof behalten wollte und durfte. Am Beispiel von Henrietta Maria von Frankreich, Braut von Charles I. von England I625, hat Anuschka Tischer festgehalten, wie sich die Braut, durch einen überdimensionierten eigenen Hofstaat "sichtbar als ein fremdes Element am englischen Hof und Repräsentantin einer fremden - und unter konfessionellem Gesichtspunkt feindlichen - Macht ${ }^{532}$ positionierte.

Besonders Renée de France, Tochter von König Louis XII., die zu ihren Prätendenten immerhin den designierten Kaiser Karl V. und dessen Bruder, Erzherzog Fer-

530 Unter »kultureller Identität« versteht man die Zugehörigkeit einer Person oder Gruppe zu einem bestimmten kulturellen Kollektiv. Die Unterscheidung durch Sprache, Religion, Nation, Wertvorstellungen, Sitten etc. von anderen Personen oder Gruppen ergibt die eigene Identität. Kulturelle Identität entsteht erst in der Kontrastierung mit anderen kulturellen Identitäten, also das »Eigene« versus das »Andere«. Dafür sind Kulturkontakte bedeutend, wenn nicht sogar Voraussetzung. Vgl. dazu und zum Begriff »Kulturtransfer« Friedrich JäGer, »Kultur«, in: Friedrich Jäger (Hg.), Enzyklopädie der Neuzeit Online, https://referenceworks.brillonline.com/entries/enzyklopaedie-der-neuzeit/kultur-COM_ 29890 I?s.num=o\&s.f.s2_parent=s.f.book.enzyklopaedie-der-neuzeit\&s.q=kultur, Zugriff: I6.9.2020. Da hier eine soziologische Belegung des Phänomens der »kulturellen Identität« den Rahmen sprengen würde, sei nur auf zwei Beiträge verwiesen, die seine Bedeutung und Aktualität beweisen: Scholz, Kulturelle Identität. Kiмmich/Schaнаdat/Hauschild, Kulturtheorie.

53 I Dazu siehe zum Vergleich die Beiträge im epochenübergreifenden Sammelband: LÜTH/KECK/WIERsing, Der Umgang mit dem Fremden.

532 Tischer, Verwandtschaft als Faktor, 49. 
dinand zählen konnte, war mit dem Gefolge einer Königin nach Italien gekommen und hatte insgesamt 167 »fremde« Personen an ihrem neuen Hof in Ferrara angesiedelt. ${ }^{533}$ Bei Erzherzogin Barbara, zweite Ehefrau von Alfonso II., waren es immerhin von 32 mitgeführten Personen, I5, die als "Deutsche" gekennzeichnet noch ${ }_{5} 572$ in ihrem Testament aufgeführt wurden. Auch wenn vergleichende Untersuchungen über die Größe und Zusammensetzung der Entourage von Fürstinnen der Frühen Neuzeit noch immer ein Desideratum ${ }^{534}$ sind, kann man in Anlehnung an die bisherigen Untersuchungen behaupten, dass Barbaras Hofstaat überdurchschnittlich und Renées Entourage außerordentlich groß war. In beiden Fällen bedeutete dies, dass der Fürst für viele zusätzliche Personen finanziell aufkommen musste, die ihm im besten Fall Kontakte zum Heimathof seiner Gemahlin, aber in den meisten Fällen Schwierigkeiten aufgrund ihrer Integrationsresistenz und wegen der Animositäten mit seinem eigenen Hofstaat einbrachten. Das kostspielige, eindrucksvolle Auftreten der französischen Entourage in der Fremde hatte u.a. auch Repräsentations- und Imagegründe. ${ }^{535}$ Für Ercole waren diese ungeheuren Ausgaben und die hohe Anzahl von landesfremden Personen, die allzeit bereit waren, jede nichtige Neuigkeit nach Frankreich zu melden, ein Dorn im Auge. Bereits ein Jahr nach Renées Ankunft I 528 gelangten die ersten Klagen über den zu großen und teilweise auch feindlich gesinnten Hofstaat nach Frankreich. Zwar rief der rex christianissimus schließlich einige der Franzosen nach Frankreich zurück, doch blieb ihr Hofstaat in Ferrara weiterhin groß und kostspielig, bis sie I 560 als Witwe mit ihm nach Frankreich zurückkehrte.

Renées "misslungene " Integration und ihre Rolle als Vermittlerin von französischen materiellen wie ideellen Kulturgütern (Sprache, Mode, Glaubenslehre) ist ein eklatantes Beispiel in der estensischen Heiratspolitik aber durchaus nicht einzigartig. Duchhardt hat bereits das Beispiel der Heirat des polnischen Königs Sigismund I. mit Bona Sforza und die Bemühungen der Italienerin und ihres Hofstaates »nach ihrer Vermählung und ihrer Installierung am Krakauer Hof [...], künstlerisches Potential

533 Taddei, Zwischen Katholizismus und Calvinismus, I73- i78. Siehe auch: Franceschini, La corte.

534 Nach Paul-Joachim Heinig behielt Leonore von Portugal nach der Heirat mit Friedrich III. I 452 nur eine Handvoll Portugiesen an ihrem Hof. Heinig, How large was the Court of Emperor Frederick III ?, I 39, I 4I ; ZierL, Kaiserin Eleonore, 202f. Anna Caterina Gonzaga, eine Nichte Barbaras, die mit Erzherzog Ferdinand II. in zweiter Ehe vermählt wurde, hatte einen fast ausschließlich deutschsprachigen Hofstaat in Innsbruck. Die Begründung ihres italophilen Ehemanns dafür war, dass der Alltag, die Sitten und alles am Hof Deutsch sei. Innsbruck, TLA, Ferdinandea pos. 37 Mantuanische Heiratshandlungen, Erzherzog Ferdinand II. an Dario Castelletti da Nomi, März I582. Maria von Aragòn, zweite Ehefrau von Leonello d'Este, brachte I444 nur neun Hofdamen nach Ferrara. Vgl. TADDEI, Barbara von Österreich, 635f. Rotraut Becker, »Gonzaga, Anna Caterina«, in: DBI 57, Roma 200 I, 682-684. Sandbichler, Anna Caterina Gonzaga. Weitere Beispiele dafür, wie verschieden groß Höfe sein konnten, sind bei Bertelli/Cardini/Gambero Zorzi, Le corti italiane, vor allem Sergio Bertelli, Luniverso cortigiano, $7-38$ zu finden.

535 Schalk, The Court as scivilizer`, 248. Für Spieß dient die Brautfahrt der "Selbstdarstellung ihres jeweiligen Landes«. Spiess, Unterwegs zu einem fremden Ehemann, 27; Gorris CAmos, »Donne ornate«. 
und Personal aus Italien in die Weichselstadt und nach Polen zu ziehen, also aus jener Region, die in kultureller Hinsicht führend war im gesamteuropäischen Vergleich« dargestellt. ${ }^{536}$ Von den 300 Personen, die Bona aus Italien mitgebracht hatte, blieben ca. 60 in ihrem Hofstaat. Mit ihrer bewussten Förderung italienischer Künstler, Musiker, Juristen, Ärzte, Architekten und Handwerker orientierten sich der Hof und die gesamte Provinz an den italienischen Idealen, sodass Duchhardt zu dem Schluss kommt, dass »die eigentliche >Explosion der `Kulturrevolution in Polen [...] auf jeden Fall erst mit der Ankunft Bona Sforzas ein[setzte], und man [...] sich ohne sie auch kaum vorstellen [kann], dass der König an so vielen Stellen architektonisch Hand angelegt und eine so große Bibliothek mit über 4.000 prachtvoll gebundenen Bänden aufgebaut hätte. «37 Diese starke Affinität zur italienischen Kultur hinterließ nicht nur in der Baukunst und Musik tiefe Spuren, sondern verständlicherweise auch in der polnischen Sprache. Mit den Kulturgütern (vor allem aus dem Bereich der Mode) und den Lebensmitteln aus Italien kamen auch ihre Namen mit. So kam es zur Bildung von - meist der Aussprache nachempfundenen - Lehnwörtern wie z.B. kalafior für Blumenkohl (ital. cavolfiore), kapusta für Kapuze (cappuccia) oder por für Lauch (porro). ${ }^{538}$

Auch auf religiösem Gebiet kam es durch Bonas Gefolge zu einer Veränderung durch die einsetzende Verbreitung des Luthertums in Polen. Ihr Beichtvater, Francesco Lismanino, und ihr Leibarzt, Giorgio Biandrata ( 1 5 I 5 - I 588 ) gehörten zu den ersten Vertretern der neuen Lehre, die von der Fürstin protegiert wurde. Dies förderte - trotz bzw. bis zum Gegenschlag durch die katholische Reform - eine relativ ungestörte Ausbreitung der neuen Glaubenslehre. ${ }^{539}$ In Ferrara hingegen kam es durch Renée Sympathien für Johannes Calvin und die von ihr aufgenommenen französischen Glaubensflüchtlinge zur Ausbreitung der calvinistischen Glaubenslehre. ${ }^{540}$

Betrachtet man die aus dem spanischen, französischen und deutschen Kulturraum stammenden Frauen der Este, so erscheinen sie nicht nur Schachfiguren der Heiratspolitik, sondern gleichzeitig Trägerinnen und Vermittlerinnen von Kultur - besonders dann, wenn sie einen eigenen, aus der Heimat stammenden, repräsentativen Hofstaat behalten durften und - wie im Fall von Renée de France - in der neuen Heimat »fremd blieben« und als »Fremde« wahrgenommen wurden. Dies geschah im erhöhten Maß dann, wenn die in die Fremde verheiratete ranghöhere Fürstin eine besondere politische Rolle als Repräsentantin ihres Heimatlandes zu spielen hatte. Durch ihr interessengeleitetes Engagement in der neuen Heimat und durch den Versuch, ihre Identität zu wahren, war sie unbewusst Initiatorin eines frühneuzeitlichen Kulturtransfers.

536 Ebd., Iо.

537 Ebd., го. Васzкоwsкi, Humanismus in Krakau, 58.

538 Vgl. Jamroziк, Litaliano in Polonia, 320.

539 Ebd., II.

540 Vgl. TADdeI, Zwischen Katholizismus und Calvinismus. 
Wenn man auf die I7 Jahre lange Zeit im Leben von Lucrezia Borgia als Gemahlin von Alfonso I. d'Este schaut, stechen ihre engagierte Förderung von Literatur und Kunst, die Einführung einer besonderen Mode »a la spagnolla « ${ }^{541}$ und ihre unternehmerischen Aktivitäten zur Steigerung ihres eigenen Wohlstandes und dem ihrer Untertanen hervor. Aus dem Inventar ihrer Privatbibliothek ragen viele spanische, italienische und lateinische religiöse sowie profane Werke, Beispiele für Erbauungsliteratur und Zeichen humanistischer Bildung heraus, von denen etliche von ihr in Auftrag gegeben worden waren. ${ }^{542}$

Anders als die legendenumwobene Lucrezia und die aufmüpfige Renée hatte Erzherzogin Barbara ein weniger blendendes Renommee. Nicht einmal ihre Hochzeit und ihre Brautreise waren einzigartig gewesen, denn sie hatte sich diese mit ihrer Schwester Johanna, die gleichzeitig mit Francesco de'Medici verehelicht wurde, teilen müssen. Die gemeinsame Hochzeitsreise sollte vor allem Kosten sparen und die Präzedenzstreitigkeiten zwischen Ferrara und Florenz nicht weiter schüren. Viele Güter für die Aussteuer der beiden Erzherzoginnen waren in Wien und Tirol in Auftrag gegeben worden, sodass eine Reihe von Alltagsgegenständen deutschen Stils, von Wiener Schneidern nach spanischer Mode gefertigte Kleider, ${ }^{543}$ Silbergeschirr und Schmuck jeweils nach Ferrara und Florenz kamen. ${ }^{54}$ In der Österreichischen Nationalbibliothek ist das in deutscher Frakturschrift aufwendig mit Silberbeschlägen und rotem Samteinband gestaltete "Gebetbuch der Erzherzogin Barbara « aufbewahrt, das sie in Ferrara als Gebetbuch für alle Tage benutzt hatte und nach ihrem Tod zurückgekehrt sein dürfte. ${ }^{545}$

Die deutsche Fürstin, die aufgrund ihrer mangelnden Sprachkenntnisse und ihres deutschen Hofstaates eher isoliert blieb, machte sich durch eine Reihe von Förderungen in ihrer neuen Heimat beliebt. Den Erwartungen in eine Landesmutter wurde die kinderlos gebliebene Barbara nämlich beim Erdbeben von I 570 gerecht, indem sie das Armenhaus, Spedale di Santa Giustizia, unterstützte und eine Einrichtung für

54I So zum Beispiel die gorgiera oder lattuga, eine teilweise sehr hohe und steife Halskrause, die ihren Ursprung im arabischen Raum hatte. Diese wurde in Italien von Lucrezia Borgia eingeführt, um die von der französischen Mode vorgegebenen tiefen Ausschnitte zu verbergen. Die hohen Krausen verlangten zudem eine besondere Frisur mit hochgestecktem Haar, wofür Lucrezia ebenfalls berühmt, ja im heutigen Sinn eine Trendsetterin wurde. ASMo, ASE, Amministrazione dei principi, b I 39 ( 15 I 6 - I 5 I 9 .); Ghirardo, Lucrezia Borgia, I37- I39.

542 Faggioli Saletti, „El Tebaldo«, I $92 f$. Neben ihrem Mäzenatentum war sie auch für ihre Frömmigkeit und Religiosität bekannt, die sie in den verschiedenen, von ihr (mit)begründeten oder zumindest nachhaltig unterstützten Klöstern Ferraras auslebte, in denen sie sich regelmäßig in Meditation zurückzog. Vgl. Nalini Montanari, I luoghi della devozione, 25-27 und Ghirardo, Lucrezia Borgia, I36

543 Kuster, Herzogin Barbara, I 25.

544 Vgl. Groнs, Die Hochzeiten. Barbara nahm sieben »alte« Kleider und zwölf spanische Handschuhe mit. Kuster, Herzogin Barbara, Katalogteil, i 25.

545 SeIdL, Herzogin Barbara, Katalogteil, I 26. In der Handschriftenabteilung der ÖNB befindet sich auch ein Exemplar der Rime vom Literaten und Diplomat im estensischen Dienst, Battista Guarino, in denen die Stanzen zum Tod Barbaras enthalten sind. Ebd., I34. 
die durch die Naturkatastrophe elternlos gewordenen Mädchen der Stadt, genannt Conservatorio delle orfane di Santa Barbara, gründete. ${ }^{546}$ Doch ihr größtes Verdienst im Bereich des kulturellen Austausches war die Ansiedlung der Jesuiten aus dem Tiroler und süddeutschen Raum im estensischen Fürstentum. Mit ihrer Unterstützung wurde in Ferrara die Jesuitenkirche (Chiesa del Gesù) errichtet, in der sie auch bestattet wurde. Durch ihr Engagement konnte sich der Jesuitenorden als besonderer Katalysator der katholischen Konfessionalisierung in weiten Teilen Norditaliens etablieren. ${ }^{547}$

Erzherzogin Barbara von Österreich benutzte jedoch ihre Netzwerke und Kontakte zum Kaiserhaus auch, um italienische wie deutsche Kaufleute, Gesandte, Hofdamen und Höflinge zu empfehlen bzw. an anderen Höfen unterzubringen. So empfahl sie zum Beispiel den italienischen Kaufmann Thomaso Magrodi, der eine neue und günstigere Methode entwickelt hatte, um Salz zu raffinieren, ihrem Bruder Ferdinand von Tirol und bat für ihn um eine Audienz in Innsbruck. ${ }^{548}$ Durch ihr Bemühen wurden einige Hofdamen mit Italienern verheiratet. Dank ihrer Kontakte im Reich förderte sie - wie oben bereits gezeigt - den regen Austausch von Lebensmitteln, Holz, Obstbäumen, Tieren und Kunstgegenständen ${ }^{549}$ zwischen Ferrara und den Höfen von Wien, Innsbruck, Graz, München und Prag. ${ }^{50}$

Diese verschiedenen Beispiele aus Ferrara zeigen, wie ausländische Fürstinnen an ihrer kulturellen Identität vor allem durch die Beibehaltung ihrer Sprache und Lebensweise und durch die Förderung der eigenen Landsleute festhielten. Im Laufe des I6. Jahrhunderts kamen Hofleute, Diener/innen, Künstler, Prediger und Flüchtlinge spanischer, französischer und deutscher Herkunft, Anhänger des Calvinismus, Luthertums oder der katholischen Konfessionalisierung in das Herzogtum von Ferrara und Modena. Einige kamen nur für kurze Zeit, andere wurden sesshaft und blieben ein Leben lang. Wie die jeweilige Fürstin, die sie begleiteten oder die sie nach Italien geholt hatte, waren sie bestrebt, ihre kulturelle Identität in der Fremde zu wahren. Dadurch kam es unweigerlich zum Austausch, zur Beeinflussung der neuen Heimat, forciert von eben diesem Bestreben, die eigene (fremde) Identität gegenüber dem »Anderen«, »Neuen« zu festigen und zu bewahren. Dieser Austausch und die permanente Interaktion zwischen dem Herkunftsland und der neuen Heimat finden ihren Ausdruck in jenem Phänomen, das wir - retrospektiv betrachtet auch für das I6. Jahrhundert - Kulturtransfer« bezeichnen.

546 Dazu siehe: Calore, Ferrara delle donne, r 35 f.

547 Vgl. dazu: Vedi Pepe, I gesuiti. Eine Detailansicht ihrer Büste aus dem Grabmalkomplex der Jesuitenkirche in Ferrara ist bei BACCHI, Sculpteurs, 308 mit Abbildung.

548 Innsbruck, TLA, Ferdinandea, cart. 3 I, pos. 26 Barbara Herzogin von Ferrara an Erzherzog Ferdinand II., Januar 1569 .

549 Darunter wahrscheinlich auch die begehrten cofanetti aus der Werkstatt der Embriachi in Venedig. Schlosser, Die Kunst- und Wunderkammern, 89.

$550 \mathrm{Zu}$ diesem regen Warenaustausch siehe die Korrespondenzen in Innsbruck, TLA, Ferdinandea, cart. 3 I, pos. 26, November 1566 bis September 1569 . 


\subsection{Die Universität als Ort des Kulturaustausches und Wissenstransfers}

Die Gründung (und die mehrfache Wiedereröffnung) der meisten spätmittelalterlichen und frühneuzeitlichen italienischen Universitäten war auf Betreiben eines Fürsten erfolgt, der außer durch seinen renommierten Hof und sein weitreichendes Mäzenatentum auch durch ein Zentrum des Wissens und der Gelehrtheit Prestige gewinnen wollte. Das Renommee der Universität wuchs mit ihren Bücherbeständen und mit den Namen der vom Fürsten an sein Bildungszentrum gerufenen Gelehrten. Dennoch darf auch ein ökonomischer Aspekt nicht ganz außer Acht gelassen werden: Wenn die Universität von Ferrara regen Zulauf genoss, so war hierfür nicht ausschließlich der Ruf der Dozenten ausschlaggebend, sondern auch die mit Studium und Doktortitel verbundenen Kosten, die z.B. in Bologna oder Pisa viel höher waren als in Ferrara. Mit Burke gesprochen war Ferrara »die Zuflucht der nicht ganz so Betuchten «. ${ }^{551}$

Die I39I von Markgraf Alberto d'Este gegründete Universität von Ferrara ${ }^{52}$ bestand aus der juridischen Fakultät mit den beiden Rechten, der Artistenfakultät, der Medizin und der theologischen Fakultät. Um den Gelehrtennachwuchs im Land zu behalten, legte Ercole I. per Dekret fest, dass die Ferraresen nirgendwo anders als an ihrer Heimatuniversität studieren durften. Doch im Laufe des I6. Jahrhunderts musste die Einrichtung aufgrund der kriegerischen Ereignisse immer wieder für kürzere und längere Zeiten geschlossen werden. Ercole II. war 1557 aus Geldnot ${ }^{53}$ sogar gezwungen, die Gehälter der Lehrenden zurückzuhalten. In guten Zeiten hingegen wurde die Universität von den Herzögen finanziell und personell unterstützt und gefördert, war sie schließlich ein fürstliches Prestigeobjekt. Ihre Bekanntheit zeigte sich nicht nur in ihren prominenten Abgängern, sondern auch in der Tatsache, dass der englische Hof ${ }_{5} 3$ o die Universität Ferrara beauftragte, die Annullierung der Ehe zwischen Henry VIII. und Catarina von Aragón zu begutachten. Der englische Beauftragte, der Philologe und Professor für Griechisch, Richard Croke, ${ }^{554}$ wandte sich an den Univer-

55 I Burke, Die Renaissance in Italien, 58.

$55^{2}$ Vgl. Visconti, La storia dell'università di Ferrara. Im Anhang ist die Liste der Lektoren und ihre Besoldung.

553 Auch die Este, die in der europäischen Wahrnehmung als reich und stets liquide galten, gerieten in der zweiten Hälfte des I6. Jahrhunderts immer wieder in Geldnot. Für die Geldleihen des französischen Königs, zur Deckung der enormen Kosten der Stadterweiterungen oder der aufwendigen Trockenlegungsmaßnahmen machten die Este innerhalb und außerhalb ihres Herzogtums Schulden. Zu ihren Gläubigern zählten neben den jüdischen Geldverleihern aus Ferrara auch die Familien Romani, Lardi, Sardi, Machiavelli, Strozzi, die - wenig verwunderlich - in der herzoglichen Kammer beschäftigt waren und sich somit ihrer Investitionen sicher sein konnten. Guerzoni, Le corti estensi, Io3f.

554 Adalbert Horawitz: »Croke, Richard«, in: ADB 4, Leipzig I 876, 602-604. 
sitätsdozenten Celio Calcagnini, der wiederum die Doktoren des theologischen Kollegiums mit Geldgeschenken zu einem positiven Gutachten zu überreden versuchte, allerdings ohne Erfolg. Als Ercole II. durch die Anfrage des englischen Agenten seine Beziehungen zum Papst gefährdet sah, ging man nicht weiter darauf ein. ${ }^{555}$

Wie auch andere oberitalienische Hochschulen war die Universität von Ferrara in der Renaissance nicht nur ein bedeutendes Zentrum der Gelehrsamkeit und des Austausches mit vielen Professoren und Studierenden aus den Ländern jenseits der Alpen, sondern auch ein Forum sowohl für den geistigen Austausch von sogenannten heterodoxen (Glaubens)Lehren als auch für deren vehemente Zurückweisung. ${ }^{556}$

Bedeutend am estensischen Hof und unter den Lehrenden der Universität von Ferrara war der herzogliche Leibarzt und Professor für Medizin ${ }^{557}$ und Naturphilosophie,

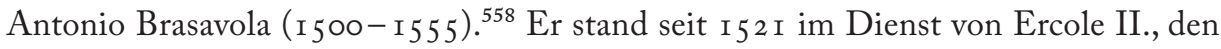
er I 528 nach Frankreich zur Brautabholung begleitete, wo er an der Sorbonne mit seinem Wissen glänzte, sodass der französische König François I. ihm den Beinamen "Musa« und den Orden vom Heiligen Michael verlieh. Seine Kenntnisse beschränkten sich nicht nur auf die Medizin; er bereicherte durch eigene Schriften auch den Bereich der Theologie ${ }^{559}$ und der Botanik. Ihm verdankte man die Anlegung des an exotischen Pflanzen äußerst reichen botanischen Gartens in der Delizia Belvedere ${ }^{560}$ sowie die Erstellung eines detaillierten Pflanzenkatalogs mit der Beschreibung ihrer

555 Chiappini, Gli Estensi, 337-349. Chiappini hat in einer Detailuntersuchung die seit der Mitte des I 5. Jahrhunderts bestehenden und sich ab dann intensivierenden Beziehungen zwischen dem englischen und dem estensischen Hof eingehender studiert. Der estensische Gesandte Biagio Birago z.B. berichtete Borso laufend über den Rosenkrieg und bemühte sich auch dessen Nachfolger, Ercole I., für den englischen Hosenbandorden vorzuschlagen, mit dem der Este I 480 durch den englischen Gesandten Lorenzo Reinford von König Eduard IV. auch tatsächlich bedacht wurde. Die estensischen Gesandtschaften in England waren im i6. Jahrhundert, wenn auch nicht permanent, doch zumindest häufig. In der Korrespondenz zwischen den beiden Höfen ist der Austausch von Geschenken, die Bitten um Empfehlungen und Passierscheine und der Austausch von Neuigkeiten dokumentiert. Ferrara war für Engländer aber vor allem ein interessanter Studienort. Zwar gingen im Zuge der Glaubensverfolgungen einige italienische Gelehrte auf die Insel, doch bedeutender für die Verbreitung des Humanismus in England war das, was die Studierenden im Zuge ihres Aufenthaltes aus Italien und speziell Ferrara mitbrachten. Nach Chiappini gab es nach I 500 I 4 englische Studierende in Ferrara, die meisten waren Kleriker und studierten Rechtswissenschaften. Vgl. Chiappini, Le relazioni.

556 Adriano Prosperi hat sich mit dem Umfeld der Universität in Ferrara und im Speziellen mit der literarischen Produktion, die in der ersten Hälfte des I6. Jahrhunderts aus diesem Ambiente hervorging, beschäftigt. Pros PERI, Università.

557 Vgl. Raspadori, I maestri, 20If.

$55^{8}$ Dazu vgl. Giuliano Gliozzi, »Brasavola, Antonio«, in: DBI I 4, Roma I 972, 5 If. An seine Gelehrtheit und Berühmtheit erinnert heute noch eine Gedenktafel am Eingang der Biblioteca Ariostea.

559 In seinem um 538 verfassten aber Manuskript gebliebenen Werk Vita di Cristo versuchte er die Heiligenlegenden des Mittelalters und das Leben Christi wissenschaftlich aufzuarbeiten.

560 Eine der delizie estensi. Andere Lustgärten und Jagdreviere waren Barchetto, Belfiore, Belriguardo und Consandolo. Vgl. dazu: Zaniboni, Gli Estensi, ro9-i 35 und I55-i 8 I. 
heilenden Eigenschaften. ${ }^{561}$ Brasavolas theologische Werke bauten - in der besten Tradition des italienischen Evangelismo ${ }^{562}$ - auf der imitatio Christi auf. Daneben findet man aber auch eine besonders vehemente Kirchenkritik. Trotzdem stellte sich der Gelehrte nicht auf die Seite Luthers, dessen Werke und Lehren er rezipierte. Diesen nannte er eine »hydra dalle cento teste « ${ }^{563}$ noch weniger konnte er sich für Calvins Prädestinationslehre erwärmen. Er befand sich also, wie viele andere in dieser Zeit und besonders am estensischen Hof, in einer Grauzone, zwischen der Erkenntnis der Krise der Kirche, der Notwenigkeit von Reformen und der Rezeption von neuen Glaubenslehren von jenseits der Alpen. ${ }^{564}$

I 544 sammelte und überarbeitete Brasavola einige Schriften seines Freundes, des oben genannten ferraresischen Protonotars Celio Calcagnini, ${ }^{565}$ und veranlasste mit der finanziellen Unterstützung Ercoles II. deren Veröffentlichung beim Baseler Drucker Johann Froben. Der in Ferrara geborene, aus adeliger Familie stammende Calcagnini hatte eine vorzügliche Ausbildung genossen, die es ihm ermöglichte, den Doktortitel im zivilen und kanonischen Recht zu erwerben, einen Lehrstuhl für klassische Philologie in Ferrara zu besetzen, als Diplomat im Reich im Dienst von Kardinal

56I Examen omnium simplicium medicamentorum quorum in officinis usus est, Romae 1536. In ihrem Werk über die Gartenkunst der Renaissance nimmt Hilda Lietzmann in der Beschreibung der Anlage des Pfalzgrafen Ottheinrich an, dass dieser - wahrscheinlich seit seiner Pilgerreise ins Heilige Land I 52 I von Venedig aus - Kontakte nach Ferrara und besonders zu Musa Brasavola hatte; dieser beschaffte für Ercole II. d'Este Samen und Pflanzen aus Kleinasien und ließ wahrscheinlich dem Pfalzgrafen einige davon zukommen. Vor allem die in der Anlage von Neuburg angenommenen Zitruspflanzen könnten aus Ferrara stammen. Lietzmann, Irdische Paradiese, i i i, i zof. Nach Lazzari gab es auf der Höhe der Porta di S. Benedetto (heute Porta Po) einen windgeschützten Zitrusfrüchtehain genannt la Cedrara. Lazzari, Le ultime tre duchesse, I64. Ottheinrichs Hauptlieferant für Gewächse, Samen, Tiere etc. war aber Mitte des I6. Jahrhunderts vorrangig Ulrich Fugger, mit dem er die Hinwendung zu den neuen Glaubenslehren teilte. Lietzmann, Irdische Paradiese, i 25; Andreas Edel, »Ottheinrich« in: NDB 19 (1 999), 655 f. [Onlinefassung]; URL: http://www.deutsche-biographie.de/ppn r 187387 I 2. html, Zugriff: 7.7.2020.

562 Mit dem Sammelbegriff Evangelismo ist ein weites Spektrum religiöser Ideen und Bewegungen verschiedener sozialer Gruppen speziell im Italien des ausgehenden I 5. und des I 6. Jahrhunderts gemeint. Diese traten anfangs vor allem für eine religiöse und moralische Erneuerung für den Einzelnen ein und beriefen sich dabei auf die Heilige Schrift und auf die Paulinischen Briefe. Ein zentrales Thema war die Rechtfertigung allein durch den Glauben (sola fide), ohne das Zutun menschlicher Werke. Dieser Bewegung, die an sich keinen Bruch mit der Lehre der katholischen Kirche anstrebte, gehörten verschiedene Kirchenmänner an, wie die Kardinäle Reginald Pole und Gasparo Contarini, die zum Kreis der Spirituali zählten und auf diesem Weg institutionelle Reformen durchzusetzen versuchten. Trotz ihrer "Harmlosigkeit« wurde die Bewegung von der Inquisition aufgrund ihrer Nähe zur evangelischen Lehre verfolgt. Klaus Ganzer, "Evangelismus« in: Lexikon für Theologie und Kirche (LThK) 3, Freiburg/Basel/Rom ${ }^{3}$ I 995, Sp. ro54f. Dazu auch Simoncelli, Evangelismo.

563 GLiozzi, "Brasavola, Antonio«, 5 I.

564 Vgl. auch Horne, Reformation.

565 Valerio Marchetti, »Calcagnini, Celio«, in: DBI i6, Roma i973, 492-495. Augusto de Ferrari, »Calcagnini, Celio, Opere«, in: DBI r6, Roma I973, $495 \mathrm{f}$. 
Ippolito d'Este zu wirken und zum Hofhistoriker des Hauses Este bestellt zu werden. I 54 I trug er kurz vor seinem Tod zur Gründung der ersten literarischen Akademie in Ferrara, der Accademia degli Elevati, bei. ${ }^{566}$

Ein weiteres bedeutendes Bindeglied zwischen dem estensischen Hof und der Universität war der Professor für alte Sprachen an der Universität von Ferrara und Lehrer der Fürstenkinder, Fulvius Peregrinus Moratus (Fulvio Pellegrino Morato), Vater der gelehrten Olimpia Morato (I 526- I 555) ${ }^{567}$ Als der begabtesten unter seinen Töchtern ließ der Kommentator der Werke Ciceros, Vergils und Horaz' ihr eine für ein Mädchen der damaligen Zeit überdurchschnittlich sorgfältige humanistische Erziehung in Latein und Griechisch zuteilwerden. Nicht nur von ihrem Vater, sondern auch von den am Hofe tätigen Gebrüdern Sinapius (Senf), ${ }^{568}$ Söhne des Schweinfurter Bürgermeisters Kaspar Senf, wurde die junge Olimpia unterrichtet und erntete ob ihrer Gelehrsamkeit und ihres Wissens am Hof wie in der Akademie viel Lob und Anerkennung. Auf Empfehlung des genannten Calcagnini wurde sie später als Gesellschafterin und Lerngefährtin von Anna, der ältesten Tochter von Ercole II. und Renée, in die Dienste der Herzogin aufgenommen.

Durch den von Melanchthons Schriften beeinflussten Vater und andere am Hof tätige Gelehrte wandte sich auch Olimpia den neuen Glaubenslehren und den reformatorischen Schriften zu. Dies war schließlich mitunter ein Grund, mit ihrem Ehemann, Andreas Grunthler, der in Ferrara Doktor der Medizin geworden war, nach Schweinfurt und dann Heidelberg zu ziehen, wo sie noch jung starb.

Auch andere, von den Este engagierte und hochgeschätzte Gelehrte - wie der Physiker Giovanni Grillenzoni, der Rechtsgelehrte Ludovico Castelvetro, ${ }^{569}$ der Verfasser

566 Prosperi, Università, I I 5 . Neben der Universität waren die accademie, Gelehrten- bzw. Künstlerzirkel, an deren Veranstaltungen sowohl Adel als auch Patriziat und Teile des Fürstenhofes teilnahmen sowie Zentren des Wissens und der Kulturvermittlung. In Ferrara gab es mehr als 30 verschiedene und somit viel mehr als in Florenz, Rom oder Padua. Vgl. Prandi, Il »Cortegiano«, $52 \mathrm{f}$ und im Personenregister, 233 die Auflistung der accademie von Ferrara. Siehe auch Maylender/Rava, Storia delle accademie.

567 Lisa Saracco, »Morato (Morata), Olimpia Fulvia«, in: DBI 76, Roma 201 2, online verfügbar unter http://www.treccani.it/enciclopedia/olimpia-fulvia-morato_\%28Dizionario-Biografico \%29/, Zugriff: i6.9.2020. Immer noch lesenswert Jules Bonnet, Vie d'Olympia Morata, Paris I 85 I.

568 Von den beiden Brüdern Kilian und Johann Senf aus Schweinfurt war sicher Letzterer, ein Mediziner und Humanist ( ${ }_{5} \mathrm{O}_{5}$ - I $56 \mathrm{I}$ ), der Bedeutendere. Nach dem Studium der artes in Erfurt und Heidelberg und einer Tätigkeit als Griechischlehrer, begann er mit dem Medizinstudium in Ferrara, wo er von I 534 bis 1539 Lektor für Medizin war. Seit 1548 finden wir ihn als Leibarzt des Würzburger Fürstbischofs Melchior Zobel von Giebelstadt. Dazu siehe: Alfred Wendenorst, Das Bistum Würzburg. Teil 3: Die Bischofsreihe von I455 bis r6r7 (= Germania Sacra, Neue Folge 13), Berlin/New York I 978, I 24-I 27. Vgl. auch »Sinapius, Johann«, in: Deutsche Biographische Enzyklopädie 9, München I 998, 337 und RASPADORI, I maestri, I62.

569 Giovanni Grillenzoni (ca.I50 - I 55 I), Sprössling einer der bedeutendsten Familien Modenas, Arzt und Humanist, war Schüler des Pomponazzi. Ab 1530 versammelte er Literaten, Philosophen und Gelehrte in seinem Haus zu täglichen Textlektüren und Diskussionen. Dieser Kreis, zu dem u.a. Ludovico Castelvetro, Francesco Porto und Camillo Molza gehörten, bekam den Namen Accademia dei 
eines Fürstenspiegels Filippo Valentini und der Griechischlehrer der Fürstenkinder, Francesco Porto - beschäftigten sich und sympathisierten mit den Ideen des heimischen Evangelismo und/oder mit den reformierten Lehren aus dem Norden. Diesbezüglich scheinen Alfonso I. und nach ihm sein Sohn Ercole II. lange Zeit Augen und Ohren vor dem Ruf, den manche hatten, und vor den Nachrichten über religiöse Unruhen, die von jenseits der Alpen kamen, verschlossen zu haben, bis schließlich der Papst erfolgreich darauf drängte, die freie Meinungsäußerung der Akademiker über religiöse Dinge einzuschränken.

Vor allem in den Naturwissenschaften und in der Medizin war die ferraresische Universität (oder nach der damaligen Bezeichnung Studio ferrarese) ein vorbildliches und anerkanntes Bildungszentrum. Durch die Bemühungen der Herzöge, fremde Studierende und Lehrende aufzunehmen, kamen berühmte Männer wie Nikolaus Kopernikus ( I 473-I 543) ${ }^{570}$ und Paracelsus ${ }^{571}$ zum Studium nach Ferrara und wurden hier promoviert.

Auch der deutsche Humanist, Literat und Theologe Rudolf Agricola studierte in Ferrara und drückte seine Bewunderung für die Gelehrsamkeit und die Pflege der Wissenschaften an der oberitalienischen Universität, in den Akademien und Gelehrtenkreisen im Unterschied zu seiner »barbarischen und ungebildeten« Heimat aus. Er besetzte an der Universität von Ferrara den Lehrstuhl für Philosophie.

Grillenzoni oder auch Accademia Modenese. Hier verbreiteten sich auch die Ideen der Reformation; sogenannte häretische Texte wurden übersetzt und weitergereicht. Als der Bischof von Modena, Kardinal Morone, seine Befürchtungen aussprach, dass sämtliche Mitglieder dieser Gesellschaft der Häresie bezichtigt werden könnten, mussten diese ${ }_{542}$ ein »Glaubensformular» unterzeichnen. Ein Edikt von Ercole II. verbot I 545 das Lesen verdächtiger Bücher und gab den Anstoß zur Auflösung der Accademia Modenese. Floriana CALıтtı, „Grillenzoni, Giovanni«, in: Letteratura Italiana I, 953. Zu Grillenzoni und Castelvetro siehe auch: CAntù, Gli eretici, I $54 \mathrm{f}$.

570 Während seines achtjährigen Italienaufenthaltes studierte Kopernikus in Padua Medizin und in Bologna und Ferrara Rechtswissenschaften, wo er auch I 503 zum Doktor des Kanonischen Rechts promoviert wurde. Jürgen Hüвner, »Kopernikus«, in: TRE i 9, I 990, 393-395. Auf die Frage, warum Kopernikus von einer großen und renommierten Universität wie Krakau nach Italien zog, antwortet Visconti mit zwei Argumenten: Einerseits sei in Krakau das Studiengeld viel höher gewesen als an den italienischen Universitäten, die für auswärtige Studierende zumeist noch günstige Sonderregelungen besaßen und andererseits zeichnete sich gerade die Universität Krakau um I 500 durch einen fortschreitenden Niedergang aus, weil sie in der scholastischen Weltauffassung verhaftet blieb und sich dem Humanismus weitgehend verschloss. Vgl. Viscontı, Storia dell'Università di Ferrara, 47 und Righini, Sul soggiorno italiano di Nicolò Copernico.

57I Theofrastus Paracelsus, eig. Theophrastus Bombast von Hohenheim (I 493- I 54I), Arzt, Naturphilosoph und Laientheologe, latinisierte in Ferrara, wo er Doktor der Medizin wurde, seinen Namen. Hartmut Rudolph, »Paracelsus«, in: LThK 7, ${ }^{3}$ I 998, Sp. I 358 - I 359 und Visconti, Storia dell'Università di Ferrara, 48. Siehe auch die Beiträge in: Heinz Dopsch (Hg.), Paracelsus und Salzburg. Vorträge bei den internationalen Kongressen in Salzburg und Badgastein anläßlich des Paracelsus-Jahres I993, Salzburg I 994 . 
Ein großer Anziehungspunkt war auch das Studium der Astronomie; hier lernte Kopernikus unter Giovanni Bianchini (14Io- I469?) und Domenico Maria Novara. Bianchini verfasste zahlreiche astronomische Tafeln (Tabulae caelestium motuum novae), die er Leonello d'Este widmete und die anlässlich des Besuchs von Friedrich III. in Ferrara dem Kaiser vorgestellt wurden. ${ }^{572}$ Domenico Maria Novara befasste sich zusammen mit Nikolaus Kopernikus, zuerst sein Schüler dann sein Assistent, mit besonderen astronomischen Beobachtungen und deren Deutungen, die für die weiteren Forschungen von Kopernikus von großer Bedeutung sein sollten.

Im I 5. und I6. Jahrhundert wurden zahlreiche ausländische Dozenten vor allem für mathesis und astrologia von den Este-Fürsten an die Universität von Ferrara gerufen oder sie erhielten hier eine Anstellung nach Abschluss ihres Studiums. I 450 kam Georg Purbach (auch von Peuerbach, I 423 - I 46 I $^{573}$ ), ein bedeutender Astronom der Wiener Universität und Vorläufer von Kopernikus, Freund des Philosophen und Theologen Nikolaus von Kues nach Ferrara. Der deutsche Gelehrte wollte sich hier vor allem im Griechischen verbessern. In Ferrara lernte er Leonellos Hofastrologen und Professor für Mathematik und Astronomie, Giovanni Bianchini, kennen. Ebenso zum Griechischlernen kam in den I46oer Jahren Purbachs Schüler, Johannes Müller, genannt Regiomontanus (I436- I 476), ${ }^{574}$ der erste Verfasser eines Traktates über astronomische Trigonometrie nach Ferrara, gefolgt in den letzten I 49oer Jahren auch vom jungen Kopernikus ( 473 - I 543), der ebenso - mit Unterbrechungen - in Ferrara neben dem Doktortitel seine Griechischkenntnisse ${ }^{575}$ erwarb. In Ferrara traf Kopernikus auf den Hofastrologen von Borso d'Este, Pellegrino Prisciani (um I435 - I 5 Io/ I 8), auf den die Inhalte des Freskenzyklus im Salone dei Mesi von Palazzo Schifanoia zurück-

572 Fünf wertvolle Codices haben nicht, wie alles andere bewegliche Gut, im Zuge der Devolution den Weg von Ferrara nach Modena gefunden. Darunter auch jener Codex, der die astrologischen Tafeln von Giovanni Bianchini (ms. I, I 47) enthält, die Kaiser Friedrich III. bei seinem Aufenthalt vorgestellt wurden. Der Codex war noch 598 zum Zeitpunkt der Devolution in Ferrara im Privatbesitz des Kardinals Cornelio Bentivoglio und dann des Markgrafen Guido Bentivoglio, bevor er I750 der Stadtbibliothek verkauft wurde. ChiAppini, Notizie di codici, 350. Massimo Medica geht hingegen von zwei Kopien der Tabulae aus, von denen eine dem Kaiser übergeben wurde, wofür Bianchini das Privileg erhielt, das kaiserliche Zeichen des Adlers in sein Wappen aufnehmen zu dürfen, und die andere im Besitz von Bianchini blieb. Medica, Giovanni Bianchini, i $88 f$.

573 Vgl. Hermann Haupt, »Peu(e)rbach (auch Purbach), Georg von«, in: NDB 20, Berlin 200I, 28If. (Digitalisat).

574 Vgl. Menso Folkerts/Andreas Kühne, »Regiomontanus, Johannes«, in: NDB 21, Berlin 2003, 270 f. (Digitalisat).

575 Während das Konzil von Ferrara/Florenz I438/39 das Ziel der Wiedervereinigung der griechischen und römischen Kirche nicht erreichte, führte diese Zusammenkunft unter der Schirmherrschaft der Este zur Ausbildung der diplomatischen Vertretung und zur Bereicherung des schon verbreiteten Humanismus durch griechische Gelehrte und Bücherschätze aus Byzanz. War das Konzil ein erster Anlass zum Austausch mit des Griechischen mächtigen Kirchenmännern gewesen, so kamen infolge der Eroberung Konstantinopels durch die Türken 1453 weitere Gelehrte und mit ihnen wertvolle Handschriften nach Italien. Vgl. KristelLer, Der italienische Humanismus. 
gehen. ${ }^{576}$ Dieser bedeutendste Moderator des Magnifizierungsprogramms der Este ließ nicht nur die Dynastie verherrlichende Theateraufführungen inszenieren, sondern war auch Historiker, Bibliothekar, Archivar und vor allem kultureller Ratgeber von Ercole I.

576 Vasoli, L'astrologia a Ferrara, 473f. KLett ke, Ferrara und sein Fürstenhof, 93-96. Vgl. dazu auch WARburg, Italienische Kunst. Aby Warburg hat I9I 2 den astrologischen Teil der Fresken von Schifanoia erstmalig richtig gedeutet, indem er die rätselhaften Figuren neben den Tierkreiszeichen den Beschreibungen im arabischen Astrologietraktat von Albumasar Introductiorum in astronomiam, welches sich in Mittelalter und Renaissance großer Beliebtheit erfreute, zugeordnet hat. Es handelt sich hier um sogenannte Dekane. Die ${ }_{3} 6$ Dekane sind die Herren der zehn Tage, göttliche Wesen mit den Attributen von Sternen und Konstellationen. Die Darstellungen der Stadt im Freskenzyklus von Schifanoia stehen in Relation zur theoretischen Abhandlung De re aedificatoria von Leon Battista Alberti, an die sich der Erfinder des Zyklus, Pellegrino Prisciani, angelehnt haben mag. Alberti ist auch unter den dargestellten Personen des Hofes zu finden. Olivato/Barbieri, Ferrara, i 8f. Der 1586 von Giovanni Battista Fontana, Hofmaler Erzherzog Ferdinands II., für die Decke des Speisesaals von Schloss Ambras angefertigte Sternenhimmel sieht ebenfalls eine Dreiteilung in Sternzeichen, Sternenbilder, Gottheiten vor. 


\subsection{Kulturaustausch im Rahmen des Gesandtschaftswesens}

Die oben gezeigten lehensrechtlichen Verstrickungen und die Krisen des r6. Jahrhunderts führten zu einer früh einsetzenden diplomatischen Vertretung der Este am Papst- und Kaiserhof sowie an anderen bedeutenden Fürstenhöfen der Zeit. ${ }^{577}$ Für jene Dynastien der Po-Ebene, die ihre Herrschaft vom Kaiser hatten, war es nämlich unabdingbar, Agenten und Gesandte an den kaiserlichen Hof und zu den Reichstagen zu schicken, um aktuelle Themen ebenso zu verhandeln wie die inständigen und wiederholten Bitten um Titel und Privilegien. ${ }^{578}$ Dieselbe Notwendigkeit der diplomatischen Vertretung bestand auch am Heiligen Stuhl und so hatten die Este, als Diener zweier Herren, zur Vertretung ihrer Interessen sehr früh ein fein strukturiertes diplomatisches Netz nach Norden und nach Süden ausgebaut.

Die frühneuzeitlichen italienischen (und estensischen) Gesandten werden in den Quellen als nunzi, legati, ambasciatori, residenti oder oratori bezeichnet. $Z$ u ihren vorrangigen Aufgaben am Kaiserhof zählte die Ehr- und Treuebekundung, die Bestätigung der Freundschaft und Ergebenheit, die Besprechung und Verteidigung von Ansprüchen und Rechten, vor allem in Bezug auf die Investitur, aber gerade bei den Este auch bezüglich der Rangordnung, die Führung von Heirats-, militärischen und politischen Verhandlungen. Letztere waren situationsbedingte Agenden, die oft die Anwesenheit von zwei oder mehreren Gesandten erforderten. Im »Tagesgeschäft « hatten Diplomaten zu beobachten, Informationen einzuholen und nach Hause zu berichten. Sie waren Augen und Ohren ihres Dienstherrn und Vertretung seiner Person bzw. seines Hauses. Bei ihrem Aufbruch zum Kaiser-, Papst- oder einem anderen Fürstenhof wurden ihnen Kredentialien (Berechtigungsnachweise), Instruktionen und oft Briefe zur Weiterleitung ausgehändigt. Für die Dauer ihrer Mission, die nach der Einführung von residierenden Gesandten in der ersten Hälfte des I 5 . Jahrhunderts auch einige Jahre lang sein konnte, genossen sie Immunität der Person und der mitgeführten Sachen, waren aber bei einem Verbrechen nicht vor Verfolgung und Verurteilung geschützt. ${ }^{579}$ Die frühneuzeitliche Diplomatie war bis zur Mitte des 18. Jahrhunderts und der Entstehung des internationalen Rechts höfisch und daher aristokratisch; sie basierte auf der Einhaltung des (diplomatischen) Zeremoniells als Verhaltenskodex und Wertesystem. ${ }^{580}$ Sie war eines der bedeutendsten Mittel politischer Kommunikation.

577 Vgl. Frigo, La corte, 267; Mattingly, Renaissance diplomacy, 58-60; Prodi, Diplomazia.

578 Frigo, La corte, $270 \mathrm{f}$.

579 Mattingly, Renaissance diplomacy, 29 und passim. Die ersten residierenden italienischen Gesandten aus Mantua und Mailand finden sich bereits Ende des I 4. Jahrhunderts. Ebd., 69, 74.

580 Frigo, La corte, 284 . 
Die estensischen Gesandten waren nach Marco Folin in der ersten Hälfte des I5. Jahrhunderts nicht anders als jene von Mailand, Mantua oder Florenz: Es handelte sich noch um eine fluktuierende, wenig homogene und spärlich spezialisierte Gruppe. Trotzdem kann man hier bereits zwei Typen ausmachen: Es gab einerseits Kanzler und Kammernotare, die als Prokuratoren des Fürsten im estensischen Gebiet seine Ländereien verwalteten und mit Verordnungen in Namen des Fürsten tätig waren. Auf der anderen Seite gab es estensische Gesandte, die als Repräsentanten des Herzogs zu politisch bedeutenden Anlässen außerhalb des Fürstentums reisten. Hierbei handelte es sich um Männer von Rang, Hofadelige, Großgrundbesitzer oder Prälaten. Je höher deren Stellung, desto mehr Prestige drückte ihre Entsendung für den Fürsten und für den Empfänger aus. Diese Gesandten wurden mit offiziellen Empfehlungsschreiben ausgestattet und blieben bis zur Mitte des 15. Jahrhundert ad hoc Gesandte. Erst ab I467, nach dem Tod von Francesco Sforza, verlangte die instabile politische Lage von Borso eine besondere diplomatische Feinarbeit vor allem mit dem Heiligen Stuhl, von dem er sich die Herzogswürde erhoffte. Ab diesem Zeitpunkt wurde es Praxis, am Papsthof, aber auch an den Höfen von Mailand, Venedig, Florenz, Neapel einen residierenden Gesandten in loco zu haben, eine Person, die regelmäßig instruiert wurde und befugt war, den Fürsten am fremden Hof ständig zu vertreten, wobei sie nicht selten (stellvertretend) Opfer von Präzedenzstreitigkeiten wurde. Ein Beispiel soll hier für viele andere genannt werden und geht dem vorne besprochenen langwierigen Präzedenzstreit der Este mit den Medici voran: 1470 wurde der estensische Gesandte, Nicolò Roberti, in Florenz gebeten, dem auf der Durchreise befindlichen Sohn des Markgrafen von Mantua den ihm zustehenden prestigevolleren Platz auf der Tribüne der Würdenträger zu überlassen. Roberti verweigerte dies empört und berichtete sofort seinem Fürsten, Borso d'Este, was er auf diese Impertinenz geantwortet habe: Er habe den Florentinern zu bedenken gegeben, dass der junge Gast erst Thronanwärter und noch nicht einmal Fürst sei und selbst als Fürst wäre er nur Markgraf. Weder aufgrund seines Alters, noch seiner Würde oder Titels und schon gar nicht wegen der Altehrwürdigkeit seines Hauses dürfe er ihm, als Repräsentant des Herzogs von Ferrara, vorgezogen werden. ${ }^{581}$

Die späteren residierenden Gesandten waren zum größten Teil Adelige mit einem Adelstitel wie Graf oder Pfalzgraf, oft auch am Hof verankerte Würdenträger, Doktoren der Rechte, mit guter humanistischer, literarischer Bildung, die weit wichtiger war als ihre juristischen Kenntnisse, da sie damit in der Konversation brillieren konnten und ihre Berichte zu literarischen Kunstwerken fürstlicher Unterhaltung wurden. Nicht selten trat ein Sohn als Gesandter in die Fußstapfen seines Vaters, lernte das »Handwerk« und bot dem Fürsten eine gewisse, meist willkommene Kontinuität und seiner Familie die Weiterführung eines nützlichen Netzwerkes. Obwohl sich die residierenden Gesandten immer mehr durchsetzten, schickten die Este im r6. Jahr-

58 I Vgl. Folin, Rinascimento estense, I 50- i6o. 
hundert weiterhin Sondergesandte, Agenten oder Familienangehörige, die für ein bestimmtes Anliegen eigens instruiert wurden und damit besser die Interessen ihres Herrn/Verwandten vertreten konnten.

Obwohl die Gesandten oft über ihre zu geringe oder unregelmäßig ausbezahlte Besoldung jammerten, ist klar, dass sie nicht des Geldes wegen, sondern des Prestiges diese Position anstrebten. Ein residierender Gesandter in Rom hatte z.B. die Möglichkeit, fast täglich den Papst und die hohen Würdenträger zu sprechen, einer in Mailand, Venedig oder Florenz kam mit wichtigen Bankiers- und Kaufmannsfamilien zusammen. Hier konnte ein fähiger Repräsentant nicht nur für seinen Herrn, sondern auch für die eigene Familie wichtige Kontakte knüpfen und ein Netzwerk aufbauen. Der Nachteil war, dass die Dauer des Aufenthaltes nicht vorauszusehen war, aber selbst bei kurzem Aufenthalt die Ausgaben für Repräsentationszwecke enorm sein konnten. Deshalb entsandte der Fürst Männer, die auf große Rücklagen zurückgreifen konnten oder unterstützte sie auf andere Weise als durch eine Besoldung. Schließlich waren sie sein alter ego und je reicher, prächtiger und würdevoller sie auftraten, desto mehr Glanz und Ehre bedeutete das für ihn. Außerdem war es wichtig, dass sie mit anderen Adeligen und Würdenträgern an den Höfen von gleich zu gleich reden konnten, weshalb man nicht einen einfachen Sekretär oder Notar schicken konnte. ${ }^{582}$

Einige Aspekte der frühneuzeitlichen Diplomatie ${ }^{583}$ sind eng mit dem Phänomen des Kulturtransfers verstrickt, da es sich hierbei um ständigen oder wiederholten Kontakt von Vertretern eines Kulturraumes mit jenen eines anderen, um Austausch von Wissen, Informationen, Wertvorstellungen und Normen, Erfahrungen und schließlich von Objekten handelte. ${ }^{584}$ Denn die ständige Vertretung durch Gesandte war zwar eine italienische Erfindung gewesen, doch die anderen, zumeist mächtigeren Fürsten übernahmen nach und nach diese Entwicklung. Vor allem in dem seit Karls V. Abdankung geteilten habsburgischen Reich brauchte es fähige Gesandte, um den Kommunikationsfaden zwischen den beiden dynastischen Linien aufrechtzuhalten. Berühmte Botschafter des Kaisers in der zweiten Hälfte des I6. Jahrhunderts in Spanien waren Adam von Dietrichstein und Johann Khevenhüller, deren weites Arbeitsfeld sie zu politischen Vertretern wie zu Vermittlern und Übersetzern machten, da eine ihrer wich-

582 Siehe auch Folin, Gli oratori estensi.

583 Dazu siehe den Artikel von Anuschka Tischer, »Diplomatie«, in: Friedrich Jäger, Enzyklopädie der Neuzeit 2, Sp. I027-IO4I.

584 Strohmeyer, Kulturtransfer durch Diplomatie, 208f. Interessante Ergebnisse zum Thema des Wissenstransfers durch Diplomaten hat die in Rom im Juni 20 I 5 stattgefundene Tagung »Wissenskulturen und Erfahrungsräume der Diplomatie in der Frühen Neuzeit« hervorgebracht, in der die Schlüsselfunktion von Gesandten als diplomatische Akteure und Mediatoren nicht nur am Hof, sondern auch an den Reichstagen und Friedenskongressen betont wurde. Vorerst liegt ein Tagungsbericht von Claudia Curcuruto in: Quellen und Forschungen aus italienischen Archiven und Bibliotheken 95 (2015) als Digitalisat vor. Eine Publikation der Tagungsbeiträge wäre sehr wünschenswert. 
tigsten und oft schwierigsten Pflichten die Suche, Beschaffung und Übersendung von gefragten Kulturgütern war. ${ }^{585}$

In der Untersuchung dieser beiden kaiserlichen Langzeitdiplomaten am Hof von Philipp II. ${ }^{586}$ und Philipp III. von Spanien hat Friedrich Edelmayer ${ }^{587}$ gezeigt, wie sehr die Beherrschung der Landessprache und der Integrationswille über Erfolg oder Misserfolg der diplomatischen Tätigkeiten entschieden, ähnlich wie im oben beschriebenen Fall der fremden Fürstinnen. ${ }^{588}$ Die in Innerösterreich aufgewachsenen Gesandten Adam von Dietrichstein und Johann Khevenhüller waren in ihrer Ausbildungszeit mit verschiedenen Sprachen in Berührung gekommen und hatten in Italien studiert. Zudem war Dietrichstein mit einer Frau aus dem aragonesischen Hochadel verheiratet. Während dieser also fließend Kastilisch sprach, musste sich Khevenhüller erst die Sprache aneignen und war anfangs in den Verhandlungen mit Philipp II. sprachlich im Nachteil. ${ }^{589}$ Umgekehrt taten sich die spanischen Gesandten am Kaiserhof mit der Kommunikation schwer, wie Edelmayer festgestellt hat, denn Francisco Hurtado de Mendoza, Conde de Monteagudo, Marqués de Almazan, der von I 570 bis I 577 am Kaiserhof tätig war, erlernte bis zu seinem Dienstende nicht die deutsche Sprache, während Maximilian II. und Rudolf II. sehr wohl Kastilisch sprachen und schrieben. ${ }^{590}$

Die beiden kaiserlichen Gesandten hatten mit König Philipp II. zudem ein sehr freundschaftliches Verhältnis und konnten durch Verschwägerung mit dem kastilischen Adel ein wichtiges Netzwerk aufbauen. ${ }^{591}$ So sind in Khevenhüllers Tagebuch des Öfteren Essen mit venezianischen, genuesischen, florentinischen, englischen und portugiesischen Gesandten, mit italienischen Adeligen wie mit Vespasiano Gonzaga und päpstlichen Nuntien verzeichnet. ${ }^{592}$ Eine derartige Vertrautheit und ein enger Kontakt unter Gesandten war durchaus üblich und wurde als »diplomatische Währung" gehandelt. Besonders venezianische Gesandte verschwiegen nicht ihre Informationsquellen, sondern gaben sie als Wahrheitsgaranten an. Alvise Mocenigo behauptete sogar mit dem ferraresischen Kollegen gut befreundet zu sein und sich oft im Vertrauen auszutauschen: "Il reverendo orator di Ferrara, con il quale tengo

585 Strohmeyer, Kulturtransfer durch Diplomatie, 206. Vgl. auch die Untersuchung zur Familie Crivelli als bayerische Gesandte in Rom und die Aspekte des Kulturtransfers hier: Scherbaum, Die bayerische Gesandtschaft, I06- I 2 I.

586 Zu diesem siehe u.a. Martínez Millán, Felipe II.

587 Edelmayer, Habsburgische Gesandte; Ders. Das soziale Netzwerk.

588 Edelmayer, Habsburgische Gesandte, 60.

589 Edelmayer, Das soziale Netzwerk, 94.

590 Edelmayer, Habsburgische Gesandte, 6if. Monteagudo litt nach Edelmayer auch unter der Tatsache, von »Häretikern«, also Protestanten, umgeben zu sein und mit ihnen verhandeln zu müssen. Ebd., 63 .

59 I Khevenhüller wurde ${ }_{5} 87$ in den Orden vom Goldenen Vlies aufgenommen. Edelmayer, Das soziale Netzwerk, 96f. Dieser bezeichnet ihn als »den wichtigsten Pateigänger König Philipps II. am Kaiserhof.« Edelmayer, Söldner und Pensionäre, 75.

592 Ebd., 98-ror. 
molta amicitia, confidentemente ragionando meco, come fa sempre, mi ha detto che, $[\ldots] \ll .593$

Im »Ausland « war, wie Guido Braun und andere bereits festgehalten haben, neben Latein das Italienische unter den Gesandten und an zahlreichen Fürstenhöfen die gängige »Arbeitssprache«. Zudem gab es an verschiedenen Höfen und am Kaiserhof selbst Personal, das des Italienischen mächtig war und z.B. in München in einer eigenen Kanzleiexpedition organisiert war. ${ }^{594}$ Dabei diente die gemeinsame Kommunikationssprache nicht nur der Besprechung von politischen, kriegerischen oder dynastischen Angelegenheiten. Sieht man die Gesandtenkorrespondenz der Zeit durch, fällt auf, dass ein Großteil davon der Beschaffung und Vermittlung von materiellen Kulturgütern diente. Hatten die Diplomaten das gewünschte Kunst- oder Naturobjekt ausfindig gemacht, galt es, dieses unversehrt dem Dienstgeber zuzustellen. Zur Übermittlung benutzten die Gesandten sowohl die von der Familie Thurn und Taxis ${ }^{595}$ seit den 152 oer Jahren eingerichtete "Ordinari Post «, als auch teurere Sonderkuriere wie die Fugger-Kuriere, Gesandte anderer Fürsten, ${ }^{596}$ Kaufleute ${ }^{597}$ oder Verwandte. ${ }^{598}$ Venedig und in der Folge auch Spanien war mit seinen Handelskontakten bzw. Überseegebieten und seinem feinmaschigen Gesandtschaftsnetz ein besonderer Umschlagplatz für Exotika aller Art (Samen seltener Pflanzen, Mineralien, indianisches Kunsthandwerk, Waffen, Porzellan, lebende oder präparierte Tiere, aber auch antike römische oder griechische Statuen und Gemälde bekannter Künstler, Automaten und Messinstrumente etc.). Manches war sehr schwer zu beschaffen, wie die von Kaiser Rudolf II. I 598 bestellten Aplomadofalken aus Mittel- und Südame-

593 Turba, Venezianische Depeschen r, Alvise Mocenigo an die Zehn, Ingolstadt, September I 546, Nr. $224,677 \mathrm{f}$.

594 Braun untersucht dies auf der Basis der Nuntiaturberichte. Braun, Imagines imperii, I 98.

595 Vgl. Behringer, Thurn und Taxis.

596 So wurde für die Überbringung eines Bezoarsteines für Rudolf II. ein Sonderkurier des Herzogs von Ferrara benutzt. Khevenhüller an Rudolf II., Madrid, 24. November I 584, Linz, Oberösterreichisches Landesarchiv (OÖLA), Khevenhüller-Briefbücher 4, fol. 67v-69v, zit. n. Stieglecker, "Was ich eingethan und erkhauft«, 240, Anm. 77. Die Zusammenarbeit mit anderen italienischen Gesandten anstelle von teuren Sonderkurieren wurden auch von den Nuntien genutzt. Braun spricht zu Recht von "Synergieeffekte[n]«. Braun, Imagines imperii, 469 .

597 Der venezianische Gesandte Alvise Mocenigo berichtete dem Rat der Serenissima über eine Übereinkunft zwischen dem Papst und dem englischen König im Mai I 546, die einem englischen Kaufmann zum Transport anvertraut worden war. Interessant dabei ist nicht nur der Beweis, dass Handelstätige mit diplomatischen Missionen beauftragt wurden, sondern auch wie Gesandte zu diesen Informationen gelangten: Mocenigo hatte dies vom ferraresischen Gesandten Galasso Ariosto erfahren, der erklärte, sie im geheimsten Vertrauen (»in secretezza grande«) vom französischen Gesandten bekommen hatte, der dies wiederum vom Rex Christianissimus selbst erfahren hatte. Die Aufforderung nach Geheimhaltung machte die Information bedeutend und interessant; dass die Geheimhaltung nicht gewahrt wurde, war da eigentliche Ziel eines diplomatischen Auftrages. Turba, Venetianische Depeschen I, Alvise Modenigo und Bernardo Navager an die Zehn, Regensburg, Mai I 546, Nr. I44, $484 f$.

598 Strohmeyer, Kommunikation. 
rika oder die heiß begehrten Bezoarsteine. ${ }^{599}$ Diese Suche nach "fremd aussehenden« Objekten, ihr Erwerb und schließlich ihre aufwendige Übersendung war zeit- und kostenintensiv für Gesandte, die mitunter die Erwerbs- und Transportkosten vorstrecken mussten. $\mathrm{Zu}$ Recht schreibt Pieper den Gesandten eine bedeutende »Mittlerrolle zwischen den Konsumenten von Exotika in Zentraleuropa und Italien einerseits und den Importeuren fremdartiger Lebewesen und Gegenstände auf der Iberischen Halbinsel andererseits ${ }^{600} \mathrm{zu}$.

Wie aufwendig, kompliziert und teuer die Übermittlung der erworbenen Luxusgüter ${ }^{601}$ war, hat Maria Stieglecker am Beispiel des Pferdetransports aus Spanien rekonstruiert. Hier zeigt sie, dass Gesandte bei den Fuggern Kredite für den Einkauf, Erhalt und Transport der Tiere aufnehmen mussten und dass diese Ausgaben unregelmäßig und erst spät durch den Kaiser erstattet wurden. Wie die estensischen Gesandten im Rahmen ihrer Bemühungen für die Lösung der Präzedenzfrage oder bei Alfonsos Bewerbung um den polnischen Thron bediente sich auch Khevenhüller finanzieller Zuwendungen für »Fachpersonal«, in seinem Fall für den Obersten Stallmeister, von dem er überzeugt war, dass er besonders gute Tiere für den Kaiser aussuchen würde, wenn ihm ein entsprechendes Geschenk zukommen würde. ${ }^{602}$

Für die Beschaffung und Übermittlung von Informationen jeder Art, vor allem über Aufenthaltsort, Erreichbarkeit und Kosten von begehrten Objekten, griffen Langzeitdiplomaten auf ihr mühevoll über die Jahre aufgebautes Informationsnetz zurück. Wichtig war auch ihre Integration in das Klientelsystem des Fürsten, um in der Fremde ein zweites Standbein zu haben. Für die oben genannten kaiserlichen Gesandten bedeutete dies die Aufnahme in einen spanischen Ritterorden bzw. den Orden vom Goldenen Vlies. ${ }^{603}$

Auch die Este hatten in der zweiten Hälfte des r6. Jahrhunderts Langzeitdiplomaten am Kaiserhof, wie Renato Cato oder Ascanio Geraldini, die wie manche ihrer Vorgänger und Nachfolger über mehrere Jahre gewichtige Themen im Reich und am Kaiserhof zu vertreten hatten: Neben den obligaten Neubelehnungsansuchen, von de-

599 Pieper, Papageien, 2 I 8f. Siehe auch Rauch, Gesammelte Wunder, 24 f und Lein, Über den Naturabguss. Im Katalogteil sind ein verarbeitetes Straußenei, eine Kokosnuss und ein Bezoarstein abgebildet, jeweils II 3,7 I, II 8.

600 Pieper, Papageien, 223.

6or Hiermit sind in Anlehnung an die Definition von Hirschbiegel und Ewert jene Güter gemeint, die »bei höherem verfügbarem Einkommen und steigendem Preis überproportional stärker nachgefragt« wurden. Es ist der hohe Preis, der unabhängig davon, ob er dem realen Wert entspricht, einen Gegenstand zu einem Luxusprodukt macht. Hirsch biegel/Ewert, Mehr als nur der schöne Schein, 36.

602 Stieglecker, »Was ich eingethan und erkhauft«, 226-230. Zu weiteren Geldgeschenken der kaiserlichen Gesandten in Spanien siehe Edelmayer, Habsburgische Gesandte, 65 f.

603 Stronmeyer, Kulturtransfer durch Diplomatie, 2 r6f. Vgl. als weiteres Beispiel für ein Gesandtennetzwerk bestehend aus Einladungen, Besuchen, Geschenken und Aspekten der Patronage die Tätigkeit der spanischen und mailändischen Gesandten in der Eidgenossenschaft bei WindLER, Diplomatie als Erfahrung, 18-26. 
nen einige mit schwer zu rechtfertigenden Gebietserweiterungswünschen verbunden waren, galt es immer wieder, die Treue und Loyalität der Este-Dynastie gegenüber Kaiser und Reich zu beteuern. Dabei war dies aufgrund des zweiten Lehensverhältnisses mit dem Papst, aber besonders mit den intensiven Beziehungen der Herzöge von Ferrara zu Frankreich, eine echte Herausforderung. Doch das aufreibendste Thema für die Vertreter der Este war - nach der Wiederbelehnung mit den kaiserlichen Lehen I 53 I - sicher jenes der Präzedenz. Dabei bedienten sich die Gesandten der Topoi des alten, ehrwürdigen Geschlechts im Vergleich zu den Medici, die als Kaufleute, Krämer und »Neuadelige« beschimpft wurden. Schließlich gab es - neben dem Heiratsprojekt mit einer Kaisertochter und dem Häresieverdacht gegen Renée de France - die Nachfolgeregelung, die sich auch über Jahre hinzog und die mit Geld und Geschenken ausgestatteten estensischen Gesandten - aufgrund der kaiserlichen Verzögerungstaktiken - fast zur Verzweiflung brachte.

Natürlich hatten auch die estensischen Gesandten ähnliche Aufgaben wie die spanischen Diplomaten, so die regelmäßige Überbringung von Gunstbekundungen, Grüßen oder Wünschen sowie von begehrten Geschenken. Auch hier gestaltete sich der Transport, vor allem von lebenden Tieren wie den begehrten estensischen Pferden, als heikle Angelegenheit und erforderte diplomatisches Fingerspitzengefühl. Ohne Zweifel spielten die estensischen Gesandten, ähnlich wie ihre spanischen Kollegen eine bedeutende Vermittlerrolle im kulturellen Austausch zwischen Italien/Ferrara und dem Reich. 


\subsection{Exkurs: Kulturaustausch mit Frankreich}

Wenn auch der Fokus der Untersuchung auf den Beziehungen und Austauschprozessen zwischen den Este und dem Heiligen Römischen Reich liegt, so darf nicht vergessen werden, dass dieses italienische Fürstengeschlecht ein viel länger zurückreichendes und intensiveres Verhältnis zu Frankreich hatte, das für Konfliktpotenzial in der Kommunikation mit dem Kaiser sorgte. Nicht erst seit der Heirat Ercoles II. mit Renée de France $5_{5} 8$ gab es intensive politische Beziehungen zum französischen Hof und vielseitigen kulturellen Austausch, sondern bereits im frühen I 5. Jahrhundert. ${ }^{604}$ Hier sollen nur einige Beispiele für diesen über Generationen anhaltenden Kontakt nach Westeuropa genannt werden.

Zunächst sei daran erinnert, dass mehrere Este-Fürsten und Mitglieder dieser Dynastie über den Alpenhauptkamm nach Norden und des Öfteren nach Frankreich gereist waren. Den Höhepunkt der Frankreichbesuche bildeten sicher die längeren Aufenthalte von Kardinal Ippolito II. d'Este und die »Flucht« von Alfonso II. zum bzw. der Verbleib am französischen Hof, während die mehr oder weniger durchgängige Präsenz von estensischen Gesandten am französischen Hof seit den I 47oer Jahren belegt ist. ${ }^{605}$

$\mathrm{Zu}$ einer ersten Intensivierung der französisch-estensischen Beziehungen kam es Ende des I 5 Jahrhunderts unter Charles VIII. und Ercole I. Als der französische König zur Eroberung Neapels nach Italien aufbrach, bat ihn Ercole, seinen Sohn Ferrante zur Ausbildung bei sich aufnehmen zu wollen. Obwohl es durchaus im Trend dieser Zeit lag, dass sich Fürstensöhne an anderen Höfen ausbildeten, setzte dieser Austausch dennoch eine gewisse, bereits Jahrhunderte vorher entstandene und gewachsene Vertrautheit und Nähe voraus. Tatsächlich hatte bereits Obizzo II. d'Este als Markgraf von Ferrara und Verteidiger der Kirche Charles von Anjou I 265 den Durchzug durch seine Gebiete erlaubt und ihn auch durch die Gründung einer Liga im Kampf gegen die Hohenstaufen unterstütze, nicht ohne den Hintergedanken einer Stärkung und Erweiterung seines Herrschaftsgebietes. Der Durchzug der Franzosen durch die estensischen Gebiete und ihr Aufenthalt am Hof von Ferrara beeinflusste stark die dortige Kultur und verstärkte die schon gepflegte provenzalische Lyrik mit den Inhalten aus dem karolingischen und bretonischen Sagenzyklus. ${ }^{606}$

604 Magoni, I gigli d'oro. Siehe auch: Carile, Considerazioni introduttive.

605 Magoni, I gigli d'oro, 9. Siehe auch: Folin, Les ambassadeurs.

606 Schon früh waren französische/provenzalische Minnesänger und Troubadoure von jenseits der Alpen am Hof von Ferrara aufgenommen worden. Vor allem Azzo VI. war ein großzügiger Gastgeber für diese musischen Reisenden, die die estensischen Fürstinnen besangen. Rimondi, Estensi, I I - I 2. Siehe auch: Balmas, Ferrara e la Francia: Balmas spricht im Zusammenhang mit Ferrara vom Phäno- 
Der Nachfolger von Obizzo II., Azzo VIII., empfing Charles von Valois, Bruder des französischen Königs Philipp III., in Reggio und Modena, der auf dem Weg nach Rom zum Papst war. Er überhäufte ihn mit kostbaren Geschenken und lieh ihm I 0.000 Goldgulden ohne Rückversicherung. Der italienische Fürst und seine Familie kleideten sich dem Anlass entsprechend à la francese und schmückten die Stadt mit estensischen und französischen Wappen. I305 wurde diese Beziehung weiter durch die Heirat von Azzo VIII. mit Beatrice von Anjou konsolidiert, die für die Este eine so ehrenvolle Verbindung darstellte, dass sie nicht nur auf die Mitgift verzichteten, sondern der Braut 5 1.ooo Gulden in Geld und Besitzungen, im Gegenzug zum Lehen Andria mit seinem Grafentitel, überließen. ${ }^{607}$

I43 I bedachte der französische König Charles VII. den estensischen Fürsten Nicolò III., der im Zuge seiner Pilgerfahrten I 4 I 4 auch nach Saint-Antoine de Vienne in die Dauphiné gelangt war, ${ }^{608}$ als Zeichen der besonderen Zuneigung und Verbundenheit mit der besonderen Würde, seinem Wappen die drei französischen goldenen Lilien hinzufügen zu dürfen, die die Este bis zum Aussterben der Dynastie I 829 trugen. ${ }^{609}$ Zeit seines Lebens blieb Nicolò III. ein begeisterter Verehrer der französischen Literatur, was sich auch in der aus dem Artuszyklus entnommenen Namensgebung seiner zahlreichen Kinder (Meliaduse, Leonello, Borso, Gurone, Ginevra, Isotta) niederschlug.

Als Ercole I. I493 seinen Sohn Ferrante an den französischen Hof schickte, baute er also auf eine bereits bestehende und intensive Beziehung auf. Als Charles VIII. zu seinem Italienzug aufbrach, ritt ihm Ercole I. entgegen und huldigte ihm in Asti. Der Nachfolger von Charles VIII., Louis XII., hatte ähnliche Ambitionen in Italien und wollte das Herzogtum Mailand erobern. Ercole I. besuchte ihn I 499 bei seinem Einzug und ließ von Ferrara Leoparden und Falken nach Mailand bringen, um den König zu unterhalten. Als Ercole I. I 505 starb, war nicht nur Alfonso in französischer Mode gekleidet, sondern es nahmen auch zwei französische Gesandte am Begräbnis teil. Im Jahr davor war Alfonso I. nach Frankreich, Flandern und England gereist und vom französischen König aufs wärmste empfangen worden. Nach Magoni trugen die gegenseitigen Besuche und der kulturelle Austausch (Mode, Literatur, Kunst, Musik, Bestattungsrituale) viel mehr zur Intensivierung der Beziehungen bei als die politischen Bündnisse zwischen Frankreich und Ferrara. ${ }^{610}$

men des »infranciosamento« (357). Tatsächlich haben sich weder Mailand noch Florenz oder Neapel in dem Maß an Frankreich ausgerichtet wie Ferrara.

607 Vgl. Magoni, I gigli d'oro, I 5-20.

608 Vgl. Folin, Les ambassadeurs, i 4if.

609 Im Laufe des I 5. und I6. Jahrhunderts kamen der kaiserliche Adler und die päpstliche Tiara hinzu. Ercole II. fügte seinem Wappen I 557 noch die Kollane des französischen Ordens vom Heiligen Michael bei. Magoni, I gigli d'oro, I 9, Anm. 32. Zur Entwicklung des estensischen Wappens siehe http://www. isco-ferrara.com/wp-content/uploads/2018/oI/Gli-stemmi-estensi.pdf, Zugriff: i6.9.2020.

6ro Ebd., 38-4r. 
Auch François I. war als Nachfolger auf dem französischen Thron an einer Weiterführung der Italienpolitik, an der Rückeroberung Mailands und an der Intensivierung der Beziehungen mit den Este interessiert. Diese wiederum erhofften sich Unterstützung bei der Rückgewinnung der an den Papst verlorengegangenen Lehen. In der Weihnachtszeit des Jahres I 5 I 8 reiste Alfonso I. d'Este deshalb nach Frankreich; offiziell trat er in die Liga mit Henry von England ein, aber eigentlich ging es darum, Frankreich für die Rückgewinnung von Modena und Reggio zu mobilisieren. Als Anreiz erhielten die Valois finanzielle Unterstützung von den Este, die wie die übrigen nie rückerstattet wurde. ${ }^{611}$

Die Weiterführung der Beziehungen zwischen den Este und Frankreich lag in den I 53 oer Jahren immer mehr in den Händen von Ippolito II. d'Este, der längere Zeit in Frankreich verbrachte und eine innige Freundschaft zum Monarchen entwickelte. ${ }^{612}$ Dieser unterstützte ihn 1539 bei der Erhebung zum Kardinal und bedachte ihn in Frankreich mit reichen Pfründen sowie bedeutenden Aufgaben. Ippolito und später Luigi d'Este waren nicht die einzigen Kirchenmänner, die in Frankreich sesshaft wurden und mit reichen Benefizien ausgestattet wurden. Magoni spricht von einer regelrechten »Invasion« von italienischen Geistlichen, die sich - sehr zum Missfallen des französischen Klerus - in Frankreich und besonders am französischen Hof niederließen. Auch mit dem neuen Thronfolger Henri II. büßte Ippolito nichts von seinem Einfluss ein, sondern gelangte mit dem Amt des Protektors der französischen Angelegenheiten in Rom (des affaires de France en Cour de Rome) zu weiteren großen Ehren und weitreichendem Einfluss. ${ }^{613}$

Zur Intensivierung der Beziehungen trugen schließlich auch die nach Frankreich gerichteten Heiratsprojekte der Este bei. Durch die Eheschließung mit Renée de France, die, wie oben beschrieben, mit einem übermäßig großen französischen Hofstaat nach Ferrara kam, verdichtete sich der Einfluss der französischen Kultur und Sprache und schließlich auch jener der calvinistischen Glaubenslehre ${ }^{614}$ im estensischen Herzogtum. ${ }^{615}$ Renée machte mithilfe von Gelehrten wie Clément Marot ihren eigenen Hof in Consandolo bzw. das nahe Argenta in den I 53 oer Jahren zu einem künstlerischen Treffpunkt mit besonderer Berücksichtigung der französischen und italienischen Lyrik und zu einem Zentrum der Verbreitung der calvinistischen Glaubenslehre. ${ }^{616}$ Der sogenannte Karfreitag-Zwischenfall, demzufolge einige Mitglieder

6I I MaGoni, I gigli d'oro, 45,58 .

6I 2 Als Erzbischof von Mailand ab i5 I9 konnte er im Kaiserlehen Trauerfeierlichkeiten für den verstorbenen König von Frankreich, den kaiserlichen Erzfeind François I, in der Kathedrale in Auftrag geben. Signorotto, Note sulla politica, $62 \mathrm{f}$.

6I 3 Magoni, I gigli d'oro, 62-64.

6I 4 Zum religiösen Austausch zwischen Frankreich und Italien siehe die einzelnen Beiträge im Sammelband Benedict/Seidel Menchi/Tallon, La réforme en France et en Italie.

6i 5 Siehe auch Belligni, Reti eterodosse; Franceschini, Tra Ferrara e la Francia.

6 I6 Vgl. GorRis, »D'un château d'autre«, I47. 
der französischen Entourage Renées verhaftet wurden und anschließend auf Intervention des französischen Königs zwar freigelassen, aber nach Frankreich zurückgeschickt werden mussten, zeigt, dass es sich bei ihrem Gefolge um mehr als nur um "fremde«, intrigante Höflinge handelte. Einige waren vehemente Vertreter der neuen Glaubenslehre und gefährdeten durch ihr Verhalten (Weigerung, die Messe zu besuchen oder die Eucharistie zu empfangen) Ercoles Glaubwürdigkeit als orthodoxer Lehensnehmer des Papstes und des Kaisers, der ja ebenfalls Verteidiger des (rechten) Glaubens war. Deshalb war die Entfernung von Mitgliedern des französischen Hofstaates seiner Ehefrau nicht nur eine Entlastung, sondern diente auch seiner Imagepflege. Auf Nachfrage konnte ihm sein Gesandter Feruffini mitteilen, dass ihn nach der Vertreibung der Rädelsführer aus Renées Hofstaat in Frankreich alle für sehr kaisertreu hielten: »[...] e la tengon per molto imperiale «. ${ }^{617}$

Um den Unmut seiner Lehensherren nicht weiter auf sich zu ziehen, waren Ercoles II. Heiratsprojekte für seine Kinder zunächst außerhalb Frankreichs angesiedelt: Für seine älteste Tochter Anna dachte er zunächst an die Heirat mit dem Thronnachfolger in Polen, während nur die jüngere Tochter Lucrezia eventuell für einen französischen Prätendenten in Frage kommen sollte. François I. hatte aber bereits einige Kandidaten vorgeschlagen, darunter den jungen Herzog von Guise, der sich dadurch auf Umwegen mit dem Herrscherhaus der Valois verschwägern wollte. Da das polnische Heiratsprojekt scheiterte, willigte Ercole II. I 548 schließlich ein, seine Älteste dem Guise zur Frau zu geben, nachdem Henri II., der diese Verbindung besonders rasch abgeschlossen sehen wollte, sich bereit erklärt hatte, die Mitgift zu bezahlen. ${ }^{618}$

Auch diese Heiratsverbindung zwischen Frankreich und Italien, zwischen den Guise und den Este zeichnete sich durch eine Reihe von Aspekten kulturellen Austausches und Transfers aus. Anders als ihre Mutter aber integrierte sich Anna in Frankreich hervorragend. Natürlich war es von Vorteil, dass sie aufgrund der mangelhaften Integration ihrer Mutter am ferraresischen Hof mit der französischen Sprache und dem französischen Lebensstil aufgewachsen war. Allerdings wurde ihre schnelle Anpassung nach der 1548 erfolgten Heirat mit François de Lorraine, Herzog von Aumale, Sohn des Herzogs von Guise, auch durch die Familie des Bräutigams forciert: Anders als bei ihrer Mutter wurden die Italienerinnen und Italiener aus ihrem Hofstaat bald durch französische Mitglieder ersetzt; bereits auf der Brautfahrt hatte sie die italienische mit der französischen Landestracht getauscht und der Kontakt mit ihrer Familie wurde limitiert. ${ }^{619}$ So passte sich Anna d'Este schnell nach ihrem Eintreffen in Frankreich den Gepflogenheiten des französischen Adels an und wurde dadurch auch wohlwol-

6I 7 ASMo, ASE, Casa e Stato, Carteggio di Ambasciatori, Francia b i 2, Feruffini an Ercole II., Juli I 536.

6I 8 Diese Heiratsverbindung mit der mächtigen Familie de Guise trübte erneut die Verhältnisse der Este mit dem Reich und mit den dem Reich gegenüber treuen italienischen Fürsten. MAGonI, I gigli d'oro, $78-80$.

6r 9 Siehe Coester, »alla italiana«, 73-75. Siehe auch: Diess., Schön wie Venus. 
lend aufgenommen. Nicht trennen konnte sie sich von den bewährten Heilmethoden italienischer Ärzte, von einzelnen italienischen Hofdamen, mit denen sie aufgewachsen war und von italienischen Stallmeistern, wie auch sonst der französische Adel auf diese Fachkräfte zurückgriff. ${ }^{620}$ Auch die italienischen Geschichtswerke in ihrer Bibliothek zeugen von ihrer Herkunft und wahrscheinlich auch von ihrem Heimweh. ${ }^{621}$ Wie ihre Mutter in Ferrara Schutzherrin und Förderin französischer Reisender und (Glaubens)Flüchtlinge war, so war sie es für die Italiener/innen in Frankreich. Mit ihren Verwandten in Ferrara tauschte sie später regelmäßig Briefe, Kulturgüter (Obst, Käse, Hunde, Pferde), Empfehlungen und Informationen aus. Auch kam ihr Sohn Charles-Emmanuel de Savoie-Nemours aus ihrer zweiten Ehe zur Ausbildung an den Hof seines Onkels, während der jüngere Henri unter die Fittiche ihres Bruders, Luigi d'Este, die geistliche Laufbahn einschlagen sollte. ${ }^{62}$

Ercoles und Renées ältester Sohn Alfonso hatte - man könnte sagen - von Geburt an eine enge Beziehung zu Frankreich. Auf Bitte seiner Mutter stand ihm König François I. Pate und schickte dafür seinen Kämmerer als Stellvertreter mit einer Ampulle jenes Öls, mit dem die französischen Könige gesalbt wurden. Diese Salbung, sowie den seit der Heirat Ercoles II. mit einer Königstochter neu eingeführten Titel »principe di Ferrara « sollten Alfonso an Frankreich und das Könighaus binden. ${ }^{623}$

$\mathrm{Zu}$ einer engeren Verschwägerung wäre es fast während Alfonsos II. erstem, »unerlaubtem« Frankreichaufenthalt gekommen, als ihm mehrere französische Heiratskandidatinnen, darunter die Schwester des Königs, vorgeschlagen wurden. Allerdings war er nicht bereit, seinen Vater mit einer unerlaubten Heiratsverbindung vor den Kopf zu stoßen. Dieser wollte vorerst keine neue Verbindung mit Frankreich eingehen, auch nicht für seine jüngste Tochter Lucrezia, für die Jacques von Nemours, Freund der Guise, vorgeschlagen wurde. Henri II. versuchte den Vater mit dem Argument umzustimmen, dass er aufgrund der »Häresie« der Mutter, Renée de France, keine besseren Kandidaten für seine Tochter finden werde. Doch Ercole II. ließ sich nicht einschüchtern und hielt dem entgegen, dass der Nemours weder reich noch edel genug für seine Tochter sei. ${ }^{624}$

Dennoch waren und blieben die Beziehungen der Este zu Frankreich stark. Nicht nur Alfonso II., sondern auch der zweite Sohn Luigi d'Este war an den französischen Hof geflohen, sodass I 559 zum Zeitpunkt des Friedens von Cateau-Cambrésis und des Todes von Ercole II. ${ }^{625}$ von den fünf Kindern der Este drei in Frankreich weilten:

620 Vgl. Coester, «alla italiana«, $8 \mathrm{I}-84$.

62 I Ebd., 85 f. Hier findet sich auch das oft genannte 1570 erschienene Werk »Historia de'principi d'Este« von Giovan Battista Pigna. Ebd., 86.

622 Ebd., 87 f.

623 LAZZARI, Le ultime tre duchesse, rof.

624 Vgl. MAgoni, I gigli d'oro, 86-9i.

625 Selbst in seiner letzten Stunde vergaß Ercole II. nicht die alte Freundschaft mit dem französischen König, dem er in seinem Testament das schönste Pferd in seinem Stall vermachte, Ebd. 75. 
Anna als Herzogin de Guise, Alfonso (II.) als nominelles Mitglied des Geheimen Rates des neuen französischen Königs François II. und Luigi als kirchlicher Pfründennehmer. So wie François de Guise Alfonso (II.) in die Kriegskunst eingeweiht und unter seine Fittiche genommen hatte, so tat der Este dies später für dessen Sohn, seinen Neffen Henri de Guise, indem er ihn zum Kampf gegen die Türken auf der Seite des Kaisers nach Ungarn mitnahm. Als Kaiser Maximilian II. der Auseinandersetzung mit einem Waffenstillstand ein vorläufiges Ende bereitete, reiste der Franzose mit seinem Onkel nach Ferrara, wo er sich einige Monate aufhielt. 1572 hielt sich sein Bruder Charles, der künftige Herzog von Mayenne, auf dem Weg nach Korfu für den Kampf gegen die Osmanen in Ferrara auf. I 58 I kam Charles-Emmanuel de Savoie-Nemours, Sohn aus zweiter Ehe von Anna d'Este in Begleitung von Kardinal Luigi d'Este nach Venedig und mit Don Cesare und Don Alfonso d'Este nach Ferrara. Diese Besuche seiner französischen Verwandten garantierten Alfonso II. d'Este zusammen mit der Position seines Bruders, Kardinal Luigi d'Este, eine Wahrung und Vertretung seiner Interessen in Frankreich. Die Familie Guise wiederum hatte ein großes Interesse daran, König Henri III. zu schwächen und suchte dafür Unterstützung bei Papst Sixtus V., der dem französischen König nicht wohlgesonnen war, und beim Herzog von Ferrara, von dem sie sich finanzielle Unterstützung erhofften. ${ }^{626}$

Die Beziehungen Este-Frankreich setzten sich auch in der herausfordernden Zeit der französischen Religionskriege fort. Im Juli ${ }_{5} 64$ reist Alfonso II. mit Emanuele Filiberto von Savoyen nach Lyon zum französischen König Charles IX., um diesen im Kampf gegen die Hugenotten vor allem nach dem Mord an seinem Schwager, François de Guise, zu unterstützen. Der eigentliche Besprechungspunkt war allerdings der enorme Kredit, den die französische Krone bei den Este im Zuge der Italienkriege angehäuft hatte und seine Rückzahlungsmodalität. ${ }^{627}$ Im November ${ }^{2} 564$ kam der Herzog allerdings mit leeren Händen nach Ferrara zurück. Um die Habsburger nicht zu beunruhigen, hatte Alfonso Philipp II. vorab über die Gründe seiner Reise informiert, damit dieser darin nicht einen Seitenwechsel vermuten konnte. Und prompt gab der spanische König, auf der Suche nach Verbündeten auf der italienischen Halbinsel, daraufhin sein Einverständnis zur Verheiratung einer Erzherzogin mit dem Herzog von Ferrara. Dennoch wurden die französischen Verwandten nicht im Stich gelassen: Beim Ausbruch des zweiten Religionskrieges 1567 schickte Alfonso eine Gruppe Truppenanführer (capitani), die an den Angriffen auf die Hugenotten teilnahmen und

626 Ebd., I34-I37.

627 Mit den Finanzproblemen und den hohen, vor allem bei italienischen und süddeutschen Kaufleuten aufgenommenen Krediten der französischen Könige François I. und Henri II. hat sich im Rahmen eines von der Fritz-Thyssen-Stiftung geförderten Forschungsprojekts mit dem Titel »Frühneuzeitliche Staatsbankrotte. Akteurszentrierte Analyse der europäischen Kreditmärkte um I 55 \% Heinrich Lang beschäftigt, der im Jahrbuch des italienisch-deutschen historischen Instituts in Trient einen ersten Einblick in die Forschungsergebnisse gegeben hat: LANG, Credito e insolvenza sovrana. 
selbst sein Onkel, Don Alfonso d'Este von Montecchio, kam mit Pferden und Waffen Frankreich zu Hilfe. ${ }^{628}$

Selbst bei ihren viel gerühmten Waffensammlungen orientierten sich die Este dezidiert am französischen Vorbild. Nicht nur die estensischen Kriegsapparate zeugten von Alfonsos mehrjährigem Engagement in Frankreich, sondern auch seine Rüstung war nach einer französischen Machart mit Festornaten an den Rändern und einer besonderen Öffnung der Augenpartie angefertigt worden, die sich von den Rüstungsproduktionen in Augsburg, Nürnberg oder Innsbruck unterschied. ${ }^{629}$

Seine große Sympathie für und Verbundenheit mit Frankreich zeigte Alfonso II. schließlich auch beim Besuch von Michel de Montaigne I58 I in Ferrara: „Der Herzog griff nach dem Hut als sie eintraten und blieb unbedeckt, solange der Herr von Montaigne mit ihm sprach, was ziemlich lange dauerte. Er stellte zuerst die Frage, ob er die Sprache verstehe; als sie bejaht wurde, versicherte er sehr lebhaft auf Italienisch, er sähe die Edelleute der französischen Nation sehr gern bei sich, er sei ja selbst der Diener des allerchristlichsten Königs und ihm sehr ergeben. [...] Der Herzog hatte sein Haupt nicht wieder bedeckt. ${ }^{630}$

Obwohl der französische Hof auf Betreiben der Guise der einzige gewesen war, der I 580 , spät aber doch, definitiv den Vorrang der Este vor den Medici festlegte ${ }^{631}$ und Alfonso II. somit einen kleinen bzw. den einzigen Sieg in dieser 40 Jahre langen Auseinandersetzung gewährte, begannen sich die langjährigen guten Beziehungen zu Frankreich gegen Ende des Jahrhunderts zu trüben. Erste Anzeichen dafür waren die geringe Unterstützung des französischen Königshauses bei Alfonsos Bewerbung um die polnische Krone und bei der Lösung der Präzedenzfrage mit den Medici bei Kaiser und Papst. Im Februar I 598 beglückwünschte Henri IV., König von Frankreich aus dem Haus Bourbon, sogar Papst Clemens VIII. zur Rückholung Ferraras. Diese Haltung mag nach Magoni die veränderten Beziehungen zwischen dem französischen Herrscherhaus und den Este zeigen, beweist aber vor allem realpolitisches Reagieren auf unausweichliche Gegebenheiten. Als sich in Ferrara die Nachfolgeproblematik eröffnete, waren auch die Guise als Kandidaten in Frage gekommen. Doch im Dezember I 588 wurden Herzog Henri de Guise und sein Bruder Kardinal Charles de Guise in Blois ermordet. Auf diesem Mordanschlag folgte jener auf König Henri III. im Au-

628 Magoni, I gigli d'oro, Io6-i io.

629 Vgl. Scalini, Appunti, i9i.

630 Montaigne, Tagebuch einer Reise, ro4. Weitere Eindrücke Montaignes von Ferrara und von der unrühmlichen Causa der Reklusion des Dichters Torquato Tasso angeblich wegen geistiger Umnachtung sind bei: Vittorini, Montaigne.

63 I So berichtet der Nuntius Malaspina vom Kaiserhof, dass am Neujahrstag ( $55^{80}$ ) der König dem estensischen Gesandten den Vorrang gegenüber jenem des Großherzogs von Toskana gegeben hatte, der daraufhin abgereist sei. Koller, Nuntiaturberichte III/ıo, Malaspina an Gallio, Prag, I 580 Februar I6, 265 . 
gust I 589 , der kinderlos einen vakanten Thron zurückließ, woraufhin das Haus Valois ausstarb. Sein Nachfolger wurde Henri IV.von Bourbon, König von Navarra, Anführer der Hugenotten. Dieser konnte die französische Krone nur durch seine Konversion an sich nehmen. Sein Gesandter, Graf von Piney, kam auf dem Weg nach Rom I 58 9, wo er um Absolution für Henri IV. bitten sollte, in Ferrara vorbei. ${ }^{632}$ Als Henri de Navarre endlich fest auf dem französischen Thron saß, einigten sich die Guise mit diesem, erwogen ihre Nachfolge in Ferrara nach dem Tod Alfonsos und baten den König um Unterstützung beim Papst dafür. Doch schließlich bot der mit den Este weniger eng verbundene Bourbone nicht Cesare d'Este, sondern dem Papst militärische Hilfe für die Rückholung Ferraras an. Der Hauptgrund für diese Umkehrung der Allianzen war sicher die dem Papst geschuldete Dankbarkeit des eben erst »bekehrten« französischen Königs. Allerdings hat es - nach Magoni - doch eine kleine Unterstützung für Cesare d'Este aus Frankreich gegeben. Im Dezember I 597 kamen der Sohn des Herzogs von Mayenne und einige französische Edelleute nach Ferrara, um Cesare im Kampf gegen den Papst zu unterstützen, während Henri IV. dem Papst militärische Hilfe angeboten hatte, ohne allerdings jemanden daran zu hindern, den Este zu unterstützen. Am Ende musste aber der Schein gewahrt werden und man rechtfertigte sich damit, dass die Franzosen eigentlich Alfonso II. besuchen wollten, doch dieser in der Zwischenzeit verstorben war. ${ }^{63}$ Auch der Grazer Nuntius Girolamo Portia ließ sich nicht täuschen und wertete in seinem Schreiben an Pietro Aldobrandini diese Erklärung als Vorwand (pretesto): »Ho avviso di Baviera che in Monaco fosse arrivato un figliuolo del duca di Mena con 20 altri soldati et capitani, da quali si è inteso c'habbino d'andare a trovar Don Cesare et porsi in Ferrara; dicendo il figliuolo del sudetto duca ch'egli sia partito di Francia con animo di venire in Italia a visitar il duca chè hor morto et che trovandosi hor in camino egli habbi pensiero di visitar Don Cesare come suo parente. Questo è il pretesto, ma le verità si dice che debba esser come s'è detto di sopra. « ${ }^{634}$

Ein leidiger Punkt in den französisch-estensischen Beziehungen waren auch die durch die Heiratsverbindungen entstandenen Erbschaftsansprüche. François I. hatte anstelle einer Mitgift in Bargeld Herrschaftsrechte und (spärliche) Einkünfte aus den Herrschaften von Gisors, Montargis und Chartres vergeben, doch hatte er die Verträge zur Naturalisierung der Este nie dem Parlament vorgelegt, sodass Alfonso II. keine Möglichkeit hatte, aus den Besitzungen der Mutter in Frankreich eine Rendite zu erhalten. Zudem hatte Renée testamentarisch verfügt, dass ihre Tochter Anna bis

632 Vgl. Knecht, The Rise, 527-548.

633 Magoni, I gigli d'oro, I 50- I64.

634 »Ich habe Nachricht aus Bayern, dass ein Sohn des Herzogs von Mayenne mit 20 Soldaten in München angekommen und auf dem Weg zu Cesare d'Este nach Ferrara sei. Der junge Fürst sagte, er habe den Herzog von Ferrara besuchen wollen, der nun verstorben ist weshalb er, da er bereits auf dem Weg sei, Cesare d'Este als seinen Verwandten besuchen wolle. Das ist eine Ausrede, man sagt, es sei wie oben angeführt«. Rainer, Grazer Nuntiatur, II/4, Nr. 368, 397, Girolamo Portia an Pietro Aldobrandini, Graz I 597 , Dezember I. 
zu ihrem Lebensende die Nutzung ihrer Erbgebiete haben sollte. Nichts galten die Beschwerden Alfonsos II. an die Mutter und den König. Als schließlich Cesare als Nachfolger und Erbe Ansprüche in Frankreich stellte, kam ihm Anna als letzte rechtmäßige Erbin zuvor und bekam schließlich I6or vom französischen Gericht ${ }^{635}$ Recht, wodurch auch die Seitenlinie der Este alle Ansprüche in Frankreich verlor. ${ }^{636}$

Zum Abschluss dieses Überblicks über die französischen-estensischen Beziehungen soll noch auf einen Ausdruck kulturellen Austausches eingegangen werden. Es handelt sich hierbei um das aus dem französischen Brauchtum nach Oberitalien exportierte Bestattungsritual, ${ }^{637}$ dem sich besonders Giovanni Ricci in seinen Forschungen gewidmet hat. ${ }^{638}$

Die größte Gefahr für jedes große wie kleine Herrschaftsgebiet ist bekanntlich das Interregnum, die Zeit der translatio imperii, wo der tote Fürst noch nicht formell beigesetzt ist und der neue offiziell die Macht noch nicht übernommen hat. In Ferrara gab es mehrere Akteure, die in einer Vakanz bzw. bei der Machtübergabe an den neuen Fürsten eine Rolle spielten: die herzogliche Familie, der Rat der Savi, die Lehensherren - der Papst und der Kaiser -, der König von Frankreich als politischer Schutzherr und schließlich im weitesten Sinn das Volk selbst. Als Ercole II. am 3. Oktober I 59 starb, dauerte es 50 Tage, bis der neue Fürst, sein in Frankreich weilender Sohn Alfonso II., die Macht übernahm. Diese lange Vakanz definierte das Bestattungsritual und das Zeremoniell der Machtübergabe neu.

Als Alfonso am 20. November I 559 in Belvedere, einer Delizia vor den Stadtmauern Ferraras, eintraf, begann ein Prozedere, das Inthronisationsfest und Bestattungszeremoniell in einem war. Es handelte sich dabei um ein doppeltes Begräbnis, das seine Tradition im England des I 4. Jahrhunderts hatte, wie z.B. die Beisetzung des englischen Königs Eduard II. I327 zeigt. Von der britischen Insel setzte sich diese Tradition in Frankreich fort, wo sie bereits ${ }_{4} 422$ für die Beisetzung von Charles VI. belegt ist. Es handelt sich dabei um das Anbringen einer mit den Insignien der Macht ausgestatteten Effigie, eines Porträts oder einer lebensechten Statue, auf dem Sarg. Im Sarg ruhte der natürliche Körper des Herrschers, außerhalb lebte der politische »Körper« in Form einer bildlichen Darstellung noch solange fort, bis durch die translatio imperii die Macht vom alten auf den neuen Fürsten übergegangen war.

635 Ironischerweise hatte der herzogliche Sekretär Pigna in seinem Hoftraktat über den Fürsten (Il principe nel qual si descrive come debba essere il Principe Heroico sotto il cui governo un felice popolo possa tranquillamente e beatamente vivere, Venezia, Sansovino I56I) als Modell für die italienische und estensische Gerichtsbarkeit das französischn Parlement herangezogen. Folın, Gli Estensi, 68, Anm. 84.

636 Magoni, I gigli d'oro, 208-2I6.

637 Zum Ritual siehe auch in diesem Zusammenhang Stollberg-Rilinger, Rituale.

638 Ricci, Vacanze. Ausführlicher Ders., Il principe e la morte; Ders., Sepolture multiple; Ders., Centro e periferie, $372-379$. 
Zahlreiche Beispiele aus Frankreich belegen die Verbreitung des doppelten Begräbnisses: Dem Bild der I 5 I 4 verstorbenen Anne de Bretagne, der Mutter von Renée de France, wurden reiche Speisen vorgelegt; beim Begräbnis von François I. I 547 wurde die Effigie 40 Tage ausgestellt, in den ersten elf Tagen wurden ihr Gerichte vorgesetzt. Weil also die Effigie wie der lebende Fürst gesehen wurde, näherte sich ihr der neue Fürst nicht, bzw. er trat nicht gleichzeitig mit ihr auf, da sie ja noch die politische Macht des Vorgängers darstellte und es gleichzeitig nur einen König geben konnte. Durch die langlebigen kulturellen Kontakte mit Frankreich war dieser Bestattungsritus, den Alfonso und seine Mutter ${ }^{639}$ selbst in Frankreich erlebt hatten, nach Ferrara gekommen. Der ferraresische Humanist Lilio Gregorio Giraldi hatte bereits I 539 eine Abhandlung über antike und moderne Bestattungsriten verfasst und war darauf eingegangen. ${ }^{640}$

Durch den plötzlichen Tod ihres Gemahls und die Abwesenheit des Thronfolgers war die Herzogin von Ferrara in der politischen Führung des vakant gewordenen Fürstentums und in den Anforderungen des Bestattungszeremoniells alleingelassen worden. Zunächst ließ sie am 6. Oktober den fürstlich gekleideten Leichnam im Innenhof des Castello aufbahren und dem Volk präsentieren. Dies entsprach der spätgotischen Tradition der chapelle ardente. Dann ging man zur Einbalsamierung über. Dann wurde der Sarg geschlossen und blieb 50 Tage lang bis zur Ankunft Alfonsos ständig bewacht in der Hofkapelle. Als Alfonso am 20. November in Ferrara ankam, besuchte er auf geheimen Wegen und ungesehen den Leichnam des Vaters zum letzten Gruß, der dann sofort und ohne Pomp im Kloster Corpus Domini ${ }^{641}$ beigesetzt wurde. Alfonso blieb bis zum 26. November außerhalb der Stadtmauern und zeigte sich nicht in der Öffentlichkeit. Währenddessen bestätigten die Savi seine Nachfolge und übergaben nach altem kommunalen, aber mittlerweile nur mehr zeremoniellen Recht die Stadt dem neuen Herrn. Man konnte sich Zeit lassen, denn es bestand keine Gefahr aus Rom, da es hier auch gerade eine Papstvakanz gab. ${ }^{642}$ Am nächsten Tag wurde Ercoles Statue in einem Sarg, der nur Kopf und Füße sichtbar ließ, in der Hofkapelle aufgestellt. Diese Effigie zeigte den toten Fürsten, während die erste den lebenden Fürsten dargestellt hatte. Nach der Totenrede des Hofsekretärs Pigna, in der die Tugenden

639 Renées Eltern sind in ihrem Grabdenkmal in St. Denis ebenfalls lebend und in königlichen Gewändern dargestellt. Ricci, Vacanze, I 23

640 Ricci, Vacanze, I04-ro9. Außerdem ist in der Biblioteca Estense in Modena ein anonymes italienisches Manuskript über die Beisetzungsrituale beim Tod des französischen Königs erhalten. Ebd., I 22.

64I Das Klarissinnenkloster Corpus Domini in Ferrara war sowohl Unterbringungsmöglichkeit für ranghohe weibliche Verwandte (Töchter, Schwestern, verwitwete Mütter), die hier ein ehrbares, kulturell und spirituell reiches Leben, ohne die Gefahr der Konkurrenz durch neue Heirat bzw. den Verlust der Mitgift führen konnten, als auch letzte Ruhestätte und Ort der estensischen memoria. Vgl. ZARRI, Monache.

642 Papst Paul IV starb am I8. August I559, Pius IV. trat sein Pontifikat mit dem 25. Dezember an und die Lehensbestätigung für Alfonso II. kam erst im Frühjahr 1560. 
und Leistungen des Verstorbenen aufgezeigt wurden, begleitete der Leichenzug die Statue in den Dom und von hier in das Kloster Corpus Domini. Alfonso, der bereits die Macht übernommen hatte, begleitete den Trauerzug mit einem Kapuzenmantel französischer Art, der Trauermantel der Burgunder, der in Frankreich und darüber hinaus üblich geworden war. Nicht genannt wird Renée. Es ist nicht klar, ob sie den Inthronisations- und den Trauerfeierlichkeiten beigewohnt hat. ${ }^{643}$ Allerdings ist die Teilnahme Alfonsos am Begräbnis der Effigie eine ferraresische Besonderheit, denn in Frankreich war dies nicht üblich; meistens nahmen die Nachfolger heimlich und nur vom Weiten teil.

Das doppelte Begräbnis französischer Tradition findet sich aber nicht nur in Ferrara, sondern auch am Hofe der Medici, so I 574 für Cosimo I. Ricci sieht die Gemeinsamkeit darin, dass es sich hierbei um Fürstentümer handelte, in denen die Herrschaft nicht von Gottes Gnaden, sondern von der Gunst eines Kaisers, eines Papstes oder eines Königs/Lehnsherrn kam. Dieses Beharren auf der Blutslinie entsprang der Notwendigkeit und Angst, die natürliche Nachfolge könnte von einer höheren Macht in Frage gestellt oder einfach nicht akzeptiert werden. Daher rührte die Notwendigkeit, die Macht des Toten durch die Effigie darzustellen und die ungebrochene Kontinuität zum Nachfolger zu beweisen. Alfonso II. ließ seiner ersten Frau Lucrezia de’Medici eine ähnliche letzte Ehre zuteil werden, obwohl sie keine eigene politische Rolle wie z.B. Anne de Bretagne ausgeübt hatte. Für die Medici-Frau gab es in Ferrara und daraufhin auch in Florenz das doppelte Begräbnis mit einer Effigie, welches Ricci als "Generalprobe« für Cosimos Beisetzung in effigie - I 574 mittlerweile als Großherzog - wertet. So kann dieser Kulturtransfer des angepassten französischen doppelten Bestattungsrituals unter Einsatz einer Effigie als ein kleiner Nachlass der unscheinbaren ersten Heiratsverbindung Alfonsos II. gewertet werden, welche das Ziel, den Präzedenzstreit zu tilgen, ja nicht erreicht hatte. ${ }^{644}$

Die Este waren also auch rituell stark an Frankreich angelehnt. Bereits bei Borsos Tod waren sein Körper einbalsamiert und seine Eingeweide und sein Herz getrennt voneinander in der Kirche San Paolo in einer Säule bestattet worden. Diese Bestattungsform war in England und Frankreich seit dem Mittalter verbreitet, aber von der Kirche, die die Bedeutung der Integrität des Körpers betonte, eigentlich unerwünscht und verboten, sodass die französischen Könige von den avignonesischen Päpsten einen Dispens dafür erhalten hatten. Schließlich sah auch die Kirche den Vorteil dieses Bestattungsritus in der Erhebung von Kirchen und Klöstern zu Ruhestätten und Aufbewahrungsorten fürstlicher Gebeine und Eingeweide und somit zuwendungsreichen Pilgerstätten. Doch Borso blieb vorerst der einzige, der diesem ultramontanen Bestattungsritus unterlag. Erst Kardinal Luigi d'Este, der frankophile Sohn von Ercole II. und Renée de France, verfügte testamentarisch, dass sein Körper in Tivoli bei der be-

643 Ricci, Vacanze, i io- i I 4.

644 Ricci, Prigioniera dei simboli, $226 f, 230$. 
rühmten Villa seines Vorgängers begraben werden sollte, während seine Eingeweide nach Rom zur Kirche San Luigi dei Francesi überführt werden und sein Herz den Weg nach Frankreich in sein Erzbistum finden sollte. So hatte die memoria des EsteKardinals einen italienischen und einen französischen Sitz. Ähnlich machte es seine zur Gänze Französisch gewordene Schwester Anna, die verfügte, dass ihr Herz in der Champagne in Joinville bei ihrem ersten Ehemann François de Guise, ihr Köper in Notre-Dame de Annecy bei ihrem zweiten Mann Jaques de Nemours und ihre Eingeweide in der Augustinerkirche von Paris begraben werden sollten. ${ }^{645}$

Alfonso II. d'Estes Begräbnis hingegen war aufgrund der päpstlichen Bedrohung an Schlichtheit gar nicht zu übertreffen, wie im Kapitel Devolution bereits gezeigt wurde: keine Messe im Dom, kein Totengedenken, kein Leichenzug, sondern nur eine stille Beisetzung im Kloster Corpus Domini. Cesare d'Este, der designierte Nachfolger, hatte alle Hände voll zu tun, in größter Eile seine Macht aus den Händen der Savi zu übernehmen, im Dom die Antrittsmesse zu hören und schließlich sofort mit dem Ritt durch die Stadt die Inbesitznahme zu demonstrieren. Zu diesem tristen Abgang des letzten Herzogs von Ferrara hat sich Ricci mit Anspielung auf die prompt erfolgte Devolution an den Kirchenstaat ein sehr passendes Wortspiel erlaubt: Statt eines Staatsbegräbnisses kam es zum Begräbnis eines Staates. ${ }^{646}$

645 Ricci, Sepolture multiple, 203.

646 Ricci, Vacanze, I 24. 


\subsection{Zusammenfassung}

Dieser zweite Teil der Arbeit geht auf verschiedene Aspekte des reichen kulturellen Austausches und Transfers zwischen den Este und dem Reichsoberhaupt sowie einzelnen Reichsfürsten ein. Das Zentrum der Este-Herrschaft, Ferrara, war einer der glänzendsten Renaissancehöfe und das von den Herzögen betriebene Mäzenatentum kostspielig, aber vorbildhaft wie auch die von ihnen gegründete Universität. ${ }^{647} \mathrm{Um}$ ihre Macht zu inszenieren, um internationalen Ruhm und Prestige zu erreichen, förderten die estensischen Fürsten und Fürstinnen - unter anderem mithilfe des hier früh entwickelten Gesandtenwesens - Kunst, Literatur, Musik, Architektur, aber auch den Warenverkehr, den Austausch von Delikatessen und von edlen Pferden aus der eigenen Zucht. Darüber hinaus erfreuten sich die Este zahlreicher Besuche, waren doch die Universität und der Hof obligatorische Station auf jeder Bildungsreise oder Wallfahrt nach Süden. Mithilfe des Gabentausches, der Erfüllung von Bitten und Gesuchen (z.B. bezüglich des Sprachaufenthaltes von Fürstensöhnen und Hofeliten) und einer ungebrochenen Kommunikation spannten die Este ein immer dichter werdendes Netz an Beziehungen, das auch durch ihre internationale Heiratspolitik gestärkt wurde. Objekte, weiterempfohlene Menschen und ihre Dienste und nicht zuletzt die italienische Sprache ${ }^{648}$ als lingua franca stärkten und pflegten das durch Freundschaft und Verwandtschaft entstandene und verdichtete Netzwerk. Der Nutzen dieses Beziehungsgeflechtes war reziprok: Die Este erkauften sich die Unterstützung der Fürsten im Reich und deren Fürsprache bei Kaiser und Reichstag und waren im Gegenzug für diese wichtige Bezugsquelle jener materiellen wie geistigen Güter, die Herrscher jenseits der Alpen benötigten, um den Status von Renaissancefürsten zu erreichen. Das Phänomen des kulturellen Austausches versetzte die Herzöge von Ferrara und Modena von der räumlichen Peripherie ins Zentrum der Wahrnehmung und des Interesses der Reichsmitglieder. ${ }^{649}$

647 Vgl. Bertozzi, Alla corte degli Estensi.

648 Siehe auch BraUn, Imagines imperii, besonders das Kapitel »Sprache und Fremdwahrnehmung« und Wagner, Princeps litteratus, I $53 \mathrm{f}$.

649 Vgl. zum Konzept Zentrum-Peripherie siehe Wallerstein, Das moderne Weltsystem, r 3 of und auch unten. Für regionale Beispiele zum Verhältnis von Zentrum und Peripherie siehe besonders die Beiträge Fasano Guarini, Centro e periferia und Povolo, Centro e periferia. 
3. KOMMUNIKATION UND WAHRNEHMUNG 
Publikation im Sinne der CC-Lizenz BY 4.0 


\subsection{Fremd- und Eigenwahrnehmung allgemein}

Es ist ein schwieriges Unterfangen nachzuzeichnen, wie mit einander in Austausch stehende Personen bzw. Personengruppen in der Frühen Neuzeit sich selbst und andere wahrnahmen, welche Bedeutung sie anderen zumaßen, vor allem dann wenn sie in der gesellschaftlichen Hierarchie nicht auf der gleichen Stufe standen. Einen Einblick in diese komplizierte und von Abhängigkeitsverhältnissen, Netzwerken, Stereotypen beherrschte Welt der gegenseitigen Wahrnehmung können Korrespondenzen zwischen ranggleichen Fürsten und Fürstinnen oder zwischen diesen und dem Reichsund Kirchenoberhaupt geben, wenn auch der gebotene Austausch von Höflichkeiten, Demutsbekundungen und Geschenken im Rahmen von politischer Kommunikation nur zum Teil ausdrücken kann, ob der Andere gefürchtet, bewundert oder als gleichwertig und sogar als Freund gesehen wurde. Aussagekräftiger erscheinen Informationen über Dritte innerhalb dieser Korrespondenzstränge und noch mehr im Rahmen von Gesandtenberichten. Direkte Korrespondenzen mit Gleich- oder Höherrangigen drücken im Habitus der Zeit zumeist Freundschaft, emotionale (verwandtschaftlich begründete) Bindung, Gunst, Dankbarkeit, Dienstbereitschaft aus und bestehen zu einem großen Teil aus Ergebenheitsadressen. ${ }^{1}$ Ergiebiger für die Rekonstruktion von Eigen- und Fremdwahrnehmung ${ }^{2}$ sind - wenn auch keineswegs frei von tradierten Vorurteilen - Gesandtenkorrespondenzen und -relationen, die trotz Gunstpflege und Dienstergebenheit ein Bild des Anderen geben können.

Die Intensivierung der internationalen Beziehungen zu Beginn der Frühen Neuzeit, die Kontakte mit alten wie neuen Anders- und sogenannten Ungläubigen ${ }^{3}$ und die Entwicklung des europäischen Staatensystems führten ganz allgemein zu einer vermehrten Auseinandersetzung mit dem Anderen und demzufolge zur Reflexion des Eigenen, zu Partikularisierungs- aber auch Integrationsprozessen, sodass "nationale Kulturen an Gestalt gewannen und sich auch innerhalb der europäischen Völkerfamilie die Sensibilität für Alterität erhöhte«. ${ }^{4}$ In den Erläuterungen zum richtungsweisenden Sammelband Wabrnehmung des Fremden hat Arno Strohmeyer zu Recht Fremdheit nicht als objektive Größe, sondern als »Beziehung, das Ergebnis der Unterscheidung

I Christian Kühner spricht in seiner Untersuchung zur Freundschaft am französischen Hof im I7. Jahrhundert von einer utilitaristischen Freundschaft. KüHnER, »Quand je retournai«,74.

2 Als allgemeine und wegweisende Literatur zum Thema der Fremd- und Eigenwahrnehmung dienen: Rohrschneider/Strohmeyer, Wahrnehmung des Fremden; Burschel, Das Eigene.

3 Zur Genese und Wandlung des Bildes des Fremden bezogen vor allem auf Muslime, Juden und außereuropäische Kulturen siehe auch die Beiträge unter dem Kapitel "Das Fremde und das Eigene« in Dinzelbacher, Europäische Mentalitätsgeschichte, insbesondere zum Mittelalter den Beitrag von Harry Kühnel, 4I 5-429 und zur Neuzeit jenen von Albrecht Classen, 429-450.

4 Strohmeyer, Wahrnehmungen, 5 . 
des Eigenen vom Anderen « definiert. ${ }^{5}$ Daher zeichnet sich Fremdheit durch unterschiedliche Intensität aus und hängt stets von der Perspektive ab, von der aus etwas oder jemand als fremd wahrgenommen wird. »Das Eigene geht dem Fremden zeitlich und erkenntnistheoretisch voraus, es ist geradezu die Bedingung der Möglichkeit der Erkenntnis des Fremden. Erst das Interesse ermöglicht die Erkenntnis, aber es prägt sie dann auch. $\ll^{6}$

Nach Peter Burschel können die Fremd- und Eigenwahrnehmung in der Analyse von Gegenbegriffen wie hier und dort, wir und sie und von Analogien oder Unterschieden sowie durch Ansätze des Vergleichs und der Übersetzung in Texten sichtbar gemacht werden. ${ }^{7}$ Die bisherigen Forschungsarbeiten zur Frühen Neuzeit zeigen, dass sich gerade Diplomaten, deren Hauptaufgabe die Weiterleitung von Informationen, Eindrücken und vom eigenen Habitus divergierenden Besonderheiten aus der Fremde war, von den vorgefertigten Meinungen und den konstruierten Feind- und Fremdbildern, den tradierten Stereotypen ${ }^{8}$ und Schablonen ${ }^{9}$ nicht - oder nur vereinzelt - lösen konnten. ${ }^{10}$ Deshalb verwundern nicht die vereinfachenden bzw. verallgemeinernden Bilder, die immer wiederkehrenden Wendungen und Merkmalbeschreibungen sowohl des Anderen (Heterostereotype) wie auch des Eigenen (Autostereotype). Beide dienten der Ordnung und Einordnung von Unbekanntem und wenig Geläufigem, aber auch der Abgrenzung und Erhöhung vom Eigenen, wenn z.B. die intellektuelle oder kulturelle Überlegenheit durch die Benutzung von Stereotypen gefestigt wurde; ${ }^{11}$ z.B. erhielten auch noch zu Beginn des I7. Jahrhunderts Nuntien die Warnung, im Reich nur abgekochtes Wasser zu trinken, denn deutsches Wasser sei - im Gegenteil zum italienischen - schlecht. ${ }^{12}$ Außerdem weist Strohmeyer zurecht darauf hin, dass das Fremde und die mit seiner Andersartigkeit verbundenen Schwierigkeiten oft als Grund für die Erfolglosigkeit einer diplomatischen Mission herangezogen wurden:

5 Ebd., 8.

6 Reinhard, Historische Anthropologie, 58.

7 Vgl. Burschel, Das Eigene, 26o-27i. Strohmeyer, Wahrnehmungen, io.

8 Wie lang sich diese tradierten Fremdbilder hielten, zeigt die am Beginn des I 8. Jahrhunderts entstandene Steirische Völkertafel. In Wort und Bild wurden hier die Eigenschaften einzelner europäischer Völker verglichen. So galten die Deutschen immer noch als offenherzig, während die Italiener als hinterhältig beschrieben wurden. Die Ersten liebten das Trinken, die Zweiten das Geld. Zu den weiteren Eigenschaften siehe STAnZel, Europäischer Völkerspiegel.

9 Besonders hartnäckig hielten sich die Topoi zu Witterung und Klima jenseits der Alpen oder das durch Porträts zwar widerlegte, aber dennoch weiterbestehende Stereotyp der blonden und blauäugigen Deutschen Zucchi, Deutschland und die Deutschen, ${ }_{403} \mathrm{f}$.

io Siehe z.B. Edelmayer, Habsburgische Gesandte; Levin, Agents of Empire; Windler, Tribut und Gabe; Lutter, Politische Kommunikation; Jarren, Die Vereinigten Niederlande, wo auch auf Zeremonialfragen und Rangstreitigkeiten eingegangen wird, 68-82.

I I Etliche Beispiele dafür in den venezianischen Gesandtschaften bei Zucchi, Deutschland und die Deutschen, besonders Kap. 4: »Venezianische Skizzen der deutschen Nation«.

I2 Reinhard, Historische Anthropologie, 68. 
Die Langsamkeit bei der Entscheidungsfindung, die Unaufrichtigkeit bei der Weitergabe von Informationen oder die Einhaltung von Versprechen, die Wankelmütigkeit oder Falschheit eines Volkes/einer Person wurden auch von estensischen Gesandten gerade in den heiklen Lehensangelegenheiten immer wieder für ihre Erfolglosigkeit verantwortlich gemacht. ${ }^{13}$ Wo es sich zudem um ein anderes Umfeld handelte als das höfische, so z.B. die bündischen Strukturen mit ihren von den Gesandten beschriebenen eidgenössischen Eigenheiten, beriefen sich diese umso mehr auf die Unterschiede in der Handhabung von Agenden oder bei der Entscheidungsfindung. ${ }^{14}$ Allerdings hat Windler zu Recht darauf hingewiesen, dass »je fremdartiger und komplexer die Beziehungsverhältnisse waren, desto größer waren die Handlungsspielräume subalterner Akteure «. ${ }^{15}$

Strohmeyer hat im Zusammenhang mit frühneuzeitlicher Eigen- und Fremdwahrnehmung auch von einer Authentizitätsfunktion von Stereotypen gesprochen, denn sie »dienten schließlich dazu, die Glaubwürdigkeit der Diplomaten zu erhöhen, wurde doch auf diese Weise bereits vorhandenes, also vermeintlich wahres Wissen bestätigt «. ${ }^{16}$ $\mathrm{Zu}$ den Wahrnehmungsmustern gehörten auch die Feindbilder, die Vorurteile aber vor allem die Konfliktrealität widerspiegelten. Wolfgang Reinhard ist sogar einen Schritt weitergegangen und hat behauptet, dass gerade Nuntien das Fremde gar nicht wahrnehmen wollten oder konnten, da für ihr Ordnungsschema und Verständnis das Eigene das einzig Wahre, Richtige und daher Mögliche war. Er spricht vom »Modus der Wahrnehmungsverweigerung « ${ }^{17}$

Obgleich diese Muster, Vorbilder und Ordnungskriterien weit verbreitet und immer wiederkehrend waren, äußerten Diplomaten in ihren oft ausführlichen Berichte über Land und Leute vereinzelt auch ihre Sicht der Dinge und der Personen, ihre persönliche, von der eigenen Sozialisierung, Bildung, Herkunft und Erfahrung geprägte und manchmal auch ungefärbte Wahrnehmung. ${ }^{18}$

Der Aktionsraum von Nuntien und Gesandten war zumeist der Fürstenhof. In der Untersuchung des Kaiserhofes unter Friedrich III. und der von Enea Silvio Piccolomini tradierten "fremdenfeindlichen" Haltung sowie der Integrationsprobleme von vielen »Fremden« am Hof, nicht zuletzt der Kaiserin Eleonore von Portugal selbst, hat Paul-Joachim Heinig frühe Beispiele von Selbst- und Fremdwahrnehmung vorgelegt. Die portugiesische Braut hatte nur wenige Landsleute, darunter eine einzige früh verstorbene Hofdame am stark »österreichisch« ausgerichteten Hof behalten dürfen. Die Fremdheit der Kaiserin und ihrer engsten Vertrauten rührte von der Tatsache

I3 Vgl. Strohmeyer, Wahrnehmungen, 26-29.

I4 Windler, Diplomatie als Erfahrung, 3 If.

I5 Ebd., 42. Zum Handlungsspielraum von Gesandten unter Berücksichtigung ihrer eigenen Interessen siehe: Thiessen, Gestaltungsspielräume.

i6 Strohmeyer, Wahrnehmungen, 30 .

I7 Reinhard, Historische Anthropologie, 67, 7r Reinhard spricht von »Scheinempirie«, 58.

i 8 Strohmeyer, Wahrnehmungen, 3i, 34 
her, dass sie die Sprache und Gepflogenheiten der neuen Heimat nicht kannten und durch ihr Auftreten, ihre Interessen, ihren Wissenstand, ihre Mode und Sprache als "Exoten« galten. Doch sollte dies nicht die Vermutung nahelegen, dass diese »Exoten« einer kompakten »heimischen « Gruppe gegenüberstanden. Das Reich und besonders der Hof waren, so Heinig, regionalisiert. Diese regionalen Gruppierungen, der Adel, der in seinen Erbländern eine starke Stellung auch gegenüber dem Reichsoberhaupt innehatte, änderten sich stets mit dem Wahlkönigtum, die einen schieden aus, andere kamen hinzu und alle kämpften um die führenden Positionen am Hof. Dennoch ließen sie - trotz ihrer Heterogenität und zumeist kurzen Präsenz am Hof - Auswärtige fremd erscheinen und strahlten eine scheinbare Homogenität aus, die ein Gefühl der Alterität provozierte. ${ }^{19}$

Das Problem der Selbst- und Fremdwahrnehmung äußerte sich, wie auch Heinigs Beispiel gezeigt hat, besonders im Fall von Heiraten mit ausländischen Partnern, wo mit der Braut nicht nur eine Person, sondern ein ganzer Hofstaat für kurz oder lang in einen bereits bestehenden Hof integriert werden sollte oder beide zumindest nebeneinander her bestehen mussten. Mit Karl-Heinz Spieß gesprochen: »Bei internationalen Ehen wurden andere Nationalitäten demnach nicht - wie sonst üblich - in der Form von zeitweilig am Hof befindlichen Ausländern wahrgenommen, sondern eine fremde Personengruppe drang plötzlich in den innersten Kern des Hofes, in die engste Umgebung des Herrschers vor und nistete sich dort auf Dauer ein. ${ }^{20}$

Nicht immer gab es nach Spieß die Möglichkeit einer vorehelichen Annäherung der Eheleute, die sich daher bei ihrer Verheiratung zumeist nicht kannten, nicht die gleiche Sprache sprachen, aus unterschiedlichen Kulturkreisen stammten und manchmal sogar verschiedener Konfession waren. Allerdings gab es einige Beispiele früh einander versprochener Fürstenkinder, bei denen idealerweise ein Ehepartner bereits als Kind zur Erziehung an den Hof des/der Zukünftigen kam, wie die ro-jährige Markgräfin Barbara von Brandenburg nach Mantua geschickt wurde. Problematisch war allerdings dabei, dass Verlobungen aufgelöst wurden und neue politische Konstellationen andere Heiratsverbindungen erforderten. So war der konventionelle Weg der Heiratsverbindung die Erkundung von geeigneten Kandidat/inn/en und die offizielle Werbung durch die in der Fremde angesiedelten Gesandten. Diese handelten nicht nur stellvertretend die Formalitäten der Verbindung aus, sondern überbrachten Geschenke und Porträts, während sie informell das Aussehen, den Ruf, die Gewohnheiten und nach Möglichkeit die potenzielle Reproduktionsfähigkeit des/der Heiratspartners/in eruierten. Mit der Mitgift und der Brautausstattung kamen dann neue Stoffe, Formen, Muster, Moden und Kunstobjekte im Sinne eines, so Spieß, regelrechten »Kunstexport $[\mathrm{s}] \ll$ in die Fremde. ${ }^{21}$ Ausschlaggebend, wenn nicht sogar überlebens-

\footnotetext{
i9 Heinig, Der regionalisierte Herrscherhof, i i6- I 22.

20 Spiess, Fremdheit, 268.

2 I Ebd., 270-273.
} 
wichtig für die fremde Braut war die Anpassung an den neuen Hof und an die neue Familie: Das Erlernen der Sprache, was aufgrund der oft wechselnden Heiratsprojekte erst spät und vor Ort erfolgte, oft aber - wie im Fall von Renée de France gezeigt wurde - aus Trotz, Überheblichkeit oder mangelndem Integrationswillen zeitlebens nicht geschah. Eine große Unterstützung für die in die Fremde Verheiratete war der sie begleitende Hofstaat. Manche Fürsten duldeten allerdings keine »Fremden« an ihrem Hof und schickten bis auf einige wenige Hofdamen und den Beichtvater, evtl. noch einen Arzt oder Koch die Entourage wieder nach Hause.

Ausschlaggebend für die Integration einer fremden Fürstin waren neben dem Erlernen der Sprache und der Anpassung an die neuen Sitten die baldige Erfüllung ihrer Pflicht zur Erhaltung der Dynastie und im Weiteren die Verankerung ihres Hofes durch die Anbahnung neuer Heiratsverbindungen und/oder die Verheiratung ihrer Hofdamen und Hofbediensteten mit einheimischen Höflingen. Belastend für die fremde Fürstin und Hemmschuh einer erfolgreichen Integration konnten das Verhältnis zu einem oft in Alter, Wesen, Interessen oder Konfession verschiedenen Ehemann, ihre Kinderlosigkeit oder das Ausbleiben der Mitgift aus ihrer Heimat zuzüglich zu einem unwillkommenen "fremden« Hofstaat sein.

$\mathrm{Zu}$ Recht betont Spieß auch die Auswirkungen einer interkulturellen Heirat für die nachfolgenden Generationen. Das Fremde konnte - wenn die politischen Bedingungen günstig standen - durch das Verwandtschaftsverhältnis vertraut werden; Kinder, meist nachgeborene Söhne wurden zum Erlernen der Fremdsprache oder zur Verfeinerung der Ausbildung an den Hof der ausländischen Mutter geschickt, wie Gianfrancesco Gonzaga, der fünf Jahre bei seinem deutschen Großvater in Franken verbrachte oder die Erzherzöge Ernst und Rudolf, die am spanischen Hof aufwuchsen. Auch Alfonsos II. d'Este "Flucht« nach Frankreich an den Heimathof seiner Mutter kann unter diesem Aspekt des »Kindertausches« betrachtet werden. Dadurch wurde das Fremde vertraut, ja sogar teilweise zum Eigenen. ${ }^{22}$

22 Spiess, Fremdheit, 283 f, 289 f. 


\subsection{Italien und Reich: Gegenseitige Wahrnehmung}

Das Verhältnis Reichsitaliens zum Reich unterschied sich von dem zwischen dem Reich und Böhmen darin, dass es als Regnum Italiae nie im Regnum Teutonicum inkorporiert war und deshalb einen besonderen Status im Reichsverband hatte. Die Bindung zwischen Kaiser/Reich und Italien war lehensrechtlicher Natur und die Halbinsel hatte bis zur Abdankung Karls V. zudem als Krönungsort eine große Bedeutung. ${ }^{23}$ Die konkurrierenden Lehensordnungen, die Bestrebungen mancher italienischer Reichsgebiete die Oberhoheit des Reiches nicht anerkennen zu wollen sowie die Expansionsbestrebungen Spaniens und des Papstes, die vor allem die kleineren Lehen zu »integrieren« drohten, schwächten die kaiserliche Macht in Italien, wie eingangs gezeigt wurde. ${ }^{24}$ Positiv in der Wahrnehmung und Bedeutung Italiens für den Kaiser war es sicher, dass die italienischen Vasallen nicht, wie die deutschen Stände, Bewilligungsrecht bei finanziellen Ressourcen hatten und unkomplizierter, wenn auch unregelmäßiger und nicht immer gewinnbringend zu Kontributionen und als Durchgangs- und Rekrutierungsraum für die gegen die Osmanengefahr notwendigen Streitkräfte verpflichtet werden konnten. ${ }^{25}$

Durch bestimmte Reichsinstitutionen wie dem Reichshofrat, als oberstes Lehensund Reichsgericht für Italien, dem Reichsvikariat und später die Plenipotenz war Italien auch institutionell an das Reich gebunden. Negativ war, dass die Mitglieder des Reichshofrates, an die sich die Italiener in Rechtsachen wenden konnten, fast ausschließlich Deutsche waren, die oft des Italienischen nicht mächtig waren, und diese Institution somit nach Schnettger »aus italienischer Perspektive als ein Organ der Fremdherrschaft perzipiert wurde. $\aleph^{26}$ Doch sowohl im Reich als auch in Italien war der Reichshofrat, wie Siegrid Westphal dargestellt hat, weniger ein kaiserliches Machtinstrument als vielmehr eine Vermittlungsinstanz. Die Einflussnahme des Kaisers war eher im Bereich der Reservat- und Gnadenrechte als in dieser Institution gegeben. ${ }^{27}$ Darüber hinaus beschäftigten sich in der Frühen Neuzeit auch Kurfürsten mit italienischen Fragen und Problemen, denn das Kurkolleg konnte, vor allem im Rahmen des Reichstages, für die

23 Schnettger, Das Alte Reich, 345-348.

24 Ebd., $350-353$.

25 Ebd., 359f. Wallerstein schränkt aus ökonomischer Sicht die Bedeutung Italiens allerdings ein. Zwar war der Kampf um Italien gegen Frankreich für die politische Vorherrschaft und die Errichtung eines Weltreiches von größter Bedeutung; doch für einen "zentralen Platz in der kapitalistischen Weltwirtschaft mögen solche Kriege jedoch als Verschwendung von Ressourcen und Energien erscheinen.« Wallerstein, Karl V., 37I. Ab der Mitte des I6. Jahrhunderts und mit dem Ende des französisch-habsburgischen Konfliktes nahm die »weltwirtschaftliche Bedeutung Norditaliens« sukzessive ab. Ebd., 38 I.

26 Ebd., 375.

27 Westphal, Der Reichshofrat, I $_{3} 6 f$. 
Italiener ebenso Anlaufstelle für Beschwerden und Bitten sein. ${ }^{28}$ War das Reich somit für die reichsitalienischen Fürsten trotz ihrer betonten Eigenständigkeit von Bedeutung, so waren umgekehrt auch diese - rangniederen - italienischen Fürsten für Kaiser und Reich vor allem im Rahmen einer politisch gewinnbringenden Heiratspolitik wichtig, wie die Verbindungen der zweiten Hälfte des I6. Jahrhunderts und darüber hinaus beweisen. Doch wie sahen nun jenseits dieser gegenseitigen Bedeutungszuschreibungen die Deutschen die Italiener und diese die Deutschen in der Frühen Neuzeit?

Klaus Heitmann ${ }^{29}$ hat in den Schriften Francesco Petrarcas ein frühes Beispiel italienischer Wahrnehmung der Deutschen zutage gebracht. Wiederholt tritt an der Wende vom Mittelalter zur Neuzeit die Perzeption kriegslustiger, rasender, die Halbinsel überfallender deutscher Heerscharen auf, selbst dann, wenn dies jahrzehntelang nicht mehr der Fall gewesen war. Zahlreich sind die Hinweise auf das Bild der Deutschen als - im Vergleich zu den Italienern - minderwertige Barbaren. Ebenso erkennbar ist die stets tradierte »kulturelle[n] Überlegenheit Italiens« und die »Ablehnung der deutschen Fremdlinge «. ${ }^{30}$ Das spätestens seit dem Hochmittelalter geprägte negative Bild des Deutschen in Italien umfasst die Kritik über die barbarische Sprache, die Rohheit des Charakters, die Maßlosigkeit im Essen und Trinken und die Käuflichkeit im Kriegsdienst. Petrarca reiste 1333 freiwillig und ohne Auftrag ins Reich (Aachen, Köln) und widerlegte in seinen Briefen zunächst das negative Deutschlandbild, indem er von der Kultiviertheit, mit der man ihm begegnete, und von dem gegen allen Erwartungen warmen und sogar heißen Wetter berichtete. Dennoch reichten diese Eindrücke nach Heitmann nicht aus »für die Erweckung dauerhafter Sympathie für Land und Leute. «1 $^{31}$ Nach Italien zurückgekehrt bediente sich Petrarca wieder der tradierten Stereotypen vom rauen, unwirtlichen, Charakter prägenden Klima bis zum Mangel an Kultur. Er versuchte wie die meisten vor und nach ihm mit der Abwertung des Fremden die Aufwertung des Eigenen und festigte weiter ein Freund-Feind-Bild, das schließlich das italienische Nationalbewusstsein noch prägen sollte. ${ }^{32}$

Auch ein späterer italienischer Reichsbesucher konnte sich von derartigen, tradierten und nicht hinterfragten Vorstellungen nicht lösen. Zwar hat Heitmann bei dem

28 r657/8 bat der Herzog von Modena beim Wahltag den Kaiser dazu zu verpflichten, dass er ihm mit dem Fürstentum Correggio belehnen möchte, was bis dato wegen seiner Frankreichverbundenheit verwehrt worden war. Dies wurde in der Wahlkapitulation für Leopold I. zur Auflage gemacht. Dass italienische Bitten aber in die Wahlkapitulationen kamen, blieb eher eine Ausnahme. I6 57 brachte der Herzog von Modena eine Beschwerde gegen Österreich beim Frankfurter Reichsdeputationstag vor, da dieses »ungeachtet des im Westfälischen Frieden ausgesprochenen Verbotes einer Unterstützung Spaniens in dem andauernden Krieg mit Frankreich, gegen den mit Paris verbündeten Herzog ein Heer entsandt hatte«. Schnettger, Das Alte Reich, 405-4i 2.

29 Heitmann, Zum Bild der Deutschen.

30 Ebd., I07.

3 I Ebd., Iо8.

32 Heitmann, Zum Bild der Deutschen, iogf. Siehe auch: Ders., Das italienische Deutschlandbild. 
ins Reich reisenden Niccolò Machiavelli ein leicht relativierendes positives Bild der Deutschen gefunden, dennoch überwiegt auch in den Darstellungen des Florentiners das stereotype Wissen. ${ }^{33}$ Machiavelli war I 507 für ein halbes Jahr in diplomatischer Mission für die Republik Florenz im Reich, d.h. in der Schweiz, die er zu den tedeschi zählte, und in Tirol unterwegs. Seine Erkenntnisse aus dieser Zeit und aus seinen Begegnungen, aber vor allem seine vorgefassten, auf tradiertem Wissen beruhrenden Meinungen hielt er in dem im Juni I 508 verfassten Rapporto di cose della Magna und in dem im darauffolgenden Jahr geschriebenen Discorso sopra le cose della Magna e sopra l'imperatore fest. Neben dem Nationalcharakteristikum der Deutschen, ihrer »vita rozza«, dem einfachen, ungeschliffenen, auch ärmlichen und anspruchslosen Dasein, erkennt Machiavelli ihre kriegerische und militärische, durch Disziplin erreichte Stärke, ihre Religiosität, Unverdorbenheit und Rechtschaffenheit (»bontà«) an. Dabei vergleicht er sie mit den frühen Römern und zieht somit, wie Tacitus, Parallelen zwischen der verkommenen eigenen Gesellschaft und der rauen, unfeinen, aber eben rechtschaffenden anderen Gesellschaft jenseits der Alpen. Ebenso bewundert der Florentiner die Freiheit der deutschen Städte (»liberissime«) und dementsprechend die Freiheitsliebe ihrer Bewohner. ${ }^{34}$

Dass die Meinung über die Rechtschaffenheit und die tiefere Religiosität der "Deutschen« noch lange nach der Glaubensspaltung weiterbestand, beweist nicht zuletzt die in Erzherzogin Johanna als Herzogin von Florenz gesetzten Erwartungen. Die Habsburgerin sollte - so erhofften sich die Verfasser der laudationes bei ihrem Einzug - die laschen Sitten der Florentiner beenden und ihre Frömmigkeit fördern. Es wundert nicht, dass Johanna in verschiedenen Situationen dieser Wahrnehmung ihrer Person und der Dynastie, die sie vertrat, gerecht wurde. So nahm sie eine besondere Rolle in den diplomatischen Beziehungen der Medici mit dem Heiligen Stuhl ein, die schlussendlich zur Erhebung zum Großherzogtum führten, und in der Causa der deutschen Studenten in Siena, die sich von der Inquisition und der kirchlichen Rechtsprechung stark eingeschränkt fühlten. Über diese habsburgische Ansprechpartnerin aus dem Reich wandte sich die natio germanica an Großherzog Cosimo und weiter an den Papst, bis sie schließlich ihre Rechte gegenüber der Inquisition behaupten konnten. Johannas gute Beziehungen zu Rom fanden schließlich auch in der Verleihung der Goldenen Rose 568 ihren Ausdruck. ${ }^{35}$

Die Betonung der Katholizität des Kaisertums, also des »Heiligen« im »Römischen Reich«, rührte u.a. auch von der in einigen venezianischen Finalrelationen geäußerten Kritik, dass die Casa de Austria seit der Glaubensspaltung der Kaiserwürde unwürdig sei. ${ }^{36}$

33 Heitmann, Machiavelli.

34 Heitmann, Machiavelli, 62 - 66, 7of, 74f, 85, 93. Zur Bandbreite und den Möglichkeiten der »teutschen Libertät« in der Neuzeit vgl. Duchinardt/Schnettger, Reichsständische Libertät; sowie Schmidt, Die »deutsche Freiheit«.

35 Fubini Leuzzi, Un'Asburgo a Firenze, 235f, $248-25$ o.

36 Vgl. die Relationen der venezianischen Gesandten Vincenzo Querini und Alvise Mocenigo, die sich - im 
So »zitiert« der venezianische Gesandte Mocenigo in seinem Bericht an den Rat der Zehn euphorisch den angeblichen Ausspruch des Landgrafen von Hessen, der, die Ansprüche der katholischen Habsburger auf die Kaiserwürde in Frage stellend, meinte, dass der vom Reich gewählte Kaiser vom Reich auch wieder abgewählt werden könnte: »[...] nel ragionare con lanthgravio, havendo esso detto a certo proposito: ‘La $\mathrm{M}^{\text {tà }}$ dell'Imperator<, lanthgravio mostrando di haverlo a male disse: >Che $\mathrm{M}^{\text {tá }}$ dell'Imperator? Lui è Carlo da Gant, come io son Filippo d'Hassia, et se la Germania l'ha potuto elegger Imperatore, lo può anco privare.$"{ }^{37}$

Der Venezianer verstärkte - nach einem vertraulichen Gespräch mit dem ferraresischen Gesandten - dieses Bild des »unwürdigen« Kaisers mit dem Bericht über den mit Verrat und Betrug gewonnenen Kampf Karls V. gegen die protestierenden Reichsfürsten. Dieser hatte nämlich eigene Leute in das feindliche Lager einzuschleusen versucht, die den Landgrafen von Hessen ermorden sollten. ${ }^{38}$

Wenn Gesandtenberichte allgemein eine der ergiebigsten Quellen in Bezug auf die frühneuzeitliche Fremdwahrnehmung sind, so zeigen die letzten beiden Beispiele auch, dass die Diplomaten hervorragende Meister der Stereotypisierung waren. ${ }^{39}$ Ein gängiges und hartnäckig vertretenes Vorurteil über Deutschland in den Nuntiatur- ${ }^{40}$ und Gesandtenberichten des I6. und I7. Jahrhundert waren die "geoklimatischen Theorien des Altertums «, ${ }^{41}$ die eine Parallele zwischen dem rauen Klima und den gefühlskalten, entscheidungs- und charakterschwachen, sowie leicht zu umschmeichelnden Deutschen zogen. ${ }^{42}$ Diese "Wahrnehmung " gibt auch der Nuntius Atilio Amalteo zu Beginn des r6. Jahrhunderts in Köln wider, der sich sowohl über das unwirtliche Wetter, wie die Langsamkeit ${ }^{43}$ und Unbedachtsamkeit der Deutschen, sowie über ihre

besten Einklang mit Venedigs antikaiserlicher Haltung - über den Ursprung des deutschen Kaisertums und seine Rechtmäßigkeit Gedanken gemacht haben, bei Zucchi, Deutschland und die Deutschen, 242-255.

37 Turba, Venezianische Depeschen 2, Alvise Mocenigo an die Zehn, aus dem kaiserlichen Lager [bei Sontheim], Oktober I 546, Nr. $27,66 f$.

38 Turba, Venezianische Depeschen 2, Alvise Mocenigo an die Zehn. Aus dem kaiserlichen Lager [bei Sontheim], Oktober I 546, Nr. 28, 67-70, hier 70 .

39 Dies ist insofern verständlich, als dass - wie Matthias Schnettger bereits gezeigt hat - es in Reichsitalien kein eigentliches Bild des Reiches als Impero und keine systematische Darstellung darüber gab. Zudem waren einzelne italienische Reichsvasallen, wie die Republiken Venedig und Genau, bestrebt die Verbindung des Reiches zum mittelalterlichen Regnum Italiae zu meiden, um ihre Unabhängigkeit hervorstreichen zu können. Schnettger, Impero romano, 63 f.

40 Vgl. dazu die Studien von Koller, Vademecum für einen Nuntius; Ders., Nuntienalltag.

4i Heitmann, Zum Bild der Deutschen, i i i.

42 Reinhard, Historische Anthropologie, 69. Zu den Klagen über das Wetter im Reich siehe auch die Beispiele aus den Nuntiaturberichten bei BraUn, Imagines imperii, Kap. „Erfahrungen von Naturereignissen und Wetterverhältnissen«, 486-496, 573f. Siehe die Klagen der spanischen Gesandten bei Edelmayer, Söldner und Pensionäre, 55-57.

43 Der kaiserliche Gesandte Khevenhüller beklagte sich wiederum über die Langsamkeit am spanischen Hof, die weniger vom König als von seinen Räten kam, welche wiederum wenig Sachkenntnisse hätten. Edelmayer, Habsburgische Gesandte, 63 f. Die Langsamkeit der Deutschen - und weniger der wohl 
maßlosen Trink- und Essgewohnheiten beklagte. ${ }^{44}$ Dem gegenüber stand das Bild der Italiener, die als liebenswürdig, von angenehmen Umgangsformen, mäßig im Essen und Trinken und selten der Trunksucht verfallen, allerdings aber auch sehr sinnlich bzw. sinngetrieben, rachsüchtig, eifersüchtig und träge galten. ${ }^{45}$ Ein weiteres, wiederkehrendes Stereotyp ist jenes der auffälligen Bedeutungslosigkeit standesgemäßer Kleidung im deutschen Raum. Fürsten und Fürstinnen, so die allgemeine Meinung, würden im Reich wenig Wert auf ihre äußere Erscheinung legen. ${ }^{46}$ An einem Vorfall mit Gefolgsleuten des päpstlichen Legaten, Giovanni Ludovico di Madruzzo, am Reichstag von Augsburg I582 hat Leeb das viel benutzte Stereotyp dieser »welschen Arroganz«, das den Italienern und Spaniern nachgesagte überhebliche Auftreten, aufgezeigt. ${ }^{47}$ Dieses und viele weitere Beispiele sind gleichzeitig auch Beleg für die Anwesenheit der Vertreter italienischer Reichsfürsten am Kaiserhof und am Reichstag: »Von den Fürsten und Kommunen Reichsitaliens, die aufgrund der lehensrechtlichen Bindung keine Ausländer im eigentlichen Sinn waren, aber als solche wahrgenommen wurden und auch nicht an den Verhandlungen des Reichstags teilnahmen, waren in Augsburg vertreten: Florenz, Ferrara, Parma, Mantua und Venedig «. ${ }^{48}$

Wenn auch die italienischen Vertreter - mit Ausnahme des Herzogs von Savoyen, wo er von seinem Recht Gebrauch machte - nicht an den Verhandlungen und am Entscheidungsprozess der Reichstage beteiligt waren, nutzten sie dennoch diese Orte der Begegnung und des kulturellen Austausches außerhalb des rechtspolitischen Rahmens, um in den zeremoniellen Akten, Empfängen, Bällen, Jagden, Einzügen und Banketten ${ }^{49}$ die Interessen ihrer Fürsten zu vertreten, Netzwerke zu knüpfen, zu sehen und gesehen/ wahrgenommen zu werden. So erfahren wir ausschließlich über die verschiedenen Berichterstatter von den fremd anmutenden Gewändern der moskowitischen Diplomaten und von ihren exotischen Geschenken an besagtem Reichstag von Augsburg. ${ }^{50}$

eher zutreffende Widerwille - führte nach dem Nuntius auch zur verzögerten und schleppenden Einführung des Gregorianischen Kalenders I 582 . BraUn, Imagines imperii, 470.

44 Samerski, Römische Ordnung, 73. Alvise Mocenigo berichtete: »[...] del qual vino aßai piu, che di Martin Luther tutta questa natione è devotißima e partiale« (mehr dem Wein als Martin Luther ist diese Nation zugetan und verfallen). ASVe, Col. V, Rel. Amb. I I ( 15 ), 9 I , zit. n. Zucchi, Deutschland und die Deutschen, 406, Anm. i 470. Siehe auch Amelung, Das Bild des Deutschen.

45 Schudt, Italienreisen, I94f, 198.

46 Lutter, Differenz- und Kongruenzerfahrungen, I38. Auch bei Zucchi, Deutschland und die Deutschen, 40 r. Auch Luisa de Ávalos, eine Hofdame im Gefolge des spanischen Sondergesandten Fajardo ließ kein gutes Haar an der Kleidung der Damen am Wiener Hof. Vgl. Edelmayer, Söldner und Pensionäre, 5 I. Zur symbolgeladenen Bedeutung von Kleidung siehe auch: Dinges, Der »feine Unterschied«, 5 If.

47 Leeb, Stereotype, I72.

48 Leeb, Stereotype, I73, Siehe auch Aulinger, Das Bild, besonders Kap. »Die ausländischen Gesandten«, I $45-\mathrm{I} 63$.

$49 \mathrm{Zu}$ diesen »Veranstaltungen und Begebenheiten im Umkreis des Reichstags« siehe ausführlicher bei Aulinger, Das Bild, 263-327.

5О LеEв, Stereotype, I74f. 
Selbstverständlich sind auch diese Berichte nach Hause keineswegs frei von Stereotypen und Vorurteilen. Dennoch überraschen einige Stellungnahmen und vereinzelte Perzeptionen relativieren einige der tradierten Bilder, wenn z.B. vom pompösen Einzug von Kurfürst August von Sachsen mit Familie und einem überdurchschnittlich großen Hofstaat in die Reichstagsstadt berichtet wurde, der den Erwartungen in den Auftritt eines deutschen Fürsten entgegenstand. Hier zeigte ein deutscher Reichsfürst, dass er der größte und mächtigste unter seinesgleichen war und widersprach dem Bild des schlicht gekleideten, auf die äußere Erscheinung wenig Wert legenden Deutschen, das man in Italien auch von Karl V. hatte..$^{51}$ Dem gegenüber stand der Kardinallegat Giovanni Ludovico di Madruzzo, ein Italiener, der mit einem Gefolge von nur 6o Personen und keinem allzu großen Pomp zum Reichstag reiste. Entgegen den Erwartungen stand diesmal nicht die »Welsche Pracht« der deutschen Einfachheit gegenüber, sondern umgekehrt. ${ }^{52}$

Neben der nachgesagten italienischen Arroganz und Prunksucht, der auch Alfonso II. d'Este in seinem kurzen Auftritt im Türkenkrieg gefrönt hatte, waren in dem von Kämpfen geprägten I6. Jahrhundert die prekäre Reichs- und Kaisertreue, die fehlende Ehrfurcht und mangelnde Loyalität der Reichsfürsten ein viel benutztes politisches Argument, das - wie noch zu zeigen sein wird - auch die Este in hohem Maße betraf. Beispiele für die angeblich geringe Achtung des Reiches von Seiten der italienischen Fürsten besonders nach dem Tod Karls V. erkennt Niederkorn in der Fürstenkorrespondenz zwischen Philipp II. und Kaiser Ferdinand I. In seinen Bemühungen um die Funktion eines »Vicario Imperial en Italia« betonte Philipp II., dass Ferdinand im Reich und in Ungarn alle Hände voll zu tun hätte und nicht imstande sei, sich gegen die italienischen Fürsten durchzusetzen, »die vor dem Kaisertum nur wenig Ehrfurcht zeigten «. ${ }^{53}$ Der auf dem Fuß folgende Beweis dieser Treulosigkeit lag in der unangemessenen oder sogar unverschämten Behandlung kaiserlicher Vertreter und der Missachtung von kaiserlichen Anweisungen und Dekreten, die von den Spaniern in Italien ebenso ausging wie von den mit diesen verbündeten italienischen Fürsten. ${ }^{54}$

5 I Burke, Präsentation, 408f.

52 Lees, Stereotype, I 78. Jenseits der Wahrnehmung steht die Tatsache, dass das »schlichte« Auftreten des Fürstbischofs eher an den konfessionellen Rahmenbedingungen als an der vorgeworfenen mangelhaften Imagepflege lag. Vgl. Braun, Imagines imperii, Kap. IV.C. »Der Augsburger Reichstag I 582«, 385-4 Io. Vielleicht war die Dienerschaft des päpstlichen Legaten unterdurchschnittlich an Zahl; die »familia« des Fürstbischofs mit drei ihn begleitenden Neffen und mehreren Sekretären war mit 3 I Reichstagsteilnehmern in seinem Gefolge aber beachtlich. Vgl. VAreschi, La legazione del cardinale.

53 Instruktion für den Bischof von Avila vom 2 I. Mai ${ }_{5} 58$ in Correspondencia de los príncipes de Alemania con Felipe II, y de los embajadores de éste en la corte de Viena ( 556 à I 98 ) hg. v. M. de la Fuensanta del Valle/J. Sancho Rayón/F. de Zabálburu, in: Colección de documentos inéditos para la historia de Espana 98, Madrid I 89 I zit. n. Nieder korn, Reichsitalien und der Kaiserhof, 59.

54 Doch wenn auch viele kaiserliche Kommissäre, wie Bartolomeo Beccaria I 584 , in Italien im Zuge ihrer Kontributionensammlung schlechte Erfahrungen machten, so gab es dort, wo die italienischen Fürsten die Gunst des Kaisers gewinnen wollten, Gegenforderungen hatten oder die kaiserliche Seite gerade 


\subsection{Präsenz zeigen: Reisen und Besuche der Kaiser in Italien}

Wie schon im Kapitel über den Präzedenzstreit gezeigt wurde, war die Zuwendung eines höherrangigen Fürsten und explizit des Reichsoberhauptes eine Ehrerweisung, ein Ausdruck von Bevorzugung, Begünstigung, Zuneigung und Vorrang vor anderen Fürsten. Aber auch für den Gunstgebenden ist die Bedeutung von Begegnungen im Rahmen der Patronage nicht zu unterschätzen. So hat Ronald G. Asch festgehalten, dass es für einen Adeligen »immer auch eine Frage der Ehre [war], Anerkennung bei seinen Freunden zu finden, mochten sie nun mächtiger oder schwächer sein als er selber. ${ }^{55}$ Diese Anerkennung drückte sich in Freundlichkeit, Aufmerksamkeit und Freigebigkeit, in Geschenken, Besuchen und Gastfreundschaft und Fürsprache aus. Mit Heiko Droste gesprochen, ermöglichte Patronage »eine soziale und kulturell akzeptierte Möglichkeit der Umsetzung von Eigeninteressen, ohne notwendig gegen die Interessen von Fürst und Krone zu verstoßen. ${ }^{56}$

War Patronage an sich immer möglich, so war bei Reisen und Aufenthalten ein besonderer Handlungsraum in persona gegeben. Die fürstlichen Gastgeber, so wie auch die Städte, bemühten sich um einen pompösen und beeindruckenden Empfang, um die Organisation von Festen, Banketten, Aufführungen, Jagden und anderen Vergnügungen, um dem Gast den Aufenthalt so angenehm und denkwürdig wie möglich zu gestalten. Handelte es sich dabei um das Reichsoberhaupt, so bedankte sich dieses zumeist mit Adelserhebungen, Privilegien oder der Aufnahme von Familien- oder Hofmitgliedern in den kaiserlichen Dienst. Von den Kaisern des hier besprochenen Zeitraumes (I450-I600) kamen nicht alle im Laufe ihrer Regentschaft nach Italien. Manche hingegen zeigten, vor allem im Zuge der Italienkriege, wiederholt persönliche Präsenz in Reichsitalien.

Friedrich III. zog I 45 I/52 zur Kaiserkrönung nach Rom und hielt sich - wie oben schon beschrieben - sowohl bei der Hin- als auch bei der Rückreise in Ferrara auf, wurde von Borso d'Este feierlich und glanzvoll empfangen und bedankte sich bei seinem Gastgeber mit der Erhebung der kaiserlichen Lehen Modena und Reggio zu Herzogtümern. Ein zweites Mal reiste Kaiser Friedrich III. I468 im Zuge einer Pilgerfahrt nach Rom durch Italien, ${ }^{57}$ ohne diesmal Spuren in den estensischen Quellen zu hinterlassen.

die gewinnbringendere gegenüber der spanischen und französischen zu sein schien, auch erfolgreiche kaiserliche Emissäre. Nieder korn, Reichsitalien und der Kaiserhof, 6o-62.

55 Asch, Freundschaft, 274.

56 Droste, Patronage, 589 .

57 Lнотsку, Friedrich III. 
Maximilian I., König seit I 486, Nachfolger seines Vaters I 493 und erwählter römischer Kaiser seit I 508, trat I 496/97 einen Italienzug als Anführer der Heiligen Liga an. Nachdem er Lehenshuldigungen in Oberitalien entgegengenommen hatte, kam er nach Genua und Pisa und kehrte dann mittellos über Tirol zurück, ohne sein Ziel Rom erreicht zu haben. Die estensischen Gebiete hat er nicht besucht; in den Archivquellen findet sich vielmehr die Aufforderung an Ercole I., zur Huldigung nach Mailand bzw. Vigevano zu kommen. Da sein Plan und Wunsch eines Romzuges und einer Krönung durch den Papst von diesem und von Venedig verhindert wurden, kam Maximilian im Februar I 508 nur bis an die Reichsgrenze zu Italien, wo er in Trient zum »Erwählten Römischen Kaiser« ausgerufen wurde. Im darauffolgenden Venezianischen Krieg I 508 - I 5 I 6 hielt er sich weiter an der Reichsgrenze zu Italien auf. Schließlich führte er I 5 I6 sein Heer in die Lombardei, musste sich aber vor Mailand wieder zurückziehen. Diese »Aufenthalte« Maximilians waren vorrangig Kriegsmanöver in Reichsitalien, für die er die Este hauptsächlich mit Aufforderungen nach Durchzugsmöglichkeiten der Truppen und Geldmitteln behelligte. Nichtsdestotrotz rückte er durch seine Kriegszüge Italien in den Mittelpunkt der kaiserlichen Politik und vererbte seinem Enkel Karl zwar keine wiederhergestellten Reichsrechte auf der italienischen Halbinsel, aber zumindest den Anspruch darauf und den Flair des antiken, von Kanzler Gattinara forcierten universalistischen Herrschaftsgedanken.

Tatsächlich war der aktivste Italienbesucher Kaiser Karl V., wobei auch hier die häufigsten Aufenthalte kriegerischer Natur waren, wie I 52 I/22 die Eroberung Mailands, I 522 der Sieg bei La Bicocca und schließlich jener von Pavia I 525 . Nach dem Sacco di Roma I 527 und dem Frieden von Barcelona I 529 trat Karl V. eine lange - friedliche und Frieden bringende - Italienreise an, deren Höhepunkt I 530 die Kaiserkrönung in Bologna darstellte. ${ }^{58}$ Hier konnte er für den in Ungnade gefallenen Alfonso I. d'Este, von dem er auf seiner Hinreise in Reggio und Modena herzlich aufgenommen worden war, nach der Krönung freies Geleit nach Bologna erwirken, um mit ihm und dem Papst in Verhandlungen zu treten. Vom Este wurde er auch weiter nach Mantua und bis an die Grenzen des Fürstentums Richtung Trient begleitet. Ein zweites Treffen des Reichsoberhauptes mit Papst Clemens VII. gab es I532/33 in Bologna zur Besprechung der dringenden Konzilsforderung des Kaisers als »vicarius ecclesiae ${ }^{59}$ Im Anschluss an den Tunisfeldzug I 534 besuchte Karl V. das ihm wieder bestätigte Le-

58 Hierbei wurden dem Papst Ravenna, Modena und Reggio zur Angliederung an den Kirchenstaat in Aussicht gestellt, sowie die Wiedereinsetzung der Medici in Florenz zugesichert. Neben der Erneuerung der Investitur Karls mit dem Königreich Neapel wurde auch die Heirat seiner natürlichen Tochter Margarete mit Alessandro de'Medici vereinbart. Siehe Alfred Kohler, »Karl V.«, in: Deutsche Biographie Online, http://www.deutsche-biographie.de, Zugriff: I3.6.2020.

59 Wie Hubert Jedin hervorragend dargestellt hat, fühlte sich Karl V. verpflichtet, in den ihm zugefallenen Ländern das Christentum zu bewahren. Es war sein Dienst als weltliches Oberhaupt an der Christenheit "gegen die Ungläubigen [zu] kämpfen, die Ketzerei aus[zu]rotten, die Kirche von Mißbräuchen [zu] reinigen«. Jedin, Geschichte des Konzils von Trient I, I80. 
hen des Königreichs Neapel und den neuen Papst Paul III. in Rom, wo er mit einem kritisch beäugten Triumphzug die kaiserliche Macht demonstrierte. Der zur selben Zeit bestätigte Thronfolger im estensischen Herzogtum, Ercole II., war zu Kaiser (und Papst) zur Huldigung und Investiturbestätigung gereist. I 538 versammelte Karl seine Truppen in Italien, um mit ihnen gegen die türkische Bedrohung vorzugehen. I 543 kam es in Busseto bei Parma erneut zu einem Treffen mit Papst Paul III. zur Besprechung der Lösung der Religionsfrage, an dem der Herzog von Ferrara als Begleiter des Reichsoberhauptes teilnahm. ${ }^{60}$ Im Zuge dieser Italienreise kam Karl V. zum zweiten Mal nach Mantua, wo die Verlobung des Thronfolgers, Francesco III. Gonzaga, mit Erzherzogin Katharina, Tochter von Ferdinand (I.) beschlossen wurde; die I 549 geschlossene Vermählung dauerte gerade einmal vier Monate bis zum Tod des Gonzagas. Doch auch der ob eines Buckels schwer vermittelbare Nachfolger und Reichsvasall, Guglielmo Gonzaga, konnte eine habsburgische Erzherzogin für sich gewinnen, Eleonore, die er I 56 I heiratete. ${ }^{61}$

Für die Nachfolger Karls V., Ferdinand I., Maximilian II. und Rudolf II. sind trotz intensiver Beziehungsgeflechte und reichen Austauschs mit italienischen Fürsten, worunter auch die Este zu zählen sind - keine Aufenthalte in Italien/Reichsitalien verzeichnet, sondern lediglich einige Durchzugsreisen als junge Erzherzöge nach und von Spanien. ${ }^{62}$

60 Kohler, »Karl V.«Vgl. auch Pastor, Geschichte der Päpste 5, 45 6f.

6i SAndbichler, Eleonore, Erzherzogin von Österreich, 83- I Io.

62 Siehe Adam Wandruszka, »Ferdinand I.«. Volker Press, »Maximilian II.« und Robert J.W. Evans, »Rudolf II.«, alle in: http://www.deutsche-biographie.de, Zugriff: I3.6.2020. 


\subsection{Reisen, Besuche und Kontakte der Este}

Römische Könige und Kaiser an der Wende vom Spätmittelalter zur Frühen Neuzeit mussten besonders mobil sein, regierten ihr großes Reich zumeist zu Pferd oder mussten, selbst nachdem sich eine fixe Residenz entwickelt hatte, zu Reichstagen, Krönungen, Kriegen und anderen Ereignissen reisen. Auch Fürsten und Fürstinnen waren - entgegen älteren Ansichten - oft auf Reisen. Sowohl für das Reichsoberhaupt als auch für die einzelnen Reichsfürsten war das Verlassen der Erbländer stets gefährlich. Ungeachtet der Tatsache, dass es auch für die Este als Fürsten eines mittelgroßen und bedrohten Gebietes riskant war, ihr Territorium ungeschützt zurückzulassen, waren einige Mitglieder dieser Dynastie auffällig reisefreudig. Ein Großteil ihrer Mobilität war natürlich dem Kriegsgeschehen in Italien gezollt und ergab sich aus der Ausführung ihrer Funktion als condottieri. Darüber hinaus gab es auch notwendige, beschwerliche und gefährliche Investitur- und Huldigungsreisen, wobei die Este ihrem päpstlichen Lehensherrn öfter ihre Aufwartung machten als ihrem kaiserlichen Lehensgeber. Auch »freiwillige « Pilgerreisen, ${ }^{63}$ Wallfahrten und Besuche an anderen Fürstenhöfen bewegten die Herzöge von Ferrara und ihre Ehefrauen.

Der erste Este-Fürst des Untersuchungszeitraums, Borso, bewegte sich in seinen jungen Jahren aufgrund seiner militärischen Laufbahn, zu der er - trotz seiner geringen Eignung - vom Vater verpflichtet wurde, viel auf der italienischen Halbinsel und kam mehrmals bis nach Neapel. Nachdem er I 445 nach Ferrara zurückgekehrt war, um seinen Bruder bei den Regierungsgeschäften zu unterstützten und dann I 450 selbst die Herrschaft zu übernehmen, unternahm er nur noch eine größere Reise, nämlich jene nach Rom, wo er I 47 I im Zuge der Osterfeierlichkeiten zum Herzog des päpstlichen Lehens Ferrara erhoben wurde. ${ }^{64}$ Ins Reich kam er nie. Die Erhebung der kaiserlichen Lehen zu Herzogtümern wurde ihm von Kaiser Friedrich III. auf dessen Romreise zuteil.

Borsos Nachfolger, Ercole I., wuchs weit weg von seiner Heimat entfernt am aragonesischen Hof von Neapel auf. Nach seinem Herrschaftsantritt I 47 I war er als condottiere zuerst für, dann gegen Venedig in Oberitalien tätig und viel unterwegs. Doch gerade die venezianische Bedrohung während seiner Regentschaft ließ bis zum Ende des Krieges I 479 keine längere Absenz zu. Dann aber reiste Ercole nach Loreto und zu den Tremiti-Inseln, um ein Gelübde einzulösen. Ansonsten bewegte er sich von Ferrara aus nur bis Modena, Venedig und zu den Thermen im Montferrat. Sein Wunsch, I 487

63 Die Pilgerreise von Markgraf Alberto V. d'Este r39 I nach Rom wurde mit einer Statue desselben in Pilgergewand an der Fassade des Doms von Ferrara verewigt. Sein Sohn Nicolò III. pilgerte I4I3 ins Heilige Land. Zu dieser Reise ist ein im I9. Jahrhundert publizierter Bericht vom Schreiber des Markgrafen, Luchino dal Campo, erhalten. Ghinassi, Viaggio a Gerusalemme. Vgl. auch Nori, La corte itinerante und Nolte, Erlebnis und Erinnerung.

64 Chiappini, »Borso«. 
nach Santiago de Compostella zu pilgern, brachte ihn nur bis Mailand, da der Papst, der den Verdacht hegte, der Este wolle hiermit nur einen Besuch beim französischen König kaschieren und diesen zum Eingriff in Italien motivieren, ihm die Weiterreise verwehrte. So reiste er bis zu seinem Tod ${ }_{5} 05$ nur in Italien zwischen Venedig, Lucca, Mailand, Rom (zur Investiturerneuerung) und kam jährlich nach Mantua. Selbst der Aufforderung Maximilians, ihn I 496 in Vigevano (in der heutigen Provinz Pavia) zur Huldigung zu treffen, kam er nur durch die Entsendung eines Gesandten nach, wobei diese Weigerung eher politische als mobilitätsbedingte Hintergründe hatte. ${ }^{65}$

Alfonso I. war, neben seinem gleichnamigen Enkel Alfonso II., der reisefreudigste Este-Fürst, wobei im Unterschied zu diesem seine Reiseziele ausschließlich im Westen, also in Frankreich, lagen. Als ihm Louis XII. zur Heirat mit Lucrezia Borgia I $5 \mathrm{O}_{2} \mathrm{Co}_{-}$ tignola, einst im Besitz der Sforza, schenkte, reiste Alfonso I. bis nach Grenoble, um sich bei dem nach Süden ziehenden französischen König zu bedanken, nachdem er bereits 499 seinen Vater Ercole I. nach Mailand zur Huldigung des rex christianissimus begleitet hatte. I 504 reiste er zu geheimen Absprachen bezüglich des Kampfes gegen Venedig nach Blois; dann wurde er vom Vater auf „Vernetzungsreise« nach Brüssel und London geschickt. Als Ercole I. erkrankte, verzichtete der Sohn auf die Weitereise nach Spanien, kam wieder bei Louis XII. in Paris vorbei und kehrte schließlich nach Ferrara zurück, um I 505 die Herrschaft zu übernehmen. In den darauffolgenden Jahren kämpfte er an der Seite Kaiser Maximilians I. gegen Venedig, bis er dann aufgrund der päpstlichen Kehrtwende sein Fürstentum verlor. Seine Reise nach Rom I 5 I 2 war ein erfolgloser Bittgang zum Papst, mit dem er seine Lehen zurückzubekommen versuchte. Als auch der in Aussicht gestellte »Rückkauf« der kaiserlichen Lehen, Modena und Reggio, nicht erfolgte, reiste er I 5 I 8/ I 9 nach Frankreich, um François I. zu seinen Gunsten zu bewegen. Wieder auf die kaiserliche Gunst hoffend, begleitete er Karl V. von Genua über »seine« Lehen bis kurz vor Bologna, wo er erst nach der Krönung freies Geleit zu Verhandlungen erhielt. Nachdem er I53 I in Modena und Reggio wiedereingesetzt worden war, blieb er bis zu seinem Tod $\mathrm{I} 534$ in seinem Fürstentum. ${ }^{66}$

Sein Nachfolger, Ercole II., reiste I 522 mit I4 Jahren nach Rom, um Papst Hadrian VI. und im Jahr darauf Papst Clemens VII. im Namen seines Vaters zu huldigen. Seine nächste lange Reise brachte ihn ${ }_{5} 28$ nach Frankreich, wo er - unüblich für diese Zeit und das gängige Zeremoniell ${ }^{67}$ - seine ranghöhere Braut, Renée de France, persönlich abholte. Neben seinen Tätigkeiten als condottiere, die ihn z.B. nach Florenz brachten, reiste er zusammen mit Bruder und Vater Kaiser Karl V. auf dem Weg zur Krönung entgegen. I 532 begab er sich wiederum nach Frankreich, um den König an

65 DeAn, »Ercole I«.

66 Quazza, »Alfonso I«.

67 Nach Spieß entsprach es nicht dem höfischen Zeremoniell, dass der Bräutigam die Verlobte abholte, sehr wohl aber ein naher Verwandter, also ein Bruder oder Onkel oder die zukünftige Schwiegermutter. SpIEss, Fremdheit, 275. Der Rangunterschied der Braut zu ihrem Bräutigam dürfte hier wohl auch eine Rolle gespielt haben. 
die Ausschüttung der Erträge aus den Besitzungen, die als Mitgift vereinbart worden waren, zu erinnern. I 535 reiste er nach Rom, um dem über die Entscheidung des Kaisers, den Este Modena und Reggio zurückzugeben, immer noch erzürnten Papst zu huldigen und die Investitur zu erneuern, was aber erst in einem zweiten Moment und durch kaiserliche Intervention erfolgte. Von Rom zog er weiter nach Neapel, um Kaiser Karl V.zu huldigen und die Investitur bestätigen zu lassen. Nach einem Aufenthalt in Venedig reiste er 548 nach Turin, um Henri II. von Frankreich zu huldigen und im Jahr darauf nach Mantua, um dasselbe für Philipp II. zu tun.

Der letzte Herzog von Ferrara, Modena und Reggio, Alfonso II., hatte sicher das bewegteste Leben und reiste als Einziger mehrmals zu den mittlerweile sesshaft gewordenen Kaisern. Doch zuvor zog er als Jugendlicher I 552 zunächst ohne väterliche Erlaubnis und dann wieder I 556 und I 558 mit väterlichem Segen nach Frankreich, wo er im Dienst des französischen Königs stand. Nachdem der I 559 die Herrschaft übernommen - und vorher in Florenz die ihm angetraute Lucrezia de'Medici besucht hatte - reiste er 1560 nach Rom zur Huldigung vor dem Papst und Bestätigung seiner Investitur. I 564 kam er zu Heiratsverhandlungen mit Kaiser Maximilian II. und zum Begräbnis von dessen Vater nach Wien, I 566, nach der Heirat mit Erzherzogin Barbara, und erneut, um den Kaiser im Türkenkrieg zu unterstützen. ${ }^{68}$ Zur Behandlung der Präzedenzfrage nach der Erhebung der Medici zu Großherzögen durch den Papst, reiste Alfonso II. auch im Dezember I 57 I nach Wien. ${ }^{69}$ Nach Barbaras Tod 1572 machte er sich auf dem Weg nach Rom, um über die Möglichkeit, einen Erben für das päpstliche Lehen bestimmen zu können, zu verhandeln. I 574 reiste er bezüglich der Präzedenzstreitigkeiten und seiner Titelerweiterung nach Innsbruck und Wien. Nach seiner Rückkehr fuhr er nach Venedig, um den von Polen nach Frankreich ziehenden Henri III. zu begrüßen. Als sich Papst Gregor XIV. als Befürworter seiner Vorschläge in der Nachfolgeregelung zeigte, reiste er I 59 I erneut nach Rom, ohne jedoch seine Forderungen realisiert zu sehen. Noch in den letzten Lebensjahren zeigte er sich bereit zum Aufbruch nach Ungarn in den Türkenkrieg, sobald aus Rom die Entscheidung über die Frage der Nachfolge gefallen wäre. ${ }^{70}$

68 Wenn auch Alfonso ruhm- und kampflos vom Türkenkrieg wieder heimwärts zog, so hatte er sich laut venezianischen Gesandtenberichten an der Front durch sein »technisches« Können ausgezeichnet, denn er beteiligte sich persönlich an der Planung und Ausführung von Schützengräben, besichtigte mit dem Kaiser die Befestigungsanlage von Raab/Györ und konnte diesem Verbesserungsvorschläge gegen die Unzulänglichkeit der Verteidigungsmauern unterbreiten. Außerdem zeugt die Tatsache, dass er den Kaiser, entgegen den Ratschlägen von dessen Ministern, davon abhielt, nach Wien zurückzukehren, da dies seinem Ruf schaden würde, von einer gewissen Vertrautheit mit Maximilian II. Turba, Venezianische Depeschen 3, Geronimo Albini an Leonardo Contarini, aus dem Lager bei Raab, September I $566, \mathrm{Nr}$. I 69, 352-357, hier 356 und Anm. 4 und 24. September 1 566, Nr. I70, 358-362, hier 359, Anm. I.

69 Er blieb am Krankenlager des Kaisers bis zum io. Januar I 572 . Hierbei beklagte sich der Herzog von Ferrara einmal mehr beim venezianischen Gesandten, dass über ihn böse Gerüchte kursierten, vor allem aufgrund seiner Beziehungen zu Frankreich. Turba, Venezianische Depeschen 3, Giovanni Micheli an den Dogen, Prag, Juni I 57 I, Nr. 201, 5 I6-522, hier 52 I, Anm. 4.

70 Quazza, »Alfonso II«. 


\subsection{Informieren - empfehlen - rechtfertigen}

Wie Katrin Keller und andere vor ihr bereits festgehalten haben, war das Alte Reich, vor allem im hier beschriebenen Zeitraum und auf der Ebene der hier behandelten fürstlichen Akteure und Akteurinnen, ein Kommunikationsraum. ${ }^{71}$ Kommunikation in all ihren verschiedenen Facetten ${ }^{72}$ - war ein Instrument der Herrschaftsausübung und -gestaltung und betraf in unterschiedlicher Weise beide Geschlechter: Wo die männliche fürstliche Kommunikation stark auf die Ausübung von Macht ausgerichtet war, wurde sie durch den Handlungsspielraum der Fürstin, der vor allem die Pflege sozialer Kontakte, die Stimmungsmache und die informelle "Anbahnung" zustanden, ergänzt. Fürstinnen reisten, begleiteten ihren Ehemann auf Reichstagen oder bei Fürstenbesuchen, lernten andere Fürstinnen und deren Hofstaat kennen und begannen - wie Keller dies für Kurfürstin Anna von Sachsen gezeigt hat - einen mehr oder weniger langjährigen brieflichen Kontakt, begleitet von gegenseitigem Austausch von Gaben und von Empfehlungen, Vermittlungen und anderen Aspekten der Patronage. ${ }^{73}$ Das Beispiel von Anna von Sachsen zeigt auch eindrücklich, dass Fürstinnen sowohl mit Männern als auch mit Frauen korrespondierten; an erstere wandten sie sich hauptsächlich bezüglich bestimmter Anliegen und Fragen; mit den Frauen bestanden jahrzehntelange Kontakte, die vorrangig der Pflege der freundschaftlichen und familiären Beziehungen dienten, wodurch sich erst die Möglichkeit und »emotionale Verpflichtung « der Fürsprache ergab und die Fäden des Beziehungsnetzes geflochten wurden. Um es mit Gießmann zu sagen: „Netze halten, verbinden und fangen; sie verfangen, binden und verstricken ${ }^{74}$ Nach Keller waren diese Fürbitten »Kulminationspunkte in den oft Jahre oder Jahrzehnte langen Korrespondenzen « ${ }^{75}$ Bedeutend war auch die Wahrnehmung einer Fürstin als »Maklerin fürstlicher Gunst«. Die brief-

7I Vgl. Keller, Kommunikationsraum, $206 \mathrm{f}$ und die hier angeführten zahlreichen Verweise.

72 Gemeint ist die politische Korrespondenz von Herrschern und Fürsten mit Ständen, Räten, Kommissaren und Gesandten sowie die höfische Korrespondenz von Fürsten und Fürstinnen untereinander und mit Mitgliedern des Hofes. Eine themenspezifische Trennung, wie sie Pflüger in ihrer Arbeit versucht und z.T. auch selbst relativiert hat, scheint nicht möglich und auch wenig sinnvoll zu sein. Gerade die Beispiele der Heiratsanbahnungen oder der Präzedenzfrage zeigen, dass solche Agenden nicht ausschließlich in der Sparte der politischen oder der höfischen Korrespondenz verankert waren, sondern eben mit allen Mitteln und Medien und über verschiedene Kanäle vorangetrieben wurden. Außerdem müssen auch der Gabenaustausch, die Empfehlungen und Bitten um Besorgung, selbst die Höflichkeitsadressen und Glückwünsche als Politikum oder als Aspekte eines aufrechtzuerhaltenden Netzwerks unter Fürsten und Herrschaften gewertet werden. Vgl. Pf Lüger, Kommissare, $78-80$. Nubola/Würgler, Politische Kommunikation und Kultur des Bittens.

73 Keller, Kommunikationsraum, 208f.

74 Giessmann, Die Verbundenheit der Dinge, I 5.

75 Keller, Kommunikationsraum, 225. 
liche höfische Korrespondenz war somit für Frauen wie Männer ein wichtiges Mittel der Verständigung und Kommunikation, eine »simulierte Präsenz« mit »emotionale[r] Wirkung " ${ }^{76}$ und diente der Aufrechterhaltung von familiären, verwandtschaftlichen und dynastischen Netzwerken. Zwischen Fürsten und Fürstinnen entwickelte sich parallel zur allgemeinen Verdichtung der Schriftlichkeit ein »unablässiger Kreislauf von Briefen und Geschenken aller Art und insbesondere von Porträts«. ${ }^{77}$

Umso bedeutender war dabei die Einhaltung der Regeln der Ehrerweisung, d.h. eines eigenen Briefzeremoniells, um sowohl Bluts- als auch Anverwandten mit dem gebührenden Protokoll und in Einhaltung der Rangordnung (schriftlich) zu begegnen. So gebührte dem ranghöheren Schreiber wie z.B. dem Kaiser die Ehre, sich sowohl am Anfang als auch am Ende des Briefes zu nennen, während der Rangniedere zwischen der Nennung des Ranghöheren und seiner Unterschrift so viel Platz wie nötig (je größer der Rangunterschied desto größer der Abstand) ließ, dass er unter Umständen trotz freier Beschreibfläche - erst am untersten Rand des Blattes und somit in größter Demut seinen Namen setzte. ${ }^{78}$

Korrespondenzen zwischen Fürst/inn/en dienten meistens nur zweitrangig dem Austausch von Neuigkeiten und Informationen politischer Natur, war es doch vorrangig Aufgabe der Gesandten, Fürst und Hof informiert zu halten. Den größten Raum in Fürstenkorrespondenzen nehmen daher Ehren- und Höflichkeitsadressen ein, die »der Aufrechterhaltung oder Einrichtung eines Kontaktes und der Konfirmation gegebener Beziehungen, aktueller Rangfolgen etc.« dienten. Dazu gehören nach Ruppel Gruß- und Gratulationsschreiben zu verschiedenen Anlässen (Geburt, Heirat, Sieg), Kondolenzbriefe, aber auch Briefe, mit denen sich der/die Schreiber/in bei dem/der Adressaten/in »nur« in Erinnerung rief und Wertschätzung für das andere Haus, Gunst- und Treuebekundungen oder seine/ihre Dienstbereitschaft ausdrückte: "Der Brief ersetzt hier gewissermaßen die körperliche Anwesenheit des Absenders«, so Ruppel. ${ }^{79}$ Vor allem durch die Eheverbindung entstand mit den Mitgliedern der verschwägerten Familie eine emotionale Beziehung, die, wie Antenhofer am Beispiel der Gonzaga bereits eindrücklich gezeigt hat, eine regelmäßige Kommunikation zur Folge, ja zur Pflicht, hatte. ${ }^{80}$

Auch wenn für die Renaissance der Begriff des »Privatbriefes« unbrauchbar und eine Unterscheidung in öffentlich und privat nicht sinnvoll und machbar ist, so kann man dennoch heikle Anliegen mit politischer Tragweite innerhalb der Familien- und Freundschaftsbriefe ${ }^{81}$ daran erkennen, dass die betreffenden Passagen oder sogar ganze

76 Fouquet, Fürsten unter sich, I 72.

77 Paravicini, Von materieller Attraktion, 277.

78 Vgl. Ruppel, »Das Pfand«, 2 I I - 2 I 3.

79 Eвд., 2 I 5.

80 Vgl. Antenhofer, Briefe, 39 f. Diess. Briefe zwischen Süd und Nord.

8i Fouquet, Fürsten unter sich, I73. Vgl. dazu auch Spiess, Familie und Verwandtschaft. Siehe als historischen Überblick und zum Forschungsstand: SeIdel/Schuster, Freundschaft und Verwandtschaft. 
Schreiben chiffriert wurden, wie auch die Beispiele aus der Korrespondenz Ercole II. d'Este mit Kurfürst Moritz von Sachsen bezeugen. ${ }^{82}$ Meistens kamen Briefe zusammen mit Geschenken und auch mit Menschen, die im Zuge von Vermittlungen empfohlen wurden und selbstverständlich auch mit Boten oder Gesandten, die die Korrespondenz begleiteten, um deren Inhalt und Zweck mit Nachdruck zu erläutern. Auf diese Schreiben folgten wiederum Dankesschreiben bzw. Empfangsbestätigungen. Die Notwendigkeit, den Erhalt von Briefen meist mit Angabe des Datums des Einlangens zu bestätigen, zeigt, wie unsicher die Übermittlung und wie wichtig eine rasche Antwort auf ein Schreiben waren, dessen Verzögerung nur aufgrund des Verlustes von Briefen entschuldbar erschien. ${ }^{83}$ Der Inhalt konnte über die Ergebenheitsadresse hinaus informativer Natur sein und über den Gesundheitszustand, über einen Kriegsverlauf, Neuigkeiten über Ereignisse wie Konzil, Reichstag etc. berichten. Darüber hinaus konnte er auch eine Anfrage/Bitte des Absenders selbst oder von Personen enthalten, die sich an diesen bezüglich eines Rechtsfalles oder einer Anstellungssuche gewandt hatten. ${ }^{84}$ Das persönliche Zutun in der Korrespondenz, das eigenhändige Verfassen oder Unterschreiben deuten des Weiteren auf eine intensivere "persönliche« Ebene der Beziehung hin.

In den im estensischen Archiv aufbewahrten Briefen von Kaiser Friedrich III. und seines Nachfolgers Maximilian I. gibt es nur selten eine eigenhändige Unterschrift (manu propria, $m$ p). Zumeist sind die Schreiben von Sekretären verfasst, die diese Beauftragung mit der Angabe "ad mandatum imperatoris« vermerkt haben; oft steht gar keine Unterschrift und eine Zuordnung ist nur durch die Anrede am Anfang des Schreibens möglich. Karl V. hingegen hat in der Korrespondenz mit den Este durchgängig seine Unterschrift, in einer grafisch sehr ausladenden Form (Carolus) und mit dem Vermerk $m p$ angebracht. Oft befindet sich am untersten Rand des Briefes auch gleichzeitig die Unterschrift des Schreibers, nicht selten war es Juan de Valdés. Dasselbe gilt für die Korrespondenz von Ferdinand I. mit den Herzögen von Ferrara, der auch zusammen mit dem Schreiber unterzeichnet hat. Anders hingegen die Schreiben von Maximilian II.: Dieser hat nicht nur die Briefe an die Este selbst unterschrieben, sondern sie auch selbst auf Spanisch oder Italienisch verfasst, wie der Handschriftenvergleich und die Tatsache beweisen, dass kein Schreiber genannt ist oder mitunterzeichnet. Diese Eigenhändigkeit und hinzukommend der oft verwendete $\mathrm{Zu}$ satz »buon amico e fratello« »quanto fratello« oder spanisch »buen amigo y hermano» (»guter Freund und Bruder«) zeugen von einem vertrauten, freundschaftlichen und

82 Die Wettiner waren Vorreiter in der Kunst der Kryptografie. Im Sächsischen Hauptstaatsarchiv in Dresden befinden sich über I.300 Chiffrenschlüssel, die Anne-Simone Rous im Rahmen ihres Habilitationsprojektes erforscht hat. Anne-Simone Rous, Geheimdiplomatie in Sachsen I 50o-r 763. Spione - Chiffren - Interzepte, Habilitationsschrift, Univ. Erlangen 2014. Diess., Informationssicherheit, I3, 20.

83 Vgl. die Klage der Nuntien über die Unzuverlässigkeit der Postbeförderung bei Braun, Imagines imperii, $464 \mathrm{f}$.

84 Vgl. Ruppel, »Das Pfand«, 21 8-221. 
innigen Verhältnis zu Alfonso II. d'Este, da gerade diese Ergebenheits- und Gefühlsbekundungen Teil der Freundschaftssemantik der Zeit waren. »Freundschafts- und Patronagebindungen [mussten] gerade deshalb, weil sie nicht rechtlich zementiert waren, beständig durch symbolische Akte, durch zeichenhaftes Handeln, durch Rituale und eben auch durch verbale Ergebenheitsbekundungen gefestigt werden $[\ldots] . .^{85}$ Die Wahl der Sprache und die Handschriftlichkeit zeugen von einer bestimmten Bedeutung, Vertrautheit oder fallweise auch von einer auf Freundschaft basierenden Beziehung zwischen Maximilian II. und Alfonso II. ${ }^{86}$

In der Korrespondenz zwischen den Este und Kaiser Rudolf II. hingegen kehrte man zum formalisierten ad mandatum zurück; die Schreiben sind auf Lateinisch in eleganter makelloser Kanzleischrift verfasst; nur die Unterschrift scheint durchwegs manu propria zu sein.

Die Este beendeten als Untergebene und Vasallen ihre Briefe an die Kaiser meist mit der Wendung "humilissimo et devotissimo servitore ${ }^{87}$ oder "humilissimo et obedientissimo vasallo ${ }^{88}$ und in der Steigerung sogar »humilissimo e obedientissimo servitore di core et vasallo ${ }^{89}$

Selbst in der unterwürfigen Grußformel unterschrieben die Este in der Kommunikation mit ihrem kaiserlichen Lehensherrn stets mit ihrem päpstlichen Lehenstitel. So heißt es beispielhaft für alle Korrespondenzen mit dem Kaiser in einem Brief Ercoles II. an den Römischen König Ferdinand: „Humilissimo et obedientissimo Servitor et vassallo el Duca di Ferrara«. ${ }^{90}$

Das Phänomen der einseitigen Titulatur der Este - d.h. die Angabe Herzog von Ferrara und nicht Herzog von Ferrara, Modena und Reggio oder, was in der Korrespondenz mit dem Kaiser naheliegender wäre, Herzog von Modena und Reggio - wurde bereits anderweitig behandelt. ${ }^{91}$ Hier sei nur zusammenfassend daran erinnert, dass die Este-Fürsten des I 5. und 16. Jahrhunderts bis heute noch meistens nur als Herzöge von Ferrara und ihr Fürstentum überwiegend als Stato di Ferrara tituliert werden. So nennt Romolo Quazza Alfonso I. und Alfonso II. im Dizionario Biografico degli Italiani jeweils auch nur »duca di Ferrara«. Dass die anderen nach I 598 einzigen Herr-

85 Die Freundschaftssemantik als Bestandteil der adeligen Kommunikation und Zeichen der Loyalität, sowie die verschiedenen Facetten von Freundschaft in der frühen Neuzeit hat zuletzt KüHner, Politische Freundschaft bei Hofe, untersucht.

86 Reinhard, Historische Anthropologie, 65.

87 »Untertänigster und ergebendster Diener«. Z.B. Wien, HHStA, Serie Italien - Kleine Staaten, Karton io, Alfonso I. an Karl V., Dezember I 530.

$88 »$ Untertänigster und gehorsamster Vasall«. Z.B. ebd., Sigismondo d'Este an Ferdinand I., Februar I 557. $89 »$ Untertänigster und gehorsamter treuer (liebender) Diener und Vasall«. Ebd., Alfonso II. an Maximilian II., Septemberi 569 .

90 »Untertänigster und gehorsamster Diener und Vasall, der Herzog von Ferrara«. ASMo, ASE, Casa e Stato, Minute di lettere ducali a Principi e signori fuori d'Italia b r63 I/ I an Kaiser Ferdinand I., Oktober I 544 .

9I Vgl. bereits TAddei, Die Este, Herzöge von Ferrara. 
schaftsgebiete, nämlich die kaiserlichen Lehen Modena, Reggio und Carpi mitsamt allen anderen dazu gehörenden kleineren Fürstentümern nur selten genannt werden, ist nicht nur der Kürze, Bequemlichkeit oder Unachtsamkeit zuzuschreiben, sondern größtenteils selbst verschuldet. Die Este identifizierten sich mit dem Renaissancehof von Ferrara, unterzeichneten zumeist nur mit dem Titel Duca di Ferrara und wurden infolgedessen auch so wahrgenommen. Dies änderte sich erst nach dem Tod des kinderlosen Alfonso II. und der von Rom nicht anerkannten Nachfolge von Cesare d'Este aus der illegitimen Seitenlinie der Markgrafen von Montecchio. Als das Herrschaftszentrum Ferrara im Zuge des »Rückfalls des Lehens« dem Kirchenstaat einverleibt wurde, mussten die Este nach Modena ziehen und ein neues Machtzentrum aufbauen. Nun begann die Ära der Herzöge von Modena und Reggio, die erst jetzt national und international als solche wahrgenommen wurden, obwohl die Este den Herzogstitel für die kaiserlichen Lehen im I 5. Jahrhundert - wenn man hier nur diesen bedeutenden Meilenstein nennen wollte - fast 20 Jahre früher erhalten hatten als jenen für das päpstliche Ferrara.

Bezüglich der Häufigkeit des schriftlichen Austauschs zwischen den Kaisern und den Este-Fürsten lässt sich eine Verdichtung der Kommunikation ab der zweiten Hälfte des I 5. Jahrhunderts feststellen, die zwar der allgemeinen Zunahme der Schriftlichkeit in der Frühen Neuzeit entspricht, ${ }^{92}$ gerade in der Regentschaft Karls V. oder Maximilians II., aber auch Ausdruck einer Intensivierung der Beziehungen (und Probleme) mit den italienischen Fürsten und insbesondere mit den Este ist. Vergleicht man die Regentschaft von Kaiser Maximilian I. mit der Karls V., so stellt man fest, dass sich im ungefähr gleichen Zeitraum von 30 Jahren die Anzahl der (erhaltenen) kaiserlichen Schreiben an die Este von 30 auf 64 mehr als verdoppelt hat. Auch wenn von Ferdinand I. "nur« I 2 Briefe im Staatsarchiv von Modena erhalten sind, so handelt es sich im Verhältnis zur kurzen, fünfährigen Regentschaft des Bruders Karls V. um eine rege Schreibaktivität mit den Fürsten von Ferrara. Der briefliche Austausch zwischen den Este und Maximilian II. beginnt bereits vor dessen Herrschaftsantritt und intensiviert sich nach der Übernahme der Kaiserwürde. Die 76 Briefe an Alfonso II. zwischen ${ }_{5} 63$ und 1576 können als Ausdruck einer innigen Beziehung, wenn nicht sogar Freundschaft der beiden Gleichaltrigen gewertet werden. Während der im Vergleich längeren Regentschaft Rudolfs II. erhielt Alfonso II. 75 Briefe vom Kaiser und auch für den in den kaiserlichen Lehen als Nachfolger anerkannten Cesare d'Este kann in den ersten zehn Jahren nach der Devolution ein reger Briefwechsel mit dem Reichsoberhaupt verzeichnet werden.

92 Vgl. die Angaben zur Zunahme der politischen Korrespondenz, d.i. der schriftliche Austausch mit den Reichsständen, Räten und Kommissären Königs Ferdinands in den I 55 oer Jahren und ihre Bedeutung für die Stabilisierung seiner (angehenden) Herrschaft bei PfLÜger, Kommissare, 75-8I. 
Auch die Zahl der im Staatsarchiv von Modena aufbewahrten Schreiben der EsteFürsten an die Kaiser bzw. an deren Kanzlei spiegelt - wie die folgende Tabelle zeigt den Intensivierungstrend fürstlicher Kommunikation im Sinne einer »verdichteten Kommunikation « wider, wie sie Axel Gotthard für die Regentschaft von Ferdinand I. und Maximilian II. gezeigt hat. ${ }^{93}$

Tabelle 1: Im ASMo erhaltene Briefe der Kaiser an die regierenden Este-Fürsten

\begin{tabular}{|c|c|c|c|c|}
\hline Absender & Zeitraum $^{94}$ & Empfänger & Anzahl & Summe der Schreiben \\
\hline Friedrich III. & $1452-1490$ & Borso/Ercole I. & 13 & 13 \\
\hline Maximilian I. & $1480-1510$ & Ercole I. & 26 & \\
\hline Maximilian I. & $1480-1510$ & Alfonso I & 4 & 30 \\
\hline Karl V. & $1522-1556$ & Alfonso I & 29 & \\
\hline Karl V. & $1522-1556$ & Ercole II. & 35 & $64^{95}$ \\
\hline Ferdinand I. & $1559-1564$ & Ercole II. & 3 & \\
\hline Ferdinand I. & $1559-1564$ & Alfonso II. & 9 & $12^{96}$ \\
\hline Maximilian II. & $1547-1563$ & Alfonso II. & 38 & \\
\hline Maximilian II. & $1563-1576$ & Alfonso II. & 75 & $113^{97}$ \\
\hline Rudolf II. & $1576-1594$ & Alfonso II. & 53 & \\
\hline Rudolf II. & $1593-1597$ & Alfonso II. & 22 & \\
\hline Rudolf II. & $1597-1607$ & Cesare & 23 & 98 \\
\hline
\end{tabular}

ASMo, ASE, Casa e Stato, Carteggio di principi esteri, Germania bb 1575/1, 1576/2, 1577/3.

93 Diese beiden Kaiser zeichneten sich durch einen »ausgesprochen kommunikativen Führungsstil« aus. Gotthard, Das Alte Reich, 62.

94 Die hier angegebenen Zeitspannen entsprechen den auf den Faszikeldeckeln angegebenen Daten der Korrespondenz und beziehen sich nicht unbedingt auf die Regierungszeit, wenn auch sie sich zumeist mit dieser decken.

95 Hier müssen noch 20 Schreiben von den beiden Granvellas an die Este dazugerechnet werden, die im selben Bestand aufbewahrt sind. Diese erstaunlich reiche Korrespondenz zwischen den Beratern Karls V. und den Este bestätigen Bonoras Hinweis auf die Zusammenarbeit der kaiserlichern Minister mit den italienischen Fürsten für das Projekt eines »Italiens des Kaisers« gegen die päpstliche Vormacht. Vg1. Bonora, Aspettando l'imperatore, I4.

96 Zuzüglich ein Schreiben der kaiserlichen Kanzlei.

97 Zuzüglich zwei Schreiben der kaiserlichen Kanzlei. 
Tabelle 2: Im ASMo aufbewahrte herzogliche Briefe (Minute) an die Kaiser

\begin{tabular}{lccl}
\hline Empfänger & Zeitraum & Anzahl & Zusätze \\
\hline an Friedrich III. & bis 1490 & 1 & \\
an Maximilian I. & $1491-1518$ & 26 & zzgl. 3 an kaiserl. Sekretär Polheim \\
an Karl V. & $1522-1555$ & 31 & zzgl. 11 an kaiserl. Kanzlei/Granvella \\
an Ferdinand I. & $1533-1563$ & 36 & zzgl. 6 an kaiserl. Kanzlei \\
an Maximilian II. & $1547-1576$ & 67 & zzgl. 24 an kaiserl. Kanzlei \\
an Rudolf II. & $1572-1614$ & 117 & zzgl. 20 an kaiserl. Kanzlei \\
\hline
\end{tabular}

ASMo, ASE, Casa e Stato, Minute di lettere ducali a Principi e signori fuori d'Italia, b 1631/1. 


\subsection{Gegenseitige Wahrnehmung in den Gesandtschafts- berichten und Fürstenkorrespondenzen}

Neben den Bündnissen, Heiratsallianzen und einer regelmäßigen, facettenreichen Kommunikation war es vorrangig die diplomatische Vertretung, durch die ein mittelgroßes italienisches, lehensabhängiges Fürstentum ein hilfreiches Netzwerk innerhalb und außerhalb Italiens knüpfen konnte. Die Diplomatie war auch ein essentieller Faktor der Souveränität und ein Mittel zur Konstruktion politisch einsetzbarer Selbstdarstellung, wenn die Gesandten z.B. nicht müde wurden, die "Altadeligkeit ${ }^{98}$ der Este zu bewerben, was wiederum ein Kriterium bei der Vergabe des Vorrangs sein konnte. ${ }^{99}$

Gerade aufgrund der bescheidenen Größe und der Notwendigkeit, im Kampf um die Vorherrschaft in Italien nicht unterzugehen, hatten die Stati estensi sehr früh ein ausgebildetes Gesandtschaftswesen etabliert. 1423 tauchte in Ferrara zum ersten Mal die Figur des rechtskundigen »secretarius« später »referendarius-consiliarius« auf. Seit den I 43oer Jahren hatte der Markgraf von Ferrara, als einer der ersten neben Mailand, eine konstante diplomatische Vertretung und eine residierende Gesandtschaft, die er vor allem am Papst- und Kaiserhof sowie in Frankreich einsetzte. Gleichzeitig finden wir in Ferrara auch sehr früh eine gut strukturierte Verwaltung, die zusammen mit der diplomatischen Vertretung die bereits vor der Verleihung des Herzogstitels durch den Kaiser eine gewisse Selbstständigkeit und Souveränität evozierte. ${ }^{100}$

$\mathrm{Zu}$ Beginn des Ausbaus der diplomatischen Vertretung wurden Literaten und Gelehrte wie Ludovico Ariosto, Giovan Battista Pigna oder der oben genannte Annibale Romei nach Rom geschickt, wo sie vor allem aufgrund ihrer feinen Sprache und Rhetorik glänzen konnten. Daneben waren sie als Dichter, Verfasser von Leichenreden oder Familienchroniken mit der Pflege der fürstlichen memoria beschäftigt. ${ }^{101} \mathrm{Als}$ dann das »technische know-how« für einen diplomatischen Vertreter immer bedeutender wurde, begann man in der ersten Hälfte des I6. Jahrhunderts mit der Entsendung von juristisch ausgebildeten Doktoren, aber vor allem von Diplomaten, die aufgrund ihres Geburtsstandes den Anforderungen der höfischen Repräsentation und des Zeremoniells gewachsen waren. Ausschlaggebend war hierfür sicher die Kaiserkrönung Karls V. in Bologna I530, aber auch die zunehmenden Beziehungen zum spanischen Hof. So kam I53 I nach der Rückgabe der kaiserlichen Lehen an die Este der hochrangige Graf Alfonso Bevilacqua als Gesandter an den Kaiserhof. ${ }^{102}$

98 Diesen Begriff hat Horst Carl im Zusammenhang mit den vom deutschen Adel benutzten Kategorien zur Randdefinierung und -hierarchisierung verwendet. Vgl. CARL, Europäische Adelsgesellschaft, I 92.

99 Frigo, »Small States«, I48-I 53.

ioo Santini, Lo Stato Estense, i6f.

Ior Zu diesen siehe: Prandi, Il »Cortegiano« und Baldi, Giovan Battista Pigna.

IO2 Vgl. Frigo, »Small States«, I54-I 59. 
Immer mehr bildeten sich auch am estensischen Hof Gesandtensippen aus, Familien, in denen Brüder oder Vater und Sohn die diplomatische Vertretung übernahmen und wo die Jüngeren gezielt diese Karriere anstrebten. Darunter befanden sich auch nicht wenige Geistliche, wie Gaspare Silingradi, ${ }^{103}$ Bischof von Modena, die neben dem jeweiligen sogenannten Cardinale di famiglia (Alessandro d'Este, Ippolito I/II. d'Este, Luigi d'Este) für besonders heikle Missionen um Kirche und Glauben und vor allem beim Heiligen Stuhl eingesetzt wurden.

$\mathrm{Zu}$ den Aufgaben des Gesandten gehörten - wie bereits im Rahmen des Kulturaustausches festgehalten - die regelmäßige Berichterstattung, die Vertretung der Interessen des Entsenders, die offizielle Repräsentation desselben und das Auskundschaften ${ }^{104}$ von Entscheidungen und Handlungen. Voraussetzung für die Funktion als Gesandter war eine allgemeine gute Bildung, gewandtes Latein und idealerweise Fremdsprachenkenntnisse, Kenntnisse im Römischen und Kanonischen Recht, sodass vor allem humanistisch und juristisch gebildete Geistliche und Adelige für diese Funktionen in Frage kamen. Darüber hinaus bedienten sich sowohl das Reichsoberhaupt wie die (deutschen und italienischen) Fürsten je nach Dringlichkeit und Bedeutung der Mission auch Geschäftsleuten, Verwandter und anderer Vertrauensleute selbst niedrigeren Standes. ${ }^{105}$

Die Ergebnisse diplomatischer Tätigkeiten mündeten in regelmäßigen, oft täglichen Briefen an den Fürsten und Abschlussberichten, sogenannten relazioni. Gesandtenkorrespondenzen waren stark formalisiert und räumten den Anrede- und Schlussformeln viel Platz ein ; ${ }^{106}$ behandelten sie heikle Themen oder befürchtete man, dass sie in falsche Hände kommen könnten, wurden sie chiffriert, d.h. die Buchstaben wurden durch Zahlen- oder Symbolreihen ersetzt. ${ }^{107}$ Christina Lutter, die sich intensiv mit dem venezianischen Gesandtschaftswesen der Frühen Neuzeit auseinandergesetzt hat, gibt zu Recht zu bedenken, dass man sich im Umgang mit dieser Quellengattung bewusst sein soll, dass Gesandte "Kinder ihrer Zeit«, von den vorherrschenden Bildern, teilweise auch von den Stereotypen und Vorurteilen geprägt und zudem Angehörige einer kulturellen und gesellschaftlichen Elite mit bestimmten Vorstellungen und Erwartungen bezüglich Lebensweisen, Kleidung, Umgang etc. waren. ${ }^{108}$ Auch

I03 Ricci, Le ambascierie estensi.

I04 Für die hier besprochene frühe Regentschaft des Römischen Königs bedeutete dies insbesondere die Ermittlung des Standes der Vorbereitungen für den geplanten Italienzug. Vgl. Voigt, Die Briefe Antonio de'Costabilis, ro7.

I05 Wiesflecker, Kaiser Maximilian I. V, 483.

ro6 Zur Formalisierung in der schriftlichen Kommunikation am Beispiel der Kanzlei und der Gesandten der Sforza siehe Senatore, »Un mundo de carta«; Ders., Ai confini del »mundo de carta«.

I07 $\mathrm{Zu}$ dieser üblichen Vorgangsweise siehe die Beispiele im Tagungsband Rous/Mulsow, Geheime Post, und hier besonders den Beitrag von Strasser, Die Wissenschaft der Alphabete.

I08 Lutter, Differenz- und Kongruenzerfahrungen, I23-r26; Diess. Selbstbilder; Diess. Diplomatie und Nachbarschaft. Zu den Klagen der Nuntien über diese wenig passenden Unterredungsorte bzw. zur Aufforderung, jede sich bietende Gelegenheit für eine Unterredung außerhalb des Audienzzimmers zu nutzen, siehe bei Braun, Imagines imperii, 6 r $6 f$. 
Peter Burschel räumt diesen Quellen nur eine eingeschränkte Möglichkeit einer unverzerrten Darstellung des/der Fremden ein: »[...] immer wieder lässt sich beobachten, wie schwer es ihnen [den Nuntien, E.T] fällt, die >Fremde` als `System` mit systemimmanenten Regeln zu verstehen - und sich dieser Regeln zu bedienen. ${ }^{109}$ Doch trotz ihrer Fülle an zeit- und situationsbedingten Klischees und Stereotypen haben Gesandtschaftsberichte unbestritten einen großen Quellenwert, weil sie oft als einzige ein ungeschminktes Bild des fremden Herrschers und seines Hofes zeichnen. Darüber hinaus zitieren sie oft wörtlich das in den Audienzen oder von anderen Vertretern Gesagte und gewähren somit »einzigartige Einsichten in die politisch-diplomatische Argumentation « ${ }^{110}$ der Dialogpartner. Vor diesem vorurteilsreichen Hintergrund sind auch zwei Gesandtenberichte aus dem letzten Drittel des r6. Jahrhunderts über die Regierung und den Hof von Alfonso II. zu lesen, die jedoch deshalb nichts an Spannung und Bedeutung einbüßen. Auf der einen Seite steht der eher nüchterne Bericht von Emiliano Manolesso für den venezianischen Senat von $1575^{111}$ und auf der anderen jener - hier bereits mehrfach zitierte - viel ironischere und offenere von Orazio Della Rena, dem Sekretär des florentinischen Gesandten Raffaello Medici.

Della Rena (I564-I630) stammte aus einer alteingesessenen und illustren toskanischen Familie und war als Sekretär der Republik und als Gesandter am Hof des Königs von Spanien in Portugal sowie in Rom tätig. Neben anderen historiografischen, biografischen und sakralen Werken veröffentlichte er I 589 die Relazione dello Stato di Ferrara, die in zwei Teilen zunächst die Geschichte und Geografie des estensischen Fürstentums und dann die Person und Regentschaft von Alfonso II., seinen Hof und die Sitten und Bräuche des Landes beschreibt. ${ }^{112} \mathrm{Zu}$ den Höhepunkten der estensischen Geschichte gehört nach Della Rena die Herzogserhebung von Borso, die er wie folgt aus den Quellen zusammenfasst:

Nel 1452 venendo Federigo Terzo in Italia per farsi coronare dal Pontefize e sposar Leonora figlia di Odoardo Re di Portogallo passò per Ferrara, e da Borso da Este successo di poco nello Stato al Marchese Nicolò suo Padre fu incontrato, e ricevuto magnificamente, et al partir presentato di cinquanta falconi peregrini, e di 40 corsieri bellissimi abbigliati con coperte ricamata d'oro superbissimamente; et andato a Roma, e poi ritornato a Ferrara fra pochi giorni, tenendo sempre impresse le grandezze nell'animo con che fu regalato da Borso, si risolvè di erigere i Territorj di Modona, et di Reggio in Ducato, et crearlo Duca dell'una, et dell'altra Città, et cos' a' I 8 di Maggio, giorno dell'Ascensione, Federigo con l'abito Imperiale sedendo sopra un Palco accomodato sulla Piazza del Duomo per quell'effetto in mezzo al Re di Ungheria suo Nipote,

rog Burschel, Das Eigene, 264.

i io Lutter, Politische Kommunikation, i67.

i i I Manolesso, Relazione di Ferrara.

I 2 Diana Toccafondi Fantappiè, »Della Rena, Orazio«, in: DBI 37 (I989), online verfügbar http:// www.treccani.it/enciclopedia/orazio-della-rena_\%28Dizionario-Biografico \%29/, Zugriff: r 6.9.2020. 
et ad Alberto Arciduca d'Austria suo Fratello, e tra di molti Signori Tedeschi, et Ungheri, creò Borso Duca di Modona, et di Reggio, et Conte di Rovigo, et nel I47 I a' I 4 d'Aprile il giorno della Resurrezione sendosi il suddetto Borso trasferito a Roma fu da Paolo Secondo innalzato alla Dignità di Duca di Ferrara, ch'egli riconosceva in Vicariato dalla Sede Apostolica. ${ }^{113}$

Bedeutend und folgenreich war auch der Verlust der Herrschaft unter Alfonso I., die der Autor eher auf die Allianz der Este mit Frankreich als auf die päpstlichen Expansionsbestrebungen zurückführt. ${ }^{114}$ Auch die Rückkehr der Reichsgebiete unter die estensische Herrschaft interpretiert Della Rena wenig quellenkritisch als Wunsch der Städte und Bevölkerung, wieder unter die Führung der Familie d'Este zu kommen.

Morto Adriano, e successogli Clemente Settimo si buttò [Alfonso I., E.T.] a parte Imperiale, e mentre che l'esercito di Borbone assediava Castel S. Angelo andò e [sic] Modona armato, e cole medesmo favor del Popolo ne prese il dominio, perchè i Modanesi cacciati fuora i presidii Pontificii dopo I 7 anne, che eran stati soggetti alla Chiesa volson ritornare al suo primo Signore. ${ }^{115}$

Pointiert hat der toskanische Gesandte auch die Beziehungen der Este zu den ausländischen Mächten und den italienischen Fürsten beschrieben: Das innigste Verhältnis bestehe, so der Diplomat, zu Frankreich, während mit den Reichsfürsten und dem Kaiser nur eine gute, auf Geschenkaustausch (er nennt Früchte, Mortadella, eingelegte Fische, Salami "piante di Frutti, o Pesci salati, diversi Caviali, Mortadelle, o Salami«) basierende Beziehung gegeben sei. $\mathrm{Zu}$ den benachbarten italienischen Fürsten aber herrsche Hass, Neid oder Furcht: »Verso i Principi, e Potentati d'Italia è stato openione, che per l'addietro si sia trovato mal'affetto con tutti, e a tutti universalmente abbia portata odio o invidia. ${ }^{116}$ Gerade bei diesem letzten Zitat aus Della Renas Bericht wird ersichtlich, wie Gesandte - aus Überzeugung, Kalkül oder Beauftragung - gerade

I 33 "Als I452 Friedrich III. zur Kaiserkrönung und Heirat mit Leonore, Tochter des Königs von Portugal, nach Italien zog, kam er in Ferrara vorbei, wo Borso d'Este seinem Vater Markgraf Nicolò kurz davor nachgefolgt war; und als er prächtig empfangen wurde und bei seiner Abreise mit 50 Wanderfalken und 40 wundervollen Pferden mit goldbestickten Pferdedecken und auch auf seiner Rückreise reichlich beschenkt wurde, beschloss er, die Gebiete Modena und Reggio zu Herzogtümern zu erheben. Und so machte Friedrich am I8. Mai, Tag von Christi Himmelfahrt, im kaiserlichen Gewand auf einer Bühne am Domplatz neben dem König von Ungarn und Albert, Erzherzog von Österreich, sitzend und in Anwesenheit vieler deutscher und ungarischer Fürsten, Borso zum Herzog von Modena und Reggio und zum Graf von Rovigo; am I4. April I47 I, am Osterfest, wurde der gleiche Borso in Rom von Papst Paul II. zum Herzog von Ferrara erhoben, welches er als Vikariat vom Heiligen Stuhl besaß.« Della Rena, Relazione, 2 of.

II4 Ebd., 21.

I 5 "Als Papst Hadrian starb und Clemens VII. folgte, stellte sich Alfonso I. auf die kaiserliche Seite; während das kaiserliche Heer unter der Führung von [Charles de] Bourbon die Engelsburg umstellte, ging [Alfonso] bewaffnet nach Modena und nahm die Stadt mithilfe der Bevölkerung wieder ein, weil die Modeneser die päpstlichen Vertreter verjagt hatten und nach I 7 Jahren gerne wieder unter ihrem früheren Herrn sein wollten.« Ebd., 22.

in6 Ebd., 70. 
bei heiklen Themen die allgemein vertretene oder die zu vertretende Meinung ihres Fürsten übertrugen und dadurch die (Fremd)Wahrnehmung ihrer Arbeitsumgebung prägten, wodurch sie nach Strohmeyer auch »trennend « wirkten. ${ }^{117}$

Die Register über die Gesandtschaften der Este im Archivio di Stato di Modena lassen leider keinen genauen Vergleich zwischen der Anzahl der von und nach Rom, Frankreich und an den Kaiserhof entsandten estensischen Botschaftern zu. Lediglich die "Ambasciatori e agenti in Alemannia« sind im Register übersichtlich nach Jahrhunderten geordnet, mit Angabe der Aufenthaltsdauer am Kaiserhof, Reichstag oder wo der Kaiser sich gerade aufhielt, erfasst. Aus der Übersicht, die als Register für den Bestand »Carteggio di ambasciatori in Germania bb $40 \mathrm{o}$ « dient, wird ersichtlich, dass zwischen I 486 und 503 vier estensische Gesandte ins Reich entsandt wurden. Im I6. Jahrhundert ( I 50 I- I 599) waren es 47, im I 7. Jahrhundert 83. Die beigefügten Jahresangaben zeigen, dass einige estensische Vertreter über viele Jahre, oft auch mehr als ein Jahrzehnt, im Reich residierten. ${ }^{118}$ Für gewisse Zeitspannen sind zwei oder drei Gesandte gleichzeitig im Reich registriert bzw. deren Aufenthalte überschneiden sich. In Einzelfällen wird auch der begleitende Sekretär namentlich genannt.

Ein stichprobenartiger Vergleich mit dem Register der estensischen Gesandten in Frankreich und am Heiligen Stuhl zeigt, dass es in Frankreich bereits ab I470 und bis I6oo schätzungsweise über 200 estensische Gesandtschaften gab. Die diplomatischen Beziehungen zum Papst begannen noch früher, bereits I455 mit einer gewissen Regelmäßigkeit, waren aus gegebenem Anlass, dauerten kürzer, ${ }^{119}$ machten aber eine größere Anzahl aus. Allein zwischen I 455 und I 499 konnten I04 gezählt werden. Im I6. Jahrhundert gab es weitere 200 bis zur Jahrhundertmitte und über 300 mehr bis I 600, also ca. 500 insgesamt. ${ }^{120}$

Der Einsatz von ständigen Gesandtschaften und ihre diplomatischen Fähigkeiten waren ausschlaggebend für die Etablierung der Macht und das Überleben der Dynastien. ${ }^{121}$ So sieht Frigo bei den Este das Versagen des von Cesare d'Este nach Rom geschickten Girolamo Giglioli als entscheidenden Grund für den endgültigen Schritt zur Rückholung des päpstlichen Lehens Ferrara. ${ }^{122}$

I 7 Strohmeyer, Kulturtransfer durch Diplomatie, 2 I 8.

I 8 So Giovanni Muzzarelli, der von I 505 bis I 52 I oder Andrea Minucci, der von I 586 bis I 597 Gesandter der Este im Reich war.

I 9 Mattingliy hat bereits darauf hingewiesen, dass: „But resident embassies are a secular institution, and the Roman curia played only a slight role in their development«. MATtingLY, Renaissance diplomacy, 65. Erst in den I 46oer Jahren hatten fast alle italienischen Fürsten einen residierenden Gesandten am Papsthof. Ebd., I05.

I 20 Die Zählung erfolgte anhand des alten, nicht aufbereiteten Registers ASMo, ASE, Cancelleria Ducale, Sezione Estero, Carteggio Ambasciatori Francia bb. 227 und Ambasciatori Roma.

I I Vgl. zum frühen Einsatz von residierenden Gesandten durch die Gonzaga bei Mattingly, Renaissance Diplomacy, 7 I -82 .

I 22 Frigo, »Small States«, I 53, I62. 
Nicht nur das Gesandtschaftswesen erlebte mit dem r6. Jahrhundert eine Spezialisierung und einen Wandel, sondern auch die allgemeine Pflege der sogenannten Außenbeziehungen am estensischen Hof. War im I 5 . Jahrhundert dafür noch der Consiglio segreto zuständig, so kümmerte sich im I6. Jahrhundert ausschließlich der Consiglio di Stato um die Beziehungen zu ausländischen Mächten mit Kanzler und Sekretären und vollrechtsfähigen Ministern, die sich im Laufe des I7. Jahrhunderts auf bestimmte räumliche und thematische Gebiete spezialisierten. ${ }^{123} \mathrm{Zu}$ den Quellen über "Außenbeziehungen« zählen im Archivio di Stato di Modena neben den Gesandtenberichten und den Korrespondenzen mit ausländischen Fürsten und Fürstinnen auch die sogenannten fogli di avvisi. ${ }^{124}$ Diese frühe Form von Nachrichtenvermittlung im Sinne einer Zeitung ${ }^{125}$ war in Venedig und Rom entstanden und ging von diesen beiden Zentren aus. Sowohl die Gonzaga als auch die Este erhielten und bewahrten diese Informationsblätter und ließen sie von eigens dafür besoldeten Schreibern kopieren, zusammenstellen und vertreiben. ${ }^{126}$

\subsubsection{Die Beziehungen zwischen den Este und Maximilian I. ${ }^{127}$}

In seiner fünfbändigen Biografie Kaiser Maximilians I. (I 459- I 5 I 9, seit I 486 Römischer König, seit I 508 Erwählter Römischer Kaiser) hat Hermann Wiesflecker fest-

I 23 Frigo, »Small States«, I6 If. Siehe auch Tocci, Persistenze feudali, 9-29.

I 24 ASMO, ASE, Cancelleria ducale, sezione estero: Avvisi e notizie dall'Estero. Die verschiedenen deutschen und italienischen Fürsten erhielten Informationen nicht nur direkt über die Zeitungen, sondern über befreundete und verwandte Fürsten aus diesen Blättern. So tauschen Herzog Albrecht von Bayern, König Maximilian (II.) und Kurfürst August von Sachsen Zeitungen und Informationen über Kriegsgeschehen und relevante Entwicklungen im Reich und Italien aus. Vgl. Pflüger, Kommissare, $79 \mathrm{f}$ und die hier angegebenen Archivalien.

I 25 Die sicher bedeutendsten "Zeitungen« der zweiten Hälfte des I6. Jahrhunderts, die in dieser Arbeit bereits mit der Ausgabe von Klarwill Eingang gefunden haben, sind die sogenannten Fuggerzeitungen, ein von den Brüdern Octavian Secundus (I 549- I60o) und Philipp Eduard Fugger (I 546- I6 1 8) zusammengestellter und in 30 Bänden gebundener Bestand an handschriftlichen Zeitungen aus dem Zeitraum von 568 bis I 600 bzw. durch die Sammeltätigkeit des Nachfolgers Philipp Eduard Fugger bis 1604. Seit 2015 ist die Wiener Sammlung der Fuggerzeitungen dank eines von Katrin Keller geleiteten FWF-Projekts »Die Fuggerzeitungen. Ein frühneuzeitliches Informationsmedium und seine Erschließung« digitalisiert und erschlossen. http://fuggerzeitungen.univie.ac.at/, Zugriff: 3.6.2020. Die Zeitungen, die viele Reichsfürsten, wie die Kurfürsten von Sachsen erhielten, beinhalten vor allem Informationen aus Italien für das Reich. Die Nachrichten kamen aus Agenturen in Rom und Venedig nach Augsburg. Eine erste Abfrage hat ergeben, dass Alfonso II. d'Este mit 443 über den Gesamtzeitraum verteilten Nennungen gleich oft vertreten ist wie Cosimo II. und sein Sohn Franesco II. de'Medici zusammen. Der Streit um die Präzedenz zwischen den beiden und der Verlust des Papstlehen Ferrara kommen in diesen Nachrichten mehrmals vor.

I 26 Frigo, »Small States«, I64. Vgl. ausführlicher Molino, Siebenbürgischen corriers.

I 27 Siehe hierzu die Beiträge in Noflatscher/Chisholm/Schnerb, Maximilian I. und Noflatscher, Stereotypen. 
gehalten, dass die kaiserliche Gewalt aus Reichsitalien fast ganz verdrängt worden und nur mehr schwach vertreten war, die italienischen Fürsten sich zunehmend verselbstständigt hatten, sodass der Kaiser Schwierigkeiten hatte, hier seine potestas imperialis durchzusetzen. ${ }^{128}$ Das Bild des Kaisers in Italien ähnelte demzufolge dem eines Plünderers, Kriegsführers und Steuereintreibers. Doch wenn auch Maximilian die säumig gepflegte kaiserliche Italienpolitik intensivierte, konnte er seine großen Pläne in und mit Italien nicht verwirklichen. ${ }^{129}$

Ein bedeutender Aspekt seiner Italienpolitik war seine dynastische Verbindung mit Bianca Maria Sforza, durch die er sich einen sicheren Stützpunkt auf der Halbinsel und das bedeutende Mailand, die »Pforte Italiens«, zu garantieren versuchte. ${ }^{130}$ Gerade im Zusammenhang mit dieser Heiratsverbindung kam es zu einer Stärkung der Beziehungen und Kontakte des Reiches zu Italien durch Gesandtschaften, durch mitgereistes oder angefordertes italienisches Hofpersonal, durch Gelehrte, Künstler etc. Das ergab sich aus der Tatsache, dass Maximilian in Italien ein Kulturzentrum ebenso wie auch »einen Geldschrein«, »sein Waffenarsenal« und »den Kornspeicher « ${ }^{131}$ sah. Mehr als sein Nachfolger Karl V. war er der italienischen Lebensart zugetan und konnte so gut Italienisch, dass er mit den Gesandten kommunizieren konnte. Allerdings trübten die Feindschaft mit Venedig, die Angst um die Kaiserkrone und seine utopische Idealvorstellung, Venedig, Pisa oder Florenz wie Reichsstädte behandeln zu können, ${ }^{132}$ sein Verhältnis zu Italien. ${ }^{133}$

Nach Wiesflecker wog das Interesse des Königs an Reichsitalien, dem »Herzland seines Römischen Kaisertums « ${ }^{134}$ noch mehr als die hohe Mitgift und die Belehnungstaxe von 400.000 Gulden, die Bianca Maria Sforza mitbrachte, vereinbart wurden. Dieses Interesse bewog Maximilian in der Folge auch zum Beitritt zur wenig tatkräftigen und mäßig erfolgreichen Heiligen Liga von Venedig im März i 495 zusammen mit Spanien, dem Papst und Mailand gegen Frankreich und zum weiteren Kampf um die südliche Peripherie des Heiligen Römischen Reiches, trotz der Forderung der Kur- und Reichsfürsten, nur das Allernotwendigste für Reichsitalien zu investieren und sich mehr auf die Abwehr der Türken zu konzentrieren. ${ }^{135}$ Die Wiederherstellung der kaiserlichen Macht, die stärkere Bindung Reichsitaliens an das Heilige Römische Reich war nach Wiesflecker die "politische Leitlinie seines Lebens, um die sein gan-

I 28 Vgl. besonders Wiesflecker, Kaiser Maximilian I. 2, Kap. I : „Wiederherstellung des Reiches? Maximilians Italienfeldzug I 496 ."

I29 Rainer, Maximilian I. und Italien, I34f, I39.

I3O Wiesflecker, Italien in der Kaiserpolitik Maximilian I., 272.

i3 I Wiesflecker, Kaiser Maximilian I., II., 67.

I32 Vgl. TanZini, Mai vi fu maggior fortuna in quello porto, 148 .

I33 NofLatsCher, "Italien«, 694.

I34 Wiesflecker, Italien in der Kaiserpolitik Maximilian I., 273.

I 35 Siehe auch Negri, Milano, Ferrara, ${ }_{2} 3 \mathrm{f}$. 
zes Planen, Rüsten und Kriegen sich drehte, bis zum enttäuschenden Abschluß der Italienkriege in den Jahren I 5 I 6/ I 8.« ${ }^{136}$

Während sich um die Jahrhundertwende Spanien und Frankreich Italien aufzuteilen begannen, wurde für Maximilian der Romzug als Lösung der Italienfrage immer dringlicher. Doch die Serenissima verweigerte ihm den bewaffneten Durchzug durch ihr Gebiet. Mit der Liga von Cambrai i 508 schlossen sich Kaiser, Papst, Frankreich, Spanien und England im Kampf gegen Venedig zusammen. ${ }^{137}$ Erst als sich Maximilian I 5 I 2 von der Liga von Cambrai löste, gelang es mithilfe der Schweizer die Franzosen aus Mailand zu vertreiben, sodass I 5 I 2 die Lage für den erwählten Kaiser in Reichsitalien wieder günstig aussah. ${ }^{138}$

Die Mailänder Heirat, die Finanzspritze durch die Mitgift und die hinausgezögerte Belehnung von Ludovico il Moro mit Mailand führten Maximilian an der Jahrhundertwende zum Höhepunkt seiner Macht und Bedeutung sowie seines Engagements für eine verstärkt wahrnehmbare Präsenz des Kaisers/Reichs in Italien. Diese drückte sich u.a. auch durch zahlreiche Gesandtschaften von und nach Italien aus, die ein wichtiges Bindeglied in den Beziehungen zwischen Maximilian und den italienischen Fürsten darstellten. ${ }^{139}$ Dabei blieben der Kaiser und sein Hof lange Zeit eher der empfangende als der aussendende Part, wenn auch etliche Italiener als Diplomaten in kaiserlichem Dienst standen, so u.a. Francesco da Collo und Antonio de Conti, die im Sommer I 5 I 8 als kaiserliche Gesandte zum moskowitischen Großfürsten geschickt wurden. ${ }^{140}$ Das von den Diplomaten - und darunter auch den estensischen Gesandten $^{141}$ - vermittelte Bild Kaiser Maximilians I. ist ein immer wiederkehrendes: Er galt als »Meister im Simulieren und Dissimulieren; er pflegte an ein und demselben Tag die verschiedensten politischen Absichten auszustreuen, um dadurch seine eigentlichen Pläne zu verhüllen. Daraus entstand dann der Gemeinplatz von einem Kaiser, der jede Stunde etwas anderes rede und nicht wisse, was er eigentlich wolle. ${ }^{142}$ Dies diente dem politischen Taktieren und Verhandeln.

Es fällt auch auf, dass italienische Gesandte das oft schlechte Latein der deutschen Kollegen und des Kaisers belächelten. Es wundert also nicht, dass auch jenseits der Alpen Italiener im Dienst des Kaisers standen, um das sprachliche Manko auszugleichen.

I 36 Wiesflecker, Italien in der Kaiserpolitik Maximilian I., 276.

I37 Zum kriegerischen Vorgehen Maximilians gegen Venedig und dem Höhepunkt seines Erfolges im Cadore siehe die Beiträge im Tagungsband: Bertoldi Lenoci, La presa del Castello di Botestagno und hier vor allem TADDEI, La politica italiana. 364 .

I38 Ebd., 278-28r.

I39 Negri, Milano, Ferrara, 424-439.

I 4 O Vgl. Bojcov, Maximilian, 5 of.

I4I Einige Aspekte der estensischen Gesandtschaften sind bereits hier untersucht worden: TADDEI, Der Römische König Maximilian.

I42 Wiesflecker, Kaiser Maximilian I. V, 490. Diese Wahrnehmung wurde auch von Maximilians Interesse für Geheimschriften und Verschlüsselungstechniken gefördert. Vgl. WALder, Der letzte Ritter. 
Reichsständische Diplomaten zeichneten sich oft durch Unbeholfenheit und mangelhaftes Verhandlungsgeschick aus, wobei hier natürlich die subjektive und interessensgeleitete Sichtweise der italienischen Vertreter nicht außer Acht gelassen werden darf. Unmut verursachte auch das Verhalten Maximilians gegenüber manchen Gesandten, die oft tagelang auf eine Audienz warten mussten, während andere vorgelassen, zum Mitreisen gezwungen oder vom Kaiser für eigene Botengänge »benutzt « wurden. ${ }^{143}$ In diesem Zusammenhang hat Lutter das Beispiel des venezianischen Gesandten Zaccharia Contarini vorgebracht, der sich beklagte, in I 7 Monaten am königlichen Hof nicht mehr als fünf Tage an einem Ort gewohnt zu haben. Wie die Venezianer beschwerten sich auch die estensischen Gesandten über die langen Wartezeiten für eine Antritts- oder Abschiedsaudienz bei Maximilian, der stattdessen - vor allem während seiner Aufenthalte am Innsbrucker Hof $-{ }^{144}$ zumeist mit Jagen beschäftigt war. Lutter hat zu Recht darauf hingewiesen, dass die langen Wartezeiten, die ungewöhnlichen Audienztermine beim Messbesuch oder auf der Jagd neben den Geschenken und Aufmerksamkeiten eine »bewusste Inszenierung königlicher Herrschaft« waren. ${ }^{145}$ Das Warten auf das Reichsoberhaupt begann bereits vor der vereinbarten Eheschließung mit Bianca Maria Sforza. Als die mailändische Braut in Innsbruck einzog, war die estensische Gesandtschaft mit dem Humanisten Pandolfo Collenuccio ${ }^{146}$ und Francesco Ariosti eine der ersten, die im Dezember 4993 eintraf. Man hoffte auf ein baldiges Erscheinen des Römischen Königs und harrte seiner im nahegelegenen Zirl. Doch Maximilian kam erst am 9. März I 494 und den estensischen Gesandten gingen zwischenzeitlich fast die Mittel für Unterkunft und Kost aus. Collenuccio nutzte die Zeit, um als scharfer Beobachter über Hofleben und Alltag zu berichten und schließlich auch über die Hochzeitsfeierlichkeiten, die der Gesandte als eher bescheiden, »assai tenue et legere ${ }^{147}$ wertete, so wie auch der Alltag »nur « aus Kartenspielen, sonntäglichen Bällen und Falkenjagden bestand. ${ }^{148}$ Der Gesandte verabsäumte es nicht, die Aufmachung der neuen Königin festzuhalten. Gewissenhaft berichtete er, dass diese beim

I43 Ebd., 493-497.

I44 Dass Maximilian mit Tirol und Innsbruck aber auch anderes verband hat zuletzt der Beitrag von Wiesflecker-Friedhuber, Kaiser Maximilian I. gezeigt.

I45 Lutter, Differenz- und Kongruenzerfahrungen, I 29- I3 I.

I 46 Pandolfo Collenuccio, Diplomat und Humanist (I 444-I504); neben seinen Gesandtschaftsberichten verfasste er postumus, erschienen ein Compendio de le istorie del Regno di Napoli (I 539), verschiedene lateinische und italienische Dichtungen und Dialoge sowie ein geografisches Werk über das Reich ( 546 ). Eduardo MELFI, »Collenuccio, Pandolfo«, in DBI 27 ( I 982 ), online verfügbar http://www.trec cani.it/enciclopedia/pandolfo-collenuccio_\%28Dizionario-Biografico\%29/, Zugriff: г6.9.2020.

I47 ASMo, ASE, Casa e Stato Carteggio di Ambasciatori, Germania b r, Collenuccio an Ercole I., März I 494 .

I 48 Lutter definiert die ständigen, oft durch Jagd bedingten Ortwechsel Maximilians einerseits als notwendige Selbstdarstellung und andererseits auch als Mittel, um Distanz zwischen sich und »den informationshungrigen Gesandten zu schaffen«. Lutter, Differenz- und Kongruenzerfahrungen, I 55, I6 I. $\mathrm{Zu}$ den Folgen des von Maximilian exzessiv praktizierten Jagdkultes siehe: Büchner, Schattenseiten. 
Essen eine Kopfbedeckung getragen habe, in der ihr Haar so gefasst war, dass sie wie ein Mann oder ein putto aussah. Dies täten die deutschen Frauen immer dann - präzisierte er - wenn sie besonders anmutig aussehen wollten (»tucte le todesche quando vogliono parere più legiadre«). Wie es scheint, hatte sich die Mailänderin in ihrer langen Wartezeit in Innsbruck der Mode des Landes bereits angepasst. Diese »modische Anpassung"war - wie oben bereits behandelt - nicht nur eine Frage des Geschmacks, sondern ein eindeutiges Zeichen der Akzeptanz und des Integrationswillens von in die Fremde verheirateten Fürstinnen.

Für den Herzog von Ferrara mögen auch noch die weiteren Beschreibungen des Gesandten interessant oder wenigstens amüsant gewesen sein: Die des gichtgeplagten Erzherzogs von Österreich, Sigismund, der so alt und gebrechlich war, dass er in einer Sänfte getragen werden musste, ${ }^{149}$ oder die des Herzogs Albert von Sachsen, von dem der Gesandte sehr angetan schien, sicher auch, weil er von den intensiven Beziehungen zwischen dem Haus d'Este und Sachsen wusste. Der Herzog von Sachsen sei - so Collenuccio - ein Mann von 55 Jahren, groß, wunderschön in Körper und Aussehen mit kurzen grauen Haaren, die er nach italienischer Mode trug (»con capilli corti e bigi a la italiana«), und mit einem Bart. Er werde als sehr weiser und mutiger Anführer geschätzt. ${ }^{150}$

Nach den Feierlichkeiten wurde Collenuccio vom König empfangen, vor dem er eine Meisterrede hielt, die von diesem und den übrigen Gesandten in ihren Berichten lobend erwähnt wurde. Daraufhin folgte Collenuccio dem König auf seiner Reise, da er noch eine wichtige Mission für den Herzog von Ferrara zu erledigen hatte: Ercole I. erbat den Herzogstitel und die kaiserliche Neubelehnung mit allen alten (Modena und Reggio) und noch nicht zurückeroberten Gebieten (Polesine di Rovigo), die er in der Belehnungsurkunde dezidiert aufgelistet haben wollte. Dabei setzte der EsteFürst auch die finanzielle Hilfe seines Schwiegersohnes, Ludovico il Moro, ein, um die größtmögliche territoriale Ausdehnung durch den Kaiser bestätigt zu bekommen. Allerdings war er nicht bereit, deswegen eine höhere Lehenstaxe zu bezahlen. Er ließ den Gesandten damit argumentieren, dass die Kontrolle, der Schutz und die Verbesserung seines Fürstentums so kostspielig seien, dass er es sich nicht leisten konnte, den einstigen Lehenszins von 4.000 Gulden, die Borso noch bereit gewesen war zu zahlen, dem König zu entrichten. Negri hat errechnet, dass die Einnahmen der Este bei ca. I 2.000 Gulden lagen. So gesehen und unter Berücksichtigung des jährlichen Lehenszinses von 4.108 Gulden für das päpstliche Lehen, blieb den estensischen Fürsten wirklich nicht viel. ${ }^{151}$ Das Argument, das Ercole seinen Gesandten gegen den hohen Zins vorbringen ließ - allerdings nur beim kaiserlichen Lehensherrn - war, dass Borso

\footnotetext{
I 49 ASMo, ASE, Casa e Stato, Carteggio di Ambasciatori, Germania b r, Collenuccio an Ercole I., März I 494.

I 50 Ebd., Collenuccio an Ercole I., März I 494.

I 5 I Zu den Quittungen des entrichteten Lehenszinses: ASMo, ASE, Casa e Stato, Serie generale, cass. $25-27$.
} 
aufgrund seiner illegitimen Geburt berechtigterweise zu einer hohen Lehenstaxe verpflichtet worden war. Doch Ercole I. sei aus der legitimen Linie der Este und sollte deshalb nicht gleichermaßen finanziell belastet werden. ${ }^{152}$ Diese feine Unterscheidung zwischen legitimen und illegitimen Nachfolgern hielt ihn allerdings nicht davon ab, die Belehnung auch für seine unehelichen Nachkommen zu erbitten. ${ }^{153}$ Besonders heikel war die Forderung nach der Belehnung jener Gebiete, die einst den Este gehört hatten, aber verloren gegangen waren, wie Rovigo und das Polesine, das trockene Stück Land zwischen den zwei Armen des Flusses Po. Diese Forderungen waren nämlich für Maximilian gewichtig und entscheidend auch für die zukünftige Politik mit Venedig. Darüber hinaus herrschte im Reichsrat ganz allgemein die Meinung, dass keine neuen Belehnungen gewährt werden sollten. Maximilians erster Hofkanzler, Konrad Stürtzel ( I 433 - I 509 $)^{154}$ plädierte für die Wiederbestätigung der Belehnungsurkunde, die einst für Borso ausgestellt worden war, ohne genaue Nennung der einzelnen Gebiete; damit sollte nicht mehr und nicht weniger gemeint sein, als das, was Ercole schon besaß. Collenuccio konnte den Kanzler in keiner Weise bewegen, diese Einstellung zu revidieren. Der Gesandte sprach daraufhin bei Maximilian vor und versuchte zu beweisen, dass Ercole nicht nur der rechtmäßige, sondern auch der allseits anerkannte Herrscher des estensischen Fürstentums sei, wie z.B. die Anreden in den Briefen bewiesen. Selbst einen Ausdruck überhöhter Eigenwahrnehmung verwendete der Gesandte als Argument für die gewünschte Belehnung: Diese werde Maximilian zu noch größerer Ehre gereichen, da er dann unter seinen Reichsfürsten eines der ältesten und angesehensten Geschlechter Italiens zählen könnte: "per vetustà e nobiltà de casa el primo signor de Italia e tra li principi imperiali d'Italia el secundo, e per dignità e potentia el tertio principe, con un bon stato, oportuno, gagliardo e da valersene.${ }^{155}$ Doch schließlich wurde die Investitur den Vorgaben von Kaiser und Rat entsprechend in der »bescheideneren«, Ercoles Wünschen nicht entsprechenden Variante beschlossen; die Ausstellung erfolgte aber erst im September I 509 unter Alfonso I. d'Este, nachdem man sich - unter Berücksichtigung des immer unwahrscheinlicher werdenden Italienzuges Maximilians - auf einen ebenso bescheideneren Lehenszins geeinigt hatte. Von den anfänglichen von Maximilian geforderten 220.00o Dukaten zahlte der Herzog von Ferrara, der zu Beginn selbst 50.000 angeboten hatte, schließlich nur 40.000 Dukaten. ${ }^{156}$

Doch nicht nur diese Belehnungsproblematik, sondern auch die mangelhafte Unterstützung der Este für den Römischen König und seinen Italienzug trübten die Lehensbeziehungen weiter. Als Maximilian I. I 496 seine Reise nach Italien antrat, zögerte Ercole I. gekonnt seine Entscheidung bezüglich der estensischen Unterstützung

\footnotetext{
I 52 Negri, Milano, Ferrara, 444f.

I53 ASMo, ASE, Carteggio di Ambasciatori, Germania, b I, Collenuccio an Ercole I, März I 494.

I 54 Wiesflecker, Kaiser Maximilian I. V, 228-230.

I 5 Negri, Milano, Ferrara, 447.

I 6 Voigt, Die Briefe des Antonio de'Costabilis, I I 2.
} 
für das Reichsoberhaupt hinaus und ließ schließlich dem Kaiser gerade einmal roo Reiter zukommen. ${ }^{157}$

Das in diese Lehensdivergenzen eingebettete Bild, das der Gesandte Collenuccio von Maximilian zeichnete, entsprach jenem der meisten Gesandtschaften. Wie die anderen Diplomaten, so hatte auch der Vertreter des Herzogs von Ferrara unter der Flatterhaftigkeit des Reichsoberhauptes zu leiden. Einige vereinbarte Audienzen, in denen der Gesandte die Forderungen seines Herrn erneut vorbringen sollte, fanden nicht statt, weil Maximilian die ausgemachten Besprechungen »vergessen« hatte. Enttäuschend war auch, dass in der Belehnung der Herzogstitel nicht fixiert und auch nicht das große goldene Siegel angebracht wurde, da das Reichsoberhaupt verschmitzt meinte, er habe es nicht bei sich. Collenuccio wollte aber nicht eher von Maximilians Seite weichen, bis alle Forderungen erfüllt waren. Während er dem Königspaar folgte, forderte er seinen Dienstherrn auf, ihm zur Beweisführung alle Briefe zukommen zu lassen, in denen Friedrich III. und Maximilian I. selbst Ercole als Herzog betitelt hatten. Collenuccio war zuversichtlich, da der König betont hatte, dass er nicht abgeneigt sei, den Forderungen stattzugeben, aber im Moment nicht die Reichsfürsten vor dem Kopf stoßen wolle. ${ }^{158}$ Außerdem wollte sich der König einiges für die Zeit aufbewahren, wenn er nach Italien ziehen würde: »[...] sia contento che reserviamo qualche altra cosa da fare quando veniremo in Italia e che sua Signoria habbia cagione di rivederci un'altra volta, quia quod differtur non affertur ${ }^{159}$ Doch der einsichtige Herzog von Ferrara rief seinen engagierten Gesandten nach Ferrara zurück in dem Bewusstsein, dass von dem vom Romzug besessenen König vorerst nichts mehr zu erwarten war. Dieser schickte indessen zur Vorbereitung seines Italienzuges seinen aus dem oberösterreichischen Adelsgeschlecht stammenden Vertrauten, Bernhard von Polheim, ${ }^{160}$ an die Höfe der italienischen Fürsten, um sie zur Unterstützung in Form von Truppen und Geld zu bewegen. Polheim wurde in Ferrara sehr ehrenvoll und herzlich empfangen und konnte dem König berichten, dass Ercole, trotz seines engen Kontakts zum französischen König, dem Reich ein treuer Untertan sei. ${ }^{161}$ Doch als

I 57 Ein halbes Jahrhundert später wird die estensische Unterstützung für den Kaiser (Karl V.) gegen den Schmalkaldischen Bund mit I 50 ferraresischen Reitern ebenso bescheiden ausfallen: „Il Duca di Ferrara ha mandato al presente uno suo in posta a Sua $M^{\text {tà }}$ per farli intendere ch'l manderà $\mathrm{I} 50$ cavalli per questa guerra, al governo di quali, se così è in piacere di Sua $M^{\text {tà }}$ deputerà uno fratello di sua excellentia, desiderando massime che sempre li sia qualche uno di soi al servitio di Sua $\mathrm{M}^{\text {tà }}$, et Cesare così si ha contentato.«TUr Ba, Venezianische Depeschen I, Alvise Mocenigo und Lorenzo Contarini an den Dogen, Regensburg, Juli I 546, Nr. I 85, 577-580. Am 22. August berichtet der venezianische Gesandte von der Ankunft von Don Alfonso und von Francesco d'Este. Ebd. Nr. 2 I I , 644-646.

I 58 Vgl. Negri, Milano, Ferrara, 462-466.

I59 Ebd., 465 .

I60 Einige Mitglieder dieses alten oberösterreichischen Adelsgeschlechts wechselten zum reformierten Glauben, blieben aber weiterhin im Hofdienst und dem Herrscherhaus treu. Vgl. Aspernig, Die Adelsfamilie Polheim.

I6I Ebd., 468. 
Maximilian I 496 nach Vigevano, eine Stadt $35 \mathrm{~km}$ südwestlich von Mailand in der heutigen Provinz Pavia, kam und die italienischen Fürsten zur Huldigung und zur Unterstützung im Kampf gegen Frankreich erwartete, schickte auch der Herzog von Ferrara wie Savoyen, Montferrat und Mantua nur seine Bevollmächtigten. ${ }^{162}$ Dass er nicht persönlich dem Ruf Maximilians folgte und nur seinen Gesandten, Antonio de'Costabilis, schickte, begründete der Herzog von Ferrara und Modena mit der »Ausrede«, dass sich der Römische König in der Nähe von Castelletto di Genova befand, einem Zankapfel zwischen Reich und Frankreich. Ercole, dem Castelletto, das Ludovico il Moro als Unterpfand seiner Vertragstreue hatte aushändigen müssen, zur interimistischen Verwaltung übertragen worden war, hatte als Fürst super partes seine Neutralität geschworen. ${ }^{163}$ Er befürchtete, dass der französische König sein Agieren als Meineid verstehen könnte, wenn er zu dem in Italien weilenden Reichsoberhaupt eilen würde. Als Fürst und Ehrenmann wollte er nicht den Anschein erwecken, einen geleisteten Schwur zu brechen. ${ }^{164}$ Dieses ausweichende und listige Verhalten soll Maximilian mit dem Spruch kommentiert haben: „Ora che vede che noi veniamo in Italia egli fa la gatta morta«. ${ }^{165}$

Die Causa Castelletto begleitete die weiteren Audienzen des estensischen Gesandten Collenuccio. Als dieser ins Reich zurückkehrte, versuchte er darzustellen, dass sich sein Herr nicht hätte anders verhalten können, da Maximilian nicht als Vertreter des Reiches, sondern als Anführer der Heiligen Liga mit seinen Forderungen an Ercole herangetreten sei. Als Maximilian das Verhalten des Este-Fürsten als Ungehorsam dem kaiserlichen Lehensherrn gegenüber definierte, erwiderte der Gesandte, dass ihn dies sehr verwundere, da sein Herr bereit wäre, sein Herz und Castelletto herzugeben, wenn der Kaiser, der Vertreter des Reiches, ihn darum gebeten hätte. Obwohl Ercole das Reichsoberhaupt augenscheinlich hinhalten wollte und die vorgebrachten Auslegungen seine typische lavierende Taktik widerspiegelten, so kann der Entrüstung über die Vermischung der Funktionen Maximilians durchaus etwas abgewonnen werden. Schließlich wurde diesem dezidiert vor Augen geführt, dass er noch immer nicht gekrönter Kaiser sei, und dass zwischen Liga und Reich sehr genau unterschieden werden musste, da die italienischen Fürsten keinen Machtmissbrauch dulden würden. ${ }^{166}$

I62 Siehe Wolff, Die Beziehungen, 30.

I63 Vgl. Wolff, Die Beziehungen, I $5-23$.

I64 Auch der Vorschlag Maximilians und seiner Berater, der designierte Kaiser könnte einen solchen Eid lösen, konnte Ercole nicht zum Umlenken bewegen, der hingegen anmerkte, dass die Gefolgschaftspflicht dort aufhöre, wo keine Ehre sei: »il servire non havesse honestade, et quando col pretexto de l'obedire se venisse contra a la fede et juramento nostro prestato in caso promisso et licito come havemo dicto«. Zit. n. Negri, Milano, Ferrara, 47of.

I65 Sinngemäß und in Anlehnung an die Fabel des Äsop über den Kater und die Mäuse: »Jetzt wo wir nach Italien kommen, stellt er sich tot.« Dispacci al Senato veneto di Francesco Foscari, zit. n. NEgRI, Milano, Ferrara, 469, Anm. I.

I66 Negri erläutert Ercoles undurchsichtiges und widersprüchliches Verhalten gegenüber Maximilian mit 
Dieser Vorfall zeigt darüber hinaus auch die Erwartungshaltung des Reichsoberhauptes gegenüber den italienischen Fürsten und Vasallen. Das persönliche Erscheinen war hierbei von großer Bedeutung für den in Italien nicht weiterkommenden Römischen König. Andersherum gesagt enttäuschte die Entsendung von Gesandten die Erwartungen Maximilians an die oberitalienischen Fürsten.

Wenn Maximilians Berater und Vertraute über die Sturheit und Verbissenheit ihres Herrn klagten, so beschwerten sich viele Gesandte mehr über seine Wankelmütigkeit und seine »Politik des Hinhaltens $« .{ }^{167}$ So auch der estensische Vertreter Collenuccio, als er in Sachen Investitur für seinen Fürsten wiederholt beim König vorsprechen musste, da dieser ständig vergaß, dass er versprochen hatte, sich um die Sache zu kümmern. ${ }^{168}$ Lazzarini meint dazu, dass dieses Verhalten verständlich sei, wenn man bedenkt, dass Maximilian als erster ein so facettenreiches "Amt « hatte: Herzog von Burgund, Erzherzog von Österreich, Römischer König/Kaiser über ein heterogenes Gebilde bestehend aus Reichsstädten, kirchlichen Territorien, Republiken, Lehensgebieten etc. und Verteidiger der Christenheit gegen die osmanische Gefahr. Dies ermöglichte ihm zwar auf viele verschiedene Ressourcen zurückzugreifen, aber andererseits musste er mit den verschiedenen Partnern und Kontrahenten dieser unterschiedlichen Funktionen interagieren. ${ }^{169}$ Außerdem ließ sich das Reichsoberhaupt weder von den eigenen Leuten noch von den Vertretern fremder Fürsten in die Karten schauen, verhielt sich stets bedeckt, antwortete und handelte oft widersprüchlich, schrieb Vieles eigenhändig ohne es zu delegieren, wie Collenuccio nach Hause berichtete: » [...] che mai se ha lassato intendere la sera quello ha voluto fare la matina. Me dicono questi soi etiam de li intimi, che non possono immaginare alcun suo concepto. Responde sempre ambiguo; scrive assai de sua mano; mai sta ociosa; se fida poco, dorme pochissimo; tuctavia sempre alegro ${ }^{170}$ Aus den Beschreibungen des Gesandten ergibt sich das Bild eines schwer durchschaubaren, unberechenbaren und sehr misstrauischen Mannes. ${ }^{171}$

dem Hinweis, dass er zusammen mit Ludovico il Moro Charles VIII. von Frankreich entgegenritt und ihn von ständigen Gesandten begleiten ließ, während er die estensischen Vertreter beim Römischen König immer wieder mit der Begründung zurückberief, dass diese ständige Repräsentanz stark ins Geld gehe. Negri, Milano, Ferrara, 467, $477 \mathrm{f}$.

I67 Gesandte wurden als Personen zwar vom launenhaften König unterschiedlich gut oder schlecht behandelt, doch hingen Ehrungen, Art des Empfanges und Behandlung vorrangig von der Macht und dem Ansehen der zu vertretenden Herrschaft ab. Vgl. Lut ter, Differenz- und Kongruenzerfahrungen, I 34. I68 "Sua Maestà begninamente me promise de farlo dolendosse che la matina havendome veduto in Chiesa se ne era recordato, ed havea deliberato in quella matina expedirme, che havea cum sé el consiglio et non sapeva in che modo gli era ussito de mente. Il dì seguente anchora gli parlai, e dixe de farlo quello die medesimo. Non lo fece; anzi indusò fino al mercuri seguente [...].« ASMo, ASE, Casa e Stato, Carteggio di Ambasciatori, Germania b I, Collenuccio an Ercole I., April I 494.

i69 LazZarini, News from Mantua, ir 6

I70 ASMo, ASE, Casa e Stato, Carteggio di Ambasciatori, Germania b I, Collenuccio an Ercole I., Januar I497.

I7 I Lutter hat am Beispiel der venezianischen Gesandtschaften ebenso festgestellt, dass Maximilian wich- 
Manche Unterredungen der estensischen Gesandten mit Maximilian gingen an der Politik ganz vorbei und hatten einen literarischen oder philosophischen Inhalt. Da es nach Meinung der Diplomaten in der spärlichen, ihnen vorbehaltenen Zeit Wichtigeres zu besprechen gab, wertete Collenuccio auch diese »Exkurse« als politisches Kalkül des Reichsoberhauptes, um Zeit zu gewinnen oder um sich nicht festlegen zu müssen. So kam er zu dem Schluss, der Römische König sei »un mago incantatore« $(» \text { Verzauberer })^{172}$

Mithilfe des in Ferrara weilenden kaiserlichen Beraters Polheim wurde auf Maximilian eingeredet, er solle kein Geld mehr in das sinnlose Italienunternehmen stecken und einen friedlichen Konsens mit Frankreich finden. Ercole bot sich deseinem Lehensherrn als Vermittler und Garant für den Frieden an, damit dieser stattdessen den Kampf gegen die Andersgläubigen führen und somit den christlichen Glauben retten könne. Dass mit diesem Angebot das Reichsoberhaupt von Italien und den estensischen Interessen ferngehalten werden sollte, ist mehr als eindeutig. Zunächst verkündete Maximilian, er wolle über diesen Vorschlag nachdenken. Doch der Gesandte drängte zur Eile und ermahnte den König, er möge dies selbst entscheiden und sich nicht von bösen Zungen und schlechten Beratern beeinflussen lassen. ${ }^{173}$ Pikiert lehnte Maximilian schließlich das estensische Mediationsangebot ab und versicherte dem Gesandten, dass er die Vermittlungen eines italienischen Fürsten nicht nötig hätte. ${ }^{174}$ Aber er bot Ercole als Ersatz eine andere ehrenvolle Aufgabe an, nämlich die des Schiedsrichters im Streit zwischen Florenz und Pisa. ${ }^{175}$ Doch kaum hatte er dies entschieden, zog er diesen Vorschlag auch schon wieder zurück. ${ }^{176}$ Collenuccio schloss daraus wieder einmal, dass dem Römischen König nicht zu trauen sei und dieser selbst nicht wisse, was er tue: "In breve de tucto questo discorso cavo questa conclusione: Che Sua Maestà Cesarea è ambigua et dubiosissima, nè scia che fare «. ${ }^{177}$

Nichtsdestotrotz fand Collenuccio auch lobende Worte für Maximilians Fleiß, Geduld, Entschlossenheit und seinen Arbeitswillen: „Sua Maestà ogni dì è in conseglio, in audientia, in fatiche, a modo usato che mai non han posa quelle orecchie. E lui de sua mano scrive assai e lettere e memoriali e mille sue altre cose. Homo veramente

tige Entscheidungen spontan und oft nur mit den engsten Beratern traf. Diese Sprunghaftigkeit und Unberechenbarkeit verlangten von den Gesandten nicht nur die bloße Präsenz und die Nähe zum Herrscher, sondern auch besonders freundschaftliche Kontakte, regelmäßige Beschenkungen und Austausch von Gefälligkeiten mit den herrschaftlichen Beratern und Vertrauten. LutTer, Differenz- und Kongruenzerfahrungen, I 54, I64.

I72 ASMo, ASE, Casa e Stato, Carteggio di Ambasciatori, Germania b i, Collenuccio an Ercole I., Januar I 497, zit. auch bei Negri, Milano, Ferrara, 478.

I73 ASMo, ASE, Casa e Stato, Carteggio di Ambasciatori, Germania b r, Collenuccio an Ercole I., Januar I 497 .

I74 Ebd., Collenuccio an Ercole I., Januar I 497.

I75 Ebd., Collenuccio an Ercole I., Februar I 497.

I $76 \mathrm{Ebd}$.

I77 Ebd. 
degnissimo de ogni bona fortuna qual però male con la bontà se accorda. « ${ }^{178}$ Wiederholt berichtete der Italiener nach Ferrara von der Besessenheit des Römischen Königs vom Italienzug und vom Kampf gegen die Türken. Des Weiteren sitze er jeden Tag mit seinen Beratern zusammen und versuche die Differenzen unter den einzelnen Fürsten mit bewundernswerter Geduld zu schlichten. ${ }^{179}$

Aus Maximilians I. Regierungszeit sind fünfzehn Briefe an Ercole I. d'Este (für den Zeitraum I 49I-1502) und drei an Alfonso I. d'Este (für die Jahre I 508-1 5 10) erhalten. Die Schreiben sind alle von Sekretären auf Lateinisch und mit dem Hinweis ad mandatum imperatoris verfasst. Darin sind die wiederholte Bitte um Unterstützung im Kampf gegen die Türken enthalten, Lehensangelegenheiten, Bedenken Maximilians wegen der Heiratsverbindung des Este-Sohnes mit Lucrezia Borgia, Aspekte der kaiserlichen Patronage, so z.B. die Empfehlung des Sohnes des Herzogs von Mecklenburg, den das Reichoberhaupt zur Ausbildung nach Ferrara weiterschickte, der lang beabsichtigte Romzug sowie schließlich das Treffen in Vigevano, bei dem der Kaiser alle oberitalienischen Fürsten anwesend haben wollte. Dem gegenüber stehen drei im Archivio di Stato di Modena erhaltene Briefentwürfe (minute di lettere) Ercoles I. an Maximilian zwischen I 502 und I 505, zwei auf Italienisch, einer auf Lateinisch, in denen um Instruktionen für die Italienreise des Kaisers gebeten wurde. Von Alfonso I. sind acht Briefe zwischen ${ }_{5} 09$ und I 5 I 8 erhalten (je die Hälfte auf Italienisch und Lateinisch), in denen es um Patronage für Italiener, um den Krieg mit dem Papst, den Durchzug spanischer Truppen in Italien und um die dringliche Bitte, seinen Bruder, der zum Kaiser geschickt wurde, anhören zu wollen. ${ }^{180}$ Tatsächlich ist auch eine Korrespondenz zwischen dem Bruder des Herzogs von Ferrara, dem späteren Kardinal Ippolito d'Este mit Kaiser Maximilian im Modeneser Staatsarchiv erhalten. ${ }^{181}$ Zwei italienische und drei lateinische Briefe der kaiserlichen Kanzlei aus den Jahren I 506 bis I 509 empfehlen Rechtsgelehrte und Sänger und tauschen militärische Informationen bezüglich Spionen aus, die sich angeblich in der Nähe von Ferrara aufhielten. ${ }^{182}$ Der in der Korrespondenz mit den Este immer wieder angeführte Romzug und die angestrebte Kaiserkrönung durch den Papst waren für Maximilian von größter Bedeutung. Dennoch überraschte und belustigte er bei einer Messfeier in Kempten I 494 die

I78 ASMo, ASE, Casa e Stato, Carteggio di Ambasciatori, Germania b i, Collenuccio an Ercole I., Januar I 497 .

I79 »Sua Maestà mai parla de altro, non desidera altro, nè ha piacere che li sia parlato de altro che de impresa contra Turchi.« ASMo, ASE, Casa e Stato, Carteggio di Ambasciatori, Germania b I, Collenuccio an Ercole I., März I 494.

I80 Siehe diese Korrespondenz in ASMo, ASE, Casa e Stato, Carteggio di principi esteri, Germania b I $575 / \mathrm{r}$.

I8 I Dies mag auch als Beleg dafür gelten, dass die taktische und militärische Führung in der Este-Familie auch beim Zweitgeborenen lag, der zeitgemäß eine geistliche Laufbahn hatte einschlagen müssen.

I82 ASMo, ASE, Casa e Stato, Carteggio di principi esteri, Germania b i 575/r. 
Anwesenden mit einer fast frevelhaften Auffassung über die Hierarchie der weltlichen und geistlichen Macht auf Erden. Als er vom päpstlichen Gesandten das Schwert umgehängt bekam, betonte der Nuntius, dass der Papst beide Schwerter der Macht besäße und eines, nämlich das der weltlichen Macht, dem Reichsoberhaupt zur Verteidigung der Kirche gegen die Ungläubigen übergebe. Darauf ließ das Reichsoberhaupt durch seine Berater präzisieren, dass die weltliche Macht des Kaisers nicht vom Papst, sondern nur von Gott abhängig sei. Als der Kanzler festhielt, dass der König das Schwert nicht nur gegen die Türken, also zur Verteidigung der katholischen Kirche, sondern auch zur Bekämpfung dieser einsetzen werde, wertete der estensische Gesandte belustigt diese Behauptung als Versprecher. Gemeint sei wohl die Bekämpfung der Feinde der Kirche gewesen, explizierte er in seinem Brief nach Ferrara. ${ }^{183}$ Trotz dieses - gewollten oder ungewollten - Versprechers war für Maximilian wie auch für Karl V. die Frage des Krönungsortes und der Zeremonie nicht unerheblich. In ihrer Auffassung galten Rom und der päpstliche Segen - so uneinig man sich mit dem Oberhaupt der Kirche auch war - als die letztgültige und unumstößliche Legitimierung ihrer Herrschaft. ${ }^{184}$

Um dieses ersehnte Ziel zu erreichen, musste Maximilian sowohl Stärke zeigen als auch auf seine Unversehrtheit achten. Doch Letzteres scheint ihm schwer gefallen zu sein, wenn in den Berichten an den Herzog von Ferrara der estensische Gesandte Collenuccio manche - seiner Ansicht nach - unbesonnenen und waghalsigen Züge des Reichsoberhauptes kritisierte, so bei den Karnevalsfeierlichkeiten, auf den Jagden oder bei einem Turnier mit dem Herzog von Sachsen, bei dem Maximilian schwer zu Boden fiel und - in den Augen des Italieners - leichtsinnig dann noch den ganzen Abend tanzte. Auch bei anderen Turnieren schlug er sich so heftig, dass er fast sein Leben riskierte: "gioco veramente non da re« (»wahrlich kein königliches Spiel«) merkte Collenuccio an. Ebenso rümpfte der Gesandte die Nase über die zahlreichen Vergnügungen wie Bälle, Turniere und Jagden, denen sich das Reichsoberhaupt hingab, anstatt wichtige politische Entscheidungen zu treffen, die dadurch verlangsamt wurden: "Anzi oltra li consigli ordinarij et audientie de Sua Maestà per le cose de questi

I 83 "Ne la sua oratione disse colui [il nuntio E.T.] che l'papa havea utrumque gladium e che in segno che la podestà imperiale dependeva dal papa el papa glie la mandava e che la dovesse exercitare contra i Turchi et esser protectore e fidele de Santa Chiesa. E1 Re (comme è suo costume in ogni cosa) odite le parole chiamò el suo Consiglio et havuto colloquio con epso fece respondere per el cancelliere grande, el quale expressamente dixe che l'gladio temporale era de l'imperatore e de Dio e che lo adopraria contra Turchi, pregando et exhortando però el papa a prestare el debito aiuto. E dixe queste parole (de le quali ce ne siamo risi molti di noi) che non solo l'adoperaria a defensione de la Chiesa ma etiam ad offensione. Credemo però che tal parole furono dicte da lui inadvertentemente o volesse sobiungere ad offensione de li inimici de la Chiesa. «ASMo, ASE, Casa e Stato, Carteggio di Ambasciatori, Germania b i, Collenuccio an Ercole I., April r 494.

I 84 Vgl. Kohler, Karl V., I95- I98. Gattinara hegte z.B. Zweifel daran, dass die Lutheraner eine in Bologna erfolgte Krönung für gültig erachten würden. Ebd., 207. 
stati, el resto del tempo se dispensa in giostre e danze, e ragionare de caccia. Et in ogni modo dal canto de qua li homeni se pigliano manco de pensieri che non famo noi in Italia e vassi ne le cose più lenti ${ }^{185}$ Über die zahlreichen Feiern und Trinkgelage, durch die Regierungsgeschäfte und politischen Entscheidungen angeblich liegen blieben, mokierten sich auch die spanischen Gesandten. ${ }^{186}$

Neben der Zierde der humanistischen Bildung, des Kunstverständnisses und der Gelehrtheit verliehen naturgemäß die Kleidung, der pompöse Auftritt und der Glanz des Hofes dem Reichsoberhaupt die notwendige und hart verfolgte Aura eines Herrschers von Gottes Gnaden. Auch der estensische Gesandte verabsäumte es nicht, seinem Dienstherrn regelmäßig über das Erscheinungsbild des Reichsoberhauptes, seine Kleidung und sein Auftreten zu berichten. Als Maximilian am Turnier teilnahm, berichtete Collenuccio nach Ferrara positiv überrascht über die gar nicht so »deutsche« Reitkunst desselben (»maneggiando quel suo cavallo con tanta gratia che non si porria dir più veramente e non miga da Todescho«) und seinen italienischen Haarschnitt (»con li capilli sparci, ma a l'italiana«). ${ }^{187}$

Wie es der Natur der Gesandtschaft entsprach, informierte Collenuccio seinen Herrn nicht nur über Verhandlungen und Gespräche mit dem König, sondern regelmäßig auch über die Umgebung und die Personen des Hofes, allen voran über die engsten Berater des Reichsoberhauptes und schließlich über das fremde Land, in dem er sich lange aufhalten musste. Dabei scheint Collenuccio anders als andere Gesandte einen weniger voreingenommenen Standpunkt eines kulturell höher Stehenden vertreten zu haben und wusste die Schönheiten der Alpenlandschaft, die Offenherzigkeit der Menschen und die oft noch verborgenen Schätze mancher Klosterbibliotheken zu schätzen. ${ }^{188}$ Auch wenn er in Tirol oft frieren musste, freute er sich 1497 über den Fund einer antiken ungarischen Chronik in der Innsbrucker Hofbibliothek, in der die Heirat von König Andreas II. von Ungarn mit einer Este-Fürstin im I3. Jahrhundert verzeichnet war. ${ }^{189}$ Auch bewunderte der estensische Gesandte die von ihm wahrgenommene authentische und aufrichtige Bewunderung, die das Volk seinem Herrscher entgegenzubringen schien und bediente den taciteischen Topos des zwar rohen aber

I 85 »Außer mit regulären Beratungen und Audienzen für die Reichsangelegenheiten verbringt Seine Majestät die übrige Zeit mit Turnieren und Bällen und im Gespräch über die Jagd. Auf jeden Fall machen sich die Menschen hier viel weniger Gedanken als wir das in Italien tun und sie gehen die Dinge hier viel langsamer an." ASMo, ASE, Casa e Stato, Carteggio di Ambasciatori, Germania b r, Collenuccio an Ercole I., Januar und Februar I 497. Über diese »Zeitverschwendung«, Karnevalstreiben oder auch Jagdausflügen, wodurch die Geschäftsführung Maximilians und seiner Nachfolger beeinträchtigt wurde, mokierten sich auch die Nuntien. Vgl. Braun, Imagines imperii, 6 12 2, 6 I 5 .

i86 Edelmayer, Söldner und Pensionäre, $54 \mathrm{f}$.

I8 7 Ebd., Collenuccio an Ercole I., Januar r497, zit. auch bei: Negri, Milano, Ferrara, 48 I.

I 88 ASMo, ASE, Casa e Stato, Carteggio di Ambasciatori, Germania b i, Collenuccio an Ercole I., April I494. Im ASMo gibt es auch ein Manuskript aus der Feder Collenuccios mit dem Titel Summa rerum germanicarum.

i89 Lazzarini, News from Mantua, i I3, Anm. 8. 
edelmütigen, treuen, seinem Herrscher zujubelnden Volkes. Vielleicht vermisste er diese hochstilisierte Untertanenliebe für seinen eigenen Fürsten, der diese Loyalität unter seinen Gefolgsleuten oft vergeblich suchte. Die Geschichte der Etablierung und Festigung der Herrschaft der Este war durchdrungen von Verrat in der eigenen Familie, Usurpationen und gewaltsamen Unterwerfungen von Volkserhebungen. ${ }^{190}$

Collenuccio berichtete von den Eigenheiten dieses Volkes, seinen Traditionen und Gebräuchen, die er bereitwillig übernahm. So gab er zu, in der Fastenzeit nicht gefastet zu haben, wie das alle nach deutscher Art und durch päpstlichen Dispens taten, die aufgrund des harten Berglebens und der unwirtlichen Witterung den Körper vor Abzehrung schützen mussten. ${ }^{191}$

In Summe fällt der estensische Gesandte ein relativ positives Urteil ${ }^{192}$ über das Land, in dem er sich aufhalten musste, um dem Reichsoberhaupt nahe zu sein. Anders verhielt es sich bei seinem Nachfolger, Antonio de'Costabilis, consiliarius secretus von Herzog Alfonso I. und später von Ercole II. d'Este und dessen Sekretär, der cancellarius Cesare Mauro, die in zwei relazioni kein gutes Haar an den Menschen und am Klima jenseits der Alpen ließen. ${ }^{193}$

Doch nicht nur die italienischen Gesandten »im Ausland « waren Opfer des harten Klimas jenseits der Alpen, das in der zweiten Hälfte des I6. Jahrhunderts jenseits aller Stereotypen, im Rahmen der sogenannten kleinen Eiszeit tatsächlich kühler geworden war, ${ }^{194}$ sondern auch die Menschen in Ferrara selbst. So beschreibt der toskanische Diplomat Orazio Della Rena das feuchte, ungesunde Klima in Ferrara und schreibt

I 90 Siehe u.a. den gewaltsam gerächten Ehebruch von Laura Malatesta genannt Parisina und ihrem Stiefsohn Ugo I 425, den Volksaufstand gegen Nicolò III. I395, den Aufstand der Familie Pio aus Carpi gegen Borso I 469. Rimondi, Estensi, 35, 47, 64.

I 9 I Vgl. Negri, Milano, Ferrara, 450-452.

I92 Die Klagen, die Collenuccio des Öfteren nach Ferrara schrieb, betrafen neben dem Klima und der Beengtheit der meist unzumutbaren Unterkünfte die Strapazen der ständigen Reisen in der Vor- oder Nachhut Maximilians. Der große Hofstaat und die zahlreichen königlichen Begleiter belegten stets die wenigen brauchbaren Unterkünfte in der Nähe des Herrscherpaares. Diese Beschwerden verband der Gesandte mit der ständigen Bitte um Geld, um seine von den hohen Lebenskosten und der Währungsdifferenz diktierten Geldnot zu lindern: "[...] per tucta questa Alemagna è carissimo vivere, et la comitiva grande che ne precede de die in die ne fa anche mazore carestia et qualche volta non si po' havere roba per dinari." ASMo, ASE, Casa e Stato, Carteggio di Ambasciatori, Germania b I, Collenuccio an Ercole I., Dezember 493 und Januar I 494.

I93 Vgl. Voigt, Die Briefe Antonio de'Costabilis, 8 I - I36. Der venezianische Gesandte Marino Giustinian ging sogar so weit, den Sacco di Roma von I 527 als Fortführung der spätantiken Barbareneinfälle der Deutschen zu bezeichnen. Diesem negativen Bild schloss sich auch der venezianische Gesandte Vincenzo Querini an. Vgl. Zucchi, Deutschland und die Deutschen, 253.

I94 Zur zweiten Hauptphase ( 570 - I630) dieses klimatischen Phänomens und vor allem den damit verbundenen Folgen siehe die Beiträge im Sammelband Behringer/Lehmann/Pfister, Kulturelle Konsequenzen und hier vor allem den beispielreichen Überblicksbeitrag von Wolfgang BeHRINGER, »Kleine Eiszeit« und Frühe Neuzeit, 4 I 5-508. 
diesem die zahlreichen Erkrankungen von fremden Fürstinnen zu, die gerne neben den übelriechenden stehenden Gewässern spazieren gingen. ${ }^{195}$

Am Beispiel von Sir Robert Wingfield, einem Berater und ersten am Kaiserhof residierenden englischen Diplomaten im Dienst von König Henry VIII., hat Chisholm die hier beschriebenen, ähnliche Wahrnehmungen des Gesandtenlebens am Hof von Maximilian aufgezeigt. ${ }^{196}$ Auch der englische Diplomat kämpfte nämlich um Gehör beim Kaiser und um eine Audienz. ${ }^{197}$ Weitere Parallelen zu den Berichten der italienischen und besonders der estensischen Gesandten sind die Klagen über die hohen Kosten für Verpflegung und Unterkunft im Reich (und gleichzeitig die unzureichende und unregelmäßige Besoldung durch den eigenen Dienstherrn), die Kälte und die unwirtliche Gegend der Tiroler Berge. Nicht nur, dass Wingfield sich aufgrund der Selbstfinanzierung seiner Gesandtschaften verschuldete, er nahm auch bei den Fuggern für Maximilian einen Kredit über 6.00o Gulden auf und hoffte dadurch, einen Vorteil für seinen König in den Niederlanden zu erreichen. ${ }^{198}$

Doch jenseits aller Kritik fand auch Wingfield bewundernde Worte für Wien und für den Kaiserhof, an dem sich - nach Maximilians Wunsch - Personen aller Nationen, selbst solche in türkischen Gewändern, wie der Engländer festhielt, einfanden. ${ }^{199}$ Dieses Verlangen Maximilians nach der Anwesenheit möglichst vieler Fürsten oder deren Vertreter war I 496 bereits in Vigevano aufgefallen und war Auslöser schlechter Stimmung zwischen dem Römischen König und den italienischen Fürsten gewesen. Es war nicht nur eine politisch motivierte Aufforderung, sondern ein kaiserlicher Habitus, wenn er an seinem Hof (wo auch immer er sich gerade aufhielt) stets die Gesandten aller bedeutenden Fürsten Europas inklusive der östlichsten/südöstlichsten Gebiete haben wollte. ${ }^{200}$

Trotz der Schwierigkeiten und Divergenzen zwischen Ercole I. d'Este und Maximilian I. wird klar, dass der Herzog von Modena und Reggio für das Reichsoberhaupt nicht bloß ein Vasall, sondern ein ernst zu nehmender Fürst in der Po-Ebene war, den er für seine Italienpolitik zu gewinnen und dem französischen Einfluss zu entreißen versuchte. Wie bedeutend Letzteres war, zeigt beispielhaft ein Passus in den Friedensverhandlungen zwischen dem Römischen und dem französischen König. Als es I 504 zum Friedensvertrag zwischen den beiden Kontrahenten kam, betraf ein Punkt darin die Este und andere italienische Fürsten, die sich dem "französischen Eindringling" genähert hatten und somit dem Reichsoberhaupt in den Rücken gefallen waren. Den sogenannten Verbündeten Frankreichs, namentlich den Herzögen von Savoyen und

I95 Della Rena, Relazione, 27, 53.

i 96 Chisholm, Robert Wingfield.

I 97 Снisнolm, Robert Wingfield, 74.

I98 Ebd., $76 f$.

199 Ebd., 78.

$200 \mathrm{Zu}$ Maximilians Verbindungen dahin siehe auch: Gröвlacher, König Maximilians I. 
von Ferrara, den Markgrafen von Montferrat und von Mantua, der Herrschaft von Florenz, den Kommunen von Siena und Lucca, dem Herrn von Carpi und Giovanni Gonzaga sollten ihre dezidierte Verletzung der Lehensplicht großzügig vergeben werden. ${ }^{201}$ Doch dies verbesserte nicht die Beziehungen zum Reichsoberhaupt: Fünfzig Jahre später sollte im Zuge der Fürstenverschwörung gegen den nächsten Kaiser, Karl V., eine ähnliche Generalamnestie für die aufmüpfigen Fürsten Reichsitaliens gewährt werden.

\subsubsection{Die Beziehungen zwischen den Este und Karl V. ${ }^{202}$}

Karl V. (I 500-I558) war seit I 5 I6 Regent in Aragonien und Kastilien, seit I 520 Römischer König und wurde I 530 in Bologna zum Kaiser gekrönt.

Sowohl in der zwar einseitigen, aber immer noch brauchbaren Arbeit von Salvatore Pugliese »Le prime strette dell'Austria in Italia«, in Aretins Untersuchungen zu Reichsitalien, ${ }^{203}$ als auch den jüngeren Spezialuntersuchungen ${ }^{204}$ herrscht die Meinung vor, dass die Ära Karls V. als Wendepunkt bzw. point of no return gewertet werden kann. ${ }^{205}$ Alle diese Arbeiten haben einhellig festgehalten, dass dieses Reichsoberhaupt eine starke Macht verkörpert hat und in Italien die kaiserliche Präsenz auf verschiedene Art und Weise merklich intensivieren konnte.

Manche Untersuchungen wie jene von Chabod, ${ }^{206}$ Fantoni, ${ }^{207}$ Rodríguez-Salgado oder Martínez Millán, ${ }^{208}$ die die Beziehungen Karls V.zu Italien mehr in den Vordergrund rücken, haben das tradierte Bild des tyrannischen und alles beherrschenden Kaisers revidiert bzw. divergiert, u.a. auch, indem sie den Fokus auf den Hof und auf andere (Macht)Persönlichkeiten neben dem Kaiser wie Kanzler Mercurino Arborio di Gattinara gelegt haben. Rodríguez-Salgado nennt Karl V. die einflussreichste und exponierteste Persönlichkeit der ersten Hälfte des I6. Jahrhunderts, die um I 550 den Höhepunkt ihrer Macht erreichte. In den zahlreichen Biografien verdichtet sich das

20I Wolff, Die Beziehungen, $76 f$.

202 Dazu siehe Kohler, Karl V.; Brandi, Karl V 2; Rassow/Schalk, Karl V. Neben der gängigen zumeist biografischen Literatur siehe auch: CANtù/Visceglia, L'Italia di Carlo V. Einen immer noch aktuellen und kritischen Überblick über die anlässlich des 500 . Geburtstages Kaiser Karls V. erschienene Literatur bietet der Bericht von Rевітsсн, Neue Literatur zu Kaiser Karl V.

203 Siehe besonders Aretin, Das Reich. Kap.»Reichsitalien in der Zeit der spanischen Vorherrschaft. Die Neuordnung Italiens unter Karl V und ihre Folgen«, Ior - I 27.

204 Z.B. Magna, I feudi imperiali rurali, 3, 43-70. Für Savoyen siehe: Zwierlein, Savoyen-Piemonts Verhältnis zum Reich. Siehe auch die Beiträge des Tagungsbandes Cremonini/Musso, I feudi imperiali.

205 Cremonini, Considerazioni, 259.

206 Chabod, Carlo V. Siehe auch Mattingly, Renaissance diplomacy.

207 Fantoni, Carlo V.

208 Vgl. Martínez Millán, Carlos V. Rodríguez-Salgado, Metamorfosi. 
Bild des geizigen und arroganten, die ritterlichen und martialischen Ideale verkörpernden, nach I 55 I oft auch melancholischen und gegenüber den Ratschlägen anderer wenig geneigten Herrschers über ein riesiges, heterogenes Reich und einen neu entstandenen bedeutenden Wirtschaftsraum. ${ }^{209}$ Die Heterogenität dieses bemerkenswerten Territoriums spiegelte sich auch im Hofstaat wider: Karl V. umgab sich mit vielen Ministern und Beratern, von denen die meisten Spanier oder Italiener waren und in geringerem Maß Deutsche und Niederländer. ${ }^{210}$ Er weitete die Gefolgschaftsplicht und die Verpflichtung zur Unterstützung bis zum Äußersten aus und machte aus jedem Krieg eine Verteidigungskampagne zum Schutz des Reiches, wodurch er große Ressourcen mobilisieren konnte, um gegen Frankreich, die Osmanen oder die protestierenden Reichsfürsten vorzugehen. Außerdem maß er die Loyalität und Treue seiner Untertanen und Lehensnehmer an der Höhe ihrer Kontributionen zur Finanzierung der Kriege. Er erwartete, dass die Fürsten dafür die Ressourcen ihrer Staaten bereitstellten, ohne den Unmut der Steuern zahlenden Bevölkerung zu fürchten - obwohl dem Kaiser diesbezügliche Klagen vorgebracht wurden. So wundert es nicht, dass es überall in seinem riesigen Reich und so auch in Reichsitalien aufgrund der Finanzlast immer wieder zu Unruhen kam. Auch aus diesem Grund war es besonders wichtig, dass der Kaiser Präsenz zeigte, um die Gemüter zu beruhigen. Für die Italiener bot seine Anwesenheit die Möglichkeit zu Erhebungen und Privilegienvergaben, die die Fürsten wieder friedlich stimmten. Außerdem erhöhte die Präsenz des Kaisers das Prestige und die Bedeutung der Territorien, sodass man bereit war, für die Ehre bringende Gastfreundschaft auch tief in die Tasche zu greifen. ${ }^{211}$

Cinzia Cremonini hat zu Recht darauf hingewiesen, dass es im Nachhinein, am Ende des i 7. und zu Beginn des i 8. Jahrhunderts, zu einer gewissen Idealisierung der Epoche Karls V. als der Zeit der innigsten Beziehungen zwischen Kaiser und italienischen Vasallen gekommen sei. ${ }^{212}$ Diese Idealisierung ist weit entfernt von der historischen Realität, wenn man bedenkt, dass der Aufenthalt des Kaisers in Italien zum Zeitpunkt seiner Krönung für die italienischen Reichslehen nicht periodisierend war. ${ }^{213}$ Das Bild des Kaisers war in Italien nicht nur mit dem Sieg bei Pavia über François I. I 525, sondern auch mit dem verheerenden Sacco di Roma negativ konnotiert. Seine Präsenz in Italien I 5 29/30 diente also nicht nur der Etablierung der Reichsidee (monarchia universalis) Gattinaras, sondern auch der Suche nach Konsens und Zustimmung unter den italienischen Fürsten, die man durch (Neu- oder Wieder)Belehnungen gerade der kleineren Reichslehensnehmer (die sogenannten feudi imperiali minori) aber auch durch verschiedene Treffen und Zusammenkünfte kaiserfreundlich stimmen

\footnotetext{
209 Wallerstein, Karl V., 367.

2 Io Vgl. Rodríguez-Salgado, Metamorfosi, I3-20.

2 I I Ebd., 3I-35.

2 I 2 Dazu siehe Verga, Dilatar l'Impero.

2i 3 Cremonini, Considerazioni, 265.
} 
wollte. $^{214}$ Im Zuge dieser Italienaufenthalte kam es zur Versöhnung mit Francesco Maria II. Sforza und seiner Bestätigung als Herzog von Mailand, zur Erhebung von Federico Gonzaga ${ }^{215}$ zum Herzog und zu den ausschlaggebenden Vorgesprächen für die Wiedereinsetzung der Este in den kaiserlichen und päpstlichen Lehen. ${ }^{216}$

Für ein Bild Karls V. als Herrscherpersönlichkeit in Italien sind wir wiederum auf Beschreibungen von Gesandten und ihre meist stereotypisierten Wahrnehmungen angewiesen. Vor allem die schreibfreudigen Venezianer hielten anfangs keine großen Stücke auf den noch jungen unscheinbaren König von Kastilien (»non è hom di far molto conto « $)^{217}$ und die antikaiserliche Propaganda ${ }^{218}$ arbeitete mit Begriffen wie »spanische Servitut«, »Tyrannei«, Heuchelei oder Machtgier. ${ }^{219}$

Zusätzliche Eindrücke der Wahrnehmung Karls V. in Italien bietet die Satire sowohl in literarischen als auch bildlichen Quellen, die u.a. Diane H. Bodart untersucht hat. ${ }^{220}$ Zum ersten Typus gehört das Pronostico satirico ${ }^{221}$ von I 534, in dem Pietro Aretino unverhohlen auch über Kaiser Karl V. herzog. Dabei sparte der bekannte Dichter inhaltlich weder den kaiserlichen Geiz »taciturna avarizia cesarea «, noch ein angebliches unziemliches (Liebes)Verhältnis Karls mit seiner Schwägerin, der Herzogin von Savoyen, noch den wenig glorreichen Türkenfeldzug aus.

Eigentlich blühte die Satire als Genre vor allem in den reformierten Ländern auf, bediente zumeist bildlich Konfessionsthemen und richtete sich oft gegen den Papst und die Mitglieder der römisch-katholischen Kirche, während der Kaiser nur eine zögernde Nebenrolle einnahm. Italien, das von der Reformation nur gestreift wurde, blieb von der Flut an kirchenpolitischen Satireschriften größtenteils verschont, wo hingegen die äußere Erscheinung des Kaisers, allem voran sein fliehendes Kinn auch

2 I 4 Vgl. ebd., 267-269. Siehe auch: Bоsвасн, Selbstauffassung.

2 I 5 Als Karl V. am 25. März I 530 mit Federico Gonzaga in Mantua einzog, gehörte Alfonso I. auch dem Ehrenzug von Rittern und Fürsten an. Cremonini, Considerazioni, 272f. Der Gonzaga wurde durch den Aufenthalt des Kaisers in Mantua nach der Krönung, bei dem jede Art von Aufmerksamkeit und Vergnügungen zur Erholung Karls organisiert wurden, nicht nur geehrt und in den Herzogstand erhoben, sondern politisch »konsekriert« (»una sorta di consacrazione politica«). Der Ausdruck davon zeigt sich in den Wappen und Bildprogrammen Mantuas, mit denen Federico Gonzaga vor allem Giulio Romano beauftragte und die den kaiserlichen Mythos, die Nähe und Verbundenheit zu Kaiser und Reich darstellen sollten. Vgl. Frigo, Guerra e diplomazia.

2 i 6 Cremonini, Considerazioni, 276. Vgl. auch Bonora, Aspettando l'imperatore.

2 I 7 Paolo Giustiniani zit. n. SAnudo, Diarii 24, 89.

2 I 8 Dass diese vor allem von Diplomaten in ihren Berichten und Reden vorangetriebene Propaganda nicht wirkungslos war und gerade im Fall der Serenissima politische Entscheidungen und Haltungen beeinflusste, hat Zucchi an verschiedenen Beispielen gezeigt: „Der Überlebenskampf der Republik Venedig zwischen Habsburg und Rom, Osmanischem Reich und Frankreich wurde nicht nur mit dem Schwert, sondern auch mit der Feder geführt.« Z UCCHI, Deutschland und die Deutschen, 26o.

2 I 9 Lutz, Karl V., 33.

220 Bodart, L'immagine di Carlo V.

22 I Luzio, Un pronostico satirico, 9,4, I3. 
in Reichsitalien literarisch der Lächerlichkeit preisgegeben wurde. ${ }^{222}$ Hatte man in Italien über Maximilians I. Erscheinung wenig zu kritisieren gehabt, so bot Karl V. schon äußerlich Anlass zur Berichterstattung. Der venezianische Gesandte Gaspare Contarini beschrieb ihn I 525 folgendermaßen:

[La Cesarea Maestà] è di statura mediocre non molto grande, né piccolo, bianco, di colore più presto pallido che rubicondo, del corpo ben proporzionato, bellissima gamba, buon braccio, il naso un poco aquilino, ma poco, gli occhi avari, l'aspetto grave, non però crudele, né severo, né in lui altra parte del corpo si può incolpare, ecetto il mento, anzi tutta la mascella inferiore, la quale è tanto larga e tanto lunga, che non pare naturale di quel corpo, ma pare posticcia, onde avviene che non può, chiudendo la bocca, congiungere i denti inferiori con li superiori, ma gli rimane spazio della grossezza d'un dente, onde nel parlare, massime nel finire della clausula, balbutisce qualche parola, la quale spesso non s'intende molto bene. ${ }^{223}$

Auch für den spitzzüngigen Aretino bot die auffallende Kinnpartie, die er mit den Wortschöpfungen »mascellata maestà oder »mascelle cattoliche« bedachte, wiederholt Anlass zur Belustigung. ${ }^{224}$

Bodart ist auf der Basis dieser literarischen Satiren, die die Wahrnehmung des Kaisers in Italien geprägt haben, der Frage nachgegangen, ob in der bildlichen Darstellung, die in Italien ebenso verbreitet war wie im Reich, dieses Lächerlich-Machen des Kaisers durch ein übermäßiges Prononcieren des Kinns übertragen wurde. Oder anders gesagt: Machte man sich mit den »hässlichsten« Porträts des Kaisers über ihn lustig oder standen sie »nur« der Wahrheit/Natur am nächsten? Neben den zahlreichen berühmten und weniger bekannten Porträts und Stichen des Kaisers gibt es auch die genaue Zeichnung der gut erhaltenen kaiserlichen Mumie vom Maler Martin Rico y Ortega von I 87 I, die schlussendlich wirklich die unglaubliche Vorstellung des Unterkiefers und somit die Vorrückung des Kinns aufgrund des Verlustes der Backenzähne des kaum 30-Jährigen bezeugen konnte. Diese auf Medaillen und Porträts vor allem in der flämischen Maltradition betonte körperliche Schwäche, ließ den Kaiser ein-

222 Ebd., i $16 f$.

223 "[Der Kaiser] ist von mittlerer Statur, weder sehr groß noch klein, weiß, eher blass als rot im Gesicht; körperlich gut proportioniert, mit wunderschönen Beinen, guten Armen, einer leichten Adlernase, die Augen sind schmal, die Erscheinung ist schwerfällig, aber weder grausam noch streng; man kann bei ihm keinen anderen Körperteil beanstanden als das Kinn, eigentlich den Unterkiefer, welcher so lang und breit ist, dass er unnatürlich erscheint, als gehöre er nicht zum Körper; er scheint verschoben, sodass er die oberen und unteren Zähne nicht zusammenführen kann, wenn er den Mund schließt; es bleibt hingegen eine Öffnung in der Größe eines Zahnes, sodass er beim Reden, und vor allem am Satzende, stottert und nuschelt«. Giovanni Comisso, Gli ambasciatori veneti ( $5_{5} 25$ - I 792 ). Relazioni di viaggio e di missione, Milano r 960 203f, zit. n. Bodart, L'immagine di Carlo V, i i 8.

224 Luzıo, Un pronostico satirico, 6, I 4, 26, 57, zit. n. Bodart, L'immagine di Carlo V, i r 9. Zu übersetzen mit »kieferbetonte Majestät, katholischer Kiefer«. 
fältig ja fast schwachsinnig erscheinen. Erst das Tragen eines Bartes und das Kürzen der Haare verbesserten Karls Erscheinungsbild am Vorabend seiner Kaiserkrönung in Italien. ${ }^{25}$ Maßgeblich beteiligt an dieser Kaschierung, die aber aus Gründen des Wiedererkennungswertes den körperlichen Defekt nicht ganz vertuschen sollte, war Tizian. Dem Meister der Renaissance-Porträtmalerei gelang eine Verbesserung des kaiserlichen Aussehens durch großformatige Bilder, Dreiviertel-Darstellungen, eine Porträtierung mit Vollbart und einer nur angedeuteten Öffnung des Mundes, die in Wirklichkeit prominent und immerwährend war. Bodart kommt zu dem Schluss, dass, da die (Porträt)Malerei vor allem in der italienischen Renaissance als eine zu edle Kunst verstanden wurde, als dass man sie für Spottdarstellungen heranziehen konnte, es sich bei den Porträts Kaiser Karls V. nicht um satirische, sondern weitgehend um "naturgetreue« Darstellungen handeln muss. ${ }^{226}$

Doch neben den Porträts des Kaisers selbst, zierten auch andere Bildprogramme vor allem nach der Kaiserkrönung in Bologna italienische Städte und Fürstenhöfe, die verschiedene interessante Aspekte der Imagepflege Karls V. und der Rezeption in Italien widerspiegeln. ${ }^{227}$

Karls Auffassung von einer monarchia universalis, von seinem Großkanzler Mercurino Gattinara konzipiert und verfestigt, sah eine auf die Universalherrschaft ausgerichtete (Italien)Politik vor, setzte Reichsitalien, il giardino dell'impero nach Dante, ${ }^{228}$ in den Mittelpunkt seiner Bestrebungen und Interessen und drängte gleichzeitig die territorialen Ansprüche und Ausdehnungswünsche des Papstes und Frankreichs zurück. Diese Ambitionen zeigte der Kaiser nicht zuletzt durch seine Präsenz zwischen I 529 und I $543^{229}$ auf der italienischen Halbinsel und, wie Ullrich eindrücklich zeigen konnte, ebenso massiv durch die in diesem Zusammenhang entstandenen ikonografischen Programme.

Das gängigste Bild Karls V. war nach dem Sacco di Roma jenes eines Barbaren, aber auch eines miles christianus, eines neuen römischen Imperators sowie nach der Krönung in Bologna eines dem Papst untergeordneten, dessen Fuß küssenden Herrschers. Auch die von Karls Präsenz in Italien wenig erfreuten Päpste drückten ihren Unmut in Bildprogrammen aus, so z.B. Papst Paul III., der in der Sala dei Cento Giorni im Palazzo della Cancelleria, im Salotto von Palazzo Farnese oder in der Sala dei Fasti Far-

225 Bodart, L'immagine di Carlo V, i I9- I $26 f$.

226 Ebd., I30-I32.

227 Dazu siehe: Ullrich, Der Kaiser; Strong, Feste, vor allem das Kapitel: „Das Reich in der Bildsymbolik. Karl V. und die kaiserlichen Reisen«, I36- I73. Hinweise auch in der Biografie von KohLER, Karl V., besonders Kap.: »Hofkultur und Selbstdarstellung Karls V.«, Iо3 - I I r. Burke, Präsentation, besonders das Unterkapitel »Imagepflege«, 394-396.

228 Allighieri, Divina Comedia, Purgatorio VI, I05.

229 Er kam nachgewiesen sechs Mal nach Italien. Außerdem intensivierte er die diplomatische Vertretung nach und aus Italien durch Gesandte italienischer Abstammung. Vgl. Осно Brun, Die Diplomatie Karls, I 85 f. 
nesiani die neudefinierten Ansprüche des Kaisers auf Italien Lügen strafte und ihn als einen dem Kirchenoberhaupt untergeordneten, im Dienst von Religion und Kirche stehenden Herrscher darstellen ließ. ${ }^{230}$

Nichtsdestoweniger spielte die Kaiserkrönung Karls V. in Bologna I 530 für Italien eine große Rolle, beendete vorläufig die Machtkämpfe in und außerhalb Italiens zwischen Frankreich und dem Reich und etablierte die Habsburger auf der Apenninenhalbinsel auch durch die Symbolhaftigkeit der ersten (und gleichzeitig letzten) Krönung durch den Papst seit I 452. Die Bedeutung der kaiserlichen Präsenz von Ende Oktober I 529 bis Anfang April I 530 und vor allem während des Krönungsaktes und der dazugehörenden Feierlichkeiten wurde in zahlreichen Bildprogrammen von teilnehmenden Adelsfamilien in Rom, Florenz, Vicenza, Pesaro und Verona festgehalten. ${ }^{231}$ Auch für die Medici wie für andere reichstreue Lehensnehmer wurde die Bologneser Kaiserkrönung zum »zentralen Topos der familiären Bildpropaganda «. ${ }^{232}$

Für Karl, der sich als Verteidiger des Glaubens und der Christenheit verstand, war die Anerkennung seiner Funktion durch Kirche und Papst und der Segen für sein Amt von großer Aussagekraft. Für ihn lag die Bedeutung des Aktes zudem in der Tatsache, dass er gemäß der Goldenen Bulle nur als vom Papst gekrönter Kaiser seinen Nachfolger von den Kurfürsten zum Römischen König wählen lassen konnte. ${ }^{233}$ Außerdem diente die Zusammenkunft mit dem Papst in Bologna der Ratifizierung der Vereinbarungen des Friedens von Barcelona. Dazu war es durch eine Annäherung von Papst Clemens VII. an den Kaiser aufgrund der Einnahme von Kirchenbesitz (Ravenna und Cervia) durch Venedig und der Aufstände in Florenz gekommen. Im Friedensvertrag wurden dem Papst Cervia, Ravenna, Modena, Reggio und Rubiera zugesichert. Karl V. wurde mit Neapel neu investiert und es wurde besprochen, dass die englische Ehescheidungsangelegenheit König Heinrichs VIII. nicht zu Ungunsten von Karls Tante Katharina von Aragón entschieden werden sollte. ${ }^{234}$ Schließlich kam es auch zur offiziellen Wiedereinsetzung der im Zuge des Sacco di Roma in Florenz vertriebenen Medici durch den Kaiser. Hier wurde Karl nach dem Sieg von Tunis im April I 536 im Rahmen seines Italienzuges prächtig empfangen, wofür die Medici im Jahr darauf mit dem Herzogstitel belohnt wurden. Die Bologneser Krönung galt somit als folgenschwerer Auftakt zur Intensivierung der Beziehungen Italiens zum Kaiser und wurde deshalb vielseitig ikonografisch verarbeitet (Palazzo Vecchio, Sala Grande, Udienza, Grabmal Clemens' VII. in Rom in Santa Maria sopra Minerva etc.). Diese Bemühungen um die kaiserliche Gunst hielt sich noch bis kurz nach Karls Tod und dann, spätestens mit der Hochzeit von Francesco de'Medici mit Erzherzogin Johanna

\footnotetext{
230 Vgl. Ullrich, Der Kaiser, 29-3 I.

23 I Vgl. Visceglia, »Farsi imperiale«. Zum Ausdruck der Reichszugehörigkeit von Adelsfamilien aus dem venezianischen Raum beim Italienzug Karls V. I 532 siehe: SAvıo, Nobili vicentini.

232 UllRich, Der Kaiser, I4I.

233 Ebd., I43.

234 Kohler, Karl V., I98f.
} 
I 565, waren die Florentiner Machthaber in den Dunstkreis der Großen aufgestiegen und benötigten ihren einstigen Förderer nicht mehr im gleichen Ausmaß, schon gar nicht nach der päpstlichen Erhebung zu Großherzögen und nach der Beendigung des Präzedenzstreites mit den Este zu ihren Gunsten. ${ }^{235}$

Auch für Francesco Maria I. della Rovere brachten die Präsenz des Kaisers in Italien und die Kaiserkrönung in Bologna eine Wende in seinem den Este ähnlichen Schicksal: Zunächst von Papst Julius II. als Herzog von Urbino und Herr über Pesaro bestätigt, war er dann von Leo X. aufgrund verschiedener Auseinandersetzungen I 5 I 6 seiner Ämter, Privilegien und seiner herzoglichen Macht enthoben worden. Auch ihn traf der Kirchenbann. Erst I 523 erlangte er unter Hadrian VI. seinen Besitz wieder und wurde in der Folge Generalkapitän von Florenz und Venedig. Papst Clemens VII. wollte aber seine Ansprüche im Kirchenstaat nicht anerkennen. Erst anlässlich der Kaiserkrönung konnte der Papst zur Anerkennung Francesco Marias bewogen werden. Der Hintergedanke des Kaisers und Venedigs war dabei die Schwächung des Kirchenstaates auf territorialer Ebene. Francesco Maria della Rovere wurde in Bologna wieder zum Stadtpräfekten Roms ernannt und spielte in der Krönungszeremonie als Träger des Reichsschwerts neben Bonifacio di Monferrato, der das Zepter trug, Pfalzgraf Philipp von Bayern mit dem Reichsapfel und Carlo di Savoia mit der Kaiserkrone $^{236}$ eine bedeutende Rolle. ${ }^{237}$ Karl V. erweiterte della Roveres Fürstentum um Maiuolo und San Leo. ${ }^{238}$ Was dem Este in Bologna noch nicht vergönnt war, nämlich »seine Position zwischen Papst und Kaiser« und »seine gesellschaftliche wie politische Rehabilitierung « ${ }^{239}$ hatte der Herzog von Urbino bereits erreicht. So wundert es nicht, dass Francesco Maria I. della Rovere das für ihn zentrale Ereignis der Kaiserkrönung und seine aktive Teilnahme daran in den an Allegorien reichen Fresken seiner Villa Imperiale in Pesaro verewigte, in denen auch das Thema des Verlustes des Fürstentums und der Wiedererlangung aufgrund der Tugendhaftigkeit seines Besitzers verarbeitet wurde. $^{240}$

Sogar die nur mehr theoretisch zum Reich gehörende aber de facto unabhängige Seerepublik Venedig wusste im Rahmen des »mito di Venezia« die Figur Karls V. ikonografisch zu nutzen. Im r 6. Jahrhundert erreichte der Mythos Venedigs ${ }^{241}$ als freie

235 Ebd., I $46 f$, $165 f$.

${ }_{23} 6$ Zum Ereignis und Symbol der Kaiserkrönung siehe: Gentile, Dipendenza e legittimazione, 88; Bernardi, Analisi; Righi, Carlo V a Bologna.

237 Von den Reichsfürsten war nur Pfalzgraf Philipp als Träger des Reichsapfels anwesend. Kohler, Karl V., 208.

238 UllRich, Der Kaiser, I 85 f.

239 Ebd, r 86. Dennoch ist Signorotto zuzustimmen, wenn er die Position der Montefeltro aufgrund ihres bescheidenen Herrschaftsgebietes und der Nähe zu Rom als angreifbarer und gefährdeter einschätzt als jene der Este. Signorot to, Note sulla politica, 50.

240 Vgl. Ullerich, Der Kaiser, i 88 - I90.

24I Dazu weiterführend: Lionello Puppi, Nel mito di Venezia. Autocoscienza urbana e costruzione delle 
territoriale Einheit mit der besten und stabilsten Regierungsform ihren Höhepunkt, die für Ordnung, Sicherheit und Wohlergehen für den Einzelnen sorgte. Nichtsdestotrotz war das Verhältnis zu den Kaisern des r6. Jahrhunderts und ihren Expansionsund Unterwerfungszielen problematisch. Gerade in der Regierungszeit Karls V. entwickelte sich ein Misstrauen gegenüber dem Reich und den Habsburgern, das sie an die erste Stelle der Liste der Feinde der Serenissima noch vor den Osmanen setzte: »Nemici più infesti che i turchi«! ${ }^{242}$ Diese feindselige Haltung ist insofern verständlich, als dass die Seerepublik nach dem Frieden von Madrid Cervia und Ravenna dem Papst und Monopoli, Bari und Trani dem Kaiser zurückgeben musste. ${ }^{243}$

Ein anderer Wind wehte hingegen in den Gebieten der Terraferma, nominell Teil des Reiches, wo die kaiserliche Autorität als oberste Lehensmacht und Kontrapunkt zur venezianischen Macht weiterhin bestand. Der Adel in den im Zuge des I 5. und I6. Jahrhunderts hinzugekommenen Städten Verona und Vicenza war und blieb größtenteils prokaiserlich und hatte schon Maximilian I. in seiner Italienpolitik unterstützt. Auch nach der Einnahme bzw. Übernahme durch Venedig blieben die kommunalen Statuten und Privilegien, eine gewisse Autonomie und die ghibellinischen Tendenzen dieser Städte bzw. ihres Patriziats erhalten. Diese zunächst von Venedig tolerierten kaiserlichen Sympathiebekundungen äußerten sich auch in ikonografischen Programmen, bei denen wiederum die Kaiserkrönung ein zentrales Thema, um nicht zu sagen einen Topos bildete. Auf seiner Italienreise I 532 hielt sich Karl V. in Vicenza und Verona auf und wurde mit Empfängen und Festlichkeiten geehrt, für die kaiserliche Insignien, Kaiserstatuen und Bilder/Fresken in Auftrag gegeben wurden. Weitere Zeichen entstanden nach seinem Besuch und verarbeiteten die im Zuge seines Aufenthalts erfolgten kaiserlichen Handlungen wie Erhebungen, Ritterschlag und Titelverleihungen für die führenden kaisertreuen Familien wie die Da Porto, Sesso, Chiericati, Thiene, Trissino, Valmarana, deren Mitglieder auch im kaiserlichen Heer und am Hof tätig waren. Verständlicherweise war die Verarbeitung dieser Begegnungen (bei der Kaiserkrönung I 530 und beim Italienzug I 532) nicht allein der Kaisertreue, sondern auch dem Vorteil der einzelnen Familien, ihrer Selbstbehauptung gegenüber Venedig und ihrer Selbstdarstellung geschuldet.

Einem dieser kaisertreuen Adeligen aus Vicenza verhalf der im Gefolge von Francesco d'Este im Schmalkaldischen Krieg anwesende estensische Gesandte, Jurist und Poet Girolamo Falletti, zu seinem in der Folge auch ikonografisch verwerteten Ruhm. In seiner Darstellung der Ereignisse während des Schmalkaldischen Krieges korrigierte Falletti das Gerücht, spanische Soldaten hätten Kurfürst Johann Friedrich von

immagini. Saggi di lettura, Venezia 1994; Peter Schreiner (Hg.), Il mito di Venezia. Una città tra realtà e rappresentazione (= Venetiana. Centro Tedesco di Studi Veneziani 5), Roma/Venezia 2006.

242 Ullrich, Der Kaiser, I92, Anm. 6.

243 Ebd., I94, I97. Nichtsdestotrotz hat Ullrich in Venedig literarische Arbeiten von venezianischen Adeligen und Gesandten, wie Gasparo Contarini, zu Karl V. aus der Mitte des r6. Jahrhunderts gefunden, die diesen Kaiser als Verteidiger der Kirche gegen die türkische Gefahr lobten. 
Sachsen gefangen genommen und dem Kaiser vorgeführt. Nicht diese, sondern einer jener kaisertreuen und I 532 von Karl V. besonders bedachten Vicentiner Adeligen, nämlich Ippolito Da Porto, der schon länger im militärischen Dienst des Kaisers stand, soll die wertvolle Geisel vorgeführt haben. Unbeachtet der tatsächlichen Rolle des Vicentiners bei diesem bedeutenden Ereignis wurde seine Rolle in der Schlacht bei Mühlberg in einem Freskenzyklus in der Villa Da Porto verewigt. ${ }^{244}$ "Karls Präsenz in Malerei und Stuck ist in erster Linie die Bild gewordene Erinnerung an diese konkreten historischen Augenblicke ${ }^{245}$ hat Ullrich zu Recht festgehalten; dabei wird die Bedeutung dieser vielfältigen plastischen Darstellung der Beziehungen zu Kaiser und Reich zum Zwecke der Behauptung im Konkurrenzkampf gegen andere Familien und gegen Venedig und der nachhaltigen, über mehrere Generationen hinweg reichenden Ehrung der gesamten Familie Da Porto betont. Bei aller Verehrung für das Reichsoberhaupt und dem Bedürfnis, ihre Beziehungen zum Reich auszudrücken, hegten die einzelnen Familien der Terraferma aber kaum den Wunsch Dantes nach einem starken Kaiser, der nach Italien kommen sollte. »Wie generell für die Terraferma festgestellt, ist auch im Falle Vicenzas die Rezeption des Habsburgers aber weniger als der zum Ausdruck gebrachte Wunsch nach einer tatsächlichen Veränderung der aktuellen politischen Verhältnisse, d.h. als Forderung nach einer Ablösung der venezianischen durch eine kaiserliche Oberherrschaft zu sehen. Sie erscheint eher als `Kompensationsventik für den Verlust einstiger Machtpositionen. ${ }^{246}$

Im April r 536 zog Karl V. nach seinem Siegeszug von Tunis nach Rom und es kam wieder zu einer Demonstration kaiserlicher Macht auf der einen und päpstlich-römischen Misstrauens und antikaiserlicher Haltung auf der anderen Seite, bei gleichzeitiger Notwendigkeit, den Verteidiger des Glaubens und Sieger über die Ungläubigen gebührend empfangen zu müssen. So thronte im Rahmen der Einzugsikonografie ${ }^{247}$ als Zeichen der kaiserlichen Unterordnung und des unumstößlichen Vorrangs des Papstes die Statue der Roma über jener des Habsburgers. ${ }^{248}$ Dennoch gab es während des Romaufenthalts Karls V. auch Kontakt zu kaisertreuen Parteien ${ }^{249}$ wie den Colonna oder Caffarelli, welche die Begegnung mit dem Reichsoberhaupt ebenso, wenn auch in bescheidenerem Maß als in den norditalienischen Reichsgebieten ikonografisch verarbeiteten. ${ }^{250}$

\footnotetext{
244 UllRich, Der Kaiser, 208-2 IO.

245 Ebd., 2 I 3.

246 Ebd., 2 r 6.

247 Vgl. dazu auch Philipp, Ehrenpforten für Kaiser Karl V., zu Italien vor allem Kap. 8.3.

248 Ullaich, Der Kaiser, 4 I.

249 Wie Heinz Noflatscher für die Gruppierungen am Hof von Rudolf II. festgestellt hat, war »Partei« ein relativ neutraler Begriff, während »Fraktion« eher negativ konnotiert eine konkurrierende Clique meinte. Vgl. Noflatscher, Regiment aus der Kammer?, 2 I of.

250 Ullrich, Der Kaiser, 98. Zum Kunstgeschmack Karls V. bzw. zu Kunst und Dichtung, die er in
} 
Diese sich nach der Kaiserkrönung intensivierenden Ausdrücke der Kaisertreue führt Elena Bonora auch auf das Präferieren eines kaiserlichen Italiens (»l'Italia dell'imperatore») vor einem Italien des Papstes (»l'Italia del papa«) zurück, der auf der Halbinsel mehr als Wolf als als Hirte wahrgenommen wurde. Zu diesem »Italien des Kaisers« gehörten die Fürsten von Mantua und Ferrara und hierbei auch die Kirchenfürsten wie Kardinal Ercole Gonzaga. Zusammen mit seinem Namensvetter, Ercole II. d'Este, versuchte er beim Tod von Papst Paul III. die Wahl auf Kardinal Giovanni Salviati, Bischof von Ferrara, zu lenken, scheiterte jedoch am kaiserlichen Veto. Damit zeigt Bonora, dass es einerseits eine eigenständige kaiserliche "Partei« in Reichsitalien gab, aber andererseits auch, dass die Macht und der Wille des Kaisers selbst an der Peripherie des Reiches nicht zu unterschätzen waren. ${ }^{251}$

Die Beziehungen zwischen Karl V. und Italien waren - wie gezeigt - intensiv. Seine zahlreichen Reisen auf der und durch die Apenninenhalbinsel haben zum Teil bis heute noch sichtbare Spuren hinterlassen und seine Krönung in Bologna sowie die darauffolgenden Amtshandlungen haben viele Vasallen wieder näher an das Reich gebracht; darunter sind sicher auch die Este zu zählen. Durch die Teilnahme an diesem Ereignis und durch die kaiserlichen Aufenthalte an deren Höfen wurden die italienischen Fürsten aufgewertet. Mit der Vergabe von Privilegien, Lehen und Titeln ehrte der Kaiser nicht nur seine Lehensmänner, von denen viele in den kaiserlichen Dienst im Heer oder am Hof eingetreten waren, sondern er band sie stärker an die kaiserliche Macht als Legitimation und Recht bringende Instanz in Reichsitalien. Doch auch der Kaiser nahm von Italien einiges mit: Hofleute und Kriegsmänner, Finanzierungen, aber auch Kulturgüter und den wiederbelebten kaiserlichen Mythos, den die italienischen Künstler in der klassizistischen Ausdrucksform der Zeit auf den Höhepunkt brachten. ${ }^{252}$

Dank italienischer Künstler, die sich mit dem Bild des Kaisers im Zuge der Kaiserkrönung oder bei seinen triumphalen Einzügen auseinandersetzen und ihn dabei in klassizistischer Manier in die Reihe der römischen Imperatoren aufnahmen, ${ }^{253}$ erwachte der Mythos des Kaisers im Sinne einer renovatio imperii in ganz Europa und dauerte auch über Karls Tod hinaus. Reiterstatuen, Darstellungen Karls als Kriegsherr, Caesar, Herkules, Mars oder Jupiter evozierten den antiken Herrschermythos. Der Hang zur romanitas in diesen symbolischen Programmen zeigt sich nach Fantoni auch in der Titelführung Karls als Rex Romanorum (schließlich wurde er auch mit der Eisernen Krone gekrönt), in der Wahl seines Mottos Plus ultra und der Darstellung der Säulen des Herkules sowie in der Verwandlung, die seine Krönungsstadt Bologna erfuhr, als sie zu einem Rom des Nordens wurde. ${ }^{254}$

Renaissanceitalien kennenlernte und zur politischen Propaganda nutzte, siehe auch: Trevor-Roper, Princes and artists, I I -43 .

25 I Bonora, Aspettando l'imperatore, 5-7 und zur Papstwahl 265-27 I.

252 Vgl. Fantoni, Introduzione. Siehe auch Polleross, Romanitas, 207-2 I I.

253 Vgl. Kloosterhuis, Erben der Caesaren.

254 Fantoni, Carlo V, IO2-IO4. 
Karl V. und sein Inszenierungsapparat waren in Italien auf verschiedenen Ebenen erfolgreich gewesen und hatten die Etablierung des spanischen Machtsystems in Reichsitalien gefördert. ${ }^{255}$ Für die Staaten und Territorien der Po-Ebene spricht Frigo von dieser Zeit als von einem »Scharnier «. ${ }^{256}$ Es ist eine markante Übergangphase, die von der Kaiserkrönung und nach I 530 von einer Reihe von »negozi«, intensiven diplomatischen Tätigkeiten, triumphalen Einzügen und Aufenthalten, Heiratsverbindungen, Besuchen, Austausch von Geschenken, Informationen über Truppenbewegungen etc., charakterisiert war. Diese Highlights waren Merkmale eines neu erblühten, intensiveren Kontakts zwischen Kaiser und Reichsitalien. Frigo spricht nach 530 von einem regelrechten kaiserlichen System (sistema imperiale) in Italien und vom Bedürfnis der kleineren und größeren norditalienischen territorialen Einheiten, sich als Verbündete des Kaisers zu präsentieren, nicht zuletzt, um beim Wettlauf um Titel und Vorrang vorne dabei zu sein. Eine besondere Ehre war es, im militärischen Dienst des Kaisers zu stehen und dadurch neben den militärischen Verdiensten auch die Aufnahme in den Orden vom Goldenen Vlies ${ }^{257}$ zu erwerben. Von den italienischen Fürsten des Cinquecento erreichten dies als erste Ferrante Gonzaga, Andrea Doria, Emanuele Filiberto di Savoia, Cosimo de'Medici und Ottavio Farnese. ${ }^{258}$

Diese Ausdrücke ostentativ genutzter kaiserlicher Ideologie fielen in Italien - wie gezeigt wurde - auf fruchtbaren Boden, wo die im Hof- oder Kriegsdienst stehenden Vasallen und Fürsten damit ihrem Herrn huldigten, dass sie seine Symbole aufgriffen, um in verschiedenen Bildprogrammen ihre Nähe zum Kaiser und ihre potestas, als von diesem eingesetzten Fürsten, zu beweisen. Jedoch waren sie nicht nur »mecenati delle sue effigi e gli artefici del suo successo ${ }^{259}$ wie Frigo es formuliert hat, sondern sie setzten sich gleichzeitig (manchmal sogar vorrangig) selbst in Szene, wie das von Federico Gonzaga in Auftrag gegebene und oft nachgeahmte Camerino dei Cesari von Tizian beweist. ${ }^{260}$

Eine Darstellung Karls V. zu besitzen oder in Auftrag zu geben, drückte mehr aus, als nur die Zugehörigkeit zum Reich, vielmehr die unterwürfige Huldigung, die Positionierung unter den gleichgesinnten Fürsten und gegen die anderen Mächte. Durch die Umsiedlung der estensischen Gemäldesammlung im Zuge der Devolution und

255 Frigo, Guerra e diplomazia, I8. Siehe auch Mitchell, The Majesty of the State.

256 Frigo, Guerra e diplomazia, 22. Siehe auch BAzzoli, Il piccolo stato.

${ }_{257} \mathrm{Zu}$ seiner (begrenzten, aber dennoch fortdauernden) symbolischen und instrumentellen Bedeutung siehe: Melville, Rituelle Ostentation.

258 Die Este mussten dafür bekanntlich bis zum I7. Jahrhundert warten und bereits um die Mitte des I6. Jahrhunderts flaute - nachdem ihre Herrschaft wiederhergestellt war - deren »Reichs-Euphorie» wieder ab, wie man aus Karls V. wiederholten Vorwürfen der Untreue, Illoyalität und geringen Reichsanhänglichkeit herausliest. Dabei riefen vor allem die intensiven und alten Beziehungen der Este zu Frankreich beim Kaiser wenig Sympathie hervor. Frigo, Guerra e diplomazia, 28.

259 Ebd., ro6.

260 Ebd., I07. 
den späteren Verkauf eines Großteils der Kunstwerke nach Dresden ist nicht mehr nachzuvollziehen, ob die Este Darstellungen von Karl V. oder eines anderen Kaisers besaßen. Umgekehrt hingegen ist belegt, dass Karl V. ein Porträt von Alfonso I. erbat und es auch erhielt, was weniger auf das Verhältnis zu seinem Vasallen als vielmehr auf die Bewunderung des Kaisers für den ausführenden Künstler zurückging. I 525 bekam Tizian, der gerade ein Gemäldezyklus für Alfonsos Camerini d'alabastro beendet hatte, den Auftrag, ein Porträt des Fürsten zu malen. Das Bild, das einen eleganten, edel gekleideten reifen Mann mit einer Hand auf einem Kanonenrohr und die andere am Knauf des Schwertes in sehr viriler und dominanter Pose zeigt, stellt den condottiere und zugleich kultivierten Hofmann in einem dar und huldigt dem Erfinder neuer Feuerwaffen und dem Bewahrer bzw. Rückeroberer der Stati estensi. Als Karl V. im Zuge des Aufenthalts in Italien anlässlich seiner Kaiserkrönung das Gemälde sah, wollte er es als Geschenk haben. Um die Gunst des Kaisers in der Frage der Lehensrückgabe nach der zwanzigjährigen Krise zu gewinnen, überließ ihm Alfonso das Kunstwerk und beauftragte Tizian ein zweites, im Original nicht mehr existierendes, aber in Kopie von Girolamo da Carpi oder Sebastiano Filippi in Florenz erhaltenes Porträt zu malen. Das Sujet ist ähnlich, wieder steht Alfonso in imposanter Haltung an ein Kanonenrohr gelehnt, doch diesmal sieht man - als Zeichen der Wieder-in-Besitznahme durch den Este-Fürsten - die ferraresische Landschaft im Hintergrund. Außerdem trägt Alfonso die Kollane des Ordens vom Heiligen Michael, die er von Louis XII. von Frankreich erhalten hatte. ${ }^{261}$

Auch die Literatur bediente sich des Bildes Karls V. als Kriegsherr und condottiere. Gerade der im estensischen Dienst stehende Historiker und Sekretär Giovan Battista Pigna verewigte den Kaiser in seinem Werk über den idealen Fürsten Il Principe [nel qual si descrive come debba essere il Principe Heroico [...], Venezia ${ }_{5} 6$ 6, als idealen, nur zur Verteidigung der Religion und des Friedens kriegführenden Fürsten.

Eine weitere Quelle zur Kaiserkrönung ist der oben genannte Bericht aus der Feder von Luigi Gonzaga, einem mantuanischen Hofmann aus der Linie der Corradi, der in der Gefolgschaft der Gonzaga nach Bologna kam. Das von Giacinto Romano in der Universitätsbibliothek Pavia entdeckte Manuskript über die tagebuchartigen Aufzeichnungen mit dem Titel Cronaca del soggiorno di Carlo V in Italia ${ }^{262}$ wurde vom

26 I Zu diesen beiden Porträts und der Rekonstruktion ihrer Entstehungsgeschichte siehe den ausführlichen Artikel von Burgess Williams, Power and Painting. Tizian malte in diesem Zusammenhang auch Alfonsos Geliebte Laura Dianti und stellte sie mit einem afrikanischen Pagen dar - ein Exoticum in zweifacher Hinsicht: Es ist in der europäischen Kunst eines der frühesten Werke mit der Darstellung eines dunkelhäutigen, in Diensten stehenden Menschen und es sollte Lauras »Außergewöhnlichkeit«, nämlich eine aus dem Handwerkermilieu kommende, zu einer humanistisch gebildeten und vom Fürsten an Stelle einer neuen Ehefrau auserwählten Frau symbolisieren. Ebd. 88-95. Eine Darstellung dieses Porträts ist im Ausstellungskatalog Bentini/Agostini, Une Renaissance singulière, 253.

262 Romano, Cronaca del soggiorno. 
Autor mit Gesandtenberichten und Inhalten der Verhandlungsabschriften bzw. Chroniken bereichert. ${ }^{263}$

Luigi Gonzaga beginnt seine Aufzeichnungen mit der Begründung der Reise Karls nach Italien: Das Reichsoberhaupt kam einerseits zur Krönung (»prima per coronarsi «) und dann, um alle italienischen Angelegenheiten friedlich zu regeln (»et poi per addattare, sel sarà possibile, tutte le cose de Italia pacificamente, et fare tutto il possibile per fare und pace universale«). ${ }^{264}$ Nach Luigi Gonzaga brach der Kaiser gut gelaunt, weil ihn am 27. Oktober die Nachricht seines Bruders über den Rückzug der Türken erreicht hatte, erst am 3 r. Oktober von Parma nach Reggio auf, wo ihm der Herzog von Ferrara mit großem Geleit entgegenritt. ${ }^{265}$ Für den kaiserlichen Besuch hatte Alfonso I. d'Este alle Straßen ausbessern und in Reggio die Gemächer mit besonders feinen Tapisserien schmücken lassen. Persönlich ritt er Karl V. mit fast 600 Reitern fünf Meilen entgegen, um ihm, im Schlamm kniend und im Ausdruck höchster Demut (»se buttò in terra con gli ginochi nel fango alli piedi dil Cavallo di sua M. ${ }^{\text {à̀ }}$ ) die Schlüssel von Modena und Reggio darzubieten. Der Kaiser ließ ihn erheben, aufsitzen und umarmte ihn, während er ihm Hoffnung auf sein Versprechen auf Gerechtigkeit gab (»lo fece levare suso, et fecelo montare a cavallo, et poi lo abbraciò et gli disse che dovesse stare di buono animo «). ${ }^{266}$

Daraufhin soll Alfonso erleichtert mit dem zu Krönenden über Verschiedenes geplaudert haben, bis sie Reggio erreichten, wo die führenden Familien der Stadt den Kaiser mit Salutschüssen empfingen. Am r. November geleitete Alfonso den Kaiser nach Modena, wo er ebenfalls feierlich empfangen wurde. Am 3. November begleitete ihn der Este noch bis zur Grenze seines Reichslehens auf dem Weg nach Bologna. Wieder kam es zum Austausch von Höflichkeiten und Zeichen der Unterwürfigkeit durch den Este und großzügiger Milde durch den Kaiser, der nicht zuließ, dass der Herzog seine Hand küsste und ihn stattdessen umarmte und ihm für die Gastfreundschaft dankte (»et smontato da cavallo, prese licentia da sua M.tà, et li volse basciare la mano, ma sua M.tà non volse, et lo abbraciò, et assai lo ringratiò del honore et dimostratione fattogli «). ${ }^{267}$ Und so kehrte Alfonso nach Ferrara zurück und wartete auf die vom Kaiser versprochene Mediation in Hinblick auf die Differenzen zwischen ihm und dem Papst. Nachdem Karl die Probleme mit Mailand gelöst hatte, versuchte er - so der Autor der Chronik - alles Mögliche, um den Papst in dessen feindlicher Haltung gegenüber dem Herzog von Ferrara umzustimmen. ${ }^{268}$ Der Papst bat den

263 Zum Manuskript und seinem Verfasser siehe: Romano, Cronaca del soggiorno, Introduzione, 4 I -70. Eine ausführliche kommentierte Zusammenstellung über die schriftlichen Quellen anlässlich des Aufenthalts des Kaisers und der Krönung in Bologna bietet Righi, Carlo V a Bologna.

264 Romano, Cronaca del soggiorno, 75.

265 Ebd., го8.

266 Ebd., rogf.

267 Ebd., II I.

268 Man bemerke, dass die Este auch hier immer nur »Herzöge von Ferrara« genannt wurden, obwohl es im Konflikt um die Reichslehen Modena und Reggio ging, da sie in Ferrara wieder eingezogen waren. 
Kaiser, das Versprechen, das er ihm vor seiner Abreise aus Spanien über seinen Nuntius gegeben hatte, zu halten. Karl beteuerte, dass er nicht von seinem Versprechen abkommen werde, dass er aber bedauere, nicht Frieden stiften zu können. So ließ das Reichsoberhaupt dem Herzog von Ferrara ausrichten, dass er - wenn er nicht in einem Krieg verwickelt sein wollte, dem der Kaiser als sein Gegner auch beitreten werde - sich dem Willen des Papstes beugen müsse. Außerdem müsse er auch das kaiserliche Lehen Carpi zurückgeben. Romano bzw. Luigi Gonzaga interpretierte die Zuweisung Carpis als Mitgift der unehelichen Tochter des Kaisers, Margarete, als mögliche Braut für Alfonsos Sohn Ercole. Obwohl es angedachte - aber keine konkreten - Heiratspläne gab (sie sollte daraufhin Alessandro de'Medici heiraten), waren diese nicht so weit gediegen, dass das Reichslehen Carpi als Mitgift überlassen worden wäre. Der Autor der Chronik entschärft diese Argumentation schließlich selbst mit der Anmerkung, dass der Kaiser mit dieser Rückforderung Carpis Clemens VII. wohlgesonnen stimmen und in Sicherheit wiegen wollte, aber dass gleichzeitig die Gesandten des Herzogs anderweitig informiert waren, weshalb sie sorglos und sich der kaiserlichen Gunst sicher waren. ${ }^{269}$ Auch als Alfonso antworten ließ, dass er zum Krieg gegen beide Lehensherren bereit sei und der Kaiser darauf erwiderte, dass es dann Krieg geben werde, war dies eine mehr oder weniger gelungene Inszenierung. Dass alles nur Fassade war, davon war auch der Gesandte Malatesta überzeugt, der behauptete, ihm schiene es, als hätte der Herzog von Ferrara alle Räte des Kaisers und vielleicht auch diesen selbst bestochen. ${ }^{270}$

Es wundert nicht, dass der Papst sich in keiner Weise umstimmen ließ, den Herzog von Ferrara an der Krönung teilnehmen zu lassen. ${ }^{271}$ Erst nach der Krönung erreichte der Kaiser, dem dafür keine Mühe zu groß zu sein schien, das freie Geleit für Alfonso, damit er vor der Abreise vor ihm und dem Papst erscheine und Aussprache halten könne: "la quale S.tà è stata contenta di compiacere sua M. à Ces.a di questo salvo condotto per esso Duca. Dove la M. ${ }^{\text {à }}$ Ces.a ha mandato homo a posta a Ferrara ad portarvi tal salvo condotto et far intendere al p.to Duca che vada a Bologna, che ha speranza di acconciare benissimo le cose sue talmente che si contentarà. ${ }^{272}$

269 Romano, Cronaca del soggiorno, I 7 I - 73 und Anm. 2. Vgl. auch Righi, Carlo V a Bologna. Introduzione, XVIII.

270 Ebd., I8I, Anm. I.

27 I Ebd., I 96. Auch die kurz davor in Ferrara eingetroffene, zukünftige Herzogin Renée de France, durfte nicht nach Bologna reisen. Sie wurde aber in einem ausführlichen Brief der Markgräfin Isabella d'EsteGonzaga über den Einzug des zu Krönenden, seine militärische Begleitung und vor allem die Pracht der Gewänder der Anwesenden unterrichtet. Dieser Brief wurde erstmals im Archivio storico italiano ossia raccolta di opere e documenti finora inediti o divenuti rarissimi riguardanti la storia d'Italia, Appendice II, Firenze I 845, 319-32 I abgedruckt. Das Original ist im Archivio di Stato di Mantova, b 3000 , libro 49, carte 65-67 aufbewahrt, während es im ASMo keine auffindbare Kopie gibt. Der Brief ist abgedruckt, übersetzt und kommentiert bei: TADDEI, Karls V. Einzug.

272 Romano, Cronaca del soggiorno, 224. 
Am 6. März erreichte Alfonso mitten in der Nacht mit 40 Mann Gefolge Bologna. Am nächsten Tag begab er sich zuerst zum Kaiser, der ihn gut gelaunt (»con bonissima ciera«) empfing und sich nicht die Hand küssen ließ, sondern ihn umarmte (»et li volse basciare la mano, ma sua M. ${ }^{\text {tà }}$ non volse, et lo abbracciò, et ragionorno uno grandissimo pezo insieme«). Danach begab sich Alfonso für den Fußkuss zum Papst. ${ }^{273}$ Anders als der Kaiser verwehrte dieser die Ehrenbekundung nicht und ließ den Este kniend seinen Fuß küssen. Erst nachdem Alfonso leise einige huldvolle und demütige Worte gesprochen hatte, versprach der Papst eine längere Audienz im Beisein des Kaisers. Trotz der immer noch zögerlichen Haltung des Kirchenoberhauptes und seines nur zaghaften Einlenkens ist sich der Autor der Chronik sicher, dass der Papst sich dem Kaiser beugen werde: »il Papa farà tutto quello vorrà l'Imperatore«. ${ }^{274}$

Aber trotz vieler langer Gespräche stellte sich kein rascher Erfolg ein und so schlug aufgrund der Unnachgiebigkeit beider Parteien der Kaiser vor, die Sache an sich zu nehmen und nach bestem Gewissen lösen zu wollen, womit schließlich alle einverstanden waren. Alfonso legte Modena in die Hände des Kaisers, der innerhalb von sechs Monaten eine für alle annehmbare Entscheidung treffen sollte. Konkret ging es darum, ob Modena, Reggio und Rubiera an den Papst oder zurück zu den Este kommen sollten. Außerdem galt es über den Lehenszins für Ferrara zu entscheiden, der seit der Heirat Alfonsos I. mit der Papsttochter Lucrezia Borgia stark vermindert worden war. Hinfällig scheint mittlerweile die Frage der Rückgabe Ferraras gewesen zu sein.

So verblieben, reiste Kaiser Karl am 23. März von Bologna Richtung Mantua ab, tangierte auf der Heimreise wieder Modena und hatte auch in Mantua noch jene oben beschriebene symbolträchtige Begegnung mit Alfonso d'Este und seinen Söhnen. ${ }^{275}$ Die Demutsbekundung unter Einsatz der eigenen Sprösslinge brachte Alfonso noch in Mantua den Zuspruch von Carpi als Lehen gegen eine ansehnliche Lehenstaxe. Als sich Alfonso empfahl, um nach Ferrara zurückzukehren, wurde er wieder davon abgehalten, dem Kaiser die Hand zu küssen und stattdessen herzlich umarmt und ihm wurde für den Empfang und die Gastfreundlichkeit gedankt. ${ }^{276}$

Die in den Berichten dargestellte Gelassenheit Alfonsos I. in diesem an sich alles entscheidenden Treffen lässt darauf schließen, dass Karl V. trotz seiner Versprechungen in Spanien und erneut in Bologna, kein Interesse an einer Erweiterung der päpstlichen Territorialmacht in Oberitalien hegte und den Este von kaiserlicher Seite eigentlich keine echte Gefahr drohte, ihrer Lehen wirklich enthoben zu werden. Bei aller Strenge gegen die »Verfehlung« seines Lehensnehmers sich durch Heirat und Allianz dem Erzfeind Frankreich zugewandt zu haben, ${ }^{277}$ blieb doch die Tatsache,

273 Ebd., 227-229.

274 Ebd., 230.

275 Romano, Cronaca del soggiorno, 256.

276 Ebd., 278.

277 Er wird mit dem Sforza, Gonzaga und Venedig zu den »Feinden« gezählt, denen der Kaiser auf dem Weg nach Italien verzeihen und sich nicht an ihnen rächen wollte. KoHLER, Karl V., I 95 . 
dass die Este-Dynastie für den Kaiser von Bedeutung war. Alfonso I. hatte die meuternden Truppen, die sich $5_{527}$ auf dem Weg nach Rom gemacht hatten, so gut es ging unterhalten, er hatte den kranken Frundsberg in Ferrara gesund pflegen lassen und er war von Gattinara zum Nachfolger von Bourbon in der Führung der Truppen vorgeschlagen worden. ${ }^{278}$ Darüber hinaus konnte der Kaiser keinen Vorteil in ein erweitertes päpstliches Herrschaftsgebiet in der Po-Ebene und im Verlust eines - wenn auch nicht immer vorbildlich treuen - Vasallen erkennen, den er bei Bedarf mit dem Lehensrecht unter Druck setzen konnte. Nichtsdestotrotz war es im Zusammenspiel mit dem Kirchenoberhaupt notwendig, die eingeleitete Farce weiterzuführen, Strenge gegenüber dem illoyalen Vasallen zu zeigen und Demutsbekundungen von diesem zu verlangen. Es bedurfte einer der Ehrerhaltung dienlichen Inszenierung bestehend aus verschiedenen Aspekten symbolischer Kommunikation, aus Drohungen, Vermittlungen, Gesprächsangeboten, Bedenkzeit und Hinhaltetaktiken. Auch die Darbietung der eigenen Söhne, der Stammhalter und designierten Nachfolger sollte einen Beweis der wiederhergestellten Treue und ein symbolisches Pfand für die Zukunft darstellen.

Bereits der Historiograf des I 9. Jahrhunderts, Giuseppe De Leva, hat die mehrfachen Richtungswechsel des Kaisers (»somiglianti giravolte usò Cesare col duca di Ferrara«) und die harschen Worte für den Herzog von Ferrara (»rispose secco: se mi bisognerà, comanderò») nur als Inszenierung für den Papst gewertet (»per compiacere o per non dar ombra al papa«). Alfonso I. durfte zwar nicht an den Krönungsfeierlichkeiten teilnehmen - was sicher einer Ehr- und Prestigeminderung gleichkam - aber er konnte sich schon vor den im Anschluss an die Feierlichkeiten stattfindenden Verhandlungen mit Kaiser und Papst der Weiterführung seiner Herrschaftsrechte gewiss sein, denn der Kaiser, so Leva, hatte ihn schon wieder insgeheim in seine Gunst und Gnade aufgenommen, denn er bevorzugte einen treuen, mittelmächtigen weltlichen Fürsten gegenüber einem zu mächtigen Papst: „Ma Cesare che già lo aveva rimesso segretamente in sua grazia, e maggior assegnamento faceva sulla obbedienza di un piccolo principe temporale, che di un papa troppo potente $[\ldots] .{ }^{279}$

Betrachtet man nun die Beziehung zwischen Karl V. und den Este abseits dieser Lehenskrise und des politischen Machtspiels mit dem Papst, so fällt auf, dass es nach I 530 veremehrt Kommunikation und Kontakte zwischen dem Reichsoberhaupt und den wieder eingesetzten Vasallen gab. Was die fürstliche Korrespondenz anbelangt, so sind im Staatsarchiv von Modena I7 Briefe (I 526 - I 532) Karls V. an Alfonso I. und 30 (I 534- I 556) an Ercole II. erhalten, die alle mit der ausladenden eigenhändigen Unterschrift des Kaisers versehen sind. Das erste Konvolut beinhaltet sieben spanische (davon einer teilweise chiffriert) und zehn lateinische Briefe, in denen Gesandte angekündigt und Personen empfohlen werden, der Kaiser Alfonsos Treue zu ihm und zu

278 Ebd., Kap. »Der Sacco di Roma«, I85 - I9 I, hier besonders I 88f.

279 De Leva, Storia documentata, I 45, 594. 
Frankreich abwägt, seinen Besuch I 530 ankündigt oder um Türkenhilfe und den Aufenthalt der kaiserlichen Truppen im Herzogtum bittet. Das Konvolut mit den an Ercole II. gerichteten Schreiben enthält 24 spanische, einen spanisch-italienischen und fünf lateinische Briefe. Darin kondoliert der Kaiser Ercole II. zum Tod seines Vaters, hofft, dass er sich, wie dieser, der Liga zur Verteidigung Italiens anschließen werde, bittet um militärische Hilfe für den Italienkrieg und im Kampf gegen die »Ungläubigen«, empfiehlt Personen und kündigt Gesandtschaften an. Außerdem geht es in einigen Schreiben um die Causa Parmas. ${ }^{280}$ Hier sahen der Kaiser und seine Berater sowie die italienischen Fürsten der Po-Ebene die Gefahr der Destabilisierung Reichsitaliens. Nach Bonora, die sich auf eine Aussage von Kardinal Ercole Gonzaga, eines großen Anhängers Karls V., in dessen Brief an Ercole II. d'Este beruft, waren Mantua und Ferrara nie in echter Gefahr, denn sie wurden stets vom Kaiser beschützt, der Freunde und Vasallen nicht verlieren wollte, die er für die Eindämmung der farnesischen Hausmacht aber dringend benötigte. ${ }^{281}$

Alfonso I. hat sich den erhaltenen Schreiben nach zwischen I 523 und I 532 viermal brieflich auf Lateinisch und Italienisch an den Kaiser gewandt. Darin bedauerte er, dem Reichsoberhaupt nicht mit der Zusendung eines fähigen Architekten dienen zu können, da er Ferrara nach eigenen Plänen befestigt hatte (er sah sich als der Architekt der Stadtbefestigungen). Neben den obligaten Gunstbekundungen und der Patronage für verschiedene Personen fühlte sich Alfonso außerdem bemüßigt, eine üble Nachrede über seine Unfähigkeit als Herrscher am Kaiserhof zu berichtigen.

Unter den sieben italienischen Briefen Ercoles II. an den Kaiser zwischen ${ }_{5} 36$ und I 554 mit der Bestätigung der Entsendung und des Empfangs von Gesandten und den üblichen Gunstbekundungen findet sich auch die Rechtfertigung des estensischen Lehensnehmers für seine Zuwendung an Frankreichs und seine Abwendung vom Papst. Diese politische Haltung Ercoles II., gekennzeichnet vom Lavieren zwischen den Mächten, stand im Gegensatz zur Haltung seines ältesten Sohnes Alfonso, der aus seiner Anhänglichkeit gegenüber Frankreich keinen Hehl machte, sondern bereitwillig auf der Seite des französischen Königs gegen den Kaiser zu Felde zog. Henri II. hatte ihn durch zwei Frankreich nahestehende Höflinge, Aurelio Fregoso und Guido Bentivoglio, zur Flucht nach Frankreich überreden lassen, nahm ihn am Hof auf, gewährte ihm die Ehre, ihm bei der Tafel die Serviette zu reichen, eine Apanage und die Aufnahme in den Orden vom Heiligen Michael. ${ }^{282}$

Neben der aus Höflichkeitsadressen und Rechtfertigungsschreiben bestehenden Korrespondenz hat der ferraresische Historiker Guido Guerzoni in den Beständen

\footnotetext{
280 Zum Krieg um Parma siehe PAstor, Geschichte der Päpste 6, Kap. 3: DDie Kriegswirren und Oberund Mittelitalien«, 97- I I 7 .

28 I Bonora, Aspettando l'imperatore, I 58 , I69.

282 Die Korrespondenz von und mit Karl V. befindet sich in ASMo, ASE, Casa e Stato, Carteggio di principi esteri, Germania b I 575/I und Wien, HHStA, Serie Italien-Kleine Staaten, Karton Io.
} 
des estensischen Archivs Quellen zu einem weiteren interessanten und bisher wenig beachteten Aspekt des Aufenthaltes Karls V. in Bologna und der Beziegung zu den Este entdeckt. ${ }^{283}$ Unter die Kosten der Este für die militärischen, aber vor allem diplomatischen Verhandlungen in den I 52 oer und I 53 oer Jahren fallen natürlich auch die beachtlichen Ausgaben für den langen Aufenthalt Karls V. in Bologna. Es stellt sich allerdings die Frage, warum die Ausgaben auch nach dem Ende des langen Aufenthaltes des frisch Gekrönten (vom 6. Dezember I 529 bis Ende März I 530) noch weite Kreise zogen. Dazu sollen zunächst einige Vorüberlegungen finanzieller Natur angeführt werden. Wie Guerzoni nachgezeichnet hat, waren die estensischen Beziehungen zum Papsttum aufgrund der Langsamkeit und Unregelmäßigkeit, mit denen der Lehenszins der Este nach Rom floss, bereits vor der von Papst Julius II. verhängten Exkommunikation, der Amtsenthebung und dem Verlust des Herzogtums I 5 Io kompromittiert. Kurz darauf schloss Kardinal Ippolito I. d'Este als Vertreter des Herzogs ein Abkommen mit dem Papst bezüglich der Nutzung der Salinen von Comacchio. Im Gegenzug zur päpstlichen Hauptnutzung dieses bedeutenden Wirtschaftszweiges konnten die Este-Fürsten wieder in Ferrara einziehen. Offen blieb aber die oben beschriebene Causa der kaiserlichen Lehen. Aus finanzieller Sicht betrachtet fehlten Alfonso I. die Einnahmen von zwei Dritteln seines Herzogtums und nun auch ein großer Teil der Einnahmen aus Comacchio, mit denen er den Krieg für die Wiedereroberung hätte finanzieren können. ${ }^{284}$

In den anfänglichen I 52 oer Jahren hatte Alfonso wieder hohe Kriegsausgaben (z.B. I 52 I über I I0.000 lire allein für den Sold). Dazu kamen noch fällige Zinsen aus den Darlehen (z.B. an die Familie Strozzi), sodass diese "Kriegskosten« allein 80 \% aller Ausgaben ausmachten. Dies führte zu strengen Sparmaßnahmen am Hof mit der Verpfändung von Juwelen und Silbergeschirr sowie der Halbierung der Gehälter der Hofbediensteten. Zur Erholung der Finanzen trugen nur die beiden Ehen Alfonsos I. bei, da Anna Sforza I 50.000 Golddukaten (zusätzlich zur Ausstattung) und Lucrezia Borgia I 75.00o Golddukaten (zusätzlich zur Ausstattung und zu reichen Gebieten) in die Ehe mitbrachten. Die wenig überzeugende französische Unterstützung während der Jahre der Verbannung führte dazu, dass sich Alfonso I. notgedrungen wieder dem Kaiser zuwandte. Eine erste Annäherung war im November I 526 von einer Geldleihe von 2.000 scudi d'oro del sole (6.700 lire) begleitet. Einen Monat später folgten I0.000 scudi d'oro del sole (33.500 lire) für den Kaiser. Alfonso war nun gefangen in stetig steigenden Geldforderungen, denn im März I 527 überwies er r.675 lire dem Marchese del Vasto, Anführer der kaiserlichen Truppen, und 71.256 lire den kaiserlichen Emissären. Kein Wunder also, dass er zu seinen einstigen französischen Verbündeten zurückkehrte und dies I 528 mit der Verheiratung seines Nachfolgers mit der Schwägerin des französischen Königs besiegelte. Die Rache des Kaisers ob dieser Umkehr ließ

283 Guerzoni, Di alcune ignote e poco nobili cause.

284 Ebd., I98-202. 
nicht lange auf sich warten, zumal Alfonso mittlerweile die Schwächung des Papstes durch den Sacco di Roma für die Rückholung der kaiserlichen Lehen ausgenutzt hatte. Es blieb also nichts anderes übrig, als die Gunst des Kaisers wiederzuerlangen, ihm zu huldigen (»carezzarlo«), als er sich auf dem Weg zur Krönung machte, wie oben bereits gezeigt wurde. Am Ende trug diese Hinwendung Früchte, denn im Erlass von Köln vom 2 I. Dezember I 53 I setzte Karl die Este als Lehensnehmer des Reiches in Modena und Reggio gegen »Entschädigung« des Papstes mit ıoo.00o Dukaten und der Erhöhung des Lehenszinses auf Ferrara auf 7.000 Dukaten wieder ein. ${ }^{285}$

Guerzoni hat die estensischen Ausgaben aber genauer unter die Lupe genommen und feststellen können, dass diese Wiedereinsetzung weit mehr gekostet haben dürfte, wie auch der ständige Gesandte der Este am Kaiserhof in dieser Zeit, Matteo Casella, bezeugt. Dieser trug die Causa der Rückgabe der Lehen beständig weiter und benötigte dafür am I 4. Februar I 530850 lire, am ıo. März 2.040 lire, am 23. I.020 lire und am 28. März I.005 lire für seine "Ausgaben am Kaiserhof " (»per spexe che lui fa drietto ala corte di sua Maestade«). ${ }^{286}$ Im April I 530, wenige Wochen nach seiner Abreise, wurden dem Kaiser in mehreren Auszahlungen insgesamt roo.ooo Dukaten für den Erwerb des den Pio entzogenen Lehens Carpi übergeben, eine Summe, die allerdings in keinem Verhältnis zu den Erträgen des kleinen Fürstentums lag, da dieses I 5.000- I 8.000 lire im Jahr abwarf. Hier versteckte sich also auch ein Teil des »Rückkaufs« von Modena und Reggio, die der Kaiser in dieser Form vom Papst als neuem »Besitzer« nicht hätte einfordern können. ${ }^{287}$

Nach Guerzoni hatte der nach außen hin so unbestechlich wirkende Karl V. ${ }^{288}$ seinen Italienaufenthalt I 530 (und das Spiel sollte sich beim nächsten Italienzug I 536/7 wiederholen) wirtschaftlich gut genutzt und die oft aufmüpfigen italienischen Fürsten (Federico Gonzaga kostete die Erhebung zum Herzog auch viel Geld) gekonnt "gerupft« ${ }^{289}$ Sowohl die Rückgabe der kaiserlichen Lehen, wie auch später die Belehnung der Seitenlinie boten finanzielle Ressourcen für das Reichsoberhaupt, die aber durch die Neubelehnung mit Carpi zuerst und die Türkenhilfe später gekonnt verschleiert wurden.

285 Vgl. Guerzoni, Di alcune ignote e poco nobili cause, 205-2 I 2.

286 ASMo, Archivio Camerale Estense, Libri Camerali diversi, nr. 316: Zornale de ussita I530, zit. n. Guerzoni, Di alcune ignote e poco nobili cause, 2 I 3.

287 Guerzoni, Di alcune ignote e poco nobili cause, 2 I 3 - 2 I 5.

288 Dieser konnte allerdings den venezianischen Gesandten Alvise Mocenigo nicht täuschen, der sehr wohl das von Maximilian I. eingeführte Phänomen der Korruption auch bei ihm ausgeprägt erkannte, als er die Kurfürsten mit Geld zur Wahl seines Bruders zum Römischen König »überredete«. »Et perchè li Elettori non lo volevan dare, dicendo che l'Imperatore non havea bisogno di tal elettione li suburnò tuttj, come s'intende, et con danari ge lo fece fare. « ASVe, Col. V, Rel. Amb. I I ( I 5), I I 7, zit. n. Zucchi, Deutschland und die Deutschen, 283, Anm. ro68.

289 Guerzoni, Di alcune ignote e poco nobili cause, 2 I 6. 


\subsubsection{Die Beziehungen zwischen den Este und Ferdinand I. ${ }^{290}$}

Ferdinand I. (1503-1564), seit 1527 König von Böhmen (und somit Reichserzmundschenk und Kurfürst) und König von Ungarn, seit I53 I Römischer König, seit I 558 (formell) Kaiser, lebte stets im Schatten seines älteren Bruders. ${ }^{291}$ Anders als bei diesem oder bei Maximilian I. geben keine autobiografischen Aufzeichnungen ${ }^{292}$ oder aufwendige Bildprogramme ${ }^{293}$ und nur wenige Viten Auskunft über sein Wesen und Charakter. I 565 veröffentlichte Alfonso Ulloa in Venedig eine erste Vita des kurz davor verstorbenen Kaisers und im Jahr darauf tat ihm dies der Venezianer Lodovico Dolce nach. 578 fand Ferdinand I. im biografischen Werk von Heinrich Pantaleon »Teutscher Nation Heldenbuch« Eingang. In diesen frühen Biografien wurde der Zweitgeborene als Hersteller des Friedens und milder, freundlicher Herrscher gewürdigt. ${ }^{294}$ Zweifellos war seine politische Rolle von Anfang an bedeutend, war er doch der erste und wichtigste Vertreter des Kaisers im Reich, der oft einzige Ansprechpartner und derjenige, der mit unzureichenden Mitteln große Gefahren, wie jene durch die Osmanen, einzudämmen versuchte. Er zeichnete sich durch große (in den Augen Karls zu große) Kompromissbereitschaft und Problemlösungsorientiertheit sowie ein ausgeprägtes Verhandlungsgeschick aus. Obwohl seine Macht- und Herrschaftsansprüche für sich und seine Kinder nicht zur vollsten Zufriedenheit aufgeteilt wurden, zeigte er stets große Hartnäckigkeit und Beharrlichkeit, zwei Eigenschaften, die Karl oft unterschätzte. ${ }^{295}$ Anders als sein berühmterer Bruder verband er mit Italien vorrangig seine ausgedehnte Heiratspolitik ohne hier aber - unfreiwillig, wie Laubach gezeigt hat - Präsenz zu zeigen. Sein Bemühen und Interesse um eine Italienpolitik, die die feudi imperiali wieder an das Reich festigten, waren zwar gegeben, jedoch unzureichend und wurden von Karl eingedämmt. ${ }^{296}$ Mit Laubach gesprochen »mangelte es ihm im Unterschied zu Karl V. an einem eigenen Territorium in Italien. « $^{297} \mathrm{Karl}$ V. wollte den Einfluss und ein dauerhaftes Engagement seines zum Nachfolger designierten Bruders in Italien zugunsten seines Sohnes Philipp (quasi als Entschädigung für dessen Nachreihung in der Thronfolge) minimieren. Obwohl Ferdinand versuchte,

290 Dazu siehe: Sicken, Ferdinand I. (1556-1564). Außerdem die Beiträge im Sammelband Fuchs/ Kohler, Kaiser Ferdinand I.; SкÝвоvé, Ferdinand I.

29I Siehe Kohler, Kaiser Ferdinand I., 235 f.

292 Gemeint sind Karls »Commentaires«, I 550 auf Französisch verfasst und nur als portugiesische Übersetzung erhalten. Vgl. Lutz, Karl V., 35 .

293 Bis auf das Auftragswerk seines Sohnes Erzherzog Ferdinands II. für den Spanischen Saal von Schloss Ambras, wo er unter den Landesfürsten und Kaisern zu finden ist.

294 Vgl. Laubach, Ferdinand I., hierzu das Kapitel »Imago Ferdinandi: Zum Bild des Habsburgers in der Mit- und Nachwelt«, 727-74I.

295 Rodríguez-Salgado, Metamorfosi, i 8 f.

296 Kohler, Karl V., Ferdinand I., $67 \mathrm{f}$.

297 Laubach, Politik, I 24. 
die Reichsitalienpolitik weiterzubetreiben, scheiterte er an der mittlerweile etablierten spanischen Vormachtstellung. Seine Weigerung, Philipp II. das Reichsvikariat über Italien zu verleihen bzw. zu bestätigen (Karl hatte dementsprechende Vorkehrungen dafür bereits eingeleitet), geschah zum Schutz der kaiserlichen Macht und des Images des Reiches auf der italienischen Halbinsel. Er argumentierte damit, dass das Reichsvikariat nur jemand vor Ort innehaben konnte, da es sich schließlich um eine Statthalterschaft für den abwesenden Kaiser handelte. ${ }^{298}$ Auch als die im Sommer 1558 sich zuspitzende Causa des Reichslehens Finale in Ligurien ${ }^{299}$ mit der Vertreibung des markgräflichen Lehensnehmers des Reiches zeigte, dass die spanische Macht in Italien ernst zu nehmen war, war Ferdinand I. nicht bereit, die Reputation und das Ansehen von Kaiser und Reich in Italien aufs Spiel zu setzen. ${ }^{300}$

Für Ferdinand, der nach Sutter Fichtner die Interessen seiner Familie mit herausragender Hartnäckigkeit verfolgte, ${ }^{301}$ war Reichsitalien also vor allem im Rahmen seiner Heiratspolitik ein wichtiger Markt, da er sich nicht an evangelische Fürsten binden wollte. ${ }^{302}$ So reihten sich hier die Este neben den Gonzaga und den Medici unter den bedeutenden Heiratspartnern für das Reich in der Zeit der Glaubensspaltung ein. Dabei erhoffte sich der Kaiser genügend Einflussmöglichkeit der Bräute auf ihre deutschen wie italienischen oder polnischen Ehemänner zugunsten einer vorteilhaften Reichspolitik. In diesem Sinne heiratete Anna den angehenden Herzog Albrecht von Bayern, um die Beziehungen zu diesen Reichsfürsten jenseits des alten Antagonismus zu festigen und Erzherzogin Maria ehelichte Herzog Wilhelm von Jülich-Kleve, um ihn nach dem Kleveschen Krieg, indem er Ansprüche auf Geldern gestellt hatte, wieder mit den Habsburgern zu versöhnen bzw. um ihn dem Einfluss Frankreichs zu entreißen. Ferdinands Sohn und Nachfolger Maximilian (II.) heiratete die Tochter Karls V., um die habsburgische Hausmacht wieder zu vereinen. Elisabeth und Katharina sicherten durch ihre Ehen mit Sigismund August die Verbindung zu Polen. Die Ehen von Eleonore mit Guglielmo Gonzaga, Johanna mit Francesco de'Medici und Barbara mit Alfonso II. d'Este dienten der Allianz mit wichtigen katholischen Fürsten Reichsitaliens. Vor allem die Este wollte man durch diese Verbindung von Frankreich weglocken. ${ }^{303}$ Die Verbindung mit den Medici diente der (vorläufigen) Beilegung der die Reichsmacht in Italien bedrohenden Bestrebungen um Rangerhöhung Cosimos de'Medici, wogegen sich Ferdinand entschieden stellte.

298 Laubach, Kaiser Ferdinand I., 65 I -657.

299 Vgl. Edelmayer, Maximilian II.

300 Laubach, Kaiser Ferdinand I., 659 f.

30i Sutter Fichtner, Ferdinand I., 7.

302 Kohler, Ferdinand I., 294. Ferdinand I. selbst wurde zur Festigung des Friedens mit Frankreich kurz mit jener Renée de France verlobt, die dann Ercole II. d'Este heiraten sollte. Ebd. 4of.

303 Laubach, Ferdinand I., vor allem das Kapitel zur Heiratspolitik Ferdinands I., 702-725, besonders 704-709. 
So war Ferdinands I. Italienpolitik nach Laubach aufgrund der Anstrengungen zur Wiederherstellung des Friedens im Reich defensiv und vorrangig auf die Festigung der Reichsrechte konzentriert. ${ }^{304}$ Zudem stieß sich sein Sendungsbewusstsein als »Schutzschild der Christenheit« am angespannten, fast feindseligen Verhältnis zum Papst, von dem er sein Amt und seine Herrschaft als »höchste weltliche Obrigkeit der Christenheit« getrennt wissen wollte. ${ }^{305}$

Der erste Kontakt Ferdinands mit den Este erfolgte zu Beginn seiner Karriere als (designierter) Römischer König. ${ }^{306}$ Zwischen I 528 und ${ }_{5} 35$ ließ er fünf lateinische Briefe an Alfonso I. verfassen, die Empfehlungen für Bedienstete, Verhandlungen zu Getreideankäufen, Gratulationen zum Nachwuchs, Dankbekundungen für die Zusendung von Tieren und auch eine Instruktion für die Teilnahme der Este an der Heiligen Liga enthalten. Ferdinand bat die Herzöge von Ferrara als stets dem Reich und Kaiser gegenüber treue Vasallen (affectos et addictos) über die Einnahme Roms zu berichten und Geld für den Krieg in Italien bereitzustellen. I 533 teilte Alfonso I. Ferdinand mit, dass ihm ein Enkel und dem Römischen König ein neuer Vasall und Diener geboren worden war: "Madama mia Nuora ha partorito a me un bello e ben formato Nepotino et a V. M.ta und altro servitore ${ }^{307}$

Als Kaiser richtete Ferdinand I. im Zeitraum I 556- I 563 drei im Staatsarchiv von Modena aufbewahrte Schreiben an Ercole II. und neun an Alfonso II. Sie beinhalten, neben dem diplomatischen Austausch und einer Dankesbekundung für die Zusendung von Falken, vor allem ausweichende Argumentierungen bezüglich einer kaiserlichen Entscheidung im Präzedenzstreit der Este mit Florenz. In einem weiteren Brief von 1558 bat Ferdinand I. den Tiroler Hauptmann Franciscus a Castellalto mit 200 Leichtbewaffneten für den Türkenkrieg durch die Stati estensi passieren zu lassen. Von Ercole II. sind insgesamt vier italienische Briefe erhalten (I 544- I 558) mit Gesandtenankündigung, Empfehlungen von Bediensteten, Glückwünschen zum Sieg in Ungarn und der Erlaubnis, die Truppen durch sein Herzogtum führen zu dürfen, denen hier auch Aufenthalt gewährt wurde.

Der Briefverkehr zwischen Kaiser Ferdinand und Alfonso II. ist fast ausschließlich vom Thema des Präzedenzstreits und der Heirat mit einer der Kaisertöchter geprägt. Der Este dankte dem Kaiser für dessen Bereitschaft, die Causa vor dem Reichstag bringen zu wollen, während der Kaiser bedauerte, den Präzedenzstreit der Este mit den Medici nicht lösen zu können.

\footnotetext{
304 Laubach, Ferdinand I., 66 If, 740f.

305 Laubach, Politik, I 28, I 35.

306 Diese Korrespondenz ist in: ASMo, ASE, Carteggio con principi esteri b I 575/r und in Wien, HHStA, Serie Italien-Kleine Staaten, Karton ro.

307 Ebd., Alfonso I. an Ferdinand I., November 1533.
} 
Neben den regierenden Este-Fürsten haben sich auch Francesco d'Este, der Bruder von Ercole II., und Sigismondo von der Seitenlinie der Este di San Martino an Kaiser Ferdinand I. gewandt. Der Erste bat I 559 darum, als Dank für seinen Einsatz im Türkenkrieg weiterhin Warengeschäfte durchführen zu können, wie es ihm unter Karl V. erlaubt worden war. Sigismondo hingegen beschwerte sich I 5 57, dass er, wie vom Kaiser verlangt, den Fürstbischof von Trient und den König von Spanien mit seinen Truppen durchgelassen habe, woraufhin der Herzog von Ferrara seinen Onkel Don Alfonso d'Este geschickt habe, um mit Waffengewalt seine Besitzungen einzunehmen. Nun bat er um Gerechtigkeit und verlieh seinem Ansuchen Druck mit der Behauptung, dass wenn seine Bitte nicht erhört werde, in Italien keiner mehr dem Kaiser folgen werde, wie schon manche das bereits nicht mehr taten: »[...] che non sara alcuno da qui inanzi in Italia che pensi di ubidirla, come di gia se ne è cominciato a vedere qualche effetto «. ${ }^{308}$ Mit dieser Aussage, die die Wahrnehmung der kaiserlichen Macht in Reichsitalien in der Zeit Ferdinands I. gut trifft und gleichzeitig eine Vorhersage enthält, endet der schriftliche Verkehr zwischen den Mitgliedern des Hauses Este und dem Nachfolger Karls V.

\subsubsection{Die Beziehungen zwischen den Este und Maximilian II.309}

Maximilian II. ( $5_{5} 27$ - I 576), seit I 562 König von Böhmen und Römischer König, seit I 563 König von Ungarn und seit I 564 Kaiser, hat in der Literatur viele Charakterbeschreibungen erfahren, als berechnender, dickköpfiger und aufgrund der vehementen Verteidigung seiner Erb- und Machtansprüche aggressiver Herrscher. Aber er wurde auch als »rätselhaft« hinsichtlich seiner konfessionellen Positionierung gewertet. Allen Beschreibungen gemein ist aber seine Bedeutung als Wiederhersteller und Fortführer des Religionsfriedens.

Maximilian II. war zusammen mit seinem Bruder Erzherzog Ferdinand II. erzogen worden und hatte die Tochter Karls V., Maria, geheiratet, mit der er - trotz divergierender Religionsauffassungen - eine glückliche Ehe geführt haben soll. Als Gegenpol zu der in seinen Augen zu milden Politik seines Vaters überwarf er sich mit Karl V. und Philipp II. und näherte sich - seinen prolutherischen Neigungen folgend - bedeutenden protestantischen Fürsten wie Moritz ${ }^{310}$ und August von Sachsen und Christoph von Württemberg an, wobei dieses Vorgehen nicht maßgeblich von der Politik seines Vaters abwich, der sich während seiner Herrschaft ebenfalls an die einflussreichen und

308 Wien, HHStA, Serie Italien-Kleine Staaten, Karton ro, Sigismondo d'Este an den Kaiser, Februar I 557 .

309 Vgl. Rodríguez Raso, Maximiliano de Austria; Bıbl, Maximilian II.; Rudersdorf, Maximilian II., $79 f$.

3 Io Mit diesem soll er sich besonders gut verstanden haben. Sutter Fichtner, Emperor Maximilian II, 28 . 
erfahrenen protestantischen Fürsten von Sachsen und von Brandenburg angelehnt hatte. ${ }^{311}$ Anders als seine Vorgänger konnte er - vielleicht gerade wegen seiner offenen religionspolitischen, vom "römisch-spanischen Offensivkatholizismus « ${ }^{312}$ freien Haltung - bei den deutschen und italienischen Fürsten (allen voran den Este) viel Sympathie gewinnen. Er war gebildet, sprachbegabt (er sprach und schrieb gut Spanisch, Italienisch, Deutsch und zufriedenstellend Französisch, er hatte Grundkenntnisse in Tschechisch, Ungarisch und Niederländisch), ${ }^{313}$ umgab sich mit italienischen und niederländischen Gelehrten, ließ exotische Tiere und Pflanzen sammeln und förderte Künstler, wie Arcimboldo, die bereits am väterlichen Hof waren. Er pflegte eine rege Korrespondenz - wie gesagt auch mit protestantischen Fürsten. Besonders gute Beziehungen hatte er zu Bayern und seinem Schwager Albrecht V. Obwohl er nicht nach Italien zog, sondern nur durchreiste, ${ }^{314}$ pflegte er durch Korrespondenz und Austausch und durch die Tatsache, dass fünf seiner Schwestern mit italienischen Fürsten verheiratet worden waren, eine innige Beziehung zu Reichsitalien, dessen kaiserlichen Ansprüche und Rechte er gewahrt wissen wollte, so z.B. im Falle der Erhebung der Toskana zum Großherzogtum durch den Papst. Diesen Akt hatte er zunächst als Affront gewertet und erst I 575 nach der Anerkennung der Lehensabhängigkeit der Toskana vom Reich durch Francesco de'Medici - und großen finanziellen Zuwendungen für den Türkenkrieg - akzeptiert, auch wenn die Spannungen in Italien durch diesen Akt nicht nachließen, sondern vielmehr zunahmen. ${ }^{315}$

Interessante Aspekte zur Rezeption Italiens in der Regierungszeit Maximilians II. hat Heinz Noflatscher in seiner Studie über die sogenannten Italienexperten des Kaisers hervorgebracht. ${ }^{316}$ Allein das Umfeld des Erzherzogs und späteren Kaisers lassen auf eine gewisse Vertrautheit mit Italien schließen, hatte er in seinem Bruder Erzherzog Ferdinand II. und mit verschiedenen Mitgliedern des Hofstaates vehemente Vertreter italienischer Moden und Trends (à la italiana). Von der Gruppe der Italienexperten im Umkreis Maximilians, also jener Personen, die sich aufgrund ihres Amtes und ihrer Funktion mit Italien auseinandersetzen mussten, wie Räte, Gesandte,

3 I I Laubach, Politik, i26. Siehe auch: Blasch ke, Alte sächsisch-böhmische Nachbarschaft.

3 I 2 BIвL, Maximilian II., 40 I.

3I3 Sutter Fichtner, Emperor Maximilian II, 9. Zur tatsächlichen und erwarteten sprachlichen Ausbildung früher Regenten, aber vor allen zu den Erfordernissen sprachlicher Kenntnisse siehe WaGNER, Princeps litteratus.

3I4 Er verbrachte einige Winter in den I53oer Jahren in Tirol. Vgl. Sutter Fichtner, Emperor Maximilian II, 7. Auf seinen Reisen nach Spanien zog er durch Norditalien, passierte aber, wie der Reiseund Kostenbericht von 1548 bezeugt, von Augsburg kommend Innsbruck, Bozen, Ala, Mantua und zog dann weiter nach Cremona, um dann in Genua mit Admiral Dorias Schiffen nach Barcelona überzusetzen. Laut Reiseplan kam er weder nach Ferrara noch nach Modena. Siehe Menčıк, Die Reise Kaiser Maximilian II., 6f.

3 I 5 Volker Press, »Maximilian II.« in: Deutsche Biographie Online, http://www.deutsche-biographie.de, Zugriff: 13.6 .2020 .

3 i6 Noflatscher, Sprache und Politik. 
Sekretäre, Reichshofratsmitglieder (besonders der Lateinischen Abteilung), hatten viele in Italien studiert oder sich im Rahmen ihrer Tätigkeit mit Reichsitalien befasst. Dazu kam die in Wien und dann in Prag große Gruppe der italienischen Baumeister und Handwerker, Kaufleute, Söldner und Kirchenmänner und schließlich der Künstler, Architekten, ${ }^{317}$ Musiker und Leibärzte, die am Kaiserhof tätig waren. Auch haben etliche oberitalienische Familien wie die Trivulzio, Valmarana oder Pallavicini immer wieder Mitglieder in die Heeresreihen oder die Verwaltung des Kaisers abgesandt. Viele Italienexperten kamen aus dem Tiroler und Trientiner Raum (Khuen, Arco, Lodron) und waren wegen ihrer Herkunft aus den Randgebieten des Reichs und der daraus resultierenden Zweisprachigkeit gefragt. ${ }^{318}$

Wie sein Bruder Erzherzog Ferdinand war Maximilian ein begeisterter Reiter und Jäger und ließ aufwendige Turniere ausrichten. Außerdem war er ebenso ein Sammler von größtenteils aus Italien stammenden Kuriositäten und ein großzügiger Geber von ausgefallenen Geschenken. ${ }^{319}$ Hier hatte er mit den Este gemeinsame Interessen, die in der Zusendung von Gaben, der Einholung von Informationen und Empfehlung von Fachleuten ihren Ausdruck fanden.

Die im Staatsarchiv von Modena erhaltene reiche Korrespondenz zeigt, dass Maximilian II. sowohl als Erzherzog als auch als Kaiser eine überaus intensive Beziehung zur Familie d'Este hatte. ${ }^{320}$ Zwischen I 547 und I 556 schrieb er Ercole II. eigenhändig acht italienische und 2 I spanische Briefe mit Empfehlungen für Hofleute und Untertanen, zur Ankündigung von Gesandtschaften, Mitteilungen über die Geburt einer Tochter, den Tod seines Sohnes und seinen eigenen Gesundheitszustand, Berichte von seinen Reisen nach Spanien und nach Polen zu seiner Schwester, aber auch über die Beziehung Kaiser Karls V. zu Moritz von Sachsen.

An Alfonso II. d'Este sind I I 3 Briefe (der Großteil auf Spanisch, der Rest auf Lateinisch, nur ein Brief ist Italienisch) in Modena erhalten, die ebenfalls die Ankündigung und den Empfang von Gesandten enthalten, Empfehlungen und Vermittlung von Personen weiterleiten, Neuigkeiten, Gunstbekundungen und Gesundheitswünsche übermitteln, für Geschenke danken und den Präzedenzstreit behandeln. Obwohl Maximilian Alfonsos II. erstes Angebot von I 567, den Kaiser in Ungarn gegen die Türken zu unterstützen, mit der Begründung abgeschlagen hatte, dass der Schwager gerade seine Schwester geheiratet und noch keine Erben habe, ${ }^{321}$ übermittelte er den-

3I7 Dazu siehe letztens auch die Untersuchung der Architektenfamilie Angielini im Dienst Kaiser Ferdinands I. für die Befestigung Wiens. Ferdinand Opll/Heike Krause/Christoph Sonnlechner, Wien als Festungsstadt im I6. Jahrhundert: zum kartografischen Werk der Mailänder Familie Angielini, Wien/Köln/Weimar 2017.

3 I 8 Noflatscher, Sprache und Politik, I44-I56.

3 I 9 Sutter Fichtner, Emperor Maximilian II, 95 f.

320 Die Korrespondenz ist in: ASMo, ASE, Casa e Stato, Carteggio di principi esteri, Germania b I 576/2.

32 I Die Bedeutung, die allgemein und hier insbesondere von Kaiser Maximilian der gesicherten Nachfolge zugemessen wurde, wird an diesem und an einem weiteren Beispiel deutlich. Als Wilhelm V. von Bay- 
noch regelmäßig Informationen über den Fortgang der Türkenabwehr in Ungarn und bat um brieflichen Rat und finanzielle Unterstützung. Diese Bitte bewog den Este schließlich zum Aufbruch nach Wien.

In den I 9 im Archivio di Stato di Modena und im Haus-, Hof- und Staatsarchiv in Wien $^{322}$ erhaltenen italienischen Briefen (I 547- I 576) Alfonsos II. an Maximilian II. wird für Geschenke und die Zustimmung zum Heiratsprojekt mit Erzherzogin Barbara gedankt; außerdem wiederholen sich tiefste Gunstbekundungen und Ausdrücke von Demut, überschwänglicher Treue und Ergebenheit. Es fehlt aber in den Briefen nicht eine leise Kritik im Bezug auf den erfolglosen Präzedenzstreit und die Unentschlossenheit des Kaisers, eine endgültige Entscheidung zu treffen. Tatsächlich wandte Maximilian wie oftmals in der Reichs- und Konfessionspolitik auch hier die Kunst des "Dissimulierens« an. ${ }^{323}$

Ein letzter Hinweis auf die Freundschaft, die Maximilian II. und Alfonso II. verband, soll diese Überlegungen abschließen. Als der Este I 564 zu Heiratsverhandlungen und anläßlich des kaiserlichen Begräbnisses Ferdinands I. nach Wien kam, wurde er von Maximilian persönlich vor der Stadt empfangen. Francesco de'Medici hingegen musste bei seiner Ankunft in Wien für seine Aufwartung beim Kaiser Geduld aufbringen. Alfonso II. war auch I 57 I in Wien und erhielt sogar eine Audienz am Krankenbett des Kaisers. Davon berichtete er Erzherzog Ferdinand II. und fügte hinzu, dass der Kaiser gern auch die Meinung der ferraresischen Ärzte bezüglich seiner Leiden und die Möglichkeiten der Genesung hätte. ${ }^{324}$ Noch von Wien aus ließ Alfonso II. für den kranken Kaiser Boten nach Ferrara schicken, die eine ärztliche (Fern)Meinung einholen sollten. ${ }^{325}$

\subsubsection{Die Beziehungen zwischen den Este und Rudolf II.326}

Rudolf II. (I 552-I6 I 2), seit I 572 König von Ungarn, seit I 575 König von Böhmen und Römischer König und seit I 576 Kaiser, hatte eine zweigeteilte Erziehung zuerst

ern endlich die 23-jährige Renata von Lothringen ehelichte, drängte Maximilian auf die schnelle erbliche Absicherung durch Kindersegen, denn die Herzogin - so das Reichsoberhaupt - sei auch nicht mehr die Jüngste: »allain wegen propagation und erzielung ainer lieben posteritet angesehen und aber das freulin nunmehr ire manbare jahr zimblich erraicht, dass si von tag zu tag nit junger, sonder nur elter wirdet, darumben dann der christlich beischlaf unsers erachtens vilmehr zu furdern als in lengern verzug erwachsen zu lassen.« Maximilian II. an Albrecht V. von Bayern, 9. August 1567, zit. in: BIBL, Die Korrespondenz 2, Nr. 207, 2 I6.

322 Wien, HHStA, Serie Italien-Kleine Staaten, Karton ro.

323 Press »Maximilian II."

324 Innsbruck, TLA, Kart. 3 I Pos. 26 Ferrara, Alfonso II. an Erzherzog Ferdinand II., Dezember 157 I.

325 Innsbruck, TLA, Kart. 20I Pos. I 82 Welsche Schreiben, Erzherzog Ferdinand II. an Alfonso II., August 1572 .

326 Vgl. Press, Rudolf II., 99- I I i ; Vocelka, Rudolf II., I 985 ; Evans, Rudolf II. 
in der kosmopolitischen und relativ toleranten Umgebung Maximilians II. und später in der katholischen Strenge der Obhut seines Onkels Philipp II. von Spanien, an dessen Hof er sich mit seinem Bruder Ernst von I 563 bis I 57 I aufhielt, erfahren. Er reiste über Genua und Oberitalien nach und von Spanien und berührte ausschließlich im Zuge dieser Reisen italienisches Reichsgebiet. Sein Wesen war gekennzeichnet von einer guten humanistischen Bildung, der Beherrschung mehrerer Sprachen, aber auch von gebieterischen und argwöhnischen Zügen, einem großen Zaudern und geringer Entschlusskraft. Seine Depressionen wie auch die geringe Arbeit an den Regierungsorganen, die sich gerade im Konfessionskonflikt stark verselbstständigten, und die nur sporadische Teilnahme an den Reichsversammlungen verzögerten - teils auch gewollt - etliche Entscheidungsfindungen, wie jene der Nachfolgeregelung der Este. ${ }^{327}$ Wie sein Großvater Karl V. war er von einem unumstößlichen Glauben an die kaiserliche Autorität geleitet; er demonstrierte sein Herrscherbewusstsein vor allem gegenüber Frankreich und Spanien und besonders in der Behauptung der kaiserlichen Rechte in Reichsitalien und den Niederlanden. Demzufolge verweigerte auch er, wie seine Vorgänger, Philipp II. das Reichsvikariat in Italien. ${ }^{328}$

Seine Weigerung, die spanische Cousine Isabella zu heiraten und auch alle anderen möglichen und angedachten Verbindungen einzugehen, die unüberlegte Entlassung erfahrender Räte (Wolfgang Siegmund Rumpf und Paul Sixt Trautson), ${ }^{329}$ die Zurückgezogenheit am Prager Hof, die Flucht in andere Welten, so in jene der Künste, der okkulten Wissenschaften und der Naturwissenschaften ${ }^{330}$ zeichnen ihn als wankelmütige und bereits früh psychisch angeschlagene Persönlichkeit aus. Selbst seine Frömmigkeit bot Anlass zu Spekulationen. Nach Hugh Trevor-Roper war er weder Katholik noch Protestant, sondern eher religionslos. ${ }^{331}$ Diese Vermutung könnte das damit einhergehende Verhalten gegenüber der römischen Kurie erklären. In Rom war man gespannt, in welchem Verhältnis der Sohn des schwierigen Maximilian II. zur Kirche stehen würde und ob und wie er den sich ausbreitenden Protestantismus zurückzudrängen gedachte. Zur Informationseinholung über die Person des neuen Kaisers, seinen Charakter und seine Einstellung vor allem zur Religion wurde der Nuntius Annibale di Capua entsandt. ${ }^{332}$ Dieser hatte wie die anderen Nuntien der zweiten Hälfte des r 6. Jahrhunderts die Stärkung des Papsttums in und außerhalb Italiens zur

327 Zum wenig reisefreudigen und auch der politischen Arbeit nicht sehr zugetanen Kaiser siehe die Einschätzungen bei Noflatscher, Regiment aus der Kammer, 2 I $2 f$.

328 Press, Rudolf II., ior, ro4.

$329 \mathrm{Zu}$ Rudolfs II. Hof und speziell den genannten Geheimen Räten siehe auch: Hausenblasová, Der Hof, 204-2 r6. Mit dem Typus dieses Favoritenduos und mit deren "plötzlicher "Entlassung hat sich u.a. Heinz Noflatscher auseinandergesetzt. Noflatscher, Monarchische Willkür?

330 Press, Rudolf II., I02. So fand auch der Philosoph und Okkultist Giordano Bruno I 588 in Prag Gehör.

33 I Trevor-Roper, Princes and artists, 79- i I 5 .

332 Vgl. dazu Koller, Der Kaiserhof. 
Aufgabe. Wichtige Errungenschaften in diesem Vorhaben waren die Devolutionen von Ferrara und Urbino, die Ketzerverfolgung vor allem in kleineren Herrschaftsgebieten oder auch das Interdikt gegen Venedig durch Papst Paul V. Diese Vorhaben, zusammen mit der Überwachung der Applikation der Bestimmungen des Konzils von Trient zur Stärkung der katholischen Reform, verlangten eine große diplomatischen Präsenz auf italienischer wie europäischer Ebene. ${ }^{333}$

Als Rudolf II. im Oktober I 575 zum römischen König gewählt wurde, erhielt er vom Nuntius im Namen von Papst Gregor XIII. die Aufforderung, die Bestätigung seiner Wahl vom Papst zu erbitten und den Gehorsamseid zu leisten, den schon die Kaiser des Mittelalters während der Krönung durch den Papst abgelegt hatten. Auch andere Fürsten oder Städte der italienischen Halbinsel leisteten als Vasallen des Papstes bei jedem Pontifikatswechsel durch sogenannte Obödienzgesandtschaften diesen Eid, so auch die Este. ${ }^{334}$ Rudolf zögerte lange die Entsendung der Obödienzbotschafter bzw. der ständigen kaiserlichen Gesandten in Rom hinaus und ließ zunächst das Argument der leeren Kassen und der hohen damit verbundenen Kosten anführen. Zu einer weiteren Verzögerung kam es, als das angehende Reichsoberhaupt eine sprachliche Umformulierung verlangte: Nicht oboedentia (Gehorsam), oder wie Maximilian II. bereits schwächer formuliert hatte, obedientissimus filius (gehorsamster Sohn), sondern nur obsequentissimus filius (willfährigster Sohn) sollte es im Wortlaut des Eides heißen. Damit drohte die Wahl Rudolfs, der jedes Einlenken verweigerte, vom Papst nicht anerkannt zu werden. Erst im Juli I 577, nach Zusendung einer beglaubigten Abschrift des Krönungseides, einigte man sich auf die schwächere Formel des obedientissimus filius. Ein weiterer Affront war die Weigerung Rudolfs, die schließlich zustande gekommene Konfirmationsbulle anzunehmen, da auch seine Vorgänger keine solche in ihren Schriftbeständen aufbewahrt hatten. So kam sie über den Nuntius zurück nach Rom. Rudolf sah nämlich keine Notwendigkeit und keinen Zusammenhang zwischen seiner Wahl/seinem Amt und dem Gehorsamseid, den der Papst verlangte. Er leistete ihn schließlich als Person, aber nicht als Kaiser oder König für seine Herrschaftsgebiete, darunter natürlich auch Reichsitalien. ${ }^{335}$ Trotz der glimpflichen Lösung dieses Kräftemessens hat der schwierige Beginn von Rudolfs Herrschaft Spuren in Italien hinterlassen. Es wundert nicht, dass bei derartigen schlechten Beziehungen zum Papst das Reichsoberhaupt für Alfonso II. d'Este noch in späteren Jahren keine große Hilfe in der Nachfolgeregelung für das päpstliche Lehen Ferrara sein konnte.

Kaiser Rudolfs II. Italienpolitik war vor allem vom Langen Türkenkrieg ( I 593 - I 606) und von der Notwendigkeit, aus Reichsitalien Kontributionen in verschiedenster Form zu erhalten, geprägt. ${ }^{366}$ Auch wenn er wenig kaiserliche Präsenz auf der italienischen

333 Andreatta, Le nunziature, $29 \mathrm{f}$.

334 Koller, Der Konflikt um die Obödienz, r $48 f$.

335 Koller, Der Konflikt um die Obödienz, I 52 - i 64.

336 Siehe bei Jan Paul Niederkorn die "Besuche« der kaiserlichen Gesandten bei den italienischen Fürs- 
Halbinsel zeigte, so erleichterte Rudolf in seiner Sammelwut vom weit entfernten Kaiserhof manche italienische Fürsten, die ein Anliegen vorzubringen hatten, um wertvolle Kunstwerke und ausgefallene Raritäten. ${ }^{337}$

Auch mit Rudolf II. pflegten die Este eine reiche (reich erhaltene) Korrespondenz. In den Staatsarchiven von Modena und Wien sind für den Zeitraum von I 576 bis I 597 , also bis zum Aussterben der Hauptlinie der Este, 7 I meist auf Lateinisch gehaltene (nur vier sind auf Italienisch) Briefe Rudolfs II. an Alfonso II. überliefert. ${ }^{338}$ Ihr Inhalt reicht von der Kondolenz zum Tod Maximilians II., über Nachrichten zur Pestausbreitung in Wien bis zur Ankündigung von Gesandten und der Weiterbestellung von estensischen Gesandten, die schon unter dem Vorgänger am Kaiserhof tätig waren. Es fehlen nicht Gunstbekundungen, Empfehlung von Personen vor allem für jene, die nach Italien kommen wollten. Rudolf beauftragte Alfonso, sich um verschiedene Streitigkeiten im kaiserlichen Lehen zu kümmern; auch sollte er nicht erlauben, in Modena und Reggio den Kirchenzehnt eintreiben zu lassen. Schließlich kamen vom Kaiser, der sich als Türkensieger deklarierte, ohne im Heereslager anwesend gewesen zu sein, ${ }^{339}$ regelmäßig Berichte und Beschreibungen der Kriegssituation in Kroatien und Ungarn zusammen mit der Bitte um Türkenhilfe. Mit diesem letzten Kaiser des I6. Jahrhunderts hatte der letzte Herzog von Ferrara um die Verleihung des Titels Illustrissimo (1585) und um die Nachfolgeregelung in den kaiserlichen und päpstlichen Lehen zu verhandeln, wie oben bereits gezeigt wurde. Um diese schwerwiegende Agenda der Investitur einer estensischen Seitenlinie, von der schließlich Alfonsos Teilnahme am Türkenkrieg abhängen sollte, ging es in den 33 italienischen Briefen, die Alfonso II. zwischen I 572 und I 597 an den Kaiser richtete. Neben Huldigungen, Ehrerbietung, Versicherung der Loyalität und Dienstpflicht, ging es auch in der Regentschaft Rudolfs immer noch um den Präzedenzstreit mit Florenz, der allerdings seit der Erhebung der Medici aussichtloser denn je geworden war, aber als ceterum censeo "gewohnheitsmäßig" seinen Platz in der Korrespondenz mit dem Reichsoberhaupt behalten hatte.

\subsubsection{Die Este und der Reichstag}

Die Este ließen ihre dringendste Agenda, nämlich die Präzedenz vor den Medici, nicht nur vor dem Kaiser, sondern auch (bzw. in dessen Auftrag) vor dem Reichstag ver-

ten mit den Bemühungen für eine »außerordentliche Türkenhilfe«: Nieder korn, Die europäischen Mächte, $386 f$.

337 Vgl. Evans, »Rudolf II.«; JanÁček, Les Italiens à Prague.

338 ASMo, ASE, Casa e Stato, Carteggio di principi esteri, Germania b I576/2; Wien, HHStA, Serie Italien-Kleine Staaten, Karton ro.

339 Press, Rudolf II., I05. 
handeln. Dem Reichstag des I6. Jahrhunderts gehörten als »ein Organ ständischer Interessensgruppen ${ }^{340}$ die Kurfürsten (Kurfürstenrat), die Reichsfürsten (Reichsfürstenrat) und die Reichsstädte (Städterat) an. Am Reichstag mussten neben den Mitgliedern der drei Kurien auch der Kaiser/König bzw. von diesen beauftragte Kommissare anwesend sein.

Es wurden in der Forschung bereits einige Versuche gestartet, das Wesen, die Zusammensetzung und die Arbeitsweise des Reichstages in der ersten Hälfte des I6. Jahrhunderts zu skizzieren, dessen Ablauf auf dem Gewohnheitsrecht aufgebaut war und keiner gesetzlich fixierten Geschäftsordnung folgte. ${ }^{341}$ Eine größere Formalisierung, besonders in Bezug auf die Zahl der Einzuladenden, gelang I495 durch die Festigung der Reichstagsverfassung, die nun vorsah, dass der Kaiser alle reichsunmittelbaren Stände einladen musste. Die Beratungen sollten geheim erfolgen und strenger geregelt werden. Dadurch erhöhten sich Ansehen und Bedeutung dieser Institution. Zusammen mit den Kurfürsten legte der Kaiser Termin und Austragungsort (eine Reichs- oder Bischofsstadt) fest. Sodann wurden die Teilnehmer per Formular, die Kurfürsten und einzelne bedeutende Fürsten auch mit persönlichem Schreiben eingeladen und die Gründe für die Notwendigkeit der Zusammenkunft sowie die Verhandlungspunkte angekündigt. Die Eröffnung konnte sich - sehr zum Ärgernis der entsandten Vertreter und der Gesandten - oft um Wochen oder sogar Monate verzögern, da man auf ein gewisses Quorum warten musste. Sodann begann nach dem Einzug, dem Hochamt und der Plenarsitzung der Reichstag mit der Verkündung der Proposition, die die Verhandlungspunkte festlegte. Daraufhin tagten die Stände in drei Kurien zwischen 20 Tagen und ro Monaten. In der Kurfürstenkurie gab es sieben bzw. durch die ruhende Stimme Böhmens sechs Stimmen, in der Fürstenkurie ca. 85 zwischen Viril- und Kurialstimmen und in der Städtekurie waren es I 52 I 56 Städteboten. Letztere hatte am wenigsten Mitspracherecht und bekamen meist die Vorschläge der beiden anderen Kurien zur Kenntnis (votum consultativum). Die eigentliche Arbeit fand in den verschiedenen Kurien und hier in sogenannten Ausschüssen statt. Diese leisteten die Vorarbeit, damit die Kurie rasch zu einer bestenfalls einhelligen oder zumindest mehrheitlichen Entscheidung kommen konnte. Der Mainzer Kurfürst organisierte dann den Austausch der Entscheidung zwischen den Kurien und führte an eine gemeinsame Entscheidungsfindung heran. Außerdem hatte er den Vorsitz in der Kurfürstenkurie und in den Plenarsitzungen, verfasste den Reichsabschied und wachte über den gesamten Ablauf. Schließlich empfing er auch die fremden Gesandten. ${ }^{342}$

Dauerthema der Propositionen waren die Türkenabwehr und ab den I 52 oer Jahren die Verhandlungen mit den Protestanten in den verschiedenen Stadien der Glau-

\footnotetext{
340 Neuhaus, Reichstag, 26.

34 I Oestreich, Zur parlamentarischen Arbeitsweise; siehe auch die einzelnen Beiträge im Sammelband: Lutz/Kohler, Aus der Arbeit an den Reichstagen, und hier besonders Luttenberger, Reichspolitik. 342 Vgl. Oestreich, Zur parlamentarischen Arbeitsweise, 246-250, 254.
} 
bensspaltung. ${ }^{343}$ Die Abstimmung in den Kurien erfolgte über eine nach Rang- und Sitzordnung geregelte Umfrage. Da der Vorrang somit nicht nur Ehrensache, sondern weitgehend meinungsbildend war, gab es an diesen Reichszusammenkünften ebenso heftige und lang andauernde Präzedenzstreitigkeiten, sodass die Causa der Este gegen die Medici sicher kein Exotikum darstellte.

Die verschiedenen Ausschüsse (Großer Ausschuss, Unter-, Fach- oder Sonderausschuss), die die eigentliche (Vor)Arbeit zur Entscheidungsfindung leisteten, wurden zu Beginn oder während des Reichstages meist interkurial gebildet, sodass alle $\mathrm{Ku}$ rien ihre Vertreter, die zumeist Experten in dem zu behandelnden Verhandlungsthema waren, entsenden konnten. Ein Ausschuss, der sich mit Supplikationen, Petitionen und Beschwerden an den Reichstag als letzte Rechtsinstanz auseinandersetzte, wurde aufgrund der stetigen Zunahme an zu behandelnden Fällen schließlich zur fixen Institution. $^{344}$

Supplikationen, an den Herrscher gerichtete Bittschriften, ursprünglich mündlich vor dem Rat vorgetragen und dann nur noch schriftlich vorgelegt, waren in der päpstlichen Kanzlei schon seit dem I 3. Jahrhundert Usus, ab dem I 4. Jahrhundert gab es hier sogar ein eigenes Supplikenregister mit beigefügten Entscheidungen. Es handelte sich dabei vorrangig um Justizangelegenheiten, Appellationen in erstinstanzlichen Streitfällen und Gnadenerweise, z.B. in Pfründenangelegenheiten. In der kaiserlichen Kanzlei bildete sich die institutionalisierte Erledigung solcher Bittgesuche langsamer heraus, wobei zunächst diese vorgetragenen Suppliken durch ein mündliches Verfahren, also eine Stellungnahme durch den Kaiser ad hoc entschieden wurden. Erst mit der steigenden Zahl von Bittschriften und der Zunahme der Schriftlichkeit kam es unter Kaiser Friedrich III. zur Ausstellung von schriftlichen Bescheiden an die Supplikanten. Seit dem r6. Jahrhundert breitete sich das Supplikationswesen im Heiligen Römischen Reich als letzte Möglichkeit aus, außerhalb des Rechtsweges angehört zu werden, wobei man sich nicht auf ein Recht, sondern auf eine Gunstbezeugung oder einen Gnadenerweis berief. Zumeist entsprach der Kaiser den Gnadengesuchen, soweit sie nicht Reichsangelegenheiten betrafen; in diesem Fall reichte er die Supplikation den Ständen weiter. Dadurch weitete sich der Kreis der Adressaten von Suppliken vom Kaiser auf die Kurfürsten und Stände aus. Dies ging mit dem Schwund kaiserlicher Autorität - auch am Reichstag - einher, weshalb sich Gesandte von nicht teilnahmeberechtigten Fürsten - besonders aus Reichsitalien -während der Reichstage mit ihren Gesuchen vermehrt an einflussreiche Reichsfürsten wandten. ${ }^{345}$

Der zur Institution avancierte, seit dem Wormser Reichstag I 52 I immer wieder eingesetzte Supplikationsausschuss/rat bestand aus I4 Mitgliedern, den Räten der

343 Seit dem Speyrer Reichstag von I 529 gab es in der Fürstenkurie zudem eine Spaltung nach Konfession in einen katholischen und evangelischen Rat. Ebd., 257.

344 Ebd., 25 If, 260-262.

345 Vgl. Neuhaus, Reichstag, 82-86, I I 5- i 18. 
sechs Kurfürsten, und jenen von Salzburg und Würzburg in Vertretung der geistlichen Fürsten, jenen von Bayern und Württemberg für die weltlichen Fürsten, einem Reichsprälaten, einem Reichsgrafen und den Gesandten der Reichsstädte Straßburg und Ulm. Diese Zusammensetzung konsolidierte sich ab der Mitte des r6. Jahrhunderts. Neben dem Supplikationsrat war auch die kurmainzische Kanzlei als Zentrum der Reichstagsverwaltung mit der Entgegennahme und Bearbeitung von Beschwerden und Suppliken betraut, die sie in Bearbeitungslisten zusammengefasst, den Kurfürsten und Fürsten oder direkt dem Kaiser übergab. Die kurmainzische Kanzlei spielte also auch im Bereich des reichstäglichen Supplikationswesens eine Schlüsselrolle.

Die Zahl und die Inhalte der Supplikationen waren sehr variabel und vielfältig: Am Reichstag von Augsburg I 55/I wurden I.700 Suppliken, I 559 ebenfalls in Augsburg I 4 und am Speyrer Reichstag I 5703.500 vorgelegt. Es wundert nicht, dass der Supplikationsrat bis zu seiner Auflösung Anfang des r 7. Jahrhunderts für die gesamte Reichstagsdauer im Einsatz war. ${ }^{346}$ Das Supplikationswesen breitete sich mit der institutionellen Verfestigung des Reichstages heraus und beinhaltete Bitten und Beschwerden, die weit über die Propositionen des Kaisers hinausgingen. Obwohl es keine öffentliche Ankündigung von Reichstagen und in gleichem Maße von Kurfürstentagen und Reichsdeputationstagen ${ }^{347}$ gab, an denen ebenfalls Supplikationen vorgebracht werden konnten, wundert sich Neuhaus, dass jeder Bauer wusste, wann und wo er supplizieren durfte. ${ }^{348}$ Aufgrund der bestehenden fürstlichen Netzwerke hingegen, wundert es nicht, dass auch nicht teilnahmeberechtigte Fürsten bestens Bescheid wussten, wann und wohin sie ihre Gesandten schicken sollten.

Wie Rosemarie Aulinger bereits in ihrer r 980 publizierten Dissertation über den Reichstag $^{349}$ gezeigt hat, war es seit der Mitte des I4. Jahrhunderts durchaus üblich, dass ausländische Gesandte und in Fall von Reichsitalien somit Vertreter von nicht stimmberechtigten Reichsfürsten, an den Reichstagen teilnahmen, was zu einer dem Kaiser mehr den Kurfürsten hingegen weniger willkommenen Internationalisierung der Reichsversammlung führte. Am Reichstag von Augsburg I 548 nahmen z. B. neben dem päpstlichen Nuntius die Gesandten von Frankreich, England, Polen, Portugal, Dänemark, Siebenbürgen, Sizilien, Venedig, Florenz, Ferrara, Mantua, Genua, Siena, Lucca, Mailand, der böhmischen und der ungarischen Länder teil. Die akkreditierten, weil angekündigten Gesandten, die je eine Vollmacht für den Kaiser und für den Mainzer Erzkanzler mitbrachten, saßen ab I 49I rechts neben dem Kurfürsten von

346 Neuhaus, Supplikationen, I 5of, I 56 f, I 76 f. Vgl. auch die Liste der vorgebrachten Supplikationen in den einzelnen Bänden der Deutschen Reichstagsakten, wie auch weiter unten beispielhaft angeführt.

347 Vgl. das vom modenesischen Gesandten, Baron Stom I657 vorgebrachte Anliegen bzw. die Rechtfertigung bezüglich des Vorgehens Modenas gegen Mailand als Akt der Notwehr, während der Kaiser durch seine Unterstützung Spaniens gegen die Bestimmungen des Westfälischen Friedens agiert hatte. Schnettger, Der Reichsdeputationstag, I65.

348 Neunaus, Supplikationen, 158.

349 Aulinger, Das Bild. 
Trier. Sie trugen ihre Anliegen oder Bittschriften entweder nur dem Kaiser und seinen Beratern oder den Reichsständen oder beiden vor. Nach der Beratung in den Ausschüssen erhielten die Gesandten die Beschlüsse mündlich oder schriftlich zur Weitergabe an die Fürsten, für die sie gesprochen hatten. Jene Fürsten und Territorien wie die Republik Venedig, die regelmäßig ihre Gesandten an den Reichstag schickten, ließen nicht immer ein Anliegen ${ }^{350}$ vorbringen, sondern erwarteten von ihren Vertretern aufmerksame Beobachtung und genaue Berichterstattung dieses Reichsorgans, das prinzipiell positiv bewertet wurde, wenn seine Arbeit nicht durch Präzedenzstreitigkeiten, Befindlichkeiten, Boykott, also - in ihrer Wahrnehmung - Zeitverschwendung, beeinträchtigt wurde. ${ }^{351}$

Die meisten Vertetungen nicht teilnahmeberechtigter Fürsten und Länder (wie der Este oder Polens) am Reichstag bestanden aus einem oder zwei Gesandten und einigen Sekretären; größere Gesandtschaften mit bis zu 6o Personen wurden dann entsendet, wenn der Reichsversammlung Macht und Bedeutung des zu vertretenden Fürsten vor Augen geführt werden sollte und waren eher die Ausnahme, denn die Lebenshaltungskosten am langdauernden Reichstag bedeuteten einen enormen finanziellen Aufwand. Die vorgebrachten Anliegen, wegen der sich die nicht stimmberechtigten Fürsten mithilfe ihrer Vertreter am Reichstag Gehör verschaffen wollten, waren wie im Falle der Este, oft wiederkehrende. ${ }^{352}$

Die Este hatten nicht nur eine fast permanente diplomatische Vertretung am Kaiserhof, sondern vor allem im Rahmen dringender Themen wie der Präzedenzfrage, zumeist zwei Gesandte am jeweiligen Austragungsort des Reichstages. Tatsächlich fällt im Bestand Carteggio di ambasciatori im Archivio di Stato di Modena auf, dass in der Zeit der Reichstage vermehrt istruzioni an die Gesandten im Reich gerichtet wurden. Darüber hinaus finden sich sowohl in der Korrespondenz der Este mit ihren Gesandten als auch mit anderen Fürsten, die die Gesandten vermutlich am Reichstag treffen sollten, Hinweise zu deren Entsendung und den vorzubringenden Anliegen. Der Reichstag diente, jenseits der Propositionen und der Reichspolitik, ganz allgemein der

350 Noch im r8. Jahrhundert wurden von italienischen Fürsten Angelegenheiten vor und Anfragen an den Reichstag bzw. den Wahlreichstagen vorgebracht, wie Brauneder für die Wahlreichstage von I 7 I I und I74I gezeigt hat. Am ersten nahmen mehrere italienische Fürsten teil; alle beriefen sich bei ihren Rechtsfällen und Beschwerden auf die Verletzung von kaiserlichen Rechten in Italien. Brauneder, Impero e Stato, 59 .

35 I Vgl. Aulinger, Das Bild, I43-i46. Zu den interessanten Suppliken gehört jene des Grafen von Carpi am Reichstag von Regensburg I532, wo er um seine Wiedereinsetzung als Reichsgraf bat. Ebd., I 46. Unter den spannendsten Berichten ist jener des venezianischen Gesandten Alvise Mocenigo vom Reichstag in Augsburg I548, ebd., I52- I58. Zur Wahrnehmung des Reichstages, der in seiner gesetzgebenden Funktion dem venezianischen Consiglio Maggiore gleichgesetzt wurde, seinem Ablauf und seinem Zusammenspiel mit der kaiserlichen Macht siehe auch ZUcCHI, Deutschland und die Deutschen, $328-364$.

352 Ähnliches stellt Bömelburg für Polen fest. Bömelburg, Die Wahrnehmung, 420. 
Kommunikation - und hierbei auch mit der geografischen und politischen Peripherie des Reiches - und der Festigung bestehender Netzwerke. I 594 berichtete der bayerische Herzog Ernst Alfonso II. d'Este, dass er dessen Gesandten Marcantonio Ricci am Reichstag von Regensburg gesprochen habe. ${ }^{353}$ Am Reichstag von Augsburg I 566 waren für den Herzog von Ferrara die Gesandten Sigismondo Descalzi, Guido Bentivoglio und Alfonso Gonzaga anwesend, beim Reichstag von Speyer I 570 wird in der Liste der anwesenden auswärtigen Gesandten für den Herzog von Ferrara Alessandro Fiasco genannt. ${ }^{354}$

Somit maßen die Este als nicht teilnahmeberechtigte italienische Fürsten dieser Institution, schon bevor die Präzedenzfrage in ihren Entscheidungsrahmen fallen sollte, eine besondere Bedeutung zu. Die Herzöge von Ferrara bildeten aber hierbei keine Ausnahme. Auch das Königreich Polen war nicht teilnahmeberechtigt und schickte an zwei Dritteln der Reichstage des r6. Jahrhunderts offizielle Gesandtschaften. Wo keine polnischen Diplomaten anwesend waren, war dies oft ein Ausdruck des angespannten Verhältnisses der kaiserlichen Politik gegenüber. Oder aber es waren Ort und Zeitpunkt des Reichstages noch nicht oder zu spät kommuniziert worden. Schließlich erfuhren Nichteingeladene davon nicht durch eine offizielle Ausschreibung, sondern meistens aus zweiter Hand und erst spät, da der Postweg langwierig war und der Hof nicht immer einen festen Sitz hatte. Der regelmäßige Besuch der Reichstage durch polnische Gesandte zeigt einerseits die Intensivierung der politischen wie dynastischen Beziehungen zwischen den Jagiellonen und den Habsburgern und andererseits die Notwendigkeit, seit Langem offene Fragen wie z.B. die Ungarnpolitik immer wieder vorzubringen. Die Kaiser des I6. Jahrhunderts, allen voran Maximilian I. befürworteten und unterstützten die Anwesenheit der auswärtigen Gesandten an den Reichstagen sowohl zur Steigerung des kaiserlichen Prestiges als auch, um Informationen über Verhältnisse und Zustände an der Reichsperipherie einzuholen. ${ }^{355}$ Denn der Reichstag war neben seiner politischen Funktion ein bedeutender Moment des Zusammentreffens und des Austauschs. Hier konnte man die Reichsfürsten oder ihre Vertreter bzw. das Reichsoberhaupt und idealerweise sogar alle bedeutenden geistlichen wie weltlichen Entscheidungsträger an einem Ort versammelt antreffen. Hier konnte man Informationen einholen und die »Großen« des Reiches um Unterstützung bitten. In diesem Sinne

353 ASMo, ASE, Casa e Stato, Carteggio di principi esteri, Germania b I594/20, Ernst von Bayern an Alfonso II., August 1594 .

354 Lanzinner/Heil, Deutsche Reichstagsakten, Der Reichstag zu Augsburg I566 2, I489, Anm. i9; Lanzinner, Deutsche Reichstagsakten, Der Reichstag zu Speyer 1570, Zweiter Teilband, 995, Anm. 3 .

355 Auch die polnischen Gesandten waren angehalten, am Reichstag Kontakte mit den Reichsständen zu pflegen und ihren Fürsten bzw. das Königreich betreffende Fragen und Interessen vorzubringen. Neben den Instruktionen wurden sie auch von persönlichen Briefen des Königs begleitet, Handelsfragen, Probleme der Schifffahrt auf der Ostsee, den Türkenkrieg oder die Livlandpolitik betreffend. Vgl. Bömelburg, Die Wahrnehmung, 409-4II. 
schickte Alfonso I. d'Este, da er den Herzog von Bayern im Januar 15 I 9 in Augsburg am Reichstag wähnte, seinen Gesandten mit Höflichkeitsadressen und mit der Bitte um Unterstützung bei der Rückgewinnung seiner Lehen dorthin. ${ }^{356}$

Um Auskunft vom und über den Reichstag bzw. die reichspolitischen Entscheidungen zu erhalten, beschränkten sich die nicht zur Teilnahme berechtigten Fürsten nicht nur auf die Berichte ihrer Gesandten, sondern nutzten auch ihr Netzwerk und ihre Verbindungen zu den anderen Fürsten. Obwohl der estensische Gesandte Graf Ippolito Turco I 555 am Reichstag von Augsburg, I5 57 in Regensburg und I 559 wiederum in Augsburg war, ließ sich Alfonso II. auch von Herzog Johann Albert von Mecklenburg ausführlich von den Reichstagen berichten. Seine Neugier betraf dabei vor allem die Anwesenheitsliste. ${ }^{357}$ Vermutlich lag darin die Überlegung, welcher reichstagsaktive Fürst seines Netzwerkes ein möglicher Fürsprecher seiner nächsten Anliegen sein konnte.

Der Besuch des Reichstages fiel meist in die Agenda des residierenden Gesandten am Kaiserhof, wenn auch zur Unterstützung zusätzliche Sonderbotschafter geschickt wurden. In einem Brief an Kurfürst August von Sachsen wird der estensische Gesandte, Ascanio Geraldino, angekündigt, der im Jahr davor zusammen mit dem anderen Gesandten des Herzogs von Ferrara, Renato Cato, an den Reichstag geschickt worden war und deshalb dem Kurfürsten noch in Erinnerung sein durfte, wie man hoffte. ${ }^{358}$ Dass die Fürsten des Reiches die Gesandten der italienischen und speziell der estensischen Fürsten kannten, beweist nicht zuletzt die Tatsache, dass die diplomatischen Vertreter zusammen mit ihren Instruktionen auch Briefe zur Weiterleitung an die Teilnehmer erhielten. So sollte der Gesandte des Herzogs von Ferrara, Ippolito Turco, I 558 nicht nur alles vom Reichstag berichten, sondern die mitgeführten Briefe dem Kurfürsten August von Sachsen aushändigen, von dem man in Ferrara wusste, dass er teilnehmen würde. ${ }^{359}$ Für den Reichstag von Augsburg von 1582 hatte der estensische Gesandte Cato so viele Briefe für alle anwesenden Fürsten mitbekommen, dass ihm die Kanzlei des Herzogs zur besseren Übersicht ein eigenes Verzeichnis der Schreiben erstellte. ${ }^{360}$

Wie vielfältig die diplomatischen Aufgaben eines Gesandten während einer solchen Zusammenkunft der Reichsfürsten war, zeigt eine Anweisung für Graf Ercole Rangoni aus dem Jahr I550, der am Reichstag in Augsburg nicht nur herausfinden sollte, was

356 München, BayHStA, Kurbayern_Äusseres_Archivooro, Alfonso I. an den Herzog von Bayern, Januar I 5 I 9.

357 ASMo, ASE, Casa e Stato, Carteggio di principi esteri, Germania b I603/29, Johann Albert von Mecklenburg an Alfonso II., Mai I 556, April I 559.

358 ASMo, ASE, Casa e Stato, Minute di lettere ducali a Principi e signori fuori d'Italia b I635/5, an Kurfürst August von Sachsen, Mai ${ }_{5} 8_{3}$.

359 ASMo, ASE, Casa e Stato, Carteggio di Ambasciatori, Germania b 20, an Ippolito Turco, Dezember I 558 .

360 ASMo, ASE, Casa e Stato, Carteggio di Ambasciatori, Germania b 43, an Renato Cato, Juli 1582. 
mit dem gefangen genommenen Johann Friedrich von Sachsen passiert war, sondern auch Moritz von Sachsen in Ercoles II. Namen um eine Genealogie seiner Dynastie bitten sollte. ${ }^{361}$ Darüber hinaus sollte der Gesandte dem Kaiser und allen Fürsten in der Folge ihres Ranges Gunstbekundungen vom Herzog von Ferrara überbringen. ${ }^{362}$ Dieses Versprechen von Moritz von Sachsen, eine Genealogie in Auftrag zu geben, aus der die Verwandtschaft seines Hauses mit den Este ersichtlich wurde, konnte aufgrund des plötzlichen Todes des Kurfürsten nicht gehalten werden. Doch die Este ließen sich nicht entmutigen und nutzten die Gelegenheit am darauffolgenden Reichstag, um den Bruder und Nachfolger, Kurfürst August von Sachsen, zu bitten, diesem Versprechen nachkommen zu wollen. ${ }^{363}$

Auch im Juni I 552 erwartete Ercole II. gespannt, von seinem Gesandten, Giulio Rossetti, den Bericht vom vergangenen Reichstag von Augsburg und Neues vom Verhältnis zwischen dem Kaiser und Moritz von Sachsen zu erfahren. ${ }^{364}$ Grund dafür waren einerseits sein freundschaftliches Verhältnis zum Sachsenfürsten und andererseits seine indirekte Beteiligung an dem von Moritz angeführten Fürstenaufstand gegen den Kaiser im Frühjahr I $55^{2 .}{ }^{365}$

Im April I 559 wurde der estensische Gesandte am Reichstag zu Augsburg instruiert, dass er sich - da der Herzog von Savoyen nicht zum Reichstag erscheinen würde - an andere Vertreter halten sollte, um herauszufinden, ob der Kaiser wirklich nach Frankreich zu gehen gedenke und wie am Reichstag über die Mittel für den Türkenkrieg entschieden wurde. ${ }^{366}$ Im März I 583 trug Alfonso II. d'Este seinem Gesandten im Reich, Minuccio Minucci, der auf dem Weg nach Köln war, auf, jene Fürsten, die zuvor am Reichstag in Augsburg zugegen gewesen waren, zu bitten, sich für den Titel und Vorrang eines Reichsfürsten für den Este auszusprechen. ${ }^{367}$ Hier wird ersichtlich dass, wie Schnettger bereits festgehalten hat, die italienischen Fürsten und Untertanen zwar oft den Kaiser anriefen, aber dort, wo sie sich von diesem unfair behandelt fühlten oder - wie im Falle der Este - wo dieser keine Entscheidung treffen wollte/konnte, sie ihre Bitten und Beschwerden vor den anderen Reichsfürsten und vor dem Reichstag vorbrachten. ${ }^{368}$

36r ASMo, ASE, Casa e Stato, Carteggio di Ambasciatori, Germania b i I, an Ercole Rangoni, o.D. [r 55 o]. 362 Ebd., an Ercole Rangoni, Juni 155 o.

${ }_{3} 63$ ASMo, ASE, Casa e Stato, Carteggio di Ambasciatori, Germania b 20, an Ippolito Turco, Dezember I 558 .

364 ASMo, ASE, Casa e Stato, Carteggio di Ambasciatori, Germania b I6, an Giulio Rossetti, Juni 1552.

365 Dazu siehe Rebitsch, Tirol. Àlvarez-Ossorio Alvariño, Moti di Italia, $344 f$.

366 ASMo, ASE, Casa e Stato, Carteggio di Ambasciatori, Germania b 20, an Ippolito Turco, April r 559.

367 ASMo, ASE, Casa e Stato, Carteggio di Ambasciatori, Germania b 44, an Minuccio Minucci, März I5 83. Möglicherweise reiste Alfonso selbst im Sommer $5_{5} 83$ nach Augsburg, denn in einem Brief von Juli ${ }_{5} 8_{3}$ lud ihn Herzog Ludwig von Württemberg in sein Fürstentum ein, um ihre Freundschaft zu vertiefen, da er wusste, dass sich der Este im Reich aufhielt. ASMo, ASE, Casa e Stato, Carteggio di principi esteri, Germania b I604/30, Ludwig von Württemberg an Alfonso II., Juli I 583 .

368 Schnettger, Il Sacro Romano Impero, 30. 
Auch für andere, wenn nicht für alle Teile der Reichsperipherie war diese Zusammenkunft von Bedeutung. Für den polnischen Hof hat Bömelburg die Reichstage zurecht als »zentrales mitteleuropäisches Kommunikations- und Verhandlungsforum« und als "Nachrichtenbörsen « ${ }^{369}$ definiert, von denen außer regelmäßigen Berichten auch interessante Publikationen und Flugschriften nach Polen geschickt und Briefe für die Teilnehmer mitgegeben wurden. Anders hingegen im äußersten Westen Europas, wo nach Kohler, »sowohl die Bewohner der spanischen Königreiche im I6. Jahrhundert als auch die spanische Historiographie im 20. Jahrhundert das Heilige Römische Reich im allgemeinen und die Institution des Reichstages im Besonderen eher oberflächlich und flüchtig wahrnahmen. Reich und Reichstag standen nie im Mittelpunkt des >spanischen Interesses, für das I6. Jahrhundert ist vielmehr das Gegenteil festzuhalten: die Beobachtung und sogar Ablehnung der 'Spanier durch die Reichsbewohner. ${ }^{370}$ Zwar wurden für Philipp II. Akten und Urkunden bis hin zur Goldenen Bulle ins Spanische übersetzt, damit er sich ein Bild vom Reich und seinen Institutionen machen konnte, dennoch blieben diese für die Spanier uninteressant. Wie Edelmayer gezeigt hat, baute Philipp II. weniger auf institutioneller als vielmehr auf militärischer Basis ein eigenes, weit verzweigtes Netz im Reich auf. ${ }^{371}$

Selbst die Päpste des r6. Jahrhunderts schickten ihre Gesandten in Vertretung der römischen Kurie zum Reichstag, obwohl ihre Stellung unklar, formal nicht definiert war und ihre Erhörung stark von der Person des Entsandten und seinen Überzeugungsfähigkeiten abhing. Problematisch wurden hierbei die sogenannten Reformationsreichstage nach I $530 .{ }^{372}$

Dass die Este dem Reichstag und seinem Kontext eine wichtige entscheidungsgebende Rolle zumaßen und diese Institution in vielfältiger Weise nutzten, haben die oben genannten Beispiele gezeigt. ${ }^{373}$ Die Bedeutung des Reichstages bekräftigte Ercole II. im Zuge eines ärgerlichen Verlustes von Briefen an den und vom estensischen Gesandten im Reich mit folgenden Worten: »tanto piu hora che la corte sarà in Augus. ta di dove ogni giorno havrete comodità di scriver per Vinegia, dandoci aviso di mano in mano di tutto q.llo che accorrerà et si farà in quelle Diete $\left[\ldots\right.$ «. $^{374}$

369 Bömelburg, Die Wahrnehmung, 42 I, 426.

370 Kohler, Bemerkungen zur Wahrnehmung, 453.

37 I Vgl. das Kapitel "Die Kenntnis und das Bild des Reiches in Spanien« bei Edelmayer, Söldner und Pensionäre, 38 -6o. Vgl. Braun, Imagines imperii, 576, 594. Siehe auch: Kohler, Bemerkungen zur Wahrnehmung, 457-460.

372 Braun, Die Wahrnehmung, 46If, 468.

373 Die war nicht nur auf das I6. Jahrhundert beschränkt. I 657 brachte Alfonso IV., Herzog von Modena, eine Klage gegen Kaiser Ferdinand III. vor den Frankfurter Reichsdeputationstag vor. Vgl. SchnettGER, Der Reichsdeputationstag, I65f.

374 »etzt wo der Hof in Augsburg sein wird, von wo aus ihr jeden Tag über Venedig eure Berichte schicken könnt, sodass ihr uns nach und nach über alles, was am Reichstag entschieden wird und passiert, berichten könnt.« ASMo, ASE, Casa e Stato, Carteggio di Ambasciatori, Germania b 2o, an Ippolito Turco, Dezember I $55^{8}$, tw. chiff. 
Doch waren diese Reichinstitutionen für die Este nicht nur Mittel, um eigene Rechte einzufordern, sondern sie stellten auch die Auftragsgeber an die Herzöge von Ferrara und Modena dar für die Umsetzung von Recht vor Ort. Wenn Personen Schutz, Gnade, Patronage oder Rechtsprechung benötigten, wenn sie von ihrem unmittelbaren Landesherrn aufgrund eines Verschuldens ausgewiesen wurden oder fliehen mussten, wenn sie in Not gerieten oder ihnen Unrecht widerfuhr (z.B. in Erbangelegenheiten oder als Gläubiger), so wandten sie sich an die Reichsinstitutionen, d.h. an den Kaiser, den Reichstag oder den Reichshofrat. Aber auch Personen, die eine Pfründe oder Anstellung, einen Kredit oder einen Aufenthalt zur Verbesserung ihrer Arbeits- oder Lebenssituation erbaten, nutzten die Möglichkeit der Supplikation. Dabei wurden diese Supplikationen oft nicht von den Reichshofräten bzw. deren Kommissären ${ }^{375}$ selbst zur Erledigung gebracht, sondern dem betreffenden oder benachbarten Territorialfürsten zur Ausführung weitergeleitet. In diesem Fall wandte sich der Kaiser an die unmittelbar betroffenen Fürsten in und außerhalb des Reichsverbandes und erbat in einem Vermittlungsschreiben die Übernahme der Rechtssache und die Unterstützung für den Supplikanten. Wie Ortlieb gezeigt hat, handelte es sich dabei zwar nicht um einen kaiserlichen Befehl, aber immerhin um eine dringliche Aufforderung des Reichsoberhauptes, der Bitte des Antragsstellers nachzukommen. Hiermit endete dann die kaiserliche Intervention; die erfolgreiche Umsetzung des Antrags hing hingegen von dem mit der Angelegenheit betrauten Landesfürsten (bzw. der Stadt) ab. ${ }^{376}$ Auch die Este wurden - wie die Quellen belegen - mit derartigen kaiserlichen »Aufträgen« bemüht. Oftmals wurde den kaiserlichen Vermittlungsschreiben die »Orginialsupplikation« des Bittstellers beigefügt. Einige Quellenbeispiele quer durch das I6. Jahrhundert sollen die Art dieser an den Kaiser gerichteten und an den Herzog von Ferrara und Modena zur Umsetzung weitergeleiteten Gnadengesuche zeigen.

Im November I 502 informierte Maximilian I. Ercole I. d'Este darüber, dass der Herzog von Mecklenburg seinen Sohn zu ihm geschickt hatte. Der Kaiser hatte daraufhin beschlossen, dass der junge Herzog zur Ausbildung nach Ferrara geschickt werden sollte, wofür der Este Vorkehrungen treffen sollte. ${ }^{377}$

Aus dem Jahr $5_{532}$ sind im Staatsarchiv von Modena drei spanische Schreiben Kaiser Karls V. an den Herzog von Ferrara erhalten mit der Aufforderung an A1fonso I., Gnade für einen aufgefangenen Caballero, Diener des Papstes, walten zu

375 Gut untersucht ist die Tätigkeit der Reichshofräte in den Regierungen von Maximilian II. und Rudolf II.: Ehrenpreis, Kaiserliche Gerichtsbarkeit; Ullmann, Geschichte auf der langen Bank. Hier wird nicht nur auf die oben genannten Verzögerungstaktiken des Kaisers in heiklen Entscheidungsfällen und auf die Delegierung an die Territorialfürsten im Reich hingewiesen (16- I 8, 62-67), sondern auch auf die kaiserlichen Bemühungen zur Integration des Nordens des Heiligen Römischen Reiches, des Ostseeraumes, (64-67). Die südliche Reichsperipherie indessen wird nicht behandelt.

376 Ortlieb, Gnadensachen, I94- I 97.

377 Diese und alle folgenden Beispiele befinden sich in: ASMo, ASE, Casa e Stato, Carteggio di principi esteri, Germania b I 575/r. 
lassen (Januar 1532), einem neapolitanischen Edelmann, Scipio de Suma, die Aufenthaltsgenehmigung im Herzogtum Ferrara gewähren zu wollen (Juli I532) und sich der Gläubiger und Erben Jakob Johannes und Bartholomeus de Sellis, die sich im ferraresischen Herzogtum aufhielten, annehmen zu wollen (Juli 1532). Neben einer Passiererlaubnis für Philippo Strozzi im Juni ${ }_{15} 36$ bat der Kaiser den Este-Fürsten im Juni 1540 um die Rücknahme einer Verbannung für einen gewissen Galeotto de la Concordia. Kaiser Ferdinand I. bat Alfonso II. im Februar ${ }_{5563}$ Christophorus Kress aus Augsburg bei der Eintreibung seiner Kredite im estensischen Fürstentum unterstützen zu wollen.

Zahlreich sind auch die von Kaiser Maximilian II. weitergeleiteten Supplikationen: Die Hofdame Gräfin von Lodron hatte im Juni 1565 beim Reichsoberhaupt ersucht, ihren Sohn Sigismund von Lodron, der der estensischen Camera Geld schuldete, begnadigen zu lassen; der Kaiser bat Herzog Alfonso II. darum, dass dem Jungen kein Schaden entstehe. Im Juli 1567 ließ der Kaiser den Este bitten, für Fabricio Mario Ferrarese, der wegen eines Verbrechens in Arrest war, zu intervenieren. Auch die Kaufmannsbrüder Thomas und Paulus de Cambiis aus Regensburg, die im Juni I569 eines Verbrechens bezichtigt worden waren, hatten beim Reichsoberhaupt um Gnade und Rückkehr in die Heimat bitten lassen. Maximilian II. ersuchte im Oktober 157 I beim Herzog von Ferrara um Unterstützung seines Sekretärs Galeatius Cusanus in Castelli novi (Castelnuovo), der über Schwierigkeiten wegen seiner Besitzungen und Titel in den Stati estensi geklagt hatte. Im Februar 1572 bat er um Unterstützung für Georgius Meinl aus Nürnberg, dem einige Ferraresen Geld schuldeten und im Januar 1574 setzt er sich für die Befreiung von Johannes Baptista Cartarium, Gefangener in Reggio, ein.

Kaiser Rudolf II. leitete u.a. eine Bitte um Intervention im Erbschaftsstreit von Ludovicus Ferdinandus und Christophorus de Sessis, Grafen von Rolo, (März r 586), eine Anfrage um Unterstützung bei der Eintreibung von Schulden für Martinus Antonius Maffettus (Dezember 1588 ) und die Bitte um Unterstützung der Witwe Leonora Martinega Obizza in einer Streitangelegenheit (August 1589 ) nach Ferrara weiter.

Wie Ortlieb bereits festgehalten hat, hatten die Bitten um Empfehlung, Intervention oder freies Geleit über den Kaiser bzw. im Zuge eines Reichshofratsverfahren mehr Gewicht, als wenn sie direkt an den betreffenden Herrschaftsträger vor Ort gerichtet worden wären. ${ }^{378}$ Der Unterschied zu den zahlreichen Bitten und Anfragen in der Fürstenkorrespondenz liegt im instituionellen Weg der Supplik.

Ein Treffer in der vom Erich-Schmidt-Verlag herausgegebenen Datenbank der Akten des Kaiserlichen Reichshofrates soll zum Abschluss den Mechanismus dieser Reichinstitution zeigen. Der Kläger, Hans Tuecher aus Augsburg, brachte 1564 ein Fürbitteschreiben an den Herzog von Ferrara vor den Reichshofrat, auf dass dieser seinen Gesandten im Reich, Sigismondo Descalzi, der sich im Juni ${ }_{5} 563$ vorerst vom

378 Orthieb, Gnadensachen, i 98. 
Kaiser hatte lizensieren lassen, zur Zahlung offener Schulden auffordere. ${ }^{379}$ Diese Form der indirekten Kommunikation zwischen zwei Streitparteien kann entweder auf die Tatsache zurückgehen, dass der Augsburger Kläger dem estensischen Gesandten nicht ranggleich war und ihn deshalb nicht direkt zur Zahlung auffordern konnte; oder aber es war der letzte verzweifelte Versuch, mit größerem Druck durch den Reichshofrat als anerkannte Institution und den Herzog von Ferrara als Dienstgeber Descalzis zum eigenen Recht zu kommen.

379 http://www.rhrdigital.de/id/altepragerakten.5.5726/akte.html, Suchbegriff»Ferrara«. Alte Prager Akten Band: 5 , Signatur: K. 194, Verzeichnis: AB I/16, fol. 3 I6r, Zugriff: 10.6.2020. 


\subsection{Die Beziehungen der Este zu anderen Mitgliedern des Reiches}

\subsubsection{Die Beziehung zu den Habsburgern und ausgewählten katholischen Reichsfürsten}

Mit der Heirat Alfonsos II. mit Erzherzogin Barbara von Österreich, Tochter Kaiser Ferdinands I. und Schwester Kaiser Maximilians II., intensivierten die Este - wie oben gezeigt - ihre Beziehungen zum Reich und zur habsburgischen Dynastie. Doch

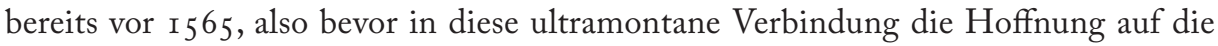
Lösung des Präzedenzstreits mit den Medici gelegt wurde, gab es Kontakte, Korrespondenzen, Austausch von Kulturgütern und Gefälligkeiten zwischen den Este und den Erzherzögen und Erzherzoginnen ${ }^{380}$ der Domus Austriae. Diese Beziehungen mit Mitgliedern der Herrscherdynastie nutzten die Herzöge von Ferrara vorrangig für eine gewinnbringende Fürsprache beim Kaiser, für die Intensivierung der Netzwerkbildung auch mit anderen Reichsfürsten und zur Stärkung der Wahrnehmung als Mitglieder des Reichsverbandes. In der Folge sollen hier die beiden Erzherzogshöfe der zweiten Hälfte des r6. Jahrhunderts, der Innsbrucker Hof der Tiroler Linie der Habsburger unter Erzherzog Ferdinand II. und der Grazer Hof der innerösterreichischen Linie unter Erzherzog Karl II. näher betrachtet werden, die Noflatscher zu Recht als » Reservoir[e] für die Rekrutierung« von Italienern und von Kulturgütern definiert hat. ${ }^{381}$ Von beiden habsburgischen Erzherzögen erhofften sich die Este Unterstützung und Fürsprache bei ihren reichspolitischen Anliegen, d.h. sowohl beim Kaiser als auch am Reichstag, wo Ferdinand II. und Karl II. - trotz der von Kaiser Ferdinand I. in seinem Vermächtnis gewünschten Einheit der Domus Austriae - individuell eine tragende Rolle spielten. Hatte ihr Vater nämlich für eine gemeinsame Stimmführung am Reichstag plädiert, so versuchte Erzherzog Ferdinand II. spätestens mit der Entsendung eines eigenen Gesandten zum Reichstag von Regensburg 5576 die Tiroler Interessen stärker zu vertreten. Ab I582 erhielt die steirische Linie in Konsequenz dazu auch das Recht auf eine eigene Vertretung, die sie vor allem für die Problematik der Verteidigung der Reichsgrenze gegen die türkische Bedrohung nutzte. Beide Erzherzöge bedienten sich - den Schein der Einheit des Erbhauses wahrend - vorrangig des Instruments der Supplikationen, Memoranden und der informellen Kanäle um Entscheidungsfindungen zu ihren Gunsten zu beeinflussen. ${ }^{382}$

\footnotetext{
380 Diese trugen - nach Pflüger zu Recht - maßgeblich zur »Verdichtung und Intensivierung der politischen Kommunikation im Reich» bei. PflüGER, Kommissare, $8 \mathrm{r}$.

38 i Noflatscher, Sprache und Politik, i68.

382 Vgl. Luttennerger, Innerösterreich, 358.
} 
Auch für die Untersuchung der Beziehungen zwischen den Este und den jeweiligen Oberhäuptern der Tiroler und der steirischen Linie des Hauses Habsburg in der zweiten Hälfte des r6. Jahrhunderts wurde die in Modena und in Innsbruck bzw. Wien aufbewahrte fürstliche Korrespondenz herangezogen. Wie Katrin Keller bereits an anderen Beispielen gezeigt hat, ist auch im vorliegenden Fall die - wenn auch oft nur mehr spärlich vorhandene - weibliche Kommunikation von besonderer Bedeutung. Sie hatte oft einen weniger offiziellen und vermehrt persönlichen Charakter und diente - gerade auf der Ebene der nachgeborenen Kaisersöhne - nicht selten der Beilegung von Konflikten und der Intensivierung von Beziehungsgeflechten, wie auch im Austausch mit den Este ersichtlich wird. ${ }^{383}$

\subsubsection{Die Beziehungen der Este zu Erzherzog Ferdinand II. und zum Innsbrucker Hof}

Der Aspekt des regen materiellen und kulturellen Austauschs zwischen Ferrara und Innsbruck wurde bereits im Kapitel Kulturtransfer an verschiedenen Beispielen behandelt und soll hier nur mehr die engen Beziehungen zwischen Erzherzog Ferdinand II. und Alfonso II. besonders nach der Heiratsverbindung mit Ferdinands Schwester Barbara unterstreichen. Noch wichtiger als diese direkte Verschwägerung waren einerseits das durch den Erzherzog initiierte Netzwerk an Bekanntschaften diesseits und jenseits der Alpen, für die der Innsbrucker Hof Dreh- und Angelpunkt wurde und andererseits eine Reihe von Anlässen und Begegnungsmomenten (Faschingsfeiern, Reisen, Einladungen, Hochzeiten, Taufen, Reichstagsbesuche ${ }^{384}$ ), die über die Jahrzehnte und Generationen hinweg die Beziehung zwischen den italienischen und den süddeutschen Reichsfürsten förderten. Nicht nur die geostrategische Lage Innsbrucks an der Nord/ Süd- und Ost/West-Route, von wo aus man von Italien kommend ins Reich, zu den Reichstagen, zu den Verwandten in München oder zum Kaiser nach Wien und Prag und von hier nach Graz reisen konnte, sondern vor allem die Person Erzherzog Ferdinands II. und seine Interessen machten Innsbruck in der zweiten Hälfte des I6. Jahrhunderts zu einem der bedeutendsten süddeutschen Residenzzentren. ${ }^{385}$ Hier trafen sich Mitglieder des Kaiserhauses, der Wittelsbacher und Braunschweig-Lüneburger mit italienischen Fürsten, hier machte die Elite des europäischen Adels im Zuge von Reisen und Kavalierstouren Halt, hier spielte sich ein Großteil der Vermittlung und des Kulturtransfers zwischen Italien und dem Reich ab. ${ }^{386}$

383 KelLer, Erzherzogin Maria von Innerösterreich, I04.

384 Von den am Reichstag teilnehmenden Erzherzögen war Ferdinand sicher jener, von dem sich die Este die zuverlässigsten und schnellsten Informationen und den größten Einfluss erhofften. Beide, Erzherzog Ferdinand und Karl waren z.B. am Reichstag von 1570 präsent. Lanzinner, Deutsche Reichstagsakten. Der Reichstag zu Speyer I 570, Zweiter Teilband, 98 I.

385 Zum Innsbrucker Hof siehe die Beiträge im Sammelband Noflatscher/Niederkorn, Der Innsbrucker Hof; zum Forschungsstand siehe den einleitenden Aufsatz von Noflatscher, Normen.

386 Vgl. schon BŮžEK, Ferdinand von Tirol, 278, $308 f$. 
Waren aller Art, Lebensmittel wie Wein, Obst, Fisch, Getreide und Delikatessen wie Aale, Zitrusfrüchte, Konfekt sowie Stoffe, Bäume und Tiere bestellte und/oder begehrte Kunstobjekte, Heilmittel und nicht zuletzt Fachpersonal wurden zwischen Ferrara und Innsbruck ausgetauscht oder nach München, Wien und Prag weitergereicht. Der reiche Waren- und Gabenaustausch war von einer ebenso ansehnlichen Korrespondenz und regen Gesandtenbesuchen begleitet. Im Archivio di Stato di Modena sind für den Zeitraum von I 567 bis I 59592 Briefe (48 auf Deutsch und davon 40 auch in einer zweiten italienischen Fassung, 44 auf Italienisch) von Erzherzog Ferdinand II. an Alfonso II. und I 2 italienische minute di lettere von Alfonso II. an Erzherzog Ferdinand II. ( I 560-94) erhalten. ${ }^{387}$ Im Tiroler Landesarchiv sind weitere 25 italienische Briefe von Alfonso II. an Erzherzog Ferdinand II. für den Zeitraum I $564-$ I 578 und 24 von Erzherzog Ferdinand an Alfonso (I 564- I 578) aufbewahrt. ${ }^{388}$ In den meisten werden Gesandte mit Briefen und Gaben angekündigt. Dabei zeigt sich, dass sowohl der Erzherzogshof in Innsbruck als auch jener in Graz bezüglich des Austauschs von Informationen und Waren eine unvergleichbare Vermittlerfunktion für den Kaiserhof und die übrigen katholischen wie protestantischen Fürstenhöfe des Reiches übernahm. Als Alfonso II. Früchte, Bäume und Samen nach Innsbruck schickte, von denen er wusste, dass der Kaiser solche haben wollte, bat er Erzherzog Ferdinand nicht nur diese Gaben weiterzureichen, sondern einen seiner Diener in der Setzung der Pflanzen unterrichten zu lassen, damit dieser dann am Kaiserhof die Bäume aus Ferrara fachgerecht pflanzen könne. ${ }^{389}$

Auch mit seiner Schwester Barbara, Herzogin von Ferrara, pflegte Erzherzog Ferdinand II. einen regen brieflichen Austausch. Die im Staatsarchiv von Modena erhaltenen 33 deutschen Briefe ( $5_{5} 65_{-}$I 572) an die Schwester enthalten zumeist Empfehlungen für Personen, die aus dem deutschen in den italienischen Raum und umgekehrt reisen wollten. Auch ihre Hochzeit mit Alfonso II., die der Tiroler Landesfürst sehr befürwortet hatte, aber bei der er, wie er bedauerte, nicht anwesend sein konnte, sowie ihre von Präzedenzschwierigkeiten begleitete Heimführung (zusammen mit der Schwester Johanna) fanden Eingang in die Korrespondenz. Tröstende Worte fand Ferdinand für Barbaras ausbleibende Schwangerschaft, deren Ursache der allgemeinen Auffassung der Zeit entsprechend, ihr zugeschrieben wurde, wenn auch Alfonso bereits in seiner zweiten kinderlosen Ehe war und seine möglicherweise beeinträchtigte Zeugungsfähigkeit schon Eingang in die schriftlichen Überlegungen seiner Ärzte gefunden hatte. Ferdinand erinnerte seine Schwester daran, dass es auch bei »unser frau mutter seligen gedechtnus 5 Jar gewesen er sie schwanger war «. ${ }^{390}$

387 ASMo, ASE, Casa e Stato Carteggio di principi esteri, Germania b ${ }_{5} 58 / 9$.

388 Innsbruck, TLA, Ferdinandea, Kart. 3 I. Pos. 26 Ferrara; Kart. 220 pos. 247 ; Kart. 201. Pos. I 82, welsche Schreiben; Kanzlei Erzherzog Ferdinand, Ein-/Auslauf, Kart. Io.

389 Innsbruck, TLA, Kart. 20I. Pos. I 82, welsche Schreiben, Alfonso II. an Erzherzog Ferdinand II., März I 575 .

390 ASMo, ASE, Casa e Stato, Carteggio di principi esteri, Germania b I $583 / 9$, Erzherzog Ferdinand II. 
Nach dem Tod von Erzherzogin Barbara I 572 flaute die Beziehung zwischen Erzherzog Ferdinand II. und Alfonso II. nicht ab, sondern intensivierte sich sogar noch bis zum fast gleichzeitigen Ableben der beiden Fürsten. Der Innsbrucker Hof war der erste Ansprechpartner für die Versorgung der »deutschen« Bediensteten der Herzogin von Ferrara nach der Aufösung ihres Hofstaates. Diejenigen, die ins Reich zurückkehren wollten, wurden dem Erzherzog zur eigenen Anstellung oder zur Weiterempfehlung übergeben. ${ }^{391}$

Den Großteil der reichen Korrespondenz zwischen Alfonso II. und Erzherzog Ferdinand II. machen vor und nach der Verschwägerung naturgemäß Dankesschreiben und Empfangsbestätigungen sowie Ankündigungen von Lieferungen aus, dicht gefolgt von Empfehlungen für Personen, die an den Höfen Anstellung suchten, ${ }^{392}$ nach Italien zum Sprachstudium reisten oder Schutz auf ihrer Durchreise benötigten. Die beiden Fürsten standen darüber hinaus auch in Notzeiten, so bei drohenden Hungersnöten aufgrund von Getreidemangel, Krieg oder Naturkatastrophen, ${ }^{393}$ einander hilfreich zur Seite. Als Zeichen der besonderen Verbundenheit erlaubte der Este-Fürst z.B. 575 den Durchgang von Waren und Menschen aus Tirol durch sein Herzogtum ohne »Sanitätskontrollen ${ }^{394}$ und ohne Besteuerung. ${ }^{395}$

Der regelmäßige Kontakt zwischen Innsbruck und Ferrara diente natürlich auch dem Austausch von Informationen: Der diesbezügliche Inhalt reichte vom eigenen Befinden bzw. jenem der Anverwandten bis über Neuigkeiten von lokaler und überregionaler Relevanz wie Wahlergebnisse, Todesfälle, Vakanzen, Mobilmachungen, Verhängung der Reichsacht oder des Kirchenbanns, Präzedenzstreitigkeiten, Seuchengefahr etc. In dieser Nachrichtenübermittlung bestand auf dem Freundschaftsverhältnis zwischen den beiden Fürsten basierend, sogar eine gewisse Bringschuld und Erwar-

an Barbara d'Este, März I 569. Tatsächlich kam die erste Tochter, Elisabeth, I 526, fünf Jahre nach der I 52 I zwischen Ferdinand und Anna geschlossenen Ehe zur Welt.

39I Innsbruck, TLA, Kart. 3 I. Pos. 26 Ferrara, Alfonso II. an Erzherzog Ferdinand II., Dezember I 572 , März I 573 .

392 Die jungen Adeligen aus Böhmen, Wilhelm von Rosenberg und Johann der Jüngere von Waldstein, wurden von Erzherzog Ferdinand II. an die Höfe von Mantua und Ferrara empfohlen und auch für ihre weitere Reise nach Malta mit Empfehlungsschreiben ausgestattet. Vgl. BŮżEK, Ferdinand von Tirol, $258 \mathrm{f}$.

393 Der selbst von einem Erdbeben kurz davor Leid geprüfte Alfonso drückte im Januar aus Graz, wo er sich gerade aufhielt, sein Mitgefühl bezüglich der Bedrohung durch das Erdbeben in Tirol, von dem er gehört hatte, aus. Innsbruck, TLA, Kart. 3 r. Pos. 26 Ferrara, Alfonso II. an Erzherzog Ferdinand II., Januar 1572 .

394 Nach Michel de Montaigne waren diese bollette della sanità unabdingbar um Einlass in italienische Städte der Po-Ebene zu bekommen, selbst wenn es keine unmittelbare Seuchengefahr gab. Er vermutete - wahrscheinlich zu Recht -, dass sie verlangt wurden, »um die paar Quattrinos herauszuschlagen, die die Scheine kosten«. Montaigne, Tagebuch einer Reise, 9I.

395 Innsbruck, TLA, Kart. 3 I. Pos. 26 Ferrara, Alfonso II. an Erzherzog Ferdinand II., Dezember 1575, Januar 1576 . 
tungshaltung, wie aus dem vorwurfsvollen Ton Erzherzog Ferdinands herausgelesen werden kann, der I 570 aus anderer Quelle erfahren hatte, dass Alfonso II. wegen der Ansteckungsgefahr ein Einreiseverbot aus allen Ländern des Reiches und so auch aus Tirol erlassen hatte und er sich eigentlich eine persönliche Vorwarnung für diese Maßnahme erwartet hätte. ${ }^{396}$

Neben der Entsendung von Gesandten und deren brieflichen Ankündigung bzw. dem Dank darüber, diese empfangen oder ihnen Briefe mitgegeben zu haben, enthalten zahlreiche Briefe »nur« Grüße oder Glückwünsche und vor allem Gunstbekundungen und dienten dazu, sich regelmäßig in Erinnerung zu rufen und den Adressaten der eigenen Liebe, Freundschaft, Treue und Dienstbereitschaft zu versichern. Die Anzahl der Schreiben intensivierte sich zwar nach der Verschwägerung, war aber auch schon vor I 565 ergiebig. In einem Brief Ferdinands an Ercole II. aus Krakau von I 553 unterzeichnet er bereits als »de Vostra Ex ${ }^{\text {cia }}$ bon amico «. ${ }^{397}$ Die Briefe an den später verschwägerten Alfonso wird er mit »buon amico et come fratello« unterzeichnen. ${ }^{398}$ Diese Diktion entspricht dem neu erworbenen Verwandtschaftsstatus, drückt aber verbunden mit dem Inhalt und dem für den Anderen betriebenen Aufwand auch ein persönliches Näheverhältnis aus. ${ }^{399}$

Nach dem Tod von Erzherzogin Barbara wurde das verwandtschaftliche Band durch ein weiteres Heiratsprojekt, diesmal über die Familie Gonzaga, erneut geknüpft. Alfonso verband sich 1576 in dritter Ehe mit Margherita Gonzaga, während Erzherzog Ferdinand II., der auf seiner Inkognito-Reise von Venedig über Ferrara nach Mantua gekommen war und hier möglicherweise seine zweite Ehe angebahnt hatte, I 582 deren jüngere Schwester, Anna Caterina Gonzaga, heiratete. ${ }^{400}$

Wichtig für die Este waren auch Erzherzog Ferdinands II. enge Beziehungen zu den verwandten Wittelsbachern, besonders seitdem eine Schwester des Erzherzogs, Anna, Herzog Albrecht V.von Bayern geheiratet hatte. Als Zeichen der Verbundenheit vertrat Herzog Ferdinand von Bayern den Habsburger I 582 bei der Heirat per procurationem mit Anna Caterina Gonzaga in Mantua. Allerdings waren die Beziehungen zwischen den Habsburgern und den Wittelsbachern nicht nur von verwandtschaftlichen und freundschaftlichen Bindungen geprägt gewesen. Neben einem steten Antagonismus in der Reichskirchenpolitik herrschte zwischen den beiden Häusern auch ein Präzedenzstreit ${ }^{401}$ bezüglich des Vorrangs im Fürstenrat, den Herzog Wilhelm

396 ASMo, ASE, Casa e Stato, Carteggio di principi esteri, Germania b I $583 / 9$, Erzherzog Ferdinand II. an Alfonso II., November 1585 .

397 Ebd., Erzherzog Ferdinand II. an Ercole II., August I 553.

398 Ebd., Erzherzog Ferdinand II. an Alfonso II., März 1562.

$399 \mathrm{Zu}$ den komplizierten und sich vermischenden Aspekten von Verwandtschaft, Freundschaft und Patronage siehe die Beiträge im Sammelband Schmidt/Guichard/Schuster/Trillmich, Freundschaft und darin besonders JANCKE, Patronage.

400 Sandbichler, Anna Caterina Gonzaga, 43.

40I Dazu siehe den reichen Akt »Ursachen warumb jetzige Erzhertzogen von Österreiche sowol Regie- 
von Bayern nur dem ältesten Erzherzog zugestehen wollte. Auch dieses Thema wurde $\mathrm{zu}$ einer wiederholt vorgebrachten Causa und u.a. in Rom besprochen, wo sich die Gesandten Wilhelms und Ferdinands gegenüberstanden. Wilhelm wollte die Causa vor die Kurfürsten bringen. Dazu kam es zwar nicht, aber der nächste Schritt der Wittelsbacher ließ das Herrscherhaus in Empörung ausbrechen: I 59I nahm Wilhelm von Bayern den Titel »Durchlaucht« an. Die Erzherzöge protestierten beim Kaiser ob dieser Anmaßung. Kaiser Rudolf wollte zwar die Rechte seines Hauses gewahrt wissen, doch nicht um den Preis eines Prozesses und eines Zerwürfnisses mit dem Herzog von Bayern. Er befürchtete, die Kurfürsten, von denen einige Bayern waren, würden sich auf Wilhelms Seite stellen. Der Kaiserhof beließ es dabei; Erzherzog Ferdinand hingegen wies, in ähnlicher Manier wie es Alfonso II. in der Korrespondenz mit Florenz tat, seine Kanzlei an, diesen Titel im Schriftverkehr nicht zu gebrauchen. ${ }^{402}$

Eine weitere Gemeinsamkeit von Erzherzog Ferdinand II. und Alfonso II. d'Este war deren Bewerbung um den Thron von Polen ${ }^{403}$ und damit verbunden wiederum der Wunsch, den Vorrang vor den anderen Erzherzögen für den einen und vor den italienischen Fürsten für den anderen zu erreichen. Ferdinand bewarb sich zweimal um die polnische Krone. I 559 hegte sein Vater, Kaiser Ferdinand I., den Plan, ihn mit der Schwester von König Sigismund zu vermählen, doch dies kam - später auch aufgrund der schon bestehenden Heirat mit Philippine Welser - nicht zustande. Als Sigismund starb, bemühte sich der Kaiser - allerdings erfolglos - eher um die Kandidatur seines Sohnes Ernst. Als Henri von Anjou, der auf den polnischen Thron gefolgt war, nach Frankreich zur dortigen Thronfolge berufen wurde, bemühte sich das Haus Habsburg um eine erste Bewerbung mit dem Kaiser selbst und den drei Erzherzögen, die sich somit gegenseitig Konkurrenz machten. Auch Erzherzog Ferdinand reizte als Nachgeborener - wie Alfonso als ein Herzog unter vielen - die Königskrone, obwohl er mit dem Land nicht viel gemein hatte. Immerhin konnte er - im Unterschied zu Alfonso vorweisen, die böhmischen Slawen und deren Sprache zu kennen. Ferdinand schickte I 575 den Hofsekretär Johann Simoneta, den Grafen Franz Thurn, den Hofvizekanzler Jakob Holzapf, den Hofkammerrat Erasmus Heidenreich und den Hofadvokaten Georg Roner als seine Fürsprecher zu Verhandlungen nach Polen. Wie die estensischen Gesandten, so berichteten auch diese wiederholt nach Tirol, für wie geeignet Volk und Wähler den Erzherzog als ihren neuen König hielten und welch gute Chancen dieser hätte. ${ }^{404}$ Über Alfonso hingegen berichtet Simoneta: »den Herzog Alfons von Ferrara würde ich nicht verachten, wenn nicht manches gegen ihn spräche; von ihm ist keine Nachkommenschaft zu erwarten, er ist verwandt mit dem entwichenen französischen

\footnotetext{
rende als nit Regierende Herrn, dem Haus Bayern an der Stoll und Session zu weichen nit schuldig“, Innsbruck, TLA, Ferdinandea, Kart. 80, Pos. 95.

402 Hirn, Erzherzog Ferdinand II. 2, I36-I 4 I.

403 Vgl. Augustynowicz, Die Kandidaten, 32.

404 Vgl. Hirn, Erzherzog Ferdinand II. 2, 240-246.
} 
König und erneut die Erinnerung an jene Königin Bona, welche so viel Unheil über das Land gebracht - einer ist, den Gott mir erhoben hat, den ich unter Tausenden mir erküre, er allein ist geeignet, uns zu dieser Zeit den Frieden zu bringen und den Krieg zu leiten, dieser eine ist Fürst Ferdinand, Erzherzog von Österreich, Herzog von Burgund. ${ }^{405}$ Die Bedingungen, die aus Polen für die Bewerber kamen, waren hart: So durfte der König zu Lebzeiten nicht die Wahl eines Nachfolgers betreiben oder ohne die Erlaubnis der Stände Krieg führen; er musste 200.000 Taler für die Erhaltung der stehenden Truppen aufbringen und durfte keine Ehe ohne Einverständnis der Stände eingehen. Erzherzog Ferdinand instruierte seine Gesandten, dass sie auf diese Bedingungen nur teilweise eingehen sollten. Diese wiederum monierten, dass die anderen Bewerber dadurch mehr Erfolg haben würden, weil sie die Bedingungen angenommen hätten und mit mehr Geldaufwand um Befürworter buhlten. Sie berichteten, dass sich der Kaiser, Alfonso von Ferrara und Stephan Báthory schon mit Zahlungen bei den polnischen Ständen beliebt gemacht hatten. Daher baten sie um die Vollmacht, die Bedingungen akzeptieren zu können, und um Bargeld. Ferdinand lenkte zwar teilweise ein, doch die größte Forderung, Philippine Welser zurückzulassen, wollte er auf keinem Fall erfüllen. So kam es gegen Jahresende dazu, dass der Kaiser zwar knapp vor Báthory die meisten Stimmen und Fürsprecher hatte, aber die Forderung der ständigen Anwesenheit in Polen nicht erfüllen konnte. Schließlich kam es zu einer Doppelwahl, denn man konnte sich nicht einigen: Maximilian und der Woiwode von Siebenbürgen wurden gewählt. Der Tod von Kaiser Maximilian II. I 576 löste den Konflikt und brachte Báthory schließlich auf den Thron. ${ }^{406}$ Dieser Konkurrenzkampf um den polnischen Thron scheint - wahrscheinlich auch aufgrund dieses glimpflichen Ausgangs - nicht die Beziehung zwischen Erzherzog Ferdinand II. und Alfonso II. d'Este getrübt zu haben.

Nicht nur brieflich oder durch Gesandte, sondern auch persönlich kamen der Habsburger und der Este mehrfach in Kontakt miteinander. Für Ferdinand ist eine Anwesenheit in Italien 1549 im Zuge der Brautreise seiner Schwester Katharina nach Mantua (möglicherweise auch jener von Eleonore I 56I) nachweisbar. Auch I 579 kam er im Rahmen seiner Inkognito-Reise nach Ferrara und Mantua. Alfonso hielt sich vor allem auf den Reisen nach Wien/Prag München bzw. auf der Rückreise davon einige Male in Innsbruck auf. Hier besuchte er seine Verlobte Barbara I564 auf der Reise zu Heiratsverhandlungen mit dem Kaiser. I 57 I hielt er sich in Schloss Ambras bei Innsbruck auf, wo er sich mit seinen Mitreisenden im Ambraser Trinkbuch verewigte. ${ }^{407}$ Drei Jahre später folgte er Ferdinands Einladung, den Fasching in Innsbruck zu

405 Zit. n. Hirn, Erzherzog Ferdinand II. 2, $246 f$.

406 Als dieser im Dezember 1586 starb, begann erneut die Suche nach einem Nachfolger und wieder bewarben sich vier Erzherzöge, darunter auch Ferdinand. Doch die Bewerbung war kurz, schließlich entschied sich Ferdinand seinen Neffen Maximilian bei der Bewerbung finanziell zu unterstützen. Vgl. ebd., $247-262,272-277$.

407 Igálffy, Die Ambraser Trinkbücher, wie bereits oben. 
verbringen, wo er auf die Wittelsbacher traf. ${ }^{408}$ I 592 war er nachweislich ein weiteres Mal in Innsbruck, denn Anna Caterina dankte ihm brieflich für seinen Besuch. ${ }^{409}$ Bei seinen frühen Besuchen kam Alfonso mit Philippine Welser in Kontakt, mit der wahrscheinlich aufgrund der nicht standesgemäßen und lange verheimlichten Verbindung - kein brieflicher Austausch bestand. Die »Welserin« soll aber den Herzog von Ferrara bei seinen Aufenthalten mit ihren Kochkünsten erfreut und ihm ein »Fässl eingemachte Peislbeeren « geschickt haben, wofür er sich mit Hunden revanchierte. ${ }^{410}$

Mit seiner Schwägerin und der zweiten Ehefrau Ferdinands, Anna Caterina Gonzaga, hingegen hatte der Herzog von Ferrara einen regen schriftlichen Austausch. 28 italienische Schreiben an Alfonso II. sind in Modena für den Zeitraum zwischen I 583 und 596 erhalten. Hier werden der Empfang von Briefen und Gesandten (vor allem jenen, die am Weg zum Kaiser waren und in Innsbruck Station machten), Neuigkeiten oder Gunstbekundungen übermittelt. Im Februar I 585 kündigte Anna Caterina ihren Besuch in Mantua und in diesem Zusammenhang auch in Ferrara an. ${ }^{411}$ Als Erzherzogin engagierte sie sich stark für ihre Landsleute und jene, die in Italien Fuß fassen wollten. So empfahl sie $5_{5} 8$ Henrics Starck aus Innsbruck, der nach Mantua gereist war, um als Sekretär und Doktor der Rechte tätig zu sein, jedoch in die Dienste des Herzogs von Ferrara treten und hier die italienische Sprache erlernen wollte. ${ }^{412}$ Schon bald nach ihrer Verheiratung verwendete sie sich für Giovanni Giacomo Panzera de Rangoni aus Verona, der vom Herzog von Ferrara gefangen gehalten wurde. ${ }^{413}$ Auch verabsäumte es die Mantuanerin nicht, Alfonso über die Krankheit und die letzten Monate von Erzherzog Ferdinand auf dem Laufenden zu halten. ${ }^{414}$ Die letzten Briefe der Erzherzogin waren zwei Empfehlungen für einen gewissen Lorenzo, der nach

408 BUீŽEK, Ferdinand von Tirol, 25 If. Zur Festkultur am Innsbrucker Hof vgl. auch SANDBichleR, Festkultur. An den Feierlichkeiten anläßlich der Hochzeit von Ferdinand und Anna Caterina Gonzaga scheint der Este nicht teilgenommen zu haben. Er wird nicht erwähnt und nimmt, anders als der Bruder der Braut, Vincenzo Gonzaga, nicht an dem im Hochzeitskodex Erzherzogs Ferdinand II. beschriebenen Umzug teil. Vgl. Sandbichler, Der Hochzeitskodex. Hier zieht die Autorin auch Parallelen zu anderen Fürstenhochzeiten (München, Graz, italienische Hochzeiten).

409 ASMo, ASE, Casa e Stato, Carteggio di principi esteri, Germania b I 586/ I2, Erzherzogin Anna Caterina Gonzaga an Alfonso II., Juni 1592.

4Io Hirn, Erzherzog Ferdinand II. 2, 336 zitiert aus einem Brief vom April I 576. Auch Kurfürst August von Sachsen bezog sich in seinen Briefen an Erzherzog Ferdinand II. nie auf Philippine, wohl auch, um es sich mit dem über diese Verbindung unglücklichen Kaiserhaus nicht zu verscherzen, wo hingegen der Erzherzog sehr wohl Grüße und Glückwünsche an Anna von Dänemark ausrichten ließ/lassen konnte. SEIdL, Philippine Welser, $76 f$.

4I I ASMo, ASE, Casa e Stato, Carteggio di principi esteri, Germania b I 586/ I 2, Erzherzogin Anna Caterina Gonzaga an Alfonso II., Februar und März (?) I5 85 . Dazu siehe auch TADdeI, Hin und her über die Alpen.

4I 2 ASMo, ASE, Casa e Stato, Carteggio di principi esteri, Germania b I586/ I2, Erzherzogin Anna Caterina Gonzaga an Alfonso II., März 1585.

413 Ebd., Anna Gonzaga an Alfonso II., Mai I 590.

4I 4 Ebd., Anna Caterina Gonzaga an Alfonso II., 4 Schreiben Januar 1595. 
Ferrara ziehen wollte und für Martin Gasser, Kaufmann aus Kempten, dem zwei mittlerweile bankrotte Juden aus Bozen Geld schuldeten. Sie bat Alfonso in dieser Sache $\mathrm{zu}$ intervenieren. ${ }^{415}$

Wie oben und im Kapitel »Kulturtransfer« bereits gezeigt wurde, kam es zwischen Erzherzog Ferdinand II. und Alfonso II. zu einem regen Austausch von Fachkräften und Künstlern und zu Empfehlungen für eben solche. So bedankte sich Erzherzog Ferdinand bei Alfonso II. für die Zusendung seines Waffenmeisters und berichtete mit Bedauern, dass dieser noch nicht arbeiten konnte, weil das passende Eisen erst von weither geholt werden musste. ${ }^{416}$

Ein gutes Beispiel für die »Wanderschaft« eines Handwerkers von einem Fürstenhof zum nächsten, wobei in diesem Fall die Mobilität konfessionsbedingt war, ist jenes des Tübinger Goldschmieds Carl Seckler, der bei seiner »Bewerbung" am Hof von Herzog Ludwig von Württemberg angab, er käme aus Innsbruck, wo er aufgrund seiner konfessionellen Ausrichtung nicht mehr geduldet wurde, er habe aber vorher für die habsburgischen Erzherzöge Karl und Ferdinand und für die Herzöge von Florenz, Ferrara und Mantua gearbeitet. ${ }^{417}$

Ebenso wurden Studierende oder Anstellungssuchende diesseits und jenseits des Alpenhauptkammes unterstützt. Erzherzog Ferdinand setzte sich dabei nicht nur für Tiroler, sondern auch für Personen aus Böhmen ein. Es waren vor allem böhmische Adelige, die nach Innsbruck kamen und von hier aus von Ferdinand nach Mantua oder Ferrara weiterempfohlen wurden. ${ }^{418}$

Im Staatsarchiv von Modena sind auch einige Briefe von Erzherzog Ferdinands II. zweitem Sohn aus der Verbindung mit Philippine Welser, Karl von Burgau (I 560I6 I 8), ${ }^{419}$ erhalten, ${ }^{420}$ die beweisen, dass die Abstammung von einer im Nachhinein legitimierten Verbindung kein Hindernis für die Weiterführung des vom Vater aufgebauten Netzwerkes darstellte. Tatsächlich hatte Karl mit der Heirat mit Sibylle, der Tochter von Herzog Wilhelm und Erzherzogin Maria von Jülich-Kleve-Berg, sogar die Beziehungen zwischen den Kleve und den Habsburgern erneuert. ${ }^{421}$ In den I9 italienischen Schreiben (I 579-I595) des Markgrafen an Alfonso II. d'Este finden sich neben zahlreichen Gunstbekundungen, einige Kondolenzschreiben und Briefe,

4I 5 Ebd., Anna Caterina Gonzaga an Alfonso II., Juni 595 und Juni 1596.

4I6 Als Entschädigung für die dadurch verzögerte Rückkehr des Handwerkers bot der Erzherzog an, ihm vom importierten Material einen Teil abzugeben, da die Beschaffungskosten immer sehr hoch seien. ASMo, ASE, Casa e Stato, Carteggio di principi esteri, Germania b I583/9, Erzherzog Ferdinand II. an Alfonso II., Juli I 570.

4I7 Vgl. Fleischinauer, Renaissance, $224 \mathrm{f}$.

4I 8 BŮžEK, Ferdinand von Tirol, 258.

4I9 Heinrich Benedikt, »Burgau, Karl«, in: NDB 3 , Berlin 1957, 44 (Digitalisat).

420 ASMo, ASE, Casa e Stato, Carteggio di principi esteri, Germania b I585/r I, Karl von Österreich, Markgraf von Burgau an Alfonso II., I 579-I 595 .

42 I RAUCH, Verkaufte Bräute?, 62. 
die verschiedene Geschenke für Alfonso ankündigen oder begleiten, von dem Karl von Burgau sicher war: "mi tiene scolpito nel cuore ${ }^{422}$ Darüber hinaus versuchte der Sohn von Erzherzog Ferdinand einen Passierschein (salvacondotto) auf I 5 Jahre für Virginio del Vecchio zu erwirken, damit sich dieser frei im ferraresischen Raum bewegen konnte. ${ }^{423}$ Als ihm Alfonso dies gewährte, bat der Markgraf gleich um Unterstützung des Überbringers des Dankschreibens, Giovanni Walser, der in Ferrara die Doktorwürde erlangen wollte. ${ }^{424}$

Auch die einem Gott geweihten Leben votierten Erzherzoginnen Magdalena, Margarete und Helena (sie starb allerdings bereits I 566), Töchter von Kaiser Ferdinand I. und Schwestern von Alfonsos zweiter Ehefrau Barbara, pflegten einen brieflichen Austausch mit dem Herzog von Ferrara. Ihr Leben im »Königlichen Damenstift« in Hall, eine einem freien Reichskloster ähnliche Institution, bot den Erzherzoginnen einen größeren Handlungsspielraum und zum Teil mehr Freiheit und Unabhängigkeit als ihren verheirateten Schwestern, denn sie verfügten über eigenes Vermögen, mussten kein ewiges Gelübde ablegen, konnten jederzeit austreten und evtl. heiraten und waren - allen voran Magdalena - die vorletzte politische Instanz vor dem Kaiser, seine Vertreterinnen vor Ort und durch ihre Herkunft und ihren Stand einflussreiche Ansprechpartnerinnen, an die sich weltliche wie kirchliche Fürsten wandten. ${ }^{425}$

Im Haller Damenstift führten die Kaisertöchter ein vom Mäzenatentum geprägtes, hofähnliches Leben. So bemühte sich Erzherzogin Magdalena um eine den benachbarten Fürstenhöfen ebenbürtige Stiftsmusik. Mit dem Hof von Ferrara stand sie seit der Vermählung ihrer Schwester dorthin in brieflichem Kontakt und hatte den Bräutigam bereits ${ }_{15} 65$ auf seiner Reise zum/vom Kaiser in Hall empfangen. ${ }^{426}$ In ihren Schreiben standen Gratulationen zur Eheschließung mit ihrer Schwester, Nachrichten über deren Gesundheitszustand, Grüße und Kondolenzen im Vordergrund. Aber die Erzherzoginnen, allen voran die Gründerin und Administratorin des Haller Damenstifts, Magdalena, nutzten die durch Barbara entstandene Familienbeziehung zu den Este auch, um Personen, wie Alexander Stetner, zu empfehlen, der bei Alfonso in militärische Dienste treten wollte. ${ }^{427}$

Auch mit dem natürlichen Sohn von Kaiser Karl V. und Barbara Blomberg, Juan de Austria; ${ }^{428}$ in den Modeneser Quellen Giovanni d'Austria genannt, pflegten die

422 »er hält mich im Herzen gemeißelt«. ASMo, ASE, Casa e Stato, Carteggio di principi esteri, Germania b I 585/r r, Karl von Österreich, Markgraf von Burgau an Alfonso II., Januar I 58 I.

423 Ebd., Karl von Österreich, Markgraf von Burgau an Alfonso II., Februar I 58 I.

424 Ebd., Karl von Österreich, Markgraf von Burgau an Alfonso II., März I 58 I.

425 Rauch, Verkaufte Bräute?, 30 und Robert Rebiтsch, »Magdalena, Erzherzogin«, in: BiographischBibliographisches Kirchenlexikon 2I (Ergänzungen 8), Herzberg 2003, 876-88I.

426 ASMo, ASE, Casa e Stato, Carteggio di principi esteri, Germania b ${ }_{5} 85 /$ I I , Erzherzoginnen Magdalena, Margarete und Helena an Alfonso II., Juli ${ }_{5} 65$.

427 Ebd., Erzherzoginnen Magdalena, Margarethe und Helena an Alfonso II., März r 568.

428 Don Juan de Austria (Ritter Johann von Österreich), illegitimer Sohn von Kaiser Karl V. und der Bür- 
Este brieflichen Kontakt. Zwischen ${ }^{5} 565$, also mit dem Eintritt Alfonsos in den Familienkreis der Habsburger, und bis zum Tod des Befehlshabers der spanischen Flotte und Statthalter der habsburgischen Niederlande 1578 schrieb der Sieger von Lepanto 2I erhaltene spanische Briefe an den Herzog von Ferrara. In diesen beglückwünschte er den Este zur Vermählung mit Barbara, ${ }^{429}$ empfahl den nach Ferrara reisenden Don Miguel de Moncada vom königlichen Rat ${ }^{430}$ und schickte eine Relazione della battaglia di Lepanto inviata dal Duca Don Giovanni d'Austria I57I auf Spanisch mitsamt Begleitbrief. ${ }^{431}$ Darüber hinaus berichtete Juan Neues vom spanischen Hof und besonders von den Plänen Philipps II., gegen die Türken vorzugehen, ihn nach Mailand zu schicken und von der Armada. ${ }^{432}$ Im Juni 575 erläuterte er Alfonso II., wie er auf Befehl des Kaisers über Cartagena nach Neapel und Sizilien gereist war

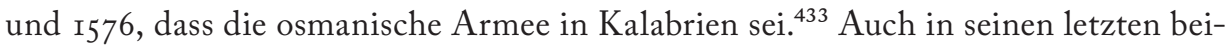
den Lebensjahren tauschte er sich mit dem Herzog von Ferrara über die schwierige Situation - nun bezogen auf die Unruhen in den Niederlanden - und über verschiedene andere Kriegsgeschehen aus, die ihm wenig Zeit zum Schreiben ließ, wie er stets bedauerte. ${ }^{434}$

\subsubsection{Die Beziehungen der Este zu Erzherzog Karl von Innerösterreich und zum Grazer Hof}

Die Beziehungen zwischen dem letzten Herzog von Ferrara und der innerösterreichischen Linie des Hauses Habsburg bestanden mit Erzherzog Karl (II.) hauptsächlich ab dem Zeitpunkt seiner Übernahme des innerösterreichischen Teilerbes.

Erzherzog Karl II. (I 540- I 590) ${ }^{435}$ hatte bei der von seinem Vater, Kaiser Ferdinand I., bestimmten Dreiteilung des habsburgischen Hausbesitzes ${ }_{5} 64$ Innerösterreich und somit die Herzogtümer Steiermark, Kärnten und Krain, die Grafschaft Görz, Gradiska, die Windische Mark und Istrien erhalten. Graz wurde zur Residenz erhoben und dementsprechend ausgebaut. ${ }^{436}$ Durch die Teilung der Erblande kam es zur Intensivierung der Herrschaft vor Ort. Die Erzherzöge Ferdinand und Karl etab-

gerstochter Barbara Blomberg (I 547-I 578). Constantin von WurzBach, "Don Juan d'Austria«, in: Biographisches Lexikon des Kaiserthums Oesterreich 6, Wien I 860, 33 I-336 (Digitalisat). Wilhelm Maurenbrecher, Juan de Austria, in: ADB i4, Leipzig i 88 I, 278-28I.

429 ASMo, ASE, Casa e Stato, Carteggio di principi esteri, Germania b I585/I I, Juan de Austria an Alfonso II., Juli I 565 .

430 Ebd., Juan de Austria an Alfonso II., Juli I 57 I.

43 I Ebd., Juan de Austria an Alfonso II., Oktober I 572.

432 Ebd., Juan de Austria an Alfonso II., Oktober I 572, März, April und November I 574, Februar und Mai I 575 , Februar 1577 .

433 Ebd., Juan de Austria an Alfonso II., Juni I 575, August I 576 und über weitere Reisen Dezember I 576.

434 Ebd., Juan de Austria an Alfonso II., August I 577, Februar I 578.

435 Vgl. Berthold Sutter, »Karl II.«, in: NDB i , Berlin I 977, 24 of.

436 Vgl. Sutter, Graz als Residenz; Novotny/Sutter, Innerösterreich. 
lierten sich jeweils in Innsbruck und in Graz als Territorialfürsten und - anders als ihr irenischer Bruder - als vehemente Verfechter der katholischen Reform. ${ }^{437}$

Bevor Karl ${ }_{5} 64$ die Erbhuldigung der ihm zugesprochenen Gebiete an der südöstlichen Reichsgrenze entgegennahm, reiste er für seinen Bruder Maximilian II. in politischer Mission nach Spanien und in die Niederlande. Im Zuge einer weiteren Reise nach Spanien I 568/69, wo er mit König Philipp II. über die für den Kaiser unergründliche Gefangennahme (und den Tod) des Infanten Don Carlos ebenso wie über die Beschwerden der Niederländer über die Statthalterschaft des Herzogs von Alba sprechen sollte, ${ }^{438}$ hielt er sich auf dem Heimweg sowohl bei seiner Schwester in Florenz als auch bei jener in Ferrara auf. ${ }^{439}$ Im Mai I 569 hier eingetroffen, wurde er neun Tage lang mit großen Festen, Aufführungen, Jagden und einem »Teutsch Gestech» (Tunier mit Lanze) erfreut. Auch von diesen Ehrungen und der besonders aufmerksamen Gastfreundschaft versprach sich Alfonso II. eine positive Fürsprache des Erzherzogs im Reich bezüglich der Präzedenzfrage. ${ }^{440}$ Mit dem Herzog von Ferrara reiste Karl weiter nach Venedig und logierte in dessen Palazzo am Canal Grande, das die Serenissima 1380 dem Markgrafen Nicolò II. d'Este geschenkt hatte. ${ }^{441} \mathrm{Nach}$ dem Venedigaufenthalt kehrten die beiden Fürsten nach Ferrara zurück, amüsierten sich beim außerplanmäßigen Karnevalstreiben im Mai, bevor der Erzherzog zur Verwandtschaft in Mantua aufbrach. ${ }^{442}$

Für Karl von Innerösterreich war eine in jedem Sinn weitreichende Heiratsververbindung mit Elisabeth I. von England oder mit Maria Stuart angedacht gewesen. Als die diesbezüglichen Verhandlungen scheiterten, ${ }^{443}$ ehelichte er im August I 57 I in Wien seine Nichte Maria, die Tochter seiner Schwester Anna und Herzogs Albrecht V. von Bayern. ${ }^{444}$ Mit dieser weiteren Verbindung wurden die Beziehungen zwischen den

437 Rudersdorf, Maximilian II., 88.

438 Friedrich Edelmayer hat gezeigt, dass weder diese Reise - wo der persönliche Kontakt sehr begrenzt blieb, wie auch die Korrespondenz sehr bescheiden war - noch die hohe Pension, die Erzherzog Karl von Innerösterreich erhielt, auf eine die Einheit der Casa de Austria ausdrückende innige Beziehung zwischen dem König von Spanien und dem Oberhaupt der steierischen Linie schlussfolgern lassen. Das Interesse Spaniens lag eher an der Verteidigung der Reichsgrenzen und an der Möglichkeit der Truppenaushebung, sowie letztendlich am Kampf gegen den Protestantismus. Edelmayer, Einheit der Casa de Austria?, 380-385.

439 Zur Reise siehe: Loserth, Die Reise Erzherzog Karls II., i64.

440 Eine Darstellung des Turnieres ist bei: Venturi, Culture et société, $56 \mathrm{f}$.

44I Lazzari, Le ultime tre duchesse, i 78 - I80.

442 Loserth, Die Reise, I65.

443 Vgl. weiterführend Kurt Diemer, Die Heiratsverhandlungen zwischen Königin Elisabeth I. von England und Erzherzog Karl von Innerösterreich I $55^{8-1}$ 570, unveröff. Diss., Universität Tübingen, [Selbstverlag] Biberach 1969 .

444 Unter den Gästen befand sich auch Erzherzog Ferdinand. Vg1. BŮžEK, Ferdinand von Tirol, 226. Als Hochzeitsgeschenk brachte er einen goldenen Becher im Wert von 4.00o ungarischen Dukaten. SuTTER, Graz als Residenz, I I 5. Laut der hier zitierten Sitzordnung bei der Hochzeitstafel war kein Gesandter aus Ferrara da, wohl aber zwei aus Venedig und einer aus Mantua. Ebd. I I 4 f. 
Habsburgern und den Wittelsbachern und gleichzeitig die katholische Seite im Reich gestärkt. ${ }^{445}$

Mit Maria hatte Karl die gut ausgebildete Tochter eines großen Mäzens und Musikliebhabers geheiratet, der zudem eine bedeutende Büchersammlung und eine der ersten Kunstkammern im deutschen Raum an seinem Renaissancehof sein Eigen nannte. Mit ihrem Vater teilte die Braut die große Leidenschaft für die Musik: Albrechts Hofkapelle umfasste 6r Sänger und Instrumentalisten, darunter etliche Italiener. ${ }^{446}$ In Sachen Kunst- und Wunderkammer wetteiferten die Herzöge von Bayern ebenfalls mit Erzherzogs Ferdinand II. Ambraser Sammlung ${ }^{447}$ und Erzherzog Karl von Innerösterreich versuchte, seinen Schwiegervater und seinen Bruder darin nachzuahmen. Seine in der Grazer Residenz errichtete Kunstkammer stach dabei vor allem aufgrund der reichen Sammlung von Musikinstrumenten hervor. ${ }^{448}$

Durch Maria von Innerösterreich gab es eine intensive Beziehungsachse nach Sachsen und besonders zu Kurfürstin Anna, mit der bereits ihre Mutter, Anna von Bayern, in Kontakt gewesen war. Dank der guten Beziehungen zu Sachsen konnte auch Karl von Innerösterreich seiner Leidenschaft für Waffen mithilfe des vom Kurfürsten entsandten sächsischen Erzgießers Martin Hilliger frönen. ${ }^{449}$ Aus diesen Kontakten und dem geistigen wie materiellen Austausch wird einmal mehr ersichtlich, dass, „Glaubensdifferenzen innerhalb des eigenen, des fürstlichen Standes kein Hindernis für persönliche Kontakte« waren. ${ }^{450}$ Jenseits der Besuche, Beziehungen und des Austauschs mit evangelischen Fürsten bekämpfte das Erzherzogspaar in Innerösterreich und besonders in Graz die Ausbreitung der lutherischen Glaubenslehre. Eine weibliche Strategie, die auch Fürstinnen wie Anna Caterina Gonzaga in Tirol oder ihre Tochter Anna als Gemahlin von Kaiser Matthias anwandten, war dabei eine ostentativ zur Schau gestellte Frömmigkeit. Dabei dienten nicht nur Stiftungen und sakrale Gebäude, sondern auch die geistliche Musik der Stärkung des Katholizismus. Zwar gab es schon vor der Eheschließung mit Karl von Innerösterreich Musikkontakte zwischen München und Graz, ${ }^{451}$ doch die neue Erzherzogin von Innerösterreich förderte die weltliche wie geistliche Musik in hohen Maßen und bestellte in München Noten für italienische Lieder vor allem für die Kompositionen von Orlando di Lasso. Einige

445 Hierbei waren die Wittelsbacher den Habsburgern der innerösterreichischen Linie Ansporn und Vorbild in der Bekämpfung des Protestantismus und in der »Rekatholisierung« des Landes. Vgl. Kohler, Bayern als Vorbild. Zu den »Rekatholisierungsmaßnahmen« siehe auch: Amon, Abwehr der Reformation.

446 Keller, Erzherzogin Maria von Innerösterreich, I7. Zu den italienischen Musikern in Graz mit Kurzbiografien siehe: Einstein, Italienische Musik, Io- I 4.

447 Vgl. Sandbichler, "Ambras«.

448 Schlosser, Die Kunst- und Wunderkammern, i I 8.

449 Vgl. Thomas, Erzherzog Karl II.

450 Keller, Erzherzogin Maria von Innerösterreich, ro9.

45 I Vgl. Federhofer, Musikpflege; Hubmann, Musik am Grazer Habsburgerhof. 
ihrer Musiker kamen aus Italien über München nach Graz, wie Simone Gatto und Pietro Antonio Bianco (Bianchi) ${ }^{452}$ oder wurden bei ihrem Italienaufenthalt auf der Rückreise aus Spanien in Mailand und Mantua rekrutiert; etliche Musiker fanden beim Tod der Erzherzogin Maria I608 Anstellung in der Hofkapelle ihres Sohnes, des späteren Kaiser Ferdinands II. ${ }^{453}$ Gerade von den Werken des am bayerischen Hof tätigen Orlando di Lasso gab es durch Maria einen systematischen Import. Der vor allem von Oberitalien (Mantua, Ferrara), aber auch von Rom ausgehende musikalische Transfer nach Norden fand in Erzherzogin Maria von Innerösterreich zuerst und in der Folge in den beiden Kaiserinnen Eleonora d.Ä. und d.J. Gonzaga in Wien bedeutende Vermittlerinnen. ${ }^{454}$

Wie ihr Tiroler Pendant, Anna Caterina Gonzaga, versuchte Maria somit den in Innerösterreich ausufernden Protestantismus durch künstlerische Mittel ebenso wie durch Wallfahrten und Klostergründungen vehement entgegenzutreten. ${ }^{455}$

Die Kontakte zwischen Graz, München und Ferrara wurden vor allem über Innsbruck durch eine reiche Korrespondenz, einen regelmäßigen Gabenaustausch und durch die gegenseitige Besorgung von benötigten oder erwünschten Gütern, vor allem aus Italien, sowie durch Besuche gepflegt. I 584 reiste das Erzherzogspaar von Innerösterreich zur Taufe der zweiten Tochter von Erzherzog Ferdinand II. und Anna Caterina Gonzaga eigens nach Tirol. Keller wertet diesen Aufwand nicht nur als Ausdruck von persönlicher Verbundenheit, sondern zu Recht auch als politisches Handeln; schließlich musste jede Verbindung, alte wie neue durch regelmäßigen Kontakt und Geschenke aufrechterhalten werden. ${ }^{456}$

Als Landesfürst an der südöstlichen Reichsgrenze hatte Karl nicht nur mit dem sich ausbreitenden Protestantismus, sondern besonders mit der unmittelbaren ständigen Türkengefahr zu kämpfen. ${ }^{457} \mathrm{Um}$ diese Bedrohung in den Griff zu bekommen, war er genötigt, dem evangelischen Adel Konzessionen ${ }^{458}$ zu gewähren. Dies brachte ihm

452 Beispiele von Notenhandschriften dieser Musiker sind in Sutter, Graz als Residenz, 2 I 8.

453 Keller, Erzherzogin Maria von Innerösterreich, $77 \mathrm{f}$.

454 Vgl. Koldau, Familiennetzwerke, 55-66. Federhofer, Musikpflege.

455 Erzherzogin Maria hinterließ zu ihrer memoria eine Stiftung des Klarissinnenklosters in Graz, für dessen Gründung sie sich ab 1597 in Rom bemühte und es I602 auch konkretisieren konnte. Anna Caterina Gonzaga hatte 1607-16 I 2 auf dem Grundbesitz ihrer Innsbrucker Residenz, der Ruhelust, ein Doppelkloster, bestehend aus dem Regelhaus der Terziarinnen, eine halbweltliche Einrichtung mit Keuschheits- und Gehorsamsgelübde, und dem Versperrten Kloster der Servitinnen mit strenger Klausur und der gemeinsamen Kirche der Maria Opferung gegründet. I $783 / 84$ wurden beide Einrichtungen von Kaiser Joseph II. aufgehoben, ihr Vermögen und Teile des Archivs veräußert oder eingezogen. Beimrohr, Das Tiroler Landesarchiv, 323 f. Taddei, Anna Caterina Gonzaga, 23 I-234; Diess., Anna von Tirol.

456 Keller, Erzherzogin Maria von Innerösterreich, I 5 I - I60, I 98.

457 Vgl. LoserTh, Innerösterreich.

$45^{8}$ I 572 die Grazer, 1578 die Brucker Religionspazifikation: nur Gewissens-, nicht Kultusfreiheit. Vg1. Luttenberger, Innerösterreich, $362-365$. 
u.a. den päpstlichen Vorwurf der »Ketzerförderung« ein, dem Karl nach Vorbild der Tiroler und der italienischen Verwandten mit einer forcierten Glaubenspolitik entgegenzuwirken versuchte. Im Zuge dessen förderte er Ordensniederlassungen und holte die Jesuiten nach Graz, mit deren Hilfe er die katholische Konfessionalisierung ${ }^{459}$ vorantrieb. Diesen Orden hatte auch Erzherzogin Barbara als zweite Ehefrau von Alfonso II. d'Este in Ferrara stark gefördert, nicht zuletzt dadurch, dass sie in seiner Kirche ihre letzte Ruhestätte fand.

Die Korrespondenz zwischen Alfonso II. d'Este und dem fast gleichaltrigen Erzherzog Karl beginnt, laut Überlieferung im Archivio di Stato di Modena, mit dem Jahr I $_{5} 65$, also gleich nach der Übernahme der Landesherrschaft in Innerösterreich des einen und dem »Eintritt « des anderen in den Familienverband der Habsburger. ${ }^{460}$ Zwischen ${ }_{5} 65$ und $5_{586}$ sind 42 Briefe (I 5 davon auf Italienisch, die restlichen auf Latein) von Erzherzog Karl an Alfonso II. in Modena erhalten (die Antwortschreiben hingegen sind nicht erhalten). ${ }^{461}$ Dabei werden gegenseitige Gesandtschaften angekündigt bzw. der Erhalt von Briefen durch diese bestätigt, Grüße, Gunstbekundungen und Freundschaftsversicherungen sowie Neuigkeiten wie Karls Heiratspläne mit Maria von Bayern ${ }^{462}$ ausgetauscht. Erzherzog Karl hatte nicht selten Streit mit der Republik Venedig und erhielt I 568 auf seine Bitte hin rechtlichen Beistand aus Ferrara. Doktor Roncagalli, ein Rechtsgelehrter aus dem Herzogtum Ferrara, wurde ihm für die Verhandlungen gegen Venedig im Streit um Friaul zur Seite gestellt, wofür er sich im Januar 1570 bei Alfonso herzlich bedankte. ${ }^{463}$ Als dieser am Ende desselben Jahres sein Vorhaben bekannt gab, zum Kaiser zu reisen, lud ihn Karl ein, auf der Durchreise in seinen Ländern Halt zu machen. ${ }^{464}$ Von dieser im Januar 1572 erfolgten Reise wissen wir allerdings nur aus einem Brief des Este an Erzherzog Ferdinand, in dem er mitteilte, er habe - momentan in Graz weilend - vom Erdbeben in Innsbruck gehört. ${ }^{465}$ Im Oktober des gleichen Jahres berichtete Alfonso von der Krankheit der Herzogin Barbara d'Este, Karls Schwester, und schließlich von ihrem Tod; ihm wurde

459 Mezler-Andelberg, Erneuerung des Katholizismus.

460 Allerdings gibt es bereits 555 einen italienischen Brief, mit dem Karl Alfonsos Vater, Ercole II., Gunstbekundungen und die Versicherung der gegenseitigen Liebe und des Wohlwollens aller erzherzoglichen Brüder sandte. ASMo, ASE, Casa e Stato, Carteggio di principi esteri, Germania b I $585^{/ \text {I I , }}$ Erzherzog Karl an Ercole II., Oktober I 555.

46 I ASMo, ASE, Casa e Stato, Carteggio di principi esteri, Germania b ${ }_{5} 8_{5}$ / I I.

462 Ebd., Erzherzog Karl an Alfonso II., August I57I. Alfonso stand, wie viele andere Fürsten, auf der vom Brautvater Herzog Albrecht aufgestellten Hochzeitsliste, doch es trafen - vor allem aufgrund der Pestgefahr - viele Entschuldigungen ein, darunter auch die aus Ferrara. Vgl. Keller, Erzherzogin Maria von Innerösterreich, 24-27.

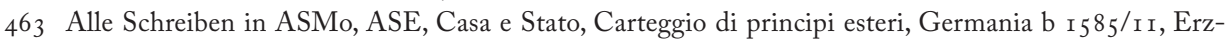
herzog Karl an Alfonso II., Juni I 568 und Januar und August I 570.

464 Ebd., Erzherzog Karl an Alfonso II., Dezember I 57 I.

465 Innsbruck, TLA, Kart. 3 I. Pos. 26 Ferrara, Alfonso II. an Erzherzog Ferdinand II., Januar I 572. 
von Graz aus mit einem Brief und durch den Gesandten kondoliert. ${ }^{466}$ In den darauffolgenden Jahren bat der Erzherzog wiederholt um Passiererlaubnis durch die estensischen Gebiete für seine Untertanen auf dem Weg nach Rom. Wiederholt dankte er für die von Alfonso geschickten, für den Kaiser in Prag bestimmten Bäume und Samen und versprach, sie verlässlich weiterzuleiten. ${ }^{467}$ Nach der Nachricht über den Tod Kaiser Maximilians II. im Februar I577 bat Karl im März desselben Jahres Alfonso um Unterstützung für die Verteidigung der Grenzen gegen die Osmanen. ${ }^{468}$

In den letzten Jahren der Korrespondenz zwischen Graz und Ferrara wurden Untertanen empfohlen wie der Kammerdiener Fulvio Molza oder um Gnade für einige gebeten, die im estensischen Fürstentum in Haft waren. Außerdem benötigte Karl erneut einen Gelehrten der juridischen Fakultät von Ferrara, um mit Venedig über die freie Durchfahrt in der Adria nach Malta zu verhandeln. ${ }^{469}$

Erzherzog Karl schrieb zwischen I565 und I57 I seiner Schwester Barbara, Herzogin von Ferrara, elf erhaltene deutsche Briefe. Darin wurden vor allem Grüße und Glückwünsche, vor allem nach ihren Genesungen, übermittelt. Auch benachrichtigte er seine Schwester über seine bevorstehende Reise nach Spanien im August I 568 und über seine angedachte Heirat mit Maria von Bayern. Die Schwester wurde in diesem Belang viel früher, nämlich bereits im Januar I 57 I darüber informiert, während ihr Gemahl Alfonso offiziell die Nachricht erst unmittelbar vor der Hochzeit im August übermittelt bekam. ${ }^{470}$

In zwei Briefen an Kardinal Luigi d'Este, den Bruder des Herzogs von Ferrara, bat Erzherzog Karl den estensischen Familiengeistlichen um Unterstützung für einen mit dem Bann belegten Kaplan ( 1580 ) und für seinen Berater, den Bischof von Triest $(\mathrm{I} 585)^{471}$

Im Modeneser Staatsarchiv ist auch ein kleiner Bestand an Briefen von Maria von Innerösterreich an den Herzog von Ferrara, bzw. die letzten drei an Cesare, Herzog von Modena, erhalten. ${ }^{472}$ Dabei nutzte die Erzherzogin die Familienverbindung nach Ferrara um Personen, die sich an sie gewandt hatten, weiterzuempfehlen oder zu vermitteln, wie Fabricius de Malaspina, der in die Dienste Alfonsos II. d'Este eintreten

466 ASMo, ASE, Casa e Stato, Carteggio di principi esteri, Germania b $5_{5} 85 /$ I I, Erzherzog Karl an A1fonso II., Oktober 1572 .

467 Ebd., Erzherzog Karl an Alfonso II., November I 573, März I 575, April I 575.

468 ASMo, ASE, Casa e Stato, Carteggio di principi esteri, Germania b I 585/ I , Erzherzog Karl an Alfonso II., Februar und März I 577 .

469 Ebd., Erzherzog Karl an Alfonso II., März I 580 , September I 580 , Februar 1585.

470 Ebd., Erzherzog Karl an Barbara d'Este, i s Schreiben I 565 - I 57 I.

47 I Ebd., Erzherzog Karl an Kardinal Luigi d'Este, September 1580 und Oktober 1585.

472 Wenn von Fürstinnen, von denen man weiß, dass sie viel geschrieben haben, Briefe fehlen, so ist das oft darauf zurückzuführen, dass ihre Schreiben nicht in eigenen Beständen, sondern in anderen Sachzusammenhängen abgelegt wurden oder aber aufgrund der Tatsache, dass weibliche Korrespondenz archivarisch weniger wertvoll erschien, skartiert wurden. KeLLER, Erzherzogin Maria von Innerösterreich, I6r. 
wollte oder Bartolomeo Brachino, der einen Erbschaftsstreit in Ferrara hatte. ${ }^{473}$ Der Rest sind Gunstbekundungen und Dankesschreiben, so für Cesares Gratulation zur königlichen Heirat von Marias Tochter, Margarethe, mit Philipp (III.) von Spanien, die der Papst im November 1598 in Ferrara geschlossen hatte, nachdem der Herzog aus dem eingezogenen Lehen vertrieben worden war. ${ }^{474}$ Seine Vertreibung aus Ferrara war unter anderem auch durch Unterstützung aus Innerösterreich zugunsten des Papstes erfolgt. Der sehr engagierte Nuntius Girolamo Portia hatte sich um Hilfestellung für das Kirchenoberhaupt von Seiten der Erzherzogspaares und des Kaisers bemüht, damit sie keinen einzigen Soldaten für Cesare passieren ließen (»di non permettere che a favor di Don Cesare passi pure un soldato da quei paesi«) und Waffen für den bevorstehenden Kampf um Ferrara besorgten. ${ }^{475}$ Vom Nuntius kam auch der Vorschlag, nachdem er in Graz mit großem Zulauf die Exkommunikation Cesares veröffentlicht hatte, dass der Kaiser die Situation nutzen könnte, um die Reichslehen Modena und Reggio zurückzuholen. ${ }^{476}$

Nach dem Abschluss der Devolution und Cesares Rückzug nach Modena traf Erzherzogin Maria auf dem Weg nach und von Spanien I 599 in Ferrara den Papst und nutzte die Zusammenkunft, um das Kirchenoberhaupt über die Glaubenslage in Innerösterreich zu informieren. ${ }^{477}$ Nichtsdestotrotz waren die Beziehungen zwischen Graz und Modena nicht sichtlich getrübt, wenn Maria I604 Cesare d'Este für die herzliche Aufnahme ihres Sohnes Ernst Maximilian in Italien dankte, der sich dort sichtlich wohl gefühlt hatte. ${ }^{478}$

Auch der I 590 für den jungen Erzherzog Ferdinand vormundschaftlich in Innerösterreich regierende Erzherzog Ernst ${ }^{479}$ hat eindeutige Spuren in der im estensischen Archiv aufbewahrten Korrespondenz hinterlassen. Von diesem zweiten Sohn Kaiser Maximilians II. sind I9 spanische, italienische, lateinische und deutsche Schreiben erhalten. Anders als Matthias und Maximilian (III.) oder Rudolf, die sich als Erzherzöge meistens gemeinsam an die Este wandten, korrespondierte er zumeist allein mit

473 ASMo, ASE, Casa e Stato, Carteggio di principi esteri, Germania b I 585 / r r, Erzherzogin Maria an Alfonso II., Dezember I 578 , November 1598 .

474 Ebd., Erzherzogin Maria an Cesare d'Este, November 1598. Keller, Erzherzogin Maria von Innerösterreich, $\mathrm{I} 84 \mathrm{f}$.

475 Rainer, Grazer Nuntiatur II/4, Nr. 373 und 374, 40 If, Pietro Aldobrandini an Portia, Dezember I 597. Und zur ausstehenden Bezahlung für die Besorgung der Waffen: Zingerle, Grazer Nuntiatur II. 5, Nr. 96.3, 253, Pietro Aldobrandini an Portia, Dezember 1599 und Nr. I22.2, 297, Aldobrandini an Portia, April I600.

476 Ebd., Nr. 392, 420, Portia an Pietro Aldobrandini, Januar 1598.

477 Keller, Erzherzogin Maria von Innerösterreich, 60, I35; ZIngerle, Grazer Nuntiatur II/5, Nr. I 59.2, 390, San Giorgio an Portia, September I600 und Nr. I64.I, Oktober 1600.

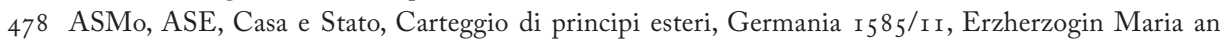
Cesare d'Este, Juni I604.

479 Vgl. Constantin von Wurzbach, »Ernst, Erzherzog von Österreich«, in: Biographisches Lexikon des Kaiserthums Oesterreich 6, Wien I860, I 8of. (Digitalisat). 
den italienischen Verwandten. Bei den Briefen handelt es sich um Gunstbekundungen, Kondolenzschreiben, Bestätigungen von Gesandtschaften, aber auch um die Vermittlung von Personen, die nach Italien oder dezidiert nach Ferrara kommen wollten. ${ }^{480}$ In einem Schreiben bat Ernst um Intervention für die im estensischen Herzogtum in Schwierigkeiten geratene mantuanische Adelige Fulvia Andreasi, die ihren Besitz an der Grenze zu Ferrara hatte. ${ }^{481}$

Wie dieser Streifzug über die erhaltenen Korrespondenzen zwischen den Este und den Mitgliedern der Habsburg-Familie gezeigt hat, spannten die Herzöge von Ferrara ein über Generationen andauerndes, sehr feingliedriges, die Zweit- und Drittgeborenen, die weltabgewandten Töchter und die illegitim Geborenen miteinbeziehendes Netzwerk, das seit der Verheiratung mit einer habsburgischen Erzherzogin besonders stark war und über ihren Tod hinaus anhielt.

\subsubsection{Die Beziehungen der Este zu den Wittelsbachern}

Trotz der Schwächung durch drei spätmittelalterliche Landesteilungen, der gegenläufigen Interessen und der Uneinigkeit einzelner Mitglieder war das Fürstentum und Haus $^{482}$ Bayern den Habsburgern an Einfluss und Macht fast ebenbürtig. So standen sie in Konkurrenz zueinander bei der Bewerbung um den böhmischen Thron ${ }_{5} 26$ und um die deutsche Königswürde I53 I sowie in dem vor allem von Erzherzog Ferdinand II. betriebenen Präzedenzstreit. Einig waren sich die Wittelsbacher und Habsburger hingegen im Kampf gegen die neuen Glaubenslehren: Die Herzöge von Bayern drückten ihre Orthodoxie mit insgesamt drei Mandaten (I 527 , I 530, I 53 I) gegen die Täufer und alle anderen aus, die von der alten Glaubensordnung abwichen, und stärkten dadurch noch mehr ihre jahrhundertelange enge kirchenpolitische, aber auch kulturpolitische Verbindung nach Italien und Rom. ${ }^{483}$

Des Weiteren war die Domus Austriae neben der Pfalz der Hauptheiratsmarkt für die Wittelsbacher. ${ }^{484}$ Albrecht IV., genannt der Weise ( ${ }^{*}$ I447), zunächst Herzog von Bayern-München und nach dem Landshuter Erbfolgekrieg von I505 bis I 508 Her-

480 Hier gibt es (auch wiederholte) Empfehlungen für einen gewissen Petrus von Ondegerts oder einen Antonius von Egg sowie für den jungen Johannes Christophorus Ferenberger für ihren Aufenthalt in Italien. Auch der Sohn von Sigfried Preynes, Freiherr von Stubing, wird zum Studium in Padua empfohlen. Bonifacius Brama hingegen sollte bei seinen Geschäften in Italien unterstützt werden. ASMo, ASE, Casa e Stato, Carteggio di principi esteri, Germania I 585 / I , Erzherzog Ernst an Alfonso II., August I 578, Oktober I 584 und Juni I 587 , Juni I 584 , Oktober I 585 , Dezember I 594.

48 I Ebd., Erzherzog Ernst an Alfonso II., Juni I 583.

482 Über den »Haus-Begriff«und einigen Parallelen zwischen den Habsburgern und den Wittelsbachern hat Reinhard Stauber Schlüsse gezogen: Stauber, Herrschaftsrepräsentation, $376 f$.

483 Weitlauff, Wilhelm IV. und Ludwig X. Vgl. auch Scherbaum, Die bayerische Gesandtschaft in Rom.

484 Ziegler, Die Herzöge von Landshut, I37-r4 I. Stauber, Die Herzöge von München. 
zog von ganz Bayern, vereinte nicht nur das Land, sondern verhinderte durch das Primogeniturgesetz weitere Erbteilungen. Er hatte mit Kunigunde von Österreich ( 465 - I 520) drei Söhne: Wilhelm IV. genannt der Standhafte (*I493) regierte als Herzog von Bayern I 508 - I 550 zusammen mit seinem Bruder Ludwig X. (* ${ }^{4} 494$, reg. I 5 16- I545), was beweist, dass die Primogeniturordnung sich nur langsam durchsetzen konnte. ${ }^{485}$ Wilhelm IV. heiratete I 522 Markgräfin Maria Jakobäa von Baden ( 507 - I 580). Der dritte Sohn, Ernst, (I 500- I 560) wurde Administrator von Passau und dann von Salzburg. Eine Tochter Albrechts IV., Susanne (I $502-$ I 543), heiratete in erster Ehe I5 I 8 Markgraf Kasimir von Brandenburg-Kulmbach († I 527 ) und in zweiter Ehe I 529 Pfalzgraf Ottheinrich von Pfalz-Neuburg (I 502-I 559). ${ }^{486}$ Eine weitere Tochter, Sibylle (I489-I5 I9), heiratete I5 I I Kurfürst Ludwig V. von der Pfalz (I 478- I 544), während ihre Schwester Sabine (I492-I564) im gleichen Jahr Herzog Ulrich I. von Württemberg ( I 487- I 550) ehelichte.

Zwischen Ercole II. d'Este und Herzog Wilhelm IV., bzw. dessen Sohn Albrecht V., sowie Susannes zweiten Ehemann, Ottheinrich, bestand eine rege Korrespondenz. I 4 Briefe sind im Staatsarchiv in Modena vom reformierten Fürst Ottheinrich, Herzog von Bayern, Pfalzgraf bei Rhein an Ercole II. (I533- I 542) und sechs von Wilhelm IV. aufbewahrt.

Ottheinrich, dessen Ruf, wenig an der Reichspolitik interssiert gewesen zu sein, zwar von Axel Gotthard revidiert wurde, war nichtsdestoweniger ein dem Tanz, der Jagd und den Künsten besonders zugewandter Fürst. ${ }^{487}$ Um seiner Leidenschaft zu frönen, erhielt er aus Ferrara Jagdtiere, für die er sich I 533 bei Ercole II. bedankte. ${ }^{488}$ I 536 beglückwünschte der Pfalzgraf den Este zu seinen auch im Reich bekannten Turnierfähigkeiten und bat gleichzeitig um die Zusendung von einigen Exemplaren aus der berühmten estensischen Pferdezucht. ${ }^{489}$ Als Gegengabe erhielt der Este durch den Kämmerer Rudpertus eine Rüstung übermittelt. ${ }^{490}$ Dieser Bedienstete und seine Familie wollten Italienisch lernen und wurden gleichzeitig mit der Überreichung des Geschenks von Ottheinrich dem Herzog von Ferrara aufs wärmste empfohlen. ${ }^{491}$ Zwei Jahre später wurde durch Leonhard Rachlinger eine Ganzkörperrüstung ${ }^{492}$ für Ercole

$485 \mathrm{Zu}$ ihrer Regentschaft vgl. Lutz/Ziegler, Das konfessionelle Zeitalter I, 322-372.

$486 \mathrm{Zu}$ diesem, der in seinen jungen Jahren nach Italien und von hier ins Heilige Land reiste, siehe: EdeL, "Ottheinrich«, 655f, sowie die Beiträge im Sammelband Pfalzgraf Ottheinrich. Politik, Kunst und Wissenschaft im I6. Jahrhundert, hg. v. der Stadt Neuburg an der Donau, Regensburg 2002.

487 Gotthard, »Frölich gewest«.

488 ASMo, ASE, Casa e Stato, Carteggio di principi esteri, Germania b I593/r9, Pfalzgraf Ottheinrich von Bayern an Ercole II., Juli I 533

489 Ebd., Pfalzgraf Ottheinrich von Bayern an Ercole II., September 1536.

490 Ebd., Pfalzgraf Ottheinrich von Bayern an Ercole II., August 1537.

49I Ebd., Pfalzgraf Ottheinrich von Bayern an Ercole II., August I 537.

492 So führend die Este in der Feuerwaffenproduktion waren, so sehr begehrten sie Erzeugnisse der Plattnerkunst von jenseits der Alpen. I 542 schickte auch Herzog Ulrich von Württemberg Ercole II. eine 
übersandt; I 540 kam der bayerische Gesandte erneut mit Falken nach Ferrara. ${ }^{493}$ Im Gegenzug zur Übersendung des Plattenharnisches erhielt Ottheinrich, der im Begriff war, seine Hofkapelle aufzubauen, von Ercole II. sechs Harfen. ${ }^{494}$ Auch versuchte der Pfalzgraf Personen an den ferraresischen Hof zu vermitteln bzw. zu empfehlen, so einen Leonhard Schwartz aus Nürnberg und einen Höfling namens Martinus Mayor de Furchstadt. ${ }^{495}$

Nachdem Georg Stockhamer, der Kämmerer von Herzog Wilhelm IV. von Bayern, Ercole II. I 535 besucht und dabei den Wunsch seines Herrn nach einem Maultier geäußert hatte, machte sich der Este sogleich auf die Suche nach einem geeigneten Tier. ${ }^{496}$ Als Stockhamer 1540 als Gesandter auf dem Weg nach Rom war, war sein Austausch mit dem Este ernsterer Natur: Er berichtete von den Schwierigkeiten seines Dienstherrn mit dem Pontifex und mit Kaiser Karl V. in Glaubenssachen. ${ }^{497}$

In den vier erhaltenen Briefen von Jakobäa Gräfin von Baden, Pfalzgräfin bei Rhein, Herzogin von Bayern, Ehefrau von Wilhelm IV. an Alfonso II. sind ausschließlich Gunstbekundungen, Dankes- und Kondolenzschreiben sowie die Ankündigung von Gesandten enthalten. ${ }^{498}$

Zwischen I 530 und I 542 wandte sich auch der bayerische Mitregent, Ludwig X., in neun Briefen (zumeist gleichzeitig) an Alfonso I. und Ercole II.. Hierbei übersandte er Gunstbekundungen $^{499}$ und Empfehlungen, so für den Hauptmann Valentin Schirm ${ }^{500}$ oder für den jungen Johannes Wolfgang, Sohn des Freiherrn von Sarnthein, der nach Italien kommen wollte. ${ }^{501}$ Aus der Korrespondenz wird ersichtlich, dass auch Ludwig Pferde aus der estensischen Zucht erhielt. ${ }^{502}$

Wilhelms IV. Sohn und Nachfolger war Albrecht V. ${ }^{503}$ genannt der Großmütige (* $\left.{ }^{*} 528\right)$. Er regierte als Herzog von I 550 bis I 579, als erster alleiniger Souverän, und wurde r 546 mit Erzherzogin Anna von Österreich, Tochter Kaiser Ferdinands I., verheiratet. Mit dieser Verbindung stärkte er nicht nur das Beziehungsgeflecht mit den

Stirnplatte und eine Rüstung. ASMo, ASE, Casa e Stato, Carteggio di principi esteri, Germania b I604/30, Ulrich von Württemberg an Ercole II., Oktober I 542.

ASMo, ASE, Casa e Stato, Carteggio di principi esteri, Germania b I593/r 9 , Pfalzgraf Ottheinrich von Bayern an Ercole II., April I 539, April I 540.

494 Vgl. Brunner, »Die Lieblich Kunst der Musica«, 252.

495 ASMo, ASE, Casa e Stato, Carteggio di principi esteri, Germania b I593/r 9, Pfalzgraf Ottheinrich von Bayern an Ercole II., März I 540 und Mai I 542.

496 München, BayHStA, Kurbayern, Äußeres Archiv ooog, Ercole II. an Wilhelm IV., April I 535.

497 ASMo, ASE, Casa e Stato, Carteggio di principi esteri, Germania b I593/I 9, Pfalzgraf Ottheinrich von Bayern an Ercole II., März, April und November 1540.

498 Ebd., Jakobäa von Bayern an Alfonso II., November I 572-März I5 80, 4 Briefe.

499 Ebd., Herzog Ludwig X. an Alfonso I. und Ercole II., Mai 1535.

500 Ebd., Herzog Ludwig X. an Alfonso I. und Ercole II., März I 532.

50I Ebd., Herzog Ludwig X. an Ercole II., Juni I 542.

502 Ebd., Herzog Ludwig X. an Alfonso I. und Ercole II., März, Juni, November I 536.

503 Dazu und in der Folge: Baumstark, Albrecht V. 
Habsburgern, sondern reklamierte für sich auch die Erbfolge des Hauses Österreich im Falle eines Erlöschens des Mannesstammes. Darüber hinaus band er sich mit seinem Regierungsantritt I $55^{\circ}$ an seinen Schwiegervater Ferdinand und an seine Nachfolger Maximilian II. und Rudolf II. als einer der treuesten Vasallen und befreundeten Fürsten im Reich. Doch die Münchener Fürsten näherten sich durch die Familienbande nicht nur dem Kaiserhof an, sondern auch den Erzherzogshöfen von Graz und Innsbruck und durch Ferdinands Heiratspolitik den Herzogsfamilien von Mantua, Florenz und Ferrara. Die enge Verbindung zu Philipp II. ergab sich auch durch die Aufnahme des Wittelsbachers in das Netz von Pensionsempfängern des spanischen Königs. ${ }^{504}$

Albrecht V. gilt als der erste große Mäzen des Hauses Wittelsbach, als Ahnherr und Gründer der meisten heute noch erhaltenen bayerischen Kunstsammlungen und als Schöpfer Münchens als Hauptstadt der Künste. Seine großartigen Sammlungen von antiken Plastiken, Münzen, Kleinkunst, Malerei und deren »standesgemäße« Unterbringung in eigens dafür errichteten Gebäuden sowie seine starke Förderung der Musik und von Musikern, wie Orlando di Lasso, brachten ihm Ruhm, aber auch einen enormen Schuldenberg ein. ${ }^{505}$ Das Interesse an artificalia und naturalia (wie der ihm von Maximilian II. geschenkte Elefant), Kunstwerken und eigens für ihn komponierten Musikstücken, an edler Kleidung und kostspieliger Lebensführung war Teil der Repräsentation und Reputation von Rang und Würde dieses Renaissancefürsten. Behilflich bei der Inszenierung seiner Gelehrtheit und seines Kunstsinns waren ihm der flämische Arzt Samuel Quiccheberg, der ab I 559 seine Sammlungen konzeptionell plante und koordinierte, Hans-Jakob Fugger und Jacopo Strada, die als Agenten und Kaufleute seine Erwerbungen vermittelten und koordinierten. Durch diese "Fachleute« erschuf Albrecht die bedeutendste Sammlung nördlich der Alpen, die zum Vorbild für jene in Ambras, Dresden, Prag, Mantua und Florenz wurde. ${ }^{506}$ Gerade durch die fürstliche Repräsentation brachte er Bayern an die Spitze des Reiches und durch die strenge, zusammen mit seiner Gemahlin vorangetriebene katholische Reform (z.B. I 555 Verankerung des Jesuitenordens in Ingolstadt) errichtete er ein katholisches Bollwerk im süddeutschen Raum. ${ }^{507}$ Auch Erzherzogin Anna unterstützte die Sammelleidenschaft ihres Ehegatten, indem sie das Familiennetzwerk nutzte und den neu gewonnenen florentinischen Schwager, Francesco de'Medici, um Kunstwerke aus Florenz bat. ${ }^{508}$ Ein Werk Giambolognas (Betsabea) wurde als Dank für den überaus

504 Vgl. Edelmayer, Söldner und Pensionäre, i ro - I 46. Vgl. auch das Kapitel »Pensionen als Geschenke« bei Groebener, Gefährliche Geschenke, I89- I 94.

505 Zur Förderung der Musik und zur herzöglichen Hofkapelle unter Wilhelm IV. und Albrecht V. siehe: Nösselt, Ein ältest Orchester, $33 \mathrm{f}$.

506 Baumstark, Albrecht V., I 8 i - i 83, I 86. Strada wurde 1558 Antiquar am Kaiserhof, doch noch in den I $560 e r$ Jahren konnte er Albrecht erfolgreich fünfzig antike Skulpturen aus Rom vermitteln.

507 Baumstark, Albrecht V., I74f. Ausführlich: Lutz/Ziegler, Das konfessionelle Zeitalter, 373-392.

508 RaUch, Verkaufte Bräute?, 59. 
herzlichen Empfang Francescos am Münchener Hof auf seiner Reise über die Alpen zu Braut und Kaiser geschickt. Dies sollte nicht der einzige Austausch von Kunstobjekten mit dem Hof der Wittelsbacher sein, der nun zum Verwandtschaftskreis der Medici gehörte, denn Wilhelm V. erbat sich noch I 595 von Großherzog Ferdinando I. eine bronzene Christusstatue für sein Grabmal. ${ }^{509}$ Eine besondere Gemeinsamkeit, die einige bayerische Herzöge, die Este und die Habsburger des I 6. Jahrhunderts verband, war der Habitus der fürstlichen Arbeit an der Drechselbank. Sowohl in Ferrara als auch auf Schloss Ambras und in der Münchener Neuveste gab es eine Drechslerwerkstatt für die fürstliche Betätigung. ${ }^{510}$

Von Albrecht V. von Bayern sind für den Zeitraum zwischen I 553 und I 57834 Briefe an Ercole II. und an Alfonso II. erhalten. Darin werden Personen empfohlen wie Georgius a Paumgarten, der in Ercoles Dienste treten wollte, ${ }^{511}$ oder der junge Sebastianus Zenger, der militärisch versiert und aus gutem Haus war und in Italien die Sprache erlernen wollte. ${ }^{512}$ Der Herzog von Bayern wünschte sich aber mit dem ferraresischen Hof und dem Musikliebhaber Ercole vor allem einen Austausch von »schönen Melodien« und dachte vor allem an die Werke für die Messe des Kapellmeisters Cyprianus. ${ }^{513}$ Die letzten Schreiben aus Bayern, die Ercole II. erreichten, baten ihn in einer Schuldnercausa für Petrus Bonaventura aus Ferrara eintreten ${ }^{514}$ und nach Möglichkeit schöne Pferde nach München schicken zu wollen. ${ }^{515}$

Die beiden Herzöge, Albrecht V. und Ercole II. verband auch ein zum politischen Eklat avancierter Heiratsfall, dessen Lösung die Grenzen der Legalität weit ausdehnte. ${ }^{516}$ Graf Ladislaus Fraunberger zum Haag, einer der letzten freien Reichsgrafen an der Grenze des bayerischen Herzogtums, diente I 524 im Heer Kaiser Karls V. gegen Frankreich. Als er in französische Gefangenschaft geriet, wurde ihm vorgeworfen, zum Feind übergelaufen zu sein. Daraufhin wurde seine Grafschaft eingezogen und er wurde geächtet. Erst I 53 I konnte er sein mittlerweile anderweitig vergebenes Gebiet zurückkaufen. Wieder in kaiserlicher Gnade zog er den Zorn des bayerischen Herzogs auf sich, als sich unter Förderung seiner Frau, Marie Salome von Baden, die lutherische Lehre in seiner Grafschaft auszubreiten begann. Der Konflikt mit Herzog

509 Marx, Politica culturale al femminile, I 5 I.

5 Io Stierhof, Die bildenden Künste, 4r. Zur künsterlichen Betätigung von Fürsten und Fürstinnen siehe den Tagungsband von Annette Cremer/Matthias Müller/Klaus Pietschmann (Hgg.), Fürst und Fürstin als Künstler. Herrschaftliches Künstlertum zwischen Habitus, Norm und Neigung (= Schriften zur Residenzkultur I I), Berlin 2018.

5 I I ASMo, ASE, Casa e Stato, Carteggio di principi esteri, Germania b I 593/I 9, Albrecht V. von Bayern an Ercole II., Januar I 553.

5 I 2 Ebd., Albrecht V. von Bayern an Ercole II., Februar 1555.

5 I 3 Ebd., Albrecht V. von Bayern an Ercole II., April I 557.

5 I 4 Ebd., Albrecht V. von Bayern an Ercole II., Januar I 559.

5 I 5 Ebd., Albrecht V. von Bayern an Ercole II., Juli I 559.

5 I6 Damit haben sich bereits auseinandergesetzt: Janker, Grafschaft Haag; Wieland, German Aristocracies, $270 f$. 
Albrecht verschärfte sich im Laufe der folgenden Jahre. I 555 reiste Ladislaus nach Ferrara, wo er in zweiter Ehe Emilia, eine Tochter aus dem Haus der Pio von Carpi, im estensischen Herzogtum heiraten wollte. Zwischen Ercole d'Este, den Pio und Ladislaus kam es zu stark umstrittenen Heiratsverhandlungen, die schließlich in einem versuchten Giftanschlag auf den Grafen endeten. Da dieser auf die gestellten Bedingungen, nämlich in die Mitgift im estensischen Herzogtum zu investieren und seinen Wohnsitz nach Italien zu verlegen, nicht eingehen wollte, da er befürchtete, seine Abwesenheit in Haag könnte ihm zum Vorwurf gemacht werden, verschärfte sich die angespannte Situation in Ferrara weiter. Schließlich wurde ihm vorgeworfen, ein Ketzer zu sein und seine erste Frau vergiftet zu haben. Die bereits mit ihm verheiratete Emilia wurde in dem Kloster San Bernardo in Ferrara untergebracht. Ladislaus kehrte zwar rechtlich verheiratet, aber ohne Braut, die ihm den ersehnten Erben hätte schenken können, nach Haag zurück; da er nicht erneut heiraten konnte, wurde das Gebiet nach seinem Tod I 566 dem Herzogtum Bayern einverleibt. Damit hatten die Este den Wittelsbachern einen besonders wertvollen Dienst erwiesen, denn Albrecht V. erhielt nicht nur eine Gebietserweiterung, sondern konnte die lutherische Enklave, die Ladislaus in der Grafschaft Haag geschaffen hatte, auflösen. ${ }^{517}$ In der Korrespondenz zwischen den Herzögen von Bayern und den Este erinnert nur ein Brief vom November I 574 bezüglich eines noch offenen Erbschaftsstreits zwischen den Erben der Emilia Pio und jenen des Grafen von Haag an diesen Vorfall. ${ }^{518}$

Die Unterstützung in heiklen Angelegenheiten war allerdings nicht einseitig: Als Albrecht V. erfuhr, dass Alfonso im Sommer I 565 zu Heiratsverhandlungen zum Kaiser reiste, schickte er ihm seinen Gesandten, Johann Georg von Preysing in Huebenstain, und zudem Sigismund Viehauser, einen Doktor beider Rechte, die ihm beim Vorbringen seines Anliegens behilflich sein sollten. ${ }^{519}$

Neben Glückwünschen, Kondolenzschreiben und Gunstbekundungen erreichten Alfonso II. d'Este vor allem Empfehlungen aus Bayern, so für den Musikus Johannes Baptista Pinelli ${ }^{520}$ oder für die Gräfin von Aremberg und ihre Familie, die nach Rom wollten. ${ }^{521}$ Auch die bayerischen Gesandten sollten mit dem Hinweis, dass sie keine ansteckenden Krankheiten hätten, ungestört nach Süden reisen dürfen. ${ }^{522}$ In seinen letzten beiden (erhaltenen) Briefen bat Albrecht V. von Bayern darum, Johannes von

5 I 7 Janker, Grafschaft Haag, 233-240.

5 I 8 ASMo, ASE, Casa e Stato, Carteggio di principi esteri, Germania b I 593/r 9, Wilhelm V. von Bayern an Alfonso II., November I 574.

5 I 9 Ebd., Albrecht V. von Bayern an Alfonso II., Juli I565. Auch bei der darauffolgenden Reise Alfonsos ins Reich schickte ihm Albrecht seinen Gesandten Wilhelm Leschius, ebd., Dezember I 57 I.

520 Ebd., Albrecht V. von Bayern an Alfonso II., Juni I 570.

52 I Ebd., Albrecht V. von Bayern an Alfonso II., April I 575.

522 ASMo, ASE, Casa e Stato, Carteggio di principi esteri, Germania b I 593/I 9, Albrecht V. von Bayern an Alfonso II., März und Mai I 577 . 
Puebenhausen in die herzoglichen Garde Alfonsos II. aufnehmen zu wollen ${ }^{523}$ und fragte um Hilfe für seinen Sohn Ernst, der im Reich gegen die Häresie und für die Verteidigung des katholischen Glaubens kämpfte.

Albrechts V. Ehefrau Anna schrieb Alfonso II. (I565-I585) sechs lateinische Briefe, gleich viele wie ihrer Schwester Barbara in einem Jahr (I560) auf Deutsch (weitere Briefe sind nicht erhalten). Während die Schreiben an Alfonso höfliche Dankoder Kondolenzbekundungen sind, ${ }^{524}$ enthalten jene an Barbara vorrangig Empfehlungen für die Tochter der Bayernfürstin, Helena, und für zwei Prediger auf dem Weg nach Rom, ${ }^{525}$ was einmal mehr die weibliche Seite von Patronage zeigt.

Wie verschiedene Korrespondenzbeispiele zeigen, bestand auch vor Alfonsos »Einheiratung ins Reich« eine Vernetzung mit dem bayerischen Fürstenhaus, ein regelmäßiger Austausch von Gesandten, Gaben und Informationen. Ab dem Zeitpunkt aber, als durch die habsburgischen Schwestern ein enge(re)s Verwandtschaftsband entstand, wurde der Inhalt der Korrespondenz persönlicher und intimer. Außerdem nehmen die Schreibenden in ihren Briefen ab diesem Moment Bezug auf das familiäre und verwandtschaftliche Beziehungsgeflecht, aufgrund dessen sie einen erhöhten Informationsstand besaßen. So wurde Alfonso I 57 I von Herzog Albrecht gebeten, dasselbe Arzneiöl, von dem er wusste, dass Erzherzog Ferdinand II. es aus Ferrara erbeten und erhalten hatte, auch nach München zu schicken. ${ }^{526}$

Der Sohn und Nachfolger von Albrecht V. und Anna von Österreich, Wilhelm V., ${ }^{527}$ genannt der Fromme (I 548- I626), regierte wie Alfonso II. bis I 597/98 und wurde mit seiner I 568 geschlossenen, maßgebenden Prunkhochzeit ${ }^{528}$ mit Prinzessin Renata von Lothringen berühmt. ${ }^{529}$

523 Ebd., Albrecht V. von Bayern an Alfonso II., März und April I 578.

524 Ebd., Anna von Bayern an Alfonso II., August I 565-Juni I 586, 6 Briefe.

525 Ebd., Anna von Bayern an Barbara d'Este, April I 5 68-Juni I 568, 6 Briefe.

526 München, BayHStA, Kurbayern, Äußeres Archiv oor 9, Alfonso II. an Albrecht V. von Bayern, Dezember 157 I.

527 Vgl. Sammer, Wilhelm V.

528 Maßgebend deshalb, weil nach Marx: „Die Verbindung von höfischer Repräsentation und musikalischer Ausführung war seit der Veröffentlichung des Berichts über die Münchner Fürstenhochzeit von I 568 und des in ihr enthaltenen enthusiastischen Lobs der Hofkapelle ein obligates Indiz der italianità im deutschen Raum.« MarX, Italianità, 22. Zu den Feierlichkeiten in München im Vergleich zu anderen Fürstenhochzeiten: SAndiichler, Der Ehrenkodex, 44-66. Siehe auch: Nösselt, Ein ältest Orchester, 37 mit dem Musikprogramm.

529 Die Einladung war auch an die Fürsten von Mantua, Ferrara, Florenz sowie nach Spanien. Polen und Sachsen und an den Wiener Hof ergangen. BAAder, Der bayerische Renaissancehof, 38 . Aus Ferrara und Mantua war niemand da. Nur die Medici hatten einen Gesandten geschickt. Der Verfasser der Hochzeitsbeschreibung des Musikus am Münchener Hof, Massimo di Troj(i)ano, führt dies eher auf die Kurzfristigkeit der Vorbereitungen als auf Unwillen zurück. Vgl. Die Vermählungsfeier des Herzogs Wilhelm des Fünften von Bayern mit Renata, der Tochter des Herzogs Franz des Ersten von Lothringen zu München im Jahre I 568, in italienischer Sprache geschrieben von Massimo di Trojano, frei übersetzt von Friedrich Würthmann, München I 842, 8, Digitalisat, https://books.google.at/books? 
Das Herzogspaar Albrecht und Anna hatte eine Tochter, Maria Anna (I 55 I - I608), die I 57 I Erzherzog Karl II. von Innerösterreich ehelichte, und einen weiteren Sohn Ernst (I554-I6r2), der Erzbischof von Köln und Bischof von Lüttich wurde. Ein dritter Sohn, Ferdinand (* I550- I608), Prinz von Bayern, war zunächst für eine geistliche Karriere vorgesehen, schlug aber die militärische Laufbahn ein. I 588 heiratete Herzog Ferdinand in morganatischer Ehe, Maria von Pettenbeck, Tochter des Haager Landrichters. Wegen dieser nicht standesgemäßen Verbindung musste er der bayerischen Thronfolge entsagen und begründete die Ferdinandische Seitenlinie der Wittelsbacher, der Grafen von Wartenberg. ${ }^{530}$ Von ihm, der aufgrund seiner italienischen Beziehungen Erzherzog Ferdinand auf dessen Inkognitoreise nach Venedig, Ferrara und Mantua begleitet hatte, sind in Modena für den Zeitraum von I 563 bis I 58820 Briefe an Alfonso II. erhalten. Da er ${ }_{5} 65$ unter den Hochzeitsgästen bei der Vermählung von Erzherzogin Johanna mit Francesco de'Medici war, genoss er auf dem Weg dorthin die hervorragende Gastfreundschaft der Herzöge von Ferrara. ${ }^{531}$ Am ferraresischen Hof muss der junge Fürstensohn beeindruckende Turnierarten kennengelernt haben, da ihm Alfonso ein Jahr nach seinem Besuch "palloni« und »bracciali« samt Bedienungsanleitung zukommen ließ, die der Fürst versprach mit seinem Bruder ausprobieren zu wollen. ${ }^{532}$ Der Gegenbesuch erfolgte im Jahr darauf: Auf dem Rückweg von seiner erfolgslosen Türkenmission kam Alfonso im Oktober/November I 566 nach München und besuchte dort seine Anverwandten, um dann erst im Dezember, nach vier Monaten, zu seiner Ehefrau Babara nach Ferrara zurückzukehren. ${ }^{53}$

In den meisten Schreiben Ferdinands von Bayern geht es um Gunstbekundungen und die Ankündigung von Gesandtschaften. Doch der Herzogssohn setzte sich auch für junge Adelssöhne ein, die nach Italien reisen wollten. So empfahl er einen gewissen Giovan Pietro de Gevarra, der auf dem Weg ins Königreich Neapel in Ferrara Aufnahme finden sollte, ${ }^{534}$ ebenso wie der Italienreisende Johannes Werner Riederer ${ }^{535}$

$\mathrm{id}=\mathrm{c}_{3}$ RBAAAAcAAJ\&pg=PA $\&$ \&hl=de\&source=gbs_toc_r\&cad=2\#v=onepage\&q\&f=false, Zugriff: I 6.9. 2020.

530 Vgl. Schreiber, Geschichte des bayerischen Herzogs Wilhelm V. Hier siehe Kap. 4 zur Ferdinandischen Linie und den Grafen von Wartenberg.

53 I ASMo, ASE, Casa e Stato, Carteggio di principi esteri, Germania b I 593/r 9, Ferdinand von Bayern an Alfonso II., Januar und März I 566.

532 Ebd., Ferdinand von Bayern an Alfonso II., Mai I 567 . Bei Baader ist die Zusendung solcher Bälle (pilas ventosas) auch für I 57 I belegt, BAADER, Der bayerische Renaissancehof, 68 .

533 LAzzari, Le ultime tre duchesse, I 54.

534 ASMo, ASE, Casa e Stato, Carteggio di principi esteri, Germania b I 593/I 9, Ferdinand von Bayern an Alfonso II., September I 568. Bei Baader wird ein Stallmeister namens Gian Pietro Givara genannt, der 574 mit Empfehlungsschreiben und Geschenken nach Mantua und Ferrara geschickt wurde und der wohl derselbe wie I 568 gewesen sein dürfte. BAAder, Der bayerische Renaissancehof, 9i, Anm. I 59 und 160 .

535 ASMo, ASE, Casa e Stato, Carteggio di principi esteri, Germania b I 593/r 9, Ferdinand von Bayern an Alfonso II., Juli I 570 . 
oder Johannes Fröschlin, der mit spärlichen Italienischkenntnissen in römische Dienste treten sollte ${ }^{536}$ oder einen jungen Mann am bayerischen Hof, der in Ferrara die Reitkunst erlernen wollte. ${ }^{537}$

Auch der Nachfolgeanwärter Wilhelm V., der in vieler Hinsicht die Regierung seines Vaters weiterführte, hatte Beziehungen nach Ferrara. Als Bekämpfer der Reformation und Erneuerer der katholischen Kirche behielt er die Bistumspolitik seines Vaters bei, förderte den Jesuitenorden, sammelte und gab Kunstwerke in Auftrag und förderte mit der Weiterverpflichtung von Orlando di Lasso ${ }^{538}$ weiterhin die Musik in München. ${ }^{539}$ Diesen Kapellmeister, der 1585 mit dem Organist Joseph Ascanius nach Italien reiste und u.a. in Ferrara Halt machen sollte, ${ }^{540}$ empfahl Wilhelm Alfonso und bedankte sich anschließend für das vom Herzog von Ferrara ausgesprochene Lob für »seinen« Künstler. ${ }^{54}$ Schließlich war ein fürstliches Kompliment eines Protegés eine Ehrung für den Patron selbst.

Herzog Wilhelm V. führte einen prächtigen Hof und war (daher) wie sein Vater bzw. sogar noch höher als dieser verschuldet. Von Letzterem hatte er 6 10.00o Gulden an Schulden geerbt, zu denen die hohen Ausgaben für den Kölner Krieg kamen. Von seinem Vater unterschieden ihn ein ausgeprägter Reliquien- und Wallfahrtskult - er kam selbst bis Loreto - und eine größere Versessenheit auf die Erhaltung der Reinheit des katholischen Glaubens. Auch diese religionspolitischen Aspekte gehörten wie das Mäzenatentum zur herrschaftlichen Darstellung und Repräsentation. Als er am I 5. Oktober I 597 zugunsten seines Sohnes Maximilian I. von Bayern abdankte, hinterließ er nicht nur ein kulturell blühendes und katholisch relativ gefestigtes Herzogtum, sondern auch einen neuen beachtlichen Schuldenberg und eine wirtschaftlich ruinöse Lage. ${ }^{542}$

Von Wilhelm V. ist im Staatsarchiv von Modena eine reiche Korrespondenz für den Zeitraum zwischen I 569 und I 597 erhalten: 70 Briefe sind an Alfonso II., weitere vier an Barbara gerichtet. Auch von Wilhelms Ehefrau, Renata von Lothringen, gibt es vier Briefe an Alfonso II. und zwei an seine dritte Gattin, Margherita Gonzaga-d'Este. Die Korrespondenz mit Wilhelm ist vorrangig von Empfehlungen für Hofleute und

536 Ebd., Ferdinand von Bayern an Alfonso II., September 1573.

537 Ebd., Ferdinand von Bayern an Alfonso II., März 1577.

538 Orlando di Lasso war 1530 in Mons (Bergen, heute Belgien) geboren worden, hielt sich I 544 - I 553 in Neapel und Mailand auf und trat I 557 als Tenorist in die bayerische Hofkapelle ein. 1562 wurde er Hofkapellmeister. 1567 reiste er erneut nach Italien. Drei Jahre später wurde er in den Adelsstand erhoben. 1573 und $I_{57} 8$ war er in Venedig, ${ }_{5} 582$ in Verona, ${ }_{5} 52$ und ${ }_{5} 544$ hielt er sich mit Herzog Wilhelm V. am Innsbrucker Hof auf. Er starb 1594 in München. Vgl. Albrecht, Das Herzogtum Bayern, 30 .

539 Vgl. Nösselt, Ein ältest Orchester, 45-56.

540 ASMo, ASE, Casa e Stato, Carteggio di principi esteri, Germania b I593/rg, Wilhelm V. an Alfonso II., September 1585 .

54I Ebd., Wilhelm V. an Alfonso II., Dezember 1585.

542 Vgl. Sammer, Wilhelm V., i $89-200$. 
Untertanen, Passieranfragen für Italien- und besonders Romreisende und von Warenund Geschenkeaustausch geprägt. I 568 empfahl der bayerische Herzog den jungen Johannes Mattheus Soner, der in Ferrara die italienische Sprache erlernen wollte und später als Gesandter hier eingesetzt wurde, ${ }^{543}$ sowie Wolfgang Goppolt, der sich durch den Herzog von Bayern als Kriegsmann für den Herzog von Ferrara empfahl. ${ }^{544}$

Auch der Güteraustausch kam nicht zu kurz: I 57 I wurde durch einen Kaufmann die Sendung eines Mörsers aus Bayern brieflich angekündigt, ${ }^{545}$ drei Jahre später kamen Pferde aus dem Königreich Neapel über Ferrara nach Bayern zusammen mit Armbrüsten, einer Uhr und einem Schreibtisch. ${ }^{546}$ Aus seinem Herzogtum schickte Alfonso regelmäßig Fische und Konfekt ${ }^{547}$ sowie nicht näher definierte »balle ${ }^{548}$ Auch die berühmten Majoliken aus Ferrara kamen nach München durch den Gesandten Ascanio Geraldino und erfreuten sich so großer Beliebtheit, dass noch weitere Vasen bestellt wurden. ${ }^{549}$ Noch mehr als diese Kunstwerke interessierte den bayerischen Herzog das estensische Gestüt. Immer wieder fragte Wilhelm nach guten Rassepferden aus Ferrara für sich ${ }^{550}$ und für seine Freunde..$^{551}$

Neben dem brieflichen Kontakt, dem Gabentausch und verschiedenen Bemühungen um Patronage kam es zwischen den Wittelsbachern und den Este auch zu (einseitigen) finanziellen Anfragen und Geldleihen. Kredite oder Bürgschaften waren unter frühneuzeitlichen Adeligen gängige Aspekte von verwandtschaftlichen und freundschaftlichen Beziehungen und erst mit der Verdrängung der Freundschaft in den Bereich des Privaten im Zuge des späten I 8. Jahrhunderts war man immer mehr darauf bedacht, Geldgeschäfte davon zu trennen. ${ }^{552}$ I 582 ließ Wilhelm V. nachfragen, ob Alfonso bereit sei, zum Antritt seines Bruders als Bischof von Hildesheim diesem 2.00o Gulden zu leihen, die mit dem St. Michaeler Feiertag eingenommen werden würden. ${ }^{553}$ Dies war nicht der erste Kredit durch die Este, denn im September I 582 war der Gesandte

543 ASMo, ASE, Casa e Stato, Carteggio di principi esteri, Germania b I593/r9, Wilhelm V. an Alfonso II., Februar 1 569. Zu den Sprachaufenthalten am Hof von Ferrara siehe: TADDEI, »Nach Italien nit allein zur Erlehrnung der Sprache«.

544 Ebd., Wilhelm V. an Alfonso II., April I 58 I, deutscher Brief Goppolts und italienische Übersetzung beigefügt.

545 Ebd., Wilhelm V. an Alfonso II., November I 57 r.

546 Ebd., Wilhelm V. an Alfonso II., Februar I 574 (Auflistung der Gegenstände).

547 Ebd., Wilhelm V. an Alfonso II., März I 574.

548 Ebd., Wilhelm V. an Alfonso II., September 1576.

549 München, BayHStA, Fürstensachen 0007 und oo г Kasten Schwarz 7603, der Herzog von Ferrara an den Herzog von Bayern, Dezember I 589 , Mai 1590.

$55^{\circ}$ ASMo, ASE, Casa e Stato, Carteggio di principi esteri, Germania b r593/r9, Wilhelm V. an Alfonso II., Juli, Oktober I 577 , Oktober 1578.

55 I Ebd., Wilhelm V. an Alfonso II., Mai ${ }_{5} 83$.

552 Asch, Freundschaft, 277, 282.

553 ASMo, ASE, Casa e Stato, Carteggio di principi esteri, Germania b r593/r9, Wilhelm V. an Alfonso II., August 1582 . 
Cato beauftragt worden, die Rückzahlung der acht Jahre zuvor verliehenen I 2.00o Golddukaten, die für die Verteidigung des alten Glaubens in Köln ${ }^{554}$ benötigt worden waren, zur Erhaltung der guten Freundschaft zwischen Bayern und Ferrara, zurückzuverlangen. ${ }^{555}$ Doch dieser Aufforderung wurde nicht nachgekommen; im Gegenteil kam es im darauffolgenden Jahr mit der Versicherung einer schnellen Rückzahlung ${ }^{556}$ sogar zu weiteren Geldanfragen (18.00o Gulden) für den Bruder Ernst, die Alfonso schließlich erhörte. Die Bemühungen des bayerischen Gesandten Arenitus Collius und seine beim Herzog von Ferrara erreichten Zugeständnisse sind in einem Extract aus der Relation zusammengefasst. Hier beschreibt der Gesandte, wie Alfonsos II. Berater, Montecatinus, zunächst keine Möglichkeit gesehen hatte, weiteres Geld zu verleihen, schließlich jedoch eingelenkt und weitere 18.000 bereitgestellt hatte, sodass die Wittelsbacher dem Herzog von Ferrara schlussendlich 30.000 Golddukaten schuldeten. ${ }^{557}$ Bereits im Dezember I 585 zeichneten sich Schwierigkeiten ab, die geschuldete Summe aufzutreiben, da sowohl die Fugger als auch Venedig (angeblich) Liquiditätsprobleme hatten. ${ }^{558}$ Diese und weitere Beispiele zeigen, dass die Este im Reich als wohlhabend galten und imstande waren, größere Geldsummen zu verleihen, sodass die missliche wirtschaftliche Lage des estensischen Fürstentums in der zweiten Hälfte des r 6. Jahrhunderts, die den Abfall Ferraras von den Este beschleunigte, im Reich gar nicht ernst genommen wurde. Dies war auch auf die Tatsache zurückzuführen, dass die Herzöge von Ferrara den Stereotyp des reichen, stets liquiden italienischen Fürstenhauses selbst bedienten und nach anfänglichem Zögern zumeist auf die Geldbitten eingingen. Alfonsos Bereitschaft, den Wittelsbachern Geld auf unbestimmte Zeit zu leihen, vergalten diese ihm allerdings nicht, als er in Notzeiten um Getreidelieferungen aus Bayern bat. I 59 I bedauerte Wilhelm V., wie bereits schon Jahre zuvor, ihm aus Knappheit die erbetene Getreidemenge nicht zukommen lassen zu können. ${ }^{559}$

554 Zum Krieg um das Erzstift Köln und die damit gewonnene einflussreichste Mitgliedschaft im Kurkolleg für die Wittelsbacher siehe: Albrecht, Das konfessionelle Zeitalter 2, 396-400; Pastor, Geschichte der Päpste 9, Kap. 9. "Katholische Reform und Restauration in Deutschland und der Schweiz.« Dritter Teil, $595-662$.

555 München, BayHStA, Kurbayern, Äußeres Archiv o026-27, Renatus Catus an den Herzog von Bayern, September 1582.

556 ASMo, ASE, Casa e Stato, Carteggio di principi esteri, Germania b I593/rg, Wilhelm V. an Alfonso II., Mai, Juli, August 1583 .

557 München, BayHStA, Kurbayern, Äußeres Archiv oo68-88, Extract aus der Relation des Arenitus Collius was er bis Juni 1583 beim Herzog von Ferrara erreicht hat, Juni 1583 .

558 ASMo, ASE, Casa e Stato, Carteggio di principi esteri, Germania b I593/r9, Wilhelm V. an Alfonso II., Dezember I 585 . Angesichts der Tatsache, dass Herzog Albrecht V. eigene und von seinem Vater geerbte Schulden in der Höhe von mehr als einer Million Gulden hatte, das Herzogtum aber jährlich gerade einmal I 20.000 Gulden Ertrag abwarf, wundert der Rückzahlungsverzug nicht. BAUMSTARK, Albrecht V., I 77 .

559 ASMo, ASE, Casa e Stato, Carteggio di principi esteri, Germania b I593/r9, Wilhelm V. an Alfonso II., Februar, April r 59 r. Ebd., Ludwig X. an Ercole II., Februar 1540. 
Mit der Bitte um einen Kredit wandte sich auch Ernst, der verschuldete Fürstbischof von Freising, Hildesheim, Lüttich, Münster, Fürstabt der Reichsabtei StabloMalmedy und ab I 583 Erzbischof von Köln, persönlich an Alfonso II. In den I6 erhaltenen Briefen ( $1574-$ I 585 ) sind verschiedene Empfehlungen enthalten sowie die Ankündigung eines Vertrauten des Kirchenfürsten, der die bis nach Italien gelangten bösen Gerüchte über Ernst bereinigen sollte. ${ }^{560}$ Er bedankte sich für das ferraresische Geld, das er über seinen Bruder Wilhelm erhalten hatte und bat zu Jahresende I 575 um noch weitere 5.000 scudi d'oro mit der erneuten Beschwichtigung, seine eklatante Geldnot und horrende Verschuldung seien nur böse Gerüchte. ${ }^{561}$ Als ihn Alfonso sieben Jahre später an die mittlerweile auf I 2.000 scudi d'oro gestiegenen Kredite erinnerte, versicherte der Erzbischof, dass er diese nicht vergessen habe, bedauerte aber, dass die Pfründe, die er als "Braut« erhalten habe, nicht so viel abwerfe wie gedacht, sodass er seine Schulden nicht so schnell zurückzahlen könne wie gewünscht. ${ }^{562}$ In den darauffolgenden Jahren berichtete er laufend über den Krieg in Köln nach Ferrara, wofür er nun neben Geld auch Soldaten benötigte. ${ }^{563}$ Selbst des Herzogs Bruder, Kardinal Luigi d'Este, wurde von Ernst über den Kampf für den katholischen Glauben in Köln unterrichtet und über die Notwendigkeit weiterer Geldmittel in Kenntnis gesetzt. Darüber hinaus bat Ernst den estensischen Kardinal, sich für den Erzbischof von Lyon stark zu machen, damit dieser für das Kardinalat empfohlen werde, woraus ein gewisser Einfluss des estensischen Familiengeistlichen, der wider Willen diese Laufbahn eingeschlagen hatte, geschlussfolgert werden kann. ${ }^{564}$

Alfonsos II. 33 Briefe an Herzog Wilhelm V. im Bayerischen Hauptstaatsarchiv beinhalten Gunstbekundungen des Este, der stets angab, sich der Liebe und Freundschaft des Herzogs von Bayern sicher zu sein, ${ }^{565}$ Todesnachrichten, so z.B. zum Ableben des Herzogs von Mantua und Mitteilungen über umgesetzte oder gescheiterte Fürbitten. ${ }^{566}$ Über Bayern und durch die lothringische Verwandtschaft lief auch der Austausch von Neuigkeiten über Frankreich und die dortige Entwicklung der Religionskriege. $^{567}$

560 ASMo, ASE, Casa e Stato, Carteggio di principi esteri, Germania b I593/r9, Ernst von Bayern an Alfonso II., Oktober 1585 .

56r Ebd., Ernst von Bayern an Alfonso II., Dezember 1575.

562 Ebd., Ernst von Bayern an Alfonso II., Oktober 1582. Die Schulden nach dem Kölner Krieg beliefen sich auf 700.00o Gulden. Vgl. Sammer, Wilhelm V., I93.

563 ASMo, ASE, Casa e Stato, Carteggio di principi esteri, Germania b I593/r9, Ernst von Bayern an Alfonso II., Oktober 1586 und Juli 1587 : dass der Kriegsmann Antonio Maria Bigi in Ferrara Soldaten anheuern dürfe.

564 Ebd., Ernst von Bayern an Kardinal Luigi d'Este, März 1582.

565 München, BayHStA, Fürstensachen ooor 8 Kasten Schwarz 7603, der Herzog von Ferrara an den Herzog von Bayern, 322/I, Juli I 586.

566 So z.B. für den inhaftierten Arzt Francesco Lasso. Ebd., der Herzog von Ferrara an den Herzog von Bayern 322/r, Dezember 1589 .

567 Ebd., der Herzog von Ferrara an den Herzog von Bayern 322/I, April I 59 I : Neues über die Kriegs- 
Wilhelm V. und Renata von Lothringen hatten insgesamt zehn Kinder. Neben dem Thronfolger Maximilian überlebten das Kindesalter Maria Anna (I574-16r6), die I60o den späteren Kaiser Ferdinand II. heiratete, Philipp Wilhelm ( I 576 - I 598), der Kardinaldiakon und Fürstbischof von Regensburg wurde, während sein Bruder Ferdinand (I 577-1650), Kurfürst von Köln, Fürstbischof von Lüttich, Münster, Hildesheim und Paderborn war; der jüngste Sohn, Albrecht VI. der Leuchtenberger (I 584-i666), heiratete I6 I 2 Prinzessin Mechthild von Leuchtenberg (I588- I634) und die letzte Tochter Magdalene (I587-i628) ehelichte i6r3 Herzog Wolfgang Wilhelm von Neuburg. ${ }^{568}$

Der Thronfolger Maximilian ${ }^{569}$ war nach der Abdankung seines Vaters von I 5 97/98 bis I65 I Herzog und von I623 an Kurfürst von Bayern; er heiratete zunächst Elisabeth-Renata von Lothringen und in zweiter Ehe Maria Anna von Österreich. Maximilian von Bayern schaffte es, als kluger aber vor allem absolutistisch regierender Fürst mithilfe eines Spar- und Reformprogramms innerhalb von zehn Jahren den Schuldenberg seiner Vorgänger abzubauen. ${ }^{570}$ Gleichzeitig konnte er ein schlagkräftiges Heer aufbauen und zur bedeutendsten Macht im Reich avancieren. Er war auf sein Regierungsamt gut vorbereitet worden, hatte Latein, Französisch, Italienisch und Tschechisch gelernt und auf einer Kavalierstour die bedeutendsten katholischen Höfe kennengelernt. Er kam als 20-Jähriger I 593 an den Kaiserhof nach Prag und von dort nach Rom, wo er seine Brüder aus dem päpstlichen Dienst nach Hause holte. Auf dieser Reise kam er auch nach Mantua, Ferrara, Mailand, Parma, Florenz und Neapel. Auf der Rückreise traf er Alfonso II. am mantuanischen Hof. ${ }^{571}$ Trotz seiner Sparmaßnahmen war er wie seine Vorgänger ein beachtenswerter Kunstmäzen und -förderer. ${ }^{572}$

Von Herzog Maximilian I. von Bayern sind in Modena I 4 Briefe an Alfonso II. in dessen letztem Lebensjahrzehnt (I 586- I 596) erhalten. Einige Schreiben von und an Maximilians Vater Wilhelm im Frühjahr I593 betrafen die Reise des jungen Bayernfürsten nach Rom: Der Vater bat den Este um wohlwollende Aufnahme seines Sohnes

entwicklung in Frankreich. Siehe auch: BHSTA, Kurbayern, Äußeres Archiv, o r ro, Ascanio Geraldini an den Herzog von Bayern, Januar und Februar 1589.

568 Vgl. Schmid/Weigand, Die Herrscher Bayerns, Stammtafel 446. Sigmund von Riezler, Wilhelm IV., in: ADB 42, Leipzig 1897, 705-717. Hans Rall, Albrecht IV., der Weise, in: NDB I, Berlin i 953, I 57. Johannes Laschinger, Ludwig X., Herzog von Ober- und Niederbayern, in: NDB I5, Berlin 1987, 366f. Walter Goetz, Albrecht V., in: NDB i, i58-i6o. Sigmund von Riezler, Wilhelm V., der Fromme, Herzog von Baiern, in: ADB 43, Leipzig I 898, 88-9o. Dieter Albrecht, Maximilian I., in: NDB I6, Berlin I990, 477-480.

569 Vgl. Immler, Maximilian I. Albrecht, Das konfessionelle Zeitalter, 406-4I4.

570 Zur Restaurationspolitik Maximilians siehe: Stıeve, Die Politik Baierns, vor allem Fünfter Abschnitt, $\mathrm{I}-240$.

57 I Zu dieser Reise siehe: Ebd., I32, I36. Anders bei Dotterweich, wo auch ein Aufenthalt in Modena genannt ist: Dotтеrweich, Der junge Maximilian, 52-65, I 27 - I 30.

572 Vgl. Volk-KnÜttel, Maximilian I. sowie das Inventar seiner Kammergalerie: Bachtler/Diemer/ Erichsen, Die Bestände. 
Alfonso und beglückwünschte sich ob der Ehre dieses Besuchs. ${ }^{573}$ Maximilian selbst erbat sich die estensische Unterstützung für Ascanio Geraldino, den Gesandten des Herzogs von Ferrara, der im Reich komplizierte Erbschaftsangelegenheiten zu regeln hatte. ${ }^{574}$ Auch empfahl und schickte Maximilian einen - etwas älteren - Pagen für Cesare d'Este und bedankte sich für dessen Aufnahme. ${ }^{575}$ Dies zeigt wieder einmal, dass fürstliche Empfehlungen im Rahmen von Verwandten- und Familiennetzwerken wirksam waren. Neben den obligaten Gunstbekundungen und der Ankündigung von Gesandtschaften fragte der neue Herzog von Bayern nach Informationen über Truppenbewegungen: Er wusste aus anderen Quellen, dass Soldaten aus Italien nach Ungarn ziehen sollten und bat Alfonso um Auskunft über ihre Anzahl und den Zeitpunkt ihres Durchmarschs. ${ }^{576}$

Auch der vom päpstlichen Vorgehen gegen Ferrara bedrohte Cesare d'Este erhielt in seiner verzweifelten Lage die Kommunikation mit den Wittelsbachern aufrecht. In verschiedenen eigenen bzw. vom Gesandten Riccardus Aranus an Wilhelm und Maximilian I. von Bayern gerichteten Briefen zwischen I596 und I 597 hielt er die deutschen Verwandten über den Vormarsch der päpstlichen Truppen, seine eigenen Kriegsvorbereitungen, den über ihn verhängten Bann und schließlich über seinen Verzicht auf Ferrara und seine Übersiedlung nach Modena informiert. ${ }^{577}$

\subsubsection{Die Beziehungen der Este zu den protestantischen Reichsfürsten}

\subsubsection{Die Este und die Herzöge und Kurfürsten von Sachsen}

Ähnlich wie in anderen Fürstentümern des Reiches (Bayern, Mecklenburg, Hessen etc.) war es in dem durch Bergbau mächtig gewordenen Fürstentum der Wettiner ${ }^{578}$ I 485 nicht zur ersten, aber zur folgenschwersten, sogenannten Leipziger Landesteilung gekommen, woraufhin die einstig gemeinsam regierenden Brüder, Kurfürst Ernst (reg. I 464-I486) und Herzog Albrecht (I464-I500), nach zwei Jahrzehnten getrennte

573 München, BayHStA, Fürstensachen o042-0043, Kasten Schwarz 7603, Wilhelm V. an Alfonso II., März I 593, Alfonso II. an Wilhelm V., April I 593.

574 ASMo, ASE, Casa e Stato, Carteggio di principi esteri, Germania b I 593/r 9, Maximilian I. von Bayern an Alfonso II., Juli I 586.

575 Ebd., Maximilian I. von Bayern an Alfonso II., März, April r 596. Cesare bedankte sich in einem eigenen Brief: München, BayHStA, Fürstensachen ooo48 Kasten Schwarz 7603, Cesare d'Este an den Herzog von Bayern, März I 596.

576 ASMo, ASE, Casa e Stato, Carteggio di principi esteri, Germania b I 593/r 9, Maximilian von Bayern an Alfonso II., Juni I 595.

577 München, BayHStA, Fürstensachen oo5 2-00680003-o6, Kasten Schwarz 7603, Cesare d'Este an Wilhelm bzw. Maximilian von Bayern, Dezember I 596-Dezember I 597 .

578 Als Überblick und Einführung dienen: Kroll, Geschichte Sachsens; Czoк, Geschichte Sachsens; Gross, Die Wettiner. 
Wege gingen. ${ }^{579}$ Mit diesem von Ernst gewollten, aber von Albrecht nur widerstrebend angenommenen Einschnitt entstanden ein ernestinisches (thüringisches) Kurfürstentum Sachsen mit Wittenberg, Torgau, Altenburg, Zwickau und dem größeren Teil Thüringens und ein albertinisches (meißnisches) Herzogtum Sachsen mit Chemnitz, Dresden, Freiberg, Leipzig und dem nördlichen Thüringen. Diese politische und territoriale Teilung war, wenigstens zu Anfang, auch eine konfessionelle Spaltung: Kurfürst Friedrich III., genannt der Weise (reg. I 486-I 525), ${ }^{580}$ war seinem Vater Ernst, der eine Tochter Herzog Albrechts III. von Bayern-München geehelicht hatte, ein Jahr nach der Leipziger Teilung gefolgt und hatte Luther und die Reformation in seinem Landesteil unterstützt. Auf dem Sterbebett war er selbst zum neuen Glauben übergetreten. Neben seinem Mäzenatentum waren seine wechselhafte Frömmigkeit, die in einer exorbitanten Reliquiensammlung, der Gründung der Universität Wittenberg I 502 und seiner Pilgerfahrt ins Heilige Land Ausdruck fanden, Merkmale einer in einer Sattelzeit aufgewachsenen Persönlichkeit.

Sein Bruder, Mitregent und Nachfolger Kurfürst Johann, genannt der Beständige (reg. I 525-1532), ${ }^{581}$ hatte I 500 Herzogin Sophia von Mecklenburg und nach deren frühen Tod in zweiter Ehe Margarete von Anhalt geheiratet. Kurfürst Johann bekannte sich von Anfang an zum lutherischen Glauben und führte ihn in Kursachsen ein. Das Verhältnis zu den Habsburgern und zum neu gewählten Kaiser Karl V. hatte sich ab I 523 zunehmend und besonders nach einer Brüskierung und Ehrverletzung im Zuge eines gescheiterten, bereits vertraglich fixierten Heiratsprojekts zwischen Karls Schwester Katharina und Johann Friedrich, der schließlich Sibylla von JülichKleve-Berg heiratete, verschlechtert. Schließlich stellte sich der Kurfürst an die Spitze des Schmalkaldischen Bundes gegen das Reichsoberhaupt.

Johann Friedrich von Sachsen, genannt der Großmütige (reg. I 532- I 547/54), ${ }^{582}$ führte die väterliche Politik weiter und zeichnete sich in seiner Regentschaft durch eine gründliche Erneuerung der kursächsischen Verwaltung aus. Sein Hof in Torgau gehörte zu den prächtigsten im Reich und war mit Kulturgütern von überall her geschmückt. Doch konnte er diese Pracht nicht lange genießen, denn im Zuge seines Angriffs auf Herzog Heinrich den Jüngeren von Braunschweig-Wolfenbüttel wurde die Reichsacht über ihn verhängt. Als Karl V. endgültig zum Gegenschlag gegen den Schmalkaldischen Bund ausgeholte, unterlag der Wettiner bei Mühlberg, wurde verletzt, gefangen genommen und verlor in der Wittenberger Kapitulation vom r 9. Mai I 547 die Kurwürde und große Teile seines Gebietes.

579 Bünz, Die Kurfürsten, 5 r. Die Landesteilung soll u.a. infolge einer Romreise Ernsts I 480, bei der er den Räten und nicht seinem Bruder die Regierung übertragen hatte, erfolgt sein.

580 Schirmer, Die ernestinischen Kurfürsten, 55-65.

58 I Ebd., 65-70.

582 Ebd., $70-75$. 
In der albertinischen Linie blieb Herzog Georg, genannt der Bärtige (reg. I $500-$ I 539), ${ }^{583}$ als Gegner der Reformation katholisch. Er heiratete I 496 Barbara, Tochter von König Kasimir von Polen, und machte Dresden zur dauerhaften Residenz der Albertiner. Mit dem Zusammenschluss mit den Herzögen von Bayern und Braunschweig zum Nürnberger Bund I 538 versuchte er die katholische Seite im Reich zu stärken. Um die Verbreitung des Luthertums in seiner Familie einzudämmen, veranlasste er, dass sein Neffe Severin, der Sohn seines Bruders Heinrich, in Innsbruck am Hof König Ferdinands I. erzogen wurde, wo dieser aber nach wenigen Monaten verstarb. ${ }^{584}$ An diesem Aufenthalt des sächsischen Fürstensohns kann man den Beginn der Rolle von Innsbruck als Drehkreuz zwischen Wien/Prag, München und Italien ansetzen, die sich unter Erzherzog Ferdinand II. noch weiter verstärken sollte. ${ }^{585}$ Letzterer pflegte die Beziehungen zu Sachsen bis zu seinem Lebensende weiter, wie die reiche, freundschaftliche Korrespondenz zwischen dem Erzherzog und Kurfürst August von Sachsen bezeugt. ${ }^{586}$

Georgs nachfolgender Bruder Heinrich, genannt der Fromme (reg. I 539- I 54 I), 587 regierte nur etwas mehr als zwei Jahre, führte aber in seinem Herrschaftsgebiet die Reformation ein. Auch er war durch seine Heirat mit Katharina, der Tochter von Herzog Magnus II., an das Haus Mecklenburg gebunden, die eine treibende Kraft in der Förderung der lutherischen Glaubenslehre war und die Erziehung des gemeinsamen Sohnes Moritz ${ }^{588}$ prägte. Dieser vollendete die Etablierung der Reformation im Herzogtum, stellte sich aber trotz seines lutherischen Bekenntnisses auf die Seite Kaiser Karls V. gegen die ernestinischen Verwandten, deren Kurwürde er begehrte und die er nach dem kaiserlichen Sieg bei Mühlberg im Zuge der Wittenberger Kapitulation I 547 auch erhielt. ${ }^{59}$ Der neue Kurfürst stach durch eine innovative politische Linie

583 Bünz/Volkmar, Die albertinischen Herzöge, 79-85.

584 In der Osterzeit $5_{533}$ war der elfährige Severin bereits gesundheitlich angeschlagen nach Tirol gekommen und erlag am io. Oktober einer Harnretention. Vgl. Reвiтsсн/Schmitz-Esser, Herzog Severin von Sachsen. Obwohl es sich eindeutig um die Zuspitzung eines bestehenden und zum Tode führenden Leidens handelte, bemühte man sich, das Ableben des jungen Sachsenfürsten aus lutherisch gesinntem Haus am katholischen Hof zu Innsbruck durch eine penible Obduktion transparent und eindeutig aufzuklären. Vgl. Schmitz-Esser/Taddei, Der Todesfall.

585 Bůżek hat bereits die kulturelle Kommunikation zwischen diesen Höfen unter Erzherzog Ferdinand II. vor allem bezüglich der Präsenz und Vermittlung von böhmischen Adeligen aufgezeigt. BŮżEK, Ferdinand von Tirol, besonders $308 \mathrm{f}$.

586 Vgl. Kuster, »Eur Lieb gannz williger Brueder«, 47. Eine Tafel in den kurfürstlichen Gemächern in Dresdener Schloss erinnerte an ein Rennen des Kurfürsten August gegen Erzherzog Ferdinand.

587 Bünz/Volkmar, Die albertinischen Herzöge, $85-89$.

588 Als maßgebliche Literatur zu Moritz von Sachsen wurde hier verwendet: BorN, „Moritz von Sachsen«; Wartenberg, Moritz von Sachsen; Günter Wartenberg, »Moritz, Herzog von Sachsen«, in: NDB I 8. Berlin i 997, I4I - I 43; Herrmann/Wartenberg/Winter, Politische Korrespondenz; Blasch Ke, Moritz von Sachsen. Älter, aber in manchen Detailfragen immer noch brauchbar: IssLEIB, Aufsätze.

589 Vgl. Rudersdorf, Moritz I54I/47-I 553 . 
hervor, man könnte auch sagen er regierte auf einer Gratwanderung, zwischen Gehorsam und Treue zum Reichsoberhaupt und Festhalten an der lutherischen Lehre und somit an der eigenen reichsständischen Freiheit und Selbstbestimmung. Unterstrichen wurde dies auch durch seine Bindung durch Heirat mit Agnes an Philipp von Hessen, den Vorkämpfer der Glaubensspaltung im Reich und somit an das evangelische Lager. Seine Loyalität zum Reich und hier aber vorrangig zu König Ferdinand I. war mitunter auch von der Tatsache bestärkt, dass der König von Böhmen als Lehensherr im sächsischen Gebiet weitreichende Befugnisse hatte und die gewonnene territoriale Macht - wenigstens rechtlich und theoretisch - vom Reichsoberhaupt eingeschränkt werden konnte. Außerdem basierte die Loyalität des sächsischen Kurfürsten auch auf dem habsburgisch-albertinischen Vertrag von I 546, der ihn zur Neutralität zwang. Es war also ein Do-ut-des-Spiel: religiöse Freiheit gegen Anerkennung des Reiches und seiner Hoheitsrechte. Dennoch wechselte Kurfürst Moritz erneut die Fronten und stellte sich I 55 I an die Spitze eines Bundes evangelischer Fürsten, darunter jenen von Mecklenburg, Brandenburg-Küstrin und Preußen, die das Interim und die Rekatholisierungsmaßnahmen des Kaisers ablehnten und eine freie Religionsausübung verlangten. Unterstützung von außen erhielt dieser Bund für den Fürstenaufstand von 1552 von Henri II. von Frankreich. Trotz dieses kurzlebigen Paktes mit dem »Erzfeind der Habsburger« blieb Moritz mit König Ferdinand ebenso wie mit dem Herzog von Bayern für eine Friedenslösung in Kontakt und fuhr somit von Anfang an zweigleisig. ${ }^{590}$ Nach dem Rückschlag für Karl V. in Tirol ${ }^{591}$ wurde im Passauer Vertrag im August I $55^{2}$ diese für die katholische Seite aussichtslos gewordene religionspolitische Auseinandersetzung mit der (vorläufigen) Anerkennung des protestantischen Bekenntnisses beendet, die schließlich I 555 im Augsburger Religionsfrieden mündete. Diesen Abschluss erlebte Moritz von Sachsen allerdings nicht mehr. Im Kampf gegen Albrecht Alkibiades, Markgraf von Brandenburg-Kulmbach, der zunächst Teil der Kriegsfürstenkoalition gewesen war und dann - nachdem er als Einziger den Passauer Vertrag nicht angenommen hatte - eine eigenständige plünderische Expansionspolitik begonnen hatte, blieb Moritz I 553 zwar siegreich, fand aber den Tod. ${ }^{592}$

In seiner kurzen Zeit als Kurfürst hatte Moritz sein Fürstentum zu einem geschlossenen Flächenstaat mit einer landesstaatlichen Zentralverwaltung und einem kulturellen Zentrum am Hof von Dresden gemacht. Diese Vorarbeiten gereichten seinem Bruder und Nachfolger August I. (reg. I 553- I 586), der trotz seines prominenten Bruders als »überragender Vertreter der Fürstengeneration zwischen Augsburger Religionsfrieden und Dreißigjährigem Krieg « ${ }^{593}$ gilt, zum Vorteil. Er konnte in seiner langen,

590 Nach Winter war es ein »Vertrauensverhältnis zwischen Moritz und Ferdinand, das an die traditionell von guter Nachbarschaft geprägte sächsisch-böhmische Landespolitik anknüpfte«. WINTER, Kurfürst Moritz, 53 .

59 I Vgl. dazu Reвiтsch, Der Kaiser, und ausführlicher die veröffentlichte Dissertation: Ders. Tirol.

592 Vgl. Kroll, Geschichte Sachsens, 29-35.

593 Bruning, August, i i r. Vgl. auch im Detail: Schirmer, Die Staatsverschuldung. 
von zahlreichen Reformen begleiteten Regentschaft Kursachsen zu einem frühmodernen und wohlhabenden, weil von den Schulden (ca. 2 Mio. Gulden) ${ }^{594}$ seines Vorgängers befreiten Staat ausbauen. August setzte auf eine weitgehend habsburgfreundliche Politik, hatte er ja während seines Aufenthalts am Hof König Ferdinands I. I 542 zum Kaiserhaus und besonders zu den Erzherzögen Ferdinand II. ${ }^{595}$ und Maximilian II. Kontakte geknüpft, die mit Letzterem, ähnlich wie im Fall von Alfonso II. d'Este sogar in Freundschaft übergingen. ${ }^{596}$ I 548 heiratete er zur Festigung seiner Beziehungen zum Norden Anna, Tochter von König Christian III. von Dänemark, und in zweiter Ehe Agnes Hedwig, Tochter von Joachim Ernst von Anhalt. In seiner über dreißigjährigen Regentschaft festigte er nicht nur sein Fürstentum, sondern machte es auch zu einem "protestantische[n] Leitterritorium $[\ldots]$ im Reich « ${ }^{597}$.

Das I6. Jahrhundert ging in Sachsen mit einer kleinen Zäsur zu Ende. Der früh erfolgte und reichspolitisch gefestigte Übergang zum lutherischen Bekenntnis wurde durch Augusts Nachfolger Christian I. (reg. I 586- I59I) ${ }^{598}$ und seinen einflussreichen Kanzler Nikolaus Krell, der sein Land unter dem calvinistischen Bekenntnis neu ordnen wollte, (kurz) unterbrochen. Einem zügellosen Lebensstil frönend starb Christian I. bereits nach fünf Regierungsjahren. Sein Nachfolger aus der Ehe mit Sophie von Brandenburg war der noch unmündige Christian II. (reg. I59I- I6 I I), ${ }^{599}$ für den der brandenburgische Großvater Friedrich Wilhelm von Sachsen-Weimar regierte. Unter diesem Vormund und seiner Mutter kehrte das Kurfürstentum dem Druck des Adels und der Stände nachgebend zum lutherischen Bekenntnis zurück, doch der Anschluss an die aktiven evangelischen Reichsfürsten (Torgauer Bund) war verloren, sodass sich Kursachsen bis zum bzw. im Dreißigjährigen Krieg wieder stark an die Habsburger anlehnte. ${ }^{600}$

Wenn sich die Este also um intensive Beziehungen mit den protestantischen Kurfürsten aus dem weiten Norden bemühten, so hatten sie deren Bedeutung und Einfluss in der Reichspolitik - neben den Herzögen von Bayern - erkannt und versuchten dieses Netzwerk zu ihrem Vorteil zu nutzen. ${ }^{601}$

594 Nach Bruning machten Augusts Bargeldvorräte bei seinem Tod I,8 Mio. Gulden aus. Bruning, August, i 6 .

595 Deren Beziehung wurde durch die geografische Nähe zu Dresden und Prag, wo Ferdinand als Statthalter vorerst tätig war, intensiviert und schlug sich nicht an den konfessionellen Unterschieden, sondern wuchs an ihrer gemeinsamen Sammelleidenschaft. Vgl. Syndram, »Diese dinge sind warlich wohl wirdig «, 20.

596 Ein ähnliches, besonderes Verhältnis zu Maximilian hatte auch Moritz selbst. Winter, Kurfürst Moritz, 54. Ohne Zweifel war die »Freundschaft« mit dem bedeutendsten Reichsfürsten und Träger des Reichsschwerts als Reichsmarschall von großem Nutzen. Vgl. Kuster, »Eur Lieb gannz williger Brueder «, 43.

597 Bruning, August, I I 4.

598 Nicklas, Christian I., I $26 f$.

599 Vgl. NickLas, Christian II., I $33-\mathrm{I} 36$.

600 Vgl. Kroll, Geschichte Sachsens, 35-4I.

6or Dies war nicht nur eine estensische Wahrnehmung, sondern eine Tatsache, denn August von Sachsen 


\subsection{Die Korrespondenz zwischen den Este und den Kurfürsten von Sachsen}

Die Herzöge und Kurfürsten von Sachsen waren mit den Este in regem brieflichem Austausch, der, trotz der humanistischen Ausbildung der Wettiner, die auch das Beherrschen fremder Sprachen und darunter des Italienischen vorsah, stets auf Lateinisch erfolgte. Barbara Marx hat festgestellt, dass sich erst Kurfürst Johann Georg I. an der Wende zum I 7. auf Italienisch verständigen konnte. Er hatte eine Studienreise nach Italien unternommen und dort zahlreiche Bücher gekauft. ${ }^{602}$ Auch wenn sein Vater Christian I. von einem italienischen Hofmeister erzogen worden war und es am Dresdener Hof eine an italienischen Grammatiken ${ }^{603}$ und Wörterbüchern reiche Bibliothek sowie einen, wie gezeigt wurde, regen Künstler- und Handwerkeraustausch gab, wurde im Sinne der streng formalisierten Sprachdiplomatie dennoch auf Latein kommuniziert, außer man fiel »affektrhetorisch« ins Italienische. ${ }^{604}$

Der Reigen sächsischer Schreiben im Staatsarchiv von Modena beginnt I 480 mit zwei Briefen Herzog Ernsts an Ercole I., die neben Gunstbekundungen die Bitte um Zusendung seines Falkners beinhalten. Der spätere Herzog Johann Friedrich hingegen berichtete Ercole II. I 537 vom Übereinkommen zwischen Kaiser Karl V. und Papst Paul III. bezüglich des Kampfes gegen die Häresie und eines Konzils.

Reicher und interessanter ist die Korrespondenz zwischen Kurfürst Moritz und Ercole II. Von den ro lateinischen Briefen aus dem Zeitraum von I 549 bis I 553 sind einige teilweise chiffriert, andere haben eine beigefügte italienische Übersetzung, doch bestehen sie meist aus Ankündigungen von Gesandtschaften und Grüßen. Über seinen Gesandten Johann Heise versprach Moritz im Frühjahr 1553 die Zusendung der in Aussicht gestellten Genealogie der beiden Häuser Este und Sachsen und eines fähigen deutschen Büchsenschmieds. Dafür erbat er aber eine Abschrift des Grundrisses der Festung Brescello, die Alfonso II. zum Schutz gegen die kaiserlichen Truppen ausbauen ließ. ${ }^{605}$ Der Austausch mit den Este in der kritischen Phase des Fürstenaufstandes erfolgte aus Sicherheitsgründen weniger schriftlich als vielmehr mündlich durch Vertraute und eigens instruierte Gesandte, die - dem Wortlaut der Briefe nach angehört werden sollten, weil sie wichtige Inhalte überbrachten.

Die in Modena erhaltenen wenigen Kopien der Briefe von Ercole II. an Moritz beinhalten neben Gunst- und Treuebekundungen die Bitte um Unterstützung bei der Freilassung des Herzogs von Aumale, Bruder des Herzogs von Guise, mit dem Ercole

und Albrecht V. von Bayern waren z.B. I 570 die ersten, die das Ausschreiben für den Reichstag von Speyer einsehen und kopieren lassen konnten. Lanzinner, Deutsche Reichstagsakten. Der Reichstag zu Speyer 1 570, Erster Teilband, I 28.

602 Vgl. auch Marx, Die Italienreise.

603 Vgl. dazu: Matarrese, Una grammatichetta.

604 Marx, Italianità, 24-26. Hier ist auch ein italienisches Autograf von Johann Georg abgedruckt, Ebd. 25.

605 Korsch, Ein »heimlicher Vorschlag«, $43 \mathrm{f}$. 
durch die Heirat seiner Tochter Anna verwandtschaftlich verbunden war. ${ }^{606}$ Zahlreicher sind Ercoles II. ( I 5 ) und Alfonsos II. (5) erhaltene Schreiben an Moritz im Sächsischen Staatsarchiv. Hierbei wird ersichtlich, dass Ercole durch die sächsischen Gesandten Damian von Sibottendorf ${ }^{607}$ und Johann Heise, welcher offiziell am Hof des Fürstbischofs von Trient Italienisch lernte und dann nach Ferrara weiter vermittelt wurde, ${ }^{608}$ über die Belagerung Magdeburgs und allgemein über die Fortschritte im Reich auf dem Laufenden gehalten wurde. Ercole wiederum hielt den Sachsenfürst über die Entwicklungen in Italien informiert und berichtete u.a. vom Krieg um Siena. ${ }^{609}$

Wie Korsch bereits gezeigt hat, bemühte sich der Herzog von Ferrara nach Moritz' Tod mit einigen persönlichen Schreiben und durch darin angekündigte Gesandtschaften, die Beziehungen zum Dresdener Hof aufrechtzuhalten und den neuen Kurfürsten August I. für die mit Moritz geschmiedeten Pläne zu gewinnen. Dabei betonte der Este die innige Freundschaft und Verbundenheit mit dem Haus Sachsen und die große Bewunderung für den verstorbenen Kurfürsten. ${ }^{610}$ Auch sein Sohn und Nachfolger, Alfonso, schlug in diese Kerbe und ließ auf Deutsch (sehr wahrscheinlich von Heise) schreiben, der neue Kurfürst möge in Erinnerung und Gedenken an den Bruder seine Dienste annehmen (»Derweg bitth ich ganz vleissig meinen Dienst und gutwillig erbiehten gnedigst auffnehmen «). ${ }^{611}$

Nach den geheimnisvollen Verhandlungen und Informationen im Rahmen des Fürstenaufstandes und der Kondolenz für den Tod von Kurfürst Moritz kehrte man in der estensisch-sächsischen Korrespondenz aber zur brieflichen Normalität zurück: Zwischen August und Alfonso II. wurden Informationen über die Zustände in Italien und im Reich wie auch Empfehlungen ausgetauscht, so z.B. für den jungen Baron

606 ASMo, ASE, Casa e Stato, Minute di lettere ducali a Principi e signori fuori d'Italia b I635/5 an Moritz von Sachsen, I $547-\mathrm{I} 553$, vier Briefe.

607 Christian Winter hat sich mit den Räten des Kurfürsten beschäftigt, darunter dem für den Austausch mit den Este wichtigen Damian von Sibottendorf ( 15 19- I 585 ), Geheimschreiber und Reichspfennigmeister sowie Begleiter während des Fürstenaufstandes. Christian Winter, Kurfürst Moritz, 207.

608 Korsch, Ein »heimlicher Vorschlag«, 42.

609 Die Belagerung dieser mit der Reichsacht belegten Stadt auf Befehl des Kaisers war die »Nagelprobe» für Moritz und eine Gratwanderung in der Erfüllung seiner Pflicht in der Exekution der Acht und dem Versuch unter seinen evangelischen Mitstreitern kein Misstrauen zu erregen. Winter, Kurfürst Moritz, 54f. Dresden, SächHStA, Geheimer Rat, Loc. 8499/r, Ercole II. an Kurfürst Moritz, April I 55 I , Februar 1552.

6ro Ebd., Loc. 85 ro/3, Ercole II. an August I. von Sachsen Oktober 1552.

6r I Ebd., Loc. 8510/3, Kanzler von Alfonso II. an August I. von Sachsen, Oktober 1552. Obwohl die estensischen Gesandten im Reich, Sigismondo Descalzi und Alessandro Fiaschi, gleich nach der Heiratsverbindung mit dem Kaiserhaus von Alfonso II. beauftragt worden waren, ihm deutsche Musterbriefe auch in der originalen Kurrentschrift zu Übungszwecken zukommen zu lassen, so blieben die Deutschkentnnisse des Herzogs von Ferrara äußerst bescheiden. ASMo, ASE, Casa e Stato, Carteggio di Ambasciatori, Germania b 25, Dispacci ducali per la Germania an Sigismondo Descalzi und Alessandro Fiaschi, Juli 1567 . 
Hugo von Schönburg, der in Italien erzogen werden sollte. ${ }^{612}$ Es wurden Gunstbekundungen ausgesprochen, Gesandtschaften angekündigt wie jene von Andreas Pauli und Fürbitten für in Not geratene Personen vorgebracht. ${ }^{613}$ Auch Augusts Ratgeber, Georg Craloj, wandte sich I 574 an Alfonso II. mit der Bitte, seinen Sohn, der in Bologna studieren wollte, wohlwollend aufnehmen zu wollen. ${ }^{614}$

Von den an August gerichteten Briefen zwischen I 560 und I 583 sind acht als Kopie in Modena aufbewahrt. In diesen minute di lettere von Alfonso II. geht es vorrangig um die Bitte um Unterstützung und Fürsprache (»patrocinium«) im Präzedenzstreit mit Florenz ${ }^{615}$ aufgrund der freundschaftlichen und verwandtschaftlichen Verbindung (»quae intima amicitia ac prope familiaritas inter te et parentem meum intercessit«) zwischen dem Haus d'Este und den Wettinern. ${ }^{616}$ Girolamo Falletti, der estensische Beauftragte im Reich, schrieb in dieser Causa ausführlich an August von Sachsen, beleuchtete den Präzedenzstreit seit seinen Anfängen und erörterte die genealogischen und historischen Begründungen für den Vorrang der Este, untermalt mit Vergleichen aus dem Reich. In einem zweiten Brief erinnerte er Kurfürst August an die Verbundenheit der Häuser Este und Wettin, an die innige Beziehung zum verstorbenen Bruder Moritz und bat um Unterstützung beim Kaiser für den Herzog von Ferrara. ${ }^{617}$ Vor allem in den I $570 e r$ Jahren betonte Alfonso II. in seinen Schreiben immer wieder die Verbundenheit der beiden Familien aufgrund der gemeinsamen Abstammung und nach seiner »kaiserlichen Einheiratung « auch wegen ihrer (wenn auch weitläufigen) neuen Blutsverwandtschaft. Der I 572 nach Dresden geschickte Architekt und Ingenieur Rochus de Linar brachte nicht nur Briefe, sondern auch weitere Gunstbekundungen und Beteuerungen dieser Freundschaft und Verwandtschaft mit. ${ }^{618}$ Der Austausch von Gaben mit dem Kurfürsten von Sachsen kam ebenfalls nicht zu kurz: I575 dankte August I. für die Zusendung von schön gemusterten italienischen Teppichen ("peripetasmata italica«). ${ }^{619}$

Ein wichtiger Verbindungsmann in der Beziehung der Este zu den Kurfürsten von Sachsen war Andrea(s) Paul(1)i, Rat des Kurfürsten August, der sich auch zwischen I 58 I und I590 mit italienischen Briefen an Alfonso II. wandte und zu dessen Mittelsmann bei den Kontakten zu den Herzögen von Braunschweig sowie zum Land-

6r 2 Ebd., August I. von Sachsen an Alfonso II., Juni I 579 mit beigefügtem Schreiben des Fürbittenden.

6r 3 So bat August Alfonso um Vermittlung in der Befreiung des Geschäftsmannes Johanne Reiboldus, der zwischen Ferrara und Venedig gefangen genommen worden war. Ebd., August I. von Sachsen an Alfonso II., Oktober I 575 .

6 I 4 Ebd., Georg Craloj, Rat von August I. von Sachsen an Alfonso II., März I 574.

6r 5 ASMo, ASE, Casa e Stato, Minute di lettere ducali a Principi e signori fuori d'Italia, an August von Sachsen, Januar I 562 .

6 r 6 Ebd., Minute di lettere an August von Sachsen, April I 560.

6r 7 Dresden, SächHStA, Geheimer Rat, Loc. 85 ro/3, Girolamo Falletti an August von Sachsen, November I 56 I.

6 I 8 Ebd., Alfonso II. an August I. von Sachsen, April I 566, Januar und April I 572 , August I 573.

6 I 9 Ebd., August I.von Sachsen an Alfonso II., März I 575 . 
grafen Wilhelm von Hessen avancierte. ${ }^{620}$ Für Landgraf Wilhelm von Hessen erbat Pauli je ein Porträt von Ercole II. und von Alfonso II. d'Este und dann gleich zwei weitere, damit Kurfürst August auch eine Kopie erhalte. Pauli informierte Alfonso, dass August ${ }_{5} 82$ zum Reichstag nach Augsburg reisen würde und er ihn dort treffen könnte, wenn der Este nach Norden reisen würde. ${ }^{621}$ Auf diese Weise wurden nicht teilnahmeberechtigte Fürsten wie die Este über Reichstagstermine informiert. Alfonso hatte dann prompt die Porträts in Auftrag gegeben, denn Pauli bestätigte im Januar I 583 deren Erhalt und bedankte sich für die Zusendung. Der sächsische Rat war es auch, der Alfonso vom Tod von Kurfürst August I 586 berichtete und noch I 590 den Drang verspürte, seine Gunstbekundungen auszusprechen und in Erinnerung zu bleiben: „voglia conservarmi sempre la sua buona grazia et tenermi per suo humilissimo et obedientissimo servitor «. ${ }^{622}$

I 590 schickte Augusts Nachfolger, Kurfürst Christian I. neue Gesandte, nämlich Otto von Starschedel und Wolfgang Zindelinum, nach Italien an die Höfe von Ferrara, Mantua und Florenz. Die neuen kurfürstlichen Repräsentanten händigten allen drei italienischen Fürsten ähnliche lateinische Briefe aus; jener an Ferrara unterschied sich aber durch einen Hinweis auf die innige Freundschaft, die bereits unter Moritz bestand und in memoriam weitergeführt werden sollte, während der Großherzog von Toskana für seine Fähigkeit, die Republik zu beherrschen, gelobt wurde. ${ }^{623}$ Alle drei Fürsten (Florenz, Ferrara, Mantua) wurden aufgefordert, die Freundschaft mit den Wettinern zum Schutz der res publica christiana weiterzuführen. ${ }^{624}$

\subsection{Kurfürst Moritz, die Este und der Fürstenaufstand ${ }^{625}$}

Die Beziehung zwischen Ercole II. d'Este und dem ersten Kurfürsten von Sachsen aus der albertinischen Linie hat bereits Ende des I 9. Jahrhunderts Interesse geweckt. Luigi Napoleone Cittadella hat 1877 in einem Beitrag im Archivio storico ${ }^{626}$ im Rahmen der Untersuchung der Beziehungen zwischen Ercole II. d'Este und Frankreich

620 Den Braunschweigern ließ Pauli Alfonsos Briefe zukommen und versprach, die Zusendung ihrer Antworten zu verwalten. ASMo, ASE, Casa e Stato, Carteggio di principi esteri, Germania b I603/29, Andrea Pauli, Rat von August I. von Sachsen an Alfonso II., Oktober I 58 I.

62 I Ebd., Andrea Pauli, Rat von August I. von Sachsen an Alfonso II., September I 582.

622 ASMo, ASE, Casa e Stato, Carteggio di principi esteri, Germania b I603/29, Andrea Pauli, Rat von August I. von Sachsen an Alfonso II., Mai I 586 und März I 590.

623 Dresden, SächHStA, Geheimer Rat, Loc. 8274/4, Schriften betreffend die Abordnung und Schickung Sr. Churfürstlichen Gnaden Rath und Diener Otten von Starschedels und Wolfgang Zindelinum in Italien zu den Herzogen in Ferrara, Herzogen Ferdinanden zu Hetruria und Herzogen zu Mantua, März I 590.

624 Ebd., mehrere Schreiben.

625 Dieser besondere Aspekt der Beziehungen zwischen den Wettinern der albertinischen Linie und den Este wurde bereits anderweitig von der Autorin untersucht: TAdDEI, Moritz von Sachsen.

626 Cittadella, Saggio di storia politica. 
den beiden Fürsten und ihrem freundschaftlichen Verhältnis erste Aufmerksamkeit geschenkt. Dabei betonte Cittadella, dass Ercole als (angeheirateter) Onkel des neuen französischen Königs, Henri II. (I 547-I559), ${ }^{627}$ und als Lehensmann des Papstes gar nicht umhinkam, sich der unter Moritz formierenden antikaiserlichen Liga anzuschließen, obwohl seine Teilnahme bis zum Schluss geheim und unauffällig blieb, um kein Missfallen bei seinem anderen Lehensherrn, dem Kaiser, zu erregen. So versuchte der Este durch den Besuch des in Mantua weilenden kaiserlichen Sohnes Philipp II. (I527-I598) I 549 und durch die Großzügigkeit von vier prächtigen Streitrössern keinen Verdacht dahingehend zu erregen. Auch Moritz folgte dem Rat des Fürstbischofs von Trient, Cristoforo di Madruzzo, und reiste Philipp II. entgegen. In Trient brachte er neben seiner Ehrerbietung das Ansuchen um Freilassung seines Schwiegervaters, Landgraf Philipp von Hessen, und um Philipps Fürsprache beim Kaiser vor. ${ }^{628}$ Doch unter Ausflüchten, ein zu kleines und daher nicht ehrenvolles Gefolge bei sich zu haben, gab Moritz Philipp kein Geleit nach Brüssel, sondern reiste nach Oberitalien weiter. Er kam nach Venedig, Ferrara und Mantua. Hier wurden die Beziehungen zu den Este intensiviert, es kam zu Fürsprachen für den Sohn des Landgrafen, der in Ferrara Italienisch lernen sollte, und für ein mögliches bayerisch-estensisches Heiratsprojekt ${ }^{629}$ sowie zu kultureller Beeinflussung und networking. ${ }^{630}$

In einem anderen, gleichzeitig erschienenen Werk für die Bayerische Akademie der Wissenschaften hat sich August von Druffe ${ }^{631}$ besonders mit zwei Schwerpunkten des Verhältnisses zwischen Moritz von Sachsen und Ercole II. d'Este auseinandergesetzt: Zum einen ging es um ein langjähriges Heiratsprojekt zur Festigung der Allianz und zum anderen um die Hilfestellung Ferraras beim Aufbau, der Intensivierung und schließlich der Wiederherstellung (nach dem »Richtungswechsel« des Kurfürsten von Sachsen) der Beziehungen mit Frankreich, die in Italien in ein militärisches Aufgebot gegen den Kaiser hätten münden sollen.

Da Kurfürst Moritz selbst keinen Sohn hatte, den er möglicherweise mit einer EsteTochter hätte verheiraten können, stand ab I 550 ein Heiratsprojekt für seinen Bündnispartner, den Markgrafen Albrecht Alkibiades von Brandenburg-Kulmbach, ${ }^{632}$ mit

627 Klaus Malett ke, »Heinrich II.«, in: LThK $4,{ }^{3}$ I 994, Sp. 3384 f.

628 Nach dem venezianischen Gesandten war dies auch I 552 noch die Begründung gegenüber dem Fürstbischof von Trient, allerdings mit der versteckten Drohung, Moritz hätte auch erobernd nach Italien ziehen können und hätte dort große Unterstützung gefunden. Turba, Venezianische Depeschen 2, Marcantonio Damula an die Zehn, Augsburg, August I $55_{2}^{2}$, Nr. 2 I 9, 549 - 55 I, hier 550.

629 Dazu siehe die Korrespondenz von Moritz von Sachsen bzw. des Kardinals von Augsburg, Otto Truchseß von Waldburg, an Ercole II.: Dresden, SächHStA, Geheimer Rat, Loc. 8499/ı März I 548. Auch der spanische Gesandte Monteagudo berichtete im Mai 1573 nach Spanien von einer möglichen Heiratsverbindung zwischen Alfonso II. d'Este und einer Tochter von Albrecht V. von Bayern. EdELMayer, Söldner und Pensionäre, r 22, Anm. 58

$630 \mathrm{KoRsch}, »$ Ein heimlicher Vorschlag«, $38 \mathrm{f}$.

63 I Druffel, Herzog Herkules.

632 Albrecht Alkibiades Markgraf von Brandenburg-Kulmbach (I $522-$ I 557 ) zeichnete sich als Söldner- 
einer estensischen Herzogstochter auf dem Plan. Die Hoffnungen des Kurfürsten und des Markgrafen lagen hierbei vor allem auf einer reichen Mitgift der italienischen Braut für den verschuldeten Truppenführer. ${ }^{633}$ Die Este hatten demnach auch in Sachsen den Ruf von wohlhabenden Fürsten. Doch während die Heiratsverbindung mit Frankreich für die älteste Este-Tochter ${ }^{634}$ relativ rasch und reibungslos beschlossen worden war, schob man die mögliche Verbindung nach Norden wie eine Zwangsbeglückung, die man aber in einer Krisensituation bereit war einzugehen, auf die lange Bank. ${ }^{635}$ Die Gründe dafür lagen sicher auch im schlechten Ruf des Markgrafen als »wilde[n], rohe[n] Geselle[n] «, ${ }^{636}$ der ihm vorauseilte, aber mehr noch in der Gefahr einer solchen Verbindung für einen kaiserlichen und päpstlichen Vasallen sowie nicht zuletzt in der unumgänglichen Notwendigkeit, den Konsens des Papstes ${ }^{637}$ für die Heirat mit einem Protestanten einholen zu müssen. ${ }^{638}$ Schließlich barg auch die Frage der Mitgift einige Unstimmigkeiten.

Allen Beteiligten war es wichtig, dass diese Verhandlungen zwischen Ferrara und Sachsen vor allem dem Kaiser gegenüber geheim blieben. Der Wunsch der Geheimhaltung, ${ }^{639}$ die Tatsache, dass das Heiratsprojekt in den Briefen ganz vage "negotium « ${ }^{640}$ genannt wurde und die Verhandlungen meist nur mündlich von den instruierten Gesandten vorgebracht wurden, wundern nicht, denn Ercole musste als Folge einer sol-

und Reiterführer durch Zügellosigkeit und Rauheit aus. Er wechselte im Zuge des Fürstenaufstandes vom kaiserlichen Dienst zum antikaiserlichen Bündnis über, entfesselte den »Markgräfler Krieg« und verwüstete die Mainzer und Trierer Stiftslande. Als er schließlich den Passauer Vertrag verwarf, traten ihm der Fürstenbund mit Ferdinand I. und Moritz von Sachsen in der Auseinandersetzung bei Sievershausen entgegen. Siehe Erich von Gutt EN BERG, »Albrecht Alkibiades«, in: NDB I, Berlin I 953, I63.

$633 \mathrm{Zu}$ dieser »Heirat als Mittel der Sanierung« und zur Rolle des Markgrafen im Fürstenaufstand siehe: BADEA, "Es trieb ihn«, ro8f.

634 Die erstgeborene Tochter von Ercole II. und Renée de France, Anna (I53I-I607), heiratete zwei angesehene, den Este standesgleiche französische Herzöge: Zunächst François de Lorraine, Herzog von Aumale und Guise, und nach dessen gewaltsamem Tod Jacques de Savoie, Herzog von Nemours Zu Anna d'Este vgl. Matteo SAnfilippo, »Anna d'Este«, in: DBI 43, Roma I 993, 31 5 - 320. Ausführlicher: Coester, Schön wie Venus.

635 Druffel, Herzog Herkules, 322.

636 Ebd., 322 f. In Frankreich auch »Wüterich der Nation« genannt, zit. n. BADEA, »Es trieb ihn«, I I 5 .

637 Dazu siehe auch den Bericht des sächsischen Gesandten Damian von Sibottendorf von Ende Juli I 55 I, zitiert in: Herrmann/Wartenberg/Winter, Politische Korrespondenz, Nr. I49, $290-292$.

638 "Der erste Punkt, welcher zu Anständen Veranlassung bot, war, dass Herzog Herkules auf seine Eigenschaft als Lehnsmann der Kirche hinwies, und auf die Möglichkeit, dass er seine Lehen verlieren könne, da kraft päpstlicher Consitution die Eltern, welche ihr Kind einem Nichtkatholiken gäbe, gleich den Neuvermählten dem Banne verfielen.« Druff EL, Herzog Herkules, 324.

639 Gerade darin sieht Druffel die Ebenbürtigkeit der beiden Fürsten: »Mag derselbe [Ercole, E.T.] auch an geistiger Bedeutung wie an äusserer Machtstellung dem Sachsenfürsten nachstehen, er hat denselben erreicht in der Kunst, Praktiken im Verborgenen zu spinnen, und über das Geplante den undurchdringlichsten Schleier zu werfen«. Ebd., 33 I.

640 Siehe z.B. ASMo, ASE, Casa e Stato, Carteggio di principi esteri, Germania b I603/29, Moritz von Sachsen an Ercole II., Mai 155 I. 
chen Verbindung von kaiserlicher Seite ein Vorgehen gegen ihn als illoyalen Vasallen befürchten. Dies bestätigte auch der Bräutigam in spe, Markgraf Albrecht, in einem Brief, in dem er Moritz nachdrücklich darauf hinwies, den Herzog von Ferrara um Geheimhaltung zu bitten. ${ }^{641}$

Das Heiratsprojekt, für das zuerst die jüngste aber gesundheitlich angeschlagene Tochter Leonora, ${ }^{642}$ dann aber auf Wunsch des Markgrafen die ältere Lucrezia vorgesehen war, ${ }^{643}$ wurde schließlich - zur Erleichterung der Este, deren Hinhaltetaktik wieder einmal erfolgreich gewesen war - nie konkretisiert. ${ }^{644}$ Dennoch hatte dieser Fehlschlag keine Folgen für die estensisch-sächsischen Beziehungen. ${ }^{645}$

Der zweite Schwerpunkt der Beziehung zwischen Moritz und Ercole und der eigentliche Hauptgrund für die ansehnliche Korrespondenz bzw. den Gesandtenaustausch war nach Druffel das Projekt, Ercole als Vermittler und Helfer für die Wiederherstellung der nach dem »Sinneswandel« angeschlagenen Beziehungen Sachsens zu Frankreich zu nutzen. Dezidiert bat Moritz durch seinen Gesandten Johann(es) Heise den Herzog von Ferrara um Verwendung beim französischen König vorher und um Hilfe im geplanten Fürstenaufstand später. Die estensische Unterstützung bei diesem Vorhaben sollte nach Druffel einerseits mit einer für einen Vasallen sträflich geringen militärischen Hilfestellung für den Kaiser im französisch-kaiserlichen Krieg I 544 und andererseits mit der Weiterführung der Beziehungen zu Frankreich und den Schmalkaldener erfolgen. Trotzdem konnte sich Ercole II. d'Este kein offenes Vorgehen, keinen Verrat an den Kaiser leisten. Deshalb war es notwendig, den Lehensherrn auch weiterhin in dem Glauben zu lassen, er hätte mit den Este loyal ergebene Vasallen in Italien. So war die Empörung Ercoles über das Abwandern seines Sohnes Alfonso (II). d'Este ${ }^{646}$ nach Frankreich auch nach Druffel nur gespielt, um den Verdacht des Kaisers zu beschwichtigen, so wie es eine bloße Farce war, dass der Herzog die französischen Gesandten, mit denen die weitere Vorgehensweise gegen den Kaiser in Italien besprochen werden sollte, nicht in Ferrara, sondern in Chioggia empfing, um nicht den Missmut des Kaisers auf sich zu ziehen. ${ }^{647}$

64 I Herrmann/Wartenberg/Winter, Politische Korrespondenz, Nr. i54, 30if, Markgraf Albrecht an Kurfürst Moritz von Sachsen, Juli I 55 I, Nr. I43, 283 f und Ercole d'Este an Moritz von Sachsen, August I $55 \mathrm{I}$.

642 Die dritte Tochter des estensischen Herzogspaares, Leonora d'Este ( $5_{537}$ - I 5 8 I), blieb aufgrund ihrer zarten Gesundheit unverheiratet, lebte am Hof von ihrer Apanage und wurde vom berühmten Dichter Torquato Tasso bis zu dessen geistiger Umnachtung ob ihrer hervorragenden Bildung angebetet und besungen. Für eine Kurzbiografie siehe: Berengan, Le dame, r68-i 7 I.

643 ASMo, ASE, Casa e Stato, Carteggio di principi esteri, Germania b I603/29, Moritz von Sachsen an Ercole I, August I 55 I.

644 Druffel, Herzog Herkules, 325 f.

$645 \mathrm{KoRsch}$, Ein »heimlicher Vorschlag«, 4I.

646 QuAzza, "Alfonso II«.

647 Druffel, Herzog Herkules, 330, 335. 
Als auch auf der italienischen Halbinsel bekannt wurde, dass Moritz von Sachsen mit Ferdinand I. ${ }^{648}$ in Linz Friedensverhandlungen führte, wurden von Ferrara dringend dahingehende Informationen von sächsischer Seite erbeten, um die weiteren Schritte planen zu können, denn »im Falle, dass jener [Moritz, E. T.] einen Vertrag mit dem Kaiser abschlösse, würden sie [Ercole, Urbino u.a. italienische Fürsten] sich wohl hüten, offen als des Kaisers Feinde aufzutreten. « ${ }^{649}$ Wie Druffel bereits klar hervorgehoben hat, hatte die Parteibildung gegen den Kaiser in Italien schon konkrete Züge angenommen und eine (vorerst nur angenommene) Kehrtwende des Sachsen hätte sich auf das Verhältnis zwischen dem Kaiser und den einzelnen italienischen Fürsten in negativer Weise ausgewirkt.

Nicht zu unterschätzen war nach Karl Erich Born auch die Tatsache, dass bis zum Frühjahr r 55 I Moritz in der Ungewissheit lebte, ob er sich an den Kaiser annähern oder durch eine Verbindung mit Frankreich einen antikaiserlichen Weg einschlagen sollte; außerdem ließ Karls V. Macht zunehmend und für alle offensichtlich nach. Dies muss auch den italienischen Lehensmännern nicht verborgen geblieben sein, die sich - wie der Kurfürst - nach anderen Möglichkeiten zur Sicherung ihrer Herrschaft umsahen. Es ist anzunehmen, dass der Herzog von Ferrara ebenfalls die wachsende protestantische Bedrohung und die verschwindende kaiserliche Macht erkannte, sodass er sich - kaiserlicher Lehensmann hin oder her - mit einer möglichen (neuen) Macht im Kaiserreich gut stellen wollte. Dieses Bedürfnis nach Rückenstärkung durch Bündnisse war kein auf das Reich beschränktes Phänomen, sondern war auch bei Fürsten der italienischen Halbinsel erkennbar. ${ }^{650}$

Nach Born war die Intervention Ercoles für die Annäherung an den Rex christianissimus des Kurfürsten notwendig, da das Verhältnis zwischen diesem und Moritz von Misstrauen getrübt und die Idee eines Präventivkriegs gegen den Kaiser noch sehr vage war. ${ }^{651}$ Auf der anderen Seite benötigte auch Henri II. Bündnishilfe für die sich abzeichnende kriegerische Auseinandersetzung mit dem Kaiser in Italien. Der Kriegsschauplatz Italien war eine für Frankreich willkommene zweite Front, um den Kaiser zu schwächen. ${ }^{652}$

Dann aber kam der Seitenwechsel: Moritz von Sachsen einigte sich mit König Ferdinand und kündigte das Bündnis mit Frankreich. Wäre Moritz beim Vertrag von

648 Aufgrund der großen Sympathien, die bei den deutschen Fürsten genoss, konnte Ferdinand I. als Nachfolger Karls V. im Reich punkten. In der Fürstenverschwörung gegen seinen Bruder fungierte er als Vermittler. Seine Annäherung an Moritz von Sachsen in Linz im April I $55_{2}$, der Passauer Vertrag im Juli I 552 und schließlich der Augsburger Religionsfrieden I 555 waren von ihm mitgestaltete, wichtige Schritte für die weiteren politischen und religionspolitischen Entwicklungen im Reich. Siehe WANDRUSZKa, »Ferdinand I.«.

649 Druffel, Herzog Herkules, 327.

650 Born, Moritz von Sachsen, 29.

65 I Ebd., 29, 31, 37.

652 Ebd., 47. 
Chambord mit Frankreich geblieben, wäre er - so Born - deklarierter Feind des Kaisers und Verbündeter Frankreichs geworden. Die Enttäuschung des französischen Verbündeten war groß, ${ }^{653}$ doch wie Winter bereits festgehalten hat, war Frankreich »für ihn eben nur ein Zweckpartner «. ${ }^{654}$

Die geheimen Verhandlungen des Sachsenfürsten mit König Ferdinand in Linz waren nicht unbemerkt geblieben und hatten schon bald das Misstrauen aller Verbündeten geschürt, auch wenn das Ergebnis noch nicht greifbar war. Zwei Tage nach dem Treffen in Linz, am 3. Mai I 552 , schrieb Moritz an Henri II. und kündigte höflich das Bündnis auf mit der Begründung, dass es aussehe, als ob man den Frieden und Philipp von Hessens ${ }^{655}$ Freilassung ohne weiteres Blutvergießen erreichen könne. ${ }^{656}$ Ercole II. d'Este aber erfuhr vom Ende der kriegerischen Auseinandersetzung mit dem Kaiser und der Kehrtwende des verbündeten Sachsenfürsten offiziell erst nach Abschluss der Verhandlungen in Passau im August I $55_{2}$, wie ein Brief von Moritz von Sachsen beweist, auf den unten noch einzugehen sein wird.

Diese »unheilige Allianz« zwischen dem König von Frankreich, Moritz von Sachsen und verschiedenen italienischen Protagonisten, darunter Ercole II. d'Este, war für den Rex christianissimus eine Möglichkeit des Kampfes gegen den Erzfeind und für Moritz der Versuch, sich von Abhängigkeit und Unsicherheit zu befreien. Unterstützend dabei waren die Herzöge von Guise, Nebenlinie des lothringischen Herzogshauses, mit denen die Este durch die Tochter Anna verschwägert waren, die am französischen Hof eine neue politische Vorherrschaft erlangt hatten. Sie propagierten die Schwächung Karls V. und die Stärkung und Ausdehnung der Macht und Herrschaft der Valois. Den Grund für den Kontakt des Sachsenfürsten mit anderen Mächten sieht Nicklas in der Notwendigkeit nach Stabilisierung ${ }^{657}$ und war zum Teil auch von der Geldnot diktiert gewesen, ${ }^{658}$ wie auch Uwe Schirmer betont hat: "Es mangelte ihm [Moritz von Sachsen, E.T.] - insbesondere im europäischen Vergleich - auch und vor allem an fiskalischem Gewicht «, ${ }^{659}$ das er möglicherweise bei den italienischen Fürsten-Freunden zu finden erhoffte.

653 Ebd., 62.

654 Winter, Kurfürst Moritz, 63.

655 Philipp der Großmütige, Landgraf von Hessen ( I $_{504}-$ I $_{5} 67$ ), der sich als Förderer der reformatorischen Lehre in seinem Fürstentum und als Bigamist den Zorn des Kaisers zugezogen hatte, wurde von letzterem im Zuge des Schmalkaldischen Krieges 547 gefangen genommen und fünf Jahre lang in den Niederlanden festgehalten. Vgl. Fritz Wolff, »Philipp der Großmütige, Landgraf von Hessen«, in: NDB 20, Berlin 2001, 376-378.

656 Born, Moritz von Sachsen, 64. Die verlängerte Inhaftierung seines Schwiegervaters war für Moritz eine Ehrbeleidigung und mitunter Grund für seinen »Verrat«. Winter, Kurfürst Moritz, 56.

657 Nicklas, Das Wagnis, 39.

658 Ebd., 27 f.

659 Schirmer, Umfang, i62. Zwar finden sich vorerst in den unchiffrierten Schreiben von Moritz von Sachsen an Ercole II. d'Este keine expliziten Geldanfragen, doch da die Quellenbelege, die Cittadella vorbringt, erkennen lassen, dass 1556 mehrfach größere Summen von Ferrara nach Frankreich zur 
Einen letzten Aspekt dieser estensisch-sächsischen Beziehung hat Evelyn Korsch in beeindruckender Straffheit beleuchtet. Ausgehend von den persönlichen und diplomatischen Beziehungen zwischen Moritz und Ercole, dem nicht realisierten Heiratsprojekt mit dem Markgrafen von Brandenburg-Kulmbach und dem italienischen Transfer von Kulturgütern ist Korsch auf einen »heimliche[n] Vorschlag«, nämlich jenen eines ungarischen Königreichs unter osmanischer Oberhoheit, aber sächsischer Herrschaft, bei dem Moritz als Tributarier des Osmanischen Reiches walten sollte, eingegangen. ${ }^{660}$

Diese vielseitigen gemeinsamen Projekte ließen, wie Evelyn Korsch zu Recht festgehalten hat, die Korrespondenz zwischen den Este und den Wettinern der albertinischen Linie vom »konventionellen Rahmen, in dem europäische Fürstenhöfe Höflichkeitsfloskeln und Glückwünsche austauschen« in eine »neue Dimension« aufsteigen. ${ }^{661}$

Das im Bestand »Carteggio di Principi Esteri, busta 1603/29« im Staatsarchiv von Modena aufbewahrte Faszikel zur Korrespondenz zwischen Kurfürst Moritz von Sachsen und Herzog Ercole II. d'Este ${ }^{662}$ zwischen I 549 und I 553 enthält zehn Briefe, von denen die zwei längsten (und wohl interessantesten) jeweils aus den Jahren I 55 I und 1553 chiffriert sind. ${ }^{663}$ Manche andere sind zudem in einem schlechten konservatorischen Zustand und daher ganz oder zum Teil unlesbar. Bis auf den ersten Brief vom I 3. Februar I 549, der in italienischer Sprache verfasst ist, sind alle - unchiffrierten - auf Lateinisch.

In seinen Schreiben bezeichnet Moritz den Herzog von Ferrara wiederholt als »amice« und »frater« und benutzt das formlose, vertraute ${ }^{664}$ »du«. In einigen Schreiben wird der kontinuierliche Austausch ${ }^{665}$ mittels sächsischer Gesandte in Aussicht gestellt,

Finanzierung der kriegerischen Auseinandersetzungen flossen, kann angenommen werden, dass dies auch schon vor diesem Datum der Fall war. Cittadella, Saggio di storia politica, 208f.

660 KoRsch, Ein »heimlicher Vorschlag«. Im Anhang ist der »heimliche Vorschlag« ediert. In dieser sonst klar strukturierten Rekapitulation der komplizierten diplomatischen und politischen Aktivitäten der verschiedenen Akteure ist eine Verwechslung passiert: Moritz soll nach Korsch nicht nur mit Ercole, sondern auch mit Alfonso korrespondiert haben. Dies belegen auch die Fürstenkorrespondenzen im ASMo. Allein war Alfonso Ercoles Sohn und nicht, wie Korsch, sein Bruder. Ebd., 40.

66 I Korsch, »Ein heimlicher Vorschlag«, 37, 54.

662 Vgl. bereits: Taddei, Moritz von Sachsen.

663 Bereits am 4. April I55 I schlug Ercole dem Kurfürsten Moritz von Sachsen vor, einerseits den Gesandten Sibottendorf oder einen anderen Vertrauten zu schicken, um nur mehr mündlich zu verhandeln und andererseits die weitere Korrespondenz zu chiffrieren. Den Schlüssel sollte der kurfürstliche Gesandte mitbringen. Herrmann/Wartenberg/Winter, Politische Korrespondenz, Nr. I49, 29of, Ercole II. d'Este an Moritz von Sachsen, April I 55 I.

664 Damit wurde emotionelle Nähe und Vertrautheit ausgedrückt. Vgl. FouQUET, Fürsten unter sich, I 82. 665 Robert Rebitsch, der sich in seiner 2000 publizierten Dissertation mit dem Fürstenaufstand aus Tiroler Sicht beschäftigt hat, zitiert in seiner Arbeit eine interessante Quelle, die den Austausch zwischen Ferrara und Sachsen besonders eindeutig darstellt. Im Mai I 552 berichtet der kursächsische Gesandte Johann Heise vom Hof Herzog Ercoles II. d'Este an Kurfürsten Moritz von Sachsen über die zu erwartende Stärke der Truppen des Herzogs von Alba, über die Geldlieferungen aus dem Vizekönig- 
ein Brief vom I3. März I 550 zeugt überdies von einem kontinuierlichen Informationsaustausch zwischen Moritz und Ercole auch über den estensischen Legaten beim Kaiser, Herzog Ercole Rangoni. Sowohl Ercole II. als auch sein Sohn Alfonso (II.) versicherten dem Kurfürsten in ihren Schreiben wiederholt Hilfe und Unterstützung. ${ }^{666}$ Persönlich informierte Moritz in einem Brief vom I 5. August $\mathrm{I}_{5} 5^{267}$ den Herzog von Ferrara über die Verhandlungen in Passau und über deren Ausgang. In seinem Schreiben versuchte er dem italienischen Verbündeten seine »Kehrtwende« zu erklären. Zunächst entschuldigte er sich dafür, dass er Ercole lange in Ungewissheit hatte lassen müssen. Da aber nun der Krieg vorbei und der Friede gemacht sei, wollte er ihm den Gesandten Johann Heise schicken, damit dieser alles genau berichten könne. Der Kurfürst rechtfertigte seine Zustimmung zu den Friedensverhandlungen mit dem Argument, dass der Krieg, wie auch immer er ausgehe, immer furchtbar und verwüstend sei, und er, von der ehrbaren Einhaltung der Abmachungen überzeugt, nun den Frieden eingeleitet habe. Vorrangiges Ziel sei dabei die Beendigung der Gefangenschaft des Landgrafen Philipp von Hessen gewesen, die mit französischer Unterstützung gelungen sei. Er versicherte dem Este, dass trotz des Seitenwechsels ihre Beziehung und Freundschaft unverändert sei und bleiben werde. Diesem lateinischen Brief, von dem es im gleichen Faszikel eine Abschrift gibt, ist ein Folio beigefügt, auf dem die wichtigsten "Errungenschaften« der Friedensverhandlungen von Passau auf Italienisch festgehalten wurden: Die Freilassung des Landgrafen Philipp von Hessen, dass der Kaiser Moritz und all seinen Verbündeten verzeihe (bis auf Markgraf Albrecht Alkibiades), dass im Reich die territoriale Glaubensspaltung bestehen bleibe und dass der Kaiser keine Soldaten anderer Länder ins Reich führen könne.

L'Angravio è stato liberato et come prima posto nel stato suo dandogli libertà di ridur' le fortezze delle sue terre come prima.

Che l'Imperator' perdona al Duca Mauritio, et a tutti generalmente che gli sono stati contro et Rebelli eccetto al Marchese Alberto et a coloro che sono con lui.

Che la Germania non sia soggetta piu a questo Imperador, non con altre conditioni che sia stata a gli altri suoi Antecessori, per l'adietro.

Della Religione: che vivano et credano, come faccevano prima.

Che facendo l'Imper.re Guerra in Germania non possi condurvi genti d'altra natione che allemani.

reich Neapel, über die Kämpfe in Italien und die Lage und Truppenbewegungen in der Grafschaft Tirol. Dresden, SächHStA, Ferrair, Hertzog Herculis I 548-53, Locat. 8499/r, fol. 6o-6I'. Undatiertes Schreiben des kursächsischen Gesandten Johann Heise vom Hof des Herzogs Ercole di Ferrara, nach 8. und vor I4. Mai I 552, zitiert bei Rebitsch, Tirol, 309-3 I I.

666 Herrmann/Wartenberg/Winter, Politische Korrespondenz, Nr. 3 I 9, 594, Alfonso II. an Moritz von Sachsen, Januar I 552.

667 ASMo, ASE, Casa e Stato, Carteggio di principi esteri, Germania b I603/29, Moritz von Sachsen an Ercole II., August I $55^{2}$. 
Per l'obligatione di questi capitoli: sono sigurtadi il Re de Romani il duca di Baviera il Duca di Plaon ${ }^{668}$ il Car.le di Salisburg ${ }^{669}$ il Card.le di Passa ${ }^{670}$ et alcuni altri Vescovi et sono molti. ${ }^{671}$

Gerade der zweite Punkt, in dem es heißt, dass allen Aufständischen bis auf Markgraf Albrecht Alkibiades, mit dem sich die Este um ein Haar verschwägert hätten, verziehen werden sollte, dürfte Ercole II. d'Este große Erleichterung bedeutet haben, hatte er sich doch durch seine Beziehungen nach Norden offensichtlich gegen seinen Lehensherrn gestellt.

Die Kehrtwende des Sachsenfürsten hatte den Este allerdings nicht gänzlich unvorbereitet getroffen. Ein so großes Risiko hätte er sich als Vasall des Kaisers, der in Begriff war, in Italien militärisch einzugreifen, nicht leisten können. Die Berichte der estensischen Gesandten (vor allem Antonio Rossetti, Ercole Rangoni und Antonio Maria di Savoia Collegno) aus dem Reich ${ }^{672}$ zeigen, dass der Herzog von Ferrara schon vor dem Schreiben von Moritz von Sachsen über die Entwicklungen und die »Wende« informiert bzw. vorgewarnt worden war. So wusste Ercole bereits am 5. Mai I 552 , dass Moritz in Linz mit König Ferdinand zu Verhandlungen zusammengekommen war, dass Frieden im Gespräch war und dass man beschlossen hatte, sich in Passau wieder zu treffen. ${ }^{673}$ Die oben genannten Punkte, die als Forderungen von Moritz in die Verhandlungen von Linz eingeflossen waren, wurden Ercole bereits am Io. Mai I 552 in groben Zügen in den Gesandtenbriefen Collegnos mitgeteilt. ${ }^{674}$ Am 25. Juni wurde erstmals angedeutet, dass sich Moritz und Ferdinand bald einigen könnten, sodass Karl V. in Kürze gegen Frankreich vorgehen könnte. Dies bedeutete unweigerlich, dass auch Oberitalien in diese Auseinandersetzung verwickelt werden würde. Am 3. August gab es nur erste Gerüchte, dass Moritz den Friedensvertrag angenommen hatte; aber am 6. August konnte der estensische Gesandte selbiges bestätigen. Neun Tage bevor Moritz selbst dem Verbündeten Ercole II. d'Este eine schriftliche Erklärung sandte, wurde dieser über seine Gesandten informiert, dass der Vertrag ratifiziert worden war und dass darin die "Vergebung « aller "ribelli di Germania« enthalten war. ${ }^{675}$ Der sächsische Gesandte Heise brachte auf Wunsch Ercoles dennoch eine Abschrift des Passauer Vertrages mit.

668 Heinrich von Plauen, Burggraf von Meißen, oberster Kanzler des Königreichs Böhmens und Rat Ferdinands I. war maßgeblich an den Verhandlungen zum Passauer Vertrag beteiligt. Vgl. zu diesem und den weiteren Protagonisten: Drecoll, Der Passauer Vertrag, $72-84$.

669 Herzog Ernst von Bayern war ab i 540 Erzbischof von Salzburg.

670 Damit muss Wolfgang Graf von Salm, seit I 540 Bischof von Passau gemeint sein.

67 I Ebd., beigefügtes Folio.

672 ASMo, ASE, Casa e Stato, Carteggio di Ambasciatori, Germania bb ro- i6.

673 Ebd., b I 3 , von Collegno, Mai I 552.

674 Ebd., von Collegno, Mai I 552.

675 Jeweils ebd., von Collegno, Juni und August 1552. Im Anhang an Moritz' Brief heißt es etwas abgewandelt »a tutti generalmente che gli sono stati contro et Rebelli«. 
Der Beziehung zum Kurfürsten von Sachsen tat diese »Kommunikationsverzögerung « mit der erst nachträglichen Übermittlung der wichtigen Vertragspunkte, jedenfalls keinen Abbruch. Eine der letzten Gefälligkeiten, mit denen Ercole Moritz seiner Loyalität und Freundschaft versichern wollte, war die Ablehnung eines Geldgesuchs von Johann Friedrich von Sachsen. Dieser hatte um 200.000 Gulden für den Kampf gegen Moritz gebeten. Doch Ercole lehnte die Geldleihe mit der Begründung einer eigenen finanziellen Krise ab und berichtete dem Kurfürsten vom Vorhaben seines Vetters. ${ }^{676}$ Auch hier erkennt man einen gewissen wirtschaftlichen Neid gegenüber den Italienern und die Wahrnehmung der Este im Reich als reiche und liquide Fürsten. Die Loyalität der Este beruhte allerdings auch auf das Versprechen von Moritz 4.00o Soldaten zu entsenden, falls dem estensischen Fürstentum Gefahr drohe. Den Kaiser hatte der Kurfürst mit einer viel geringeren Truppenstärke unterstützt, eine Tatsache, die ihm zum Vorwurf gemacht wurde und die er mit den Este gemein hatte. ${ }^{677}$ Beide hatten nämlich wiederholt das Reichsoberhaupt spärlich unterstützt, während sie dem kaiserlichen Gegner (im Falle der Este war dies Frankreich) umso größere militärische und finanzielle Hilfestellung ${ }^{678}$ gewährten. Für den Fürstenaufstand wollte Ercole I 5.000 Soldaten und 300.000 Dukaten bereitstellen.

Selbst als sich Moritz von Sachsen schließlich durch die Bereitmachung zum Türkenkrieg im Herbst I 552 wieder in die Dienste des Reiches und der Habsburger stellte, verfolgte er insgeheim den als Handelsgeschäft getarnten Plan seiner Regentschaft über Ungarn unter Vorherrschaft der Feinde des Reiches, der Osmanen. Dieses Vorhaben hatte er mit dem Herzog von Ferrara insgeheim angedacht und besprochen. ${ }^{679}$ Für Ercole hätte eine Freundschaft mit dem zukünftigen »König von Ungarn«, der ein gewichtiger Kontrahent der Habsburger und dadurch noch einflussreicher im Reichsverband werden würde, ein Machtzuwachs bedeutet und womöglich die Präzedenzfrage unter den italienischen Fürsten zu seinem Vorteil gelöst.

Wie gezeigt wurde, saß Ercole II. d’Este Mitte des I6. Jahrhunderts zwischen mehreren Stühlen: Zwischen dem Kaiser und Frankreich, zwischen dem Kaiser und dem Papst und schließlich sogar zwischen der »Rechtgläubigkeit« und seiner Aufgabe, den katholischen Glauben zu verteidigen und dem Verdacht mit den protestierenden Reichsfürsten gemeinsame Sache zu machen. In einer solchen verzwickten Lage musste der Este-Fürst versuchen, eine Gleichgewichtspolitik zu führen, die aus zahlreichen halben Zusagen, freundlichen Aufschüben, keinen eindeutigen Positio-

676 Dresden, SächHStA, Loc. 8499/r bl. 74 r-v. Ausschnittsweise zitiert bei Korsch, Ein »heimlicher Vorschlag«, 42f.

677 Ebd., 44 .

678 Zum Finanzbedarf des Fürstenaufstandes vgl. auch Schirmer, Die Finanzierung der Fürstenrebellion. »Er [Moritz, E.T.] hoffte auf französische Subsidien und er schloss das Bündnis mit Frankreich schon aus dem Grunde, damit es nicht andere gegen ihn schließen."NICKLAs, Das Wagnis, 3 I.

679 Vgl. Korsch, Ein »heimlicher Vorschlag«, 49-54. 
nierungen und dem Versuch, den Kaiser aus Italien fernzuhalten, bestand. Obwohl er sich bemühte, seinen Einfluss in Oberitalien mithilfe von Frankreich und Sachsen zu vergrößern, ging der Herzog von Ferrara stets vorsichtig vor, tastete sich an diese Möglichkeit heran und konnte sich - im letzten Moment - noch rechtzeitig zurückziehen, bevor er sich den kaiserlichen Zorn zuzog. Moritz' "Kehrtwende« sollte ihm schließlich Recht geben. Auch war Ercole II. d'Este im Fürstenaufstand in einer Außenseiterposition, die sowohl positiv als auch negativ zu beurteilen ist. Ihm fehlte zwar die direkte Anbindung an die aufständischen Reichsfürsten und er war »nur« über Moritz von Sachsen und Frankreich an der Auflehnung gegen den Kaiser beteiligt. Auf der anderen Seite war er ausgesprochen gut vernetzt und seine "Teilnahme« aus der Ferne spricht für seine Wahrnehmung als wichtiges Bündnismitglied unter den »rebelli di Germania«. Dank seiner räumlichen Distanz zu den »Hauptakteuren« blieb er schließlich von einem gezielten Vergeltungszug des Kaisers im Krieg in Italien verschont. Ercole konnte somit - wie die anderen involvierten italienischen Fürsten - während der angespannten Zeit des Fürstenaufstandes nur eine abwartende und indirekt antikaiserliche Position einnehmen und genau verfolgen, wie sich die Beziehungen zwischen Frankreich und dem Reich sowie zwischen Moritz von Sachsen und dem Kaiser bzw. König Ferdinand entwickelten. Die Gründe für seine Vorsicht als kaiserlicher und päpstlicher Lehensmann und für die Geheimhaltung seiner Beziehungen mit Sachsen sind mehr als nachvollziehbar: Sein oberitalienisches Herzogtum und seine Existenz standen auf dem Spiel.

Mit Moritz verband Ercole den Wunsch, die kaiserliche Idee der monarchia universalis in territorialer (für Ferrara) und konfessionspolitischer Hinsicht (für Sachsen) zu verhindern. Den Wettinern gelang dies, da sie mit Moritz und dem ihm folgenden August zu den mächtigsten deutschen Fürsten im Reich nach den Habsburgern avancierten. Die Este hatten zwar die kaiserliche Präsenz und Rache »überstanden «, doch mit Spanien sollte eine erneute Bedrohung auf sie zukommen.

\subsection{Die Este und die Wettiner nach Kurfürst Moritz von Sachsen}

Der Nachfolger von Moritz im Kurfürstentum war sein Bruder August, der gute Beziehungen zum Kaiserhaus aufgebaut hatte und durch seine Heirat mit Anna, Tochter von Christian III. von Dänemark, auch im Norden verankert war. Dieses Fürstenpaar war besonders hinsichtlich seiner europaweiten Vernetzung ein vorbildliches »Arbeitspaar«, wie Katrin Keller in ihrer biografischen Studie zu Kurfürstin Anna erschlossen hat. Anna begleitete August oft zu Reichstagen (I 562, I 566, I 576, I 582), reiste des Öfteren nach Dänemark, kam mit ihrem Ehemann an die Höfe der Herzöge von Mecklenburg, von Braunschweig-Lüneburg, von Bayern und an die Kaiserhöfe Wien und Prag (I 570, I 573). Diese ausgedehnte Mobilität förderte neben ihren Interessen für Kunst, Gartenbau und Musik die Netzwerkbildung mit Fürsten und Fürstinnen innerhalb und außerhalb des Reiches. Aufgrund dieser Beziehungsgeflechte ka- 
men Fürstensöhne und -töchter zur Aus- und Weiterbildung nach Dresden. ${ }^{680}$ Annas Netzwerk reichte bis nach Italien: Der kursächsische Leibarzt Johann Neefe, ${ }^{681}$ mit dem sich die arzneikundlich und medizinisch versierte Kurfürstin gut verstand, hatte u.a. in Ferrara studiert. ${ }^{62}$ Lebensmittel, Delikatessen, aber auch Obstbäume, Zitrusfrüchte oder Tulpenzwiebeln und Samen, die nicht über Leipzig nach Dresden kamen, wurden aus Italien oder über Wien/Prag oder Innsbruck (von hier besonders Murmeltierschmalz) bezogen. ${ }^{683}$ Über Erzherzog Ferdinand II. und Innsbruck erhielt August für seine Hoffeste und Fasnachtsmummereien in den I 57 oer Jahren Abbildungen und Muster von in Ferrara üblichen Masken. ${ }^{64}$ Was hingegen die Mode am sächsischen Hof anbelangte, so behielt Anna zeit ihres Lebens die »dänische« Kopfbedeckung, Barette mit Federbüschen, die sie auch weiterverschenkte. Die Mode, die sie am Hof festlegte, war »Deutsch« oder »Dänisch« und kein Ausdruck italienischen Kulturtransfers. $^{685}$

Im Unterschied zu anderen - auch protestantischen - Reichsfürsten gibt es allerdings keinen einzigen erhaltenen Brief der schreibfreudigen Kurfürstin ${ }^{686}$ an die Este, während bei den anderen hier untersuchten Dynastien zumindest Gunstbekundungen und Grüße von Gattinnen der mit dem jeweiligen Herzog von Ferrara korrespondierenden Fürsten vorhanden sind. Auch Keller hat feststellen können, dass die weitaus geringere Korrespondenz Kurfürstin Annas mit katholischen Höfen auf Anna von Bayern und ihre Tochter Maria von Innerösterreich und den Kaiserhof beschränkt waren, die mit Briefen, Geschenken und Fürbitten bedacht wurden. ${ }^{687}$

Die Präsenz der Italiener in Dresden, im kulturellen wie auch persönlichen Sinn, blieb nichtsdestotrotz über das I6. Jahrhundert hinaus erhalten. Das Italienische war neben dem aufstrebenden Französischen und dem niedergehenden Lateinischen weiterhin auch am sächsischen Hof eine lingua franca. August der Starke machte eine Kavalierstour, die ihn u.a. nach Italien führte, verstand neben Französisch und Spanisch auch Italienisch und holte in seiner Regierungszeit zahlreiche Handwerker, Künstler und Musiker aus Italien an seinem Hof. Mit Friedrich August bzw. August III. von

680 Keller, Kurfürstin, 27, 4I.

68 I Dazu siehe die Einträge in der Datenbank Frühneuzeitliche Ärztebriefe des deutschsprachigen Raums (I 500-I 700), GND-Nummer I 2 I $82795 \mathrm{X}$ in: http://www.aerztebriefe.de/, Zugriff: I 4.7.2020.

682 Ebd., I62.

683 Ebd., 47, I 55 .

684 Ebd., 6o. Brief zit. in: Kuster, »Eur Lieb gannz williger Brueder«, 50, Anm. 47. I 5 I 2 führte auch Henry VIII. diese im estensischen Fürstentum verbreiteten Masken in England ein. Vgl. CAnovaGreen, The English court masque, $525 \mathrm{f}$.

685 Keller, Kurfürstin, 49, 5 I. Vgl. auch Kappel, »... im heiligen Ehestande«.

686 Nach Keller sind es geschätzte 25.000 Briefe von und an Anna von Sachsen in ca. 30 Jahren der fast lückenlos erhaltenen Korrespondenz. Keller, Kurfürstin, 72 f.

687 Ebd., 74-76. Die Bedeutung dieses weiten Korrespondenznetzwerks hat Katrin Keller auch in den Zusammenhang der Außenbeziehungen des Kurfürstentums gestellt: Keller, Mit den Mitteln einer Frau. 
Polen erreichte der Kulturtransfer aus Italien einen erneuten Höhepunkt. Letzterer vermittelte im Streit um Comacchio zwischen dem Papst und dem Kaiser, der I 708 im Zuge des Spanischen Erbfolgekriegs diesen Küstenstreifen, den schon die Este bei der Devolution als Reichslehen für sich reklamiert hatten, besetzen ließ. ${ }^{688}$ Unter August III. kam es im Zuge der Heirat zwischen Rinaldo d'Este und Charlotte Felicitas von Braunschweig-Lüneburg I 695 zur (erneuten) Suche nach der gemeinsamen Abstammung durch die Gelehrten L(u)odovico Antonio Muratori und Gottfried Wilhelm Leibniz. ${ }^{689}$ Außerdem heiratete sein Sohn Friedrich August I 7 I 9 Maria Josepha, eine Cousine von Francesco III. d'Este, in Modena. Schließlich kamen I 746 im Zuge der Vendita di Modena s oo Gemälde italienischer, deutscher und flämischer Maler aus der Sammlung der Este für roo.ooo zecchini nach Dresden. Darunter befanden sich viele Werke von Vertretern der ferraresischen Schule, wie Dosso und Battista Dossi, Garofalo und Girolamo da Carpi, die Ercole II. für die Neugestaltung des Castello Estense in Auftrag gegeben hatte. ${ }^{690}$

\subsubsection{Die Beziehungen zwischen den Este und den Herzögen von Mecklenburg}

Bedeutend für die Entwicklung des Fürstentums Mecklenburg war die Anlehnung der Grafen von Schwerin an Kaiser Karl IV. (I316-I378), der das Gebiet von der sächsischen Lehenshoheit befreite, und I 348 Albrecht II. und seinen Bruder Johann zu Herzögen und somit reichsunmittelbaren Fürsten erhob. Zehn Jahre später kam die Grafschaft Schwerin zum Herzogtum dazu. Dieser territorialen Erweiterung folgte I 352 jedoch eine Schwächung des Fürstentums durch eine Teilung des Landes in Mecklenburg-Schwerin und Mecklenburg-Stargard (bzw. Strelitz). Mit Heinrich IV. (der Dicke) kam es durch Erbfall zu einer vorläufigen Wiedervereinigung, ab I 47 I war er Herzog von Mecklenburg, Fürst von Wenden, Graf von Schwerin, Herr von Rostock und Stargard. Im I 5. und I6. Jahrhundert bemühten sich die Herzöge von Mecklenburg wiederholt um die Vergrößerung ihrer Macht durch die Bewerbung um

$688 \mathrm{Zu}$ diesen und folgenden Transfermomenten im i7. und I8. Jahrhundert: Lieber, Die italienische Präsenz.

689 Dazu siehe Marri/Lieber/Weyers, Lodovico Antonio Muratori, I3-i8. Lodovico Antonio MuRATORI, Delle antichità estensi ed italiane. Trattato, Parte prima in cui si espone l'Origine ed Antichità della Casa d'Este, e la sua diramazione nella Linea Reale ed Elettorale del Regnante Monarca della gran Bretagna Giorgio I e de i duchi di Brunsuic, e Luneburgo, e nella Linea de'Marchesi d'Este, e di Duchi di Ferrara, e Modena, Modena, Stamperia ducale i 7 I 7.

690 Francesco III. benötigte aufgrund der Belagerung Modenas I740 durch österreichische und französisch-savoyische Truppen Geld. Ebd. und Weber, La collezione di pittura ferrarese, 37-40. Ein Werk Tizians (Cristo della moneta) war bereits von Flaminio Torre kopiert worden. Um zu vermeiden, dass die Kopie in die Dresdner Sammlung gelangte, wurde verfügt, dass beide Werke nach Sachsen transportiert und nach eingehender Prüfung die Kopie zurückgeschickt werden sollte, was aber nicht geschah. Es wurden hingegen stets beide Werke ausgestellt. Ebd., 43. 
die dänische bzw. schwedische Krone ${ }^{691}$ intern hatten sie - wie auch die Este - mit Bandenwesen an ihren Grenzen und Räubereien zu kämpfen. ${ }^{692}$ Eine weitere Gemeinsamkeit war, dass beide Fürstentümer und ihre Akteure am Rande des Heiligen Römischen Reiches lagen und dennoch in den Strudel der europäischen Entwicklungen des r6. Jahrhunderts gerieten.

Der Nachfolger von Heinrich dem Dicken, Magnus II. (reg. I477- I 503), stärkte das Fürstentum durch Straffung und Zentralisierung der Verwaltung mithilfe ausgebildeter Beamter, durch Förderung der Wirtschaft (Holz- und Getreidehandel) und durch die Unterbindung der Autonomiebestrebungen der Seestädte. Weniger erfolgreich war er in der Vermeidung einer erneuten Teilung des Herrschaftsgebietes in zwei Territorien mit den jeweiligen Zentren Schwerin und Güstrow. Auch in der "Zähmung« des Adels, der aus I 70 Dynastien bestand, waren die mecklenburgischen Herzöge nicht übermäßig erfolgreich. Durch die notwendige Repräsentationspolitik häuften sich zudem bereits Anfang des I6. Jahrhunderts höhere Schulden an. ${ }^{693}$ Magnus erkrankte wahrscheinlich auf seiner Pilgerfahrt ins Heilige Land an Lepra, von der ihn auch der Leibarzt Conrad Schwestermüller, ${ }^{694}$ den er sich vom brandenburgischen Hof zwei Jahre lang ausgeliehen hatte, nicht heilen konnte. ${ }^{695}$

Die faktische Teilung des Landes beibehaltend haben in der nachfolgenden Generation Herzog Ulrich (I 527- I603) und sein Bruder Johann Albrecht I. (I 525 - I 576) die Politik und Kultur Mecklenburgs geprägt. Johann Albrecht besaß am Schweriner Hof eine Sammlung von 5.000 Büchern und somit eine der bedeutendsten deutschen Fürstenbibliotheken des r6. Jahrhunderts, bestückt mit Werken aus allen humanistischen Wissensbereichen. Darunter waren ein Reiseführer der antiken Stätten Roms, eine venezianische Ausgabe von Leon Battista Albertis L'Architettura und ein Skizzenbuch mit Darstellungen eleganter Italienerinnen und Italiener. ${ }^{696}$

Mecklenburgs Übergang zum Luthertum war bereits unter Heinrich V. (reg. I $503-$ I $55_{2}$ ) - entgegen den Bestrebungen seines Bruders Albrecht VII. (reg. I 534- I 547) mithilfe einer Kirchenreform vonstattengegangen; ${ }^{697}$ die offizielle Annahme dieser Glaubenslehre erfolgte ab I 549 und ging mit einer starken Hinwendung zur Renaissance und zur Vermittlung und Förderung von Künstlern aus ganz Europa einher, die an die beiden Renaissancehöfe Güstrow und Schwerin geholt wurden. Die fruchtbarste Zeit aber war sicher die lange Regierungszeit von Ulrich von Mecklenburg

69I So wurde Albrecht III., Sohn von Albrecht II. (reg. I385-r 3 38), König von Schweden (I $364-$ I389).

692 Als Überblick siehe: MÜNCH, Glanz, 42 - 47.

693 MüNcH, Mecklenburgs widerspruchsvoller Übergang, 57-6o.

694 Vgl. den Eintrag GND-Nr. I03 15 I 265 in: http://www.aerztebriefe.de/, Zugriff: 14.7.2020.

695 Im Schweriner Schloss befindet sich die Porträtgalerie der Herzöge von Mecklenburg bzw. von Mecklenburg-Schwerin von Albrecht II. (I 3 I 8 - I 379) bis Herzog Ludwig (I 725 - I 778). Vgl. BorchardT/ Borchardt, Mecklenburgs Herzöge, 40.

696 Stuth, Zwischen Tradition und Moderne, 254, $258 \mathrm{f}$.

697 Borchardt/Borchardt, Mecklenburgs Herzöge, 4If. 
I 550- I603 und seiner beiden Gemahlinnen Elisabeth von Dänemark und Anna von Pommern, Tochter von Herzog Philipp I. und Maria von Sachsen, die sich ebenfalls als Mäzeninnen und Auftraggeberinnen einen Namen machten. ${ }^{698}$

Herzog Ulrich von Mecklenburg wurde $5_{527}$ in Schwerin als zweiter Sohn von Albrecht VII. (des Schönen) und Anna von Brandenburg, Tochter von Kurfürst Joachim I., geboren. Er erhielt seine Ausbildung ab I 539 am Hof des kunstsinnigen bayerischen Herzogs Wilhelm IV.zusammen mit dessen Sohn Albrecht (V.) in München und an der Universität Ingolstadt. Hier lernte Ulrich die italienische Renaissancekultur und ihre Künstler kennen. Am Münchener Hof und auf seinen Reisen in süddeutsche Städte knüpfte er wichtige Kontakte, die er, insbesondere jene zu Augsburger Kunsthandwerkern, als späterer Herrscher von Mecklenburg und anlässlich seiner Besuchen bei den Reichstagen, z.B. von Augsburg I 566 und I 582 weiter pflegte. ${ }^{699}$ Als teilnahmeberechtigte Reichsfürsten waren Ulrich und Johann Albrecht also auch potenzielle Fürsprecher der Este am Reichstag, ${ }^{700}$ obwohl sich das Verhältnis der Mecklenburger zu Kaiser und Reich bereits vor der Reformation stark gelockert hatte. ${ }^{701}$

I 55 I kehrte Ulrich aus Bayern wieder in seine Heimat zurück und wurde zunächst Administrator des Bistums Schwerin. Sein Verhältnis zu seinem regierenden älteren Bruder Johann Albrecht I., der am brandenburgischen Hof von Kurfürst Joachim II. erzogen worden war, war nicht besonders gut und steigerte sich bald zu einem Konflikt. Schließlich wurde I 555 durch den Wismarer Vertrag beschlossen, dass Mecklenburg zwar gemeinschaftlich regiert werden sollte, aber Johann Albrecht I. in Schwerin und Ulrich in Güstrow residieren sollte. Als sein älterer Bruder I 576 starb, herrschte Ulrich als Vormund für dessen unmündigen Sohn und nach dessen Tod bis I603 über das gesamte Fürstentum. Er galt als »der Nestor der deutschen Fürsten «, so Neumann, und war Oberster des niedersächsischen Reichskreises. ${ }^{702}$ Beide Herzöge von Mecklenburg, aber vor allem Ulrich, unterhielten ausgedehnte Korrespondenzen mit zahlreichen europäischen Fürstenhäusern, so Philipp II. von Spanien, Wilhelm von Oranien, Kaiser Rudolf II., Elisabeth I. von England und mit den Verwandten in Dänemark, Schweden, Schleswig-Holstein und Preußen. Eines der bedeutendsten von Ulrich in Auftrag gegebenen Kunstwerke war die gedruckte Fürstengenealogie von I 578, die den genealogischen Auftragswerken der Este ähnelte. Neben der Geschichte des mecklenbur-

698 Neumann, Die Renaissancekunst, I 5 - I7.

699 Ebd., 23.

700 Johann Albrecht und Ulrich von Mecklenburg nahmen am Reichstag in Speyer I 570 teil. Lanzinner, Deutsche Reichstagsakten. Der Reichstag zu Speyer I 570, Zweiter Teilband, 983.

70 I Definitiv wurde das Luthertum I549 nach der Übereinkunft mit den Landständen eingeführt; von Johann Albrecht I. wurden die Landeskirche ausgebaut und die letzten Spuren des Katholizismus entfernt. Diese Entwicklung führte zu einer Blütezeit der Universität Rostock und des geistig-kulturellen Lebens in Mecklenburg, aber auch zu einer Entfernung von der habsburgischen Dynastie. MüNCH, Glanz, 52, 64 f.

702 Neumann, Die Renaissancekunst, $24 \mathrm{f}$. 
gischen Fürstenhauses waren reformatorische Themen, Porträt- und Repräsentationskunst sowie die Grabmalkunst die bedeutendsten geförderten Gattungen. ${ }^{703}$

Durch seine Ausbildung am bayerischen Hof, wo die Landshuter Stadtresidenz im italienischen Stil des von Giulio Romano geprägten Palazzo Tè errichtet worden war, war die erste Phase der Kunstförderung Ulrichs am Güstrower Hof ebenso von der italienischen Renaissance geprägt: Das Schloss wurde von der italienischen Baumeisterfamilie Parr aus der Lombardei umgestaltet; die Außenfassade des Schlosses aus heimischen Backsteinen wurde nach einem italienischen Verfahren so verputzt, dass sie kostbarem Sandstein ähnelte. Herzog Ulrich engagierte für seine Schloss(um-) bauten italienische und niederländische Handwerker und schmückte seine Residenzen mit italienischen Stuckarbeiten und Sammlungsstücken aus Italien, Fayencen (aus Urbino), Gemälden und Möbeln (aus Florenz) aus. Das Geld dafür kam vor allem aus der reichen Mitgift seiner ersten Frau Elisabeth von Dänemark. ${ }^{704}$ Auch sein Bruder Johann Albrecht war von der italienischen Kunst, vor allem von der Terrakotta-Architektur Oberitaliens, fasziniert und ließ diesen italienischen Einfluss in den Residenzen von Schwerin und Wismar einfließen. Nach I570 kamen aufgrund der Konfessionskonflikte immer mehr niederländische Künstler nach Mecklenburg und hatten mit ihrem Ornamentstil des Roll- und Beschlagwerks großen Erfolg, sodass man die Zeit bis I6oo in Mecklenburg die niederländisch geprägte Kunstphase nennt. ${ }^{705}$ Die beiden Brüder konkurrierten nicht nur in der Herrschaft, sondern auch in ihrer Bautätigkeit und ihrem Mäzenatentum. In Bezug auf die Umgestaltung von Schloss Schwerin und der Residenz Wismar ${ }^{706}$ sprach man sogar vom »JohannAlbrecht-Stil ${ }^{707}$

703 Ebd., 3I-33, 37, 4I.

704 Der italienische Einfluss intensivierte sich mit Albrecht von Wallenstein, der vom Kaiser Mecklenburg erhalten hatte, die beiden nachfolgenden Herzöge vertrieb und seine Residenz in Güstrow nahm. Hierher berief er den italienischen Baumeister Pironi; dessen Veränderungen sind aufgrund der erneuten Bautätigkeit der 163 I zurückgekehrten Herzöge von Mecklenburg heute nicht mehr ersichtlich. Staatliches Museum Schwerin, Schloß Güstrow, 4-io, i 4 .

705 Neumann, Die Renaissancekunst, 38-4I, 55.

706 Als ein Vorbild für den Wismarer Fürstenhof und die Verwendung von Terrakottaplatten in der Fassade gelten Palazzo Rovella oder Palazzo Schifanoia in Ferrara. Vgl. Genrig, Die bürgerliche Baukunst, I I- I3 zit. n. Neumann, Die Renaissancekunst, 507 Anm. I07. Auch im Band der Deutschen Kunstdenkmäler zu Mecklenburg wird festgehalten - ohne Quellenangaben - dass der Bauplan und die horizontale Wandgliederung im Stil der lombardischen Renaissancearchitektur auf die Beziehungen zu Ercole II. d'Este zurückzuführen seien. Ноотz, Deutsche Kunstdenkmäler, 4ro. Matthias Barth führt ebenso die Formensprache auf die Beziehung der Mecklenburger zum Herzog von Ferrara zurück. BARth, Mecklenburgische Residenzen, I9. Auch wenn in den Quellen kein direkter Hinweis im Sinne eines Bauplanes oder einer Beschreibung zu finden ist, könnte die Entsendung des Architekten von Johann Albrecht, Francisco Vuarano, nach Ferrara ${ }_{5} 56$ dafür sprechen. ASMo, ASE, Casa e Stato, Carteggio di principi esteri, Germania b I603/29, Johann Albrecht I. von Mecklenburg an Ercole II., November 1556 .

707 Staatliches Museum Schwerin, Schloß Güstrow, 7. 
Auch der seit I 558 in Güstrow bezeugte Lustgarten folgte italienischen Vorbildern mit ausländischen Blumen und Früchten. Noch unter Wallensteins Herrschaft wurde ein Gärtner nach Italien geschickt, um die dortige Gartenkunst zu lernen und Samen mitzubringen. ${ }^{708}$

Johann Albrecht I. war ebenso wie sein Bruder ein kunstsinniger und schaffensfroher Renaissancefürst. Er stand in regem Briefwechsel mit Melanchthon, der für ihn eine neue Kirchenordnung verfasste, und mit Cosimo de'Medici. ${ }^{709}$ Auch gründete er eine bemerkenswerte Hofkapelle und einen Schlosschor. Er machte aus Schwerin ein »nordisches Florenz«. Durch das Voranschreiten der lutherischen Reformation und die damit einhergehende Aufhebung der Klöster flossen große Reichtümer in seine Kasse, die jedoch seine hohen Ausgaben nicht decken konnten. Während sein Bruder Ulrich trotz ausgedehntem Mäzenatentum sparsam war, hinterließ Johann Albrecht einen verschuldeten Landesteil. ${ }^{710}$

Im Staatsarchiv von Modena sind I 7 Briefe von Johann Albrecht an Ercole II. und neun an Alfonso II. erhalten. ${ }^{711}$ Der Herzog von Mecklenburg bat darin um estensische Pferde, ${ }^{712}$ empfahl zwei Männer, Daniel a Lahden und Baltazar Klinten, die nach Italien reisen sollten, um Sprache und Land kennenzulernen, ${ }^{713}$ berichtete im April 1556 über das Bündnis der deutschen Fürsten (Sachsen, Mecklenburg, Brandenburg, Lüneburg, Hessen, Polen, Pommern) gegen die Türken und forderte den Este auf, auch Mitglied zu werden. ${ }^{714}$ Der mecklenburgische Hof scheint für die Este ein wichtiges Informationszentrum gewesen zu sein, denn Johann Albrecht verabsäumte es nicht, Ercole über die Kriegsunruhen im Reich oder in Polen und Ungarn und über Reichstruppenbewegungen gegen Frankreich auf dem Laufenden zu halten. Ebenso

708 Ebd., 44. Mit der Gartenkunst an norddeutschen und französischen Höfen und ihren fürstlichen Gestalterinnen beschäftigte sich letztens Editha Weber, Fürstinnen im Grünen. Spaziergänge durch Schlossgärten, Berlin 2016.

709 Im Bestand sind einige Briefe an die Herzöge von Mantua und Florenz erhalten, die bezeugen, dass die Herzöge von Mecklenburg mit diesen italienischen Fürsten ebenso Austausch und Kontakt hatten. So kamen ${ }_{5} 6_{3}$ Pferde von Cosimo de'Medici nach Schwerin. Schwerin, LHA, 2-I I-2/r Auswärtige Beziehungen einschl. Reich 3628 Italica, Johann Albrecht an Cosimo de'Medici, September ${ }_{5} 63$. Der Florentiner wurde 1566 um einen Arzt/Chirurgen gebeten, den er dem verwandten Markgrafen von Brandenburg hatte zukommen lassen. Doch Cosimo konnte dieser Bitte nicht nachkommen, da der Arzt, der den Markgrafen von Brandenburg geheilt hatte, mittlerweile 66 Jahre alt war und die beschwerliche Reise über die winterlichen Alpen nicht mehr unternehmen konnte. Ebd., Johann Albrecht an Cosimo de'Medici, September 1566; Antwortschreiben von Cosimo Johann Albrecht, ebd., November I 566 .

7 Io Borchardt/Borchardt, Mecklenburgs Herzöge, 48 - 5 I.

7 I I Zu Johann Albrechts I. Korrespondenz mit Ercole II. d'Este: Barth, Mecklenburgische Residenzen, I 9 .

7I 2 ASMo, ASE, Casa e Stato, Carteggio di principi esteri, Germania b r603/29, Johann Albrecht I. von Mecklenburg an Ercole II., Juli I 554.

7r 3 Ebd., Johann Albrecht I. von Mecklenburg an Ercole II., Juni 1555.

7I4 Ebd., Johann Albrecht I. von Mecklenburg an Ercole II., April 1556. 
berichtete er vom Reichstag in Regensburg I 557 und in Augsburg I 559 und wurde dadurch, mehr als sein Bruder, zur nützlichen Kontaktperson für die Este im Reich. ${ }^{715}$ Wiederholt wurden Gesandte mit Briefen angekündigt und geschickt, in denen die große Freundschaft und Liebe (»amice \& frater charissime«, "nam et amori erga te meo nihil decedet unquam «) zwischen den beiden Häusern und Fürsten betont wurde, vor allem dann, wenn es längere Schreibpausen (»silentio enim tuo«) gegeben hatte. ${ }^{716}$

Auch den Nachfolger Alfonso II. hielt Johann Albrecht I. über die Entwicklungen im Reich informiert. ${ }_{5} 6_{3}$ berichtete er über den Krieg um Polen und Litauen sowie über die Türkengefahr und bat um die Unterstützung des Este. ${ }^{717}$ Darüber hinaus wurden Menschen und Güter ausgetauscht: Bartholomäus Gryphius wurde nach Ferrara geschickt, um Ampullen von acqua [de]stillata zu besorgen, die der Herzog von Mecklenburg benötigte, um Kräuter anzusetzen, ${ }^{718}$ und Davide Wilde brachte jenes Pferd nach Schwerin, das Alfonso dem Herzog zum Geschenk gemacht hatte. ${ }^{719}$ Der famulus Jacopo Moretti kam für ein paar Jahre an den mecklenburgischen Hof; da er eine große Familie hatte, bat Johann Albrecht I. den Herzog von Ferrara um ein Stück Land in Ferrara oder um ein Pferd für diesen, damit er seinen Lebensunterhalt bestreiten könne. ${ }^{720}$ Im März I 572 empfahl Johann Albrecht Thomas Bautsche, Sohn eines Waffenmeisters, der sich am ferraresischen Hof in dieser Kunst ausbilden lassen wollte, und bat um dessen wohlwollende Aufnahme. ${ }^{721}$

Von Herzog Ulrich von Mecklenburg ist in Modena hingegen nur ein Brief erhalten, in dem er durch einen Gesandten seinen Besuch auf der Reise durch Italien ankündigte. ${ }^{722}$

In den vier minute di lettere an Johann Albrecht I. wird ersichtlich, dass die Este ebenfalls Personen nach Mecklenburg empfahlen ${ }^{723}$ und Gesandte, die auf dem Weg zum Kaiser waren, vorbeischickten. ${ }^{724}$

Im Bestand "2-I I-2/I Auswärtige Beziehungen einschl. Reich 3628 Italica« im Hauptstaatsarchiv Schwerin sind verschiedene Schreiben der Este-Fürsten und Johann Albrechts I. aufbewahrt. In den erhaltenen sieben Briefen Ercoles II., die in den

7I5 Ebd., Johann Albrecht I. von Mecklenburg an Ercole II., April, Mai I556, November I557, Juni, Oktober I 5 58, April I 559 .

716 Ebd., Johann Albrecht I. von Mecklenburg an Ercole II., Juni 1559.

7I7 ASMo, ASE, Casa e Stato, Carteggio di principi esteri, Germania b I603/29, Johann Albrecht I. von Mecklenburg an Alfonso II., September, November ${ }_{5} 63$.

718 Ebd., Johann Albrecht I. von Mecklenburg an Alfonso II., Januar 1568.

7 I 9 Ebd., Johann Albrecht I. von Mecklenburg an Alfonso II., April I 57 I.

720 Ebd., Johann Albrecht I. von Mecklenburg an Alfonso II., April I57 I, September 1575.

72 I Ebd., Johann Albrecht I. von Mecklenburg an Alfonso II., März 1572.

722 Ebd., Ulrich von Mecklenburg an Alfonso II., April I 582.

723 Wie auch einen Hauptmann namens Francesco, ASMo, ASE, Casa e Stato, Minute di lettere ducali a Principi e signori fuori d'Italia b I635/5, an Johann Albrecht von Mecklenburg, Januar I 557 .

724 So Fulvio Rangoni im April I 56o, ebd., Minute di lettere an Johann Albrecht von Mecklenburg, April I560. 
verschiedenen Sprachen (Lateinisch, Italienisch, deutsche Übersetzung) stets mit der Bezeichnung »Bruder und guter Freund« enden, wird ein Pferdezähmer (»equorum domitor«) mit Briefen und Gunstbekundungen angekündigt. Zugleich wird in einem italienischen postscriptum die Bedrohung durch die spanischen Truppen an der Grenze zu Guastalla erörtert. ${ }^{725}$ Ercole hielt den mecklenburgischen Herzog mehrfach über die Ereignisse in Italien auf dem Laufenden. So erwähnt er, neben der Empfehlung für Christophorus Schenk, der Briefe überbracht hatte und in einen Erbschaftsstreit verwickelt war, dass es I 557 aus Italien nichts weiteres Neues gab, außer dass der Papst Gesandte zum Kaiser und zum französischen König geschickt hatte, um über den Frieden zu verhandeln. ${ }^{726}$ Eingebettet in seinen Bericht über die Tatsache, dass er jemand zum Kaiser geschickt habe, um sein Lehensverhältnis zu erneuern, teilte Ercole im Mai I 559 dem Herzog von Mecklenburg mit, dass der Papst erkrankt und der Frieden aufgrund dessen nicht gesichert sei. ${ }^{727}$

In den sechs im Schweriner Archiv aufbewahrten Briefen des estensischen Nachfolgers, Alfonso II., an Johann Albrecht geht es um die Ankündigung von Gesandten wie um die Bestätigung des Erhalts von Briefen. Nur im einem Schreiben an den Gesandten Bottini, der nach Mecklenburg reisen sollte, ließ Alfonso Johann Albrecht um Unterstützung für seine Kandidatur für den polnischen Thron bitten, was der Herzog - dem Gesandten nach - in Form von Empfehlungsschreiben und Fürsprache tun wollte. ${ }^{728}$

Weitaus interessanter, weil sie das Bild der Este als wohlhabende Fürsten im Reich erneut bestätigen, sind die in Schwerin erhaltenen Abschriften der Briefe Johann Albrechts I. an Ercole II. mit der wiederholten Bitte um finanzielle Unterstützung im Livland-Krieg. ${ }^{729}$ Im Januar I 556 bat der Herzog von Mecklenburg-Schwerin den Herzog von Ferrara im Namen ihrer innigen Freundschaft um eine Geldleihe von

725 Schwerin, LHA, 2-I I-2/I Auswärtige Beziehungen einschl. Reich 3628 Italica, Ercole II. an Johann Albrecht von Mecklenburg, September 1554.

726 Schwerin, LHA, 2-I I-2/I Auswärtige Beziehungen einschl. Reich 3628 Italica, Ercole II. an Johann Albrecht von Mecklenburg, Juni 1556 . Ein Jahr später berichtete Ercole, dass in Italien alles ruhig sei, auch im Piemont. Ebd., Ercole II. an Johann Albrecht von Mecklenburg, Juni I 557.

727 Ebd., Ercole II. an Johann Albrecht von Mecklenburg, Mai 1559.

728 Ebd., Alfonso II. an Johann Albrecht von Mecklenburg und an den Gesandten Bottini nach Mecklenburg, beide Juni 1574 .

729 Hierbei ging es vor allem darum, dass Herzog Albrecht von Preußen Livland dem Einflussbereich des Deutschen Ordens und der livländischen Fürsten entziehen und unter die Herrschaft von PolenLitauen bringen wollte, von der er sich mehr Spielraum erhoffte. Zur offenen Auseinandersetzung sollte es durch den von Preußen unterstützten Koadjutorplan kommen: die Bewerbung von Herzog Christoph von Mecklenburg, Bruder von Johann Albrecht, zum Koadjutor des Erzbischofs von Riga. Für diese Kandidatur benötigten die Mecklenburger Hilfe und Unterstützung. Anfang des Jahres I 556 wurde Christoph als Koadjutor bestätigt und die Krise spitzte sich zu. Zur Livlandkrise und dem Koadjutorplan siehe: Rasmussen, Die livländische Krise, 28-33. Zum Konflikt um Livland aus der Sicht des Reiches siehe das Kapitel „Der Krieg um Livland« bei Lanzinner, Friedenssicherung, 409-425. Siehe auch: Luttenberger, Kurfürsten. 
20.000 Talern, die über Vertrauensmänner - es sollten dann Augsburger Kaufleute sein - transportiert werden sollten. Ercole blieb in seiner Antwort vage und sagte trotz großer Gunstbekundungen - nicht auf Anhieb zu. ${ }^{730} \mathrm{Im}$ Jahr darauf erzählte Ercole von seinen eigenen Sorgen und Problemen durch die spanische Vorherrschaft in Italien und wie er einen Komplott gegen ihn und sein Fürstentum entlarvt hatte. Philipp II. von Spanien und der Kardinal von Trient hätten nach und nach als Studenten verkleidete Soldaten in seine Stadt geschleust und diese für einen Angriff eingesetzt. Es wäre zu Schlimmerem gekommen, wenn nicht seine Wache diesen Komplott vereitelt und die Eindringlinge gefasst und verhört hätte. ${ }^{731}$

Auch der nachfolgende Herzog von Ferrara wurde von Johann Albrecht mit dem Problem des Baltischen Krieges konfrontiert. In dieser Auseinandersetzung mit Moskau und Polen benötigte der Herzog von Mecklenburg weiterhin dringend Geld. ${ }^{732}$ Im Bestand 2.I I-I/I Auswärtige Beziehungen (Acta externa) Livland ror 2- го го befindet sich ein ganzer Faszikel mit dem Titel »Bemühungen des Herzogs Johann Albrecht z.M. bei den Herzogen Hercules und Alphons von Ferrara um eine Geldanleihe zur Unterstützung der livländischen Angelegenheit I 555/56- I 560/6 I «. Hier sind sowohl direkt an die beiden Fürsten gerichtete als auch einige an den Gesandten Mecklenburgs in Ferrara, Johann Schwenkbecher, adressierte Schreiben erhalten. ${ }^{733}$ Die erste Antwort Ercoles auf die Bitte um Geld war wenig erfreulich gewesen, da dieser auf ein Einlenken im Krieg um Livland hoffte; er selbst müsse sich in Italien gegen Frankreich, Reich und Papst rüsten und könne der Bitte um Kredit somit nicht nachkommen. ${ }^{734}$ Auch Alfonso II. bedauerte die Kriegssituation in Livland und auch könne er nicht mit Geld aushelfen. ${ }^{735}$ Doch schließlich müssen die Este eingelenkt haben, denn der letzte Brief Johann Albrechts an Ercole II. vom Sommer I 559 (Ercole starb im Oktober) sollte schließlich den Transport der verhandelten Geldleihe aus Ferrara mittels Kaufleuten aus Augsburg regeln. ${ }^{736} \mathrm{Im}$ Jahr darauf wurden erneut

730 Schwerin, LHA, 2-1 I-2/I Auswärtige Beziehungen einschl. Reich 3628 Italica, Johann Albrecht an Ercole II, Januar I 556 und Antwortschreiben vom März I 556.

73 I Schwerin, LHA, 2-I I-2/I Auswärtige Beziehungen einschl. Reich 3628 Italica, Ercole II. an den Herzog von Mecklenburg, Juni 1557.

732 Ebd., Johann Albrecht an Ercole II., Juni r 56r

733 Schwerin, LHA, 2-I I-I/I Auswärtige Beziehungen (Acta externa) Livland (ohne Nummerierung, daher in der vorliegenden Ordnung selbst nummeriert) 2-9, Dezember I 555 . Darüber hinaus berichtete der Gesandte, dass der Sohn des Herzogs, Alfonso, nach Frankreich gezogen sei, dass er in Basel schöne Bücher für seinen Herrn erstanden habe und dass es Neuigkeiten über den Papst und den Türkenkrieg gebe. Ebd. Juni I 556 .

734 Schwerin, LHA, 2-ı I-I/I Auswärtige Beziehungen (Acta externa) Livland I8-2 I (eigene Nummerierung), Ercole II. an Johann Albrecht, November 1556.

735 Schwerin, LHA, 2-I I-I/r Auswärtige Beziehungen (Acta externa) Livland 35-36 (eigene Nummerierung), Alfonso II. an Johann Albrecht, Oktober I 560.

736 ASMo, ASE, Casa e Stato, Carteggio di principi esteri, Germania b r6o3/29, Johann Albrecht I. von Mecklenburg an Ercole II., Juni 1559. 
zwei Gesandte aus Mecklenburg nach Ferrara geschickt, um Alfonso zu einer weiteren finanziellen Unterstützung zu überreden. Darüber ist im Schweriner Archiv ein Faszikel »Relation und Bericht was Heinrich Peliran und Jonas Viererkel beim Hertzogen zu Ferrar in Geltsachen verrichtet haben, von Hertzog Johann Albrechten zu Mecklenburg dahin geschickt Anno I 56 I « erhalten. ${ }^{737}$ Warum sich die Este bei den Mecklenburger Fürsten mehr geziert haben, bis sie sich - ihrem Ruf als stets liquide italienische Fürsten gerecht werdend - doch zu einem Kredit haben überreden lassen, ist schwer nachzuvollziehen und aus den Quellen nicht ersichtlich. Einerseits könnte der Krieg um Livland für die Italiener abstrakter gewesen sein als z. B. der Krieg um Köln. Andererseits könnte der Grund in einer Abstufung der Beziehungsqualität liegen: Über die durch die habsburgischen Erzherzoginnen verwandten Wittelsbacher war schnellere und substantiellere Hilfe zu erwarten als von den räumlich entfernten und nicht über eine Heiratsverbindung verwandten Herzögen von Mecklenburg. Die Konfession hingegen scheint nicht relevant gewesen zu sein, denn schließlich erhielt Johann Albrecht eine finanzielle Unterstützung aus Ferrara, ebenso wie der reformierte Kurfürst von Sachsen.

\subsubsection{Die Beziehungen zwischen den Este und den Herzögen von Braunschweig- Lüneburg}

Auf dem Gebiet des heutigen Bundeslandes Niedersachsen war I 235 auf dem Mainzer Hoftag aus einem Teil des Herzogtums Sachsen das Herzogtum BraunschweigLüneburg hervorgegangen und zum Reichsfürstentum erhoben worden. Bereits I 269 kam es zur ersten von einer ganzen Reihe von Teilungen des Gebietes in den Fürstentümern Braunschweig und Lüneburg, denen auch immer wieder durch Aussterben der Linien Zusammenführungen folgten. Die Belehnung der welfischen Herzöge, ein ursprünglich fränkisches Adelsgeschlecht aus dem Maas-Mosel-Raum, die sich mit den Wittelsbachern, Wettinern und Este einen gemeinsamen Stammvater teilten, ${ }^{738}$ erfolgte im I 3. und I 4. Jahrhundert separat für die einzelnen Fürstentümer. I 4 I 4 kam es zu einer vertraglichen Vereinigung der welfischen Linien Braunschweig-Wolfenbüttel und Lüneburg, worauf I 420 durch König Sigismund erstmals eine Gesamtbelehnung, aber ohne die Fürstentümer Göttingen und Grubenhagen erfolgte, da aufgrund von

737 Schwerin, LHA, 2-I I-I/I Auswärtige Beziehungen (Acta externa) Livland 47-60 (eigene Nummerierung), I56r. Die Quellen lassen keine sichere Aussage zu, ob die Gesandten erfolgreich waren. Doch allein die Art, wie die Este deswegen »bearbeitet « wurden, zeigt, dass sie im Reich als potenzielle Unterstützer und wohlhabende Fürsten am Rande des Reiches galten.

738 Dazu siehe bereits oben. Bezüglich der gemeinsamen Geschichte der Häuser Este und Braunschweig gibt es auch einen Brief von Triburtius Dreyfelder, deutscher Sekretär des Herzogs von Ferrara, an Herzog Julius bzw. seinen Sekretär Wulf Ewert in: Wolfenbüttel, Niedersächsisches Staatsarchiv, Akte I Alt 9, Nr. 38, Fol. 2- 5 an Ewert, November I 582. 
Vereinbarungen beim Aussterben einer Linie die Teilfürstentümer an andere Linien übergingen und nicht an den Kaiser zurückfielen. ${ }^{739}$

Die Braunschweiger Linie hatte die Residenz ihres Fürstentums BraunschweigWolfenbüttel ab I432 in der umgebauten Wasserburg in Wolfenbüttel, zwölf Kilometer südlich von Braunschweig entfernt und mit einer herzoglichen Kanzlei, Gerichten und einem Archiv als Zentrum des Fürstentums ausgestattet. I 584 kam das Fürstentum Calenberg mit der Residenzstadt Göttingen an die Wolfenbüttler Linie zurück. I 596 starb die Linie Grubenhagen aus und das Gebiet wurde daraufhin von Herzog Heinrich Julius aus Wolfenbüttel unter Protesten der Lüneburger Linie besetzt, aber erst I 665 mit Calenberg vereinigt. Im Fürstentum Lüneburg war die Linie der Welfen bereits I 369 ausgestorben. Dies hatte den Lüneburger Erbfolgekrieg entfacht, der zugunsten der Welfen der Braunschweiger Linie ausging.

Otto II. von Braunschweig-Harburg, auch der Jüngere oder der Berühmte genannt (1528-1603), war der älteste Sohn Herzogs Otto I. von Braunschweig-Harburg ( I 495 - I 549) aus dessen morganatischer Ehe mit Meta von Campe († I 580 ), wodurch er in der Nachfolge als Herzog von Braunschweig-Harburg nicht sofort anerkannt wurde. I560 wurde er dann mit kaiserlicher Hilfe als Nachfolger in der Herrschaft bestätigt und führte die Bautätigkeiten seines Vaters hier weiter, wofür Sonderabgaben und Steuererhöhungen erforderlich wurden. Otto II. unterzeichnete die Konkordienformel von 577 und das Konkordienbuch von I 580. In erster Ehe heiratete er Margarete (I 530 - I 559), Tochter des Grafen Johann Heinrich von Schwarzburg-Leutenberg. Seine zweite Ehefrau war Hedwig (1535-16r6), Tochter des Grafen Enno II. von Ostfriesland. Die Herzöge von Braunschweig-Lüneburg waren am Reichstag teilnahmeberechtigt und z.B. an jenem von Speyer I 570 anwesend, ${ }^{740}$ sodass sie für die Este auch in der Hinsicht der Fürsprache und der Informationsgewinnung von Nutzen und Interesse waren.

Otto II. von Braunschweig unterhielt als erster eine Korrespondenz mit den Herzögen von Ferrara (bzw. vor dieser Zeit sind keine Schreiben erhalten). Von ihm gibt es neun Briefe (alle auf Lateinisch bis auf einen auf Deutsch mit italienischer Übersetzung) im Staatsarchiv von Modena. In diesen geht es vorrangig um die Vorbereitungen für den Aufenthalt des Herzogssohnes, Johann Friedrich (1557-16 I9), in Ferrara im Zuge von dessen Italienreise. Grund für den ausgiebigen Schriftverkehr war aber vor allem der wiederholte Aufschub der geplanten Reise wegen der Annahme des jungen Herzogs als Administrator von Magdeburg und aufgrund der religiösen Bedenken des Vaters. ${ }^{71}$ Gleichzeitig befand sich ein weiteres Familienmitglied der Braunschweiger

739 Ausführlich und immer noch hilfreich: Havemann, Geschichte der Lande Braunschweig; Schubert, Geschichte Niedersachsens 2/r.

740 Lanzinner, Deutsche Reichstagsakten. Der Reichstag zu Speyer I 570, Zweiter Teilband, 983.

74I ASMo, ASE, Casa e Stato, Carteggio di principi esteri, Germania b I 599/25, Otto von BraunschweigLüneburg an Alfonso II., Januar I58 I, April I58 I, Juni 158r. Zu diesem Aufenthalt in Ferrara siehe auch das Schreiben von Johann Friedrich an seinen Vater: Celle, HStAH Br. $6 \circ \mathrm{Nr} .53$ sowie das »Ne- 
in Italien: Otto Heinrich von Braunschweig-Lüneburg-Harburg (I555-I59I), der älteste Sohn von Herzog Otto II. von Braunschweig-Harburg und dessen erster Ehefrau Margarete von Schwarzburg-Leutenberg, sollte eigentlich die geistliche Laufbahn einschlagen, studierte an der Universität Straßburg, war zunächst Domherr in Bremen, bevor er dann eine Militärlaufbahn begann. Hierbei trat er in die Dienste Erzherzogs Ferdinands II. und des spanischen Königs ein und zeichnete sich im Achtzigjährigen Krieg aus.

Als Otto II. die Reise seines Sohnes Johann Friedrich nach Italien durch den Gesandten Nicolas Rasch vorbereitete, hielt sich sein anderer Sohn Otto Heinrich in Venedig auf und entschuldigte sich bei Alfonso II. d'Este, dass er ihn nicht in Ferrara besuchen konnte, da ihm die Zeit gefehlt habe; er bat lediglich um die Empfehlung eines Soldaten, der bereits in der ferraresischen Wache diente. ${ }^{742}$ Im August ${ }_{15} 80$ bereitete der immer noch in Venedig weilende Erbprinz Otto Heinrich von Braunschweig-Lüneburg die angedachte Reise seines Bruders Johann Friedrich nach Italien mit Aufenthalt in Ferrara vor, wofür der Gesandte Nicolas Rasch zu Vorgesprächen an den estensischen Hof geschickt wurde, nachdem er sich in den vorangegangenen Jahren bereits brieflich mit Alfonso darüber ausgetauscht hatte. ${ }^{743}$ Wiederholt ließ Otto Heinrich Alfonso wissen, dass es von seinem Vater nichts Neues bezüglich der Italienreise des Bruders gäbe. ${ }^{74} \mathrm{Im}$ September desselben Jahres sollte Rasch in einer erneuten Gesandtschaft eruieren, wie die Glaubenssituation in Ferrara sei und ob die Messe verpflichtend besucht werden müsse, da, wie Otto Heinrich in seinem Begleitbrief erklärte, sein Vater sehr religiös sei. ${ }^{745}$ Wieder von Venedig aus entschuldigte sich Otto Heinrich erneut bei Alfonso II. d'Este, dass er ihn - obwohl in der Nähe - nicht besuchen konnte; dennoch bat er um die versprochenen 500 scudi, die er dringend benötigte. Wahrscheinlich um die Großzügigkeit des Este zu fördern, ließ er sich im gleichen Brief ein Geheimnis entlocken: Sein Mentor, Erzherzog Ferdinand II., spiele mit dem Gedanken, sich mit einer Markgräfin von Baden zu vermählen. ${ }^{746} \mathrm{Zu}$ Beginn des neuen Jahres revidierte er aber oben genanntes Heiratsprojekt und äußerte große Bedenken an der geplanten Reise seines Bruders, da der Vater diesen aus Glaubensgründen nicht gern an andere (katholische) Höfe reisen lassen wolle. ${ }^{747}$ Doch schließ-

gotium an Hertzog Alfonso zu Ferrarae...« und die Instruktionen für den Gesandten Rasch bezüglich der Italienreise, samt der Briefe zwischen Alfonso und Otto, die sich mit "cognato et amico carissimo» betiteln, Celle, HStAH Br. 7 I Nr. 62 r.

742 ASMo, ASE, Casa e Stato, Casa e Stato, Carteggio di principi esteri, Germania b I 599/25, Otto Heinrich von Braunschweig-Lüneburg an Alfonso II., Dezember 1577 .

743 ASMo, ASE, Casa e Stato, Carteggio di principi esteri, Germania b I599/25, Otto Heinrich von Braunschweig-Lüneburg an Alfonso II., September 1579 und August 1580.

744 Ebd., Otto Heinrich von Braunschweig-Lüneburg an Alfonso II., April I 580.

745 Ebd., Otto Heinrich von Braunschweig-Lüneburg an Alfonso II., September I 580.

746 Ebd., Otto Heinrich von Braunschweig-Lüneburg an Alfonso II., November 1580.

747 Ebd., Otto Heinrich von Braunschweig-Lüneburg an Alfonso II., Januar I 5 8 I. 
lich lenkte Herzog Otto II. ein und verkündete, dass Johann Friedrich, der es - seiner Meinung nach - mit der Religion nicht sehr ernst nehme, mit vielen Vorbehalten zu Ostern I 58 I Alfonsos Einladung nach Ferrara folgen werde. ${ }^{748}$ Noch im März gestand der älteste Sohn Otto Heinrich, dass er immer noch keine Nachricht von zu Hause habe, wann sein Bruder tatsächlich nach Italien reisen würde, Ostern war in jenem Jahr immerhin bereits am 26. März. ${ }^{749}$ Der im Dienst von Erzherzog Ferdinand stehende Otto Heinrich erhielt selbst keine Hinweise von seinem Heimathof, ob und wann sein Bruder gegen Süden reisen durfte. Dem Herzog von Ferrara blieb er weiterhin in Dankbarkeit verbunden, da dieser ihm die 500 scudi geborgt hatte und ihm die Schulden erließ. ${ }^{750}$ Im April berichtete der Herzog von Braunschweig-Lüneburg, dass sein Sohn nun aus Gesundheitsgründen und da er ein Amt übernehmen müsse doch nicht nach Ferrara reisen würde. ${ }^{751} \mathrm{Im}$ Spätsommer trat Johann Friedrich aber dennoch die Reise nach Süden an und sein Vater bedankte sich im November I 58 I bei Alfonso II. d'Este für die herzliche Aufnahme seines Sohnes am Hof von Ferrara. Gleichzeitig bat er den Herzog, von dem er durch seinen Gesandten Rasch wisse, dass er Johann Friedrich nicht zur Beichte und Kommunion verpflichte, diesen auch vom Messbesuch zu befreien. ${ }^{752}$ Nachdem der junge Braunschweiger im Frühjahr 1582 wieder an seinem Heimathof zurückgekehrt war, dankte der Herzog von Braunschweig Alfonso für die großzügige und herzliche Aufnahme und die Gastfreundschaft für seinen Sohn sowie in einem zweiten Schreiben auch für den Erhalt des Bildes eines weißen Pferdes. ${ }^{753} \mathrm{Im}$ darauffolgenden Jahr revanchierte er sich beim Herzog von Ferrara mit der Zusendung eines Exemplars einer sächsischen Chronik in deutscher Sprache aus dem Jahr I 402. ${ }^{754}$ Kurz darauf empfahl er - wahrscheinlich mit gutem Gewissen ob der positiven Erfahrung seines Sohnes - gewisse Adelige, die nach Italien gekommen waren und entlegene Gegenden und unbekannte Sitten kennenlernen wollten (»regiones remotissimas perlustrando hominum mores cognoscerent $)^{755}$

748 Ebd., Herzog Otto von Braunschweig-Lüneburg an Alfonso II., Januar 158r. Siehe auch Celle, HStAH, Br. 6o, Nr. 53, Otto von Braunschweig-Lüneburg an Alfonso II., Januar I 58 I.

749 Hermann Grotefend, Taschenbuch der Zeitrechnung des deutschen Mittelalters und der Neuzeit, Hannover ${ }^{13}$ I 99 I, I 52 (alter Stil).

750 ASMo, ASE, Casa e Stato, Carteggio di principi esteri, Germania b I599/25, Otto Heinrich von Braunschweig-Lüneburg an Alfonso II., März I 58 I.

75 I Ebd., Otto von Braunschweig-Lüneburg an Alfonso II., April I 58 r.

$75^{2}$ Ebd., Otto von Braunschweig-Lüneburg an Alfonso II., November I 58 I.

753 Möglicherweise ein »Tierporträt« als Vorbereitung für ein lebendes Geschenk. Ebd., Otto von Braunschweig-Lüneburg an Alfonso II., Mai und September 1582.

754 Ebd., Otto von Braunschweig-Lüneburg an Alfonso II., April I 583 . Die Chronik ist in »lingua nostra vernacula« gehalten, die Alfonso übersetzen lassen wollte: »in Italicam lingua converti«, Celle, HStAH Br. 7 I Nr. 62 I.

755 ASMo, ASE, Casa e Stato, Carteggio di principi esteri, Germania b I 599/25, Otto von BraunschweigLüneburg an Alfonso II., Mai 1583 . 
Schlussendlich klopfte auch Herzog Otto II. von Braunschweig-Lüneburg an die Tür der immer liquiden oder vermeintlich reichen Este und bat im Oktober I 583 um 6.00o Taler. ${ }^{756}$ Diese Bitte sollte ihm Alfonso aber erst im Februar I 584 erfüllen. ${ }^{757}$

Von dem oft in Venedig weilenden Erbprinzen Otto Heinrich von BraunschweigLüneburg (I 555- I 59I), sind in Modena 23 Briefe an Alfonso II. erhalten, die meisten in italienischer Sprache, andere auf Deutsch mit italienischer Übersetzung. Auch er bedankte sich beim Herzog von Ferrara für die seinem Bruder zuteilgewordene Gastfreundschaft am ferraresischen Hof. In den darauffolgenden Jahren berichtete Otto Heinrich, der nun definitiv die Militärlaufbahn eingeschlagen hatte und oft nach Spanien reiste, von den dortigen Neuigkeiten und bat um Empfehlung von Dienstmännern aus seinem Umkreis. So empfahl er Francesco Mazzuolla, der während seines Besuchs in Ferrara sein Kämmerer gewesen war und den Hauptmann Alfonso Pegolorto, der wegen Problemen und des feuchten Klimas in der Po-Ebene das estensische Fürstentum verlassen wollte. ${ }^{758}$ Otto Heinrich berichtete im März I 582 über seine Audienz beim Papst und im Jahr darauf über seinen Aufenthalt in Spanien. In einem Schreiben vom Februar I 583 informierte er Alfonso, dass er - stets als Mittelsmann im Einsatz Briefe für ihn vom spanischen Hof mitgebracht habe, die aber aufgrund des Regens und der Tatsache, dass er in einem Bach gefallen sei, nass geworden waren. ${ }^{759}$

Nachdem Johann Friedrich gesund und unversehrt von seinem Italienaufenthalt zurückgekehrt war, blieb auch er mit Alfonso II. brieflich sowie über Gesandtschaften in Kontakt. Erzählfreudig berichtete er im April I582 in einem deutschen Schreiben (mit italienischer Übersetzung) von seiner Rückreise, aber auch vom Frieden zwischen dem Großherzog von Moskowien und dem König von Polen und von der bevorstehenden Heirat des Sohnes des Kurfürsten von Sachsen mit einer Tochter des Kurfürsten von Brandenburg. Außerdem informierte er den Este, dass der Bischof von Würzburg Erzbischof von Mainz werden sollte. Johann Friedrich fasste alle Ereignisse zusammen, die während seiner Anwesenheit relevant geworden waren, und brachte dadurch seinen Gastgeber auf den neuesten Stand. Diese Aufgabe als Informant behielt er weiter bei und berichtete von der Hochzeit seiner Schwester »auf deutsche Art«, die sehr anstrengend gewesen sein muss, wenn er zugab, daraufhin ${ }_{4} 4$ Tage in medizinischer Behandlung gewesen zu sein; auch informierte er über einen Flurstreit seiner Familie mit Hamburg und dass die englische Königin eine Delegation von soo Personen mit reichen Geschenken nach Dänemark geschickt hatte. ${ }^{760}$ Dabei rügte sich der junge Herzog selbst, dass er zu selten schrieb, während so viel geschehe. Schuld an etwaigen Lücken in

756 Ebd., Otto von Braunschweig-Lüneburg an Alfonso II., Oktober 1583.

757 Celle, HStAH Br. 7 I Nr. 62 I.

758 ASMo, ASE, Casa e Stato, Carteggio di principi esteri, Germania b 1599/25, Otto Heinrich von Braunschweig-Lüneburg an Alfonso II., September und Oktober 1584.

759 ASMo, ASE, Casa e Stato, Carteggio di principi esteri, Germania b I599/25, Otto Heinrich von Braunschweig-Lüneburg an Alfonso II., Februar 1583.

760 Ebd., Johann Friedrich von Braunschweig-Lüneburg an Alfonso II., April und September 1582. 
der Information waren auch verloren gegangene Briefe. So hielt er im Januar I 583 fest, dass die Briefe aus Ferrara nicht angekommen seien; dennoch hoffte er, das Geschäft mit den »bombardatam «, den Feuergeschützen aus Ferrara, abschließen zu können. ${ }^{761}$

Johann Friedrich betätigte sich aufgrund seines Beziehungsvorteils nach dem Aufenthalt am ferraresischen Hof auch als Patron für seine Untertanen: Im Mai I 583 empfahl er zwei junge Adelige aus seinem Fürstentum, die nach Ferrara reisen wollten, ${ }^{762}$ und im Sommer und Herbst hielt er Alfonso über den Krieg um Köln sowie die Kurfürsten-Nachfolge informiert. Zu Beginn des neuen Jahres übermittelte er ihm sogar ein Büchlein zur Kölnischen Causa, ${ }^{763}$ das den Herzog von Ferrara interessiert haben dürfte, hatte er ja die verwandten Wittelsbacher in diesem Krieg finanziell unterstützt. Nachdem sich Johann Friedrich dann fast ein halbes Jahr nicht mehr gemeldet hatte, gab er im Juni die geplante Heirat der Tochter des sächsischen Kurfürsten, Dorothea, mit Heinrich Julius Herzog von Braunschweig-Lüneburg, als einzige, erwähnenswerte Neuigkeit bekannt. ${ }^{764}$ Heinrich Julius (I 564- I6 I 3) war postulierter Bischof von Halberstadt, Herzog zu Braunschweig und Lüneburg und Fürst von Braunschweig-Wolfenbüttel, von ${ }_{5} 82$ bis ${ }_{5} 85$ auch Administrator des Bistums Minden gewesen und heiratete, nachdem er von seinen kirchlichen Ämtern in Halberstadt und Minden zurückgetreten war.

Nach diesem letztgenannten Schreiben des Braunschweigers gab es offensichtlich Übermittlungsschwierigkeiten, die uns den Aufwand und die Unsicherheit der frühneuzeitlichen Kommunikation vor Augen führen. Johann Friedrichs Schwierigkeiten bei der Überstellung der Briefe nach Ferrara lag an der Tatsache, dass die bis dahin engagierten Überbringer aus dem Bereich der Handeltreibenden verstorben waren und die Erben deren Geschäfte nicht übernehmen wollten. So mussten erst andere vertrauenswürdige Kaufleute gefunden werden. Die Korrespondenz lief also nicht über die Ordinari-Post, sondern über Handelsvertreter, die auch die »Geldüberweisungen« erledigten. Alfonso hatte nämlich auch Johann Friedrich wie dessen Bruder Geld geliehen. Der Braunschweiger versprach in einem seiner Briefe, die geliehenen soo scudi sobald wie möglich zurückzuzahlen. ${ }^{765}$

Von der weiblichen Seite der Herzogsfamilie von Braunschweig wandte sich die eingeheiratete Herzogin Dorothea von Lothringen (I545-I6 I2), Tochter von François I. von Lothringen und Christina von Dänemark, brieflich an Alfonso II. Sie war die zweite Ehefrau von Erich II. von Braunschweig-Calenberg-Göttingen, genannt

76r Ebd., Johann Friedrich von Braunschweig-Lüneburg an Alfonso II., Januar I 583 [im Brief aber fälschlich 1582 ] und Februar 1583 .

762 Ebd., Johann Friedrich von Braunschweig-Lüneburg an Alfonso II., Mai $5_{5} 83$.

763 Ebd., Johann Friedrich von Braunschweig-Lüneburg an Alfonso II., August, November I583, Januar, Februar 1584 .

764 Ebd., Johann Friedrich von Braunschweig-Lüneburg an Alfonso II., Juni I 584.

765 Ebd., Johann Friedrich von Braunschweig-Lüneburg an Alfonso II., August, Oktober 1584, Oktober I 585 . 
»der Jüngere«, Herzog zu Braunschweig-Lüneburg ( ${ }_{5} 28$ - I 584 ), ${ }^{766}$ ein Söldnerführer im Dienst des spanischen Königs in den Niederlanden, ${ }^{767}$ der in Pavia am Witwensitz seiner Schwiegermutter Christina den Tod fand. Dorothea wandte sich in fünfzehn italienischen Briefen an den Herzog von Ferrara. Den Anfang machte sie I 580 mit der Fürsprache für einen gewissen Michel Bardeler, der von ihrem Hof nach Italien ziehen wollte. ${ }^{768}$ Kurz darauf meldete sie den Tod ihres Gatten infolge eines Lungenkatarrhs. ${ }^{769}$ Nach einer längeren Pause - wobei anzumerken ist, dass einige Briefe kein Datum tragen - wandte sie sich erneut an Alfonso II. mit Empfehlungen für den Cavaliere Giuliano Mazzei, der in die Dienste des Fürsten von Massa treten wollte, und für Giovanni Piaggio da Carpi. ${ }^{770}$ In diesen Jahren unternahm sie eine Italienreise und bat Alfonso bei der Durchreise durch sein Herzogtum um Hinweise über den sichersten Weg, da das Land ja bekanntlich voller Banditen sei. ${ }^{771}$ Im August I 589 informierte sie Alfonso, um sein Interesse für Nachrichten aus ihrer Heimat Frankreich wissend, über die Kriegszüge des französischen Königs. ${ }^{772}$ Im Namen der Juden Grassini Pavia, die mit der herzoglichen Kammer bereits Verhandlungen für die Errichtung einer Synagoge in Reggio führten, bat sie um Empfehlung und Unterstützung. ${ }^{773}$ Sie machte sich auch zur Fürsprecherin des Conte Uberto da Gambara, mit dessen Familie sie eng befreundet war und der im estensischen Fürstentum zu Unrecht beschuldigt wurde. ${ }^{774}$ Hinzu kamen zwei schon oben dargestellte Momente der Patronage: Einerseits verwendete sie sich für das gesangsbegabte Mädchen aus Perugia, das sich in ihren Sekretär verliebt hatte, und deren Aufnahme am ferraresischen Hof ${ }^{775}$ und andererseits für den Pagen Vergi, den Alfonso von ihr übernommen hatte, als sie von der Hochzeit des Großherzogs von Toskana nach Ferrara gereist war und der nun ausgebildet war und in die Heimat zurückkehren wollte. ${ }^{776}$

Da Erich II. und Dorothea kinderlos blieben, fiel das verschuldete Fürstentum an den Neffen Herzog Julius von Braunschweig-Wolfenbüttel und Lüneburg ( I 528 - I 589 ),

766 Vgl. Klaus Friedland, »Erich II., Herzog von Braunschweig-Lüneburg«, in: NDB 4 (1959), $584-585$.

767 Vgl. auch Edelmayer, Söldner und Pensionäre, r 87-202.

768 ASMo, ASE, Casa e Stato, Carteggio di principi esteri, Germania b I599/25, Dorothea von Braunschweig-Lüneburg an Alfonso II., Juni 1580.

769 Ebd., Dorothea von Braunschweig-Lüneburg an Alfonso II., November 1580.

770 Ebd., Dorothea von Braunschweig-Lüneburg an Alfonso II., August, Okotber I 586 und [?].

77 I Ebd., Dorothea von Braunschweig-Lüneburg an Alfonso II., ohne Datum.

772 Ebd., Dorothea von Braunschweig-Lüneburg an Alfonso II., August I 589.

773 Ebd., Dorothea von Braunschweig-Lüneburg an Alfonso II., Oktober I 589 [?]. Es kann sich hier nur um eine Haussynagoge handeln, von denen es in der personenreichen jüdischen Gemeinde in Modena und Reggio verschiedene gab, denn die eigentliche Synagoge wurde erst Ende des 17. Jahrhunderts erbaut. Vgl. Bonilauri/Maugeri, Le comunità ebraiche.

774 ASMo, ASE, Casa e Stato, Carteggio di principi esteri, Germania b I599/25, Dorothea von Braunschweig-Lüneburg an Alfonso II., Juli i 59r.

775 Ebd., Dorothea von Braunschweig-Lüneburg an Alfonso II., September I 590.

776 Ebd., Dorothea von Braunschweig-Lüneburg an Alfonso II., August I 596. 
dessen Sohn Heinrich Julius (1564-r6r3), wie oben gesagt, Prinzessin Dorothea von Sachsen (1563-1587) und in zweiter Ehe Prinzessin Elisabeth von Dänemark ( 573 - I626), die älteste Tochter von König Friedrich II., heiratete. ${ }^{777}$

Aus den zwei sehr verblassten lateinischen Briefen von Heinrich Julius an Alfonso vom September I 58 I und Juni I 582 lässt sich nur ein angekündigter Austausch von Informationen über Andreas Pauli, den Gesandten des Kurfürsten von Sachsen erkennen. ${ }^{778}$ Sein Vater Julius hingegen berichtete Alfonso in einem deutschen Brief I 585 über seine Gesundheit, sein Nierenstein- und Gichtleiden (Podagra). Drei Jahre später teilt er ihm die Besserung seines Gesundheitszustandes mit und fragte, ob und welche Früchte er aus seinem Land haben wolle, damit er sie ihm schicken könne. Er bot Alfonso II. an, seine Antwort auf Italienisch, Latein oder Französisch zu schreiben, da er, der humanistisch und sprachlich selbst vorbildlich gebildet war, an seinem Hof in der Zwischenzeit verschiedene fähige Übersetzer engagiert hatte. ${ }^{779}$

Weitere Briefe im Staatsarchiv von Modena stammen von einem Heinrich dem Jüngeren, Herzog von Braunschweig, der dem Datum der Schreiben nach nur mit Heinrich von Braunschweig-Dannenberg identifiziert werden kann. Heinrich, Herzog zu Braunschweig und Lüneburg (I533- I598) war von I 559 bis I 569 Fürst von Lüneburg sowie von $5_{5} 69$ bis 1598 Inhaber der Herrschaft Dannenberg. Auch Heinrich unterzeichnete die Konkordienformel von I 577 und das Konkordienbuch von I 580.

Heinrich berichtete nach Ferrara von seinem glänzenden Empfang in Madrid I 579 und auch von Alfonsos Gesandten dort. Sein Aufenthalt in Spanien dauerte länger als geplant, da der König ihn - wie er voller Stolz festhielt - bei sich haben wollte. Im September I 580 kündigte er an, auf dem Weg nach Venedig zu sein und in Ferrara vorbeikommen zu wollen, entschuldigte sich aber dann im Mai I 58 I, dass er so plötzlich abreisen musste und Alfonso nicht hatte rechtzeitig informieren können. Im Juli I 583 meldete er, dass er mit seiner Herzogin gut in Venedig angekommen sei und im Oktober des gleichen Jahres bat er um Passierscheine für fünf Schiffe, die Waren von seinem Haus in Venedig auf dem Fluss Po bis in die Lombardei transportieren sollten. ${ }^{780}$

Damit endet die erhaltene Korrespondenz zwischen den Este und den Herzögen von Braunschweig-Lüneburg. Wie gezeigt wurde, bestand auch zu diesen, nicht mit den Herzögen von Ferrara verschwägerten, protestantischen Fürsten des Reichsnordens eine von Gaben- und Informationsaustausch, Gesandtschaften, Besuchen und Patronage geprägte Beziehung.

777 Vgl. Havemann, Geschichte der Lande Braunschweig 2.

778 ASMo, ASE, Casa e Stato, Carteggio di principi esteri, Germania b 1599/25, Heinrich Julius von Braunschweig-Lüneburg an Alfonso II., September 158 I , Juni 1582.

779 Ebd., Julius von Braunschweig-Lüneburg an Alfonso II., Mai I 585, Juli I 588.

780 ASMo, ASE, Casa e Stato, Carteggio di principi esteri, Germania b I 599/25, Heinrich der Jüngere von Braunschweig-Lüneburg an Alfonso II., Januar, August 1579, September I580, Mai 1581, Juli, Oktober 1583 . 


\subsection{Zusammenfassung}

Eng mit dem Aspekt des kulturellen Austausches ist die Frage nach der Eigen- und Fremdwahrnehmung sowie der Tradierung von Stereotypen verbunden. In diesem Rahmen wurde im dritten Teil der vorliegenden Arbeit anhand der fürstlichen Korrespondenz und der Gesandtenberichte darzustellen versucht, wie die Este im Reich und wie der Kaiser und andere Mitglieder des Reiches in Italien und von den Este wahrgenommen wurden. Entlang dieser Wahrnehmungen wurde versucht, auf die jeweilige Bedeutung der Protagonisten füreinander zu schließen. Dafür wurden die verschiedenen Kontaktmomente (Briefe, Besuche, Geldleihen) hervorgehoben und gewertet. Die Korrespondenzen mit dem Reichsoberhaupt, dem Kaiserhof und den ausgewählten Reichsfürsten(familien) beinhalten sowohl formelhafte Grußschreiben und allgemein gehaltene Höflichkeitsadressen, mit denen man sich in regelmäßigen Abständen "nur« in Erinnerung rufen wollte, als auch inhaltlich konsistente, auf ein bestehendes Beziehungsnetzwerk Bezug nehmende Briefe mit Bitten und Gesuchen.

Daneben wurden in diesem Abschnitt auch die Besuche der Kaiser in Italien und der Este im Reich im Verhältnis zu den Kontakten mit dem Papst, Frankreich und anderen Fürsten gestellt. Mit Kaiser Maximilian II. erreichten die Kontakte und Beziehungen zwischen dem Kaiser und den Este ihren Höhepunkt, was sich u. a. auch an der Anwesenheit des estensischen Gesandten beim Einzug des Kaisers in Nürnberg 1570 zeigt. ${ }^{781}$ Die Intensivierung der Beziehungen und Kontakte zu den anderen katholischen Reichsfürsten ist u.a. als Folge der Heiratsverbindung mit einer habsburgischen Erzherzogin zu verstehen. Mit den protestantischen Reichsfürsten hingegen waren Kontakt und Wahrnehmung der Este vor dieser Verschwägerung in den 155 oer Jahren am intensivsten und dienten vor allem der antikaiserlichen Bewegung.

Der kulturelle Austausch, die Korrespondenzen und Besuche, die Beziehungsintensivierung als Folge der estensischen Heiratspolitik gehörten zum Strategiepaket dieser reichsitalienischen und gleichzeitig dem Papst gegenüber verpflichteten Fürsten für ihre Politik des »Obenbleibens«. Diese intensive, notwendige Auseinandersetzung mit dem Anderen prägte dessen Perzeption, die in den schriftlichen wie materiellen Quellen sichtbar geblieben ist.

78 I Vgl. Rudolph, Das Reich als Ereignis, ro3, Anm. гоo. 
Publikation im Sinne der CC-Lizenz BY 4.0 


\section{Schlussbetrachtung}

In Reichsitalien, dem zum Territorium und Rechtssystem des Heiligen Römischen Reiches gehörenden Teil der italienischen Halbinsel, versuchten die Kaiser des Mittelalters und der Frühen Neuzeit unterschiedlich intensiv und erfolgreich die hier größtenteils zu Lehen vergebenen Gebiete (feudi imperiali italiani) an die kaiserliche Macht zu binden. Im Rahmen der Entwicklung von der italienischen Kommune zur Signoria bedienten sich die Reichsoberhäupter - oft notgedrungen - der sich etablierenden italienischen Familien an der Spitze einer Stadt, deren Stellung sie u.a. durch die Vikariatswürde legitimierten. Über dieses Amt wurden Adelsfamilien wie die Este zu erbberechtigten Fürsten und blieben gleichzeitig päpstliche oder kaiserliche Vasallen - im vorliegenden Fall bis zum Ende des I6. Jahrhunderts sogar beides. ${ }^{1}$ Als kaiserliche und päpstliche Vikare hatten die Este Machtbefugnisse und Kontrolle über Gerichtsverhandlungen, Urteile und Richter. Außerdem ermöglichte ihnen die kaiserliche und päpstliche Belehnung die Schaffung von Organen zur Unterstützung und zum Ausbau der juridischen und allgemeinen potestas und somit zur Etablierung ihrer Hausmacht.

Innerhalb ihres so entstandenen heterogenen Fürstentums, den Stati estensi, blieben aber weiterhin kleine und kleinste kaiserliche Lehen bestehen, bzw. entstanden neue Lehen für von den Este investierte Familien oder Einzelpersonen. Dadurch und durch die historisch unterschiedliche Entwicklung der kaiserlichen Lehen Modena und Reggio und des päpstlichen Lehens Ferrara herrschten die Este seit ihrer Erhebung zu Herzögen in der zweiten Hälfte des I5. Jahrhunderts über ein in Verwaltung, Rechtsprechung und Feudalsystem sehr heterogenes Gebiet. Indem sie fast ausschließlich ihren herzoglichen Titel von Ferrara betonten, versuchten sie einerseits den Zentralismus der päpstlichen Lehen (gegenüber den stark dezentralisierten kaiserlichen Lehen) zu unterstreichen und drückten andererseits auch die für die italienischen Staaten des Alten Reiches charakteristische Verflechtung von Hof und Staat aus. In einzelnen Fällen jedoch, besonders in der heiklen Situation des Lehensverlustes am Anfang des I6. Jahrhunderts, schien es seit der Erhebung zum Herzogtum und bis zur Schaffung des Stato di Modena (und darüber hinaus) immer wieder angebracht und notwendig gewesen zu sein, auf die kaiserliche Investitur, die Zugehörigkeit zum Reich und die lange und meist als "liebevoll und freundschaftlich« bewertete Lehensbeziehung zum Reichsoberhaupt hinzuweisen.

Im ersten Abschnitt der vorliegenden Arbeit wurde auf die Einbindung der Stati estensi im Reichslehnsverband als Teil Reichsitaliens eingegangen. Dabei wurde versucht, die Entwicklung und Bedeutung dieses Bestandteiles der südlichen Reichsperipherie

I RILL, Reichsvikar, I 86f. 
nachzuzeichnen. Die aus der kommunalen Tradition hervorgegangenen italienischen Territorien Ober- und Mittelitaliens hatten keine Stimme im Reichstag, waren de facto nicht Mitglieder des Reiches, sondern Vasallen, für die der Kaiser (oder der Papst) oberster Lehensherr und Richter und das Reich eine bedeutende Schutzmacht gegen die Expansionsbestrebungen und Ansprüche anderer Mächte auf der Halbinsel (Papst, Frankreich, Spanien) war. Zusammen mit den übrigen kaiserlichen Vasallen in Italien mussten die Este bei jedem Machtwechsel im Reich sowie auch in ihrer dynastischen Folge die Investitur mit dem Reichslehen erneuern. Zwar waren ihre Lehen de facto bereits seit dem Mittelalter erblich geworden und diese italienischen Fürsten besaßen eine superioritas territorialis (Landeshoheit) bzw. eine media sovranitas, eine eingeschränkte Souveränität; das Lehensrecht sah dennoch bei jedem Herrscherwechsel auf beiden Seiten die rituelle Erneuerung der Investitur und des Treueverhältnisses vor. Päpstliche Vasallen bezeugten ihre Unterordnung mit der regelmäßigen Zahlung einer Abgabe, wie die Este dies für das Lehen Ferrara taten. Als Reichsvasallen entrichteten sie für die Lehen Modena und Reggio hingegen mit dem Treueeid eine einmalige Taxe bei der Investiturerneuerung. ${ }^{2}$

Es gab im Italien des I6. und I7. Jahrhunderts - wie Aretin gezeigt hat - drei verschiedene, nebeneinander bestehende Lehensordnungen: Die kaiserliche Lehensordnung, die fast alle nord- und mittelitalienischen Herzogtümer, Grafschaften und Städte betraf, die päpstliche für Neapel-Sizilien, den Kirchenstaat und einzelne kleinere Lehen in Nord- und Mittelitalien wie Ferrara, und schließlich versuchte auch Spanien eine Lehensordnung einzurichten und reichstreue Vasallen auf seine Seite zu ziehen. Darüber hinaus gab es kleinere Lehen mit einer regionalen, aus einem Gemisch aus kaiserlicher und päpstlicher Lehensordnung entstandenen, von den regierenden Fürsten forcierten und z.T. zu eigenen Gunsten abgewandelten Ordnung. ${ }^{3}$ Diese unübersichtliche und konfliktreiche Konstellation mit unterschiedlichen Kompetenzen, Ansprüchen und Befugnissen war in den meisten italienischen Territorien Ober- und Mittelitaliens anzutreffen und kein ausschließlich estensisches Phänomen. Anders aber als andere Lehensnehmer wie die benachbarten Gonzaga, mussten die Herzöge von Ferrara zudem mit der starken Heterogenität ihres Herrschaftsgebietes umzugehen lernen, das nicht grundlos den Namen Stati estensi im Plural trug. Es bestand aus zwei unterschiedlichen Lehen, einer Hauptstadt/Residenz, drei stark von ihrer kommunalen Vergangenheit und Entwicklung geprägten Städten, einem agra-

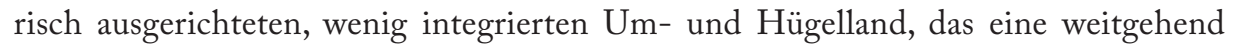
selbstständige Tradition aufwies, und schwer erreichbaren Gebirgstälern, die sich der herrschaftlichen Kontrolle zu entziehen wussten. Die Macht lag in den Hauptstädten konzentriert, wobei es augenscheinliche Unterschiede zwischen der stark zentralistisch ausgerichteten Hauptstadt des päpstlichen Lehens Ferrara, Sitz des Hofes und der

2 Schnettger, Kleinstaaten, 6 i $2 \mathrm{f}$.

3 Aretin, Die Lehensordnungen, 53-57. 
Universität, und den dezentralisierten Hauptstädten der kaiserlichen Lehen, Modena und Reggio gab. ${ }^{4}$

Neben den Laudemien, den bei der Investiturerneuerung zu entrichtenden Abgaben, sollten von den italienischen Fürsten, die sich nach der Überwindung der kommunalen Vergangenheit zum Teil auch mit päpstlicher und/oder kaiserlicher Unterstützung als signori und dann mit der Erblichkeit der Nachfolge als principi etablieren konnten, Kontributionen zur Verteidigung des Reiches, vor allem vor der osmanischen Gefahr kommen. Solche finanzielle Unterstützung kam immer dann aus Italien, wenn es galt, in einer Angelegenheit die Gunst des Kaisers zu gewinnen und wenn die kaiserliche Seite gerade die gewinnbringendere gegenüber der spanischen und französischen zu sein schien. ${ }^{5}$ Denn obgleich die Este in ihren beiden Lehen spätestens seit dem I 4. Jahrhundert fest im Sattel saßen, kam es im Cinquecento zu einer Reihe von Krisen, die kaiserlicher Intervention bedurften: Gleich zu Beginn des I6. Jahrhunderts kam es zur Lehenskrise, in deren Rahmen Alfonso I. einige Jahre lang Ferrara und fast 20 Jahre die kaiserlichen Lehen Modena und Reggio entzogen wurden. Verursacht durch die päpstliche Expansionspolitik ist die Bedrohung der estensischen Vasallen, die der Kaiser zunächst widerspruchslos zuließ, sicher als »Bestrafung« des stets an Frankreich, dem Erzfeind des Hauses Habsburg, angelehnten und als treulos geltenden Herzogs von Ferrara zu sehen. Ein Warnschuss, könnte man sagen, wenn man die Inszenierung der Wiedereinführung der Este als Vasallen in beiden Lehen und die vom Kaiser vermittelte Versöhnung mit dem Papst im Rahmen der Kaiserkrönung in Bologna und der darauffolgenden kaiserlichen Italienpolitik bedenkt.

Der Vorwurf der »Treulosigkeit« der estensischen Vasallen wiederholte sich noch einige Male, vor allem aufgrund der Intensivierung der Beziehungen der Herzöge von Ferrara zu Frankreich und im Zuge ihrer Teilnahme am Fürstenaufstand ${ }_{5} 55_{2} / 3$ gegen Kaiser Karl V. Hier wird die starke Erwartungshaltung ersichtlich, die besonders Maximilian I. und sein Nachfolger Karl V. gegenüber den Este und allgemein gegenüber den italienischen Vasallen hatte, die mit der Schwächung der französischen Bedrohung in Oberitalien ab der zweiten Hälfte des I6. Jahrhunderts stetig abnahm. Viel mehr als von den deutschen Reichsfürsten erwarteten die beiden Kaiser der ersten Jahrhunderthälfte von den italienischen Fürsten Präsenz und einen ostentativen Ausdruck von Treue und Ergebenheit. Diese kaiserliche Erwartungshaltung konnte aber auch als Druckmittel der italienischen Vasallen auf das Reichsoberhaupt genutzt werden. Der Wechsel von der französischen Präsenz und Bedrohung in Reichsitalien zur spanischen Vorherrschaft schwächte in der Folge auch die kaiserliche Erwartungshaltung gegenüber den italienischen Fürsten merklich ab, sodass in den Regentschaften von Maximilian II. und Rudolf II. kaum vergleichbare »Empörungen« über die »Treulosigkeit« oder »il poco amore« der Este in den Korrespondenzen wiederzufinden sind.

4 Santini, Lo Stato Estense, I 2.

5 Niederkorn, Reichsitalien und der Kaiserhof, 6o-62. 
Eine weitere "Nagelprobe« in der Beziehung zwischen den Este und den Kaisern der zweiten Hälfte des I6. Jahrhunderts war der I 540 entstandene und fast 50 Jahre anhaltende Streit um die Präzedenz des Hauses Este vor den Medici. Ein bedeutender Handlungsspielraum für die Vertreter von Kleinstaaten war nämlich neben der Repräsentation (Diplomatie) und dem Patronage- und Klientelwesen ${ }^{6}$ das Zeremoniell. ${ }^{7}$ Vor allem die Patronage mit ihren Ansprüchen, Erwartungen und der Möglichkeit des "Aushandelns « bot den Fürsten Reichsitaliens einen Handlungsspielraum, der ihnen als Vasallen von Rechts wegen nicht oder nur beschränkt gegeben war. ${ }^{8}$ Stark vertreten war in diesen Aushandlungsprozessen der durch Titel, (Vor)Rang und Auszeichnungen ausgedrückte soziale Status der einzelnen Fürsten. Daraus erklären sich u.a. auch die zahlreichen Streitigkeiten um die Rangordnung im I6. und I7. Jahrhundert, welche die Kleinstaaten paradoxerweise in eine zum Teil noch größere Abhängigkeit versetzten. ${ }^{9}$ Mit dem Streit um den Vorrang zwischen den Medici und den Este, den Letztere spätestens durch die Erhebung der Florentiner zu Großherzögen verloren hatten, sind weitere Themen wie die Bedeutung von Ehre und Rangordnung in der Frühen Neuzeit, die Rolle des Kaisers und des Reichstags, die Appellationsmöglichkeiten beim Wettlauf um Titel, eng miteinander verwoben und in diesen Zusammenhang betrachtet worden. An die Frage des Vorranges haben die Este ihr ausdifferenziertes Netzwerk, ihre Kontakte und Fürsprecher, ihre besseren Beziehungen zu den Kaisern der zweiten Hälfte des I6. Jahrhunderts, ihre Kulturförderung und ihre diplomatischen Bemühungen geheftet. In fast keinem Brief ins Reich, ob an den Kaiser selbst, an einen Reichsfürsten oder an den eigenen Gesandten, fehlte die Aufforderung, die Klärung des Präzedenzstreits voranzutreiben bzw. beim Kaiser oder im Rahmen des Reichstages zu intervenieren. Es war dies ein kostspieliger und nervenaufreibender Kampf, der das Verhältnis der Herzöge von Ferrara zu den diesbezüglich wenig entscheidungsfreudigen Kaisern Ferdinand I., Maximilian II. und zum Teil Rudolf II. geprägt und mitunter auch gestört hat. So bedeutend die Este als Fürsten eines Gebietes waren, das die Expansionsbestrebungen Venedigs und des Papstes im Zaum halten sollten, so wichtig war es, dass von den italienischen Reichsfürsten der Po-Ebene keiner die Oberhand gewinnen sollte. Mit ihrer Unentschlossenheit und der wiederholten Vertagung der definitiven Klärung der Präzedenzfrage versuchten die Kaiser der zweiten Hälfte des I6. Jahrhunderts dieses Gleichgewicht zu halten ebenso wie mit einer nach Italien ausgerichteten, alle Prätendenten bedienenden Heiratspolitik. Die Verleihung der Großherzogswürde an die Medici durch den Papst brachte schließlich diese Balance ins Wanken; die ständige Bedrohung der Ostgrenze durch die Osmanen und die Spaltung des Reiches sowie die permanente Finanznot des Kaisers beendeten

\footnotetext{
6 Molho, Patronage 242.

7 Schnettger, Kleinstaaten, 6r 4. Stollberg-Rilinger, Was heißt Kulturgeschichte, i 95.

8 Zur integrierenden Kraft von Patronage siehe die Beiträge in Asch/Emich/Engels, Integration.

9 Schnettger, Kleinstaaten, 6i 7.
} 
schließlich diese Ausgleichspolitik zugunsten der finanzstarken Medici durch deren Bestätigung als Großherzöge durch das Reichsoberhaupt. Damit hatten die Este endgültig jede Hoffnung auf den Vorrang verloren.

Die letzte »Nagelprobe« im Verhältnis der Este zu Kaiser und Reich ergab sich durch die Nachfolgeregelung beim Aussterben der Hauptlinie im Mannesstamm aufgrund der Kinderlosigkeit von Alfonso II. Konnte nach langwierigen Verhandlungen der estensischen Gesandten mit Kaiser Rudolf II. und nach einer substantiellen Kontribution von 400.000 scudi für den Türkenkrieg endlich Cesare d'Este aus der Seitenlinie der Markgrafen von Montecchio als Nachfolger in den Reichslehen Modena und Reggio eingesetzt werden, so ließ sich trotz kaiserlicher Intervention und großer Versprechungen der Este, den Kampf gegen die Osmanen noch weiter unterstützen zu wollen, die Devolution, der Heimfall des päpstlichen Lehens Ferrara, nicht abwenden. Keines der verlockenden Angebote (Truppen, Waffen, Heeresleitung) des letzten Herzogs von Ferrara konnte die Bestimmung der Bulle Admonet nos, die die Neuvergabe von kirchlichen Lehen ausschloss, die zum Teil damit legitimierten Expansionsbestrebungen des Kirchenstaates aufhalten.

Die Ära der Herzöge von Ferrara ging somit I 598 zu Ende, jene der Herzöge von Modena begann mit dem Umzug des ersten Fürsten aus der estensischen Seitenlinie und eines geringen Teiles des Hofes nach Modena, die zur neuen Hauptstadt des Reichslehens avancierte. Zwar hatten die Este die kaiserliche Erhebung von Modena und Reggio zu Herzogtümern durch Kaiser Friedrich III. bereits 1452 und somit I 9 Jahre früher als die päpstliche Erhebung Ferraras erhalten, dennoch hatten sie ausschließlich in Ferrara ein Renaissancezentrum und einen prestigeträchtigen Hof erschaffen, mit dem sie sich identifizierten. Die Abtretung Ferraras war somit nicht nur ein territorialer Aderlass, sondern ein folgenschwerer Imageverlust.

War die Beziehung der Este zu den Kaisern des I6. Jahrhunderts also von verschiedenen, auch schweren Krisen geprägt gewesen, so überwog am Ende der Vorteil ihrer Wiedereinsetzung nach der Kaiserkrönung I 530 und der Neubelehnung der Seitenlinie mit den Reichslehen Modena und Reggio. Durch die Weiterführung der Beziehungen zu diesen - wenn auch nicht immer vorbildlichen Vasallen - sollten nämlich die päpstlichen und französischen (später auch die spanischen) Expansionsbestrebungen gebremst werden. So sehr sich die Kaiser des r6. Jahrhunderts auch geziert haben mögen, den italienischen Fürsten in ihren dringlichsten Anfragen und Bitten entgegenzukommen, so sehr muss ihnen auch bewusst gewesen sein, dass sie Vasallen wie die Este in Reichsitalien unbedingt brauchten.

Dass die Herzöge von Ferrara (und Modena) für die Habsburger wertvoll waren, bezog sich nicht nur auf ihre Funktion als »Verwalter« eines Reichslehens, als militärische Bündnispartner, als katholisch gebliebene und deshalb in Frage kommende Heiratskandidaten oder als Zahler von Abgaben- und Kontributionen; mehr als die Gonzaga und die finanzstarken Medici hatten sich die Este im Reich verankert und konnte nicht so leicht »ersetzt« werden. Dieser auf einem dichten Kommunikationsnetzwerk 
und einem ausgeprägten Beziehungsgeflecht basierenden »Verankerung« widmet sich der zweite Teil der vorliegenden Arbeit. Für die verschiedenen Aspekte des reichen und vielseitigen kulturellen Austauschs zwischen den Este und dem Reichsoberhaupt sowie einzelnen Reichsfürsten waren vor allem zwei Faktoren ausschlaggebend. Zunächst war der Fürstenhof von Ferrara in der Renaissance in und außerhalb Italiens einer der glänzendsten und eindrucksvollsten und galt neben anderen wie jenem von Mantua, Florenz oder dem Papsthof, als Maßstab der Hofkultur und des RenaissanceHumanismus. Die von den Este gegründete und geförderte Universität von Ferrara gehörte nach Padua zu den am häufigsten von Studierenden und Gelehrten aus dem Reich besuchten Hochschulen Oberitaliens. Im Rahmen des estensischen Mäzenatentums und der Inszenierung der herzoglichen Macht erreichte der Hof von Ferrara in verschiedenen Bereichen (Künste, Literatur, Musik, Architektur, Turnierwesen, Handwerk, Feuerwaffenkunst) einen Qualitätsstatus und ein Renommee, was ihn zu einem nachahmungswürdigen Vorbild in Italien und Europa machten. Auch die Tatsache, dass von den oberitalienischen Höfen, und darunter von Ferrara, die frühesten Ansätze einer diplomatischen Vertretung ausgingen und die Stadt, die Universität und der Hof obligatorische Stationen auf jeder Bildungsreise, Kavalierstour oder Wallfahrt nach Rom/Loreto waren, diente dem hervorragenden Ruf der Dynastie und ihres Territoriums bis in den Reichsnorden. Gerade diese Bekanntheit jenseits des Alpenhauptkamms und die Anwesenheit von Gelehrten und Künstlern ließ den estensischen Hof im I6. Jahrhundert zu einem sprachlichen und höfischen »Ausbildungszentrum« für Fürstensöhne und Hofeliten avancieren. Mithilfe der verschiedenen im Reich nachgeahmten künstlerischen Produktionen aus Ferrara oder den gefragten edlen Pferden aus der estensischen Zucht vernetzten sich die Este, die im Rahmen des Gabentauschs und ihrer überregionalen Heiratspolitik wiederum Kulturgüter aus dem Reich nach Ferrara brachten. Neben der glanzvollen Hofkultur und einem ostentativ eingesetzten Mäzenatentum war die Heiratspolitik ein weiterer wichtiger Faktor zur Stärkung und Pflege des kulturellen Austausches. Mit der Eheschließung Alfonsos II. mit Erzherzogin Barbara von Österreich ${ }_{5} 6_{5}$ heirateten die Este nicht nur in die Casa de Austria ein, sondern auch ins Reich. Durch dieses Einheiraten intensivierten sich die schon bestehenden Kontakte, Korrespondenzen, Besuche, der Austausch von Gaben und Leistungen, die regelmäßigen Gesandtschaften und verschiedene Aspekte der Patronage mit den katholischen Reichsfürsten und dem Haus Habsburg. Der Austausch mit reformierten Fürsten wie den Kurfürsten von Sachsen, den Herzögen von Mecklenburg und jenen von Braunschweig-Lüneburg war hingegen bereits vor I 565 und vor allem in den 155 oer Jahren besonders intensiv geworden. Das Netzwerk, das die Este des ausgehenden I 5. und beginnenden I6. Jahrhunderts im Reich gesponnen hatten, wurde durch die Verschwägerung von I 565 verstärkt, ausgebaut und blieb im Reich - im Sinne des »einmal verschwägert, immer verschwägert« - auch nach dem frühen Tod der habsburgischen Braut bestehen bzw. konsolidierte sich zum Teil sogar weiter, wenn man an die Beziehungen Alfonsos zum Tiroler Hof Erzherzogs Ferdi- 
nand II. denkt. Die Häufigkeit des Kontakts und der Grad des Austauschs von Gaben und Gefälligkeiten weist verständlicherweise stets in die Richtung, welche die Este in ihrer Allianzbildung einschlugen, und zeigt, von welcher Seite sie sich gerade mehr Unterstützung für ihre verschiedenen Anliegen erhofften. Dabei ist hier die von Birgit Emich betonte instrumentelle (zweckgeleitete) Dimension von Patronage mit der Patronage als Kulturform eng verflochten. ${ }^{10}$

In den einzelnen Kapiteln dieses zweiten Teils wurde nicht nur gezeigt, wie weitgespannt und ausdifferenziert das Netzwerk der Este als Fürsten eines mittelgroßen, in seiner (reichs)politischen wie militärischen Bedeutung bescheidenen Lehenskonglomerats war, sondern auch wie stark sich der Kontakt im Rahmen des kulturellen Austauschs auf die politischen Gegebenheiten und Interessen auswirkte. Als bestes Beispiel gilt sicher der Austausch und intensive Kontakt mit Kurfürst Moritz von Sachsen, der schließlich in der Teilnahme der Este - wenn auch nur aus der Ferne - am Fürstenaufstand gegen Kaiser Karl V. mündete.

Der in dieser Studie anhand verschiedener Beispiele untersuchte kulturelle Austausch und Transfer ist stark von der Präsenz von »Fremden« und hierbei vorrangig von nach Ferrara verheirateten Fürstinnen und ihrem jeweiligen Hofstaat sowie von Gesandten geprägt. Die Berührungspunkte des kulturellen Transfers sind vor allem in der Mode, im Gelehrtenwissen, im Hofalltag und mit der Heirat Ercoles II. mit Renée de France, einer Sympathisantin des Calvinismus und Unterstützerin von französischen Glaubensflüchtlingen, auch im Bereich der neuen Glaubenslehren zu finden. Gerade diese Heiratsverbindung bietet die Möglichkeit, einen Vergleich zum intensiven und viel früher begonnenen kulturellen Austausch der Herzöge von Ferrara mit Frankreich zu ziehen, wobei zu beachten ist, dass es sich hierbei um den Kontakt und die Beziehungen zwischen den Este und dem zentralen Hof eines kompakten Herrschaftsgebiets handelte, während das Reich verständlicherweise auch unter dem Aspekt des kulturellen Austauschs und der Netzwerkbildung und insbesondere im Zuge der Glaubensspaltung als »zerstückelter Flickenteppich ${ }^{11}$ wahrgenommen wurde.

In diesem Rahmen konnte wiederholt gezeigt werden, welche Bedeutung der regelmäßige Gabentausch, die Erfüllung von Wünschen und Anfragen, das Nachgehen von Bitten und Empfehlungen im Rahmen der Patronage sowie die gegenseitigen Besuche und die regelmäßige Gunstbekundung zur »Etablierung von Anerkennungsverhältnissen «, ${ }^{12}$ d.h. zum Ausbau und Erhalt lebensnotwendiger Netzwerke hatten. Objekte und deren besonderer $»$ Wert,$^{13}$ aber auch die weiter-

Iо Емісн, Staatsbildung, $33 \mathrm{f}$.

I I Vgl. diese Diktion in der deutschen Ausgabe von Whaley, Das Heilige Römische Reich I, bes. Kap.

»Der Flickenteppich der Territorien «, 67-78. In diesem instruktiven Überblick über die Geschichte des

Reiches spielt Italien nur als Kriegsschauplatz oder geografischer Begriff eine Rolle, eine Bezugnahme auf Reichsitalien fehlt hingegen auch in der englischen Originalausgabe.

I2 Hirschbiegel/Ewert, Mehr als nur der schöne Schein, 4I.

I3 Vgl. die Habilitationsschrift von Antenhofer, Mensch-Objekt-Beziehungen. 
empfohlenen und am Hof aufgenommenen Menschen und ihre Dienste trugen zur Stärkung und Erhaltung des durch Freundschaft und Verwandtschaft entstandenen und verdichteten Beziehungsgeflechts bei. Der Zweck dieser Bemühungen um eine meist über Generationen bestehende Verbindung lag für die Este gerade in Hinblick auf ihre verschiedenen Krisen des I6. Jahrhunderts und in ihrer Strategie des »Obenbleibens« Hoffnung auf Unterstützung und Fürsprache durch im Reich mächtige Entscheidungsträger. Hinweise auf diese Maßnahmen dzur Erhaltung der Position im italienischen und europäischen Mächtesystem finden sich besonders in den Korrespondenzen unter Fürsten, wenn z. B. die Gründe für die Klärung des Präzedenzstreits mit den Medici oder jene für die Nachfolgeregelung für die Seitenlinie detailreich angeführt werden. Noch stärkere Erwähnung finden die Argumente für die Befürwortung der estensischen Anliegen in den Instruktionen für die ferraresischen Gesandten im Reich.

Aus der Sicht der Reichsfürsten hingegen waren die italienischen Verwandten eine sehr wichtige Bezugsquelle jener materiellen wie geistigen Güter, die sie benötigten, um zu den humanistisch Gebildeten, den prestigevollen Mäzenen und den bedeutenden Renaissancefürsten zu zählen. Mit deren Hilfe sowie durch fähige Kunstagenten und Gesandte konnten die Fürsten des Nordens ihre Kunstkammern füllen, die Hofmusikkapellen mit geeigneten Musikern besetzen oder den italienischen palazzi und Gärten nachempfundene architektonische Prachtbauten errichten lassen. Der kulturelle Austausch mit dem Kaiser, seinem Hof und seiner familia erfüllte zudem den Zweck, die Treue und Loyalität des Vasallen gegenüber seinem Lehensherrn und die Liebe und Fürsorge desselben für seinen Lehensnehmer auszudrücken. Doch der wichtigste Aspekt des kulturellen Austauschs zwischen den Este und dem Reich war die Tatsache, dass in diesem Rahmen die reichsitalienischen Fürsten aus ihrer Position in der geografischen und politischen Peripherie des Reiches in die Semiperipherie ${ }^{14}$ der Bedeutung und Wahrnehmung und für eine kurze Zeit, am Höhepunkt des Renaissance-Humanismus, sogar in das Zentrum rückten, wenn man Wallersteins Weltsystemtheorie auf dieses Phänomen angewendet haben will. In eine ähnliche Richtung ist bereits Wolfgang Behringer im Rahmen seiner Untersuchungen zum Kommunikations- und Postnetzwerk des Heiligen Römischen Reiches gegangen. ${ }^{15}$ Er hat darauf hingewiesen, dass das frühe kaiserliche Postwesen sein Zentrum in der Reichsstadt Augsburg hatte und von hier aus Antwerpen mit Innsbruck und Venedig verbunden waren. Diese Route, entlang der sich weitere Aspekte des kulturellen Austauschs (Besuche, Gabentausch, Warenverkehr) abspielten, rückte den geografischen Reichsrand

\footnotetext{
I4 Der Begriff Semiperipherie ist aus der Weltsystem-Theorie von Immanuel Wallerstein entlehnt und bezieht sich auf die Tatsache, dass ein Raum der Peripherie für eine bestimmte Zeit und in bestimmten Bereichen der Produktion Zentrumsfunktionen wahrnehmen kann, auch wenn er insgesamt nicht zum Zentrum gehört. Wallerstein, Das moderne Weltsystem, izof.

i5 Behringer, Core and Periphery, 349 f.
} 
Italien ins Zentrum. Die protestantischen Territorien im Reich, allen voran Sachsen, an welches sich die Este als einflussreichste Macht im Reich wandten, beklagten hingegen selbst nach der Gründung der Reichspost I 597 das Fehlen eines vergleichbar kapillaren Kommunikationsnetzes und gingen dazu über, eigene Postsysteme einzuführen. ${ }^{16}$

Die Bedeutung des kulturellen Austauschs in seinen vielfältigen Facetten liegt also nicht nur im Geben und Erhalten von materiellen und geistigen Gütern an sich, in der Mobilität von Personen und Dingen oder deren Assimilierung und Weiterentwicklung durch den Empfänger, sondern in seiner Funktion als Mittel zur Netzwerkbildung. Denn erst durch den persönlichen und gegenständlichen Kontakt durch Kulturgüter wird eine Verbindung aufgebaut, die sich zur Bindung und - zumeist unterstützt durch Momente Patronage, der Familienpolitik und durch neuentstandene Verwandtschaftsstrukturen - zu einem Beziehungsgeflecht entwickelt. Für die italienischen Fürsten Reichsitaliens und noch mehr für die Este als »Diener zweier Herren« war es überlebenswichtig, ein weitreichendes Netz ins Reich zu spinnen. Die Mittel, die ihnen dafür zur Verfügung standen, waren der Austausch aufgrund ihrer kulturellen Vorreiterrolle, die ständige briefliche, persönliche oder durch Gesandte vertretene Präsenz, die Mobilität und eine durchdachte Heiratspolitik.

Eng mit dem Aspekt der Netzwerkbildung und des kulturellen Austauschs und Transfers verbunden ist jener der Eigen- und Fremdwahrnehmung, also kurz gesagt der Frage, wodurch sich das Andere/der Andere vom Eigenen in Wesen, Charakter, Kultur, Sitten etc. unterscheidet und inwiefern dieser Unterschied Bewunderung oder - vor allem durch die von Gesandten tradierten Stereotypen genährt - Verachtung hervorruft und diese Einstellungen die Beziehungen prägen. Diese Überlegungen leiten zum dritten Teil der Arbeit über, wo auf mehreren Ebenen untersucht wurde, wie die Este im Reich und wie der Kaiser sowie andere Mitglieder des Reiches in Italien und von den Este wahrgenommen wurden. Mit der Frage nach Wahrnehmung und Rezeption kann auf die Bedeutung des Gegenübers geschlossen werden. Daher war es notwendig, die Kontakte (Briefe, Besuche) zu quantifizieren und - wo möglich - zu qualifizieren, d.h. festzumachen, ob es sich beim Inhalt der Schreiben »nur« um obligate Gratulations- und Kondolenzschreiben oder um Anfragen, Bitten und besondere Freundschaftsbekundungen etc. handelte. Hierbei ist wichtig nachzuvollziehen, woher ein Schreiber/eine Schreiberin über die Beschaffungs- und Erfüllungsmöglichkeiten der Este bei bestimmten Anfragen wusste und inwiefern hier das weitreichende Netzwerk die Funktion einer »Kartografierung der Dienstleistungen« erfüllte.

Die Herzöge von Ferrara wurden im Reich wahrgenommen und erreichten einen bemerkenswerten Bekanntheits- und Bedeutungsgrad, weil sie auch alle Register dafür zogen. Die ständigen Gesandtschaften im Reich, die Erfüllung von Bitten, der Verleih von Geldmitteln und die oft ungefragte Zusendung von begehrten Geschenken,

I6 Ebd., 353 . 
die Besuche und eine meist regelmäßige Korrespondenz sowie ihre frühe Vorbildwirkung als Renaissancefürsten und -mäzene machten sie jenseits der Alpen bekannt und greifbar. Doch sie waren nicht nur präsent, sondern für Reich und (Reichs)Italien von Bedeutung. Viele Kulturprodukte des ferraresischen Hofs wurden angefragt, rezipiert und/oder kopiert; Reichsmitglieder wollten Ercoles I. Stadterweiterung bewundern und fähige Handwerker für die eigene Bautätigkeit ins Reich holen; von Alfonso I. erbat man sich Feuerwaffen und die Baupläne seiner Kanonen. Wollte man besonders edle Pferde erwerben oder die italienische Sprache an einem kulturell bedeutenden Fürstenhof erlernen, wandte man sich ebenso an die Herzöge von Ferrara. Dank ihres dadurch aufgebauten Renommees waren die Este bereit, ja sogar darauf erpicht, über ihre Landesgrenzen hinaus wahrgenommen zu werden und eine Rolle auf dem internationalen Parkett zu spielen.

In ihrer Beziehung zum Haus Habsburg wuchs die Wahrnehmung und Bedeutung der Este - die allgemeine Zunahme der Schriftlichkeit bedenkend - mit der Zahl der Briefe vom und an das Reichsoberhaupt seit dem Beginn des i6. Jahrhunderts kontinuierlich an. Doch während Maximilian I. selten eigenhändig unterschrieb und seine Briefe meistens das ad mandatum imperatoris tragen, personalisierten Karl V. und Ferdinand I. durch das manu propria die Schreiben an die italienischen Vasallen. Die engste, sicher auch auf die mittlerweile erfolgte Verschwägerung zurückzuführende Beziehung und die intensivste gegenseitige Wahrnehmung bestand aber zwischen Alfonso II. d'Este und Kaiser Maximilian II., der die Briefe nicht nur eigenhändig unterschrieb, sondern auch auf Spanisch oder Italienisch selbst verfasste. Dazu kommt noch der bei der Unterschrift oft verwendete Zusatz "buon amico e fratello«, "come/ quanto fratello« oder spanisch »buen amigo y hermano«. Alle diese Aspekte sind Indizien für eine, wie Fouquet es ausgedrückt hat, »vertraute und auf Vertrauen bauende Korrespondenz «. ${ }^{17}$

Mit Kaiser Maximilian II. gab es die meisten persönlichen Kontakte durch Besuche, d.h. die meisten Reisen eines Este-Fürsten ins Reich. Dieses Beziehungsgeflecht in der zweiten Hälfte des I6. Jahrhunderts dehnte sich auch auf andere Mitglieder des Herrscherhauses aus, so besonders auf die Erzherzöge Karl, Landesfürst von Innerösterreich, und Ferdinand, Landesfürst von Tirol und der Vorlande. Vom Innsbrucker Hof ausgehend, einem Dreh- und Angelpunkt der Beziehungen zwischen Italien und dem Reich, wurde das Netzwerk zu den Herzögen von Bayern aufrechterhalten, mit denen die Este aufgrund der reichen Töchterschar Kaiserin Annas und der weitsichtigen Heiratspolitik Ferdinands I. ebenso verschwägert waren.

Über die estensischen Gesandten am Kaiserhof oder am Reichstag wurden hingegen die Beziehungen zu den evangelischen Reichsfürsten des Nordens (Sachsen, Mecklenburg und Braunschweig-Lüneburg) gepflegt. Die beiden Letzteren erbaten sich des Öfteren (wie auch die Wittelsbacher) Geld von den Este, die im Reich den

i7 Fouluet, Fürsten unter sich, I 89 . 
Ruf hatten, wohlhabende Fürsten zu sein bzw. dieses Stereotyp des reichen Italieners weiter pflegten. Dem Ruf, stets liquide und finanzstark zu sein, wurden die Herzöge von Ferrara und Modena insofern gerecht, als dass sie sich zwar anfangs oft zierten und die Bitten um Geld mit der Angabe eigener finanzieller Engpässe abzuwenden versuchten, aber schließlich meistens die erbetenen Kredite gewährten, durch deren späte und zögerliche Rückzahlung die Reichsfürsten oft über Generationen in der Schuld der Este blieben. Diese Abhängigkeit wussten die Herzöge von Ferrara für das Vorantreiben der eigenen Anliegen im Reich zu nutzen.

Wenn die zahlreichen Briefe an die verschiedenen Reichsfürsten und an das Herrscherhaus wie auch die Gesandtschaften immer wieder die heikle Agenda der Präzedenz vorbrachten, so war der Grund dafür die Tatsache, dass die Este alle diese Protagonisten als Entscheidungsträger am Reichstag und als Gestalter der Reichspolitik wahrnahmen. Von diesen versprachen sie sich nämlich Befürwortung und Fürsprache und nahmen den Reichstag als Reichsinstitution ernst, zu dem sie aber keinen Zugang hatten, so wie sie den Reichshofrat als Gerichtsinstanz auch in den italienischen Angelegenheiten akzeptierten und für diesen auf kaiserliche Beauftragung hin die Exekution von Urteilen vor Ort übernahmen.

Dieser dritte Teil der Arbeit zeigt somit, dass die Este, wie auch andere italienische Dynastien, für Kaiser und Reich im Laufe des I6. Jahrhunderts an Bedeutung gewannen und in der Jahrhundertmitte sicher den Höhepunkt in dieser Fremdwahrnehmung erreichten. Dabei war das "Einheiraten ins Reich" ein entscheidender Schritt in diese Richtung gewesen. War die Verbindung mit einer Erzherzogin für alle reichsitalienischen Fürsten erstrebenswert und von Nutzen, so weist das estensische Beispiel darüber hinaus eine erhöhte Erwartungshaltung gegenüber dem Reichsoberhaupt und den Reichsfürsten in Bezug auf bestimmte Anliegen wie jenem der Präzedenz und der Nachfolgeregelung auf. Die Hinwendung zum Reich ab der Kaiserkrönung in Bologna und verstärkt ab der Mitte des I6. Jahrhunderts wurde aber schließlich auch von der enttäuschenden Hilfestellung des alten Bündnispartners Frankreich und von der neuen spanischen Vorherrschaft in Oberitalien gefördert.

Die Strategie des »Obenbleibens« dieses reichsitalienischen und gleichzeitig dem Papst verpflichteten Fürstengeschlechts war somit geprägt von Präsenz durch Gesandtschaften, Besuchen oder Briefen, mit denen man sich oft nur in Erinnerung rufen wollte, von der kontinuierlich produzierten Wahrnehmung (gerade durch die Gesandten), von Dienstbarkeit und Verfügbarkeit. Die Involvierung in den Fürstenaufstand und in den Konflikten in Italien, die Bereitstellung von Truppen für den Türkenkrieg sowie das Renommee als Waffenhersteller zeigen den Willen der Este, trotz ihrer bescheidenen Stärke auch militärisch wahrgenommen zu werden - als ernst zu nehmende Bedrohung (unter Ercole II.) oder als wichtiger Allianzpartner (unter Alfonso II.).

Der langersehnte und nicht erfüllte Wunsch, den anderen italienischen Fürsten, allen voran den Medici, vorgezogen zu werden und somit den Vorrang auf der Halbinsel 
zu haben, war nicht nur ein dem sozialen Kapital der Ehre gezolltes Unterfangen, sondern reiht sich in die Bemühungsstrategien der Este ein, an Bedeutung im/für das Reich zu gewinnen. Auf der anderen Seite zeigt gerade die Anrufung des Kaisers, der Reichsfürsten und des Reichstages in der Präzedenzfrage, dass man der Institution Kaiser und Reich und ihren Akteuren von estensischer Seite aus maßgebende Bedeutung und Macht zuschrieb.

So kann zum Schluss festgehalten werden, dass die Este trotz der »aufgeweichten« Lehensabhängigkeit und ihrer media sovranitas den Kaiser und das Reich brauchten. Besonders im Rahmen ihrer Krisen im I6. Jahrhundert wandten sie sich an das Reichsoberhaupt, erbaten sich Unterstützung und Fürsprache durch die Reichsfürsten und erkannten die Machtbefugnisse des Reichstages als Institution an.

Für die Einbettung Reichsitaliens in den durch die Glaubensspaltung stark gelockerten Reichsverband und für eine gewinnbringende Italienpolitik brauchten die Kaiser des r6. Jahrhunderts ihrerseits Dynastien wie die estensische, die sie, angesichts ihrer Bedeutung für das Reich - abseits einiger »Warnschüsse« - nicht aufzugeben gedachten. Diese Bedeutung versuchten die Este Kaiser Rudolf II. in ihrer Überzeugungsarbeit bei der Nachfolgeregelung dezidiert vor Augen zu halten, indem sie das Reichsoberhaupt daran erinnerten, dass sie ihre Lehen zu glanzvollen, über Italien hinaus und in fast ganz Europa anerkannten Herrschaftsgebieten gemacht hatten. ${ }^{18}$ Im Gegenzug erwarteten sie dafür vom Reichsoberhaupt, dass es sich freigebig und gnädig gegenüber solchen edlen und bedeutenden Dynastien zeige: „Convenir agli Imperatori et esser lor proprio ufficio mostrarsi liberali et clementi verso si nobili Famiglie et mantener la grandezza loro più che possono. ${ }^{19}$ Ungeachtet ihrer Hinwendung zu Frankreich und ihrer Konspiration mit Kursachsen gegen Karl V. hielten die Este fest, dass sie dem Reich und dem Kaiser stets zu Diensten gewesen waren, sodass ihnen allein deswegen die Lehen als »Entschädigung" oder "Belohnung« zustünden: »Che sono stati congiuntissimi all'Impero adoperando valoriosamente in suo servizio onde si può dire che i feudi siano stati dati loro per rimuneratione.«

Nimmt man die einzelnen Aspekte der Fremd- und Eigenwahrnehmung zusammen, so ergibt sich ein Bild der Este als nicht immer loyale reichsitalienische Fürsten, »Trendsetter«, Mäzene und Renaissancekulturförderer, Informanten, Bezugsquelle, nachahmungswürdige Vorbilder und bedeutsame Akteure innerhalb eines weitgesponnenen europäischen Netzwerks.

I 8 »Che hanno i Principi di Este mantenuto per molti secoli uno splendor infinito non solo in Italia ma quasi in tutta Europa con una serie non mai interrotta.«ASMo, ASE, Casa e Stato, Carteggio di Ambasciatori, Germania b 46, Istruzioni an Ascanio Geraldini, November ${ }_{5} 87$.

I 9 ASMo, ASE, Casa e Stato, Carteggio di Ambasciatori, Germania b 46, Istruzioni an Ascanio Geraldini, November 1587 . 
ANHANG

Publikation im Sinne der CC-Lizenz BY 4.0 
Publikation im Sinne der CC-Lizenz BY 4.0 


\section{Die Dynastie der Este - biografischer Abriss}

\subsection{Der Beginn der Este-Herrschaft bis zur herzoglichen Erhebung}

Hofhistoriker und Chronisten des r6. Jahrhunderts haben mit sehr viel Fantasie und einigen Quellenkenntnissen die Wurzeln der Familie d'Este auf Karl den Großen, auf die Römer, die Etrusker und sogar auf die Trojaner zurückzuführen versucht. Getrieben waren sie dabei von der Notwendigkeit, im Rahmen von Herrschaftsinszenierung im Allgemeinen und des Präzedenzstreits mit den Medici im Besonderen dem kleinen und militärisch wie wirtschaftlich eher mittelmäßigen estensischen Fürstentum ehrwürdige und bedeutende Ahnherren zu verschaffen. Der hier folgende Überblick in Form von Kurzbiografien soll deshalb gerade in Hinblick auf den immer wieder herangezogenen Verweis auf die Ahnen der Herzöge von Ferrara und die Langlebigkeit der Dynastie nicht nur die Akteure des »langen« I6. Jahrhunderts, sondern auch ihre Vorfahren zumindest grob beleuchten. ${ }^{1}$

Es ist mittlerweile bestätigt, dass die Gebiete des Kernlandes der Este-Dynastie einst der Toskana zugehörig waren und ihre Ahnen somit von dort stammten. Die Ursprünge dieser Dynastie jedoch liegen im Reich, genauer gesagt in Bayern. Ein gewisser Bonifaz I. kam mit Karl dem Großen 8 I 3 nach Italien und regierte hier als Herzog von Toskana. Von ihm stammte (bereits von Muratori rekonstruiert) vier Generationen später jener Oberto I. ab - 962 von Kaiser Otto zum Pfalzgrafen und somit zum zweithöchsten Rang in Italien erhoben -, der als Stammvater der Familien der Este, Malaspina, Pallavicini und Massa Parodi gilt. Er regierte als kaiserlicher Vikar über eine große Anzahl von Städten und hatte eine weite Gerichtsbarkeit inne, die von Pavia bis zur Toskana reichte. Hier ist bereits die erste Verbindung des Hauses Este zum Reich erkennbar. Auch die frühe Verwendung einer eigenartigen impresa, gemeint ist ein nicht heraldisches Zeichen, Symbol oder Motto mit Wiedererkennungscharakter, mit dem sich viele Renaissancefürsten schmückten, zeugt von dieser im weitesten Sinn - Abstammung vom Reich. Jeder Este-Fürst hatte verschiedene imprese in Gebrauch, ${ }^{2}$ die gängigsten waren der Diamant, der umzäunte Garten, der Wasserschutzwall, das Einhorn, das Segel, der geflochtene Korb, das Taufbecken und der ungewöhnliche worbas. Diese Fantasiefigur, die u. a. auch auf einem der Türme des

I Die maßgebliche Literatur zur biografischen Übersicht über die Dynastie der Este ist: Chiappinı, Gli Estensi; Dean, »Este«; Gundersheimer, Ferrara; Rimondi, Estensi; Milano, Gli Estensi; Ders., Casa d'Este. Eine letzte prosopografische Aufarbeitung hat Goldoni, Atlante Estense, vorgelegt.

2 Unlängst hat Bernhard Schirg am Beispiel des Kardinals Ippolito I. d'Este gezeigt, welche Bedeutung diese imprese auch im schriftlichen Bereich, nämlich in der Privatkorrespondenz, hatten und wie sich Künstler, wie im vorliegenden Fall Leonardo da Vinci, durch die Erfindung eines solchen »Markenzeichens« die Gunst des Patrons erwerben konnten. Schirg, Decoding da Vinci’s Impresa. 
Castello Estense zu finden ist, stellt einen Luchs mit Greifflügeln und Drachenschwanz dar. Der Name »wor-bas« soll eine antike Version des deutschen »worwaerts« oder noch früher »vorbass«/»furbass« sein und meint das unverzagte, furchtlose Weitergehen/Vorwärtsgehen. Diese Deutung sollte auch auf etymologischer Ebene die germanische Abstammung der Este betonen. ${ }^{3}$

Gleichzeitig lehnte sich das Haus d'Este aber schon früh auch an die in den meisten Kommunen bevorzugte päpstliche Macht an und versuchte von Anbeginn an eine Gleichgewichtspolitik zwischen den beiden Universalmächten zu führen. Nach Oberto fiel beim Tod des kinderlosen Ugo, Markgraf von Toskana, ein großer Teil der Erbschaft an die Familie d'Este, die um die Jahrtausendwende bereits die Herrschaft über das Gebiet von Este, Monselice, Rovigo und Teile Friauls ausübte. Mit Alberto Azzo II. (um 996- I097), einziger Sohn des ro29 verstorbenen Alberto Azzo I., etablierte sich der obertengische Zweig der Markgrafen d'Este mit der neuen, Namen gebenden Residenz in der Stadt Este (43 km Luftlinie nördlich von Ferrara gelegen). ${ }^{4}$

Alberto Azzo II. d'Este war bestrebt, seine politischen Beziehungen über Italien hinaus jenseits der Alpen auszudehnen. Er heiratete Kunigunde, Tochter von Welf II. Graf von Altdorf, die neben einer reichen Mitgift eine engere Beziehung zum Reich mitbrachte. Mit dem Ziel, die größtmögliche Unterstützung für sein Haus zu erhalten, stellte er sich auf die Seite der Kaiser Konrad II. und Heinrich III. Außerdem dehnte er seine Besitzungen in den Gebieten von Padua, Ferrara, Vicenza, Verona, Parma, Cremona, Piacenza und Modena aus. In zweiter Ehe heiratete Alberto Azzo II. Garsenda, Tochter des Grafen von Maine, Eriberto Svegliacane, Vasall des Grafen von Anjou, sodass hier als zweite ultramontane Beziehung jene zu Frankreich entstand, die die Este bis zu ihrem Aussterben pflegen sollten. Die Bedeutung von Alberto Azzo II. ist nicht zu überschätzen, nahm er an der ersten von Papst Gregor VII. Io74 einberufenen Synode teil und er fungierte als Vermittler zwischen dem Papst und dem auf die Knie gefallenen Kaiser. ${ }^{5}$

Alberto Azzo II. gilt also als der Urvater von mehreren großen Geschlechtern diesseits und jenseits der Alpen: der Este, der Herzöge von Bayern, von Sachsen und jener von Braunschweig-Lüneburg. Während sein Sohn aus erster Ehe Welf (Guelfo) IV. ${ }^{6}$ mit der Erbschaft seiner Mutter den Titel eines Herzogs von Bayern annahm, sich im Reich etablierte und Stammvater des Hauses Braunschweig und Sachsen wurde, erhielten die beiden anderen Söhne aus zweiter Ehe, Ugo II. und Folco I., jeweils die Erbschaft der Mutter in Frankreich und die Besitzungen des Vaters in Italien. Trotz heftiger Erbstreitigkeiten konnte sich Folco in Italien etablieren und in Ferrara

\footnotetext{
di Pietro Lombardi, Le imprese estensi, igif.

Chiappini, Gli Estensi, i5-20. Zur Entwicklung dieser Stadt siehe Selmin, Este.

Chiappini, Gli Estensi, 2 of.

6 Mit diesem nach Bayern versetzten »Italiener« begann die intensive persönliche Beziehung zwischen Bayern und Italien und im weitesten Sinn den Este, weshalb Welf IV. auch Nennung im Katalog zur Ausstellung Bayern - Italien fand. NADLER, Welf IV., 86f.
} 
seinen Herrschaftssitz einrichten. Seine Söhne, Obizzo, Bonifacio, Folco II., Alberto und Azzo IV., teilten nicht nur die väterliche Herrschaft untereinander auf, sondern trugen auch zum ersten Mal den Titel »Marchiones de Este«, der sich - wie Chiappini betont - nicht aus einer noch inexistenten estensischen Markgrafschaft ergab, sondern aus der Tatsache, dass das Geschlecht der Obertenghi, Pfalzgrafen von Italien, ${ }^{7}$ den Titel der Markgrafen von Toskana tragen durften und die Este diesen auf ihr Herrschaftsgebiet übertrugen. ${ }^{8}$

Von allen regierenden Söhnen Folcos gelangte Obizzo I. (reg. II37-1193) zu größter Bekanntheit und den meisten Ehren: I 777 nahm er am Frieden von Venedig zwischen Papst Alexander II. und Kaiser Friedrich Barbarossa mit einem Gefolge von I 80 Personen teil und stach damit die meisten anderen Potentaten aus. Im gleichen Jahr wurde er zum podestà von Padua gewählt, I 184 erhielt er vom Kaiser die Investitur von Genua und Mailand, wenn auch nicht als direkte Herrschaft, sondern mehr als Ehrentitel. I 88 wurde er von der Kirche mit der Pfründe des Klosters von San Romano in Ferrara belehnt, eine Auszeichnung, an welche die Pflicht zur Verteidigung der Rechte der Kirche gekoppelt war. Mit diesen Titeln und Funktionen verankerte er das Schicksal des Hauses Este in Ferrara. ${ }^{10}$

Obizzos Enkel Azzo VI., genannt Azzolino (reg. I I96-I2 I2) ${ }^{11}$ trat jung, aber politisch bereits versiert die Nachfolge in einer Zeit an, in der zwar die Kommune noch vorherrschte, aber Ferrara - wie auch andere norditalienische Städte - bereits von internen Machtkämpfen zerrissen wurde und deshalb bereit war, sich der Führung eines Einzelnen bzw. einer Familie zu unterstellen. Als eine der mächtigsten und reichsten Familien Ferraras, die guelfischen Adelardi-Marchesella, im Mannesstamm ausstarben, ergriff Azzo VI. die Gelegenheit, sich durch ein Heiratsprojekt mit deren einzigen minderjährigen Tochter und Erbin des Einflusses und der Ressourcen dieser Familie zu bemächtigen. Doch dies war auch der Plan der zweiten mächtigen Sippe, der ghibellinischen Torelli-Salinguerra aus Bologna, die sich in Ferrara angesiedelt hatten und mit den Adelardi-Marchesella konkurrierten. Eine Heirat zwischen den beiden verfeindeten Familien hätte endgültig Frieden gebracht. Doch die junge Braut wurde entführt und Azzo ausgehändigt, der sogleich die Heiratsverhandlungen einleitete. Durch diese Verbindung konnten die Este in Ferrara Fuß fassen, auch wenn das Heiratsprojekt schließlich gar nicht zustande kam, da die junge Verlobte - ohne die Ehe vollzogen und ein Testament gemacht zu haben - i 86 starb. Diese Situa-

$7 \mathrm{Zu}$ dieser Familie von Grafen und Markgrafen siehe den knappen Eintrag von Silvio Pivano, »Obertenghi«, in: Enciclopedia Italiana 26, Roma I949, ro4f.

8 Chiappini, Gli Estensi, 22 - 26. Im Januar i i6o investierte Herzog Welf VI. auch zur Bereinigung der Kontroversen zwischen den deutschen und dem italienischen Zweig der Welfen die Markgrafen von Este mit Este und anderen Besitzungen. Riedmann, Die Welfen, Io2.

9 Zu seiner Biografie vgl. Trevor DeAn, »Obizzo d'Este«, in: DBI 43, Roma I 993, 407-409.

io Chiappini, Gli Estensi, $26 f$.

i I Für die biografischen Angaben vgl. Trevor DeAn, "Azzo (Azzolino) d'Este«, in: DBI 43, 320-322. 
tion leitete eine lange Zeit von Unruhen, Kämpfen und Auseinandersetzungen um die Vorherrschaft in Ferrara ein, geprägt von Siegen, Niederlagen und Exilen der Este und schließlich vom Übergang der Stadt Ferrara von der freien Kommune zur signoria. Gleichzeitig begannen die Auseinandersetzungen zwischen Kaiser und Papst in und um Ferrara: Obizzo I. war von Kaiser Friedrich Barbarossa zum Appellationsrichter (Giudice di appello) der Marca Veronese ernannt worden. Daraufhin aber hatten sich die politischen Ereignisse gewandelt und die Este waren Guelfen, also Papstanhänger geworden, als Papst Urban III. I I 87 nach Ferrara kam und den Kaiser bannte. Obizzo war durch den darauffolgenden Tod des Pontifex erspart geblieben, sich dezidiert gegen den Kaiser stellen zu müssen. Auch Azzo VI. stellte sich auf die Seite von Papst Innozenz III. und nutzte den Moment, als der Pontifex Kaiser Otto IV. exkommunizierte, um die kaisertreuen Salinguerra und den kaiserlichen Vikar aus Ferrara zu vertreiben und sich dann aber dennoch mit dem Staufer Friedrich II. in seiner Auseinandersetzung um die Kaiserkrone gegen den Welfen Otto IV. zu verbünden. ${ }^{12}$

Azzo IV. war seit I I 96 podestà von Ferrara und verfolgte nach dem Tod der Erbtochter der Adelardi-Marchesella eine gewinnbringende Heiratspolitik, indem er zunächst eine Aldobrandini, in zweiter Ehe eine Frau aus dem Haus Savoyen und in dritter Ehe Alisia, Tochter von Rinaldo und Costanza d'Antiochia, ehelichte. Zwar stand er in den weiteren Auseinandersetzungen auf der Seite des Papstes, doch pflegte er auch zu Kaiser Heinrich VI. Kontakt und war mit ihm verbunden. Als Azzo IV. auch in Verona als podestà die Macht übernahm, machten ihm die Salinguerra I 206 Ferrara streitig. Erst zwei Jahre später konnte er sich Amt und Macht in Ferrara zurückholen und ließ dies durch einen Akt des Volkswillens untermauern. Seine Wahl per Akklamation durch das Volk, das ihm und seinen rechtmäßigen Erben die volle Macht übertrug, wurde (allerdings erst nachträglich) in den Statuten der Stadt aufgenommen. So war dieser Fürst, der darüber hinaus vom Papst mit der Markgrafschaft Ancona belehnt und vom Kaiser darin bestätigt worden war, der Herrscher über Ferrara geworden. Diese Erfolge gingen mit seinem Tod I 2 I 2 und der Einsetzung seines jungen Sohnes allerdings wieder verloren. Der neue Markgraf Aldobrandino I. d'Este ${ }^{13}$ versuchte mit den Salinguerra wieder eine Teilung der Macht zu erwirken, um sich auf die Rückeroberung der mittlerweile verloren gegangenen Mark Ancona konzentrieren zu können. Unter seinem Sohn Azzo VII. (Novello ca. I 205- I 264) ${ }^{14}$ spitzte sich die Situation zu, bis er und seine Familie I 222 schließlich von ihren Kontrahenten aus Ferrara vertrieben wurden. Bis I 240 regierten die Salinguerra allein, doch die Machtkämpfe zwischen Guelfen und Ghibellinen gingen auch ohne die Este weiter. I 240 wagte Azzo einen riskanten Schritt zur Eroberung Ferraras. Er verbündete sich mit Venedig, Mantua

\footnotetext{
i 2 Chiappini, Gli Estensi, 28-30; Milano, Casa d'Este, I 2- i 4 .

I $3 \mathrm{Zu}$ diesem ältesten Sohn von Azzo VI., der I 2 I 5 in der Mark Ancona starb, siehe: Trevor DeAn, "Aldobrandino d'Este«, in: DBI 43, 300-301.

I 4 Vgl. Trevor Dean, »Azzo (Novello) d'Este«, in: DBI 43, 322-324.
} 
und Alberico da Romano, Bruder des berühmt-berüchtigten Ezzelino da Romano. Als das älteste Mitglied der Salinguerra-Familie, Verbündete des Papstes und Mailands, zu Verhandlungen vor die Tore der Stadt kam, wurde er in einen Hinterhalt gelockt und Azzo nahm Ferrara ein. Die kriegerischen Auseinandersetzungen hielten allerdings bis 1259 an und waren nun gegen die einstigen Verbündeten da Romano gerichtet, bis diese vernichtend geschlagen werden konnten. Das letzte Problem des condottiere Azzo war die Nachfolge. Er musste die illegitimen Kinder seines in Apulien verstorbenen Sohnes nach Ferrara holen. Er ließ Obizzo von Papst Innozenz IV. legitimieren und stärkte seine Stellung durch die Heirat mit Giacoma dei Fieschi, eine Papstverwandte, sodass Obizzo I 264 Azzo in einer nahezu vollständig wiederhergestellten Herrschaft folgen konnte. ${ }^{15}$

Der Übergang der Macht von Azzo VII. auf den noch unmündigen Obizzo II. (reg. I 264 in Ferrara, I 288 in Modena, I 289 in Reggio- I 293) ${ }^{16}$ im Jahr I 264 war nach Ernesto Milano ein einzigartiger, widersprüchlicher politischer Akt zwischen einer Alleinherrschaft und einer kommunalen Führung mit Volksbeteiligung. Obizzo war beim Tod seines Großvaters zwar noch minderjährig, aber dennoch wählte das zusammengerufene Volk den jungen Spross per Akklamation zum Nachfolger. Voraussetzungen dafür waren die Gunst des Volkes, die Azzo in den Jahren gewonnen hatte und die Tatsache, dass sein treuer Berater, Aldighieri della Fontana, alle Befürworter der Este auf den Platz rief, während die bekannten Gegner geschickt von der Stadt ferngehalten wurden. Es installierte sich also mit diesem Akt eine frühe Form der erblichen Macht, während andererseits die kommunalen Institutionen, die kommunale Freiheit, die sich in der Wahl und ihrer Ratifizierung ausdrückte, - wenigstens dem Schein nach - weiter aufrechterhalten wurden. Wie in anderen Städten auch begann auf diesem Weg der Übergang von einer oligarchischen und sehr instabilen Form der kommunalen Regierung zu einer absoluten und despotischen, aber dafür stabileren Form der Herrschaft, die den Namen signoria trug, von der sich das Volk die Beendigung der Machtkämpfe und die Rückkehr zu mehr Sicherheit, Frieden als Voraussetzungen für wirtschaftliches Wachstum erhoffte. Doch Obizzos II. Alleinherrschaft zeigte auch die andere Seite der Medaille: Er brachte r 286 die Zünfte unter die Kontrolle des Consiglio minore und des Stadtherrn. Der Este wurde sukzessive vom Verteidiger der Rechtsprechung zum Gesetzgeber. Der podestà wurde entmachtet und ebenso wie die Magistrate zu befehlsausführenden Funktionären des Stadtherrn gemacht. I 292 erhielt Obizzo zudem eine der wichtigsten Voraussetzungen für seine Alleinherrschaft, nämlich das Privileg, seinen Nachfolger selbst bestimmen zu dürfen, auch wenn dieser weiterhin die formale Bestätigung durch das Volk benötigte. Hinter dieser städtischen Machtübernahme stand auch die Unterstützung der obersten Gewalten, des Kaisers und des Papstes. Urban IV. hatte Obizzo sofort nach der Thronbesteigung als Vertei-

i5 Chiappini, Gli Estensi, 39-4I; Rimondi, Estensi, 6-8.

i6 Siehe Dean, »Obizzo«, 409-4I I. 
diger der Kirche bestätigt. I 289 übernahm er auf gleiche Weise die Herrschaft über Modena. Auch hier führten die Machtkämpfe zwischen Guelfen und Ghibellinen zur Wahl eines »Externen«, der den Frieden garantieren konnte. Die Stadt bot Obizzo II. die Herrschaft an, die er nicht nur annahm, sondern schließlich an sich riss, indem er einen Macht demonstrierenden Ansitz bauen ließ, das Capitanato del popolo und die 24 Mitglieder der Società del popolo und schließlich den Consiglio del popolo absetzte. Reggio Emilia sollte es nach vielen internen Machtkämpfen Modena gleichtun und I 290 Obizzo die podesteria anbieten, die er annahm, um dann im Jahr darauf mit Waffengewalt die signoria einzusetzen. Obizzo II. war kein guter Herrscher; er belastete die Bevölkerung mit hohen Steuern und wurde dank seines schlechten Rufs von Dante in seiner göttlichen Komödie in der Hölle aufgenommen. ${ }^{17}$ Als er I 293 starb, ohne von seinem Privileg Gebrauch gemacht und einen Nachfolger ernannt zu haben, war die Dynastie schon so weit etabliert, dass das Volk seinen Erstgeborenen Azzo VIII. zum Herrn über Ferrara, Modena und Reggio akklamierte. Es waren hingegen die Brüder, Aldobrandino und Francesco, ${ }^{18}$ die sich gegen die Wahl des Erstgeborenen stellten, da man sich bisher an das langobardische Recht gehalten hatte, das die Aufteilung der Erbschaft auf alle Söhne vorsah. Dieser familiäre Zwist sollte die gesamte Herrschaftszeit von Azzo VIII. prägen. ${ }^{19}$

Azzo VIII. ${ }^{20}$ heiratete I 305 Beatrice von Anjou, Tochter des Königs von Neapel, und ging damit zwar eine gewinnbringende, aber kostspielige und kinderlose Verbindung ein. Sein Vorhaben, den illegitimen Sohn seines natürlichen Sohnes Fresco, ${ }^{21}$ Folco, zum Nachfolger zu machen, löste einen Machtkampf unter seinen Brüdern aus, der auch Venedig und den Papst involvierte. Nach einer Volkserhebung am 22. Juli I3 I7 kamen die Este mit den gemeinsam regierenden Söhnen von Aldobrandino, nämlich Rinaldo, Obizzo und Nicolò und jenen von Francesco, Azzo IX. und Bertoldo, wieder an die Macht. Dies gefiel dem Papst nicht, der über die estensischen Usurpatoren Bann und Interdikt verhängte und die Inquisition einschaltete. ${ }^{22}$

Als dann Kaiser Ludwig der Bayer nach Italien kam, um gegen seinen Feind, Papst Johannes XXII., vorzugehen und die kaiserlichen Rechte auf der italienischen Halbin-

I7 "[...] E quella fronte, ch'ha pel così nero / E`Azzolino; e quell'altro, che è biondo, / È Obizzo da Este, il qual per vero / Fu spento dal figliastro su nel mondo. / [...].« Dante Alighieri, Commedia con il commento di Benvenuto da Imola nella traduzione di Giovanni Tamburi, anast. Auflage der Ausgabe von I 855 - i 856, Imola 2008, Bd. I : Inferno, I 2. Gesang, Verse i Io- I I 2.

i8 Vgl. Gianluca Battioni, »Francesco d'Este«, in: DBI 43, 342-345.

i9 Vgl. Milano, Casa d'Este, r 7-2o.

20 Azzo VIII. wurde nach I 263 geboren und folgte seinem Vater in der Regentschaft I 293. Nach zahlreichen Kämpfen, auch gegen die eigenen Brüder, starb er I 308. Vgl. Trevor Dean, »Azzo d'Este«, in: DBI $43,324-326$.

2i Frescos Geburtsdatum ist unbekannt; er starb I 3 I 2 in Venedig. Vgl. Paolo Bertolini, »Fresco d'Este«, in: DBI 43, 349-359.

22 Rimondi, Estensi, 25 f. 
sel zu bestätigen, verbündeten sich die eigentlich papsttreuen Este - von den jüngsten Entwicklungen veranlasst - mit dem Kaiser, der als Zeichen der Dankbarkeit Rinaldo, Obizzo III. und Nicolò I. belehnte. ${ }^{23}$ Erst I 329 kam es zum Frieden mit dem Heiligen Stuhl und Rinaldo II., ${ }^{24}$ Obizzo III. und Nicolò I. wurden zu päpstlichen Vikaren ernannt. I 5 Jahre lang regierten sie gemeinsam, bis Obizzo III. ${ }^{25}$ - seine Verwandten überlebend - allein regierte. Er hatte aus seiner ersten Ehe mit Elisabeth, einer Tochter Albrechts II. von Sachsen-Wittenberg, keine legitimen Erben und so heiratete er seine Langzeitgeliebte Lippa Ariosti und legitimierte dadurch seine elf Kinder mit ihr. Als er I 352 starb, folgte ihm sein (legitimierter) Sohn Aldobrandino III. ohne Probleme. ${ }^{26}$ Obizzo III. hatte entscheidend zur Etablierung der estensischen Alleinherrschaft beigetragen, indem er einschneidende Veränderungen in den bestehenden Institutionen vorantrieb. Mit seiner Regierung entstand eine erste Form von Bürokratie durch die Schaffung einer Kanzlei Domini Marchonis und innerhalb dieser einer Kammer (Camera), die sich um die Verwaltung und die Finanzen kümmerte. Unter ihm kam es zur Prägung einer ersten estensischen Währung, den sogenannten Ferrarini oder Ferraresi. Damit war die Kontrolle des Fürsten über die Wirtschaft und die Finanzen seines Gebietes erreicht. ${ }^{27}$ Dank seiner reichsnahen Haltung wurde der von seinem Vater legitimierte Aldobrandino III. (reg. I 352- I36r) ${ }^{28}$ I 354 von Karl IV. zum kaiserlichen Vikar von Modena, Adria, Lendinara, Sant'Alberto, Argenta und Comacchio ernannt.

Nach Aldobrandino III. regierte sein von der Gicht geplagte Bruder Nicolò II. (reg. I 36I-I388), ${ }^{29}$ der die politische Vernetzung seiner Familie vor allem durch Heiratspolitik zu intensivieren versuchte, indem er sich an die Scaligeri von Verona und die Malatesta von Rimini band. Um Mailands Macht einzuschränken, setzte er sich für die Rückkehr des Papstes nach Rom ein und reiste dafür I364 sogar selbst nach Avignon, huldigte dem zurückgekehrten Urban V. in Viterbo, gab ihm mit 700 Bewaffneten Geleit und hielt die Zügel des päpstlichen Rosses, als dieser am I6. Oktober I 367 in Rom einzog. Dafür wurden er und seine Söhne zu Gonfalonieri di Santa Romana Chiesa ernannt, ein Titel, den die Este - mit Unterbrechungen - bis zur Devolution führen sollten. Mit Vorsicht und Bedacht erreichte Nicolò II. eine territoriale Vergrößerung seines Herrschaftsgebietes. Von Papst Innozenz VI. und Kaiser Karl IV. wurde er jeweils im Vikariat bestätigt. Intern reformierte er die Verwaltung und führte I 38 I eine neue Währung, die Lira marchesana, ein, was eine starke Unabhängigkeitsbehauptung und Identitätsstiftung für das estensische Herrschaftsgebiet bedeutete. ${ }^{30}$

23 Milano, Casa d'Este, 26.

24 Vgl. Paolo Bertolini, »Rinaldo d'Este«, in: DBI 43, 429-436.

$25 \mathrm{Zu}$ diesem siehe Paolo Bertolini, »Obizzo d'Este«, in: DBI 43, 4I I-429.

26 Rimondi, Estensi, $26 f$.

27 Milano, Casa d'Este, 28.

28 Vgl. Paolo Bertolini, "Aldobrandino d'Este«, in: DBI 43, 303-3 io.

29 Zu seiner Biografie siehe: Antonio Menniti Ippolito, »Nicolò d'Este«, in: DBI 43, 393-396.

30 Rimondi, Estensi, 29. 
In seine Regierung fiel eine sehr düstere und von Überschwemmungen (1362, I369, I3 85 ), wiederholten Hungersnöten und einer Pestseuche (I 382 ) geplagte Zeit, die eine starke Dezimierung der Bevölkerung zur Folge hatte. Trotz dieser Notzeiten wurden die Steuern regelmäßig erhöht. Dies schürte den Zorn der Bevölkerung, die sich schließlich an Nicolòs Berater, den Giudice dei savi, Tommaso da Tortona, rächte. Bei der Stürmung der Kanzlei durch das Volk am 3. Mai I 385 wurde er getötet. ${ }^{31}$ Die Revolteanführer wurden zwar hingerichtet, aber die Steuereintreibung wurde infolgedessen reformiert. Der Aufstand hatte den Este die vom Volk ausgehende Gefahr und die Notwendigkeit eines größeren Schutzes vor den eigenen Untertanen vor Augen geführt. Deshalb lieh sich Nicolò von den Gonzaga 25.00o Dukaten und begann mit dem Bau einer uneinnehmbaren Festung, dem Castello di San Michele (heute Castello Estense), nach dem Plan von Bartolino Ploti da Novara. Die Festung sollte einerseits Schutz vor neuen Revolten gewähren und andererseits ein wahrnehmbares Zeichen der unumstößlichen Herrschaft der Este sein. Weitere bedeutende bauliche Maßnahmen von Nicolò II. waren die Trockenlegung des ferraresischen Umlandes, die Pflasterung von Straßen und der Bau von Plätzen und Gebäuden zur Verschönerung Ferraras. Es lag ihm viel daran, seinen Reichtum und sein Ansehen zu zeigen und einflussreiche Persönlichkeiten, Fürsten, Künstler und Literaten wie Petrarca an seinen Hof einzuladen. ${ }^{32}$

Alberto V. (reg. I388- I 393) ) $^{33}$ war der Bruder und Nachfolger von Nicolò II. und musste sich gegen die Herrschaftsansprüche seines Neffen Obizzo behaupten. Besonders gewinnbringend für seine Beziehungen zum päpstlichen Lehensherrn war seine Pilgerfahrt nach Rom zu Papst Bonifaz IX. im Jahr I39I. Um sich die Unterstützung des Este gegen die kaisertreuen Visconti zu sichern, bedachte der Pontifex Alberto mit zahlreichen Privilegien. Er tilgte alle wegen Nichtbezahlung des jährlichen Lehenszinses angehäuften Schulden der Este bei der Apostolischen Kammer und gewährte das Privileg des freien Handels und die Befreiung von Veräußerungs- und Erbschaftshindernissen auf kirchlichen Besitzungen. Mit der Bulle In supreme dignitatis wurde zudem die Gründung der Universität in Ferrara mit allen Fakultäten festgelegt. In Ferrara zurückgekehrt, ließ Alberto verschiedene Prestigeobjekte wie Palazzo Paradiso oder Palazzo Schifanoia errichten. Als er I 393 starb, bestimmte er seinen natürlichen, vom Papst legitimierten, aber erst zehnjährigen Sohn Nicolò III. (reg. I 393- I 44I ${ }^{34}$ zum Nachfolger. ${ }^{35}$ Dieser kam zunächst unter die Vormundschaft eines Herrschaftsrates, dem nach den Vorgaben des Verstorbenen Mitglieder der führenden ferraresischen Adelsfamilien angehörten. Der junge Fürst, für den sein Vater eine besondere

\footnotetext{
3i Vgl. Easton Law, Popular Unrest.

32 Milano, Casa d'Este, $30-32$.

33 Vgl. Antonio Menniti Ippolito, "Alberto d'Este«, in: DBI 43, 294-297.

$34 \mathrm{Zu}$ diesem vgl. Antonio Menniti Ippolito, "Nicolò d'Este«, in: DBI 43, 396-403.

35 Rimondi, Estensi, 33 f.
} 
humanistische Ausbildung verlangt hatte, und der Rat hatten mit großen finanziellen Schwierigkeiten zu kämpfen. Die Vorgänger hatten nämlich viele Schulden angehäuft; den Gonzaga allein schuldeten die Este mittlerweile 44.00o Dukaten für den Bau des Castello. Vorrangiges Ziel dieser Ratsregierung war es, die Ausgaben zu reduzieren, sodass die neu entstandene Universität kurzerhand wieder geschlossen wurde. Zu diesen internen Problemen kam ein Umsturzversuch durch den verschwägerten Francesco Novello da Carrara, Herr über Padua, bei dem die Este ebenso Schulden hatten. Auch ein Vetter namens Azzo versuchte Nicolò III. die Herrschaft streitig zu machen. Erst I 395 schaffte es das Heer des Stadtrates, den angriffslustigen Azzo zu besiegen, allerdings nicht ohne die Hilfe Venedigs. Dafür erhielt die Serenissima das gesamte Polesine di Rovigo als Pfand und Azzo als Geisel. 1397 heiratete Nicolò III. Gigliola da Carrara, Tochter des oben genannten Francesco Novello, mit dem - allerdings erfolglosen - Ziel, den Konkurrenten durch Heiratsverbindung im Zaum zu halten. Erst nach und nach schaffte es Nicolò, die Paduaner endgültig aus Ferrara zu vertreiben und die Mitglieder des Rates durch seine Vertrauensmänner zu ersetzen, sodass er bis 1402 daraus einen Geheimen Rat mit ausschließlicher Beratungsfunktion gemacht hatte. Gleichzeitig eröffnete er wieder die Universität. Nicolòs Aufmerksamkeit konzentrierte sich auf die südliche Grenze seines Fürstentums, wo sich mit Reggio und Parma unter Ottobuono de'Terzi, der nun Modena bedrohte, ein neues Herrschaftsgebiet aufgetan hatte. Nicolò gelang es mithilfe seines Freundes, Muzio Attendolo Sforza, Ottobuono durch einen Hinterhalt zu ermorden und das bereits 1306 verloren gegangene Reggio zurückzugewinnen. Nach diesen kriegerischen Aktionen wandte er sich einer auf Diplomatie basierenden, dem Frieden gewidmeten Gleichgewichtspolitik zu. Sein persönlicher Erfolg war die Wahl Ferraras als Austragungsort des von Papst Eugen IV. einberufenen ökumenischen Konzils von I438. Die Stadt wurde für die Dauer des Ereignisses zum wichtigsten kulturellen und politischen Zentrum Italiens. Als allerdings offiziell durch eine Pestwelle und inoffiziell durch die Geldknappheit ${ }^{36}$ das Konzil nach einiger Zeit nach Florenz verlegt werden musste, waren die Este nicht wenig erfreut, verschlang doch solch ein Ereignis Unmengen an Geld. Bereits hier stellten die Medici mit ihren finanziellen Ressourcen die Este in den Schatten. Dennoch war das erste Konzilsjahr für die Herren von Ferrara ein bedeutender politischer Akt gewesen.

Unter Nicolò III. kam es auch zu einer Erweiterung des Territoriums ohne Blutvergießen, als sich ihm I 430 die toskanische Provinz Garfagnana freiwillig unterwarf, die ihm drei Jahre später von Kaiser Sigismund als Vikariatslehen bestätigt wurde. Vom Heiligen Stuhl wurde ihm zeitgleich Lugo wieder zugeteilt. Außerdem wurde der Lehenszins für das Vikariat Ferrara von I0.000 auf 4.000 Gulden herabgesetzt.

War sein Vater »nur « nach Rom gepilgert, so übertraf ihn Nicolò in seiner zur Schau gestellten Frömmigkeit mit einer Pilgerreise ins Heilige Land I4I 3 und zum Wall-

36 Peverada, Istituzioni ecclesiastiche, 32 If. 
fahrtsort Saint Antoine de Vienne I 4I $4 .{ }^{37}$ I 429 hatte er von Papst Martin V. die Legitimierung seines Sohnes Leonello (reg. I44 I - I 450), ${ }^{38}$ den er mit Stella dei Tolomei hatte, erhalten und bestimmte ihn daraufhin zum Nachfolger. I 43 I erhielt er vom französischen König Karl VII. als Zeichen seiner Verbundenheit mit der französischen Krone das Privileg, seinem Wappen drei goldene Lilien auf blauem Feld hinzuzufügen. Als großer Mäzen ließ er in Flandern Sänger und Musiker für den ferraresischen Hof rekrutieren. So avancierte Ferrara unter ihm zu einer der prestigeträchtigsten Hauptstädte der italienischen Renaissance. ${ }^{39}$ Nicolò III. d'Este war auch der Erbauer von verschiedenen Delizie, Lustschlössern und Ansitzen mit großen Gärten bzw. landwirtschaftlichen Betrieben inner- und außerhalb der Stadtmauern. Die etwas mehr als $20 \mathrm{~km}$ von Ferrara entfernte, von ihm in Auftrag gegebene Delizia di Consandolo war so prächtig, dass sie eine würdige Unterkunft für Kaiser Friedrich III. und eine ständige Residenz für die Königstochter Renée de France darstellen sollte. ${ }^{40}$

Sein designierter Nachfolger Leonello war militärisch durch den condottiere Braccio da Montone ${ }^{41}$ und humanistisch durch Guarino Guarini da Verona ${ }^{42}$ im Sinne der harmonischen Entwicklung von Körper und Geist ausgebildet worden. I 435 heiratete er die durch Vittorino da Feltre ${ }^{43}$ ebenso hervorragend ausgebildete Margherita Gonzaga, um - der Heiratspolitik seines Vaters folgend - die Beziehungen mit den Mantuanern zu intensivieren und einen Schuldenerlass im Zuge der Mitgiftverhandlungen $\mathrm{zu}$ erzielen. Als Leonello an die Macht kam, versuchte er seine Brüder mit Verwaltungsaufgaben in Schach zu halten: Borso wurde Statthalter des Polesine, während die legitimen Kinder Nicolòs, Ercole und Sigismondo, zur Ausbildung an den weit entfernten neapolitanischen Hof geschickt wurden. Leonello betrieb ebenso wie seine Vorgänger eine Gleichgewichtspolitik und machte sein Fürstentum zur Vermittlerinstanz zwischen Venedig, Mailand, Mantua, dem Papst und den auf den neapolitanischen Thron gelangten Aragonesen. Dem neapolitanischen Hof näherte er sich nicht nur durch seine Stiefbrüder, sondern auch indem er in zweiter Ehe I 444 Bianca Maria von Aragón, Tochter des Königs von Neapel, Sizilien und Sardinien ehelichte. Innerhalb seines Fürstentums setzte Leonello die wichtigen Bonifizierungsarbeiten

37 Rimondi, Estensi, 35-50.

38 Vgl. Giampiero Brunelli, „Leonello d'Este«, in: DBI 43, 374-380; Chiappini, Gli Estensi, Kap. V: »Leonello«, I03- I 8.

39 Milano, Casa d'Este 39-4I.

40 Olivato/Barbieri, Ferrara: Un'urbanistica ricorsiva, i $8 f$.

4I Vgl. Pier Luigi Falaschi, »Fortebracci, Andrea«, in: DBI 49 Roma I 997, online verfügbar: http://www. treccani.it/enciclopedia/andrea-fortebracci_\%28Dizionario-Biografico \%29/, Zugriff: 16.9.2020.

$42 \mathrm{Zu}$ diesem Griechischlehrer, Fürstenerzieher und Universitätsdozent siehe: Gino Pistilli, „Guarini, Guarino«, in: DBI 6o, Roma 2003, online verfügbar: http://www.treccani.it/enciclopedia/guarino-guarini_\%28Dizionario-Biografico \%29/, Zugriff: I6.9.2020.

$43 \mathrm{Zu}$ diesem Erzieher von Fürstinnen und Fürsten sowie Rhetorikprofessor mit eigentlichem Namen Vittorino Rambaldoni siehe den Artikel unter http://www.treccani.it/enciclopedia/vittorino-da-feltre/, Zugriff: 16.9 .2020 . 
seiner Vorgänger fort, ließ die Ufer befestigen und die Binnenschifffahrt ausbauen. Er gründete in Ferrara das erste städtische Hospital, das Ospedale di Sant'Anna. Mit seinem Lehrer Guarino scharte er einen Kreis von bereits renommierten Künstlern (Antonio Pisanello, Giovanni Bellini, Mantegna, Rogier van der Weyden, Piero della Francesca $)^{44}$ um sich, die seinen Hof mit ihren Werken zierten. Eine enge Freundschaft verband ihn mit dem Florentiner Architekten, Maler und Theoretiker Leon Battista Alberti, der mit seiner Unterstützung das berühmte De re aedificatoria verfasste. Darin beschäftigte sich der Gelehrte gerade aufgrund auch mit den Techniken der Wasserregulierung, mit der Kontrolle über die Gewässer, Kanalisationen, Uferverbauungen, Brunnen, $\mathrm{Zu}$ - und Abflüssen, Trockenlegungs- und Überflutungsmaßnahmen, worüber er nicht zuletzt in Ferrara Erfahrungen gesammelt hatte. ${ }^{45}$

Neben der Verschönerung der Ansitze, Delizia di Belriguardo und Delizia Belfiore, errichtete Leonello ein studiolo, das alle Vorstellungen des idealen Rückzugsorts eines gebildeten Renaissancefürsten übertraf. ${ }^{46}$ Unter seiner Herrschaft erlebte auch die Universität neue Impulse und wurde zum Anziehungspunkt für Studierende aus dem Reich, so wie aus England, Ungarn und Polen. Das Studio di Ferrara stand den Hochschulen in Padua und Bologna in nichts nach, auch weil Leonello sich bemühte, anerkannte Dozenten wie Angelo degli Ubaldi für Zivilrecht, Francesco Accolti für das Kanonische Recht, Michele Savonarola für Medizin, Guarino Veronese für Latein und Theodor Gaza für Griechisch nach Ferrara zu holen. Dank seiner Ausbildung machte der Este mit Literaten wie Matteo Maria Boiardo und Ludovico Ariosto seinen Hof in Ferrara zu einem Zentrum der italienischen literarischen Elite, der philologischen und linguistischen Studien und der Ritterepik. ${ }^{47}$

\subsection{Die Herzöge von Ferrara, Modena und Reggio}

\subsubsection{Borso (reg. 1450-1471)}

Als Leonello I 450 überraschend starb, hinterließ er ungeordnete Nachfolgeverhältnisse: Der eigentliche Nachfolger Nicolò ${ }^{48}$ war erst ro Jahre alt und dessen Stiefbruder

44 Vgl. FABer, Ercole II., 27-36, wo die Autorin auf die Bedeutung der Vorgänger Ercoles II., Leonello, Borso und Ercole I. als Mäzene eingeht.

45 Donattini, Cultura geografica, 423. Nach den Este, d.h. nach der Einverleibung Ferraras in den Kirchenstaat sollten die Päpste als neue Landesherren mit diesen Problemen der Versandung, Überflutung und Regulierung konfrontiert sein, wie Birgit Emich in ihrer Untersuchung ab I6oo bereits aufgezeigt hat. Емісн, Territoriale Integration, besonders Kap. III., I77-365 und Dies., Mit Luhmann im Kirchenstaat. Zur Frührenaissance in Ferrara einige Hinweise auch bei Burke, Die europäische Renaissance, 64-69.

46 Liebenwein, Lo studiolo.

47 Varese, Il sistema delle »delizie«. Rosenberg, Arte e politica.

48 Vgl. zu diesem Nadia Convini, »Nicolò d'Este«, in: DBI 43, 403-405. 
Ercole, der legitime Sohn Nicolòs III., hielt sich am neapolitanischen Hof auf. Die Eile und Notwendigkeit, die Vakanz zu schließen, führten zur Wahl von Borso, ${ }^{49}$ Bruder des Verstorbenen und ebenso illegitim Geborener. Er war schon früh zur militärischen Laufbahn bestimmt worden und hatte unter der Serenissima und unter den Visconti gedient, ohne sich jedoch als condottiere einen Namen zu machen. I44 I war er an den estensischen Hof zurückgekehrt und hatte für den Bruder, dem er als Berater zur Seite stand, wichtige Verwaltungs- und diplomatische Aufgaben übernommen. Für seine Wahl sprachen von Anfang an sein guter Ruf, eine breite ihn unterstützende Gruppierung am Hof, seine Regierungs-, militärische und diplomatische Erfahrung durch die enge Zusammenarbeit mit seinem Bruder und sein reifes Alter. ${ }^{50}$ Die »Wahl« des ferraresischen Volkes wurde kurz darauf von Papst Nikolaus V. bestätigt und die Nachfolge sogar auf Borsos legitimen oder legitimierten Nachkommen ausgedehnt, was alle Bestimmungen des päpstlichen Vorgängers zunichtemachte.

Borso hegte von Anfang an den Wunsch, sein Territorium zu vergrößern, wofür er die Gleichgewichtspolitik seiner Vorgänger aufgab. Er stellte sich gegen die Sforza auf die Seite Venedigs, das er oft besuchte. Als Alfonso von Aragón, der sich Mailand angenähert hatte, starb, unterstützte Borso die Nachfolge von Johann von Anjou gegen Ferrante, Sohn des Verstorbenen. Dabei ging er auch arglistig vor, indem er seinen am aragonesischen Hof aufgewachsenen Halbbruder Ercole überredete, den Freund und rechtmäßigen Nachfolger Ferrante zu verraten und auf die Seite des Anjou zu wechseln. Daraufhin schickte er dem Betrogenen eine Gesandtschaft, die seine Entrüstung über das »treulose Verhalten« seines Halbbruders zum Ausdruck brachte. Auch als in Florenz Cosimo der Ältere starb und sich eine Partei gegen die Medici unter Luca Pitti bildete, unterstützte Borso diese im Versuch der gewaltsamen Eliminierung von Piero de'Medici.

Berühmt wurde der Markgraf von Ferrara, Modena und Reggio nicht nur wegen seines Ehrgeizes, sondern auch wegen seiner Eitelkeit, die sich in der ständigen Suche nach Titeln und Ehren niederschlug. I 452 erlebte er die höchste Auszeichnung und einen großen persönlichen Erfolg, als Kaiser Friedrich III., Feind der Sforza, auf dem Weg nach Rom in Ferrara Halt machte. Um die Este noch enger an das Reich zu binden, aber vor allem aufgrund der Fürsprache seines Beraters Enea Silvio Piccolomini, ${ }^{51}$ der mit Borso befreundet war, gewährte der Kaiser dem Este den Titel eines Herzogs von Modena und Reggio und stellte ihn dadurch auf die gleiche Stufe mit den großen Fürsten des Reiches. ${ }^{52}$ Bedeutend war die Erweiterung des estensischen Wappens: Dieses bestand aus vier Feldern: heraldisch oben rechts und unten links stand nun der

49 Chiappini, »Borso«; Rimondi, Estensi, 57-6o. Milano, Casa d’Este, 4i-45. Alfonso Lazzari, Borso d'Este, il primo duca di Ferrara, Ferrara I 945.

50 Chiappini, »Borso«; Milano, Casa d'Este, 46.

5 I $\mathrm{Zu}$ diesem vor allem als späteren Papst Pius II. siehe letztens Reinhardt, Pius II.

52 Chiappini, »Borso«; Rimondi, Estensi, 62-64; Milano, Casa d'Este, 49. 
schwarze Doppeladler auf goldenem Feld, der den ursprünglichen weißen Adler auf blauem Feld verdrängt hatte und in den anderen Feldern die französischen Lilien, die Karl VI. I 4I 4 Nicolò d'Este verliehen hatte. I 474 kamen durch Papst Sixtus IV. die Petrusschlüssel hinzu, ${ }^{53}$ nachdem Borso am Osterfest I 47 I in Rom zum Herzog von Ferrara erhoben worden war. ${ }^{54}$

Die beiden Investituren lagen nicht nur I 9 Jahre auseinander, sondern waren sehr unterschiedlich: Borso war in der Hauptstadt des päpstlichen Lehens Ferrara zum Herzog über die kaiserlichen Lehen Modena und Reggio erhoben worden und erst im Nachhinein in die betreffenden Städte zur Huldigung gereist, während er für die Erhebung Ferraras selbst ins Zentrum der päpstlichen Macht nach Rom reisen musste. Diese zweite Erhebung war außerdem nur mit dem Privileg, sich Herzog nennen zu dürfen, verbunden, also nur ein (noch) nicht übertragbarer Ehrentitel, während die kaiserliche Erhebung auch auf die Nachkommen vererbbar war.

Neben diesen herrschaftlichen Errungenschaften wurde Borso durch die Ausschmückung des Palazzo Schifanoia mit der Sala dei Mesi berühmt, an der Künstler wie Ercole de'Roberti und Francesco del Cossa ${ }^{55}$ beteiligt waren. Borso war auch am wirtschaftlichen Wachstum seines Fürstentums interessiert und veranlasste wichtige Maßnahmen für die Verbesserung der Verteidigungsanlage und die Trockenlegung der Sumpflandschaft. ${ }^{56}$

1.2.2 Ercole I. (reg. 1471-1505)

Borso hatte von Kaiser Friedrich III. nicht nur die Herzogswürde, sondern auch das Recht erhalten, seinen Nachfolger für Modena und Reggio zu ernennen. Da er nicht die Absicht hegte, eine Heiratsverbindung einzugehen, bestimmte er bereits I46I, zehn Jahre vor seinem Tod, seinen I43 I aus der ehelichen Verbindung von Nicolò III. und Rizzarda di Tommaso di Saluzzo hervorgegangenen Halbbruder Ercole I. dazu. Diesem hatte er bereits die Führung Modenas übertragen und mit Venedig eine Anstellung als Heeresführer für ihn ausgehandelt.

Ercole war am aragonesischen Hof von Neapel aufgewachsen. Seinen auf Borsos Geheiß vollzogenen Verrat durch die Unterstützung der Anjou glich er mit seiner Heirat mit

53 Tor воli, L'araldica estense, 88f. In anderen heraldischen Darstellungen ist der Adler geteilt, d.h. eine Hälfte ist schwarz auf goldenem Feld, die andere Hälfte weiß/silber auf blauem Feld. Eine besonders schöne Darstellung des Wappens ist im Beitrag von Prosperi, Histoire, 3 I abgebildet.

54 Chiappini, »Borso«; Rimondi, Estensi, 66-68. Im Zuge der Erhebung zum Herzog von Ferrara übergab Papst Paul II. Borso d'Este am Ostermontag die Goldene Rose, nachdem er ihn am Tag zuvor mit Schwert, Hut und Sporen beschenkt hatte. Zu dieser Verleihung der päpstlichen Auszeichnung und den folgenden siehe: Cornides, Rose und Schwert, 87f, 96, го3-i i 6.

$55 \mathrm{Zu}$ den beiden siehe die Kurzbiografien von Jürgen Goтtschalk In: Weber, Il trionfo di Bacco, I $65-$ r 68 .

56 Bocchi, Gli Estensi, 339 f. Rimondi, Estensi, 5o, Milano, Casa d’Este, 48 - 50. 
Eleonora von Aragón, Tochter von König Ferrante, wieder aus. Dadurch entfernte sich Ercole, der als junger condottiere im Dienst der Serenissima gestanden hatte, wieder von Venedig und legte den Grundstein für die jahrzehntelange Feindschaft zwischen Ferrara und Venedig. Angetrieben wurde er von der nicht unbegründeten Befürchtung einer wirtschaftlichen und dann territorialen Vereinnahmung durch die Lagunenstadt. Tatsächlich griff Venedig mit päpstlicher Zustimmung I 482-84 Ferrara an und nahm sich im Frieden von Bagnolo das Polesine di Rovigo. Nach diesem Krieg erkannte Ercole die Notwendigkeit einer Allianz mit benachbarten und vor allem einflussreichen Fürstenhäusern durch eine strategisch kluge Heiratspolitik. So verheiratete er seine illegitime Tochter Lucrezia mit Annibale Bentivoglio, Sohn des Herrn von Bologna. Seine Töchter Isabella und Beatrice wurden jeweils mit Francesco Gonzaga und Ludovico Sforza, genannt il Moro, verheiratet. Sein Sohn Alfonso heiratete Anna Sforza, Tochter von Galeazzo Maria. Darüber hinaus festigte er die estensische Präsenz an bedeutenden kirchlichen Stellen: für Nicolò Maria d'Este, Sohn von Gurone, erlangte er das Bistum Adria, während sein zweiter Sohn Ippolito mit Unterstützung von Kardinal Ascanio Sforza als Achtjähriger Erzbischof von Ezstergom in Ungarn und kurz danach zum Kardinal ernannt wurde. ${ }^{57}$

Eine weitere Maßnahme, um sein Herzogtum und seine Position als Fürst zu stärken, war die Befestigung und Erweiterung des Machtzentrums Ferrara durch die additio erculea. Es handelte sich dabei um eine I 490 durch Enteignung und Umwidmung von Flächen nahe dem mittelalterlichen Stadtkern begonnene Stadterweiterung, -verschönerung und Befestigung. ${ }^{58}$ In weniger als zehn Jahren wurden im neu gewonnenen Raum, der Terran(u)ova, ${ }^{59}$ nach dem akkuraten Plan des Architekten Biagio Rossetti ${ }^{60}$ zwanzig Paläste und zwölf Kirchen erbaut. Die Erweiterung sollte Platz für mehr Bewohner bieten; Ferrara zählte nach der additio tatsächlich zu den größten (und modernsten) Städten Italiens. Mit dieser »Ansiedlungspolitik« verfolgte Ercole I. natürlich das Ziel, dass die militärische Schwäche mit der Vergrößerung seines bescheidenen Staates und mit dem Ruf der Unangreifbarkeit der neuen Stadtbefestigung ${ }^{61}$ ausgeglichen werden sollte. Es handelte sich hier somit um mehr als die »standardmäßige« Modernisierung, von der auch andere mittelalterliche Städte wie Rom, Urbino, Florenz und Ferrara selbst unter Ercoles Vorgänger betroffen gewesen waren. ${ }^{62}$ Hier bemühte

57 Chiappini, Gli Estensi, I44-i65, i 7of; Milano, Casa d’Este, 55 ; Dean, »Ercole I.«.

58 Vgl. dazu Taddei, Optimo architecto.

59 Bоссні, La »Terranova«.

60 Zum Architekten und herzoglichen Ingenieur Biagio Rossetti (I447- I 5 I6) siehe: Zevi, Biagio Rossetti.

6r Tatsächlich aber fiel diese nicht so imposant aus, dass sie einen potenziellen Angreifer abgeschreckt hätte. Dies ist mitunter auch ein Beweis dafür, dass die Begründung für das Bauvorhaben, die Stadt benötige eine bessere, vor allem gegen Venedig gerichtete Verteidigungsanlage, eher dazu diente, die für den Bau notwendigen Steuereintreibungen "für das Wohl aller« zu erleichtern. Toffanello, Ferrara, Io7- I I I. BAssi, Perché Ferrara è bella, 232-240. ZEvi, Saper vedere l'urbanistica.

62 Vgl. dazu: Benevolo, La città, 96- io i mit einem Plan der Stadterweiterungen. Tuohy, Herculean Ferrara. 
man sich nun mit einer Neuplanung und gezielten Urbanistik, auch die Funktionalität und Symbolkraft von neuralgischen Punkten der Stadt zu verstärken. Die bisherige Geschichtsschreibung und allen voran Thomas Tuohy ${ }^{63}$ haben bereits glaubhaft belegen können, dass diese einzigartige Stadterweiterung und -regulierung das langwierige und viel diskutierte Produkt von mehreren Köpfen war und dass Ercole I. selbst maßgeblich daran beteiligt gewesen ist. Diese Beschäftigung mit der Baukunst, die in Ferrara spätestens seit der Zusammenarbeit von Ercoles Vater Leonello mit Leon Battista A1berti anlässlich der Planung des Glockenturms der Kathedrale ${ }^{64}$ als die edelste aller Künste galt, brachte dem Este über sein Fürstentum hinausreichende Bekanntheit ein, da andere Fürsten in dieser Materie Rat und Unterstützung bei ihm einholten. Rossetti brachte hier vor allem sein technisches Wissen ein, während der von Ercole überaus geschätzte Hofhistoriker und Astrologe Pellegrino Prisciani ${ }^{65}$ mit einem auf den Werken von Alberti und Vitruv ${ }^{66}$ basierenden theoretischen Hintergrund zur Ideenfindung beitrug; auch beriet er den Fürsten mit seinen Kenntnissen über die Möglichkeiten der Repräsentation fürstlicher Größe und gleichzeitiger Volkserziehung und -belustigung in einer anderen der Architektur nahen Kunst, nämlich jener der Theaterinszenierungen und Bühnendarstellungen. ${ }^{67}$

Neben den Bauprojekten verschlangen auch andere kulturelle Aktivitäten und Vergnügungen sowie zahlreiche Reisen ${ }^{68}$ Unmengen an Geld. Vor allem anlässlich großer Feierlichkeiten oder des Karnevals ließ Ercole Theaterstücke ${ }^{69}$ aufführen. Auch diese mit der Architektur eng verbundene Theaterkunst diente der politischen Repräsentation und zog Fürsten und Besucher aus ganz Norditalien an. ${ }^{70}$

Ercole war mehr ein Bauherr als ein Staatsmann und erkannte nicht die schwerwiegenden Folgen eines derartigen finanziellen Aderlasses; die Bewältigung von Staatsgeschäften, Beschwerden, Entscheidungen überließ er zum Großteil seiner fähigen

63 Tuону, Herculean Ferrara.

64 Chiappini, Ferrara, 27. Marino, L'architettura, 37of.

65 Pellegrino Prisciani (I 435 ca.- I 5 I 8), Hofsekretär, Verwalter, Geheimer Rat, Gesandter, Archivar, conservator jurium der Kommune und der herzoglichen Kammer, Bibliothekar, Hofhistoriker und -astrologe. Dazu siehe: Franco Pignatti Morano di Custoza, »Pellegrino Prisciani«, in: Letteratura Italiana. Gli Autori. Dizionario bio-bibliografico e Indici 2, Tornio i 99 I. I 45 If; Bertozzi, L'astrologia a corte. Pellegrino Prisciani hatte öffentliche Ämter und Funktionen außerhalb Ferraras inne, wie z.B. das des podestà von Massalombarda. Sein bekanntestes Werk sind die Ferrariensium Historiarum et Antiquitatum libri, eines der ersten ferraresischen Geschichtswerke, das sich mit dem Po und den Gewässern im estensischen Territorium beschäftigt. Donattini, Cultura geografica, 4I 4 .

66 Siehe auch: Molinari, Il teatro.

$67 \mathrm{Vgl}$. Toffanello, Ferrara, 7If, 79-8I.

68 Er kam nach Bologna, Venedig, Florenz, Siena, Pienza, Orvieto, Rom, Gubbio, Urbino, Pesaro und Rimini. Sein Interesse galt vor allem den Befestigungsanlagen und Klöstern. Folin, L'architettura, 65.

69 Dazu siehe auch das Kapitel über das Theater bei Тчонy, Herculean Ferrara, 257-264.

70 DeAn, »Ercole I.«. Ercole I. liebte es, seine additio und die neuen oder erneuerten palazzi den Gesandten und anderen Fürsten zu zeigen und sie hier unterzubringen. Siehe Farinelli Toselli, Il Palazzo, 38. 
Gemahlin Eleonora, deren Tod im Oktober I493 ihn nicht nur persönlich traf, sondern auch die Führung des Fürstentums beeinträchtigte. ${ }^{71}$ Diese Heirat mit der aragonesischen Königstochter hatte dem Este nicht nur einen großen Prestigezuwachs wegen des Ranges der Braut eingebracht, sondern auch eine fähige Verwalterin und Mitregentin. Vor allem kontrollierte sie persönlich die Beamten, Funktionäre und die Finanzen des Herzogtums. War Ercole außer Landes, wurde er von Eleonora durch eine regelmäßige Berichterstattung auf dem Laufenden gehalten. ${ }^{72}$ Auch kümmerte sie sich um das Hofleben und scharte einen Kreis von Gelehrten und Künstlern um sich.

Im letzten Abschnitt der Regentschaft Ercoles I. brach eine instabile Zeit an, nachdem der über die Maßen simonistische und nepotistische Papst Alexander VI. Borgia auf den Stuhl Petri kam und der französische König Charles VIII. I 494 einen Italienzug startete, um Neapel zurückzugewinnen. Er wurde auch von Ercole I. willkommen geheißen, der sich mit allen Parteien gut stellen wollte. Auch als sich der französische König wieder zurückzog, sicherte sich Ercole weiterhin dadurch ab, dass er einen Sohn, Alfonso, in den Dienst der antifranzösischen Liga und den anderen, Ferrante ${ }^{73}$, in jenen des französischen Königs stellte. Selbst das problematische Heiratsangebot aus Rom schlug er für seinen Ältesten nicht ab, um sein Fürstentum vor dem Vormarsch der Borgia zu schützen. Zwar war die Heirat mit der Papsttochter, Lucrezia Borgia, wegen des Rufes der Braut nicht verlockend, doch der König von Frankreich unterstützte diese Verbindung, und die außergewöhnliche Mitgift sowie die in Aussicht gestellte Reduzierung des Lehenszinses überzeugten den Este. ${ }^{74}$ Für den Papst bedeutete diese Verbindung, einen Verbündeten gegen Venedig und eine gute Partie für die zu Recht oder Unrecht in Ungnade gefallene Tochter gefunden zu haben. Für die Este bedeutete die Heirat eine Unterstützung gegen Venedig, die Verschonung von den Expansionsgelüsten des Papstsohnes Cesare Borgia und eine Bereicherung aufgrund der überaus großzügigen Mitgift der Braut. ${ }^{75}$

\subsubsection{Alfonso I. (reg. 1505-1534)}

Der I 476 als erster Sohn von Ercole I. und Eleonora von Aragón geborene Alfonso I. ${ }^{76}$ ehrte mit seinem Namen den königlichen Großvater mütterlicherseits. Bei seinem

\footnotetext{
7i Chiappini, Gli Estensi, i77-i83.

72 Eleonora kann in diesem Sinn sicher als ein leuchtendes Beispiel für das von Katrin Keller letztens hervorgehobene Phänomen von im Rahmen des Hofes politisch aktiven Frauen gesehen werden. KelLer, Mit den Mitteln einer Frau, 226.

$73 \mathrm{Zu}$ diesem zweiten Sohn von Ercole I. und Eleonora von Aragón, I 477 geboren, zuerst in französischem, dann venezianischem militärischem Dienst tätig siehe Paolo Portone, »Ferrante d'Este«, in: DBI 43, $337-339$.

74 Vgl. Rimondi, Estensi, $76-87$.

75 Vgl. Chiappini, Gli Estensi, I83-i 89.

76 Quazza, »Alfonso I«. Zu Alfonso I. gibt es einige frühe Versuche einer Biografie: Cronica Estense di
} 
Herrschaftsantritt hatte sich Alfonso bis dahin weder militärisch noch intellektuell hervorgetan, sondern war nur als »tüchtiger Handwerker« aufgefallen. Seit seiner Jugend hatte er sich anscheinend ungern und wenig mit den literarischen Fächern auseinandergesetzt und sich mehr der Arbeit an der Drechselbank, den verschiedenen Methoden der Bronzeherstellung und der Entwicklung von immer fortschrittlicheren Feuerwaffen gewidmet. ${ }^{77}$ Trotz seines Hangs zu diesen Handwerkskünsten und seiner wahrscheinlich bescheideneren humanistischen Ausbildung war er ein großer Mäzen von Literaten und Künstlern. ${ }^{78}$ Nach seiner Inthronisation führte Alfonso eine Reihe von klugen Neuerungen ein, um die finanziellen Defizite aus den früheren Regentschaften auszugleichen. Sofort wurde der Ämterverkauf gestoppt, viele Zölle und Steuern seines Vaters wurden wieder abgeschafft, verhasste Steuereintreiber und Funktionäre entlassen und den Strozzi das Monopol über die Salinen von Comacchio und die Fischereirechte dort entzogen, sodass die herzogliche Kammer wieder auf zwei ertragreiche Einnahmequellen zurückgreifen konnte. ${ }^{79}$

Eine bedeutende Maßnahme zur Festigung seiner Macht war - neben der Eindämmung des Handlungsspielraums der kleinen Vasallen im estensischen Fürstentum eine starke und vor allem innovative Bewaffnung. Unter Alfonso I. gelangte die estensische Feuerwaffenherstellung zu einem Höhepunkt, die selbst die großen innovativen Produktionsstätten der Serenissima und Frankreichs überholte. ${ }^{80}$ Als er sich I 5 Io an die Rückeroberung des an Venedig verloren gegangenen Gebietes Polesine machte, hatte er bereits zwei seiner Erfindungen, die Kanonen Gran Diavolo und Terremoto dabei. Zu diesen Schmuckstücken der Feuerwaffenkunst kam kurz darauf die Kanone La Giulia hinzu. ${ }^{81}$ Dieser Name kam nicht von ungefähr und spielte natürlich auf

Fra Paolo da Lignago de'Frati Camelitani di S. Polo, ASMo, Biblioteca Manoscritti ms. 69, I73-235; Paolo Giovio, La vita di Alfonso da Este, duca di Ferrara ..., Firenze 1553.

77 Zur Bedeutung der künstlerischen und technischen Fertigkeiten und Tätigkeiten von Fürstinnen und Fürsten siehe die Beiträge im Tagungsband Fürst als Künstler.

78 Immer noch brauchbar in diesem Zusammenhang sind: Campori, Gli artisti italiani; Franceschini, Artisti a Ferrara. Ceriana, Gli Este. Im Zuge der Ausstellung zum Renaissancehof der Este im Castello Estense wurde erstmalig das studiolo von Alfonso I. mit den 34 Marmorreliefs aus der Ermitage von Sankt Petersburg, dem Louvre und der Liechtenstein-Sammlung wiederhergestellt. Siehe auch Borella, Il Palazzo di Corte, 20-22. Hope, Les »Camerini d'Alabastro«.

79 Rimondi, Estensi, 99.

8o Vgl. TaddeI, Optimo architecto. Alfonso I. hatte als besondere impresa, als Erkennungszeichen, die Darstellung einer verpuffenden Granate (granata svampante) als Hinweis auf seine militärtechnischen Fähigkeiten und auf seine europaweit bekannte Artillerie. Di Pietro Lombardi, Le imprese estensi, 2 I2. Die Waffenproduktion war Aufgabe des Fürsten/Staates und diente nicht nur der eigenen Verteidigung, sondern auch dem gewinnbringenden Handel, da die meisten europäischen Fürsten ihre Waffen, Rüstungen und insbesondere Feuerwaffen aus Frankreich oder Norditalien bezogen. Besonders in der zweiten Hälfte des r6. Jahrhunderts lässt sich in den Quellen der Austausch von Waffen und von waffenkundigen Handwerkern zwischen Ferrara und dem Reich nachweisen. Siehe auch Locatelli, La fabbrica, I $8-26$.

8i Locatelli, La fabbrica, $38 f$. 
den kriegerisch und expansionistisch gesinnten Papst Julius II. an, der Alfonso für viele Jahre sein Herzogtum entrissen hatte. Ein ähnliches Schicksal erlitten die Bentivoglio $^{82}$ in Bologna unter diesem Kirchenoberhaupt, tituliert "secondo faraone ", ${ }^{83}$ die ihre Stadt aber wenigstens für kurze Zeit aus der päpstlichen Besetzung befreien konnten, bevor sie dann ab I 507 endgültig dem Kirchenstaat einverleibt wurde. Im Zuge dieser kurzzeitigen Zurückdrängung der päpstlichen Truppen zerstörte das wütende Volk die von Michelangelo geschaffene $3 \mathrm{~m}$ hohe und I $7.000 \mathrm{~kg}$ schwere, über dem Kirchenportal angebrachte Bronzestatue von Julius II., die den majestätisch sitzenden Papst mit Robe und Zepter, mit einer Hand die Schlüssel greifend und die andere in einer Geste der Segnung und des Kommandos ausgestreckt, zeigte. ${ }^{84} \mathrm{Al}-$ fonso I. tauschte nach der Volkserhebung die Trümmer der Statue gegen Feuerwaffen ein; dabei war er nicht nur am wertvollen Rohmaterial interessiert, sondern am symbolischen Wert des erstandenen Kunstwerks, aus dem er eine Kanone goss, die er fortan La Giulia nannte. ${ }^{85}$

Innenpolitisch bemühte sich Alfonso I. um Absicherung, indem er seine Brüder in die Regierung miteinbezog bzw. großzügig versorgte: Ippolito, für den eine kirchliche Laufbahn vorgesehen war, wurde im diplomatischen Dienst eingesetzt, Don Giulio, ${ }^{86}$ aus der Verbindung von Ercole I. mit Isabella Arduini geboren, war mit den legitimen Kindern am Hof erzogen worden und erhielt eine großzügige Apanage wie auch Don Ferrante, der in Neapel geboren war, als Eleonora ihre Heimatstadt besuchte, und hier aufwuchs. Als Zweitgeborener war er für die militärische Laufbahn bestimmt. Ippolito, der lieber die Waffen als den Kardinalshut ergriffen hätte, war hingegen mit fünf Jahren schon Abt von Castelnuovo, mit acht Erzbischof von Ezstergom in Ungarn, mit I 4 Kardinal und mit 77 Erzbischof einer der bedeutendsten Diözesen Italiens, Mailands, geworden.

I 508 hatte sich Alfonso I., vom Papst zum Gonfaloniere della Chiesa ernannt, der Liga von Cambrai mit Frankreich und dem Papst gegen Venedig angeschlossen, die ihm die Rückgabe des Gebietes von Polesine und die Aufhebung des verhassten Insti-

$82 \mathrm{Zu}$ dem von Papst Julius II. gegen Bologna und die Bentivoglio aus ähnlichen Gründen (Ungehorsam, Rebellion, Majestätsbeleidigung) wie gegen die Este geführten Krieg siehe Pastor, Geschichte der Päpste 3/2, Kap.3: »Unterwerfung von Perugia und Bologna. Sturz der Baglioni und Bentivoglio«, 723-745 und zuletzt: Rospocher, Il papa guerriero, IO8- I 20.

83 Rospocher, Il papa guerriero, I 77 .

84 Dieses Werk wird unter den verloren gegangenen Werken Michelangelos bei Goldscheider, Michelangelo, I 5 I angeführt. Die Schändung und Zerstörung der Statue bezahlten viele Bologneser nach der päpstlichen Verurteilung mit dem Leben. Rospocher, Il papa guerriero, i95. Zum angespannten Verhältnis zwischen dem Papst und Michelangelo und dem Auftrag der genannten Bronzestatue siehe auch Pastor, Geschichte der Päpste 3/2, 959-966.

85 Einen derartigen »Kreislauf« hat Michael Jucker bei anderen Beute- und Schatzstücken nachgewiesen und - wie im vorliegenden Fall - die »Umwertung« von Objekten als »Schmach der Verlierer« bezeichnet.Vgl. Jucker, Raub, $63,67$.

$86 \mathrm{Zu}$ diesem natürlichen Sohn siehe: Paolo Portone, »Giulio d'Este«, in: DBI 43, 359-36r. 
tuts des Visdomino veneto ${ }^{87}$ in Ferrara versprach. ${ }^{88}$ Anfangs war das Unternehmen von Erfolg gekrönt, doch als sich Venedig mit den einzelnen Gegnern verständigte und dem Papst Gebiete in der Romagna versprach, stand Alfonso allein da und musste den Gegenschlag Venedigs hinnehmen. Es folgten grausame und gewaltreiche Einmärsche in das estensische Fürstentum. Erst im Dezember I 509 gelang Alfonso mithilfe seines Bruders, Kardinal Ippolito d'Este, ${ }^{89}$ ein Sieg über die Serenissima und die Besetzung des Polesine. Aus dieser militärischen Aktion entstand das oben untersuchte gravierende Lehensproblem mit dem Heiligen Stuhl, das ihn fast 20 Jahre lang intensiv beschäftigte.

Kurz bevor Alfonso I. am 3 I. Oktober I 534 angeblich an einer durch den Verzehr von zu vielen Melonen hervorgerufenen Magenverstimmung verstarb, hatte sich sein Verhältnis zum Papsttum leicht verbessert und jenes zum Kaiser war nur durch die Flucht seines Bruders Francesco an den französischen Hof getrübt. Was über seinen Tod hinaus ungeklärt und fatal für die Este-Dynastie in Ferrara bleiben sollte, war die Frage, ob er mit seiner langjährigen Konkubine, Laura Dianti, die ihm während seiner Witwerschaft zwei Söhne schenkte, insgeheim verheiratet gewesen war, sodass die Sprösslinge aus dieser Verbindung, allen voran Cesare d'Este, der Sohn von Don Alfonso, ${ }^{90}$ Markgraf von Montecchio, als legitime Nachfolger gelten konnten oder nicht. Die Este selbst, allen voran der nachfolgende Ercole II., der Laura Dianti und ihre Söhne von Anfang an ausgrenzte, zeigten sich hinsichtlich der Rechtmäßigkeit dieser zweiten, nicht standesgemäßen Verbindung wenig ein- und weitsichtig bzw. verfolgten verständlicherweise andere Interessen zum Schutz der legitimen Linie der Dynastie. Und so hatte sich Ercole II. weder um die Rechtmäßigkeit einer eventuellen Eheschließung seines Vaters mit Laura Dianti gekümmert noch hatte er die illegitimen Söhne in seiner Investiturbestellung integrieren wollen. Im Gegenteil, er bemühte sich sogar darum, dass Papst Paul III. in der Wiederbelehnungsbulle den Stiefbruder, Don Alfonso Markgraf von Montecchio, ausschloss und dass in dem I 555 gedruckten estensischen Stammbaum neben dessen Namen das rote Kreuzchen der

87 Im Fondaco dei Tedeschi in Venedig waren die visdomini die Zollbeamte der Serenissima, die »die gesamte Abwicklung des Warenhandels von der Anlieferung über den Kauf und den Abtransport kontrollierten, um die Zölle, die sowohl für die Einfuhr als auch für den Export der Waren von und nach Oberdeutschland erhoben wurden, einzutreiben«. BACKMANN, Kunstagenten, I 80.

88 Chiappini, Gli Estensi, 2 I3-222. Quazza, "Alfonso I«.

89 Im gleichen Jahr stand der Kardinal auch seiner Schwester Isabella d'Este-Gonzaga zur Seite, deren Ehemann Francesco Anfang August I 509 von den Venezianern gefangen genommen worden war. Nicht nur, dass die Markgräfin, als sie sich an den Lehensherrn der Gonzaga, Maximilian I., mit der Bitte um Hilfe wandte, keine maßgebliche Unterstützung bei der Befreiung ihres Gatten erhielt; sie wurde vom Kaiser während ihrer stellvertretenden Regentschaft des Öfteren sogar mit Lebensmittelabgaben für die kaiserlichen Truppen und Geldanleihen behelligt. Dazu siehe: BeEr, Die Beziehungen.

$90 \mathrm{Zu}$ diesem illegitimen Sohn von Alfonso I. mit Laura Dianti siehe: Luisa Bertoni, "Alfonso d'Este«, in: DBI 43 , 3 I 2-3 I 4 . 
Illegitimen angebracht wurde. ${ }^{91}$ In der Familienkorrespondenz wurde zudem von Don Alfonso d'Este als vom »nostro illustrissimo bastardo« gesprochen. ${ }^{92}$

\subsubsection{Ercole II. (reg. 1534-1559)}

Ercole II. war auf Wunsch und Anweisung seines Vaters Alfonso I. aufs Beste sowohl in den humanistischen Studien als auch in der Kriegsführung ausgebildet worden. Mit den ihm angebotenen Heiratskandidatinnen, Margarete von Österreich, illegitime Tochter von Kaiser Karl V., Caterina de'Medici, Verwandte des Medici-Papstes, und Renée de France, Schwägerin des französischen Königs, standen den Este die Möglichkeit der Verbesserung der Beziehungen zum Kaiser und die Hoffnung auf die Rückgabe Modenas, die Sicherung des päpstlichen Lehens Ferrara oder die Intensivierung der Beziehungen zu Frankreich offen. Ercoles Vater entschied sich schließlich für den französischen Weg und gab dem Sohn Renée de France zur Frau. ${ }^{93}$

Nachdem Ercole II. I 535 die Nachfolge angetreten hatte, reiste er zunächst zum Papst nach Rom, um die Wogen zu glätten und seine Investitur über Ferrara bestätigen zu lassen. Papst Paul III. gab jedoch erst I539- nachdem er den Herzog wegen der Weigerung, den Zehnt für den Türkenkrieg einzutreiben, fast wieder gebannt hätte dem Wunsch des Kaisers nach Aussöhnung nach und bestätigte die Este in ihrer Investitur mit Ferrara gegen Entrichtung eines Lehenszinses von I 80.000 Dukaten. Im Sinne einer ausgeprägten Gleichgewichtspolitik zwischen Frankreich und dem Reich ließ Ercole seinen Bruder Ippolito, Erzbischof von Mailand und seit I 539 Kardinal, mit I 30 Hofleuten nach Frankreich ziehen, während sein anderer Bruder, Francesco, ${ }^{94}$ beim Kaiser in den militärischen Dienst eintrat. Dieser letztgeborene Sohn von Alfonso I. und Lucrezia Borgia hielt sich zunächst ohne väterliche Erlaubnis am fran-

9i Chiappini, Gli Estensi, 244-247, 286.

92 Zit. n. Lazzari, Le ultime tre duchesse, 206. Dazu siehe auch die an der Universität von Verona angenommene Dissertation von Marchesi, L'«illustrissimo bastardo«.

93 Chiappini, Gli Estensi, 248f. Taddei, Zwischen Katholizismus und Calvinismus. Vgl. auch Iotti, La Politica dell'amore.

94 Er war schon früh für die Übernahme von diplomatischen Angelegenheiten ausgebildet worden. Als Lieblingssohn verletzte er den Vater durch seine von Höflingen von Renée de France unterstützte Flucht an den französischen Hof. Als Ausgleich für seinen Bruder Alfonso II., der in jungen Jahren in französischen Diensten stand, schickte der Vater ihn zum Kaiser, wo er unter Karl V. große militärische Erfolge verbuchen konnte. Er erlangte den Rang eines Hauptmannes der kaiserlichen Leichtbewaffneten. Als solcher kam er in ganz Europa herum und war in der wichtigen Gesandtschaft an Henry VIII. von England, die Hilfe gegen Frankreich erbeten sollte, dabei. Francesco war im Reich im Krieg gegen den Herzog von Kleve im Einsatz und in Gand um die Revolte gegen die Statthalterin zu schlichten. I544 erhob ihn der Papst zum Markgrafen von Massalombarda in der Romagna, ein Lehen, dass er sehr pflegte und mit einer Münzprägestätte und einer Stadtmauer versorgte. Als Alfonso II. im estensischen Herzogtum nachfolgte, wollte er ihn wieder in seine Dienste haben und beauftragte ihn bis zu seinem Tod I 578 mit wichtigen Agenden. Bertoni, »Francesco d'Este«. Rimondi, Estensi, i iof. 
zösischen Hof auf und wechselte erst später an den Kaiserhof. Durch die Teilnahme an verschiedenen Feldzügen gewann er die Gunst des Kaisers, der ihn mit Maria di Cardona, Markgräfin von Padulia und Gräfin von Avellino verheiratete. Als er zum französischen König zurückfand, wurde er von diesem zum luogotenente von Toskana ernannt und mit der Verteidigung der Republik Montalcino betraut. Der Wechsel in den französischen Dienst war auf seine Enttäuschung über die geringe Wertschätzung, die ihm der Kaiser im kriegerischen Einsatz gegen die protestierenden Reichsfürsten entgegengebracht hatte, erfolgt. Aus der Sicht des venezianischen Gesandten Alvise Mocenigo war Francesco d'Este besonders enttäuscht gewesen, dass er I 546 keinen militärischen Auftrag erhalten hatte, dass ihm Philipp von Lannoy, Fürst von Sulmona, vorgezogen wurde und dass er vom Kaiser für seine Verdienste auch nicht mit dem Orden vom Goldenen Vlies ausgezeichnet worden war. Als Francesco nach zehn Dienstjahren keine verantwortungsvollen Aufträge erhielt, bat er um Lizenz, nach Italien zurückkehren zu können, die ihm der Kaiser auch gewährte. Mocenigo vermutet hinter diesem distanzierten Verhalten die Enttäuschung Karls V. über die profranzösische Haltung von Ercole II. d'Este und andererseits auch über das undankbare Verhalten Francescos, der nach dem letzten Krieg gegen Frankreich die ihm angebotenen 3.000 scudi des Kaisers abgelehnt hatte. Dieser sei - so der Venezianer - zwar ob seiner Knauserigkeit bekannt, doch störe er sich sehr an der Undankbarkeit und der Zurückweisung seiner Gaben. ${ }^{95}$

Ein Ungleichgewicht in seiner Schaukelpolitik entstand, als Ercole II. I 549 entschied, das französische Heiratsangebot für seine älteste Tochter Anna ${ }^{96}$ mit dem Herzog von Guise anzunehmen. Überzeugend war hierbei besonders die Tatsache gewesen, dass er sich aufgrund der offenen Kredite der französischen Krone ihm gegenüber, weigern konnte, eine Mitgift zu bezahlen. Diese Heiratsverbindung, der frankophile Bruder Kardinal Ippolito d'Este und schließlich die »Flucht« der beiden Söhne nach Frankreich, denn nach Francesco zog es auch den Thronerben Alfonso I $55^{2}$ an den Hof von Henri II., deuteten auf sich intensivierende Beziehungen mit Frankreich hin, die über die Verschwägerungspflichten hinausgingen und zu Recht das Misstrauen des Kaisers schürten. ${ }^{97}$

Aus den Erfahrungen seines Vaters klug geworden, vermied es Ercole wo nur möglich, auf die Seite des einen oder des anderen in den Kampf zu ziehen und konnte sich mit dem Argument, Vasall des Kaisers, treuer Diener und Lehensmann der Kirche oder Verwandter des französischen Königs zu sein, aus der jeweiligen Verantwortung

95 "[...] perchè esso Don Francesco non volse accettare scudi tre mille, che li donò finita che fu l'ultima guerra con Franza, la qual cosa fu molto ingrata, per quanto si dice alla $\mathrm{M}^{\text {tà }}$ Sua, perché se ben è opinione che la sia stretta nel donare, ha però piacere che li presentati da lei mostrino esser statisfatti di quello che li dona.«Turba, Venezianische Depeschen I, Alvise Mocenigo und Lorenzo Contarini an den Dogen, Regensburg, Juni I 546, Nr. I67, 538 f.

96 Vgl. Sanfilippo, »Anna d'Este«.

97 Benzoni, »Ercole II«. 
ziehen. ${ }^{98}$ Dadurch gelang es ihm, sein Fürstentum und seine Familie vor längeren kriegerischen Auseinandersetzungen zu verschonen und die estensische Dynastie in Ferrara und Modena wieder zu etablieren.

\subsubsection{Alfonso II. (reg. 1559-1597)}

Alfonso II. d'Este, ${ }^{99}$ der 1533 geborene Sohn von Ercole II. und Renée de France, erhielt in Ferrara und am französischen Hof von Henri II. eine humanistische und höfische Ausbildung. Nicht einmal seine I 558 mit der Tochter von Cosimo I. geschlossene Ehe hinderte ihn daran, in Frankreich zu bleiben. Er kam erst mit dem Tod seines Vaters I 559 nach Ferrara und führte auf seiner Heimreise seine Angetraute heim. ${ }^{100}$

Auch Alfonso II. konnte in den kirchlichen Reihen auf eine bedeutende Stütze für seine Dynastie zählen. Nach Kardinal Ippolito I., ${ }^{101}$ Sohn von Ercole I., stand dem letzten Herzog von Ferrara sein Onkel, der Zweitgeborene von Alfonso I., Ippolito II. ${ }^{102}$ zur Seite. Dieser stand in der Gunst des französischen Königs und erlangte mit dessen Unterstützung I 539 den Kardinalshut. Er blieb weiterhin als königlicher Berater an der Seite von François I. und von dessen Nachfolger Henri II., unter dem er Protektor der französischen Angelegenheiten in Rom wurde. Er war in zahlreiche militärische und diplomatische Angelegenheiten als Vertreter des französischen Königs oder seines Bruders, des Herzogs von Ferrara, involviert. ${ }^{103}$ Ein ähnliches Schicksal des "Zweitgeborenen« ereilte den jüngsten Sohn von Ercole II. und Renée de France, Luigi, ${ }^{104}$ der - wenn auch wider Willen - ebenso die geistliche Laufbahn einschlug.

Aber nicht nur mithilfe seiner Verwandten, sondern vor allem mit seinen Heiratsverbindungen brachte Alfonso II. das Prestige seiner Dynastie zu einem erneuten letzten - Höhepunkt. Kurz nachdem er aus Rom zurückgekehrt war, wo er I 560 dem Papst gehuldigt und um die Neubelehnung gebeten hatte, starb im Frühjahr I 56 I seine Ehefrau, Lucrezia de'Medici, und der Präzedenzstreit mit ihrer Familie wurde erneut entfacht.

Mit einer neuen Verbindung suchte der Este nicht nur größeren politischen Halt, sondern auch Unterstützer für die oben besprochene Causa der Präzedenz. Mögliche Verbindungen schienen die mit Elisabeth I. von England, Maria Stuart, Königin von

98 In dieser Schaukelpolitik war Ercole II. nicht der einzige wie aus den Untersuchungen zur savoyischen Politik hervorgeht. Vgl. Rabà, La nuova "porta d'Italia«, 230. Vgl. auch MerLin, La croce e le aquile.

99 Quazza, "Alfonso II" und Lazzari, I »ricordi di governo«.

Iо० Quazza, "Alfonso II«.

Io I Der Kardinal und Erzbischof von Mailand war kein Geistlicher, sondern ein Krieger und fähiger Staatsmann, wie sein Einsatz gegen Venedig an der Seite des Bruders bewies. Byatt, »Ippolito d'Este«; Rimondi, Estensi, I08.

IO2 ByATt, »Ippolito d'Este«, in: DBI 43, 367-374; Lutz, Il cardinale Ippolito d'Este.

I03 QuAzza, "Alfonso II«.

Io4 Zu seiner Biografie vgl. Paolo Portone, »Luigi d'Este«, in: DBI 43, 383-39o. 
Schottland, und einer Schwester von Philipp II. von Spanien zu sein, die jedoch alle bald verblassten. So wandte sich Alfonso dem Kaiserhaus zu und sah in der Erzherzogin Johanna eine passende Ehefrau. Doch seine Anfrage war wiederum von den Medici antizipiert worden. Am Ende beugte sich Alfonso dem Vorschlag des Kaisers, die ältere Tochter Barbara zu ehelichen, während die jüngere Johanna dem Medici-Sohn zugesprochen werden sollte. Die neue Verwandtschaft und die Suche nach Ruhm und Ehre veranlassten Alfonso II. sich für den Krieg gegen die Türken an der Seite des Kaisers zur Verfügung zu stellen. Durch diesen militärischen Einsatz zur Verteidigung von Kirche und Reich wollte er seine politische Position stärken und sein Prestige steigern, um nicht zuletzt zu beweisen, dass er über ein schlagkräftigeres Heer verfügte als Florenz. ${ }^{105}$

Nach dem Tod seiner zweiten Frau Barbara I 572, veranlasste ihn die I 576 erfolgte kaiserliche Bestätigung der vorangegangenen päpstlichen Erhebung der Medici zu Großherzögen zu einem Bündnis mit den Gonzaga durch die Heirat I 579 mit Margherita Gonzaga, Tochter von Guglielmo Gonzaga und Eleonore von Österreich, also einer Nichte der verstorbenen Barbara. ${ }^{106}$

Auch diese dritte Ehe blieb kinderlos, sodass sich Alfonso II. um die Bestellung von Don Cesare d'Este aus der Linie von Montecchio, als Nachfolger sowohl in den kaiserlichen als auch im päpstlichen Lehen bemühte. Erfolgreich war er aber nur beim Kaiser, während der Papst nach einem kurzen Intermezzo Ferrara dem Kirchenstaat einverleibte.

\subsection{Der erste Herzog von Modena und Reggio - Cesare d'Este (reg. 1598-1628)}

Nachdem seine Anfrage beim Papst erfolglos geblieben war, hatte sich Alfonso II. mit seiner Bitte, den Nachfolger selbst bestimmen zu können, mit Nachdruck an Kaiser Rudolf II. gewandt. Dieser, der Geld für den Türkenkrieg benötigte, genehmigte schließlich gegen Auszahlung einer beträchtlichen Summe die Investitur für Don Cesare d'Este, ${ }^{107}$ Markgraf von Montecchio. Der neue Herzog von Modena und Reggio kam am 29. Januar I 598 mit seiner Frau Virginia de'Medici ${ }^{108}$ in seine neue Residenzstadt, wo er von der Bevölkerung mit Jubel empfangen wurde. Er brachte, wie in der Convenzione faentina festgelegt, viele (wenn auch nicht alle) Kunstwerke, das herzogliche Archiv und die berühmte estensische Bibliothek nach Modena mit. Die

I05 Alfonso zog mit goldener Rüstung auf einem edlen Streitross mit 300 Edelleuten mit ebenso vielen Pagen, 6oo Schützen und Fußsoldaten, die insgesamt eine Truppe von 4.00o Mann darstellten, nach Ungarn. Vgl. auch: Ricci, Cavalleria e crociata.

io6 Chiappini, Gli Estensi, 3oof.

io7 Signorotto, Modena, 23f. Siehe auch: Signorotto, Papato. Boccolari, Gli Estensi a Modena, 24. ro8 Sie war die Tochter von Cosimo I. de’Medici und seiner zweiten Frau Camilla Martelli. Vgl. die einzige biografische Aufarbeitung bisher bei VAnnuccI, Le donne. 
Stadt, die selten Residenz der Este-Fürsten gewesen war, hatte dennoch ein beachtenswertes kulturelles Leben und erhielt mit der Etablierung des Hofes und den aus Ferrara mitgeführten Schätzen einen neuen Aufschwung. Der Castello, der bisher nur eine Festung gewesen war, wurde den Ansprüchen des neuen Fürstenhofs angepasst und vergrößert, die Stadt mit neuen Profan- und Sakralbauten geschmückt. ${ }^{109}$ Trotz des herzlichen Empfangs und der Möglichkeiten, die sich den Herzögen von Modena und Reggio nun boten, ihrem Mäzenatentum und ihrer fürstlichen Größe neuen Ausdruck zu verleihen, bedeutete der Umzug aus der glanzvollen Residenzstadt Ferrara ein Abstieg für die Este-Dynastie. ${ }^{110}$ Cesare bewahrte - von vielen deshalb kritisiert weiterhin eine unterwürfige Haltung gegenüber dem Papst, dem er, als dieser auf dem Weg nach Ferrara war, in Imola entgegenreiste und ihm als treuer Sohn der Kirche die Ehrerbietung des Fußkusses erwies. Wenn auch diese Haltung nichts am Verlust Ferraras für den Este änderte, so ermöglichte sie I 599 die Kardinalserhebung für Cesares Bruder Alessandro d'Este, ${ }^{111}$ der hingegen wiederholt seine diplomatischen Beziehungen vor allem zu Frankreich nutzte, um eine Möglichkeit zur Rückholung Ferraras zu finden. Die resignierte Haltung des neuen Herzogs von Modena beflügelten Kardinal Bandini, Legat der Romagna, die päpstlichen Ansprüche weit über die Convenzione faentina auszudehnen und das bedeutende Comacchio militärisch zu besetzen, welches als ein - umstrittenes, d.h. nicht eindeutig belegbares - kaiserliches Lehen galt. ${ }^{112}$ Doch auch dagegen wusste sich Cesare nicht zur Wehr zu setzen. Weitere Demütigungen ergaben sich durch das Testament der kurz nach Abschluss der Verhandlungen verstorbenen Lucrezia d'Este, Schwester von Alfonso II., die ihren gesamten Besitz dem Besetzer von Ferrara, Kardinal Pietro Aldobrandini, vererbte und Cesare nur mit den Schulden seiner Vorfahren zurückließ. Um diese wenigstens teilweise zu tilgen, musste er Aldobrandini auch den Palazzo Estense in Venedig auf dem Canal Grande sowie den Palazzo Belvedere bei Ferrara überlassen. ${ }^{113}$

Io9 Tiziano Ascari, „Cesare d'Este«, in: DBI 24, Roma I980, http://www.treccani.it/enciclopedia/cesared-este-duca-di-modena-e-reggio_ \%28Dizionario-Biografico \%29/, Zugriff: r6.9.2020.

I Io Die Bevorzugung Modenas als neuer Fürstensitz vor Reggio hatte sich aus der geografischen Lage und am Vorhandensein einer - wenn auch bescheidenen - ausbaufähigen Infrastruktur für die Aufnahme des Hofes ergeben. Dennoch war die neue Hauptstadt des Herzogtums klein und wenig glanzvoll im Vergleich zum einstigen Herrschaftszentrum der Este mit nur halb so vielen Einwohnern wie Ferrara, sehr schlechten hygienischen Verhältnissen, meist engen und noch nicht durchgängig gepflasterten Straßen. Mit der Ankunft des Hofes wuchs die Bevölkerung von Modena jedoch rasant, vor allem durch die Ansiedlung von Bediensteten und Beamten, der Soldaten sowie der Juden, die in Ferrara keine Existenzperspektiven mehr hatten, jedoch auch vom ultrakonservativen Cesare schlecht behandelt wurden. Rimondi, Estensi, 202.

i i I Vgl. Paolo Portone, "Alessandro d'Este«, in: DBI 43 (i993), http://www.treccani.it/enciclopedia/ alessandro-d-este_\%28Dizionario-Biografico \%29/, Zugriff: r 6.9.2020.

I 2 In der Mission Garzweiler vom 3r. Mai r604 galt Comacchio trotz päpstlicher Besetzung seit der Devolution Ferraras als Reichslehen. Vgl. Aretin, Das Reich, I05.

I I3 Milano, Gli Estensi, I3-i6. 
Cesare beeilte sich nach seiner Niederlage die Kontakte und Beziehungen zu den anderen italienischen und zu den europäischen Fürsten sowie zum Papst wiederherzustellen. Das schändliche Verhalten Frankreichs noch im Hinterkopf, versuchte er sich Spanien anzunähern und erhielt I606 von König Philipp III. die Aufnahme in den Orden vom Goldenen Vlies. Um das Image seiner Dynastie wieder aufzupolieren, verheiratete er seinen Sohn Alfonso mit Isabella von Savoyen, Tochter von Herzog Carlo Emanuele I. und Catalina Micaela, wiederum Tochter des spanischen Königs Philipp II. ${ }^{114}$

Ein wichtiger Moment in der schwierigen Anfangszeit seiner Regentschaft war die Causa Sassuolo, die schließlich zu einer - teuer erkauften - Gebietserweiterung führte. Marco Pio, der Herr über Sassuolo, mit den heimischen Adelsfamilien und dem neuen Herzog von Modena und Reggio verfeindet, versuchte sein Gebiet aus der Herrschaft der Este zu lösen, indem er sich zuerst an den Papst wandte und sich diesem unterstellen wollte und dann an die kaiserliche Kanzlei mit der Bitte wandte, Sassuolo zum Herzogtum erheben zu wollen. Der Kaiser erhörte seine Bitte, bestätigte aber die Este in ihrer Herrschaft über dieses Fürstentum. Nach Bekanntwerden des Ansuchens an Kaiser und Papst klagte Cesare seinen Lehensmann des Verrats an. Der Pio fiel r 599 einem Attentat zum Opfer und Sassuolo wurde nach heftigen Kämpfen den estensischen Gebieten einverleibt. Da Marco Pio ohne Erben starb, ließ Cesare aus Furcht, Sassuolo könnte Ferrara einverleibt werden - die Stadt besetzen. Der Erbe aus der Seitenlinie, Enea Pio, wandte sich an den Papst und den Kaiser. Der Streit, der nun auf europäischer Ebene ausgetragen wurde, konnte erst neun Jahre später durch Intervention von Carlo Emanuele I. di Savoia geschlichtet werden. Damit das Gebiet schließlich dem estensischen Fürstentum einverleibt wurde, mussten erst 2 I 5 .0oo scudi romani an die Pio bezahlt werden, was einen weiteren Aderlass für Cesares ohnehin leere Kassen bedeutete. ${ }^{115}$

Obwohl sich der Este bemühte, Modena den Status einer Hauptstadt zu verleihen und durch eine Friedenszeit und mit Sparsamkeit die Finanzen des Fürstentums zu sanieren, kam er nicht umhin, sich in eine kriegerische Angelegenheit verwickeln zu lassen: Die Republik Lucca machte nämlich den geschwächten Este wieder Teile des angrenzenden Gebiets der Garfagnana streitig. ${ }^{116}$ Die militärische Auseinandersetzung wurde erst 1603 durch Eingriff des spanischen Statthalters von Mailand, Graf Fuentes, beendet, nachdem dieser vom Kaiser bzw. Reichshofrat, an den sich sowohl die Republik Lucca als auch Cesare gewandt hatten, beauftragt worden war, den Streit zu schlichten. ${ }^{117}$ Immer wieder wurde der Kaiser angerufen, doch erst I 606 und vor allem durch Einschaltung von Kardinal Alessandro d'Este, der dafür selbst I604 nach Prag

\footnotetext{
I 4 Rimondi, Estensi, 202.

I 5 Milano, Gli Estensi, igf.

I 6 Wien, HHSTA, Reichshofrat, Judicialia latina 250/4-253/I und 330/I I.

I 7 Vgl. dazu Auer, Appellationen, besonders Anm. 38, 73, 74 .
} 
gereist war, lag eine (vorerst) endgültige Lösung zugunsten der Este vor. Der Konflikt mit Lucca sollte im Zuge des Erbfolgekrieges um das Montferrat wieder aufflammen. Nach langen Verhandlungen und Scharmützeln wurde die Causa im August I 6 I 8 per kaiserlichem Dekret geklärt, das die Bestimmungen von I608 wieder bestätigte. ${ }^{118}$

Cesare regierte genau 30 Jahre lang. Trotz der territorialen Beschneidung und der finanzschwachen Lage schaffte er es zusammen mit seinem Nachfolger Alfonso III., die neue Hauptstadt Modena zu einem ansehnlichen und wahrnehmbaren kulturellen Zentrum zu machen, wozu die Gründung einer ersten accademia r6o9 und schließlich kurz darauf die Eröffnung einer eigenen Universität ${ }^{119}$ wesentlich beitrugen.

i 8 Milano, Gli Estensi, 2 I-23.

I I 9 Die Universität von Modena entstand als Rechtsfakultät gleichzeitig mit der Stadtkommune nach dem Tod von Mathilde von Canossa ir I 5 . Es handelte sich um ein "studio comunale«, eine von der Stadtkommune finanzierte Hochschule. Als I 283 die internen Machtkämpfe die Este nach Modena brachten, wurde die Universität geschlossen und erst 1306 nach der Vertreibung derselben und der Wiederherstellung der kommunalen Struktur wiedereröffnet. Als die Este 1326 wieder nach Modena kamen, wurde das studio zwar nicht geschlossen, allerdings stark eingeschränkt. I39I kam durch die Gründung der Universität Ferrara nicht nur eine Konkurrentin, sondern auch die Verpflichtung für die Untertanen, in der Este-Hauptstadt und nicht anderswo zu studieren und das Studium abzuschließen. Die modenesische Hochschule fristete bis ins I7. Jahrhundert hinein ein trauriges Dasein, als dann unter Francesco III. ab r682 dem Rechtstudium weitere Doktorate hinzugefügt wurden, nämlich Medizin, Theologie und Philosophie. 1772 gab der Fürst der Universität einen neuen Studienplan, stellte sie unter staatliche Führung und vermehrte die Studiengänge der nunmehr vier Fakultäten. Di Pietro, Rapporti degli Estensi. Venturi Barbolini, Percorsi, i8 I - I 9 I. 


\section{2. Übersicht der estensischen Gesandten im Reich}

Ambasciatori e agenti in Alemannia ${ }^{120}$

\begin{tabular}{|c|c|}
\hline \multicolumn{2}{|c|}{ 15. Jahrhundert } \\
\hline 14867 & Cesare Valentini \\
\hline 1493 & Guido Manfredi \\
\hline $1493 / 4$ & Francesco Ariosti \\
\hline $1493-1503$ & Pandolfo Collenuccio \\
\hline \multicolumn{2}{|c|}{ 16. Jahrhundert } \\
\hline 1501 & Ercole Tassoni \\
\hline $1505-1521$ & Giovanni Muzzarelli, Medico \\
\hline $1509-1512$ & Girolamo Cassola \\
\hline 1521 & Giovanni Andrea Valentini \\
\hline 1532 & Alfonso Bevilacqua \\
\hline $1546-1547$ & Claudio Ariosti, Prof. \\
\hline $1546-1560$ & Giulio Sertorio, Conte \\
\hline $1547-1561$ & Girolamo Falletti \\
\hline $1549-1552$ & Ercole Rangoni, Conte \\
\hline 1549 & Alfonso Rossetti (Secr.) \\
\hline $1550-1555$ & $\begin{array}{l}\text { Antonio Maria Collegno di } \\
\text { Savoia, Conte }\end{array}$ \\
\hline $1553-1565$ & Camillo Montecuccoli, Conte \\
\hline $1553-1582$ & Camillo Gualengo, Cavalliere \\
\hline $1555-1565$ & Ippolito Turco, Conte \\
\hline 1558 & Ippolito Montecuccoli \\
\hline 1559 & Vincenzo Cartari \\
\hline $1559-1562$ & Fulvio Rangoni, Conte \\
\hline $1559-1561$ & Attilio Tombesi \\
\hline $1561-1571$ & Sigismondo Descalzi, Don \\
\hline 1565 & Paolo Emilio Bernieri Cavalliere \\
\hline 1565 & Sigismondo Morani, Don \\
\hline
\end{tabular}

\begin{tabular}{|l|l|}
\hline 1566 & Guido Bentivoglio \\
\hline $1566-1582$ & Renato Cati/o, \\
\hline $1569-1571$ & Alessandro Fiaschi, Cavalliere \\
\hline $1574-1577$ & Paolo Carrandini \\
\hline 1575 & Alessandro Baranzoni \\
\hline $1575-1590$ & Ascanio Gualdini \\
\hline 1576 & Gherardo Bevilacqua \\
\hline $1577-1578$ & Valentino Florio \\
\hline 1578 & Ottavio Landi, Conte \\
\hline $1579-1607$ & Alfonso Montecuccoli \\
\hline $1581-1588$ & Minuccio Minucci \\
\hline $1582-1585$ & Giovanni Matteo Soner \\
\hline $1584-1602$ & Marcantonio Ricci \\
\hline $1585-1609$ & Dario Castelletti \\
\hline $1586-1597$ & Andrea Minucci \\
\hline 1592 & Ercole Bevilacqua \\
\hline 1592 & Guido Calcagnini \\
\hline $1592-1594$ & Valentino Florio \\
\hline 1593 & Luigi Montecuccoli \\
\hline 1595 & S.U. Bonarelli, Conte \\
\hline $1596-1613$ & Ercole Rondinelli \\
\hline 1596 & Ercole Angiara, Cavalliere \\
\hline $1596-1599$ & Alessandro Naldi \\
\hline $1597-1603$ & Francesco Mella \\
\hline 1597 & \\
\hline $1598-1599$ & Gudovico da Fino \\
\hline
\end{tabular}

I 20 Diese Auflistung der estensischen Gesandten im Reich wurde vom Register im ASMo übernommen. Dementsprechend sind nur die hier angegebenen Adelstitel bzw. akademische Grade angeführt. 


\section{Bibliografie}

\subsection{Archivquellen und Manuskripte}

Dresden, Sächsisches Hauptstaatsarchiv (SächHStA)

Geheimer Rat (Geheimes Archiv), Loc. 8499/r, 8503/r I, 8233/7, 8274/4.

Innsbruck, Tiroler Landesarchiv (TLA)

Ferdinandea, Kart. 3 I Pos. 26: Ferrara; Kart 3 I Pos. 27: Ferraresische und Florentinische Heimführung; Kart. I 29, Pos. I20: Reisen aus Italien; Kart. 201 Pos. I 82: Welsche Schreiben; Kart. 220 Pos. 247 : Schreiben an Agenten.

Kanzlei Erzherzog Ferdinand II. Ein-/Auslauf, Kart. ıo.

Kanzlei Erzherzog Maximilian III. Einlauf, Kart. I.

Modena, Archivio di Stato di Modena (ASMo)

Archivio Segreto Estense (ASE), Casa e Stato, Carteggio di ambasciatori, Germania buste I - 66. Archivio Segreto Estense (ASE), Casa e Stato, Carteggio di principi esteri, Germania Imperatori (I 452-I795), Casa d'Asburgo buste I 575/I, I 576/2, I 577/3, I 583/9, I 585/I I, I 586/I 2.

Archivio Segreto Estense (ASE), Casa e Stato, Carteggio di principi esteri, Minute di lettere ducali a Principi e Signori fuori d'Italia, buste I63 I/ I bis I638/8.

Archivio Segreto Estense (ASE), Casa e Stato, Carteggio tra principi.

Archivio Segreto Estense (ASE), Casa e Stato, Carteggio fra principi, ramo ducale.

ASE, Casa e Stato, Controversie di Stato.

ASE, Camera Ducale, Amministrazione principi, buste I I 37, I I 38 , I 5 I 3.

Biblioteca Manoscritti, Cronica Estense di Fra Paolo da Lignago de'Frati Camelitani di S. Polo, ms. 69, I73-235.

Archivio privato Fiaschi, busta 42, fasc. II., I 527 : Dote di Madama Renea con rinunzie di diritti sui beni paterni.

Modena, Biblioteca Estense

Codice latino 498, Girolamo Brasavola, Consilia medica.

Annali di Ferrara [...] per Filippo Rodi Dottor di Leggi, e Cittadino della medesima Patria [...], alpha, H. 3.7- iо.

München, Bayerisches Hauptstaatsarchiv (BayHStA)

Fürstensachen, 37 I/2, Kasten schwarz 7603, 8662.

Kurbayern, Äusseres Archiv, Italienische Korrespondenz, 4576-4580.

Rom, Archivio Secreto Vaticano (ASV)

Raccordi diversi della città di Ferrara, Cronaca Pio, Nr. I I 4, Io7.

Schwerin, Landeshauptarchiv (LHA)

2.I I-2/I Auswärtige Beziehungen einschl. Reich, 3628, Italica.

2.1 I-2/r Auswärtige Beziehungen (Acta externa), 363 I, Livland.

Wien, Österreichisches Staatsarchiv, Abteilung Haus-Hof- und Staatsarchiv (HHStA)

Serie Italien-Kleine Staaten, Kart. Io.

Reichslehensakten, Feuda latina, Kart. 43. 
Reichslehensakten der Lateinischen Expedition, Kart. 43, 44.

Miscellanea Gratialia der Lateinischen Expedition, Kart. 23.

Wolfenbüttel, Niedersächsisches Landesarchiv, Staatsarchiv Wolfenbüttel

Acta publica des Herzogs Julius I Alt $9 \mathrm{Nr} 38$.

Wolfenbüttel, Niedersächsisches Landesarchiv, Hauptstaatsarchiv Hannover

Herzogliches Haus Braunschweig-Lüneburg, Haus, Hof, Regierung, Nr. I 76.

Harburgisches Archiv, Nr. 62 I.

\subsection{Literatur}

Lexionartikel aus Allgemeine Deutsche Biographie (ADB), Biographisch-Bibliographisches Kirchenlexikon (BBKL), Dizionario Biografico degli Italiani (DBI), Enciclopedia dei Papi, Enciclopedia Italiana (EI), Enzyklopädie der Neuzeit, Handwörterbuch zur deutschen Rechtsgeschichte (HdRG), Lexikon des Mittelalters (LMa), Lexikon für Theologie und Kirche (LThK), Neue Deutsche Biographie (NDB), Theologische Realenzyklopädie (TRE) sind nur in der ersten Anmerkungen vollständig zitiert und nicht in der Bibliografie aufgelistet. Auch etwaige weiterführende Literatur ist nur in den jeweiligen Anmerkungen angegeben.

Accorsi, Sara, Le donne estensi. Donne e cavalieri, amori, armi e seduzione, Ferrara 2009.

Albèri, Eugenio (Hg.), Relazioni degli Ambasciatori veneti al Senato, Firenze r 84 I.

Albrecht, Dieter, Das Herzogtum Bayern und seine Herzöge zur Zeit Orlando di Lassos, in: Bayerische Staatsbibliothek, Orlando di Lasso, 23-38.

Albrecht, Dieter, Das konfessionelle Zeitalter. Zweiter Teil: Die Herzöge Wilhelm V. und Maximilian I., in: Kraus, Handbuch der Bayerischen Geschichte 2, 393-459.

Alfani, Guido, Population and Environment in Northern Italy during the Sixteenth Century, in: Population 62/4 (2007), 559-595, online verfügbar: http://www.jstor.org/stable/2 76 45325, Zugriff: I I.7.2020.

Algazi, Gadi/Groebener, Valentin/Jussen, Bernhard (Hgg.), Negotiating the Gift. PreModern Figurations of Exchange (= Veröffentlichungen des Max-Planck-Instituts für Geschichte I 88), Göttingen 2003.

Alvar Ezquerra, Alfredo, Felipe II, la Corte y Madrid en I56r, Madrid i 985.

Álvarez-Ossorio Alvariño, Antonio, The State of Milan and the Spanish Monarchy, in: Dandelet/Marino, Spain in Italy, 99- I34.

Àlvarez-Ossorio Alvariño, Antonio, Moti di Italia e tumulti di Germani: la crisi del I 552 , in: Cantù/Visceglia, L'Italia di Carlo V, 337-374.

Amelung, Peter, Das Bild des Deutschen in der Literatur der italienischen Renaissance (I 400I 559) (= Münchner Romanische Arbeiten 20), München I 964.

Ammerer, Gerhard, Präzedenz und Kommunikation an einem geistlichen Hof - Beobachtungen am Beispiel Salzburgs in der Frühen Neuzeit, in: Hlavačka/Holý, Präzedenz, I 88-209.

Amon, Karl, Abwehr der Reformation und Rekatholisierungsversuche in Innerösterreich unter Ferdinand I. und Karl II., in: Dolinar/Liebmann/Rumpler/Tavano, Katholische Reform, $405-4$ I 8 . 
Andreatta, Stefano, Le nunziature in Italia nei secoli XVI e XVII, in: Koller, Kurie und Politik, I7-34.

Angiolini, Enrico, Rettori, consiglieri e comunità nella Romagna Estense del Cinquecento, in: Fregni, Archivi, I 2 I - I 47.

Angiolini, Franco, Diplomazia e politica nell'Italia non spagnola nell'etá di Filippo II. Osservazioni preliminari, in: Rivista storica italiana 92/2 (I 980), $432-469$.

Angiolini, Franco, Medici e Savoia. Contese per la precedenza e rivalità di rango in età moderna, in: Paola Bianchi/Luisa Clotilde Gentile (Hgg.), L'affermarsi della corte sabauda. Dinastie, poteri, élites in Piemonte e Savoia fra tardo medioevo e prima età moderna, Torino 2006, 435-479.

Annas, Gabriele/Müller, Heribert, Kaiser, Kurfürsten und Auswärtige Mächte. Zur Bedeutung der Goldenen Bulle im Rahmen von Rangstreitigkeiten auf Reichsversammlungen und Konzilien des I 5. Jahrhunderts, in: Brockhoff/Matthäus, Die Kaisermacher, ıo6- I 28.

Antenhofer, Christina, Briefe zwischen Süd und Nord. Die Hochzeit und Ehe von Paula de Gonzaga und Leonhard von Görz im Spiegel der fürstlichen Kommunikation (I473- I 50o), (= Schlern-Schriften 336), Innsbruck 2007 .

Antenhofer, Christina, Briefe, Besuche, Hochzeiten. Die Gonzaga im Kontakt mit deutschsprachigen Fürstenhäusern ( 354 - I686), in: Bellabarba/Niederkorn, Le corti come luogo di comunicazione, 39-6o.

Antenhofer, Christina, Mensch-Objekt-Beziehungen im Mittelalter und in der Renaissance am Beispiel der fürstlichen Höfe des süddeutschen und oberitalienischen Raums: Habsburg - Tirol - Görz - Wittelsbach - Württemberg - Visconti - Sforza - Gonzaga, unveröff. Habilitationsschrift, Universität Innsbruck 2014.

Antenhofer, Christina/Taddei, Elena, Fürstliche Körper und ihre Fortpflanzungsfähigkeit als Politikum. Medizinische und nicht-medizinische Gutachten als Medien dynastischer Heiratspolitik (I5.- I6. Jh.), in: Österreichische Zeitschrift für Geschichtswissenschaften, in Druck.

Arcangeli, Letizia/Peyronel, Susanna (Hgg.), Donne di potere nel Rinascimento, Roma 2008.

Arend, Stefanie, »Rezeption/Rezeptionsforschung«, in: Reinalter/Brenner, Lexikon der Geisteswissenschaften, 687-704.

Aretin, Karl Otmar von, Das Reich. Friedensgarantie und europäisches Gleichgewicht I648- i 806, Stuttgart I 986.

Aretin, Karl Otmar von, Die Lehensordnungen in Italien im I6. und I7. Jahrhundert und ihre Auswirkungen auf die europäische Politik. Ein Beitrag zur Geschichte des europäischen Spätfeudalismus, in: Hermann Weber (Hg.), Politische Ordnungen und soziale Kräfte im alten Reich, Wiesbaden I980, 53-84.

Aretin, Karl-Otmar von, L'ordinamento feudale in Italia nel XVI e XVII secolo e le sue ripercussioni sulla politica europea, in: Annali dell'Istituto italo-germanico 4 (I 978), 5 I - 93.

Aretin, Karl-Otmar von, Der Heimfall des Herzogtums Mailand an das Reich im Jahre i 700. Ein Beitrag zur Geschichte Reichsitaliens im I7. und I8. Jahrhundert, in: Ernst Schullin (Hg.), Gedenkschrift für Martin Göring. Studien zur europäischen Geschichte (= Veröffentlichungen des Instituts für Europäische Geschichte Mainz 50), Wiesbaden I968, 78 - 90. 
Aretin, Karl-Otmar von, Die Geschichte der italienischen Renaissance, in: Erich Lessing (Hg.), Die italienische Renaissance. In Bildern erzählt, München I983, I I - Ioo.

Aretin, Karl-Otmar von, The Old Reich: A Federation or Hierarchical System?, in: Evans/ Schaich/Wilson, The Holy Roman Empire, 27-42.

Armstrong, C. A. J., Das goldene Zeitalter von Burgund. Herzöge stechen Könige aus, in: Dickens, Europas Fürstenhöfe, 55-76.

Asch, Ronald G., Freundschaft und Patronage zwischen alteuropäischer Tradition und Moderne: Frühneuzeitliche Fragestellungen und Befunde, in: Descharmes/Heuser/Krüger/Loy, Varieties of friendship, $265-286$.

Asch, Ronald G., Hof, Adel und Monarchie: Norbert Elias' Höfische Gesellschaft im Lichte der neueren Forschung, in: Opitz, Höfische Gesellschaft, I I 9 - I 42.

Asch, Ronald G./Arndt, Johannes/Schnettger, Matthias (Hgg.), Die frühneuzeitliche Monarchie und ihr Erbe. Festschrift für Heinz Duchhardt zum 6o. Geburtstag, Münster/ New York/München/Berlin 2003.

Asch, Ronald G./Birke, Adolf M. (Hgg.), Princes, Patronage and the Nobility. The Court at the Beginning of the Modern Age, c. I450- I650, Oxford I99 I.

Asch, Ronald G./Емісн, Birgit/Engels, Jens Ivo (Hgg), Integration - Legitimation - Korruption. Politische Patronage in Früher Neuzeit und Moderne, Frankfurt a.M. u.a. 20 I I .

Asch, Ronald G./Емісн, Birgit/Engels, Jens Ivo, Einleitung, in: Asch/Emich/Engels, Integration, 7-32.

Asch, Ronald G./Freist, Dagmar (Hgg.), Staatsbildung als kultureller Prozess. Strukturwandel und Legitimation von Herrschaft in der Frühen Neuzeit, Köln/Weimar/Wien 2005.

Asche, Matthias, Glaubensflüchtlinge und Kulturtransfer. Perspektiven für die Forschung aus der Sicht der sozialhistorischen Migrations- und der vergleichenden Minderheitenforschung, in: North, Kultureller Austausch, 89- I I 4.

Aspernig, Walter, Die Adelsfamilie Polheim und ihre Rolle in der konfessionellen Geschichte Oberösterreichs, in: Vocelka/Leeb/Scheichl, Renaissance und Reformation, 75-80.

Auer, Leopold, Appellationen an den Reichshofrat aus Reichsitalien, in: Taddei/Schnettger/ Rebitsch, Reichsitalien, I99-2 I 8.

Auer, Leopold, Das Archiv des Reichshofrats und seine Bedeutung für die historische Forschung, in: Bernhard Diestelkamp/Ingrid Scheurmann (Hgg.), Friedenssicherung und Rechtsgewährung. Sechs Beiträge zur Geschichte des Reichskammergerichts und der obersten Gerichtsbarkeit im alten Europa, Bonn/Wetzlar I 997, I I 7- I30.

Auer, Leopold, Reichshofrat und Reichsitalien, in: Schnettger/Verga, L'Impero e l'Italia, 27-39. Auer, Leopold, The Role of the Imperial Aulic Council in the Constitutional Structure of the Holy Roman Empire, in: Evans/Schaich/Wilson, The Holy Roman Empire, 63-75.

Auer, Leopold/Ogris, Werner/Ortlieb, Eva (Hgg.), Höchstgerichte in Europa. Bausteine frühneuzeitlicher Rechtsordnungen, Köln/Weimar/Wien 2007.

Auge, Oliver, Ausbildung und Verbreitung des Lehnswesens im Reich und in Italien im I 2. und I3. Jahrhundert - eine Zusammenfassung, in: Spieß, Ausbildung, 337-355.

Auge, Oliver, Ein Integrationsmodell des Nordens? Das Beispiel der Kalmarer Union, in: Maleczek, Fragen der politischen Integration, 509-542.

Auge, Oliver, Reichsverdichtung und kulturelle Aneignung an der Peripherie. Die Fürsten im 
Nordosten des Reiches und Maximilian, in: Noflatscher/Chisholm/Schnerb, Maximilian I., I9I-222.

Augustynowicz, Christoph, Die Kandidaten und Interessen des Hauses Habsburg in PolenLitauen während des zweiten Interregnums I 574- I576 (= Dissertationen der Universität Wien 7I), Wien $200 \mathrm{I}$.

Aulinger, Rosemarie, Das Bild des Reichstages im i6. Jahrhundert (= Schriftenreihe der Historischen Kommission bei der Bayerischen Akademie der Wissenschaften I8), Göttingen I 980 .

Aulinger, Rosemarie, Die Reichstage des r6. Jahrhunderts im Spiegel bildlicher Quellen, in: Lanzinner/Strohmeyer, Der Reichstag, 3 I 3-342.

BaAder, Berndt Ph., Der bayerische Renaissancehof Herzog Wilhelms V. (I568- I 579). Ein Beitrag zur bayerischen und deutschen Kulturgeschichte des I6. Jhdts., Leipzig/Straßburg I943.

Babel, Rainer, Heinrich II. in: Peter Claus Hartmann (Hg.), Französische Könige und Kaiser der Neuzeit: von Ludwig XII. bis Napoleon III. I 498 - I 870, München I 994, 7 I - 90.

Babel, Rainer/Paravicini, Werner (Hgg.), Grand Tour. Adeliges Reisen und europäische Kultur vom I 4. bis zum i 8. Jahrhundert. Akten der internationalen Kolloquien in der Villa Vigoni 1999 und im deutschen historischen Institut Paris 2000 (= Beihefte der Francia 60), Ostfildern 2005 .

BACCHI, Andrea, Sculpteurs et sculptures à Ferrare au XVIe siècle, in: Bentini/Agostini, Une Renaissance singulière, $305-309$.

Bachtler, Monika/Diemer, Peter/Erichsen, Johannes, Die Bestände von Maximilians I. Kammergalerie. Das Inventar von I64I/42, in: Glaser, Quellen und Studien, I9 I-252.

Backmann, Sibylle, Kunstagenten oder Kaufleute? Die Firma Ott im Kunsthandel zwischen Oberdeutschland und Venedig ( $5_{5} 5^{0}-\mathrm{I}_{5} \mathrm{O}$ ), in: Bergdolt/Brüning, Kunst und ihre Auftraggeber, I75- I 97 .

Bасzкошsкi, Krysztof, Humanismus in Krakau und Wien um die Wende vom 15. zum I6. Jahrhundert, in: Langer/Michels, Metropolen und Kulturtransfer, 53-64.

BAdeA, Andreea, »Es trieb ihn längst zum Krieg in der Unruhe seines Geistes«. Markgraf Albrecht von Brandenburg-Kulmbach und der Fürstenaufstand, in: Fuchs/Rebitsch, Kaiser und Kurfürst, 99- i I 7 .

Badini, Gino, La città e il Ducato di Reggio nello Stato di Modena (I 598 - I 859), in: Spaggiari/ Trenti, Lo Stato di Modena, 5 I 3-540.

Baethgen, Friedrich, Das Reich und Italien, in: Mediaevalia. Aufsätze, Nachrufe, Besprechungen von Friedrich Baethgen I (= Schriften der Monumenta Germaniae Historica I 7/I), Stuttgart I 960, 3-24.

Baldi, Rita, Giovan Battista Pigna. Uno scrittore politico nella Ferrara del Cinquecento, Genova 1983 .

Ballarin, Alessandro, La devoluzione di Ferrara alla Santa Sede. Intermezzo storico, in: Ders. (Hg.), Il camerino delle pitture di Alfonso I, 6 Bde. 4, Padova 2002-2007, 479-5 I 3.

Ballett i, Andrea, Gli ebrei e gli Estensi, Reggio Emilia ${ }^{2}$ I 930.

Balmas, Enea, Ferrara e la Francia nel XVI secolo: uno sguardo d'insieme, in: Bertozzi, Alla corte degli Estensi, 355-364.

Barbiche, Bernard, La politique de Clément VIII à l'ègard de Ferrare en novembre et décem- 
bre 1597 et l'excommunication de César d'Este, in: Mélanges d'Archéologie et d'Historie 74 (I 962$), 289-328$.

Barbieri, Giovanni Maria, Entrata solenne di Alfonso II duca di Ferrara in Modena, hg. v. Tommaso Sandonnini, Modena I 880.

Barletta, Laura/Cardini, Franco/Galasso, Giuseppe (Hgg.), Il piccolo stato. Politica, storia, diplomazia. Atti del convegno di studi, San Marino, Antico Monastero di Santa Chiara, I I - I 3 ottobre 200I, San Marino 2003.

Barotтi, Riccardo, Esiste uno Stato del Rinascimento nei feudi malaspiniani della Lunigiana?, in: Cremonini/Musso, I feudi imperiali, $366_{3}-388$.

Barth, Matthias, Mecklenburgische Residenzen. Landesfürstliche Repräsentationsarchitektur aus sieben Jahrhunderten, Leipzig I 995.

BAssi, Carlo, Perché Ferrara è bella. Guida alla comprensione della città, Ferrara I 994.

Bauer, Volker, Wurzel, Stamm, Krone: fürstliche Genealogie in frühneuzeitlichen Druckwerken. Ausstellung der Herzog August Bibliothek Wolfenbüttel, Augusteerhalle, Schatzkammer, Kabinett vom r. September 2013 bis zum 23. Februar 2014, Wiesbaden 2013.

Baumann, Zygmunt, Liquid Modernity, Cambridge 2000.

Bäumel, Jutta, »so vil Dings zu sehen«. Die Dresdner Rüstkammer als Festausstatter, in: Schnitzer/Hölscher, Eine gute Figur machen, 39-45.

Baumstark, Reinhold, Albrecht V. der Renaissancefürst und seine Sammlungen, in: Schmid/ Weigand, Die Herrscher Bayerns, I73- i 88.

Bausinger, Hermann (Hg.), Reisekultur. Von der Pilgerfahrt zum modernen Tourismus, München I99I.

Bayerische Staatsbibliothe (Hg.), Orlando di Lasso. Musik der Renaissance am Münchner Fürstenhof. Ausstellung zum 450. Geburtstag 27. Mai - 31. Juli I982, Wiesbaden I 982.

Bayreuther, Magdalena, Pferde in der Diplomatie der frühen Neuzeit, in: Häberlein/Jeggle, Materielle Grundlagen, 227-256.

Bay reuther, Magdalena, Pferde und Fürsten. Repräsentative Reitkunst und Pferdehaltung an fränkischen Höfen ( $1600-$ I 800) (= Stadt und Region in der Vormoderne I), Würzburg 20 I 4.

BAzzoli, Marco, Il piccolo Stato nell'età moderna. Studi su un concetto della politica internazionale tra XVI e XVII secolo, Milano I 990.

Becker, Sebastian, Das Montefeltro und die Herzöge von Urbino im Spannungsfeld zwischen Florenz, Papsttum und Reich, in: Taddei/Schnettger/Rebitsch, Reichsitalien, 79-96.

Becker, Sebastian, Dynastische Politik und Legitimationsstrategien der della Rovere. Potenziale und Grenzen der Herzöge von Urbino (I 508 - I63 I) (= Bibliothek des Deutschen Historischen Instituts in Rom I29), Berlin/Boston 2015.

Ведомi, G., I primi anni di governo di Cesare d'Este sconvolti da vicende dinastiche ed ereditarie (1597-1602), in: Atti e memorie della Deputazione di Storia Patria per le Antiche Province Modenesi XI, XX (1998), 67-92.

Beer, Christa, Die Beziehungen Kaiser Maximilians I. zu Mantua während der Regentschaft Markgräfin Isabellas d'Este (I 5 O5 - I 5 Io), in: Höflechner/Mezler-Andelberg/Pickl, Domus Austriae, $50-56$.

Béhar, Pierre/Watanabe-O'Kelly, Helen (Hgg.), Spectaculum Europæum. Theatre and Spectacle in Europe/Histoire du spectacle en Europe (I $580-$ I750), Wiesbaden 1999.

Behringer, Wolfgang, »Kleine Eiszeit« und Frühe Neuzeit, in: Wolfgang Behringer/Hartmut 
Lehmann/Christian Pfister (Hgg.), Kulturelle Konsequenzen der »Kleinen Eiszeit«/Cultural Consequences of the »Little Ice Age« (= Veröffentlichungen des Max-Planck-Instituts für Geschichte 2I 2), Göttingen 2005, 4I 5-508.

Behringer, Wolfgang, Core and Periphery: The Holy Roman Empire as a Communication(s) Universe, in: Evans/Schaich/Wilson, The Holy Roman Empire, 347-358.

Behringer, Wolfgang, Im Zeichen des Merkur. Reichspost und Kommunikationsrevolution in der Frühen Neuzeit, Göttingen 2003.

Behringer, Wolfgang, Thurn und Taxis. Die Geschichte ihrer Post und ihrer Unternehmen, München/Zürich I990.

Beiderbeck, Friedrich, Deutsche kulturelle Referenzen in der französischen Außenpolitik im I6. Jahrhundert, in: Schmale, Kulturtransfer, I $85-203$.

Beiderbeck, Friedrich, Wahrnehmung des Reichstages in der Reichspolitik König Heinrichs IV. von Frankreich, in: Lanzinner/Strohmeyer, Der Reichstag I486- I6 I 3, 497-52 I.

Beimrohr, Wilfried, Das Tiroler Landesarchiv und seine Bestände (= Tiroler Geschichtsquellen 47 , Innsbruck 2002).

Bellabarba, Marco/Merlotti, Andrea (Hgg.), Stato sabaudo e Sacro Romano Impero, Bologna 2014.

Bellabarba, Marco/Niederkorn, Jan-Paul (Hgg.), Le corti come luogo di comunicazione. Gli Asburgo e l'Italia (secoli XVI-XIX)/Höfe als Orte der Kommunikation. Die Habsburger und Italien ( 6 6. bis I 9. Jahrhundert) (= Annali dell'Istituto storico italo-germanico in Trento/ Jahrbuch des italienisch-deutschen historischen Instituts in Trient, Contributi/Beiträge 24), Bologna/Berlin 20 io.

Belligni, Eleonora, Evangelismo, riforma ginevrina e nicodemismo: l'esperienza religiosa di Renata di Francia, Cosenza 2008.

Belligni, Eleonora, Reti eterodosse e maestri d'eresia: La corte di Renata di Francia tra Ferrara e Consandolo, in: Schifanoia. Notizie dell'Istituto di Studi rinascimentali di Ferrara, 28/29 (2005), 233-246.

Bellinazzi, Anna/Martelli, Francesco, Le relazioni del Granducato di Toscana con lo Stato di Modena nei carteggi politici del Principato mediceo, in: Spaggiari/Trenti, Lo Stato di Modena 2, I I 79- I 209.

Beцoch, Karl Julius, Bevölkerungsgeschichte Italiens 2: Die Bevölkerung des Kirchenstaates, Toscanas und der Herzogtümer am Po, Berlin r 965.

Bender, Eva/Herzog, Doris/Niehaus, Petra, Die Kavalierstour. Pergrinomania oder die Raserey zu Reisen, in: Eva Bender et al. (Hgg.), Erdengötter. Fürst und Hofstaat in der Frühen Neuzeit im Spiegel von Marburger Bibliotheks- und Archivbeständen. Katalog, Marburg I 997, 57 I-6I9.

Benedict, Philip/Seidel Menchi, Silvana/Tallon, Alain (Hgg.), La réforme en France et en Italie. Contacts, comparaisons et contrastes (= Collection de l'école française de Rome 384), Rome 2007.

Benevolo, Leonardo, La città nella storia d'Europa, Roma/Bari 2004.

Bentini, Jadranka (Hg.), Gli Este a Ferrara. Una corte nel Rinascimento, catalogo della mostra, Castello di Ferrara I4 marzo-I 3 giugno 2004, Milano 2004.

Bentini, Jadranka, La pittura nel Cinquecento, in: Bocchi, Storia illustrata di Ferrara 2, $385-400$. 
Bentini, Jadranka/Agostini, Grazia (Hgg.), Une Renaissance singulière. La Cour des Este à Ferrare, Bruxelles, Palais des Beaux-Arts, 3 octobre 2003- I I janvier 2004, Milano 2003.

Bepler, Jill, Women's Books and Dynastic Networks in Early Modern Germany. Female Practices of Collecting and Bequeathing, in: Rode-Breymann/Tumat, Der Hof, 295-3 I 3.

Berengan, Giuliana u.a. (Hgg.), Le dame della corte estense, Ferrara 1998.

BERG, Christian, »Netz/Vernetzung «, in: Reinalter/Brenner, Lexikon der Geisteswissenschaften, $578-584$.

Bergdolt, Klaus/Brüning, Jochen (Hgg.), Kunst und ihre Auftraggeber im i6. Jahrhundert. Venedig und Augsburg im Vergleich (= Colloquia Augustana 5), Berlin 1997.

Bernardi, Tiziana, Analisi di una cerimonia pubblica. L'incoronazione di Carlo V a Bologna, in: Quaderni storici 6r (I986), I7 I - I99.

Bertelli, Sergio/Cardini, Franco/Gambero Zorzi, Elvira (Hgg.), Le corti italiane del Rinascimento, Milano I 995 .

Bertelli, Sergio/Crifò (Hgg.), Giuliano, Rituale, ceremoniale, etichetta, Milano i 985.

Bertoni, Giulio, La biblioteca estense. La coltura ferrarese ai tempi del duca Ercole I ( 477 I I 5 O5), Torino I 903 .

Bertozzi, Marco (Hg.), Alla corte degli Estensi. Filosofia, arte e cultura a Ferrara nei secoli XV e XVI. Atti del convegno internazionale di studi, Ferrara, 5-7 marzo i 992, Ferrara I 994.

Bertozzi, Marco, L'astrologia a corte, in: Bocchi, Storia illustrata di Ferrara 2, 449-464.

Besozzi, Cerbonio, Die Chronik des Cerbonio Besozzi I 548 - I $56_{3}$, hg. v. Walter Friedensburg, Wien I904.

Bestor, Jane Fair, Bastardy and Legitimacy in the Formation of a Regional State in Italy: The Estense Succession, in: Comparative Studies in Society and History 38/3 (July I 996), $549-585$.

Bestor, Jane Fair, Gli illegittimi e beneficiati della Casa estense, in: Prosperi, Storia di Ferrara 6,78 - Iог.

Bianchi, Alessandro, Al servizio del principe. Diplomazia e corte nel ducato di Mantova (= Politica Estera e Opinione Pubblica, N.S.), Milano 20 I 2.

BIAnchi, Alessandro, Una rivalità di lungo periodo: i rapporti politico-diplomatici tra gli Este e i Gonzaga, in: Fumagalli/Signorotto, La corte estense, 349-367.

Bıвц, Viktor, Die Erhebung Herzog Cosimos von Medici und die kaiserliche Anerkennung (1569-1576), Sonderdruck aus dem Archiv für Österreichische Geschichte 103/r, Wien I9II.

Bıв L, Viktor, Die Korrespondenz Maximilians II. 2 : Familienkorrespondenz 9. August I $566-27$. Dezember I 567 , Wien I 92 I.

Вıв L, Viktor, Maximilian II., der rätselhafte Kaiser. Ein Zeitbild, Hellerau bei Dresden I 929.

Bini, Mauro (Hg.), Gli Estensi 2: La Corte di Modena, Modena 1999.

Biondi, Albano, Ferrara: cronache della caduta, in: Prosperi, Storia di Ferrara 6, 493- 508.

Bızzocchi, Roberto, Genealogie incredibili. Scritti di storia nell'Europa moderna (= Annali dell'Istituto storico italo-germanico, Monografie 22), Bologna I 995.

Blasch кe, Karlheinz (Hg.), Moritz von Sachsen - Ein Fürst der Reformationszeit zwischen Territorium und Reich. Internationales wissenschaftliches Kolloquium vom 26. bis 28. Juni 2003 in Freiberg (Sachsen) (= Quellen und Forschungen zur sächsischen Geschichte 29), Stuttgart 2007 . 
Blaschкe, Karlheinz, Alte sächsisch-böhmische Nachbarschaft und reichspolitische Begegnung zwischen Moritz von Sachsen und Ferdinand I 546/47, in: Fuchs/Kohler, Kaiser Ferdinand I., I67- I 76 .

Bocchi, Francesca (Hg.), Storia illustrata di Ferrara 2, Milano I 987.

Bocchi, Francesca, Gli Estensi nel Rinascimento I44I- I598, in: Bocchi, Storia illustrata di Ferrara 2, 337-352.

Bocchi, Francesca, Il dominio estense (1527-1796), in: Francesca Bocchi (Hg.), Atlante storico delle città italiane, Bologna I 986, 22-25.

Bocchi, Francesca, La »Terranova« da campagna a città, in: Papagno/Quondam, La corte e lo spazio, I67-192.

Boccolari, Giorgio, Gli Estensi a Modena, in: Spaggiari/Trenti, Lo Stato di Modena, 23-43.

Bodart, Diane H., L'immagine di Carlo V in Italia tra trionfi e conflitti, in: Cantù/Visceglia, L'Italia di Carlo V, i I 5 - I 39 .

Boенеiм, Wendelin, Inventar des Nachlasses von Erzherzog Ferdinand II. in Innsbruck und Ambras vom 30. Mai I 596, in: Jahrbuch der kunsthistorischen Sammlungen des Allerhöchsten Kaiserhauses 7: Urkunden und Regesten aus der k.k. Hofbibliothek (1888), 227-3 I 3.

Вӧнме, Hartmut, Einführung. Netzwerke. Zur Theorie und Geschichte einer Konstruktion, in: Jürgen Barkhoff/Hartmut Böhme/Jeanne Riou (Hgg.), Netzwerke. Eine Kulturtechnik der Moderne ( = Literatur - Kultur - Geschlecht. Studien zur Literatur- und Kulturgeschichte 29), Köln/Weimar/Wien 2004, I7-36.

Bojcov, Michail A., Maximilian und sein Hof r 5 18 - von den russischen Gesandten her (nicht?) gesehen, in: Noflatscher/Chisholm/Schnerb, Maximilian I., 45-69.

Bömelburg, Hans-Jürgen, Adelige Mobilität und Grand Tour im polnischen und litauischen Adel (1 500-1700), in Babel/Paravicini, Grand Tour, 309-326.

Bömelburg, Hans-Jürgen, Die Wahrnehmung des Reichstags in Polen-Litauen. Mitteleuropäische Kommunikationsstrukturen und die polnischen Gesandtschaften zum Reichstag I486-I6I3, in: Lanzinner/Strohmeyer, Der Reichstag I486-I6I3, 405-437.

Bonacini, Pierpaolo, Capitanei e ceto dominante a Modena nei secoli XI-XII, in: Castagnetti, La vassallità maggiore, $263-284$.

Bonacini, Pierpaolo, Giovan Battista Muneretti. Rapporti tra ducato estense e Impero nel Settecento attraverso la mediazione di un agente presso il Reichshofrat, in: Quellen und Forschungen aus italienischen Archiven und Bibliotheken 92 (201 2), 430-497.

Bonazza, Mirna, »Frammenti« di biblioteche nella Ferrara di Lucrezia Borgia: Note sulla circolazione libraria tra i secoli XV e XVI, in: Farinelli Toselli, Lucrezia Borgia a Ferrara, 23-33.

Bongiovanni, Giannetto, Isabella d'Este. Markgräfin von Mantua. Ein Frauenleben der Renaissance, aus dem Italienischen von Werner Guggenheim, Zürich/Leipzig I 94I.

Bonilauri, Franco/Maugeri, Vincenza (Hgg.), Le Comunità ebraiche a Modena e a Carpi. Dal Medioevo all'età contemporanea, Firenze r 999.

Bonora, Elena, Aspettando l'imperatore. Principi italiani tra il Papa e Carlo V (= Einaudi storia 57), Torino 2014.

Borchardt, Erika/Borchardt, Jürgen, Mecklenburgs Herzöge. Ahnengalerie Schloß Schwerin, Schwerin I99I.

Borella, Marco (Hg.), Gli Este a Ferrara. Il Castello per la città, Milano 2004. 
Borella, Marco, Il Palazzo di Corte dei duchi d'Este in Ferrara (I47I-I 598), in: Weber, Il trionfo di Bacco, I 7-26.

Borgia, Luigi, Atti imperiali di grazia a favore di famiglie italiane, successivamente al I 400, in: Rassegna degli Archivi di Stato 49 (I989), 33 I-36r.

Born, Karl Erich, »Moritz von Sachsen und die Fürstenverschwörung gegen Karl V.«, in: Historische Zeitschrift I9 I/ I ( 1960), I 8-66.

Bозвасн, Franz, Selbstauffassung und Selbstdarstellung Karls V. bei der Kaiserkrönung in Bologna, in: Kohler/Haider/Ottner, Karl V., 82 - го3.

Bösel, Richard/Kuingenstein, Grete/Koller, Alexander (Hgg.), Kaiserhof - Papsthof (г6.- г8. Jahrhundert) (= Publikationen des Historischen Instituts beim Österreichischen Kulturforum in Rom, Abhandlungen I 2), Wien 2006.

Bourdieu, Pierre, Die feinen Unterschiede. Kritik der gesellschaftlichen Urteilskraft, Frankfurt a.M. ${ }^{3}$ I 989 .

Bourdieu, Pierre, Die verborgenen Mechanismen der Macht, Hamburg 1992.

Bourdieu, Pierre, Entwurf einer Theorie der Praxis auf der ethnologischen Grundlage der kabylischen Gesellschaft, Frankfurt 1979.

Bozza, Tommaso, Calvino in Italia, Roma 966.

Brakensiek, Stefan, Herrschaftsvermittlung als kultureller Austausch, in: North, Kultureller Austausch, I63-I73.

Brandi, Karl, Karl V. Werden und Schicksal einer Persönlichkeit und eines Weltreiches 2 Bde., München I 94I.

Brandstätter, Klaus, Aspekte der Festkultur unter Maximilian, in: Noflatscher/Chisholm/ Schnerb, Maximilian I., I 56- I70.

Brandstätter, Klaus/Hörmann, Julia (Hgg.), Tirol - Österreich - Italien. Festschrift für Josef Riedmann zum 65. Geburtstag, Innsbruck 2005.

Braudel, Fernand, L'Italia fuori d'Italia. Due secoli e tre Italie, in: Storia d'Italia. Dalla caduta dell'Impero romano al secolo XVIII 4: L'economia delle tre Italie, Milano 2005, 209 I - 2248.

BräUer, Helmut, Probleme der Migration von Handwerkern und Gesellen während des Spätmittelalters und der frühen Neuzeit, in: Beiträge zur historischen Sozialkunde 3 (I989), $78-84$.

Braun, Bettina/Keller, Katrin/Schnettger, Matthias (Hgg.), Nur die Frau des Kaisers? Kaiserinnen in der Frühen Neuzeit (= Veröffentlichungen des Instituts für Österreichische Geschichtsforschung 64), Wien/Köln/Weimar 2016.

Braun, Guido, Die Wahrnehmung der Reichstage des r6. Jahrhunderts durch die Kurie, in: Lanzinner/Strohmeyer, Der Reichstag I486- i6 13 3, 46 I- 495 .

Braun, Guido, Imagines imperii. Die Wahrnehmung des Reiches und der Deutschen durch die römische Kurie im Reformationsjahrhundert (I523-I585) (= Schriftenreihe der Vereinigung zur Erforschung der Neueren Geschichte 37), Münster 2014.

Brauneder, Wilhelm, Impero e Stato a sud delle Alpi nel XVIII secolo, in: Mozzarelli/Olmi, Il Trentino nel Settecento, 59-84.

Brendecke, Arndt (Hg.), Praktiken der Frühen Neuzeit. Akteure - Handlungen - Artefakte, Weimar/Köln/Wien 20I5.

Brenner, Peter J., Der Reisebericht in der deutschen Literatur. Ein Forschungsüberblick als 
Vorstudie zu einer Gattungsgeschichte (= Internationales Archiv für Sozialgeschichte der deutschen Literatur, 2. Sonderheft), Tübingen r 990.

Broскноғғ, Evelyn/Matтнӓus, Michael (Hgg.), Die Kaisermacher. Frankfurt am Main und die Goldene Bulle 1 356- I 806. Aufsätze, Frankfurt a.M. 2006.

Bruning, Jens, August I 553 - I 586 , in: Kroll, Die Herrscher Sachsens, I Io- I 25.

Brunner, Georg, »Die Lieblich Kunst der Musica« oder Ottheinrichs »Feine Cantorey und gute Instrumentisten«. Musik am Hofe Ottheinrichs in Neuburg, in: Stadt Neuburg an der Donau, Pfalzgraf Ottheinrich, 249-274.

Büchner, Robert, Schattenseiten der höfischen Jagd: Maximilians übertriebene Wildhege und schonungslose Greifvogelvernichtung, in: Noflatscher/Chisholm/Schnerb, Maximilian I., 4I I -439 .

Buck, August/Kauffmann, Georg/Spahr, Blake Lee/Wiedemann, Conrad (Hgg.), Europäische Hofkultur im I6. und I 7. Jahrhundert. Vorträge und Referate gehalten anlässlich des Kongresses des Wolfenbütteler Arbeitskreises für Renaissanceforschung und des Internationalen Arbeitskreises für Barockliteratur in der Herzog August Bibliothek Wolfenbüttel vom 4. bis 8. September 19793 Bde. (= Wolfenbütteler Arbeiten zur Barockforschung 8-1o), Hamburg I98I.

Bünz, Enno, Die Kurfürsten von Sachsen bis zur Leipziger Teilung I 423-I485, in: Kroll, Die Herrscher Sachsens, 39-54.

Bünz, Enno/Volkmar, Christoph, Die albertinischen Herzöge bis zur Übernahme der Kurwürde ( 1485 - I 547), in: Kroll, Die Herrscher Sachsens, 76- ro9.

Burckhardt, Jacob, Die Kultur der Renaissance in Italien. Ein Versuch, Leipzig ${ }^{17}$ I 925.

Büren, Guido von, Der Ausbau Jülichs zu einer Residenzstadt des Herzogtums Jülich-KleveBerg in der Mitte des r6. Jahrhunderts, in: Paravicini/Wettlaufer, Der Hof und die Stadt, $249-260$.

Burgess Williams, Allyson, Power and Painting in Sixteenth-Century Ferrara: Titian's Portraits of Alfonso I d'Este, in: Visual Resources: An International Journal of Documentation 28/I (20I2), 80- IO2.

Bur ke, Peter, Die europäische Renaissance. Zentrum und Peripherien, aus dem Englischen von Klaus Kochmann, München I 998.

Bur Ke, Peter, Die Renaissance in Italien. Sozialgeschichte einer Kultur zwischen Tradition und Erfindung, aus dem Engl. von Reinhard Kaiser, Darmstadt 1992.

Bur ke, Peter, Kultureller Austausch, aus dem Engl. von Burkhardt Wolf (= Erbschaft unserer Zeit. Vorträge über den Wissensstand der Epoche 8), Frankfurt a.M. 2000.

Burke, Peter, Präsentation und Re-Präsentation. Die Inszenierung Karls V., in: Soly, Karl V., $393-475$.

Burke, Peter, Translating Knowledge, Translating Cultures, in: North, Kultureller Austausch, $69-77$.

Burkhart, Dagmar, Eine Geschichte der Ehre, Darmstadt 2006.

Burschel, Peter, Das Eigene und das Fremde. Zur anthropologischen Entzifferung diplomatischer Texte, in: Koller, Kurie und Politik, 260-27 I.

Bussi, Emilio, Lo studio del Sacro Romano Impero della Nazione Tedesca come esigenza della scienza storica, in Diritto \& storia 3 (maggio 2004), Online verfügbar unter http://www. 
dirittoestoria.it/3/In-Memoriam/Emilio-Bussi/Cent'anni-di-Emilio-Bussi/Bussi-Ultimalezione.htm, Zugriff: i 8.7.2020.

Bussi, Luisa, Tradizione e innovazione nella formazione delle leggi nel Sacro Romano Impero del XVIII secolo in: Diritto \& storia 7 (2008) Online verfügbar unter http://www.dirittoestoria.it/ 7 /Tradizione-Romana/Bussi-Tradizione-innovazione-leggi-Sacro-Romano-Impero.htm, Zugriff: I 8.7.2020.

BŮžeк, Václav, Ferdinand von Tirol zwischen Prag und Innsbruck. Der Adel aus den böhmischen Ländern auf dem Weg zu den Höfen der ersten Habsburger, aus dem Tschechischen von Thomas Pimingsdorfer, Wien/Köln/Weimar 2009.

CAirns, Christopher, La commedia dell'arte en Europe, ins Französische übersetzt von P. Béhar, in: Béhar/Watanabe-O'Kelly, Spectaculum Europæum, 77- i i 8.

Callegari, E., La devoluzione di Ferrara alla S. Sede da documenti inediti degli Archivi di Stato di Modena e Venezia, in: Rivista Storica Italiana I 2 (I 895 ), I - 57.

Calore, Marina et alii (Hgg.), Ferrara delle Donne. Le custodi del sacro, Ferrara I 999.

Calvi, Giulia/Spinelli, Riccardo (Hgg.), Le donne Medici nel sistema europeo delle corti XVI-XVIII secolo r. Atti del convegno internazionale, Firenze-San Domenico di Fiesole, 6-8 ottobre 2005 , Firenze 2008.

Cam pori, Giuseppe, Carlo V in Modena. Commentario storico, Firenze i 848.

CAM PORI, Giuseppe, Gli artisti italiani e stranieri negli stati estensi. Catalogo storico corredato di documenti inediti, Modena I 855, http://babel.hathitrust.org/, Zugriff: I 5.7.2020.

Canova-Green, Marie-Claude, The English court masque, in: Béhar/Watanabe-O'Kelly, Spectaculum Europæum, 523-546.

Cantù, Cesare, Gli eretici d'Italia. Discorsi storici 2, Torino I 865.

Cantù, Francesca/Visceglia, Maria Antonietta (Hgg.), L'Italia di Carlo V. Guerra, religione e politica nel primo Cinquecento. Atti del convegno internazionale di studi, Roma, $5-7$ aprile 2001 , Roma 2003.

CAPei, P., Saggio di atti e documenti nella controversia di precedenza tra il duca di Firenze e quello di Ferrara negli anni I 562-I 573, in: Archivio storico italiano 7 (I 858), 93- i I6.

Cappelletti, Francesca, Le decorazioni nel Rinascimento e l'immagine del Castello alla fine del Cinquecento, in: Borella, Gli Este a Ferrara, 95 - Io6.

CARile, Paolo, Considerazioni introduttive sui rapporti culturali tra Ferrara e la Francia nel Rinascimento, in: Bertozzi, Alla corte degli Estensi, 247-254.

Carl, Horst, Europäische Adelsgesellschaft und deutsche Nation in der Frühen Neuzeit, in: Georg Schmidt (Hg.), Die deutsche Nation im frühneuzeitlichen Europa. Politische Ordnung und kulturelle Identität (= Schriften des Historischen Kollegs. Kolloquien 80), München 2010, I $8 \mathrm{I}-200$.

Carroll, Linda, »Fools of the Dukes of Ferrara $:$ Dosso, Ruzante and Changing Este Alliances, in: Modern Languages Notes I I 8/I, Italian Issue (Jan., 2003), 6o-84, http://www.jstor. org/stable/325 I 57 I, Zugriff: 27.6.2020.

Castagnetti, Andrea (Hg.), La vassallità maggiore del Regno Italico. I. Capitanei nei secoli XI-XII. Atti del convegno, Verona, 4-6 novembre i 999, Roma 20 I I.

Castagnetti, Andrea, Da Verona a Ravenna per Vicenza, Padova, Trento e Ferrara, in: Castagnetti, La vassallità maggiore, $345-5 \mathrm{I} 2$.

Castagnetti, Andrea, Dai da Ganaceto (Modena) ai da Calaone (Padova) fra conti vero- 
nesi, Canossa ed Estensi, in: Reti Medievali Rivista IV 2003/I (gennaio-giugno), Digitalisat, http://www.retimedievali.it, Zugriff: 3.7.2020.

Castagnetti, Andrea, Introduzione, in: Castagnetti, La vassallità maggiore, 7-23.

Castor, Markus A., Rocco di Linar und die Mathematica Militaris der Dresdner Fortifikation in italienischer Manier. Städteplanung von der Bild- zur Raumordnung, in: Marx, Elbflorenz, IOI-I34.

Cavalcaselle, Giovanni Battista/Crowe, Joseph Archer, Tizian. Leben und Werke I, deutsche Ausgabe von Max Jordan, Leipzig 1877.

Cavallera, Marina, Les fiefs impériaux dans l'Italie nord-occidentale au XVIIIe siècle, in: Paul Delsalle/André Ferrer (Hgg.), Les enclaves territoriales aux Temps Modernes (XVIe-XVIIIe siècles), Besançon 2000, I85-208.

Cavallina, Diego, Leditoria ferrarese nei secoli XV e XVI, in: Rossi, Il Rinascimento nelle corti padane, $34 \mathrm{I}-360$.

Cavicchi, Adriano, Le Cavallerie estensi, in: Bentini, Gli Este a Ferrara, 45-5 I.

Cazzola, Franco, Acque di frontiera. Il governo idraulico nella Bassa Pianura Padana in Età Moderna, in: Fregni, Archivi, r69- r 88.

Cazzola, Franco, La politica del territorio, in: Borella, Gli Este a Ferrara, 85-94.

Cazzola, Franco, Lorto di Belfiore, la villa, il barco: una campagna per diletto, in: Mottola Molfino/Natale, Le muse e il principe 2, 203-222.

Cazzola, Franco: Economia e politica della ospitalità in una corte rinascimentale. Gli ospiti alla corte di Ferrara dal I 56 i al I 566, in: Antonio Samaritani/Ranieri Varese (Hgg.), L'aquila bianca. Studi di storia estense per Luciano Chiappini (= Deputazione provinciale Ferrarese di Storia Patria, Atti e memorie, serie IV, I 7), Ferrara 2000, 230-282.

Ceccarelli, Francesco, Palazzi, castalderie e delizie. Forme degli insediamenti estensi nel Ferrarese tra Quattrocento e Cinquecento, in: Borella, Gli Este a Ferrara, 73-84.

Ceccarelli, Francesco, Principi, città e architettura. Ferrara nel Cinquecento, in: Bentini, Gli Este a Ferrara, I35-I45.

Ceccarelli, Francesco/Folin, Marco (Hgg.), Delizie estensi: architetture di villa nel Rinascimento italiano ed europeo, Firenze 2009.

Ceriana, Matteo (Hg), Gli Este a Ferrara: il camerino di alabastro: Antonio Lombardo e la scultura all'antica. Catalogo della mostra, Milano 2004.

СнавоD, Federico, Carlo V e il suo Impero, Torino i 985.

Снавод, Federico, Esiste uno Stato nel Rinascimento?, in: Federico Chabod, Scritti sul Rinascimento, Torino I 967, 59 I-623.

Cheles, Luciano, Il ritratto di corte a Ferrara e nelle altre corti centro-settentrionali, in: Mottola Molfino/Natale, Le muse e il principe I, I3-24.

Chiappini, Alessandra, Notizie di codici estensi presso la biblioteca Ariostea di Ferrara, in: Iotti, Gli Estensi I, 347-355.

Chiappini, Luciano, Eleonora d'Aragona. Prima duchessa di Ferrara, in: Atti e memorie della deputazione provinciale ferrarese di storia patria I6 (I956), 5- I 25.

Chiappini, Luciano, Ferrara. Guida illustrata a colori, Bologna i 992.

Chiappini, Luciano, Gli Estensi, Milano ${ }^{2}$ i 967.

Chiappini, Luciano, Le relazioni tra Ferrara estense e Inghilterra nel '40o e nel '500, in: Salmons/Moretti, The Renaissance in Ferrara, I75- I89. 
Chiarelli, Alessandra, Fonti e vita musicale estense tra corte, collezionismi e accademia. Raccolta bibliografica e tradizione inventariale, in: Bini, Gli Estensi 2, 263-3 Io.

Chiarini, Paolo/Zeman, Herbert (Hgg.), Italia-Austria. Alla ricerca del passato comune/Österreich-Italien. Auf der Suche nach der gemeinsamen Vergangenheit, Roma I 995.

Chisнolm, Michael A., Robert Wingfield: English Ambassador to the Holy Roman Empire ( 5 Io-I 5 I 7), in: Noflatscher/Chisholm/Schnerb, Maximilian, 7 I-83.

Chittolini, Giorgio, Cities, „City-States« and Regional States in North-Central Italy, (= Theory and Society 18/5: Special Issue on Cities and States in Europe. I000-1800) (1989), 689-706.

Снitтolini, Giorgio, Feudalherren und ländliche Gesellschaften in Nord- und Mittelitalien (I 5.- I 7. Jahrhundert), in: Mączak, Klientelsysteme, 243-259.

Chit tolini, Giorgio, Il particolarismo signorile e feudale in Emilia fra Quattro e Cinquecento, in: Rossi, Il Rinascimento nelle corti padane, $23-52$.

Chittolini, Giorgio, Italienische und deutsche Fürstentümer im I5. Jahrhundert: ein Vergleich, in: Rückert/Lorenz, Die Visconti, 63-86.

Chittolini, Giorgio, Stati padani, »Stato del Rinascimento«: problemi di ricerca, in: Tocci, Persistenze feudali, $9-29$.

Chittolini, Giorgio/Molho, Anthony/Schiera, Pierangelo (Hgg.), Origini dello Stato. Processi di formazione statale in Italia fra medioevo ed età moderna (= Annali dell'Istituto storico italo-germanico. Quaderno 39), Bologna I 994.

Chittolini, Giorgio/Willoweit, Dietmar (Hgg.), Lorganizzazione del territorio in Italia e Germania: secoli XIII-XIV (= Annali dell'Istituto storico italo-germanico. Quaderno 37), Bologna I 994 .

Choné, Paulette, Triomphes, entrées, feux d'artifice et fêtes religieuses en Italie, in: Béhar/Watanabe-O'Kelly, Spectaculum Europæum, 643-662.

Cipriani, Giovanni, LImpero e la cultura politica italiana nel primo Cinquecento, in: Schnettger/Verga, L'Impero e l'Italia, 393-4I 5 .

Cittadella, Luigi Napoleone, Saggio di storia politica di Ferrara. Ultimo decennio di Ercole II duca IV (I 549-I 559), in: Archivio storico italiano 25, terza serie (I 877 ), 43-64.

Clough, Cecil, »Montefeltro«, in: Reinhardt, Die großen Familien, 360-37 I.

Cochrane, Eric W./Villani, Pasquale/Cialdea, Basilio (Hgg.), Gli Stati italiani e la pace dei Pirenei. Saggio sulla diplomazia Seicentesca, Milano i 96r.

Coester, Christiane, »alla italiana" und »alla francese«. Die Integration einer italienischen Fürstin in die französische Hofgesellschaft im I6. Jahrhundert, in: Nolde/Opitz, Grenzüberschreitende Familienbeziehungen, 73-92.

Coester, Christiane, Schön wie Venus, mutig wie Mars. Anna d'Este, Herzogin von Guise und von Nemours (I53 I-I607) (= Pariser historische Studien 77), München 2007.

Cogotti, Marina/Fiore, Francesco Paolo (Hgg.), Ippolito II d'Este cardinale, principe, mecenate, Roma 2013.

Comensoli Antonini, Lorenzo, Per uno studio dei titoli imperiali e dei privilegi minori nel Reichsitalien. Una nomina comitale a Bergamo nella prima metà del XV secolo, in: Taddei/ Schnettger/Rebitsch, Reichstitalien, I7-34.

Coniglio, Giuseppe, I Gonzaga, Varese i 967.

Conrad, Sebastian/Randeria, Shalini, Einleitung. Geteilte Geschichten - Europa in der 
postkolonialen Welt, in: Sebastian Conrad/Shalini Randeria (Hgg.), Jenseits des Eurozentrismus. Postkoloniale Perspektiven in den Geschichts- und Kulturwissenschaften, Frankfurt a.M./New York 2002, 9-49.

Conrads, Norbert, Das Inkognito. Standesreisen ohne Konventionen, in: Babel/Paravicini, Grand Tour, 59i-607.

Contini, Alessandra, Aspects of Medicean Diplomacy in the Sixteenth Century, in: Frigo, Politics and Diplomacy, 49-94.

Contini, Alessandra, La concessione del titolo di granduca e la »coronazione« di Cosimo I fra papato e Impero (I 569-I 572), in: Schnettger/Verga, L'Impero e l'Italia, 4I 7-459.

Cornides, Elisabeth, Rose und Schwert im päpstlichen Zeremoniell. Von den Anfängen bis zum Pontifikat Gregors XIII., Wien 1967.

Corradini, Elena, Genealogia dei principi d'Este, in: Mottola Molfino/Natale, Le muse e il principe 2, 49-59.

Corradini, Elena, Spes publica: Medaglie estensi, in: Bini, Gli Estensi 2, 3 I I - 32 I.

Corradini, Elena/Cavani, Pier Luigi, »La preziosa Galleria delle Medaglie, e ricco Museo« degli Estensi nel Palazzo Ducale di Modena, in: Spaggiari/Trenti, Lo Stato di Modena, 4I $3-429$.

Cremonini, Cinzia, Considerazioni sulla feudalità imperiale italiana nell'età di Carlo V, in: Cantù/Visceglia, L'Italia di Carlo V, 259-276.

Cremonini, Cinzia, Das Reichslehnswesen in Italien zwischen Kaisertreue und spanischen Interessen: Einige Überlegungen, in: zeitenblicke - online-Journal für Geschichtswissenschaften 6/I (2007), ins Deutsche übersetzt von Matthias Schnettger, http://www.zeitenblicke. de/2007/I/cremonini/index_html, Zugriff: I3.6.2020.

Cremonini, Cinzia, I feudi imperiali italiani tra Sacro Romano Impero e monarchia cattolica (seconda metà XVI-inizio XVII secolo), in: Schnettger/Verga, L'Impero e l'Italia, 4I-65.

Cremonini, Cinzia, Impero e feudi italiani fra Cinque e Settecento, Roma 2004.

Cremonini, Cinzia, La mediazione degli interessi imperiali in Italia in: Cremonini/Musso, I feudi imperiali, $3 \mathrm{I}-48$.

Cremonini, Cinzia/Musso, Riccardo (Hgg.), I feudi imperiali in Italia tra XV e XVIII secolo. Atti del Convegno di studi, Albenga-Finale Ligure-Loano, 27-29 maggio 2004 (= Istituto internazionale di studi liguri. Atti dei convegni XV), Bordighera/Albenga/Roma 2010.

Cresseri, Elena, La Repubblica di Lucca tra fedeltà all'Impero e adesione alla Spagna, in: Cremonini/Musso, I feudi imperiali, 45 I-462.

Czernin, Ursula, Gattinara und die Italienpolitik Karls V.: Grundlagen, Entwicklung und Scheitern eines politischen Programmes (= Europäische Hochschulschriften, Reihe 3: Geschichte und ihre Hilfswissenschaften 559), Frankfurt a.M. u.a. I993.

Czoк, Karl (Hg.), Geschichte Sachsens, Weimar 1989.

Сzок, Karl/Gross, Reiner, Das Kurfürstentum, die sächsisch-polnische Union und die Staatsreform (I 547-1789), in: Czok, Geschichte Sachsens, 208-296.

D'Ascia, Luca, La biblioteca di Celio Calcagnini umanista ferrarese, in: Prosperi, Storia di Ferrara 6, 396-405.

DaCosta Kaufmann, Thomas, Giuseppe Arcimboldo. The Habsburgs's Leonardo, in: Konečný, Rudolf II, I69- I76. 
Dandelet, Thomas J./Marino, John A. (Hgg.), Spain in Italy. Politics, Society and Religion I $500-$ I 700 , Leiden/Boston 2007.

Daniel, Ute, Kompendium Kulturgeschichte. Theorien, Praxis, Schlüsselwörter, Frankfurt a.M. 200 I.

Dartmann, Christoph, Lehnsbeziehungen im kommunalen Italien des i i. und i2. Jahrhunderts, in: Spieß, Ausbildung, I05-1 32 .

Dattero, Alessandra, Corte, esercito e professioni: italiani al servizio degli Asburgo durante il XVIII secolo, in: Bellabarba/Merlotti, Stato sabaudo, 343-358.

De Benedictis, Angela, Il Seicento. Politica e società, in: Bocchi, Storia illustrata di Ferrara $2,48 \mathrm{I}-496$.

De Leva, Giuseppe, Storia documentata di Carlo V in correlazione all'Italia, 5 Bde., Venezia I $893-94$.

Dean, Trevor, Commune and Despot: The Commune of Ferrara under Este Rule. I $300-$ I 450 , in: Ders./Chris Wickham (Hgg.), City and Countryside in Late Medieval and Renaissance Italy. Essays presented to Philipp Jones, London I 990, I83- I 97.

Dean, Trevor, »Este«, in: Reinhardt, Die großen Familien, 243-258.

Dean, Trevor, Ferrara and Mantua, in: Gamberini/Lazzarini, The Italian State, I I 2 - I 3 I.

Dean, Trevor, Land and Power in late Medieval Ferrara. The Rule of the Este, I350- I450, Cambridge University Press, Cambridge/New York/New Rochelle/Melbourne/Sydney I 988.

DeAn, Trevor, Le corti. Un problema storiografico, übersetzt von Flavio Zeni, in: Chittolini/ Molho/Schiera, Origini dello Stato, $425-448$.

Dean, Trevor, Lords, vassals and clients in Renaissance Ferrara, in: English Historical Review Ioo/394 (Jan. I985), Iо6- I I9, online verfügbar unter http://www.jstor.org/stable/569929, Zugriff: $8.7 \cdot 2020$.

Dean, Trevor, »Malatesta«, in: Reinhardt, Die großen Familien, 324-330.

Dean, Trevor, The Courts, in: The Journal of Modern History 67, Supplement: The Origins of the State in Italy, I300-1600 (Dec. I 995), I36- I5 I, http://jstor.org/stable/2 I 25 I 49, Zugriff: 8.6.2020.

Dean, Trevor/Lowe, Kate (Hgg.), Marriage in Italy, I300- I600, Cambridge 1998.

Deibel, Gertrud, Die finanzielle Bedeutung Reichsitaliens für die staufischen Herrscher im zwölften Jahrhundert, in: Zeitschrift der Savigny-Stiftung für Rechtsgeschichte: Germanistische Abteilung 54 (I934), I34-I77.

Del Piazzo, Marcello, Il carteggio »Medici-Este« dal secolo XV al I 532 . Regesti delle lettere conservate negli Archivi di Stato di Firenze e Modena (= Quaderni della Rassegna degli Archivi di stato 34), Roma I964.

Del Pino, Guido, Un problema burocratico: La plenipotenza per i feudi imperiali in Italia e il suo archivio tra XVII e XVIII secolo, in: Rassegna degli Archivi di Stato 54 ( I 994), 55 I - 583.

Della Rena, Orazio, Relazione dello Stato di Ferrara I 589, hg. v. Giuseppe Agnelli, Ferrara [I896].

Delumeau, Jean, Les progrès de la centralisation dans l'État pontifical au XVIe siècle, in: Revue Historique 226, Fasc. 2 (I 96I), 399-4 Io, http://www.jstor.org/stable/4094950 I, Zugriff: 24.6.2020.

De-Magistris, Carlo Pio, L'elevazione di Cosimo I de’Medici alla dignità di Granduca di 
Toscana nelle lettere dell'ambasciatore di Francia a Roma ( $569-70$ ), in: Miscellanea di studi storici in onore di Antonio Manno, Turin I912, 563-587.

Denter, Tom, »Bourdieu, Pierre«, in: Reinalter/Brenner, Lexikon der Geisteswissenschaften, I I 59 - II 62 .

Descharmes, Bernardette/Heuser, Eric Anton/Krüger, Caroline/Loy, Thomas (Hgg.), Varieties of friendship. Interdisciplinary perspectives on social relationships (= Freunde - Gönner - Getreue. Studien zur Semantik und Praxis von Freundschaft und Patronage I), Göttingen $20 \mathrm{II}$.

Di Pascale, Barbara, Banchetti Estensi. La spettacolarità del cibo alla corte di Ferrara nel Rinascimento (= Mosaico 8), Imola I 995 .

Di Pietro Lombardi, Paola, Gli Este e i loro più significativi emblemi, in: Bentini, Gli Este a Ferrara, 8 I -87 .

Di Pietro Lombardi, Paola, Le imprese estensi come ritratto emblematico del principe, in: Iotti, Gli Estensi I, I83-232.

Di Pietro, Pericle, Rapporti degli Estensi con l'Università di Modena, in: Spaggiari/Trenti, Lo Stato di Modena, I87- I89.

Dickens, Arthur Geoffrey (Hg.), Europas Fürstenhöfe. Herrscher, Politiker und Mäzene I 400 - I 800, dt. Ausgabe, Graz/Wien/Köln I 978.

Diedenhofen, Wilhelm, Die Italienreise des Prinzen Karl Friedrich von Jülich-Kleve-Berg I $574 / 75$, Kleve 2008 .

Diemer, Peter, Vergnügungsfahrt mit Hindernissen. Erzherzog Ferdinands Reise nach Venedig, Ferrara und Mantua im Frühjahr I 579, in: Archiv für Kulturgeschichte 66 (I984), 249-3 I 4.

Diestelkamp, Bernhard (Hg.), Oberste Gerichtsbarkeit und zentrale Gewalt im Europa der Frühen Neuzeit (= Quellen und Forschungen zur höchsten Gerichtsbarkeit im Alten Reich 29), Köln/Weimar/Wien I 996.

Diestelkamp, Bernhard, Zur ausschließlichen Zuständigkeit des Reichshofrats für die Kassation kaiserlicher Privilegien, in: Auer/Ogris/Ortlieb, Höchstgerichte in Europa, r63 - I 76.

Dilcher, Gerhard, Das lombardische Lehnsrecht der Libri Feudorum im europäischen Kontext. Entstehung - zentrale Probleme - Wirkungen, in: Spieß, Ausbildung, 4I-9I .

Dinges, Martin, Der »feine Unterschied«. Die soziale Funktion der Kleidung in der höfischen Gesellschaft, in: Zeitschrift für Historische Forschung I9 (I 992), 49-76.

Dinzelbacher, Peter (Hg.), Europäische Mentalitätsgeschichte. Hauptthemen und Einzeldarstellungen, Stuttgart 1993 .

Distelberger, Rudolf, »Quanta rariora tanta meliora«. Die Faszination des Fremden in Natur und Kunst, in: Seipel, Exotica, I9-2 I.

Dmitrieva-Einhorn, Marina, Case molto simile all'italiane. Italienrezeption und Kulturtransfer in Ostmitteleuropa im I6. Jahrhundert, in: Schmale, Kulturtransfer, 23 I - 246.

Dolinar, France M./Liebmann, Maximilian/Rumpler, Helmut/Tavano, Luigi (Hgg.), Katholische Reform und Gegenreformation in Innerösterreich/Katoliška prenova in protiteformacija v notranjeavstrijskih deželah ${ }_{5}{ }_{5} 64-$ I628/Riforma cattolica e controriforma nell' Austria Interna I 564-i628, Klagenfurt/Ljubljana/Wien I 994.

Doмвrows кi, Damian, Dresden-Prag: Italienische Achsen in der zwischenhöfischen Kommunikation: in: Marx, Elbflorenz, 65-99. 
Donati, Claudio, Una famiglia lombarda tra XVI e XVIII secolo: Gli Este di San Martino e i loro feudi, in: Fregni, Archivi, 435-453.

Donattini, Massimo, Cultura geografica ferrarese del Rinascimento, in: Prosperi, Storia di Ferrara 6, $407-45^{8}$.

Dotterweich, Helmut, Der junge Maximilian. Jugend und Erziehung des bayerischen Herzogs und späteren Kurfürsten Maximilian I. von I 573 bis I 593, München I 962.

Drecoll, Volker Henning, Der Passauer Vertrag ( 1552 ). Einleitung und Edition (= Arbeiten zur Kirchengeschichte 79), Berlin/New York 2000.

Droste, Heiko, Patronage in der Frühen Neuzeit - Institution und Kulturform, in: Zeitschrift für Historische Forschung 30 (2003), 555-590.

Druffel, August von, Herzog Herkules von Ferrara und seine Beziehungen zu dem Kurfürsten Moritz von Sachsen und zu den Jesuiten, in: Sitzungsberichte der königl. bayer. Akademie der Wissenschaften, Philos.-philol. u. Hist. Classe, München i 878, 3 I 8-367.

Duchinardt, Heinz u.a. (Hgg.), Jahrbuch für Europäische Geschichte 8, München 2007.

Duch hardt, Heinz, Deutsche Verfassungsgeschichte I495 - i 806, Stuttgart/Berlin/Köln I 99 I.

Duch hardt, Heinz, Die dynastische Heirat als politisches Signal, in: Mirosława Czarnecka/ Jolanta Szafarz (Hgg.), Hochzeit als ritus und casus. Zu interkulturellen und multimedialen Präsentationsformen im Barock (= Orbis linguarum I 2), Worcław 200 I, 67-70.

Duchinard, Heinz, Die dynastische Heirat, in EGO: Europäische Geschichte online, erschienen 2010-I2-03 http://ieg-ego.eu/de/threads/europaeische-netzwerke/dynastischenetzwerke/heinz-duchhardt-die-dynastische-heirat, Zugriff: I6.6.2020.

Duchinardt, Heinz, Kleinstaaten zwischen den Grossreichen, in: Langewiesche, Kleinstaaten in Europa, 79-94.

Duchinardt, Heinz/Schnettger, Matthias (Hgg.), Reichsständische Libertät und habsburgisches Kaisertum (= Veröffentlichungen des Instituts für Europäische Geschichte Mainz 48), Mainz I 999.

Duindam, Jeroen, The Keen Observer versus the Grand-Theorist: Elias, Anthropology and the Early Modern Court, in: Opitz, Höfische Gesellschaft, 87- ro4.

Duindam, Jeroen, Vienna and Versailles: The Courts of Europe's Dynastic Rivals, I 550- I 780, Cambridge University Press 2003.

Dülmen, Richard van, Der infame Mensch. Unehrliche Arbeit und soziale Ausgrenzung in der Frühen Neuzeit, in: Ders. (Hg.), Arbeit, Frömmigkeit und Eigensinn, Frankfurt a.M. I990, I06- I 40 .

Dülmen, Richard van, Historische Kulturforschung zur Frühen Neuzeit. Entwicklung - Probleme - Aufgaben, in: Geschichte und Gesellschaft 2I (I995). 403-429.

Easton Law, John, Popular Unrest in Ferrara in $\mathrm{I}_{3} 85$, in: Salmons/Moretti, The Renaissance in Ferrara, 4I-6o.

Ebert-Schifferer, Sybille (Hg.), Scambio culturale con il nemico religioso. Italia e Sassonia attorno al I600 (= Studi della Bibliotheca Hertziana 2), Milano 2007.

Eco, Umberto, Die Enzyklopädie als Labyrinth, ins Deutsche übersetzt von Christiane Trabant-Rommel und Jürgen Trabant, in: Umberto Eco, Im Labyrinth der Vernunft. Texte über Kunst und Zeichen, Reclam-Verlag Leipzig I990, I04- I 2.

EdEL, Andreas, Johann Baptist Weber (I $526-$ I584). Zum Lebensweg eines gelehrten Juristen 
und Spitzenbeamten des r6. Jahrhunderts, in: Mitteilungen des Österreichischen Staatsarchivs (MÖSTA) 45 (I 997), I I I - I 85.

Edelmayer, Friedrich (Hg.), Hispania-Austria 2. Die Epoche Philipps II. (1556-I598) (= Studien zur Geschichte und Kultur der iberischen und iberoamerikanischen Länder 5), Wien/München I 999.

Edelmayer, Friedrich, Das soziale Netzwerk der kaiserlichen Gesandten am Hof Philipps II., in: Edelmayer, Hispania-Austria 2, 89- I08.

Edelmayer, Friedrich, Einheit der Casa de Austria? Philipp II. und Karl von Innerösterreich, in: Dolinar/Liebmann/Rumpler/Tavano, Katholische Reform, 373-386.

Edelmayer, Friedrich, Habsburgische Gesandte in Wien und Madrid in der Zeit Maximilians II. Ein Vergleich der innerhabsburgischen Begegnungen auf der Ebene der Diplomatie, in: Krömer, Spanien und Österreich, 57-70.

Edelmayer, Friedrich, Kaisertum und Casa de Austria. Von Maximilian I. zu Maximilian II., in: Kohler/Edelmayer, Hispania - Austria, I 57- r 70.

Edelmayer, Friedrich, Maximilian II., Philipp II. und Reichsitalien: die Auseinandersetzungen um das Reichslehen Finale in Ligurien (= Veröffentlichungen des Instituts für Europäische Geschichte Mainz I30: Abteilung Universalgeschichte. Beiträge zur Sozial- und Verfassungsgeschichte des alten Reiches 7), Stuttgart 1988.

Edelmayer, Friedrich, Söldner und Pensionäre. Das Netzwerk Philipps II. im Heiligen Römischen Reich (= Studien zur Geschichte und Kultur der iberischen und iberoamerikanischen Länder 7), Wien/München 2002.

Edelmayer, Friedrich/Kohler, Alfred (Hgg.), Kaiser Maximilian II. Kultur und Politik im I6. Jahrhundert (= Wiener Beiträge zur Geschichte der Neuzeit I9), Wien/München 1992.

Ehlers, Joachim, Friedrich I. Barbarossa, in: Schneidmüller/Weinfurter, Die deutschen Herrscher des Mittelalters, 232-257.

Ehlers, Joachim, Heinrich VI., in: Schneidmüller/Weinfurter, Die deutschen Herrscher des Mittelalters, $258-272$.

Ehrenpreis, Stefan, Kaiserliche Gerichtsbarkeit und Konfessionskonflikt: der Reichshofrat unter Rudolf II. (I576-I6I2) (= Schriftenreihe der Historischen Kommission bei der Bayerischen Akademie der Wissenschaften 72), Göttingen 2006.

Ehrenpreis, Stefan, Navigatoren des Imperiums. Die Rolle der Reichshofratsagenten in der politischen Kommunikation des Alten Reiches, in: Wendehorst, Die Anatomie frühneuzeitlicher Imperien, 245-264.

Eıскецs, Klaus van, Friedrich II. mit Heinrich VII., in: Schneidmüller/Weinfurter, Die deutschen Herrscher des Mittelalters, 293-3 I4.

Einstein, Alfred, Italienische Musik und italienische Musiker am Kaiserhof und an den erzherzoglichen Höfen in Innsbruck und Graz, in: Studien zur Musikwissenschaft 2 I (I934), $3-52$.

Elias, Norbert, Die höfische Gesellschaft, Untersuchungen zur Soziologie des Königtums und der höfischen Aristokratie, Darmstadt/Neuwied ${ }^{4}$ I 977.

Elliott, John, A Europe of composite monarchies, in: Past and Present I 37 (I 992), 48-7I.

Емісн, Birgit, Bologneser libertà, Ferrareser decadenza: Politische Kultur und päpstliche Herrschaft im Kirchenstaat der Frühen Neuzeit, in: Asch/Freist, Staatsbildung, I I 7- I 34 .

Емісн, Birgit, Frühneuzeitliche Staatsbildung und politische Kultur. Für die Veralltäglichung 
eines Konzepts, in: Stollberg-Rilinger, Was heißt Kulturgeschichte des Politischen?, I 9 I205 .

Емісн, Birgit, Mit Luhmann im Kirchenstaat. Die römische Wasserbauverwaltung in verfahrenstheoretischer Sicht, in: Barbara Stollberg-Rilinger/André Krischer (Hgg.), Herstellung und Darstellung von Entscheidungen. Verfahren, Verwalten und Verhandeln in der Vormoderne (= Zeitschrift für Historische Forschung. Vierteljahresschrift zur Erforschung des Spätmittelalters und der frühen Neuzeit, Beiheft 44), Berlin 2010, 275-30I.

Емісн, Birgit, Staatsbildung und Klientel. Politische Integration und Patronage in der Frühen Neuzeit, in: Asch/Emich/Engels, Integration, 33-48.

Емісн, Birgit, Territoriale Integration in der Frühen Neuzeit. Ferrara und der Kirchenstaat, Köln/Weimar/Wien 2005.

Emiliani, Andrea, Il ritorno delle Muse, in: Bentini, Gli Este a Ferrara, I 5 - I 9.

Endemann, Klaus, Die Fassaden des Italienischen Baus - Befund, Analyse, Überlegungen zur Frage der Autorenschaft, in: Gerhard Hojer (Hg.), Der italienische Bau. Materialien und Untersuchungen zur Stadtresidenz Landshut, Ausstellungskatalog, Landshut/Ergolding I 994, 55-IO2.

Erfen, Irene/Spiess, Karl-Heinz (Hgg.), Fremdheit und Reisen im Mittelalter, Stuttgart I 997 .

Ertzdorff, Xenia von/Neukirch, Dieter (Hgg.), Reisen und Reiseliteratur im Mittelalter und in der Frühen Neuzeit. Vorträge eines interdisziplinären Symposiums vom 3.-8. Juni I99I an der Justus-Liebig-Universität Gießen (= Chloe. Beihefte zum Daphnis I3), Amsterdam/Atlanta I 992.

Espagne, Michel, Der theoretische Stand der Kulturtransferforschung, in: Schmale, Kulturtransfer, $63-75$.

Espagne, Michel, Die Rolle der Mittler im Kulturtransfer, in: Hans-Jürgen Lüsebrink/Rolf Reichardt (Hgg.), Kulturtransfer im Epochenumbruch I, Leipzig I 997, 309-329.

Espagne, Michel,Jenseits der Komparatistik. Zur Methode der Erforschung von Kulturtransfer, in: Ulrich Mölk (Hg.), Europäische Kulturzeitschriften um I 900 als Medien transnationaler und transdisziplinärer Wahrnehmung, Göttingen 2006, I3-32.

Espagne, Michel, Kulturtransfer und Fachgeschichte der Geisteswissenschaften, in: Comparativ Io/I (2000), 42-6r.

Evans, Robert J.W., Rudolf II. Ohnmacht und Einsamkeit, aus dem Engl. von Uta Szyszkowitz, Graz/Köln/Wien I980.

Evans, Robert J.W./Schaich, Michael/Wilson, Peter H. (Hgg.), The Holy Roman Empire I 495- I 806 (= Studies of the German Historical Institute London), Oxford University Press 2011 .

Evans, Robert J.W./Wilson, Peter (Hgg.), The Holy Roman Empire, I 495- i 806. A European Perspective, Leiden 2012.

Ewert, Ulf Christian, Der Fürst als Unternehmer. Agency-Problematik und Wandel der Governance-Strukture in den portugiesischen Entdeckungsfahrten, in: Fouquet/Hirschbiegel/Paravicini, Hofwirtschaft, I 43- I 70.

Ewert, Ulf Christian/Hirschiegel, Jan, Gabe und Gegengabe. Das Erscheinungsbild einer Sonderform höfischer Repräsentation am Beispiel des französisch/burgundischen Gabentausches zum neuen Jahr um I400, in: Vierteljahrschrift für Sozial- und Wirtschaftsge- 
schichte 87/I (2000), 5-37, online-Version: http://www.jstor.org/stable/20740066, Zugriff: 2 I.6.2020.

Ewert, Ulf Christian/Hirschiegel, Jan, Nur Verschwendung? Zur sozialen Funktion der demonstrativen Zurschaustellung höfischen Güterverbrauchs, in: Paravicini, Luxus und Integration, I05- I 2 I.

Externirink, Sven, »Internationaler Calvinismus« als Familiengeschichte: Die Spanheims (ca. I 550- I 7 Io), in: Nolde/Opitz, Grenzüberschreitende Familienbeziehungen, I 37- I 55.

Fавв в, Lorenzo, Da Firenze a Ferrara. Gli Strozzi tra Casa d'Este e antichi legami di sangue, in: Bertozzi, Alla corte degli Estensi, 9I - ro8.

Faвbri, Paolo, Gli Este e la musica, in: Bentini, Gli Este a Ferrara, 53-6r.

Fabbri, Paolo, Una capitale in musica, in: Prosperi, Storia di Ferrara 6, 334-367.

Faber, Kirsten, Ercole II d'Este, mecenate nella tradizione estense del Quattrocento e del Cinquecento, in: Weber, Il trionfo di Bacco, 27-36.

Faggioli Saletti, Maria Alberta, „El Tebaldo mio familiare presente exhibitore ...«, in: Gianna Vancini, (Hg.), Lucrezia Borgia nell'opera di cronisti, letterati e poeti suoi contemporanei alla Corte di Ferrara, Ferrara 2002, I89-222.

Fantoni, Marcello, Un castello in forma di città. Architettura e potere dei Pio da Carpi, in: Fregni, Archivi, 407-424.

Fantoni, Marcello (Hg.), Carlo V e l'Italia. Seminario di studi Georgetown University a Villa Le Balze I 4 - I 5 dicembre 2000 (= «Europa delle Corti« Centro studi sulle società di antico regime. Biblioteca del Cinquecento Ior), Roma 2000.

Fantoni, Marcello, Carlo V e l'immagine dell'imperatore, in: Fantoni, Carlo V, io i - i i 8.

Fantoni, Marcello, Corte e Stato nell'Italia dei secoli XIV-XVI, in: Chittolini/Molho/Schiera, Origini dello Stato, $429-466$.

Fantoni, Marcello, Feticci di prestigio: Il dono alla corte medicea, in: Bertelli/Crifò, Rituale, I $4 \mathrm{I}-\mathrm{I} 6 \mathrm{I}$.

Farinelli Toselli, Alessandra (Hg.), Lucrezia Borgia a Ferrara. Testimonianze librarie e documentarie di un mito, [Ferrara] 2002.

Farinelli Toselli, Alessandra, Il Palazzo attraverso i documenti, in: Olivato, Il palazzo di Renata di Francia, 37-95.

Fasano Guarini, Elena, Centro e periferia, accentramento e particolarismi: dicotomia o sostanza degli Stati in età moderna?, in: Chittolini/Molho/Schiera, Origini dello Stato, I 47I 76 .

Fattori, Maria Teresa, Clemente VIII e il Sacro Collegio i 592-r6o5. Meccanismi istituzionali e accentramento di governo (= Päpste und Papsttum 33), Stuttgart 2004.

Fattori, Maria Teresa, Lehnsrecht und Stärkung des Territorialstaates im Kontext der Devolution Ferraras am Ende des i6. Jahrhunderts, in: zeitenblicke. online-Journal für Geschichtswissenschaften 6/I (2007), ins Deutsche übersetzt von Matthias Schnettger, http:// www.zeitenblicke.de/2007/I/fattori, Zugriff: 30.5.2020.

Feci, Simona, Signore di curia. Rapporti di potere ed esperienze di governo nella Roma papale (metà XV-metà XVI secolo), in: Arcangeli/Peyronel, Donne di potere nel Rinascimento, I $95-222$.

Federhofer, Hellmut, Musikpflege und Musiker am Grazer Habsburgerhof der Erzherzöge Karl und Ferdinand von Innerösterreich (I564- I6 I9), Mainz I 967. 
Federzoni, Laura, Gli Stati di Casa d'Este nella cartografia, in: Spaggiari/Trenti, Lo Stato di Modena, $45 \mathrm{I}-480$.

Fellner, Thomas/Kretschmayr, Heinrich, Die österreichische Zentralverwaltung, I. Abteilung: Von Maximilian I. bis zur Vereinigung der österreichischen und böhmischen Hofkanzler (I 749) I : Geschichtliche Übersicht, Wien I 907.

Fenlon, Iain, Gender and Generation: Patterns of Music Patronage among the Este, I 47 I - I 539 , in: Pade/Waage Petersen/Quarta, La Corte di Ferrara, 2 I3-232.

Ferino-Pagden, Sylvia/Seipel, Wilfried (Hgg.), Isabella d'Este: »la prima donna del mondo«. Fürstin und Mäzenatin der Renaissance. Ausstellungskatalog des Kunsthistorischen Museums, Wien r 994 .

Ferrari, Giuliana, La corte degli dei: La ripresa del mito di Ercole nella Ferrara di Ercole I d'Este ( 477 I - I 505), in: Mozzarelli, »Familia« del principe, 695-7 Io.

FeuchtmüLler, Rupert (Hg.), Renaissance in Österreich. Geschichte - Wissenschaft - Kunst, Horn in Niederösterreich I 974 .

Fiala, David, Les musiciens italiens dans la documentation de la cour de Bourgogne entre 1467 et I 506: quelques silhouettes, in: Guidobaldi, Regards croisés, 6 I - 82.

Ficker, Julius, Forschungen zur Reichs- und Rechtsgeschichte Italiens 2, Innsbruck I 869.

Fleischhauer, Werner, Renaissance im Herzogtum Württemberg (= Veröffentlichung der Kommission für geschichtliche Landeskunde in Baden-Württemberg), Stuttgart [1971].

Folin, Marco, Gli Estensi e Ferrara nel quadro di un sistema politico composito, I 452- I 598 , in: Prosperi, Storia di Ferrara 6, 22-76.

Folin, Marco, Gli oratori estensi nel sistema politico italiano (I440-1505), in: Fragnito/ Miegge, Girolamo Savonarola, 5 i - 83.

Folin, Marco, Il Castello come emblema di potere: architettura e politica alla Corte degli Estensi, in: Borella, Gli Este a Ferrara, 55-72.

Folin, Marco, L'architettura e le città nel Quattrocento, in: Bentini, Gli Este a Ferrara, 63-77.

Folin, Marco, Le cronache a Ferrara e negli Stati estensi (secoli XV-XVI), in: Prosperi, Storia di Ferrara 6, 459-493.

Folin, Marco, Les ambassadeurs des Este à la cour des Valois (I470-I 505), in: Guidobaldi, Regards croisés, I 35- I70.

Folin, Marco, Officiali e feudatari nel sistema politico estense (secoli XV-XVII), in: Fregni, Archivi, 8 I - I 20.

Folin, Marco, Rinascimento estense. Politica, cultura, istituzioni di un antico Stato italiano, Roma/Bari 200 .

Fontana, Bartolommeo, Renata di Francia, duchessa di Ferrara. Sui documenti dell'Archivio Estense, del Mediceo, del Gonzaga e dell'Archivio Secreto Vaticano 3 Bde., Roma I 889 - I 899.

Forti Grazzini, Nello, Gli arazzi di Ferrara nei secoli XV e XVI, in: Bentini, Gli Este a Ferrara, I $97-200$.

Forti Grazzini, Nello, Leonello d'Este nell'autunno del Medioevo. Gli arazzi delle »Storie di Ercole«, in: Mottola Molfino/Natale, Le muse e il principe I, 53-62.

Fosi, Irene, Convertire lo straniero. Forestieri e Inquisizione a Roma in età moderna, Roma $201 \mathrm{I}$.

Fosi, Irene, Conversions de voyageurs protestants dans la Rome baroque, in: Babel/Paravicini, Grand Tour, 569-578. 
FouQuet, Gerhard, Fürsten unter sich - Privatheit und Öffentlichkeit, Emotionalität und Zeremoniell im Medium des Briefes, in: Nolte/Spieß/Werlich, Principes, I 72 - I 98.

Fouquet, Gerhard/Hirschiıgel, Jan/Paravicini, Werner (Hgg.), Hofwirtschaft. Ein ökonomischer Blick auf Hof und Residenz in Spätmittelalter und Früher Neuzeit. Io. Symposium der Residenz-Kommission der Akademie der Wissenschaften zu Göttingen (= Residenzforschung 2 I), Ostfildern 2008.

Fragnito, Gigliola/Miegge, Mario (Hgg.), Girolamo Savonarola da Ferrara all'Europa. Atti del convegno internazionale, Ferrara 30 marzo-3 aprile r 998, Firenze 2000.

Franceschini, Adriano, Artisti a Ferrara in età umanistica e rinascimentale. Testimonianze archivistiche 3 Bde., Ferrara I 997.

Franceschini, Chiara, La corte di Renata di Francia (1528-1560), in: Prosperi, Storia di Ferrara 6, I 85-2I4.

Franceschini, Chiara, Tra Ferrara e la Francia: notizie su orefici e pittori al servizio di Renée de France, in: Franco-Italica: Rivista di studi franco-italiani I 9/20 (2003), 65- I04.

Frank, Karl Friedrich von, Standeserhebungen und Gnadenakte für das Deutsche Reich und die Österreichischen Erblande bis I 806 sowie kaiserlich österreichische bis I 823 mit einigen Nachträgen zum »Alt-Österreichischen Adels-Lexikon« I823- I9 8 I (A-E), Schloss Senftenegg I 967 .

Franke, Birgit/Welzel, Barbara, Morisken für den Kaiser: Kulturtransfer?, in: Müller/Spieß/ Friedrich, Kulturtransfer am Fürstenhof, I 5 - 5 I.

Fregni, Euride (Hg.), Archivi, territori, poteri in area estense (secc. XVI-XVIII) (= Europa delle Corti«. Centro studi sulle società di antico regime. Biblioteca del Cinquecento 92), Roma I 999.

FREGNI, Euride, Assetti istituzionali, organizzazione amministrativa e produzione documentaria nei territori estensi, in: Fregni, Archivi, 55-64.

Fregni, Euride, Premessa, in: Fregni, Archivi, I3- i 7 .

Frenz, Thomas, Italien im Mittelalter (950-I454), in: Wolfgang Altgeld (Hg.), Kleine italienische Geschichte, Stuttgart 2002, I 5 - I 22.

FREY, Carola, Fürstliche Kultinnovationen im Spiegel sakraler Schätze. Beispiele von wittelsbachischen Höfen des späten Mittelalters, in: Müller/Spieß/Friedrich, Kulturtransfer am Fürstenhof, I $22-$ I 38 .

Friedell, Egon, Kulturgeschichte der Neuzeit. Die Krisis der europäischen Seele von der schwarzen Pest bis zum Ersten Weltkrieg I, München ${ }^{14} 200$ I.

Frigo, Daniela (Hg.), Politics and Diplomacy in Early Modern Italy. The Structure of Diplomatic Practice, I 450- I 800, übersetzt von Adrian Belton, Cambridge University Press 2000.

Frigo, Daniela, »Small States« and Diplomacy: Mantua and Modena, in: Frigo, Politics and Diplomacy, I47-I75.

Frigo, Daniela, Ambasciatori e nunzi. Figure della diplomazia in età moderna (= Cheiron 30), Roma I999.

Frigo, Daniela, Guerra e diplomazia: Gli stati padani nell'età di Carlo V, in: Fantoni, Carlo V, I $7-46$.

FRIGO, Daniela, La corte e »le corti«: sovranità e diplomazia nei ducati padani, in: Fregni, Archivi, $267-288$. 
Frigo, Daniela, Politica estera e diplomazia: figure, problemi e apparati, in: Greco/Rosa, Storia degli antichi stati italiani, I I7-I6r.

FrizzI, Antonio, Memorie per la Storia di Ferrara 4, Ferrara ${ }^{2}$ I 848.

Fubini Leuzzi, Maria, Un'Asburgo a Firenze fra etichetta e impegno politico: Giovanna d'Austria, in: Calvi/Spinelli, Le donne Medici, 233-256.

Fuchs, Martina/Kohler, Alfred (Hgg.), Kaiser Ferdinand I. Aspekte eines Herrscherlebens, Münster 2003.

Fuchs, Martina/Rebiтsch, Robert (Hgg.), Kaiser und Kurfürst. Aspekte des Fürstenaufstandes I $55_{2}$ (= Geschichte in der Epoche Karls V. I I), Münster 20 I I.

Fuchs, Thomas/Tranulhum, Sven (Hgg.), Das eine Europa und die Vielfalt der Kulturen. Kulturtransfer in Europa I 500- I 850, Berlin 2003.

Fuchs, Thomas/Trakulhum, Sven, Kulturtransfer in der Frühen Neuzeit. Europa und die Welt, in: Fuchs/Trakulhum, Das eine Europa, 7-24.

Fučí ková, Eliška u.a. (Hgg.), Rudolf II and Prague. The Court and the City. Catalogue to the exhibition: Rudolf II and Prague: The Imperial Court and Residential City as the Cultural and Spiritual Heart of Central Europe, 30 may- 7 september 1997, London 1997.

Fumagalli, Elena, Duchi e granduchi: relazioni diplomatiche e artistiche tra Modena e Firenze ( $1600-\mathrm{I} 658$ ), in: Fumagalli/Signorotto, La corte estense, 305-348.

Fumagalli, Elena/Signorotto, Gianvittorio (Hgg.), La corte estense nel primo Seicento. Diplomazie e mecenatismo artistico, Roma 2012.

Galasso, Giuseppe, »Piccolo Stato« e storiografia italiana dal Rinascimento al Risorgimento, in: Barletta/Cardini/Galasso, Il piccolo stato, I 27 - I 47.

Galasso, Giuseppe, Il quadro internazionale, in: Giuseppe Gullino (Hg.), L'Europa e la Serenissima. La svolta del I 509. Nel V centenario della battaglia di Agnadello, Venezia 20 I , $3-\mathrm{I} 8$.

Galtarossa, Massimo, Padova città imperiale, in: Taddei/Schnettger/Rebitsch, Reichsitalien, $35-50$.

Gamberini, Andrea, Das Herzogtum Mailand, die italienischen Staaten und die aktuelle Forschungsdiskussion - eine historiographische Bilanz, in: Rückert/Lorenz, Die Visconti, 89-IO2.

Gamberini, Andrea/Lazzarini, Isabella (Hgg.), The Italian Renaissance State, Cambridge University Press 2012.

Gamвi, Lucio, Stato degli studi sulla produzione cartografica presso la corte degli Este, in: $\mathrm{Pa}-$ pagno/Quondam, La corte e lo spazio, 223-232.

GARDI, Andrea, Legati a Bologna e poteri signorili dell'area estense all'epoca di Alfonso II, in: Fregni, Archivi, 317-345.

Gasparini, Alberto, Cesare d'Este e Clemente VIII, Modena i 960.

Gasser, Hubert, Lo Stato di Modena e l'Impero, in: Spaggiari/Trenti, Lo Stato di Modena, II 5 I - II 58 .

Gattoni, Maurizio, L'antagonismo pontificio-ferrarese come »exemplum« di conflitto tra potere ecclesiastico e laico nell'Italia del Rinascimento, in: Ricerche Storiche 26/3 (I 996), 6 I 9 674 .

Gehrig, Oscar, Die bürgerliche Baukunst Wismars (= Mecklenburgische Bilderhefte 3), Rostock 1925 . 
Gentile, Luisa Clotilde, Dipendenza e legittimazione. Il legame con l'Impero nel sistema emblematico e cerimoniale dei duchi di Savoia, in: Bellabarba/Merlotti, Stato sabaudo, 69-92.

Ghelfi, Barbara, »Le pitture spontano al fine quel che non possono spuntare i nostri stenti, et le nostre fatiche«. Doni artistici di Cesare d'Este a Rodolfo II (I 598 - I604), in: Fumagalli/ Signorotto, La corte estense, 93 - I33.

Ghinassi, Giovanni, Viaggio a Gerusalemme di Nicolò d'Este descritto da Luchino dal Campo ed ora per la prima volta messo in luce da Giovanni Ghinassi, in: Miscellanea di opuscoli inediti o rari dei secoli XIV e XV i (I 864), 99- i6o.

Ghirardo, Diane, Lucrezia Borgia, imprenditrice nella Ferrara rinascimentale, in: Arcangeli/ Peyronel, Donne di potere, I 29 - I 43.

Giessmann, Sebastian, Die Verbundenheit der Dinge. Eine Kulturgeschichte der Netze und Netzwerke, Berlin 2014.

Giovio, Paolo, La vita di Alfonso da Este Duca di Ferrara, Venezia I 597.

Giraldi Cinzio, Giovan Battista: De Ferraria et atestinis Princibus Commentariolum, Ferrariae 1556 .

Girgensohn, Dieter, »Da Carrara«, in: Reinhardt, Die großen Familien, I 49- I 54.

Glaser, Hubert, Quellen und Studien zur Kunstpolitik der Wittelsbacher vom I6. bis zum I 8. Jahrhundert (= Mitteilungen des Hauses der Bayerischen Geschichte I), München/Zürich I980.

Goetz, Hans-Werner, Der >rechte< Sitz. Die Symbolik von Rang und Herrschaft im Hohen Mittelalter im Spiegel der Sitzordnung, in: Gertrud Blaschnitz/Helmut Hundsbichler/Gerhard Jaritz/Elisabeth Vavra (Hgg.), Symbole des Alltags. Alltag der Symbole. Festschrift für Harry Kühnel zum 65. Geburtstag, Graz I 992, i I - 47.

Goez, Elke, Geschichte Italiens im Mittelalter, Darmstadt 20 ıо.

Goez, Werner, Das hochmittelalterliche Imperium. Probleme der Integration von Reichsitalien (95 I - I 220), in: Maleczek, Fragen der politischen Integration, 49-65.

Goez, Werner, Möglichkeiten und Grenzen des Herrschens aus der Ferne in Deutschland und Reichsitalien (I I 52 - I 220), in: Theo Kölzer (Hg.), Die Staufer im Süden. Sizilien und das Reich, Sigmaringen r 996, 93- I I I.

Goldoni, Claudio Maria, Atlante Estense. Mille anni nella storia d'Europa. Gli Estensi a Ferrara, Modena, Reggio, Garfagnana e Massa Carrara, Modena 20 I I.

Goldscheider, Ludwig, Michelangelo - Die Skulpturen. Gesamtausgabe, London 1950.

Goldtwaite, Richard A., Wealth and the Demand for Arts in Italy r $300-$ I60o, Baltimore I993.

Gorris Camos, Rosanna, »Donne ornate di scienza e di virtù«: Donne e francesi alla corte di Renata di Francia, in: Schifanoia. Notizie dell'Istituto di Studi rinascimentali di Ferrara 28/29 (2005), I75-205.

Gotтhard, Axel, Frühe »neutralitet«. Der Fürstenkrieg in einer Archäologie des Neutralitätsrechts, in: Fuchs/Rebitsch, Kaiser und Kurfürst, 9-3 I.

Gotthard, Axel, »Frölich gewest « - Ottheinrich, ein unpolitischer Fürst?, in: Stadt Neuburg an der Donau, Pfalzgraf Ottheinrich, $7 \mathrm{I}-93$.

Gotthard, Axel, Das Alte Reich I495-i 806 (= Geschichte kompakt), 4. überarbeitete Auflage, Darmstadt 2009. 
GräF, Holger Thomas/Pröve, Ralf, Wege ins Ungewisse, Reisen in der Frühen Neuzeit I $500-$ I 800 , Frankfurt a.M. I 997 .

Greco, Gaetano/Rosa, Mario (Hgg.), Storia degli antichi stati italiani (= Manuali Laterza 7 I), Roma/Bari 1996.

Gregorovius, Ferdinand, Geschichte der Stadt Athen im Mittelalter. Von der Zeit Justinians bis zur türkischen Eroberung, München ${ }^{2}$ I 980 .

Greschat, Martin (Hg.), Das Papsttum II. Vom Großen Abendländischen Schisma bis zur Gegenwart (= Gestalten der Kirchengeschichte I 2), Stuttgart/Berlin/Köln/Mainz I 985 .

Gribaudi, Pietro, Questioni di precedenza fra le corti italiane nel secolo XVI. Contributo alla storia della diplomazia italiana, Sonderdruck aus: Rivista di scienze storiche I ( 904$)$, Pavia I 904 .

Gröвlacher, Johann, König Maximilians I. zweite Gesandtschaft zu Sultan Bayezid II. (I 504-I 505), in: Höflechner/Mezler-Andelberg/Pickl, Domus Austriae, I 59- I69.

Groebener, Valentin, Gefährliche Geschenke. Ritual, Politik und die Sprache der Korruption in der Eidgenossenschaft im späten Mittelalter und am Beginn der Neuzeit, Konstanz 2000.

Groнs, Brigitte, Die Hochzeiten der Erzherzoginnen Barbara und Johanna von Habsburg Beispiele politischer Verbindungen im I6. Jahrhundert, unveröff. Staatsprüfungsarbeit am Institut für Österreichische Geschichtsforschung, Wien I 986 und eine Kurzfassung unter dem Titel: Italienische Hochzeiten. Die Vermählung der Erzherzoginnen Barbara und Johanna von Habsburg im Jahre ${ }_{5} 6_{5}$, in: Mitteilungen des Instituts für Österreichische Geschichtsforschung (MIÖG) 96/3-4 (I 988), 33 I-38 I.

Gross, Reiner, Die Wettiner, Stuttgart 2007.

Grubb, James S., Corte e cronache: il principe e il pubblico, in: Chittolini/Molho/Schiera, Origini dello Stato, $467-48 \mathrm{r}$.

Gruber, Bettina, »Elias, Norbert«, in: Reinalter/Brenner, Lexikon der Geisteswissenschaften, I I 97 - I I 99 .

GRüN, Klaus-Jürgen, »Symbol«, in: Reinalter/Brenner, Lexikon der Geisteswissenschaften, 772 780 .

Gschliesser, Oswald von, Der Reichshofrat. Bedeutung und Verfassung, Schicksal und Besetzung einer obersten Reichsbehörde von I559 bis I 806 (= Veröffentlichungen der Kommission für neuere Geschichte des ehemaligen Österreich 33), Wien I 942.

Guarini, Marco Antonio, Compendio historico dell'origine, accrescimento e prerogative delle chiese, e luoghi pii della Città e Diocesi di Ferrara, e delle memorie di que' personaggi che in esse sono sepeliti [...], Ferrara I62 I.

Guerzoni, Guido, Di alcune ignote e poco nobili cause del soggiorno bolognese di Kaiser Karl $\mathrm{V}$, in: Fantoni, Carlo V, I 97-217.

Guerzoni, Guido, Le corti estensi e la devoluzione di Ferrara del i 598 (= Quaderni dell'archivio storico X), Modena 2000.

Guicciardini, Francesco, L'historia d'Italia di Messer F.G., Livorno (I 56r) I8 32.

Guidobaldi, Nicoletta (Hg.), Regards croisés. Musique, musiciens, artistes et voyageurs entre France et Italie au $\mathrm{XV}^{\mathrm{e}}$ siècle (= Centre d'études supérieures de la renaissance. Collection »Épitome musical«), Paris/Tours 2002.

Guidoni, Enrico, L'Addizione erculea, in: Bocchi, Storia illustrata di Ferrara 2, 353-368. 
Gundersheimer, Werner L., Ferrara. A Style of Renaissance despotism, Princeton University Press, New Jersey 1973 .

Gutfleisch, Barbara/Menzhausen, Joachim, »How a Kunskammer should be formed«. Gabriel Kaltemarckt's advice to Christian I of Saxony on the formation of an art collection I 587 , in: Journal of the History of Collections I ( 1989), 3-32, Digitalisat: http://jhc.oxfordjournals.org/, Zugriff: 29.5.2020.

Guthmüller, Bodo (Hg.), Deutschland und Italien in ihren wechselseitigen Beziehungen während der Renaissance (= Wolfenbütteler Abhandlungen zur Renaissanceforschung I9), Wiesbaden 2000.

HaAG, Sabine (Hg.), Dresden \& Ambras. Kunstkammerschätze der Renaissance. Eine Ausstellung des Grünen Gewölbes und der Sammlungen Schloss Ambras, Schloss Ambras, Innsbruck, I 4.6.-23.9.201 2, Wien 2012.

HaAg, Sabine (Hg.), Fürstlich Tafeln, Ausstellungskatalog, Schloss Ambras, 25. März-3 r. Mai 2015 , Wien 2015 .

HaAg, Sabine (Hg.), Nozze italiane. Österreichische Erzherzoginnen im Italien des I6. Jahrhunderts, Ausstellungskatalog, Schloss Ambras, Innsbruck 25. Juni- I7. Oktober 20 Io, Wien 2010.

HaAg, Sabine (Hg.), Trinkfest! Bacchus lädt ein, Ausstellungskatalog, Schloss Ambras 7. April-3r. Mai 20I I, Wien 20I I

Häв ERlein, Mark, Aneignung, Organisation und Umsetzung von Kaufmannswissen in Süddeutschland im r6. und I 7. Jahrhundert, in: North, Kultureller Austausch, 273-288.

Häвerlein, Mark, Die oberitalienischen und die oberdeutschen Städte im Zeitalter der Renaissance: Beziehungen - Einflüsse - Wechselwirkungen, in: Michael Gehler (Hg.), Die Macht der Städte. Von der Antike bis zur Gegenwart (= Historische Europa-Studien/Historic Europe Studies 4), Hildesheim/Zürich/New York 20I I, I99-2 I 9.

Häberlein, Mark/Jeggle, Christof (Hgg.), Materielle Grundlagen der Diplomatie. Schenken, Sammeln und Verhandeln in Spätmittelalter und Früher Neuzeit (= Irseer Schriften. Studien zur Wirtschafts-, Kultur- und Mentalitätsgeschichte 9), Konstanz/München 2013.

Häвerlein, Mark/Jeggle, Christof, Einleitung, in: Häberlein/Jeggle, Materielle Grundlagen, I I - 30.

Hajós, Géza, Renaissancegärten zwischen Repräsentation und Wissenschaft, in: Vocelka/Leeb/ Scheichl, Renaissance und Reformation, I $83-$ i 96.

Hansmann, Ruth, »Schilderey von dem gutten maister andrea von mantua« für Kurfürst Friedrich den Weisen, in: Müller/Spieß/Friedrich, Kulturtransfer am Fürstenhof, 27 I - 304.

Hausenblasová, Jaroslava, Der Hof Kaiser Rudolfs II. Eine Edition der Hofstaatsverzeichnisse 1576-I6r 2 (= Fontes Historiae Artium 9), Prag 2002.

Hausenblasová, Jaroslava, Prag als Knotenpunkt der höfischen Handelsnetzwerke in der Zeit Ferdinands I. ( $1526-$ I 564 ), in: Hlavačka/Holý, Präzedenz, I I - 25.

Havemann, Wilhelm, Geschichte der Lande Braunschweig und Lüneburg 3 Bde., Hannover ${ }^{2}$ I $974 / 75$.

Have rkamp, Alfred, Italien im hohen und späten Mittelalter 1056- I 454, in: Theodor Schieder (Hg.), Handbuch der Europäischen Geschichte 2: Europa im Hoch- und Spätmittelalter hg. v. Ferdinand Seibt, Stuttgart I987, 546-680. 
Headley, John M., The emperor and his chancellor. A study of the imperial chancellery under Gattinara, Cambridge University Press, Cambridge u.a. I983.

Heckmann, Marie-Luise, Stellvertreter, Mit- und Ersatzherrscher, Regenten, Generalstatthalter, Kurfürsten und Reichsvikare in Regnum und Imperium vom I 3 . bis zum frühen I 5 . Jahrhundert 2 Bde. (= Studien zu den Luxenburgern und ihrer Zeit 9), Warendorf 2002.

Heinemann, Olav, Das Herkommen des Hauses Sachsen. Genealogisch-historiographische Arbeit der Wettiner im I6. Jahrhundert (= Schriften zur sächsischen Geschichte und Volkskunde 5 I), Leipzig 2016.

Heinig, Paul-Joachim, Der regionalisierte Herrscherhof. Kaiser Friedrich III. und das Reich in Fremd- und Selbstwahrnehmung, in: Zotz, Fürstenhöfe und ihre Außenwelt, I I 5 - I 30.

Heinig, Paul Joachim, Friedrich III., in: Schneidmüller/Weinfurter, Die deutschen Herrscher des Mittelalters, 495-5 I7.

Heinig, Paul-Joachim, How large was the Court of Emperor Frederick III?, in: Asch/Birke, Princes, Patronage and the Nobility, I39- I 56.

Heitmann, Klaus, Das italienische Deutschlandbild in seiner Geschichte (= Studia Romanica I 14 ), Heidelberg 2003.

Heitmann, Klaus, Machiavelli und die »antica bontà» der Deutschen, in: Guthmüller, Deutschland und Italien, 6 I - ror.

Heitmann, Klaus, Zum Bild der Deutschen im Oberitalien des Spätmittelalters, in: Rückert/ Lorenz, Die Visconti, I03-II3.

Hell, Helmut, Orlando di Lasso. Ein biographischer Abriss. Nach der Lasso-Biographie von H.[orst] Leuchtmann zusammengestellt, in: Bayerische Staatsbibliothek, Orlando di Lasso, $50-54$.

Herbers, Klaus/Neuhaus, Helmut, Das Heilige Römische Reich. Ein Überblick, Köln/Weimar/Wien 2010.

Herrmann, Johannes/Wartenberg, Günther/Winter, Christian (Bearb.), Politische Korrespondenz des Herzogs und Kurfürsten Moritz von Sachsen 5 (9. Januar I 55 I - I. Mai I 55 2), hg. von der Historischen Kommission bei der Sächsischen Akademie der Wissenschaften zu Leipzig, Berlin 1998.

Hesse, Christian, Städtisch-bürgerliche Eliten am Hof. Die Einbindung der Residenzstadt in die fürstliche Herrschaft, in: Paravicini/Wettlaufer, Der Hof und die Stadt, 47 I - 486.

Heyın K, Rainer, Fest und Musik als Mittel kaiserlicher Machtpolitik in Rom, in: Bösel/Klingenstein/Koller, Kaiserhof - Papsthof, 285-302.

Hirn, Josef, Erzherzog Ferdinand II. 2 Bde., Innsbruck I 885-88.

Hirschibegel, Jan/Ewert, Ulf Christian, Mehr als nur der schöne Schein. Zu einer Theorie der Funktion von Luxusgegenständen im zwischenhöfischen Gabentausch des späten Mittelalters, in: Häberlein/Jeggle, Materielle Grundlagen, 33-58.

Hirschiegel, Jan/Paravicini, Werner (Hgg.), Das Frauenzimmer: Die Frau bei Hofe in Spätmittelalter und früher Neuzeit, Stuttgart 2000.

Hirschbiegel, Jan/Paravicini, Werner (Hgg.), Der Fall des Günstlings. Hofparteien in Europa vom I3. bis zum I 7. Jahrhundert. 8. Symposium der Residenzen-Kommission der Akademie der Wissenschaften zu Göttingen (= Residenzenforschung I 7), Ostfildern 2004.

Hlavačka, Milan/HolÝ, Martin (Hgg.), Präzedenz, Netzwerke und Transfers. Kommunika- 
tionsstrukturen von Herrscherhöfen und Adelsresidenzen in der Frühen Neuzeit, Leipzig 2016.

Höflechner, Walter/Mezler-Andelberg, Helmut J./Pickl, Othmar (Hgg.), Domus Austriae. Eine Festgabe für Hermann Wiesflecker zum 70. Geburtstag, Graz I983.

Ноотz, Reinhard (Hg.), Deutsche Kunstdenkmäler. Ein Bildhandbuch. Mecklenburg, München/Berlin/Leipzig I 97 г.

Hope, Charles, Les »Camerini d'Alabastro«, in: Bentini/Agostini, Une Renaissance singulière, $279-288$.

Hoppe, Stephan, Die Wittelsbacher Residenzen in Landshut und Neuburg an der Donau in den Netzwerken des Kulturtransfers, in: Müller/Spieß/Friedrich, Kulturtransfer am Fürstenhof, I39- I59.

Horne, Philipp Russell, Reformation and Counter-Reformation at Ferrara: Antonio Musa Brasavola and Giambattista Cinthio Giraldi, in: Italian Studies I 3 (I958), 62-82.

Hrdička, Josef, Kommunikation durch Geld: Zur Rolle des Kredits am südböhmischen Adelshof der Frühen Neuzeit (I550-I600), in: Fouquet/Hirschbiegel/Paravicini, Hofwirtschaft, $36 \mathrm{I}-380$.

Нubach, Hanns, Kurfürst Ottheinrich als Hercules Palatinus. Vorbemerkungen zur Ikonographie des Figurenzyklus' an der Fassade des Ottheinrichbaus im Heidelberger Schloss, in: Stadt Neuburg an der Donau, Pfalzgraf Ottheinrich, 23 I - 248.

Hubmann, Klaus, Musik am Grazer Habsburgerhof unter dem Einfluss der Gegenreformation, in: Dolinar/Liebmann/Rumpler/Tavano, Katholische Reform, 6о7-6 г 2.

IAnZITI, Gary, »Sforza«, in: Reinhardt, Die großen Familien, 5 o I - 5 I 5.

Igálffy von Igály, Ludwig, Die Ambraser Trinkbücher Erzherzog Ferdinands II. von Tirol. Erster Band ( ${ }_{5} 67-{ }_{1577}$ ). Transkription und Dokumentation (= Schriften des Kunsthistorischen Museums I 2), Wien 20 Iо.

Immlen, Gerhard, Maximilian I. Der Große Kurfürst auf der Bühne der europäischen Politik, in: Schmid/Weigand, Die Herrscher Bayerns, 202-2 I 7.

Iотті, Roberta (Hg.), Gli Estensi r : La Corte di Ferrara, Modena I 997.

Iotт , Roberta, La Politica dell'amore. Alcuni casi di alleanze matrimoniali in Casa d'Este, in: Iotti, Gli Estensi I, I 47- I 8 I.

Iотті, Roberta, La politica dell'amore. Seconda parte: Altri casi matrimoniali in Casa d'Este, in: Bini, Gli Estensi 2, I 39- I 80.

Irrgang, Stephanie, Peregrinatio academica. Wanderungen und Karrieren von Gelehrten der Universitäten Rostock, Greifswald, Trier und Mainz im I 5. Jahrhundert (= Beiträge zur Geschichte der Universität Greifswald 4), Stuttgart 2002.

Iserloh, Erwin, Die Päpste im Zeitalter der Reformation und des Konzils von Trient. Von Leo X. bis Pius IV, in: Greschat, Das Papsttum II., 53- io2.

Issleib, Simon, Aufsätze und Beiträge zu Kurfürst Moritz von Sachsen (1877- I 907), hg. von Reiner Groß 2 Bde. (= Mitteldeutsche Forschungen, Sonderreihe: Quellen und Darstellungen in Nachdrucken 8/r), Köln/Wien I989.

Itter, Wilhelm, De Feudis Imperii Commentatio Methodica, Frankfurt a.M. I685.

ЈАков, Reinhard, Zucker, Edelsteine und ein Rhinozeros. Briefe aus Portugal (I 494- I 522 ), in: Anzeiger des Germanischen Nationalmuseums (2002), 74-89. 
Jамrozıк, Elżbieta, L'italiano in Polonia ieri e oggi, in: Vanvolsem/Vermandere/d'Hulst/Musarra, LItaliano oltre frontiera 2, 31 9-328.

JanÁček, Josef, Les Italiens à Prague à l'époque précédant la bataille de la Montagne Blanche (I $526-1620$ ), in: Historica 23 (1983), 5-45.

Jancke, Gabriele, Patronage, Freundschaft, Verwandtschaft: Gelehrtenkultur in der Frühen Neuzeit, in: Schmidt/Guichard/Schuster/Trillmich, Freundschaft und Verwandtschaft, I 8 I -200 .

Janker, Stephan M., Grafschaft Haag (= Historischer Atlas von Bayern. Teil Altbayerns 59), München 1996.

Jansen, Dirk Jacob, Gli strumenti del mecenatismo: Jacopo Strada alla corte di Massimiliano II, in: Mozzarelli, »Familia del principe, 7 I I -743 .

Jansen, Dirk Jacob, The Instruments of Patronage. Jacopo Strada at the Court of Maximilian II: A case study, in: Edelmayer/Kohler, Kaiser Maximilian II., I 82-202.

Jansen, Dorothea, Einführung in die Netzwerkanalyse. Grundlagen, Methoden, Forschungsbeispiele, 3. überarbeitete Auflage, Wiesbaden 2006.

Jarren, Volker, Die Vereinigten Niederlande und das Haus Österreich r648-i748: Fremdbildwahrnehmung und politisches Handeln kaiserlicher Gesandter und Minister, in: Helmut Gabel/Volker Jarren, Kaufleute und Fürsten. Außenpolitik und politisch-kulturelle Perzeption im Spiegel niederländisch-deutscher Beziehungen I648-I748 (= Niederlande-Studien I 8), Münster/New York/München/Berlin I 998, 39-354.

Jedin, Hubert, Geschichte des Konzils von Trient I : Der Kampf um das Konzil, Freiburg ${ }^{2}$ I 95 I. Jensen, Niels Martin, Music at Ferrara under Ercole II and Alfonso II, in: Pade/Waage Petersen/Quarta, La Corte di Ferrara, 329-336.

Jordan, Stefan, Theorien und Methoden der Geschichtswissenschaft, Paderborn ${ }^{2} 2013$.

Jucker, Michael, Raub, Geschenke und diplomatische Irritationen. Die ökonomische Zirkulation und Distribution von Beutestücken und Luxusgegenständen (I 3.- I6. Jahrhundert), in: Häberlein/Jeggle, Materielle Grundlagen, 59-77.

Kaelble, Hartmut, Die interdisziplinären Debatten über Vergleich und Transfer, in: Ders./ Jürgen Schriewer (Hgg.), Vergleich und Transfer. Komparatistik in den Sozial-, Geschichtsund Kulturwissenschaften, Frankfurt a.M. 2003, 469-493.

Kappel, Jutta, »... im heiligen Ehestande wie eine Turteltaube gelebet«? Prinzessin Anna von Dänemark an der Seite Kurfürst Augusts von Sachsen, in: Haag, Dresden \& Ambras, 65 - 7 I .

Karge, Wolf/Münch, Ernst/Schmied, Hartmut, Die Geschichte Mecklenburgs von den Anfängen bis zur Gegenwart, Rostock ${ }^{4} 2004$.

Katritzky, M. A., The Florentine Entrata of Joanna of Austria and Other Entrate described in a German Diary, in: Journal of the Warburg and Courtauld Institutes 59 (I 996), I 48 - I 73.

Kebluser, Marika, Commerce and Cultural Transfer. Merchants as Agents in the Early Modern World of Books, in: North, Kultureller Austausch, 297-307.

Kelle r, Hagen, Adel in den italienischen Kommunen, in: Otto Gerhard Oexle/Werner Paravicini (Hgg.), Nobilitas. Funktion und Repräsentation des Adels in Alteuropa, (= Veröffentlichungen des Max-Planck-Instituts für Geschichte I33), Göttingen I 997, 257-272.

Kelle r, Hagen, Adelsherrschaft und städtische Gesellschaft in Oberitalien 9.- I 2. Jahrhundert (= Bibliothek des deutschen historischen Instituts in Rom 52), Tübingen 1979.

Kelle r, Katrin (Proj.leit.), Die Fuggerzeitungen. Ein frühneuzeitliches Informationsmedium 
und seine Erschließung digitalisiert und erschlossen, FWF-Projekt, http://fuggerzeitungen. univie.ac.at/, Zugriff: 22.8.2020.

Keller, Katrin, Das Frauenzimmer. Hofdamen und Dienerinnen zwischen Transfer und kultureller Praxis, in: Rode-Breymann/Tumat, Der Hof, s 85-206.

Keller, Katrin, Die italienische Reise. Pilgerfahrt, Kavalierstour, Bildungsreise, in: Wolfgang Huschner/Enno Bünz/Christian Lübke (Hgg.), Italien - Mitteldeutschland - Polen. Geschichte und Kultur im europäischen Kontext vom Io. bis zum I 8. Jahrhundert, (= Schriften zur sächsischen Geschichte und Volkskunde 42), Leipzig 2013, 601-626.

Keller, Katrin, Erzherzogin Maria von Innerösterreich (155 I-1608). Zwischen Habsburg und Wittelsbach, Wien/Köln/Weimar 2012.

Keller, Katrin, Frauen - Hof - Diplomatie. Die höfische Gesellschaft als Handlungsraum von Frauen in Außenbeziehungen, in: Corina Bastian u.a. (Hgg.), Das Geschlecht der Diplomatie. Geschlechterrollen in den Außenbeziehungen vom Spätmittelalter bis zum 20. Jahrhundert (= Externa 5), Köln/Weimar/Wien 20I4, 33-50.

Keller, Katrin, Hofdamen. Amtsträgerinnen im Wiener Hofstaat des I 7. Jahrhunderts, Wien/ Köln/Weimar 2005 .

Keller, Katrin, Kommunikationsraum Altes Reich. Zur Funktionalität der Korrespondenznetze von Fürstinnen im I6. Jahrhundert, in: Zeitschrift für Historische Forschung 3 I (2004), 205-230.

Keller, Katrin, Kurfürstin Anna von Sachsen (1532- I 585 ), Regensburg 20 io.

Keller, Katrin, Mit den Mitteln einer Frau: Handlungsspielräume adliger Frauen in Politik und Diplomatie, in: Thiessen/Windler, Akteure der Außenbeziehungen, 2 I 9-244.

Keller, Katrin, Von der Nützlichkeit des Reisens. Bemerkungen zu Erscheinungsbild und Konsequenz der Kavalierstour am Beispiel kursächsischer Befunde, in: Babe1/Paravicini, Grand Tour, 429-454.

Keller, Katrin, Zwischen Wissenschaft und Kommerz. Das Spektrum kultureller Mittler im I6. Jahrhundert, in: Schmale, Kulturtransfer, $27 \mathrm{I}-285$.

Kellner, Beate, Formen des Kulturtransfers am Hof Kaiser Maximilians I., in: Müller/Spieß/ Friedrich, Kulturtransfer am Fürstenhof, 52 - 103.

Kenyeres, István, Die Kosten der Türkenabwehr und des Langen Türkenkrieges (I593- I606) im Kontext der ungarischen Finanzen des I6. und I7. Jahrhunderts, in: Rauscher/Serles/ Winkelbauer, Das »Blut des Staatskörpers«, I9-42.

Kettering, Sharon, Patrons, Brokers and Clients in Seventeenth Century France, New York/ Oxford I986.

Kimmich, Dorothee/Schah adat, Schamma/Hauschild, Thomas (Hgg.), Kulturtheorie, Bielefeld 2 oro.

Kintzinger, Martin, Karl IV., in: Schneidmüller/Weinfurter, Die deutschen Herrscher des Mittelalters, $408-432$.

Klarwill, Victor, Fugger-Zeitungen. Ungedruckte Briefe an das Haus Fugger aus den Jahren I 568 - I605, Wien/Leipzig/München I 923.

Klettke, Cornelia, Ferrara und sein Fürstenhof als frühneuzeitlicher Begegnungsraum und Brennpunkt europäischer Identitätsfindung, in: Cornelia Klettke/Ralf Pröve (Hgg.), Brennpunkt kultureller Begegnungen auf dem Weg zu einem modernen Europa. Identitäten und 
Alteritäten eines Kontinents (= Schriften des Frühneuzeitzentrums Potsdam I), Göttingen 20II, 7I-IO5.

Kloosterhuis, Elisabeth, Erben der Caesaren. Die letzten europäischen Kaiserkrönungen I 530 und I 804, in: Asch/Arndt/Schnettger, Die frühneuzeitliche Monarchie, I53- I 78.

Knecht, Robert J., La corte di Francia nel XVI secolo, in: Mozzarelli, »Familia« del principe, 225-244.

Knecht, Robert J., The Rise and Fall of Renaissance France r483-i6ro, London I 996.

Koenigsberger, Helmut Georg, Patronage and Bribery during the Reign of Charles V, in: Ders., Estates and Revolutions: Essays in Early Modern European History, New York, I 97 I, I66-I75.

Kohler, Alfred, »Tu felix Austria nube ...«Vom Klischee zur Neubewertung dynastischer Politik in der neueren Geschichte Europas, in: Zeitschrift für Historische Forschung 2 I (I 994), $46 \mathrm{I}-482$.

Kohler, Alfred, Bayern als Vorbild für die innerösterreichische Gegenreformation, in: Dolinar/ Liebmann/Rumpler/Tavano, Katholische Reform, 387-403.

Kohler, Alfred, Bemerkungen zur Wahrnehmung von Reich und Reichstag in den spanischen Königreichen, in: Lanzinner/Strohmeyer, Der Reichstag I 486- I6 I3, 453-46o.

Kohler, Alfred, Das Reich im Kampf um die Hegemonie in Europa I 52 I- I648, München I 990.

Kohler, Alfred, Expansion und Hegemonie. Internationale Beziehungen I 450- I 559 (= Handbuch der Geschichte der Internationalen Beziehungen I), Paderborn/München/Wien/Zürich 2008 .

Kohler, Alfred, Die spanisch-österreichische Begegnung in der ersten Hälfte des I6. Jahrhunderts. Ein mentalitätsgeschichtlicher Versuch, in: Krömer, Spanien und Österreich, 4I - 55 .

Kohler, Alfred, Ferdinand I. I 503 - I 564 . Fürst, König, Kaiser, München 2003.

Kohler, Alfred, Kaiser Ferdinand I. - Zur Forschungsgeschichte eines Zweitgeborenen, in: Fuchs/Kohler, Kaiser Ferdinand I., 235-245.

Kohler, Alfred, Karl V. I 500 - I 55 8. Eine Biographie, München I 999.

Kohler, Alfred, Karl V., Ferdinand I. und das Reich. Bemerkungen zur Politik der habsburgischen Brüder, in: Vogler, Europäische Herrscher, 58-70.

Kohler, Alfred, Wege der Politik. Vom habsburgischen Gesamtsystem Karls V. zu den Teilsystemen Philipps II. und Maximilians II., in: Edelmayer/Kohler, Kaiser Maximilian II., I 3 - 37.

Kohler, Alfred/Edelmayer, Friedrich (Hgg.), Hispania - Austria. Die Katholischen Könige, Maximilian I. und die Anfänge der Casa de Austria in Spanien/Los Reyes Católicos, Maximiliano I y los inicios de la Casa de Austria en España. Akten des Historischen Gespräches, Innsbruck, Juli r992, Sonderdruck, Wien/München r 993.

Kohler, Alfred/Haider, Barbara/Ottwer, Christine (Hgg.), Karl V. i 500-I 558. Neue Perspektiven seiner Herrschaft in Europa und Übersee (= Österreichische Akademie der Wissenschaften, Philosophisch-Historische Klasse, Historische Kommission, ZentraleuropaStudien 6), Wien 2002.

Kohler, Alfred/Lutz, Heinrich (Hgg.), Alltag im r6. Jahrhundert. Studien zu Lebensformen in mitteleuropäischen Städten (= Wiener Beiträge zur Geschichte der Neuzeit I4), Wien I987. 
Kolв, Karin, Lucas Cranach d.J., Der schlafende Herkules und die Pygmäen und Der erwachte Herkules vertreibt die Pygmäen, in: Marx/Kluth, Glaube und Macht, I 47- I 59.

Koldau, Linda Maria, Familiennetzwerke, Machtkalkül und Kulturtransfer: Habsburgerfürstinnen als Musikmäzeninnen im I6. und I 7. Jahrhundert, in: Nolde/Opitz, Grenzüberschreitende Familienbeziehungen, 55-72.

Koller, Alexander (Bearb.), Nuntiaturen des Orazio Malaspina und des Ottavio Santacroce. Interim des Cesare dell'Arena (I578-I58I) (= Nuntiaturberichte aus Deutschland III. Abteilung IO: I $572-\mathrm{I} 585)$, Berlin/Boston 2012.

Koller, Alexander (Hg.), Kurie und Politik. Stand und Perspektiven der Nuntiaturberichtsforschung (= Bibliothek des Deutschen Historischen Instituts in Rom 87), Tübingen I 998.

Koller, Alexander, Der Kaiserhof am Beginn der Regierung Rudolfs II. in den Berichten der Nuntien, in: Bösel/Klingenstein/Koller, Kaiserhof - Papsthof, I3-24.

Koller, Alexander, Der Konflikt um die Obödienz Rudolfs II. gegenüber dem H1. Stuhl, in: Koller, Kurie und Politik, I 48 - I64.

Koller, Alexander, Maria von Spanien, die katholische Kaiserin, in: Braun/Keller/Schnettger, Nur die Frau des Kaisers?, 85-95.

Koller, Alexander, Nuntienalltag. Überlegungen zur Lebenswelt eines kirchlichen Diplomatenhaushalts im I 6. und I 7. Jahrhundert, in: Rupert Klieber/Hermann Hold (Hgg.), Impulse für eine religiöse Alltagsgeschichte des Donau-Alpen-Adria-Raumes, Wien/Köln/Weimar 2005, 95- 108 .

Koller, Alexander, Reichsitalien als Thema in den Beziehungen zwischen Kaiser und Papst. Der Fall Borgo Val di Taro, in: Schnettger/Verga, L'Impero e l'Italia, 323-345.

Koller, Alexander, Vademecum für einen Nuntius, in: Römische Historische Mitteilungen 47 (2007), I 79-226.

Konečný, Lubomír u.a. (Hgg.), Rudolf II, Prague and the World. Papers from the International Conference, Prague, 2-4 september 1 997, Prague 1998.

Korsch, Evelyn, Ein »heimlicher Vorschlag « - die politischen Beziehungen zwischen Dresden und Ferrara in der Mitte des I6. Jahrhunderts, in: Marx, Elbflorenz, 37-64.

Korsch, Evelyn, Geschenke im Kontext von Diplomatie und symbolsicher Kommunikation. Der Besuch Heinrichs III. in Venedig I 574, in: Häberlein/Jeggle, Materielle Grundlagen, IO3- I 20.

Kraus, Andreas (Hg.), Handbuch der Bayerischen Geschichte 2, München ${ }^{2}$ I 988.

Kristeller, Paul Oskar, Der italienische Humanismus und Byzanz, in: Eckhard Keßler (Hg.), Humanismus und Renaissance I. Die antiken und mittelalterlichen Quellen, Humanistische Bibliothek Reihe I: Abhandlungen 2 I, aus dem Englischen übersetzt von Renate SchweyenOtt, München r 974, I 45- i6o.

Kroll, Frank-Lothar, Die Herrscher Sachsens. Markgrafen, Kurfürsten, Könige ro89- I918, München 2004.

Kroll, Frank-Lothar, Geschichte Sachsens, München 2014.

Krömer, Wolfram (Hg.), Spanien und Österreich in der Renaissance. Akten des Fünften Spanisch-Österreichischen Symposions, 2 I.-25. September I 987 in Wien (= Innsbrucker Beiträge zur Kulturwissenschaft, Sonderheft 66), Innsbruck I 989 .

Krones, Hartmut, Die Geschichte der Wiener Hofmusikkapelle bis zum Tod Kaiser Maximilians I., in: Susanne Antonicek/Günter Brosche, Musica Imperialis: 5 oo Jahre Hofmu- 
sikkapelle in Wien. I498 - I998, Ausstellung der Musiksammlung der Österreichischen Nationalbibliothek, Prunksaal, i r. Mai bis ro. November I 998, Tutzing, I 998, I 5-26.

Kruse, Margot, Sprachlich-literarische Aspekte der höfischen sjeux de conversation in Italien und Frankreich, in: Buck/Kauffmann/Spahr/Wiedemann, Europäische Hofkultur 2, 33-40.

Kubersky-Piredda, Susanne/Salort Pons, Salvador, Ein Hofnarr als Agent. Zum diplomatischen Geschenkwesen am Hof Philipps II., in: Häberlein/Jeggle, Materielle Grundlagen, I $23-\mathrm{I} 55$.

KüHner, Christian, »Quand je retournai, je trouvai toutes les cabales de la cour changées«: Friendship under the Conditions of Seventeenth-Century Court Society, in: Descharmes/ Heuser/Krüger/Loy, Varieties of friendship, 59-76.

Kühner, Christian, Politische Freundschaft bei Hofe. Repräsentation und Praxis einer sozialen Beziehung im französischen Adel des I 7. Jahrhunderts (= Freunde - Gönner - Getreue. Studien zur Semantik und Praxis von Freundschaft und Patronage 6), Göttingen 2013.

Kunoff, Wolfgang, »Da Polenta« in: Reinhardt, Die großen Familien, 44I-462.

Kunoff, Wolfgang, »Ordelaffi«, in: Reinhardt, Die großen Familien, 384-388.

Kümmel, Ute, Heirat, Reise, Beute. Kulturtransferprozesse anhand von spätmittelalterlichen Fürstenschätzen, in: Müller/Spieß/Friedrich, Kulturtransfer am Fürstenhof, I 04 - I 2 I .

Kunze, Stefan, Höfische Musik im I6. und I7. Jahrhundert, in: Buck/Kauffmann/Spahr/Wiedemann, Europäische Hofkultur I, 69-80.

Kuster, Thomas, »Eur Lieb gannz williger Brueder«. Fürstliche Freundschaft am politischen Parkett? Die Beziehungen der Habsburger und der Wettiner in der frühen Neuzeit, in: Haag, Dresden \& Ambras, 43- 53 .

Kuster, Thomas, Herzogin Barbara - »allain, dass mir di waill gar lang ist«, in: Haag, Nozze italiane, Katalogteil, I I 4 - I 36.

Landwenr, Achim, Die Erschaffung Venedigs. Raum, Bevölkerung, Mythos I 570-I750, Paderborn 2007.

Landweh R, Achim, Kulturgeschichte, Stuttgart 2009.

Landwenr, Achim/Stocкноrst, Stefanie, Einführung in die Europäische Kulturgeschichte, Paderborn/München/Wien/Zürich 2004 .

LAng, Heinrich, Credito e insolvenza sovrana: I prestiti alla Corona francese di mercantibanchieri toscani e tedeschi meridionali ( I 500- I 559), in: Annali dell'Istituto storico italogermanico in Trento/Jahrbuch des italienisch-deutschen historischen Instituts in Trient 4I/I (2015), I I -38 .

LANG, Stefanie (Hg.), Kulturelle Identität, soziale Netzwerke und Kognition. Berichte ethnologischer Forschungen aus Köln, Wiesbaden 1997.

Langer, Andrea/Michels, Georg (Hgg.), Metropolen und Kulturtransfer im i 5./r6. Jahrhundert. Prag - Krakau - Danzig -Wien (= Forschungen zur Geschichte und Kultur des östlichen Mitteleuropa I 2), Stuttgart 200 I.

Langewiesche, Dieter (Hg.), Kleinstaaten in Europa. Symposium am Liechtenstein-Institut zum Jubiläum 200 Jahre Souveränität Fürstentum Liechtenstein I806-2006 (= Liechtenstein Politische Schriften 42), Schaan 2007.

Lanzinner, Maximilian (Bearb.), Deutsche Reichstagsakten, Reichsversammlungen ${ }_{5} 56$ I 662 hg. v. der Historischen Kommission bei der Bayerischen Akademie der Wissenschaften. Der Reichstag zu Speyer I 570, Zweiter Teilband: Akten und Abschied, Göttingen I 988. 
Lanzinner, Maximilian, Der Gemeine Pfennig, eine richtungsweisende Steuerreform? Zur Entwicklung des Reichssteuersystems ${ }_{4} 22$ bis I608, in: Rauscher/Serles/Winkelbauer, Das »Blut des Staatskörpers«, 26 I - 3 I 8.

Lanzinner, Maximilian, Friedenssicherung und politische Einheit des Reiches unter Kaiser

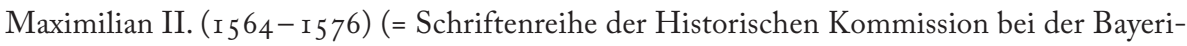
schen Akademie der Wissenschaften 45), Göttingen 1993.

Lanzinner, Maximilian/Heil, Dietmar (Bearb.), Deutsche Reichstagsakten, Reichsversammlungen I 556- I662 hg. v. der Historischen Kommission bei der Bayerischen Akademie der Wissenschaften. Der Reichstag zu Augsburg 1566, 2 Bde., München 2002.

Lanzinner, Maximilian/Strohmeyer, Arno (Hgg.), Der Reichstag I486-i6r 3. Kommunikation - Wahrnehmung - Öffentlichkeiten (= Schriftenreihe der Historischen Kommission bei der Bayerischen Akademie der Wissenschaften 73), Göttingen 2006.

Larivaille, Paul, Familiari, consiglieri, segretari ne Il Principe di Giambattista Pigna, in: Mozzarelli, „Familia del principe, 27-50.

Laubach, Ernst, Ferdinand I. als Kaiser. Politik und Herrscherauffassung des Nachfolgers Karls V., Münster 200I.

Laubach, Ernst, Politik und Selbstverständnis Kaiser Ferdinands I., in: Fuchs/Kohler, Kaiser Ferdinand I., I $23-\mathrm{I} 46$.

Lazzari, Alfonso, Borso d'Este, il primo duca di Ferrara, Ferrara I 945.

Lazzari, Alfonso, I »ricordi di governo« di Alfonso II d'Este duca di Ferrara, in: Archivio storico italiano 78 ( I 920), I IO-I 23.

Lazzari, Alfonso, Le ultime tre duchesse di Ferrara e la corte estense al tempo di Torquato Tasso, Rovigo 1952.

LAZZARINI, Isabella, Il linguaggio del territorio fra principe e comunità : il giuramento di fedeltà a Federico Gonzaga, Mantova I479, Firenze 2009.

Lazzarini, Isabella, L'Italia degli Stati territoriali. Secoli XIII-XV, Roma/Bari 2003.

Lazzarini, Isabella, News from Mantua: Diplomatic Networks and Political Conflict in the Age of the Italian Wars (I493-I499), in: Noflatscher/Chisholm/Schnerb, Maximilian I., I I I I 29.

Leве, Reinhard, Ein Königreich als Mitgift. Heiratspolitik in der Geschichte, Stuttgart 1998.

Leев, Josef (Bearb.), Deutsche Reichstagsakten, Reichsversammlungen I 556-I662, hg. v. der Historischen Kommission bei der Bayerischen Akademie der Wissenschaften. Der Reichstag zu Augsburg 1582, Zweiter Teilband, München 2007.

Leeb, Josef, Stereotype und Feindbilder an einem Ort interkultureller Begegnung: Augsburg während des Reichstags von I 582, in: Rohrschneider/Strohmeyer, Wahrnehmung des Fremden, I 7 I - 200 .

Lein, Edgar, Über den Naturabguss von Schlangen, Kröten, Krebsen und anderen kleinen Tieren, in: Seipel, Die Entdeckung der Natur, 77- I32.

Levin, Michael J., Agents of Empire. Spanish Ambassadors in Sixteenth-Century Italy, Ithaca u.a. 2005 .

LÉvi-Strauss, Claude, Die elementaren Strukturen der Verwandtschaft, Frankfurt a.M. I 98 I.

Lнот sкy, Alphons, Kaiser Friedrich III. Sein Leben und seine Persönlichkeit, in: Amt der Niederösterreichischen Landesregierung (Hg.), Friedrich III. Kaiserresidenz Wiener Neustadt. 
Ausstellungskatalog, St. Peter an der Sperr/Wiener Neustadt, 28.5.-30. Io. I 966, Wien I 966 , I6- 47 .

Liebenwein, Wolfgang, Lo studiolo come luogo del principe, in: Mottola Molfino/Natale, Le muse e il principe I, I35- I 44 .

Lieber, Maria, Die italienische Präsenz am Hofe Augusts des Starken und seiner Söhne - erste Überlegungen, in: Marx, Elbflorenz, I 43 - I 57 .

Lietzmann, Hilda, Der kaiserliche Antiquar Jacopo Strada und Kurfürst August von Sachsen, in: Zeitschrift für Kunstgeschichte 6o (1997), 377-399.

Lietzmann, Hilda, Irdische Paradiese. Beispiele höfischer Gartenkunst der I. Hälfte des I6. Jahrhunderts, München/Berlin 2007.

Limentani Virdis, Caterina, La corte estense e l'arte fiamminga, in: Bertozzi, Alla corte degli Estensi, I63-I80.

Lindell, Robert, New Findings on Music at the Court of Maximilian II, in: Edelmayer/Kohler, Kaiser Maximilian II., 23 I -245 .

Locatelli, Francesco, La fabbrica ducale estense delle artiglierie. Da Leonello ad Alfonso II d'Este, Bologna, I 985 .

Lockwood, Lewis, Adrian Willaert and Cardinal Ippolito I d'Este: New Light on Willaert's Early Career in Italy. I 5 I 5 - 2 I, in: Early Music History 5 (I 985 ), 85 - I I 2, https://www.jstor.org/sta ble $/ 853920$ ? Search =yes\&resultItemClick=true\&search Text=adrian+willaert\&searchUri $=\% 2$ Faction $\%_{2} \mathrm{FdoB}$ asicSearch $\%_{3} \mathrm{FQuery} \%_{3}$ Dadrian $\%_{2}$ Bwillaert\&ab_segments=0 \% $2 \mathrm{Fba}$ sic_search \%2Fcontrol\&refreqid=fastly-default \%3 $\%_{2} 60_{3} 2$ I I 4 I 8 b 8 a 2 I 695 8eegd 7 cb86 b 3 I I \&seq=I\#metadata_info_tab_contents, Zugriff: I6.9.2020.

Lockwood, Lewis, Musica a corte e in chiesa nel XV secolo, in: Prosperi, Storia di Ferrara 6, 3I 4 - 33 I.

Loserth, Johann, Die Reise Erzherzog Karls II. nach Spanien (1568-1569). Ein Beitrag zur Geschichte des Don Carlos, in: Mittheilungen des historischen Vereins für Steiermark 44 (1896), I30-204.

Loserth, Johann, Innerösterreich und die militärischen Maßnahmen gegen die Türken im I6. Jahrhundert: Studien zur Geschichte der Landesdefension und der Reichshilfe, Graz I934.

Louthan, Howard, The quest for compromise. Peacemakers in Counter-Reformation Vienna (= Cambridge Studies in Early Modern History), Cambrigde University Press 1997.

Lucco, Mauro, Mantegna a Mantova e i suoi eredi, in: Ders. (Hg.), Mantegna a Mantova I 460-I 506, Catalogo della mostra, Palazzo Te, Mantova r6 settembre- I 4 gennaio 2007 , Milano 2006, 3-i7.

Ludwig, Christoph, Untersuchungen über die frühesten »Podestaten« italienischer Städte (= Dissertationen der Universität Wien 90), Wien I 973.

Lunelli, Renato, Contributi trentini alle relazioni musicali fra l'Italia e la Germania nel Rinascimento, in: Acta Musicologica 2 I (I 949), 4I - 70, https://www.jstor.org/stable/93 I 534? Search $=y e s \& r e s u l t I t e m C l i c k=$ true $\&$ search Text $=$ Contributi+trentini + alle + relazioni + musicali\&searchUri=\% 2 Faction $\%_{2}$ FdoBasicSearch $\%_{3}$ FQuery $\%_{3}$ DContributi $\%_{2}$ Btrentini $\%_{2}$ Balle $\%_{2}$ Brelazioni $\%_{2}$ B Bmusicali\&ab_segments $=0 \%{ }_{2}$ Fbasic_search $\%_{2}$ Fcontrol

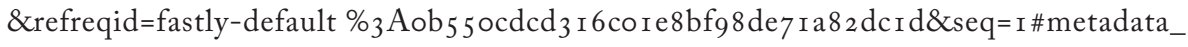
info_tab_contents, Zugriff: I6.9.2020. 
LüNIG, Johann Christian, Codex Italiae Diplomaticus: Quo non solum Multifariae Investiturarum Literae, ab Augustissimis Romanorum Imperatoribus Italiae Principibus \& Proceribus concessae atque traditae $[\ldots]$ 4 Bde., Frankfurt/Leipzig, I 725-35.

Lüth, Christoph/Keck, Rudolf W./Wiersing, Erhard (Hgg.), Der Umgang mit dem Fremden in der Vormoderne. Studien zur Akkulturation in bildungshistorischer Sicht (= Beiträge zur Historischen Bildungsforschung I 7), Köln/Weimar/Wien I 997.

Luttenberger, Albrecht P., Innerösterreich und das Reich im Zeitalter der Gegenreformation, in: Dolinar/Liebmann/Rumpler/Tavano, Katholische Reform, 357-371.

Luttenberger, Albrecht P., Kurfürsten, Kaiser und Reich. Politische Führung und Friedenssicherung unter Ferdinand I. und Maximilian II. (= Veröffentlichungen des Instituts für Europäische Geschichte Mainz, Abteilung Universalgeschichte I49), Mainz I 994.

Luttenberger, Albrecht P., Pracht und Ehre. Gesellschaftliche Repräsentation und Zeremoniell auf dem Reichstag, in: Kohler/Lutz, Alltag im r6. Jahrhundert, 29I-326.

Luttenberger, Albrecht P., Reichspolitik und Reichstag unter Karl V.: Formen zentralen politischen Handelns, in: Lutz/Kohler, Aus der Arbeit an den Reichstagen, I 8-68.

Lutter, Christina, »An das Volk von Venedig!«. Propaganda Maximilians I. in Venedig, in: Karel Hruza (Hg.), Propaganda, Kommunikation und Öffentlichkeit (I I.- I6. Jahrhundert), Wien 2002, 235-254.

Lutter, Christina, Differenz- und Kongruenzerfahrungen von Gesandten der Republik Venedig und Maximilians I. um I 500, in: Rohrschneider/Strohmeyer, Wahrnehmung des Fremden, I 23 - I 46 .

Lutter, Christina, Diplomatie und Nachbarschaft. Zur frühneuzeitlichen Kommunikation zwischen Österreich und Venedig, in: Gerhard Kofler/Jacques Le Rider/Johann Strutz (Hgg.), Kulturelle Nachbarschaft. Zur Konjunktur eines Begriffes, Klagenfurt/Wien/ Ljubljana/Sarajevo 2002, I 29-I48.

Lutter, Christina, Geschlecht, Beziehung, Politik. Welche Möglichkeiten und Grenzen »erfolgreichen« Handelns hatte Bianca Maria Sforza?, in: Noflatscher/Chisholm/Schnerb, Maximilian I., 25 I -266.

Lutter, Christina, Politische Kommunikation an der Wende vom Mittelalter zur Neuzeit. Die diplomatischen Beziehungen zwischen der Republik Venedig und Maximilian I. (I 495I 508) (= Veröffentlichungen des Instituts für Österreichische Geschichtsforschung 34), Wien 1998.

Lutter, Christina, Selbstbilder und Fremdwahrnehmung des habsburgischen Kaisertums um I 500 am Beispiel der venezianisch-maximilianischen diplomatischen Kommunikation, in: Duchhardt/Schnettger, Reichsständische Libertät, $25-42$.

Lutter, Christina/Unterholzner, Daniela, Fürstin ohne Ort. Vom Scheitern der Bianca Maria Sforza, in: Braun/Keller/Schnettger, Nur die Frau des Kaisers?, 65-84.

Lutz, Heinrich, Christianitas afflicta. Europa, das Reich und die päpstliche Politik im Niedergang der Hegemonie Kaiser Karls V. ( $1552-$ I 556 ), Göttingen I 964.

Lutz, Heinrich, Il cardinale Ippolito d'Este (I509-I572). Schizzo biografico di un principe mondano della Chiesa, in: Atti e Memorie della Società tiburtina di Storia e d'Arte 39 ( 1966$)$, I $27-$ I56.

Lutz, Heinrich, Karl V. - Biographische Probleme, in: Vogler, Europäische Herrscher, 3 I - 57.

Lutz, Heinrich/Kohler, Alfred (Hgg.), Aus der Arbeit an den Reichstagen unter Kaiser 
Karl V. Sieben Beiträge zu Fragen der Forschung und Edition (= Schriftenreihe der Historischen Kommission bei der Bayerischen Akademie der Wissenschaften 26), Göttingen I 986.

Lutz, Heinrich/Ziegler, Walter, Das konfessionelle Zeitalter. Erster Teil: Die Herzöge Wilhelm IV. und Albrecht V, in: Kraus, Handbuch der Bayerischen Geschichte 2, 322-372.

Luzio, Alessandro, Un pronostico satirico di Pietro Aretino, Bergamo i 900.

Machiavelli, Niccoló di Bernardo dei, Il Principe, hg. v. Sálvio M. Soares, MetaLibri, 2005, http://metalibri.wikidot.com/title:il-principe, Zugriff: 22.8.2020.

Mączaк, Antoni (Hg.), Klientelsysteme im Europa der Frühen Neuzeit, München 1988.

Mączaк, Antoni, Il principe e l'alta nobiltà: Alcuni modelli di strategie famigliari nell'Europa del nord nel XVI e XVII secolo, in: Mozzarelli, »Familia« del principe, I 49- I 57.

Mączak, Antoni, Ungleiche Freundschaft. Klientelbeziehungen von der Antike bis zur Gegenwart, aus dem Polnischen von Peter Oliver Loew (= Klio in Polen 7), Osnabrück 2005.

MĄczaK, Antoni, Viaggi e viaggiatori nell'Europa moderna, aus dem Polnischen übersetzt und adaptiert von Renzo Panzone und Andrzej Litwornia, Roma/Bari 2002.

Magirius, Heinrich, Das Moritzmonument im Freiberger Dom - ein Gemeinschaftswerk italienischer, niederländischer und deutscher Künstler zum Andenken an eine hervorragende Fürstenpersönlichkeit, in: Dresdner Hefte 52 ( 1997 ), 87-92.

Magna, Cesare, I feudi imperiali rurali della Lunigiana nei secoli XVI-XVIII, in: Studi di storia e diritto in onore di Enrico Besta per il XI anno del suo insegnamento in 4 voll. 3, Milano 1937- I939, 43-70.

Magoni, Clizia, I gigli d'oro e l'aquila bianca. Gli Estensi e la corte francese tra '400 e '500: un secolo di rapporti (= Deputazione provinciale ferrarese di storia patria. Atti e memorie, serie IV, XVIII), Ferrara 200 I.

Maleczeк, Werner (Hg.), Fragen der politischen Integration im mittelalterlichen Europa (= Vorträge und Forschungen 63), Ostfildern 2005.

Manfredini, Ilario, Identità storica e progettualità ideologica nell'età di Emanuele Filiberto e nei primi anni di Carlo Emanuele I, in: Bellabarba/Merlotti, Stato sabaudo, 233-249.

Mancini, Augusto, Storia di Lucca, Florenz i95o.

Manini Ferranti, Giuseppe, Compendio della storia sacra e politica di Ferrara 4 Bde., Ferrara I 808, online verfügbar: https://reader.digitale-sammlungen.de/de/fs I/object/display/ bsbroo78679_00005.html /, Zugriff: I6.9.2020.

Manolesso, Emiliano, Relazione di Ferrara, Firenze i 84 I.

Marchesi, Andrea, L'«illustrissimo bastardo« di Casa d'Este: don Alfonso di Montecchio ( $5_{527}$ I 587). Vicende di un principe malnoto, tra episodi di committenza e strategie mecenatesche, Dissertation Università Ca'Foscari, Venezia 2015 .

Maresti, Alfonso, Teatro geneologico et istorico dell'antiche et illustri famiglie di Ferrara 3, Ferrara I 708.

Marini, Lino, Lo stato estense, in: Marini/Tocci/Mozzarelli/Stella, I Ducati padani, 3 - 2 I 4.

Marini, Lino/Tocci, Giovanni/Mozzarelli, Cesare/Stella, Aldo (Hgg.), I Ducati padani, Trento e Trieste (= Storia d'Italia hg. v. Giuseppe Galasso I 7), Torino I 979.

Marino, Angela, L'architettura nel Quattrocento, in: Bocchi, Storia illustrata di Ferrara 2, $369-384$.

Marri, Fabio/Lieber, Maria/Weyers, Christian, Lodovico Antonio Muratori und Deutsch- 
land. Studien zur Kultur- und Geistesgeschichte der Frühaufklärung (= Italien in Geschichte und Gegenwart 8), Frankfurt a.M./Berlin/Bern/New York/Paris/Wien I 997, I3- I 8.

Martínez Millán, José (Hg.), Felipe II (I 527 - I 598) Europa y la Monarqía Católica 4 Bde., Madrid I 998.

Martínez Millán, José (Hg.), Carlos V y la quiebra del humanismo político en Europa (I530-I 558) 5 Bde., Madrid 2000.

Marx, Barbara (Hg.), Elbflorenz. Italienische Präsenz in Dresden r6.- I9. Jahrhundert, Dresden 2000.

Marx, Barbara, Die Italienreise Herzog Johann Georgs von Sachsen (I6or - I602) und der Besuch von Cosimo III. de'Medici (r668) in Dresden. Zur Kausalität von Grand Tour und Kulturtransfer, in: Babel/Paravicini, Grand Tour, 373-427.

MARX, Barbara, Italianità und frühneuzeitliche Hofkultur: Dresden im Kontext, in: Marx, Elbflorenz, 7-36.

Marx, Barbara, Künstlermigration und Kulturkonsum. Die Florentiner Kulturpolitik im r6. Jahrhundert und die Formierung Dresdens als Elbflorenz, in: Guthmüller, Deutschland und Italien, 2 I I -297.

MArx, Barbara, Politica culturale al femminile e identità medicea, in: Calvi/Spinelli, Le donne Medici, I 47- I67.

Marx, Harald/Kluth, Eckhard (Hgg.), Glaube und Macht. Sachsen im Europa der Reformationszeit. Katalog der 2. Sächsischen Landesausstellung Torgau, Schloss Hartenfels 2004, Dresden 2004.

Masetti Zannini, Gianlodovico, La capitale perduta. La devoluzione di Ferrara i 598 nelle carte vaticane, Ferrara 2000.

Matarrese, Tina, Una grammatichetta italiana alla corte di Sassonia, in: Vanvolsem/Vermandere/d'Hulst/Musarra, L'Italiano oltre frontiera I, 403-4Io.

Matschinegg, Ingrid, Ausländer in Italien. Überlegungen zu den Italienbesuchern im I 5 . und I6. Jahrhundert, in: Beiträge zur historischen Sozialkunde 3 (I 988), 73-77.

Matschinegg, Ingrid, Das Studium in Italien und die Kavalierstour oberösterreichischer Adeliger. Adelige als Reisende im r6. Jahrhundert, in: Vocelka/Leeb/Scheichl, Renaissance und Reformation, I6I-I7I.

Matschinegg, Ingrid, Studium und Alltag in der Fremde. Das Reiserechnungsbuch innerösterreichischer Studenten in Padua (I 548-I 550), in: Ingrid Matschinegg/Brigitte Rath/Barbara Schuh (Hgg.), Von Menschen und ihren Zeichen. Sozialhistorische Untersuchungen zum Spätmittelalter und zur Neuzeit, Bielefeld r 990, 99- I 22.

Matschinegg, Ingrid, Zum Universitätsbesuch der Innerösterreicher in der Frühen Neuzeit, in: Dolinar/Liebmann/Rumpler/Tavano, Katholische Reform, 507-522.

Mattingly, Garrett, Renaissance diplomacy, London 1955.

Mauss, Marcel, Die Gabe. Form und Funktion des Austauschs in archaischen Gesellschaften, übersetzt von Eva Moldenhauer, (Org. Essai sur le don, I950), Frankfurt a.M. ${ }^{2}$ I 984.

Maylender, Michele/Rava, Luigi, Storia delle accademie d'Italia, 2 Bde., Bologna I 926 - I 930.

Mazzei, Rita, La Repubblica di Lucca e l'Impero nella prima età moderna. Ragioni e limiti di una scelta, in: Schnettger/Verga, L'Impero e l'Italia, 299-32 I.

Medica, Massimo, Giovanni Bianchini: Tabulae Astrologiae, in: Mottola Molfino/Natale, Le muse e il principe 2, I 86 - I 89 . 
Meijer, Bert W., Ferrara e il Nord, in: Bentini, Gli Este a Ferrara, I47-i 57.

Meine, Sabine, Die Frottola: Musik, Diskurs und Spiel an italienischen Höfen, I 50o- I 530, Turnhout 2013.

Meine, Sabine, Hofmusik als Herrschaftsraum. Das Beispiel der Isabella d'Este Gonzaga, in: zeitenblicke 8/2 (2009), http://www.zeitenblicke.de/2009/2/meine, Zugriff: r6.9.2020.

Melville, Gert, Rituelle Ostentation und pragmatische Inquisition. Zur Institutionalität des Ordens vom Goldenen Vlies, in: Heinz Duchhardt/Gert Melville (Hgg.), Im Spannungsfeld von Recht und Ritual. Soziale Kommunikation in Mittelalter und Früher Neuzeit (= Norm und Struktur. Studien zum sozialen Wandel in Mittelalter und Früher Neuzeit 7), Köln/ Weimar/Wien I 997, 2 I 5-27I.

Menčı , Ferdinand, Die Reise Kaiser Maximilian II. im Jahre I 548, Wien I 898.

Merlin, Pierpaolo, La croce e le aquile: Savoia, Impero e Spagna tra XVI e XVII secolo, in: Bellabarba/Merlotti, Stato sabaudo, 25 I - 267.

Merlin, Pierpaolo, Savoia ed Este: due dinastie nel secolo di ferro, in: Fumagalli/Signorotto, La corte estense, I $35-\mathrm{I} 48$.

Messisburgo, Cristoforo da, Banchetti, composizioni di vivande e apparecchio generale, Ferrara I 549 (moderne Ausgabe hg. von Fernando Bandini, Vicenza ${ }^{2}$ I 992).

Messmer, Franzpeter, Orlando di Lasso. Ein Leben in der Renaissance. Musik zwischen Mittelalter und Neuzeit, München I 982.

Metzig, Gregor M., Kommunikation und Konfrontation. Diplomatie und Gesandtschaftswesen Kaiser Maximilians I. (1486 - I 5 I 9) (= Bibliothek des Deutschen Historischen Instituts in Rom I 30), Berlin/Boston 2016.

Mezler-Andelberg, Helmut J., Erneuerung des Katholizismus und Gegenreformation in Innerösterreich, in: Südostdeutsches Archiv I 3 (1970), 97- I I 8.

Middell, Katharina/Middell, Matthias, Forschungen zum Kulturtransfer: Frankreich und Deutschland, in: Grenzgänge 2 (I 994), I07- I 22.

Middell, Matthias (Hg.), Kulturtransfer und Vergleich (= Comparativ: Leipziger Beiträge zur Universalgeschichte und vergleichende Gesellschaftsforschung ro/I), Leipzig 2000.

Middell, Matthias, Von der Wechselseitigkeit der Kulturen im Austausch. Das Konzept des Kulturtransfers in verschiedenen Forschungskontexten, in: Langer/Michels, Metropolen und Kulturtransfer, I 5-5 I.

Milano, Ernesto, Casa d'Este dall'Anno Mille al I 598, in: Iotti, Gli Estensi r, 9- I 45 .

Milano, Ernesto, Genealogia dei Principi d'Este, in: Iotti, Gli Estensi r, 95 - I 45.

Milano, Ernesto, Gli Estensi. La corte di Modena, in: Bini, Gli Estensi 2, 9- I38.

Milano, Ernesto, Vicissitudini della Biblioteca Estense alla Corte di Modena, in: Spaggiari/ Trenti, Lo Stato di Modena, I 5 I - I 79.

Minges, Klaus, Das Sammlungswesen der frühen Neuzeit, Münster I 998.

Minning, Martina/Kuster, Thomas, Schenken \& Sammeln, in: Haag, Dresden \& Ambras, I $94 \mathrm{f}$.

Мiотті, Mariangela, I simboli del trionfo: Ferrara accoglie Enrico III, in: Bertozzi, Alla corte degli Estensi, 287-298.

Mitchell, B., The Majesty of the State. Triumphal Progresses of Foreign Sovereigns in Renaissance Italy (I494- I600), Firenze I 986.

Mitchell, J. Clyde (Hg.), Social networks in urban settings, Manchester i 969. 
Mitterbauer, Helga, Kulturtransfer - ein vielschichtiges Beziehungsgeflecht, in: Newsletter Moderne 2/I (I999), http://www-gewi.kfunigraz.ac.at/moderne/dok.htm, Zugriff: I 9.6. 2020.

Molno, Anthony, Patronage and the State in Early Modern Italy, in: Mączak, Klientelsysteme, 233-242.

Molinari, Cesare, Il teatro nella tradizione vitruviana: da Leon Battista Alberti a Daniele Barbari, in: Biblioteca teatrale I ( 197 I), 30-46.

Molıno, Paola, Siebenbürgischen corriers mündtlich anzaigen - Per lettere di Transilvania. Die Fuggerzeitungen im Kontext italienischer Sammlungen, in: Katrin Keller/Paola Molino (Hgg.), Die Fuggerzeitungen im Kontext. Zeitungssammlungen im Alten Reich und in Italien (= Mitteilungen des Instituts für Österreichische Geschichtsforschung, Ergänzungsband 59), Wien 2015, I $37-$ I 83 .

Mondaini, Giuseppe, La questione di precedenza tra il duca Cosimo I de'Medici e Alfonso II d'Este, Firenze I 898.

Montaigne, Michel de, Tagebuch einer Reise durch Italien, die Schweiz und Deutschland in den Jahren I 580 und I 58 I, hg. und aus dem Französischen übertragen von Otto Flake, Insel Verlag, Frankfurt a.M. I 988.

Montanari, Gian Carlo (Bearb.), Vita del segretario Giovanni Galliani scritta da lui medesimo, Modena 2016.

Monti, Aldino, La microfisica degli stati padani: l'eccezionalismo geopolitico bolognese in età moderna, in: Fregni, Archivi, 347-368.

Moser, Johann Jacob, Neues Teutsches Staats-Recht 9: Von der teutschen Lehens-Verfassung, Frankfurt a.M./Leipzig I774.

Mottola Molfino, Alessandra/Natale, Mauro (Hgg.), Le muse e il principe. Arte di corte nel Rinascimento padano: Saggi 2 Bde., Modena r 99I.

Mozzarelli, Cesare (Hg.), „Familia« del principe e famiglia aristocratica 2 (= „Europa delle Corti«. Centro studi sulle società di antico regime. Biblioteca del Cinquecento 4I), Roma I988.

Mozzarelli, Cesare, I Gonzaga di Mantova e l'Impero, in: Cremonini/Musso, I feudi imperiali, 20I-209.

Mozzarelli, Cesare, Introduzione, in: Fregni, Archivi, 49-52.

Mozzarelli, Cesare/Ormi, Giuseppe (Hgg.), Il Trentino nel Settecento fra Sacro Romano Impero e antichi stati italiani (= Annali dell'Istituto storico italo-germanico, Quaderno I 7 ), Bologna I 985 .

Müller, Matthias/Spiess, Karl-Heinz/Friedrich, Udo (Hgg.), Kulturtransfer am Fürstenhof. Höfische Austauschprozesse und ihre Medien im Zeitalter Kaiser Maximilians I. (= Schriften zur Residenzkultur 9), Berlin 2013.

Mülle R, Rainer, Der Fürstenhof in der Frühen Neuzeit (= Enzyklopädie deutscher Geschichte 33), München I 995 .

Müller, Rainer, Hofstaat - Hofmann - Höfling. Kategorien des Personals an deutschen Fürstenhöfen der Frühen Neuzeit, in: Klaus Malettke/Chantal Grell (Hgg.), Hofgesellschaft und Höflinge an europäischen Fürstenhöfen in der Frühen Neuzeit (I 5- I 8. Jh.)/Société de cour et courtisans dans l'Europe de l'époque moderne (XVe-XVIII ${ }^{\mathrm{e}}$ siècle). Internationales Kolloquium veranstaltet vom Seminar für Neuere Geschichte des Fachbereichs Geschichte 
und Kulturwissenschaften der Philipps-Universität Marburg in Zusammenarbeit mit der Universität Versailles Saint Quentin (ESR I7- I8) vom 28. bis zum 30. September 2000 in Marburg (= Forschungen zur Geschichte der Neuzeit. Marburger Beiträge I), Münster/ Hamburg/Berlin/London 2001, 37-53.

MüNCH, Ernst, Glanz und Elend des spätmittelalterlichen Herzogtums Mecklenburg I 348 I 477, in: Karge/Münch/Schmied, Die Geschichte Mecklenburgs, 42-56.

MÜNCH, Ernst, Mecklenburgs widerspruchsvoller Übergang in die frühe Neuzeit I477- I62 I, in: Karge/Münch/Schmied, Die Geschichte Mecklenburgs, 57-68.

MüNCH, Paul, Grundwerte der frühneuzeitlichen Ständegesellschaft? Aufriß einer vernachlässigten Thematik, in: Winfried Schulze (Hg.), Ständische Gesellschaft und soziale Mobilität, München I988, 53-72.

Muratori, Lodovico Antonio, Delle antichità estensi ed italiane. Trattato, Parte prima in cui si espone l'Origine ed Antichità della Casa d'Este, e la sua diramazione nella Linea Reale ed Elettorale del Regnante Monarca della gran Bretagna Giorgio I e de i duchi di Brunsuic, e Luneburgo, e nella Linea de' Marchesi d'Este, e di Duchi di Ferrara, e Modena, Modena, Stamperia ducale i 7 I 7 .

Musso, Riccardo, I feudi imperiali delle Langhe tra Impero e Stato di Milano (XV-XVIII secolo), in: Cremonini/Musso, I feudi imperiali, 67- r 20.

Muzzarelli, Maria Giuseppina, Beatrice de Luna, vedova Mendes, alias Donna Gracia Nasi: un'ebrea influente ( 5 Io-I569 ca.), in: Ottavia Niccoli (Hg.), Rinascimento al femminile, Bari I99I, 83-Ii6.

Muzzarelli, Maria Giuseppina, Gli ebrei, in: Bocchi, Storia illustrata di Ferrara 2, 465-480.

Nadle R, Michael, Ludwig der Bayer - Krönungszug nach Italien, in: Riepertinger, Bayern Italien, 95- I04.

Nadler, Michael, Welf IV. und Konradin - Erbschaft verpflichtet, in: Riepertinger, Bayern Italien, 86f.

Naffei, Venocchio, Dal titolo di Duca di Firenze e Siena a Granduca di Toscana, Firenze i 905.

Nalin montanari, Gina, I luoghi della devozione cari a Lucrezia Borgia, in: Farinelli Toselli, Lucrezia Borgia a Ferrara, $5 \mathrm{I}-59$.

Natale, Mauro, Les artes à Ferrare au XVe siècle, in: Bentini/Agostini, Une Renaissance singulière, ro9- I 50 .

Negri, Paolo, Milano, Ferrara e Impero durante l'impresa di Carlo VIII in Italia, in: Archivio storico lombardo 44 (I9I7), 423-57 I.

Neunaus, Helmut, Reichstag und Supplikationsausschuß. Ein Beitrag zur Reichsverfassungsgeschichte der ersten Hälfte des I6. Jahrhunderts (= Schriften zur Verfassungsgeschichte 24), Berlin 1977 .

Neuhaus, Helmut, Supplikationen auf Reichstagen des r6. Jahrhunderts. Zahl, Inhalt und Funktion, in: Lanzinner/Strohmeyer, Der Reichstag I 486- I6 I3, I 49- I6o.

Neumann, Carsten, Die Renaissancekunst am Hofe Ulrichs zu Mecklenburg (= Bau + Kunst. Schleswig-Holsteinische Schriften zur Kunstgeschichte I 5), Kiel 2009.

Neuwirth, Markus, Diplomatischer Austausch und globaler Kunsthandel um r6oo, in: North, Kultureller Austausch, 39i -408.

Nicklas, Thomas, Christian I. I586- I59r/Christian II. I59i-i6ri , in: Kroll, Die Herrscher Sachsens, I $26-\mathrm{r} 36$. 
Nicklas, Thomas, Das Wagnis reichsfürstlicher Außenpolitik: Moritz von Sachsen zwischen Habsburg und Frankreich, in: Blaschke, Moritz von Sachsen, 25-4I.

Nieder korn, Jan Paul, Die dynastische Politik der Habsburger im i6. und i 7. Jahrhundert, in: Duchhardt, Jahrbuch für Europäische Geschichte 8, 29-50.

Nieder korn, Jan Paul, Die europäischen Mächte und der "Lange Türkenkrieg« Kaiser Rudolfs II. (I593-r606) (= Archiv für österreichische Geschichte I35), Wien I 993.

Nieder korn, Jan Paul, Die Geheimverhandlungen des Prager Nuntius Spinelli über die Abtretung von Modena und Reggio an den Heiligen Stuhl (r6oo/r6or), in: Bösel/Klingenstein/ Koller, Kaiserhof - Papsthof, 33-43.

Nieder korn, Jan Paul, Reichsitalien als Finanzquelle des Kaiserhofs. Subsidien und Kontributionen (I6.- I7. Jahrhundert), in: Schnettger/Verga, L'Impero e l'Italia, 67-84.

Nieder korn, Jan Paul, Reichsitalien und der Kaiserhof im Zeitalter der Hegemonie Spaniens I 559-I659, in: Chiarini/Zeman, Italia-Austria, 59-7 r.

Noflatscher, Heinz, »Italien« in der politischen Wahrnehmung Maximilians I., in: Studi Trentini di Scienze Storiche. La proclamazione imperiale di Massimiliano I d'Asburgo (4 febbraio I 508) 87/4 (2008), 663-705.

Noflatscher, Heinz, Normen, Feste, Integration am Innsbrucker Hof, in: Noflatscher/Niederkorn, Der Innsbrucker Hof, 9-30.

Noflatscher, Heinz, Funktionseliten an den Höfen der Habsburger um I 500, in: Günther Schulz (Hg.), Sozialer Aufstieg. Funktionseliten im Spätmittelalter und in der frühen Neuzeit (= Deutsche Führungsschichten in der Neuzeit 25), München 2002, 29I - 3 I 4.

Noflatscher, Heinz, Glaube, Reich und Dynastie. Maximilian der Deutschmeister (I558-I6I8) (= Quellen und Studien zur Geschichte des Deutschen Ordens I I), Marburg 1987 .

Noflatscher, Heinz, Monarchische Willkür? Zur Demission des Wolf Rumpf und Paul Sixt Trautson am Hof Kaiser Rudolfs II. ( I600), in: Brandstätter/Hörmann, Tirol - Österreich Italien, 493-5 I 6 .

Noflatscher, Heinz, Regiment aus der Kammer? Einflußreiche Kleingruppen am Hof Rudolfs II., in: Hirschbiegel/Paravicini, Der Fall des Günstlings, 209-234.

Noflatscher, Heinz, Sprache und Politik. Die Italienexperten Kaiser Maximilians II., in: Edelmayer/Kohler, Kaiser Maximilian II., I 43- i 68.

Noflatscher, Heinz, Stereotypen und Fremdbilder im politischen Verhalten Maximilians I., in: Ursula Kocher/Andrea Sieber/Johannes Helmrath (Hgg.), Maximilians Welt. Kaiser Maximilian im Spannungsfeld zwischen Innovation und Tradition, Göttingen 20 I 8, I 59- I 90.

Noflatscher, Heinz/Chisholm, Michael A./Schnerb, Bertrand (Hgg.), Maximilian I. I 459-I5I9. Wahrnehmung - Übersetzung - Gender (= Innsbrucker Historische Studien 27), Innsbruck/Wien/Bozen 20 I I .

Noflatscher, Heinz/Niederkorn, Jan Paul (Hgg.), Der Innsbrucker Hof. Residenz und höfische Gesellschaft in Tirol vom I5. bis I 9. Jahrhundert (= Archiv für Österreichische Geschichte 138), Wien 2005 .

Nolde, Dorothea, Was ist Diplomatie und wenn ja, wie viele? Herausforderungen und Perspektiven einer Geschlechtergeschichte der frühneuzeitlichen Diplomatie, in: Historische Anthropologie 2 I (2013), I79- I98. 
Nolde, Dorothea/Opitz, Claudia (Hgg.), Grenzüberschreitende Familienbeziehungen. Akteure und Medien des Kulturtransfers in der Frühen Neuzeit, Köln/Weimar/Wien 2008.

Nolde, Dorothea/Opitz-Belakhal, Claudia, Kulturtransfer über Familienbeziehungen - einige einführende Überlegungen, in: Nolde/Opitz, Grenzüberschreitende Familienbeziehungen, I- I6.

Nolhac, Pierre de/Solerti, Angelo, Il viaggio in Italia di Enrico III, re di Francia e le feste a Venezia, Ferrara, Mantova e Torino, Torino I 89o; Digitalisat: https://books.google.at/books/ about/Il_viaggio_in_Italia_di_Enrico_III.html?id=gnMkNZ9gLeMC\&redir_esc=y, Zugriff: I6.9.2020.

Nolte, Cordula, Erlebnis und Erinnerung. Fürstliche Pilgerfahrten nach Jerusalem im I 5. Jahrhundert, in: Erfen/Spieß, Fremdheit und Reisen, 65-92.

Nolte, Cordula/Spiess, Karl-Heinz/Werlich, Ralf-Gunnar (Hgg.), Principes. Dynastien und Höfe im späten Mittelalter. Interdiszipliniäre Tagung des Lehrstuhls für allgemeine Geschichte des Mittelalters und Historische Hilfswissenschaften in Greifswald in Verbindung mit der Residenzen-Kommission der Akademie der Wissenschaften zu Göttingen vom I 5.- I 8. Juni 2000 (= Residenzenforschung I 4), Stuttgart 2002.

Nori, Gabriele, La corte itinerante. Il pellegrinaggio di Nicolò III in Terrasanta, in: Papagno/ Quondam, La corte e lo spazio, 233-246.

North, Michael (Hg.), Kultureller Austausch. Bilanz und Perspektiven der Frühneuzeitforschung, Köln/Weimar/Wien 2009.

North, Michael, Kultureller Austausch in der Frühen Neuzeit. Eine Einleitung, in: North, Kultureller Austausch, I-7.

Nösselt, Hans-Joachim, Ein ältest Orchester I530-i980. 450 Jahre Bayerisches Hof- und Staatsorchester, München I980.

Novotny, Alexander/Sutt er, Bernhard (Hgg.), Innerösterreich I564-i6r 9 (= Joannea: Publikationen des steiermärkischen Landesmuseums und der steiermärkischen Landesbibliothek 3), Graz [1967].

Nubola, Cecilia, Die »via supplicationis« in den italienischen Staaten der frühen Neuzeit (I 5.- I 8. Jahrhundert), in: Nubola/Würgler, Bittschriften und Gravamina, 53-94.

Nubola, Cecilia/Würgler, Andreas (Hgg.), Bittschriften und Gravamina. Politik, Verwaltung und Justiz in Europa (I4.-I8. Jahrhundert) (= Schriften des italienisch-deutschen historischen Instituts in Trient I9), Berlin 2005.

Nubola, Cecilia/Würgler, Andreas, Politische Kommunikation und Kultur des Bittens in: Dies., (Hgg.) Forme della comunicazione politica in Europa nei secoli XV-XVIII. Suppliche, gravamina, lettere/Formen der politischen Kommunikation in Europa vom I 5. bis I 8. Jahrhundert. Bitten, Beschwerden, Briefe (= Jahrbuch des italienisch-deutschen historischen Instituts in Trient, Beiträge I 4), Berlin 2004, 7- I 2.

Nuovo, Angela, Il commercio librario a Ferrara tra XV e XVI secolo. La bottega di Domenico Sivieri, Firenze I 998.

ohne Herausgeber, Vie d'acqua nei ducati estensi, Reggio Emilia i 990.

Ochoa Brun, Miguel-Ángel, Die Diplomatie Karls V., in: Kohler/Haider/Ottner, Karl V., I 8 I- I96.

Oestreich, Gerhard, Zur parlamentarischen Arbeitsweise der deutschen Reichstage unter Karl V. (I 5 I9-I556). Kuriensystem und Ausschußbildung, in: Heinz Rausch (Hg.), Die 
Geschichtlichen Grundlagen der modernen Volksvertretung. Die Entwicklung von den mittelalterlichen Korporationen zu den modernen Parlamenten 2 (= Wege der Forschung 469), Darmstadt I974, 242-278.

Ognibene, Giovanni, Le relazioni della Casa d'Este coll'estero, in: Atti e memorie della Regia Deputazione di Storia Patria per le province modenesi, Serie 8 (I 904), 223-3 I 5.

Olivato, Loredana (Hg.), Il palazzo di Renata di Francia, Ferrara I 997.

Olivato, Loredana/Barbieri, Giuseppe, Ferrara: Un'urbanistica ricorsiva?, in: Olivato, Il palazzo di Renata di Francia, $15-34$.

Olmi, Giuseppe, Linventario del mondo. Catalogazione della natura e luoghi del sapere nella prima età moderna, Bologna 1992.

Opıtz, Claudia (Hg.), Höfische Gesellschaft und Zivilisationsprozess. Norbert Elias' Werk in kulturwissenschaftlicher Perspektive, Köln/Weimar/Wien 2005.

Opll, Ferdinand/Krause Heike/Sonnlechner Christoph, Wien als Festungsstadt im r6. Jahrhundert: zum kartografischen Werk der Mailänder Familie Angielini, Wien/Köln/ Weimar 2017.

Ores Ko, Robert, The House of Savoy in search for a royal crown in the seventheenth century, in: Robert Oresko/G.C. Gibbs/H.M. Scott (Hgg.), Royal and Republican Sovereignty in Early Modern Europe, Cambridge University Press I 997, 272-350.

Ortlieb, Eva, Gnadensachen vor dem Reichshofrat (I5 I9-1564), in: Auer/Ogris/Ortlieb, Höchstgerichte in Europa, $\mathrm{I} 77-202$.

Ortlie b, Eva, Vom königlichen/kaiserlichen Hofrat zum Reichshofrat. Maximilian I., Karl V., Ferdinand I., in: Bernhard Diestelkamp (Hg.), Das Reichskammergericht: der Weg zu seiner Gründung und die ersten Jahrzehnte seines Wirkens (I45I-I527) (= Quellen und Forschungen zur Höchsten Gerichtsbarkeit im Alten Reich 45), Köln/Weimar/Wien 2004, 22 I 289.

Pacchi, Domenico, Ricerche istoriche sulla provincia della Gafagnana, Modena i 785 .

Pade, Marianne/Waage Petersen, Lene/Quarta, Daniela (Hgg.), La Corte di Ferrara e il suo mecenatismo I44I - I598/The Court of Ferrara \& its Patronage. Atti del convegno internazionale, Copenhagen maggio r 987, Modena r 990.

Palos, Joan-Lluís/Sánchez, Magdalena (Hgg.), Early Modern Dynastic Marriages and Cultural Transfer (= Transculturalisms, I400- I 700), Aldershot 2016.

Pandimiglio, Leonida, »Medici«, in: Reinhardt, Die großen Familien, 338 - 359 .

Pandimiglio, Leonida, »Strozzi«, in: Reinhardt, Die großen Familien, 5 I6- 52 I.

Papagno, Giuseppe/Quondam, Amedeo (Hgg.), La corte e lo spazio: Ferrara estense, Roma 1982.

Paravicini, Werner (Hg.), Höfe und Residenzen im spätmittelalterlichen Reich. Ein dynastisch-topographisches Handbuch 2 Bde. (= Residenzenforschung I 5, I+2), Ostfildern 2003/ 2005 .

Paravicini, Werner (Hg.), Luxus und Integration. Materielle Hofkultur Westeuropas vom i 2. bis zum i 8. Jahrhundert, München 2010.

Paravicini, Werner (Hg.), Zeremoniell und Raum. 4. Symposium der Residenzen-Kommission der Akademie der Wissenschaften in Göttingen, Potsdam, 25.-27. September I994, Sigmaringen 1997 . 
Paravicini, Werner, Der Fall des Günstlings. Hofparteien in Europa vom I 3. bis zum I 7. Jahrhundert, in: Hirschbiegel/Paravicini, Der Fall des Günstlings, I3-22.

Paravicini, Werner, The Court of the Dukes of Burgundy: a Model for Europe?, in: Asch/ Birke, Princes, Patronage and the Nobility, 69- ro3.

Paravicini, Werner, Von materieller Attraktion, adligem Dienst und politischer Macht. Über den tieferen Sinn höfischer Lebensführung. Eine Zusammenfassung, in: Paravicini, Luxus und Integration, $27 \mathrm{I}-284$.

Paravicini, Werner/Wettraufer, Jörg (Hgg.), Der Hof und die Stadt. Konfrontation, Koexistenz und Integration in Spätmittelalter und Früher Neuzeit. 9. Symposium der Residenzen-Kommission der Akademie der Wissenschaften zu Göttingen, Halle an der Saale, 25.-28. September 2004 (= Residenzforschung 20), Ostfildern 2006.

PARDI, Giuseppe, Diario ferrarese dall'anno I 409 sino al I 502 di autori incerti (= Rerum Italicarum Scriptores 2), Bologna 1927-28.

Pardi, Giuseppe, Lo Studio di Ferrara nei secoli $\mathrm{XV}^{\circ}$ e XVI ${ }^{\circ}$ con documenti inediti, Ferrara I903.

Pardi, Giuseppe, Sulle cause della devoluzione di Ferrara alla Santa sede, in: Atti e Memorie della Deputazione Provinciale Ferrarese di Storia Patria, serie prima 24 (I 922 ), I I3 - I4 I.

Pauler, Roland, Die deutschen Könige und Italien im I4. Jahrhundert. Von Heinrich VII. bis Karl IV., Darmstadt I 997.

Pastor, Ludwig von, Geschichte der Päpste seit dem Ausgang des Mittelalters 3/2: Geschichte der Päpste im Zeitalter der Renaissance von der Wahl Innozenz' VIII. bis zum Tode Julius' II. I 484 - I 5 I3, Freiburg/Rom I 956.

Pastor, Ludwig von, Geschichte der Päpste seit dem Ausgang des Mittelalters 4/r: Geschichte der Päpste im Zeitalter der Renaissance und der Glaubensspaltung von der Wahl Leos X. bis zum Tode Klemens' VII. (I 5 I 3- I 534), Freiburg/Rom ${ }^{13}$ I 956.

Pastor, Ludwig von, Geschichte der Päpste seit dem Ausgang des Mittelalters 5 : Geschichte Papst Pauls III. (I 534-I 549), Freiburg i.B. ${ }^{8}$ I 925 .

Pastor, Ludwig von, Geschichte der Päpste seit dem Ausgang des Mittelalters 6: Geschichte der Päpste im Zeitalter der katholischen Reformation und Restauration. Julius III., Marcellus II. und Paul IV. (I 550-I 559), Freiburg i.B. ${ }^{\text {I2 }}$ I 928.

Pastor, Ludwig von, Geschichte der Päpste seit dem Ausgang des Mittelalters 8: Geschichte der Päpste im Zeitalter der katholischen Reformation und Restauration.Pius V. ( I 566 - I 572 ), Freiburg i.B. 1920 .

Pastor, Ludwig von, Geschichte der Päpste seit dem Ausgang des Mittelalters 9: Geschichte der Päpste im Zeitalter der katholischen Reformation und Restauration. Gregor XIII. (I572-I585), Freiburg i.B. I923.

Pastor, Ludwig von, Geschichte der Päpste seit dem Ausgang des Mittelalters i i : Geschichte der Päpste im Zeitalter der katholischen Reformation und Restauration. Klemens VIII. (1592-1605), Freiburg i.B. I 927 .

Paulmann, Johannes, Kulturtransfer: Einführung in ein Forschungskonzept, in: Rudolf Muhs/ Johannes Paulmann/Willibard Steinmetz (Hgg.), Aneignung und Abwehr. Interkultureller Transfer zwischen Deutschland und Großbritannien im I9. Jahrhundert, Bodenheim I 998, $2 \mathrm{I}-43$. 
Paulus, Stefan, Zwischen Kontinuität und Wandel. Deutschsprachige Architekturtraktate an der Schwelle vom Mittelalter zur Neuzeit, in: North, Kultureller Austausch, 237-252.

Pepe, Luigi (Hg.), I gesuiti e i loro libri a Ferrara. Frontespizi figurati del Seicento, Ferrara I 998.

PÉricard-MÉa, Denise, La noblesse en pèlerinage à Compostelle (XIVe-XVe siècle), in: Babe1/Paravicini, Grand Tour, 275-289.

Perini, Leandro, La stampa a Ferrara nel Cinquecento, in: Prosperi, Storia di Ferrara 6, 370393 .

Peverada, Enrico, Istituzioni ecclesiastiche XV-XVI secolo, in: Bocchi, Storia illustrata di Ferrara 2, 32 I-336.

Pezzarossa, Fulvio, »Bentivoglio«, in: Reinhardt, Die großen Familien, 57-65.

Pezzarossa, Fulvio, »Pio di Carpi«, in: Reinhardt, Die großen Familien, 434-440.

Pflüger, Christine, Kommissare und Korrespondenzen. Politische Kommunikation im Alten Reich (I $55_{2}-\mathrm{I}_{55}$ 8) (= Norm und Struktur. Studien zum sozialen Wandel in Mittelalter und Früher Neuzeit 24), Köln/Weimar/Wien 2005.

Philipp, Marion, Ehrenpforten für Kaiser Karl V. Festdekorationen als Medien politischer Kommunikation, Berlin 20 I I.

Pieper, Renate, Informationszentren im Vergleich. Die Stellung Venedigs und Antwerpens im I6. Jahrhundert, in: Michael North (Hg.), Kommunikationsrevolutionen. Die neuen Medien des I6. und I 9. Jahrhunderts (= Wirtschafts- und Sozialhistorische Studien 3), Köln/Weimar/Wien I 995, 45-6o.

Pieper, Renate, Papageien und Bezoarsteine. Gesandte als Vermittler von Exotica und Luxuserzeugnissen im Zeitalter Philipps II., in: Edelmayer, Hispania-Austria 2, 2 I 5-224.

Podestà, Gian Luca, Die Herzöge von Parma und Piacenza zwischen Papsttum und Reich, in: zeitenblicke - online-Journal für Geschichtswissenschaften 6/I (2007), ins Deutsche übersetzt von Matthias Schnettger, http://www.zeitenblicke.de/2007/r/podesta/dippArticle.pdf, Zugriff: 16.9.2020.

Polle ross, Friedrich, Romanitas in der habsburgischen Repräsentation von Karl V. bis Maximilian II., in: Bösel/Klingenstein/Koller, Kaiserhof - Papsthof, 207-223.

Povolo, Claudio, Centro e periferia nella Repubblica di Venezia. Un Profilo, in: Chittolini/ Molho/Schiera, Origini dello Stato, 207-224.

Prandi, Stefano, Il »Cortegiano« Ferrarese. I Discorsi di Annibale Romei e la cultura nobiliare nel Cinquecento (= Biblioteca di »Lettere italiane«. Studi e testi 38), Firenze I 990.

Press, Volker, Matthias, in: Schindling/Ziegler, Die Kaiser der Neuzeit, I I 2 - I 24.

Press, Volker, Patronat und Klientel im Heiligen Römischen Reich, in: Mączak, Klientelsysteme, $19-46$.

Press, Volker, Rudolf II. (I 576 - I6 6 2), in: Schindling/Ziegler, Die Kaiser der Neuzeit, 99 - i I I .

Prinzivalli, Virginio, La devoluzione di Ferrara alla Santa Sede, secondo una relazione inedita di Camillo Capilupi, in: Atti della Deputazione ferrarese di storia patria ro ( I 898), i I9-333.

Prizer, William F., Isabella d'Este and Lucrezia Borgia as Patrons of Music: The Frottola at Mantua and Ferrara, in: Journal of the American Musicological Society 38/I (Spring I 985), I-33, https://www.jstor.org/stable/83 I 548 ? seq= I \#metadata_info_tab_contents, Zugriff: I 6 . 9.2020 .

Prodi, Paolo, Diplomazia del Cinquecento. Istituzioni e prassi, Bologna I963.

Prodi, Paolo, La sovranità temporale dei papi e il Concilio di Trento, in: Hubert Jedin/Paolo 
Prodi (Hgg.), Il Concilio di Trento come crocevia della politica europea (= Annali dell'Istituto italo-germanico, Quaderno 4), Bologna I 979, 65-83.

Prodi, Paolo, Lo sviluppo dell'assolutismo nello stato pontificio (secoli XV-XVI) i : La monarchia papale e gli organi centrali di governo, Bologna i 968.

Prosperi, Adriano (Hg.), Storia di Ferrara 6: Il Rinascimento. Situazioni e personaggi, Ferrara 2000.

Prosperi, Adriano, Histoire de la maison d'Este, in: Bentini/Agostini, Une Renaissance singulière, $27-36$.

Prosperi, Adriano, Università e fermenti ereticali a Ferrara nel '500. Note in margine a una ricerca su Giorgio Siculo, in: Bertozzi, Alla corte degli Estensi, ro9- I 24.

Pugliese, Salvatore, Le prime strette dell'Austria in Italia, Milano I932 / zweite Auflage unter dem Titel »I1 Sacro Romano Impero in Italia«, Milano I 935.

Quazza, Romolo, Preponderanza spagnuola. I 559- i 700, Milano I 950.

RAвÀ, Michele, La nuova "porta d'Italia«. Il Piemonte di Carlo II tra Francia e Impero: un'analisi geopolitica, in: Bellabarba/Merlotti, Stato sabaudo, 2 I3-232.

Raffler, Marlies, Von »studiolo« und »acutezza«. Zeit - Raum - Objekt: Formen der Wahrnehmung, in: Schmale, Kulturtransfer, 3 I $5-335$.

Raggi, Pier Luigi, La Garfagnana negli Stati estensi, in: Spaggiari/Trenti, Lo Stato di Modena, $55 \mathrm{I}-570$.

RaIne R, Johann, Maximilian I. und Italien, in: Edelmayer, Hispania-Austria 2, I 32 - I 40.

Rainer, Johann, Österreich und Ferrara, in: Carinthia. Zeitschrift für geschichtliche Landeskunde von Kärnten I 99/I (2009), 223-230.

Rainer, Johann (Bearb.), Grazer Nuntiatur. Nuntiatur des Girolamo Portia I595- I 598 (= Publikationen des historischen Instituts beim österreichischen Kulturforum in Rom II. Abteilung: Quellen, II. Reihe, 4), Wien 2012.

Rando, Daniela, Vassalli e feudi nella Marca veronese del secolo XII, in: Jürgen Dendorfer/Roman Deutinger (Hgg.), Das Lehnswesen im Hochmittelalter. Forschungskonstrukte - Quellenbefunde - Deutungsrelevanz (= Mittelalter-Forschungen 34), Stuttgart 2010, 28 I - 298.

Rasmussen, Knud, Die livländische Krise I 554- I56 I, København I 973.

RAspadori, Francesco (Hg.), I maestri di medicina ed arti dell'università di Ferrara (= Pubblicazioni dell'Università di Ferrara 2), Firenze I 99 I.

Rassow, Peter/Schalк, Fritz (Hgg.), Karl V. Der Kaiser und seine Zeit, Köln/Graz I96o.

Rauch, Margot, Gesammelte Wunder: die Naturobjekte in den Kunstkammern und Naturalienkabinetten des I6. und I 7. Jahrhunderts, in: Seipel, Die Entdeckung der Natur, I I 38.

RAuch, Margot, Großherzogin Johanna - in hochbedrangter kommernis, in: Haag, Nozze italiane, I39- I 44 .

Rauch, Margot, Verkaufte Bräute? Kaiser Ferdinands I. Töchter zwischen Bild und Welt, in: Haag, Nozze italiane, 27-36.

Rauscher, Peter (Hg.), Kriegführung und Staatsfinanzen. Die Habsburgermonarchie und das Heilige Römische Reich vom Dreißigjährigen Krieg bis zum Ende des habsburgischen Kaisertums I740 (= Geschichte in der Epoche Karls V. Io), Münster 20 го.

Rauscher, Peter, Die Finanzierung des Kaiserhofs von der Mitte des r6. bis zu Beginn des I 8. Jahrhunderts. Eine Analyse der Hofzahlamtsbücher, in: Fouquet/Hirschbiegel/Paravicini, Hofwirtschaft, 405-44I. 
Rauscher, Peter, Nach den Türkenreichstagen. Der Beitrag des Heiligen Römischen Reichs zur kaiserlichen Kriegführung im I7. und frühen I 8. Jahrhundert, in: Rauscher, Kriegführung, 433-485.

Rauscher, Peter/Serles, Andrea/Winkelbauer, Thomas (Hgg.), Das "Blut des Staatskörpers«. Forschungen zur Finanzgeschichte der Frühen Neuzeit (= Historische Zeitschrift Beihefte Neue Folge 56), München 2012.

Raviola, Blythe Alice, L'Europa dei piccoli stati: dalla prima età moderna al declino dell'Antico Regime, Roma 2008.

Raviola, Blythe Alice, The Imperial System in Early Modern Northern Italy: a Web of Dukedoms, Fiefs and Enclaves along the Po, in: Evans/Wilson, The Holy Roman Empire, 2 I 7 236.

Reвiтsсn, Robert, Der Kaiser auf der Flucht. Die militärische Niederlage Karls V. gegen die deutsche Fürstenopposition im Jahre $155_{2}^{2}$, in: Fuchs/Rebitsch, Kaiser und Kurfürst, I I $9-$ I 38 .

Re вiтsch, Robert, Italienische Militärs im Dienste des Hauses Habsburg im I 7. Jahrhundert. Die Integration ins Habsburgische Staatswesen, in: Bellabarba/Niederkorn, Le corti come luogo di comunicazione, I 55 - I 76 .

Reвiтsсн, Robert, Tirol, Karl V. und der Fürstenaufstand von I $55^{2}$ (= Studien zur Geschichtsforschung der Neuzeit I 8), Hamburg 2000.

Reвiтsch, Robert/Schmitz-Esser, Romedio, Herzog Severin von Sachsen. Aufenthalt und Tod eines jungen Sachsenherzogs in Tirol, in: Tiroler Heimat. Jahrbuch für Geschichte und Volkskunde Nord-, Ost- und Südtirols 69 (2005), I 2 I - I 42.

Reinalter, Helmut, »Kulturgeschichte«, in Reinalter/Brenner, Lexikon der Geisteswissenschaften, $982-992$.

Reinalter, Helmut/Brenner, Peter J. (Hgg.), Lexikon der Geisteswissenschaften. Suchbegriffe - Disziplinen - Personen, Wien/Köln/Weimar 20 I I .

Reinhard, Wolfgang (Hg.), Römische Mikropolitik unter Papst Paul V. Borghese ( I605 - I62 I) zwischen Spanien, Neapel, Mailand und Genua, Tübingen 2004.

Reinhard, Wolfgang, Frühmoderner Staat - moderner Staat, in: Olaf Mörke/Michael North (Hgg.), Die Entstehung des modernen Europa r60o - I 900, Köln/Wien u.a. I998, I - го.

Reinhard, Wolfgang, Geschichte der Staatsgewalt. Eine vergleichende Verfassungsgeschichte Europas von den Anfängen bis zur Gegenwart, München ${ }^{2} 2000$.

Reinhard, Wolfgang, Historische Anthropologie frühneuzeitlicher Diplomatie: Ein Versuch über Nuntiaturberichte I592-1622, in: Rohrschneider/Strohmeyer, Wahrnehmung des Fremden, 53-72.

Reinhard, Wolfgang, Oligarchische Verflechtung und Konfession in oberdeutschen Städten, in: Mączak, Klientelsysteme, 47-62.

Reinhardt, Volker, Blutiger Karneval: der Sacco di Roma I 527 - eine politische Katastrophe, Darmstadt 2009.

Reinhardt, Volker, »Gonzaga«, in: Reinhardt, Die großen Familien, 287-30 I.

Reinhardt, Volker, »Savoyen«, in: Reinhardt, Die großen Familien, 485-500.

Reinhardt, Volker (Hg.), Die großen Familien Italiens, Stuttgart 1992.

Reinhardt, Volker, Pius II. Piccolomini. Der Papst, mit dem die Renaissance begann. Eine Biographie, München 20I3. 
Reynolds, Susan, Fiefs and Vasalls. The Medieval Evidence Reinterpreted, Oxford University Press I 994 .

Ricci, Can B [ernardino], Le ambascierie estensi di Gaspare Silingardi, vescovo di Modena, alle corti di Filippo II e Clemente VIII, 2 Bde., Pavia I 907.

Ricci, Giovanni, Cavalleria e crociata nella Ferrara del Rinascimento: un piccolo stato davanti a un grande impero, in: Franziska Meier (Hg.), Italien und das Osmanische Reich (= Studia Turcica 2), Herne 2010, 75-86.

Ricci, Giovanni, Centro e periferie nel rituale funebre estense del Cinquecento, in: Fregni, Archivi, 37I-389.

Ricci, Giovanni, Il principe e la morte. Corpo, cuore, effigie nel Rinascimento, Bologna I 998.

Ricci, Giovanni, Prigioniera dei simboli. Lucrezia de’Medici da Firenze a Ferrara in: Calvi/ Spinelli, Le donne Medici, 2 I 7-23 I.

Ricci, Giovanni, Sepolture multiple. Note sugli usi funerari di alcuni proprietari del palazzo, in: Olivato, Il palazzo di Renata di Francia, 20 I-209.

Ricci, Giovanni, Vacanze del potere. Gli interregni estensi dal I47 I al I 597, in: Prosperi, Storia di Ferrara 6, I04-i 28.

Ricci, Milena, Il libro e il monumento: Miniature ed iscrizioni per la gloria degli Estensi, in: Iotti, Gli Estensi I, 233-277.

Riedmann, Josef, Die Welfen im Tiroler Raum zur Zeit Welfs VI., in: Rainer Jehl (Hg.), Welf VI. Wissenschaftliches Kolloquium zum 80o. Todesjahr vom 5. bis 8. Oktober I 99 I im Schwäbischen Bildungszentrum Irsee, Sigmaringen r 995, 99- I I 2.

Riepertinger, Rainhard u.a. (Hgg.), Bayern - Italien. Katalog zur bayerischen Landesaustellung 2010, Augsburg 2010.

Righi, Roberto (Hg.), Carlo V a Bologna. Cronache e documenti dell'incoronazione (I 530 ) (= Collana di cronache bolognesi d'epoca medioevale, moderna e contemporanea 4 ), Bologna 2000.

Righini, Giulio, Sul soggiorno italiano di Nicolò Copernico: Copernico »doctor ferrariensis«e »magister « a Bologna, in: Atti e memorie della Real Deputazione di storia patria per l'Emilia e la Romagna I, Ferrara I942, I 5 I - i6o.

RILL, Gerhard, Die Garzweiler-Mission I603/4 und die Reichslehen in der Lunigiana, in: Mitteilungen des Österreichischen Staatsarchivs 3I ( 1978 ), 9-25.

Rill, Gerhard, Prosper Graf von Arco, kaiserlicher Orator beim H1. Stuhl I 560 bis I $_{572}$, in: Mitteilungen des Österreichischen Staatsarchivs I 3 ( I 960), I - Io6.

RiLl, Gerhard, Reichsvikar und Kommissar. Zur Geschichte der Verwaltung Reichsitaliens im Spätmittelalter und in der frühen Neuzeit, in: Annali della fondazione italiana per la storia amministrativa 2, Milano I965, I73- I 98.

Rimondi, Riccardo, Estensi. Storia e leggende, personaggi e luoghi di una dinastia millenaria, Ferrara 2004.

Rinaldi, Rossella, A Reggio, una città di forte impronta vescovile (secoli X-XII), in: Castagnetti, La vassallità maggiore, 233-262.

Rivero Rodríguez, Manuel, Felipe II y el gobierno de Italia (= Sociedad Estatal para la Conmemoración de los Centenarios de Felipe II y Carlos V, Madrid [I 998].

Rode-Breymann, Susanne/Tumat, Antje (Hgg.), Der Hof. Ort kulturellen Handelns von 
Frauen in der Frühen Neuzeit (= Musik - Kultur - Gender. Studien zur europäischen Kultur I 2), Wien/Köln/Weimar 2013.

Rodocanach i, Emanuel, Une protectrice de le Reforme en Italie et en France. Renée de France duchesse de Ferrare, Paris I 896.

Rodrìguez Raso, Rafaela (Hg.), Maximiliano de Austria, gobernador de Carlos V en Espana, Cartas al emperador, Madrid I963.

Rodríguez Salgado, María Josè, Metamorfosi di un impero. La politica asburgica da Carlo V a Filippo II (I 55 I - I 559), aus dem Englischen übersetzt von Stefano Galli, Milano I 994.

Roecк, Bernd, Kulturtransfer zwischen Bayern und Italien in der Renaissance, in: Riepertinger, Bayern-Italien, 28-37.

Rohrschneider, Michael/Strohmeyer, Arno (Hgg.), Wahrnehmung des Fremden. Differenzerfahrungen von Diplomaten im I6. und I7. Jahrhundert (= Schriftenreihe der Vereinigung zur Erforschung der Neueren Geschichte e.V.3I), Münster 2007.

Rohrschneider, Michael/Strohmeyer, Arno, Selbstbilder und Fremdwahrnehmung des habsburgischen Kaisertums um I 500 am Beispiel der venezianisch-maximilianischen diplomatischen Kommunikation, in: Duchhardt/Schnettger, Reichsständische Libertät, 25-42.

Romano, Giacinto (Hg.), Cronaca del soggiorno di Carlo V in Italia (dal 26 luglio ${ }_{5} 29$ al 25 aprile I530). Documento di storia italiana (estratto da un codice della regia biblioteca universitaria di Pavia), Milano I 892.

Romani, Marzio A., La carestia del I 590-93 nei Ducati Padani: crisi congiunturale e/o crisi di struttura?, in: Studi in onore di Gino Barbiera 3, o.O. I983, I305- 1323.

Rombaldi, Odoardo, Cesare d'Este al governo dei ducati estensi, I598-i628, Modena I989.

Roosen, William, Early Modern Diplomatic Ceremonial: A Systems Approach, in: The Journal of Modern History 52/3 (Sep. I 980), 452-476, online verfügbar: http://www.jstor.org/ stable/s 876928, Zugriff: I 8.7.2020.

Rosa, Mario, La cultura politica, in: Greco/Rosa, Storia degli antichi stati italiani, 59- i i6.

Rösch, Gerhard, Reichsitalien als Wirtschaftsraum im Zeitalter der Staufer, in: Wolfgang von Stromer (Hg.), Venedig und die Weltwirtschaft um I 200 (= Studi. Schriftenreihe des Deutschen Studienzentrums in Venedig/Centro Tedesco di Studi Veneziani 7), Stuttgart I999, 93- I I6.

Rosenberg, Charles, Arte e politica alle corti di Leonello e Borso d'Este, in: Mottola Molfino/ Natale, Le muse e il principe I, 39-52.

Rösener, Werner, Die wirtschaftlichen Ressourcen der Fürstenhöfe: Die schwindende Bedeutung der Einnahmen aus den Kammergütern, in: Fouquet/Hirschbiegel/Paravicini, Hofwirtschaft, $305-328$.

Rospocher, Massimo, Il papa guerriero. Giulio II nello spazio pubblico europeo (= Annali dell'Istituto storico italo-germanico in Trento, Monografie 65), Bologna 2015.

Rossi, Paolo et alii (Hgg.), Il Rinascimento nelle corti padane. Società e cultura, Bari I 977.

Rous, Anne-Simone, Informationssicherheit in der diplomatischen Korrespondenz der Frühen Neuzeit - eine Einführung, in: Rous/Mulsow, Geheime Post, I I - 24.

Rous, Anne-Simone/Mulsow, Martin (Hgg.), Geheime Post. Kryptologie und Steganographie der diplomatischen Korrespondenz europäischer Höfe während der Frühen Neuzeit (= Historische Forschungen I06), Berlin 2015.

Rubello, Noemi, Scrittori al servizio del potere: due libretti polemici nella contesa di prece- 
denza tra gli Este e i Medici, in: Annali dell'Università di Ferrara. Sezione storia 4 (2007), I63-igo.

Rückert, Peter/Lorenz, Sönke (Hgg.), Die Visconti und der deutsche Südwesten. Kulturtransfer im Spätmittelalter/I Visconti e la Germania meridionale. Trasferimento culturale nel tardo medioevo (= Tübinger Bausteine zur Landesgeschichte I I), Ostfildern 2008.

Ruderman, David B., Early Modern Jewry. A New Cultural History, Princeton/Oxford 20 i i.

Rudersdorf, Manfred, Maximilian II. (1564-1576), in: Schindling/Ziegler, Die Kaiser der Neuzeit, 79-95.

Rudersdorf, Manfred, Moritz I 54I/47- I553, in: Kroll, Die Herrscher Sachsens, 90- io9.

Rudersdorf, Manfred, Moritz von Sachsen und die Landgrafschaft Hessen. Protestantische

Politik im Zeichen des dynastischen Familienverbandes, in: Blaschke, Moritz von Sachsen, $75-93$.

Rudolph, Harriet, Das Reich als Ereignis. Formen und Funktionen der Herrschaftsinszenierung bei Kaisereinzügen (I558- I6 I8) (= Norm und Struktur. Studien zum sozialen Wandel in Mittelalter und Früher Neuzeit 38), Köln/Weimar/Wien 20 I I.

Rudolph, Harriet, Fürstliche Gaben? Schenkakte als Element der politischen Kultur im Alten Reich, in: Häberlein/Jeggle, Materielle Grundlagen, 79- го2.

Rudolph, Harriet, Hercules saxonicus. Über die Attraktivität eines antiken Heros für die symbolische Absicherung einer fragilen Rangerhebung, in: Archiv für Kulturgeschichte 93/I (2OI I), 57-94.

Rudolph, Harriet, Stadtliche gemeinde und gewohnlicher hofflager. Zum Verhältnis zwischen Stadt und Hof bei Herrscherbesuchen in der kursächsischen Residenz Dresden, in: Paravicini/Wettlaufer, Der Hof und die Stadt, 26r - 280.

Ruppel, Sophie, "Das Pfand und Band aller Handlungen« - Der höfische Brief als Medium des kulturellen Austausches, in: Nolde/Opitz, Grenzüberschreitende Familienbeziehungen, 2 II -223 .

Sabbatini, Renzo, La corte asburgica vista da Lucca: La Repubblica e l'Impero nel Sei-Settecento, in: Bellabarba/Niederkorn, Le corti come luogo di comunicazione, 257-296.

SAIler, Sabine, Kleidung und Mode am Hof Königin Bianca Maria Sforzas (I 493- I 5 Io), in: Noflatscher/Chisholm/Schnerb, Maximilian I., I 7 I - I 89.

SALEM, Walter, »Alla tedesca« oder »welsch« tanzen, in: Chiarini/Zeman, Italia-Austria, 2072 I 8.

Saletta V.[incenzo], Il viaggio di Carlo V in Italia (I 535 - I 536), Roma I 98 I.

Saletti, Beatrice (Bearb.), Don Domenico Messore, Viaggio del Sancto Sepolcro facto per lo illustro misere Milliaduse estense, critical edition and commentary (= Antiquitates), Roma 2009 .

Salmons, June, An Unpublished Account of the End of Este Rule in Ferrara: Nicolò Contarini's "Istorie Veneziane« and Events in Ferrara I597-I598, in: Salmons/Moretti, The Renaissance in Ferrara, I 23 - I 44 .

Salmons, June/Moretti, Walter (Hgg.), The Renaissance in Ferrara and its European Horizons/I1 Rinascimento a Ferrara e i suoi orizzonti europei, Wales/Ravenna I984.

Samerski, Stefan, Römische Ordnung und kirchenrechtliches Chaos in Deutschland: Atilio Amalteo als Nuntius in Köln (I606- I6 Io), in: Rohrschneider/Strohmeyer, Wahrnehmung des Fremden, 73-89. 
Sammer, Marianne, Wilhelm V. Katholische Reform und Gegenreformation, in: Schmid/Weigand, Die Herrscher Bayerns, I 89-201.

SAndbichler, Veronika, "Ambras [...] worinnen eine wunderwürdige, ohnschäzbare Rüst= Kunst und Raritaeten Kammer anzutreffen«. Erzherzog Ferdinand II. und die Sammlungen auf Schloss Ambras, in: Haag, Dresden \& Ambras, 3 I - 4 I .

Sandbichler, Veronika, Anna Caterina Gonzaga, in: Alfred Auer/Margot Rauch/Veronika Sandbichler/Katharina Seidl, Philippine Welser \& Anna Caterina Gonzaga. Die Gemahlinnen Erzherzog Ferdinands II., Ausstellungskatalog Schloss Ambras, Innsbruck I 998, 4 I - 46.

SAndbichler, Veronika, Eleonore, Erzherzogin von Österreich, Duchessa di Mantova e Monferrato. "Sempre così lucido specchio inanti gli occhi«, in: Haag, Nozze italiane, 83-86.

Sandbichler, Veronika, Der Hochzeitskodex Erzherzog Ferdinands II., unveröff. Diss. Universität Innsbruck 2003.

Sandbichler, Veronika, Festkultur am Hof Erzherzog Ferdinands II., in: Noflatscher/Niederkorn, Der Innsbrucker Hof, I 59- I 74 .

Santi, Venceslao, La precedenza tra gli Estensi e i Medici e l'Historia de'Principi d'Este di Giovan Battista Pigna, in: Atti della Deputazione Ferrarese di Storia Patria 9, Ferrara I 897, 37I 22 .

Santini, Giovanni, Giurisdizioni locali, magistrature cittadine e territorio, in: Fregni, Archivi, $65-80$.

SAntini, Giovanni, Lo Stato Estense nel quadro degli ordinamenti italiani preunitari, in: Spaggiari/Trenti, Lo Stato di Modena, I I - 22.

SARDI, Gaspare, Libro delle Historie Ferraresi, Ferrara 1556.

SAvio, Andrea, Nobili vicentini nei territori imperiali. Relazioni private e incarichi professionali, in: Taddei/Schnettger/Rebitsch, Reichsitalien, 5 I -6o.

Scalini, Mario, Appunti per lo studio delle armerie estensi, in: Bentini, Gli Este a Ferrara, I89-I95.

Schäffer, Hanna, Maria von Bayern und die Musik. Musik-Mäzenatentum am bayerischen und am innerösterreichischen Hof, in: Zeitschrift des Historischen Vereins für Steiermark 83 (1992), 205-272.

Schal , Ellery, The Court as >civilizer of the nobility: Noble attitudes and the Court in France in the late Sixteenth and early Seventeenth Centuries, in: Asch/Birke, Princes, Patronage and the Nobility, 245-263.

Sснатткоwsкy, Martina (Hg.), Witwenschaft in der Frühen Neuzeit. Fürstliche und adlige Witwen zwischen Fremd- und Selbstbestimmung (= Schriften zur sächsischen Geschichte und Volkskunde 6), Leipziger Universitätsverlag 2003.

Scheicher, Elisabeth, Ein »böhmisches« Schloss in Tirol. Zu den Fassadenmalereien des Ambraser Hochschlosses, in: Österreichische Zeitschrift für Kunst und Denkmalpflege 46 (I992), 4-I8.

Scherbaum, Bettina, Die bayerische Gesandtschaft in Rom in der Frühen Neuzeit (= Bibliothek des Deutschen Historischen Instituts in Rom i r6), Tübingen 2008.

Scherl, Sandra, Die Brautreise der Erzherzoginnen Barbara \& Johanna von Innsbruck nach Ferrara und Florenz I 565. Textedition und Kontextualisierung mit einem geschichtsdidaktischen Beitrag für die 6. Schulstufe, unveröff. Diplomarbeit, Universität Innsbruck 2008.

Schilling, Heinz, Konfessionalisierung und Staatsinteressen. Internationale Beziehungen 
I 559- I660 (= Handbuch der Geschichte der Internationalen Beziehungen 2), Paderborn/ München/Wien/Zürich 2007 .

Schindling, Anton, Bei Hofe und als Pomeranzenhändler: Italiener im Deutschland der Frühen Neuzeit, in: Klaus J. Bade, Deutsche im Ausland - Fremde in Deutschland. Migration in Geschichte und Gegenwart, München I 992, 287-294.

Schindling, Anton, Mindermächtige Territorien und Reichsstädte im Heiligen Römischen Reich: Stände oder Kleinstaaten, in: Langewiesche, Kleinstaaten in Europa, 37-58.

Schindling, Anton/Ziegler, Walter (Hgg.), Die Kaiser der Neuzeit i5 I9-I9I8. Heiliges Römisches Reich, Österreich, Deutschland, München r 990.

Schirg, Bernhard, Decoding da Vinci's Impresa: Leonardo's Gift to Cardinal Ippolito d'Este and Mario Equicola's De opportunitate ( $5_{507}$ ), in: Journal of the Warburg and Courtauld Institutes 78 (2015), I 35- I 55 .

Schirmer, Uwe, Die ernestinischen Kurfürsten bis zum Verlust der Kurwürde I 485 - I 547 , in: Kroll, Die Herrscher Sachsens, 55-75.

Schirmer, Uwe, Die Finanzierung der Fürstenrebellion aus kursächsischer Perspektive. Kurfürst Moritz zwischen militärpolitischem Agieren und finanzpolitischen Strukturen (I 549/50-I 553), in: Fuchs/Rebitsch, Kaiser und Kurfürst, 7 I - 82.

Schirmer, Uwe, Umfang, Strukturen und Funktionen der albertinischen Staatsfinanzen: Untersuchungen zum Haushaltsjahr I 549/50, in: Blaschke, Moritz von Sachsen, I 33- I62.

Schlesinger, Laura, Reisen und Reiseliteratur in Mittelalter und Neuzeit. Eine Bibliographie, Hamburg $20 \mathrm{II}$.

Schlosser, Julius, Die Kunst- und Wunderkammern der Spätrenaissance. Ein Beitrag zur Geschichte des Sammelwesens, Braunschweig ${ }^{2}$ I 978.

Schmale, Wolfgang (Hg.), Kulturtransfer. Kulturelle Praxis im r6. Jahrhundert (= Wiener Schriften zur Geschichte der Neuzeit 2), Innsbruck/Wien/München/Bozen 2003.

Schmale, Wolfgang, Einleitung: Das Konzept »Kulturtransfer« und das r6. Jahrhundert. Einige theoretische Grundlagen, in: Schmale, Kulturtransfer, 4I -6I.

Schmale, Wolfgang, Kulturaustausch und kulturelle Transfers in der Frühen Neuzeit, in: North, Kultureller Austausch, I I - I 4.

Schmid, Alois/Weigand, Katharina (Hgg.), Die Herrscher Bayerns. 25 historische Portraits von Tassilo III. bis Ludwig III., München 200 I.

Sснмідт, Georg, Die »deutsche Freiheit« und der Westfälische Friede, in: Ronald G. Asch (Hg.), Frieden und Krieg in der Frühen Neuzeit. Die außereuropäische Staatenordnung und die europäische Welt, München 2001, 323-347.

Sснмідт, Georg, Kultureller Austausch innerhalb der deutschen Nation, in: North, Kultureller Austausch, 8I-88.

Schmidt, Johannes F.K./Guichard, Martine/Schuster, Peter/Trillmich, Fritz (Hgg.), Freundschaft und Verwandtschaft. Zur Unterscheidung und Verflechtung zweier Beziehungssysteme, Konstanz 2007.

Schmidt, Tilmann, »Visconti«, in: Reinhardt, Die großen Familien, 586-596.

Schmitz-Esser, Romedio/Taddei, Elena, Der Todesfall des Herzogs Severin von Sachsen in Tirol - ein »Obduktionsbericht« des habsburgischen Hofarztes Georg Tannstätter von I 533, in: Virus. Beiträge zur Sozialgeschichte der Medizin 5 (2005), 9-2 I. 
Schneidmüller, Bernd/Weinfurter, Stefan (Hgg.), Die deutschen Herrscher des Mittelalters. Historische Porträts von Heinrich I. bis Maximilian I. (9I9- I 5 I 9), München 2003.

Schnettger, Matthias/Verga, Marcello (Hgg.), L'Impero e l'Italia nella prima età moderna/ Das Reich und Italien in der Frühen Neuzeit (= Annali dell'Istituto storico italo-germanico in Trento/Jahrbuch des italienisch-deutschen historischen Instituts, Contributi/Beiträge I 7), Bologna/Berlin 2006.

Schnettger, Matthias, Die kaiserliche Gerichtsbarkeit in Italien in der Frühen Neuzeit, in: Rolf Lieberwirth (Hg.), Akten des 36. Deutschen Historikertages. Halle an der Saale, ro.- I 4. September 2006, Baden-Baden 2008, 607-625.

Schnettger, Matthias (Hg.), Imperium Romanum - Irregulare Corpus - Teutscher ReichsStaat. Das Alte Reich im Verständnis der Zeitgenossen und der Historiographie (= Veröffentlichungen des Instituts für Europäische Geschichte Mainz, Beiheft 57), Mainz 2002.

Schnettger, Matthias, Die Kaiserinnen aus dem Haus Gonzaga: Eleonora die Ältere und Eleonora die Jüngere in: Braun/Keller/Schnettger, Nur die Frau des Kaisers?, I I 7- I 40.

Schnettger, Matthias, Das Alte Reich und Italien in der frühen Neuzeit, in: Quellen und Forschungen aus italienischen Archiven und Bibliotheken 79 (I 999), 344-420.

Schnettger, Matthias, Der Reichsdeputationstag r655-r663. Kaiser und Stände zwischen Westfälischem Frieden und Immerwährendem Reichstag, Münster I 996.

Schnettger, Matthias, Der Spanische Erbfolgekrieg I70I-I7I3/I4, München 20 I $_{4}$.

Schnettger, Matthias, Die Reichsgerichtsbarkeit in Italien in der Frühen Neuzeit. Das Beispiel Ligurien, in: zeitenblicke. online-Journal für Geschichtswissenschaften 3/3 (2004), http://www.zeitenblicke.de/2004/o3/schnettger/schnettger.pdf, Zugriff: i6.9.2020.

Schnettger, Matthias, Feudi imperiali - Reichsitalien, in: Wendehorst/Westphal, Lesebuch Altes Reich, I27-I3 I.

Schnettger, Matthias, Feudi, privilegi e onori. La Repubblica di Genova e la Corte di Vienna, in: Cremonini/Musso, I feudi imperiali, 279-297.

Schnettger, Matthias, Geschichte als Dekadenz?, in: Duchhardt, Jahrbuch für Europäische Geschichte 8, 5 I-75.

Schnettger, Matthias, Il Sacro Romano Impero e l'Italia: una relazione difficile, in: Bellabarba/Merlotti, Stato sabaudo, 25-48.

Schnettger, Matthias, Im Schatten der Mediatisierung. Zur Reform(un)fähigkeit deutscher und italienischer Kleinstaaten in der Frühen Neuzeit, in: Historisches Jahrbuch I 28 (2008), $25-53$.

Schnettger, Matthias, Impero romano - impero germanico. Italienische Perspektiven auf das Reich in der Frühen Neuzeit, in: Ders., Imperium Romanum, 53-75.

Schnettger, Matthias, Italienische Fürsten im deutschen Reichstag? Ein Projekt Friedrich Ludwig von Bergers aus dem Jahr I 723, in: Historisches Jahrbuch i I 8 ( 1998), 86- ro7.

Schnettger, Matthias, Kleinstaaten in der Frühen Neuzeit. Konturen eines Forschungsfeldes, in: Historische Zeitschrift 286 (2008), 605-640.

Schnettger, Matthias, Kooperation und Konflikt. Der Reichshofrat und die kaiserliche Plenipotenz in Italien, in: Anja Amend u.a. (Hgg.), Gerichtslandschaft Altes Reich. Höchste Gerichtsbarkeit und territoriale Rechtsprechung (= Quellen und Forschungen zur höchsten Gerichtsbarkeit im Alten Reich 52), Köln/Weimar/Wien 2007, I 27 - I 49.

Schnettger, Matthias, Rang, Zeremoniell, Lehnssysteme. Hierarchische Elemente im euro- 
päischen Staatensystem der Frühen Neuzeit, in: Asch/Arndt/Schnettger, Die frühneuzeitliche Monarchie, I79- I95.

Schnettger, Matthias, Reichsstadt oder souveräne Republik? Genua und das Reich in der Frühen Neuzeit, in: Schnettger/Verga, L'Impero e l'Italia, 277-297.

Schnettger, Matthias, Selektive Wahrnehmung: Die Reichskreise aus der Sicht italienischer Diplomaten, in: Wolfgang Wüst/Michael Müller (Hgg), Reichskreise und Regionen im frühmodernen Europa - Horizonte und Grenzen im spatial turn. Tagung bei der Akademie des Bistums Mainz, Erbacher Hof, 3.- 5. September 20 ro (= Mainzer Studien zur Neueren Geschichte 29), Frankfurt a.M. 20 I I, I 25 - I 42.

Schnettger, Matthias, Zwei Ehen und ihre Folgen: Die beiden Kaiserinnen aus dem Haus Gonzaga zwischen Italien und dem Reich, in: Taddei/Schnettger/Rebitsch, Reichsitalien, II 3 - I3O.

Schnitzer, Claudia/Hölscher, Petra (Hgg.), Eine gute Figur machen. Kostüm und Fest am Dresdner Hof, Ausstellungskatalog, Kupferstich Kabinett/Staatliche Kunstsammlungen Dresden, Dresden 2000.

Scholz, Rupert, Kulturelle Identität. Über Multikulturalität im Unterschied zu Multikulturalismus, in: Die Politische Meinung 465, August (2008), 35-39.

Schönpflug, Daniel, Verhandlung, Inszenierung und Erleben kultureller Unterschiede: Die seuropäischen' Heiraten der Hohenzollern I767- г8 17, in: Nolde/Opitz, Grenzüberschreitende Familienbeziehungen, I9-37.

Schreech, Michael A., Clément Marot. A Renaissance Poet discovers the Gospel. Lutheranism, Fabrism and Calvinism in the Royal Courts of France and of Navarre and in the Ducal Court of Ferrare (= Studies in Medieval and Reformation Thought 54), Leiden/New York/ Köln I 994 .

Schreiber, Friedrich Anton Wilhelm, Geschichte des bayerischen Herzogs Wilhelm V. des Frommen nach Quellen und Urkunden dargestellt. Ein Beitrag zur vaterländischen Geschichte, München I 860.

Schreiner, Klaus/Schwerhoff, Gerd (Hgg.), Verletzte Ehre. Ehrkonflikte in Gesellschaften des Mittelalters und der Frühen Neuzeit, Köln/Weimar/Wien I 995.

Schreiner, Klaus/Schwerhoff, Gerd, Verletzte Ehre. Überlegungen zu einem Forschungskonzept, in: Schreiner/Schwerhoff, Verletzte Ehre, I- 28.

Schubert, Ernst (Hg.), Geschichte Niedersachsens 2/r : Politik, Verfassung, Wirtschaft vom 9. bis zum ausgehenden I 5. Jahrhundert, Hannover 1997.

Schudt, Ludwig, Italienreisen im i 7. und I 8. Jahrhundert (= Römische Forschungen der Bibliotheca Hertziana I5), Wien/München [1985].

Schulze, Winfried, Reich und Türkengefahr im späten r6. Jahrhundert. Studien zu den politischen und gesellschaftlichen Auswirkungen einer äußeren Bedrohung, München 1978.

Sснüтz, Karl, Kunst und Mäzenatentum an den Renaissancehöfen von Mantua, Ferrara und Florenz, in: Haag, Nozze italiane, I7-23.

Schwaiger, Georg, Die Päpste der Katholischen Reform und Gegenreformation. Von Pius V. bis Leo XI., in: Greschat, Das Papsttum II, 79- го2.

Schwald, Otto, »Della Scala«, in: Reinhardt, Die großen Familien, 2 I 2 - 2 I 8.

Schweikhart, Gunter, Tizian in Augsburg, in: Bergdolt/Brüning, Kunst und ihre Auftraggeber, $2 \mathrm{I}-42$. 
Schweizer, Thomas (Hg.), Netzwerkanalyse. Ethnologische Perspektiven, Berlin r 989.

Schweizer, Thomas, Muster sozialer Ordnung. Netzwerkanalyse als Fundament der Sozialethnologie, Berlin 1996.

Seidel, Kerstin/Schuster, Peter, Freundschaft und Verwandtschaft in historischer Perspektive, in: Schmidt/Guichard/Schuster/Trillmich, Freundschaft und Verwandtschaft, I 45 - I 56.

Seidensticker, Johann Anton Ludwig, Beyträge zum Reichsstaatsrechte Welscher Nation I, Göttingen I795.

Seidl, Katharina, Herzogin Barbara - »allain, dass mir di waill gar lang ist«, in: Haag, Nozze italiane, I I I - I I 2 .

SeIdL, Katharina, Philippine Welser: die "concubine de la ville d'Auguste« oder die Ehefrau »zur Linken« Erzherzog Ferdinands II., in: Haag, Dresden \& Ambras, 73- 77.

Seidlmayer, Michael, Geschichte Italiens. Vom Zusammenbruch des Römischen Reiches bis zum Ersten Weltkrieg, Stuttgart ${ }^{2}$ I 989 .

Seipel, Wilfried (Hg.), Die Entdeckung der Natur. Naturalien in den Kunstkammern des i 6. und I7. Jahrhunderts. Ausstellungskatalog, Schloss Ambras 22.6.-31. I0. 2006, Wien 2006.

Seipel, Wilfried (Hg.), Exotica. Portugals Entdeckungen im Spiegel fürstlicher Kunst- und Wunderkammern der Renaissance, Wien 2000.

Sellert, Wolfgang (Hg.), Reichshofrat und Reichskammergericht. Ein Konkurrenzverhältnis, Köln/Weimar/Wien I 999 .

Sellert, Wolfgang, Der Reichshofrat, in: Diestelkamp, Oberste Gerichtsbarkeit, I 5-44.

Selmin, Francesco (Hg.), Este. Guida storico-artistica, Verona 2006.

Semmler, Josef, Bellum Iustum, in: Hans Hecker (Hg.), Krieg in Mittelalter und Renaissance (= Studia humaniora 39), Brühl 2005, 4I-64.

Semper, Hans/Schulze, F.O./Barth, W., Carpi ein Fürstensitz der Renaissance, Dresden I 882, italienische Neuauflage: Carpi una sede principesca del Rinascimento hg. v. L. Giordano, Pisa I 999.

Senatore, Francesco, »Un mundo de carta«. Forme e strutture della diplomazia sforzesca (= Mezzogiorno medievale e moderno 2), Napoli i 998.

Senatore, Francesco, Ai confini del »mundo de carta . Origine e diffusione della lettera cancelleresca italiana (XIII-XVI secolo), in: Reti Medievali Rivista X (2009), online http://www. retimedievali.it, Zugriff: I 5·7.2020.

Sicken, Bernhard, Ferdinand I (I556-I564), in: Schindling/Ziegler, Die Kaiser der Neuzeit, $55-78$.

Siebenhüner, Kim, Things that matter. Zur Geschichte der materiellen Kultur in der Frühneuzeitforschung, in: Zeitschrift für Historische Forschung 42 (2015), 373-409.

Signorotto, Gianvittorio, Impero e Italia in Antico Regime. Appunti storiografici, in: Cremonini/Musso, I feudi imperiali, I7-30.

Signorotto, Gianvittorio, Modena e il mito della sovranità eroica, in: Fumagalli/Signorotto, La corte estense, I I -49 .

Signorotto, Gianvittorio, Note sulla politica e la diplomazia dei pontefici (da Paolo III a Pio IV), in: Fantoni, Carlo V, 47-76.

Signorotto, Gianvittorio, Papato e principi italiani nell'ultima fase del conflitto tra Asburgo e Valois, in: Martínez Millán, Carlos V, 259-280. 
Simal López, Mercedes, La estancia en Madrid de Francesco I d'Este en r638, in: Fumagalli/ Signorotto, La corte estense, 197-237.

Simoncelli, Paolo, Evangelismo italiano del Cinquecento. Questione religiosa e Nicodemismo politico, Roma 1979 .

Sitta, Pietro, Saggio sulle istituzioni finanziarie del Ducato Estense nei secoli XIV e XVI, in: Atti e Memorie della Deputazione di Storia Patria di Ferrara, serie prima 3 (I 89I), 89-254.

Sки́воvá, Anna, Ferdinand I., der Habsburger und die Anfänge seiner Regierung im böhmischen Staat, in: Vogler, Europäische Herrscher, 7 I - 84 .

Solerti, Angelo, Ferrara e la corte estense nella seconda metà del secolo decimosesto, Città di Castello г goo.

Soly, Hugo (Hg.), Karl V. I500- I 558 und seine Zeit, Köln 2000.

Soly, Hugo, Einleitung. Karl V. und seine Zeit, in: Soly, Karl V., I I - 25.

Sombart, Werner, Liebe, Luxus und Kapitalismus. Über die Entstehung der modernenWelt aus dem Geist der Verschwendung, Berlin ${ }^{3}{ }_{1} 983$.

Spaggiari, Angelo, Gli archivi negli Stati estensi, in: Spaggiari/Trenti, Lo Stato di Modena, 933-949.

Spaggiari, Angelo/Trenti, Giuseppe (Hgg.), Lo Stato di Modena. Una capitale, una dinastia, una civiltà nella storia d'Europa, 2 Bde. Atti del convegno, Modena, 25-28 marzo I 998, Roma 200I.

Spagnoletti, Angelantonio, Feudatari imperiali nel sistema dinastico italiano (secoli XVIXVII), in: Cremonini/Musso, I feudi imperiali, 49-64.

Spagnoletti, Angelantonio, Intrecci matrimoniali tra Asburgo e casate principesche italiane tra XVI e XVIII secolo, in: Bellabarba/Niederkorn, Le corti come luogo di comunicazione, I7-38.

Spagnolett i, Angelantonio, Le dinastie italiane nella prima età moderna, Bologna 2003.

Spagnoletti, Angelantonio, Le donne nel sistema dinastico italiano, in: Calvi/Spinelli, Le donne Medici, I3-34.

Spagnoletti, Angelantonio, Matrimoni e politiche dinastiche in Italia tra gli anni Trenta e gli anni Cinquanta del Cinquecento, in: Cantù/Visceglia, L'Italia di Carlo V, 97- I I 3.

Spiess, Karl-Heinz (Hg.), Ausbildung und Verbreitung des Lehnswesens im Reich und in Italien im I2. und I3. Jahrhundert (= Vorträge und Forschungen 76), Ostfildern 2013.

SpIEss, Karl-Heinz, Einführung, in: Spieß, Ausbildung, 9- - 6.

Spiess, Karl-Heinz, Europa heiratet. Kommunikation und Kulturtransfer im Kontext europäischer Königsheiraten des Spätmittelalters in: Rainer Schwinges (Hg.), Europa im späten Mittelalter: Politik, Gesellschaft, Kultur (= Historische Zeitschrift: Beihefte N.F. 40), München 2006, 435-464.

Spiess, Karl-Heinz, Familie und Verwandtschaft im deutschen Hochadel des Spätmittelalters I3. bis Anfang des I6. Jahrhunderts (= Vierteljahrschrift für Sozial- und Wirtschaftsgeschichte Beihefte I I I), Stuttgart I 993.

Spiess, Karl-Heinz, Fremdheit und Integration der ausländischen Ehefrau und ihres Gefolges bei internationalen Fürstenheiraten, in: Zotz, Fürstenhöfe und ihre Außenwelt, 267-290.

Spiess, Karl-Heinz, Fürstliche Höfe im spätmittelalterlichen Reich zwischen Erfolg und Mißerfolg, in: Paravicini, Luxus und Integration, 2 I 7-234. 
Spiess, Karl-Heinz, Internationale Heiraten und Brautschätze im Spätmittelalter, in: Rückert/ Lorenz, Die Visconti, I I 5- I 30.

Spiess, Karl-Heinz, Rangdenken und Rangstreit im Mittelalter, in: Paravicini, Zeremoniell und Raum 4, 39-62.

Spiess, Karl-Heinz, Unterwegs zu einem fremden Ehemann. Brautfahrt und Ehe in europäischen Fürstenhäusern des Spätmittelalters, in: Erfen/Spieß, Fremdheit und Reisen, I 7 - 36.

Staatliche Kunstsammlungen Dresden/Kunsthistorisches Museum Wien (Hgg.), Kaiser Rudolf II. zu Gast in Dresden, Dresden 2007.

Staatliches Museum Schwerin (Hg.), Schloß Güstrow, Schwerin i 999.

Stadt Neuburg an der Donau (Hg.), Pfalzgraf Ottheinrich. Politik, Kunst und Wissenschaft im I6. Jahrhundert, Regensburg 2002.

Staenelin, Martin, Musikgeschichtliche Beziehungen zwischen Deutschland und Italien im I 5. und I6 Jahrhundert, in: Guthmüller, Deutschland und Italien, I73- i 94.

Stanzel, Franz K., Europäischer Völkerspiegel: imagologisch-ethnographische Studien zu den Völkertafeln des frühen I 8. Jahrhunderts, Heidelberg I 999 .

Stauber, Reinhard, Die Herzöge von München. Die Wiederherstellung der Landeseinheit, in: Schmid/Weigand, Die Herrscher Bayerns, I 42 - I 57.

Stauber, Reinhard, Herrschaftsrepräsentation und dynastische Propaganda bei den Wittelsbachern und Habsburgern um I 500, in: Nolte/Spieß/Werlich, Principes, 37 I-402.

Stefani, Federico/Berchet, Guglielmo/Barozzi, Nicolò (Bearb.), I diarii di Marino Sanuto, (I 496- I 533), 58 Bde., Venezia I 879- I 903.

Steiger, Heinhard, Völkerrecht versus Lehnsrecht? Vertragliche Regelungen über reichsitalienische Lehen in der Frühen Neuzeit, in: Schnettger/Verga, L'Impero e l'Italia, I I 5 - I 52.

Steinherz, Samuel (Bearb.), Nuntiaturberichte aus Deutschland I $560-$ I 572 nebst ergänzenden Aktenstücken II. Abteilung 4, Wien I 9r4.

Stieglecker, Maria, »Was ich eingethan und erkhauft, wille ich mit erster gelegenheit überschickhen«. Zum Gütertransfer von Spanien an den Kaiserhof, in: Edelmayer, HispaniaAustria 2, 225-244.

Stierhof, Horst, Die bildenden Künste am Münchner Hof zur Zeit Orlando di Lassos, in: Bayerische Staatsbibliothek, Orlando di Lasso, 39-49.

Stieve, Felix, Die Politik Baierns I59I-r607, zweite Hälfte (= Briefe und Acten zur Geschichte des Dreissigjährigen Krieges in den Zeiten des Vorwaltenden Einflusses der Wittelsbacher 5), München I 883 .

Stollberg-Rilinger, Barbara (Hg.), Was heißt Kulturgeschichte des Politischen? (= Zeitschrift für Historische Forschung. Vierteljahresschrift zur Erforschung des Spätmittelalters und der frühen Neuzeit Beiheft 35), Berlin 2005, 9-24.

Stollberg-Rilinger, Barbara, Das Heilige Römische Reich deutscher Nation. Vom Ende des Mittelalters bis I 806, München ${ }^{4} 2009$.

Stollberg-Rilinger, Barbara, Die Symbolik der Reichstage. Überlegungen zu einer Perspektivenumkehr, in: Lanzinner/Strohmeyer, Der Reichstag I486-I613, 77-93.

Stollberg-Rilinger, Barbara, Die Wissenschaft der feinen Unterschiede. Das Präzedenzrecht und die europäischen Monarchien vom I6. bis zum i 8. Jahrhundert, in: Majestas Io (2003), I $25-$ I 5 O.

Stollberg-Rilinger, Barbara, Rituale, Frankfurt/New York 2013. 
Stollberg-Rilinger, Barbara, Verfassungsakt oder Fest? Die »solemnis curia» der Goldenen

Bulle und ihr Fortleben in der Frühen Neuzeit, in: Brockhoff/Matthäus, Die Kaisermacher, 94-IO4.

Stollberg-Rilinger, Barbara, Was heißt Kulturgeschichte des Politischen? Einleitung, in: Stollberg-Rilinger, Was heißt Kulturgeschichte des Politischen?, 9-24.

Stollberg-Rilinger, Barbara, Zeremoniell als politisches Verfahren. Rangordnung und Rangstreit als Strukturmerkmale des frühneuzeitlichen Reichstags, in: Johannes Kunisch (Hg.), Neue Studien zur frühneuzeitlichen Reichsgeschichte (= Zeitschrift für Historische Forschung. Vierteljahresschrift zur Erforschung des Spätmittelalters und der frühen Neuzeit Beiheft I9), Berlin I 997, 91 - I32.

Stollberg-Rilinger, Barbara, Zur moralischen Ökonomie des Schenkens bei Hof (i7.I 8. Jahrhundert), in: Paravicini, Luxus und Integration, I 87-202.

Storrs, Christopher, Imperial Authority and the Levy of Contributions in »Reichsitalien« in the Nine Years War (I690-i696), in: Schnettger/Verga, L'Impero e l'Italia, 24I-273.

Strasser, Gerhard F., Die Wissenschaft der Alphabete. Universalsprachen vom i6. bis zum frühen I9. Jahrhundert im Kontext von Kryptografie und Philosophie, in: Rous/Mulsow, Geheime Post, 4I-72.

Straub, Theodor, Bayern im Zeichen der Teilungen und der Teilherzogtümer (I 347- I 450), in: Kraus, Handbuch der Bayerischen Geschichte 2, I99-283.

Strnad, Alfred A., Die Päpste der Früh- und Hochrenaissance. Von Nikolaus V. bis Julius II., in: Greschat, Das Papsttum II., 39-52.

Strnad, Alfred A., Die Rezeption der italienischen Renaissance in den österreichischen Erbländern der Habsburger, in: Georg Kaufmann (Hg.), Die Renaissance im Blick der Nationen Europas (= Wolfenbütteler Abhandlungen zur Renaissanceforschung 9), Wiesbaden I99 I, I $35-226$.

Strnad, Alfred A./Rebitsch, Robert, Der Tod kam in Innsbruck. Zum Ableben des Großkanzlers Kaiser Karls V., Kardinal Mercurino Arborio di Gattinara (Io. Juni I 465 - 5. Juni I 530), in: Historiker der Universität Innsbruck (Hgg.), Innsbrucker Historische Studien 22, Innsbruck/München/Wien 2000, I 35- I 54 .

Strohmeyer, Arno, Kommunikation und die Formierung internationaler Beziehungen: Das österreichisch-spanische Nachrichtenwesen im Zeitalter Philipps II., in: Edelmayer, Hispania-Austria 2, I09- I 49,

Strohmeyer, Arno, Kulturtransfer durch Diplomatie: Die kaiserlichen Botschafter in Spanien im Zeitalter Philipps II. und das Werden der Habsburgermonarchie (I $560-$ I $_{59}$ ), in: Schmale, Kulturtransfer, 205-230.

Strohmeyer, Arno, Wahrnehmungen des Fremden: Differenzerfahrungen von Diplomaten im I6. und I7. Jahrhundert: Forschungsstand - Erträge - Perspektiven, in: Rohrschneider/ Strohmeyer, Wahrnehmung des Fremden, I -50.

Strong, Roy, Feste der Renaissance I450-i650. Kunst als Instrument der Macht, aus dem Englischen übersetzt von Susanne Höbel und Maja Ueberle-Pfaff, Freiburg/Würzburg r 99 I. Stutн, Steffen, Zwischen Tradition und Moderne. Zur Rolle von Bildung und Erziehung am mecklenburgischen Hof unter Johann Albrecht I., in: Werner Paravicini/Jörg Wettlaufer (Hgg.), Erziehung und Bildung bei Hofe. 7. Symposium der Residenzen-Kommission der 
Akademie der Wissenschaften in Göttingen (= Residenzenforschung I3), Stuttgart 2002, $248-266$.

Sutter Fichtner, Paula, Emperor Maximilian II, New Haven/London 200 I.

Sutter Fichtner, Paula, Ferdinand I. Wider Türken und Glaubensspaltung, ins Deutsche übertragen von Uta Szyszkowitz, Graz/Wien/Köln I 986.

Sutter, Berthold (Hg.), Graz als Residenz - Innerösterreich I 564- I6 I 9, Katalog der Ausstellung, Grazer Burg 6. Mai-30. September 1964, Graz I964.

Syndram, Dirk, "Diese dinge sind warlich wohl wirdig das sie in derselben lustkammer kommen«, Kurfürst August, die Kunstkammer und das Entstehen der Dresdner Sammlungen, in: Haag, Dresden \& Ambras, I7-29.

Syndram, Dirk, Über den Ursprung der kursächsischen Kunstkammer, in: Die Dresdner Kunstsammlungen in fünf Jahrhunderten (= Dresdner Hefte. Beiträge zur Kulturgeschichte, Sonderausgabe 2004), 3- I3.

Syndram, Dirk/Kappel, Jutta/Weinhold, Ulrike, Das Historische Grüne Gewölbe zu Dresden. Die barocke Schatzkammer, München ${ }^{2} 20$ го.

ТАвассні, Stefano, Lucca e Carlo V. Tra difesa della »libertas« e adesione al sistema imperiale, in: Cantù/Visceglia, L'Italia di Carlo V, 4 I I - 432.

Тавасco, Giovanni, Lo stato sabaudo nel Sacro Romano Impero (= R. Università di Torino. Pubblicazioni della facoltà di magistero), Torino u.a. 1939.

Тавассо, Giovanni, Regni, impero e aristocrazie nell'Italia postcarolingia, Torino I 99 I.

Taвacco, Giovanni/Merlo, Giovanni Grado, Medioevo, V-XV secolo, Bologna i 98 r .

Taddei, Elena, Animals as Agents of Networking and Cultural Transfer: The Dukes of Ferrara and their Relations to German Courts in the Sixteenth Century, in: Mark Hengerer/Nadir Weber (Hgg.), Animals and Courts. Europe, c. I 200-I 800, Berlin 2020, 79-92.

Taddei, Elena, Anna Caterina Gonzaga und ihre Zeit: Der italienische Einfluss am Innsbrucker Hof, in: Noflatscher/Niederkorn, Der Innsbrucker Hof, 2 I 3-240.

TAddei, Elena, Anna von Tirol: »Kaiserin für Gottes Gnaden?«, in: Braun/Keller/Schnettger, Nur die Frau des Kaisers?, 99- I 16.

TAddei, Elena, Barbara von Österreich-d'Este. Ergänzungen zum Leben einer Habsburgerin in Ferrara, in: Brandstätter/Hörmann, Tirol - Österreich - Italien, 629-640.

Taddeı, Elena, Der Römische König Maximilian aus der Sicht der estensischen Gesandtschaft und das Beispiel eines problematischen Lehensverhältnisses in Reichsitalien, in: Noflatscher/ Chisholm/Schnerb, Maximilian I., 95 - I I

Taddei, Elena, Die Este, Herzöge von Ferrara, als Vasallen des Reiches, in: Taddei/Schnettger/ Rebitsch, Reichsitalien, 6r -78 .

Taddei, Elena, Hin und her über die Alpen: Die Reisen der Erzherzogin Anna Caterina Gonzaga, in: Annette Cremer/Anette Baumann/Eva Bender (Hgg.), Prinzessinnen unterwegs. Reisen fürstlicher Frauen in der Frühen Neuzeit (= Bibliothek Altes Reich 22), Berlin/Boston $2018,57-76$.

Taddei, Elena, Karls V. Einzug in Bologna aus der Sicht einer modebewussten Frau, in: Historiker der Universität Innsbruck (Hgg.), Innsbrucker Historische Studien 22, Innsbruck/ München/Wien, I I7- I34.

Taddei, Elena, La politica italiana di Massimiliano dopo il i5 i e le sue conseguenze, in: Liana Bertoldi Lenoci (Hg.), La presa del Castello di Botestagno i 5 I I/Die Eroberung von 
Burg Peutelstein. Atti del convegno storico internazionale/Akten der internationalen Tagung, Cortina d'Ampezzo, 29.-30. August 20 I I, Belluno 20 I 2, 349-364.

Taddei, Elena, Moritz von Sachsen und Ercole II. d'Este: Die Beziehungen zwischen Sachsen und Ferrara während des Fürstenaufstandes von $155_{2}^{2}$, in: Fuchs/Rebitsch, Kaiser und Kurfürst, $83-97$.

TAddei, Elena, »Nach Italien nit allein zur Erlehrnung der Sprache«. Ferrara als Ort des Fremdsprachenerwerbs im I6. Jahrhundert, in: Helmut Glück/Mark Häberlein/Andreas Flurschütz da Cruz (Hgg.), Adel und Mehrsprachigkeit in der Frühen Neuzeit. Ziele, Formen und Praktiken des Erwerbs und Gebrauchs von Fremdsprachen (= Wolfenbütteler Forschungen I 55), Wiesbaden 2019, 33-48.

Taddei, Elena, Optimo architecto und Duca artificere. Städte bauen und Waffen schmieden: Die Künste als Machtinstrument der Este im I6. Jahrhundert, in: Annette Cremer/Matthias Müller/Klaus Pietschmann (Hgg.), Fürst und Fürstin als Künstler. Herrschaftliches Künstlertum zwischen Habitus, Norm und Neigung (= Schriften zur Residenzkultur I I), Berlin 20I8, IO4-II 6.

TAddei, Elena, Palazzo und Delizie: Zentraler Hof und fürstliche Nebenresidenzen am Beispiel Ferraras, in: Christoph Haidacher/Richard Schober (Hgg.), Bericht über den 24. Österreichischen Historikertag in Innsbruck veranstaltet vom Tiroler Landesarchiv und dem Verband Österreichischer Historiker und Geschichtsvereine in der Zeit vom 20. bis 23. September 2005 (= Veröffentlichungen des Verbandes Österreichischer Historiker und Geschichtsvereine 33), Innsbruck 2006, I03- I I I.

Taddei, Elena, Zwischen Katholizismus und Calvinismus: Herzogin Renata d'Este. Eine Eklektikerin der Reformationszeit (= Studien zur Geschichtsforschung der Neuzeit 36), Hamburg 2004 .

Taddei, Elena/Müller, Michael/Rebitsch, Robert (Hgg.), Migration und Reisen. Mobilität in der Neuzeit (= Innsbrucker Historische Studien 28), Innsbruck/Wien/Bozen 20 I 2.

Taddei, Elena/Schnettger, Matthias/Rebitsch, Robert (Hgg.), »Reichsitalien« in Mittelalter und Neuzeit/«Feudi imperiali italiani« nel Medievo e nell'Età Moderna (= Innsbrucker Historische Studien 3I), Innsbruck/Wien/Bozen 2017.

Tagliati, Gilberto, Relazione tra la famiglia Romei e la corte estense nel secolo XV, in: Rossi, I1 Rinascimento nelle corti padane, $6 \mathrm{I}-76$.

Tanzini, Lorenzo, Mai vi fu maggior fortuna in quello porto ... Der Feldzug Maximilians I. gegen Livorno und die Politik von Florenz gegenüber dem H1. Römischen Reich, in: Noflatscher/Chisholm/Schnerb, Maximilian I., I 3 I - I 48.

TAvilla, Carmelo Elio, La giustizia suprema negli stati estensi (secc. XV-XIX), in: Spaggiari/ Trenti, Lo Stato di Modena, 905-918.

Thiessen, Hillard von, Diplomatie vom type ancien. Überlegungen zu einem Idealtypus des frühneuzeitlichen Gesandtschaftswesens, in: Thiessen/Windler, Akteure der Außenbeziehungen, $47 \mathrm{I}-503$.

Thiessen, Hillard von, Gestaltungsspielräume und Handlungspraktiken frühneuzeitlicher Diplomaten, in: Brendecke, Praktiken der Frühen Neuzeit, 199-209.

Thiessen, Hillard von/Windler, Christian (Hgg.), Akteure der Außenbeziehungen. Netzwerke und Interkulturalität im historischen Wandel (= Externa. Geschichte der Außenbeziehungen in neuen Perspektiven I), Köln/Weimar/Wien 20 го. 
Thомаs, Bruno, Erzherzog Karl II. von Steiermark als Mäzen der Waffenschmiedekunst, in: Alte und moderne Kunst, 75/Juli-August (I 964), I 2 - I 6.

Tischer, Anuschka, Verwandtschaft als Faktor französischer Außenpolitik: Auswirkungen und Grenzen dynastischer Politik im I7. Jahrhundert, in: Nolde/Opitz, Grenzüberschreitende Familienbeziehungen, 39-53.

Töbelmann, Paul, Dienst und Ehre. Wenn der Herzog dem Kaiser den Braten schneidet, in: Zeitschrift für Historische Forschung 37/4 (2010), 56 I-599.

Tocci, Giovanni (Hg.), Persistenze feudali e autonomie comunitative in stati padani fra Cinque e Settecento, Bologna I 988.

Toccı, Giovanni, Nel corridoio strategico-politico della pianura padana: Carlo V, Paolo III e la creazione del ducato farnesiano, in: Cantù/Visceglia, L'Italia di Carlo V, 375-388.

Tocci, Giovanni, Piccole e grandi città negli stati italiani (secoli XV-XVII), Firenze ²00I.

Toffanello, Marcello, Ferrara. La città rinascimentale e il delta del Po (= Il Bel Paese. Itinerari 25), Roma 2005.

Toniolo, Federica, Fantasia e intellettualismo nei manoscritti miniati per i principi di Ferrara, in: Bentini, Gli Este a Ferrara, I I 7- I 2 I.

Tönnesmann, Andreas, Anfänge der Renaissancearchitektur in Deutschland: Interesse und Intention der Auftraggeber, in: Guthmüller, Deutschland und Italien, 299-3 I 7 .

Tönnesmann, Andreas, Reisen und Bauen. Mobilität und kulturelle Aneignung in der Architektur der Renaissance, in: Babel/Paravicini, Grand Tour, 499- 5 I 2.

Tonni, Andrea, Allevamento e diplomazia tra Mantova, Torino e Londra: Lo scambio dei cavalli tra Cinquecento e Seicento, online verfügbar: http://www.unibs.it/sites/default/files/ ricerca/allegati/Tonnio8.pdf, Zugriff: 16.9 .2020$.

Tonni, Andrea, The Renaissance Studs of the Gonzagas of Mantua, in: Peter Edwards/Karl A1bert Engelbert Enenkel/Elspeth Graham (Hgg.), The Horse as Cultural Icon. The Real and Symbolic Horse in the Early Modern World, Leiden/Boston 2012, 26I- 278.

Torboli, Micaela, L'araldica estense e le arti, in: Bentini, Gli Este a Ferrara, 88-89.

Toubert, Pierre, Dalla terra ai castelli. Paesaggi, agricoltura e poteri nell'Italia medievale, Torino, 1997 .

Trenti Antonelli, Maria Grazia, Il ruolo della medaglia nella cultura umanistica, in: Mottola Molfino/Natale, Le muse e il principe I, 25-35.

Trevor-Roper, Hugh, Princes and artists. Patronage and Ideology at four Habsburgs Courts I 5 I 7- I633, New York ${ }^{2}$ I 99 I.

TRIPPs, Johannes, Pilgerfahrten als kreative Impulse für die Goldschmiedekunst der Spätgotik. Stiftungen von Pilger- und Reiseandenken durch Adel und Stadtpatriziat in Kirchenschätzen, in: Babel/Paravicini, Grand Tour, I73- r 90.

Tristano, Richard M., The Precedence Controversy and the Devolution of Ferrara: A shift in Renaissance Politics, in: Sixteenth Century Journal XLVIII/3 (20I 7), 68 I - 709.

Tristano, Richard M., Vassals, Fiefs, and Social Mobility in Ferrara during the Middle Ages and Renaissance, in: Medievalia et Humanistica N.S. I 5 (1987), 43-64.

Tsснорт, Silvia Serena/Weber, Wolfgang E.J., Grundfragen der Kulturgeschichte, Darmstadt 2007.

Tuony, Thomas, Herculean Ferrara. Ercole d'Este, I47 I-I505, and the invention of a ducal capital, Cambridge University Press I 996. 
Turba, Gustav, Venezianische Depeschen vom Kaiserhofe (Dispacci di Germania) I, Wien I 889 .

Turba, Gustav, Venezianische Depeschen vom Kaiserhofe (Dispacci di Germania) 2, Wien I 892 .

Turba, Gustav, Venezianische Depeschen vom Kaiserhofe (Dispacci di Germania) 3, Wien I 895 .

Turchi, Laura, Fra Modena, Roma e Parigi: i primi anni di cardinalato di Rinaldo d'Este, protettore di Francia (I618-1672), in: Fumagalli/Signorotto, La corte estense, 263-304.

Turchi, Laura, Fürstliches Recht und Gemeinde. Die Ercole II. d'Este vorgelegten kommunalen Statuten (I 534-I535), in: Nubola/Würgler, Bittschriften und Gravamina, 379-4 I 9.

Turchi, Laura, Istituzioni cittadine e governo signorile a Ferrara (fine sec. XIV-prima metà sec. XVI), in: Prosperi, Storia di Ferrara 6, I $30-$ I 58.

Turchi, Laura, Matrimoni e memoria genealogica fra tardo medioevo ed età moderna (genealogie estensi, Secc. XV-XVII), in: Spaggiari/Trenti, Lo Stato di Modena 2, 80 I-832.

UGHI, Luigi, Dizionario storico degli uomini illustri ferraresi i, Ferrara I 804 .

Ugolini, Piero, Percorsi di terra, percorsi d'acqua e sistema territoriale, in: Papagno/Quondam, La corte e lo spazio, I $27-165$.

Ullmann, Sabine, Geschichte auf der langen Bank. Die Kommissionen des Reichshofrats unter Kaiser Maximilian II. (I564-I 576) (= Veröffentlichungen des Instituts für Europäische Geschichte Mainz, Abteilung für Universalgeschichte 2 I 4), Mainz 2006.

Ullrich, Uta Barbara, Der Kaiser im "giardino dell'Impero«. Zur Rezeption Karls V. in italienischen Bildprogrammen des I6. Jahrhunderts (= humboldt-schriften zur kunst- und bildgeschichte 3), Berlin 2006.

Unterholzner, Daniela, Essensalltag bei Hof. Zum Frauenzimmer Bianca Maria Sforzas, in: Noflatscher/Chisholm/Schnerb, Maximilian I., 287-301.

Unterkircher, Franz, Bücher aus dem Besitz der Kaiserin Bianca Maria in der Österreichischen Nationalbibliothek, in: Höflechner/Mezler-Andelberg/Pickl, Domus Austriae, 407-4II.

Vancini, Gianna (Hg.), Lucrezia Borgia nell'opera di cronisti, letterati e poeti suoi contemporanei alla Corte di Ferrara, Ferrara 2002.

VAnnucci, Marcello, Le donne di casa Medici, Roma ${ }^{2} 2006$.

Vanvolsem, Serge/Vermandere, Dieter/d'Hulst, Yves/Musarra, Franco (Hgg.), L'Italiano oltre frontiera 2 Bde., V. convegno internazionale, Leuven, 22-25 aprile i 998, Firenze 2000.

VAranini, Gian Maria, »An den prächtigen und mächtigen Herrn«. Suppliken an italienische Signori im I 4. Jahrhundert zwischen Kanzlei und Hof: Das Beispiel der Scaliger in Verona, in: Nubola/Würgler, Bittschriften und Gravamina, 95- 132 .

Varanini, Gian Maria, Lorganizzazione del distretto cittadino nell'Italia padana dei secoli XIIIXIV (Marca Trevigiana, Lombardia, Emilia), in: Chittolini/Willoweit, Lorganizzazione del territorio, I33-234.

Vareschi, Severino, La legazione del cardinale Ludovico Madruzzo alla dieta imperiale di Augusta I 5 82. Chiesa, Papato e Impero nella seconda metà del secolo XVI (= Collana di monografie edita dalla società di studi trentini di scienze storiche 47) Trento I 990.

Varese, Ranieri, Gli affreschi di Palazzo Schifanoia, in: Bentini, Gli Este a Ferrara, ro5 - ro8. 
VArese, Ranieri, Il sistema delle »delizie« e lo »studiolo« di Belfiore, in: Mottola Molfino/Natale, Le muse e il principe I, I 87-201.

VAsoli, Cesare, L'astrologia a Ferrara tra la metà del Quattrocento e la metà del Cinquecento, in: Rossi, Il Rinascimento nelle corti padane, 469-494.

Venturi Barbolini, Anna Rosa, Percorsi della cultura, in: Bini, Gli Estensi 2, i 8 i - 26r.

Venturi, Adolfo, Zur Geschichte der Kunstsammlungen Kaiser Rudolf II., in: Repertorium für Kunstwissenschaft 8 (I885) I-23.

Venturi, Gianni, Cultura e società estensi da Nicolò III a Alfonso II, in: Bentini, Gli Este a Ferrara, 3I-4I.

Venturi, Gianni, Culture et société à Ferrare de Nicolò III à Alfonso II d'Este, in: Bentini/ Agostini, Une Renaissance singulière, 37-6o.

Venturi, Gianni, »Magnificentia« e cultura alla Corte estense: una genealogia fantastica tra Boiardo e Ariosto, in: Borella, Gli Este a Ferrara, 39-48.

Verga, Marcello (Hg.), Dilatar l'Impero in Italia. Asburgo e Italia nel primo Settecento (= Cheiron $2 \mathrm{I}$ ), Brescia I 995 .

Verga, Marcello, Gli antichi stati italiani, in: Francesco Begnigno (Hg), Storia moderna, Roma 200I, 35 I-359.

VERGA, Marcello, L'Impero in Italia. Alcune considerazioni introduttive, in: Schnettger/Verga, L'Impero e l'Italia, I I - 24 .

VIsceglia, Maria Antonietta, „Farsi imperiale«: faide familiari e identità politiche a Roma nel primo Cinquecento, in: Cantù/Visceglia, L'Italia di Carlo V, 477-508.

Visceglia, Maria Antonietta, La città rituale. Roma e le sue cerimonie in età moderna, Roma 2002.

Visceglia, Maria Antonietta/Brice, Catherine, Cérémonial et rituel à Rome (XVIe-XIX ${ }^{\mathrm{e}}$ siècle) (= Collection de l'École française de Rome 23I), Roma I997.

Visconti, Alessandro, La storia dell'università di Ferrara (I39I - i 950), Bologna I 950.

Visser Travagli, Anna Maria, L'art de la céramique et le cérémonial de cour, in: Bentini/Agostini, Une Renaissance singulière, 295-304.

Vittorini, Edwina, Montaigne, Ferrara and Tasso, in: Salmons/Moretti, The Renaissance in Ferrara, I 45 - I 74 .

Vocelka, Karl/Leeb, Rudolf/Scheichl, Andrea (Hgg.), Renaissance und Reformation. Oberösterreichische Landesausstellung 2010, Linz 20 го.

Vocelka, Karl, Die politische Propaganda Kaiser Rudolfs II. (I576-I6I 2) (= Veröffentlichungen der Kommission für die Geschichte Österreichs der Österreichischen Akademie der Wissenschaften 9), Wien I98 I.

Vocelka, Karl, Habsburgische Hochzeiten I550-r600. Kulturgeschichtliche Studien zum manieristischen Repräsentationsfest (= Veröffentlichungen der Kommission für Neuere Geschichte Österreichs 65), Wien/Köln/Graz I 976.

Voce LKa, Karl, Rudolf II. und seine Zeit, Wien/Köln/Graz I 985.

Vocelka, Karl/Heller, Lynne, Die private Welt der Habsburger. Leben und Alltag einer Familie, Graz/Wien/Köln I 998.

Vogler, Günter (Hg.), Europäische Herrscher. Ihre Rolle bei der Gestaltung von Politik und Gesellschaft vom i6. bis zum I 8. Jahrhundert, Weimar I 988.

Voigt, Klaus, Die Briefe Antonio de'Costabilis und Cesare Mauros von der Gesandtschaft Fer- 
raras zu König Maximilian I. (I 507/08), in: Römische Historische Mitteilungen I3 (I 97 I), $8 \mathrm{I}-\mathrm{I} 36$.

VöL Kel, Markus, »Farnese«, in: Reinhardt, Die großen Familien, 259-276.

VöLKel, Markus, »Romanität«/»Germanität«, in: Schmale, Kulturtransfer, 247-260.

Volk-Knüttel, Brigitte, Maximilian I. von Bayern als Sammler und Auftraggeber. Seine Korrespondenz mit Philipp Hainhofer I6 I I-I6I 5, in: Glaser, Quellen und Studien, 83- I 28.

Wagner, Wolfgang Eric, Princeps litteratus aut illiteratus? Sprachfertigkeiten regierender Fürsten um I 400 zwischen realen Anforderungssituationen und pädagogischem Humanismus, in: Fritz Peter Knapp/Jürgen Miethke/Manuela Niesner (Hgg.), Schriften im Umkreis mitteleuropäischer Universitäten um I 400. Lateinische und volkssprachliche Texte aus Prag, Wien und Heidelberg: Unterschiede, Gemeinsamkeiten, Wechselbeziehungen (= Education and Society in the Middle Ages and Renaissance 20), Leiden/Boston 2004, I4 I-I77.

Walder, Anton, Der letzte Ritter als erster Verschlüssler im Reich, in: Rous/Mulsow, Geheime Post, I2 I - I 35 .

Wallas, Monika E., Anna Caterina Gonzaga. Leben und Wirken der zweiten Gemahlin Erzherzog Ferdinands II., unveröff. Hausarbeit, Universität Innsbruck I 990.

Wallerstein, Immanuel, Das moderne Weltsystem: Kapitalistische Landwirtschaft und die Entstehung der europäischen Weltwirtschaft im I6. Jahrhundert, aus dem Amerikanischen von Angelika Schweikhart, Frankfurt a.M. I986.

Wallerstein, Immanuel, Karl V. und die Entstehung der kapitalistischen Weltwirtschaft, in: Soly, Karl V., 365-39r.

Walsh, Katherine, Verkaufte Töchter? Überlegungen zu Aufgabenstellung und Selbstwertgefühl von in die Ferne verheirateten Frauen anhand ihrer Korrespondenz, in: Festschrift für Elmar Vonbank zum 70. Geburtstag (= Jahrbuch des Vorarlberger Landesmuseumsverein I35), Bregenz I 99 I, I 29- I 44 .

Warburg, Aby, Italienische Kunst und internationale Astrologie im Palazzo Schifanoja zu Ferrara, in: Aby Warburg, Gesammelte Schriften. Die Erneuerung der heidnischen Antike. Kulturwissenschaftliche Beiträge zur Geschichte der europäischen Renaissance. Erste Abteilung I-2, hg. v. Horst Bredekamp/Michael Diers, Berlin I 998, 459-48 I.

Wartenberg, Günther, Moritz von Sachsen - Zur Politik des ersten albertinischen Kurfürsten zwischen Reformation und Reich, in: Vogler, Europäische Herrscher, ro6- 22.

Watanabe-O'Kelly, Helen, Tournaments in Europe, in: Béhar/Watanabe-O'Kelly, Spectaculum Europæum, 593-64I.

Weber, Gregor J.M. (Hg.), Il trionfo di Bacco. Capolavori della scuola ferrarese a Dresda I480- i62o, catalogo della mostra, Torino/Londra/Venezia, 2002.

Weber, Gregor J.M., La collezione di pittura ferrarese a Dresda, in: Weber, Il trionfo di Bacco, $37-48$.

Weber, Hermann, Die Bedeutung der Dynastien für die europäische Geschichte, in: Das Haus Wittelsbach und die europäischen Dynastien (= Zeitschrift für bayerische Landesgeschichte 44/I), München I 98 I, 5-32.

Weber, Max, Wirtschaft und Gesellschaft. Grundriss der verstehenden Soziologie, Tübingen ${ }^{5}$ I 980 .

Weber, Nadir, Lebende Geschenke. Tiere als Medien der frühneuzeitlichen Außenbeziehun- 
gen, in: Peter Hoeres/Anuschka Tischer (Hgg.), Medien der Außenbeziehungen von der Antike bis zur Gegenwart, Köln/Weimar/Wien, 2017, r6o- I 82.

Weinfurter, Stefan, Heinrich II., in: Schneidmüller/Weinfurter, Die deutschen Herrscher des Mittelalters, 97-i 8.

WeIss, Sabine, Habsburgs verkaufte Töchter«. Österreichische Außenpolitik in zarten Händen, in: Hermann Kuprian (Hg.), Ostarrichi - Österreich. I ooo Jahre - rooo Welten. Innsbrucker Historikergespräche I 996, Innsbruck/Wien I 997, 85 - I I 5 .

Weiss, Sabine, Zur Herrschaft geboren. Kindheit und Jugend im Haus Habsburg von Kaiser Maximlian bis Kronprinz Rudolf, Innsbruck/Wien 2008.

Weitlauff, Manfred, Wilhelm IV. und Ludwig X. Die Auseinandersetzung mit der Lehre Luthers, in: Schmid/Weigand, Die Herrscher Bayerns, I 58 - I 72.

Weller, Thomas, Theatrum Praecedentiae. Zeremonieller Rang und gesellschaftliche Ordnung in der frühneuzeitlichen Stadt. Leipzig I 500-I 800 (= Symbolische Kommunikation in der Vormoderne. Studien zur Geschichte, Literatur und Kunst), Darmstadt 2006.

Wendehorst, Stephan, Die Anatomie frühneuzeitlicher Imperien: Herrschaftsmanagement jenseits von Staat und Nation: Institutionen, Personal und Techniken (= bibliothek altes Reich 5), Berlin u.a. 20I5.

Wendehorst, Stephan/Westphal, Siegrid (Hgg.), Lesebuch Altes Reich, München 2006.

Wendehorst, Stephan/Westrhal, Siegrid, Das Alte Reich: Monstrum oder Paradies. Eine Einführung, in: Wendehorst/Westphal, Lesebuch Altes Reich, I - 7.

Weninger, Peter, Zur Sgraffitomalerei in Österreich, in: Feuchtmüller, Renaissance in Österreich, 260-269.

Werner, Michael, Zum theoretischen Rahmen und historischen Ort der Kulturtransferforschung, in: North, Kultureller Austausch, I 5 - 23.

Werner, Michael/Zimmermann, Bénédicte (Hgg.), De la comparaison à l'histoire croisée, Paris 2004 .

Werner, Michael/Zimmermann, Bénédicte, Penser l'historie croisée. Entre empirie et réflexivité, in: Annales 58 (2003), 7-36.

Westphal, Siegrid, Der Reichshofrat - kaiserliches Machtinstrument oder Mediator?, in: Auer/Ogris/Ortlieb, Höchstgerichte in Europa, I I 5 - I 37.

Westphal, Siegrid, Konversion und Bekenntnis. Konfessionelle Handlungsfelder der Fürstinwitwe Anna im Zuge der Rekatholisierung Pfalz-Neuburgs zwischen I6I4 und I632, in: Vera von der Osten-Sacken/Daniel Gerth (Hgg.), Fürstinnen und Konfession. Beiträge hochadeliger Frauen zu Religionspolitik und Bekenntnisbildung (= Veröffentlichungen des Instituts für Europäische Geschichte, Mainz, Beihefte I 04), Göttingen 201 5, 3 I 7-344.

Whaley, Joachim, Germany and the Holy Roman Empire I : From Maximilian I to the Peace of Westphalia I493-I648, Oxford University Press 2012 und die deutsche Fassung: Das Heilige Römische Reich Deutscher Nation und seine Territorien I: Von Maximilian I. bis zum Westfälischen Frieden r 493- I648, aus dem Englischen von Michael Haupt, Darmstadt 2014 .

Wieland, Christian, Fürsten, Freunde, Diplomaten. Die römisch-florentinischen Beziehungen unter Paul V. (I605- I62 I), Köln/Weimar/Wien 2004.

Wieland, Christian, German Aristocracies and Social Discipline: Noble Hierarchies, the State, 
and the Law in Sixteenth-Century Bavaria, in: Evans/Schaich/Wilson, The Holy Roman, Empire, 263-28I.

Wiesflecker, Hermann, Die Habsburgischen Staaten und Italien am Beginn der Neuzeit (I 500-I 700), in: Chiarini/Zeman, Italia-Austria, 3-26.

Wiesflecker, Hermann, Italien in der Kaiserpolitik Maximilian I., in: Der Schlern. Zeitschrift für Heimat- und Volkskunde 34 (I960), 272-285.

Wiesflecker, Herrmann, Kaiser Maximilian I. Das Reich, Österreich und Europa an der Wende zur Neuzeit, Bd. II: Reichsreform und Kaiserpolitik. I493-I500. Entmachtung des Königs im Reich und in Europa, Wien I 975.

Wiesflecker, Hermann, Kaiser Maximilian I. Das Reich, Österreich und Europa an der Wende zur Neuzeit Bd. V.: Der Kaiser und seine Umwelt. Hof, Staat, Wirtschaft, Gesellschaft und Kultur, Wien I 986.

Wiesflecker-Friedhuber, Inge, Kaiser Maximilian I. und die Stadt Innsbruck, in: Noflatscher/Niederkorn, Der Innsbrucker Hof, I 25 - I 58.

Winder, Lukas, Die Kreditgeber der österreichischen Habsburger I 5 I -I6I2. Versuch einer Gesamtanalyse, in: Rauscher/Serles/Winkelbauer, Das »Blut des Staatskörpers«, 435-458.

Windler, Christian, Diplomatie als Erfahrung fremder politischer Kulturen. Gesandte von Monarchen in den eidgenössischen Orten (I6. und I7. Jahrhundert), in: Geschichte und Gesellschaft. Zeitschrift für Sozialwissenschaften 32 (2006), 5-44.

Windler, Christian, Tribut und Gabe. Mediterrane Diplomatie als interkulturelle Kommunikation, in: Saeculum 5 I (2000), 24-56.

Winter, Christian, Kurfürst Moritz und seine Räte in der albertinischen Bündnispolitik der Jahre 155 I bis I 553 , in: Blaschke, Moritz von Sachsen, 202-224.

Winter, Christian, Kurfürst Moritz von Sachsen als Haupt der reichsständischen Opposition gegen Kaiser Karl V. in: Fuchs/Rebitsch, Kaiser und Kurfürst, 5 I -69.

Wolf f, Max von, Die Beziehungen Kaiser Maximilian I.zu Italien I 495 - I 508, Innsbruck I 909.

Wolf ram, Herwig, Konrad II, in: Schneidmüller/Weinfurter, Die deutschen Herrscher des Mittelalters, I I 9- I 36 .

Wunder, Bernd, Kleine Geschichte des Herzogtums Württemberg, Leinfelden-Echterdingen 2009 .

Wunder, Heide, »Die Fürstin bei Hofe« im Heiligen Römischen Reich (I6.- I 8. Jahrhundert), in: Rode-Breymann/Tumat, Der Hof, 2 I - 5 I.

Wunder, Heide, Herrschaft und öffentliches Handeln von Frauen in der Gesellschaft der Frühen Neuzeit in: Ute Gerhard (Hg.), Frauen in der Geschichte des Rechts. Von der Frühen Neuzeit bis zur Gegenwart, München 1997, 27-54.

ZACCH È, Gilberto, La città e il principato di Carpi nello Stato di Modena. Istituzioni, economia e società (secc. XVI-XVIII), in: Spaggiari/Trenti, Lo Stato di Modena, 57 I - 586.

Zaniвоni, Mario, Gli Estensi nelle loro delizie. Ferrara medievale e rinascimentale, mura, torrioni, castelli e delizie, Ferrara 1987.

ZArri, Gabriella, Monache e sante alla corte estense, in: Bocchi, Storia illustrata di Ferrara 2, $4 \mathrm{I} 7-432$.

Zeleny, Karin, Der Ambraser Trinkritus, in: Haag, Trinkfest!, I3-24.

Zemon Davis, Natalie, Die schenkende Gesellschaft. Zur Kultur der französischen Renaissance, aus dem Amerikanischen von Wolfgang Kaiser, München 2002. 
ZEvi, Bruno, Biagio Rossetti architetto ferrarese. Il primo urbanista moderno europeo, Torino I960.

Zevi, Bruno, Saper vedere l'urbanistica. Ferrara di Biagio Rossetti. La prima città moderna europea, Torino I97 I.

Ziegler, Walter, Die Herzöge von Landshut. Die reichen Verlierer, in: Schmid/Weigand, Die Herrscher Bayerns, I 30- I4I.

Zierl, Antonia, Kaiserin Eleonore und ihr Kreis. Eine Biographie (I436- i 467), unveröff. Phil. Diss., Wien I 966.

Zingerle, Elisabeth (Bearb.), Grazer Nuntiatur. Nuntiatur des Girolamo Portia I 599- I602 (= Publikationen des historischen Instituts beim österreichischen Kulturforum in Rom, Abteilung II: Quellen, II. Reihe, 5), Wien 20 I 2.

Zотz, Thomas (Hg.), Fürstenhöfe und ihre Außenwelt. Aspekte gesellschaftlicher und kultureller Identität im deutschen Spätmittelalter (= Identitäten und Alteritäten I6), Würzburg 2004.

Zотz, Thomas, Rudolf von Habsburg, in: Schneidmüller/Weinfurter, Die deutschen Herrscher des Mittelalters, 340-359.

Zucchi, Stefan Matthias, Deutschland und die Deutschen im Spiegel venezianischer Berichte des I6. Jahrhunderts, Inauguraldissertation, Universität Marburg, 200 I.

Zwierlein, Cornel, Deutsche und italienische Staatsbeschreibungskunst. Die Einkünfte aller Reichsstände, ca. I547/48 nach einer unbekannten Quelle, in: Zeitschrift für Historische Forschung 39/4 (2012), 593-660.

Zwierlein, Cornel, Komparative Kommunikationsgeschichte und Kulturtransfer im i6. Jahrhundert - Methodische Überlegungen entwickelt am Beispiel der Kommunikation über die französischen Religionskriege (I558-1598) in Deutschland und Italien, in: Schmale, Kulturtransfer, 85 - I20.

Zwierlein, Cornel, Savoyen-Piemonts Verhältnis zum Reich I 536 bis r6r 8, in: Schnettger/ Verga, L'Impero e l'Italia, 347-389. 


\section{Register}

Mitglieder der Familie d'Este (auch angeheiratete Fürstinnen), Kaiser und Könige sind unter ihrem Vornamen, alle anderen unter ihrem Familiensnamen angeführt.

Aachen, Hans von 253

Adelardi, Familie $98,487,488$

Adorno, Girolamo i I I

Agricola, Rudolf 238, 294

Aigoni, Familie 80

Alberto Azzo II. d'Este I36, 486

Alberto d'Este 159, I88, 237, 290

Alciati, Andrea 239

Alda d'Este I 99

Aldobrandini, Giovanni (Gian) Francesco I 70 , I 74, I79

Aldobrandini, Pietro, Kardinal 06, I70, I80, 3 I I, 508

Aldobrandino d'Este 158

Aldobrandino II. d'Este I 99

Alessandro d'Este, Kardinal 193, 344, 508, 509

Alexander VI., Papst 88, I 82, 284, 500

Alfonso d'Este, Don, Markgraf von Montecchio I 35, I 43, I 7 I, I 74, I 75, 2 I 3, 274, 309, 3 I O, 385 , 503,504

Alfonso I. d'Este 83, 88, I07-I I IO, I I 2, I I 3, I I 5 , I69, I 74, I 76, I 93, 200, 2 I 4, 233, 239, 245, 247 , $259,262,284,288,294,305,306,33$ I, 334, 339, $346,353,35^{8}, 36 \mathrm{I}, 374,375,377,378,380,384$, 397, 400, 422, 473, 480, 500-504, 506

Alfonso II. d'Este 22, 5 I , 58, 59, 90, I05- I08, I I 7, I I 8 , I22, I27-I30, I 34-I36, I39-I4I, I 43, I 45-I 48, I 5 I, I 5 2, I 54, I60, I 6 I , I63, I66, I68, I 72, I 74-I77, I 82, I 9I, I 93, I 95, I 96, 20I-203, 205, 206, 208, 2 I 2, 2 I $3,234-236,24$ I , 242, $244-246,249,256-268,27$ I , 273-278, 284, 286, 304, 308-3 г 2, 3 I 4, 3 I 5, 323, 329, 334, $335,339,340,345,383,384,387,388,390,39$ I, 396-398, 40I, 404-4II, 4I 3, 4I 4, 4I 7, 4I 8, 422, 424-428, 43I , 432, 437-44I, 457-460, $463-468,475,480,48$ I, $506-508$

Alfonso III. d'Este I 54

Amalteo, Atilio 327

Anjou, Familie 4I, I 58, 304, 305, 408, 486, 490, 496, 497

Anna d'Este I I 5, I30, I 53, I 7 I, I 99, 284, 293 , 307, 309, 3 I I, 3 I 2, 3 I 5, 439, 446

Anna, Kaiserin 56
Anna Sforza d'Este 199

Anna von Ungarn, Kaiserin 20I, 203, 220

Aragón, Alfonso V. von I9I

Aragón, Bianca Maria von 199

Aragón, Eleonora von I6o, 193, 208, 21 4, 24I, 284, 498,500

Arco, Graf Antonio d' $5 \mathrm{I}$

Arco, Graf Prospero d' I 35

Aretin, Karl Otmar Freiherr von 15,66

Ariosti, Familie 196

Ariosti, Francesco 107, 35 I, 5 I I

Ariosti, Lippa I58, 49 I

Ariosto, Ludovico 343, 495

Ascanius, Josephus 235

Ashby, William 274

Azzo d'Este 158

Azzo VIII. d'Este 86, 305, 490

Badius, Jodocus 237

Barbara von Österreich-d'Este I I 8, I 30, I3 I, I33, I3 8, I 40, I63, I76, I 77, I93, I95, 200, 202-204, 207-2I 2, 2I 4, 242, 244, 259, 264, 265, 278, 284-286, 288, 335, 383,388, 403-407, 409, 4I 2, 4I 3, 4I 7, 4I 8, 426, 428, 476, 507

Báthory, Stefan, Woiwode I 5 I, I 52, 409

Bayern, Albrecht V. von 202, 2 I 2, 22 I , 234, 235 , $248,267,273,275,386,407,4 \mathrm{I} 4,42 \mathrm{I}-426$

Bayern, Ferdinand von I75, 209, 22 I, 262, 273, 275,407

Bayern, Fürstenhaus I 2, 22, 40, 64, I 27, 205, 235, $246,248,257,267,278,369,383,386,394,397$. 407, 408, 4I 4, 4I 5, 4I 7, 4I $8,420-425,427$, $429-433,435-437,45$ I , 452, 480, 486

Bayern, Ludwig X. von 219

Bayern, Maximilian von 272

Bayern, Otto Heinrich von 266

Bayern, Wilhelm V. von 235, 267, 272, 424, 426, $428-432$

Beatrice d'Este-Sforza 199

Beccaria, Bartolomeo 51, 329

Becichemo, Marino 239

Belforte/Beaufort, Andrea 237

Bellini, Giovanni 243, 495 
Bentivoglio, Ippolito I 65

Berrecci, Bartolomeo 220

Bevilacqua, Alfonso 343

Bevilacqua, Familie I 96

Bevilacqua, Onofrio 178

Bianchini, Giovanni 295

Biandrata, Francesco de'Conti di S. Giorgio, Kardinal I 80

Biandrata, Giorgio 287

Binchois, Gilles 230

Boccacci, Laura/Eustochia Dianti I 74, I 93

Bonlei, Scipione 2 I I

Borgia, Cesare 247, 284

Borgia, Familie 88, 200, 500

Borso d'Este 2I, 22, 34, 82-84, 88, 93, IOI, IO2, IO7, I IO, I 57, I 59, I 88 - I 9I, 23 I, 240, 24 I, 276 , $295,298,305,3$ I $4,330,333,345,346,352,353$, 494, 496, 497

Boschetti, Familie 80

Botzlein, Elena 2 I I

Bouchefort, Jehannet de 234

Bourbon, Charles de 48, i I I, 378

Brandenburg, Barbara von 322

Brandenburg, Joachim Friedrich von 257, 266

Brandenburg, Sophie von 273, 437

Brasavola, Antonio Musa 261, 291, 292

Braunschweig-Lüneburg, Fürstenhaus 22, 272, 45 I, 453, 46 I-468, 476, 480, 486

Braunschweig-Lüneburg, Johann Friedrich von $242,266,272,462-466$

Braunschweig-Lüneburg, Julius von 268

Braunschweig-Lüneburg, Otto Heinrich von 246, $272,273,463-465$

Braunschweig-Lüneburg, Otto von 242

Breger, Joannes 276

Bretagne, Anne de 3 I3, 3 I 4

Brieg und Wohlau, Georg II. von 257

Brumel, Jaches 234, 235

Buglhat, Jean 238

Burgau, Karl von 25 I, 273, 4I I, 4I 2

Burgund, Karl der Kühne von 225

Burgund, Maria von 282

Burgund, Philipp von I 9 I, 225

Calcagnini, Guido I63, I 78, 238, 239, 291-293, 5 I I

Calvin, Johannes 287

Canani, Giulio I 68

Canossa, Familie 36, 78, 80, 8 I, I02, 208

$\mathrm{Ca}[\mathrm{n}]$ tino, Alberto 240
Carafa, Luigi I 57

Carandini, Paolo ro8, I4 I

Carlowitz, Christoph von 242

Carpi, Berengario da I I I

Carrara da, Familie 87, 94, 493

Carretto, Alfonso del 57

Casotti, Familie 98

Castelletti, Dario 260, 268

Castelvetro, Ludovico 293

Castracani, Castruccio 40

Cato, Renato I08, I 37-I39, I4I, 302, 397, 430

Cavedali, Antonio 2 Io

Cesare d'Este I06, I43, I60, I61, I63, I65-I72, I 74-I83, I 93, I 96, 25 I , 25 2, 309, 3 I I, 3 I 2, 3 I 5 , 340, 347, 4I 8, 4I 9, 433, 475, 500, 503, 507-5 IO

Cesi, Familie 92

Charles I., König von England 249, 285

Charles VIII., König von Frankreich 304, 305, 500

Charles IX., König von Frankreich I 5 I, I 75, 309

Cinzio, Giovan Battista Giraldi I 36

Clemens VI., Papst I 59

Clemens VII., Papst 48, I I I, I I 3, 33 I, 334, 368, 369,376

Clemens VIII., Papst I67, I69-I7 I, I74, I75, I 80, 3 Io

Colle, Giovan Francesco 242

Collegno, Antonio Maria di Savoia di I 53, 26I, 5 I I

Collenuccio, Pandolfo I07, 35 I, 5 I I

Contarini, Alvise I 33

Contarini, Gasparo 239

Contarini, Leonardo 205

Contarini, Nicolò I 8 I

Contrari, Ercole I 7

Corradi, Familie I 99, 374

Correggio da, Familie 79, 92, Ioo, 247

Corvinus, Matthias, König von Ungarn 220, 24I

Cossa, Francesco del 497

Cranach, Lucas d.J. 225

Croke, Richard 290

Cybo Malaspina, Familie I 96

D'Alemagna, Giorgio I 90

Dante, Alighieri 45, 367, 37 I, 490

Da Romano, Ezzelino 40, 489

Da Verona, Guarino 230

Dei Tolomei, Stella I 99, 494

Della Badia, Tommaso r 69

Della Francesca, Piero 243, 495

Della Rena, Orazio I 46, I 96, 234, 242, 345, 36 I 
Della Rovere, Francesco Maria I75

Della Rovere, Giulia I 74

Della Scala, Familie 86, 87, 94, I 99

Della Scala, Mastino 40, 87

Della Stella, Paolo 220

Della Viola, Francesco I 9 I, 235

Dell'Avogaro, Marco I 90

Descalzi, Sigismondo I 29, I32- I 34, 396, 40 I, 5 I I

Dietrichstein, Adam von 299, 300

Di Linar, Rocco/Rochus 222, 224

Dolfin, Giovanni I 70, I 82

Donden, Petrus Loys de 266

Doria, Familie 30, 69, 373

Dossi, Dosso 243, 244, 453

Dreyfelder, Triburtio I 38

Dufay, Guillaume $23 \mathrm{I}$

Dürer, Albrecht 2 I 9, 243

Ercole I. d'Este 88, 94, Iо I, I05, I07, I36, I60, I 73, I 77, I 90-I93, 2 I 4, 22 5, 226, 23 I, 232, 237 , 240, 24I, 245, 284, 290, 296, 304, 305, 33 I, 333, $334,35^{2}, 353,35^{8}, 362,400,438,480,497-500$, 502,506

Ercole II. d'Este 9, I I , 34, 82, 84, 88, 90, IO5, IO7, I I I, I I 4- I I 7, I 25, I36, I 53, I 54, I 76, I 93, 202, $2 \mathrm{I} 4,223,225,232,234,238,242,244,257,26 \mathrm{I}$, 266, 267, 284, 290, 291, 293, 294, 307, 308, 3 I 2, $314,332,334,338,361,372,378,379,384,385$, $387,398,399,407,42 \mathrm{I}, 422,424,438,44 \mathrm{I}, 442$, 444, 446-45 I, 453, 457, 459, 46o, 48 I, 503-506

Este von San Martino I 76

Eugen IV., Papst 45, 493

Eyb, Albrecht von 238

Falletti, Girolamo I 27, I 29, I 36, 204, 206, 24I, $370,440,5$ I I

Farnese, Alessandro I 52

Farnese, Margherita 2 I 3

Farnese, Ottavio I 27, 373

Farnese, Pier Luigi 69, I I 7

Ferdinand I., Kaiser 49, 50, 69, 7 I, I07, I I 7, I 24, I 26 - I 28 , I 33, I 46, I 57,20 I-204, 207, 208, $22 \mathrm{I}, 259,262,276,28 \mathrm{I}, 329,332,338,340,34 \mathrm{I}$, $382-385,388,4 \mathrm{OI}, 4 \mathrm{O} 3,4 \mathrm{O} 8,4 \mathrm{I} 2,4 \mathrm{I} 3,422$, $435-437,445,474,480$

Ferdinand II., Kaiser 2 I 2, 432

Ferdinand III., Kaiser 2 I 2

Ferrari, Giovan Battista 168

Fiaschi, Alessandro I32-I34, I 37- I39, 5 I I

Figueroa, Gomez Suarez de 7 I
Filippach, Nicolo 2 10

Filippo d'Este I 53, I73

Francesco d'Este I I 5, I 58, I 93, 370, 385, 503-505

Francesco III. d'Este 250, 453

François I., König von Frankreich 47, 48, I I I , I I 2 , I I 5, 200, 238, 29I, 308, 506

Fridunaldus, Johannes 235

Friedrich III., Kaiser 22, 45, 83, 84, 88, I95, 208, 295, 32 I, 330, 333, 338, 354, 393, 475, 494, 496, 497

Friedrich II., Kaiser 33, 39, 40, 488

Friedrich I., Kaiser 38, 42, 62, 64, 487, 488

Froben, Johann 292

Frundsberg, Georg von 48, I I I, 378

Fugger, Familie 228, 248, 249, 273, 292, 301, 302, $362,423,430$

Garzweiler, Paul Simon von Westerhofen 52

Gattinara, Arborio Mercurino di I3, 47, 33 I, 359, $363,367,378$

Genga, Simone 222

Genua, Republik 43, 44, 47, 48, 5 I, 53, 58, 65-67, 7 I , 72, 77, 85, I I 2, I 84, I 87, 394

Geraldini, Ascanio I 42, I 5 I, I6 I, 246, 302

Germanus, Nicolò (auch Tedesco oder Donis) 240

Giambologna 206

Giglioli, Scipione I 78

Giraldi, Familie I 78

Giraldi, Guglielmo I 90

Giraldi, Lilio Gregorio 3 I 3

Girolamo, Tonca 265

Giulia d'Este 253

Gonzaga, Anna Caterina Erzherzogin von Österreich 56, 21 3, 260, 267, 268, 275, 407, 410, 4 I 5,4 I 6

Gonzaga, Barbara 226

Gonzaga da Novellara, Familie roo

Gonzaga, Eleonora d.Ä. 2 I 2

Gonzaga, Eleonore Erzherzogin von Österreich 2 IO, 2 I I, 2 I 3

Gonzaga, Familie I 2, 30, 45, 50, 52, 53, 59, 69-72, $74,76,79,80,83,87,94$, I I 3 , I I6, I I 7, I 56, I 57 , I 68, I 84, I 95, I 99, 2 I 2, 22 5, 275, 28 I, 337, 348, $363,365,372-376,379,381,383,396,407,4$ I 6, $472,475,492-494,507$

Gonzaga, Federico 69, 225

Gonzaga, Ferrante 68, 70

Gonzaga, Francesco 498

Gonzaga, Francesco II. 228

Gonzaga, Francesco III. 332 
Gonzaga, Gianfrancesco I 59, 323

Gonzaga, Guglielmo 204, 224, 332

Gonzaga, Ludovico I. I 99

Gonzaga, Luigi i 2

Gonzaga, Margherita 83

Gonzaga-Nevers, Carlo II. 2 I 2

Gonzaga-Nevers, Eleonora d.J. 2 I 2

Gonzaga, Vespasiano 300

Gonzaga, Vincenzo I. 5 I, I 7 I, I 96, 2 I 3, 263

Gonzaga, Vincenzo II. I 57

Grandi, Alessandro 249

Granvella, Antoine Perrenot de, Kardinal I 3 I

Grasolfi, Familie 8o

Gregor XIII., Papst I 50, I 79

Gregor XIV., Papst I I I, I 72, I 73, 335

Grillenzoni, Giovanni 293

Grunthler, Andreas 293

Gualengo, Camillo I35, I 39, 277, 5 I I

Guarini, Battista I 5 I

Guidoni, Familie 80

Guise, Charles de 3 io

Guise, François de 309, 3 I 5

Guise, François de Lorraine de, I I 5

Guise, Henri de 309, 3 Io

Harrach, Leonhard Freiherr von I6I

Heinrich II., Kaiser 35

Heinrich III., Kaiser 78, 486

Heinrich VI., Kaiser 39, 488

Hengestium, Bartholomeus 262

Henri III., König von Frankreich I 40, I 5 I, 309 , 3 I0, 335

Henri II., König von Frankreich I I6, 24 I, $306-308,335,379,436,442,445,446,505,506$

Henri IV., König von Frankreich I7 I, I80, 3 Io, 3 I I

Henry VIII., König von England 290, 362

Ippolito I. d'Este, Kardinal I I 5, I68, I 93, 233, 239, 293, 358, 380, 502, 503, 505, 506

Ippolito II. d'Este, Kardinal I 48, I 93, 233, 304, 306, 506

Isaac/Isaak, Heinrich 230, 232

Isabella Clara, Erzherzogin 2 I 2

Isabella d'Este-Gonzaga Io I, I I6, I36, I 99, 232, 233, 247,498

Ivan IV., Zar I 5 I

Johann, König von Böhmen 86

Johann III., König von Schweden I 5 I
Jülich-Kleve-Berg, Anna von 277

Jülich-Kleve-Berg, Karl Friedrich von 276

Jülich-Kleve-Berg, Maria Eleonore von 277

Jülich-Kleve-Berg, Wilhelm V. von 276, 277

Jülich-Kleve, Wilhelm von 202, 276, 383

Julius II., Papst ro8, 109, 369, 380, 502

Kaltemarckt, Gabriel 223

Karcher, Nicola und Johannes 243, 244

Karl der Große 3 I

Karl IV., Kaiser 44, I 26, 453, 49 I

Karl V., Kaiser I 3, 33, 46-49, 58, 67, 68, 70, 7 I, 83, IIO-II2, I I4, I I6, I23, I25, I39, I 50, I 56, I 69, 208, 224, 22 5, 26I, 285, 299, 324, 329, $33 \mathrm{I}, 332,334,335,338,349,359,363-366$, $368-375,377,378,38$ I, 382, 385, 389, 4 I 2, 422 $434,436,438,449,473,477,480,482,504$

Khevenhüller, Johann 299, 300, 302

Khuen, Blasius 207, 264

Klinten, Baltazar 268, 457

Kobenzl, Baron Hans von 5 I

Kollowrat, Joachim 267

Konrad II., Kaiser 35, 36, 6 I, 486

Kopernikus, Nikolaus 294, 295

Kues, Nikolaus von 295

Kurz von Senftenau, Jakob I62

Lahden, Johann Albert Daniel a 268

Landi, Agostino 68, 69

Lasso, Orlando di 235, 275, 4I 5, 4I 6, 423, 428

Leibniz, Gottfried Wilhelm 54, 250, 453

Leonello d'Este I04, I Iо, I 59, I88, I90, I9 I, I99, 230, 23 I, 295, 305, 494, 495, 499

Leo X., Papst 83, Io9, i ro, 239, 369

Leopold I., Kaiser 53, 7 I

Liechtenstein, Karl von 252

Ligorio, Pirro 249, 278

Lismanino, Francesco 287

Lobkowitz, Zdeněk Vojtěch Popel von $25 \mathrm{I}$

Lodron, Beatrice von 2 I I

Lorraine, François de 307

Lothar III., Kaiser 38

Lothar I., Kaiser $3 \mathrm{I}$

Lothringen, Dorothea von 265, 466

Louis XII., König von Frankreich 47, I I I, 285 , 305, 334, 374

Lucrezia Borgia d'Este 82, 88, 91, I I 5, I 76, I 93, 200, 2 I 4, 233, 24 I, 242, 284, 285, 288, 334, 358, $377,380,500,504$ 
Lucrezia de'Medici-d'Este I93, I99, 202-204, 3I $4,335,506$

Lucrezia d'Este I7 I, I 75, I 99, 21 I3, 307, 508

Luigi d'Este, Kardinal I43, I68, I 77, I93, I95, 207, 233, 306, 308, 309, 3 I 4, 344, 4I 8, 43 I

Lünig, Johann Christian I 2 I

Lupicini, Antonio 222

Luther, Martin 239, 434

Luzzaschi, Luzzasco 235

Machiavelli, Niccoló I04, I90, 239, 326

Madruzzo, Cristoforo di, Kardinal 22 I, 222

Madruzzo, Familie I 33, 207, 328, 329, 442

Magrodi, Thomaso 289

Malatesta, Familie 45, 86, I 57, I99, 376, 49 I

Manardo, Giovanni 239

Manfredi, Familie 92, IO2, I03, 5 I I

Mantegna, Andrea 228, 243, 244, 280, 495

Mantua, Jacquet de 234

Manuzio, Aldo I43, 237

Marchesella, Familie 95, 487, 488

Marfisa d'Este 2 I 2

Margherita Gonzaga-d'Este I59, I7I, I93, I99, $213,258,267,274,284,407,428,507$

Marot, Clément 234, 306

Martini, Johannes 23I

Maximilian I., Kaiser 22, 33, 34, 46, 47, 49, 83, I07, IIO, I 50, 20I, 225, 227, 230, 232, 28I-283, 33 I, 334, 338, 340, 348-35 I, 353-360, 362, $366,370,382,387,396,400,473,480$

Maximilian II., Kaiser 49, 50, 7 I, I I 7, I 24 , I 32 - I 35, I 39, I 40, I 45 - I 49, I 54, I 5 5, 202, 203, 205, 206, $210,222,224,236,248,259,277$, 300, 309, 332, 335, 339-34I, 385-39I, 40I, 403, 409, 4I 4, 4I 8, 4I 9, 423, 437, 469, 473, 474, 480

Mazzocchi, Giovanni da Bondeno 237

Mecklenburg, Fürstenhaus I 4, 22, I 29, I 38 , $227,267,268,358,397,400,433-436,45 \mathrm{I}$, $453-455,457-459,46 \mathrm{I}, 476,480$

Mecklenburg, Johann Albrecht I. von 257, 266, 454,460

Mecklenburg, Ulrich von 455,458

Medici, Anna de' 2 I 2

Medici, Caterina de' I I I

Medici, Claudia de' 2 I 2

Medici, Cosimo de' 69, I 24-I28, I 34-I36, I 43, I 44, I 46, I49, I 54, 204, 222, 22 5, 3 I 4, 326, 373, $383,457,506$

Medici, Cosimo II. de' 2 I 2
Medici, Familie I 2, 39, 43, 50, 5 I, 69, I07- I09, II 8, I I 9, I 24-I 29, I 32-I35, I 37, I 39, I 4 I - I 43, I 46 - I 5 I, I 53 , I 5 5, I 56 , I 60 , I 77 , I 83, I 84, I 95, I99, 20I , 204, 2 I 2, 222, 22 25, 244, $28 \mathrm{I}, 298,303,3$ I0, 3 I 4, 326, 335, 368, 383, 384, 39I, 403, 424, 474, 475, 478, 48 I, 485, 493, 496, 504,507

Medici, Francesco de' I 34, I40, I43, I 46, I 47, I 54, I 5 5, 20I , 204, 205, 22 I-223, 263, 273, 288, 368, $383,386,388,423,427$

Medici, Johanna Erzherzogin von Österreich, de' I30, I3I, I 46, I 47, 202-205, 2 I 2, 273, 288, 326, $368,383,405,427,507$

Medici, Maria Magdalena de' 2 I 2

Melanchthon, Philipp 239, 457

Meliaduse d'Este ro I

Mendoza, Francisco Hurtado de 300

Messisbugo, Cristoforo di 209

Micheli, Pellegrino De 80

Minucci, Minuccio I4I, 398, 5 I I

Mirogli, Federico 2 I I

Mocenigo, Alvise 260, 300, 301, 326-328, 395, 505

Montaigne, Michel de 258, 3 Io, 406

Montecatini, Antonio 178

Montecuccoli, Cesare 102

Montecuccoli, Enea I72, 193

Montecuccoli, Familie 92, I02, 103, 5 I I

Montecuccoli, Luigi I63, I 78

Montefeltro, Familie 45, 59, 86, I 83, 247, 369

Morano, Sigismondo I3 I

Morato, Fulvio Pellegrino 293

Morato, Olimpia 293

Müller, Johannes, genannt Regiomontanus 295

Muneretti, Giovan Battista 57

Murarius, Antonius 235

Muratori, Ludovico Antonio 54, 250, 453, 485

Nemours, Charles-Emmanuel de Savoie- 308, 309

Nicolò di Francesco d'Este 99

Nicolò III. d'Este 82, I Io, I 59, I9I, 230, 240, 305, 492-494, 497

Nicolò Maria d'Este 498

Nobili, Cesare de 65

Novara, Domenico Maria 295

Obizzi, Familie 196

Obizzo d'Este 81, 86, 87, I05

Obizzo II. d'Este 97, I 58, 304

Obizzo III. d'Este I 58, I 99, 49 I 
Obrecht, Jacob 230, 232

Ockeghem, Johannes $23 \mathrm{I}$

Ordelaffi, Familie 86

Orsini, Cecilia 83

Orto, Obertus de 6o, 62

Österreich, Andreas von, Kardinal 274

Österreich, Ernst Erzherzog von I3 I, I 5 I, 235 , 323,389

Österreich, Ferdinand II. Erzherzog von 56, I 27 , I 3 I, I 40, 207, 208, 2 IO, 2 I 3, 220, 222, 224, 244, $245,249,254,256,258-262,264-266,268$, $273-275,277,283,289,385-388,403-4 \mathrm{I} 3$, $4 \mathrm{I} 5-4 \mathrm{I} 7,42 \mathrm{O}, 426,435,437,463,464,477,48 \mathrm{O}$

Österreich, Ferdinand Karl Erzherzog von 2 I 2

Österreich, Karl II. Erzherzog von I 27, I 75, 206, 2I 2, 222, 26 I , 264, 403, 4I I , 4I 3, 4I 5, 4I 7, 4I 8 , 427,480

Österreich, Katharina Erzherzogin von 332

Österreich, Magdalena Erzherzogin von 202-204, 4I 2

Österreich, Margarethe Erzherzogin von I I I, 202-204

Österreich, Maria Erzherzogin von 276

Österreich, Maria von Bayern von 2 I 2

Österreich, Maximilian III. Deutschmeister, Erzherzog von I 52, 272, 273

Ott, Familie 248, 249

Otto I., Kaiser 27, 32, 64, 208

Paggiari, Domenico 250

Paleario, Aonio 239

Pallavicini, Familie Ioo, 387,485

Paracelsus, Theofrastus (eig. Bombast von Hohenheim) 294

Pasqualini, Alessandro 277

Paul II., Papst 45, 88

Paul III., Papst I Io, I I 4, I 25, I 26, I 77, I 82, 332, $367,372,438,503,504$

Paul[li], Andreas 245

Pavia, Lorenzo da 247

Pernštein, Maria Manriquez de Lara von 252

Peter III. von Aragón, König 4I

Petrarca, Francesco 45, 325, 492

Philipp II., König von Spanien 48-50, 69, I 26, I 35, I 5 5, I 95, I 96, 202-204, 300, 309, 329, 335 $383,385,389,399,4$ I 3, 4I 4, 423, 442, 45 5, 46o, 507, 509

Philipp III., König von Spanien 50, 69, I 56, 300, 509

Piccolomini, Enea Silvio 32 I, 496
Pico, Familie 79, 92, roo

Pigge, Steven Winand 276-278

Pigna, Gian Battista I 36- I 3 8, 3 I 2, 3 1 3, 343, 374

Pinelli, Johannes Baptista 235, 425

Pio di Savoia, Familie 56

Pio, Familie 79, 83, 91, 92, гоo, го2, I69, г76, г 96, 2I I, 24I, 38I, 425, 509

Pisanello 495

Pius IV., Papst I 28, I 48, 208

Pius V., Papst 67, I32, I34, I39, I 54, I69, I 73

Polenta, da, Familie 86

Polissena dEste ro I

Pommern, Bogislaw X. von 227, 228

Portia, Girolamo I 7o, 3 I I, 4 I 9

Porto, Francesco 293, 294

Portugal, Eleonore von $32 \mathrm{I}$

Prés/Prez, Josquin des 230-232

Preußen, Albrecht Friedrich von 277

Preyner, Seyfried 265

Prisciani, Pellegrino 225, 24I, 295, 296, 499

Purbach/Peuerbach, Georg von 295

Querini, Vincenzo 326

Rangoni, Claudio I 78

Rangoni, Familie 80, I69, I76, I78, 397, 410, 448, 449, 5 I I

Rangoni, Gherardo 178

Rasch, Nicolas 272, 463

Regnac, Pierre, genannt Sandrin 233

Renée de Valois d'Este 9, I I I, I I 2, I I 5, I 47, I 53 , I 76, I 93, I 99, 200, 208, 209, 2 I I , 2 I 3, 2 I 4, 233 , 234, 238, 239, 284, 285, 287, 303, 304, 306, 308, 3 I 3, 3 I 4, 323, 334, 477, 494, 504, 506

Rhein, Philipp Ludwig Pfalzgraf bei 278

Ricci, Bartolomeo 238

Ricci, Marcantonio I63-I65, 25 I, 255, 396, 5 I I

Rinaldo d'Este 87, I 82, 453, 490, 49I

Rizzo, Giovanni Francesco 236

Roberti, Familie I03, 298, 497

Romano, Giulio 2 I 9, 244, 456

Romei, Familie Ioo, Io I, 343

Roost, Jean 244

Rorario, Gregorio I I 6, 232

Rore, Cipriano de 230, 234

Rosello, Lucio Paolo I 44

Rossetti, Giovan Battista 209

Rossetto, Stefano 236

Rossi, Francesco 238

Rotterdam, Erasmus von 237,239 
Roverella, Bartolomeo I 68

Rudolf, Kaiser 42, 86, 208

Rudolf II., Kaiser 22, 49-5 I, 55-58, 7 I, I 42, I 47, I 55, I64-I67, I 74, 236, 248, 252, 253, 259, 265 , 300, 323, 332, 339, 340, 388, 390, 391, 401, 423, $455,473-475,482,507$

Ruggieri, Fulvio 276

Rumpf, Wolf Sigmund I62, 25 1, 389

Sachsen, Anna von 22 I, 336

Sachsen, August I. von 29, I 29, I 30, 22 I, 223 , $248,254,263,266,329,385,397,398,435,436$, 439-44 I; Kurfürst 222

Sachsen, August III. von 250, 452, 453

Sachsen, Bernhard von I 25

Sachsen, Christian I. von 223, 263, 273, 437, 438, $44 \mathrm{I}$

Sachsen, Friedrich III. von 228, 434

Sachsen, Fürstenhaus I 2, I 5, 22, 29, 59, I 25, I 27 , I 29, I 34, I 38,22 I , 242, 250, 256, 352, 386, 4 I 5 , $435,438-44 \mathrm{I}, 443,45 \mathrm{I}, 457,476,479,480,486$

Sachsen, Johann Friedrich von 37 I, 398, 450

Sachsen, Moritz von I 29, 203, 22 I, 222, 242, 257 , $338,387,398,436,438,439,442,445-447$, $449-45$ I , 477

Sacrati, Tommaso I 78

Sadoleto, Giacomo I69, 239

Salinguerra, Familie 86, 487-489

Salviati, Lionardo I 43

Sassuolo, Familie 80, I 76, 509

Savignano, Familie 80

Savonarola, Girolamo 239

Savoyen, Carlo Emmanuele von $5 \mathrm{I}$

Savoyen, Emanuele Filiberto von I 53- I 55, 309, 373

Savoyen, Familie I6, 28, 30, 34, 44, 48, 5 I, 53, 57 , 66, I 29, I 40, I 4I, I 48, I 53 - I 55, I68, I 73, I 84 , I $95,203,232,246,328,355,362,365,398,488$, 509

Scandello, Antonio $22 \mathrm{I}$

Sfondrati, Paolo I 73

Sforza, Anna 498

Sforza, Bianca Maria 46, 201, 228, 28 I, 282, 349, $35 \mathrm{I}$

Sforza, Bona 286

Sforza, Familie I 2, 47, 48, I68, I 99, 334, 365, 380, 493, 496, 498

Sforza, Francesco r 99, 298

Sforza, Galeazzo Maria 23 I
Sforza, Ludovico, il Moro 46, 247, 283, 350, 352, 355,498

Sigismondo d'Este I59, I73, I74, I78, 232, 385 , 494

Sigismund I., König von Polen 286, 408

Sigismund, Kaiser 44, 45, 35 2, 46 I, 493

Sinapius (Senf), Johann 293

Sixtus V., Papst 309

Slot, Gerard 244

Soner, Johannes Mattheus 267, 429

Spaccini, Giovan Battista 252

Spinelli, Filippo I67

Spinola, Luciano, Ambrogio 69

Starck, Henrics 267, 410

Steger, Wolf 2 ro

Steuchus, Augustinus 239

Strada, Jacopo 248, 423

Strein, Gabriel 267

Strigel, Bernhard 283

Strozzi, Familie 99, 380, 40 I, 50 I

Tassoni, Familie I 78 , I 96

Tasso, Torquato I 39, 2 I I, 3 I o

Tedesco, Michele 236

Tedesco, Nicolò $23 \mathrm{I}$

Terzi, Ottobuono 82

Tettelbach, Sigismund von 266

Theti, Carlo 224

Thiene, Giulio I67, I78, 25 I, 5 I I

Thurn, Graf Raimund von $5 \mathrm{I}$

Thurn und Taxis, Familie $30 \mathrm{I}$

Tola, Benedetto 222

Tomeo, Niccolò Leonico 239

Torelli, Familie 95, 98, 487

Trautson, Paul Sixt 25 I, 255, 389

Trauttmansdorff, Maximilian von 56

Tromboncino, Bartolomeo 233

Trotti, Alfonso 239

Trotti, Cesare 178

Turco, Graf Ippolito I08, I 28, I 30, I 3 I, 397, 5 I I

Ungnad, Hans 262

Valdés, Juan de 338

Valentini, Filippo 294

Venedig, Republik 4I, 43, 44, 46-49, 75, 78, 85-87, 90, І07, го8, I28, I29, г48, г70, I $80-$ I 82, I 84, I 87 , I 94, 224, 264, 30I, 33 I, 333 , $334,349,350,353,368-37$ I, 390, 394, 4I 7, 4 I 8 , 430, 488, 490, 494, 497, 498, 500-502 
Veronese, Guarino 237, 495

Vico, Enea 249

Vignola, Familie 80

Virginia de'Medici-d'Este I43, I93, 507

Visconti, Familie 43, 44, 81, 87, 492, 496

Visconti, Gian Galeazzo 43

Visconti, Matteo 43

Vives, Juan Luis 239

Vredeman de Vries, Hans 2 I 6

Vuarano, Francisco 266

Wasa, Sigismund 152

Wazler[ine], Sabina 2 I I
Weber, Johann Baptist I 32, I 33, I38, I48, I 50, I6 I

Weyden, Rogier van der 234, 243, 495

Willaert, Adrian 230, 233

Wolgemuet, Hans 262

Württemberg, Fürstenhaus 250

Württemberg, Ludwig von 258, 4I I

Württemberg, Ulrich von 256

Zanobbio, Luigi 236

Zapolya, Johann Sigismund 204

Zenger, Sebastianus 267, 424

Ziegler, Jakob 239

Zwingli, Huldrich 239 